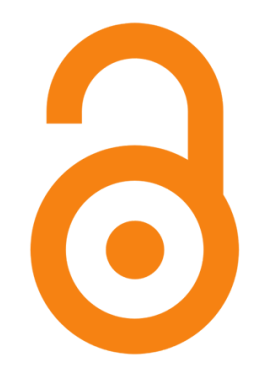

C2019 The Author(s)

This is an Open Access book distributed under the terms of the Creative Commons Attribution Licence (CC BY-NC-ND 4.0), which permits copying and redistribution for non-commercial purposes, provided the original work is properly cited and that any new works are made available on the same conditions (http://creativecommons.org/licenses/by-nc-nd/4.0/). This does not affect the rights licensed or assigned from any third party in this book.

This title was made available Open Access through a partnership with Knowledge Unlatched.

IWA Publishing would like to thank all of the libraries for pledging to support the transition of this title to Open Access through the KU Select 2018 program.

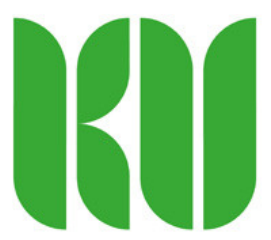

\title{
Knowledge Unlatched
}

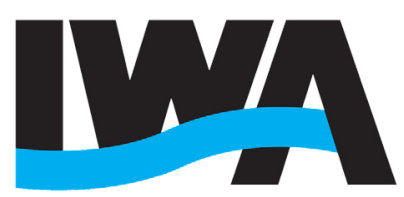

PUBLISHING 


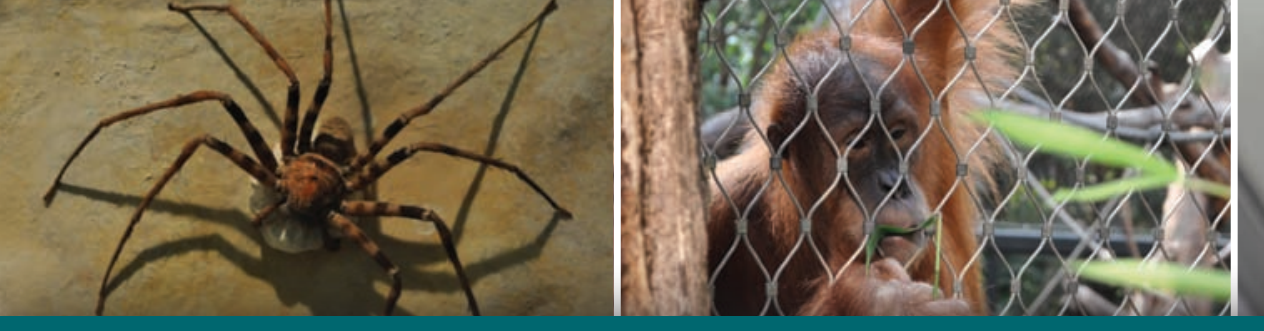

\section{Environmental Aspects of Zoonotic Diseases}

Robert Armon and Uta Cheruti

WA

Publishing

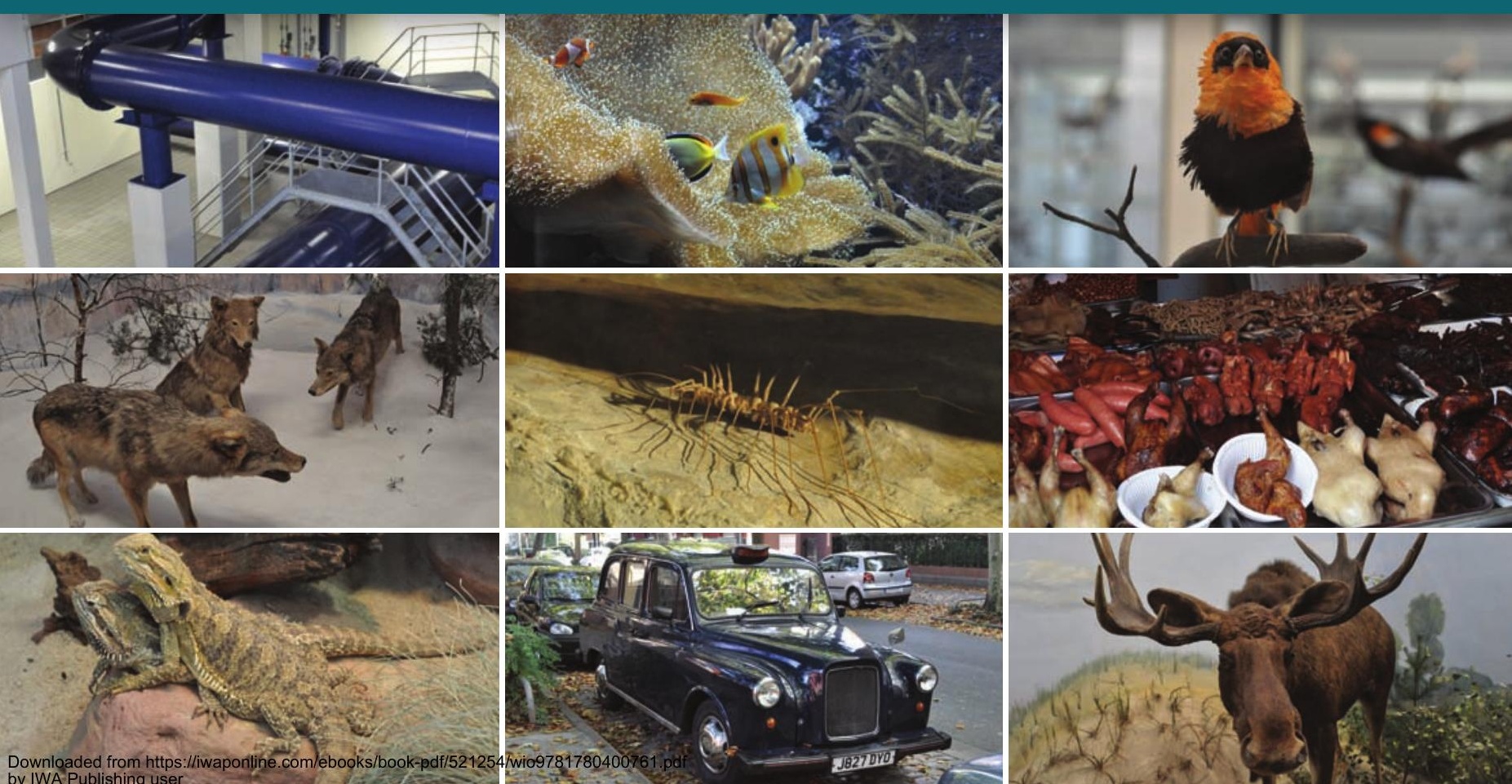




\section{Environmental Aspects of Zoonotic Diseases}


Downloaded from https://iwaponline.com/ebooks/book-pdf/521254/wio9781780400761.pdf

Downloaded trom https://Iwaponline.com/ebooks/book-pdt/521254/WI09/81/80400/61.pdt
by IWA Publishing user 


\section{Environmental Aspects of Zoonotic Diseases}

\section{Robert Armon and Uta Cheruti}

Faculty of Civil \& Environmental Engineering, Environmental, Water and Agricultural Engineering Unit, Technion, Haifa 32000, Israel e-mail:cvrrobi@tx.technion.ac.il; uta@tx.technion.ac.il 
Published by

\author{
IWA Publishing \\ Alliance House \\ 12 Caxton Street \\ London SW1H 0QS, UK \\ Telephone: +44 (0)20 76545500 \\ Fax: +44 (0)20 76545555 \\ Email: publications@iwap.co.uk \\ Web: www.iwapublishing.com
}

First published 2012

(C) 2012 IWA Publishing

Apart from any fair dealing for the purposes of research or private study, or criticism or review, as permitted under the UK Copyright, Designs and Patents Act (1998), no part of this publication may be reproduced, stored or transmitted in any form or by any means, without the prior permission in writing of the publisher, or, in the case of photographic reproduction, in accordance with the terms of licenses issued by the Copyright Licensing Agency in the UK, or in accordance with the terms of licenses issued by the appropriate reproduction rights organization outside the UK. Enquiries concerning reproduction outside the terms stated here should be sent to IWA Publishing at the address printed above.

The publisher makes no representation, express or implied, with regard to the accuracy of the information contained in this book and cannot accept any legal responsibility or liability for errors or omissions that may be made.

\section{Disclaimer}

The information provided and the opinions given in this publication are not necessarily those of IWA and should not be acted upon without independent consideration and professional advice. IWA and the Author will not accept responsibility for any loss or damage suffered by any person acting or refraining from acting upon any material contained in this publication.

British Library Cataloguing in Publication Data

A CIP catalogue record for this book is available from the British Library

ISBN 9781843390855 (Paperback)

ISBN 9781780400761 (eBook) 


\section{Contents}

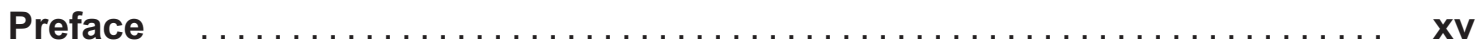

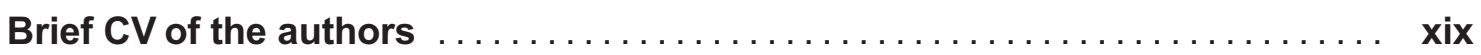

Acknowledgements $\ldots \ldots \ldots \ldots \ldots \ldots \ldots \ldots \ldots \ldots \ldots \ldots \ldots \ldots \ldots \ldots \ldots \ldots \ldots \ldots$

\section{Chapter 1}

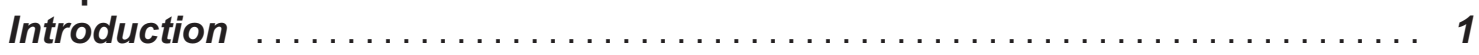

1.1 Human population and socio-economic distribution $\ldots \ldots \ldots \ldots \ldots \ldots \ldots \ldots \ldots \ldots$

1.1.1 References ............................................... 10

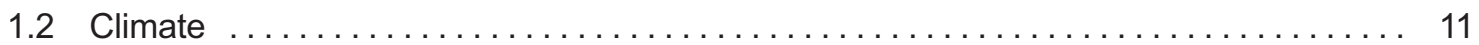

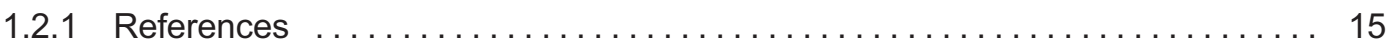

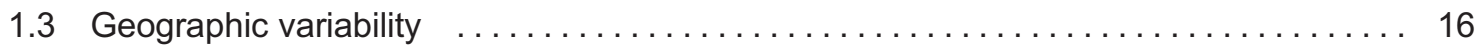

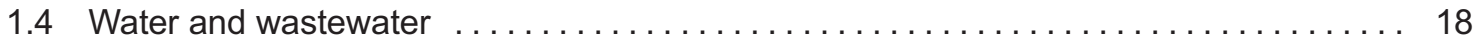

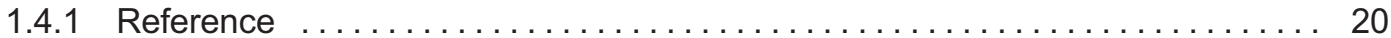

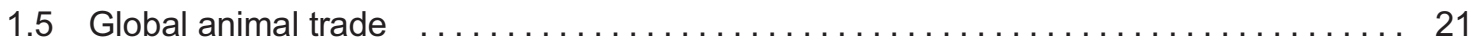

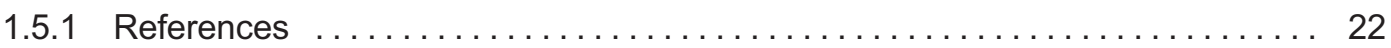

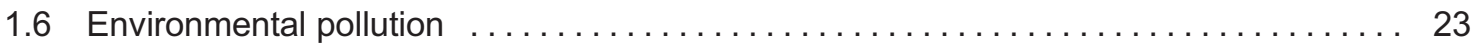

1.6.1 References $\ldots \ldots \ldots \ldots \ldots \ldots \ldots \ldots \ldots \ldots \ldots \ldots \ldots \ldots \ldots \ldots \ldots \ldots \ldots \ldots \ldots \ldots \ldots \ldots, 27$

\section{Chapter 2}

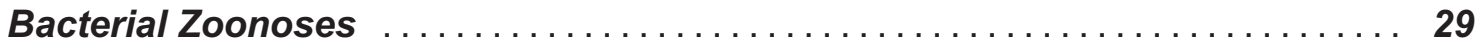

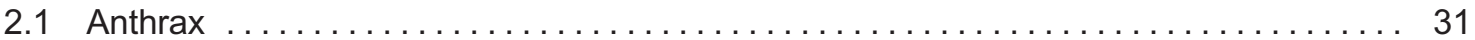

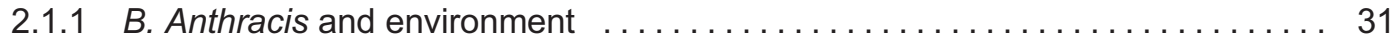

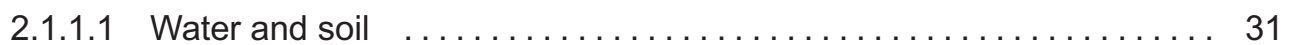

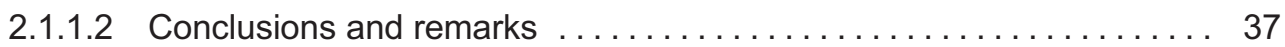

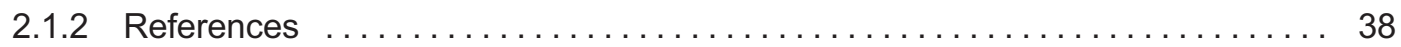


2.2 Bartonelloses (including cat scratch) $\ldots \ldots \ldots \ldots \ldots \ldots \ldots \ldots \ldots \ldots \ldots \ldots \ldots \ldots$

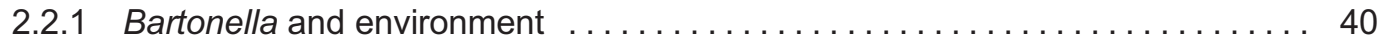

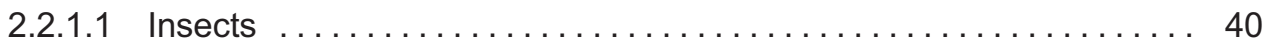

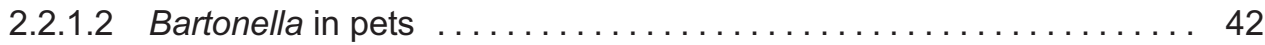

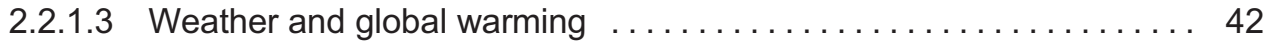

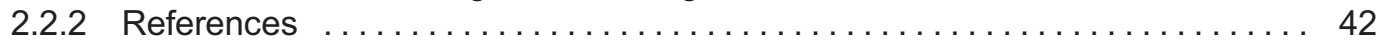

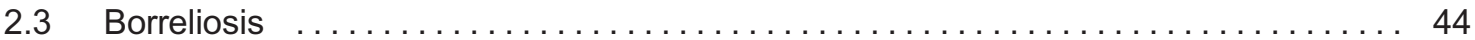

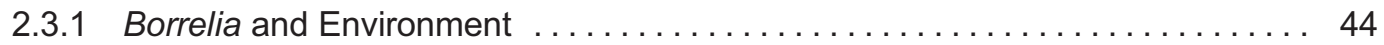

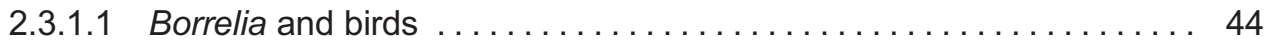

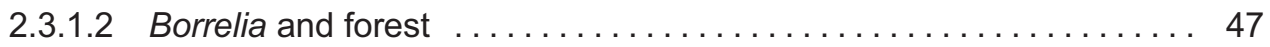

2.3.1.3 Other environmental factors $\ldots \ldots \ldots \ldots \ldots \ldots \ldots \ldots \ldots \ldots \ldots \ldots$

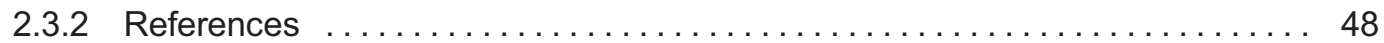

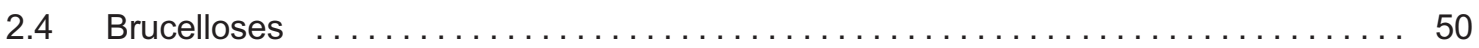

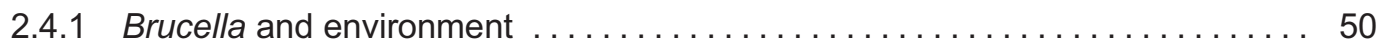

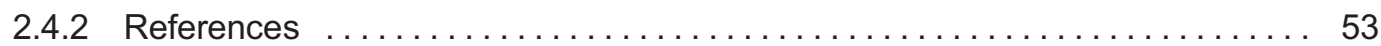

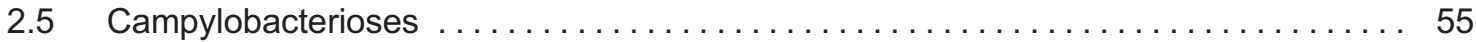

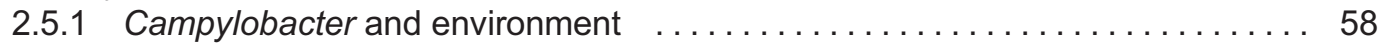

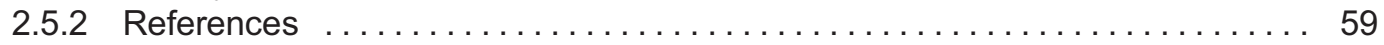

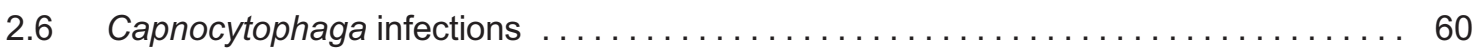

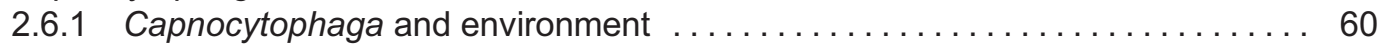

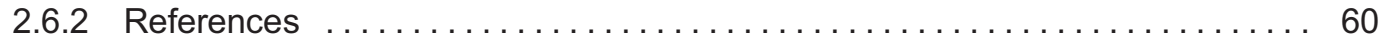

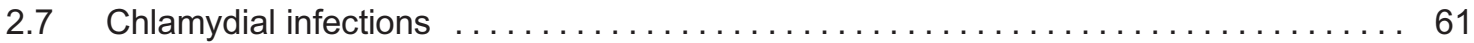

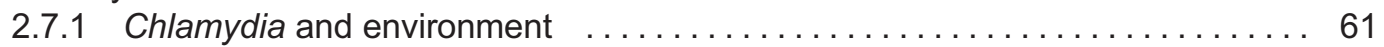

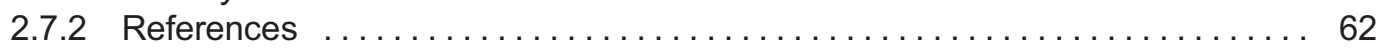

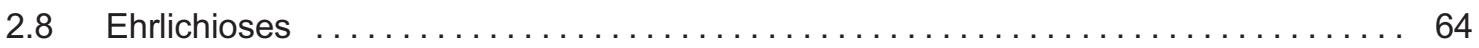

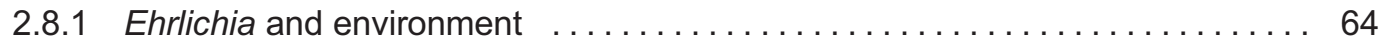

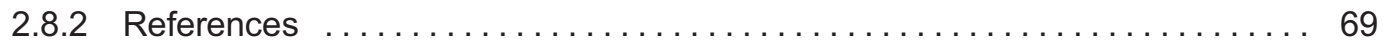

2.9 Enterohemorrhagic Escherichia coli infections $\ldots \ldots \ldots \ldots \ldots \ldots \ldots \ldots \ldots \ldots \ldots \ldots 7$

2.9.1 Enterohemorrhagic Esherichia coli (EHEC)

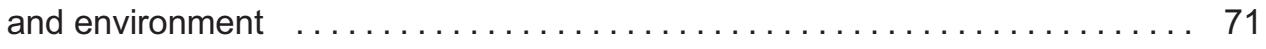

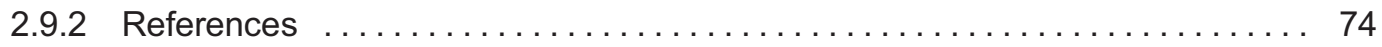

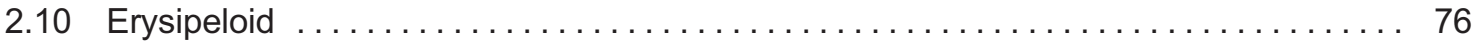

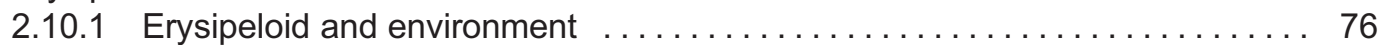

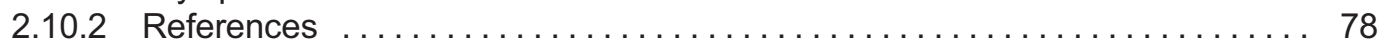

2.11 Glanders (Malleus or Farcy) $\ldots \ldots \ldots \ldots \ldots \ldots \ldots \ldots \ldots \ldots \ldots \ldots \ldots \ldots \ldots \ldots$

2.11.1 Burkholderia mallei and environment $\ldots \ldots \ldots \ldots \ldots \ldots \ldots \ldots \ldots \ldots \ldots$

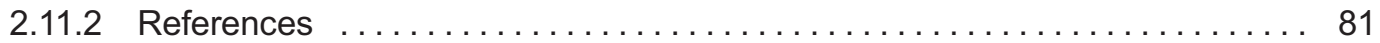

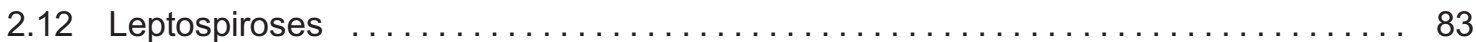

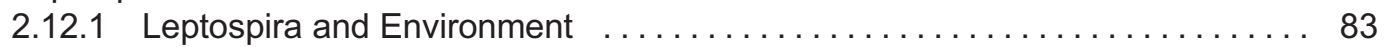

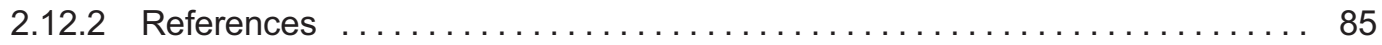

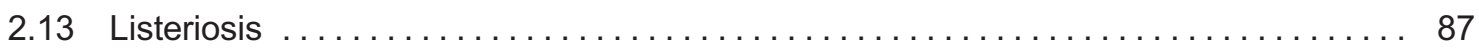

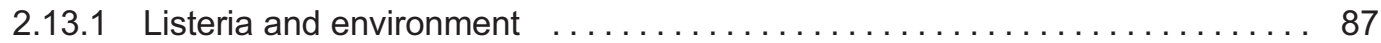

2.13 .2 References ................................. 90

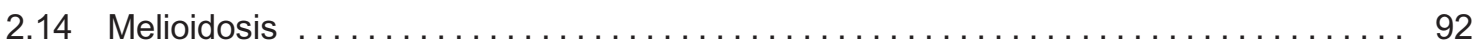

2.14.1 B. Pseudomallei and envoironment $\ldots \ldots \ldots \ldots \ldots \ldots \ldots \ldots \ldots \ldots \ldots . \ldots \ldots$

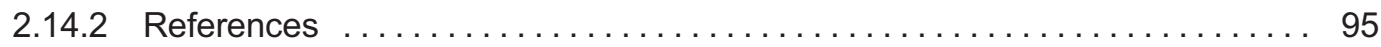


2.15 Mycobacterial Infections $\ldots \ldots \ldots \ldots \ldots \ldots \ldots \ldots \ldots \ldots \ldots \ldots \ldots \ldots \ldots \ldots \ldots \ldots$

2.15.1 Mycobacterium and environment $\ldots \ldots \ldots \ldots \ldots \ldots \ldots \ldots \ldots \ldots \ldots \ldots$

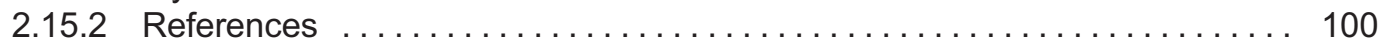

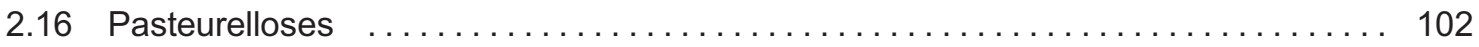

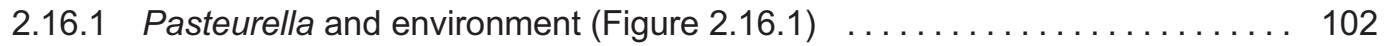

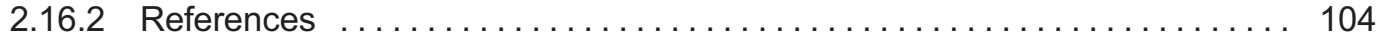

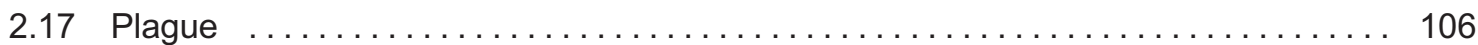

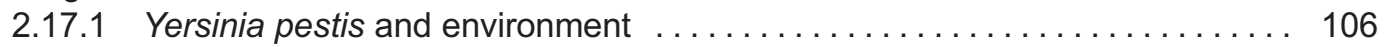

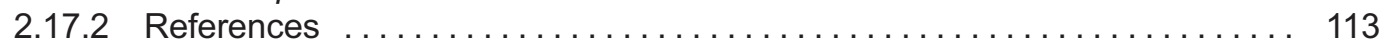

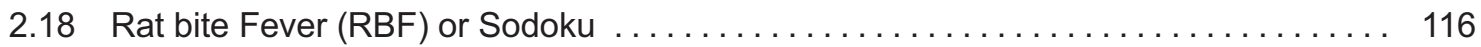

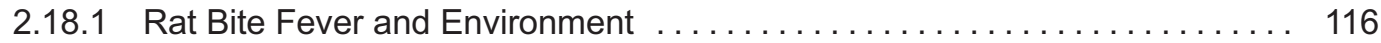

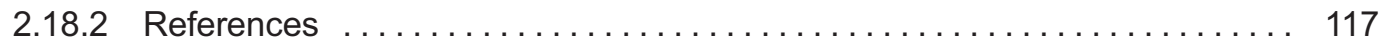

2.19 Rickettsioses .................................... 119

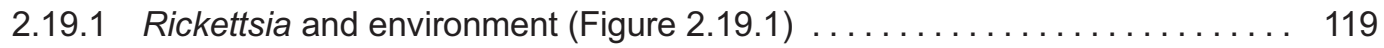

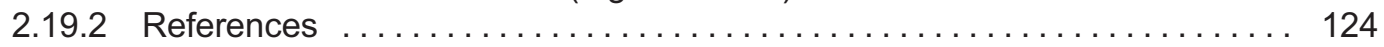

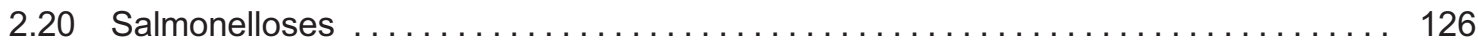

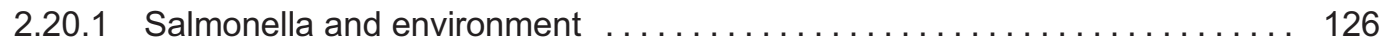

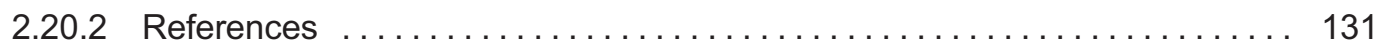

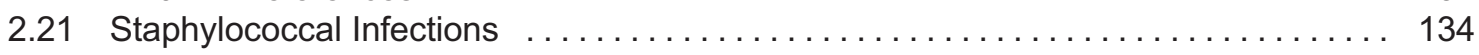

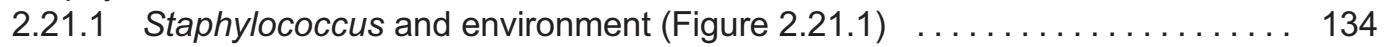

2.21 .2 References ..................................... 138

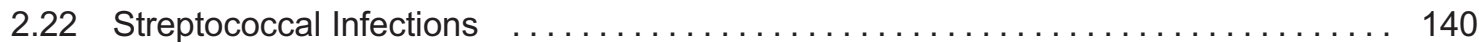

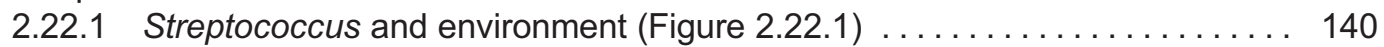

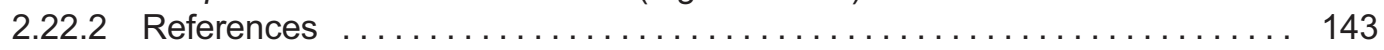

2.23 Tularemia . . . . . . . . . . . . . . . . . . . . . . . . . . . 145

2.23.1 Tularemia and environment (Figure 2.23.1) $\ldots \ldots \ldots \ldots \ldots \ldots \ldots \ldots \ldots$

2.23 .2 References . . . . . . . . . . . . . . . . . . . . . . . . . 149

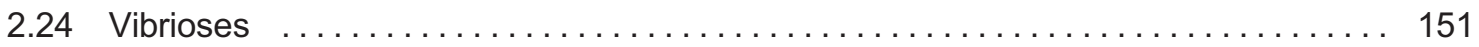

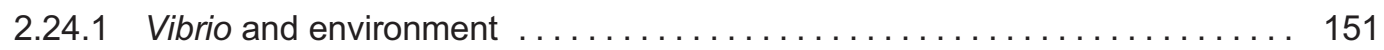

2.24 .2 References . . . . . . . . . . . . . . . . . . . . . . . . . . 157

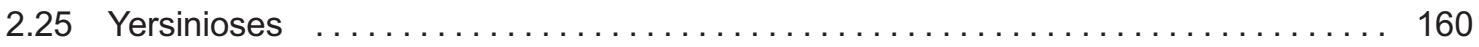

2.25.1 Y. enterocolitica, Y. pseudotuberculosis and environment (Figure 2.25.1) . . 160

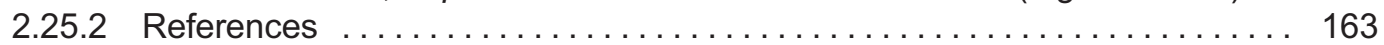

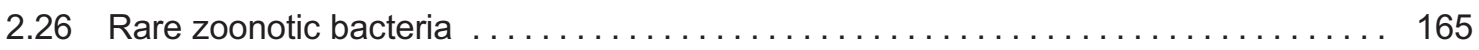

2.26.1 Miscellaneous zoonotic bacteria and environment (Figure 2.26.1) . . . . 165

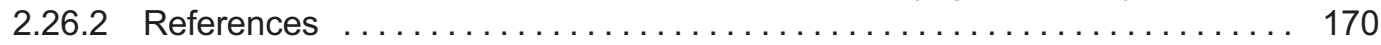

\section{Chapter 3}

Viral Zoonoses $\ldots \ldots \ldots \ldots \ldots \ldots \ldots \ldots \ldots \ldots \ldots \ldots \ldots \ldots \ldots \ldots \ldots$

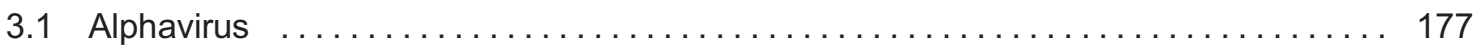

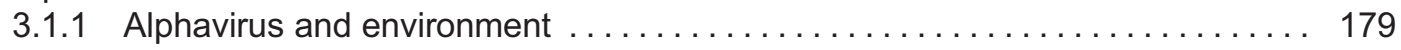

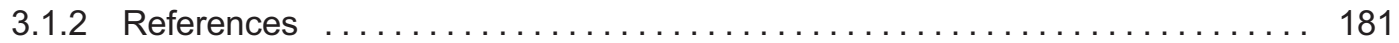

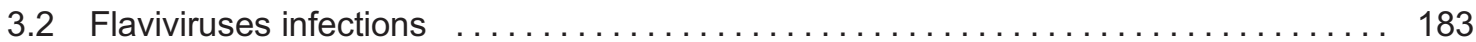

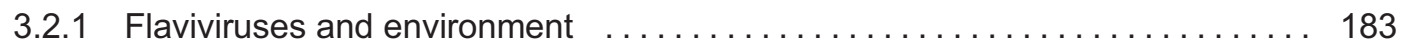

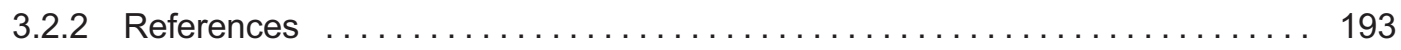




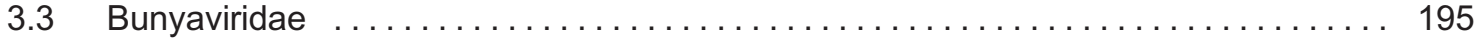

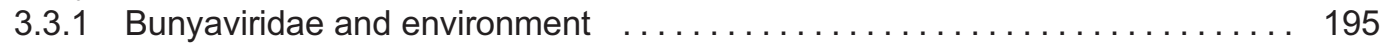

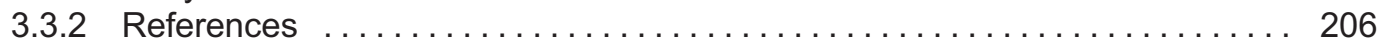

3.4 Reoviruses ..................................... 209

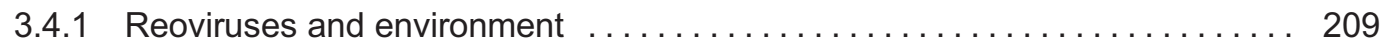

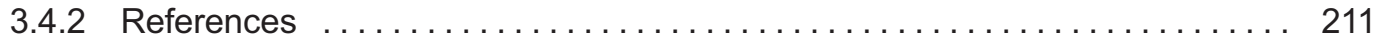

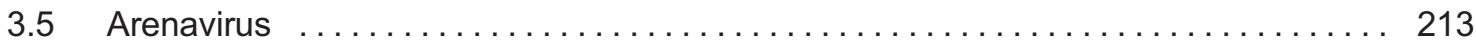

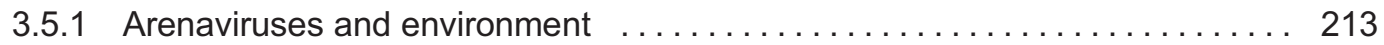

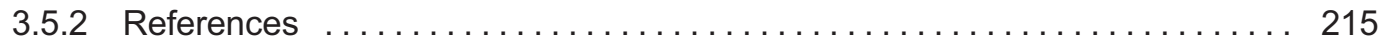

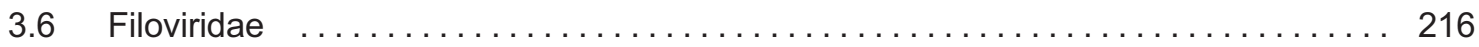

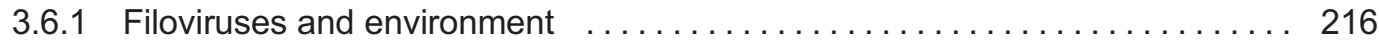

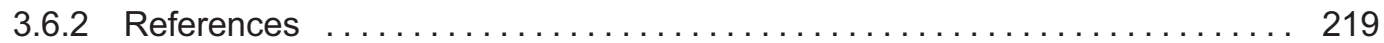

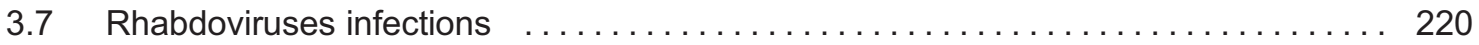

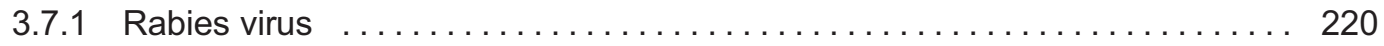

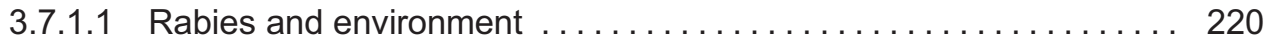

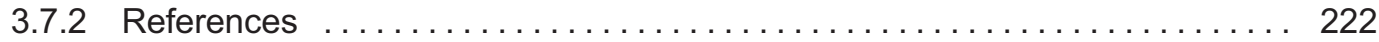

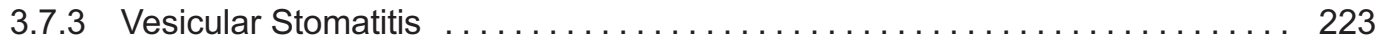

3.7.3.1 [Vesicular Stomatitis Virus-VSV,

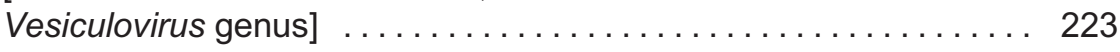

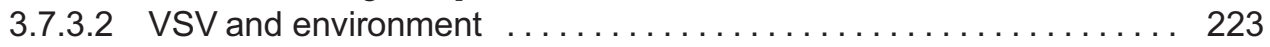

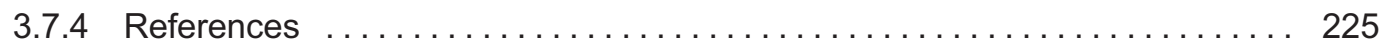

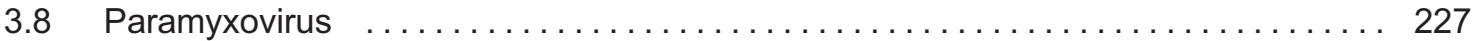

3.8.1 New Castle disease and environment $\ldots \ldots \ldots \ldots \ldots \ldots \ldots \ldots \ldots \ldots \ldots . \ldots 27$

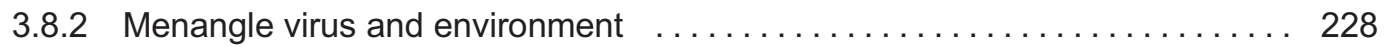

3.8.3 Hendra and Nipha viruses
and environment $\ldots \ldots \ldots \ldots \ldots \ldots \ldots \ldots \ldots \ldots \ldots \ldots \ldots \ldots \ldots \ldots \ldots 228$

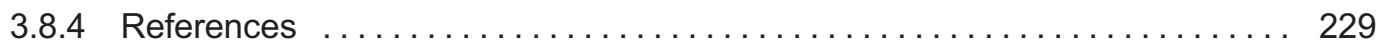

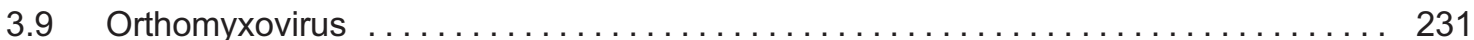

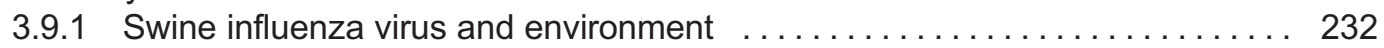

3.9 .2 Avian influenza virus and environment $\ldots \ldots \ldots \ldots \ldots \ldots \ldots \ldots \ldots \ldots \ldots \ldots$

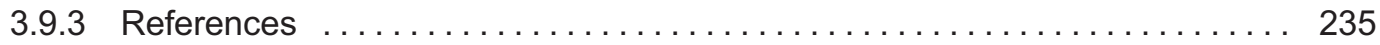

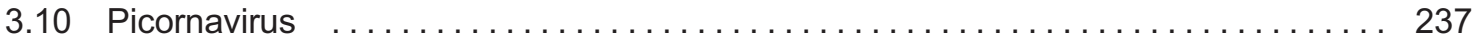

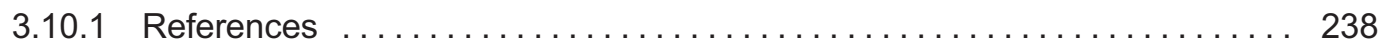

3.11 Herpesvirus ................................... 239

3.11.1 Herpes $B$ virus transmission and environment $\ldots \ldots \ldots \ldots \ldots \ldots \ldots \ldots$

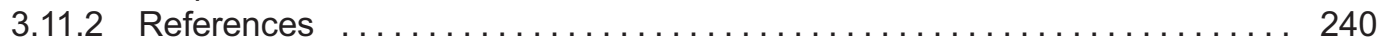

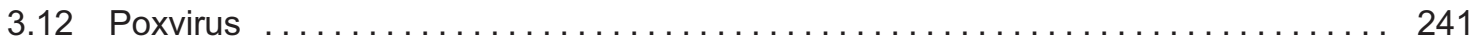

3.12.1 Poxvirus and transmission and environment . . . . . . . . . . . . . 241

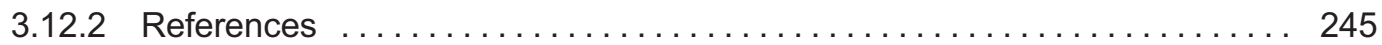

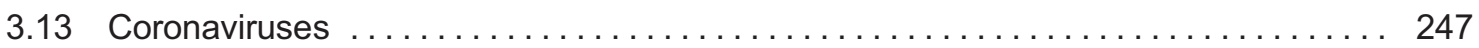

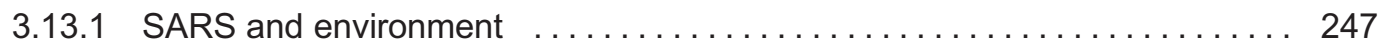

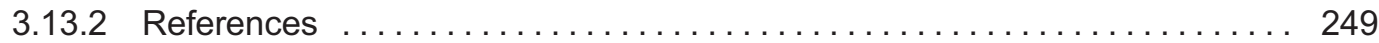

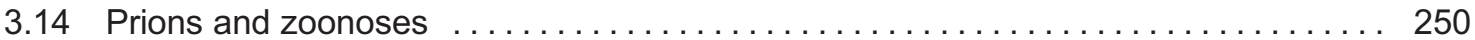

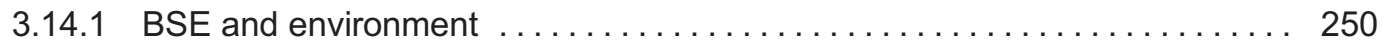

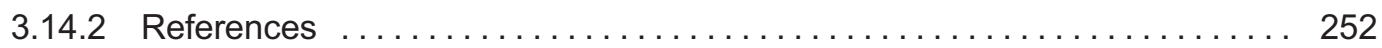




\section{Chapter 4}

Parasitic Zoonoses . . .................................. 255

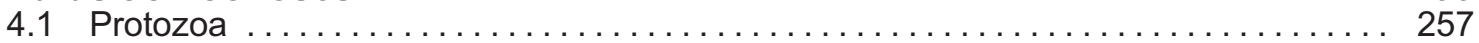

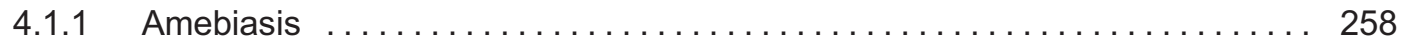

4.1.1.1 Entamoeba histolytica and environment

(Figure 4.1.1.1) .............................. 258

4.1.1.2 References ................................... 260

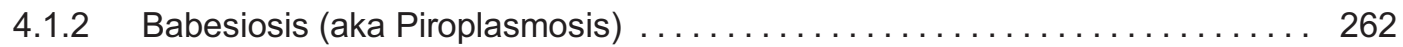

4.1.2.1 Babesia spp. and environment (Figure 4.1.2.1) $\ldots \ldots \ldots \ldots \ldots .262$

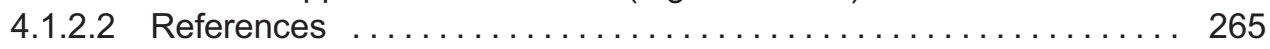

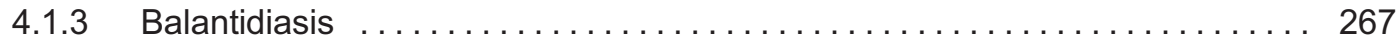

4.1.3.1 Balantidium coli and environment .................... 267

4.1.3.2 References ................................ 269

4.1.4 Chagas' disease (American Trypanosomiasis) $\ldots \ldots \ldots \ldots \ldots \ldots \ldots \ldots . \ldots 270$

4.1.4.1 Trypanozoma cruzi and environment $\ldots \ldots \ldots \ldots \ldots \ldots \ldots \ldots . \ldots \ldots$

4.1.4.2 References ...................................... 274

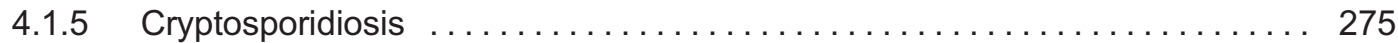

4.1.5.1 Cryptosporidium parvum and environment $\ldots \ldots \ldots \ldots \ldots \ldots .275$

4.1.5.2 References ................................... 279

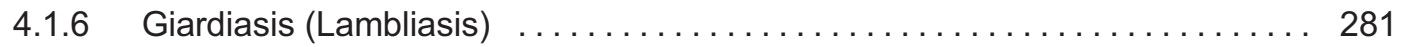

4.1.6.1 Giardia and environment (Figure 4.1.6.1) $\ldots \ldots \ldots \ldots \ldots \ldots \ldots . \ldots 281$

4.1.6.2 References ..................................... 284

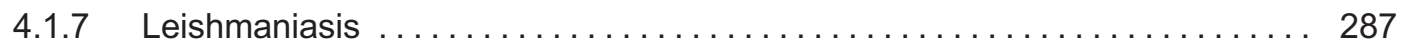

4.1.7.1 Leishmania spp. and environment $\ldots \ldots \ldots \ldots \ldots \ldots \ldots \ldots \ldots . \ldots \ldots$

4.1.7.2 References ..................................... 294

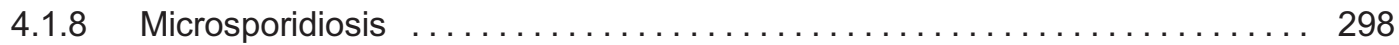

4.1.8.1 Environment and Microsporidia $\ldots \ldots \ldots \ldots \ldots \ldots \ldots \ldots \ldots \ldots 298$

4.1.8.2 References ................................. 302

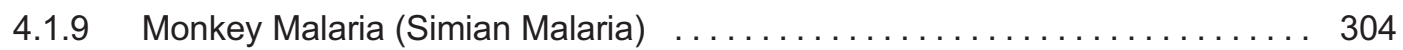

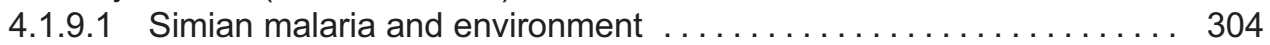

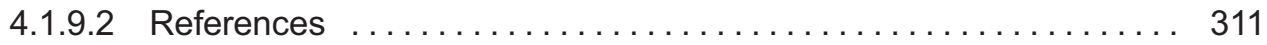

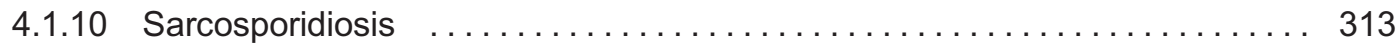

4.1.10.1 Sarcocystis and environment $\ldots \ldots \ldots \ldots \ldots \ldots \ldots \ldots \ldots \ldots \ldots \ldots$

4.1.10.2 References ................................ 315

4.1.11 Sleeping sickness (African Trypanosomiasis) $\ldots \ldots \ldots \ldots \ldots \ldots \ldots \ldots \ldots \ldots$

4.1.11.1 African trypanosomiasis and environment $\ldots \ldots \ldots \ldots \ldots \ldots .318$

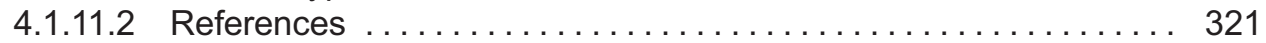

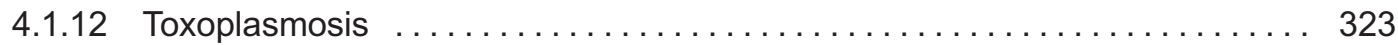

4.1.12.1 Toxoplasma gondii and environment $\ldots \ldots \ldots \ldots \ldots \ldots \ldots \ldots \ldots \ldots$

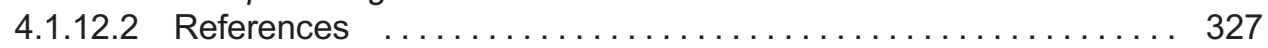

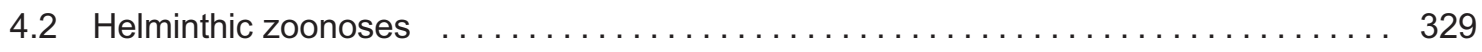

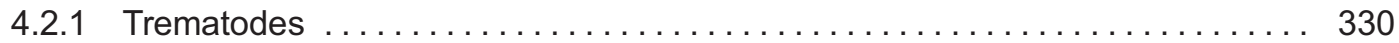

4.2.1.1 Cercarial Dermatitis .......................... 330

4.2.1.1.1 Cercarial dermatitis and environment $\ldots \ldots \ldots \ldots \ldots . \ldots 335$

4.2.1.1.2 References ......................... 335 
4.2.1.2 Clonorchiasis ............................ 336

4.2.1.2.1 Clonorchiasis and environment $\ldots \ldots \ldots \ldots \ldots \ldots \ldots 336$

4.2.1.2.2 References ...................... 338

4.2.1.3 Dicrocoeliasis (Distomatosis) . . . . . . . . . . . . . . . . 339

4.2.1.3.1 Dicrocoeliasis and environment ............ 339

4.2.1.3.2 References ....................... 340

4.2.1.4 Echinostomiasis (Intestinal Fluke Infection) . . . . . . . . . . 341

4.2.1.4.1 Echinostomiasis and environment ........... 341

4.2.1.4.2 References ..................... 343

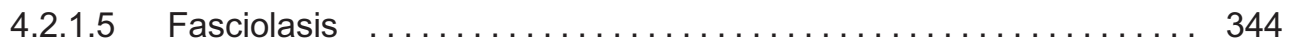

4.2.1.5.1 Fasciolasis and environment $\ldots \ldots \ldots \ldots \ldots \ldots \ldots \ldots$

4.2.1.5.2 References ........................ 347

4.2.1.6 Fasciolopsiasis . . . . . . . . . . . . . . . . . . . . 350

4.2.1.6.1 Fasciolopsiasis and environment ............ 350

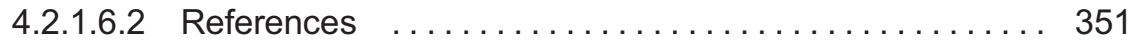

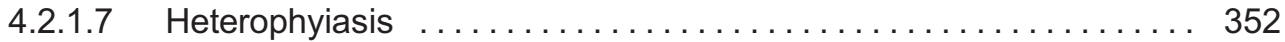

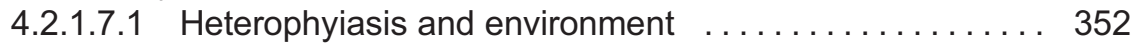

4.2.1.7.2 References ....................... 353

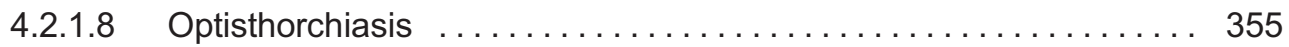

4.2.1.8.1 Opisthorchiasis and environment ........... 355

4.2.1.8.2 References ......................... 356

4.2.1.9 Paragonimiasis (Pulmonary distomatisis) $\ldots \ldots \ldots \ldots \ldots \ldots \ldots \ldots$

4.2.1.9.1 Paragonimiasis and environment . . . . . . . . . . 358

4.2.1.9.2 References ............................ 359

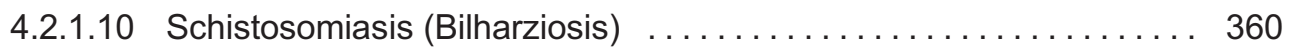

4.2.1.10.1 Schistosomiasis and environment $\ldots \ldots \ldots \ldots \ldots \ldots 361$

4.2.1.10.2 References ...................... 364

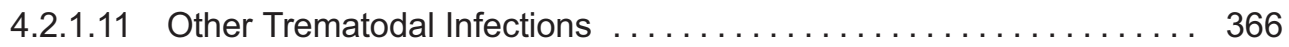

4.2.1.11.1 Eurytrema pancreaticum, Gastrodiscoides homini, Nanophyetes salmincola and environment ....... 369

4.2.1.11.2 References .................... 370

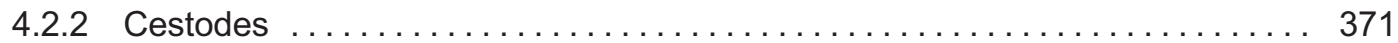

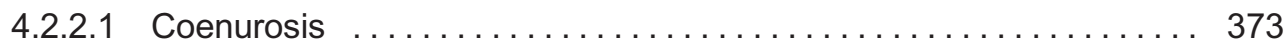

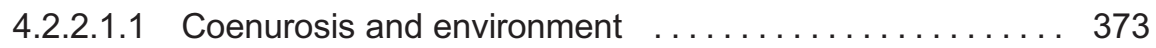

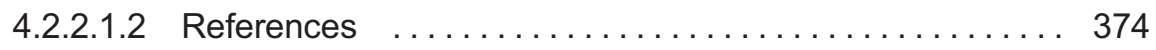

4.2.2.2 Diphyllobothriasis . . . . . . . . . . . . . . . . . 375

4.2.2.2.1 Diphyllobothriasis and environment . . . . . . . . 375

4.2.2.2.2 References .......................... 376

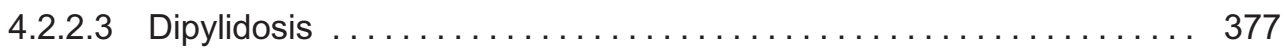

4.2.2.3.1 Dipylidosis and environment . . . . . . . . . . 377

4.2.2.3.2 References ....................... 379

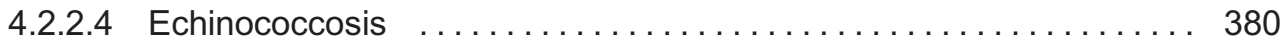

4.2.2.4.1 Echinococcosis and environment ............. 382

4.2.2.4.2 References ........................ 384

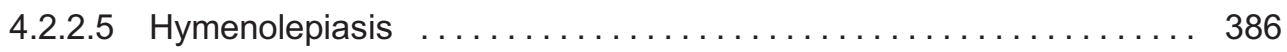


4.2.2.5.1 Hymenolepiasis and environment $\ldots \ldots \ldots \ldots \ldots \ldots . \ldots 386$

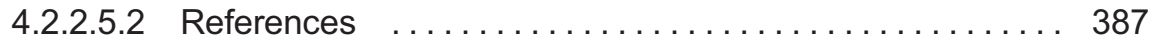

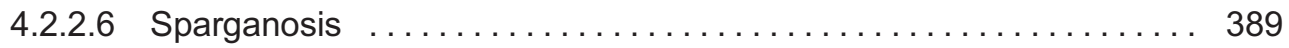

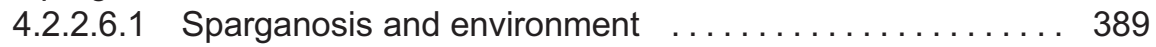

4.2.2.6.2 References .......................... 390

4.2.2.7 Taeniasis Saginata (Including Taeniasis Asiatica) $\ldots \ldots \ldots \ldots \ldots \ldots$

4.2.2.7.1 Taeniasis Saginata and environment . . . . . . . . . . . 391

4.2.2.7.2 References ......................... 393

4.2.2.8 Taeniasis Solium and Cysticercosis . . . . . . . . . . . . . . . . 394

4.2.2.8.1 Taeniasis solium and cysticercosis

and environment ........................... 394

4.2.2.8.2 References ... . . . . . . . . . . . . . . . . . . . . 395

4.2.2.9 Other Intestinal Cestode Infections . . . . . . . . . . . . . . . . 397

4.2.2.9.1 Other intestinal cestodes and environment . . . . . . . . 397

4.2.2.9.2 References ....................... 399

4.2 .3 Nematodes ................................. 400

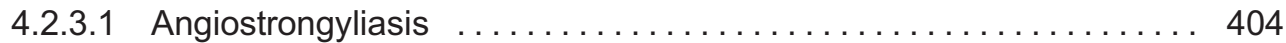

4.2.3.1.1 Angiostrongyliasis and environment . . . . . . . . 405

4.2.3.1.2 References ....................... 406

4.2.3.2 Anisakiasis (Herring Worm Disease) . . . . . . . . . . . . . 407

4.2.3.2.1 Anisakiasis and environment . . . . . . . . . . . . . 408

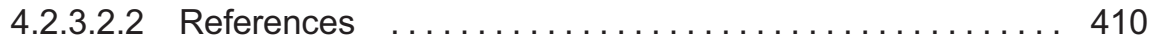

4.2.3.3 Capillariasis (hepatic, intestinal and pulmonary) . . . . . . . . 412

4.2.3.3.1 Capillariasis and environment ............... 413

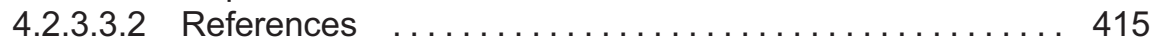

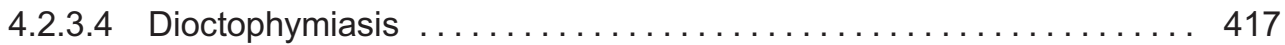

4.2.3.4.1 Dioctophymiasis and environment . . . . . . . . . . . 417

4.2.3.4.2 References .......................... 418

4.2.3.5 Dracunculiasis (Guinea worm infection) . . . . . . . . . . . . . 419

4.2.3.5.1 Dracunculiasis and environment .............. 419

4.2.3.5.2 References ............................ 420

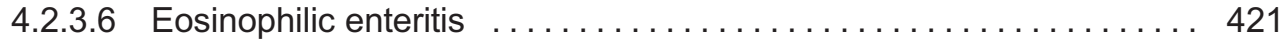

4.2.3.6.1 Eosinophilic enteritis and environment . . . . . . . . . 421

4.2.3.6.2 References .......................... 423

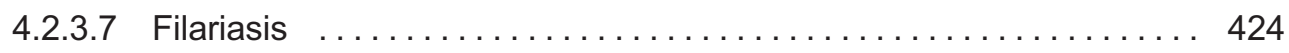

4.2.3.7.1 General ........................ 424

4.2.3.7.2 Brugia Filariasis (Lymphatic Filariasis) . . . . . . . . . 424

4.2.3.7.3 Filariasis and environment ................... 425

4.2.3.7.4 References ......................... 427

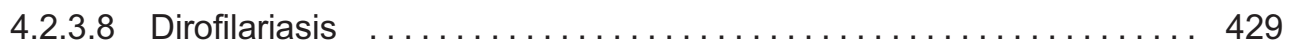

4.2.3.8.1 Dirofilariasis and environment . . . . . . . . . . . . . . 429

4.2.3.8.2 References ... . . . . . . . . . . . . . . . . . . . . . . 431

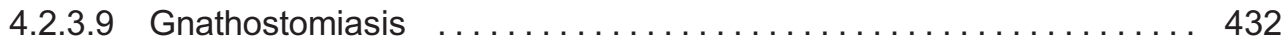

4.2.3.9.1 Gnathostomiasis and environment ............ 432

4.2.3.9.2 References ....................... 433 
4.2.3.10 Gongylonemiasis . . . . . . . . . . . . . . . . . 434

4.2.3.10.1 Gongylonemiasis and environment ........... 434

4.2.3.10.2 References ..................... 435

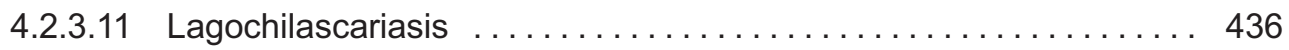

4.2.3.11.1 Lagochilascariasis and environment ......... 436

4.2.3.11.2 References ...................... 437

4.2.3.12 Larva migrans cutanea $\ldots \ldots \ldots \ldots \ldots \ldots \ldots \ldots \ldots \ldots \ldots \ldots . \ldots \ldots$

4.2.3.12.1 Larva Migrans Cutanea and environment ....... 438

4.2.3.12.2 References ..................... 440

4.2.3.13 Larva migrans visceralis . . . . . . . . . . . . . . . 441

4.2.3.13.1 Larva Migrans Visceralis and environment . . . . . . . 442

4.2.3.13.2 References ....................... 443

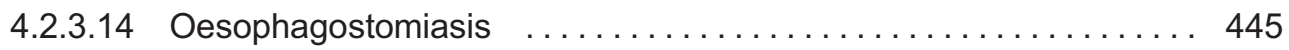

4.2.3.14.1 Oesophagostomiasis and environment ........446 446

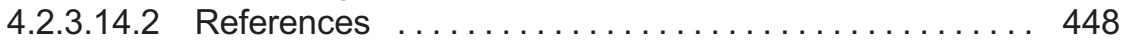

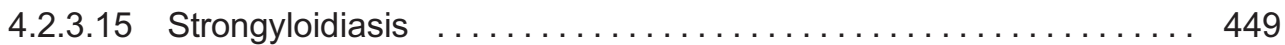

4.2.3.15.1 Strongyloidiasis and environment .......... 450

4.2.3.15.2 References ........................ 451

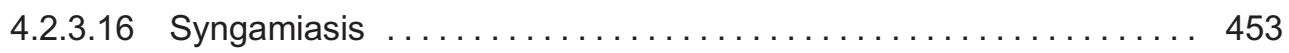

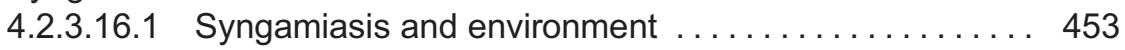

4.2.3.16.2 References ........................... 454

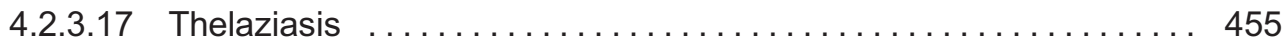

4.2.3.17.1 Thelaziasis and environment . . . . . . . . . 455

4.2.3.17.2 References ........................ 456

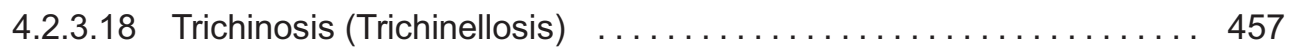

4.2.3.18.1 Trichinosis and environment ............ 461

4.2.3.18.2 References ....................... 463

4.2.3.19 Trichostrongylidiasis (Trichostrongylosis) . . . . . . . . . . . . 464

4.2.3.19.1 Trichostrongylosis and environment ........... 464

4.2.3.19.2 References ..................... 466

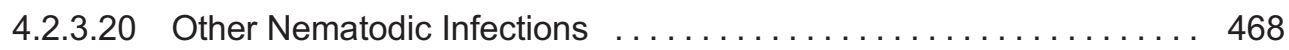

4.2.3.20.1 Ancylostoma ceylanicum, Physaloptera caucasica, Ternidens deminatus and environment ......... 468

4.2.3.20.2 References ..................... 469

\section{Chapter 5}

Fungal Zoonoses ... . . . . . . . . . . . . . . . . . . . . . . . . . . 471

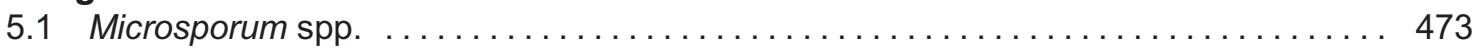

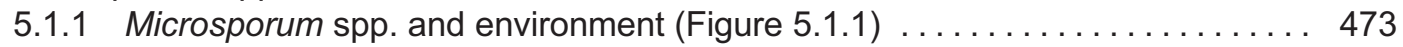

5.1 .2 References ................................ 476

5.2 Pneumocystosis (Pneumocystis pneumonia) $\ldots \ldots \ldots \ldots \ldots \ldots \ldots \ldots \ldots \ldots \ldots$

5.2 .1 Pneumocystis and environment $\ldots \ldots \ldots \ldots \ldots \ldots \ldots \ldots \ldots \ldots \ldots \ldots \ldots$

5.2 .2 References ................................... 479

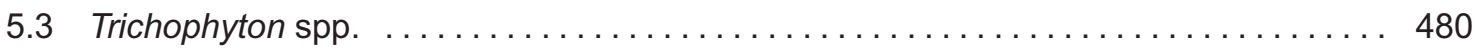

5.3.1 Trichophyton spp. and environment $\ldots \ldots \ldots \ldots \ldots \ldots \ldots \ldots \ldots \ldots \ldots \ldots$ 


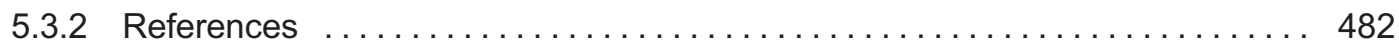

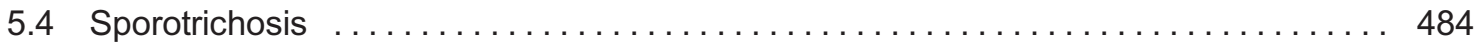

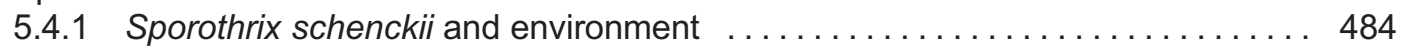

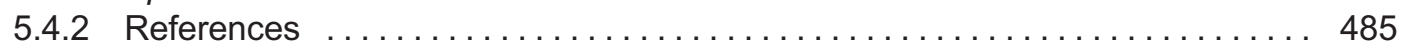

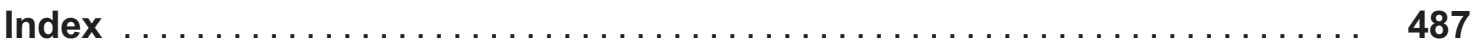


Downloaded from https://iwaponline.com/ebooks/book-pdf/521254/wio9781780400761.pdf

Downloaded trom https://Iwaponline.com/ebooks/book-pdt/521254/WI09/81/80400/61.pdt
by IWA Publishing user 


\section{Preface}

\section{"We are a cluster of molecules trying to comprehend themselves"}

During my "Sabbatical" year at ESR (Environmental Science and Research Institute) in Christchurch, New Zealand, I was startled by the small population of this country ( 4.4 millions) and the huge sheep population ( $\sim 40$ millions) both inhabiting the two islands of this country. While discussing different environmental issues with my colleague and host, Dr. Marion Savill, I wondered if such a massive ratio of domestic animals to humans does not reflect itself in water and environmental pollution and consequently in high numbers of zoonoses. Further verifications, revealed that indeed New Zealand has a high prevalence of Campylobacteriosis, a consequence of this country's vast numbers of free-grazing sheep. A brief look at a dataset published by the from Ministry of Agriculture and Forestry (NZ), according to reports for the year 2007, the country domestic animal inventory was (in millions): $\sim 6$ dairy cattle, 1.4 deer, 38.5 sheep, 0.4 pigs, 0.1 goats, 0.066 horses and 19.8 poultry. While preparing myself for the one year visit, I gained knowledge of some facts about this remote country such as, its area size is close to that of the UK and even larger (Table I). As a consequence, I decided to link some numerical data for comparison. The ratio of animals per person (animal density) in New Zealand is 6.25 higher than in the UK (in spite of there being almost twice as many animals in the UK!) and zoonoses are $\sim 6.1$ higher. These two countries have two important and comparable parameters that help in such an assessment: area size and ethnical similarity. Recently, Kabore et al. (2010) evaluated the association of potential zoonotic gastroenteritis in children (e.g., giardiasis, salmonellosis and campylobacteriosis) with environmental risk factors (livestock densities and drinking water quality) in rural Quebec (Canada). Using statistical tools (negative binomial regression models accounting for overdispersion and adjusted for clustering) the authors found that all three zoonoses were significantly correlated to animals density. In addition Giardiasis incidence was also positively associated with poor drinking water quality (without a statistically significant association). Snel et al. (2009) using a simple linear regression model, analyzed ten years of giardiasis cases in New Zealand (rural and urban cases) to find whether an association between disease rates and animal density exists, at the territorial authority level. Their results did not reveal a significant correlation between giardiasis and farm animal density at this level. Their explanation 
of the nonsignificant results was that giardiasis distribution is largely linked to anthroponotic (human) reservoirs and much less to zoonotic sources in rural environments and to contributions from overseas travel. It should be borne in mind that giardiasis is mainly a waterborne disease and zoonotic to a much smaller degree. Nonetheless, the same authors (Snell et al., 2009), using the same simple linear regression model, analyzed ten years of cryptosporidiosis cases in New Zealand (rural and urban cases) to find whether an association between disease rates and animal density exists, at the territorial authority level. This time they reported a significant correlation between farm animal density and cryptosporidiosis, with much higher rates in rural areas. In this case, the results supported the fact that the Cryptosporidium parasite is mainly zoonotic (transmitted from farm animals to humans) and animal density is indeed a significant risk factor as already pointed out by the Canadian study and our number manipulations!

Table I. Some data related to domestic animals, country area, population and zoonoses in two countries (UK and New Zealand) (based on 2007 data from both countries).

\begin{tabular}{lll}
\hline Animal & $\begin{array}{l}\text { New Zealand } \\
(\times \mathbf{1 0})\end{array}$ & $\begin{array}{l}\text { UK } \\
\left(\times \mathbf{1 0} \mathbf{7}^{\mathbf{7}}\right)\end{array}$ \\
\hline Cattle & 6 & 5.5 \\
Deer & 1.4 & 0.002 \\
Sheep & 38.46 & 14.2 \\
Pigs & 0.36 & 3.6 \\
Goats & 0.11 & 0.069 \\
Horses & 0.06 & 0.2 \\
Poultry & 19.8 & 125 \\
Total & 66.19 & 148.57 \\
Population & $4.4 \times 10^{7}$ & $62 \times 10^{7}$ \\
Country area size & $268,021 \mathrm{~km}^{2}$ & $243,610 \mathrm{~km}^{2}$ \\
Ratio-animals/human & 15 & 2.4 \\
Ratio-animals/area (No./km) & 2470 & 6098 \\
Reported zoonoses (year) & 518.100 & 84.989 \\
& $(2009)$ & $(2009)$ \\
Zoonoses ratio between NZ/UK & 6.096 & \\
Animals/human ratio between NZ/UK & 6.25 & \\
\hline
\end{tabular}

In light of these basic data, we raised an important question that had troubled us for a long time: OK, the natural situation is as it is but how do we, human kind, by our "continuous development prerogative", and unpreventable natural disasters (e.g., earthquakes, floods, draughts, global warming, tsunami, etc.) jointly impact zoonoses? The present book is a result of over 2,000 scientific publications collected, sorted and critically explored to accomplish the interesting and stimulating depiction of the various relationships between environment, anthropogenic environmental intervention and zoonoses. We are very grateful to the meticulous and comprehensible book "Zoonoses- Infectious diseases transmissible from animals to humans" (3rd edition) edited by Krauss et al. (2003) that helped us to navigate systematically our way through such a huge mass of zoonotic pathogens. 
We would like also to thank our families and students for their indulgent patience and to apologize for the unjustified absence when they needed us as a consequence of our passion for this fascinating topic.

Robert Armon and Uta Cheruti, Technion, Haifa, 2011

\section{REFERENCES}

Kabore, H., Levallois, P., Michel, P., Payment, P., Dery, P. \& Gingras, S. (2010) Association between potential zoonotic enteric infections in children and environmental risk factors in Quebec, 1999-2006. Zoonoses Public Health 57, e195-205.

Krauss, H., Weber, A., Appel, M., Enders, B., Isenberg, H.D., Schiefer, H.G., Slenczka, W., von Graevenitz, A and Zahner, H. (Eds.) (2003) Zoonoses-Infectious diseases transmissible from animals to humans. ASM Press, Washington, D.C.

Snel, S.J., Baker, M.G. \& Venugopal, K. (2009) The epidemiology of giardiasis in New Zealand, 1997-2006. N. Z. Med. J. 122, 62-75.

Snel, S.J., Baker, M.G., \& Venugopal, K. (2009) The epidemiology of cryptosporidiosis in New Zealand, 1997-2006. N. Z. Med. J. 122, 47-61. 
Downloaded from https://iwaponline.com/ebooks/book-pdf/521254/wio9781780400761.pdf

Downloaded trom https://Iwaponline.com/ebooks/book-pdt/521254/WI09/81/80400/61.pdt
by IWA Publishing user 


\section{Brief CV of the authors}

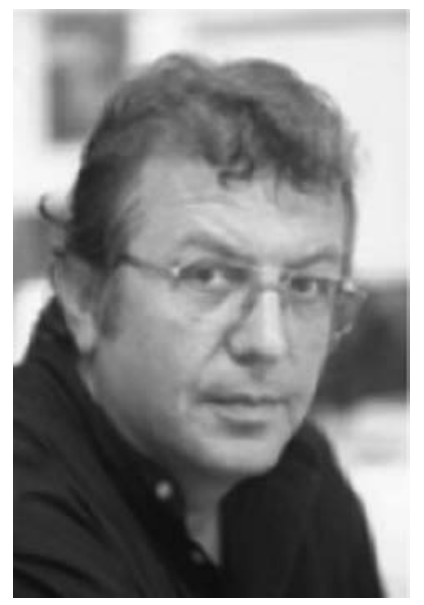

Robert Armon

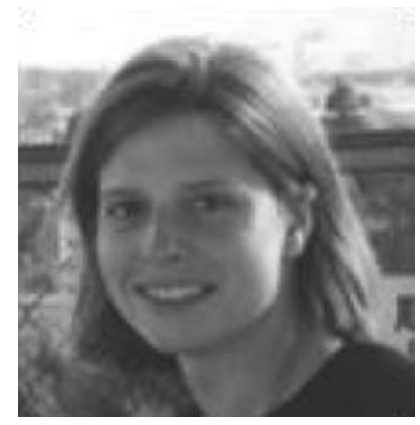

Uta Cheruti
Prof. Armon was born in Bucharest, Romania. He studied Biology (B.Sc.) and Environmental virology (M.Sc.) at Hebrew University of Jerusalem, Israel. He earned his D.Sc. in Environmental virology from the Faculty of Biotechnology and Food Engineering (Technion, Haifa, Israel). Post-Doctoral studies followed at University of Rhode Island, USA (one year) and Institut Armand-Frappier, University of Québec, Canada (two years). Since 1994, is a faculty member of Civil \& Environmental Engineering Faculty at Technion (Israel Institute of Technology, Haifa, Israel). Prof. Armon is teaching Environmental Microbiology and carries research on related issues in this area. He published over 84 scientific publications in peer-review international journals, wrote different chapters in several books and is a member of various international scientific organizations (IWA, HRWM, ISEI, ASM, etc.).

Dr. Cheruti was born in Gelsenkirchen, Germany. She completed her undergraduate degree in Biology at the Technical University RWTH Aachen and her M.Sc. in Immunology and Parasitology at Tel-Aviv University, Israel. She completed her Ph.D. (Dr. rer. nat.) in Immunology at the Johannes Gutenberg University in Mainz, Germany. After one year Postdoctoral research at Israel Oceanographic \& Limnological Research Institute, Israel, she is at present in charge with all biological laboratories (undergraduate and graduate) and advanced research at the Civil \& Environmental Engineering Faculty at Technion (Israel Institute of Technology, Haifa, Israel). 
Downloaded from https://iwaponline.com/ebooks/book-pdf/521254/wio9781780400761.pdf

Downloaded trom https://Iwaponline.com/ebooks/book-pdt/521254/WI09/81/80400/61.pdt
by IWA Publishing user 


\section{Acknowledgements}

\section{* "Tanto sa cíascuno, quanto opera" \\ [Ones knowledge is built upon his industriousness]}

To my children (Yair, Naama, Maaian, Jonathan, Adi and my grandson Yali), to my girlfriend Maya, Ilana and to my late parents (Theodor and Dorothea) for their support, patience and inspiration.

To Doron, Yarden, Meiron, Carmel (my husband and my children) and my parents (Christel and Josef) for their support.

*Bartolommeo Aquarone (1857) "Vita di Fra Jeronimo Savonarola". LIBRO SECONDO

*Pasquale Villari (2006) “La storia di Girolamo Savonarola e de'suoi tempi”. Vol. 1, Elibron Classics Series. 
Downloaded from https://iwaponline.com/ebooks/book-pdf/521254/wio9781780400761.pdf

Downloaded trom https://Iwaponline.com/ebooks/book-pdt/521254/WI09/81/80400/61.pdt
by IWA Publishing user 


\section{Chapter 1}

\section{Introduction}


Downloaded from https://iwaponline.com/ebooks/book-pdf/521254/wio9781780400761.pdf

Downloaded trom https://Iwaponline.com/ebooks/book-pdt/521254/WI09/81/80400/61.pdt
by IWA Publishing user 


\title{
Chapter 1.1
}

\section{Human population and socio-economic distribution}

\author{
"How Much Land Does a Man Need?" \\ Count Lyev Nikolayevich Tolstoy (1828-1910)
}

It is a factious reality that all the creatures upon this globe have to live together in harmony. In Genesis 7:15-17 (Old Testament) the description of man and animal contact is very much emphasized : "They had with them every wild animal according to its kind, all livestock according to their kinds, every creature that moves along the ground according to its kind and every bird according to its kind, everything with wings. ${ }^{15}$ Pairs of all creatures that have the breath of life in them came to Noah and entered the ark. ${ }^{16}$ The animals going in were male and female of every living thing, as God had commanded Noah. Then the LORD shut him in." We doubt if the zoonotic concept was clear at that time, but the story describes the close relationship between humans and other "God created" creatures. The only problem, to evolve into a serious one, was the humans themselves.

Since the start of the 20th century, human population has more than tripled its size from $\sim 1.8$ to $\sim 6.9$ billion (Figure 1.1.1) (Steck, 2010). According to United Nations database, there are several scenarios on of the human population prospect, some based on status-quo: women's productivity does not change [birth rate remains 2.82 children/woman (constant progression, red line)] and therefore the population will continue to expand to 13 billion in 2050; the more optimistic ones are based on the hypothesis that the birth rate will drop from 2.82 to 2.15 children/woman, including a life expectancy increase from 65 to 76 years [blue lines: high and low estimation dotted lines and medium continuous line] to range from 8 to 11 billion (9 billion medium) in 2050 (Figure 1.1.2). There are many reasons for this huge increment, but perhaps the most egregious one is the advanced medical treatment (scientific revolution) that followed the industrial revolution. Wars, famine, natural catastrophes, economic scrambles, etc. did not affect the global population's exponential growth as medicine did. If we want to understand this phenomenon, perhaps the most perceptive step is to glance at the records of the deceased registered throughout the centuries by the Catholic Church in Europe of the Middle Ages. An average human life of 40 years was the upper limit while people reaching the advanced ages of 50 and 60 were considered to be the village elders! These days, a retired person in his late 60's is still considered "young". In nature, the animal population is largely controlled by food availability, territory and epizootics which are in harmonious balance with environmental factors. Interestingly, we (the humans) are competent to 
control these populations for our own benefit, for instance animals' domestication in large numbers. However, who controls our own population? There are two main factors that might control it: our progressive awareness and environmental capacity. Of the awareness part, in spite of cultural "bottle necks" (illiteracy, diverse cultural and religious norms), there is a general endorsement that our population cannot grow continuously at the same rate and has to slow down or enter a "zero" growth kinetic. Of the environmental capacity part there is "no need" for direct awareness, as it blows itself up in our face. Increasing industrial capacity to its limits created a new problem of intense pollution that in turn affected the population's well-being and its environment. It is not within our scope to analyze different models as we are neither demographers nor population scientists, but the common sense of microbial growth can be in large applied to the human population based solely on reproduction, though the time scale is different. Immigration or migration cannot be considered as they do not change the population size but only its composition. In terms of socio-economic composition, it can be in general stated that the "North" is rich and "South" is poor. Indeed, large areas of the South include more developing countries than the "North" that harbors more developed countries. There is no need to say that migration/ immigration from the "South" to the "North" is a continuous process, with some positive aspects related to population growth (e.g., education merged with socio-economic progress tend to impact birth rate).

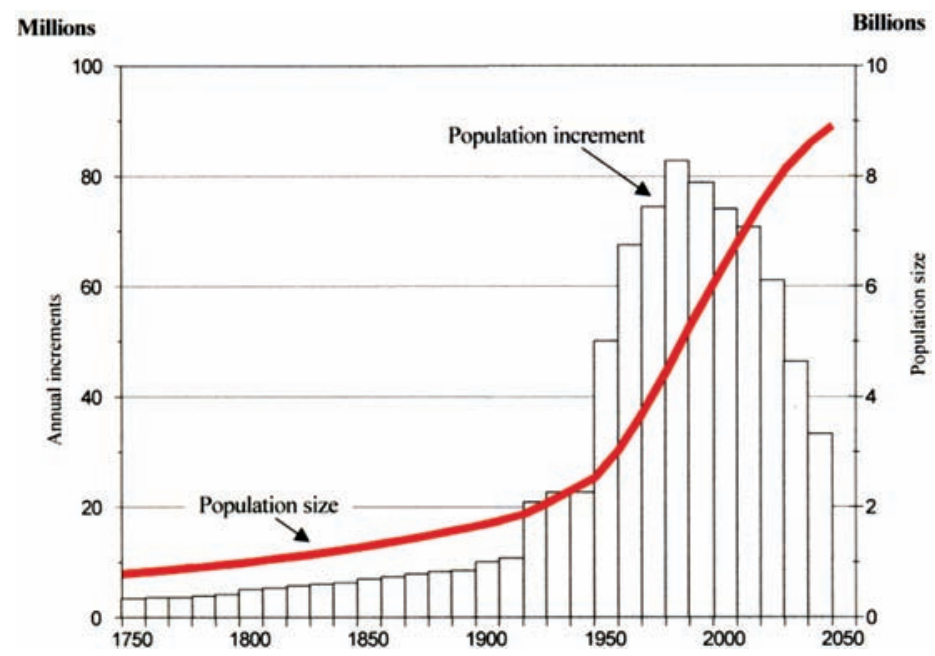

Figure 1.1.1. Historical world population growth from 1750 to 2050. (Source: United Nations Population Division)

Another interesting trend in human population is the continuous relocation from rural to urban areas in developing countries (Figure 1.1.3). The trend is linked to economic aspects such as rapid industrial development in urban areas and decline in agricultural activities that are less profitable and demand long and tiresome labor. According to 2005 FAOSTAT (Food and Agricultural Organization statistical databases), at that time the world population of 6.4 billion was divided in $49 \%$ urban and $51 \%$ rural populations. As a result, the socio-economic division of urban population between high and low $/$ middle income countries, from 1975 up to 2015, shows a steady linear increase in low/middle income countries (from 1.6 billion to 3.9 billion) with a minor increase in high income countries (from 0.5 to 0.8 billion). 


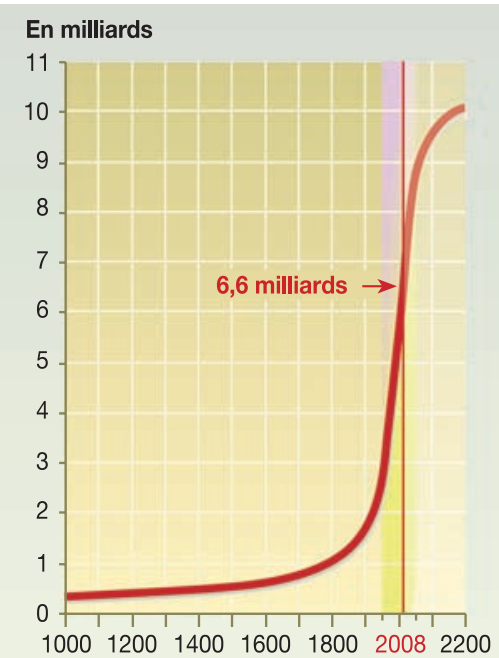

Trois hypothèses pour l'évolution de la population mondiale :

Selon le bureau de la population des Nations unies, la plus vraisemblable est l'hypothèse moyenne : pour les périodes $1995-2000$ et 2045-2050, elle prend en compte d'une part, la réduction du nombre d'enfants par femme (de 2,82 à 2,15), et d'autre part, une amélioration de l'espérance de vie à la naissance (de 65 à 76 ans). Le taux d'accroissement naturel tomberait ainsi de $1,35 \%$ en $1995-2000$ à $0,47 \%$ en 2045-2050.

Progression constante :

La ligne bleue représente ce que serait l'évolution démographique si le taux de fertilité actuel (2,82 enfants par femme) restait le même jusqu'en 2050.

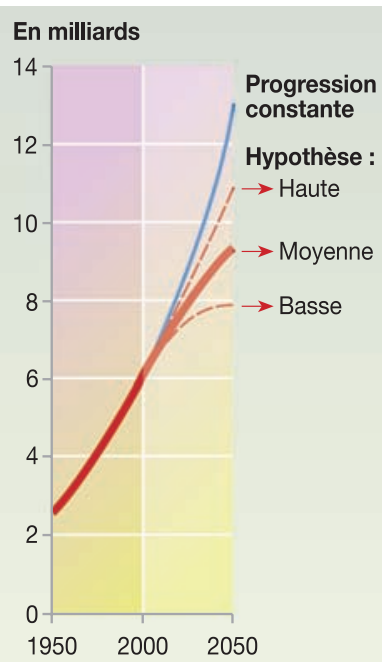

Sources : The World at Six Billion (octobre 1999) et World Population Prospects: The 2006 Revision (février 2007), Nations unies, département des affaires économiques et sociales, division de la population, New York.

Figure 1.1.2. World population evolution. (2009). In UNEP/GRID-Arendal Maps and Graphics Library. Retrieved 10:36, April 20, 2011 from http://maps.grida.no/go/graphic/world-population-evolution, credit to Philippe Rekacewicz (Le Monde diplomatique)

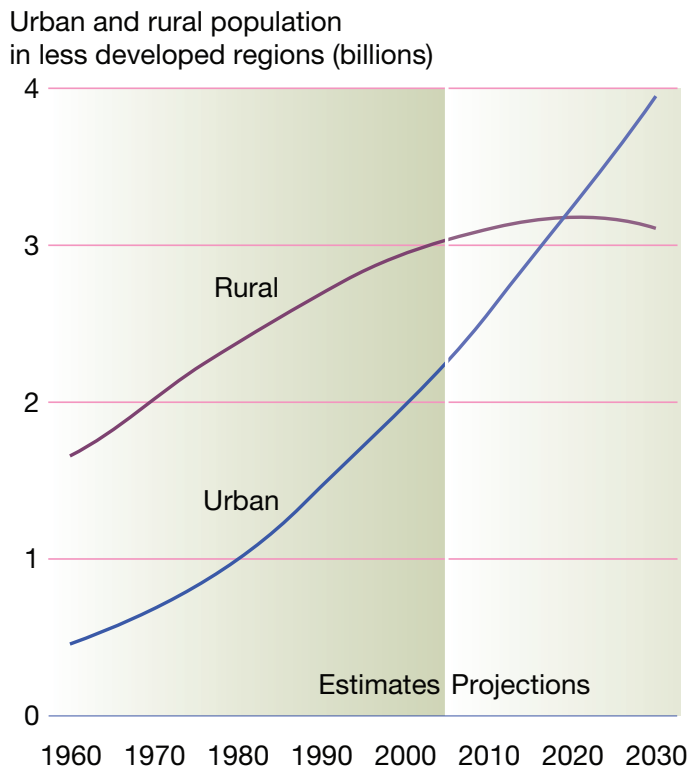

Figure 1.1.3. Trends in urban and rural populations, less developed regions, 1960-2030 (estimates and projections) . (2009). In UNEP/GRID-Arendal Maps and Graphics Library. Retrieved 21:34, May 4, 2011 from http://maps.grida.no/go/graphic/trends-in-urban-and-rural-populations-less-developed-regions-19602030-estimates-and-projections. credit to Hugo Ahlenius, Nordpil 


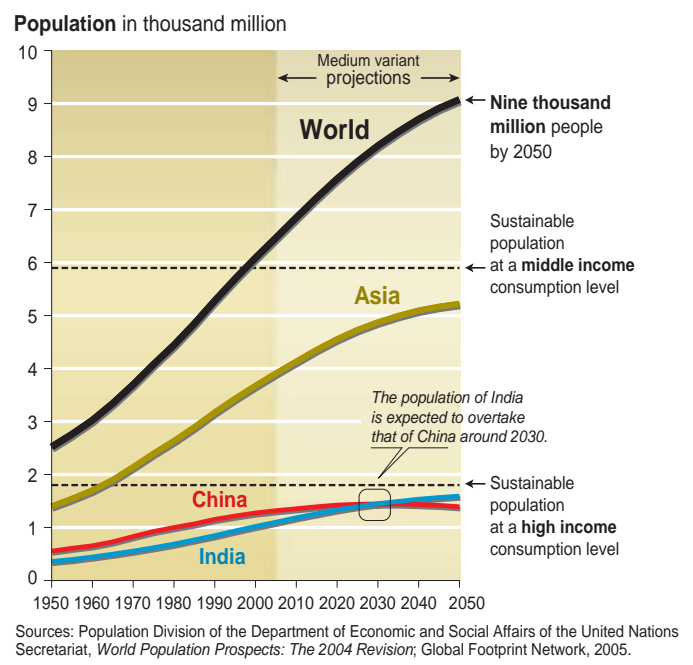

Figure 1.1.4. World Population. (2006). In UNEP/GRID-Arendal Maps and Graphics Library. Retrieved 21:28, May 4, 2011 from http://maps.grida.no/go/graphic/world_population, credit to Emmanuelle Bournay (Population Division of the Department of Economic and Social Affairs of the United Nations Secretariat, World Population Prospects: The 2004 Revision; Global Footprint Network, 2005)

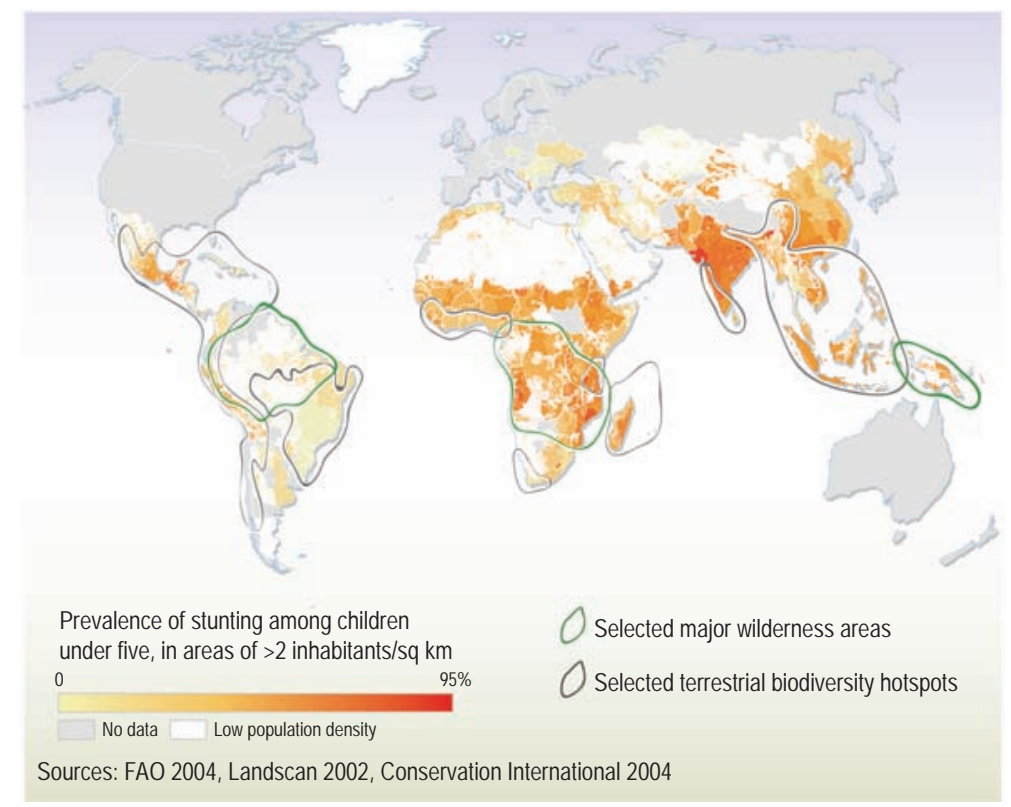

Figure 1.1.5. Global poverty-biodiversity map. (2004). In UNEP/GRID-Arendal Maps and Graphics Library. Retrieved 21:34, May 4, 2011 from http://maps.grida.no/go/graphic/global-poverty-biodiversity-map, credit to Hugo Ahlenius, UNEP/GRID-Arendal (Landscan, FAO, Conservation International) 
In relation to environmental sustainability (i.e., how many people can be supported at a certain consumption level) it seems that the growing world population will reach a point (by 2050) that $\sim 2$ billion people will be expected to be sustained at a high income consumption level, while $\sim 4$ billion at middle income consumption level and $\sim 3$ billion at a low income consumption level, of a total of $\sim 9$ billion people (Figure 1.1.4). The predicted 2050 low income population ( 3 billion people), in other words very poor populations, will reside largely in the geographic areas with high biodiversity (Figure 1.1.5). Consequently, without much choice, this population will unsustainably extract resources threatening biodiversity and their own health. Health problems expressed as stunted growth in children are also very apparent in these areas where poverty and high population density coincide. Poverty (or low income) is also an indicator of economic development however, low incomes can be also found in highly developed countries (e.g., USA, Russia, etc.) although masked by overall calculations for the entire population. The high income countries consume and also produce more waste but due to advanced technology and lower population density they will be able to sustain themselves. In contrast, the new members of the "middle income countries club" such as China and Indonesia will have deal with intense economic growth versus resources depletion and energy use that may become a "bottle-neck" as a result of their highly dense population! (Figure 1.1.6).

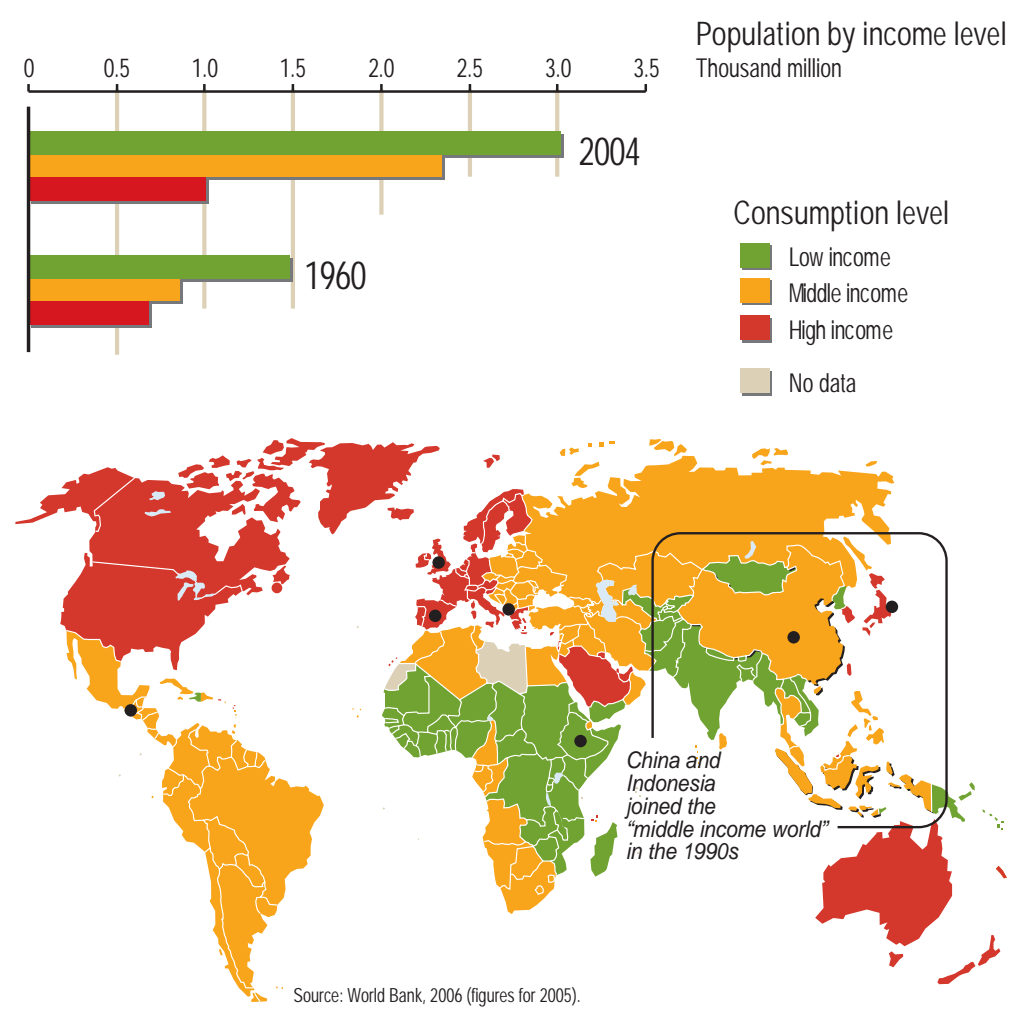

Figure 1.1.6. Population by income level. (2006). In UNEP/GRID-Arendal Maps and Graphics Library. Retrieved 21:38, May 4, 2011 from http://maps.grida.no/go/graphic/population-by-income-level, credit to Emmanuelle Bournay [World Bank, 2006 (figures for 2005)] 


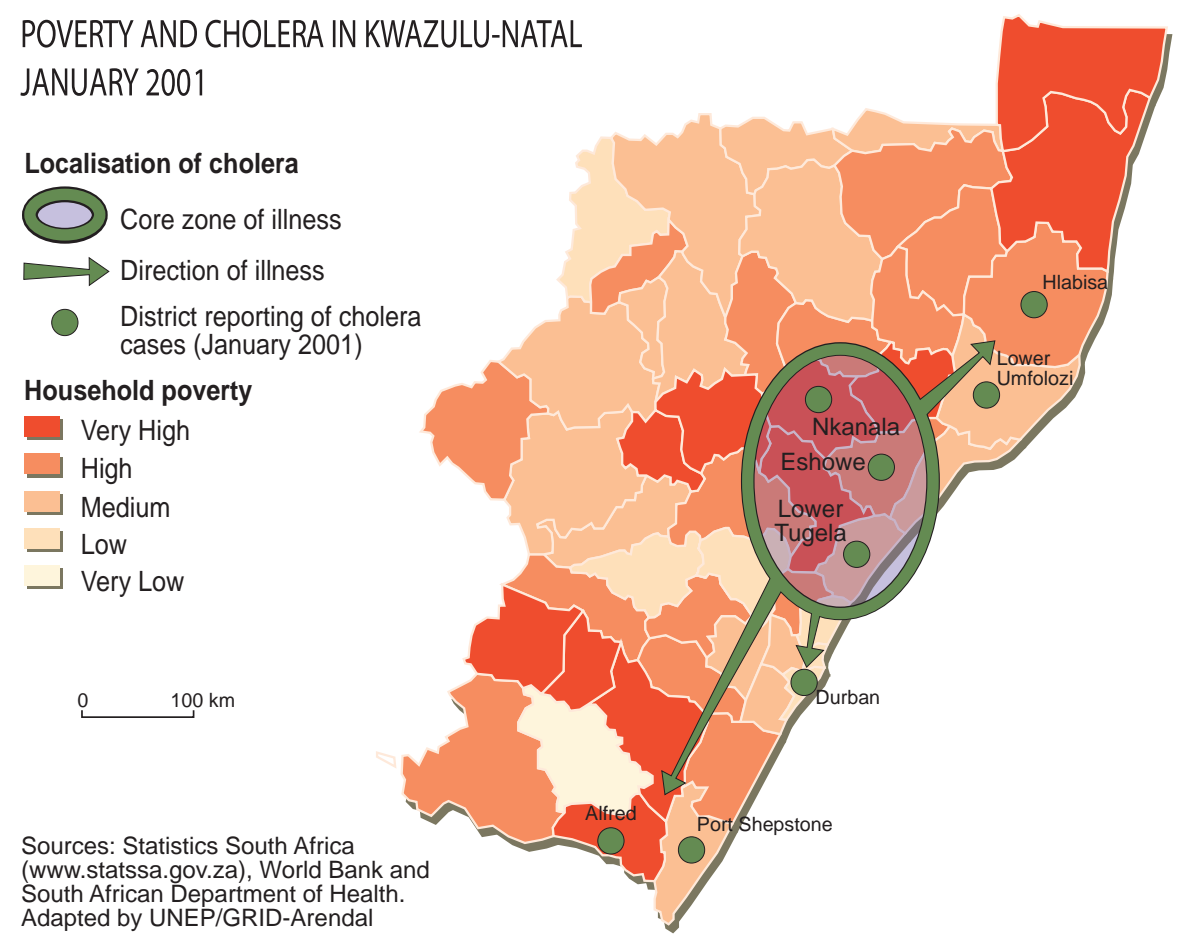

Figure 1.1.7. Socioeconomic status and cholera spread in South-Africa (Kwazulu-Natal January 2001) (2002). In UNEP/GRID-Arendal Maps and Graphics Library. Retrieved 12:37, January 20, 2011 from http://maps.grida.no/go/graphic/poverty-and-cholera-in-kwazulu-natal-january-2001, credit to Philippe Rekacewicz, UNEP/GRID-Arendal (Statistics South Africa (www.statssa.gov.za), World Bank and South African Department of Health. Adapted by UNEP/GRID-Arendal)

In summary, one of the major global holdups is population growth beyond the sustainability of our planet, coupled with other phenomena also related to population density: climate change, waste production and pollution, biodiversity decline, etc. (Dasgupta, 1995).

We wonder if even one individual among the global big poor population would understand the following equation (representing Gini coefficient-inequality measure) (Milanovic, 2002):

$$
\text { Gini }=W_{i}+B_{i}+L_{i}=\sum_{i=1}^{n} \operatorname{Gini}_{i} p_{i} \pi_{i}+\frac{1}{\mu} \sum_{i=1}^{n} \sum_{j>1}^{n}\left(y_{j}-y_{i}\right) p_{i} p_{j}+L_{i}
$$

Without much knowledge of economics and mathematics, this poor population certainly understands the everyday burden of food and water supply, health care and lack of reliable education and living conditions. All these parameters are directly linked to the spread of infectious diseases as shown in Figure 1.1.7. Diseases caused by various pathogenic organisms (universally called infectious diseases) described along this book, are significantly correlated to socio-economic level of large populations. Figure 1.1.7 shows a classical link between poverty, lack of safe drinking water and the spread of cholera in one of the poorest areas of the world (Kwazulu-Natal, South-Africa). 

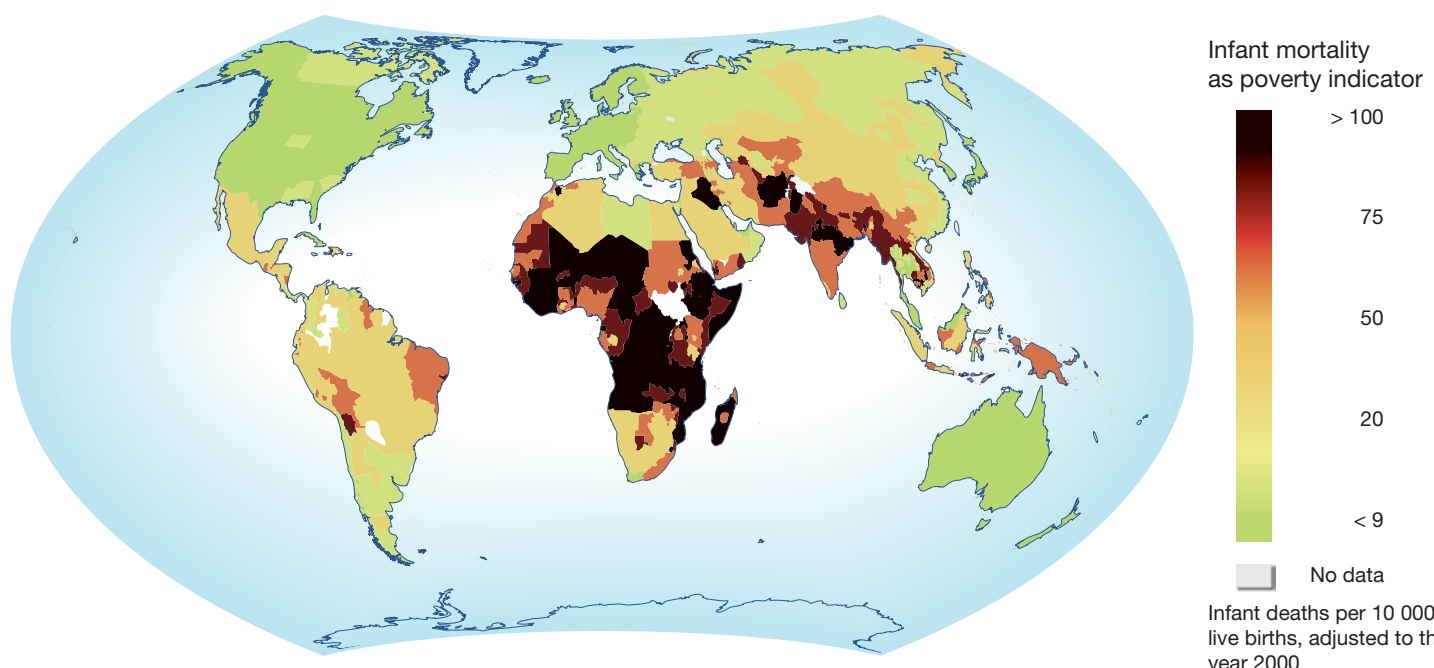

Infant deaths per 10000 live births, adjusted to the year 2000

Source: CIESIN 2005

Figure 1.1.8. World poverty distribution. (2008). In UNEP/GRID-Arendal Maps and Graphics Library. Retrieved 16:48, May 7, 2011 from http://maps.grida.no/go/graphic/world-poverty-distribution, credit to Hugo Ahlenius, UNEP/GRID-Arendal (Center for International Earth Science Information Network (CIESIN), Columbia University. 2005. Global subnational infant mortality rates. Available at: http://www.ciesin.columbia. edu/povmap/ds_global.html (Accessed April 28, 2008)

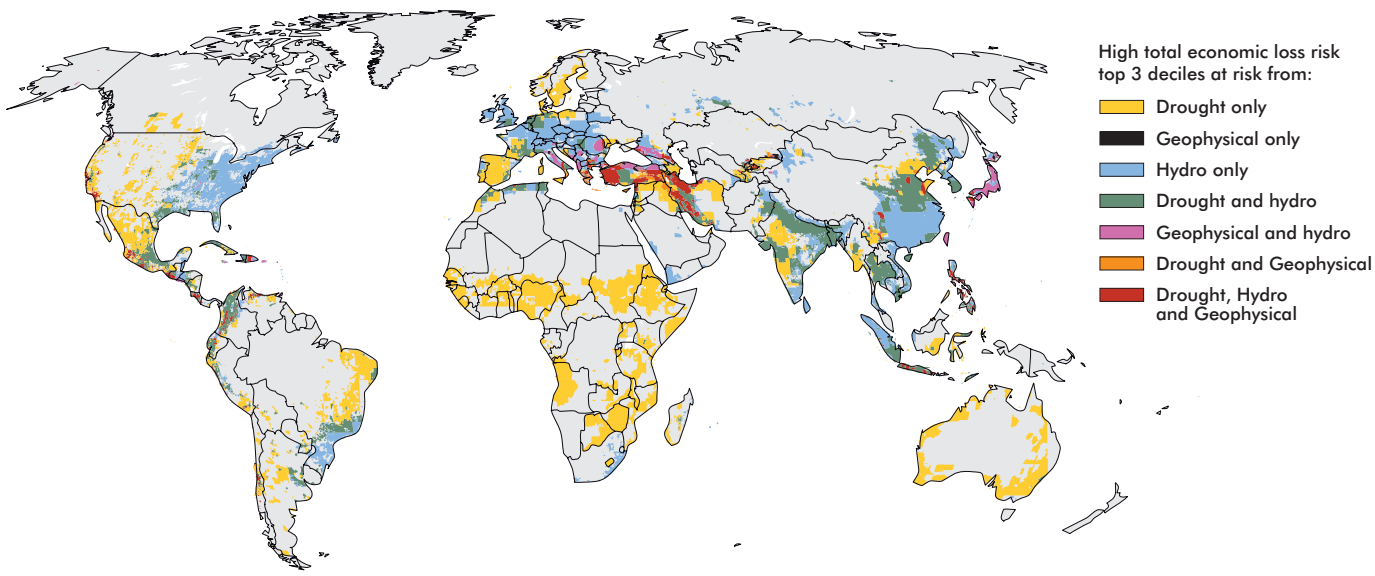

Figure 1.1.9. Natural hazard hotspots, by risk type. (2007). In UNEP/GRID-Arendal Maps and Graphics Library. Retrieved 16:53, May 7, 2011 from http://maps.grida.no/go/graphic/natural-hazard-hotspots-byrisk-type, credit to Hugo Ahlenius, UNEP/GRID-Arendal (Center for Hazards \& Risk Research. 2005. Natural Disaster Hotspots - A Global Risk Analysis: Global Multihazard Frequency and Distribution. http://www.Ideo. columbia.edu/chrr/research/hotspots/coredata.html (Accessed June 1, 2007) 
$75 \%$ of all poor people still live in rural areas, where they are heavily dependent on natural resources such as, soil, water, forests and fisheries (Figure 1.1.8). Figure 1.1.8 also represents poverty expressed by the infant death rate, an obvious measure of deprived health care and malnutrition in these areas. Many developing countries own these natural resources and therefore are still able to support a potential minimal wealth for poor people and their communities. However, as many of these natural resources are renewable they need to be properly managed in order to support these population in the long term. Poverty alleviation can occur through improved natural resource management but also by birth control in order to reduce the stress of the human population on natural resources for a sustainable development. Another interesting point related to poverty is the link to global hot spot disasters (droughts, floods, earthquakes, etc.) (Figure 1.1.9). With climate change, the frequencies of certain natural hazards are expected to increase. Figure 1.1.9 represents a graphical overview of an analysis of hazard exposures and historical vulnerability some natural hazards, together with population distribution and economy. Obviously, poor populations will suffer the most from these hazards and their ability to overcome such disasters is close to nil.

Diseases caused by various pathogenic organisms (universally called infectious diseases) described in this book are significantly correlated to socio-economic level of large populations.

\subsubsection{REFERENCES}

Dasgupta, P.S. (1995) Population, poverty, and the local environment. Sci. Am. 272, 26-31.

Milanovic, B. (2002) True world income distribution. 1988 and 1993: First calculation based on household surveys alone. Econ J (London) 112, 51-92.

Steck, T.L. (Lead Author); United.nations (Content Source); Peter Bartelmus Dr., Arun Sharma (Topic Editor) "Human population explosion". In: Encyclopedia of Earth. Eds. Cutler J. Cleveland (Washington, D.C.: Environmental Information Coalition, National Council for Science and the Environment). [First published in the Encyclopedia of Earth July 26, 2010; Last revised Date December 14, 2010; Retrieved May 5, $2011<$ http://www.eoearth. org/article/Human_population_explosion?topic=54245>. 


\section{Chapter 1.2 Climate}

"Climate is what we expect, weather is what we get."

Mark Twain (1835-1910)

It is not within the scope of this brief chapter to solve the debate whether climate changes are a consequence of human activity or just a natural succinct phenomenon that occurs periodically for millions of years (see ice age). The balance between entering energy (sun radiation) and leaving energy (energy reflected by earth), where the atmosphere plays a crucial role as a thermal isolator, are the main components that impact earth's climate (Figure 1.2.1). Our contribution to greenhouse gases is continuous through industrial development, increasing ground and air-traffic and incineration.

Natural climate forcings (forcing is a destabilizing factor of the above system) are mainly natural (e.g., the sun's brightness, small variations in Eart's orbit and axis rotations and volcanic eruptions) but also manmade (e.g., aerosol production, $\mathrm{CO}_{2}$ and greenhouse gases emission and deforestation) (Kirilenko and Sedjo, 2007) (Figure 1.2.2). Nevertheless, over a century global warming is an undisputed scientific fact, expressing itself in rapid mountain glacier retreat and a corresponding sea level rise (Berger et al., 2010) (Figure 1.2.3).

Warming has its impact on major ecological and biological systems including a large variety of parasites, their vectors and the final hosts. Varou et al. (2007), reviewing the tick-borne viral disease Crimean-Congo hemorrhagic fever (CCHF), reported that climate changes may affect CCHF epidemiology through influencing survival and reproduction of Hyalomma ticks and their hosts. For example, mild winters preceded outbreaks of this virus in Turkey and Kosovo, while interruption of agricultural activities by the reintroduction of cattle and sheep, a decrease in hare hunting and conversion of floodplains into agricultural land have been associated with CCHF outbreaks in Russia, Bulgaria, former Yugoslavia and Turkey. A different view on another tick-borne disease (tick-borne encephalitis-TBE virus) has been published by Randolph (2010). The author suggested that climate change alone could not explain the increase pattern and upsurge of the TBE virus due to its uniformity (e.g., in Baltic countries) and other factors seem to be more relevant to the phenomenon. Among these factors, Randolph (2010) suggested: “1) agricultural reforms resulting in changed land cover and land use, and an increased reliance on subsistence farming; 2) reduction in the use of pesticides, and also in the emission of atmospheric 
pollution as industries collapsed and 3) increased unemployment and poverty, but also wealth and leisure time in other sectors of the population, as market forces took hold".

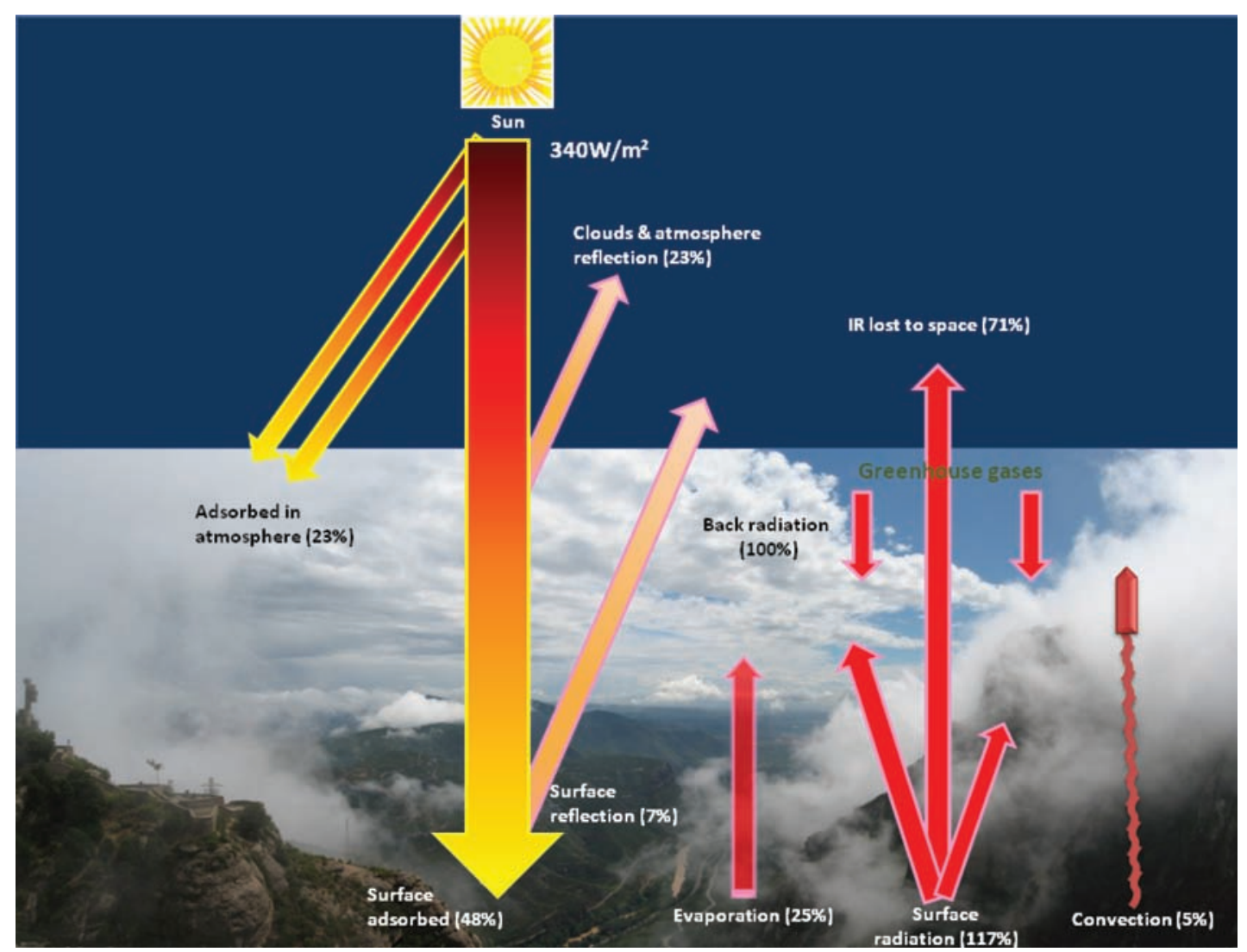

Figure 1.2.1 Radiation balance between sun and earth. (Adapted from NASA site http://earthobservatory. nasa.gov/Features/EnergyBalance/page1.php)

In Portugal, Leishmaniases, a zoonosis endemic in the Mediterranean basin, has shown a significant increase in cases number and a shift from pediatric to adult cases (mainly immunocompromised, HIV/AIDS). The authors suggested that climate amelioration may increase Leishmaniasis' arthropod vector, the phlebotomine sand flies, densities and activity favoring higher incidences (Campino and Maia, 2010). In Belgium, Nephropathia epidemica (NE), an emerging rodent-borne viral disease had shown a sharp increase in incidences for more than a decade (Clement et al., 2009). The authors suggested that bank voles might be responsible for this hantavirus through their known cyclic population peaks impacted by climate warming. In a recent study from Germany, an outbreak of Leptospirosis was recorded among strawberry harvesters (Desai et al., 2009). Leptospirosis is primarily known to be present in tropical countries with connection to agricultural exposures, and much less in temperate countries (such as Germany). The authors suspected that direct contact of humans (with hand lesions) with water, soil and infected voles may cause this disease. In addition, a preceding warm winter contributed to vole' population growth; hence the reemergence of Leptospirosis. 


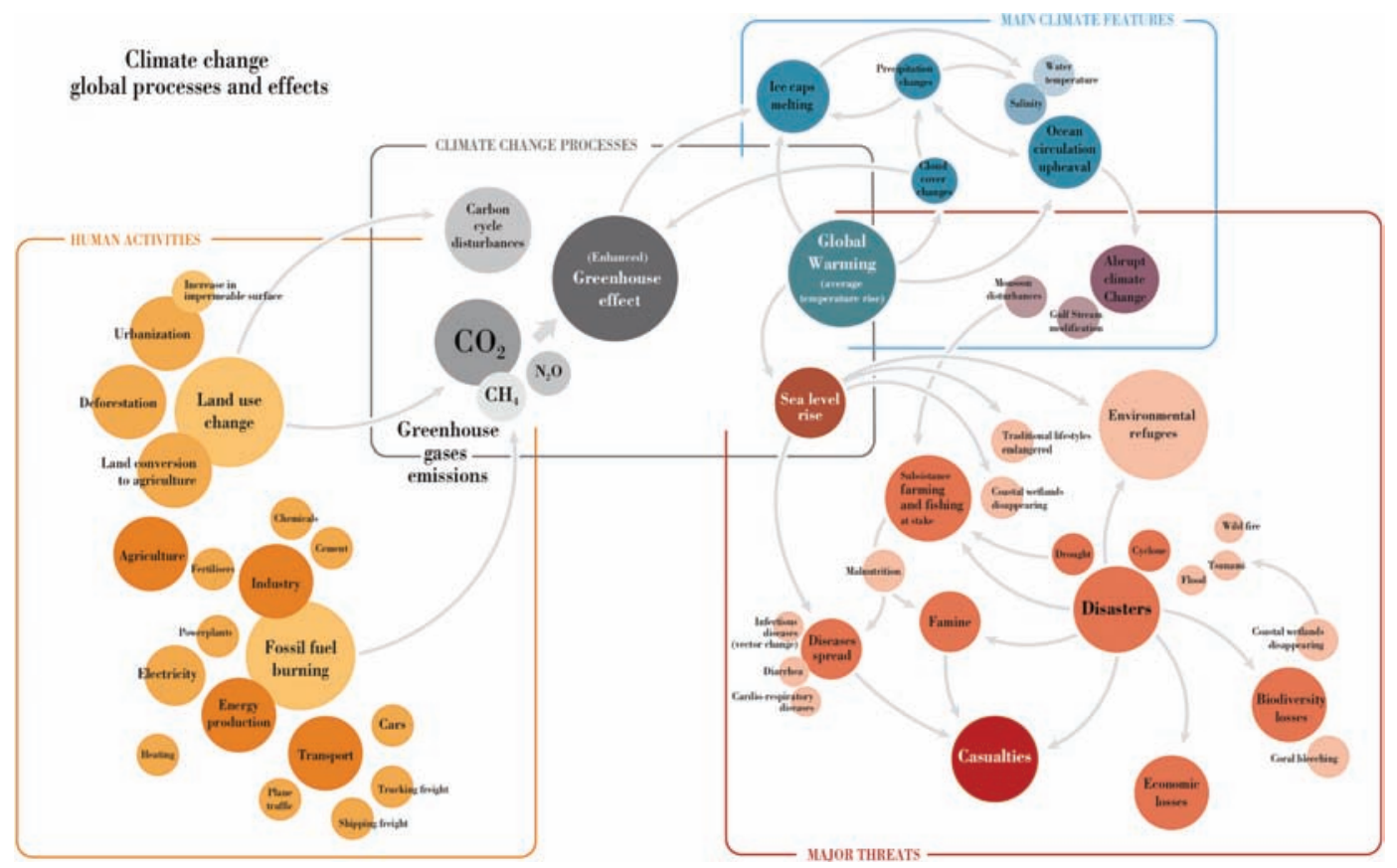

Figure 1.2.2. Climate change global processes and effects. (2009). In UNEP/GRID-Arendal Maps and Graphics Library. Retrieved 23:10, April 26, 2011 from http://maps.grida.no/go/graphic/climate-changeglobal-processes-and-effects1, credit to UNEP/GRID-Arendal

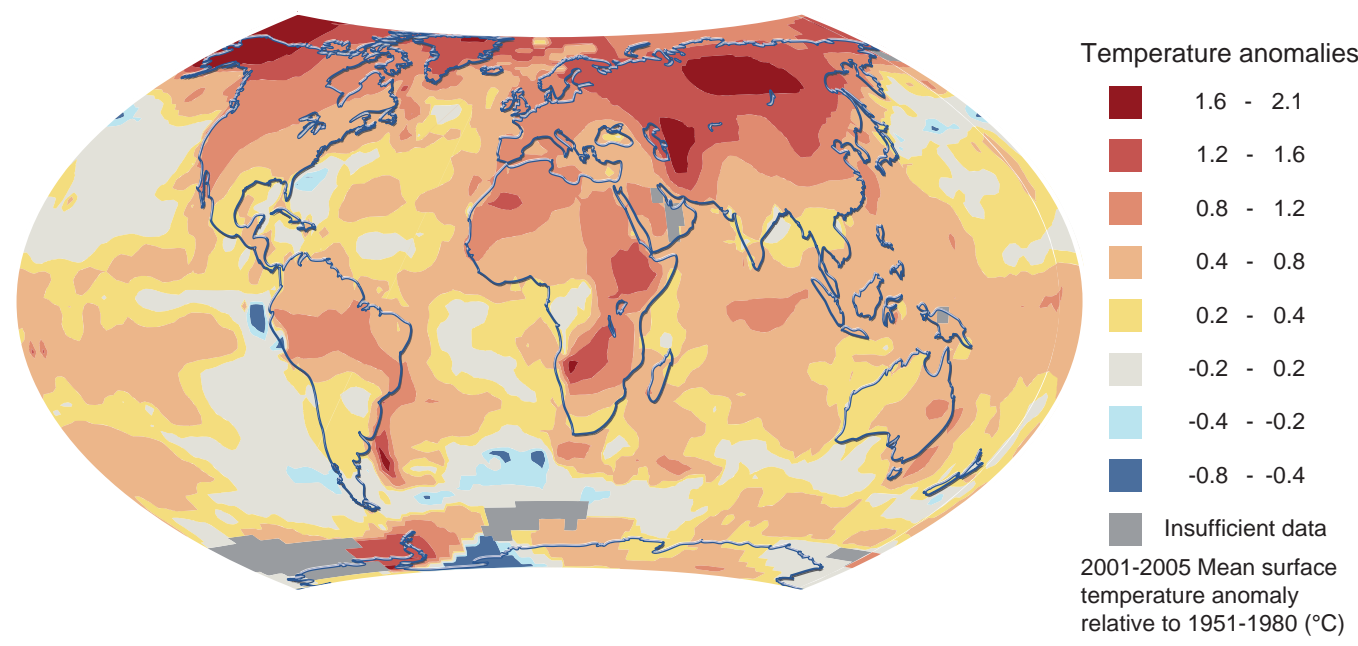

Figure 1.2.3. Increases in annual temperatures for a recent five-year period, relative to 1951-1980. (June 2007). In UNEP/GRID-Arendal Maps and Graphics Library. Retrieved 20:14, May 5, 2011 from http://maps. grida.no/go/graphic/increases-in-annual-temperatures-for-a-recent-five-year-period-relative-to-1951-1980, credit to Hugo Ahlenius, UNEP/GRID-Arendal (Hansen, J., Sato, M., Ruedy, R., Lo, K., Lea, D.W. and Medina-Elizade, M. (2006). Global temperature change. Proc. Natl. Acad. Sci., 103, 14288-14293 
Finally, the best examples of zoonotic disease spread as a partial result of climate changes are cholera and malaria. Cholera had almost disappeared, remaining endemic mainly in India, Pakistan and China; nevertheless, since 1960 it has reemerged worldwide in the last five decades (Figure 1.2.4). As this disease is connected to water and poverty conditions (see chapter 1.4 and chapter 1.1), increasing floods due to climate changes between dry periods (e.g., El Niño and its consequences in South America and other regions) support the emergence of cholera. The second best example is malaria (Plasmodium falciparum) that is connected to one of the major climate forcings: $\mathrm{CO}_{2}$ atmospheric rise. The malaria parasite is transmitted by mosquito' vectors to humans and mosquitoes in turn are impacted by $\mathrm{CO}_{2}$ concentrations that according to different models will increase in certain geographic areas, therefore increasing the vectors' natural distribution (Figure 1.2.5). Among the endless reports on reemerging zoonotic diseases connected to so many factors, including climate change, it should be emphasized also that warming (the main trend in climatology) could affect the various pathogens in a different way (bacteria will react differently from viruses or parasites or helminthes) and therefore it is not an easy task to conclude in general terms, and some reservations should be considered before major conclusions (Randolph, 2010).
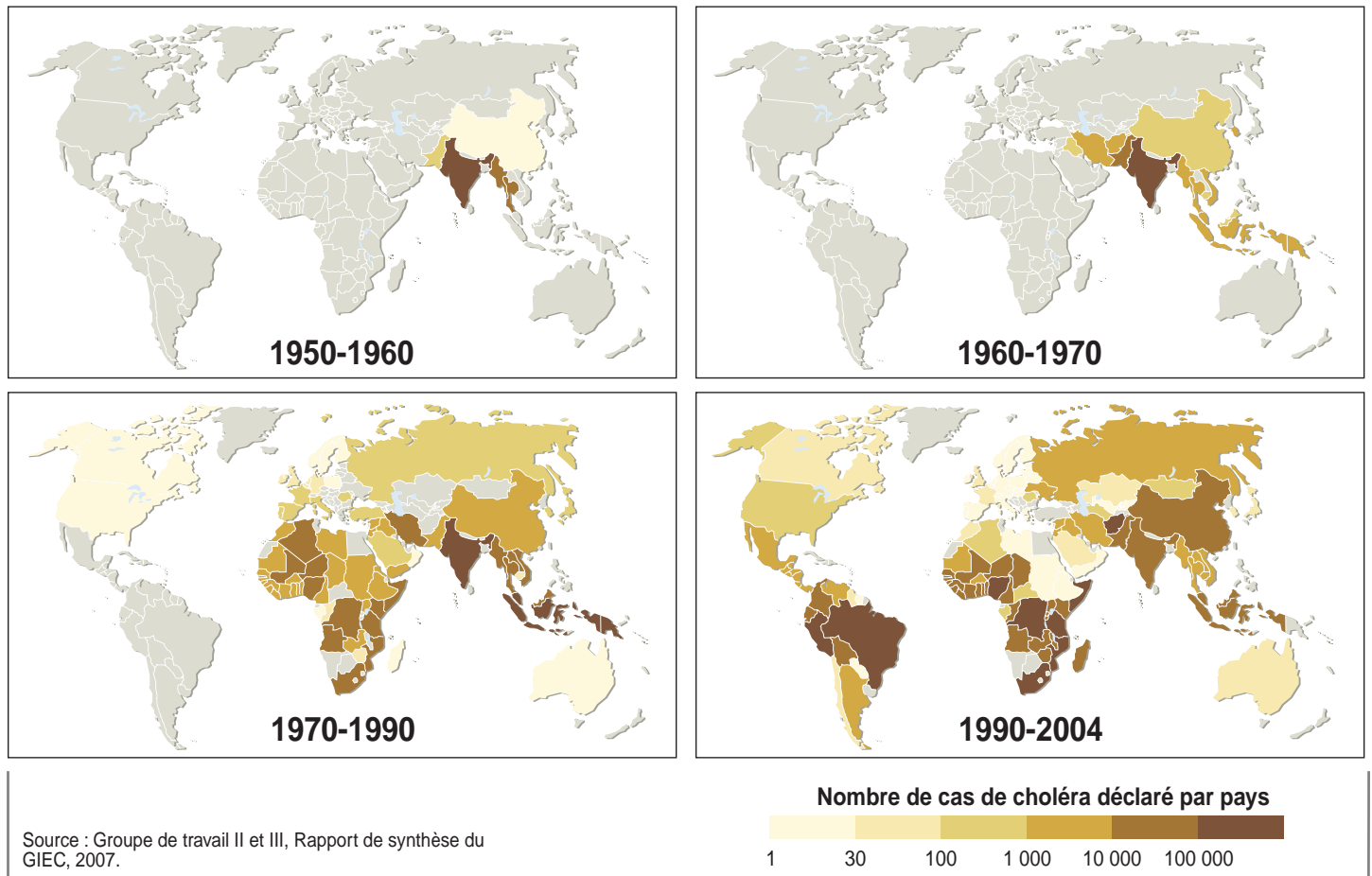

Source : Groupe de travail II et III, Rapport de synthèse du GIEC, 2007.

Figure 1.2.4. The spread of cholera 1950-2004. (2009). In UNEP/GRID-Arendal Maps and Graphics Library. Retrieved 20:21, May 5, 2011 from http://maps.grida.no/go/graphic/the-spread-of-cholera-1950-2004, credit to GRID-Arendal (Working group II and III, Synthesis Report, IPCC, 2007) 


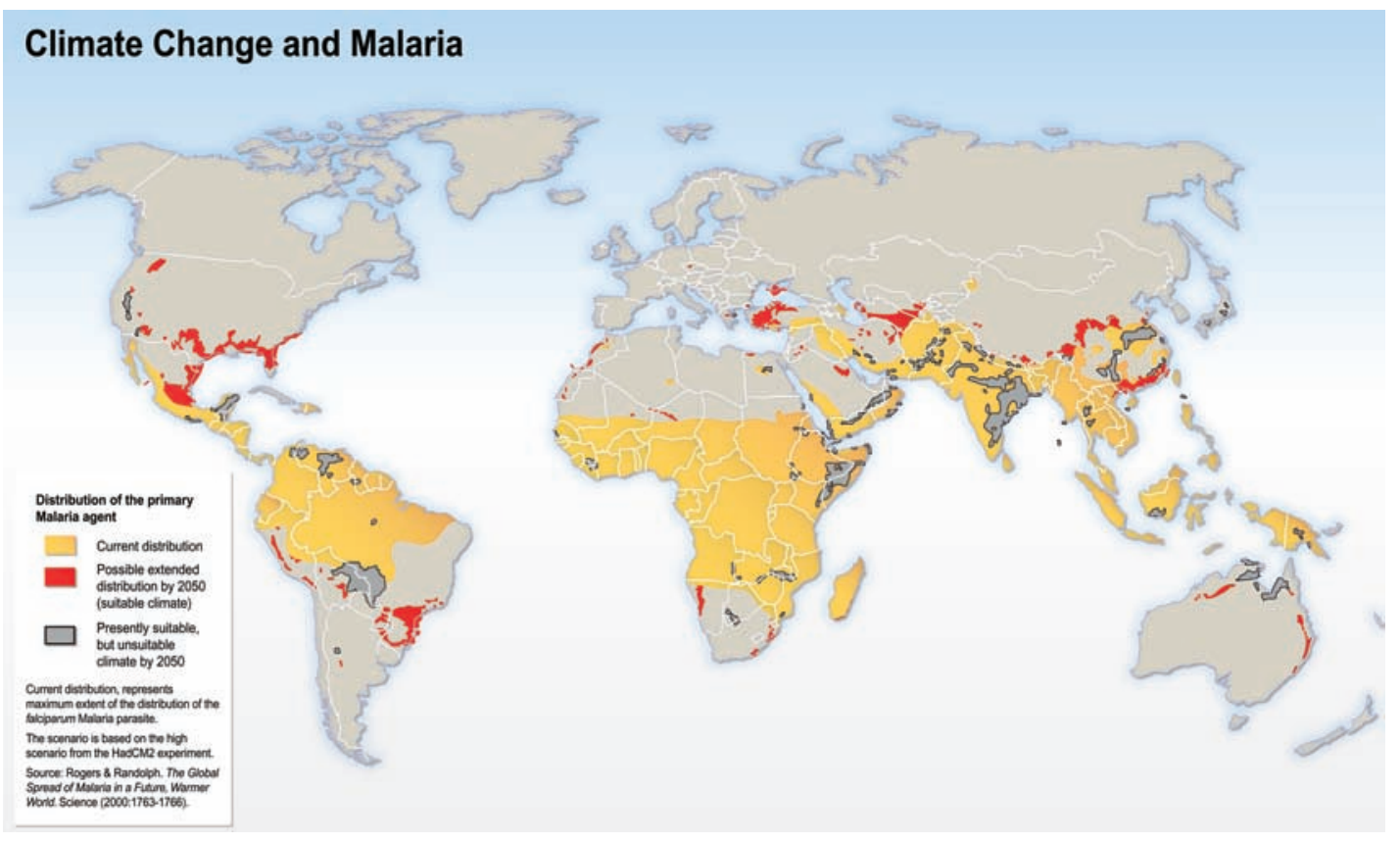

Figure 1.2.5. Climate change and malaria, scenario for 2050. (2005). In UNEP/GRID-Arendal Maps and Graphics Library. Retrieved 15:36, May 7, 2011 from http://maps.grida.no/go/graphic/climate-change-andmalaria-scenario-for-2050, credit to Hugo Ahlenius, UNEP/GRID-Arendal (Rogers \& Randolph. The Global Spread of Malaria in a Future, Warmer World. Science (2000:1763-1766)

\subsubsection{REFERENCES}

Berger, W.H., Schulz, M. \& Wefer, G. (2010) Quaternary oceans and climate change: lessons for the future? Int J Earth Sci (Geol Rundsch) 99, S171-S189.

Campino L. \& Maia, C. (2010) Epidemiology of leishmaniases in Portugal. Acta Med Port 23, 859-864.

Clement, J., Vercauteren, J., Verstraeten, W.W., Ducoffre, G., Barrios, J.M. et al. (2009) Relating increasing hantavirus incidences to the changing climate: the mast connection. Int J Health Geogr $\mathbf{8}, 1$.

Desai, S., van Treeck, U., Lierz, M., Espelage, W., Zota, L. et al. (2009) Resurgence of field fever in a temperate country: an epidemic of leptospirosis among seasonal strawberry harvesters in Germany in 2007. Clin. Infect. Dis. 48, 691-697.

Kirilenko, A.P. \& Sedjo, R.A. (2007) Climate change impacts on forestry. Proc. Natl. Acad. Sci. U.S.A. 104, 19697-19702.

Vorou, R., Pierroutsakos, I.N. \& Maltezou, H.C. (2007) Crimean-Congo hemorrhagic fever. Curr. Opin. Infect. Dis. 20, 495-500.

Randolph, S.E. (2010) To what extent has climate change contributed to the recent epidemiology of tick-borne diseases? Vet. Parasitol. 167, 92-94. 


\section{Chapter 1.3 \\ Geographic variability}

"One of my talking points will be the accident of geography."

Janis Joplin (1943-1970)

Geographic variability should be looked at in relation to continents and much less at the country level. Most of the globe's terrestrial area is mostly steppe like (shrubs and small trees) while only certain areas (in South America, Mid Africa, South and Southeast Asia and Northern parts of Canada, Scandinavia and Russia) are covered by evergreen and deciduous forests (Figure 1.3.1). Other areas are large deserts (Sahara and Serengeti in Africa, Arabian Peninsula, Gobi in Asia, Mojave and Sonoran deserts in North America and Patagonian desert in South America). Besides the North and South Poles, with their extreme climate and desert -like characteristics due to lack of available water, most global geographic areas are inhabitable by animals and humans. As zoonoses are linked to the presence of both factors, animals and humans, geographic variability (forests, rivers, lakes, etc.) may impact the spread of pathogenic agents and their vectors. For example, 240 million people (mostly from the low-economic level) depend on forested areas for their living, where in certain countries $>8 \%$ of the GDP is based on the forestry industry. Deforestation is one of the most important ecological factors that impact the greenhouse effect. According to FAO (Food and Agricultural Organization), deforestation causes 25\% of greenhouse gas emissions when combined with industrial pollution from developed countries. It should be also remembered that forests are also complex ecosystems that contribute to biological diversity and the, hydrological cycle and are a source of new plant species unknown to us that may help in the future. The reader will find in this book many examples of zoonoses' reemergence through geographic changes, such as dam construction, flooding of fertile soil and even the construction of highways, which alter the geographic variability and pose new challenges for different organisms. Biological systems are highly adjustable and in short periods of time are able to adjust to new geographic areas posing a real threat to human health. These systems are often so complex that it takes many years of research to really understand their way of action, mostly too late. 


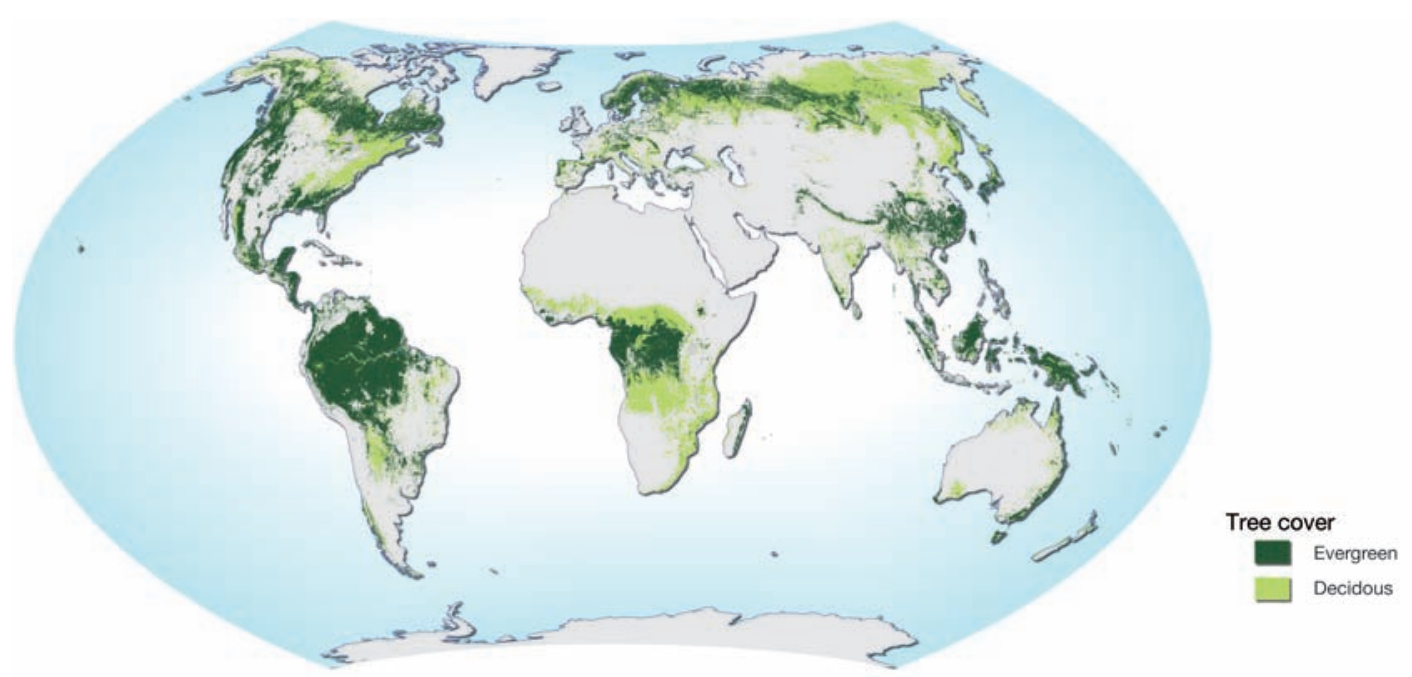

Source: EC Joint Research Centre 2003

Figure 1.3.1. World map of forest distribution (Natural resources - forests). (2008). In UNEP/GRID-Arendal Maps and Graphics Library. Retrieved 21:45, May 4, 2011 from http://maps.grida.no/go/graphic/world-mapof-forest-distribution-natural-resources-forests, credit to Hugo Ahlenius, UNEP/GRID-Arendal (European Commission, Joint Research Centre. 2003. Global Land Cover 2000 database. http://www-gem.jrc. it/glc2000 (Accessed July 15, 2007) 


\section{Chapter 1.4}

\section{Water and wastewater}

"Water is life's mater and matrix, mother and medium. There is no life without water"

Albert Szent-Gyorgyi (1937 Nobel Prize in Medicine).

It can be stated with high confidence that water is the most important component of life. Water also provides the best direct contact milieu between humans and animals, making infectious disease transfer possible.

Geographically, there is a certain injustice in the distribution of water around the globe! There are countries in which rain may reach annual precipitations of $13,299 \mathrm{~mm}$ while in others only $<200 \mathrm{~mm}$. The huge gap between these two extremities indicates the difficulties that certain countries face when water resources are over or under the global average. Potable water is a necessity without which life is not possible. However, mostly in Africa, the share of the population that has access to improved drinking water ranges from $<40$ to $55 \%$ ( $>1$ billion people), and therefore water is a source of continuous contamination with pathogenic agents (Figure 1.4.1). A second look at Figure 1.4.1 reveals that most of the same countries that suffer from poverty and infectious diseases (Figure 1.1.8 and Figure 1.2.5) have also less access to safe drinking water. Global fresh water withdrawal can be generally divided in three categories according to primary use: agricultural, industrial and domestic sectors (Figure 1.4.2). Figure 1.4.2 compares water use according to the above sectors at the national level. Indeed, developed countries predominantly but not exclusively use more fresh water for industry and developing countries for the agricultural sector. The agricultural sector is more spendthrift the domestic and industrial sectors, and therefore more problematic in countries with low water resources (e.g., Middle East countries). The solution to these problems would come from advanced agricultural technology (e.g., drip irrigation combined with extensive wastewater treatment).

Wastewater, which is the other facet of water, has also a great potential for water scarcity remediation. However, according to its nature, wastewater has to be well treated before reuse, constituting one of the major hazards in spreading infectious diseases around the globe. Wastewater problems differ according to various global regions and their economic development: for example, in Africa it impacts public health, in Europe it causes eutrophication through input of nutrients into the coastal waters reducing productivity and creating anoxic dead zones and in Asia ecosystem deterioration through river basins' pollution (Figure 1.4.3). 

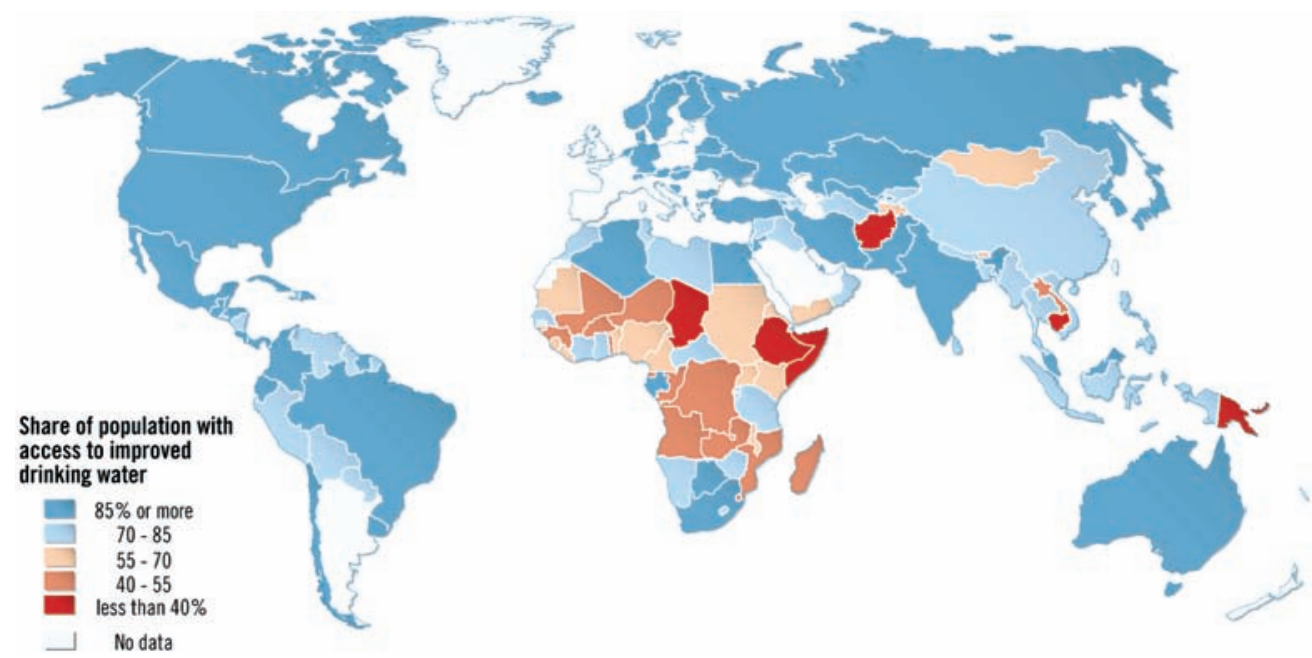

Figure 1.4.1. Access to safe drinking water. (2008). In UNEP/GRID-Arendal Maps and Graphics Library. Retrieved 16:19, May 7, 2011 from http://maps.grida.no/go/graphic/access-to-safe-drinking-water, credit to Hugo Ahlenius, UNEP/GRID-Arendal (World Health Organization and United Nations Children's Fund. 2000. Accessed through the United Nations Common Database in 2006. Online at: http://unstats.un. org/unsd/cdb/)

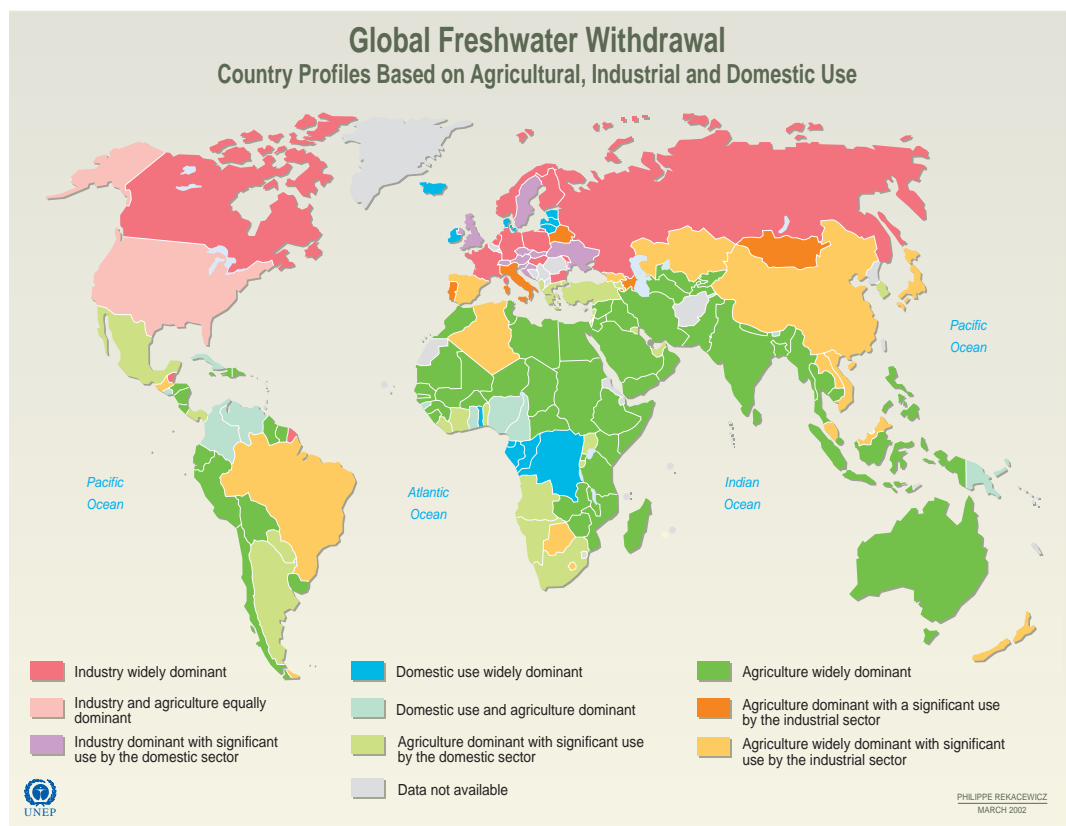

Source: Based on data fromTable FW1 inWorld Resources 2000-2001, People and Ecosystems: The Fraying Web of Life, World Resources Institute (WRI), Washington DC, 2000.

Figure 1.4.2. Global freshwater withdrawal: agricultural, industrial and domestic Use. (2002). In UNEP/GRID-Arendal Maps and Graphics Library. Retrieved 18:57, May 24, 2011 from http://maps.grida. no/go/graphic/global freshwater withdrawal agricultural, credit to Philippe Rekacewicz, UNEP/GRIDArendal (Based on data from Table FW1 in "World Resources 2000-2001, People and Ecosystems: the Fraying Web of Life", World Resources Institute (WRI), Washington DC, 2000) 


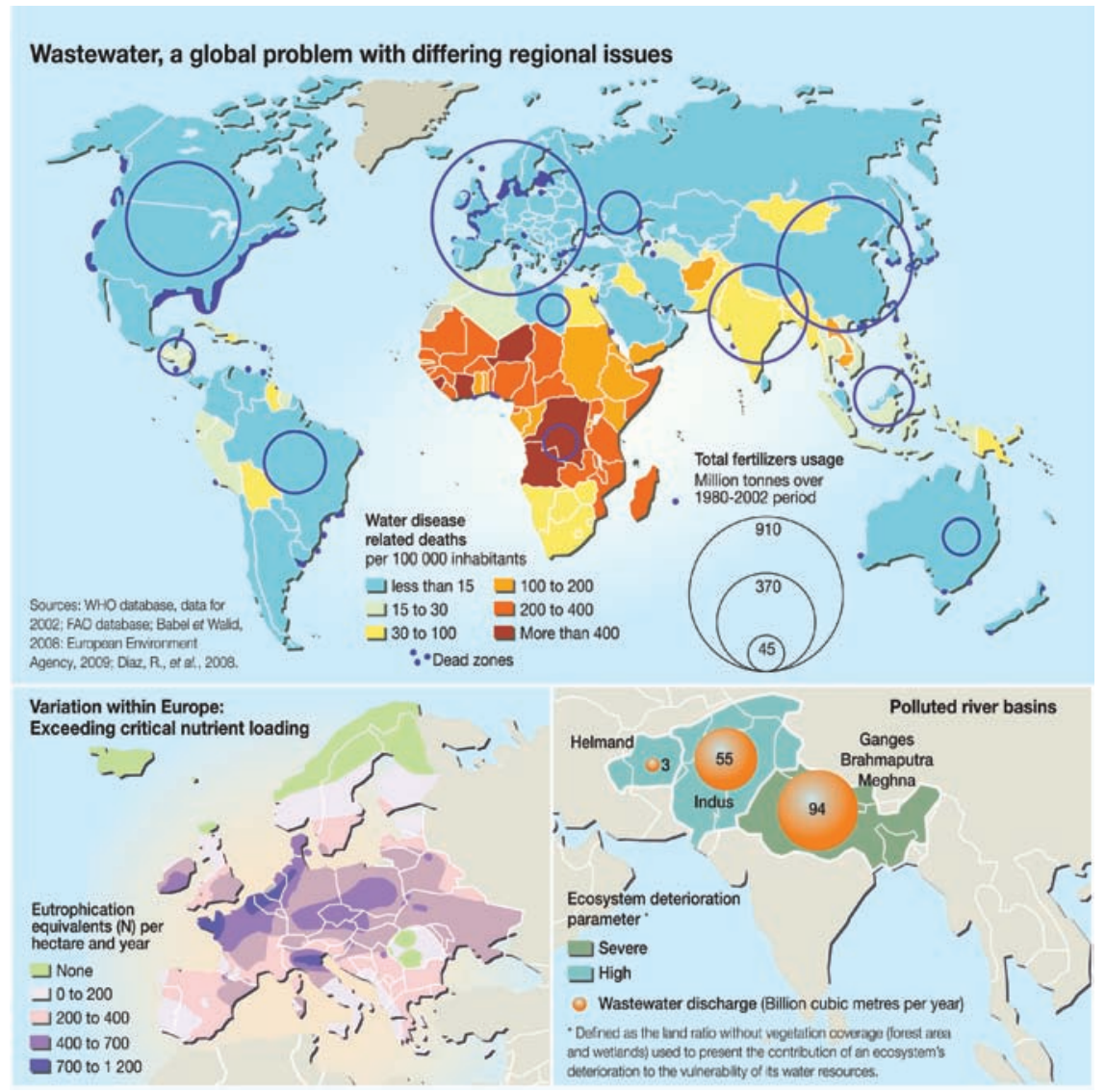

Figure 1.4.3. Wastewater, a global problem with differing regional issues. (2010 March). In UNEP/GRIDArendal Maps and Graphics Library. Retrieved 16:15, May 7, 2011 from http://maps.grida.no/go/graphic/ wastewater-a-global-problem-with-differing-regional-issues, credit to UNEP/GRID-Arendal (WHO database, data for 2002; FAO database; Babel et Walid, 2008: European Environment Agency, 2009; Diaz, R., et al., 2008)

According to the author's, more than 30 years' experience in environmental microbiology, wastewater has been one of the major bottlenecks that has affected rivers, lakes and other water bodies through contamination with many infectious agents. However, in the $21^{\text {st }}$ century, with the development of advanced treatments (e.g., membrane technology, advanced oxidation processes and molecular methods) it is possible to treat wastewater and produce excellent water quality, safe for drinking and other uses (Haarhoff and Van der Merwe, 1996). The only impasse is the economic price requisite imposed on many poor countries in order to achieve this goal.

\subsubsection{REFERENCE}

Haarhoff, J \& Van der Merwe, B. (1996) Twenty-five years of wastewater reclamation in Windhoek, Namibia. Water Sci. Technol. 33, 25-35. 


\section{Chapter 1.5}

\section{Global animal trade}

"Of all the animals, man is the only one that is cruel. He is the only one that inflicts pain for the pleasure of doing it"

Mark Twain (1835-1910)

The livestock, wildlife and animal products global trade is massive and multifaceted. There are no general predetermined rules among country members of the World Trade Organization (WTO) to control animals' movement and by and large it is based on bilateral agreements. However, member countries of WTO are bound to a sanitary and phytosanitary agreement (http://www.wto.org/english/tratop_e/sps_e/ spsagr_e.htm) concerning food safety and animal/plant health regulations based on a good veterinary infrastructure. Wild and domestic animals are the main milieu in which a large variety of zoonotic agents are seeded and disseminated. While domestic animals can be and are controlled by veterinarians, wild animals are completely out of human control when trade is illegal. Feral animals are subjected to disease through a variety of vectors: arthropods, direct contact, predation and exposure to human environments (refuse, wastewater, carcasses, slaughterhouses, etc.). According to early 1990s' estimates, TRAFFIC evaluated the value of legal wildlife products imported globally to be around USD160 billion (http:// www.traffic.org/trade). Among the imported wildlife are: 40 000 live primates, four million live birds, 640000 live reptiles and 350 million live tropical fish. In Asia, which is one of the major global wild animal trade centers, it is estimated that several billion direct and indirect contacts among wildlife, humans and domestic animals occur each year (Karesh et al., 2005). As a result new diseases affecting both humans and animals continue to emerge, such as severe acute respiratory syndrome (SARS) and highly pathogenic avian influenza (e.g., H5N1) (discussed later in this book) or the detection of Pseudamphistomum truncatum (an opisthorchid fluke parasite) in the English otter linked with the introduction of two freshwater fishes functioning as intermediate hosts for this fluke, colonizing many rivers in southern UK (Pinder and Gozlan, 2003). However, relevant legislation for international wildlife trade relates to three main areas: animal health, animal welfare and the international movement of endangered species. The issue of endangered species is probably the only positive aspect of this huge trade in wild animals, contributing to the rescue of wild animals otherwise eternally exterminated under environmental pollution and human continuous pressure. 
On the other hand, the trade volume of domestic animals (e.g., cattle, pigs, sheep and poultry) is huge with several countries importing millions of dollars's worth (cattle and pigs in the USA, pigs and chicken in Belgium, pigs in the UK, etc.) (Fèvre et al., 2006). When dealing with such enormous numbers of domestic animals it cannot be excluded that some accidental infections may happen affecting human and animal health, in spite of regular and rigorous veterinary inspections.

The problems related to the risk of contracting zoonotic infections and outbreaks in urban populations have been described. Such a risk is related to the widely-accepted practice of keeping pets and wild animals in city flats and the absence of knowledge in the general population about animals' parasites and measures of individual prophylaxis of zoonosis. Large numbers of stray dogs and the habitation of wild animal species in territories of cities represent additional threats. A conclusion about the need for the inclusion of prophylactic and anti-epidemic measures in programs of city improvement has been reached.

Pets' movement is also an important issue related to zoonoses. One of the best examples is leishmaniasis (Leishmania infantum) outbreaks in dogs (the main reservoir host) in the USA as a result of military personnel returning home with their pets from Mediterranean area. Other diseases, such as heartworm (Dirofilaria immitis), babesiosis (Babesia canis), ehrlichiosis (Ehrlichia canis), echinococcosis (Echinococcus granulosus and E. multilocularis), rabies, bovine tuberculosis, Trypanosoma brucei rhodesiense, foot and mouth disease (FMD) and Rift Valley fever are all likely to be introduced through domestic pets and their movement (Chevalier et al., 2004; Fèvre et al., 2006).

\subsubsection{REFERENCES}

Chevalier, V., de la Rocque, S., Baldet, T., Vial, L. \& Roger, F. (2004) Epidemiological processes involved in the emergence of vector-borne diseases: West Nile fever, Rift Valley fever, Japanese encephalitis and Crimean-Congo haemorrhagic fever. Rev. Sci. Tech. 23, 535-555.

Fèvre, E.M., de C. Bronsvoort, B.M., Hamilton, K.A. \& Cleaveland, S. (2006) Animal movements and the spread of infectious diseases. Trends Microbiol. 14, 125-131.

Karesh,W.B. Cook, R.A., Bennett, E.L. \& Newcomb, J. (2005) Wildlife trade and global disease emergence. Emerg. Infect. Dis. 11, 1000-1002.

Pinder, A.C. \& Gozlan, R.E. (2003) Sunbleak and topmouth gudgeon- two new additions to Britain's freshwater fishes. British Wildlife 15, 77-83. 


\section{Chapter 1.6}

\section{Environmental pollution}

"The significant problems we face cannot be solved at the same level of thinking we were at when we created them."

Albert Einstein (1879-1955)

Environmental pollution may be defined as "irresponsible discharge or disposal of toxic waste by humans based on the anticipation that Mother Nature will take care of it". Whether intentional or unintentional, environmental pollution by humans is a fact (see Figure 1.2.2). However, in the last decades, some remediation emerged following scientific community warning and political awareness. Besides the environment, pollution is a multi-edged sword that may affect also humans, animals, pathogens and their vectors (Chu et al., 2008). Briefly, pollution sources can be chemical (from various industrial activities), biological (from waste and agricultural activity) and radioactive (from domestic and military industries). The chemical pollution emitted by different industries is huge (most of chemical pollution originates from developed countries) affecting human and animal health in the short- and long-term based on production processes and practices (Figures 1.6.1 and 1.6.2).

There are three environments affected significantly by human activity and pollution: soil, water and air. It can be stated that soil pollution is more pervasive than water and air (due to its relative volume and also its structure). Figure 1.6.3 represents different human activities (industrial and municipal waste) in some European countries (developed and developing). Plants are the primary organisms that accumulate contaminants that are further consumed by animals and humans. Ingestion, inhalation and direct contact with such polluted soil may also impact their health.

Contaminated soil does contribute substantially to groundwater pollution depending on the local geology affecting many areas: potable and bathing waters, different household uses, agriculture and industry (Figure 1.6.4).

It is clear that water contamination with a large variety of chemicals and biological components has a direct impact on our health. However, some long-term effects are also noticeable, such as alteration of global nutrient cycles. Johnson et al. (2010) evaluated the impact of nitrogen and phosphorus eutrophication on human and wildlife health. According to these authors there are several postulated mechanisms that link eutrophication to several pathogen transmission modes (direct horizontal and 
indirect vector-borne or complex life cycle): 1) host abundance and distribution; 2) pathogen virulence alteration and 3) changes in host susceptibility. These links seem to occur more frequently in tropical and subtropical regions that are the most vulnerable ones. Indeed, oligotrophic limestone-based wetlands that were "polluted" by phosphorous-enriched runoff caused replacement of rush vegetation with dense cattail. This vegetation shift had important consequences on the larval mosquito community: from Anopheles albimanus to Anopheles vestitipennis (each preferring a typical habitat, respectively) which is a superior vector of the parasite Plasmodium to humans (Grieco et al., 2006). Another excellent example is nutrient input in mesocosms containing snails, larval amphibians and parasites (Johnson et al., 2007). Via eutrophication of such mesocosms, enhanced growth of algae occurred that affected positively the growth and reproduction of snail intermediary hosts (susceptible to parasitic miracidia). In addition, infected host snails from the high nutrient condition did produce, on average, twice as many parasites as did snails from a low nutrient environment.
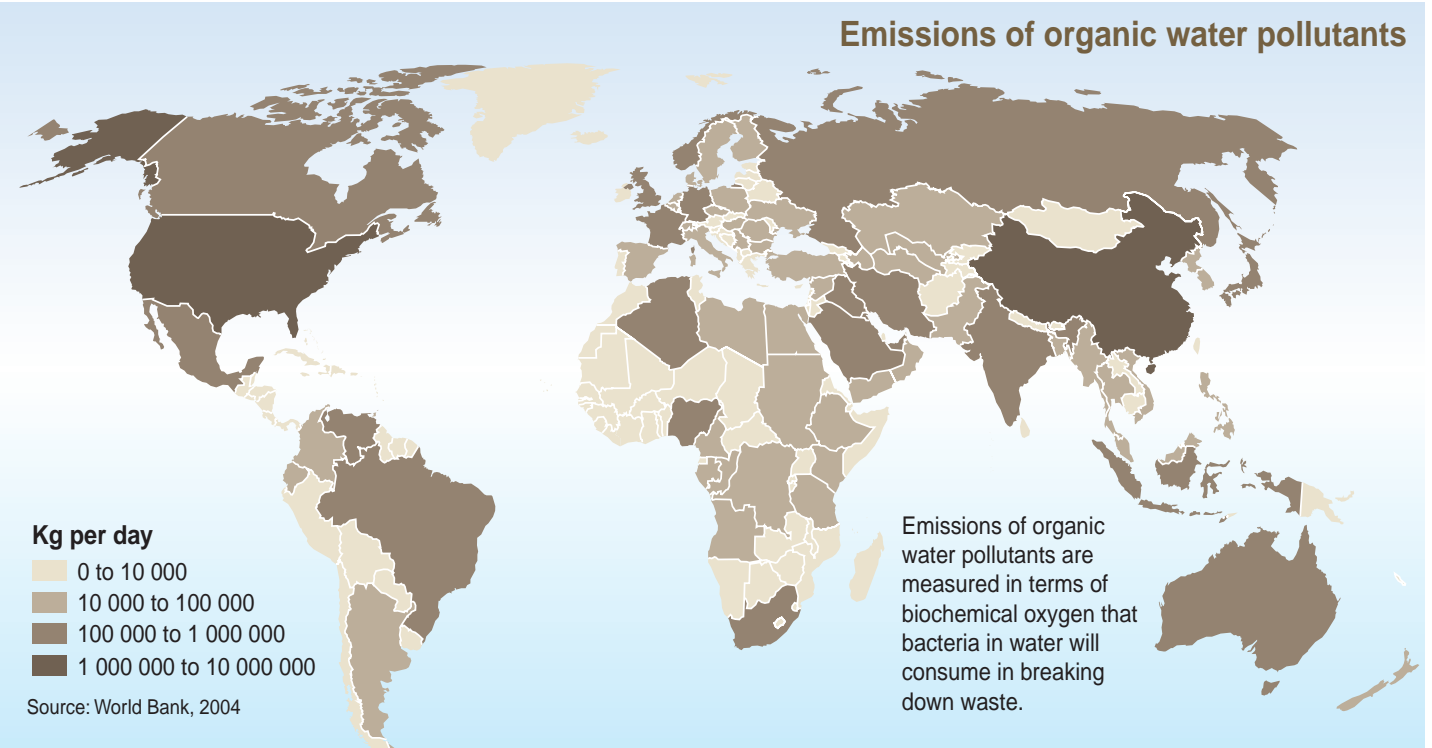

Figure 1.6.1. Emissions of organic water pollutants. (2004). In UNEP/GRID-Arendal Maps and Graphics Library. Retrieved 21:53, May 4, 2011 from http://maps.grida.no/go/graphic/emissions_of_organic_water_ pollutan, credit to Philippe Rekacewicz, UNEP/GRID-Arendal (World Bank, 2004)

A nice example of environmental pollution in urban areas that affected animals and potentially humans was described by Scialfa et al. (2010). These authors reported on the presence of Leptospira interrogans in a highly dense rat' population (Rattus norvegicus) in a suburban area of Buenos Aires. The high density of the rat' reservoir is directly connected to environmental pollution (refuse, waste, etc.) and poverty.

Finally, Fayer et al. (2004) linked land to sea environment through wastewater discharge into estuaries and coastal waters. Encysted zoonotic protozoan parasites present in raw sewage (e.g., Giardia, Cryptosporidium and Toxoplasma) contaminate bathing beaches, infect a wide range of marine animal hosts (sometimes with fatal results in some populations) and are concentrated through filtration by shellfish to be further consumed raw by humans and marine mammals. 


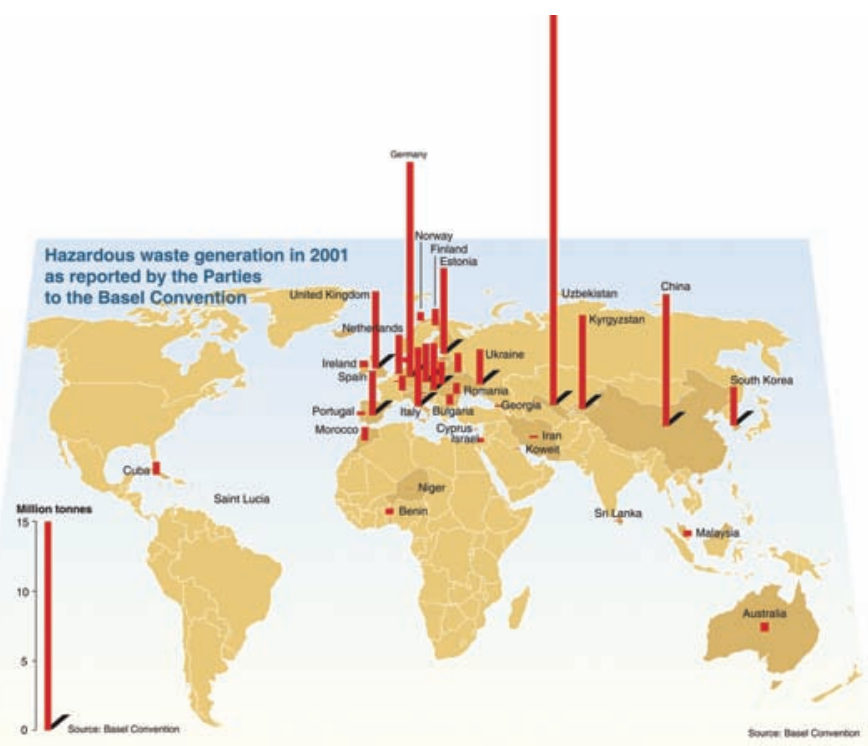

Figure 1.6.2. Hazardous waste generation in 2001 as reported by the Parties to the Basel Convention. (2004). In UNEP/GRID-Arendal Maps and Graphics Library. Retrieved 21:56, May 4, 2011 from http://maps. grida.no/go/graphic/hazardous_waste_generation_in_2001, credit to Philippe Rekacewicz, UNEP/GRIDArendal (Basel Convention)

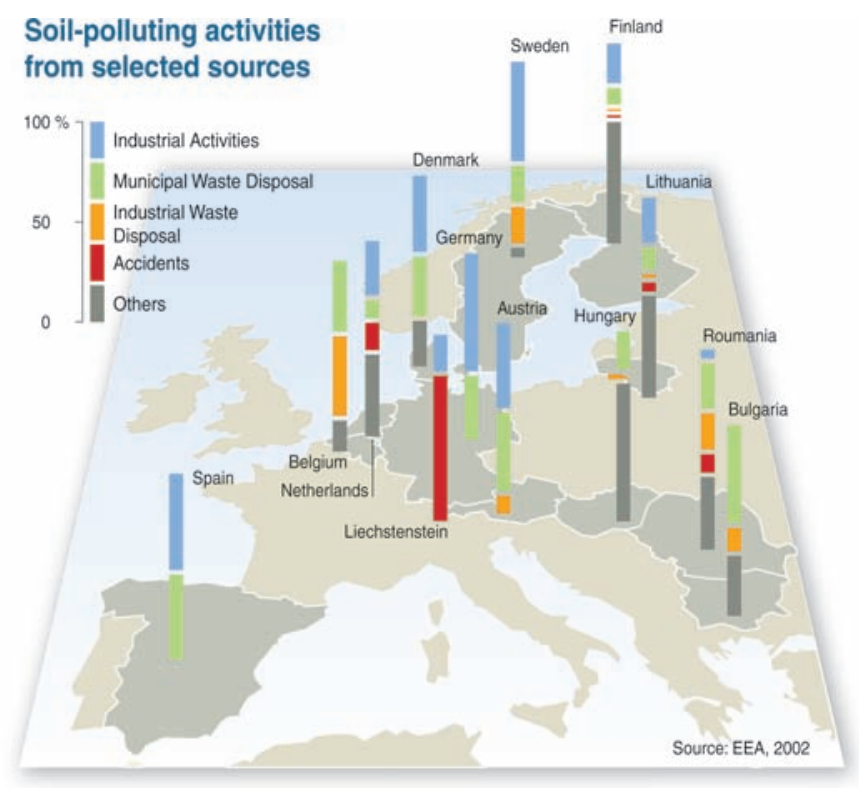

Figure 1.6.3. Soil polluting activities from selected sources. (2004). In UNEP/GRID-Arendal Maps and Graphics Library. Retrieved 21:47, May 4, 2011 from http://maps.grida.no/go/graphic/soil_polluting_ activities_from_selected_sources, credit to Philippe Rekacewicz, UNEP/GRID-Arendal (EEA, 2002) 


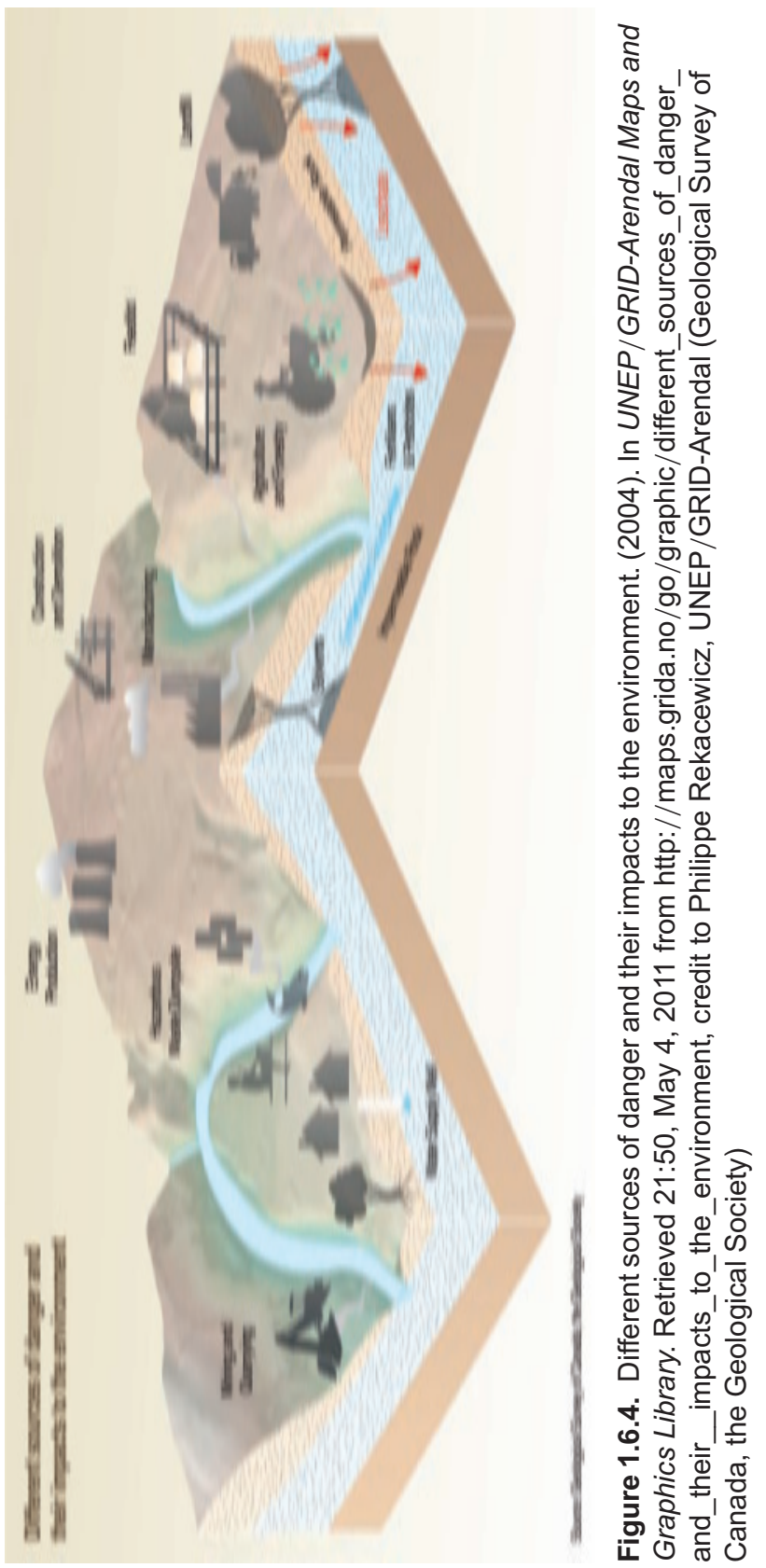




\subsubsection{REFERENCES}

Chu, I., Bowers, W.J., Caldwell, D., Nakai, J., Wade, M.G. (2008) Toxicological effects of in utero and lactational exposure of rats to a mixture of environmental contaminants detected in Canadian Arctic human populations. J Toxicol Environ Health A 71, 93-108.

Fayer, R., Dubey, J.P. \& Lindsay, D.S. (2004) Zoonotic protozoa: from land to sea. Trends Parasitol. 20, $531-536$.

Grieco, J.P., Johnson, S., Achee, N.L., Masuoka, P., Pope, K. et al. (2006) Distribution of Anopheles albimanus, Anopheles vestitipennis, and Anopheles crucians associated with land use in northern Belize. J. Med. Entomol. 43, 614-622.

Johnson, P.T.J., Chase, J.M., Dosch, K.L., Hartson, R.B., Gross, J.A. et al. (2007) Aquatic eutrophication promotes pathogenic infection in amphibians. Proc. Natl. Acad. Sci. U.S.A. 104, 15781-15786.

Johnson, P.T.J., Townsend, A.R., Cleveland, C.C., Glibert, P.M., Howarth, R.W. et al. (2010) Linking environmental nutrient enrichment and disease emergence in humans and wildlife. Ecol Appl 20, 16-29.

Scialfa, E., Bolpe, J., Bardon, J.C., Ridao, G., Gentile, J. \& Gallicchio, O. (2010) Isolation of Leptospira interrogans from suburban rats in Tandil, Buenos Aires, Argentina. Rev. Argent. Microbiol. 42, 126-128. 
Downloaded from https://iwaponline.com/ebooks/book-pdf/521254/wio9781780400761.pdf

Downloaded trom https://Iwaponline.com/ebooks/book-pdt/521254/WI09/81/80400/61.pdt
by IWA Publishing user 


\section{Chapter 2}

\section{Bacterial Zoonoses}


Downloaded from https://iwaponline.com/ebooks/book-pdf/521254/wio9781780400761.pdf

Downloaded trom https://Iwaponline.com/ebooks/book-pdt/521254/WI09/81/80400/61.pdt
by IWA Publishing user 


\section{Chapter 2.1}

\section{Anthrax}

\section{[BACILLUS ANTHRACIS]}

Bacillus anthracis is a gram-positive, facultative anaerobic, rode-shaped, spore-forming bacterium, able to synthesize a protein capsule (D-glutamate), and is the sole pathogenic bacterium to carry its own adenylyl cyclase virulence factor (edema factor). B. anthracis' spores are highly resistant and capable of surviving over decades or centuries in soil and of resisting extreme temperatures, harsh chemical treatment and low-nutrient environments. The actual infectious dose required to cause human disease via cutaneous contact is $10^{4}$ to $10^{7}$ spores (experimentally performed on shaved and abraded skin of DBA/2 mice, Hahn et al., 2005), via inhalation is considered to be between $8 \times 10^{3}$ to $1.5 \times 10^{4}$ (Seidel and Cotta, 2002) while via ingestion is still unknown, although experimental evidence suggests that it is approximately $>10^{8}$ spores (Beatty et al., 2003). The disease can represent itself in several forms dependent on the infectious routes: 1. Respiratory: flu-like symptoms for several days, followed by severe respiratory collapse (fatality ranges from 45 to 92\%); 2. Gastrointestinal (through ingestion) by hematemesis (blood vomiting), severe diarrhea, acute inflammation of the intestinal tract, loss of appetite and lesions along the gastrointestinal (GI) track (fatality ranges from 25 to $60 \%$ ) and 3. Cutaneous by appearance of skin lesions that eventually forms an ulcer with a black center ( $20 \%$ fatality if not treated).

\subsubsection{B. ANTHRACIS AND ENVIRONMENT}

\subsubsection{Water and soil}

Antrax is an acute infection of cattle, sheep and other grazing animals transmitted zoonotically to humans or by direct human-human contact. In 1875, Robert Koch was the first to identify and to show the pathogen transmission routes (Koch, 1876). There are three forms of the disease according to these routes: gastrointestinal, pulmonary and cutaneous. Bacillus anthracis [phylum: Firmicutes] has a worldwide distribution. As already mentioned, B. anthracis' spores are highly resistant to environmental conditions and can prevail for decades (Willis, 2004), therefore historically being considered as the ultimate biological weapon. Recently, Lewerin et al. (2010) reported on an outbreak of anthrax that occurred in a beef cattle herd in the southern part of Sweden, 27 years after the last outbreak. Following an 
on-site/laboratory combined investigation, the authors concluded that the contamination source was roughage (in spite of a negative laboratory analysis). The roughage contained soil and dust from a field that had been flooded in the previous year and had dried up in the following year as a result of a very dry summer. According to local history, it was reported that in the early 1900-s during anthrax outbreaks animal carcasses were dumped in the flooding river; therefore it is very possible that long-standing anthrax spores remained in this area. A closely related picture was described in Lake Rukwa Valley, Tanzania, where an epidemic of 239 human cases occurred (predominantly of males between 15 and 35 years old) (Webber, 1985). The infective source was meat from animals dying of anthrax, however no intestinal cases were reported. Interestingly, the epidemic was seasonal, reaching a peak towards the end of the dry period when cattle were close grazing, and declined rapidly once rains commenced and grass began to grow.

In another episode, Fox et al. (1977) described an epizootic anthrax event in Falls County, Texas during June and July, which resulted in the death of 236 animals (228 cattle, 5 horses, 2 mules, and 1 pig) on 48 premises without any cases of human illness. According to these authors, anthrax spores were apparently precipitated by drought, and infection appeared to be the result of intrinsic ingestion of contaminated soil and grass. Buravtseva et al. (2003) reviewing anthrax epidemiological data following floods in the Southern Federal District regions of Russia, reported that no epidemic complications were noted in the affected territories during the year of 2002.

In simulation experiments of arid environment (sand) contaminated with bacterial spores, common wind erosion preventive materials (such as Surtac and Soiltac) were topically applied to prevent airborne spores' dispersion (Lloyd et al., 2006). Surtac is a solution comprised of a carbohydrate polysaccharide blend, surfactants, mordants and water while Soiltac is a polymer-based emulsion; both are biodegradable materials. Both Surtac and Soiltac were effective dust palliatives reducing the spores' spread due to the solidification of the top surface forming a solid crust.

In 1993, a remote area of Canada (west of Great Slave Lake in the Northwest Territories) were bisons, mooses and black bears are free-ranging, was hit by anthrax resulting in 172 bisons, 3 mooses and 3 black bear carcasses (Gates et al., 1995). The outbreak occurred after a prolonged period of dryness between April and mid-July of 1993 which followed several successive years of bisons' habitat flooding. The authors provided the "spore concentration hypothesis" as the most conservative explanation for the occurrence of anthrax under those observed conditions (Figure 2.1.1). One of the major characteristics of B. anthracis's spores is their hydrophobicity (Doyle et al., 1984; Leishman et al., 2010) although in food such as milk and orange juice they revealed moderate hydrophobicity when experimentally extracted by a method using bacterial/microbial adherence to hydrocarbons (BETH/METH) (Leishman et al., 2010; Rosenberg, 1984). Basically, this theory is based on the hydrophobic characteristics of B. anthracis spores that float on the water's surface during flood and then concentrate on growing plants during drier periods, favoring the infection of grazing animals (Anonymous, b). In this study, scavenging originating from carcasses was prevented by the application of formaldehyde.

Mongoh et al. (2008) analyzed statistically an outbreak of anthrax in North Dakota, during the year 2005, that affected a large variety of mammal species such as: cattle, bison, horses, sheep, elk, deer, pigs, and llamas. In this study, the presence of very wet conditions prior to the outbreak and dry conditions during it were statistically significant for predicted occurrence of anthrax. For example, the mean precipitation during the period was 3.05 " with a median of $2.50^{\prime \prime}$. Before the outbreak, the period between mid-May and June recorded a mean of about 7.10" of precipitation (wet conditions) while between the end of June and July, when most cases were reported, the region recorded a mean precipitation of only $1.90^{\prime \prime}$ (dry conditions), therefore indicating that weather conditions do play a significant role in anthrax outbreaks. In another study, Lindeque and Turnbull (1994) analyzed anthrax mortality records of elephants and 
plain ungulates in Etosha National Park, Namibia. The seasonal peak among the elephants was November (the end of the dry season) while among ungulates it was March (towards the end of the rainy season). In their study, B. anthracis was detected in $3.3 \%$ of water and $3.0 \%$ of soil samples collected at different times of the year from 23 sites, not associated with known cases of anthrax. Higher rates $(26.0 \%)$ were found in waterholes samples at the time of an outbreak in elephants. Based on these results it is clear that climate plays a major role in the natural infection cycle of anthrax (Table 1). Scavengers' importance was confirmed by feces collection from vulture, jackal and hyena from the vicinity of confirmed anthrax carcasses, yielding $>50 \%$ positive samples of $B$. anthracis spores (some with substantial large numbers) compared to none found in feces unconnected to known anthrax carcasses. Despite typical B. anthracis levels of $>10^{7} \mathrm{FU} / \mathrm{ml}$ in sick animals' blood, spore levels in carcass contaminated soil ranged from undetectable to $10-10^{3} \mathrm{CFU} / \mathrm{ml}$. Importantly, after experimental monitoring the authors reported a rapid loss of spores' viability in soil and water in relation to their types. In addition, the extent of B. anthracis survival and sporulation in water has been shown to be related to its initial concentration.

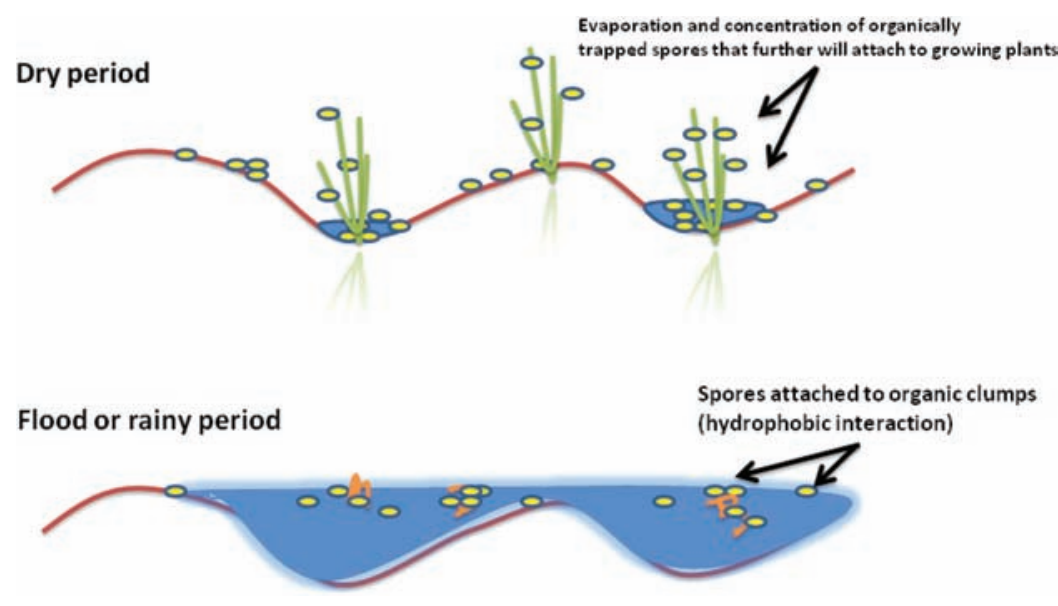

Figure 2.1.1. B. anthracis spores "concentration theory" during dry and wet weather (adapted from Dragon and Rennier, 1995)

The frequently cited Van Ness (1971) made the following observations regarding B. anthracis ecology: 1) spores persist in incubator areas where characteristically low-lying depressions or rocklands with standing water devitalized of plant life exist or dried-up water courses or hillside seeps where organic matter has accumulated during floods or runoff and 2) infections were observed only in association with limestone soils or affected by calcareous soils rich in nutrients (Hugh-Jones 1975).

Nevertheless, other means of contamination had been documented such as: spores shedding through feces and urine of infected animals (Choquette, 1970); various insects such as mosquitoes and tabanids (deer, horse, and stable flies) that have been implicated in the transmission of spores from animal to animal (Choquette, 1970; Krishna and Mohiyudeen, 1958; McKendrick 1980; Turell and Knudson, 1987) from animal to vegetation (De Vos, 1990; Choquette,1970; Ebedes 1976; Krishna and Mohiyudeen, 1958; Sen and Minett, 1944) by spore contaminated soil adhering to the coats of wallowing animals (bison) (Ebedes, 1976; Whitford, 1979); or the adherence of blood and viscera to the fur and feathers of scavengers from infected carcasses (Ebedes, 1976). 
Table 2.1.1 Selected global anthrax cases linked to soil, water and climate factors and their intersection.

Site and cases number

Year Environmental factors (rainfall)

Ascension Parish, Louisiana, USA

1971

A "dry period" followed by a "wet period" $(\mathrm{PI})^{\mathrm{a}}$

23/75 livestock premises

Falls County, Texas, USA

1974

A "dry period" not followed by a "wet period"

18/48 livestock premises

Goulburn Valley, Victoria, Australia

1997

The weather conditions preceding and

83 premises

during the epizootic approximated those of a drought (avg. $\left.29^{\circ} \mathrm{C}\right)$

Pembina, Grand Forks, Nelson, Traill, and Steele 2000

counties, North Dakota, USA 24/31

livestock premises

Kinney, Val Verde, Uvalde, Edwards, and Real

counties, Texas, USA

71 premises (1637 dead animals) 11 cases

laboratory confirmed

Etosha National Park, Namibia

2,935 cases

2001

$$
\begin{aligned}
& \text { June-September } \\
& 8^{\prime \prime}-32^{\prime \prime} \text { annual rain }
\end{aligned}
$$

1964-1992 The peak incidence of anthrax in plains ungulates occurred in March, at the end of the rainy season.

The peak incidence of anthrax in elephants occurred in November, near the end of the dry season and the beginning of the wet season.

1. Fox, M.D., Kaufmann, A.F., Zendel, S.A., Kolb, R.C., Songy, C.G. Jr. et al. (1973) Anthrax in Louisiana, 1971: epizootiologic study. J.

2. Fox, M.D., Boyce, J.M., Kaufmann, A.F., Young, J.B. \& Whitford, H.W. (1977) An epizootiologic study of anthrax in Falls County, Texas

3. Turner, A.J., Galvin, J.W., Rubira, R.J., Condron, R.J. \& Bradley, T. (1999b). Experiences with vaccination and epidemiological investigation September 1998. J. Appl. Microbiol. 87, 294-297.

4. United States Department of Agriculture, Animal and Plant Health Inspection Service, Veterinary Services [USDA APHIS, VS]. Epizootiology http://www.aphis.usda.gov/vs/ceah/cei/taf/emerginganimalhealthissues_files/anthrax.pdf.Accessed 1st of August 2010.

5. Lindeque, P.M. \& Turnbull, P.C.B. (1994) Ecology and epidemiology of anthrax in the Etosha National Park, Namibia. Onderstepoort J.

6. Gainer, R.S. \& Saunders, J.R. (1989) Aspects of the epidemiology of anthrax in Wood Buffalo National Park environs. Can. Vet. J. 30,

7. Dragon, D.C., Elkin, B.T., Nishi, J.S. \& Ellsworth, T. R. (1999) A review of anthrax in Canada and implications for research on the disease

8. Dragon, D.C. \& Rennie, R.P. (1995) The ecology of anthrax spores: tough but not invincible. Can. Vet. J. 36, $295-301$. 
Loam and clay (alkaline $\mathrm{pH}$ ) (PI)Calhoun-Olivier 1 (acidic $\mathrm{pH}$ )

Loam (PI)

Clay

Sand

Top soil (0-17mm) acidic to mildly acidic (PI)

Poorly drained swamps containing alluvial soils. The soil in the anthrax-affected region had been disturbed recently due to improvements in the irrigation system and reconstruction of channels and drainage systems.

Surface water drainage. (PI)Water permeability 15$500 \mathrm{~mm} /$ hour. (PI)

The geographical location of the epizootic was historically a major route for movement of cattle and sheep from southern Victoria to northern Victoria.

Horse mortality $(12.16 \%)$,

Cattle $(85.7 \%)$, Sheep (none).

Cervids, bovids, equids and camelids (wide range species) white tailed deer, red deer, fallow deer, elk, antelope, gazelle, water buffalo, beef cow, goat, sheep, bison, horse, mule, donkey, and llama

The persistence of spores in karstveld soils was higher than in other soil types.

Elephants and ungulates (Burchell's zebra, blue wildebeest, springbok)

$B$. anthracis was recovered from approximately 50 percent of the fecal specimens from nearby scavengers (vulture, jackal and hyena).

Only $3.3 \%$ of water and $3 \%$ of soil samples were positive. Hot, wet season (1.4\% positive samples) cold, dry season (5.7\% positive samples) and hot, dry season (3.5\% positive samples).

The concentration of spores in the soil adjacent to carcasses $\left(5.0 \times 10^{4}\right.$ maximum) compared to blood specimens from carcasses $\left(7.0 \times 10^{9}\right.$ maximum). $B$. anthracis was highly susceptible to ultraviolet radiation and to solar radiation after as few as 4 hours of exposure during laboratory experiments

$B$. anthracis was able to multiply and sporulate in spring water and water from gravel-pits during laboratory experiments, if the waters were contaminated with low dilutions (i.e., high concentrations) of blood.

Flooded soil

Am. Vet. Med. Assoc. 163, 446-451.

J. Am. Vet. Med. Assoc. 170, 327-333.

on an anthrax outbreak in Australia in 1997. 3rd International Conference on Anthrax, University of Plymouth, 7-10

and ecology of anthrax [online]. Available at:

Vet. Res. 61, 71-83.

953-956.

in northern bison. 3rd International Conference on Anthrax, University of Plymouth, 7-10 September, 1998. J. Med. Microbiol. 87, 208-213. 
Furthermore, water and wind seem also to play a major contribution in spores' dispersion from decomposing carcasses and other infected material that can be easily lifted under very dry conditions (Choquette, 1970; Ebedes, 1976; Heath and Brewitt, 1982). The 1979 Sverdlovsk (now Yekaterinburg) incident is a classical example of accidental contamination of large areas with $B$. anthracis spores originating from a biological warfare facility. A strain of $B$. anthracis produced as a bio-warfare arsenal in the Military Compound 19, near Sverdlovsk, a highly infective strain ("Anthrax 836") was accidentally released from the facility exhaust pipes that lacked the required filter. Before remounting the missing filter, the accidental released cloud of $B$. anthracis spores had spread south on the northerly wind that prevailed shortly before the outbreak. According to epidemiological data, most victims worked or lived in a narrow zone extending from the military facility to the southern city limit. Farther south, livestock died of anthrax along the zone's extended axis. Following an investigation after the event, it was undoubtedly concluded that aerosol of anthrax pathogen that escaped from the military facility caused this outbreak (Meselson et al., 1994). Fortunately, "only" 64 casualties were recorded; however, if the wind direction had been from south to north (toward Sverdlovsk city) a much higher numbers of casualties would been recorded at the time.

Dragon and Rennie (1995) in an excellent review, based on reported outbreaks summarized, the main characteristics of environmental conditions that favor B. anthracis spores epizootic infections. A summary of these factors are schematically presented in Figure 2.1.2, where some have been scientifically demonstrated while others are more speculative though they cannot be ruled out.

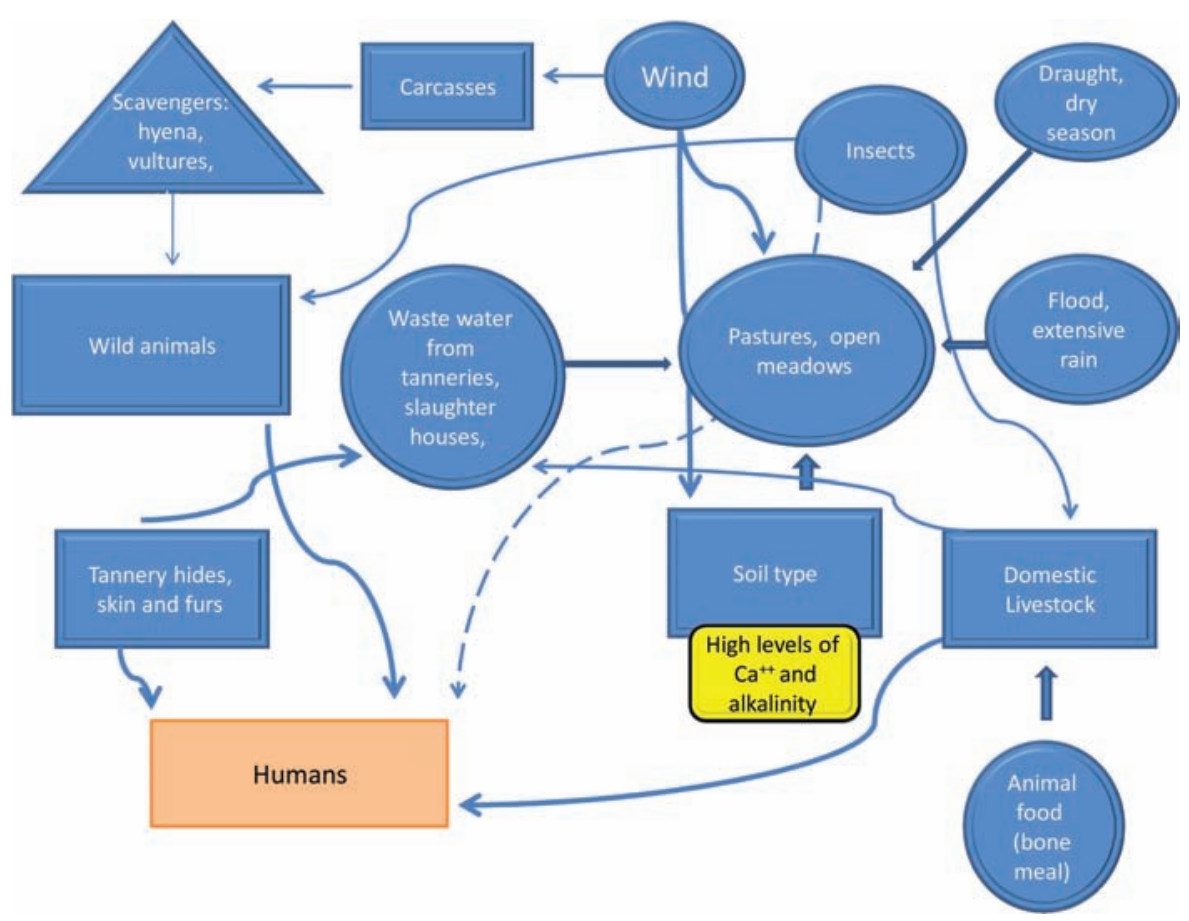

Figure 2.1.2. Environmental factors affecting human infection with $B$. anthracis 
As a final point, in order to clarify the whole conundrum picture, it is clear that environment is a very complex matrix in which many biotic and abiotic factors are involved and closely related. Schuch and Fischetti (2009) in their extensive and outstanding study, demonstrated the important role of $B$. anthracis's bacteriophages during its environmental phase through pseudolysogeny, that provides alternatives to sporulation involving the activation of soil-survival and endosymbiotic capabilities in earthworms gut (biofilm formation, etc.) (Figure 2.1.3). Birds do feed on earthworms; therefore while not being directly infected they can spread it through continents by their annual migratory cycle (Anonymous, 2010). It would be interesting to look for B. anthracis spores shed by migratory birds at their regular stop-over sites.

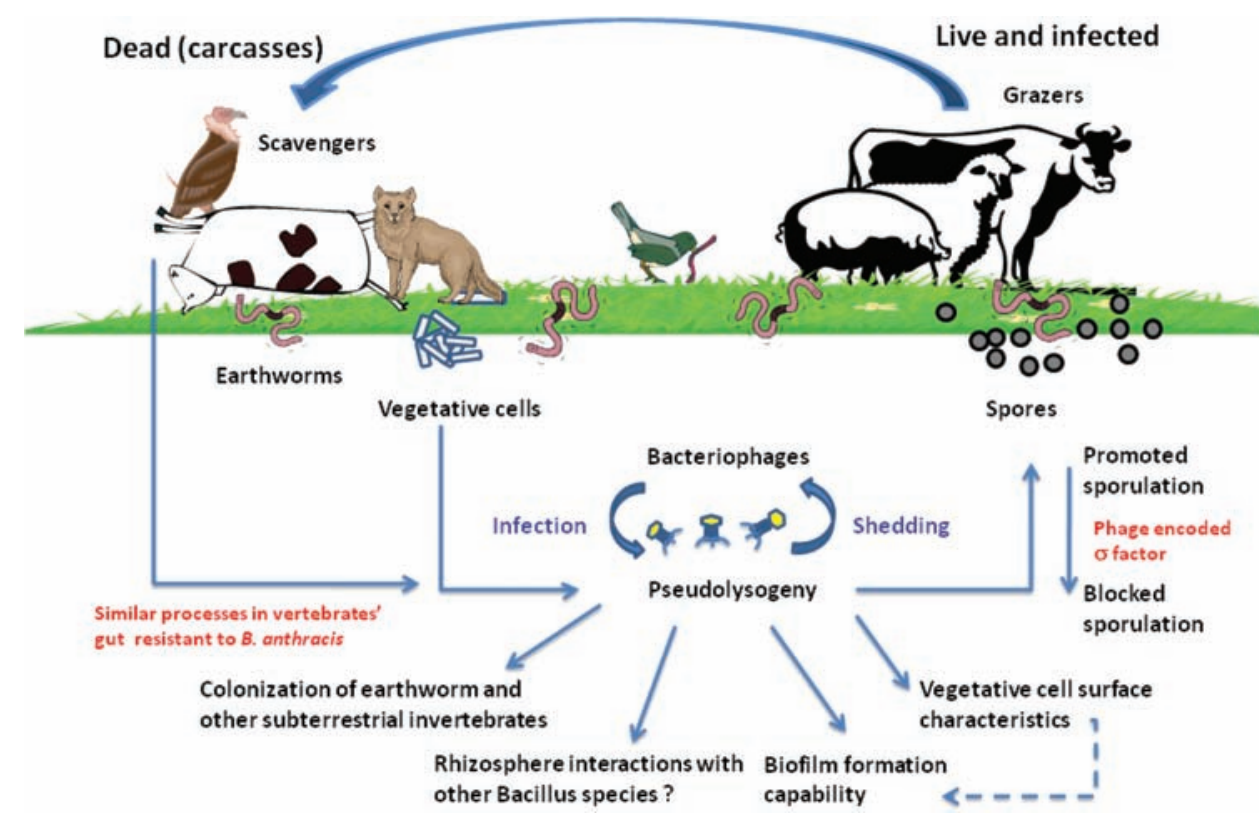

Figure 2.1.3. Biotic factors involved in B. anthracis spores dispersion (adapted from Schuch and Fischetti, 2009)

\subsubsection{Conclusions and remarks}

The scientific debate on $B$. anthracis spores ecology and their infection routes continues. Of their fierce environmental resistance there is no doubt: B. anthracis spores subsist for decades (Wilson and Russell, 1964; Willis, 2004) in spite of some reports questioning this fact (Turnbull et al., 1985) and even at extreme pressure of $600 \mathrm{Atm}$ (Certes, 1884). The published literature shows that regardless of regular herd vaccination, sporadic epizoonotic events occur around the globe. After more than 100 years of research, spores detection methodology is still inadequate to identify accurately their presence in the environment, especially from soil (Marston et al., 2008) and only a recently published report presented an antibiotic supplemented medium that supports $B$. anthracis growth (with a selectivity of 96.8 to100\%) inhibiting others Bacillus species that are commonly present and interfer in soil environment (Luna et al., 2009).

Molecular methods (PCR, DNA probes, etc.) should solve the detection problems as described by Cheun et al. (2003) that used nested and real-time PCR to detect B. anthracis spores seeded in soil samples. 
It should be pointed out at this point in time, that these methods still do not differentiate between viable and dead/injured spores while direct cultivation does.

According to the literature, the main source of $B$. anthracis spores still remains affected animals and their carcasses where soil plays a major role. Per se, water flow, winds, wildlife and human activity (such as soil transfer and agricultural activity) can turn out to be additional factors in spreading the spores (Seidel and Cotta, 2002; Metz, 1980; Masner, 1938; Lutz, 1913; Cabello and Cabello, 2008). Regulations on meadow use for domestic growth of herds as well soil transfer should include seasonal testing, while heavy rain and floods should be a warning in any country -side where anthrax is endemic. Anthropogenic activities such as deforestation, irrigation, urbanization and industrial activity can impact wildlife that is a potential carrier of the disease, bringing it closer to humans, causing reemergence of this old disease. Finally, biological warfare should be abandoned and countries violating international lows should be chastised by the international community.

\subsubsection{REFERENCES}

Anonymous (a). (2010) Food and Agriculture Organization of the United Nations, Agriculture and Consumer Protection Department. Anthrax in animals [cited 2007 Feb 14]. Available from: URL:http://www.fao. org/ag/magazine/0112sp.htm

Anonymous (b). (2010) U.S. Department of Agriculture: Animal and Plant Health Inspection Service, Veterinary Services, Centers for Epidemiology and Animal Health, Center for Emerging Issues (US). Epizootiology and ecology of anthrax [cited 2007 Feb 14]. Available from: URL: http://www.aphis.usda. gov/vs/ceah/cei/taf/emerginganimalhealthissues_files/anthrax.text.pdf

Beatty, M.E., Ashford, D.A., Griffin, P.M., Tauxe, R.V. \& Sobel, J. (2003) Gastrointestinal anthrax review of the literature. Arch.Intern.Med.163, 2527-2531.

Buravtseva, N.P., Eremenko, E.I., Kogotkova, O.I., Efremenko, V.I., Abgarian, A.G. et al. (2003) Epidemiological situation on anthrax in the regions of the Southern Federal District in connection with the flood in June 2002. Zh. Mikrobiol. Epidemiol. Immunobiol. 6, 43-46.

Cabello, C.C. \& Cabello, C.F. (2008) Zoonoses with wildlife reservoirs: a threat to public health and the economy. Rev Med Chil 136, 385-393.

Certes, A. (1884) Influence of high pressures on putrefaction. Comptes Rendus Hebdomadaires des Seances de l'Academie des Sciences, 1884, 99, 385-388. From: J. Chem. Soc., Abstr. 46, 1399. Journal of the Chemical Society, Abstracts was published from $1878-1925$.

Cheun, H.I., Makino, S.-I., Watarai, M., Erdenebaatar, J., Kawamoto, K. \& Uchida, I. (2003) Rapid and effective detection of anthrax spores in soil by PCR. J. Appl. Microbiol. 95, 728-733

Choquette, L.P.E. (1970) Anthrax. In: Davis JW, Karstad LH, Trainer DO (Eds.), Infectious Diseases of Wild Mammals. Ames: Iowa State University Press, 1970, pp. 256-266.

De Vos, V. (1990) The ecology of anthrax in Kruger National Park, South Africa. Salisbury Med Bull 68, (Spec Suppl) 19-23.

Doyle, R.J., Nedjat-Haiem, F. \& Singh, J.S. (1984) Hydrophobic characteristics of Bacillus spores. Curr.Microbiol. 10, 329-332.

Ebedes H. (1976) Anthrax epizootics in Etosha National Park. Madoqua 10, 99-118.

Fox, M.D., Boyce, J.M., Kaufmann, A.F., Young, J.B., Whitford, H.W. (1977) An epizootiologic study of anthrax in Falls County, Texas. J. Am. Vet. Med. Assoc. 170, 327-333.

Gates, C.C., Elkin, B.T. \& Dragon, D.C. (1995) Investigation, control and epizootiology of anthrax in a geographically isolated, free-roaming bison population in northern Canada. Can. J. Vet. Res. 59, 256-264.

Hahn, B.L., Sharma, S. \& Sohnle, P.G. (2005) Analysis of epidermal entry in experimental cutaneous Bacillus anthracis infections in mice. J. Lab. Clin. Med. 146, 95-102.

Heath, K.B. \& Brewitt, J.M. (1982) A winter outbreak of anthrax in cattle in Saskatchewan. Can Vet J 23, 302-303. 
Hugh-Jones, M.E. \& Hussaini, S.N. (1975) Anthrax in England and Wales, 1963-1972. Vet Rec 97, $256-261$.

Koch, R. (1876) "Untersuchungen über Bakterien: V. Die Ätiologie der Milzbrand-Krankheit, begründet auf die Entwicklungsgeschichte des Bacillus anthracis" (Investigations into bacteria: V. The etiology of anthrax, based on the ontogenesis of Bacillus anthracis), Cohns Beitrage zur Biologie der Pflanzen, 2, 277-310.

Krishna, R.N.S. \& Mohiyudeen, S. (1958) Tabanus flies as transmitters of anthrax: a field experience. Indian Vet J. 35, $348-353$.

Leishman, O.N., Labuza, T.P. \& Diez-Gonzalez, F. (2010) Hydrophobic properties and extraction of Bacillus anthracis spores from liquid foods. Food Microbiol. 27, 661-666.

Lewerin, S.S., Elvander, M., Westermark, T., Hartzell, L.N., Norstrom, A.K. et al. (2010) Anthrax outbreak in a Swedish beef cattle herd - 1st case in 27 years : Case report. Acta Vet. Scand. 52, 7.

Lindeque, P.M. \& Turnbull, P.C. (1994) Ecology and epidemiology of anthrax in Etosha National Park, Namibia. Onderstepoort $J$ Vet Res 61, 71-83.

Lloyd, C.T., Wynne, J.H., Santangelo, M.K. \& Straube, W.L. (2006) Immobilization of biological contaminants in arid environments using dust palliatives. Abstracts of Papers, $231^{\text {st }}$ ACS National Meeting, Atlanta, GA, United States, March 26-30, 2006.

Luna, V.A., Gulledge, J., Cannons, A.C. \& Amuso, P.T. (2009) Improvement of a selective media for the isolation of $B$. anthracis from soils. J. Microbiol. Methods 79, 301-306.

Lutz, L. (1913) Detection and Identification of Anthrax Bacilli in Drinking Water. Bulletin des Sciences Pharmacologiques 18, 572-574.

Marston, C.K., Beesley, C., Helsel, L. \& Hoffmaster, A.R. (2008) Evaluation of two selective media for the isolation of Bacillus anthracis. Lett. Appl. Microbiol. 47, 25-30.

Masner, L. (1938) Tannery effluent. Journal of the Society of Leather Trades' Chemists 22, 294-297.

McKendrick, D.R.A. (1980) Anthrax and its transmission to humans. Cent Afr J Med 26, 126-129.

Meselson, M., Guillemin, J., Hugh-Jones, M., Langmuir, A. et al. (1994) The Sverdlovsk anthrax outbreak of 1979. Science 266, 1202-1208.

Metz, H. (1980) Water as a vector of infection: waterborne bacteria. Zentralbl Bakteriol Mikrobiol Hyg B 172, 255-274

Mongoh, M.N., Dyer, N.W., Stoltenow, C.L. \& Khaitsa, M.L. (2008) Risk factors associated with anthrax outbreak in animals in North Dakota, 2005: a retrospective case-control study. Public Health Rep. 123, 352-359.

Rosenberg, M. (1984) Bacterial adherence to hydrocarbons: a useful technique for studying cell surface hydrophobicity. FEMS Microbiol. Lett. 22, 289-295.

Schuch, R. \& Fischetti, V.A. (2009) The secret life of the anthrax agent Bacillus anthracis: bacteriophage-mediated ecological adaptations. PLOS ONE 4, 1-23. e6532. doi:10.1371/journal.pone.0006532.

Sen, S.K. \& Minett, F.C. (1944) Experiments on the transmission of anthrax through flies. Indian J Vet Sci Anim Husb 14, 149-158.

Turell, M.J. \& Knudson, G.B. (1987) Mechanical transmission of Bacillus anthracis by stable flies (Stomos calcitrans) and mosquitoes (Aedes aegypti and Aedes taeniorhynchus). Infect Immun 55, 1859-1861.

Van Ness, G.B. (1971) Ecology of anthrax. Science 172, 1303-1307.

Webber, R.H. (1985) Anthrax in Lake Rukwa Valley, Tanzania: a persistent problem. J Trop Med Hyg. 88, 327-331. Whitford, H.W. (1979) Anthrax. In: Stoenner H, Kaplan W, Torten M, eds. CRC Handbook Series in Zoonoses, section A. Bacterial, Rickettsial and Mycotic Diseases. Boca Raton: CRC Press, 1979, pp. 31-66.

Wilson, J.B. and Russell, K.E. (1964) Isolation of Bacillus anthracis from a soil stored for 60 years. J. Bacteriol. 87, 237-238. 


\section{Chapter 2.2}

\section{Bartonelloses (including cat scratch)}

\section{[BARTONELLA SPP.]}

Bartonelloses can be found under several names (Carrion's, cat scratch, trench fever, bacillary angiomatosis and peliosis hepatis disease) that historically were reported along the years since the first described case by Carrión (in Latin the name means carcass!) in 1885 (Leonard, 1991; Scultz, 2010). Bartonella is a genus attributed to alpha subgroup 2 of phylum proteobacteria. Cells are gram-negative, aerobic, coccobacillary (pleomorphic), flagellated, motile and facultative intracellular organisms (Peters and Wigand, 1955). So far, the genus comprises 23 species identified thus far, but the following main species involved in zoonosis are: Bartonella bacilliformis, B. henselae, B. quintana, B. elizabethae B. grahamii, B. vinsoni B. washonsis, B. clarridgiae and B. rochalimae (Piemont and Heller, 1999; Guptill, 2010). Bartonella is now known to be strongly linked to various arthropod vectors (sand fly, mite, tick, lice, flea) and to wild and domestic reservoirs (including pet animals) such as: felids, canids, rodents, cattle, fishes, birds, horses, etc. summarized in Figure 2.2.1 (Podsiadly et al., 2002; Chomel et al., 2006; Chomel et al., 2006a; Holmberg et al., 2003; Guptill, 2010; Bermond et al., 2002; Jones et al., 2009; Breitschwerdt, 2008). Co-infection with several species was also reported that might well derive from different arthropods' bite or, so far unconfirmed, single arthropod species carrying several Bartonella spp. (Vissotto de Paiva Diniz et al., 2009; Welc-Faleciak, 2009). The pathogen is now known to cause human diseases such as: bacillary angiomatosis, cat-scratch disease, chronic bacteraemia and lymphadenopathy, meningoencephalitis, stellar retinitis, myelitis, granulomatous, hepatitis, endocarditis, osteomyelitis and peliosis hepatitis (Jacomo et al., 2002). The main clinical symptoms are high fever, chills, anorexia, malaise, lymphadenitis with purulent secretions, meningitis and paralysis (fatality rate 40 to $85 \%$ if untreated) (Maguiña and Gotuzzo, 2000).

\subsubsection{BARTONELLA AND ENVIRONMENT}

\subsubsection{Insects}

It is now clear that a variety of blood feeding (hematophagous) insects are the main vectors of Bartonella, while a variety of rodents and other mammals operate as reservoirs. Feliciangeli (2004) studied the natural 
breeding places of sandflies. Sandflies ecotopes occupied by immature phlebotomines are typically organically rich moist soils, such as the rain forest floor, contaminated soil of animal shelters and earthen floor of human habitations. The addition of global warming to these conditions, which has been shown to favor insects' reproduction and their populations swell, might explain to some extent the new outbreaks of bartonelloses in remote sites that supply these conditions (Frazier et al., 2006). An important contribution to the major role of arthropods in bartonelloses transmission was shown by Bown et al. (2004) in bank voles. Inoculation of bank voles with B. taylorii in an arthropod-free environment was not transmitted either horizontally or vertically, providing the clear evidence of the essential role of fleas (in this case) in Bartonella transmission among these rodents.

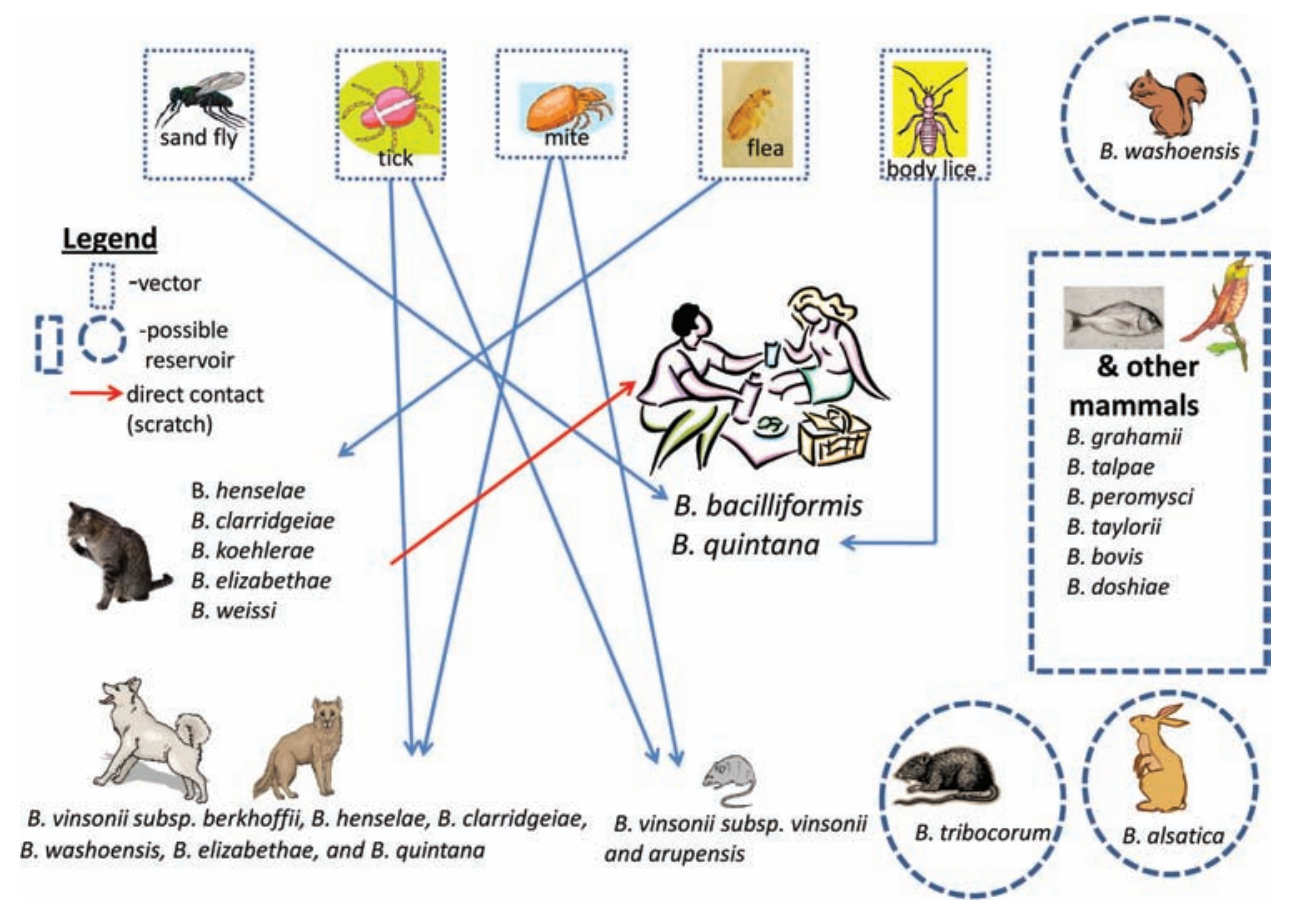

Figure 2.2.1. Bartonella spp. hosts, vectors and transmission

Ellis et al., (1999) conducted a case-study of an acute outbreak of bartonellosis in the Urubamba Valley (Peru) that was previously unknown as an endemic area. These authors found from odds-ratio analysis that the case-patients group reported sand fly bites more frequently than individuals of neighboring households. However, sand flies (Lutzomyia peruensis) captured during this study did not show increased harborage of Bartonella and the truly positive, harbored B. bacilliformis and in one case $B$. grahamii only. It should be mentioned that no rodent survey was performed assuming that $B$. bacilliformis is a human pathogens not yet found in rodents. However, it cannot be ruled out that rodents do carry this species.

Another outbreak of B. bacilliformis in Ecuador was reported by Cooper et al. (1997). According to the authors' analysis, all case houses were located in isolated areas at the forest margin with presence of dead rodents in case houses only. They suggested that human bartonellosis is a zoonosis with a natural rodent 
reservoir and that migrant humans infected in this way may become a temporary reservoir host in populated areas. Evidences of interspecies transmission and possible infection have been shown with $B$. bacilliformis in experimental animals by inoculation of susceptible animals including monkeys, dogs, donkeys, rabbits and guinea-pigs (Herrer, 1990). These authors also reported "the appearance of an epidemic of a rapidly fatal chicken illness characterized by fever, diarrhoea, and dyspnoea". The few avian survivors developed blood-containing 'verrugas' which were most noticeable on the head area. The avian epidemic spread slowly between communities, and most case households (63\%) reported its appearance before the development of disease in human cases.

\subsubsection{Bartonella in pets}

It can be stated with a high degree of certainty that globally the most common pet animals are dogs and cats. Since their early domestication, they have been one of the main sources of zoonotic diseases (Chomel et al., 2006). However, additional pet animals have been shown to harbor Bartonella spp. Inoue et al. (2009) looked for the prevalence of Bartonella spp. in 546 small mammals (28 species) that had been imported as pets into Japan from Asia, North America, Europe, and the Middle and Near East. The animals examined carried four zoonotic Bartonella spp. that cause human endocarditis and neuroretinitis and six novel Bartonella spp. at a relative high prevalence (26.0\%), presenting a marked risk of human infection with this pathogen.

\subsubsection{Weather and global warming}

Beldomenico et al. (2005) studied Bartonella vinsonii subsp. berkhoffii in the coyote population of Northern California along with two other pathogens. Applying univariate analyses, these authors concluded that Bartonella seropositivity was associated with higher precipitation and proximity to the coast (where higher precipitation occurs). Arthropods activity of flea, tick, mosquito and sandfly is closely associated with high humidity and warm temperature, explaining the ecology of Bartonella in such geographical areas. It should be mentioned that excavations, deforestation, etc. can disrupt rodents' regular habitats, setting off interchange environments and exposure of hosts to new vectors.

\subsubsection{REFERENCES}

Beldomenico, P.M., Chomel, B.B., Foley, J.E., B.N. Sacks, B.N., Baldi, C.J., Kasten, R.W., and Gardner, I.A. (2005) Environmental factors associated with Bartonella vinsonii subsp. berkhoffii seropositivity in free-ranging coyotes from Northern California. Vectorborne and Zoonotic Dis. 5, 110-119.

Bermond, D., Boulouis, H.-J., Heller, R., Van Laere, G., Monteil, H. et al. (2002) Bartonella bovis Bermond et al. sp. nov. and Bartonella capreoli sp. nov., isolated from European ruminants. Int. J. Syst. Evol. Microbiol. 52, 383-390.

Bown, K.J., Bennet, M. \& Begon, M. (2004) Flea-borne Bartonella grahamii and Bartonella taylorii in bank voles. Emerg. Infect. Dis. 10, 684-687.

Breitschwerdt, E.B. (2008) Feline bartonellosis and cat scratch disease. Vet. Immunol. Immunopathol. 123, 167-171.

Chomel, B.B., Boulouis, H-J., Maruyama, S. \& Breitschwerdt, E.B. (2006) Bartonella spp. in pets and effect on human health. Emerg. Infect. Dis. 12, 389-394.

Chomel, B.B., Kasten, R.W., Henn, J.B. \& Molia, S. (2006a) Bartonella infection in domestic cats and wild felids. Ann. N.Y. Acad. Sci. 1078, 410-415.

Cooper, P., Guderian, R., Orellana, P., Sandoval, C., Olalla, H. et al. (1997) An outbreak of bartonellosis in Zamora Chinchipe Province in Ecuador. Trans. R. Soc. Trop. Med. Hyg. 91, 544-546.

Dehio, C. (2005) Bartonella-host-cell interactions and vascular tumour formation. Nat. Rev. Microbiol. 3, 621-631. 
Diniz, P.P., Wood, M., Maggi, R.G., Sontakke, S., Stepnik, M. \& Breitschwerdt, E.B. (2009) Co-isolation of Bartonella henselae and Bartonella vinsonii subsp. Berkhoffii from blood, joint and subcutaneous seroma fluids from two naturally infected dogs. Vet. Microbiol. 138, 368-372.

Ellis, B.A., Rotz, L.D., Leake, J.A.D., Samalvides, F., Bernable, J. et al. (1999) An outbreak of acute bartonellosis (Oroya fever) in the Urubamba region of Peru, 1998. Am. J. Trop. Med. Hyg., 61, 344-349.

Feliciangeli, M.D. (2004) Natural breeding places of phlebotomine sandflies. Med. Vet. Entomol. 18, 71-80.

Frazier, M.R., Huey, R.B. \& Berrigan, D. (2006) Thermodynamics constrains the evolution of insect population growth rates: "warmer is better." Am. Nat. 168, 512-520.

Greub, G. \& Raoult, D. (2002) Bartonella: new explanations for old diseases. J. Med. Microbiol. 51, 915-923.

Guptill, L.(2010) Bartonellosis. Vet. Microbiol. 140, 347-359.

Gurfield, A.N., Boulouis, H.-J. Chomel, B.B., Kasten, R.W. Heller, R. et al. (2001) Epidemiology of Bartonella infection in domestic cats in France. Vet. Microbiol. 80, 185-198.

Herrer, A.A. (1990) Epidemiología de la Verruga Peruana. Lima: Editorial Gonzales Mugaburu. (1990).

Holmberg, M., Mills, J.N., McGill, S., Benjamin, G. \& Ellis, B.A. (2003) Bartonella infection in sylvatic small mammals of central Sweden. Epidemiol Infect. 130, 149-157.

Inoue, K., Maruyama, S., Kabeya, H., Hagiya, K., Izumi, Y. et al. (2009) Exotic small mammals as potential reservoirs of zoonotic Bartonella spp. Emerg. Infect. Dis. 15, 526-532.

Jacomo, V., Kelly, P.J. \& Raoult, D. (2002) Natural history of Bartonella infections (an exception to Koch's postulates). Clin. Diagn. Lab. Immunol. 9, 8-18.

Jones, R.T., McCormick, K.F. \& Martin, A.P. (2008) Bacterial communities of Bartonella-positive fleas: diversity and community assembly patterns. Appl. Environ. Microbiol. 74, 1667-1670.

Jones, S.L., Maggi, R., Shuler, J., Alward, A. \& Breitschwerdt, E.B. (2008) Detection of Bartonella henselae in the blood of 2 adult horses. $J$ Vet Intern Med 22, 495-498.

Kaiser, J. (2000) Ecological Society of America meeting. Global warming, insects take the stage at Snowbird. Science 289, 2031-2032.

Krebs, J.C. (1999) Current Paradigms of Rodent Population Dynamics—What Are We Missing ? In: G.R. Singleton, L. A. Hinds, H. Leirs and Z. Zhang (Ed-s) Ecologically-based Management of Rodent Pests, Australian Centre for International Agricultural Research (ACIAR), Canberra (1999), pp. 33-48.

Leonard, J. (1991) Daniel Carrión and Carrión's disease. Bull Pan Am Health Organ. 25, 258-266.

Maguiña, C. \& Gotuzzo, E. (2000) Bartonellosis-new and old. Infect Dis Clin N Am. 14, 1-22

Peters, D. \& Wigand, R. (1955) Bartonellaceae. Bacteriol Rev. 19, 150-159.

Piemont, Y. \& Heller, R. (1999) Bartonellosis. II. Other Bartonella responsible for human diseases. Ann. Biol. Clin. (Paris) 57, 29-36.

Podsiadly, E., Chmielewski, T., Marczak, R., Sochon, E. \& Tylewska-Wierzbanowska, S. (2007) Bartonella henselae in the human environment in Poland. Scand. J. Infect. Dis. 39, 956-962.

Schultz, M.G. (2010) Daniel Alcides Carrión [photo quiz]. Emerg Infect Dis [serial on the Internet]. 2010 Jun [10 August 2010]. Available from http://www.cdc.gov/EID/content/16/6/1025.htm

Vasil'eva, I.S. (2005) Bartonellosis and a possible role of Ixodes ticks (family Ixodidae, order Parasitiformes) in the transmission of pathogenic Bartonella bacteria. Med Parazitol (Mosk) 2, 44-48.

Welc-Faleciak, R. (2009) Current state of the knowledge of Bartonella infections. Przegl Epidemiol 63, 11-17. 


\section{Chapter 2.3 Borreliosis}

\section{[BORRELIA BURGDORFERI]}

Genus Borrelia are gram-negative, non-spore forming, aerobic to microaerophilic, extracellular pathogenic spirochete containing 36 known species among which Borrelia burgdorferi, B. recurrentis, B. afzelii, $B$. anserina, $B$. garinii, $B$. hermsii, $B$. valaisiana and $B$. vincentii are the best known; all are transmitted by ticks and body lice by means of reservoirs such as rodents or other mammals (Figure 2.3.1) (Samuels and Radolf, 2010; Anderson et al., 1985; Hanincová et al., 2003; Gil et al., 2005). In humans the disease is called Lyme borreliosis (named after the town Lyme in Connecticut, USA where it was first reported) (caused primarily by Borrelia burgdorfii) or relapsing fever (caused primarily by Borrelia recurrentis). The etiological factor was identified in the 70s by Willy Burgdorfer to be a tick-borne spirochetal bacterium (Burgdorf et al., 1982). The symptoms of the diseases are mainly dermatological (erythema), rheumatological (arthritic episodes), neurological (chronic lymphocytic meningitis) and cardiological (myocarditis, pericarditis, etc.). At present Borrelia bacteria have been detected globally, in a variety of ticks and animals (Table 2.3.1.).

\subsubsection{BORRELIA AND ENVIRONMENT}

\subsubsection{Borrelia and birds}

The ability of birds to carry ticks over a large geographical area is undisputable (Reed et al., 2003). There are many birds species (i.e. passerine birds that belong to the order Passeriformes, which includes more than half of all bird species), mainly ground foraging birds that are infested by ectoparasites, holding them on body sites that are difficult to preen (ear, eye and head) (Dubska et al., 2009). This way, birds are able to transfer ticks and establish new endemic foci of boreliosis all over the globe, through their migratory activity (Figure 2.3.2). The reservoir question has still to be clarified as not all birds are capable of transmitting the infectious agent to tick vectors (Mather et al., 1989).

Ground animals, including humans, seem to be the major reservoir of Borrelia (Figure 2.3.3). A surveillance study in Wisconsin and Northern Illinois, USA, showed that dogs' seroprevalence was between 0 to $40 \%$. Spatial pattern was significantly correlated with human incidences of Lyme disease's 
and with an abundance of the tick vector (Ixodes scapularis). Among surveyed dogs, seropositivity was definitely associated with increased tick exposure, time spent outdoors and living in forested and urban areas as well on sandy, fertile soils (Guerra et al., 2001).

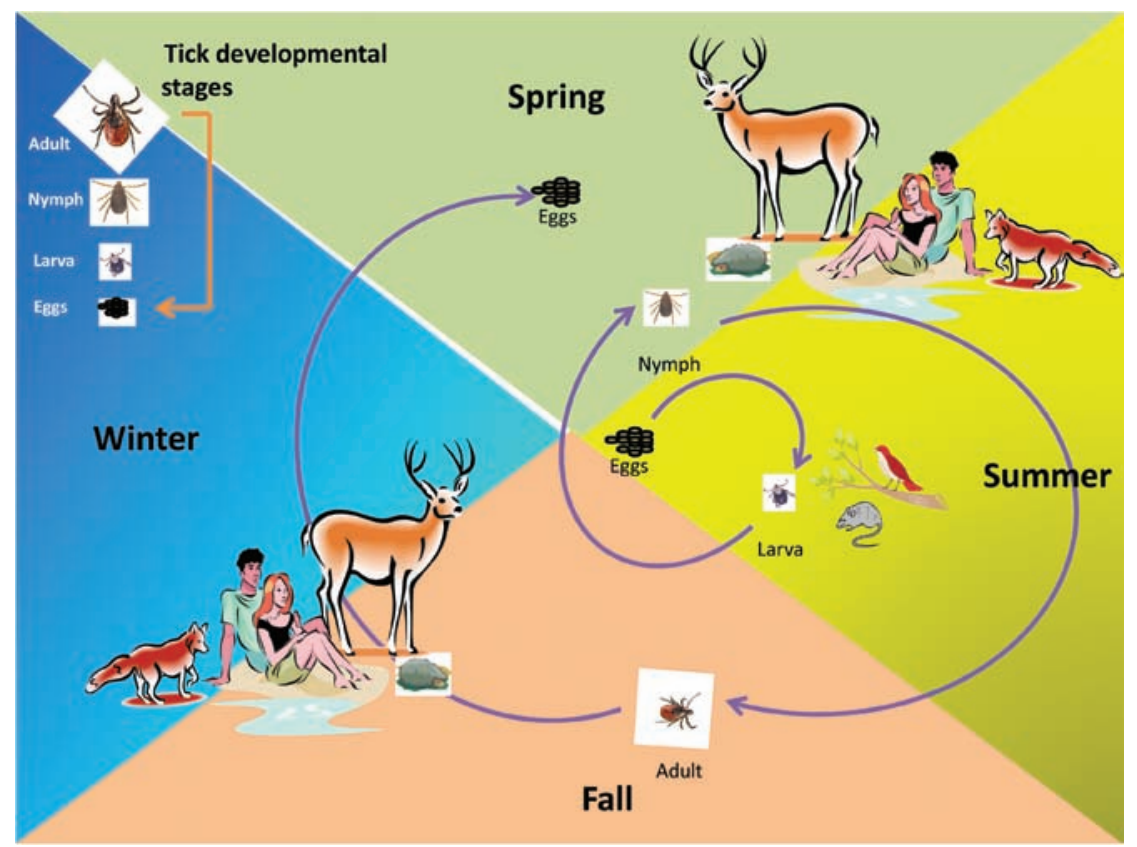

Figure 2.3.1. Borrelia burgdorfii infection cycle and environmental aspects (with permission, adapted and modified from CDC, Atlanta, GA, USA)

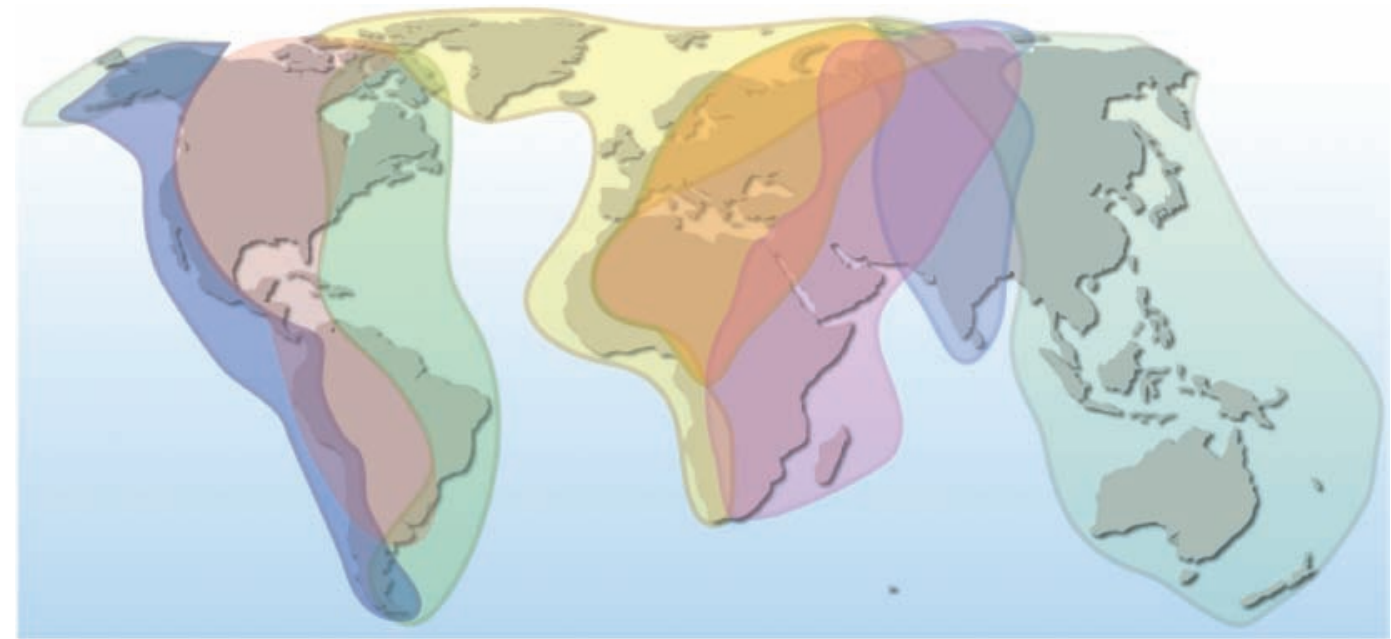

Figure 2.3.2. Global geographic areas covered by migratory birds. [With permission from http://maps.grida. no/go/graphic/major-global-bird-migration-routes-to-the-arctic (Hugo Ahlenius, UNEP/GRID-Arendal)] 


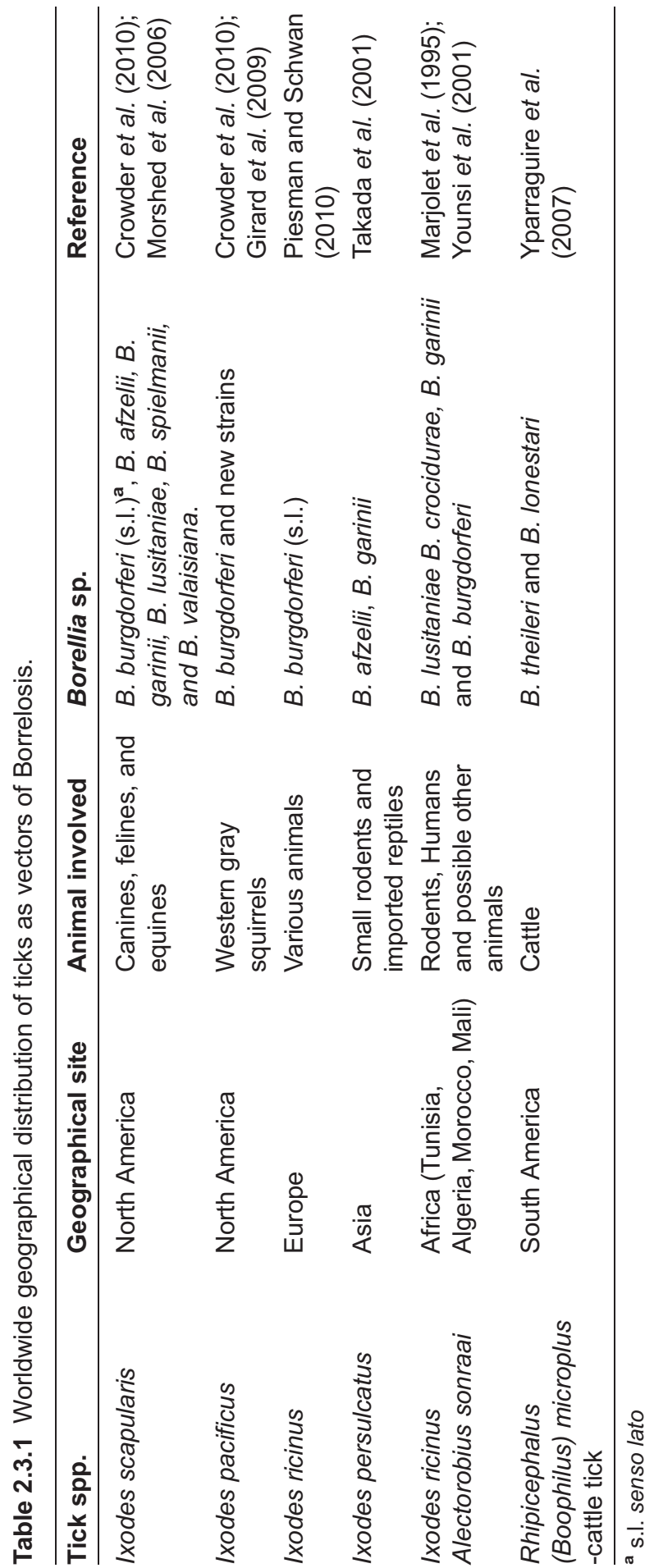




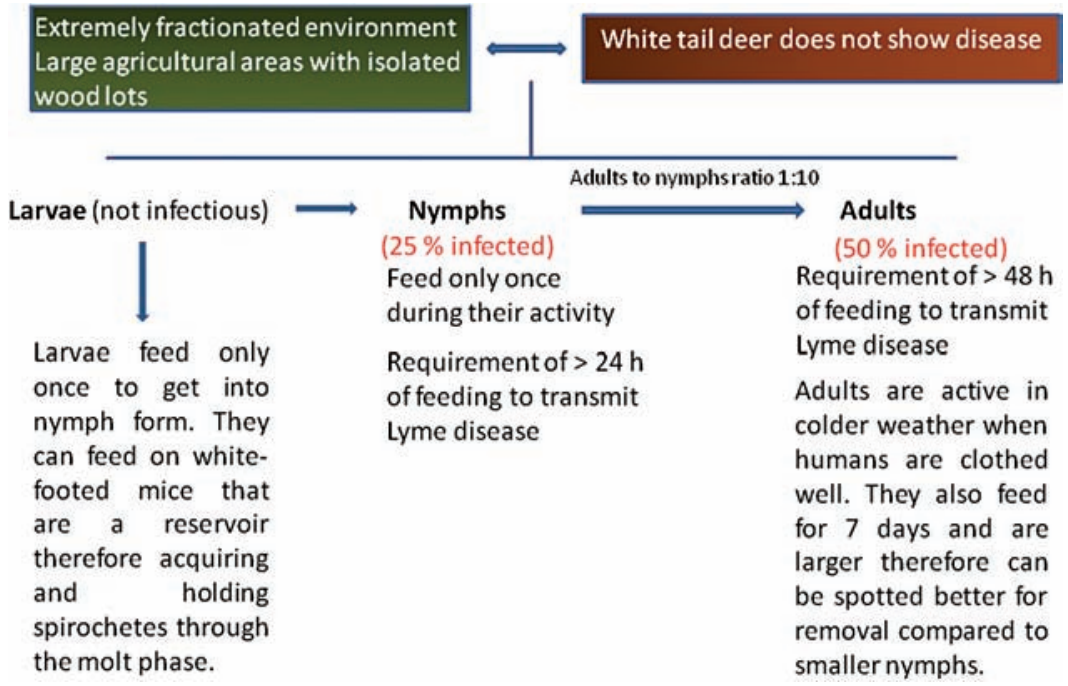

Figure 2.3.3. Environmental ground factors involved in the Lyme disease spread in USA (after Fish, 1995)

\subsubsection{Borrelia and forest}

As shown before, ticks the key vector of Lyme disease bacterium, reside mainly on the ground in humid, bushed and forested areas. A study based on the hypothesis that small forest patches $(<2$ ha) have a higher density of infected nymphal blacklegged ticks (a tick well known as the primary risk factor for Lyme disease) than larger patches (2-8 ha), was carried out in Dutchess County of southeastern New York state, USA (Allan et al., 2003). The results showed a significant exponential decline in the prevalence of nymphal density and a significant linear decline in nymphal infection with increasing patch area. Therefore, as a result of forest patch size reduction, a dramatic increase in infected nymphs' density was observed (consequently escalating Lyme disease risk). It should be also mentioned that small forest patches are predominantly prone to high densities of different local rodents (in this particular case, whitefooted mouse) and consequently higher densities of infected nymphal blacklegged ticks.

\subsubsection{Other environmental factors}

Soils moistened by rain favor multiplication of ticks, therefore increasing the vector arsenal (Medlock et al., 2008). Interestingly, in relation to rain, the relative scarceness of disease reports from Africa, where drought conditions subsist (mainly in the northern part of the continent), should be noted. Deforestation for agricultural purposes also increases the reservoir potential through the proliferation of various rodents in these areas, as already mentioned above. $\mathrm{CO}_{2}$ elevated concentrations and the consequent expansion of warm climatic zones directly and indirectly impact the tick and animal life cycle. Finally increased trade and travel may spread vectors worldwide (Sutherst, 2004).

Deer fencing and modification of wildlife behavior in the suburban residential area (bird and animal supplemental feeding) encourage other ticks carriers such as white-footed mice, raccoons and squirrels to draw in closer contact with humans (Fish, 1995). Glass et al. (1995) reported similar observations using GIS system and adjusted analyses, that residence in forested areas and specific soils (loamy) was associated with an elevated risk of getting Lyme disease. Estrada-Pena (2003) using a model approach 
based on recorded distribution of Ixodes scapularis in USA, looked for habitat changes of this tick for a period of 18 years (1982-2000). Based on discriminant analysis, the author found that the increased winter temperatures and expanded vitality of geographical vegetation (as a result of higher rainfall) resulted in the habitat switching from unsuitable to suitable for these ticks.

A more detailed report was performed in a temperate deciduous broad-leaved forest in South Moravia (Czech Republic), which looked for increased activity of local ticks under various environmental variables (Hubalek et al., 2003). Although rainfall did not correlate well, air and soil morning temperature and relative humidity were reported to be closely correlated to tick activity. Burgess et al. (1993) showed infection with Borrelia burgdorferi in cows, rodents and birds in non-Lyme endemic counties. Interestingly, they also reported pathogen vertical transmission of B. burgdorfii in rodents (transplacental transmission in $M$. musculus and P. leucopus). New strains of the bacteria that cause Lyme disease have been found in British Columbia, according to a recently published study on ticks collected from birds across Canada (Scott et al., 2001). These researchers found that the genetic makeup of three bacteria differed from previously known strains, with difference of opinions among the authors: one suggested that the novel strains did not show up (Lyme disease patients were test negative) while the others disagreed based on small genetic differences among the strains, not enough to discard the current testing for Lyme disease. In spite of this controversy, it is clear that new pathogen species are evolving continuously, while birds and ticks are excellent incubators beside humans.

In summary, forest (intensive agriculture and forest fragmentation), rain, tick population, reservoirs (rodents and other wild animals such as deer and birds), decline in pesticide use, social problems (homelessness and leisure time), increased temperatures and humidity, soil type and frequent contact with infected animals are all important factors of Borreliosis occurrence.

\subsubsection{REFERENCES}

Allan, B.F., Keesing, F. \& Ostfeld, R.S. (2003) Effect of forest fragmentation on Lyme disease risk. Conserv. Biol. 17, 267-272.

Anderson, J.F., Johnson, R.C., Magnarelli, L.A. \& Hyde, F.W. (1985) Borrelia burgdorferi from feral rodents and ticks (Dermacentor variabilis). J. Clin. Microbiol. 22, 36-38.

Bouattour, A., Ghorbel, A., Chabchoub, A. \& Postic, D. (2004) Lyme borreliosis situation in North Africa. Arch Inst Pasteur Tunis 81, 13-20.

Burgdorfer, W., Barbour, A. G., Hayes, S. F., Benach, J. L., Grunwaldt E. \& Davis, J. P. (1982) Lyme disease - a tick-borne spirochetosis? Science 216, 1317-1319.

Burgess, E.C., Wachal, M.D. \& Cleven, T.D. (1993) Borrelia burgdorferi infection in dairy cows, rodents, and birds from four Wisconsin dairy farms. Vet. Microbiol. 35, 61-77.

Ciceroni, L., Bartoloni, A., Guglielmetti, P., Paradisi, F., Barahona, H. G. et al. (1994) Prevalence of antibodies to Borrelia burgdorferi, Borrelia parkeri and Borrelia turicatae in human settlements of the Cordillera Province, Bolivia. J Trop Med Hyg 97, 13-17.

Crowder, C.D., Matthews, H.E., Schutzer, S., Rounds, M.A., Luft, B.J. et al. (2010) Genotypic variation and mixtures of Lyme Borrelia in Ixodes ticks from North America and Europe. PLoS One 5, 1-9.

Dubska, L., Literak, I., Kocianova, E.,Taragelova, V. \& Sychra, O. (2009) Differential role of passerine birds in distribution of Borrelia spirochetes, based on data from ticks collected from birds during the postbreeding migration period in central Europe. Appl. Environ. Microbiol. 75, 596-602.

Estrada-Pena, A. (2002) Increasing habitat suitability in the United States for the tick that transmits Lyme disease: a remote sensing approach. Environ. Health Perspect. 110, 635-640.

Fish, D. (1995) Environmental risk and prevention of Lyme disease. Am. J. Med. 98, 2-9. 
Gil, H., Barral, M., Escudero, R., García-Pérez, A.L. \& Anda, P. (2005) Identification of a new Borrelia species among small mammals in areas of northern Spain where Lyme disease is endemic. Appl. Environ. Microbiol. 71, 1336-1345.

Girard, Y.A., Travinsky, B., Schotthoefer, A., Fedorova, N., Eisen, R.J. et al. (2009) Population structure of the Lyme borreliosis spirochete Borrelia burgdorferi in the western black-legged tick (Ixodes pacificus) in northern California. Appl. Environ. Microbiol. 75, 7243-7252.

Glass, G.E., Schwartz, B.S., Morgan, J.M., Johnson, D.T., Noy, P.M. \& Israel, E. (1995) Environmental risk factors for Lyme disease identified with geographic information systems. Am J Public Health. 85, 944-948.

Guerra, M.A., Walker, E.D. \& Kitron, U. (2001) Canine surveillance system for Lyme borreliosis in Wisconsin and northern Illinois: geographic distribution and risk factor analysis. Am. J. Trop. Med. Hyg. 65, 546-552.

Hanincová, K., Schäfer, S.M., Etti, S., Sewell, H.S., Taragelová, V. et al. (2003) Association of Borrelia afzelii with rodents in Europe. Parasitology 126, 11-20.

Hubalek, Z., Halouzka, J. \& Juricova, Z. (2003) Host-seeking activity of ixodid ticks in relation to weather variables. J. Vector Ecol. 28, 159-165.

Marjolet, M., Gueglio, B. \& Traore, M. (1995) Does Lyme disease (or an analogous disease) exist in Mali, West Africa ?. Trans. R. Soc. Trop. Med. Hyg. 89, 387.

Mather, T.N., Telford, S.R., MacLachlan, A.B. \& Spielman, A. (1989) Incompetence of catbirds as reservoirs for the Lyme disease spirochete (Borrelia burgdorferi). J Parasitol 75, 66-69.

Maurizi, L., Marie, J-L., Aoun, O., Courtin, C., Gorsane, S. et al. (2010) Seroprevalence survey of equine Lyme borreliosis in France and in sub-Saharan Africa. Vector Borne Zoonotic Dis.10, 535-537.

Medlock, J.M., Pietzsch, M.E., Rice, N.V.P., Jones, L., Kerrod, E. et al. (2008) Investigation of ecological and environmental determinants for the presence of questing Ixodes ricinus (Acari: Ixodidae) on Gower, South Wales. J. Med. Entomol. 45, 314-325.

Morshed, M.G., Scott, J.D., Fernando, K., Geddes, G., McNabb, A. et al. (2006) Distribution and characterization of Borrelia burgdorferi isolates from Ixodes scapularis and presence in Mammalian hosts in Ontario, Canada. J. Med. Entomol. 43, 762-773.

Piesman, J \& Schwan, T.G. (2010) Ecology of Borreliae and their arthropod vectors. In: Samuels, D.S. \& Radolf, JD (Eds.), Borrelia: Molecular biology, host interaction and pathogenesis. Caister Academic Press.

Piesman, J. \& Schwan, T.G. (2010) Ecology of Borreliae and their arthropod vectors. In: Borrelia. Editor(s): Samuels, D. S. and Radolf, J. D., (2010), pp. 251-278. Publisher: Caister Academic Press, Norwich, UK.

Randolph, S.E. (2010) To what extent has climate change contributed to the recent epidemiology of tick-borne diseases? Vet. Parasitol. 167, 92-94.

Reed, K.D., Meece, J.K., Henkel, J.S. \& Shukla, S.K. (2003) Birds, migration and emerging zoonoses: West Nile Virus, Lyme disease, Influenza A and enteropathogens. Clin Med Res 1, 5-12.

Scott, J.D., Fernando, K., Banerjee, S.N., Durden, L.A., Byrne, S.K. et al. (2001) Birds disperse ixodid (Acari: Ixodidae) and Borrelia burgdorferi-infected ticks in Canada. J Med Entomol 38, 493-500.

Sutherst, R.W. (2004) Global change and human vulnerability to vector-borne diseases. Clin. Microbiol. Rev. 17, 136-173.

Takada, N., Masuzawa, T., Ishiguro, F., Fujita, H., Kudeken, M. et al. (2001) Lyme disease Borrelia spp. in ticks and rodents from northwestern China. Appl. Environ. Microbiol. 67, 5161-5165.

Takano, A., Goka, K., Une, Y., Shimada, Y., Fujita, H. et al. (2010) Isolation and characterization of a novel Borrelia group of tick-borne borreliae from imported reptiles and their associated ticks. Environ. Microbiol. 12, 134-146.

Tälleklint, L. \& Jaenson, T.G.T. (1994) Transmission of Borrelia burgdorferi s.l. from Mammal Reservoirs to the Primary Vector of Lyme Borreliosis, Ixodes ricinus (Acari: Ixodidae), in Sweden. J. Med. Entomol. 31, 880-886.

Younsi, H., Postic, D., Baranton, G. \& Bouattour, A. (2001) High prevalence of Borrelia lusitaniae in Ixodes ricinus ticks in Tunisia. Eur. J. Epidemiol. 17, 53-56.

Yparraguirre, L.A., Machado-Ferreira, E., Ullmann, A.J., Piesman, J., Zeidner, N.S. \& Soares, C.A.G. (2007) A hard tick relapsing fever group spirochete in a Brazilian Rhipicephalus (Boophilus) microplus. Vector Borne Zoonotic Dis. 7, 717-721. 


\section{Chapter 2.4 Brucelloses}

\section{[BRUCELLA SPP.]}

Brucellosis can be found under different names: Bang's disease, Gibraltar fever, Malta fever, Maltese fever, Mediterranean fever and rock fever or undulant fever. The disease was first reported by Sir David Bruce in 1884 who identified the bacterium isolated from a sick British soldier positioned in Malta. Brucella bacterium is a gram-negative, non-spore forming rod, non-motile, facultative intracellular pathogen transmitted through ingestion of raw milk, cheese and meat or direct contact with an infected animal's secretions. At the moment, the genus Brucella contains 10 species, each with slightly different host specificity (Table 2.4.1). Transmission from human to human is rare but it may occur due to Brucella's low infective dose (10-100 CFU) (Heymann and David, 2008), mainly in contact with mucous areas or skin lesions. The disease is characterized by acute undulating fever, headache, night sweats, fatigue, anorexia and complications such as arthritis, osteomyelitis and spondylitis and life persistence in chronic infection.

\subsubsection{BRUCELLA AND ENVIRONMENT}

Brucella have been isolated from a large variety of feral or domestic animals spread worldwide (Figure 2.4.1). Their association with human zoonoses is obvious and only vaccination of domestic herds can reduce the pathogen's dispersal. Another aspect, related to brucellosis transmission seen in high density animal herds, is winter elks' feed lines in Wyoming, USA (Maichak et al., 2009). These authors concluded that: "1) reduction of elk density and time attending feed grounds, particularly on feed lines; and 2) protection of scavengers on and adjacent to feed grounds would likely reduce intraspecific transmission risk of brucellosis". Similar conclusions in relation to elks' density were supported by results in the Greater Yellowstone ecosystem, revealing a significant seropositivity rise from $0-7 \%$ in $1991 / 2$ to $8-20 \%$ in $2006 / 7$ respectively, as complemented well by limited hunter access to private lands (Cross et al., 2010).

As an intracellular pathogen, Brucella would not be expected to survive extensively in environment. However, there is enough evidences revealing that this pathogen spreads through a large variety of 
Brucelloses

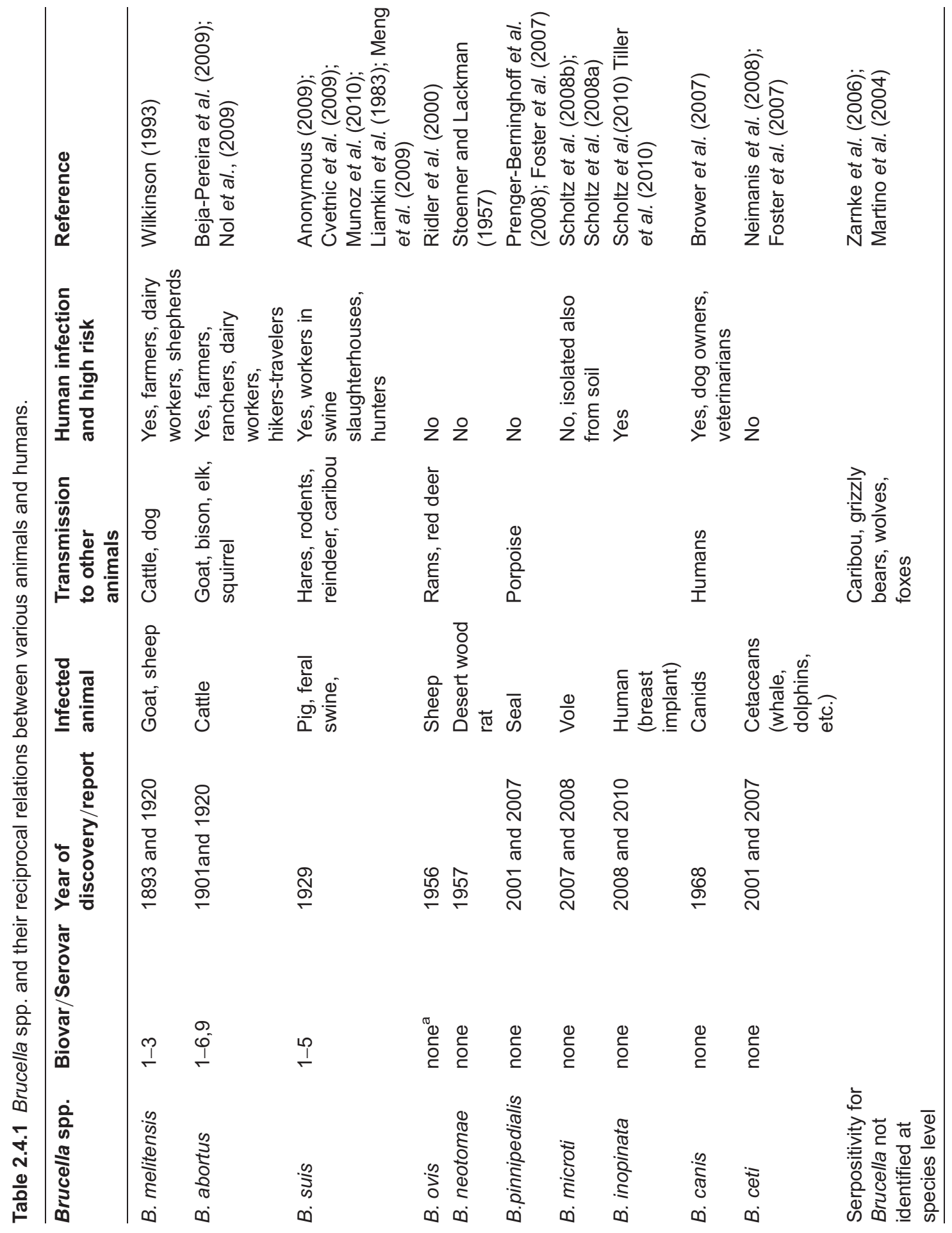


animals (including humans) and one species, B. microti, isolated primarily from a vole, was also isolated from soil samples (Scholtz et al. 2008a). How this species survives in soil is still a puzzle; however these authors supplied attractive supporting explanations for their results: 1) B. microti untypically is a fast growing bacterium with increased metabolic activity, therefore organic, moist soil can support their growth and 2) whole genome comparison of B. microti and B. suis with other soil bacteria such as Agrobacterium and Rhizobium spp. exhibited fundamental similarities (Paulsen et al., 2002). Whether soil organisms such as nematodes are the reservoir of this pathogen remains to be clarified, however some proofs exist as already shown with B. anthracis's spores fate in soil (Schuch and Fischetti, 2009).

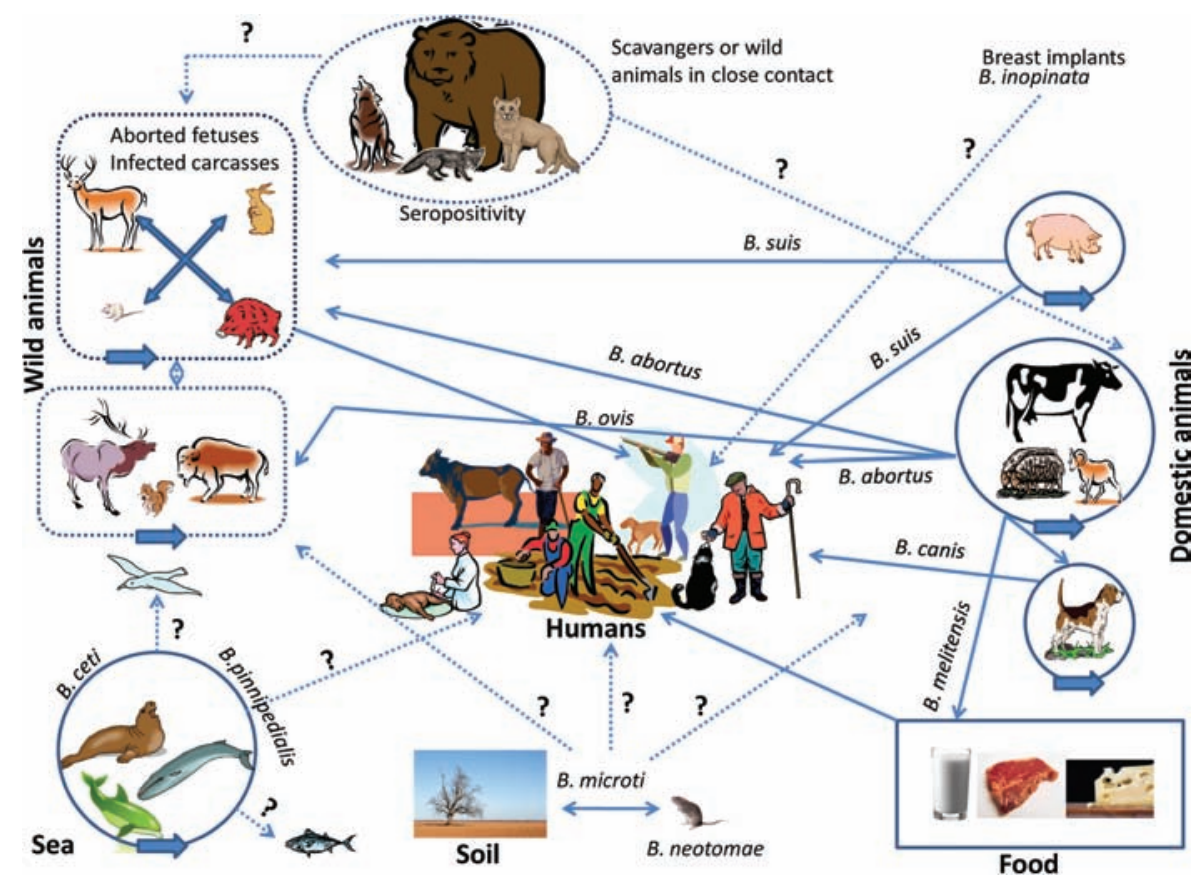

Figure 2.4.1. Brucella spp. cycles of infection among various animals and humans (full arrows-experimentally proved; dotted arrows- potentially unproved)

Interconnected with the soil ecosystem, Swartz et al. (2007) reported a "spectacular" reaction of Brucella abortus to the blue spectrum of natural light by means of a significant change in the reproduction and infectivity rate. This phenomenon was further explained by Brucella photosensing proteins (light-oxygenvoltage and histidine kinase proteins, "LOV-HK") involved in gene expression, that when knocked out impaired bacterium growth rate and infectivity significantly. This behavior fits the environmental phase of the pathogen excreted cells (in soil, exposed meat, milk, secretions or expelled placenta) exposed to blue light that activate the photosensing system in order to infect a new host successfully.

Another environmental important factor that acts as a Brucella reservoir is the wild boar (Munoz et al., 2010; Meng et al., 2009). It should be remembered here that this feral animal, like his domestic relative, feeds also on meat (carnivorous) in addition to vegetation in contrast to cattle, sheep and other ungulates.

Among the vast amount of reports on animals as Brucella carriers, reports on birds and fishes are scarce, though some are related to such potential interaction. Januszewski et al. (2001) showed that B. abortus strain 
RB51 (vaccine) can multiply in squirrel and raven without clinical signs. A recent study of infected fish (Nile catfish) with Brucella melitensis was reported (El-Tras et al. 2010) suggesting that the source of infection was probably wastewater. Bogomolni et al. (2008) substantiated these results by surveying marine birds and mammals for amplicons to sequences from Brucella spp., among other pathogens, in the Northwest Atlantic Ocean. Their findings indicated that marine mammals and birds in this geographical location are reservoirs for potentially zoonotic pathogens that may be transmitted to beachgoers, fishermen and wildlife health personnel. They also speculated that zoonotic pathogens found in marine vertebrates were possibly acquired via contamination of coastal waters by sewage, run-off and agricultural or medical waste.

Moreover, risk factors closely related to Brucella infection were reported in many studies to be: hunting, consumption of raw meat and milk (foodborne), occupational or recreational (airborne), linked to travel and even to bioterrorism (Valderas \& Roop, 2006).

\subsubsection{REFERENCES}

Anonymous. (2009) Brucella suis infection associated with feral swine hunting - three states, 2007-2008. MMWR Surveill Summ 58, 618-621.

Beja-Pereira, A., Bricker, B., Chen, S., Almendra, C., White, P. J. \& Luikart, G. (2009) DNA genotyping suggests that recent brucellosis outbreaks in the Greater Yellowstone Area originated from elk. J. Wildl. Dis. 45, 1174-1177.

Bogomolni, A.L., Gast, R.J., Ellis, J.C., Dennett, M., Pugliares, K.R. et al. (2008) Victims or vectors: a survey of marine vertebrate zoonoses from coastal waters of the Northwest Atlantic. Dis. Aquat. Org. 81, 13-38.

Brower, A., Okwumabua, O., Massengill, C., Muenks, Q., Vanderloo, P., Duster, M., Homb, K. and Kurth, K. (2007) Investigation of the spread of Brucella canis via the U.S. interstate dog trade". Int. J. Infect. Dis. 11, 454-458.

Cross, P.C., Cole, E.K., Dobson, A.P., Edwards, W.H., Hamlin, K.L. et al. (2010) Probable causes of increasing brucellosis in free-ranging elk of the Greater Yellowstone Ecosystem. Ecol Appl 20, 278-288.

Cvetnić, Z., Spicić, S., Toncić, J., Majnarić, D., Benić, M. et al. (2009) Brucella suis infection in domestic pigs and wild boar in Croatia. Rev. - Off. Int. Epizoot. 28, 1057-1067.

El-Tras, W.F., Tayel, A.A., Eltholth, M.M. \& Guitian, J. (2010) Brucella infection in fresh water fish: Evidence for natural infection of Nile catfish, Clarias gariepinus, with Brucella melitensis. Vet Microbiol. 141, 321-325.

Foster, G., Osterman, B.S., Godfroid, J., Jacques, I. \& Cloeckaert, A. (2007) Brucella ceti sp. nov. and Brucella pinnipedialis sp. nov. for Brucella strains with cetaceans and seals as their preferred hosts. Int J Syst Evol Microbiol. 57, 2688-2693.

Heymann, M.D. \& David L. (2008). Control of Communicable Disease Manual. Baltimore, MD, United Book Press, Inc.

Januszewski, M.C., Olsen, S.C., McLean, R.G., Clark, L., Rhyan, J.C. (2001) Experimental infection of nontarget species of rodents and birds with Brucella abortus strain RB51vaccine. J Wildl Dis 37, 532-537.

Liamkin, G.I., Taran, I.F., Safronova, V.M., Tikhenko, N.I. \& Shiranovich, M.P. (1983) Taxonomic position and ecology of the causative agent of brucellosis isolated from murine rodents in regions of the northern foothills of the Greater Caucasus. II. The ecological and pathogenetic characteristics of Brucella strains isolated from murine rodents. Zh. Mikrobiol. Epidemiol. Immunobiol. 7, 31-35.

Maichak, E.J., Scurlock, B.M., Rogerson, J.D., Meadows, L.L., Barbknecht, A.E. et al. (2009) Effects of management, behavior, and scavenging on risk of brucellosis transmission in elk of western Wyoming. J. Wildl. Dis. 45, 398-410.

Martino, P.E., Montenegro, J.L., Preziosi, J.A., Venturini, C., Bacigalupe, D., Stanchi, N.O. \& Bautista, E.L. (2004) Serological survey of selected pathogens of free-ranging foxes in southern Argentina, 1998-2001. Rev. - Off. Int. Epizoot. 23, 801-806.

Meng, X.J., Lindsay, D.S. \& Sriranganathan, N. (2009) Wild boars as sources for infectious diseases in livestock and humans. Philos. Trans. R. Soc. Lond., B, Biol. Sci. 364, 2697-2707. 
Munoz, P.M., Boadella, M., Arnal, M., de Miguel, M.J., Revilla, M. et al. (2010) Spatial distribution and risk factors of Brucellosis in Iberian wild ungulates. BMC Infect. Dis. 10:46.

Neimanis, A.S., Koopman, H.N., Westgate, A.J., Nielsen, K. \& Leighton, F.A. (2008) Evidence of exposure to Brucella sp. in harbor porpoises (Phocoena phocoena) from the Bay of Fundy, Canada. J. Wildl. Dis. 44, 480-485.

Nol, P., Olsen, S.C. \& Rhyan, J.C. (2009) Experimental infection of Richardson's ground squirrels (Spermophilus richardsonii) with attenuated and virulent strains of Brucella abortus. J. Wildl. Dis. 45, 189-195.

Paulsen, I.T., Seshadri, R., Nelson, K.E., Eisen, J.A., Heidelberg, J.F., Read, T.D. et al. (2002) The Brucella suis genome reveals fundamental similarities between animal and plant pathogens and symbionts. Proc Natl Acad Sci U S A. 99, 13148-13153.

Prenger-Berninghoff, E., Siebert, U., Stede, M., Koenig, A., Weiss, R. \& Baljer, G. (2008) Incidence of Brucella species in marine mammals of the German North Sea. Dis. Aquat. Org. 81, 65-71.

Ridler, A.L., West, D.M., Stafford, K.J., Wilson, P.R. \& Fenwick, S. (2000) Transmission of Brucella ovis from rams to red deer stags. $N Z$ Vet $J \mathbf{4 8}, 57-59$.

Scholz, H.C., Hubalek, Z., Nesvadbova, J., Tomaso, H., Vergnaud, G. et al. (2008a) Isolation of Brucella microti from soil. Emerging Infect. Dis. 14, 1316-1317.

Scholz, H.C., Hubalek, Z., Sedlácek, I., Vergnaud, G., Tomaso, H., Al Dahouk, S., et al. (2008b) Brucella microti sp. nov., isolated from the common vole Microtus arvalis. Int J Syst Evol Microbiol. 58, 375-82.

Scholz, H.C., Nöckler, K., Göllner, C., Bahn, P., Vergnaud, G. et al. (2010) Brucella inopinata sp. nov., isolated from a breast implant infection. Int J Syst Evol Microbiol. 60, 801-808.

Stoenner, H.G. \& Lackman, D.B. (1957) A new species of Brucella isolated from the desert wood rat, Neotoma lepida." Am. J. Vet. Res. 69, 947-951.

Tiller, R.V., Gee, J.E., Lonsway, D.R., Gribble, S., Bell, S.C. et al. (2010) Identification of an unusual Brucella strain (BO2) from a lung biopsy in a 52 year-old patient with chronic destructive pneumonia. BMC Microbiol. 27, 10:23.

Valderas, M.W. \& Roop, R.M. (2006) Brucella and bioterrorism. In: Anderson, B., Friedman, H. \& Bendinelli, M. (Eds.): Microorganisms and Bioterrorism. pp. 139-153. Publisher: Springer, New York.

Wilkinson, L. (1993) Brucellosis. In: Kiple, K.F. (Ed.), The Cambridge World History of Human Disease. Cambridge University Press.

Zarnke, R.L., Ver Hoef, J.M. \& DeLong, R.A. (2006) Geographic pattern of serum antibody prevalence for Brucella spp. in caribou, grizzly bears, and wolves from Alaska, 1975-1998. J. Wildl. Dis. 42, 570-577. 


\section{Chapter 2.5}

\section{Campylobacterioses}

\section{[CAMPYLOBACTER JEJUNI]}

The genus Campylobacter comprises gram-negative spirals, microaerophilic, motile, non-spore forming and oxidase-positive bacteria. The following species belong to Campylobacter genus: C. coli, C. concisus, C. curvus, C. fetus, C. gracilis, C. helveticus, C. hominis, C. hyointestinalis, C. insulaenigrae, C. jejuni, $C$. lanienae, C. lari, C. mucosalis, C. rectus, C. showae, C. sputorum and C. upsaliensis. $C$. jejuni and $C$. coli are the main causes of bacterial foodborne disease in many developed countries. $C$. fetus is the main cause of spontaneous abortions in cattle and sheep, but also an opportunistic pathogen in humans. Clinical symptoms of Campylobacteriosis or as once called "cholera infantum" or "summer complaint" (Condran and Murphy, 2008; Samie et al., 2007) are inflammatory diarrhea or dysentery syndrome, cramps, fever, and pain (occasionally with blood). The disease is usually self-limiting and in most cases, symptomatic treatment by reposition of liquid and electrolyte replacement is sufficient in human infections. The common routes of transmission are fecal-oral, ingestion of contaminated food or water and consumption of raw meat.

As already mentioned, Campylobacter is a pathogen related to animal food origin, especially poultry and other birds (e.g., seagulls excrete C. lari) (Figure 2.5.1). During the past decades Campylobacter has been shown to be responsible for enteritis in humans and animals. The natural habitats of most Campylobacter species are the intestines of birds and other warm-blooded animals such as: cattle, calves, sheep, dogs, cats, hamsters, guinea pigs, mice and different zoo animals. Farm pigs are the main carriers excreting C. coli (Levin, 2007). These organisms may enter the environment, including drinking water, through the feces of different mammals, birds or infected humans (Table 2.5.1). Campylobacter had been shown to survive in aqueous environment for several weeks $\left(\mathrm{at} \sim 4^{\circ} \mathrm{C}\right.$ ) and possibly enter the human food chain through the animal slaughtering process. Campylobacter is sensitive to heat, acidic $\mathrm{pH}$, food preservatives, some heavy metals and irradiation but has increasing resistance to antibiotics due to extensive exposure following farmers over utilization (Baserilashi et al., 2006). Milk, mushrooms, hamburger, pork, shellfish and eggs are vehicles of Campylobacter, however most Campylobacter enteritis is acquired by the handling and consumption of poultry. Although, many methods and media have been developed for the 
detection of the Campylobacter from various samples, universally accepted methods and media are not yet available.

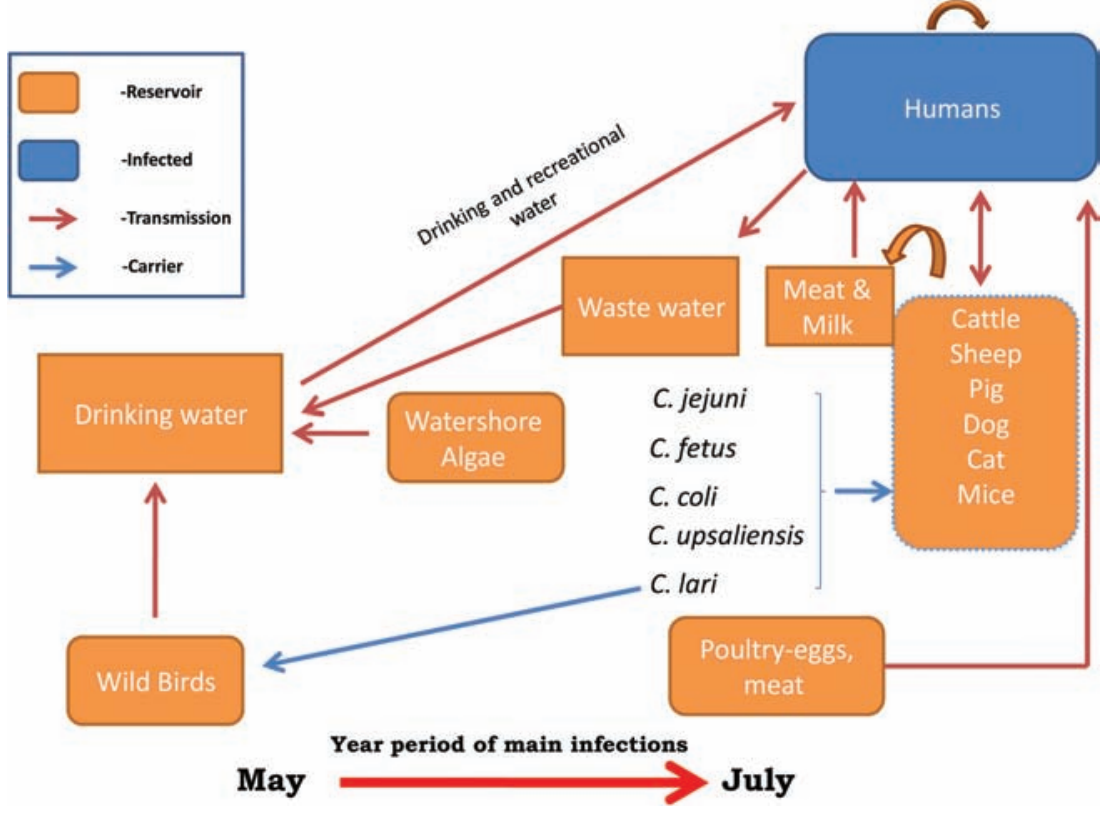

Figure 2.5.1. Campylobacter spp. infection cycles
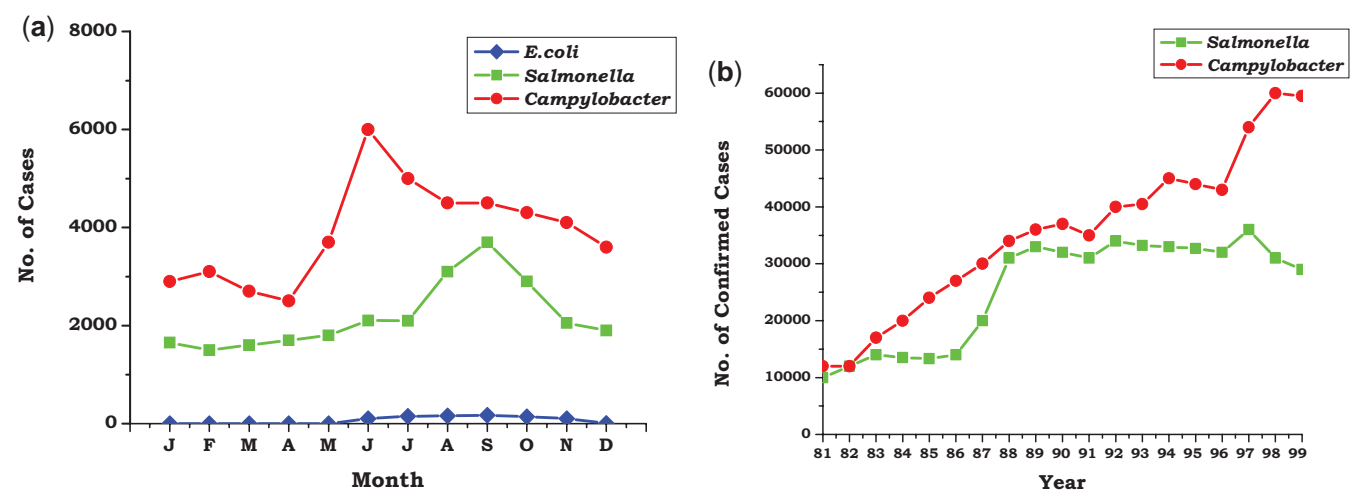

Figure 2.5.2. Number of confirmed cases of Campylobacter, Salmonella and enteropathogenic E. coli in UK and Wales related to season and years (1981-1999). A) distribution by month; B) distribution by year [adapted with permission from Elsevier Ltd., K. Jones. (2001) The Campylobacter conundrum. Trends in Microbiology, 9, 365-366.] 


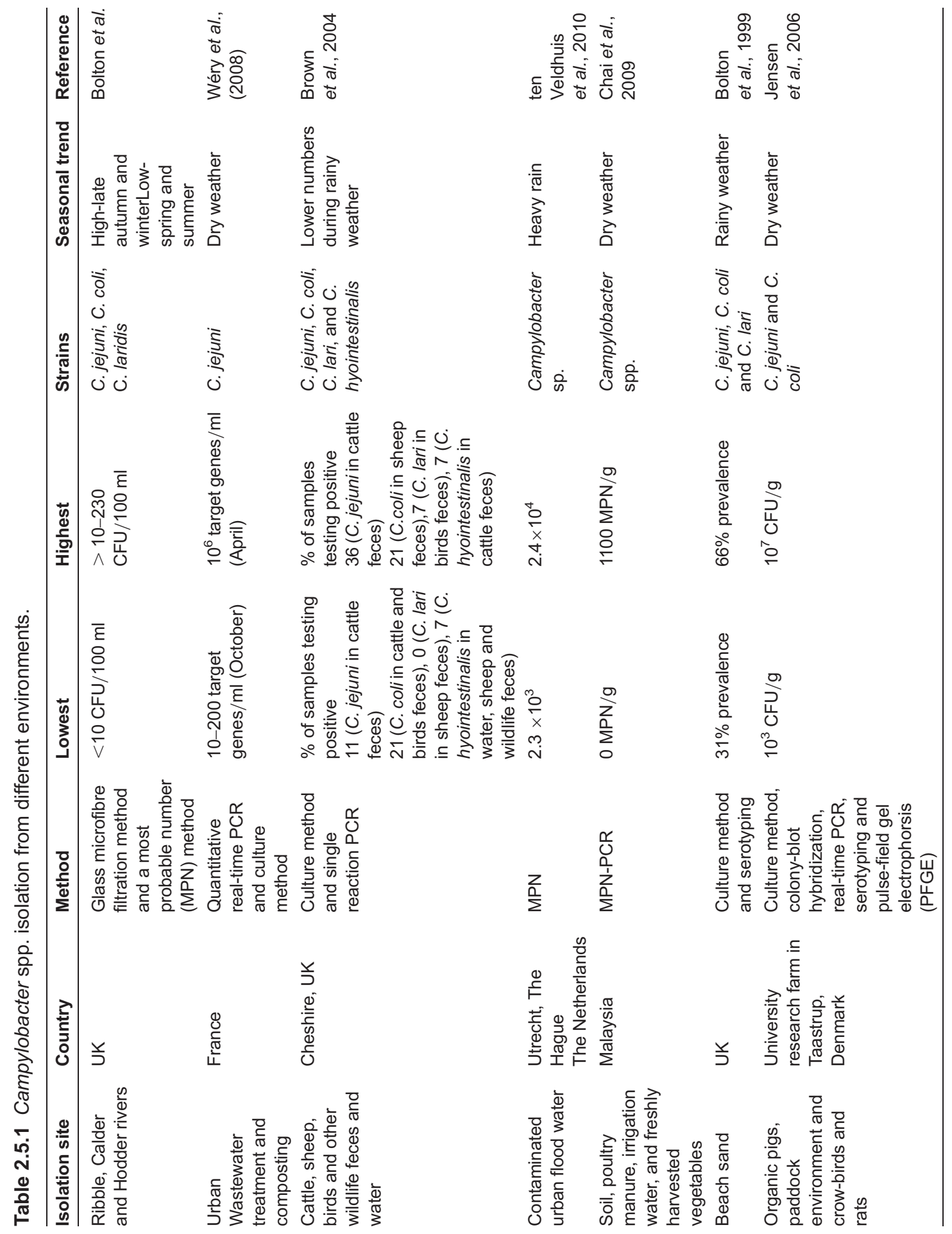




\subsubsection{CAMPYLOBACTER AND ENVIRONMENT}

Campylobacter is sensitive to dry conditions, and therefore high relative humidity and/or precipitations contribute to its environmental survival. Thomas et al. (2006) used case-crossover methodology to examine the impact of high weather events (extreme rainfall and spring snowmelt) on waterborne diseases outbreaks in Canada over a time span of 26 years (1975 to 2001). Their results based on dichotomized percentiles imply that the contributing factors such as warmer temperatures and extreme rainfall are important in the spread of waterborne disease outbreaks in Canada with implications for water management and public health initiatives.

Hartnack et al. (2009) showed that thermophilic Campylobacter spp. display seasonality in poultry and humans by means of an explorative time series analysis (in a 3 year survey in Lower Saxony, Germany). Noticeably, these authors found that the human campylobacterioses peak preceded the peak in broiler prevalence rather than occurring subsequently. Significant cross-correlations between monthly temperature and prevalence in broilers as well as between human incidence, monthly temperature, rainfall and wind force were identified. These results are also supported by Patrick et al. (2004) who examined the effects of temperature, precipitation, relative humidity, and hours of sunlight on Campylobacter incidence in humans and broiler flocks in Denmark, by using lag dependence functions, locally fitted linear models, and cross validation methods. According to their results, climatic factors explained a larger proportion of the variance in Campylobacter prevalence in broiler flocks than in humans. The authors also drew attention to Scandinavian countries where the amount of sunlight coupled with warmer temperatures during the summer months greatly affects human behavior (encouraging outdoor activities, such as picnicking and swimming) that may increase exposure to Campylobacter from environment and natural water sources (lakes and rivers). In addition, they speculated that increased exposure to UV radiation (sunlight) may interfere with the immune system, increasing susceptibility to infectious diseases (Norval, 2001).

Another study presented the interaction of Cladophora glomerata, a filamentous, green alga that grows on rocks and other hard surfaces in nearshore water, with a variety of enteric bacteria including Campylobacter by providing nutrients and possible regrowth potential (Ishii et al., 2006; Verhougstrate et al., 2010). The authors suggested that part of Cladophora mats, as a result of wind and wave action, can detach and release these attached microorganisms to surrounding waters, consequently affecting water quality.

Rainwater harvest in open reservoirs and containers was also shown to harbor Campylobacter and other enteric bacteria with possible regrowth potential (Albrechtsen, 2006; Schets et al., 2010). It should be mentioned that birds that carry Campylobacter and excrete it in large numbers are the main source of roof contamination (Dast et al., 2010).

Jones (2001) raised an interesting epidemiological question on the growing trend in Campylobacter infections levels (from 1981 to 1999 in Wales and UK) in comparison with other enteropathogens such as Salmonella and enteropathogenic E. coli that decreased in the same period (Figure 2.5.2 A,B). According to this author's opinion, the seasonality of human infections is related to two factors: 1) variability in Campylobacter population sizes in livestock and poultry and 2) variability in environmental loading (see Figure 2.5.2 A). The multi-annual increase in Campylobacter infections versus Salmonella decrease (see Figure 2.5.2 B) may be explained by the above assumptions and by slaughter industry procedures that contaminate the carcasses in spite of the fact that Campylobacter does not multiply outside the host cells, while Salmonella does. Interestingly, the peak of Campylobacter infections takes place in spring and early summer while Salmonella has its peak in late summer, related to higher temperature and regrowth potential of the later in contaminated food. As Campylobacter does 
not multiply outside the host, the most essential factor in its contamination potential is the environmental load found in close proximity to food preparation!

\subsubsection{REFERENCES}

Albrechtsen, H.J. (2002) Microbiological investigations of rainwater and gray water collected for toilet flushing Water Sci.Technol. 46, 311-316.

Baserisalehi, M., Bahador, N. \& Kapadnis, B.P. (2006) Campylobacter: an emerging pathogen Res. J. Microbiol. 1, 23-37.

Bolton, F.J., Coates, D., Hutchinson, D.N. \& Godfree, A.F. (1987) A study of thermophilic Campylobacters in a river system. J. Appl. Bacteriol. 62,167-176.

Bolton, F.J., Surman, S.B., Martin, K., Wareing, D.R.A. \& Humphrey, T.J. (1999) Presence of campylobacter and salmonella in sand from bathing beaches. Epidemiol. Infect. 122, 7-13.

Brown, P.E., Christensen, O.F., Clough, H.E., Diggle, P.J., Hart, C.A. et al. (2004) Frequency and spatial distribution of environmental Campylobacter spp. Appl. Environ. Microbiol. 70, 6501-6511.

Chai, L.C., Ghazali, F.M., Bakar, F.A., Lee, H.Y., Suhaimi, L.R.A. et al. (2009) Occurrence of thermophilic Campylobacter spp. contamination on vegetable farms in Malaysia. J. Microbiol. Biotechnol. 19, 1415-1420.

Condran, G.A. \& Murphy, J. (2008) Defining and managing infant mortality: a case study of Philadelphia, 1870-1920. Soc. Sci. History 32, 473-513.

Dasti, J.I., Tareen, A.M., Lugert, R., Zautner, A.E. \& Gross, U. (2010) Campylobacter jejuni: a brief overview on pathogenicity-associated factors and disease-mediating mechanisms. Intern. J. Med. Microbiol. 300, 205-211.

Hartnack, S., Doherr, M.G., Alter, T., Toutounian-Mashad, K. \& Greiner, M. (2009) Campylobacter monitoring in German broiler flocks: an explorative time series analysis. Zoon. Pub. Health. 56, 117-128.

Ishii, S., Yan, T., Shively, D.A., Byappanahalli, M.N., Whitman, R.L. \& Sadowsky, M. J. (2006a) Cladophora (Chlorophyta) spp. harbor human bacterial pathogens in nearshore water of Lake Michigan. Appl. Environ. Microbiol. 72, 4545-4553.

Jensen, A.N., Dalsgaard, A., Baggesen, D.L. \& Nielsen, E.M. (2006) The occurrence and characterization of Campylobacter jejuni and C.coli in organic pigs and their outdoor environment. Vet. Microbiol. 116, 96-105.

Jones, K. (2001) The Campylobacter conundrum. Trends Microbiol. 9, 365-366.

Levin, R.E. (2007) Campylobacter jejuni: A review of its characteristics, pathogenicity, ecology, distribution, subspecies characterization and molecular methods of detection. Food Biotechnol. 21, 271-347.

Norval. M. (2001) Effects of solar radiation on the human immune system. J. Photochem. Photobiol. B: Biol. 63, $28-40$.

Patrick, M.E., Christiansen, L.E., Wain $\varnothing$, M., Ethelberg, S., Madsen, H. \& Wegener, H.C. (2004) Effects of climate on incidence of Campylobacter spp. in humans and prevalence in broiler flocks in Denmark. Appl. Environ. Microbiol. 70, 7474-7480.

Samie, A., Obi, C.L., Barrett, L.J., Powell, S.M. \& Guerrant, R.L. (2007) Prevalence of Campylobacter species, Helicobacter pylori and Arcobacter species in stool samples from the Venda region, Limpopo, South Africa: studies using molecular diagnostic methods. J. Infect. 54, 558-566.

Schets, F.M., Italiaander, R., van den Berg, H.H.J.L. \& de Roda Husman, A.M. (2010) Rainwater harvesting: quality assessment and utilization in The Netherlands. J. Water Health 8, 224-235.

ten Veldhuis, J.A.E., Clemens, F.H.L.R., Sterk, G. \& Berends, B.R.. (2010) Microbial risks associated with exposure to pathogens in contaminated urban flood water. Water Res. 44, 2910-2918.

Thomas, K.M., Charron, D.F., Waltner-Toews, D., Schuster, C., Maarouf, A. \& Holt J.D. (2006) A role of high impact weather events in waterborne disease outbreaks in Canada, 1975 - 2001. Intern. J. Environ. Health Res. 16, 167-80.

Verhougstraete, M.P., Byappanahalli, M.N., Rose, J.B. \& Whitman, R.L. (2010) Cladophora in the Great Lakes: impacts on beach water quality and human health. Water Sci. Technol. 62, 68-76.

Wéry, N., Lhoutellier, C., Ducray, F., Delgenès, J-P. \& Godon, J-J. (2008) Behavior of pathogenic and indicator bacteria during urban wastewater treatment and sludge composting, as revealed by quantitative PCR. Water Res. 42, 53-62. 


\section{Chapter 2.6}

\section{Capnocytophaga infections}

\section{[CAPNOCYTOPHAGA SPP.]}

Capnocytophaga is a facultative anaerobic gram-negative bacteria with fusiform shapes (but also existent as curved filaments, coccoid and spindle forms) that belongs to Flavobacteriaceae order/genus. C. canimorsus and $C$. cynodegmi species were isolated from the oral cavity of dogs, cats and rabbits while species such as $C$. granulose, C. haemolytica, C. ochracea, C. sputigena and C. gingivalis are normal inhabitants of the human oral cavity in association with periodontitis. $C$. canimorsus and $C$. cynodegmi species are involved in human severe infections such as: endocarditis, peritonitis, osteomyelitis and meningitis through animal bites and scratch wounds.

\subsubsection{CAPNOCYTOPHAGA AND ENVIRONMENT}

Suzuki et al. (2010) carried out a prevalence study on dogs and cats for the presence of Capnocytophaga canimorsus and Capnocytophaga cynodegmi in Japan using a sensitive specific PCR method to distinguish between the two species. Capnocytophaga canimorsus prevalence in dogs was $74 \%$ and $57 \%$ in cats, while Capnocytophaga cynodegmi prevalence in dogs was $86 \%$ and $84 \%$ in cats. The high prevalence in both species indicates that this bacterium is wide spread among pet as well wild canines and felines. It should be pointed out that both animal reservoirs can transmit this pathogen to other animals (e.g. rabbit and possibly others) through bites or scratches (van Duijkeren et al., 2006). With the increasing pet populations (dogs and cats) it is feasible to predict that more infections with Capnocytophaga canimorsus and Capnocytophaga cynodegmi will be reported. The close encounter between dogs, cats and human in small habitats "as human best friend" presents a real environmental factor in the distribution of these pathogens.

\subsubsection{REFERENCES}

Suzuki, M., Kimura, M., Imaoka, K. \& Yamada, A. (2010) Prevalence of Capnocytophaga canimorsus and Capnocytophaga cynodegmi in dogs and cats determined by using a newly established species-specific PCR. Vet. Microbiol. 144, 172-176.

van Duijkeren, E., van Mourik, C., Broekhuizen, M., Leuven, M., Gaastra, W. \& Houwers, D. (2006) First documented Capnocytophaga canimorsus infection in a species other than humans. Vet. Microbiol. 118, 148-150. 


\section{Chapter 2.7}

\section{Chlamydial infections}

\section{[CHLAMYDOPHILA SPP.]}

Chlamydiales are a unique order of intracellular bacterial pathogens that cause a significant disease of birds and other animals, including humans. Chlamydiae are gram-negative, nonmotile, lacking energy producing metabolic reactions, therefore an obligate intracellular bacterium that utilizes host ATP (energy parasites). The disease transmitted from infected birds to humans is called psittacosis/ornithosis and is characterized by fever, chills, headaches, photophobia, interstitial pneumonia and myalgia. Transmission from other animals (mainly mammals) can cause: conjunctivitis, pneumonia, orchitis, endocarditis, glomerulonephritis and abortion. In Australia, new species were isolated from a variety of mammals, such as gliders, possums, bilbies, bandicoots and potoroos, revealing the wide distribution of this pathogen (Bodetti et al., 2003; Horn, 2008). The host range of the phylum Chlamydiae encompasses a large variety of animals including vertebrates: mammals, marsupials, amphibians, birds, reptiles, fish, and invertebrates, such as insects, crustaceans, mollusks and protozoa (Horn, 2008; Amann et al., 1997).

\subsubsection{CHLAMYDIA AND ENVIRONMENT}

A recent publication on Chlamydiaceae-like bacterium isolated from the feces of sea birds from the Bering Sea shows that Chlamydia has a worldwide distribution with high biodiversity (Christerson et al. 2010). Sea birds and fish, both shown to carry Chlamydia-related bacteria represent a possible interesting cross-contamination with this pathogen/symbiont and its relation to human disease from the anthropocentric point of view.

Feral pigeon populations in Europe that increased significantly in the last decades through pigeon feeding and uncontrolled reproduction is of a major concern in terms of spreading C. psittaci pathogen . The study by Magnino et al. (2009) performed on feral pigeons from eleven European countries, showed a $C$. psittaci seropositivity value ranging from $19.4 \%$ to $95.6 \%$ inculpating these birds as a real hazard to humans who can contract psittacosis through direct or indirect contact.

Other environmental resources found to contain Chlamydia species are: fountains, ponds (clear and muddy) garden pots and water treatment plants, where they are detected mostly in amoeba and mixed co-culture (Corsaro and Venditti, 2006; Corsaro and Venditti, 2009; Corsaro et al. 2009). 
Among insects, flies are possibly the ubiquitous vectors due to their flying capabilities and human/animals proximity. Flies that use feces as breeding media, were shown to transmit Chlamydia trachomatis (a human pathogen that causes trachoma, urethritis and lymphogranuloma venereum) (Emerson et al., 2001) and their direct contact with humans, food and excreta cannot dismiss the potential infection with other Chlamydial genera members, next to direct contact with carrier animals (Figure 2.7.1). Fruit bats were reported to excrete another family of Chlamydiales named Waddliaceae (Waddlia malaysiensis sp.) in their urine (Chua et al., 2005). Fruit bats are common inhabitants of tree-covered urban areas with increased activity during summer nights, dropping large amounts of excreta on cars and buildings with which humans have direct contact.

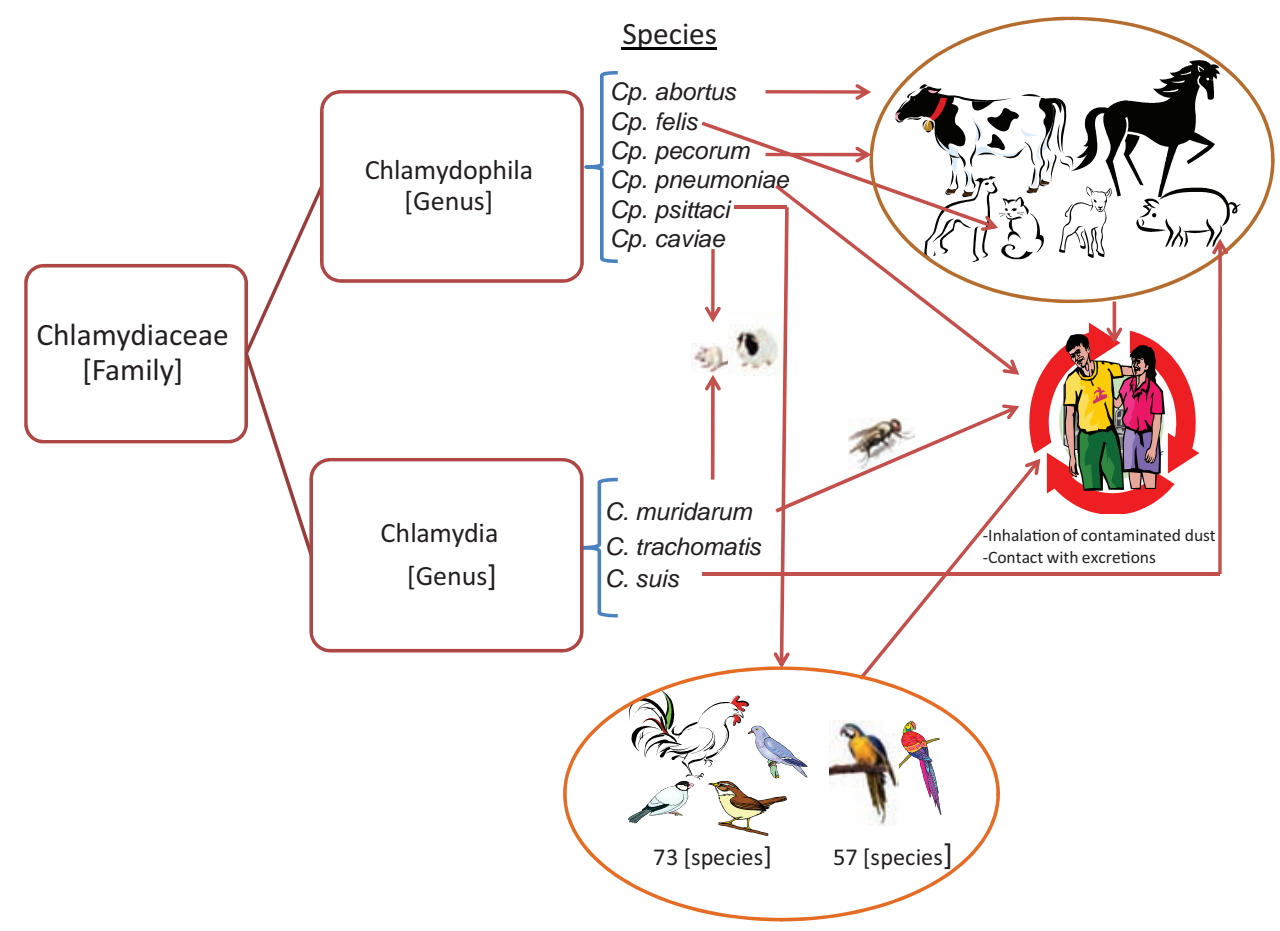

Figure 2.7.1. Chlamydiaceae in different animals and their human infection routes

Finally, Zhu and Wang (2008) reported the isolation and identification of a Chlamydia sp. from the alien Hawaiian marine sponge Suberites zeteki as a part of its associated microbial consortia.

\subsubsection{REFERENCES}

Amann, R., Springer, N., Schönhuber, W., Ludwig, W., Schmid, E.N. et al. (1997). Obligate intracellular bacterial parasites of Acanthamoebae related to Chlamydia spp. Appl. Environ. Microbiol. 63, 115-121.

Bodetti, T.J., Viggers, K., Warren, K., Swan, R., Conaghty, S. et al. (2003) Wide range of Chlamydiales types detected in native Australian mammals. Vet. Microbiol. 96, 177-187.

Christerson, L., Blomqvist, M., Grannas, K., Thollesson, M., Laroucau, K. et al. (2010) A novel Chlamydiaceae-like bacterium found in faecal specimens from sea birds from the Bering Sea. Environ. Microbiol. Rep. 2, 605-610. 
Chua, P.K.B., Corkill, J. E., Hooi, P.S., Cheng, S.C., Winstanley, C. \& Hart, C.A. (2005) Isolation of Waddlia malaysiensis, a novel intracellular bacterium, from fruit bat (Eonycteris spelaea). Emerg. Infect. Dis. 11, 271-277.

Corsaro, D. \& Venditti, D. (2006) Diversity of the Parachlamydiae in the environment. Crit. Rev. Microbiol. 32, $185-199$.

Corsaro, D. \& Venditti, D. (2009) Detection of Chlamydiae from freshwater environments by PCR, amoeba coculture and mixed coculture. Res. Microbiol. 160, 547-552.

Corsaro, D., Feroldi, V., Saucedo, G., Ribas, F., Loret, J-F. \& Greub, G. (2009) Novel Chlamydiales strains isolated from a water treatment plant. Environ. Microbiol. 11, 188-200.

Emerson, P.M., Bailey, R.L., Walraven, G.E.L. \& Lindsay, S.W. (2001) Human and other faeces as breeding media of the trachoma vector Musca sorbens. Med. Vet. Entomol. 15, 314-320.

Horn, M. (2008) Chlamydiae as Symbionts in Eukaryotes. Annu. Rev. Microbiol. 62, 113-131.

Magnino, S., Haag-Wackernagel, D., Geigenfeind, I., Helmecke, S., Dovčd, A. et al. (2009) Chlamydial infections in feral pigeons in Europe: Review of data and focus on public health implications. Vet. Microbiol. 135, 54-67.

Zhu, P., Li, Q. \& Wang, G. (2008) Unique Microbial Signatures of the Alien Hawaiian Marine Sponge Suberites zeteki. Microb. Ecol. 55, 406-414. 


\section{Chapter 2.8}

\section{Ehrlichioses}

\section{[EHRLICHIA SPP.]}

Ehrlichia is a rickettsial bacterium of the Ehrlichiaceae family. The genus is a gram-negative intracytoplasmic obligate pathogen. The main reservoirs are mammals (dog, ruminants, horses, peridomestic animals, etc.) (Dumler and Bakken, 1995; Eremeeva et al., 2009) but fish and horse nematodes were also identified as such (Wen et al., 1996; Atwill et al., 1996). Transmission occurs through a variety of infected ticks carried by different mammals and also birds (Bjöersdorff et al., 2001; Parola and Roult, 2001). Several species can cause infection (Ehrlichiosis) in humans (Figure 2.8.1). The disease symptoms are: malaise, fever, headache, skin rash and in severe cases dyspenia, renal failure and CNS symptoms.

\subsubsection{EHRLICHIA AND ENVIRONMENT}

From the entomological point of view, Ehrlichia has a sylvanic zoonotic cycle but is also able to spread in urban areas where domestic animals for instance dogs and cats live in close proximity to humans (Comer et al., 2001). Worldwide modern urban areas are highly populated due to migration from rural areas and foreign countries based on economic factors, increased mobility and continuous development. As a result, urban zoonoses increase due to homelessness, the decline of inner-city neighbourhoods, the increase in immonosuppressed individuals and additional complex factors (Olano and Walker, 2002). The reasons for the increase in these urban zoonoses are multifaceted. However, urban areas, due to their focal nature, also provide a better strategic control or prevention through physician awareness and public health surveillance support, in contrast to sylvanic or agricultural rural areas, where wildlife is almost uncontrollable.

In addition, tick species that were not classified as zoonotic vectors have been recently recognized as such (e.g., Amblyomma americanum) (Childs and Paddock, 2003) and subclinical infected companion animals could provide a reservoir for human tick-transmitted infectious agents, such as Ehrlichia chaffeensis, Ehrlichia ewingii, the Ehrlichia phagocytophila group and Rickettsia conorii (Shaw et al., 2001). 

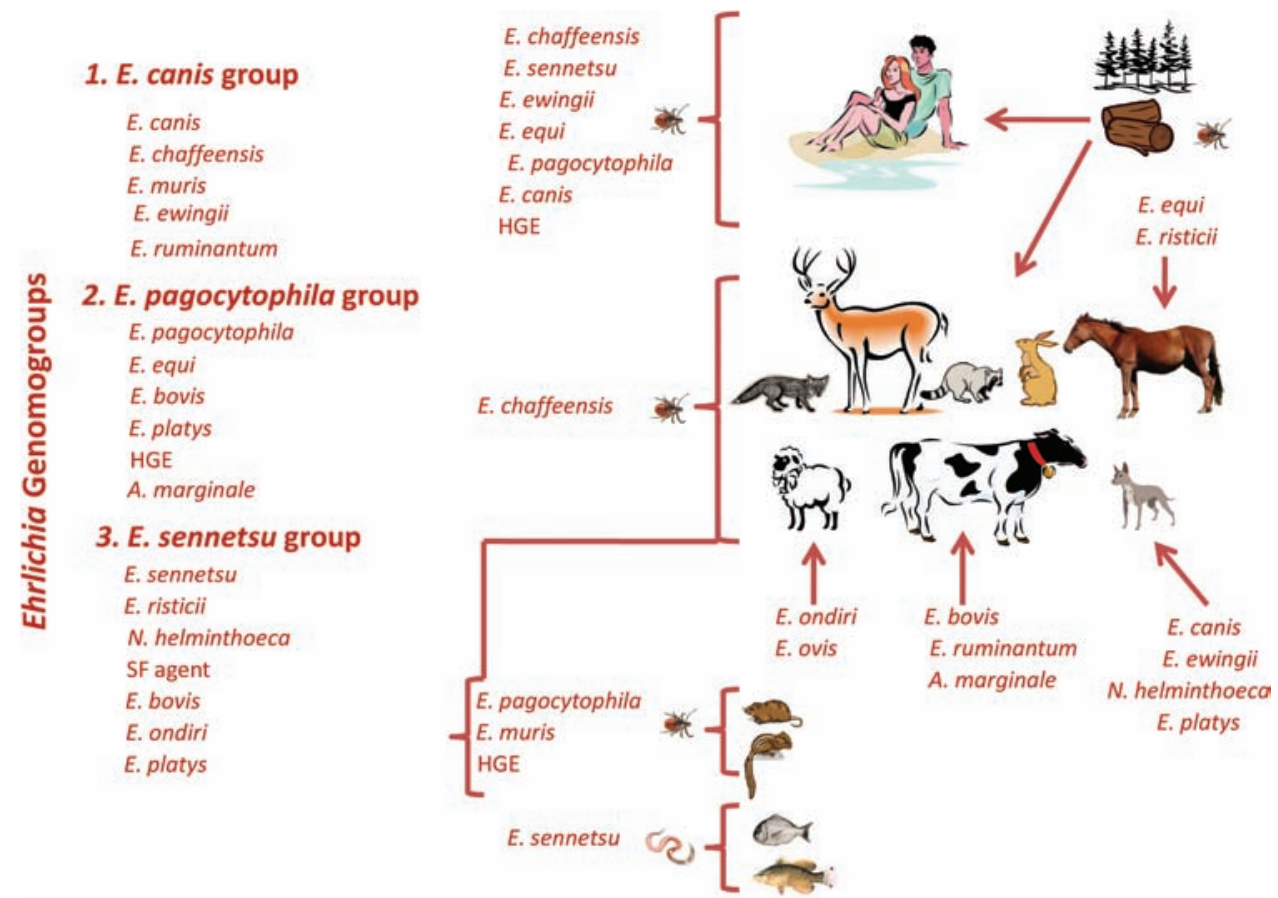

Figure 2.8.1. Ehrlichia spp. distribution in various animals and tick transmission

Fritz et al. (2005) reported two cases of Ehrlichosis in California during a period of two years (19971999). The residence area was densely populated by Ixodes pacificus ticks with over $85 \%$ of the study participants reporting tick contact in the preceding 12 months. However, the prevalence of Ehrlichia and Anaplasma in the tick population was very low, explaining the low disease frequency among humans. In South Korea, a serological survey was conducted designed to evaluate the presence of four canine pathogens among them two Ehrlichiae genera, Anaplasma phagocytophilum and Ehrlichia canis, on rural hunting and urban shelter dogs (Lim et al., 2010). Dogs used for wild boar and pheasant hunting revealed a prevalence of $18.8 \%$ for A. phagocytophilum and $6.1 \%$ for E. canis while all urban stray dogs (a total of $692 \mathrm{dogs}$ ) were seronegative for both pathogens. This study indicates that rural hunting dogs are more exposed to vector-borne diseases.

To strengthen these results, in Brazil, dogs kept in apartments were compared with dogs with yard access for the presence of ectoparasites and hemoparasites. Not surprisingly, indoor dogs harbor ectoparasites (three tick types) at a lower prevalence than yard access dogs (2-12\% compared to 14-35\% respectively). Consequently, indoor dogs did not reveal hemoparasites at all and yard access dogs tested positive for Ehrlichia canis (16\%) and another protozoan pathogen Babesia canis (2\%) (Soares et al., 2006).

The emergence of new canine tick-transmitted diseases results from several factors: expansion of tick range into urban and semi-urban areas, movement of infected dogs into non-endemic areas and the introduction of novel molecular techniques for diagnosis and pathogen identification (Shaw et al., 2001).

Manangan et al. (2007) used a logistic regression model to compare the influence of physical environment, land cover composition, and landscape heterogeneity on distributions of A. phagocytophilum and $E$. chaffeensis in white-tailed deer, at multiple spatial extents in the Mississippi alluvial valley. The 
Mississippi alluvial valley faces frequent flooding, and though it was historically covered by bottomland forests, it is presently dominated by agriculture, while the remaining forests are highly fragmented. Using white-tailed deer seropositivity results for these two pathogens (from 1981 to 2005), deer density, elevation, land cover, normalized difference vegetation index (NDVI), hydrology, and soil moisture, they found that the best fitting model was obtained for E. chaffeensis (90.5\% sensitivity) compared to $A$. phagocytophilum (only 68\% sensitivity). The lower fitting model for Anaplasma phagocytophilum was speculated to be a result of differences in the natural histories of tick vectors of this pathogen.

In a more extensive study, covering the area of southeastern United States, Wimberly et al. (2008) compared several spatial modeling approaches to predict the geographic distribution of Ehrlichia chaffeensis and Anaplasma phagocytophilum based on extended environmental modeling, such as logistic regression combined with spatial autocorrelation (pathogen tendency to cluster in space) and heterogeneity (environmental spatial variation). The results showed that the model prediction of $E$. chaffeensis based only on spatial autocorrelation had the best fit (Figure 2.8.2), while for $A$. pagocytophilum with its more complex zoonotic cycle and weak spatial pattern the combined model (spatial autocorrelation and heterogeneity) had the best fit (Figure 2.8.3).

The complexity in modeling Ehrlichia chaffeensis infection risk based on its prevalence in tick population was investigated by a deterministic model (prevalence in tick populations with spatial considerations) (Gaff and Schaefer, 2010). The complex nonlinear system interactions showed that areas that would be endemic in isolation may or may not sustain the disease depending on the surrounding habitat such as: control efforts shown to be far more effective when applied in wooded habitats than in neighboring grassy habitats and that additional increase in habitat fragmentation play a major role in predicting the endemicity of an HME (human monocytic ehrlichosis) outbreak.

Sinski (1999) in a review on vector-borne diseases in Poland pointed to the environmental crucial role of changes in farming systems in the Mazury Lakes district in which a great land area had been left under grassland and pasture favoring susceptible rodent species to become competent reservoirs. This phenomenon was observed in the whole of Europe alongside intensified agriculture.

Forest workers are expected to be at risk for Ehrlichosis. Blood samples of 4,368 forestry workers in the State of Baden-Wuertternberg (B-W), southwestern Germany, were tested for seroconversion against Ehrlichia spp. (genogroup E. phagocytophila) and other tick-borne pathogens (Borrelia burgdorferi sensu lato, TBE-virus) in parallel to the collection of 12,327 ticks (Ixodes ricinus) and analysis by PCR and genotyping (RNA and DNA) for the prevalence rate of these pathogens in this geographical area (Oehme et al., 2002). The authors stated that the 5 to $16 \%$ prevalence of Ehrlichia spp. antibodies and the 2.6 to $3.1 \%$ tick prevalence suggests "that ehrlichiosis plays a role as a tick-borne disease in Germany, but as long as no clinical data are available, this will remain unclear".

Contact with forest parts, especially sitting and considerable contact with wood parts, results in a greater acquisition of nymphs, in spite of protective wear (hiking boots, hiking sandals, or running shoes) (Lane et al., 2004). In a study conducted in southern Scotland (during 1996-1999) in three habitats for presence of the tick Ixodes ricinus as a vector of Ehrlichia phagocytophila infection, coniferous woods provided the highest risk of attachment by ticks, possibly due to ticks concentration on the grassy rides rather than other factors for example host or climatic (Walker et al., 2001).

Direct contact with animals is the highest risk factor to contract Ehrlichiosis. Among such predisposed groups are: veterinarians, slaughterhouse and zoo workers, farmers and hunters. Deutz et al. (2003) used seroconvertion test to evaluate human exposure to several zoonotic agents among them Ehrlichia, compared hunters vs. other high risk occupational groups in south-east Austria. High seroprevalence (15\%) was found in hunters compared to control (minor animal contact) and other high risk groups (veterinarians, farmers and slaughterhouse workers). 
(a) Global environmental

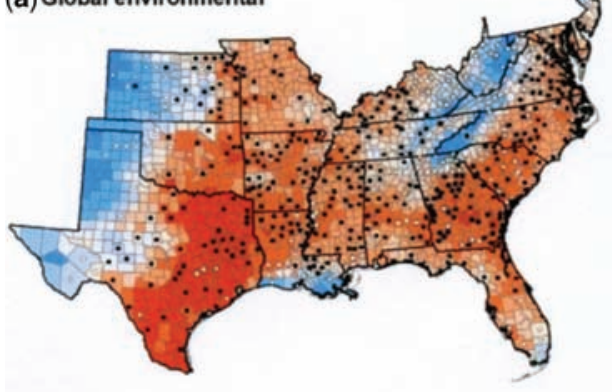

(c) Spatial autoregressive

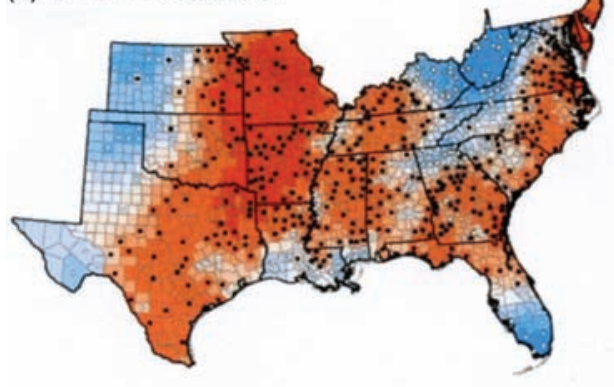

(e) Local environmental - autoregressive

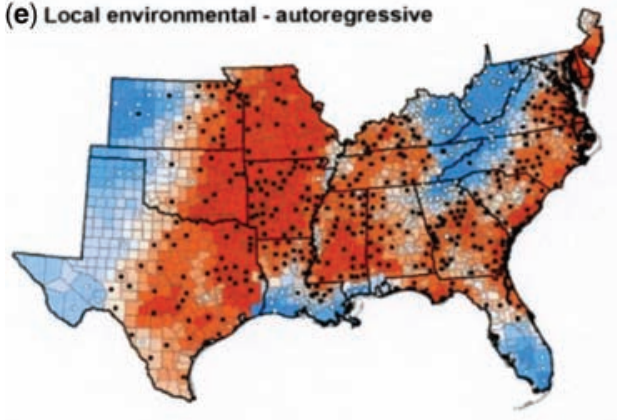

(b) Local environmental

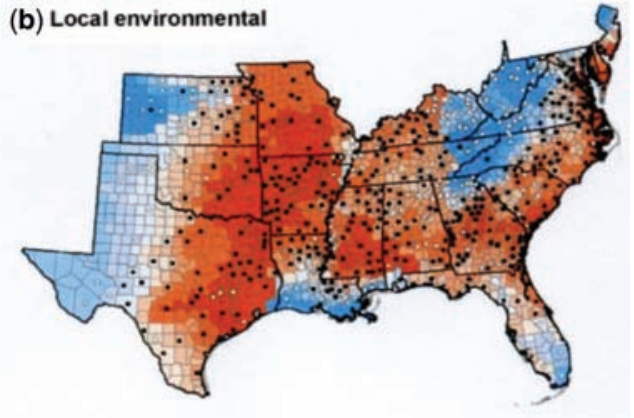

(d) Global environmental - autoregressive

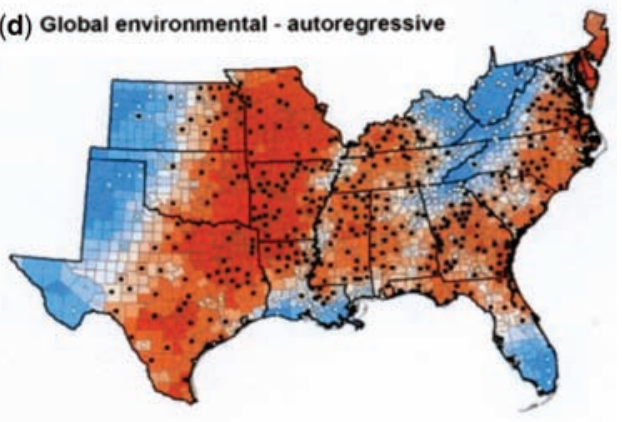

Serology

- Absent (-)

- Present (*)

Endemicity probability

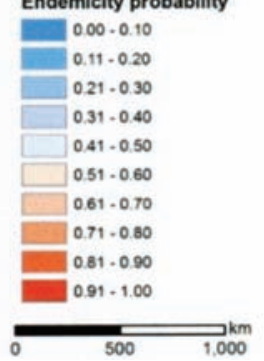

Figure 2.8.2. Predicted endemicity probabilities for Ehrlichia chaffeensis in the southeastern United States obtained from five Bayesian hierarchical models (Wimberly et al. (2008), with permission from International Journal of Health Geographics)

An interesting environmental aspect related to tick eradication by chemical means was outlined by Eisler et al., (2003). The authors emphasized the importance of anti-ticks and tsetse pyrethroid insecticide use to prevent cattle loss (between US\$ 4-5 billions/year) in Africa. However, beside its positive effect there are several risk factors that from the environmental point of view are significant: 1 . uncontrolled application of pyrethoids can lead to acaricide resistance in tick populations (Bruce and Wilson, 1998); 2. insecticides can decimate invertebrate fauna responsible for cattle dung breakdown and subsequent incorporation in soil (Dantas-Torres, 2008) and 3. reduction in ticks' numbers attaching to cattle can also lead, paradoxically, to an increase in susceptibility to tick-borne diseases (Mahoney and Ross, 1972; Norval, 1992). 
(a) Global environmental

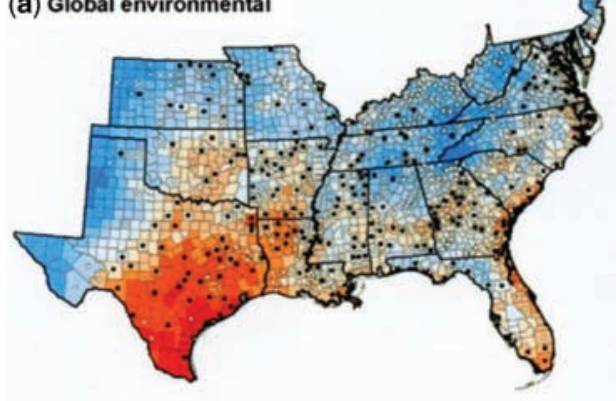

(c)Spatial autoregressive

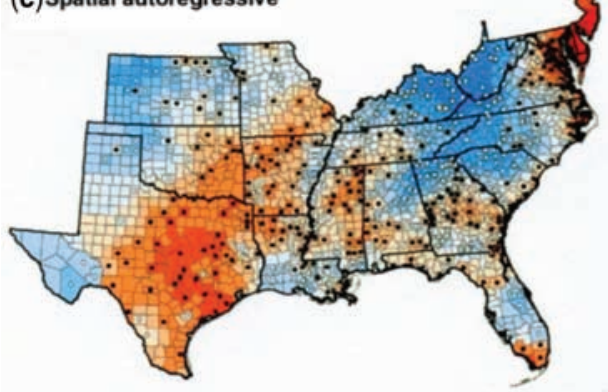

(e) Local environmental - autoregressive

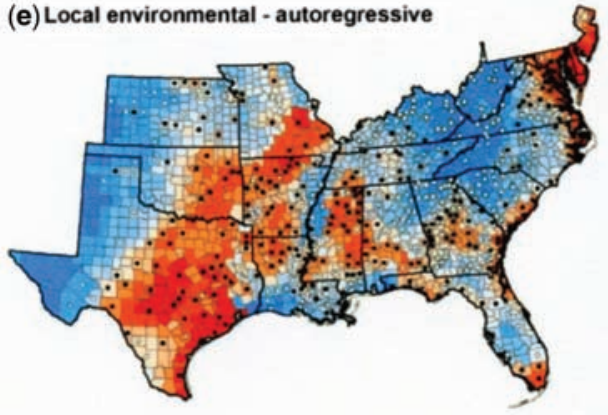

(b) Local environmental

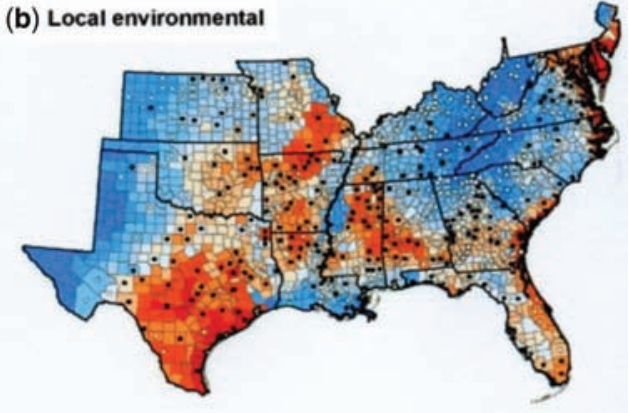

(d) Global environmental - autoregressive

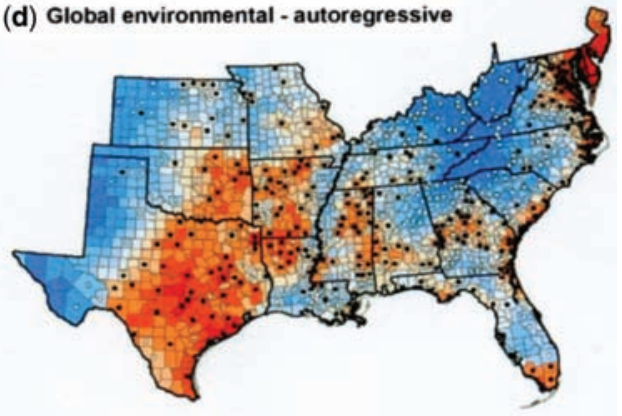

Serology

- Absent (-)

- Present (*)

Endemicity probability

$0.00-0.10$

$0.11 \cdot 0.20$

$0.21 \cdot 0.30$

0.31 .0 .40

$0.41 \cdot 0.50$

$0.51 \cdot 0.60$

$0.61 \cdot 0.70$

$0.71 \cdot 0.80$

0.81 .0 .90

$0.91 \cdot 1.00$

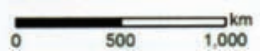

Figure 2.8.3. Predicted endemicity probabilities for Anaplasma phagocytophilum in the southeastern United States obtained from five Bayesian hierarchical models (Wimberly et al. (2008), with permission from International Journal of Health Geographics)

Gray et al. (2009) in a review article presented some evidences of climate impact on zoonotic tick-borne diseases affecting vector biology and disease transmission. The geographic extension of the vector tick Ixodes ricinus (and also Dermacentor reticulates) and increased prevalence of tick-borne encephalitis in Sweden could be partially related to climate change too (Figure 2.8.4). Warmer winters and hotter summers in this region may increase the seasonal activity of these vectors. The authors suggested that under a climate-warming scenario, ticks species establishment in more northern areas as permanent populations may be enhanced, with consequences on human health. 

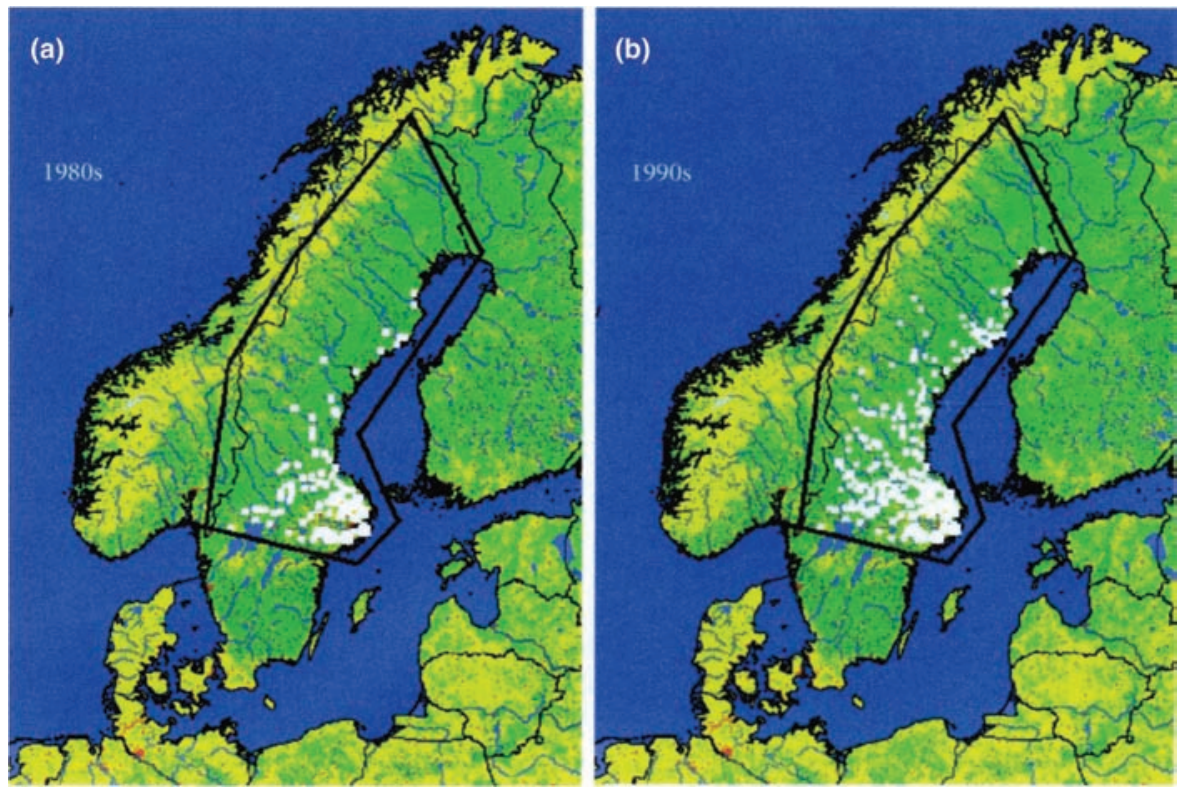

Figure 2.8.4. Tick distribution (white squares) in northern and central Sweden during two periods: (a) before 1980 and (b) in 1994-5. Black line frame represents the area studied. [with permission from Lindgren et al., 2000, Environ. Health Perspect.]

\subsubsection{REFERENCES}

Atwill, E.R., Mohammed, H.O., Lopez, J.W., Mc Culloch, C.E. \& Dubovi, E.J. (1996) Cross-sectional evaluation of environmental, host, and management factors associated with risk of seropositivity to Ehrlichia risticii in horses of New York state. Am. J. Vet. Res. 57(3), 278-285.

Bjöersdorff, A., Bergström, S., Massung, R.F., Haemig, P.D. \& Olsen, B. (2001) Ehrlichia-infected ticks on migrating birds. Emerg. Infect. Dis. 7, 877-879.

Bruce, D. \& Wilson, A. (1998) A trial to control or eradicate Amblyomma hebraeum ticks and heartwater on three ranches in Zimbabwe. Ann. N. Y. Acad. Sci. 849, 381-383.

Childs, J. E. \& Paddock, C.D. (2003) The ascendancy of Amblyomma Americanum as a vector of pathogens affecting humans in the United States. Annu. Rev. Entomol. 48, 307-337.

Comer, J.A., Paddock C.D. \& Childs, J.E. (2001) Urban zoonoses caused by Bartonella, Coxiella, Ehrlichia, and Rickettsia species. J Vector Borne Dis 1, 91-118.

Dantas-Torres, F. (2008) The brown dog tick, Rhipicephalus sanguineus (Latreille, 1806) (Acari: Ixodidae): from taxonomy to control. Vet. Parasitol. 152, 173-185.

Deutz, A., Fuchs, K., Nowotny, N., Auer, H. Schuller, W., Stunzner, D., Aspock, H., Kerbl, U. \& Kofer, J. (2003) Sero-epidemiological studies of zoonotic infections in hunters-comparative analysis with veterinarians, farmers, and abattoir workers. Wien. Klin. Wochenschr. 115, 61-67.

Dumler, J.S. \& Bakken, J.S.(1995) Ehrlichial diseases of humans: emerging tick-borne infections. Clin. Infect. Dis. 20, $1102-1110$.

Eisler, M.C., Torr, S.J., Coleman, P.G., Machila, N. \& Morton, J.F. (2003) Integrated control of vector-borne diseases of livestock - pyrethroids: panacea or poison? Trends Parasitol. 19, 341-345.

Eremeeva, M.E., Karpathy, S.E., Levin, M.L., Caballero C.M., Bermudez, S. et al. (2009) Spotted fever rickettsiae, Ehrlichia and Anaplasma, in ticks from peridomestic environments in Panama. Clin. Microbiol. Infect. 15,12-14. 
Fritz, C.L., Bronson, L.R., Smith, C.R., Crawford-Miksza, L., Yeh, E. \& Schnurr, D. (2005) Clinical, epidemiologic, and environmental surveillance for ehrlichiosis and anaplasmosis in an endemic area of northern California. J. Vector Ecol. 30, 4-10.

Gaff, H. \& Schaefer, E. (2010) Metapopulation models in tick-borne disease transmission modelling. Adv. Exp. Med. Biol. 673, 51-65.

Gray, J.S., Dautel, H., Estrada-Peña, A., Kahl, O. \& Lindgren, E. (2009) Effects of climate change on ticks and tick-borne diseases in Europe. Interdiscip Perspect Infect Dis 2009, 12 pp doi:10.1155/2009/593232.

Lane, R.S., Steinlein, D.B. \& Mun J. (2004) Human behaviors elevating exposure to Ixodes pacificus (Acari: Ixodidae) nymphs and their associated bacterial zoonotic agents in a hardwood forest. J. Med. Entomol. 41, $239-248$.

Lim, S., Irwin, P.J., Lee, S., Oh, M., Ahn, K. et al. (2010) Comparison of selected canine vector-borne diseases between urban animal shelter and rural hunting dogs in Korea. Parasit Vectors 3, 32.

Lindgren, E., Tälleklint, L. \& Polfeldt, T. (2000) Impact of climatic change on the northern latitude limit and population density of the disease-transmitting European tick Ixodes ricinus. Environ. Health Perspect. 108, $119-123$.

Mahoney, D.A. \& Ross, D.R. (1972) Epizootiological factors in the control of bovine babesiosis. Aust. Vet. J. 48, 292298.

Manangan, J.S., Schweitzer, S.H., Nibbelink, N., Yabsley, M.J., Gibbs, S.E.J. \& Wimberly, M.C. (2007) Habitat factors influencing distributions of Anaplasma phagocytophilum and Ehrlichia chaffeensis in the Mississippi Alluvial Valley. Vector Borne Zoonotic Dis. 7, 563-573.

Norval, R.A.I. et al. (1992) The epidemiology of Theileriosis in Africa, Academic Press.

Oehme, R., Hartelt, K., Backe, H., Brockmann, S. \& Kimmig, P. (2002) Foci of tick-borne diseases in Southwest Germany. Int. J.Med. Microbiol. 291, 22-29.

Olano, J.P. \& Walker, D.H. (2002) Human ehrlichioses. Med. Clin. North Am. 86, 375-392.

Parola, P. \& Raoult, D. (2001) Ticks and tickborne bacterial diseases in humans: an emerging infectious threat. Clin. Infect. Dis. 32, 897-928.

Shaw, S.E., Day, M.J., Birtles, R.J. \& Breitschwerdt, E.B. (2001) Tick-borne infectious diseases of dogs. Trends Parasitol. 17, 74-80.

Sinski, E. Enzootic reservoir for new Ixodes ricinus-transmitted infections. (1999) Wiad Parazytol 45, $135-42$.

Soares, A.O., Souza, A.D., Feliciano, E.A., Rodrigues, A.F.S. F., D’Agosto, M. \& Daemon, E. (2006) Evaluation of ectoparasites and hemoparasites in dogs kept in apartments and houses with yards in the city of Juiz de Fora, Minas Gerais, Brazil. Rev Bras Parasitol Vet 15, 13-16.

Vale, G.A. \& Grant, I.F. (2002) Modelled impact of insecticide contaminated dung on the abundance and distribution of dung fauna. Bull. Entomol. Res. 92, 251-263.

Walker, A.R., Alberdi, M.P., Urquhart, K.A. \& Rose, H. (2001) Risk factors in habitats of the tick Ixodes ricinus infuencing human exposure to Ehrlichia phagocytophila bacteria. Med. Vet. Entomol. 15, 40-49.

Wen, B., Rikihisa, Y., Yamamoto, S., Kawabata N. \& Fuerst, P.A. (1996) Characterization of the SF Agent, an Ehrlichia sp. isolated from the fluke Stellantchasmus falcatus, by 16s rRNA base sequence, serological, and morphological analyses. Intern. J. System. Bacteriol. 46, 149-154.

Wimberly, M.C., Baer, A.D. \& Yabsley, M.J. (2008) Enhanced spatial models for predicting the geographic distributions of tick-borne pathogens. Int J Health Geogr 7, 1-15. doi:10.1186/1476-072X-7-15. 


\section{Chapter 2.9}

\section{Enterohemorrhagic Escherichia coli infections}

\section{[ENTEROHEMORRHAGIC ESHERICHIA COLI (EHEC)]}

Escherichia coli is a gram-negative, rod shaped, facultative anaerobic, motile (when flagella are present), non-sporulating bacterium and generally a benign commensal of warm blooded organisms including humans. However, some strains are highly virulent and cause mainly enteric diseases in humans and animals (Table 2.9.1).

As enterohemorrhagic E. coli is the most identified zoonotic pathogen in humans, this chapter will be dedicated to its characteristics and environmental link. Enterohemorrhagic Esherichia coli (EHEC) strains are highly infective $E$. coli (infective dose $10^{1}-10^{2} \mathrm{CFU}$ ) capable of producing potent cytotoxins (Shiga toxins, expressed by Stx-s genes) or verotoxins and are able to cause A/E lesions (A/E: attachment-and-effacement) in the cecum and colon. The pathogen is transmitted through contaminated meat, milk and its products and contact with cattle feces (Whipp et al., 1994). Direct contact with infected animals such as cattle and horses are also means of transmission. EHEC isolation was also reported from sheep, goats, water buffalos, and deer (Caprioli et al., 2005). The disease presents itself as severe gastrointestinal diseases and hemorrhagic colitis characterized by watery diarrhea, abdominal pain, fever and bloody stool and sometimes with life-threatening post-infectious syndromes, such as hemolytic-uremic syndrome (HUS) or thrombotic-thrombocystopenic purpura (TTP)(Tschape and Fruth, 2001).

\subsubsection{ENTEROHEMORRHAGIC ESHERICHIA COLI (EHEC) AND ENVIRONMENT}

Farm animals, such as cattle, sheep, goats and potentially pigs are carriers and excretors of EHEC (Caprioli et al., 2005; Rios et al., 1999). Direct contact with animals or feed and their uncooked or partially cooked meat is the main transmission route to humans (Levine et al. 1993). Currently there are additional recognized environmental sources of infection and contamination: a) biotic (e.g., flies, rodents, birds and wildlife) (Miko et al., 2009; Caprioli et al., 2005) and b) abiotic factors (e.g., pasture and water) (Ogden et al., 2002; Thran et al., 2001; Ogden et al., 2001) (Figure 2.9.1). 


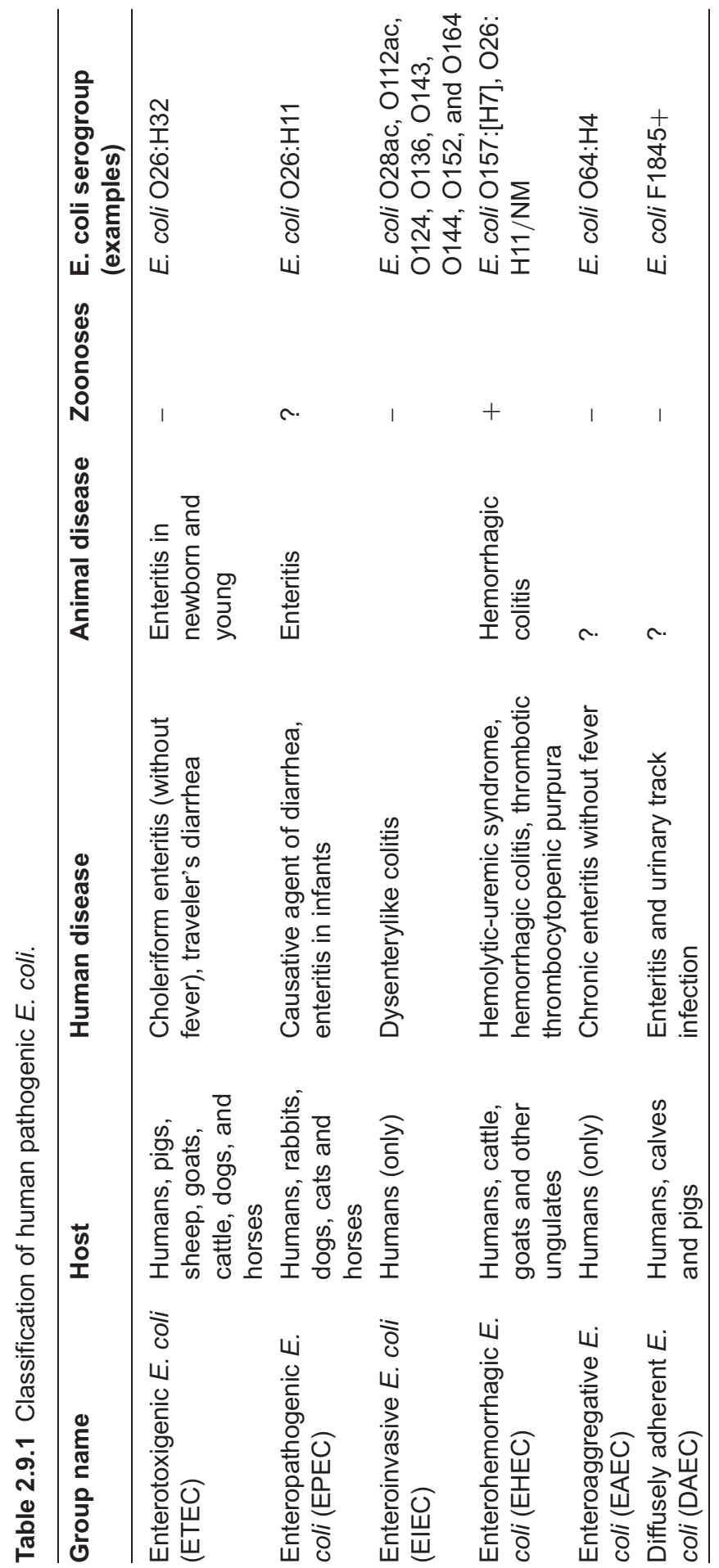




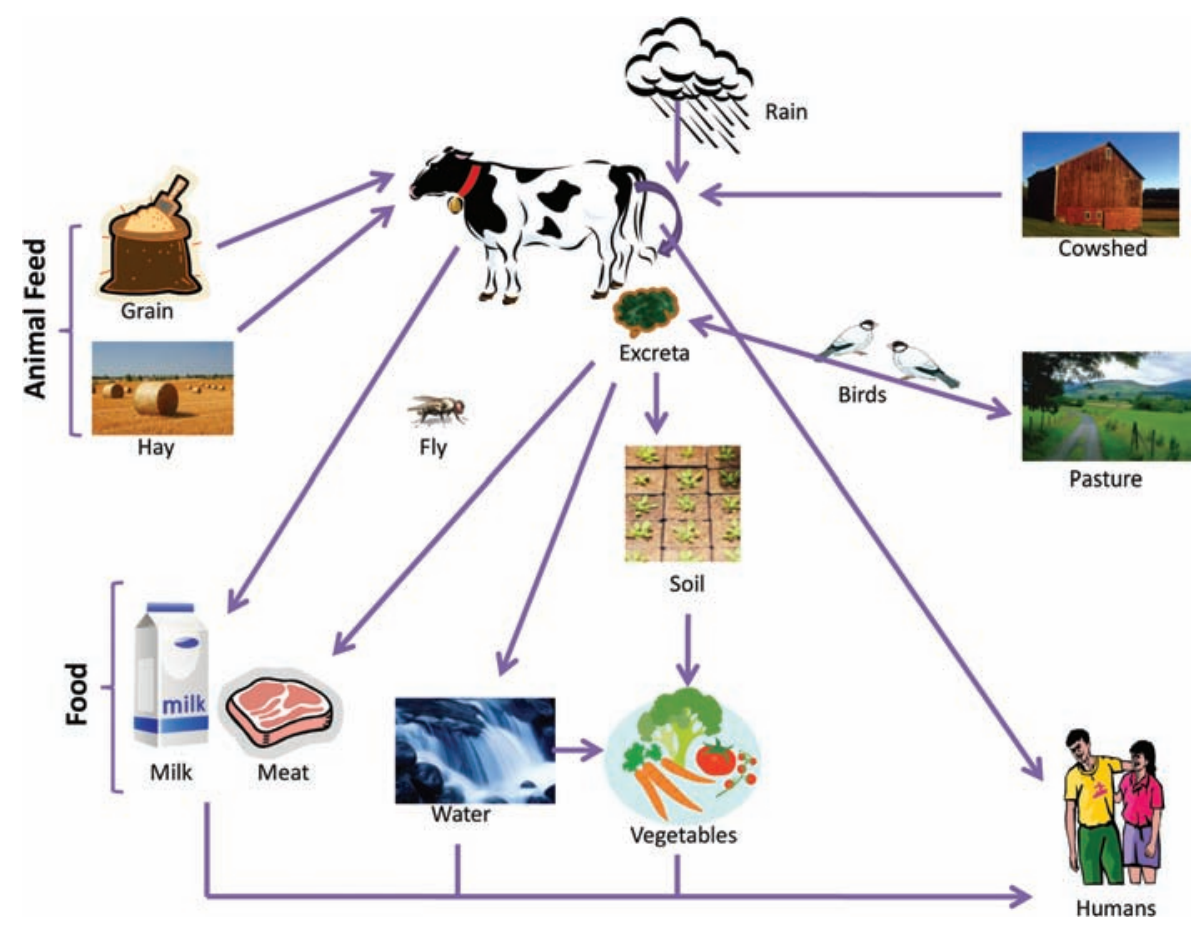

Figure 2.9.1. E. coli (EHEC) ecology and environmental aspects

A Swedish study performed on carrier calves that shed Enterohemorrhagic Esherichia coli (EHEC) revealed that those kept in a cowshed during the summer remained positive for four months after detection, while calves released to graze on pasture were pathogen free. The persistence of the pathogen in cowshed calves indicates a regular re-infection (Jonsson et al., 2001).

Czajkowska et al., (2008) looked at the survival of EHEC vs. environmental E. coli in wastewater and activated sludge of dairy sewage treatment plants during autumn-winter (temperature $\sim 6^{\circ} \mathrm{C}$ ) and spring-summer (temperature $24^{\circ} \mathrm{C}$ ). In activated sludge, E. coli $\mathrm{O} 157: \mathrm{H} 7$ bacteria were not detected (by direct plating method) after 21-28 days, and in dairy wastewater and activated sludges after 21-25 days. Environmental E. coli (non-pathogenic) survived longer: 35-42 days in activated sludge and 25-28 days in wastewater with activated sludges. However, these authors recommended based on sufficiently the extended persistence of EHEC in activated sludge, a thorough required treatment including disinfection prior to utilization of sludge as a soil fertilizer.

Wildlife meat from deer, wild boar, and hare was assessed as a potential carriers of E. coli (EHEC) by Miko et al. (2009). Based on genetic analysis, 32.8\% of high-level virulence associated genes in humans were present in experimental isolates indicating that wild animals represent a reservoir for and a potential source of human pathogenic EHEC strains.

An additional way of dispersal and transmission was observed in beef slaughter by Stopforth et al. (2006). Preevisceration of carcasses washing prior to bung bagging during beef slaughter may allow pooling of cleanse water in the rectal area and consequent spread of potential pathogens. Surface sampling from the postwash bagging procedure revealed a $58.3 \%$ incidence rate of EHEC compared to $35 \%$ from prewash bagging suggesting prewash as a much better practice for the control of pathogen 
contamination, originating from the rectal area of carcasses. Ferianc et al. (2002) looked at E. coli isolates from the Danube and Moravia rivers (Slovakia) and compared these isolates to clinical ones (collected from urinary track disease). Molecular analysis of both river and clinical isolates revealed $\mathrm{stx}_{2}$ gene carried on plasmid, a characteristic of enterohemorrhagic E. coli (EHEC) strains. The authors hinted at a possible health risk for bathers from direct contact with untreated river water. Finally, the Mediterranean fruit fly (Ceratitis capitata), a cosmopolitan pest of commercial and wild fruits, was artificially contaminated (through feed solution and enriched fecal material) with GFP (green fluorescence protein)-tagged E. coli. Flies inoculated with GFP-tagged E. coli harbored the bacteria for up to 7 days after initial contamination. Flies feeding on fruits were capable of transmitting the GFP tagged E. coli to intact apples, as were female flies that laid their eggs in fruit by puncturing the skin with their ovipositors and injecting batches of eggs into the wounds. Washing of contaminated apples with tap water did not eliminate the inoculated E. coli, revealing deeper internal inoculation of these bacteria by fruit fly into the fruit's internal tissues (Sela et al., 2005).

\subsubsection{REFERENCES}

Caprioli, A., Morabito, S., Brugère, H. \& Oswald, E. (2005) Enterohaemorrhagic Escherichia coli: emerging issues on virulence and modes of transmission. Vet. Res. 36, 289-311.

Czajkowska, D., Boszczyk-Maleszak H., Sikorska, I.R. \& Sochaj, A. (2008) Studies on the survival of enterohemorrhagic and environmental Escherichia coli strains in wastewater and in activated sludges from dairy sewage treatment plants. Pol. J. Microbiol. 57, 165-171.

Ferianc, P., Harichova, J., Proksova, M., Krepsova, K., Chovanova, K. \& Toth, D. (2002) The surface river water and clinical Escherichia coli isolates: Characteristics, diversity and epidemiological significance. Biologia 57, 321-334.

Jonsson, M.E., Aspan, A., Eriksson, E., Vagsholm, I. (2001) Persistence of verocytotoxin producing Escherichia coli O157:H7 in calves kept on pasture and in calves kept indoors during the summer months in a Swedish dairy herd. Int. J. Food Microbiol. 66, 55-61.

Levine, M.M, Ferreccio, C., Prado, V., Cayazzo, M., Abrego, P. et al. (1993) Epidemiologic studies of Escherichia coli diarrheal infections in a low socioeconomic level peri-urban community in Santiago, Chile. Am. J. Epidemiol. 138, 849-869.

McDowell, D.A. \& Sheridan, J.J. (2001) Survival and growth of Vero cytotoxin-producing E. coli in the environment. In: Duffy G., Garvey P., McDowell D. (Eds.), Verocytotoxigenic Escherichia coli, Food \& Nutrition Press Inc., Trumbull, 2001, pp. 279-304.

Miko, A., Pries, K., Haby, S., Steege, K., Albrecht, N. et al. (2009) Assessment of Shiga Toxin-Producing Escherichia coli Isolates from Wildlife Meat as Potential Pathogens for Humans. Appl. Environ. Microbiol. 75, 6462-6470.

Ogden, I.D., Fenlon, D.R., Vinten, A.J.A. \& Lewis, D. (2001) The fate of Escherichia coli O157 in soil and its potential to contaminate drinking water. Int. J. Food Microbiol. 66, 111-117.

Ogden, I.D., Hepburn, N.F., MacRae, M., Strachan, N.J., Fenlon, D.R. et al. (2002) Long-term survival of Escherichia coli $\mathrm{O} 157$ on pasture following an outbreak associated with sheep at a scout camp. Lett. Appl. Microbiol. 34, $100-104$.

Rios, M., Prado, V., Trucksis, M., Arellano, C., Borie, C. et al. (1999) Clonal diversity of chilean isolates of enterohemorrhagic Escherichia coli from patients with hemolytic-uremic syndrome, asymptomatic subjects, animal reservoirs, and food products. J. Clin. Microbiol. 37, 778-781.

Sela, S. Nestel, D., Pinto, R. Nemny-Lavy, E. \& Bar-Joseph, M. (2005) Mediterranean fruit fly as a potential vector of bacterial pathogens. Appl. Environ. Microbiol. 71, 4052-4056.

Stopforth, J.D., Lopes, M., Shultz, J.E., Miksch, R.R. \& Samadpour, M. (2006) Location of bung bagging during beef slaughter influences the potential for spreading pathogen contamination on beef carcasses J. Food Prot. 69, 1452-1455. 
Thran, B.H., Hussein, H.S., Hall, M.R. \& Khaiboullina, S.F. (2001) Shiga toxin-producing Escherichia coli in beef heifers grazing an irrigated pasture. J. Food Prot. 64, 1613-1616.

Tschape, H. \& Fruth, A. (2001) Enterohemorrhagic Escherichia coli. Contrib Microbiol 8 (Emerging Bacterial Pathogens), 1-11.

Whipp, S.C., Rasmussen, M. A. \& Cray, W.C.Jr. (1994) Animals as a source of Escherichia coli pathogenic for human beings. J. Am. Vet. Med. Assoc. 204, 1168-1175. 


\section{Chapter 2.10 Erysipeloid}

\section{[ERYSIPELOTHRIX RHUSIOPATHIAE]}

Erysipelothrix rhusiopathiae is a rod shaped gram-positive, non-motile, non-spore forming, facultative aerobic bacterium that does not contain endotoxin. Erysipelothrix rhusiopathiae has a worldwide distribution in nature and can be found in soil and decomposing vegetation (Timofeeva et al., 1978). It is primarily considered an animal pathogen, causing a disease known as erysipelas in animals and erysipeloid in humans. Pigs are most commonly affected, but cases have been reported in other animals such as birds (mainly in turkeys and ducks), sheep, fish, and reptiles (Brooke and Riley, 1999; Mutalib et al., 1993; Mutalib et al. 1995; Anonymous, 1946). In pigs, the disease is known as "diamond skin disease." Less frequent animal sources of transmission to humans are: lambs, horses, cattle, dogs, mice, rats and fur-bearing animals (Timofeeva and Golovacheva, 1959; Popugalio et al., 1983). The human disease called erysipeloid displays the following symptoms: inflammation with edema and hemorrhages on hand and fingers, itch without pus and fever. Occasional lymphangitis but rarely arthritis of joints and endocarditis may occur (Boo et al., 2003).

\subsubsection{ERYSIPELOID AND ENVIRONMENT}

Erysipelothrix rhusiopathiae bacterium is ubiquitous and able to persist for a long period of time in the environment, especially where nitrogenous substances decompose (Klauder, 1938; Molin et al., 1989). This characteristic may explain why Popugalio et al., (1983) in a shoe factory found leather and casein glue contaminated with E. rhusiopathiae. Geographically, this pathogen can be found in terrestrial and marine locations while clinical cases have been reported worldwide (Japan, Russia, Australia, USA, Europe, etc.) (Wang et al., 2010). The range of animals that are infected by and possibly transmitters of this bacterium includes vertebrates and invertebrates such as swine, sheep, cattle, horses, dogs, bears, kangaroos, reindeer, mice, rodents, seals, sea lions, cetaceans, mink, chipmunks, crustaceans, fresh and salt water fish, crocodiles, Caymans, stable flies, houseflies, ticks, mites, mouse, lice, turkeys, chickens, ducks, geese, guinea fowls, pigeons, sparrows, starlings, eagles, parrots, pheasants, peacocks, quail, parakeets, mud hens, canaries, finches, siskins, thrushes, blackbirds, turtledoves and white storks 
(Figure 2.10.1) (Bricker and Saif, 1997; Reboli and Farrar, 1989; Oli'akova and Antoniuk, 1989; Wood, 1975; Grieco and Sheldon, 1970).

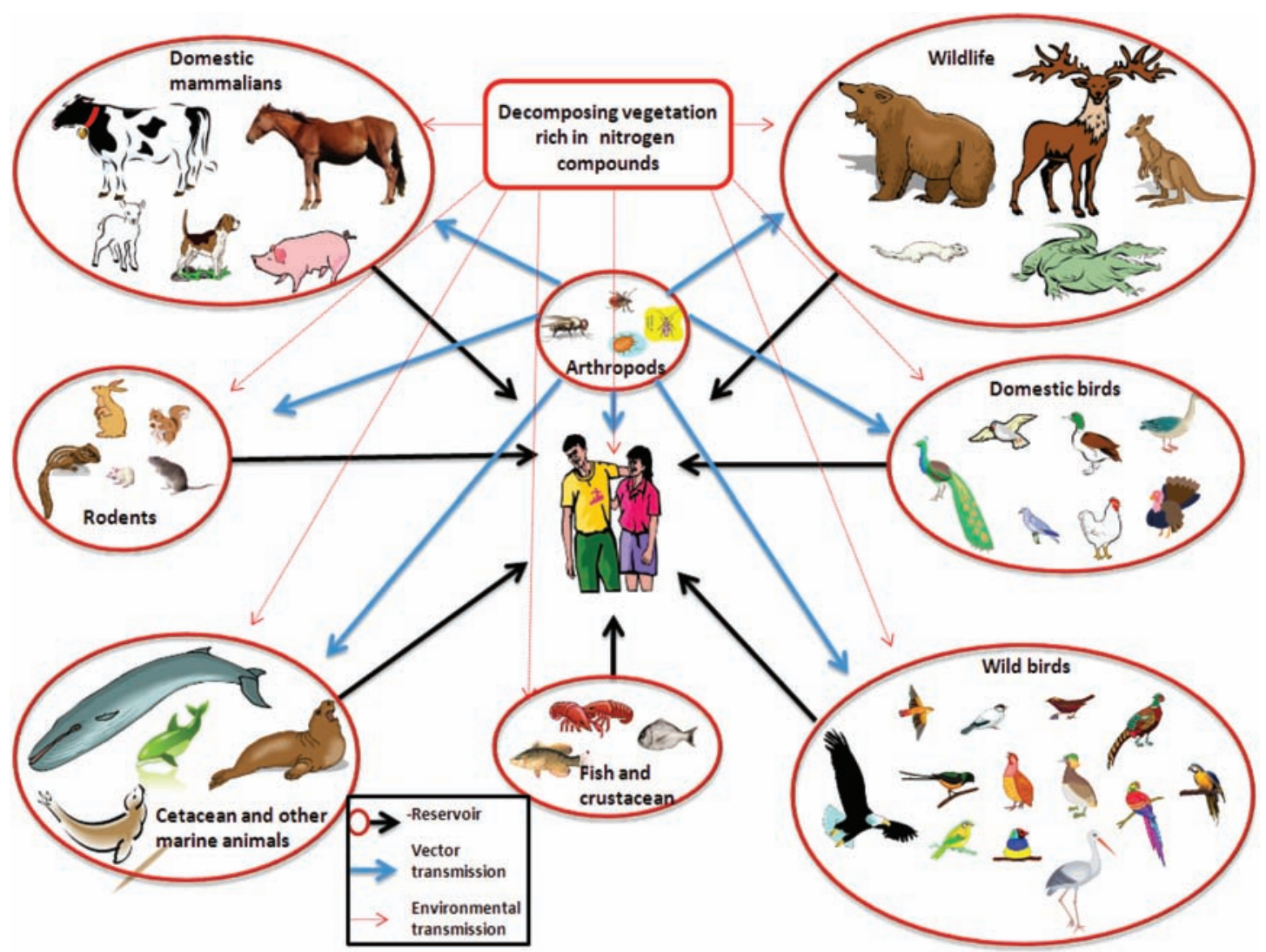

Figure 2.10.1. Ecology of Erysipelothrix spp. in biosphere related to human infection

Major transmission and infection cases were reported on persons working at meat, offal and bone processing plants where they had direct contact with infected animals (Savchenko et al., 1984).

Human infections are mainly related to direct contact with swine and turkey through slaughterhouse and meat manufacture; however, in Western Australia, an erysipeloid-like infection referred to as "crayfish poisoning" occurred in lobster fishermen and handlers (Fidalgo et al. 2004), an incidence already reported in the 40's of the last century (Anonymous, 1946).

For three years (2007-2009), Bender et al. (2010) analyzed clinical and environmental isolates from affected pigs in Midwest United States. Environmental samples included: manure, feed, water lines, oral fluids, swab samples from wall, feed lines, air inlets, exhaust fans and nipple drinker. Except for feed line, all other environmental samples were positive for Erysipelothrix spp. in the range of 21.4 to 52.9\%, feed and nipple drinkers having the highest percentage of positive samples.

A previous study demonstrated that this organism can survive for a maximum of 35 days in soil under diverse conditions of temperature, $\mathrm{pH}$, moisture and organic content (Wood, 1973). Taking into account the continuous excretion of this pathogen by infected animals and high nitrogen content of decaying 
vegetation, soil certainly can be considered as a realistic source of human infection, especially under poor hygienic conditions.

\subsubsection{REFERENCES}

Anonymous (1946) Erysipeloid. Lancet, 2, 327-328.

Bender, J.S., Shen, H.G., Irwin, C.K., Schwartz, K.J. \& Opriessnig, T. (2010) Characterization of Erysipelothrix species isolates from clinically affected pigs, environmental samples, and vaccine strains from six recent swine Erysipelas outbreaks in the United States. Clin. Vaccine Immunol., 17, 1605-1611.

Boo, T.W., Hone, R. \& Hurley, J. (2003) Erysipelothrix rhusiopathiae endocarditis: a preventable zoonosis?. Ir J Med Sci 172, 81-82.

Bricker, J.M. \& Saif, Y.M. (1997) Erysipelas. In: Calnek, B.W., Barnes, H.J., Beard, C.W., McDougald, L.R., Saif, Y.M. (Eds.), Diseases of Poultry. 10th ed. Iowa State University Press, Ames, IA, pp. 302-313.

Brooke, C. \& Riley, T. (1999). "Erysipelothrix rhusiopathiae: bacteriology, epidemiology and clinical manifestations of an occupational pathogen". J Med Microbiol 48, 789-799.

Chandler, D.S. \& Craven, J.A. (1980) Persistence and distribution of Erysipelothrix rhusiopathiae and bacterial indicator organisms on land used for disposal of piggery effluent. J. Appl. Bacteriol. 48, 361-315.

Fidalgo, S.G. \& Riley, T.V. (2004) Detection of Erysipelothrix rhusiopathiae in clinical and environmental samples. Methods Mol. Biol. 268, 199-205.

Grieco, M.H. \& Sheldon, C. (1970) Erysipelothrix rhusiopathiae. Ann. N. Y. Acad. Sci. 174, 523-532.

Klauder, J.V. (1938) Erysipeloid as an occupational disease. J. Am. Med. Assoc. 111, 1345-1348.

Kratokhvil, N.I. (1954) Case of isolation of the causative agent of erysipeloid from sexually mature ticks Ixodes ricinus. Zh. Mikrobiol. Epidemiol. Immunobiol. 3, 361-363.

Molin, G., Söderlind, O., Ursing, J., Nørrung, V., Ternstrøm, A. \& Löwenhielm, C. (1989) Occurrence of Erysipefothrix rhusiopathiae on pork and in pig slurry, and the distribution of specific antibodies in abattoir workers. J. Appl. Bacteriol. 67, 347-352.

Mutalib, A., Keirs, R. \& Austin, F. (1995) Erysipelas in quail and suspected erysipeloid in processing plant employees. Avian Dis. 39, 191-193.

Mutalib, A.A., King, J.M. \& McDonough, P.L. (1993) Erysipelas in caged laying chickens and suspected erysipeloid in animal caretakers. J. Vet. Diagn. Invest. 5, 198-201.

Ol'iakova, N.V. \& Antoniuk, V.I. (1989) The gray rat (Rattus norvegicus) as a carrier of infectious causative agents in Siberia and the Far East. Med Parazitol (Mosk) 3, 73-77.

Popugailo, V.M., Podkin, I.A., Gurvich, V.B., Kuperman, E.F. \& Zhukova, L.N. (1983) Erysipeloid as an occupational disease of workers in shoe enterprises. Zh. Mikrobiol. Epidemiol. Immunobiol. 10, 46-49.

Reboli, A.C. \& Farrar, W.E. (1989) Erysipelothrix rhusiopathiae: an occupational pathogen. Clin. Microbiol. Rev. 2 , 354-359.

Savchenko, I.L., Vasil'chenko, A.A., Krolevetskaia, N.M., Blagodatnyi, V.N. \& Serebriakova, T.L. (1984) Zoonotic infections in persons working in plants producing meat and bone meal. Zh. Mikrobiol. Epidemiol. Immunobiol. 3, 71-73.

Timofeeva, A.A., Evseeva, T.I., Shcherbina, R.D., Gaidukova, N.S., Artiukhov, N.I. (1978) Erysipeloid on the islands of the Ohhotsk Sea. 2. Landscape types of the natural foci of erysipeloid. Zh. Mikrobiol. Epidemiol. Immunobiol. 1, $41-51$.

Timofeeva, L.A. \& Golovacheva, V.I. (1959) Detection of erysipeloid in rodents in Transcaucasian steppes. Zh. Mikrobiol. Epidemiol. Immunobiol. 30, 84-89.

Wang, Q., Chang, B.J. \& Riley, T.V. (2010) Erysipelothrix rhusiopathiae. Vet. Microbiol. 140, 405-417.

Wood, R.L. (1973) Survival of Erysipelothrix rhusiopathiae in soil under various environmental conditions. Cornell Vet 63, 390-410.

Wood, R.L. (1975) Erysipelothrix infection. In: Hubbert, W.T., McCullough, W.F., Schnurrenberger, P.R. (Eds.), Diseases Transmitted from Animals to Man. 6th ed. Thomas, Springfield, IL, pp. 271-281. 


\section{Chapter 2.11}

\section{Glanders (Malleus or Farcy)}

\section{[BURKHOLDERIA MALLE]}

Burkholderia mallei is an aerobic, gram-negative rod, non-motile and non-fermentative bacterium, formerly named Pseudomonas mallei. The disease called Glanders, Malleus or Farcy can be acute and chronic and is characterized by skin lesions, multiple abscesses, respiratory tract necroses, pneumonia and sepsis. Predominant animals affected by this bacterium are: horses, donkeys, and mules, although other animals (e.g. sheep, goats, dogs, cats and zoo animals) may be infected through contact with ungulates or by consuming their meat (Alibasoglu et al., 1986). Humans who come in contact with horses (e.g., veterinarians, horse dealers, farmers or horseback riders) or consume horse meat are at high risk (Fukuyo et al., 2002; Wittig et al., 2006). In stables, airborne infections are also feasible when infected secretions are dispersed as aerosols (Lever et al., 2003; Whitlock et al., 2007; Dvorak and Spickler, 2008).

\subsubsection{BURKHOLDERIA MALLEI AND ENVIRONMENT}

The genus Burkholderia comprises $>40$ different species isolated from a large variety of ecological niches (soil, water, plant rhizosphere, fungi, animals) as endophytes, endosymbionts and pathogens (El-Safey, 2005; Vandamme et al., 2006) (Figure 2.11.1). Soil presence of B. mallei was reported in Ternate Island (Indonesia) revealing an isolation prevalence of $3.1 \%$ (Noura et al., 2009) and in Jordan in crude petroleum oil contaminated soil where it had the capability of degrading diesel fuel (Saadoun, 2002). Many are known for their biological and metabolic properties involved in the biomineralization of a diverse variety of chemicals and as such are used in biotechnology. In a study conducted on bacterial isolates from Lake Mariut sediments (a fresh water lake located south of Alexandria, Egypt), isolated $B$. malle $i$ was able to biodegrade or mineralize the phenoxy herbicide mecoprop (MCPP) under different conditions. Among the Pseudomonas spp., the highest mineralization efficiency was achieved by P. mallei (now B. mallei), while $P$. pseudomallei (now B. pseudomallei) revealed the highest biodegradation efficiency (El-Bestawy \& Albrechtsen, 2007). Remarkable examples supporting these assumptions were recently published, revealing a variety of bacteria capable of biodegrading petroleum hydrocarbons species such as $B$. mallei and $B$. pseudomallei (described later) known as human and animal pathogens 
(Malkawi et al., 2009; Sahu et al., 2008). In relation to petroleum products, Balogun and Fagade (2010) reported on emulsifying bacteria isolated from produce water with high chloride content $(650 \mathrm{mg} / \mathrm{L})$ obtained from an oil terminal in the Niger Delta, Nigeria. Among the isolated bacteria, B. mallei had the highest emulsification and de-emulsification indices (65 and 50\% respectively).

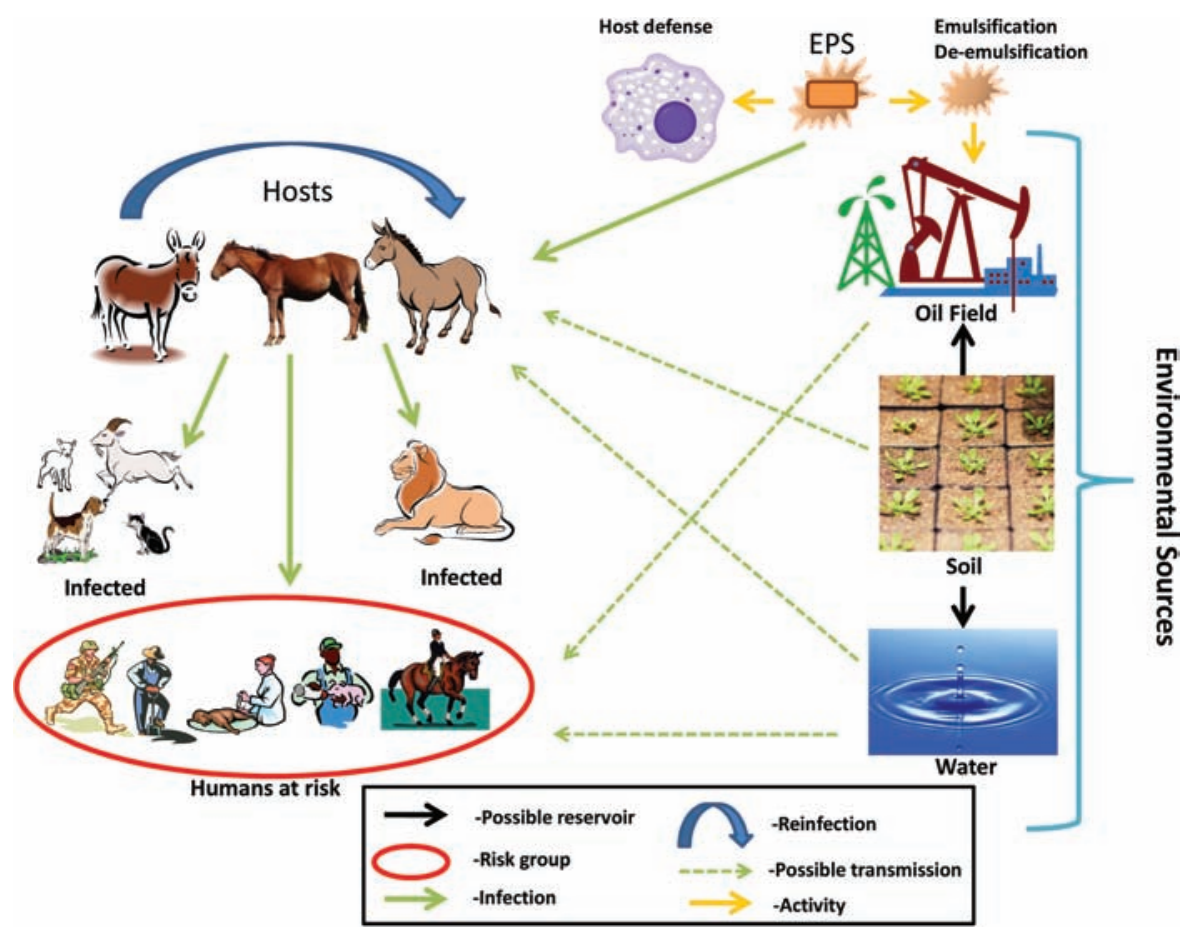

Figure 2.11.1. Burkholderia mallei infection routes and environmental sources

These characteristics are interesting as biosurfactant agents are substances that can break down the interfacial tension between polar and non-polar liquids in mixtures to form stable emulsions, however these bacteria can also de-emulsify due to the biodegradation properties of different hydrocarbons including their utilization of the excreted biosurfactants (Nadarajah et al., 2002). The dual antagonistic activities can explain the bacterial pathogenic mechanism, by enhanced cell attachment and defense against host antibacterial activity (emulsification) and detachment and spread (de-emulsification). It would be interesting to find out whether these biosurfactants naturally excreted by $B$. mallei are similar or closely related to some virulence mechanisms expressed during infection, through its extracellular polysaccharide capsule (Dvorak and Spickler, 2008).

From the genetic point of view, B. mallei and its relatives reveal an interesting trend that facilitates their survival, infection and distribution in the ecological biosphere. Shaginyan and Chernukha (2003) in their review of Burkholderia cepacia complex based on comparative genomic molecular biology, hypothesized about a possible phylogenetic relations of B. cepacia complex with phytopathogens and human or animal pathogens species, such as Burkholderia, Pseudomonas, Escherichia, B. mallei, B. pseudomallei, P. aeruginosa and E. coli. The authors describe a possible role of alterations and 
mutations in the genome of the complex B. cepacia bacteria (a genome having unusual properties, i.e., a big size and a considerable quantity of insertion sequences-IS) in creating the conditions for the "pulsing" evolution and "jerks" for a rapid change-over from saprophytism in soil environment to a pathogenic agent. Such a mechanism can explain the rapid and radical adaptation of microorganisms under new altering ecological niches. A similar trend was recently presented in a study on $B$. mallei and its genetic consistency in comparison with much more diverse species and the closely related: B. pseudomallei.

The $B$. mallei core genome shared by all these species is smaller compared to its relative $B$. pseudomalle $i$ while variable gene sets distributed across $B$. malle $i$ strains are larger, revealing insertion sequence elements that contribute to its variable virulence when introduced into an animal host. Romero et al. (2006) working on B. mallei ATCC 23344, showed that this bacterium exhibits genome variability upon passage in mouse, horse and human patient by the accumulation of genome sequence variation at sequence repeats (SSRs) and other loci. The authors reported 12,000 simple sequence repeats found in this strain that may explain its phenotypic versatility.

Finally, the potential use of $B$. malle $i$ as a biological weapon by armies and terrorists cannot be ignored based on historical experience (Larsen \& Johnson, 2009). There is solid evidence that during the first and second world wars, both sites used $B$. mallei against their opponents including the second half of the last century (Martin et al., 2007). Rose et al. (2005) challenged different potential bioterrorism agents (bacterial) also known as zoonotic pathogens, to chlorine inactivation. Among these pathogens, B. mallei revealed high susceptibility to chlorination at a low disinfectant concentration $[\mathrm{Ct}-0.2 \mathrm{mg} \mathrm{min} /$ liter for $2 \log$ reduction] compared to other highly pathogenic bacteria such as Francisella tularensis NY98 [Ct $7.8 \mathrm{mg} \mathrm{min} /$ liter for $2 \log$ reduction].

\subsubsection{REFERENCES}

Alibasoglu, M., Yesildere, T., Calislar, T., Inal, T. \& Calsikan, U. (1986) Glanders outbreak in lions in the Istanbul zoological garden. Berl. Munch. Tierarztl. Wochenschr. 99, 57-63.

Balogun, S.A. \& Fagade, O.E. (2010) Emulsifying bacteria in produce water from Niger-Delta, Nigeria. Afr J Microbiol Res 4, 730-734.

Dvorak, G.D. \& Spickler, A.R. (2008) Glanders. J. Am. Vet. Med. Assoc. 233, 570-577.

El-Bestawy, E. \& Albrechtsen, H-J. (2007) Effect of nutrient amendments and sterilization on mineralization and/or biodegradation of ${ }^{14} \mathrm{C}$-labeled MCPP by soil bacteria under aerobic conditions. Int. Biodeterior. Biodegradation 59, 193-201.

El-Safey, E.M. (2005) Microbiological quality of drinking water cooling system (water supplies) in some trains solid in Egypt. Egypt. J. Biotechnol. 20, 193-218.

Fukuyo, M., Battsetseg, G. \& Byambaa, B. (2002) Prevalence of Sarcocystis infection in horses in Mongolia. Southeast Asian J. Trop. Med. Public Health 33, 718-719.

Larsen, J.C. \& Johnson, N.H. (2009) Pathogenesis of Burkholderia pseudomallei and Burkholderia mallei. Mil Med 174, 647-651.

Lever, M.S., Nelson, M., Ireland, P.I., Stagg, A.J., Beedham, R.J. et al., (2003) Experimental aerogenic Burkholderia mallei (glanders) infection in the BALB/c mouse. J. Med. Microbiol. 52, 1109-1115.

Losada, L., Ronning, C.M., DeShazer, D., Woods, D., Fedorova, N. et al. (2010) Continuing evolution of Burkholderia mallei through genome reduction and large-scale rearrangements. Genome Biol. Evol. 2, 102-116.

Malkawi, H. I., Jahmani, M. Y., Hussein, E. H., Al-Horani, F. A., Al-Deeb, T. M. (2009) Investigation on the ability of soil bacterial isolates to degrade petroleum hydrocarbons. Int. J. Integ. Biol 7, 93-99.

Martin, J. W., Cristopher. G.W. \& Eitzen, E.M. (2007), "History of biological weapons: from poisoned darts to intentional epidemics", In: Dembek, Z. F. (Ed.), Medical Aspects of Biological Warfare, (Series: Textbooks of Military Medicine), Washington, DC, The Borden Institute, pp. 1-20. 
Nadarajah, N., Singh, A. \& Ward, O.P. (2002) Evaluation of a mixed bacterial culture for de-emulsification of water-in-petroleum oil emulsions. World J. Microbiol. Biotechnol. 18, 435-440.

Noura, S.K.M., Jusuf, N.H., Hamid, A.A. \& Yusoff, W.M.W (2009) High prevalence of Pseudomonas species in soil samples from Ternate Island-Indonesia. Pak. J. Biol. Sci. 12, 1036-1040.

Romero, C.M., DeShazer, D., Feldblyum, T., Ravel, J., Woods, D. et al. (2006) Genome sequence alterations detected upon passage of Burkholderia mallei ATCC 23344 in culture and in mammalian hosts. BMC Genomics 7:228. doi:10.1186/1471-2164-7-228.

Rose, L.J., Rice, E.W., Jensen, B., Murga, R., Peterson, A. et al. (2005) Chlorine Inactivation of Bacterial Bioterrorism Agents. Appl. Environ. Microbiol. 71, 566- 568.

Saadoun, I. (2002) Isolation and characterization of bacteria from crude petroleum oil contaminated soil and their potential to degrade diesel fuel. J. Basic Microbiol. 42, 420-428.

Sahu, K., Kumari, S., \& Shukla, S. (2008) Biodegradation studies on the selected bacterial strains isolated from hospital discharge. Nature, Environ. Pollut. Technol. 7, 107-110.

Shaginyan, I.A. \& Chernukha, M.Y. (2003) Bacteria of the Burkholderia cepacia complex: specifities of diagnosis, genome organization and metabolism. Mol. Gen. Microbiol.Virol. 2, 3-10.

Vandamme, P., Govan, J. \& LiPuma, J. (2006) Diversity and role of Burkholderia spp. In: Coenye, T. and Vandamme, P. (Eds.) Burkholderia. Molecular Microbiology and Genomics. Horizon Bioscience, UK, pp. 1-28.

Whitlock, G.C., Estes, D.M. \& Torres, A.G. (2007) Glanders: off to the races with Burkholderia mallei. FEMS Microbiol Lett 277, 115-122.

Wittig, M.B., Wohlsein, P., Hagen, R.M., Al Dahouk, S., Tomaso, H. et al. (2006) Glanders- a comprehensive review. Dtsch Tierarztl Wochenschr 113, 323-330. 


\section{Chapter 2.12}

\section{Leptospiroses}

\section{[LEPTOSPIRA INTERROGANS]}

Leptospira interrogans is a motile, aerobic, gram-negative spiral shaped bacterium with hook or crooked shaped ends. The species L. interogans contains $\sim 200$ serovars that can be subgrouped in $>20$ serogroups. Animals, water, soil and infected humans are the main reservoirs for infection (Krawczyk, 2004; Bharti et al., 2003). It affects humans and a wide range of animals, including mammals, birds, amphibians, and reptiles (Junge et al., 2007; Niwetpathomwat et al., 2006; Easterbrook et al., 2007). In humans, the disease has a wide range of symptoms and has a biphasic behavior: the first phase is characterized by flu-like symptoms (fever, chills, myalgias, and headache) and sometimes even asymptomatic while the second phase (known as Weil's disease or as sometimes called Weil Syndrome) (Aydemir et al., 2007) is much more severe presenting itself as meningitis, liver damage (ictohaemorrhagie causing jaundice), renal failure, cardiovascular problems and death (Suarez et al., 1991).

\subsubsection{LEPTOSPIRA AND ENVIRONMENT}

There are several environmental key factors that increase Leptospirosis risk in animals and humans such as: a) rodent exposure; b) wildlife exposure; c) soil and water and d) management (Barwick et al., 1997) (Figure 2.12.1). The link between Leptospira and water sources is very evident (Corwin et al., 1990; Katz et al., 1991; Aydemir et al., 2007). Water can be directly contaminated by a large variety of animals or human excreta or indirectly by soil surface wash (floods, rainfall, run-off, etc.) (Manciuc et al., 2007). Here is the place to mention a new report on Leptospira interrogans cell-binding activity in vitro, attributable to the attachment of proteoglycans (PGs) to a cell's glycosaminoglycan (GAG) chains, both shed by infected individuals in urine, making the transition from mammalian host to environment (soil and water) and vice versa possible (Breiner et al., 2009). Numerous cases involving human contact with water contaminated sources have been reported comprising athletes, adventure tourists, military and swimmers (Jackson et al., 1993: Boland et al., 2004; Aoki et al., 2001; Tunbridge et al., 2001; Hadad et al., 2006; Lettieri et al., 2004; Stephan et al., 2000). Canoe race participants and triathlon athletes were identified as having contracted Leptospira in the Liffey river, Dublin, Ireland. Investigation of both 
cases revealed that direct contact and ingestion of contaminated water increase the risk of contracting Leptospiroidosis. In the canoe race case, abundant rainfall coupled with hydroelectric water release may have contributed to the outbreak (Boland et al., 2004). Trueba et al. (2004) showed experimentally that L. interrogans serovar canicola can survive (based on motility test) for 110 days in distilled water (pH $7.2)$ and 347 days when incubated in a semi-solid medium (0.5\% purified agarose in distilled water $-\mathrm{pH}$ 7.2), on the other hand when incubated in saline it survived only 21 days (Trueba et al., 2002). Another study supports these findings, revealing that salinity critically impairs Leptospira's survival ability in sea water (Khairani-Bejo et al., 2004). In this context, it should be mentioned that Gill et al. (1985) performing a Leptospira seroconversion survey among fish farm workers, reported that fish farming has a moderate risk for this pathogen; however in their case, no data were presented on water salinity (fresh or sea water), which may impact the pathogen's survival and explain their mostly negative results. In viscous semi-solid medium, Leptospira cells form aggregates indicating on the mechanisms by which this pathogen can survive for prolonged periods of time in natural aqueous environments as a part of its lifecycle. Ristow et al. (2008) published an additional potential survival mechanism for Leptospira based on biofilm formation "that is consistent with the life of saprophytic strains in water and may help pathogenic strains to survive in environmental habitats and to colonize the host". Pathogen transmission is also water-associated in cases of catastrophic events such as floods or hurricanes. Several studies showed that floods, through soil cover and wash, can transmit Leptospira to humans and animals especially when they live in close proximity to inundated areas (Anonymous, 2006; Vanasco et al., 2002; Gaynor et al., 2007). Sanders et al. (1999) found an increase in laboratory cases following a hurricane episode. Soil environment may also support the growth and survival of Leptospira especially if they are hygroscopic, euthrophic and close to neutral pH (Maksimenkova and Karpachevskii, 1985; Yang et al., 1994). Wet soil is also a source of contamination for Leptospira (Yang et al., 1994).

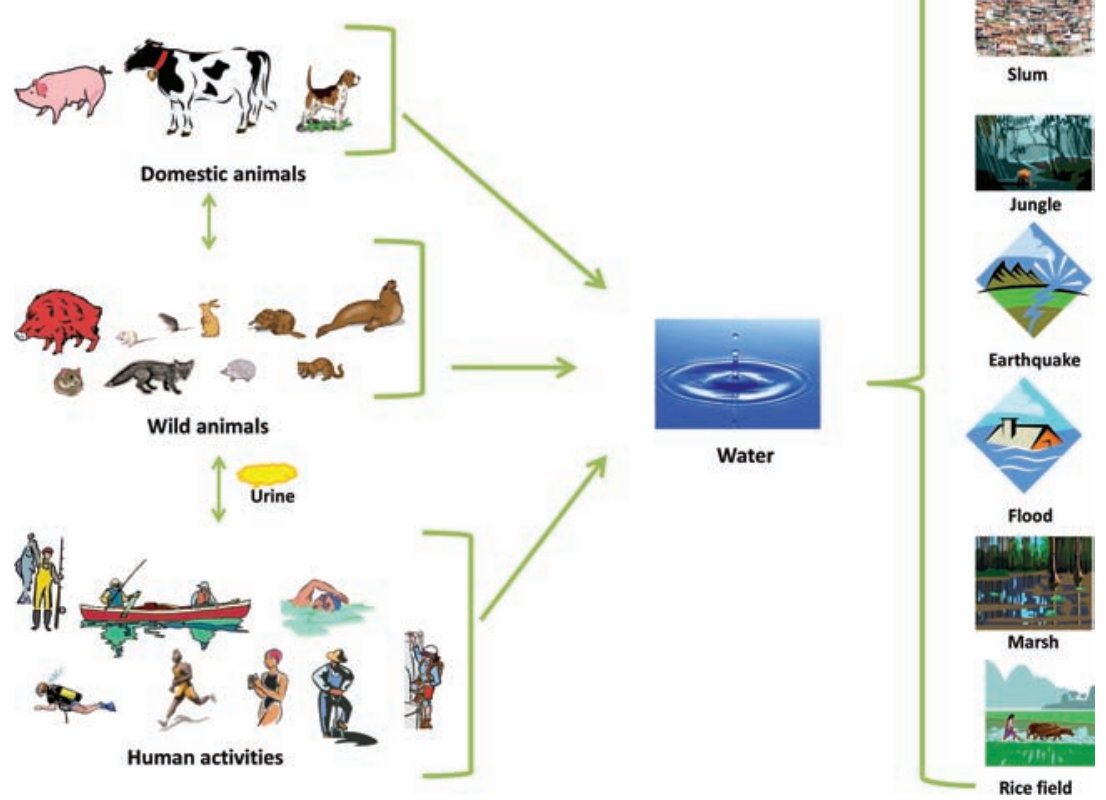

Figure 2.12.1. Leptospira spp. transmission and environmental sources 
Sea shore, with its wet sandy composition is such an environment where many animals dwelling near freshwater estuaries (including wastewater spills) increases the potential for Leptospirosis transmission to humans and domestic animals. Cameron et al. (2008) studied pinnipeds population, using advanced molecular methods (PCR), for Leptospira infection as a potential source for epizootic, enzootic, and zoonotic spread of leptospirosis in a marine environment. According to these authors, it seems that human recreational activity, estuaries outfall, rodents and the close contact of infected animals are the main vectors for the spread of Leptospirosis among marine animals. Ganoza et al. (2006) surveyed urban and rural populations in the Peruvian Amazon for prevalence of pathogenic Leptospira interrogans serovar icterohaemorrhagiae. This pathogen was isolated only in samples from urban slum market areas, gutter water and human isolates but not in rural areas, suggesting a specific mode of transmission from rats to humans in dirty and densely populated urban areas. Similar results were obtained by Pereira and Andrade (1990) in a slum area of Rio de Janeiro, Brazil and by Scialfa et al. (2010) in Buenos Aires, Argentina. Human proximity to water sources was shown also to contribute to wildlife infection with L. interrogans. In the United States, two otter populations, one from an area of low human population density (Prince William Sound, Alaska) and a second one from one of high human population density (San Juan Islands, Washington State), were studied by indirect immunofluorescent antibody (IFA) test for seroprevalence against L. interrogans (Gaydos et al., 2007). The absence of a seroprevalence shift in Alaska's otters advocates that life in proximity to excessive human density and its association with agricultural activities, domestic animals and rodent populations might enhance river otter exposure to L. interrogans.

\subsubsection{REFERENCES}

Anonymous. (2006) Brief report: Leptospirosis after flooding of a university campus-Hawaii, 2004. MMWR Morb. Mortal. Wkly. Rep. 55, 125-127.

Aoki, T., Koizumi, N. \& Watanabe, H. (2001) A case of leptospirosis probably caused by drinking contaminated well-water after an earthquake. Jpn. J. Infect. Dis. 54, 243-244.

Aydemir, H., Akduman, D., Oztoprak, N., Piskin, N., Celebi, G. \& Akkoyunlu, Y. (2007) A severe case of Weil's disease. Mikrobiyol Bul 41, 145-150.

Barwick, R.S., Mohammed, H.O., McDonough, P.L.M. \& White, M.E. (1997) Risk factors associated with the likelihood of leptospiral seropositivity in horses in the state of New York. Am. J. Vet. Res. 58, 1097-103.

Bharti, A.R., Nally, J.E., Ricaldi, J.N., Matthias, M.A., Diaz, M.M. et al. (2003) Leptospirosis: a zoonotic disease of global Importance. Lancet Infect Dis 3, 757-771.

Boland, M., Sayers, G., Coleman, T., Bergin, C., Sheehan, N., Creamer, E., O'connell, M., Jones, L. and Zochowski, W. (2004) A cluster of leptospirosis cases in canoeists following a competition on the River Liffey. Epidemiol. Infect. 132, 195-200.

Breiner, D.D., Fahey, M., Salvador, R., Novakova J., \& Coburn. J. (2009) Leptospira interrogans binds to human cell surface receptors including proteoglycans. Infect. Immun. 77, 5528-5536.

Cameron, C.E., Zuerner, R.L., Raverty, S., Colegrove, K.M., Norman, S.A., Lambourn, D.M., Jeffries, S.J., \& Gulland, F.M., (2008) Detection of pathogenic Leptospira bacteria in pinniped populations via PCR and identification of a source of transmission for zoonotic leptospirosis in the marine environment. J. Clin. Microbiol. 46, 1728-1733.

Corwin, A., Ryan, A., Bloys, W., Thomas, R., Deniega, B. \& Watts, D. (1990) A waterborne outbreak of leptospirosis among United States military personnel in Okinawa, Japan. Int J Epidemiol, 19, 743-748.

Easterbrook, J.D., Kaplan, J.B., Vanasco, N.B., Reeves, W.K., Purcell, R.H. et al. (2007) A survey of zoonotic pathogens carried by Norway rats in Baltimore, Maryland, USA. Epidemiol. Infect. 135, 1192-1199.

Ganoza, C.A., Matthias, M.A., Collins-Richards, D., Brouwer, K.C., Cunningham, C.B. et al. (2006) Determining risk for severe leptospirosis by molecular analysis of environmental surface waters for pathogenic leptospira. PLoS Med. 3, 1329-1340. 
Gaydos, J.K., Conrad, P.A., Gilardi, K.V.K., Blundell, G.M., \& Ben-David, M. (2007) Does human proximity affect antibody prevalence in marine-foraging river otters (Lontra canadensis)? J. Wildl. Dis., 43, 116-123.

Gaynor, K., Katz, A.R., Park, S.Y., Nakata, M., Clark, T.A., \& Effler, P.V. (2007) Leptospirosis On Oahu: an outbreak associated with flooding of a university campus. Am. J. Trop. Med. Hyg., 76, 882-885.

Gill, O.N., Coghlan, J.D. \& Calder, I.M. (1985) The risk of leptospirosis in United Kingdom fish farm workers. Results from a 1981 serological survey. J Hyg (Lond) 94, 81-86.

Hadad, E., Pirogovsky, A., Bartal, C., Gilad, J., Barnea, A. et al. (2006) An outbreak of Leptospirosis among Israeli troops near the Jordan river. Am. J. Trop. Med. Hyg., 74, 127-131.

Jackson, L.A., Kaufmann, A.F., Adams, W.G., Phelps, M.B., Andreasen, C. et al. (1993) Outbreak of leptospirosis associated with swimming. Pediatr. Infect. Dis. J. 12, 48-54.

Junge, R.E., Bauman, K., King, M. \& Gompper, M.E. (2007) A serologic assessment of exposure to viral pathogens and Leptospira in an urban raccoon (Procyon lotor) population inhabiting a large zoological park. J. Zoo Wildl. Med. 38, 18-26.

Katz, A.R., Manea, S.J., Sasaki, D.M. (1991) Leptospirosis on Kauai: investigation of a common source waterborne outbreak. Am J Public Health 81, 1310-1312.

Khairani-Bejo, S., Bahaman, A.R., Zamri-Saad, M. \& Mutalib, A.R. (2004) The survival of Leptospira interrogans serovar Hardjo in the Malaysian environment. J. Anim. Vet. Adv. 3, 123-129.

Krawczyk, M. (2004) Estimation of transmission hazard of Leptospira sp. infections in 2 groups of people. Przegl Epidemiol 58, 207-212.

Lettieri, C., Moon, J., Hickey, P., Gray, M., Berg, B. \& Hospenthal, D. (2004) Prevalence of leptospira antibodies in U.S. Army blood bank donors in Hawaii. Mil Med 169, 687-690.

Maksimenkova, I. A. \& Karpachevskii, L.O. (1985) Characteristics of soils of natural sites for leptospiroses and pseudotuberculosis and enteric Yersinia infection pathogens. Pochvovedenie 10, 107-115.

Manciuc, D.C., Dorobat, C., Hurmuzache, M. \& Nicu, M. (2007) Leptospirosis: clinical and environmental aspects of the Iasi county. Environ. Eng. Manage. J. 6, 133-136.

Niwetpathomwat, A., Luengyosluechakul, S. \& Geawduanglek, A. (2006) Serological investigation of leptospirosis in sows from central Thailand. (2006) S. Southeast Asian J. Trop. Med. Public Health 37, 716-719.

Pereira, M.M. \& Andrade, J. (1990) Human leptospirosis in a slum area in the city of Rio de Janeiro, Brazil-a serological and epidemiological study. Mem. Inst. Oswaldo Cruz 85, 47-52.

Ristow, P., Bourhy, P., Kerneis, S., Schmitt, C., Prevost, M-C. et al. (2008) Biofilm formation by saprophytic and pathogenic Leptospires. Microbiology 154, 1309-1317.

Sanders, E.J., Rigau-Pérez, J.G., Smits, H.L., Deseda, C.C., Vorndam, V.A. et al. (1999) Increase of Leptospirosis in Dengue-negative patients after a hurricane in Puerto Rico In 1966. Am. J. Trop. Med. Hyg., 61, 399-404.

Scialfa, E., Bolpe, J., Bardon, J.C., Ridao, G., Gentile, J. \& Gallicchio, O. (2010) Isolation of Leptospira interrogans from suburban rats in Tandil, Buenos Aires, Argentina. Rev. Argent. Microbiol. 42, 126-128.

Stephan, C., Hunfeld, K.P., Schonberg, A., Ott, M.G., Hetzenecker, M. et al. (2000) Leptospirosis after a staff outing. Dtsch. Med. Wochenschr. 125, 623-627.

Suarez, H.M., Bustelo, A.J., Perez, G.L. \& Gorgoy, G.V. (1991) Outbreak of leptospirosis, predominantly meningoencephalitic, among children in the municipality of Moron. Rev Cubana Med Trop 43, 136-139.

Trueba, G., Zapata, S., Madrid, K. \& Penafiel, N. (2002) Adaptation of Leptospira interrograns (sensu stricto) to fresh water. Rev Cubana Med Trop 54, 11-14.

Trueba, G., Zapata, S., Madrid, K., Cullen, P. \& Haake, D. (2004) Cell aggregation: a mechanism of pathogenic Leptospira to survive in fresh water. Int. Microbiol. 7, 35-40.

Tunbridge, A.J, Dockrell, D.H., Channer, K.S. \& McKendrick, M.W. (2002) A breathless triathlete. Lancet 35, 130.

Vanasco, N.B., Fusco, S., Zanuttini, J.C., Manattini, S., Dalla Fontana, M.L. et al. (2002) Outbreak of human leptospirosis after a flood in Reconquista, Santa Fe, 1998. Rev. Argent. Microbiol. 34, 124-131.

Yang, W., Pang, J. \& Li, C. (1994) An investigation on the distribution of Leptospirae interrogans in water and soil in southwest of Yunnan Province. Zhonghua Liu Xing Bing Xue Za Zhi 15, 289-291. 


\section{Chapter 2.13}

\section{Listeriosis}

\section{[LISTERIA MONOCYTOGENES]}

Listeria monocytogenes is a gram-positive rod, facultative anaerobe and motile bacterium. It is perhaps the most virulent foodborne agent causing 20-30\% fatality in infected people (Ramaswamy et al., 2007). Infection by $L$. monocytogenes causes the disease listeriosis that manifests itself in humans as: septicemia, meningitis (or meningoencephalitis), encephalitis, corneal ulcer, pneumonia, and intrauterine or cervical infections in pregnant women, which may result in spontaneous abortion. Beside infected humans, a large variety of animals can excrete the pathogen in feces, subsequently spreading it in soil, plants and surface water (Table 2.13.1).

\subsubsection{LISTERIA AND ENVIRONMENT}

Besides animals and humans, soil, water and vegetation all closely related to agricultural activities, are also carriers and reservoirs of L. monocytogenes (Moshtaghi et al., 2003) (Figure 2.13.1). Lyautey et al. (2007) found a statistically significant link between the occurrence of L. monocytogenes and proximity to an upstream dairy farm and the degree of cropped land indicating L. monocytogenes pervasiveness in these catchments.

Soil amended with fertilizers (primarily containing $\mathrm{N}$ and $\mathrm{P}$ ) was shown to support and enhance the growth of L. monocytogenes in brown podzol soils in Russia (Sidorenko and Buzelova, 2008) while the presence of herbicides (e.g. simazine or picloram at 1-100 mg/L) in water samples enhanced the growth of L. monocytogenes while inhibiting Pseudomonas and Aeromonas, known as saprophytic pollution eliminators bacteria (Karaeva, 1988). Synthetic and mineral-oil based lubricants used in food industry were also shown to support L. monocytogenes' growth, survival and spread (Aarnislo et al., 2007).

In a study on fish farms in Finland tested for presence of $L$. monocytogenes, sea bottom soil samples were the ones that preserved the L. monocytogenes contamination for prolonged periods of time (Miettinen and Wirtanen, 2006) particularly at low temperatures (L. monocytogenes can grow at very low temperatures: $1.7 \pm 0.5^{\circ} \mathrm{C}$ and a broad range of $\mathrm{pH}$ values: 4.4 to 9.6) (Junttila et al., 1988). 


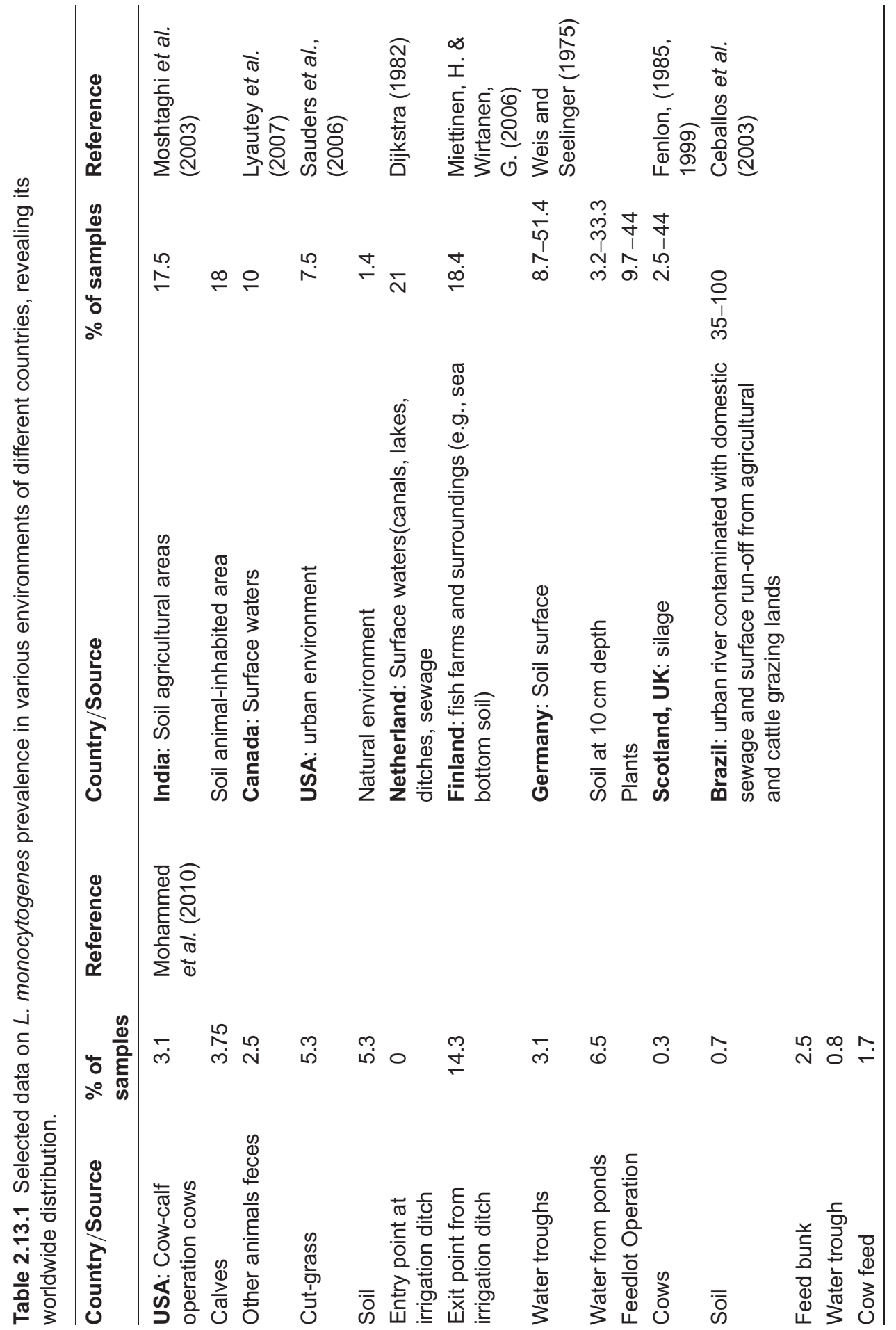




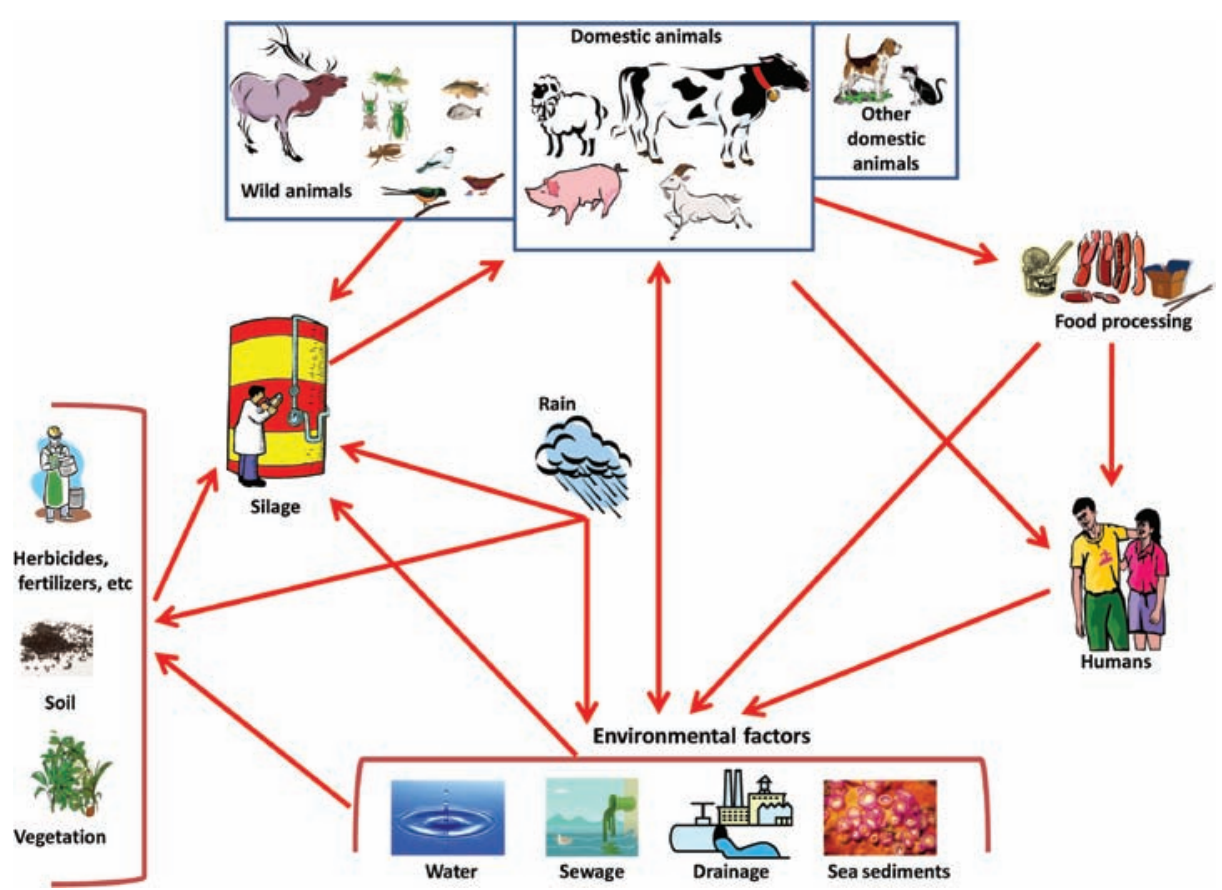

Figure 2.13.1. Environmental factors involved in the maintenance and infection of L.monocytogenes

Perhaps the major source of contamination attributed to its geographical widespread distribution is water resources with diverse qualities. Combarro et al. (1997) studying a sewage treatment plant's capability to remove L. monocytogenes found that the removal rate of $92 \%$ (in accordance with EEC regulations) was insufficient and levels of this pathogen increased in the downstream of an adjacent river. A sheep meningo-encephalithis was reported in Gippsland, Victoria, Australia caused by $L$. monocytogenes. This outbreak incident followed a period of continuous heavy rain and flooding of grazing pasture while the majority of affected flocks were located on poorly drained coastal sandy soil (Vandegraaff et al., 1981).

Girardin et al. (2005) under field conditions studied L. innocua as a surrogate for the survival and transfer of L. monocytogenes in soil and on parsley leaves (as a result of rain or irrigation splash). Leaf contamination was expected as a result of rain and irrigation of fields amended with contaminated fertilizers (i.e., manure). At $20^{\circ} \mathrm{C}$, the decline rates in soil were comparable for the two strains (L. innocua and L. monocytogenes) resulting in a decline of 7 log cycles in 90 days with a minute numbers on leaves. Improved survival was observed in winter with direct leaf contamination by spray (with bacterial low content soil) lacking internalization of L. monocytogenes in roots. Here it should be pointed out that a recent study revealed internalization of Salmonella enterica in leaves through open stomata (Kroupitski et al., 2010) that may hint at possible internalization by Listeria too, through its motility, surface polysaccharides involved in adhesion to soil (Abu-Lail et al., 2007) and persistence in poorly ripened silage of corn, grass, rye, oats and legumes (Ryser et al., 1997; Driehuis and Oude Elferink, 2000). Regrowth capability of $L$. monocytogenes was also shown in extracts of dairy-based composts under different environmental conditions (Kim et al., 2009). 


\subsubsection{REFERENCES}

Aarnisalo, K., Raaska, L. \& Wirtanen, G. (2007) Survival and growth of Listeria monocytogenes in lubricants used in the food industry. Food Control 18, 1019-1025.

Abu-Lail, N.I. \& Park, B-J. (2007) Molecular mechanisms of Listeria monocytogenes' adherence to soil through surface biopolymers. Abstracts of Papers, 234th ACS National Meeting, Boston, MA, United States, August 19-23, 2007.

Ceballos, B.S.O., Soares, N.E., Moraes, M.R., Catão, R.M.R. \& Konig, A. (2003) Microbiological aspects of an urban river used for unrestricted irrigation in the semi-arid region of north-east Brazil. Water Sci. Technol. 47, $51-57$.

Combarro, M.P., González, M., Araujo, M., Amezaga, A.C., Sueiro, R.A. \& Garrido, M.J. (1997) Listeria species incidence and characterization in a river receiving town sewage from a sewage treatment plant. Water Sci. Tech. 35, 201-204.

Dijkstra, R.G. (1982) The occurrence of Listeria monocytogenes in surface waters of canals and lakes, in ditches of one big polder and in the effluents of canals of a sewage treatment plant. Zentralbl Bacteriol [Orig. B] 176, 202-205.

Driehuis, F. \& Oude Elferink, S.J.W.H. (2000) The impact of the quality of silage on animal health and food safety: a review. Vet $Q 22,212-216$.

Fenlon, D.R. (1985) Wild birds and silage as reservoirs of Listeria in the agricultural environment. J Appl Bacteriol 59, 537-543.

Fenlon, D.R. (1999) Listeria monocytogenes in the natural environment. In Ryser, E.T. (ed.): Animals in Listeria, Listeriosis, and Food Safety. New York: Dekker, pp. 21-37.

Girardin, H., Morris, C.E., Albagnac, C., Dreux, N., Glaux, C. \& Nguyen-The, C. (2005) Behaviour of the pathogen surrogates Listeria innocua and Clostridium sporogenes during production of parsley in fields fertilized with contaminated amendments. FEMS Microbiol. Ecol. 54, 287-295.

Ivanek, R., Gröhn, Y.T. \& Wiedmann, M. (2006) Listeria monocytogenes in multiple habitats and host populations: review of available data for mathematical modeling. Foodborne Pathog. Dis. 3, 319-336.

Junttila, J.R., Niemela, S.I. \& Hirn, J. (1988) Minimum growth temperatures of Listeria monocytogenes and non-haemolytic Listeria. J. Appl. Bacteriol. 65, 321-327.

Karaeva, N. Yu. (1988) Effects of herbicides on the species structure of the microflora in bodies of water. Gig Sanit 9 , $70-71$.

Kim, J., Shepherd, M.W. Jr. \& Jiang, X. (2009) Evaluating the Effect of Environmental Factors on Pathogen Regrowth in Compost Extract. Microb. Ecol. 58, 498-508.

Kroupitski, Y., Golberg, D., Belausov, E., Pinto, R., Swartzberg, D. et al. (2009) Internalization of Salmonella enterica in leaves is induced by light and involves chemotaxis and penetration through open stomata. Appl. Environ. Microbiol.75, 6076-6086.

Lyautey, E., Lapen,D.R., Wilkes,G., McCleary, K., Pagotto, F. et al. (2007) Distribution and characteristics of Listeria monocytogenes isolates from surface waters of the South Nation river watershed, Ontario, Canada. Appl. Environ. Microbiol. 73, 5401-5410.

Miettinen, H. \& Wirtanen, G. (2006) Ecology of Listeria spp. in a fish farm and molecular typing of Listeria monocytogenes from fish farming and processing companies. Int. J. Food Microbiol. 112, 138-146.

Mohammed, H.O., Atwill, E., Dunbar, L., Ward, T., McDonough, P. et al. (2010) The risk of Listeria monocytogenes infection in beef cattle operations. J. Appl. Microbiol. 108, 349-356.

Moshtaghi, H., Garg, S.R. \& Mandokhot Usha, V. (2003) Prevalence of Listeria in soil. Indian J. Exp. Biol. 41, $1466-1468$.

Ramaswamy, V., Cresence, V.M., Rejitha, J.S., Lekshmi, M.U., Dharsana, K.S. et al. (2007) Listeria - review of epidemiology and pathogenesis. J Microbiol Immunol Infect. 40, 4-13.

Ryser, E.T., Arimi, S.M. \& Donnelly, C.W. (1997) Effects of pH on distribution of Listeria ribotypes in corn, hay, and grass silage. Appl. Environ. Microbiol. 63, 3695-3697.

Sauders, B.D., Durak, M.Z., Fortes, E., Windham, K., Schukken, Y. et al. (2006) Molecular characterization of Listeria monocytogenes from natural and urban environments. J Food Prot 69, 93-105. 
Sidorenko, M.L. \& Buzoleva, L.S. (2008) Effects of different mineral fertilizers on the reproduction of Listeria monocytogenes in soils. Agrokhimiya 5, 59-64.

Vandegraaff, R., Borland, N.A. \& Browning, J.W. (1981) An outbreak of listerial meningo-encephalitis in sheep. Aust. Vet. J. 57, 94-96.

Weis, J. \& Seeliger, H.P.R. (1975) Incidence of Listeria monocytogenes in nature. Appl Microbiol 30, 29-32. 


\section{Chapter 2.14}

\section{Melioidosis}

\section{[BURKHOLDERIA PSEUDOMALLE]}

Burkholderia pseudomallei is a motile, aerobic, gram-negative rod shaped bacteria closely related to $B$. mallei (genus Burkholderia) that causes disease in animals, humans and even plants (Ketterer et al., 1975; Lee et al., 2010). The main disease in humans is melioidosis that manifests itself as abscesses with lymphangitis, high fever, malaise, acute septicemia, acute pulmonary infection and death.

\subsubsection{B. PSEUDOMALLEI AND ENVIRONMENT}

Burkholderia pseudomallei has been isolated from soil, water and food contaminated with animal excreta (Currie et al. 2001). The main characteristics that support its survival in hostile environments are: resistance to detergents/antiseptic compounds through its biodegradation capability, growth under nutrient deficiency, low $\mathrm{pH}$, wide range of temperatures and dehydration, but susceptibility to UV irradiation (Dejsirilert et al., 1991; Chen et al., 2003; Inglis \& Sagripanti, 2006). South-east Asia is one of the world endemic areas for B. pseudomallei and this fact is apparently linked to the rainy season (monsoons) and flooded rice fields that help transmit this pathogen as a result of direct contact with water or inhalation of aerosols supported by these climatic conditions (Wuthikanum et al., 1995). Another described endemic area is northern Australia where clustered cases were associated with extreme weather events or environmental contamination (Cheng et al. 2006) (Figure 2.14.1). Water table movement, such as in cases of monsoonal rainy seasons, was speculated to have moved dormant or non-culturable state forms of this bacterium to the soil's surface, which in turn was converted into a more replicative and infectious form (Currie, 2008).

B. pseudomallei's interaction with the protozoa Acanthamoeba sp. (in a similar fashion described for another human pathogen, Legionella pneumophila, by internalization through phagocytosis and chronic infection) and pathogenicity to plants and larval insects is believed to facilitate its environmental survival (Inglis et al., 2000; Lee and Seleena, 1990). There are many factors that impact B. pseudomallei's distribution and persistence in the environment that include: a) physical factors (rainfall, flood, UV radiation, plowing/excavation, humidity and temperature) (Ketterer et al., 1975; Inglis et al., 2001) and 
b) chemical (soil chemistry, $\mathrm{pH}$, vegetation, fertilizers, genetical diversity, etc.) (Thomas et al., 1979; Wuthiekanun et al., 2009; Palasatien et al., 2009). A recent study demonstrated experimentally that $B$. pseudomallei can survive salt stress through the alteration of secreted proteins (secretome) a process which may explain its environmental epidemiology (Pumirat et al., 2009). Kaestli et al. (2009) surveyed the Darwin area in tropical Australia for soil presence of B. pseudomallei in two habitats: undisturbed and environmentally manipulated areas. Significant association at undisturbed sites was found to be linked to areas rich in grasses, and at environmentally disturbed sites the presence of livestock animals, lower soil $\mathrm{pH}$ and different combinations of soil texture and color were the significant factors. The close association to grass and livestock animals in both habitats is probably linked to B. pseudomallei's saprophytic characteristics and their excretion from infected animals (Figure 2.14.2).

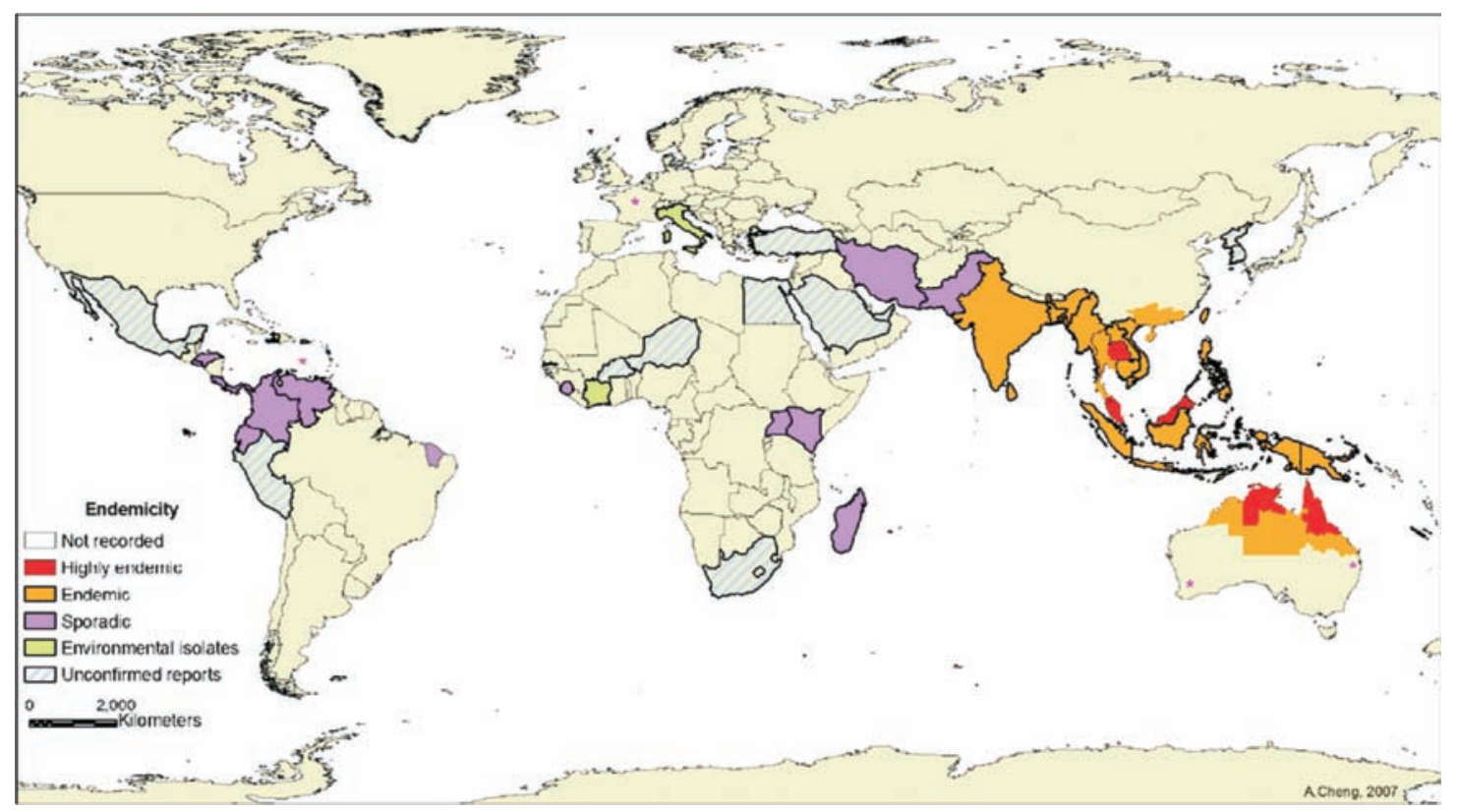

Figure 2.14.1. Global distribution of melioidosis (Burkholderia pseudomallei). (with permission from Currie, $\mathrm{B}$. J., Dance, D.A.B. \& Cheng, A.C. (2008), Trans. R. Soc. Trop. Med. Hyg. 102/S1, S1-S4.). *-documented temperate outbreaks of melioidosis: France; southeast Queensland, Australia; and southwest Western Australia

B. pseudomallei's ability to survive and biodegrade extreme concentrations of phenol $(1.5 \mathrm{~g} / \mathrm{l})$ in seven days was shown experimentally by Afzal et al. (2007) and in the context of other chemicals Gal et al. (2004) found a hand cleanse detergent as the source of human contamination with this pathogen which confirms its biodegradation capability.

As already highlighted, B. pseudomallei was also identified as a plant pathogen (Lee et al. 2009); nevertheless, this species, owing to a facultative intracellular lifestyle articulated by its presence in various eukaryotes, was demonstrated to be present in arbuscular mycorrhizal fungus (AMF) spores in vitro (Levy et al., 2009). AMF is a worldwide phenomenon of the highly evolved mutualistic relationship (symbiosis) between fungi and vascular plant, and therefore B. pseudomallei's presence 


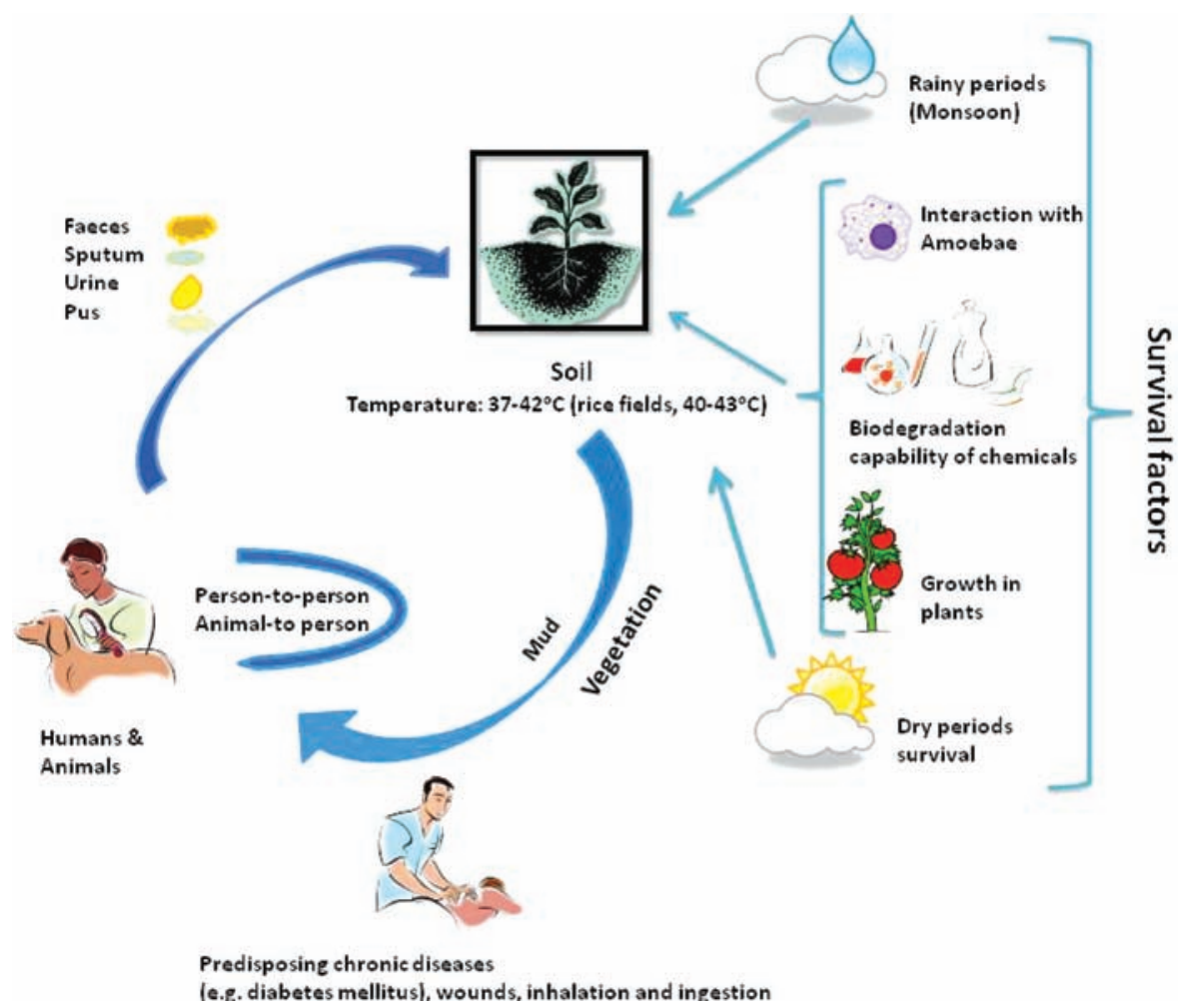

Figure 2.14.2. Melioidosis transmission cycle and environmental factors involved in Burkholderia pseudomallei survival

is very important in understanding the ecology and environmental aspects of plant-soil and animals interactions.

Another study showed an interesting biochemical divergence (utilization of L-arabinose as substrate, $\mathrm{Ara}^{+}$gene controlled) between some soil and clinical isolates of B. pseudomallei (clinical and some soil isolates were found to be $\mathrm{Ara}^{-}$). Arabinose is known to be one of the major components of hemicellulose and pectin found in plants that may explain B. pseudomallei's pathogenicity toward plants (by carrying the $\mathrm{Ara}^{+}$gene) beside animals (Sirisinha et al., 1998).

Wildlife animals were also shown to harbor B. pseudomallei as identified in a batch of feral cynomolgus monkeys (Macaca fascicularis) imported to Britain from the Philippines (Dance et al., 1992).

Human migration as well imported work forces can also contribute to the spread of this disease as reported by Cahn et al. (2009) in relation to an agricultural worker from Thailand who was diagnosed with diabetes mellitus and melioidiosis in Israel. Finally, in the Northeast part of Thailand, Limmathurotsakul et al. (2010) performed a prospective cohort study on 2,243 patients identified with culture-confirmed melioidosis, admitted to a hospital in northeast Thailand between 1997 and 2006. These authors found that diabetes mellitus was the strongest and most statistically relevant risk factor responsible for the rise over time in the melioidosis prevalence in Thailand as an endemic area. The prevalence of diabetes in the Thai population of this area was $2.3 \%$ in 1991 and increased to $6.7 \%$ in 2004 , with an average mortality rate of $42.6 \%$ from melioidosis over this study period. 


\subsubsection{REFERENCES}

Afzal, M., Iqbal, S., Rauf, S. \& Khalid, Z.M. (2007) Characteristics of phenol biodegradation in saline solutions by monocultures of Pseudomonas aeruginosa and Pseudomonas pseudomallei. J. Hazard. Mater. 149, 60-66.

Cahn, A., Koslowsky, B., Nir-Paz, R.,Temper, V., Hiller, N. et al. (2009) Imported Melioidosis, Israel, 2008. Emerging Infect. Dis. 15, 1809-1811.

Chen, Y.S., Chen, S.C., Kao, C.M. \& Chen, Y.L. (2003) Effects of Soil pH, Temperature and Water Content on the Growth of Burkholderia pseudomallei. Folia Microbiol. 48, 253-256.

Cheng, A.C. \& Currie, B.J. (2005) Melioidosis: epidemiology, pathophysiology, and management. Clin. Microbiol. Rev. 18, 383-416.

Cheng, A.C., Jacups, S.P., Gal, D., Mayo, M. \& Currie, B.J. (2006) Extreme weather events and environmental contamination are associated with case-clusters of melioidosis in the northern territory of Australia. Int $J$ Epidemiol 35,323-329.

Currie, B.J. (2008) Advances and remaining uncertainties in the epidemiology of Burkholderia pseudomallei and melioidosis. Trans. R. Soc. Trop. Med. Hyg. 102, 225-227.

Currie, B.J., Dance, D.A.B. \& Cheng, A.C. (2008) The global distribution of Burkholderia pseudomallei and melioidosis: an update. Trans. R. Soc. Trop. Med. Hyg. 102/S1, S1-S4.

Currie, B.J., Mayo, M., Anstey, N.M., Donohoe, P., Haase, A. \& Kemp, D.J. (2001) A cluster of melioidosis cases from an endemic region is clonal and is linked to the water supply using molecular typing of Burkholderia pseudomallei isolates. Am. J. Trop. Med. Hyg., 65, 177-179.

Dance, D.A., King, C., Aucken, H., Knott, C.D., West, P.G. \& Pitt, T.L. (1992) An outbreak of melioidosis in imported primates in Britain. Vet. Rec. 130, 525-529.

Dejsirilert, S., Kondo, E., Chiewslip, D. \& Kanai, K. (1991) Growth and survival of Pseudomonas pseudomallei in acidic environments. Jpn. J. Med. Sci. Biol. 44, 63-74.

Gal, D., Mayo, M., Smith-Vaughan, H., Dasari, P., McKinnon, M., Jacups, S.P., Urquhart, A.I., Hassell, M. \& Currie, B. J. (2004) Contamination of hand wash detergent linked to occupationally acquired melioidosis. Am. J. Trop. Med. Hyg. 71, 360-362.

Inglis, T.J., Mee, B. \& Chang, B. 2001. The environmental microbiology of melioidosis. Rev. Med. Microbiol. 12,1320.

Inglis, T.J.J. \& Sagripanti, J-L. (2006) Environmental factors that affect the survival and persistence of Burkholderia pseudomallei. Appl. Environ. Microbiol. 72, 6865-6875.

Inglis, T.J.J., Rigby, P., Robertson, T.A., Dutton, N.S., Henderson, M. \& Chang, B.J. (2000) Interaction between Burkholderia pseudomallei and Acanthamoeba species results in coiling phagocytosis, endamebic bacterial survival, and escape. Infect. Immun. 68, 1681-1686.

Kaestli, M., Mayo, M., Harrington, G., Ward, L., Watt, F. et al. (2009) Landscape changes influence the occurrence of the melioidosis bacterium Burkholderia pseudomallei in soil in northern Australia. PLoS Negl Trop Dis 3(1): e364. doi:10.1371/journal.pntd.0000364.

Ketterer, P.J., Donald, B. \& Rogers, R.J. (1975) Bovine melioidosis in South-Eastern Queensland. Aust. Vet. J. 51, 395398.

Lee, H.L. \& Seleena, P. (1990) Isolation of indigenous larvicidal microbial control agents of mosquitos: the Malaysian experience. Southeast Asian J. Trop. Med. Public Health 21, 281-287.

Lee, Y.H., Chen, Y., Ouyang, X. \& Gan, Y.H. (2010). Identification of tomato plant as a novel host model for Burkholderia pseudomallei. BMC Microbiol. 10:28.

Levy, A., Merritt, A.J., Mayo, M.J., Chang, B.J., Abbott, L.K. \& Inglis, T.J.J. (2009) Association between Burkholderia species and arbuscular mycorrhizal fungus spores in soil. Soil Biol. Biochem. 41, 1757-1759.

Limmathurotsakul, D., Wongratanacheewin, S., Teerawattanasook, N., Wongsuvan, G., Chaisuksant, S. et al. (2010) Increasing incidence of human melioidosis in northeast Thailand. Am. J. Trop. Med. Hyg., 82, 1113-1117.

Palasatien, S., Lertsirivorakul, R., Royros, P., Wongratanacheewin, S., \& Sermswan, R.W. (2008) Soil physicochemical properties related to the presence of Burkholderia pseudomallei. Trans. R. Soc. Trop. Med. Hyg. 102/S1, S5-S9. 
Pumirat, P., Saetun, P., Sinchaikul, S., Chen, S-T., Korbsrisate, S. \& Thongboonkerd, V. (2009) Altered secretome of Burkholderia pseudomallei induced by salt stress. Biochim. Biophys. Acta 1794, 898-904.

Sirisinha, S., Anuntagool, N., Intachote, P., Wuthiekanun, V., Puthucheary, S.D. et al. (1998) Antigenic differences between clinical and environmental isolates of Burkholderia pseudomallei. Microbiol. Immunol. 42, 731-737.

Thomas, A.D., Forbes-Faulkner, J. \& Parker, M. (1979) Isolation of Pseudomonas pseudomallei from clay layers at defined depths. Am. J. Epidemiol. 110, 515-521.

Wuthiekanun, V., Limmathurotsakul, D., Chantratita, N., Feil, E.J., Day, N.P.J., et al. (2009) Burkholderia pseudomallei is genetically diverse in agricultural land in northeast Thailand. PLoS Negl Trop Dis 3(8): e496. doi:10.1371/journal.pntd.0000496.

Wuthiekanun, V., Smith, M.D., Dance, D.A. \& White, N.J. (1995) Isolation of Pseudomonas pseudomallei from soil in north-eastern Thailand. Trans. R. Soc. Trop. Med. Hyg. 89, 41-43. 


\section{Chapter 2.15}

\section{Mycobacterial Infections}

\section{[MYCOBACTERIUM TUBERCULOSIS]}

Mycobacterium tuberculosis complex includes: M. africanum, M. bovis, M. bovis BCG, M. canettii, M. caprae, M. microti, M. pinnipedii, and M. tuberculosis all involved in chronic tuberculosis in humans and animals (Vaerewijck et al., 2005) (Figure 2.15.1). M. tuberculosis is a highly aerobic bacterium with high lipid content (mainly cell wall mycolic acid coating) which has made its Gram staining classification difficult, and therefore classical stainings such as acid-fast or Ziehl-Neelsen are used for identification. Due to their lack of an outer membrane, Mycobacteria are classified as acid-fast gram-positive bacteria. The disease is presented by subfebrile temperatures, lymphadenopathy, night sweat, cough (possibly with blood), fatigue, appetite loss/anorexia and erythema nodosum and in severe cases death (without treatment $>50 \%$ ). Extrapulmonary tuberculosis affects other organs: lymph nodes, genitourinary tract, pleura, meninges, skeletal system and peritoneum.

\section{[MYCOBACTERIUM MARINUM]}

Mycobacterium marinum was primarily isolated from a marine fish and only recently reported as an infectious source in humans causing a disease called "fish tank granuloma" (Aronson, 1926; Gray et al., 1990). Dissemination from pet fish and immunocompromised granulomas was observed. In humans, it presents as granulomas, abscesses and in severe cases tenosynovitis, bursitis, arthritis and osteomyelitis.

\section{[MYCOBACTERIUM AVIUM COMPLEX (MAC)]}

Mycobacterium avium complex includes the following species: M. avium, M. avium paratuberculosis, $M$. avium silvaticum, $M$. avium "hominissuis" and M. colombiense. M. avium is the main agent of tuberculosis in birds and possibly connected to human infection too (Chiodini and Rossiter, 1996). 


\section{[MYCOBACTERIUM ULCERANS]}

M. ulcerans is a slow-growing mycobacterium infecting the skin and subcutaneous tissues producing nodules/plaques and ulcerated lesions (Buruli ulcer) reported mostly in wetlands areas of tropical or subtropical countries (Uganda Buruli Group, 1971). It is the third most common mycobacteriosis after tuberculosis and leprosy in humans and animals (broad host range such as koalas, possums in Australia, lizards, amphibians, chick embryos, armadillos, rats, mice, captive alpaca and cattle) (Portaels et al., 2001). Focal outbreaks were connected to flooding, human migrations and man-made topographic modifications such as dams and resorts. Deforestation and increased basic agricultural activities may have significantly contributed to the recent marked increases in incidences of $M$. ulcerans infections with rapid emergence, especially in West Africa.

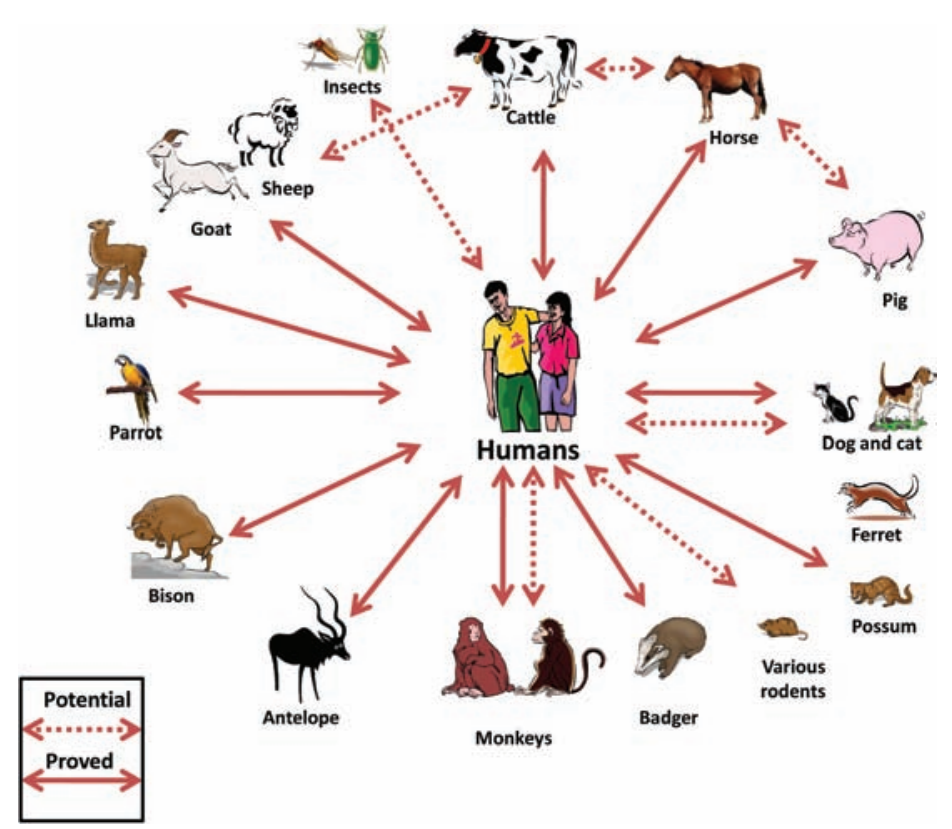

Figure 2.15.1. Mycobacteria spp. transmission from animals to humans

\subsubsection{MYCOBACTERIUM AND ENVIRONMENT}

Mycobacteria are known for their enhanced survival ability under adverse environmental conditions (dust and dried respiratory secretions). However, it is not clear what the exact mechanism that protects these pathogens in external environment of human and animal bodies is. It should be mentioned that there is a large group of Mycabacteria comprising saprophytic species (atypical/ non-tuberculous mycobacteria) that are mainly non-pathogenic or only occasionally pathogenic. There are many reports on the isolation of environmental Mycobacteria from soil, bogs, surface water, ground water and sea water as natural habitats (Norby et al., 2007; Tsintzou et al., 2000; LeChevallier et al., 2000; Young et al., 2005). However, till now there have been no reports of $M$. tuberculosis complex isolations from environmental sources but solely reports of infections through direct contact with infected domestic or wildlife animals 
(including their excretions such as sputum, urine, milk and feces), consumption of uncooked milk or meat from tuberculous animals and inhalation of droplets when in contact with ill persons or animals (O'Reilly and Daborn, 1995). Historically, based on genetic evidence, the common ancestor of the causative agents of tuberculosis emerged 40,000 years in East Africa, an area from which the modern human population disseminated around the world, too. Between 10,000 and to 20,000 years later the pathogen split into two major lineages: one which infects humanoids and a second which spread from human to animals. In recent times ( $\sim 180$ years ago), with overlapping human population expansion and industrial revolution, the human-associated pathogen lineages expanded (Wirth et al., 2008). Some authors also indicated an additional direction that may impact these pathogens' persistence besides demographic expansion, especially in crowded cities (e.g., bacterial dormancy) (Shleeva et al., 2010). The dormancy state of bacterial pathogens expresses itself by a drastic decrease of metabolic activity, enhanced resistance to harmful factors, and absence of cell division, all increasing its survival potential under unfavorable environmental conditions (Archuleta et al., 2005). Several in vitro models, including prolonged hypoxic incubation in the post-stationary phase or under microaerophilic conditions after rifampicin treatment, demonstrated that viable cells of $M$. tuberculosis are capable of transition to a "non-culturable" state and that their colony forming capacity may be restored by special procedures (Sun and Zhang, 1999; Hu et al., 2000). Whether these reports are correct or biased, the persistence of non-spore forming $M$. tuberculosis complex in less populated areas requires further research efforts.

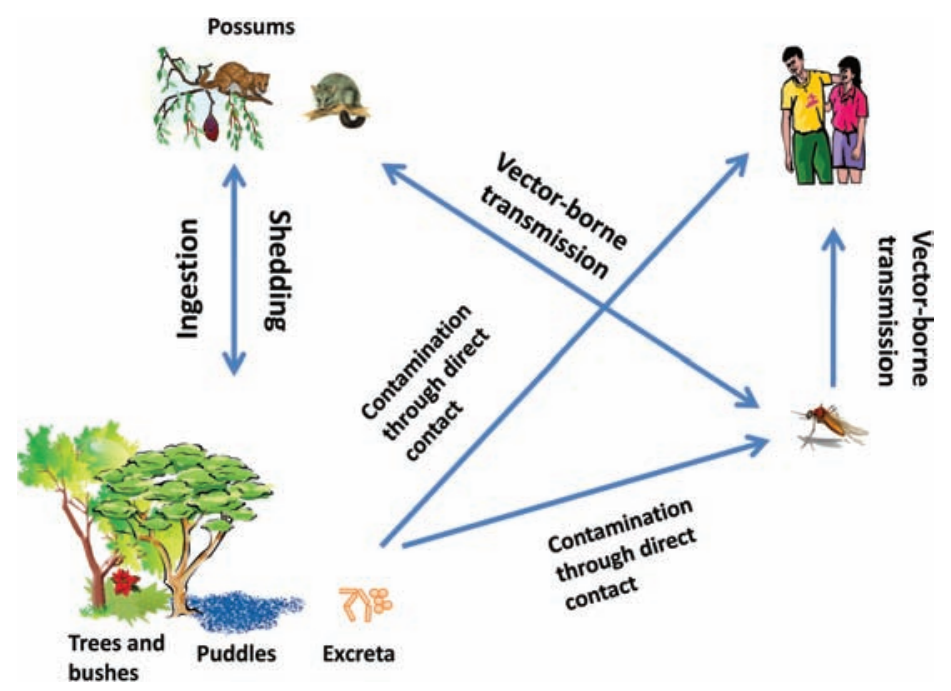

Figure 2.15.2. Suggested potential transmission routes of $M$. ulcerans shared by environment, possums, mosquitoes and humans

Finally, one should ask oneself whether this pathogen is present in the blood of infected animals there is any possible transfection through blood feeding insects such as mosquitoes, ticks, etc. Allen (1987) showed that fecal pellets (kept at room temperature) of an oriental cockroach that ingested heat-fixed sputum smears of viable $M$. tuberculosis intended for microscopic examination were positive for viable bacteria for up to 8 weeks. Fischer et al. (2003) infected experimentally nymphs of the same oriental cockroach (Blatta orientalis) with $M$. avium ssp. paratuberculosis and the avian tuberculosis M. avium ssp. avium. Both subspecies were isolated in excreta after 3 days and in homogenized bodies after 10 days. The authors 
indicated a possible viable avian pathogen shedding and transmission, while infected orally. Kovalev (1983) discussed the role of ectoparasites (ticks) and wild birds as circulators, distributors and natural foci of $M$. avium tuberculosis. Furthermore, an aquatic insect predator (Naucoris cimicoides, of the order Hemiptera, genus Nepidae, commonly called waterscorpion) was shown to be infected by M. ulcerans through coelomic plasmatocytes that act as shuttle cells that deliver M. ulcerans to the salivary glands of these insects (Marsollier et al., 2005). This is not a science fiction scenario as our cities surroundings are populated by many insects that have direct contact with humans and animals.

An interesting explanation of M. ulcerans transmission and reservoirs in Australian mammals such as possums (Fyfe et al., 2010) was recently published. The authors through intensive study of fecal content of animals in endemic areas for M. ulcerans, found $41 \%$ positive samples compared to $<1 \%$ in non-endemic areas. These findings indicate terrestrial mammals as additional reservoirs of $M$. ulcerans (Figure 2.15.2).

\subsubsection{REFERENCES}

Allen, B.W. (1987) Excretion of viable tubercle bacilli by Blatta orientalis (the oriental cockroach) following ingestion of heat-fixed sputum smears: a laboratory investigation. Trans. R. Soc. Trop. Med. Hyg. 81, 98-99.

Archuleta, R.J., Hoppes, P.Y. \& Primm, T.P. (2005) Mycobacterium avium enters a state of metabolic dormancy in response to starvation. Tuber $\mathbf{8 5}, 147-158$.

Aronson, J. D. (1926). Spontaneous tuberculosis in salt water fish. J. Infect. Dis. 39, 314-320.

Chiodini, R.J. \& Rossiter, C.A. (1996) Paratuberculosis: a potential zoonosis ? Vet. Clin. N. Am. Food Anim. Pract. 12, 457-467.

Fischer, O.A., Matlova, L. Dvorska, L., Svastova, P. \& Pavlik, I. (2003) Nymphs of the Oriental cockroach (Blatta orientalis) as passive vectors of causal agents of avian tuberculosis and paratuberculosis. Med. Vet. Entomol. 17, $145-150$.

Fyfe, J.A.M., Lavender, C.J., Handasyde, K.A., Legione. A.R., O’Brien. C.R. et al. (2010) A major role for mammals in the ecology of Mycobacterium ulcerans. PLoS Negl Trop Dis 4 (8): e791. doi:10.1371/journal.pntd.0000791.

Gray, S.F., Smith, R.S., Reynolds, N.J. \& Williams, E.W. (1990) Fish tank granuloma. Br. Med. J. 300, 1069-1070.

Hu, Y.M., Mangan, J.A., Dhillon, J., Sole, K.M., Mitchison, D.A. et al. (2000) Detection of mRNA transcripts and active transcription in persistent Mycobacterium tuberculosis induced by exposure to rifampin or pyrazinamide. J. Bacteriol. 182, 6358-6365.

Kovalev, G.K. (1983) The role of wild birds and their ectoparasites (ticks) in the circulation and distribution of M. avium and possible formation of natural foci of avian tuberculosis. J Hyg Epidemiol Microbiol Immunol 27, 281-288.

LeChevallier, M.W., Norton, C.D., Falkinham, J.O.-III, Williams, M.D. \& Taylor, R.H. (2000) Mycobacterium avium complex in drinking water. Proceedings - Annual Conference, American Water Works Association, 777-788.

Marsollier, L., Aubry, J., Coutanceau, E., Saint Andre, J-P., Small, P.L. et al. (2005) Colonization of the salivary glands of Naucoris cimicoides by Mycobacterium ulcerans requires host plasmatocytes and a macrolide toxin, mycolactone. Cell. Microbiol. 7, 935-943.

Mycobacteria in drinking water distribution systems: ecology and significance for human health. FEMS Microbiol. Rev. 29, 911-934.

Norby, B., Fosgate, G.T., Manning, E.J.B., Collins, M.T. \& Roussel, A.J. (2007) Environmental mycobacteria in soil and water on beef ranches: association between presence of cultivable mycobacteria and soil and water physicochemical characteristics. Vet. Microbiol. 124, 153-159.

O'Reilly, L.M. \& Daborn, C.J. (1995) The epidemiology of Mycobacyterium bovis infections in animals and man: a review. Tuber. Lung Dis. 76, 1-46.

Portaels, F., Chemlal, K., Elsen, P., Johnson, P.D., Hayman, J.A., Hibble, J., Kirkwood, R. \& Meyers, W. M. (2001) Mycobacterium ulcerans in wild animals. Rev. - Off. Int. Epizoot. 20, 252-264.

Shleeva, M.O., Salina, E.G. \& Kaprelyants, A.S. (2010) Dormant forms of Mycobacteria. Mikrobiologiya 79, 1-12. 
Sun, Z. \& Zhang, Y., (1999) Spent culture supernatant of Mycobacterium tuberculosis H37Ra improves viability of aged cultures of this strain and allows small inocula to initiate growth. J. Bacteriol. 181, 7626-7628.

Tsintzou, A., Vantarakis, A., Pagonopoulou, O., Athanassiadou, A. \& Papapetropoulou, M. (2000) Environmental mycobacteria in drinking water before and after replacement of the water distribution network. Water, Air, and Soil Pollution 120, 273-282.

Uganda Buruli Group (1971) Epidemiology of Mycobacterium ulcerans infection (Buruli ulcer) at Kinyara, Uganda. Trans R Soc Trop Med Hyg 65: 763-775.

Vaerewijck, M.J.M., Huys, G., Palomino, J.C., Swings, J. \& Portaels, F. (2005) Mycobacteria in drinking water distribution systems: ecology and significance for human health. FEMS Microbiol. Rev. 29, 911-934.

Wirth, T., Hildebrand, F., Allix-Béguec, C., Wölbeling, F., Kubica, T. et al. (2008) Origin, spread and demography of the Mycobacterium tuberculosis complex. PLoS Pathog 4(9): e1000160. doi:10.1371/journal.ppat.1000160.

Young, J.S., Gormley, E., \& Wellington, E.M.H. (2005) Molecular detection of Mycobacterium bovis and Mycobacterium bovis BCG (Pasteur) in soil. Appl. Environ. Microbiol. 71, 1946-1952. 


\section{Chapter 2.16}

\section{Pasteurelloses}

\section{[PASTEURELLA MULTOCIDA]}

Pasteurella multocida is a non-motile gram-negative cocobacillus (pleomorphic) facultative anaerobe that forms capsules. Pasteurella multocida strains based on capsule antigens are divided into 5 serogroups (A, B, D, E and F) and later classified into 16 serotypes (1-16) based primarily on lipopolysaccharide antigens (Carter, 1955; Heddleston et al., 1972). Other closely related species are: P. dagmatis, P. canis, P. caballi, $P$. stomatis, and P. haemolytica. Pasteurella can be found in wild and domestic animals (including pets and zoo animals) and even more exotic ones such as tortoises (Koch et al., 1996; Snipes et al., 1980).

Transmission from animals to humans is mainly through scratches or bites from carrier pets and other animals with which they come in contact (Garcia, 1997). The disease manifests itself as skin/subcutaneous septic phlegmon, edema, pain, fever, vomiting, headache, diarrhea, lymphangitis and rarely sepsis, pneumonia, meningitis and endocarditis.

\subsubsection{PASTEURELLA AND ENVIRONMENT (FIGURE 2.16.1)}

In humans, numerous reported cases revealed that $P$. multocidas' source is domestic or wild carrier animals (e.g., pets such as dogs and cats) based on a correlation between applied antibiotics in animal farms and these airborne bacteria's resistance to these specific antibiotics. According to an aerosol spread study, the authors concluded that a 250 to $500 \mathrm{~m}$ radius from source is an area of increased risk of infection mainly by dust as the bacteria carrier (Muller and Dinter, 1988). Water has been also shown to carry this pathogen. In an outbreak in Nebraska, besides carcasses of dead waterfowls, water samples from several wetlands were found positive for the presence of P. multocida (Price \& Brand, 1984). In terms of time, Blanchong et al. (2006) suggested that $P$. multocida, in spite of its presence in wetland, was not isolated after 7 weeks since the initial outbreak, indicating that wetlands are unlikely to serve as a long-term reservoir for $P$. multocida. P. multocida was isolated even from dental unit waterlines, making direct contamination through open dental procedures a possible health risk (Göksay et al., 2008). Lane et al. (1992) reported an outbreak of Pasteurollosis in cattle due to sewage and effluents flood irrigation of grass pastures following earlier excessive rain and cold weather. Bredy and Botzler (1989) tested experimentally the survival of P. multocida in water under various conditions: protein and sucrose content, $\mathrm{pH}$, temperature, $\mathrm{NaCl}$ and 
clay. $P$. multocida was found to survive the longest time period of $>1$ year under increased protein (175 $\mathrm{mg} / \mathrm{ml})$ and $\mathrm{NaCl}(>0.5 \%)$ presence. Other parameters such as clay, sucrose and $\mathrm{pH}$ did not play a significant role in the bacteria's survival. An interesting observation, supported by other studies, showed a rapid decline of this pathogen at low temperature $\left(<3^{\circ} \mathrm{C}\right)$. Temperature dependent survival was in accordance with other reports that showed growth of this pathogen between 12 to $43^{\circ} \mathrm{C}$ (Wilson \& Miles, 1975). In contrast, $P$. multocida inoculated in soil was shown to survive best at $3^{\circ} \mathrm{C}$ (Dimov, 1964). Winter is the main season of waterfowl infection and death, which is at odds with this pathogen's survival data at low temperatures. Some explanations for this discrepancy were presented based on a large quantity of excreted bacteria and high density of waterfowl in close proximity. However it should be remembered that the external temperature of these avians' skin is much higher than $3^{\circ} \mathrm{C}$ and the attached bacteria can survive for prolonged time periods. Another point that possibly explains this inconsistency is the divergence between soil, water and bacteria interactions. Bacteria are able to form biofilms on soil particles that increase their viability compared to the water free-state in which microorganisms are much more vulnerable (Armon et al., 1997). However, the species Pasteurella haemolytica have been isolated from grass, water and straw bedding samples collected from two grazing fields in use by sheep, and from ewes affected with mastitis. $P$. haemolytica supported by colder, wetter weather had prolonged survival time in environment, data confirmed also by laboratory experiments with distilled water, phosphate-buffered saline, Todd-Hewitt broth and ewe's milk kept at $4^{\circ} \mathrm{C}$ (Burriel, 1997). Ytrehus et al. (2008) reported on a Musk ox's fatal epizootic pneumonia outbreak (caused by $P$. multocida), triggered by extraordinary weather conditions, characterized by high temperatures and humidity, a pattern directly linked to global warming. According to these authors, these unusual conditions seem to modify musk ox susceptibility to infection being the decisive factors in the disease outbreak.

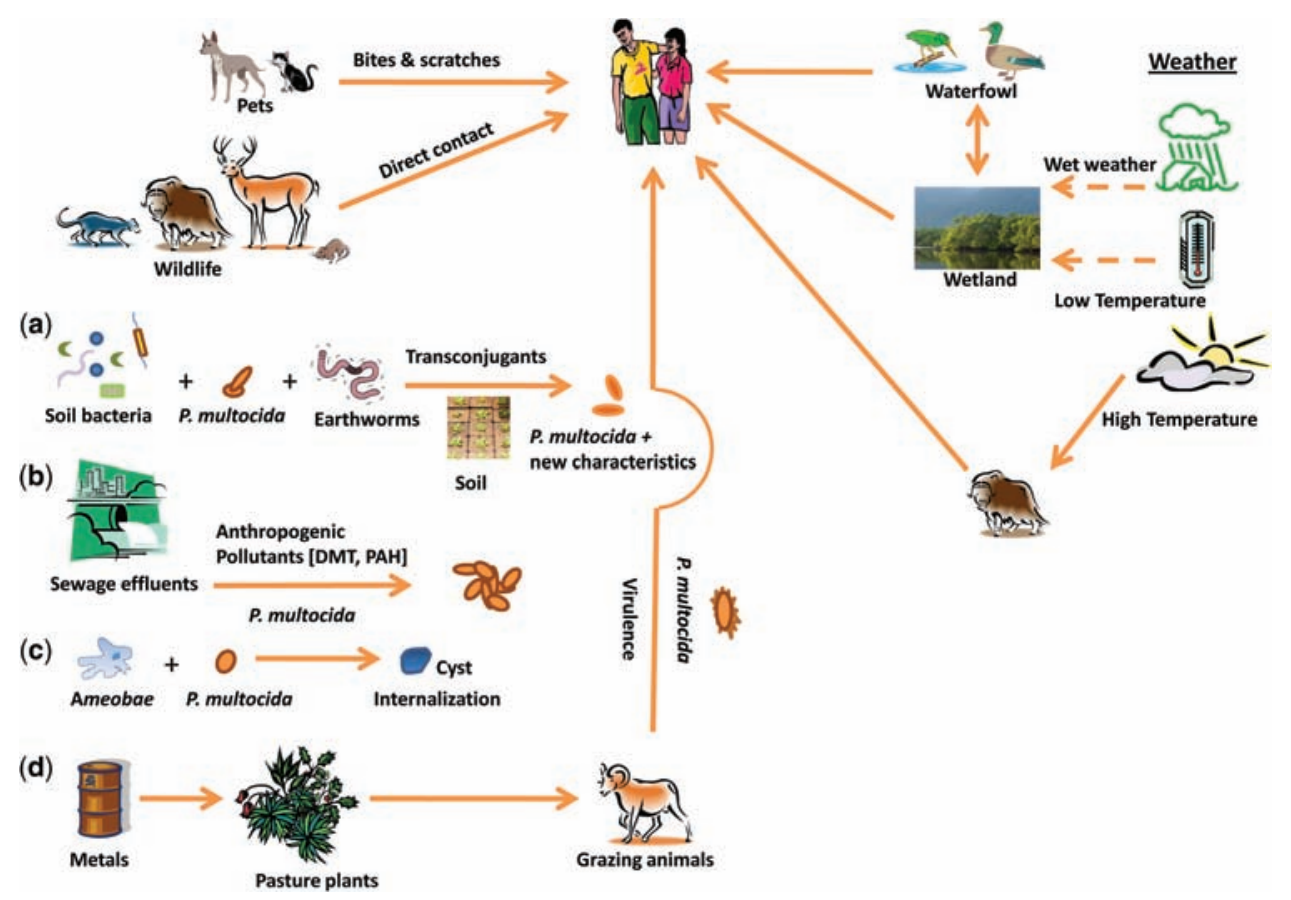

Figure 2.16.1. Pasteurella multocida infection cycle and possible environmental entangled factors 
A P. multocida strain isolated from mangrove sediment was reported to biodegrade a certain chemical, dimethyl terephthalate (DMT), commonly used in polyester production (Li \& Gu, 2006). Another Pasteurella spp. isolated from activated sludge was reported to biodegrade polyaromatic hydrocarbons (PAHs) such as phenanthrene, fluoranthene and pyrene (Sěpič et al., 1997, 1998). Recently, a Pasteurella sp. was reported to be able to multiply in soils contaminated with cadmium. This particular species precipitated $\mathrm{Cd}^{+2}$ in the form of $\mathrm{CdCO}_{3}$ in these cadmium contaminated soils (Li et al., 2010). In connection with this biochemical characteristic, Russian scientists studied large areas including the semi-desert and desert areas of Kazakhstan and Uzbekistan, as well as the steppe and forest-steppe regions of Russia and Mongolia for a relationship between infections and environmental chemistry where plague epizootics occur. In relation to Pasteurella and other microbial pathogens, they found an increased pathogenicity well correlated to several metallic elements present in pasture plants, such as $\mathrm{Ti}$, $\mathrm{V}, \mathrm{Cr}, \mathrm{Mn}, \mathrm{Fe}, \mathrm{Co}, \mathrm{Ni}, \mathrm{Cu}, \mathrm{Zn}, \mathrm{Mo}, \mathrm{Cd}$ and $\mathrm{Pb}$. Excess of Mo in animals is known to intensify the removal of $\mathrm{Cu}$ from their organisms, and increased concentrations of $\mathrm{Pb}$ and $\mathrm{Zn}$ intensify the displacement of $\mathrm{Cu}$ (also recorded during the epizootic). Therefore it is logical that ungulates feeding on vegetation exceptionally rich in $\mathrm{Mo}, \mathrm{Pb}$, and $\mathrm{Zn}$ will experience a considerable shortage of $\mathrm{Cu}$ (observed in all the plague outbreaks studied) (Rotshild, 1996; Rotshild and Zhulidov, 2000). Based on these assumption, these authors suggested the following explanation related to plant chemistry and epizootics: pathogens that survive in environment through soil saprophytic cycle, water and their host bodies (asymptomatic) having enough nutrients including trace elements for their survival and multiplication however, when deprived of some elements (e.g., Fe) they compete with their host through activation of some hidden pathogenic attributes expressing their virulence and initiating disease. This theory sounds plausible; however, there are additional questions to be verified before its acceptance, such as: a) Does excess metals impair host immunology therefore favoring already opportunistic pathogens to prevail?; b) Do certain metals have an effect on pathogens virulence genes' expression? c) Do excess metals in plants impact their biochemistry in such a way that plants as food in turn impact animals immune system? Botzler (1991) in a review on epizootiology of $P$. multocida in wildfowl (infecting more than 100 species of free-living birds), described the disproportionate mortality and year-round disease periodicity. The survival of $P$. multocida seems to be significantly linked to the presence of animal organic matter in soil and water. Another important factor involved in the persistence of this pathogen in enzootic areas, as pointed out by this author, is the availability of carrier animals. Daane et al. (1996) showed that selected terrestrial earthworm species enhance gene transfer between different bacteria present in soil. Using Pseudomonas fluorescens harboring the plasmid pJP4 [Pseudomonas fluorescens C5t (pJP4)], the authors showed that among a large variety of successful transconjugant indigenous soil microorganisms were also Pasteurella spp.. This important study strongly supports an already published report on earthworms' role in soil pathogenic bacteria spread and possible enhancement of virulence transfer through their burrowing, casting, and feeding behaviors (Schuch and Fischetti, 2009). There is increasing evidences of a large variety of microbial pathogens interaction with free-living amoebae ubiquitous in water and soil environments. Hundt and Ruffolo (2005) showed experimental amoebae infection using a particular P. multocida sp. harboring green fluorescent protein (GFP) expression. In vitro, their results showed that this $P$. multocida sp. can invade and survive, replicate, and lyse in the amoebal host with a possible related occurrence in vivo.

\subsubsection{REFERENCES}

Armon, R., Starosvetzky, J., Arbel, T., Green, M. (1997) Survival of Legionella pneumophila and Salmonella typhimurium in biofilm systems. Water Sci. Technol. 35, 293-300. 
Blanchong, J.A., Samuel, M.D., Goldberg, D.R., Shadduck, D.J. \& Lehr, M.A. (2006) Persistence of Pasteurella multocida in wetlands following avian cholera outbreaks. J. Wildl. Dis. 42, 33-39.

Botzler, R.G. (1991) Epizootiology of avian cholera in wildfowl. J. Wildl. Dis. 27, 367-395.

Bredy, J.P. \& Botzler, R.G. (1989) The effects of six environmental variables on Pasteurella multocida populations in water. J. Wildl. Dis. 25, 232-239.

Burriel, A.R. (1997) Isolation of Pasteurella haemolytica from grass, drinking water, and straw bedding used by sheep. Curr. Microbiol. 35, 316-318.

Carter, G.R. (1955) Studies on Pasteurella multocida I. A haemagglutination test for the identification of serological types. Am J Vet Res 16, 481-484.

Daane, L.L., Molina, J. A. E., Berry, E. C. \& Sadowsky, M. J. (1996) Influence of earthworm activity on gene transfer from Pseudomonas fluorescens to indigenous soil bacteria. Appl. Environ. Microbiol. 62, 515-521..

Dimov, I. (1964) Survival of avian Pasteurella multocida in soils at different acidity, humidity and temperature. Nauchni Tr Vissh Veterinarnorgo-Med. Inst Sofia 12, 339-345.

Garcia, V.F. (1997) Animal bites and Pasturella infections. Pediatr. Rev. 18, 127-130..

Göksay, D., Çotuk, A \& Zeybek, Z. (2008) Microbial contamination of dental unit waterlines in Istanbul, Turkey. Environ Monit Assess 147, 265-269.

Harper, M., Boyce, J.D. \& Adler, B. (2006) Pasteurella multocida pathogenesis: 125 years after Pasteur. FEMS Microbiol Lett 265, 1-10.

Heddleston, K.L., Gallagher, J.E. \& Rebers, P.A. (1972) Fowl cholera: gel diffusion precipitin test for serotyping Pasteurella multocida from avian species. Avian Dis 16, 925-936.

Hundt, M.J. \& Ruffolo, C.G. (2005) Interaction of Pasteurella multocida with free-living amoebae. Appl. Environ. Microbiol. 71, 5458-5464.

Jiaxi Li, J. \& Gu, J-D. (2006) Biodegradation of dimethyl terephthalate by Pasteurella multocida Sa follows an alternative biochemical pathway. Ecotoxicology 15, 391-397.

Koch, C.A., Mabee, C.L., Robyn, J.A., Koletar, S.L. \& Metz, E.N. (1996) Exposure to domestic cats: risk factor for Pasteurella multocida peritonitis in liver cirrhosis? Am. J. Gastroenterol. 91, 1447-1449.

Lane, E.P., Kock, N.D., Hill, F.W.G. \& Mohan, K. (1992) An outbreak of haemorrhagic septicemia (septicaemic Pasteurellosis) in cattle in Zimbabwe. Trop. Anim. Hlth Prod. 24, 97-102.

Li, L., Qian, C., Cheng, L. \& Wang, R. (2010) A laboratory investigation of microbe-inducing $\mathrm{CdCO}_{3}$ precipitate treatment in $\mathrm{Cd}^{2+}$ contaminated soil. J. Soils Sediments 10, 248-254.

Mezentsev, V.M., Rotshild, E.V., Medzykhovsky, G.A. \& Grazhdanov, A.K. (2000) Experimental study of the influence of trace elements on the infectious process in plague. Zh. Mikrobiol. Epidemiol. Immunobiol. 1, 41-45.

Muller, W. \& Dinter, P.S. (1988) The survival ability of pasteurella in the environment with special reference to the airborne situation. Tierarztl Prax Suppl 3, 16-20.

Price, J.I. \& Brand, C.J. (1984) Persistance of Pasteurella multocida in Nebraska wetlands under epizootic conditions. J. Wildl. Dis. 20, 90-94.

Rotshild, E.V. \& Zhulidov, A.V. (2000) Changes in the concentrations of trace elements in plants as a factor of a plague epizootic in gerbils. (In Russian). Biull Mosk Ova Ispyt Prir (Biol) 105, 10-20.

Rotshild, E.V. (1996) Disease and environment. Correlations between trace metals in plants and infectious diseases in wild animals. Science Spectra 6, 48-54.

Sěpič, E., Bricelj, M. \& H. Leskovsěk, H. (1997) Biodegradation studies of polyaromatic hydrocarbons in aqueous media. J. Appl. Microbiol. 83, 561-568.

Sěpič, E., Bricelj, M. \& Leskovsěk, H. (1998) Degradation of fluoranthene by Pasteurella sp. IFA and Mycobacterium sp. PYR-1: isolation and identification of metabolites. J. Appl. Microbiol 85, 746-754.

Snipes, K. P., Biberstein, E.L. \& Fowler, M.E. (1980) A Pasteurella sp. associated with respiratory disease in captive desert tortoises. J. Am. Vet. Med. Assoc. 177, 804-807.

Wilson, G.S. \& Miles, A. (1975) Pasteurella septic. In: Topley and Wilson's principles of bacteriology, virology and immunity, Vol.1, Edward Arnold Ltd., London, England, pp. 950-951.

Ytrehus, B. Bretten, T., Bergsjø, B. \& Isaksen, K. (2008) Fatal pneumonia epizootic in Musk Ox (Ovibos moschatus) in a period of extraordinary weather conditions. EcoHealth 5, 213-223. 


\section{Chapter 2.17}

\section{Plague}

\section{[YERSINIA PESTIS]}

Yersinia pestis (formerly Pasteurella pestis) is a gram-negative rod, non-motile, facultative anaerobe of the Enterobacteriaceae family. Microbiologists devide $Y$. pestis into three biovars: Antiqua, Medievalis, and Orientalis that can be distinguished depending on their abilities to ferment glycerol and reduce nitrate (Devignat, 1951). This pathogen is highly virulent with lethal effects, infecting humans and a large variety of animals (cat, dog, coyote, rabbit, camel, bobcat, raccoon, and bear but mainly free-living rodents that are also reinfection reservoirs) (von Reyn et al., 1976, 1976a; Gage et al., 2000; Gould et al., 2008; Clover et al., 1989; Wong et al., 2009). Transmission to humans occurs mainly by rat flea as well by other ectoparasite vector bites (Wimsatt and Biggins, 2009) however, direct transmission through cat bite was also reported (Thornton et al., 1975). Y. pestis infection has three clinical forms: pneumonic, septicemic, and the infamous bubonic plagues (connected to human demographic history). The disease expresses itself according to entry portal as follows: a) bubonic plague - fever, chills, headache, myalgias, malaise, lymphoadenopathy, septicemia, tachycardia, renal failure, gangrene, chest pain and death; b) primary pneumonic - fever, headache, myalgias, pulmonary signs (chest pain, cough, dyspnea, hypotension) and cardiac failure with $\sim 20 \%$ death rate in spite of early antibiotic treatment; c) septicemic - gastrointestinal symptoms (abdominal pain, diarrhea, vomiting, nausea), hypotension, acute respiratory distress syndrome (ARDS), intravascular coagulation, organ failure with 50\% death rate (without treatment) and $<5 \%$ (with early antibiotic treatment).

\subsubsection{YERSINIA PESTIS AND ENVIRONMENT}

It can be stated with a high percentage of confidence that plague is the most "historic" zoonotic disease with the greatest devastating impact on human population. The first records originate from the 6th century, when it was called the "Plague of Justinian" after the emperor Justinian I himself who was also infected but survived the epidemic (McCormick, 2007). The second large, devastating epidemic occurred in the 14th century in Europe and China (along the Yangtse river valley) under the name of "Great Pestilence or Plague", while the name "Black Death" was set later in the 16th century in Nordic chronicles. The origin 
seems to be the Gobi desert through fleas and rats that spread along trade routes (Crimea as one of the main ports) to Constantinople, Alexandria and further toward Western Europe (Haensch et al., 2010) (Figure 2.17.1). The 14th century death toll have been estimated to be between 75 and 200 million people (Gage, 1998). In the next centuries, outbreaks occurred more locally in larger cities such as: Seville (Spain), London (UK), Vienna, (Austria) (17th century) and Marseille (18th century). More recent cases occurred in 1994 in northern Peru with 1,104 cases and 35 deaths and sporadic cases have occurred in the 21st century (Anonymous, 2004). In North America, Y. pestis was introduced around 1900, by rat-infested ships from Asia; evidence is supported by molecular studies revealing the strains similarity (Guiyoule et al., 1994; Pollitzer, 1954).

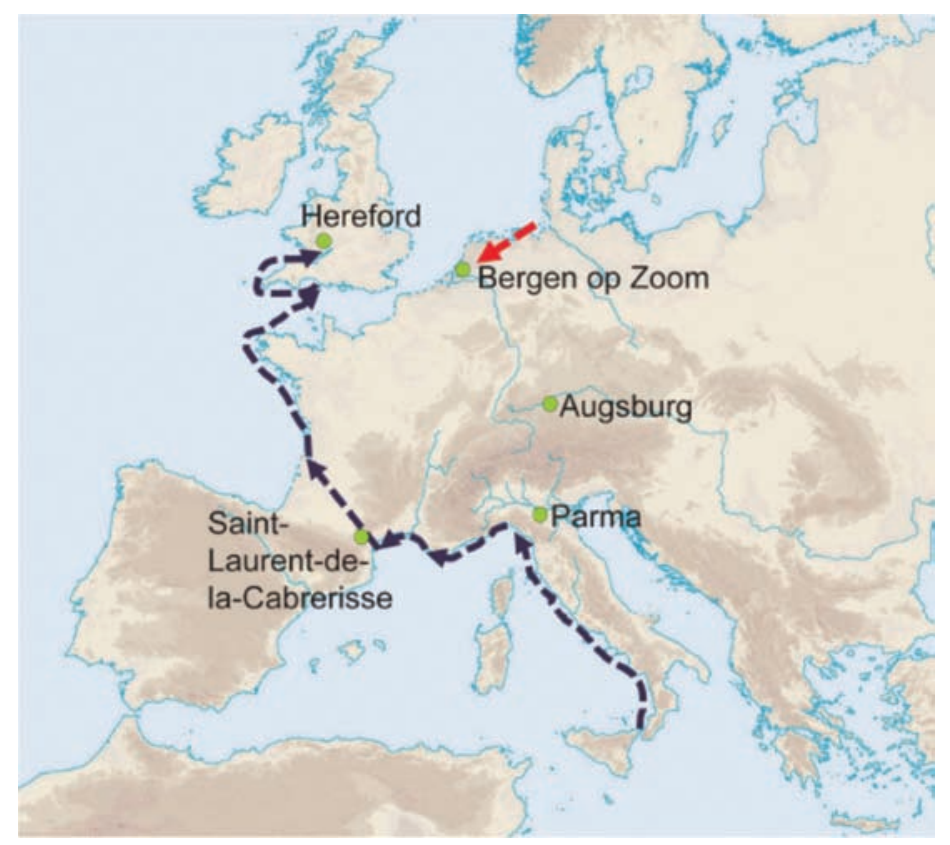

Figure 2.17.1. European sites where human skeletons from mass graves were analyzed for aDNA (ancient DNA) and F1 protein capsule antigen and found positive for $Y$. pestis and possible routes of plague spread (from: Haensch, S., Bianucci, R., Signoli, M., Rajerison, M., Schultz, M., et al. (2010) Distinct Clones of Yersinia pestis Caused the Black Death. PLoS Pathog 6(10):e1001134. doi:10.1371/journal.ppat.1001134.)

In relation to $Y$. pestis transmission path, when looking at environmental impact one should concentrate first on the two main parameters: rodents (as reservoir) and fleas (as vectors) and how these two main modules are affected by different climatic, geographic or anthropogenic factors (Mann et al., 1979; Gage and Kosoy, 2005). Primarily, both rodents and flies are much more effective in disease transmission due to their large litter size and reproduction capability, secondly, they have been in close proximity to human habitation from the early stages of human history.

Pham et al. (2009) correlated (using Poisson regression model) data on domestic fleas and rodents, temperature, sunshine duration, rainfall, humidity and plague incidents in the central part of Vietnam already recognized as an endemic area. These authors found a strong correlation between the dry season periods and plague cases, expressed in a high flea index and rodent density during hot and dry months. 
They hypothesized, that rainy weather reduces flea population through fungal, bacterial and viral increased susceptibility and decreased mobility. The same applies to the rodent population that increases according to food cascade during the tropical summer season. However, it should be mentioned that during dry seasons when rodent's food is in shorter supply, they will consequently scatter in search of food toward intensely populated areas, hence increasing plague spread (Figure 2.17.2). Parmenter et al., (1999) in a different geographic area, an arid zone (New Mexico) found an increased occurrence of human plague cases $(>60 \%)$ significantly correlated to winter-spring periods of above-average precipitation. Their analysis was performed at three spatial scales: 1) global (El Niño-Southern Oscillation Indices [SOI]), 2) regional (pooled state-wide precipitation averages) and 3) local (precipitation data from weather stations near plague case sites). The local scale was the only one that revealed a significant correlation, being explained by topical characteristics of mammal and flea populations' ecology that will respond to increased moisture only if it actually occurs in their immediate vicinity.

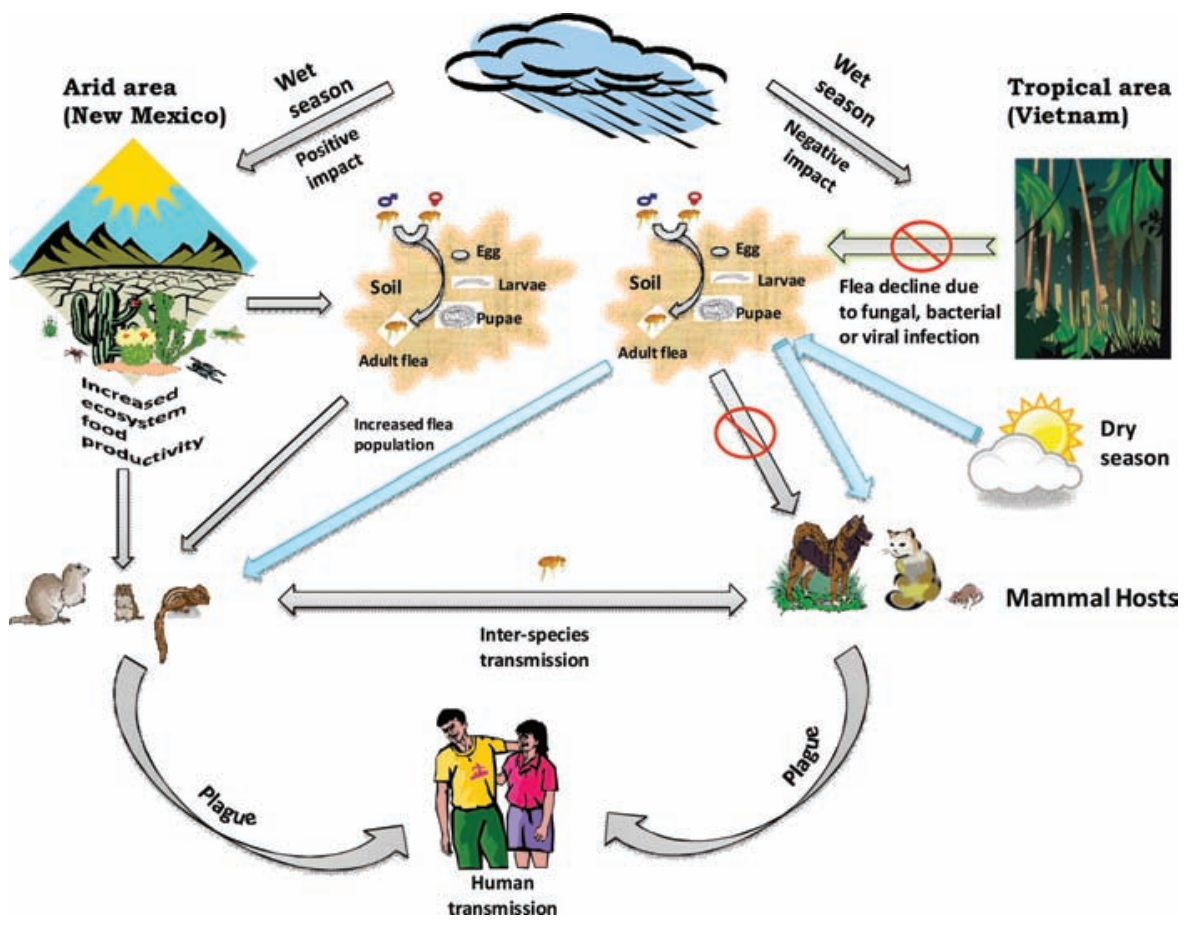

Figure 2.17.2. Ecological aspects of weather, soil, fleas and animals in human infection with Y. pestis

Davis (1953) reviewed plague history in Africa for the period of 1935-1949 and observed that seasonal incidence of human plague is strongly related to atmospheric conditions (temperature and rainfall) being more frequent in warm moist weather $\left(15-27^{\circ} \mathrm{C}\right)$ than in hot dry, or cold, weather $>27^{\circ} \mathrm{C}$ or $<15^{\circ} \mathrm{C}$. Highlands of equatorial Africa and of Madagascar appear to provide the optimum environment for the persistence of plague on the domestic plane (murine) and the high-veld and Kalahari of southern Africa on the sylvatic plane. Within these areas, Yersinia pestis finds an environment suitable for its continued survival where conditions seem to be comparable to those in endemic centers such as India. 
Ten strains of Yersinia pestis were tested for static growth at $4{ }^{\circ} \mathrm{C}$ when incubated in heart-infusion broth (Torosian et al., 2009). Nine out of the ten strains were able to grow slowly and the shortest doubling times ranged from 13.5 to 22.16 hours. These results are important showing that $Y$. pestis can grow in rich media or in this case inside putrefying meat even at a low temperature.

On the other hand, Kartman (1969) showed experimentally that temperature has a profound effect upon vector potential and the capacity of fleas infected with $Y$. pestis being optimal at $23.5^{\circ} \mathrm{C}$ and much decreased at 4 or $29^{\circ} \mathrm{C}$. These conclusions were drawn based on the successful pathogen proventricular blocking mechanism of the flea and flea longevity, and its resultant vectorial capacity at these temperatures (Bacot and Martin, 1914). The flea blocking mechanism is an exciting phenomenon described almost 100 years ago, which explains how fleas transmit $Y$. pestis (Figure 2.17.3). Briefly, the initial flea (a) with some blood residual in its stomach, having sucked from rodent uninfected with $Y$. pestis attaches this time to a new infected host and starts to suck in order to feed itself. Bacteria from infected blood colonize the proventriculus (PV) and the stomach (c) till both organs are distended with $Y$. pestis culture and partially digested blood (b). Under these conditions, a plug is formed in the proventriculus due to the gelatinous texture of blood-bacteria semi-digested complex (d) that blocks new sucked blood from entering the flea's digestive system, causing the flea to suffer from thirst and thus persist in its efforts to satisfy itself, without much success. The infected blood in the distended oesophagus may flow out again and infect a new host, on cessation of the sucking act when the insect withdraw its proboscis (sucking organ).

(a)

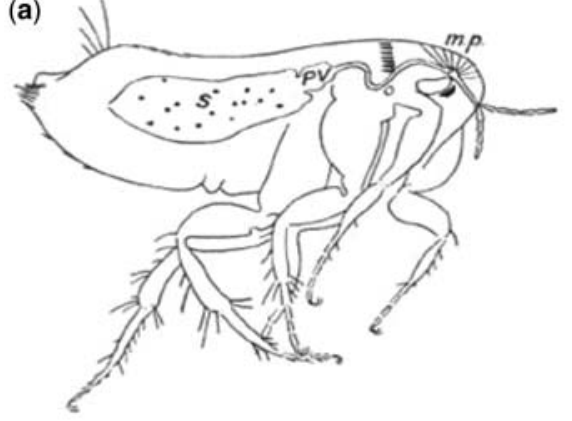

(c)

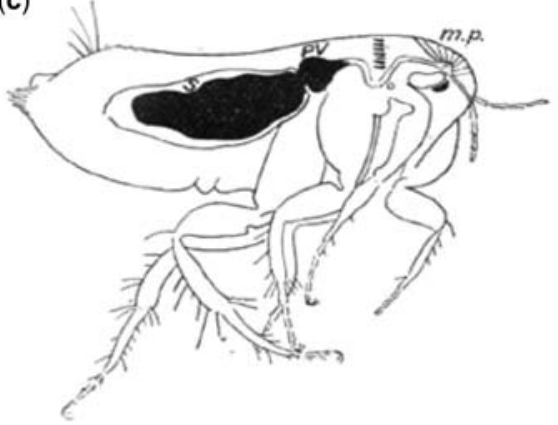

(b)

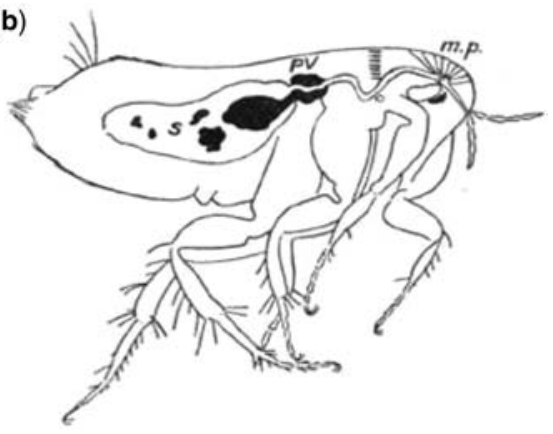

(d)

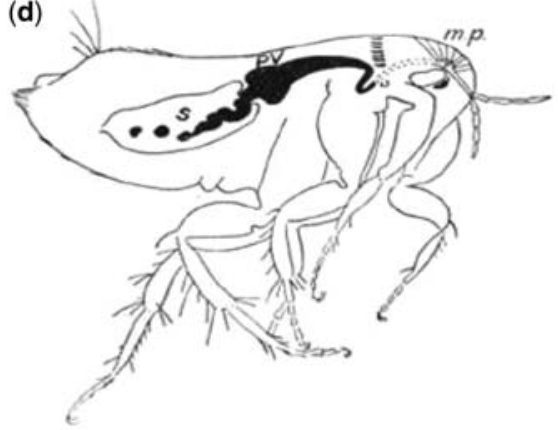

Figure 2.17.3. Flea proventricular blocking mechanism that explains $Y$. pestis animal transmission by this vector [adapted with permission from Bacot and Martin, 1914, J Hyg (Lond)] 
Another temperature related aspect was published by Zharinova et al. (2008) concerning fleas (from Caucasian mountain plague foci) co-infected with $Y$. pestis and Listeria. The dual infection revealed antagonism between the two pathogens: at $4^{\circ} \mathrm{C} \mathrm{Y}$. pestis took over Listeria while $18-20^{\circ} \mathrm{C}$ favored Listeria over $Y$. pestis. According to these authors, it cannot be excluded that such a dual-infection might occur in this environment (in mountain sousliks under natural conditions) it may also explain the suppressed vector activity of fleas spreading plague at the above temperatures.

In another report by Wild et al. (2006), in which Canadian lynxes (129 individuals) were reintroduced in a program of species recovery in southwestern Colorado for a period of 4 years, $Y$. pestis was involved in high mortality. Among 52 dead individuals, 6 were diagnosed with pneumonic Y. pestis and one with bubonic. The authors suggested that these carnivores were possibly exposed to infected prey.

Snäll et al. (2008) using a Bayesian hierarchical model on the black-tailed prairie dog, showed that the rate of plague transmission between this rodent's colonies increased with increasing precipitation (that increases primary productivity as a result of more rodents and fleas, as shown before) and decreased with increasing topographic relief (ravines between colonies) (in spite of the fact that ravines facilitate prairie dog colonies dispersal, implying another animal carrier between colonies) and that the rate of infection from unknown sources decreased with hot weather (negative effects of heat on fleas). The authors suggested other likely plague carriers such as large carnivores that can carry diseases tens of kilometers in a year while feeding on infected prey (Smith et al. 2005).

Some reports suggested the possible survival of Y. pestis in soil environment (Mollaret, 1963) even for 10 months at 4 to $8^{\circ} \mathrm{C}$ (Breneva et al., 2006), including internalization in soil protozoa (Pushkareva, 2003), form of latency (viable but not culturable, VBNC) (Suchkov et al., 1997) and plant colonization as already shown with other bacteria, such as Listeria and Salmonella enterica (Rivkus et al., 1993; Litvin, 1997; Girardin et al., 2005; Kroupitski et al., 2009).

In environment, $Y$. pestis is known to have two kinds of episodes: epizootic (disease with large scale spread) and enzootic (disease with local scale spread) that thus far are not yet well understood, especially in terms of how they move to and from, ecologically. Wimsatt and Biggins (2009) reviewed four published hypotheses on epizootic and enzootic episodes' rotation based on sylvatic plague. The first one suggests that " $Y$. pestis have a continuous propagation event of varying velocity (mainly enzootic periods punctuated by irregular epizootic periods) based on continuous supply of naive hosts and vectors (fleas)"; the second one is called "the carrier host hypothesis" and reminds one of the case of "Typhoid Mary", - where an infected individual is carrying the pathogen sequestered within, without clinical syndromes - (Anonymous, 1939), but in the present hypothesis the carrier host becomes septicemic in response to stressors, initiating an epizootic; the third hypothesis is so called " the telluric" based on the potential of $Y$. pestis to survive in soil and enhance its pathogenicity by environmental factors: soil elements, temperature, etc.; and the fourth hypothesis named "the flea reservoir hypothesis" is based on fleas capability to act as reservoirs besides their role as vectors. In their role as reservoirs, fleas were shown to be capable of unblocking themselves for longer periods of time (hence less pathogen transmission) and other environmental factors. Amongst these various hypotheses, the one that seems more adequate is that $Y$. pestis persists at foci by maintaining a more benign relationship within adapted rodents during the long time spans between outbreaks, a relationship influenced by environmental factors such as temperature, rain, soil and plants (Kartman, 1969; Mollaret, 1963; Rivkus et al., 1993; Stapp et al., 2008) (Figure 2.17.4). However, these authors emphasized the potentially pivotal role of fleas, which represent a low level plague reservoir.

Delwiche et al. (1959) studied the growth characteristics of virulent and avirulent strains of Yersinia pestis at $37^{\circ} \mathrm{C}$ under air, nitrogen and $\mathrm{CO}_{2}$ atmospheres. Their results revealed that: (a) under aerobic conditions the avirulent cells outgrew the virulent ones; (b) under nitrogen atmosphere, both virulent and 
avirulent cells grew equally well and the combined culture retained virulence and (c) under $\mathrm{CO}_{2}$ atmosphere, the initial growth rate of both avirulent and virulent cells had been suppressed, although the virulent cells continued to proliferate, maintaining the initial ratio of virulent to avirulent roughly constant, where the culture as a whole retained its virulence for animals.

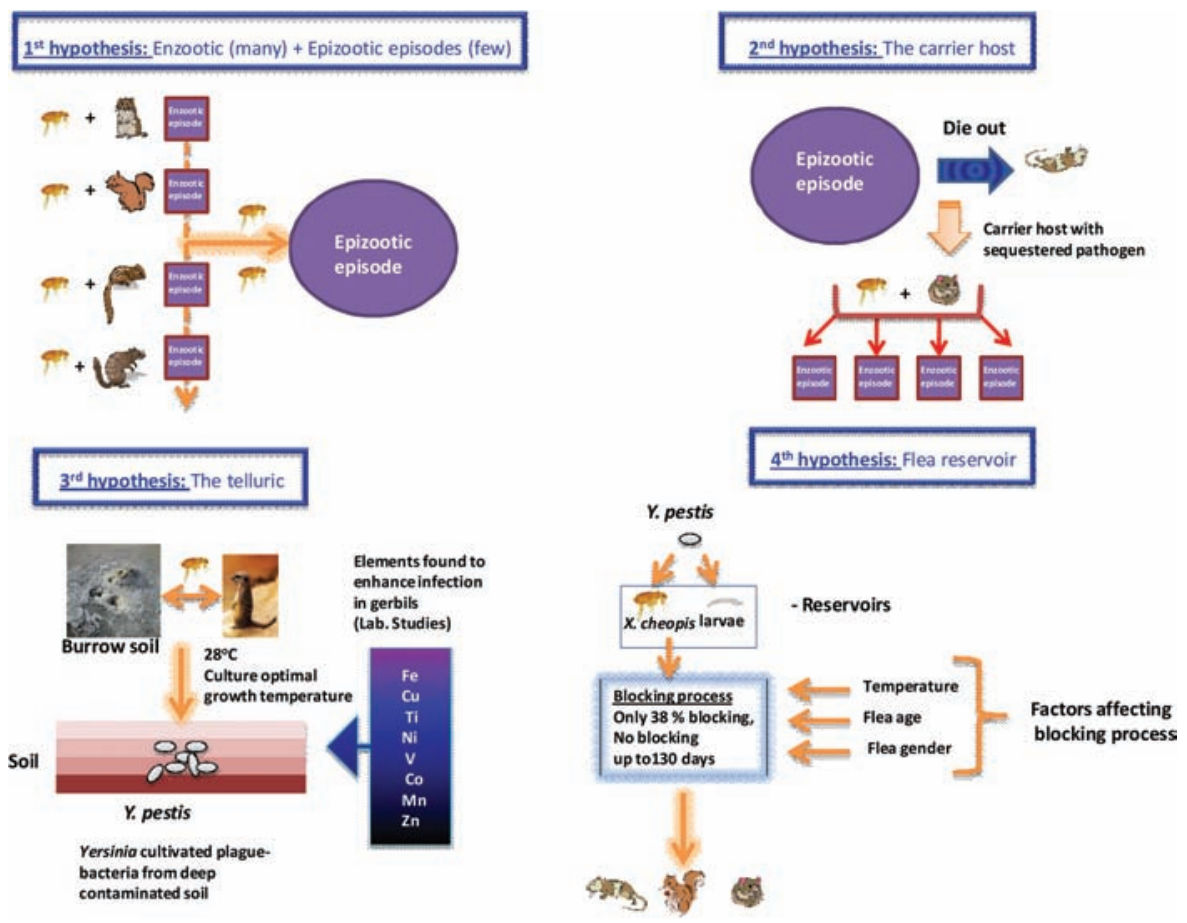

Figure 2.17.4. The four hypotheses related to Y. pestis epizootic and enzootic episodes in nature

Inevitably, $Y$. pestis is still considered a biological warfare weapon with immense disastrous consequences. Pala (2005) described the case of Vozrozhdeniye (Renaissance) Island located on the Aral Sea (now belonging to the Republics of Uzbekistan and Kazachstan), a remote site where once the Soviet military did perform field tests with plague bacteria, whose lethality had been genetically increased (including other highly pathogenic bacteria). Due to wrong political decisions (diversion of water to cotton irrigation from two rivers that had naturally supplied water to the Aral Sea for more than 30 years), the Aral Sea was drying out with $75 \%$ shrinkage and splitting into two parts: the Small Aral in the north and the Big Aral in the south. To prevent the north part from becoming completely dry, the authorities decided to build a dam in order to fill this part, which in turn might affect the southern part by exposing land in the Big Aral, in the past partially submerged, consequently increasing traffic across a land link to Vozrozhdeniye Island. The main concern is that the newly open traffic path will cause people to come in contact with existent carrier animals (rats and camels) possibly by now infected or carrying military-grade (highly virulent), antibiotic-resistant plague bacteria, extremely different from the endemic strains present in Central Asia.

Duplantier et al. (2005) analyzing the well-documented human plague cases in Madagascar, suggested using the terms of expansion or regression phases for sylvatic rodent plague foci and reserving the term 
re-emergence for human cases. According to these authors, the main factors in the re-emergence of human cases are: 1) surveillance and control reduction or discontinuance; 2) poverty and poor sanitary conditions that provide increased contacts with infected rodents and fleas; and 3) environmental changes (i.e., climatic changes, deforestation, urbanization) that could modify flea and rodent populations by (i) rodent habitats expansion (forests replacement with steppes or farmlands); (ii) modifications in population dynamics (possible outbreaks due to an increase of available food resources); but also, (iii) emergence of new vectors, reservoirs and new $Y$. pestis genotypes. An excellent example of these assumptions is the plague history in Madagascar where it was introduced in 1898 by a ship sailing from India. In an extensive survey of Y. pestis strains' analysis from 1939 till 1996, all strains up to 1982 were found to belong to biovar Orientalis (ribotype B). However, from 1982 on, new ribotypes (designated R, Q and T) were identified in one of the most active plague foci of this island. $Y$. pestis is known for its high frequency of spontaneous genomic reorganization (including conjugative transfer) that enhances its survival ability, transmission (to new hosts) and colonization of new environments (Guiyoule et al., 1994; Guiyoule et al., 1997; Hinnebusch et al., 2002). For that reason, any environmental change should be taken as a warning signal, and active surveillance programs should be initiated to prevent emergence of new potent strains.

Breneva and Maramovich (2008) infected Tetrahymena pyriformis with avirulent and virulent variants of $Y$. pestis in an artificial soil ecosystem (ASE) containing burrows soil from one of the main carrier from the Gorno-Altayski natural plague reservoir. Avirulent strains were rapidly eliminated while highly virulent strains were the most resistant to the $T$. pyriformis phagocytosis process.

From the ecological aspect, Dinsmore and Smith (2010) studied the indirect impact of prairie dog plague epizootics on the mountain plove birds that preferentially nest in the area of black-tailed prairie dog colonies. Prairie dogs do modify vegetation and landscape structure around their colonies in ways that affect other grassland species. Akin to a chain reaction, morbidity of prairie dog as a result of $Y$. pestis epizootics impacted negatively plover colonization and nesting habits.

Another recent ecological facet, using field data on prairie community ecology, flea behavior, and plague-transmission biology, revealed that plague can persist in prairie-dog colonies for prolonged periods, because host movement is highly spatially constrained. An abundance of an alternate host for disease vectors (in this case, the grasshopper mouse-Onychomys leucogaster) drives plague outbreaks through connectivity increase of the prairie dog hosts and thereby allows percolation of the disease all the way through the primary host population. Indeed, these results provide an alternative point of view of plague's ecology, suggesting that more than one single main host is involved in $Y$. pestis dissemination in Africa and Asia. Furthermore, this phenomenon of abundance thresholds of alternate hosts that may be a key phenomenon determining outbreaks in many multi-host-disease systems has been supported by additional studies (Salkeld et al., 2010; Davis et al., 2008; Christie, 1982; Smith et al., 2010).

Filipkowska (2003) examined the removal of various pathogens and indicator bacteria in a wastewater treatment plant in Lezany, Poland. The results of microbiological analyses confirmed a satisfactory removal rate of 94 to $97 \%$; however, using biochemical tests the author found $Y$. pestis among many pathogenic bacteria still present in the final phase of purification (stabilization ponds). Still, the prospect of $Y$. pestis surviving in water is questionable and needs further research.

Boone et al. (2009) showed experimentally that scavenger carnivores (coyotes, swift foxes and badgers) may spread plague as flea carriers and by consumption of carcasses at long range, thereby possibly disseminating the pathogen and its vector to distant and new host colonies. Salkeld and Stapp (2006) surveyed exposure to plague by seroconversion of different carnivorous families. They found the following seroconversion rates in this order (from highest to lowest): mustelids (e.g., budger) $>$ ursids 
(e.g., bear) $>$ felids (e.g., lynx) $>$ canids (e.g., coyote) $>$ procyonids (e.g., raccoon), probably reflecting exposure rates variation as a function of dietary habits.

Last but not least, a rough speculation linked to environmental pollution that is worth a second consideration is the phenomenon of cannibalism among rodents such as rats. Exposure of laboratory rats to environmental stresses, including teratogen (6-aminonicotinamide) and aflatoxin was found to increase cannibalism in these animals (Schardein et al., 1978; Shankarmurti et al., 1972). A number of explanations were suggested for this behavior, based mainly on experimental animal psychology including malnutrition, necessity of removing dead carcasses or defective offsprings and cross-species fostering. Regardless of what the correct answer might be, on the proviso that this phenomenon exists in wild rodents under exposure to pollutants with similar effects, it possibly explains the continuous maintenance of this pathogen enzootically through cannibalism of infected individuals.

\subsubsection{REFERENCES}

Achtman, M., Zurth, K., Morelli, G., Torrea, G., Guiyoule, A. \& Carniel, E. (1999) Yersinia pestis, the cause of plague, is a recently emerged clone of Yersinia pseudotuberculosis. Proc Natl Acad Sci U S A 96, 14043-14048.

Anonymous (1939) "Mary Mallon (Typhoid Mary)". Am J Public Health 29, 66-68.

Anonymous. (2004). Human plague. Wkly. Epidemiol. Rec. No. 33, 79, 301-308.

Bacot, A.W. \& Martin, C.J. (1914) Observations on the mechanism of the transmission of plague by fleas. J Hyg (Lond) 13(Suppl), 423-439.

Boone, A., Kraft, J.P. \& Stapp, P. (2009) Scavenging by mammalian carnivores on prairie dog colonies: implications for the spread of plague. Vector Borne Zoonotic Dis. 9, 185-189.

Breneva, N.V. \& Maramovich, A.S. (2008) Modeling of interaction between Yersinia pestis and Tetrahymena pyriformis in experimental ecosystems. Zh. Mikrobiol. Epidemiol. Immunobiol. 5, 39-41.

Breneva, N.V., Maramovich, A.S. \& Klimov, V.T. (2006) The population variability of Yersinia pestis in soil samples from the natural focus of plague. Zh. Mikrobiol. Epidemiol. Immunobiol. 2, 7-11.

Christie, A.B. (1982) Plague: review of ecology. Ecol Dis 1, 111-115.

Clover, J.R., Hofstra, T.D., Kuluris, B.G., Schroeder, M.T., Nelson, B.C. et al. (1989) Serologic evidence of Yersinia pestis infection in small mammals and bears from a temperate rainforest of north coastal California. Journal of Wildlife Diseases 25, 52-60.

Davis, D.H. (1953) Plague in Africa from 1935 to 1949; a survey of wild rodents in African territories. Bull. World Health Organ. 9, 665-700.

Davis, S., Trapman, P., Leirs, H., Begon, M. \& Heesterbeek, J.A.P. (2008) The abundance threshold for plague as a critical percolation phenomenon. Nature 454, 634-637.

Delwiche, E.A., Fukui, M., Andrews, W. \& Surgalla, J. (1959) Environmental conditions affecting the population dynamics and the retention of virulence of Pasteurella pestis: the role of carbon dioxide. J Bacteriol. 77, 355-360.

Devignat, R. (1951) Variétés de l'espèce Pasteurella pestis. Nouvelle hypothése. Bull World Hlth Org 4, 247-263.

Dinsmore, S.J. \& Smith, M.D. (2010) Mountain Plover Responses to Plague in Montana. Vector Borne Zoonotic Dis 10, 37-41.

Duplantier, J-M., Duchemin, J-B., Chanteau, S. \& Carniel, E. (2005) From the recent lessons of the Malagasy foci towards a global understanding of the factors involved in plague reemergence. Vet. Res. 36, 437-453.

Filipkowska, Z. (2003) Sanitary and bacteriological aspects of sewage treatment. Acta Microbiol. Pol. 52 Suppl, 57-66.

Gage, K.L. \& Kosoy, M.Y. (2005) Natural history of plague: perspectives from more than a century of research. Annu Rev Entomol 50, 505-528.

Gage, K.L., Dennis, D.T., Orloski, K.A., Ettestad, P., Brown, T.L. et al. (2000) Cases of cat-associated human plague in the Western US, 1977-1998. Clin. Infect. Dis. 30, 893-900.

Gage, K.L. (1998) Plague. In: Colliers, L., Balows, A., Sussman, M., Hausles, W.J., (Eds.) Topley and Wilson's microbiology and microbiological infections. Vol 3. London, Edward Arnold Press, pp. 885-903. 
Girard, J.M., Wagner, D.M., Vogler, A.J., Keys, C., Allender, C.J. et al. (2004) Differential plague-transmission dynamics determine Yersinia pestis population genetic structure on local, regional, and global scales. Proc. Natl. Acad. Sci. U.S.A. 101, 8408-8413.

Gould, L.H., Pape, J., Ettestad, P., Griffith, K.S. \& Mead, P.S. (2008) Dog-associated risk factors for human plague. Zoonoses Public Health 55, 448-454.

Guiyoule, A., Grimont, F., Iteman, I., Grimont, P.A.D., Lefevre, M. \& Carniel, E. (1994) Plague pandemics investigated by ribotyping of Yersinia pestis strains. J. Clin. Microbiol. 32, 633-641.

Guiyoule, A., Rasoamanana, B., Buchrieser, C., Michel, P., Chanteau, S. \& Carniel, E. (1997) Recent Emergence of New Variants of Yersinia pestis in Madagascar. J. Clin. Microbiol. 35, 2826-2833.

Haensch, S., Bianucci, R., Signoli, M., Rajerison, M., Schultz, M., et al. (2010) Distinct clones of Yersinia pestis caused the black death. PLoS Pathog 6(10):e1001134. doi:10.1371/journal.ppat.1001134.

Hinnebusch, B.J., Rosso, M-L., Schwan, T.G. \& Carniel, E. (2002) High-frequency conjugative transfer of antibiotic resistance genes to Yersinia pestis in the flea midgut. Mol. Microbiol. 2, 349-354.

Kartman, L. (1969) Effect of differences in ambient temperature upon the fate of Pasteurella pestis in Xenopsylla cheopis. Trans. R. Soc. Trop. Med. Hyg. 63, 71-75.

Kroupitski, Y., Golberg, D., Belausov, E., Pinto, R., Swartzberg, D. et al. (2009) Internalization of Salmonella enterica in leaves is induced by light and involves chemotaxis and penetration through open stomata. Appl. Environ. Microbiol.75, 6076-6086.

Litvin, V.Y. (1997) Mechanisms of the stable preservation of Yersinia pestis in the environment (new facts and hypotheses). Zh. Mikrobiol. 4, 26-31.

Mann, J.M., Martone, W.J., Boyce, J.M., Kaufmann, A. F., Barnes, A. M. \& Weber, N.S. (1979) Endemic human plague in New Mexico: risk factors associated with infection. J. Infect. Dis. 140, 397-401.

McCormick, M. (2007) Toward a molecular history of the Justinian pandemic. In: Little, Lester K. editor., Plague and the End of Antiquity: The Pandemic of 541-750. Cambridge University Press.

McElroy, K.M., Blagburn, B.L., Breitschwerdt, E.B., Mead, P.S. \& McQuiston, J.H. (2010) Flea-associated zoonotic diseases of cats in the USA: bartonellosis, flea-borne rickettsioses, and plague. Trends Parasitol. 26, 197-204.

Mollaret, H.H. (1963) Conservation experimentale de la peste dans le sol. Bull. Soc. Pathol. Exot. 56, 1168-1182.

Pala, C. (2005) Environmental restoration: to save a vanishing sea. Science 307, 1032-1034.

Parmenter, R.R., Yadav, E.P., Parmenter, C.A., Ettestad, P. \& Gage, K.L. (1999) Incidence of plague associated with increased winter-spring precipitation in New Mexico. Am. J. Trop. Med. Hyg., 61, 814-821.

Pham, H.V., Dang, D.T., Minh, N.N.T, Nguyen, N.D. \& Nguyen, T.V. (2009) Correlates of environmental factors and human plague: an ecological study in Vietnam. Int J Epidemiol 38, 1634-1641.

Pollitzer R. (1954) Plague. World Health Organization Monograph Series No. 22.Geneva: World Health Organ. 698 pp.

Pushkareva, V.I. (2003) Experimental evaluation of interactions between Yersinia pestis, EV and soil infusoria and the possibility of the prolonged preservation of bacteria in the protozoan cysts. Zh. Mikrobiol. 4, 40-44.

Rivkus, Y.Z., Mitropolsky, O.V., Bochkaroff, V.M., Blummer, A.G. \& Bochkaroff. S.V. (1993) Desert vegetation as a possible component in plague parasitocoenosis. Bull. Mosk. Obschestva Ispyt. Prirody. 98, 3-13.

Salkeld, D.J. \& Stapp, P. (2006) Seroprevalence rates and transmission of plague (Yersinia pestis) in mammalian carnivores Vector Borne Zoonotic Dis. 6, 231-239.

Salkeld, D.J., Salathé, M., Stapp, P. \& Jones, J.H. (2010) Plague outbreaks in prairie dog populations explained by percolation thresholds of alternate host abundance. Proc. Natl. Acad. Sci. U.S.A. 107, 14247-14250.

Schardein, J.L., Petrere, J.A., Hentz, D.L., Camp, R.D. \& Kurtz, S.M. (1978) Cannibalistic traits observed in rats treated with a teratogen. Lab. Anim. 12, 81-83.

Shankarmurti, A., Sreenivasamurthy, V. \& Parpia, H.A.B. (1972) Cannibalistic behavior of mother albino rats fed aflatoxin. Indian J. Exp. Biol. 10, 307-308.

Smith, C.R., Tucker, J.R., Wilson, B.A. \& Clover, J.R. (2010) Plague studies in California: a review of long-term disease activity, flea-host relationships and plague ecology in the coniferous forests of the Southern Cascades and northern Sierra Nevada mountains. J. Vector Ecol. 35, 1-12.

Smith, D.L., Waller, L.A., Russell, C.A., Childs, J.E. \& Real, L.A. (2005) Assessing the role of long-distance translocation and spatial heterogeneity in the raccoon rabies epidemic in Connecticut. Prev. Vet. Med. 71, 225-240. 
Smith, D.L., Waller, L.A., Russell, C.A., Childs, J.E. \& Real, L.A. (2005) Assessing the role of long-distance translocation and spatial heterogeneity in the raccoon rabies epidemic in Connecticut. Prev. Vet. Med. 71, 225-240.

Snäll, T., O'Hara, R.B., Ray, C. \& Collinge, S.K. (2008) Climate-driven spatial dynamics of plague among prairie dog colonies. Am. Nat. 171, 238-248.

Stapp, P., Salkeld, D.J., Eisen, R.J., Pappert, R., Young, J. et al. (2008) Exposure of small rodents to plague during epizootics in black-tailed prairie dogs. J. Wildl. Dis., 44, 724-730.

Stenseth, N.C., Atshabar, B.B., Begon, M., Belmain, S.R., Bertherat, E., et al. (2008) Plague: past, present, and future. PLoS Med 5(1): e3. doi:10.1371/journal. pmed.0050003.

Suchkov, I.G., Khudiakov, I.V., Emel'ianenko, E.N., Levi, M.I., Pushkareva, V.I., et al. (1997) The possibility of preserving the causative agent of plague in soil in resting (nonculturable) form. Zh. Mikrobiol. Epidemiol. Immunobiol. 4, 42-46.

Thornton, D.J., Tustin, R.C., Pienaar, B.J., Pienaar, W.N. \& Bubb, H.D. (1975) Cat bite transmission of Yersinia pestis infection to man. J S Afr Vet Assoc 46, 165-169.

Torosian, S.D., Regan, P.M. Doran, T., Taylor, M.A. \& Margolin, A. (2009) A refrigeration temperature of $4^{\circ} \mathrm{C}$ does not prevent static growth of Yersinia pestis in heart infusion broth. Can. J. Microbiol. 55, 1119-1124.

von Reyn, C.F., Barnes, A.M., Weber, N.S. \& Hodgin, U.G. (1976a) Bubonic plague from exposure to a rabbit: a documented case, and a review of rabbit-associated plague cases in the United States. Am. J. Epidemiol. 104, 81-87.

von Reyn, C.F., Barnes, A.M., Weber, N.S., Quan, T. \& Dean, W.J. (1976) Bubonic plague from direct exposure to a naturally infected wild coyote. Am. J. Trop. Med. Hyg. 25, 626-629.

Webb, C.T., Brooks, C.P., Gage, K.L. \& Antolin, M.F. (2006) Classic flea-borne transmission does not drive plague epizootics in prairie dogs. Proc. Natl. Acad. Sci. U.S.A. 103, 6236-6241.

Wild, M.A., Shenk, T.M. \& Spraker, T.R. (2006) Plague as a mortality factor in Canada Lynx (Lynx canadensis) reintroduced to Colorado. J. Wildl. Dis. 42, 646-650.

Wimsatt, J. \& Biggins, D.E. (2009) A review of plague persistence with special emphasis on fleas. J Vector Borne Dis 46, 85-99.

Wong, D., Wild, M.A., Walburger, M.A., Higgins, C.L., Callahan, M., Czarnecki, L.A., Lawaczeck, E.W. et al. (2009) Primary pneumonic plague contracted from a mountain lion carcass. Clin Infect Dis. 49, e33-e38.

Wuensch, K.L., (1993) Cross-species fostering affects meat preferences of wild house mice. J Gen Psychol 120, 413-419.

Zharinova, N.V., Briukhanova, G.D., Maletskaia, O.V., Tsareva, N.S. \& Luneva, T.M. (2008) Relations of the causative agents of plague and listeriosis during their simultaneous stay in the flea Citellophilus tesquorum at different environmental temperatures. Med Parazitol (Mosk) 1, 41-43. 


\section{Chapter 2.18}

\section{Rat bite Fever (RBF) or Sodoku}

\section{[SPIRILLUM MINUS OR STREPTOBACILLUS MONILIFORMIS]}

Rat bite fever is a disease transmitted by two bacteria species: Spirillum minus and Streptobacillus moniliformis. Spirillum minus is a gram-negative, aerobic spirochaete found in the blood and possibly in the conjunctiva of rats, but can be found in other animals such as squirrel, mice, pigs, cats, dogs, ferrets and weasels. Streptobacillus moniliformis is a rod in chains (streptobacilli) (in older culture it may form filaments) gram-negative facultative anaerobic bacterium found in normal oropharyngeal flora of rats or other rodents (Cunningham et al., 1998). Importantly, these germs can also be transmitted via food or water that was probably contaminated with rat feces or urine (Andre et al., 2005). Haverhill fever (HF) is a form of $S$. moniliformis infection considered to occur subsequent to ingestion of contaminated food or water (Gaastra, et al., 2009). The disease is characterized by acute fever, headaches, malaise, lymphoadenopathy, vomiting and other external developments (maculopapular and urticarial rashes). More serious complications may occur such as myocarditis, hepatitis, meningitis, nephritis and pneumonia and death (very low with $S$. minus under treatment and $10 \%$ with untreated $S$. moniliformis cases) (Anonymous, 2005). S. minus is asymptomatic in animals while $S$. moniliformis can cause arthritis in turkeys.

\subsubsection{RAT BITE FEVER AND ENVIRONMENT}

Close contact and increasing exposure to exotic or wild animals and in this context to rodents coupled with gradual urbanization has increased the frequency of zoonotic diseases such as RBF (Graves and Janda, 2001; van Nood and Peters, 2005; Dendle et al., 2006). Valverde et al. (2002) reported an unusual infection in two non-human primates by $S$. moniliformis.

Along with Giardia, Cryptosporidium, E. coli, S. typhi, S. paratyphi and Campylobacter, Streptobacillus moniliformis was implicated in several public and private drinking water related outbreaks in England and Wales from 1910 to 1999 as reported by Nichols et al. (2009). These outbreaks were significantly correlated to two contrasting climatic situations: low rainfall and excess cumulative rainfall prior to outbreaks. Relative drought (low rainfall) can result in the following events: a) elevated output of sewage effluents in rivers; b) 
opening up of water flow channels as the water table drops and direct contamination of groundwater; and c) dry soil surface encouraging run-off and formation of cracks that affect the soil's filtration capability. Excessive rainfall besides causing wash out and spread of rats' urine and fecal materials over extensive areas may also impact the drainage rat population through flooding. This aspect has not yet been studied, but it should be taken seriously as one of the rats' main dwelling-places is sewer system. Countries subjected to continuous floods are at high risk, especially in densely populated areas at low economic levels. With regard to climatic conditions, Lima et al. (2008), using a logistic model reported on the impact of summer precipitation on two closely related kangaroo-rat populations (Dipodomys merriami and Dipodomys ordii). It was hypothesized that increased summer precipitations intensify green vegetation needed for the reproduction of these rodents (specifically, females that require the water content of green vegetation for lactation).

Rat bite fever association with excessive rain fall was reported in a large outbreak caused by $S$. moniliformis (304 people out of 700,34\%) in a boarding school in the UK (McEvoy et al., 1987). Water (from taps) and milk were first suspected to be the transmission vectors; however following an extensive epidemiological survey, the authors deduced that water from a nearby spring was the outbreak's main pathogen reservoir. The assumption that this spring was infested with rats or even carrying a rat carcass could not be ruled out, as the water main (not connected to the spring) in this location did not cause additional cases outside the school. In this special case, digging around the building and exceptionally stormy weather had been reported, both events suspected of causing disorder of the local rat population resulting in accidental contact with spring water.

Finally, petrochemical land waste treatment was shown to induce cotton rats' dental lesions through fluorosis (Rafferty et al., 2000). This observation is important as such lesions can increase the potential rat bite fever pathogens being transmitted between these rodents as well to other animals including humans with which they may come in contact.

\subsubsection{REFERENCES}

Andre, J.M., Freydiere, A.M., Benito, Y., Rousson, A., Lansiaux, S., Kodjo, A. et al. (2005) Rat bite fever caused by Streptobacillus moniliformis in a child: human infection and rat carriage diagnosed by PCR. J. Clin. Pathol. 58, 1215-1216.

Anonymous (2005) Fatal rat-bite fever-Florida and Washington, 2003. MMWR Morb Mortal Wkly Rep 53, $1198-1202$.

Cunningham, B.B., Paller, A.S. \& Katz, B.Z. (1998) Rat bite fever in a pet lover. J. Am. Acad. Dermatol. 38, 330-332.

Dendle, C., Woolley, I.J. \& Korman, T.M. (2006) Rat-bite fever septic arthritis: illustrative case and literature review. Eur J Clin Microbiol Infect Dis 25, 791-797.

Gaastra, W., Boot, R., Ho, H.T.K. \& Lipman, L.J.A. (2009) Rat bite fever. Vet. Microbiol. 133, $211-228$.

Graves, M.H. \& Janda, J.M. (2001) Rat-bite fever (Streptobacillus moniliformis): a potential emerging disease. Int J Infect Dis 5, 151-154.

Lima, M., Ernest, S.K.M., Brown, J.H., Belgrano, A. \& Stenseth, N.C. (2008) Chihuahuan desert kangaroo rats: nonlinear effects of population dynamics, competition, and rainfall. Ecology 89, 2594-2603.

McEvoy, M.B., Noah, N.D. \& Pilsworth, R. (1987) Outbreak of fever caused by Streptobacillus moniliformis. Lancet 12, 1361-1363.

Nichols, G., Lane, C., Asgari, N., Verlander, N.Q. \& Charlett, A. (2009) Rainfall and outbreaks of drinking water related disease and in England and Wales. J Water Health. 7, 1-8.

Rafferty, D.P., Lochmiller, R.L., Kim, S., Qualls, C.W., Schroder, J. et al. (2000) Fluorosis risks to resident hispid cotton rats on land treatment facilities for petrochemical wastes. J. Wildl. Dis. 36, 636-645.

Torres, L., Lòpez, A.I., Escobar, S., Marne, C. Marco, M.L. et al. (2003) Bacteremia by Streptobacillus moniliformis: first case described in Spain. Eur J Clin Microbiol Infect Dis 22, 258-260. 
Valverde, C.R., Lowenstine, L.J., Young, C.E., Tarara, R.P. \& Roberts, J.A. (2002) Spontaneous rat bite fever in non-human primates: a review of two cases. J Med Primatol 31, 345-349.

van Nood, E. \& Peters, S.H.A. (2005) Rat-bite fever. The Neth J Med 63, 319-321. 


\section{Chapter 2.19}

\section{Rickettsioses}

\section{[RICKETTSIA SPP.]}

The genus Rickettsia are gram-negative, non-spore forming, non-motile, highly pleomorphic bacteria (cocci, rods or thread-like). All species are obligate intracellular parasites that replicate within cytoplasm of eukaryotic cells as host (mainly endothelial cells). The main species are: Rickettsia rickettsii, Rickettsia felis, Rickettsia prowazekii, Rickettsia typhi, Rickettsia conorii, Rickettsia africae and Rickettsia akari. Different ticks, fleas, and lice are the vectors of this pathogen and mammals (including humans) are the host. There are several diseases caused by Rickettsia such as typhus, scrub typhus (tsutsugamushi fever) rickettsialpox, Rocky Mountain spotted fever, Mediterranean spotted fever (Boutonneuse fever), African tick bite fever, Queensland tick typhus, Australian Tick Typhus and Flinders Island Spotted Fever. Rickettsioses can occur sporadically, endemically but also epidemically (e.g., typhus, Q fever) (Salgo et al., 1988) (Table 2.19.1). Rickettsia has also been associated with a range of plant diseases and as an arthropods' endosymbiont. Resembling viruses, they grow exclusivelly inside living cells. The name rickettsia is often used for any member of the Rickettsiales. They are thought to be the closest living relatives to bacteria that evolutionarily are thought to be the origin of the mitochondria organelle present inside most eukaryotic cells. Diseases caused by the genus Rickettsia will manifest themselves according to the infecting agent's tropism such as: skin-texanthemas and necroses; lung-pneumonia; heart-myocarditis; brain-meningoencephalitis; gastrointestinal tract-diarrehea; pancreaspancreatitis; liver-hepatitis; blood- thrombocytopenia and hemorrhages and kidney-hypoperfusion and acute renal failure.

\subsubsection{RICKETTSIA AND ENVIRONMENT (FIGURE 2.19.1)}

The ecology of rickettsiae is clearly linked to environmental factors as vector-borne pathogens. Mumcuoglu et al. (1993) investigated an outbreak of spotted fever group rickettsiae (SFGR) in a small settlement located in southern part of Israel. The settlement Kibbutz Zeelim (Z), the main source of SFGR with high morbidity was compared to another settlement of equal magnitude (Kibbutz Reim, R) located only $20 \mathrm{~km}$ away, as control. The dominant tick species isolated from site $\mathrm{Z}$ was Rhipicephalus sanguineus and from site 


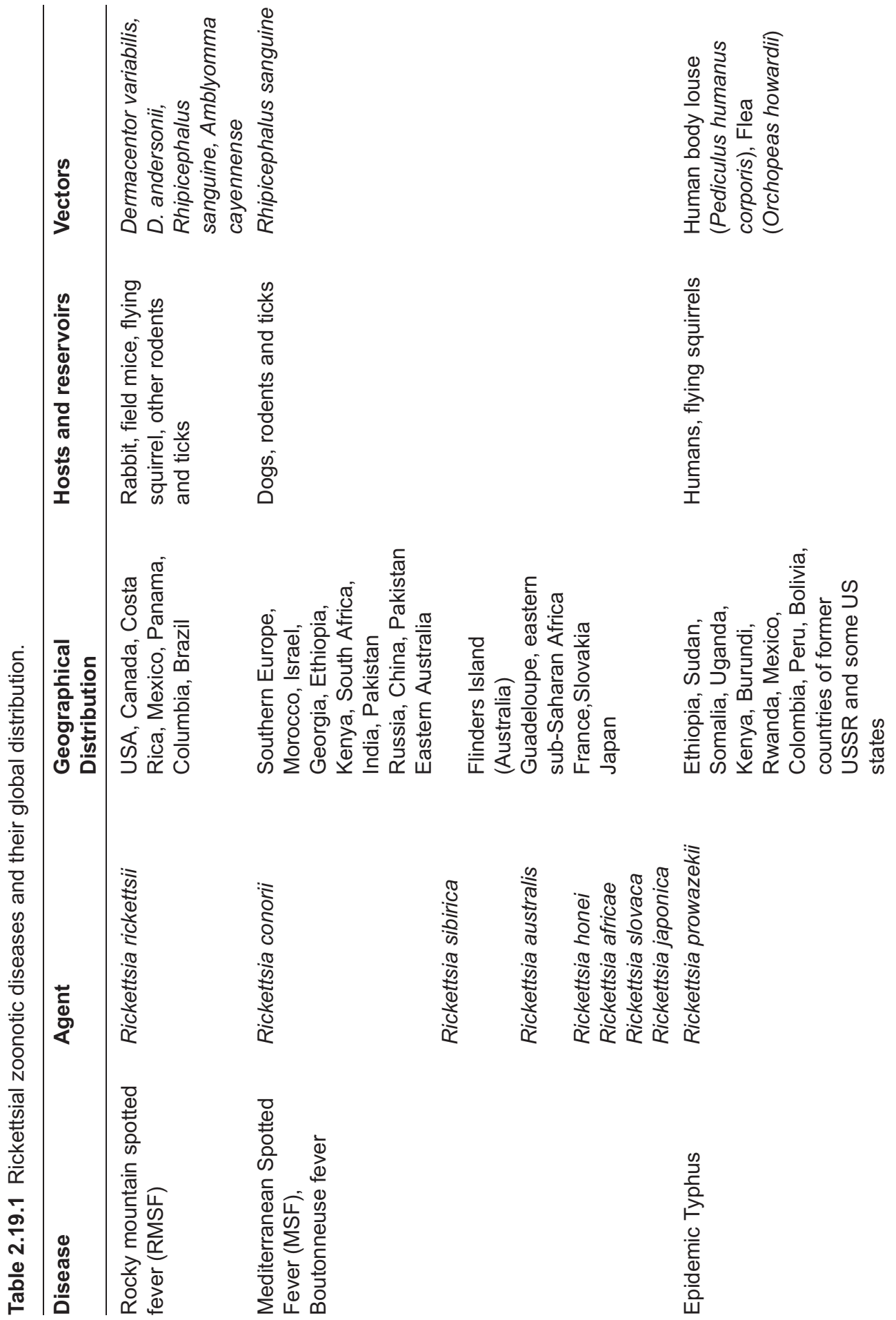


Rickettsioses
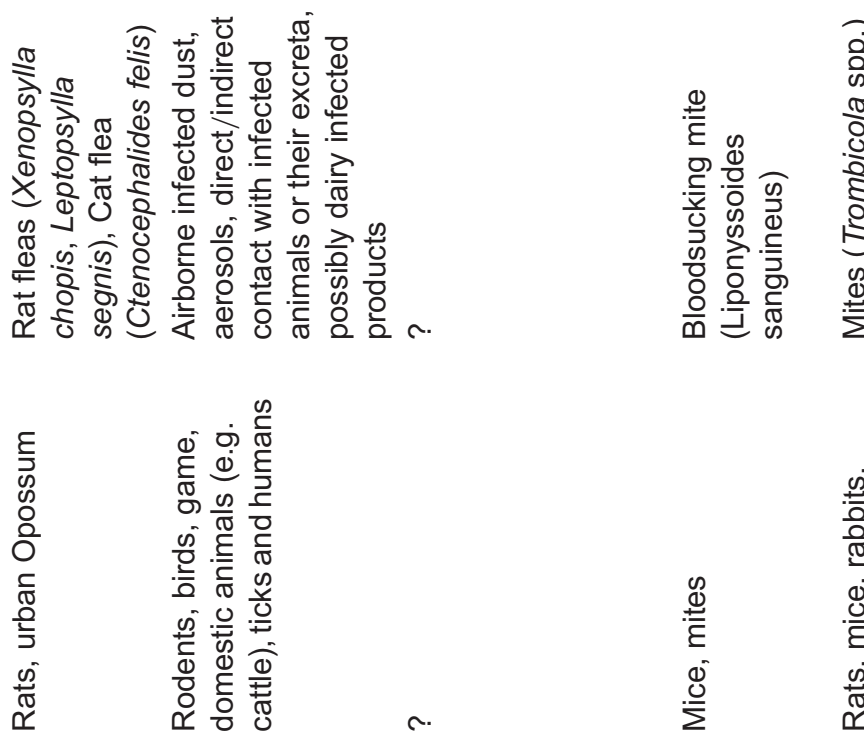

r.
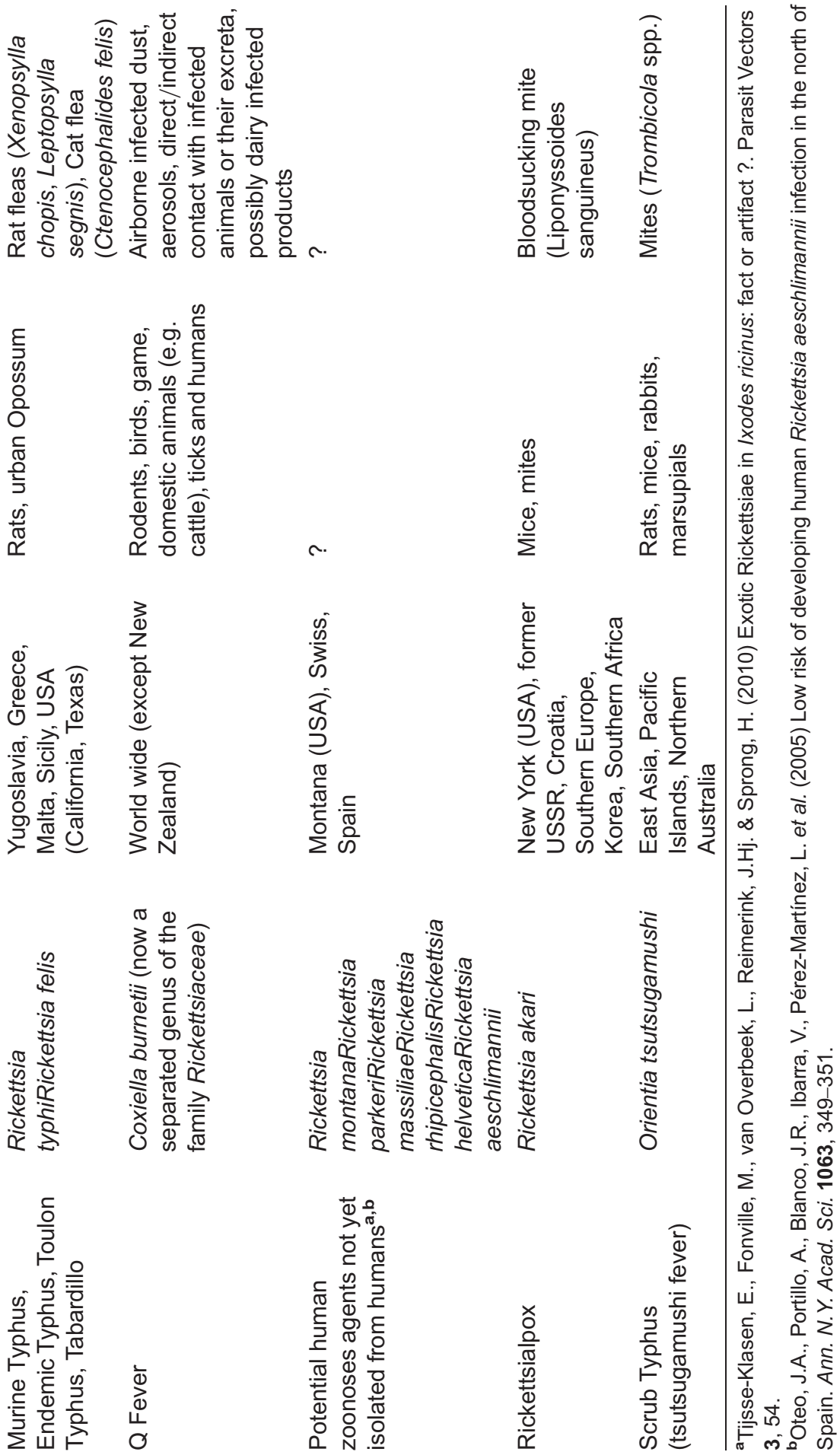

Downloaded from https://iwaponline.com/ebooks/book-pdf/521254/wio9781780400761.pdf by IWA Publishing user
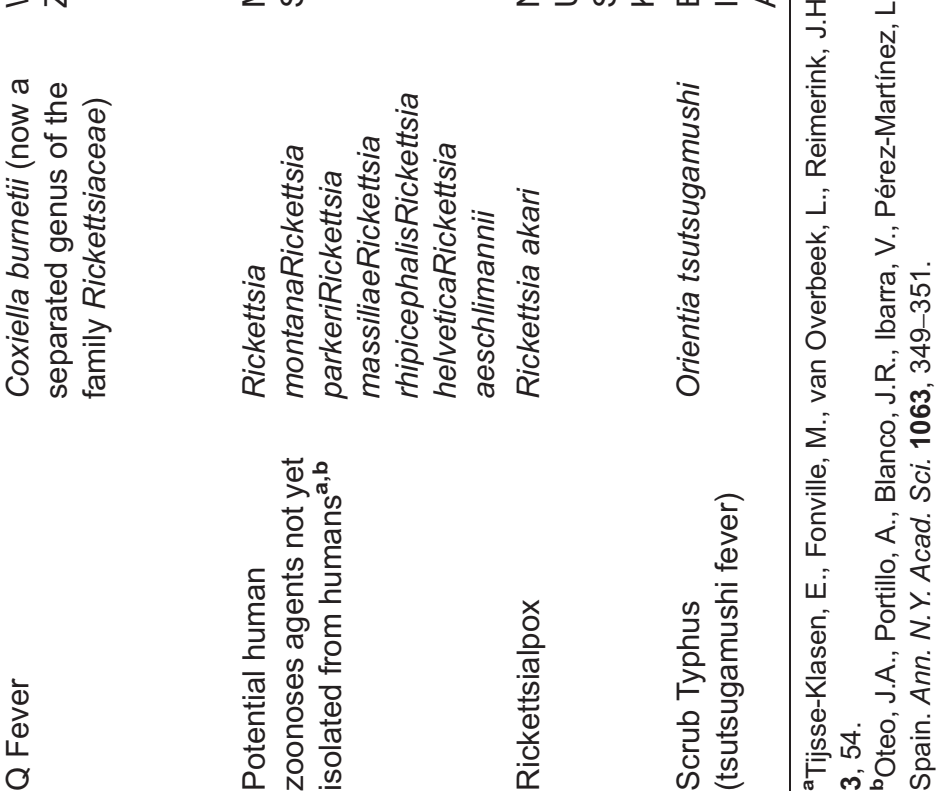

$$
\text { i }
$$


R, R. turanicus Pomerantzev. Physical factors such as soil composition and ambient surface temperatures that may clarify these differences were studied. Indeed, site $\mathrm{Z}$ had higher maximum soil and ambient temperatures well correlated with a higher tick load for a longer time span. Dogs, sheep, goats and various rodents were more heavily infested with ticks on site $\mathrm{Z}$ than on site $\mathrm{R}$, while interestingly both sites were equal in dogs and mice' seropositivity to SFGR. Both sites had dogs as pet animals; however, site Z revealed that $7.1 \%$ of dog owners acquired Mediterranean spotted fever compared with only $1.4 \%$ of people without dogs. Population education and natural growth decline can prevent infections, in the particular case of rickettsiosis that has a familial character with close contact (louse-borne). Onishchenko et al. (1997) emphasized the decrease of louse-borne typhus in Russia due to natural demographic processes.

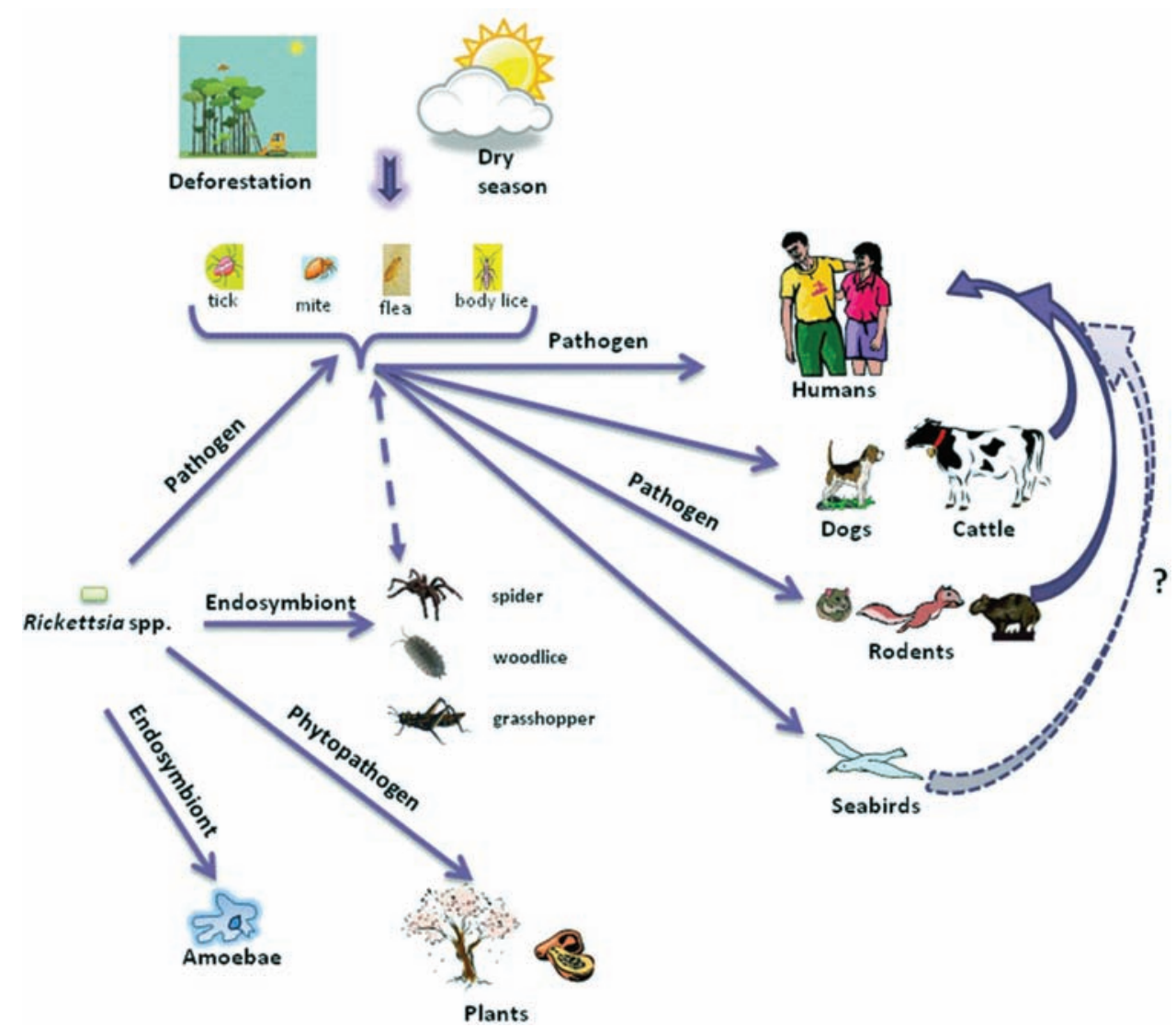

Figure 2.19.1. Zoonotic Rickettsia spp. proved and potential environmental life

As rodents are one of the main reservoirs of Rickettsia, Norway rats were surveyed for zoonotic pathogens in the Baltimore area, USA. Antibodies against Rickettsia typhi were detected in $7.0 \%$ of the live-trapped rats (Easterbrook et al., 2007). Beside rodents a Japanese researcher reported detection of Rickettsia in association with seabirds suggesting a broader environmental circulation by microorganisms, ticks and long distance migratory seabirds around the Pacific Ocean (Kawabata et al., 2006). 
In a study performed in Russia (Leningrad province), cattle were shown to be the main source of Coxiella burnetii infection in humans (Tokarevich et al., 2006). These authors showed that livestock farming modifications may impact infection with Q-fever. Over a period of 10 years, a reduction in large specialized livestock farms (subject to more advanced veterinary monitoring) occurred concomitantly with an increase in small private farms, exposing cattle to uncontrolled migration and contact with non-professional population, consequently increasing the health risk from this pathogen's transmission. It should be mentioned at this point that the $C$. burnetii is highly infectious requiring as few as one organism to cause disease via inhalation in susceptible humans (Sanders et al., 2008). In addition, these authors observed a dramatic rise in domestic dogs carrying C. burnetii (based on seroprevalence) especially in urban areas (cities). In relation to dog population, Mannelli et al. (2003) in Piemonte (Italy) reiterated that link through $R$. conorii seropositivity observed in surveyed dogs, concluding that a relatively high dog population density within a rural or semi-rural environment encourages emergent foci of Mediterranean spotted fever (MSF) in this area. A related trend was also reported in Okinawa (Japan) supporting the above result (Satoh et al., 2001).

Vector-borne diseases such as Boutonneuse fever were found to be also associated to climate change. Portuguese researchers looked at the endemic pathogen $R$. conorii (the strain involved in Malish and Israeli spotted fever) transmitted by the brown dog tick (Rhipicephalus sanguineus) and seroconversion during the off-season months (October-February) for a period of 6 years (2000-2005) (de Sousa et al., 2006). They found a significant increase in positive cases, evidently related epidemiologically to climate change expressed in low precipitation values. The main factorial argument for this increase was the milder climate, permitting vectors such as ticks and other arthropods to survive and multiply preferentially. Vescio et al. (2008) looked at climatic factors that may correlate with mediterranian spotted fever (MSF) cases in the northern part of Sardinia and found that exposure to high temperature during summer months in a given year may increase MSF incidence in the following year. These authors explained their results based on the biology of tick vector life cycle.

Previous reports of Rickettsia typhi showed that lower temperatures than that of the human body are favorable for this pathogen and possibly for its other relatives. Moragues and Pinkerton (1944) subjected two groups of laboratory dba mice strain to murine typhus rickettsiae at two different temperature ranges: $18.3-22.7^{\circ} \mathrm{C}$ and $29.4-36.6^{\circ} \mathrm{C}$ and monitored illness and fatality. At lower temperatures the fatality was $100 \%$ and only $<25 \%$ at higher temperatures.

In the USA, reported infections with epidemic typhus rickettsiae (Rickettsia prowazekii) were not associated with the classic man-louse-man cycle of epidemic typhus, but related to contact with flying squirrels (McDade et al., 1980). A ten year study in the French Alps showed that human activity such as deforestation, can enhance the spread of certain ticks species from forested to urban areas, creating new or expanding known foci of disease transmission in the vicinity of large cities (Gilot and Pautou, 1982).

Wang et al., (2004) described a new symbiont bacterium (provisional name "Candidatus Hepatincola porcellionum") that densely colonizes the midgut glands (hepatopancreas) of a terrestrial isopod (P. scaber). Isopods are an order of peracarid crustaceans, including commonly known animals such as woodlice and pill bugs. Based on comparative sequence analysis of 16S rRNA they classified this new bacterium as a distant relative of the order Rickettsiales (group known as intracellular symbionts and pathogens in many animals).

Another group of researchers analysed the genome of Rickettsiella grylli, an intracellular parasite of grasshoppers and the closest known phylogenetic relative of the Coxiella group (Seshadri and Samuel, 2005). Genomic proximity of crustacean and arthropods symbionts and pathogens suggests a broad evolutionary pattern of transition from symbiotic to pathogenicity and obligatory virulence in intracellular life. 
An indication of a possible evolutionary pathway of an endosymbiont phylogenetically related to the order Rickettsiales, came from the protozoa Acanthamoeba spp. Considering the long-standing relationship of most Rickettsiales with arthropods, the related lineage of endosymbionts in protozoan hosts has had implications in the preadaptation and/or recruitment of rickettsia-like bacteria into metazoan hosts and further to invertabrates (Fritsche et al., 1999).

Another fascinating interaction was described in a linyphiid spiders E. atra, that persists in heterogeneous environments because of its ability to recolonise areas through active long-distance airborne dispersal using silk as a sail, in a process termed "ballooning". However, a Rickettsia species endosymbiont that colonizes the sub-oesaophageal ganglion of this spider impairs the ballooning process. As mentioned earlier, in the case of $Y$. pestis and its "blocking mechanism" exercised on fleas, it is clear that this "biochemical behavior" outcome helps the pathogen to spread and infect new hosts, but in the present case of this Rickettsia sp. the ecological gain is not clear from the endosymbiont point of view and it might be that it is simply an "induced disease" through its activity on the sub-oesaophageal ganglion of this spider, unrelated directly to its ecology (Goodacre et al., 2009).

Among the insects involved in transmission of Rickettsial disease, Hucko (1984) showed that house fly fed with Coxiella burnetti suspension keep their infectivity throughout their life ( 32 days) and possibly contaminate the environment during this time interval. The author also found that $C$. burnetii can survive in the fly's feces for 80 days and in dead flies as long as 90 days, therefore constituting a real health risk as $C$. burnetti is known to be airborne transmitted.

Finally, there are an increasing number of reports on Rickettsia like organisms in plants connected with phytopathogenesis (Hopkins and Mollenhauer, 1973). Whether they belong to the Rickettsia order is not clear (Evert et al., 1981); however, Davis et al. (1998) using comparative sequence analyses, showed that papaya bunchy top disease is caused by a bacterium that is a member of the genus Rickettsia. Applying PCR method, they detected this bacterium only in diseased plants but not in healthy ones as the first evidence of genus Rickettsia as a potential plant pathogen.

\subsubsection{REFERENCES}

Davis, M.J., Ying, Z., Brunner, B.R., Pantoja, A. \& Ferwerda, F.H. (1998) Rickettsial relative associated with papaya bunchy top disease. Curr. Microbiol. 36, 80-84.

De Sousa, R., Luz, T., Parreira, P., Santos-Silva, M. \& Bacellar, F. (2006) Boutonneuse fever and climate variability. Ann. N.Y. Acad. Sci. 1078, 162-169.

Easterbrook, J.D., Kaplan, J.B., Vanasco, N.B., Reeves, W.K. Purcell, R.H. et al. (2007) A survey of zoonotic pathogens carried by Norway rats in Baltimore, Maryland, USA. Epidemiol. Infect. 135, 1192-1199.

Evert, D.R., Gaines, T.P. \& French, W.J. (1981) Rickettsia-like bacteria in peach roots preceded development of visual symptoms of phony peach disease and changes in leaf elemental concentrations J. Am. Soc. Hortic. Sci. 106, 780-782.

Fritsche, T.R., Horn, M., Seyedirashti, S., Gautom, R.K., Schleifer, K-H. \& Wagner, M. (1999) In situ detection of novel bacterial endosymbionts of Acanthamoeba spp. phylogenetically related to members of the order Rickettsiales. Appl. Environ. Microbiol. 65, 206-212.

Gilot, B. \& Pautou, G. (1982) Evolution of populations of ticks (Ixodidae and Argasidae) in relation to artificialization of the environment in the French Alps. Epidemiologic effects. Acta Trop. 39, 337-354.

Goodacre, S.L., Martin, O.Y., Bonte, D., Hutchings, L., Woolley, C. et al. (2009) Microbial modification of host long-distance dispersal capacity. BMC Biol. 7, 32 doi:10.1186/1741-7007-7-32.

Hopkins, D.L. \& Mollenhauer, H.H. (1973) Rickettsia-like bacterium associated with Pierce's disease of grapes. Science 179, 298-300. 
Hucko, M. (1984) The role of the house fly (Musca domestica L.) in the transmission of Coxiella burnetii. Folia Parasitol. 31, 177-181.

Kawabata, H., Ando, S., Kishimoto, T., Kurane, I., Takano, A. et al. (2006) First detection of Rickettsia in soft-bodied ticks associated with seabirds, Japan. Microbiol. Immunol. 50, 403-406.

Mannelli, A., Mandola, M.L., Pedri, P., Tripoli, M. \& Nebbia, P. (2003) Associations between dogs that were serologically positive for Rickettsia conorii relative to the residences of two human cases of Mediterranean spotted fever in Piemonte (Italy). Prev. Vet. Med. 60, 13-26.

McDade, J.E., Shepard, C.C., Redus, M.A., Newhouse, V.F. \& Smith, J.D. (1980) Evidence of Rickettsia prowazekii infections in the United States. Am. J. Trop. Med. Hyg. 29, 277-284.

Moragues, V. \& Pinkerton, H. (1944) Variation in morbidity and mortality of murine typhus infection in mice with changes in the environmental temperature. J. Exp. Med. 79, 41-43.

Mumcuoglu, K.Y., Frish, K., Sarov, B., Manor, E., Gross, E. et al. (1993) Ecological studies on the brown dog tick Rhipicephalus sanguineus (Acari: Ixodidae) in southern Israel and its relationship to spotted fever group rickettsiae. J. Med. Entomol. 30, 114-121.

Onishchenko, G.G., Lukin, E.P. \& Syskova, T.G. (1997) A prognostic assessment of louse-borne typhus (Rickettsia prowazekii infection) in Russia. Zh. Mikrobiol. Epidemiol. Immunobiol. 6, 30-36.

Salgo, M.P., Telzak, E.E., Currie, B., Perlman, D.C., Litman, N. et al. (1988) A focus of Rocky Mountain spotted fever within New York City. N. Engl. J. Med. 318, 1345-1348.

Sanders, D.M., Parker, J.E., Walker, W.W., Buchholz, M.W., Blount, K. et al. (2008) Field Collection and genetic classification of tick-borne rickettsiae and rickettsiae-like pathogens from south Texas: Coxiella burnetii isolated from field-collected Amblyomma cajennense. Ann. N.Y. Acad. Sci. 1149, 208-211.

Satoh, H., Tsuneki, A., Inokuma, H., Kumazawa, N., Jahana, Y. et al. (2001) Seroprevalence of antibodies against spotted fever group rickettsia among dogs and humans in Okinawa, Japan. Microbiol. Immunol. 45, 85-87.

Seshadri, R. \& Samuel, J. (2005) Genome analysis of Coxiella burnetii species insights into pathogenesis and evolution and implications for biodefense. Ann. N.Y. Acad. Sci. 1063, 442-450.

Tokarevich, N.K., Freilykhman, O.A., Titova, N.M., Zheltakova, I.R., Ribakova, N.A. \& Vorobeychikov, E.V. (2006) Anthropogenic effects on changing Q fever epidemiology in Russia. Ann. N.Y. Acad. Sci. 1078, 120-123.

Vescio, M.F., Piras, M.A., Ciccozzi, M., Carai, A., Farchi, F. et al. (2008) Short report: socio-demographic and climatic factors as correlates of mediterranean spotted fever (msf) in northern Sardinia. Am. J. Trop. Med. Hyg. 78, 318-320.

Vorobeychikov, E., Vasilenko, A., Tokarevich, N., Yakovleva, L. \& Nikolaev, B. (2005) Evaluation of low concentration aerosol for infecting humans with the Q fever pathogen. Ann. N.Y. Acad. Sci. 1063, 466-470.

Wang, Y., Stingl, U., Anton-Erxleben, F., Zimmer, M. \& Brune, A. (2004) "Candidatus Hepatincola porcellionum" gen. nov., sp. nov., a new, stalk-forming lineage of Rickettsiales colonizing the midgut glands of a terrestrial isopod. Arch. Microbiol. 181, 299-304. 


\section{Chapter 2.20 Salmonelloses}

\section{[SALMONELLA SPP.]}

Salmonella is a genus closely related to Escherichia genus, both members of the extended family of Enterobacteriaceae. Salmonella is a rod-shaped, gram-negative, facultative anaerobic, non-spore forming, predominantly motile (with peritrichous flagella) bacterium. Salmonella was isolated worldwide from both cold- and warm-blooded animals (including humans) and environments contaminated with hosts' excreta. Salmonella carried by animals (as residents of the GI tract) is transmitted to humans by direct contact but the vast majority of human cases are acquired through ingestion of contaminated food and water. Salmonella nomenclature is still evolving, but the main species are listed in Table 2.20.1 (Brenner et al., 2000; Su and Chiu, 2007). In terms of time, the disease manifests itself relatively fast (from 5 to 72 hours) and depends on virulence and number of bacteria ingested (typically high numbers as a result of overgrow in food environment). The symptoms are: sudden nausea, vomiting and watery diarrhea that may contain blood, and fever $\left(\sim 39^{\circ} \mathrm{C}\right)$. Complications can occur mainly in immunocompromised patients for example: meningitis, septicemia, osteomyelitis, arthritis, peritonitis, urinary tract infection (UTI) and endocarditis. In animals it expresses as acute gastroenteritis or is silent (carrier state in reptiles).

\subsubsection{SALMONELLA AND ENVIRONMENT}

Presently, there is an extensive literature on food- and waterborne Salmonellosis that will not be reviewed in this chapter but occasionally mentioned; however, it is important to emphasize that its transmission is in general through the oral route by consumption of contaminated food (e.g. meat, dairy products, eggs and egg products), water and direct contact (Mataragas \& Drosinos, 2009; Gomez et al., 1997; Schuster et al., 2005; Woodall, 2009). There are important aspects of global infections embroiling multi-drug resistance bacteria through meat import based on international trade (Espié et al., 2005). Other important Salmonella food borne factors are: livestock feed, animal health conditions and slaughterhouse procedures (evisceration, etc.) (Maciorowski et al., 2007). It should be mentioned that Salmonella is a highly resistant Enterobacteriaceae when outside human/animal intestine (its optimal milieu), a resistance accredited to diverse survival mechanisms (Foster and Spector, 1995). Orozco et al. (2008) 
showed that hydroponic tomato farm greenhouses were infected with Salmonella through runoff flood and gained entry of wild animals (opossums, mice, and sparrows), both factors introducing the pathogen in spite of a reasonable protection level.

Table 2.20.1 Salmonella genus classification (serovars, hosts and transmission).

\begin{tabular}{|c|c|c|c|c|c|c|}
\hline $\begin{array}{l}\text { Salmonella } \\
\text { species and } \\
\text { subspecies }\end{array}$ & $\begin{array}{l}\text { Other } \\
\text { subspecies } \\
\text { terminology }\end{array}$ & $\begin{array}{l}\text { Serotypes or } \\
\text { serovars }\end{array}$ & $\begin{array}{l}\text { No. of } \\
\text { serovars in } \\
\text { subspecies }\end{array}$ & Usual Host & $\begin{array}{l}\text { Human } \\
\text { host }\end{array}$ & Transmission \\
\hline $\begin{array}{l}\text { S. enterica } \\
\text { subsp. } \\
\text { enterica }\end{array}$ & (I) & $\begin{array}{l}\text { Choleraesuis, } \\
\text { Enteridis, } \\
\text { Paratyphi, Typhi, } \\
\text { Typhimurium }\end{array}$ & 1,504 & $\begin{array}{l}\text { Warm-blooded } \\
\text { animals }\end{array}$ & + & $\begin{array}{l}\text { Food, water, } \\
\text { direct contact }\end{array}$ \\
\hline $\begin{array}{l}\text { S. enterica } \\
\text { subsp. } \\
\text { salamae }\end{array}$ & (II) & $9,46: z: z: 39$ & 502 & $\begin{array}{l}\text { Cold-blooded } \\
\text { animals and } \\
\text { environment }\end{array}$ & + & $\begin{array}{l}\text { Food, water, } \\
\text { direct contact, } \\
\text { reptiles }\end{array}$ \\
\hline $\begin{array}{l}\text { S. enterica } \\
\text { subsp. } \\
\text { arizonae }\end{array}$ & (IIla) & 43:z29:- & 95 & $\begin{array}{l}\text { Cold-blooded } \\
\text { animals and } \\
\text { environment }\end{array}$ & + & Reptile \\
\hline $\begin{array}{l}\text { S. enterica } \\
\text { subsp. } \\
\text { diarizonae }\end{array}$ & (IIIb) & $6,7: 1, \mathrm{v}: 1,5,7$ & 333 & $\begin{array}{l}\text { Cold-blooded } \\
\text { animals and } \\
\text { environment }\end{array}$ & + & Reptiles \\
\hline $\begin{array}{l}\text { S. enterica } \\
\text { subsp. } \\
\text { houtenae }\end{array}$ & (IV) & $21: m, t:-$ & 72 & $\begin{array}{l}\text { Cold-blooded } \\
\text { animals and } \\
\text { environment }\end{array}$ & + & Food, reptiles \\
\hline $\begin{array}{l}\text { S. enterica } \\
\text { subsp. indica }\end{array}$ & $(\mathrm{VI})$ & 59:z36:- & 13 & $\begin{array}{l}\text { Cold-blooded } \\
\text { animals and } \\
\text { environment }\end{array}$ & + & $\begin{array}{l}\text { Food }(+ \\
\text { vegetables), } \\
\text { reptiles }\end{array}$ \\
\hline S. bongori & $(\mathrm{V})$ & 13,22:z39:- & 22 & $\begin{array}{l}\text { Cold-blooded } \\
\text { animals and } \\
\text { environment }\end{array}$ & + & Reptiles \\
\hline $\begin{array}{l}\text { S. } \\
\text { subterranea }\end{array}$ & & & 1 & $\begin{array}{l}\text { Environment } \\
\left(\mathrm{U}^{\mathrm{VI}} \text {-contaminated }\right. \\
\text { subsurface } \\
\text { sediment })\end{array}$ & $?$ & $?$ \\
\hline Total & & & 3,829 & & & \\
\hline
\end{tabular}

Groundwater was found to be the main significant independent risk factor linked to S. choleraesuis transmission, following adjustments for other potential confounders in a case-control study intended to identify the possible demographic and environmental risk factors associated with $S$. choleraesuis infection in Taiwan (Li et al., 2009). It should be mentioned that pigs are considered as the only animal reservoir of $S$. choleraesuis, and therefore it may very well be that the dwellings of clinical cases could be near pig farms or use groundwater somehow connected to these farms. The groundwater's proximity to contaminated sources (landfill) proved to be a high risk of contamination through the leaching process (Adeyemi et al., 2007). As previously mentioned in connection with other bacteria, Salmonellae too interact with protozoa such as $T$. pyriformis and $A$. rhysodes, using their ability to survive and replicate 
within their protozoan protective environment, increasing their environmental transmission potential (Snelling et al., 2006).

Recent publications showed that protozoa bestow protection (against low concentrations of calcium hypochlorite) and enhanced survival of the food-borne pathogen S. enterica through food vacuoles (vesicles) released by a Tetrahymena sp. isolated from moist soil (Brandl et al., 2005). Moreover, Gourabathini et al. (2008) reported the isolation of similar protozoa from fresh lettuce and spinach plants, which can internalize pathogenic bacteria such as Salmonella enterica and then release them through food vacuoles as an environmental defense mechanism against bacterial pathogens. These authors also called attention to the possible proximity of the vacuolated released pathogens to stomata cells that may possibly support further plant internalization!

Nevertheless, when various amoebae, such as Acanthamoeba, Tetramitus, Naegleria and Hartmannella, were isolated from different vertebrates it was observed that their feeding preferences on bacteria appear to reflect their environment, not their taxonomic relationships (Wildschutte and Lawrence, 2007). These authors suggested an attractive hypothesis about the survival mechanism of Salmonella spp. as human and animal pathogens against being predated by amoebae (Figure 2.20.1). They proposed that O-antigen determinant (located on bacterial outer membrane) is the main key for predation recognition by the amoebae while the prey choice is governed by their environment (host animal) and not their taxonomic relationships (genome). In a previous study, Tezcan-Merdol et al., (2004) showed that Acanthamoeba spp. can differentiate between different serovars of Salmonellae and that internalization is associated with cytotoxic effects mediated by defined Salmonella virulence loci.

Concerning the relation between plants and bacterial pathogens, Barak et al. (2007) demonstrated that $S$. enterica uses other surface polymers composing the extracellular matrix, such as cellulose and O-antigen capsule, in order to colonize plants. Schikora et al. (2008) used Salmonella enterica serovar typhimurium to prove that it is a real endopathogen of Arabidopsis thaliana and could successfully infect this plant. The definitive answer came from an Israeli group that clearly showed that Salmonella enterica induced by light can chemotactically penetrate open stomata, possibly explaining the reported high risk of Salmonellosis in connection with contaminated vegetables (Kroupitski et al., 2009; Manas et al., 2009). Another epidimeliogical study, performed in Oregon and British Columbia, showed that Salmonella transmission through plants can occur by consumption of alfalfa (Medicago sativa) sprouts originating from contaminated seeds (133 reported cases of Salmonella enterica serotype Newport-SN) (Van Beneden et al., 1999). Alfalfa sprouts are excellent means for transmission of Salmonella and other enteric bacteria, as seeds are stored for extended time periods (even years) in dry environment. The sprouting process which takes 3 to 5 days, favors Salmonella growth to 3 to 4 orders of magnitude and further refrigeration does not reduce their number significantly and final consumption occurs without washing or cooking, therefore leaving the consumer completely unprotected.

There is an extensive literature on environmental factors impacting Salmonella presence in the coastal area, mainly due to the recreational and marine food role of these sites. Setti et al. (2009) surveyed 122 $\mathrm{km}$ of the coastline of Agadir (southern Morocco) for Salmonella spp., related to environmental parameters. They sampled seawater, marine sediment and mussels and found an overall Salmonella spp. prevalence of $7.1 \%$ (at the following ratios: mussels-10\%, sediment-6.8\% and seawater-4.1\%). Amongst observed environmental variables, rainfall was the only parameter directly related to Salmonella occurrence, showing a linear positive effect well supported by other studies (Collin et al., 2008). Salmonella highest numbers in shellfish is obviously related to these bivalve mollusks high filtration potential ability to concentrate various contaminants with high efficiency. A similar trend was found in mussels, clams and oysters from the coastal seawater of Galicia (Spain) and coastal areas of Bahia de Todos Santos (Mexico) (Martinez-Urtaza et al., 2004; Simental and Martinez-Urtaza, 2008). In addition, 
on the food chain scale, California's sea otters feeding on mollusks were found to harbor different Salmonella serovars beside other enteric pathogens (Miller et al., 2010). Otters from more urbanized coastlines and areas with high freshwater runoff mainly in the rainy season (near outflows of rivers or streams) were more likely to test positive for bacterial pathogens. Otters exposure to fecally-associated protozoan pathogens such as Toxoplasma gondii and Sarcocystis neurona and enteric pathogenic bacteria, is suspected of impairing sick otters recovery in these geographical areas.

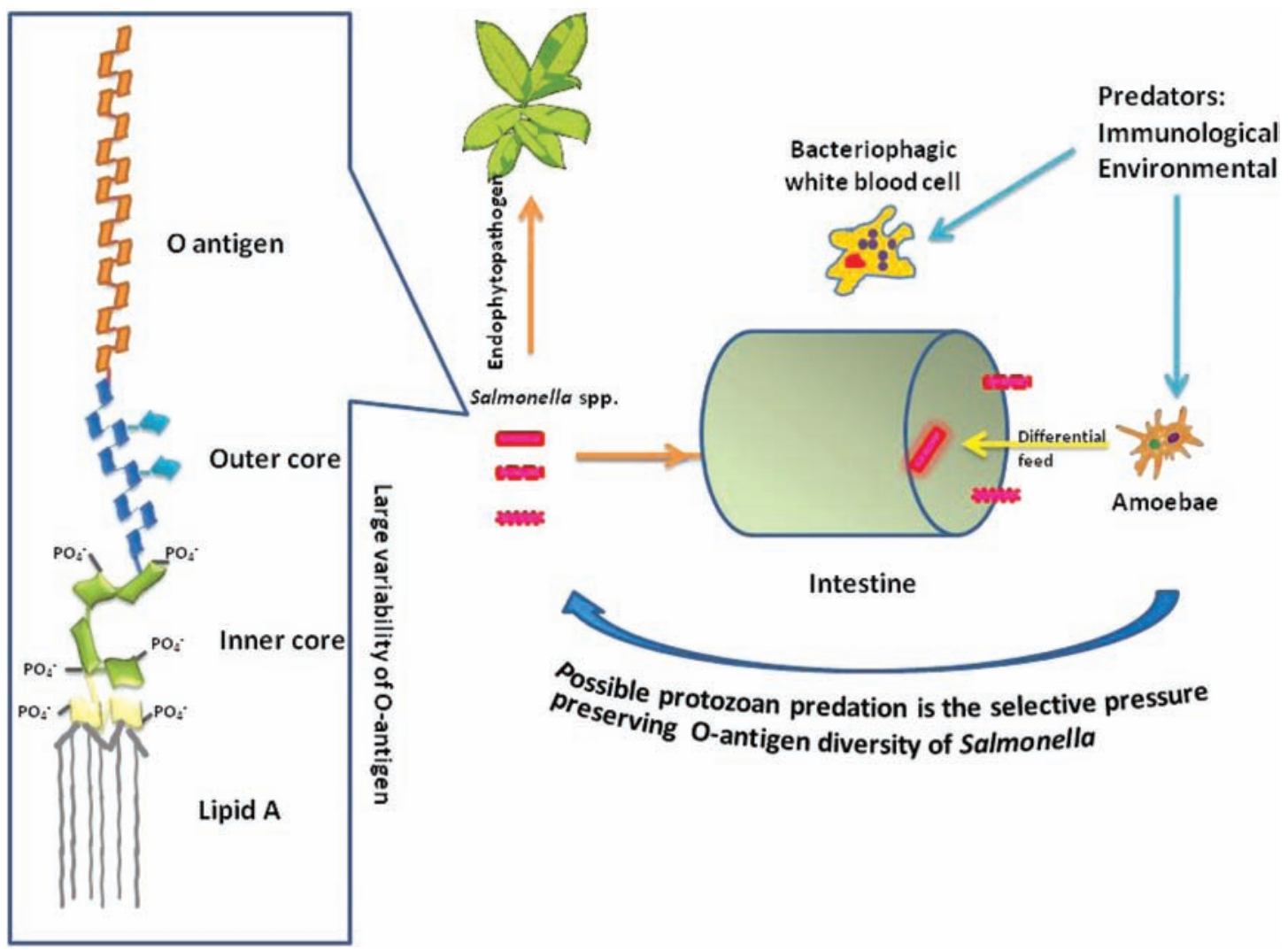

Figure 2.20.1. Predators prey choice and phytopathogenesis based on surface antigens of Salmonella spp.

In all these cases, presence of Salmonella spp. in coastal areas was merely confined to rainy periods, stream discharges and runoff, all factors involved in the transport of this pathogen via streams from source points to sea (Martinez-Urtaza et al., 2004).

In another geographical edge (Australia), comprising both tropical and sub-tropical climates, researchers found that temperature and rainfall were the only significant parameters, suggesting that a potential $1^{\circ} \mathrm{C}$ rise in maximum or minimum temperature may cause a very similar increase in the number of Salmonelloses cases in both climatic regions (Zhang et al., 2010).

Canadian researchers studied the survival of Salmonella salamae in estuarine waters of the St. Lawrence River (Monfort et al., 1994). Salmonalla salamae cells exposed to starvation, increasing salinity and solar irradiation showed a rapid decline in viability; however, when bacteria were kept in darkness while 
exposed to increasing salinity, their die-off rate was even higher than of those exposed to sunlight. Hence S. salamae cells exposed to sunlight seemed to be more resistant to gradual salinity stress than cells that were not subjected to sunlight. Bacteria exposed to sunlight irradiation are damaged by the UV short wave spectra causing DNA damage, however bacteria are able to cope with this germicidal activity. Bacterial sunlight damage repair (reactivation) has two well known enzymatic mechanisms: photoreactivation and dark repair. The photoreactivation mechanism, which requires light is much more effective than the dark mechanism. Zaafrane et al. (2004), studing Salmonella thyphimurium survival in sea water, found results similar to those of the Canadian researchers and furthermore emphasized that "bacteria grown in media with high salinity or osmolarity and transferred to sea water in stationary phase were more resistant to irradiation than those grown in media with low salinity".

Jones (1971) already reported that the death of sewage bacteria in seawater is mainly due to starvation and to natural heavy metal toxicity. In his study, other factors were found to be effective in controlling bacterial survival such as sunlight, temperature, salinity, antibiotics, bacteriophages, adsorption and sedimentation, parasitism, lysis, and protozoan predation. Enterobacteriaceae including Salmonella possess the $\sigma^{\mathrm{S}}$ subunit, encoded by rpoS gene of RNA polymerase, which functions as a master regulator of general stress responses (cessation of growth, acid resistance, thermotolerance and adaptation to growth in a medium of high osmolarity). The $\sigma^{\mathrm{S}}$ level increases in response to environmental stresses in cell; hence sunlight irradiation damage of the gene rpoS, lacking an effective repair, will decrease cell $\sigma^{\mathrm{S}}$ level leading to cell death under extreme environmental conditions.

When dealing with bodies of water it should be remembered that fish are also involved in transmission of Salmonellae. Miruka et al. (2009) studied Nile tilapia fish for contamination with members of Enterobacterioceae. Among the fish batch examined, 52.5\% were positive for Enterobacteriaceae among which $11.1 \%$ with S. typhimurium and $25.4 \%$ with S. enteridis compared to an open-air fish market where S. typhimurium was present in $20 \%$ of fish. The authors concluded that the high level of Salmonella pathogens in fish indicates that beaches in this area are contaminated with untreated municipal sewage, runoff and storm-water.

Soil is also highly related to Salmonella ecology, mainly through utilization of organic fertilizers such as manure for different soils. Castro-Del Campo et al. (2010) studied the regrowth potential of Salmonella enterica subsp. enterica in three soil types: vermicompost, Class A biosolids and amended. At 30\% moisture, the longest survival persistence of this pathogen (up to 20 days) was obtained for amended soil. Additional studies showed even more extended survival periods of time of Salmonella in soil and swine manure environments (for 45 days, temperature dependent) (Guan and Holley, 2003). On bacterial soil endurance aspect, it should be pointed out that a Salmonella typhimurium strain has been shown to survive in soil for up to 54 days with decline in colony numbers (measured by direct plate culture) but constant viable cells when measured with 5-cyano-2,3-ditolyl tetrazolium chloride (CTC), as respiration-sensitive dye. A close look at these results revealed that direct CTC soil counts of $S$. typhimurium confirmed that intact cells were still present in an intact metabolic state after 54 days in the non-sterile soil, indicating a significant proportion of unculturable but active cells (Marsh et al., 1998).

In an extra framework, soil was also reported as a possible Salmonella carrier state in amphibians and reptiles kept in terraria (private or zoological parks) (Hassl et al., 2003). In Austria, where this study was carried out, there are $\sim 90,000$ households that keep a large variety of these "kind of pets". The authors detected a strong association between Salmonella subspecies (I and III) among captive reptiles and free living lizards accordingly. Kourany and Telford (1981) surveyed lizard species in Panama for Salmonella presence. Among these species, 29.4\% were positive for Salmonella (with a range from 5.6 to $92.3 \%$ ) with highest rates during dry season. The highest infection rate was detected in secretive $(42.0 \%)$ and terrestrial $(42.6 \%)$ lizards, whereas the lowest was among the scansorial lizards $(17.5 \%)$. 
Lizard soil contact reveals the possible contamination through excreta-contaminated ground. The infected lizards' distribution varied from remote rural and forested regions to urban developments, revealing their potential reservoir role. In the same geographical area (Panama) other animals such as opossums and rodents were also positive for Salmonella ( 10 to 20\%) especially throughout the dry season (Kourany et al., 1976).

Interaction between algae and Salmonella has been shown in Lake Michigan (USA) related to algal bloom. Chladophora glomerata is a filamentous, green alga that grows in nearshore water, on rocks and other hard surfaces. After their peak bloom, these algae detach and accumulate on the shore, creating an environmental problem through aesthetic, malodorous conditions and growth enhancement of pathogens such Salmonella (Byappanahalli et al., 2009; Verhougstraete et al., 2010).

As a final point, a group of ungulate veterinarians reported on pathogens and climate influence on the fecundity of ungulates in natural conditions. Beside animal density, they identified two other major confounding effects on the reproductive success of an alpine chamois ungulate (Rupicapra rupicapra): 1) prevalence of antibodies against pathogenic bacteria (among them, Salmonella enterica serovar abortusovis (36\%), and 2) weather conditions (31\%). Bad weather conditions that may act either as a direct stress or through food availability, were linked to increased infection with pathogens including Salmonella spp. (Pioz et al., 2008).

\subsubsection{REFERENCES}

Adeyemi, O., Oloyede, O.B. \& Oladiji, A.T. (2007) Physicochemical characteristics of leachate-contaminated groundwater. Asian J. Biochem. 2, 343-348.

Barak, J.D., Jahn, C.E., Gibson, D.L. \& Amy, O. Charkowski, A.O. (2007) The Role of Cellulose and O-Antigen Capsule in the Colonization of Plants by Salmonella enteric. Mol. Plant Microbe Interact. 20, 1083-1091.

Brandl, M.T., Rosenthal, B.M., Haxo, A.F. \& Berk, S.G. (2005) Enhanced survival of Salmonella enterica in vesicles released by a soil-borne Tetrahymena species. Appl. Environ. Microbiol. 71, 1562-1569.

Brenner, F.W., Villar, R.G., Angulo, F.J., Tauxe, R. \& Swaminathan, B. (2000) Salmonella nomenclature. J. Clin. Microbiol. 38, 2465-2467.

Byappanahalli, M.N., Sawdey, R., Ishii, S., Shively, D.A., Ferguson, J.A. et al. (2009) Seasonal stability of Cladophora-associated Salmonella in Lake Michigan watersheds. Water Res. 43, 806-814.

Castro-Del Campo, N., Espinoza, E., Valdez-Torres, J.B., Gerba, C.P. \& Chaidez, C. (2010) Comparison of Salmonella enterica subsp. enterica survival in agricultural soil amended with vermicompost and class A biosolids. J. Resid. Sci. Technol. 7, 81-85.

Collin, B., Rehnstam-Holm, A-S. \& Hernroth, B. (2008) Faecal contaminants in edible bivalves from Maputo bay, Mozambique: seasonal distribution, pathogenesis and antibiotic resistance. Open Nutr J 2, 86-93.

Espié, E., De Valk, H., Vaillant, V., Quelquejeu, N., Le Querre, F. \& Weill, F.X. (2005) An outbreak of multidrug-resistant Salmonella enterica serotype Newport infections linked to the consumption of imported horse meat in France. Epidemiol. Infect. 133, 373-376.

Foster, J.W. \& Spector, M.P. (1995) How Salmonella survive against the odds. Annu. Rev. Microbiol. 49, 145-174.

Gomez, T.M., Motarjemi, Y., Miyagawa, S., Kaferstein, F.K. \& Stohr, K. (1997) Foodborne salmonellosis. World Health Stat $Q \mathbf{5 0}, 81-89$.

Gourabathini, P., Brandl, M.T., Redding, K.S., Gunderson, J.H. \& Berk, S.G. (2008) Interactions between food-borne pathogens and protozoa isolated from lettuce and spinach. Appl. Environ. Microbiol. 74, 2518-2525.

Guan, T.Y. \& Holley, R.A. (2003) Pathogen survival in swine manure environments and transmission of human enteric illness-a review. J. Environ. Qual. 32, 383-392.

Hassl, A. \& Benyr, G. (2003) Hygienic evaluation of terraria inhabited by amphibians and reptiles: cryptosporidia, free-living amebas, salmonella. Wien. Klin. Wochenschr. 115, 68-71.

Jones, G.E. (1971) Fate of freshwater bacteria in the sea. Dev Ind Microbiol Ser 12, 141-151. 
Kourany, M. \&Telford, S.R. (1981) Lizards in the ecology of Salmonellosis in Panama. Appl. Environ. Microbiol. 41, $1248-1253$.

Kourany, M., Bowdre, L. \& Herrer, A. (1976) Panamanian forest mammals as carriers of Salmonella. Am. J. Trop. Med. Hyg. 25, 449-455.

Kroupitski, Y., Golberg, D., Belausov, E., Pinto, R., Swartzberg, D. et al. (2009) Internalization of Salmonella enterica in leaves is induced by light and involves chemotaxis and penetration through open stomata. Appl. Environ. Microbiol. 75, 6076-6086.

Li, T-H, Chiu, C-H, Chen, W-C., Chen, C-M., Hsu, Y-M. et al. (2009) Consumption of groundwater as an independent risk factor of Salmonella choleraesuis infection: a case-control study in Taiwan. J. Environ. Health 72, 28-31.

Maciorowski, K.G., Herrera, P., Jones, F.T., Pillai, S.D. \& Ricke, S.C. (2007) Effects on poultry and livestock of feed contamination with bacteria and fungi. Anim. Feed Sci. Technol. 133, 109-136.

Manas, P., Castro, E. \& De Las Heras, J. (2009) Irrigation with treated wastewater: effects on soil, lettuce (Lactuca sativa) crop and dynamics of microorganisms. Journal J Environ Sci Health A Tox Hazard Subst Environ Eng 44, 1261-1273.

Marsh, P., Morris, N.Z. \& Wellington, E.M.H. (1998) Quantitative molecular detection of Salmonella typhimurium in soil and demonstration of persistence of an active but non-culturable population. FEMS Microbiol. Ecol. 27, 351-363.

Martinez-Urtaza, J., Saco, M., de Novoa, J., Perez-Piñeiro, P., Peiteado, J. et al. (2004) Influence of environmental factors and human activity on the presence of Salmonella serovars in a marine environment. Appl. Environ. Microbiol.70, 2089-2097.

Martinez-Urtaza, J., Liebana, E., Garcia-Migura, L., Perez-Piñeiro, P. \& Saco, M. (2004) Characterization of Salmonella enterica serovar typhimurium from marine environments in coastal waters of Galicia (Spain). Appl. Environ. Microbiol. 70, 4030-4034.

Mataragas, M. \& Drosinos, E.H. (2009) Microbial foodborne pathogens. In: Leo, M.L. Nollet, L.M.L. \& Toldra, F. (Eds) Handbook of Processed Meats and Poultry Analysis, CRC Press, pp. 461-497.

Miller, M.A., Byrne, B.A., S. Jang, S.S., Dodd, E.M., Dorfmeier, E. et al. (2010) Enteric bacterial pathogen detection in southern sea otters (Enhydra lutris nereis) is associated with coastal urbanization and freshwater runoff. Vet. Res. 41, 01.

Miruka, D.O., Wandili, S., Kakai, R. \& Waindi, E.N. (2009) Isolation of Salmonella and Shigella from fish harvested from the Winam Gulf of Lake Victoria, Kenya. J Infect Dev Ctries 3, 99-104.

Monfort, P., Baleux, B. \& Lamontagne, M. (1994) Effects of environmental factors present in the St. Lawrence Estuary (Quebec, Canada) on experimental survival of Salmonella salamae as determined by flow cytometry. Can. J. Microbiol. 40, 712-719.

Orozco, R.L., Iturriaga, M.H., Tamplin, M.L., Fratamico, P.M., Call, J.E., Luchansky, J.B., Escartin, E.F. (2008) Animal and environmental impact on the presence and distribution of Salmonella and Escherichia coli in hydroponic tomato greenhouses. J. Food Prot. 71, 676-683.

Pioz, M., Loison, A., Gauthier, D., Gibert, P., Jullien, J-M. et al. (2008) Diseases and reproductive success in a wild mammal: example in the alpine chamois. Oecologia 155, 691-704.

Schikora, A., Carreri, A., Charpentier, E. \& Hirt, H. (2008) The dark side of the salad: Salmonella typhimurium overcomes the innate immune response of Arabidopsis thaliana and shows an endopathogenic lifestyle. PLoS ONE 3, e2279. doi:10.1371/journal.pone.0002279.

Schuster, C.J., Ellis, A.G., Robertson, W.J., Charron, D.F., Aramini, J.J. et al. (2005) Infectious disease outbreaks related to drinking water in Canada, 1974-2001. Can J Public Health 96, 254-258.

Setti, I., Rodriguez-Castro, A., Pata, M.P., Cadarso-Suarez, C., Yacoubi, B. et al. (2009) Characteristics and dynamics of Salmonella contamination along the Coast of Agadir, Morocco. Appl. Environ. Microbiol. 75, 7700-7709.

Simental, L. \& Martinez-Urtaza, J. (2008) Climate patterns governing the presence and permanence of Salmonellae in coastal areas of Bahia de Todos Santos, Mexico. Appl. Environ. Microbiol., 74, 5918-5924.

Snelling, W.J., Moore, J.E., McKenna, J.P., Lecky, D.M., Dooley, J.S.G. (2006) Bacterial-protozoa interactions; an update on the role these phenomena play towards human illness. Microbes Infect. 8, 578-587. 
Su, L-H. \& Chiu, C-H. (2007) Salmonella: Clinical importance and evolution of nomenclature. Chang Gung Med J 30, 210-219.

Tezcan-Merdol, D., Ljungström, M., Winiecka-Krusnell, J., Linder, E., Engstrand, L. \& Rhen, M. (2004) Uptake and replication of Salmonella enterica in Acanthamoeba rhysodes. Appl. Environ. Microbiol., 70, 3706-3714.

Van Beneden, C.A., Keene, W.E., Strang, R.A., Werker, D.H., King, A.S. et al. (1999) Multinational outbreak of Salmonella enterica serotype Newport infections due to contaminated alfalfa sprouts. J Am Med Assoc 281, $158-162$.

Verhougstraete, M.P., Byappanahalli, M.N., Rose, J.B. \& Whitman, R.L. (2010) Cladophora in the Great Lakes: impacts on beach water quality and human health. Water Sci. Technol. 62, 68-76.

Wildschutte, H. \& Lawrence, J.G. (2007) Differential Salmonella survival against communities of intestinal amoebae. Microbiology 153, 1781-1789.

Woodall, C. J. (2009) Waterborne diseases - What are the primary killers? Desalination 248, 616-621.

Zaafrane, S., Maatouk, K., Gauthier, J.M. \& Bakhrouf, A. (2004) Influence of previous culture conditions and the presence of the rpoS gene in Salmonella typhimurium survival in seawater exposed to sunlight. Can. J. Microbiol. 50, 341-350.

Zhang, Y., Bi, P. \& Hiller, J.E. (2010) Climate variations and Salmonella infection in Australian subtropical and tropical regions. Sci. Total Environ. 408, 524-530. 


\section{Chapter 2.21}

\section{Staphylococcal Infections}

\section{[STAPHYLOCOCCI SPP.]}

The genus Staphylococcus is a group of gram-positive bacteria, grape-like cluster of cocci, non-spore forming, facultative anaerobes and desiccation resistant. The group has an additional differentiation based on coagulase activity (negative or positive reaction). Coagulase is an enzyme that converts blood fibrinogen to fibrin causing plasma clot (e.g., S. aureus is a coagulase-positive microorganism). The majority of Staphylococci are harmless, present in soil, water, skin of humans and animals and even human saliva (Lamka et al., 1980; Kelesidis and Tsiodras, 2010). In many animals it was isolated from skin infections and mastitis, including from more exotic ones such as the white-eared opossum (Siqueira et al., 2010). Two species are clearly recognized as zoonotic pathogens: Staphylococcus aureus a resilient foe and infrequently Staphylococcus intermedius. There are other Staphylococci family members involved in food and water-borne diseases, but they will not be described here. Staphylococcal infectious diseases exhibit themselves as: skin impetigo, folliculitis, abscesses, furuncles and in more serious cases as pneumonia, endocarditis, sinusitis, otitis, osteomyelitis and septic arthritis. Beside pathogenicity, one of the main negative aspects of $S$. aureus is its evolutionary resistance to methicilline (a narrow-spectrum $\beta$-lactam antibiotic of the penicillin class) (Livermore, 2000), though a recent publication reported skin infections among college football team members attributed to a community-acquired pathogenic $S$. aureus strain that lost its methicillin resistance, but retained important virulence factors (Fontanilla et al., 2010). The important Staphylococcal strains are presented in Table 2.21.1, including antibiotic resistance to some common antibiotics and their coagulase activity.

\subsubsection{STAPHYLOCOCCUS AND ENVIRONMENT (FIGURE 2.21.1)}

As previously mentioned, staphylococci are also inhabitants of soil environment. Their soil permanent association with diverse types of bacteria may convey a variety of genetic characteristics, including antibiotic resistance. Polak and Novick (1982) showed that a common plasmid found in bacilli and $S$. aureus is highly homologous, except for the region occupied by their resistance determinants, suggesting possible natural transfer between the two bacterial types. Soil is also the source of dust and 
therefore a carrier of airborne bacteria. Banana et al. (2001) found S. aureus as one of the most frequently isolated dust microorganisms originating from soil, which probably may explain its prevalence in human nostrils. These authors also reported its high prevalence in cinema halls (25.35\%) and residential areas $(18.75 \%)$ alluding to potential cross-contamination by air-borne particles.

Table 2.21.1 Some important characteristics of Staphylococcus species.

\begin{tabular}{|c|c|c|c|c|c|}
\hline \multicolumn{5}{|c|}{ Resistance } & \multirow[t]{2}{*}{ Coagulase } \\
\hline Species & Host & Novobiocin & Polymyxin B & Methicillin & \\
\hline S. aureus & Animals, Humans & - & + & + & + \\
\hline S.epidermidis & Humans & - & + & + & - \\
\hline S. haemolyticus & Humans, Apes, Lemurs & - & - & $d$ & - \\
\hline S. lugdunensis & Humans, Goats & - & $d$ & $?$ & + \\
\hline $\begin{array}{l}\text { S. schleiferi subsp. } \\
\text { schleiferi }\end{array}$ & Humans & - & - & + & + \\
\hline S. saprophyticus & Humans & + & - & $?$ & - \\
\hline S. intermedius & Dogs, Humans & - & - & + & + \\
\hline S. hyicus & Turkey, Swine, Cattle & - & + & $?$ & + \\
\hline
\end{tabular}

dVariable

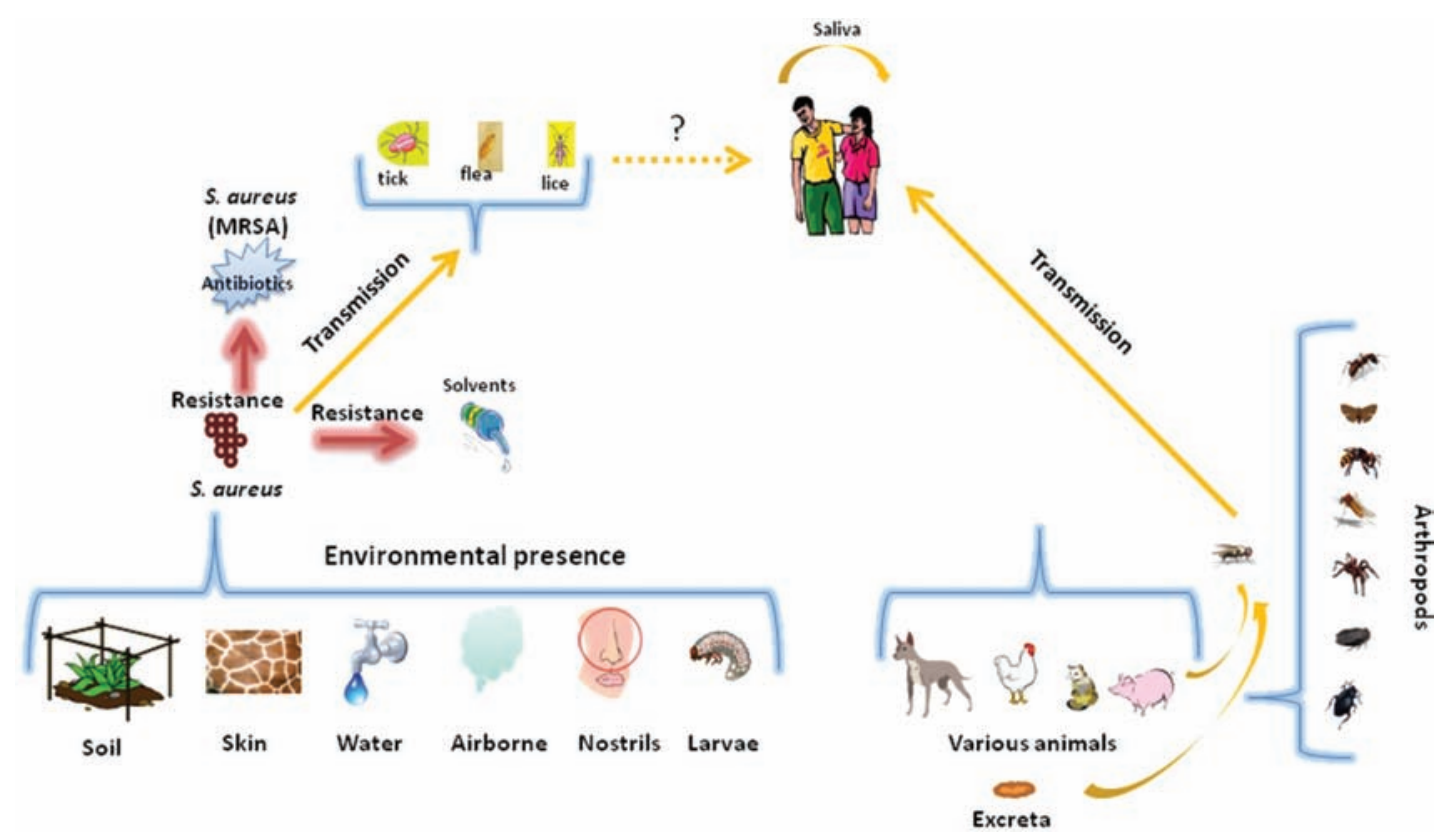

Figure 2.21.1. Staphylococci spp. environmental behavior and transmission

Most species of staphylococci are harmless and inherent in the normal flora of human and animal skin and mucous membranes. Among other species of this genus, $S$. aureus is also a persistent commensal 
organism of the anterior nares in $20 \%-40 \%$ of humans without any clinical symptoms (Wertheim et al., 2005). Nevertheless, nasal carriage seems to be a major risk factor for successive infections. The asymptomatic human group includes non- and intermittent carriers, both at low risk of reinfection. Ruimy et al. (2010) investigate different risk factors such as age, gender, underlying comorbidities, household sharing, smoking, hospital admission, contact with animals, antibiotics use and genetic polymorphism, that may explain the colonization variability of $S$. aureus in an isolated group of humans (Wayampi Amerindians living in an isolated village in the Amazonian forest). Based on bivariate analyses adjusted by Holm's test for multiple testing, the most significant and predominant factor involved was found to be the genetic variability among the group individuals.

Staphylococci ubiquity in the environment had been presented by Murrell et al. (2003) who surveyed ticks, lice and fleas for their microbial flora, in Australia. Staphylococci of the subspecies (Staphylococcus succinus, S. saprophyticus, S. xylosus, Staphylococcus sciuri, S. lugdunensis, S. warneri, S. saccharolyticus, S. capitus, S. caprae, S. epidermidis and others) had been isolated from most of the tested ticks and lice beside a large variety of other bacteria. S. aureus was absent, but $S$. intermedius was isolated from ticks. Graham et al. (2009) collected flies near broiler chicken houses and screened for antibiotic-resistant bacteria carried by these insects. The authors reported on enterococci (to be discussed further) and staphylococci (S. aureus, S. xylosus, S. saprophyticus, and S. epidermidis) that harbor antibiotic resistance [the most common reported resistance gene was: erm (A), erythromycinresistance]. Their study strongly suggests that flies can exercise as vectors and contribute to human exposures through antibiotic-resistant bacteria (present in their digestive tracts and their external surface) dispersal when in close contact with intensive poultry production areas (Nmorsi et al., 2007). The staphylococcal carrier role of the house fly was also supported by a study in peninsular Malaysia that showed a large bacterial diversity harbored by flies, revealing among other things that carrier state is horizontal and not vertical with these "hiking" bacteria (Nazni et al. 2005). Similar results with carrier flies were also obtained in Burkina Faso, in a nearby vending area close to waste and sewage, which provided food and harborage for these insects (Barro et al., 2006). Cutaneous staphylococci (60\% penicillin-resistant) possible direct transmission by flies has been also reported, based on the observation that Hippelates flies feed on purulent skin lesions (Allen and Taplin, 1974).

Additional arthropods such as mosquitoes, Tenebrionid beetles, flies, German cockroaches, wasps, ants, spiders, non-biting midges, moths, beetles isolated from a health care facility, were also shown to harbor gram-positive bacteria (13\% prevalence) while among staphylococci S. hominis was the dominant one, displaying multiple-antibiotic resistance (Sramova et al., 1992).

An interesting study was published by Robacker and Flath (1995) in which they showed that $S$. aureus grown in tryptic soy broth cultures produced volatile compounds that attract fruit flies. Odor production is one of the mechanisms by which, in a close ecosystem, a sessile organism can communicate with another motile organism and associate with it, therefore suggesting a possible bacterial transmission by these flies.

With regard to arthropods, one should remember at this point the potential use of greenbottle fly larvae to heal wounds infected with $S$. aureus and MRSA strains in severe cases, where antibiotics are useless (so called "maggot therapy") (Bexfield et al., 2004; Bruggmann et al., 2006). Park et al. (2010) reported on antibacterial acitivity of ethanol and water extracts from fly maggots against methicilline-resistant S. aureus (MRSA).

There is still a debate on the benefit of this therapeutic method, but it became increasingly clear that these larvae are of a beneficial potential. From the evolutionary point of view, it is very logical that larvae should have an antimicrobial weapon given that they are exposed to a large variety of environmental microbial flora, throughout their development (Sherman, 2009). 
On the subject of plants, Staphylococcus aureus was reported to be strongly inhibited by plants hormones such as IAA, indolebutyric acid (IBA), naphthaleneacetic acid (NA), 2,5-dichlorophenoxyacetic acid (2,5-D)(Bouillenne and Bouillenne-Walrand, 1951). This phenomenon is probably linked to a possible double role of these hormones. The authors recommended use of plant hormones in controlling human cutaneous infections. Historically, is well known in traditional medicine the use of plants to combat skin infections and various diseases (Navarro et al., 1996).

Bischoff et al. (2004) showed that infection with rhinovirus enhances the spread of coagulase-negative staphylococci through increased colonization of the latter due to nasal tissue damage inflicted by this virus. However, this problem can be easily solved by simple means such as: surgical scrubs, gowns and masks that are excellent barriers against bacteria spread (Bischoff et al., 2007).

In New Zealand, researchers reported on methicillin-resistant S. aureus isolates, the British epidemic MRSA 15 strain (EMRSA-15) from dogs, cats, cow's milk and anterior nares of a healthy hospital staff member involved in animal care. The authors concluded that "MRSA can cause clinically overt and difficult-to-treat infections in animals in New Zealand and the rapid emergence of EMRSA-15 as the dominant MRSA strain in humans, resulted in infection spillover to animals". This conclusion is also supported by an old study performed on wild boars and domestic pigs, where the authors reported on an unusual discovery that staphylococci were absent in all wild boars' fecal samples when living in their natural environment. As the specific habitat of staphylococci is in man and wild boars are the ancestors of domestic pigs, it is very plausible that humans are the origin of $S$. aureus in these animals as well other pets domesticated for thousands of years (van Dijck \& van de Voorde, 1979; Morgan, 2008; Leonard and Markey, 2008; Guardabassi et al., 2003).

In a recent review, Loeffler and Lloyd (2010) raised the same concept of community-acquired MRSA rising number of cases, pointing in the direction of animals as the reservoir of this pathogen.

According to the numerous publications on staphylococci isolation from water resources, it is evident that beside their presence in the bodies of water they will also be closely related to aquatic life. Indeed, fish surface seems to contain $S$. aureus naturally able to produce enterotoxins and infect humans coming in contact with it (Simon and Sanjeev, 2007). Yamazaki et al. (1992) showed slight staphylococcal growth on fish surface (fillets of walleye pollack) when packed in $100 \% \mathrm{CO}_{2}$ in gas-impermeable pouches and preserved at $0^{\circ} \mathrm{C}$ for 20 days.

The potential of staphylococci to survive in sea water was presented by Bochet et al. (2008) who described two patients with a skin infection caused by community-acquired methicillin-resistant Staphylococcus aureus (CA-MRSA) identical strains, when practicing scuba dive in the Philippines. The authors pointed to the scuba diving equipment as a possible new mode of acquisition of CA-MRSA.

In a periurban area of Niger, a survey on the presence of $S$. aurues in milk and on udder was carried out during two seasons: dry and rainy. Staphylococcus aureus, coagulase-negative staphylococci (CNS) and environmental microorganisms were detected in significantly more samples during the rainy season $(55.2 \%, \mathrm{p}<0.05)$ than during the dry season $(27.1 \%)$. The authors did not explain this variation however, speculatively it might be that the rainy season higher prevalence might be attributed to wash out of animal skin bacteria (know to contain staphylococci) and further contamination of udder and milk.

Finally, in relation to more unconventional environments, a special S. haemolyticus strain was isolated from larval guts of the oil fly Helaeomyia petrolei known to grow exclusively submerged in oil, where they ingest large quantities of oil and asphalt. This $S$. haemolyticus strain was able to tolerate excessive concentrations of solvents such as $100 \%$ toluene, benzene, and $p$-xylene on plate overlays and saturating levels of these solvents in monophasic liquid cultures (Nielsen et al., 2005). The elucidation of this extreme bacterial tolerance was based on increased membrane fluidity via fatty acid composition once the bacterium is exposed to various solvents, a system much different from the gram-negative bacteria 
mechanism of solvent resistance. In this case, we can merely speculate on the environmental advantage of the above attribute, such as the role of bacterial efflux pumps that are also linked to cross-resistance to antibiotics (Fernandes et al., 2003), commensalism with higher organisms (e.g., larvae), collective defense through biofilm formation or just an opportunistic saprophyte.

\subsubsection{REFERENCES}

Allen, A.M. \& Taplin, D. (1974) Skin infections in eastern Panama. Survey of two representative communities. Am. J. Trop. Med. Hyg. 23, 950-956.

Banana, U.H., Begum, F. \& Khair, A. (2001) Studies on airborne bacteria of Dhaka city. Bangladesh J Sci Ind Res 36, 6-13.

Barro, N., Aly, S., Tidiane, O.C.A. \& Sababenedjo, T.A. (2006) Carriage of bacteria by proboscises, legs, and feces of two species of flies in street food vending sites in Ouagadougou, Burkina Faso. J. Food Prot. 69, 2007-2010.

Bexfield, A., Nigam, Y., Thomas, S. \& Ratcliffe, N.A. (2004) Detection and partial characterization of two antibacterial factors from the excretions/secretions of the medicinal maggot Lucilia sericata and their activity against methicillin-resistant Staphylococcus aureus (MRSA). Microbes Infect. 6, 1297-1304.

Bischoff, W.E., Bassetti, S., Bassetti-Wyss, B.A., Wallis, M.L., Tucker, B.K. et al. (2004) Airborne dispersal as a novel transmission route of coagulase-negative staphylococci: interaction between coagulase-negative staphylococci and rhinovirus infection. Infect Control Hosp Epidemiol 25, 504-511.

Bischoff, W.E., Tucker, B.K., Wallis, M.L., Reboussin, B.A. Pfaller, M.A. et al. (2007) Preventing the airborne spread of Staphylococcus aureus by persons with the common cold: effect of surgical scrubs, gowns, and masks. Infect Control Hosp Epidemiol 28, 1148-1154.

Bochet, M., Francois, P., Longtin, Y., Gaide, O., Renzi, G. \& Harbarth, S. (2008) Community-acquired methicillinresistant Staphylococcus aureus infections in two scuba divers returning from the Philippines. J Travel Med 15, 378-381.

Bouillenne, R. \& Bouillenne-Walrand, M. (1951) Action of certain added plant hormones on the growth of the lower fungi: Trichophyton div. sp., Staphylococcus aureus, Sarcina lutea, and Pseudomonas aeruginosa. Bull Cl Sci Acad R Belg 37, 567-582.

Bruggmann, D., Tinneberg, H-R. \& Zygmunt, M.T. (2006) Maggot therapy in gynecology. Zentralbl Gynakol 128, 261-265.

Fernandes, P., Ferreira, B.S., Cabral, J.M.S. (2003) Solvent tolerance in bacteria: role of efflux pumps and cross-resistance with antibiotics. Int. J. Antimicrob. Agents 22, 211-216.

Fontanilla, J-M., Kirkland, K.B., Elizabeth, K.B., Talbot, A., Powell, K.E, Schwartzman, J.D. et al. (2010) Outbreak of skin infections in college football team members due to an unusual strain of community-acquired methicillin-susceptible Staphylococcus aureus. J. Clin. Microbiol. 48, 609-611.

Graham, J.P., Price, L.B., Evans, S.L., Graczyk, T.K. \& Silbergeld, E.K. (2009) Antibiotic resistant enterococci and staphylococci isolated from flies collected near confined poultry feeding operations. Sci. Total Environ. 407, 2701-2710.

Grinberg, A., Kingsbury, D.D., Gibson, I.R., Kirby, B.M., Mack, H.J. \& Morrison, D. (2008) Clinically overt infections with methicillin-resistant Staphylococcus aureus in animals in New Zealand: a pilot study. N Z Vet J 56, 237-242.

Guardabassi, L., Schwarz, S. \& Lloyd, D.H. (2003) Pet animals as reservoirs of antimicrobial-resistant bacteria. J. Antimicrob. Chemother. 54, 321-332.

Harouna, A., Zecchini, M., Locatelli, C., Scaccabarozzi, L., Cattaneo, C. et al. (2009) Milk hygiene and udder health in the periurban area of Hamdallaye, Niger. Trop Anim Health Prod 41, 705-710.

Kelesidis, T. \& Tsiodras, S. (2010) Staphylococcus intermedius is not only a zoonotic pathogen, but may also cause skin abscesses in humans after exposure to saliva. Int. J. Infect. Dis. 14, e838-e841.

Lamka, K.G., Lechevallier, M.W. \& Seidler, R.J. (1980) Bacterial contamination of drinking water supplies in a modern rural neighborhood. Appl. Environ. Microbiol. 39, 734-738. 
Leonard, F.C. \& Markey, B.K. (2008) Meticillin-resistant Staphylococcus aureus in animals: A review. Vet. J. 175, $27-36$.

Livermore, D.M. (2000) Antibiotic resistance in staphylococci. Int. J. Antimicrob. Agents 16, S3-S10.

Loeffler, A. \& Lloyd, D.H. (2010) Companion animals: a reservoir for methicillin-resistant Staphylococcus aureus in the community?. Epidemiol. Infect. 138, 595-605.

Morgan, M. (2008) Methicillin-resistant Staphylococcus aureus and animals: zoonosis or humanosis? J. Antimicrob. Chemother. 62, 1181-1187.

Murrell, A., Dobson, S.J., Yang, X., Lacey, E. \& Barker, S.C. (2003) A survey of bacterial diversity in ticks, lice and fleas from Australia. Parasitol Res 89, 326-334.

Navarro, V., Villarreal, Ma. L., Rojas, G. \& Lozoya, X. (1996) Antimicrobial evaluation of some plants used in Mexican traditional medicine for the treatment of infectious diseases. J Ethnopharmacol 53, 143-147.

Nazni, W.A., Seleena, B., Lee, H.L., Jeffery, J., T. Rogayah, T.A.R. \& Sofian, M.A (2005) Bacteria fauna from the house fly, Musca domestica (L.). Trop Biomed 22, 225-231.

Nielsen, L.E. Kadavy, D.R., Rajagopal, S., Drijber, R. \& Nickerson, K.W. (2005) Survey of Extreme Solvent Tolerance in Gram-Positive Cocci: Membrane Fatty Acid Changes in Staphylococcus haemolyticus Grown in Toluene. Appl. Environ. Microbiol. 71, 5171-5176.

Nmorsi, O.P.G., Agbozele, G. \& Ukwandu, N.C.D. (2007) Some aspects of epidemiology of filth flies: Musca domestica, Musca domestica vicina, Drosophilia melanogaster and associated bacteria pathogens in Ekpoma, Nigeria. Vector Borne Zoonotic Dis. 7, 107-117.

Park, S.O., Shin, J.H., Choi, W.K., Park, B.S., Oh, J.S. \& Aera Jang, A. (2010) Antibacterial activity of house fly-maggot extracts against MRSA (Methicillin-resistant Staphylococcus aureus) and VRE (Vancomycinresistant enterococci). J Environ Biol 31, 865-871.

Polak, J. \& Novick, R.P. (1982) Closely related plasmids from Staphylococcus aureus and soil bacilli. Plasmid 7, 152-162.

Robacker, D.C. \& Flath, R.A. (1995) Attractants from Staphylococcus aureus cultures for Mexican fruit fly, Anastrepha ludens. J. Chem. Ecol. 21, 1861-1874.

Ruimy, R., Angebault, C., Djossou, F., Dupont, C., Epelboin, L. et al. (2010) Are host genetics the predominant determinant of persistent nasal Staphylococcus aureus carriage in humans? J Infect Dis 202, 924-934.

Sherman, R.A. (2009) Maggot therapy takes us back to the future of wound care: new and improved maggot therapy for the 21st century. J Diabetes Sci Technol 3, 336-44.

Simon, S.S. \& Sanjeev, S. (2007) Prevalence of enterotoxigenic Staphylococcus aureus in fishery products and fish processing factory workers. Food Control 18, 1565-1568.

Siqueira, D.B., Aessio, F.M., Mota, R.A., Marvulo, M.F.V., Mauffrey, J-F. et al. (2010) Staphylococcus aureus mastitis in a white-eared opossum (Didelphis albiventris) in the Atlantic forest of northeast Brazil. J. Zoo Wildl. Med. 41, 526-529.

Sramova, H., Daniel, M., Absolonova, V., Dedicova, D., Jedlickova, Z. et al. (1992) Epidemiological role of arthropods detectable in health facilities. J. Hosp. Infect. 20, 281-292.

van Dijck, P.J. \& van de Voorde, H. (1979) Course of antibiotic sensitivities in Escherichia coli and Staphylococcus aureus from animals. Zentralbl Bakteriol B 169, 519-529.

Wertheim, H.F., Melles, D.C., Vos, M.C., et al. (2005) The role of nasal carriage in Staphylococcus aureus infections. Lancet Infect Dis 5, 751-762.

Yamazaki, K., Kawai, Y., Inoue, N. \& Shinano, H. (1992) Effect of carbon dioxide on the growth of bacteria [on fish]. Bull. Fac. Fish. Hokkaido Univ. 43, 115-123. 


\section{Chapter 2.22}

\section{Streptococcal Infections}

\section{[STREPTOCOCCUS SPP.]}

Streptococcus is a bacterial genus of cocci, gram-positive, non-spore forming, facultative anaerobes arranged in chains or pairs. Their classification is based on blood hemolytic activity and surface antigens presence (according to Lancefield group nomenclature). Streptococci are both human commensals and pathogens (e.g., S. pyogenes causes the widest range of disease in humans among all bacterial pathogens) (Stock, 2009) and a large variety of animals (most of them of domestic type such as cattle, horses, pigs, etc.). Zoonotic pathogenic strains and some associated features are listed in Table 2.22.1. The streptococcal disease spectrum is wide and includes skin and wound infections (impetigo), scarlet fever, erysipelas, pharyngitis, rheumatic fever, acute glomerulonephritis, meningitis, endocarditis, etc.

\subsubsection{STREPTOCOCCUS AND ENVIRONMENT (FIGURE 2.22.1)}

The ubiquity of streptococci constitutes a continuous threat of infection. Herva (1979) reported on an outbreak of skin infection caused by streptococci (group A, $\beta$-hemolytic) in hunters from a wild moose. Group L streptococci were isolated from meat handlers (processing chickens and pigs) together with Staphylococcus aureus (Barnham and Neilson, 1987). Feng et al. (2010), following two severe large scale outbreaks in China of $S$. suis originating from swine industry, described a new disease form of streptococcal toxic shock syndrome (STSS). The Chinese variant of $S$. suis exhibited strong invasiveness and high pathogenicity. Epidemiological data showed that $S$. suis cases occurred mainly in South China, from summer to autumn, a period characterized by high moisture and high temperature.

Cockroaches isolated from public hospitals, were also reported to carry streptococci internally and externally, consequently constituting a continuous source of human infections (Salehzadeh et al., 2007).

Water is also a source of fecal Streptococci (Enterococci) as reported during Nile flood season (Saleh, 1980), Apalachicola River, Florida (Elder, 1987) and in New Zealand where the main source of enterococci in river waters was most likely runoff from dairy farms located on the flood plains (Deely et al., 1997). Invasive infections from fish infected with $S$. iniae have been reported in humans (Weinstein et al., 1997). A recent publication described massive fish extinction in Kuwait Bay, 
Table 2.22.1 Zoonotic Streptococcus spp. classified according to their Lancefield group antigen.

\begin{tabular}{|c|c|c|c|c|c|}
\hline $\begin{array}{l}\text { Lancefield } \\
\text { group antigen }\end{array}$ & Species & Hemolysis & Associated disease & Zoonotic & Animal source \\
\hline A & $\begin{array}{l}\text { S. pyogenes } \\
\left(_{\text {GABS })^{a}}\right.\end{array}$ & $\beta$ & $\begin{array}{l}\text { Pharyngitis, tonsilitis, } \\
\text { wound and skin } \\
\text { infections, scarlet fever, } \\
\text { septicemia, pneumonia, } \\
\text { glomerulonephritis, } \\
\text { necrotizing fascitis, } \\
\text { rheumatic fever }\end{array}$ & yes & $\begin{array}{l}\text { Cattle, duck, } \\
\text { monkey }\end{array}$ \\
\hline B & S. agalactiae & $\beta$ & $\begin{array}{l}\text { Sepsis, skin infections, } \\
\text { postpartum or neonatal } \\
\text { sepsis, endocarditis, } \\
\text { septic arthritis }\end{array}$ & yes & Cattle, fish \\
\hline $\begin{array}{l}\text { C } \\
G\end{array}$ & $\begin{array}{l}\text { S. equi } \\
\text { S. canis }\end{array}$ & $\beta$ & $\begin{array}{l}\text { Pharyngitis, pneumonia, } \\
\text { cellulitis, impetigo, } \\
\text { puerperal-,neonatal- } \\
\text { sepsis, endocarditis, } \\
\text { septic arthritis }\end{array}$ & yes & $\begin{array}{l}\text { Horse, dog and } \\
\text { many other } \\
\text { animals }\end{array}$ \\
\hline D & $\begin{array}{l}\text { Enterococcal: } \\
\text { E. faecalis } \\
\text { E. faecium } \\
\text { Nonenterococcal: } \\
\text { S. bovis } \\
\text { S. equinus }\end{array}$ & $\alpha$ or $\gamma$ & $\begin{array}{l}\text { Endocarditis, UTI, } \\
\text { intra-abdominal } \\
\text { infection, cellulitis, } \\
\text { wound infection }\end{array}$ & yes & CattleHorse \\
\hline$A, C, G$ and $L$ & S. dysgalactiae & $\beta$ & Bacteremia & yes & \\
\hline $\begin{array}{l}E, P, U, V \text {, none } \\
\text { or new }\end{array}$ & S. porcinus & $\beta$ & Septicemia & yes & Pig \\
\hline \multirow[t]{3}{*}{ Viridans*- } & $\begin{array}{l}\text { S. mutans } \\
\text { S. sanguis } \\
\text { S. salivarius } \\
\text { S. mitior } \\
\text { S. milleri } \\
\text { S. viridans } \\
\text { S. gordonii }\end{array}$ & $\alpha$ or $\gamma$ & $\begin{array}{l}\text { Endocarditis, localized } \\
\text { infection (or abscesses) }\end{array}$ & & \\
\hline & S. iniae & $\beta$ & Cellulites, invasive & Yes & Fish \\
\hline & S. pneumoniae & $\alpha$ & $\begin{array}{l}\text { infections from fish, } \\
\text { pneumonia, acute } \\
\text { sinusitis, otitis media, } \\
\text { meningitis, bacteremia, } \\
\text { sepsis, osteomyelitis, } \\
\text { septic arthritis, } \\
\text { endocarditis, peritonitis, } \\
\text { pericarditis, cellulites, } \\
\text { and brain abscess }\end{array}$ & & \\
\hline $\mathrm{R}, \mathrm{S}$ and $\mathrm{T}$ & S. suis (serovar 2) & $\begin{array}{l}\text { Non- } \beta \\
\text { hemolytic }\end{array}$ & $\begin{array}{l}\text { Meningitis, myocarditis, } \\
\text { arthritis, etc. }\end{array}$ & yes & Pig \\
\hline
\end{tabular}

${ }^{a}$ GABHS- group A $\beta$-hemolytic streptococci. *No reaction with Lancefield grouping sera. 
S. agalactiae being suspected as the cause of this fatal infection (Jafar et al., 2009). The authors, using random amplification of polymorphic DNA (RAPD) analyses, found nearly identical RAPD banding patterns between $S$. agalactiae from fish and sewage sources and deduct that sewage may be the principal fish contamination source. Unfortunately, they did not report on human cases related to fish handling or consumption. An additional relationship between fish and human streptococcal disease was presented by Miller and Neely (2004) who successfully used zebra fish (Danio rerio) as a model to study these infections, presenting similar pathologies.

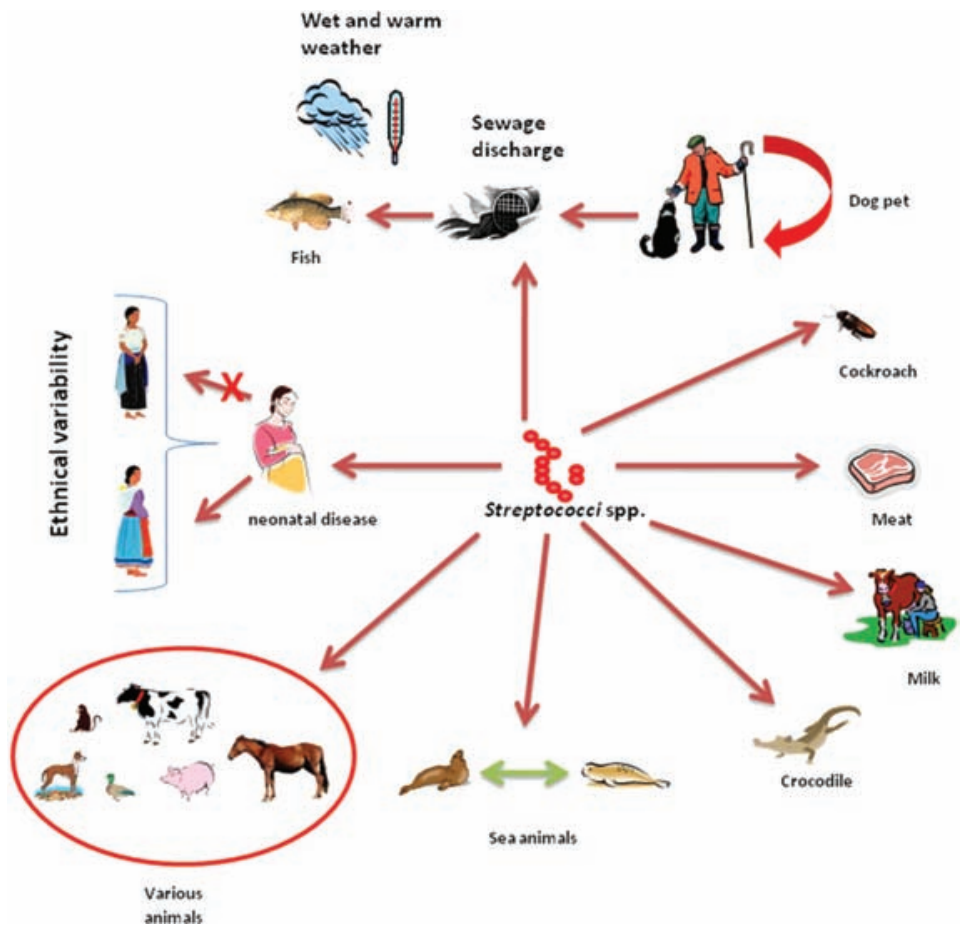

Figure 2.22.1. Streptococci spp. and various environmental aspects connected to their infection

In connection to sea environment, Streptococcus equi subsp. zooepidemicus strain was isolated from two remote seals (harbor and grey types) in the North Sea, Germany. According to authors, grey seals were probably the vectors of this strain (Akineden et al., 2007).

Some environmental parameters (temperature, $\mathrm{pH}$ and osmolarity) were found to modulate some genes (multifunctional adhesions) in S. gordonii. Some $S$. gordonii strains are harmless and commensals of the human oral cavity, however some are strongly connected to severe disease (infective endocarditis) (El-Sabaeny et al., 2000). The main question remaining is whether these environmental conditions are the only prerequisite for virulence direction change.

Harmeet et al. (2009) reported on the better capability of group B streptococci (GBS) strains isolated from asymptomatic carriers (pregnant women) to form biofilms compared to those from symptomatic patients. As mentioned before, biofilms are an environmental association designated to protect bacteria from environmental stresses. It can be postulated that more virulent strains able to penetrate human or 
animal organs are less exposed to these stresses and, owing to their defense mechanism against immunological cascade and affable environment, do not require biofilm formation but dispersal in order to succeed.

Bishop et al. (2007) reported on a necrotizing fasciitis outbreak caused by S. agalactiae in a captive crocodile species. There were several speculative suggestions on this infection's origin such as: a) high stocking density that may increase the bite wounds and captivity stress; b) infected mice used as feed; and c) inhabitation of mucous membranes by these microorganisms. However, none of these suggestions was clear cut evidence.

The in vitro optimal atmosphere (aerobic vs. anaerobic) for the isolation and growth of group A $\beta$-hemolytic streptococci is still under considerable debate. Schwartz et al. (1985) found that this group isolated from throat, grew better under anaerobic atmosphere; however, other studies did not support this conclusion (Roddey et al., 1995).

An interesting finding on the facultative anaerobe group B Streptococcus (GBS) (an opportunistic pathogen of pregnant women, newborns, and elderly persons) revealed that its invasiveness [using the dynamic in vitro attachment and invasion system (DIVAS) in neonatal mice] is significantly enhanced in the presence of $\geq 5 \%$ oxygen. The invasiveness of this group was described as linked to enhanced polysaccharide production especially under aerobic atmosphere (von Hunolstein et al., 1993).

A study of risk factors of increased carrier potential of group B streptococcus in southern Israel was performed on different human populations. Women, particularly immigrants from the former USSR, were significantly more prone to carry the pathogen than native Israeli women (comprised of ethnical groups such as Bedouins and Jews) with expected transmission rate of neonatal disease populations at low incidence.

Lam et al. (2007) described the identification of $S$. canis from dog owners associated with ulcer infections. It should be pointed out that the described cases were linked to preceding diseases such as diabetes mellitus that by itself causes permanent wounds and ulcers.

Finally, air flow was also suggested as a possible route of contamination. Thompson et al. (1978), in relation to cows infected with $S$. agalactiae, found that rapid airflow toward teats as a result of sudden vacuum loss characterized vacuum abnormalities associated with increased risk of mastitis infection in these animals.

\subsubsection{REFERENCES}

Akineden, O., Alber, J., Lammler, C., Weiss, R., Siebert, U., Foster, G., et al. (2007) Relatedness of Streptococcus equi subsp. zooepidemicus strains isolated from harbour seals (Phoca vitulina) and grey seals (Halichoerus grypus) of various origins of the North Sea during 1988-2005. Vet. Microbiol. 121, 158-162.

Barnham, M. \& Neilson, D.J. (1987) Group L $\beta$-haemolytic streptococcal infection in meat handlers: another streptococcal zoonosis?. Epidemiol. Infect. 99, 257-64.

Bishop, E.J., Shilton, C., Benedict, S., Kong, F., Gilbert, G.L., Gal, D. et al. (2007) Necrotizing fasciitis in captive juvenile Crocodylus porosus caused by Streptococcus agalactiae: an outbreak and review of the animal and human literature. Epidemiol. Infect. 135, 1248-1255.

Deely, J., Hodges, S., Mcintosh, J. \& Bassett, D. (1997) Enterococcal numbers measured in waters of marine, lake, and river swimming sites of the Bay of Plenty, New Zealand. N. Z. J. Mar. Freshwater Res. 31, 89-101.

Elder, J.F. (1987) Indicator bacteria concentrations as affected by hydrologic variables in the Apalachicola River, Florida. Water Air Soil Pollut 32, 407-416.

El-Sabaeny, A., Donald R. Demuth, D.R., Yoonsuk Parka, Y. \& Lamont, R.J. (2000) Environmental conditions modulate the expression of the $\operatorname{spA} A$ and $\operatorname{ssp} B$ genes in Streptococcus gordonii. Microb. Pathog. 29, $101-113$. 
Feng, Y., Zhang, H., Ma, Y. \& Gao, G.F. (2010) Uncovering newly emerging variants of Streptococcus suis, an important zoonotic agent. Trends Microbiol. 18, 124-131.

Harmeet, K., Praveen, K., Pallab, R., Jaswinder, K. \& Anuradha, C. (2009) Biofilm formation in clinical isolates of group B streptococci from north India. Microb. Pathog. 46, 321-327.

Herva, E. (1979) An outbreak of skin infections caused by group A $\beta$-hemolytic streptococci probably originating from wild moose. Scand. J. Infect. Dis. 11, 125-127.

Jafar, Q.A., Al-Zinki, S., Al-Mouqati, S., Al-Amad, S., Al-Marzouk, A. \& Al-Sharifi, F. (2009) Molecular investigation of Streptococcus agalactiae isolates from environmental samples and fish specimens during a massive fish kill in Kuwait Bay. Afr J Microbiol Res 3, 022-026.

Johri, A.K., Padilla, J., Malin, G. \& Paoletti, L.C. (2003) Oxygen regulates invasiveness and virulence of group B streptococcus. Infect. Immun. 71, 6707-6711.

Lam, M.M., Clarridge III, J.E., Young, E.J. \& Mizuki, S. (2007) The other group G streptococcus: increased detection of Streptococcus canis ulcer infections in dog owners. J. Clin. Microbiol. 45, 2327-2329.

Marchaim, D., Hallak, M., Gortzak-Uzan, L., Peled, N., Riesenberg, K. \& Schlaeffer, F. (2003) Risk factors for carriage of group B streptococcus in southern Israel. Isr. Med. Assoc. J. 5, 646-648.

Martel, A., Decostere, A., De Leener, E., Marien, M., De Graef, E. et al. (2005) Comparison and transferability of the $\operatorname{erm}(\mathrm{B})$ genes between human and farm animal Streptococci. Microb. Drug Resist. 11, 295-302.

Miller, J.D. \& Neely, M.N. (2004) Zebrafish as a model host for streptococcal pathogenesis. Acta Trop. 91, 53-68.

Roddey, O.F.Jr., Clegg, H.W., Martin, E.S., Swetenburg, R.L. \& Koonce, E.W. (1995) Comparison of throat culture methods for the recovery of group A streptococci in a pediatric office setting. JAMA 274, 1863-1865.

Saleh, F.A. (1980) Bacteriological quality of Nile water before and after impoundment (1963-1973): a review. Zentralbl Bakteriol Naturwiss 135, 123-129.

Salehzadeh, A., Tavacol, P. \& Mahjub, H. (2007) Bacterial, fungal and parasitic contamination of cockroaches in public hospitals of Hamadan, Iran. J Vector Borne Dis 44, 105-110.

Schwartz, R.H., Gerber, M.A. \& McCoy, P. (1985) Effect of atmosphere of incubation on the isolation of group A streptococci from throat cultures. J. Lab. Clin. Med. 106, 88-92.

Smith, K.L., Todhunter, D.A. \& P. S. Schoenberger, P.S. (1985) Environmental Mastitis: Cause, Prevalence, Prevention. J Dairy Sci 68, 1531-1553.

Stock, I. (2009) Streptococcus pyogenes-much more than the aetiological agent of scarlet fever. Med Monatsschr Pharm 32, 408-416.

Thompson, P.D., Schultze, W.D., Sauls, J.N. \& Arapis, S.C. (1978) Mastitis infection from abrupt loss of milking vacuum. J. Dairy Sci. 61, 344-351.

von Hunolstein, C., Nicolini, L., D’Ascenzi, S., Volpe, C., Alfarone, G. \& Orefici, G. (1993) Sialic acid and biomass production by Streptococcus agalactiae under different growth conditions. Appl Microbiol Biotechnol 38, $458-462$.

Weinstein, M.R., Litt, M., Kertesz, D.A., Wyper, P., Rose, D. et al. (1997) Invasive infections due to a fish pathogen, Streptococcus iniae. N. Engl. J. Med. 337, 589-594. 


\section{Chapter 2.23}

\section{Tularemia}

\section{[FRANCISELLA TULARENSIS]}

Francisella is a genus of gram-negative, strict aerobic, small non-motile rod-shaped or coccobacillary bacteria that are also facultative intracellular parasites of macrophages. The genus Francisella contains at the moment five species: F. tularensis, F. hispaniensis, F. noatunensis, F. philomiragia and F. piscicida. $F$. tularensis is the most infective and virulent zoonotic species for humans. The species $F$. tularensis has four subspecies (or serovars): 1) F. tularensis subsp. tularensis (Type A) (found in North America and the most virulent to humans and domestic rabbits; 2) F. tularensis subsp. palaearctica or holarctica (Type B) (found in North America in aquatic rodents such as beavers and muskrats, and in other small rodents in northern Eurasia); 3) F.tularensis subsp. novicida (formerly classified as a species) a relative non-virulent strain found in North America; and 4) F.tularensis subsp. mediasiatica (primarily found in central Asia, isolated from human, gerbil and tick) at the moment without information on its pathogenicity for humans (Petersen and Schrifer, 2005). A large variety of animals ( $>125$ species) has been found to host F. tularensis (Avashia et al., 2004; Park et al., 2009), among which rodents are the main reservoir with ticks, fleas, lice and flies as vectors (Hubalek et al., 1998; Meka-Mechenko et al., 2003; Eliasson and Back, 2003; Aldea-Mansilla et al., 2010). Direct contact with rodents' excreta is also known as a transmission route in addition to inhalation of contaminated dust (the ID is 10 to 50 organisms), consequently making it a possible bioterrorism weapon (Dennis et al., 2001). Water was also implicated as a reservoir of $F$. tularensis spp. foci, associated to protozoa and water related arthropods (Tikhenko et al., 2001; Ul'ianova et al., 1982). The disease is also called Francis disease, marketmen's disease, rabbit fever, deer fly fever, Pahvant valley plague (in USA), yato-byo, Ohara's disease (in Japan) and lemming fever (in Norway). The clinical manifestation is related to the entry portal: from skin purulent ulcerate papule to pharyngitis, cervical lympadenitis, stomatitis, pneumonia, gastrointestinal bleeding, meningitis, diarrhea, renal failure and hepatosplenomegaly and death ( 30\% without treatment).

\subsubsection{TULAREMIA AND ENVIRONMENT (FIGURE 2.23.1)}

Water as a transmission vector of tularemia to humans was reported in Turkey in a small village outbreak (Meric et al., 2008). The water supply of this village was a spring with a water tank. The most frequent 
clinical symptom among the farmers was cervical lymphadenopathy. Australian scientists reported on a novicida-like subspecies of $F$. tularensis from a foot wound sustained in brackish water (Whipp et al., 2003). In a study performed in an active tularemia natural focus on Martha's Vineyard, Massachusetts, during a multiyear outbreak of pneumonic tularemia, brackish pond water was found to harbor Francisella philomiragia and other Francisella species closely related to $F$. tularensis and F. novicida, but not the main causative agent, F. tularensis subsp. tularensis (Berrada et al., 2010).

\section{Environment}

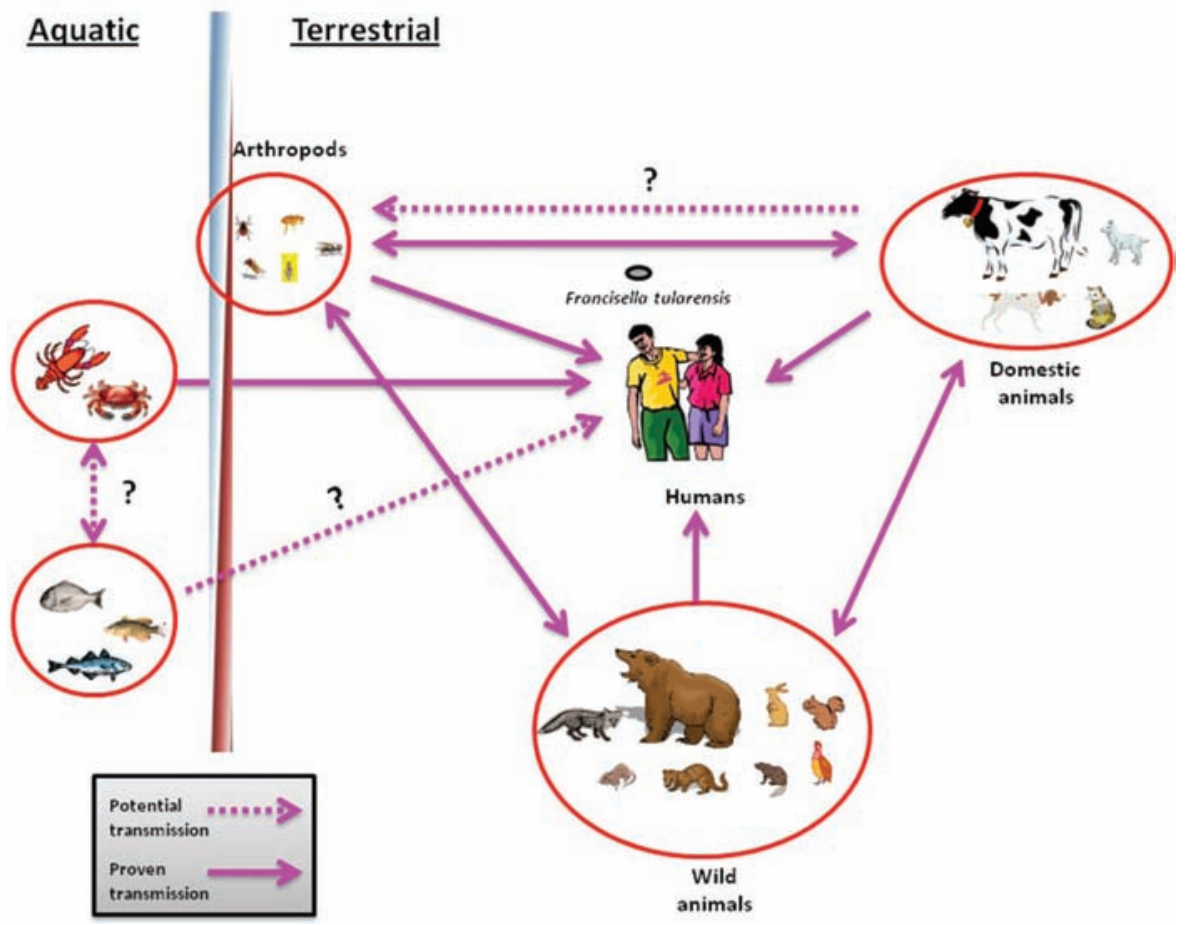

Figure 2.23.1. Francisella tularensis relation to various animals in aquatic and terrestrial environments

Other water-related sources are aquatic animals such as fish and crustaceans (e.g. crayfish) (Ottem et al., 2007; Soto et al., 2009; Anda et al., 2001; Diaz de Tuesta et al., 2001). Fish pathogenic Francisella spp. isolates were shown to be a new specific species for fish and not related to human pathogenesis, although this assumption cannot be ruled out, without additional research. On the other hand, both reports on Francisella spp. isolated from crustacean (crab and crayfish) caused human tularemia in people handling these animals (resulting in skin lesions), with strong evidences of water source contamination by sewage.

In relation to water, $F$. tularensis (strain LVS, live vaccine strain, type B) was stored in a highly oligotrophic (no carbon source) cold water environment $\left(8^{\circ} \mathrm{C}\right)$. Cell counts were stable for $>70$ days, while viable plate counts dropped to undectability for the same time interval. Metabolic activity (measured through Rhodamine 123 accumulation) declined to $\sim 35 \%$ after 140 days of storage. After this time interval, when incubated again in a rich medium, $\sim 30 \%$ of the cell population increased again. 
Mice intraperitoneal injection with these residual viable but non-culturable cells of $F$. tularensis did not cause tularemia and no lymphocyte stimulation was observed. This experimental study is important because it gives a new insight into the ecology of this pathogen (Forsman et al., 2000). The major question based on the above study should be: Is this phenomenon related to a fairly mild strain (vaccine) or a broader phenomenon?

In another village in northern Finland, located in an endemic area, the transmission was through common farming activities, such as preparing fresh hay with a hay-cutter, handling dry hay, threshing, etc. suggesting an airborne path (Syrjala et al., 1985). Another airborne case was reported when 15 people were infected by tularemia from a contaminated dog's fur disseminated when the dog shook itself among all the guests during a dinner (Siret et al., 2006).

Now, it is clear that $F$. tularensis is an arthropod-borne pathogen throughout the northern hemisphere with a wide vector array. Petersen et al. (2009) in an excellent review raised several questions about this pathogen such as: What is the mechanism of mechanical or biological transmission? What happened to the pathogen inside or outside the carrier arthropod? How do different $F$. tularensis subspecies relate to various arthropods? Are there other arthropods highly significant in transmission? etc. All these questions need a definitive answer in order to understand and control the epidemiology of this important pathogen and its relation to environment better.

Franke et al. (2010) surveyed bird feeding ticks for presence of five tick-borne pathogens, F. tularensis among them. The authors reported co-existence of one or more of these pathogens inside the blood feeding ticks, and therefore possible simultaneous transmission of the pathogens (various combinations of co-infections occurred in $10.9 \%$ of all positive ticks). These results suggest that birds are not only important reservoirs for several pathogens but also act as vehicles for infected ticks and might therefore play a key role in the dispersal of tick-borne diseases, as previously shown with other tick-borne pathogenic bacteria (Padeshki et al., 2010).

Combined county-based data for tularemia incidence (for a period of 14 years), by means of Geographic Information System (GIS)-based environmental data, were used to determine associations between coverage by different habitats (especially dry forest representing suitable tick habitat) and tularemia incidence. The results showed only a partial positive association between tularemia incidence and coverage by dry forested habitat. The authors tried to explain the partial correlation by differences in species' composition, abundance of vector ticks or vertebrate reservoirs, different transmission routes such as lagomorphs handling, and finally tick survival in those different habitats.

Hubálek et al. (1996) also reported on F. tularensis infected ticks (Dermacentor reticulates) in the flood plains forest ecosystem with warm and dry climate of South Moravia, Czech Republic. Temperature and relative humidity conditions were previously tested on $F$. tularensis survival on metal surfaces (Wilkinson, 1966). A dry atmosphere was found to support longer survival, while increased temperature decreased $F$. tularensis survival. These findings support partially the pathogen's geographical distribution: Northern hemisphere.

From the environmental point of view, one should ask a coherent question: Why are there not increased reports of $F$. tularensis transmission by mosquitoes, when these arthropods are more widespread in human surroundings than are ticks? Indeed, a new study presented the prevalence of $F$. tularensis in the Culicidae family. The results showed that among $>2,500$ tested mosquitoes (captured in Alaska) $30 \%$ of pooled samples contained Francisella DNA (Triebenbach et al., 2010). However, further examination of transmission potential revealed that ingestion of this pathogen is not efficiently transferred to pupal and adults stages and in secondary blood meals. The authors concluded that inefficient transmission on the one hand and species dependency on the other is responsible for the low vectorial role of mosquitoes in tularemia. 


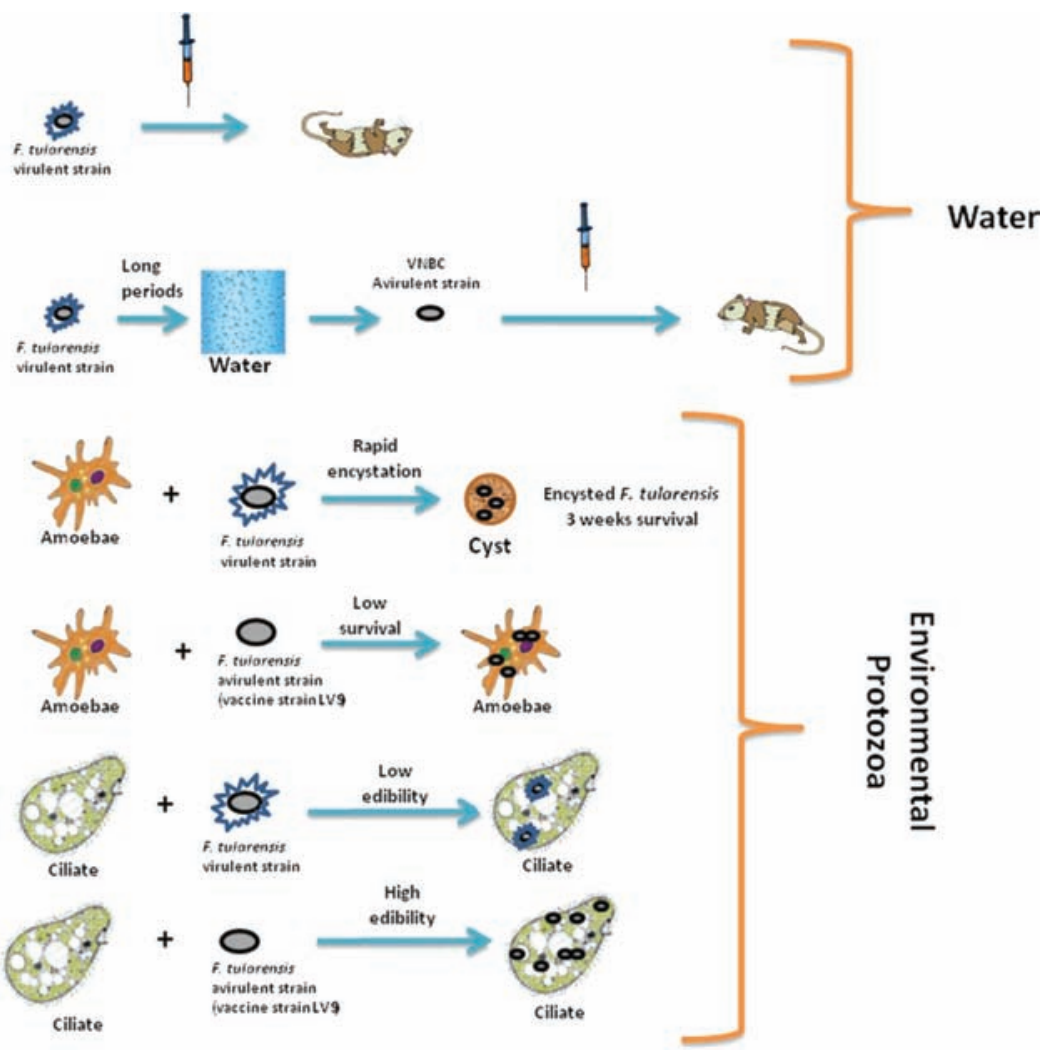

Figure 2.23.2. Francisella tularensis interactions (survival and virulence) with protozoa (amoebae and ciliate) and water

Berdal et al. (1996) investigated serologically different populations (hunters and healthy school children) for previous exposure to $F$. tularensis. The authors found up to $4.7 \%$ positivity in school children indicating spread of low-grade infections. Additionally, they studied and showed Achantamoeba castellanii pathogen internalization, growth and inactivation. In a more recent study on Acanthamoeba castellanii and its interaction with $F$. tularensis, several strains were tested for efficient internalization (survival and replication) into amoebae: a live vaccine (LVS) and clinical virulent strains. Rapid encystment was observed when amoebae were exposed to virulent strains, with 3 weeks post-infection survival of the pathogen (El-Etr et al., 2009). The authors suggested that this interaction is essential for pathogen survival and may play a role in its environmental persistence. Adiba et al. (2010) using non-pathogenic and pathogenic E. coli bacteria and grazing amoebae (a social haploid amoeba Dictyostelium discoideum) demonstrated that virulence traits in bacteria might result from selective pressure exerted by protozoan predator. Thus, grazing resistance may be an evolutionary exaptation in bacterial pathogenicity. Similar experiments were also performed with $F$. tularensis and Acanthamoeba castellanii in which the pathogen had been shown to grow and survive (Abd et al., 2003). F. tularensis internal growth affected the protozoa, reducing its numbers. This interaction demonstrated that ubiquitous protozoa might be an important environmental reservoir for F. tularensis. 
Using another protozoan, Thelaus et al. (2009) showed that virulent strains of $F$. tularensis can internalize, although at a lower rate. Importantly, the authors also found that $F$. tularensis viable but non-culturable forms (VBNC) emerged after long term incubation in lake water microcosm, while a high nutrient level as well the presence of the grazer did not prevent this shift. Francisella tularensis interactions with protozoa are summarized in Figure 2.23.2.

\subsubsection{REFERENCES}

Abd, H., Johansson, T., Golovliov, I., Gunnar Sandström, G. \& Forsman, M. (2003) Survival and growth of Francisella tularensis in Acanthamoeba castellanii. Appl. Environ. Microbiol. 69, 600-606.

Adiba. S., Nizak, C., van Baalen, M., Denamur, E. \& Depaulis, F. (2010) From grazing resistance to pathogenesis: the coincidental evolution of virulence factors. PLOS ONE 5(8): e11882. doi:10.1371/journal.pone.0011882.

Aldea-Mansilla, C., Nebreda, T., Garcia de Cruz, S., Dodero, E. et al. (2010) Tularemia: a decade in the province of Soria (Spain). Enferm. Infecc. Microbiol. Clin. 28, 21-26.

Anda, P., del Pozo, J.S., García, J.M.D., Escudero, R., Peña, F.J.G. et al. (2001) Waterborne outbreak of tularemia associated with crayfish fishing. Emerging Infect. Dis. 7, 575-585.

Avashia, S.B., Petersen, J.M., Lindley, C.M., Martin E. Schriefer, M.E., Kenneth L. Gage, K.L. et al. (2004) First reported prairie dog-to-human tularemia transmission, Texas, 2002. Emerging Infect. Dis. 10, 483-486.

Berdal, B.P., Mehl, R., Meidell, N.K., Lorentzen-Styr, A.M. \& Scheel, O. (1996) Field investigations of tularemia in Norway. FEMS Immunol. Med. Microbiol. 13, 191-195.

Berrada, Z.L. \& Sam R. Telford III, S.R. (2010) Diversity of Francisella species in environmental samples from Martha's Vineyard, Massachusetts. Microb Ecol 59, 277-283.

Dennis, D.T., Inglesby, T.V., Henderson, D.A., Bartlett, J.G., et al. (2001) Tularemia as a biological weapon medical and public health management. JAMA 285, 2763-2773.

Diaz de Tuesta, A.M., Chow-Quan, Geijo Martinez, M.P., Dimas Nunez, J., Díaz de Tuesta, F.J. et al. (2001) Tularemia outbreak in the province of Cuenca associated with crab handling. Rev Clin Esp 201, 385-389.

Eisen, R.J., Mead, P.S., Meyer, A.M., Pfaff, L.E., Bradley, K.K. \& Eisen. L. (2008) Ecoepidemiology of tularemia in the south central United States. Am. J. Trop. Med. Hyg. 78, 586-594.

El-Etr, S.H., Margolis, J.J., Monack, D., Richard A. Robison, R.A., Cohen, M., Moore, E. \& Rasley, A. (2009) Francisella tularensis type a strains cause the rapid encystment of Acanthamoeba castellanii and survive in amoebal cysts for three weeks postinfection. Appl. Environ. Microbiol. 75, 7488-7500.

Eliasson, H. \& Back, E. (2003) Myositis and septicaemia caused by Francisella tularensis biovar holarctica. Scand. J. Infect. Dis. 35, 510-511.

Forsman, M., Henningson, E.W., Larsson, E., Johansson, T. \& Sandström, G. (2000) Francisella tularensis does not manifest virulence in viable but non-culturable state. FEMS Microbiol. Ecol. 31, 217-224.

Franke, J., Fritzsch, J., Tomaso, H., Straube, E., Wolfram Dorn, W. \& Anke Hildebrandt, A. (2010) Coexistence of pathogens in host-seeking and feeding ticks within a single natural habitat in central Germany. Appl. Environ. Microbiol. 76, 6829-6836.

Hubalek, Z., Sixl, W. \& Halouzka, J. (1998) Francisella tularensis in Dermacentor reticulatus ticks from the Czech Republic and Austria. Wien. Klin. Wochenschr. 110, 909-910.

Hubálek, Z., Treml, F., Halouzka, J., Juřicová, Z., Huňady, M. \& Janík, V. (1996) Frequent isolation of Francisella tularensis from Dermacentor reticulatus ticks in an enzootic focus of tularaemia. Med. Vet. Entomol. 10, 241-246.

Meka-Mechenko, T., Aikimbayev, A., Kunitza, T., Ospanov, K., Temiralieva, G. et al. (2003) Clinical and epidemiological characteristic of tularemia in Kazakhstan. Przegl Epidemiol 57, 587-91.

Meric, M., Sayan, M., Willke, A. \& Gedikoglu, S. (2008) A small water-borne tularemia outbreak. Mikrobiyol Bul 42, 49-59.

Ottem, K.F., Nylund, A., Karlsbakk, E., Friis-Moller, A. \& Krossoy, B. (2007) Characterization of Francisella sp., GM2212, the first Francisella isolate from marine fish, Atlantic cod (Gadus morhua). Arch. Microbiol. 187, 343-350. 
Padeshki, P.I., Ivanov, I.N., Popov, B. \& Kantardjiev, T.V. (2010) The role of birds in dissemination of Francisella tularensis: first direct molecular evidence for bird-to-human transmission. Epidemiol. Infect. 138, 376-379.

Park, C-H., Nakanishi, A., Hatai, H., Kojima, D., Oyamada, T. et al. (2009) Pathological and microbiological studies of Japanese hare (Lepus brachyurus angustidens) naturally infected with Francisella tularensis subsp. holarctica. J. Vet. Med. Sci. 71, 1629-1635.

Petersen, J.M. \& Schriefer, M.E. (2005) Tularemia: emergence/re-emergence. Vet. Res. 36, 455-467.

Petersen, J.M., Mead, P.S. \& Schriefer, M.E. (2009) Francisella tularensis: an arthropod-borne pathogen. Vet. Res. 40, 07.

Siret, V., Barataud, D., Prat, M., Vaillant, V., Ansart, S. et al. (2006) An outbreak of airborne tularemia in France, August 2004. Eur. Surveill. 11, 58-60.

Soto, E., Hawke, J.P., Fernandez, D. \& Morales, J.A. (2009) Francisella sp., an emerging pathogen of tilapia, Oreochromis niloticus (L.) in Costa Rica. J. Fish Dis. 32, 713-722.

Syrjala, H., Kujala, P., Myllyla, V. \& Salminen, A. (1985) Airborne transmission of tularemia in farmers. Scand. J. Infect. Dis. 17, 371-375.

Thelaus, J., Andersson, A., Mathisen, P., Forslund, A-L., Noppa, L. \& Forsman, M. (2009) Influence of nutrient status and grazing pressure on the fate of Francisella tularensis in lakewater. FEMS Microbiol Ecol 67, 69-80.

Tikhenko, N.I., Efremenko, V.I., Omarieva, E.Ia., Levchenko, B.I., Aliev, Sh.G. et al. (2001) Outbreak of tularemia in the Republic of Dagestan. Zh. Mikrobiol. Epidemiol. Immunobiol. 6 Suppl, 68-72.

Triebenbach, A.N., Vogl, S.J., Lotspeich-Cole, L., Sikes, D.S., Happ, G.M. \& Hueffer, K. (2010) Detection of Francisella tularensis in Alaskan mosquitoes (Diptera: Culicidae) and assessment of a laboratory model for transmission. J. Med. Entomol. 47, 639-648.

Ul'ianova, N.I., Bessonova, M.A., Panasik, L.N., Svimonishvili, V.N. \& Grishina, L.S. (1982) Results of prolonged study of flood plain-swamp endemic foci of tularemia, and its prophylaxis in the Leningrad Region. $\mathrm{Zh}$. Mikrobiol. Epidemiol. Immunobiol. 2, 104-107.

Whipp, M.J., Davis, J.M., Lum, G., de Boer, J., Zhou, Y., Bearden, S.W., Petersen, J.M., et al. (2003) Characterization of a novicida-like subspecies of Francisella tularensis isolated in Australia. J. Med. Microbiol. 52, 839-842.

Wilkinson, T.R. (1966) Survival of Bacteria on Metal Surfaces. Appl Microbiol 14, 303-307. 


\section{Chapter 2.24}

\section{Vibrioses}

\section{[VIBRIO CHOLERAE]}

Vibrio cholerae species (genus Vibrio) is a gram negative, facultative anaerobe, non-spore forming, curved (comma-shaped) bacterium, highly motile with a polar flagellum. The genus Vibrio cantains 34 recognized species, among which $V$. cholerae, V. mimicus, V. anguillarum, V. harveyi, V. parahaemolyticus, V. vulnificus, V. fluvialis, V. hollisae, V. alginolyticus, V. carchariae, V. metschnikovii, V. furnissii, Photobacterium damsela, V. cincinnatiensis are human pathogens (Table 2.24.1). V. cholerae is divided into 155 serogroups (based on somatic antigens). From the epidemiological point of view, V. cholerae serogroup O1 (further subdivided into Inaba, Ogawa, Hikojima strains) is the main agent of epidemic outbreaks. V. cholerae serogroup $\mathrm{O} 1$ is further differantiated into El Tor and classical biotypes. The $V$. cholerae serogroup $\mathrm{O} 1$ classical biotype is found only in Bangladesh, whereas $V$. cholerae serogroup $\mathrm{O} 1$ (El Tor) is found throughout the rest of the world. Strains that do not belong to serogroup O1 are referred to as non-O1 V. cholerae such as $V$. cholerae $\mathrm{O} 139$ that have been isolated from an outbreak in Bengal, India. The disease presents itself as gastroenteritis, primarily watery diarrhea, vomiting, dehydration, hypotension, septicemia, renal failure and death.

\subsubsection{VIBRIO AND ENVIRONMENT}

Vibrios are perhaps the most aquatically-related microorganisms involved in human pathogenesis (Thompson et al., 2004). Beside V. cholerae that mostly lives in fresh water (Perez-Rosas \& Hazen, 1989) (however, isolated also from both temperate and tropical marine coastal waters), almost all other human pathogenic Vibrios are halophilic, and consequently isolated from coastal water, marine sediments, seaweeds and sea fauna (Hayat et al., 2006). The main transmission of Vibrio infections is through the consumption of raw or undercooked shellfish or exposure of wounds to warm seawater (Prapaiwong et al., 2009; Córdova et al., 2002). The high infective dose of $V$. cholerae (range of $10^{8}$ to $10^{9}$ cells) (Sack et al., 2004; Codeco, 2001) requires an amplification process that can occur within the gastro-intestinal system of ill people and further excreted in feces or environmentally in symbiosis with aquatic organisms. Among these organisms, amoebae are the best candidates resembling phagocytes, 


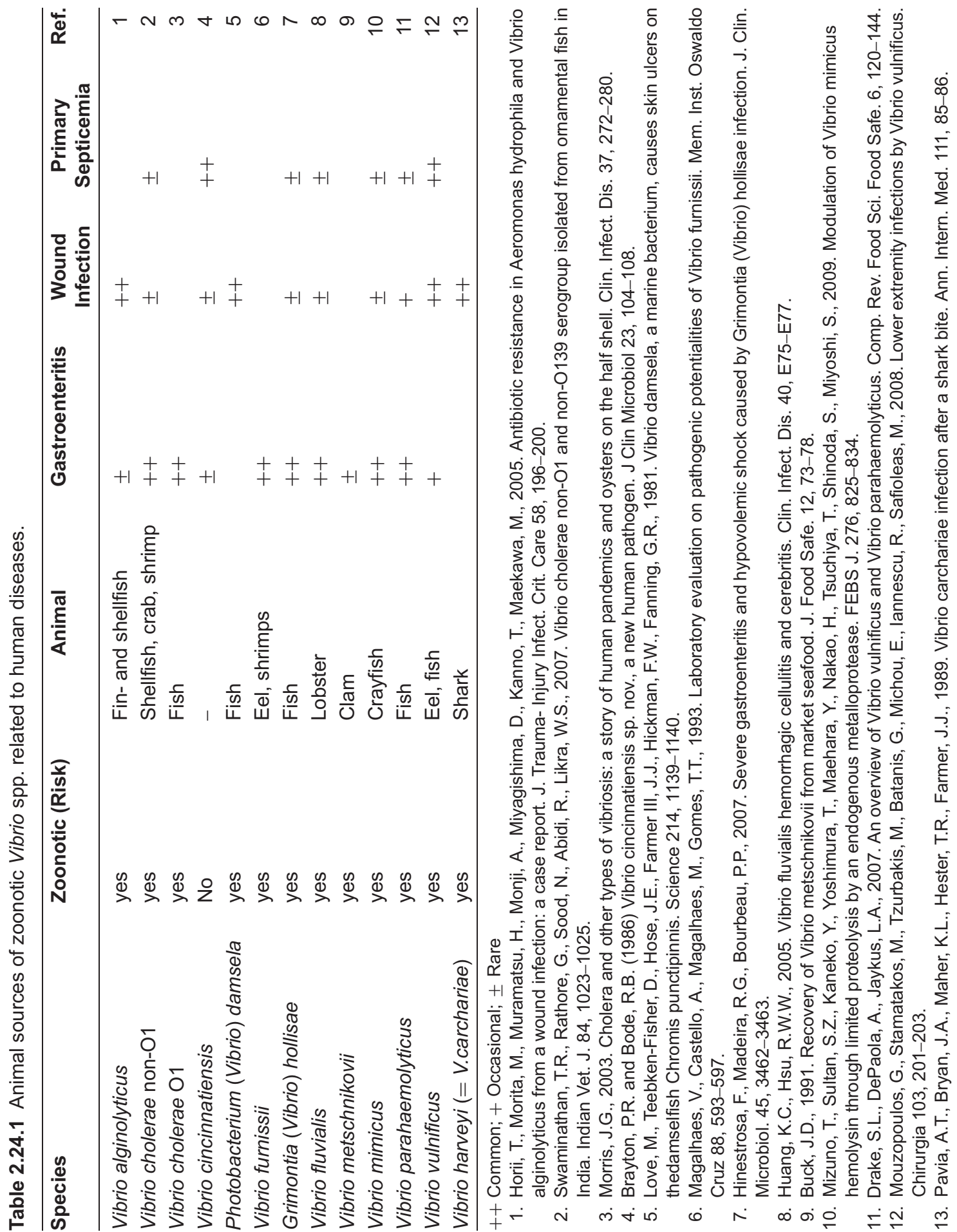


being present in aquatic environments and feeding on different bacteria. Indeed, Abd et al. (2007, 2010) recently showed experimentally an interesting interaction between $V$. cholerae and $V$. mimicus and the ubiquitous amoebae species, Acanthamoeba castellanii. Both Vibrio species revealed good growth and multiplication inside the monocellular organisms and also gained protection from antibiotics when encysted. The authors suggested that amoebae may play an important environmental role as host of these pathogens.

In the present chapter, water or foodborne infections will not be described as they were already reviewed in many excellent publications (Tantillo et al., 2004; Mouchtouri et al., 2010; Oliver and Kaper, 1997; McLaughlin, 1995; Newell et al., 2010); nevertheless, their environmental water aspects associated to zoonoses will be evaluated (Austin, 2010).

Estuarine waters used for aquaculture, fishing and recreational purposes are influenced by a large variety of factors such as climate, tidal flushing, temperature, vertical mixing, precipitation (affecting salinity) and nutrients loading (mainly through sewage discharges). These factors were shown to correlate definitely with Vibrio spp. presence and abundance, increasing human and animal infection potential (Hsieh et al., 2008; Inoue et al., 2008; Sedas, 2007). On the other hand "refractory periods" were reported, when in spite of favorable climatic conditions for "cholera" spread, clinical reported cases dropped significantly, mainly due to lack of susceptible hosts (increased immunity in previously exposed populations to infectious $V$. cholerae strains) (Koelle, 2009).

Wind as an additional climatic parameter has been suggested as a possible disseminator of Vibrio cholera (Paz and Broza, 2007). Continental winds were shown to carry aero-plankton (tiny insects such as chironomids or non-biting midges and other small flies) contaminated with cholera bacteria from one body of water to an adjacent one. Earlier, Broza et al. (2001) already showed that chironomids egg masses were infected with $V$. cholerae and can be an aquatic reservoir of this pathogen. Later, adult non-bitting midges (chironomids) were suspected of possibly carrying $V$. cholerae and becoming windborne (Broza et al., 2005). Indeed, this hypothesis is sound enough based on the wide spread of this pathogen globally, especially intra-continentally where bodies of water are secluded.

Many articles emphasized the difficulty inherent in cultivating $V$. cholera by conventional techniques, mainly in growing them as colonies on differential culture media. In a recent important report, it was shown that $V$. cholerae bacteria present in surface water may exist as conditionally viable environmental cells (CVEC), and partially as dormant cells in an aggregate form (biofilms) (Faruque et al., 2006). When these aggregates were directly inoculated into rabbit intestines they revealed complete virulence recovery. These authors also indicated two kinds of $V$. cholerae populations excreted in the stools of infected humans, planktonic and aggregates (clumps), with increased virulence of the latter.

Long et al. (2005) found that marine bacteria could inhibit the colonization of marine particles by $V$. cholera, through biosynthesis of an antibacterial agent controlled by temperature. At elevated temperature the production of this inhibitory agent diminished, giving preferentiality to V.cholera competitiveness and survival by means of particle colonization and biofilm formation. This biological pattern is compliant with El Niño-Southern Oscilliation (ENSO) and monsoonal events that cause water temperature elevation thereupon enhanced cholera outbreaks.

El Niño/La Niña-Southern Oscillation, or ENSO in brief, is a climate pattern (quasi-periodic) observed across the tropical Pacific Ocean (western part), approximately at an average of 5 years intervals (between 2 to 7 years). The main characteristics are variations in ocean water surface temperature (warming or cooling known as El Niño and La Niña, respectively) and air surface pressure in the tropical western Pacific - the Southern Oscillation. In the western Pacific, the two variations are coupled: the warm oceanic phase, El Niño, accompanies high air surface pressure, while the cold phase, La Niña, accompanies low air surface pressure (Figure 2.24.1). It is now clear that this climatic phenomenon has a global impact 
causing in other continents a variety of disastrous events (Figure 2.24.2). The oscillation mechanism remains still unclear, but its results are seen in biosphere behavior including cholera outbreaks.

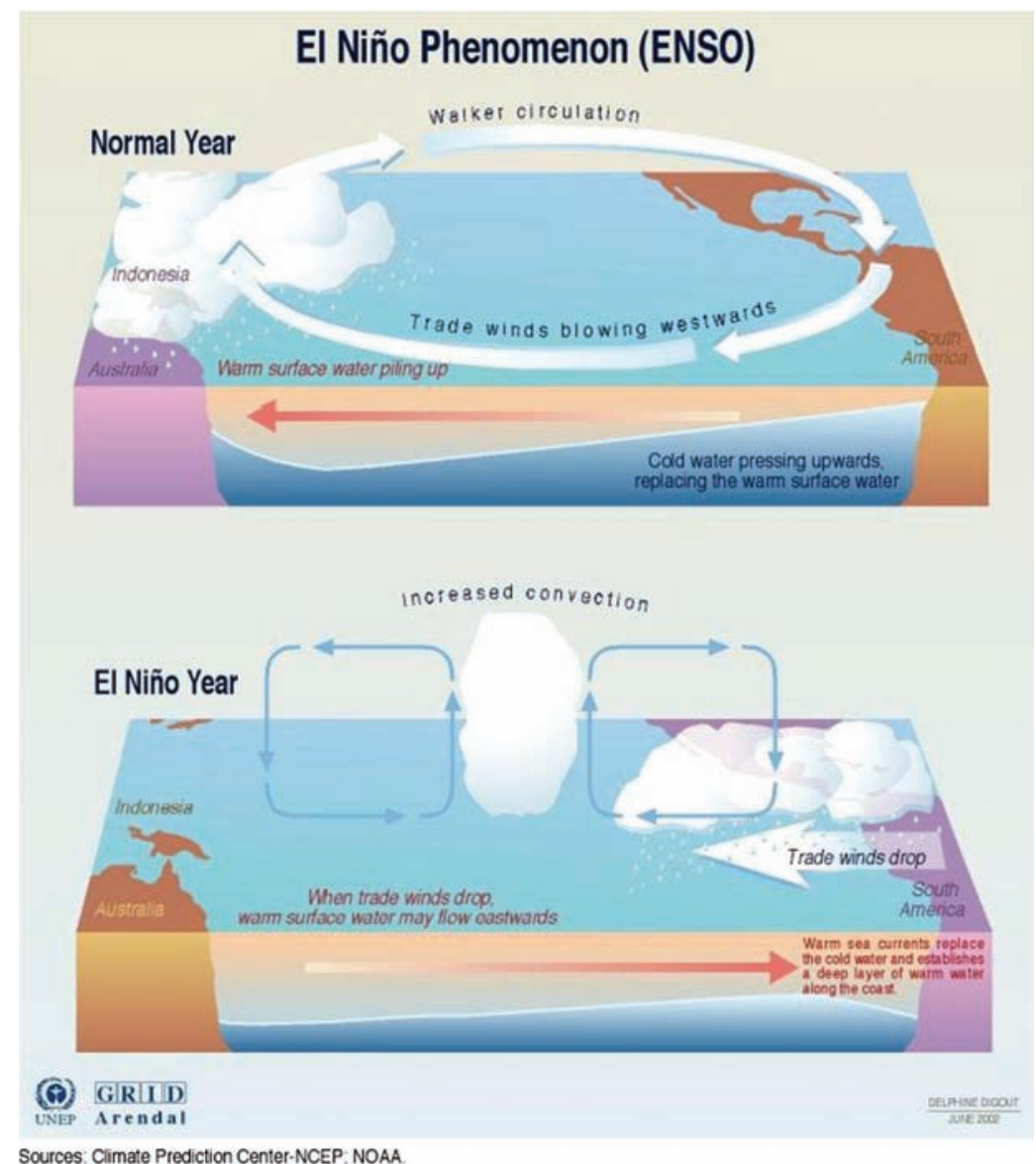

Figure 2.24.1. El Niño-Southern Oscillation (ENSO) Phenomenon. (2002) In UNEP/GRID-Arendal Maps and Graphics Library. Retrieved 14:53, January 2, 2011 from http://maps.grida.no/go/graphic/el-ni-osouthern-oscillation-enso-phenomenon, credit to Delphine Digout, UNEP/GRID-Arendal (Climate Prediction Center (CPC), National Centers for Environmental Prediction (NCEP); National Oceanic and Atmospheric Administration (NOAA)

Similar results for $V$. cholerae O1prevalence were reported in Mexico at different locations (after El Niño and La Nina) (Lizárraga-Partida et al., 2009). These authors concluded that V. cholera O1 derives from marine and estuarine origin and not from sewage contamination, linking copepod abundance with climatic conditions. In other locations such as southeastern Africa (a 35 years survey) (Paz, 2009) and South Korea (Heon and Yeon, 2010), the same trend was observed after an increase in sea surface temperature.

A similar correlation between temperature rise and another Vibrio sp. (Vibrio vulnificus) proliferation and successful human infection was reported in Israel (Paz et al., 2007). The authors clearly showed a rise in 
V. vulnificus clinical cases in fish industry workers linked to high summer temperatures. In colder temperate geographical areas such as Denmark, V. vulnificus was also reported to infect people during a particularly warm summer (Bruun et al., 1996).

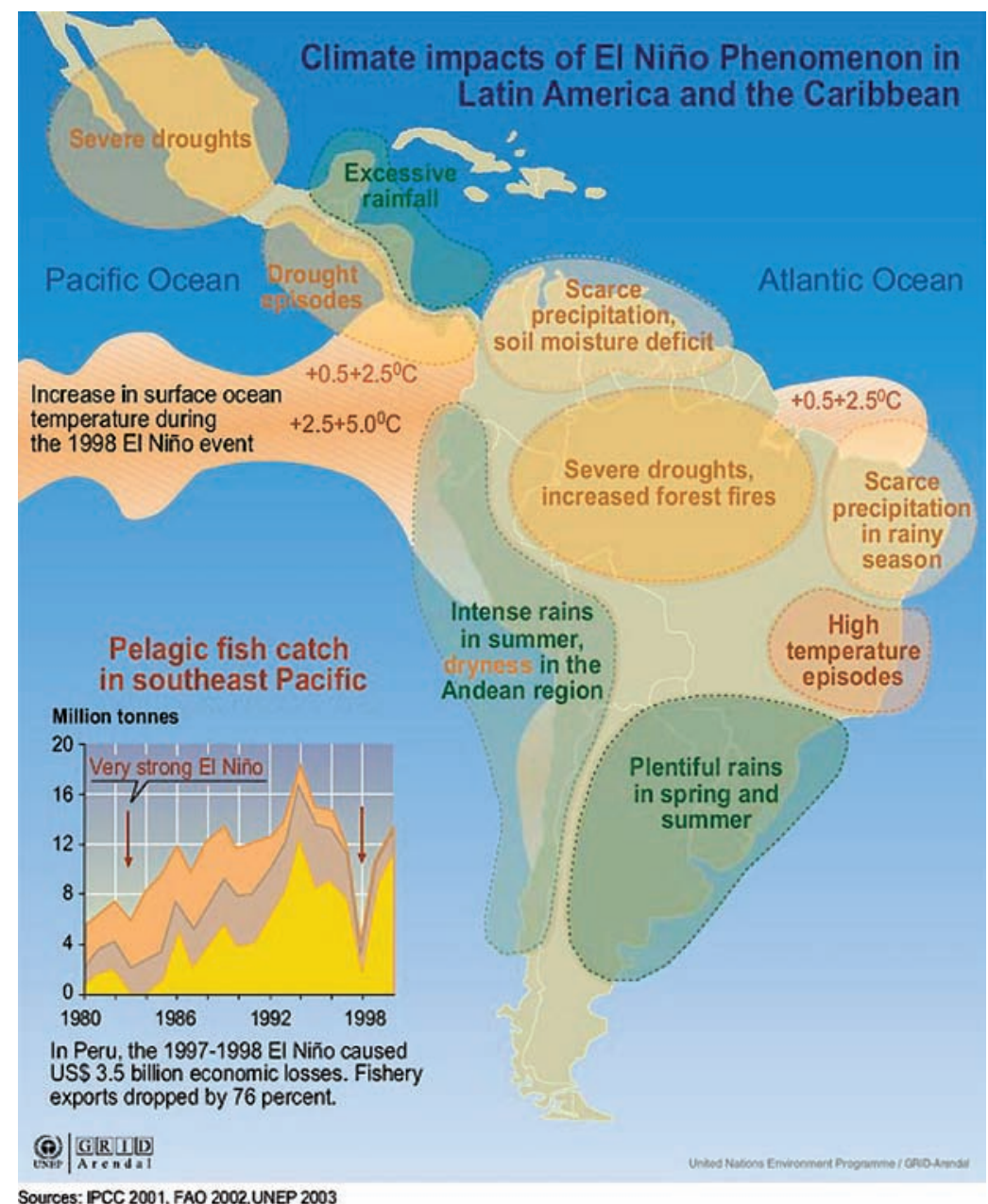

Figure 2.24.2. El Niño phenomenon impact on climate of South and Central America (2005). In UNEP/GRIDArendal Maps and Graphics Library. Retrieved 14:55, January 2, 2011 from http://maps.grida.no/go/ graphic/climate_impacts_of_el_ni_o_phenomenon_in_latin_america_and_the_caribbean, credit to UNEP/GRID-Arendal (IPCC $2001, \overline{F A O} 2002$, UNEP 2003)

Figure 2.24.3 summarizes the global spread of cholera from 1950 to 2004. For 20 years it spread from the most endemic area (India) towards China in the north, Iran in the west and Indonesia in the east. After an additional 20 years the disease agent spread globally to North and South America, Europe, Russia and even Australia.

Mezrioui and Oufdou (1996) reported on non-O1 Vibrio cholera survival in a simple domestic wastewater treatment (stabilization ponds) versus the decline of indicator bacteria (fecal coliforms). 
Seasonal distribution was reversed with increased survival of non-O1 Vibrio cholera with high densities in hot periods and low densities in cold periods.
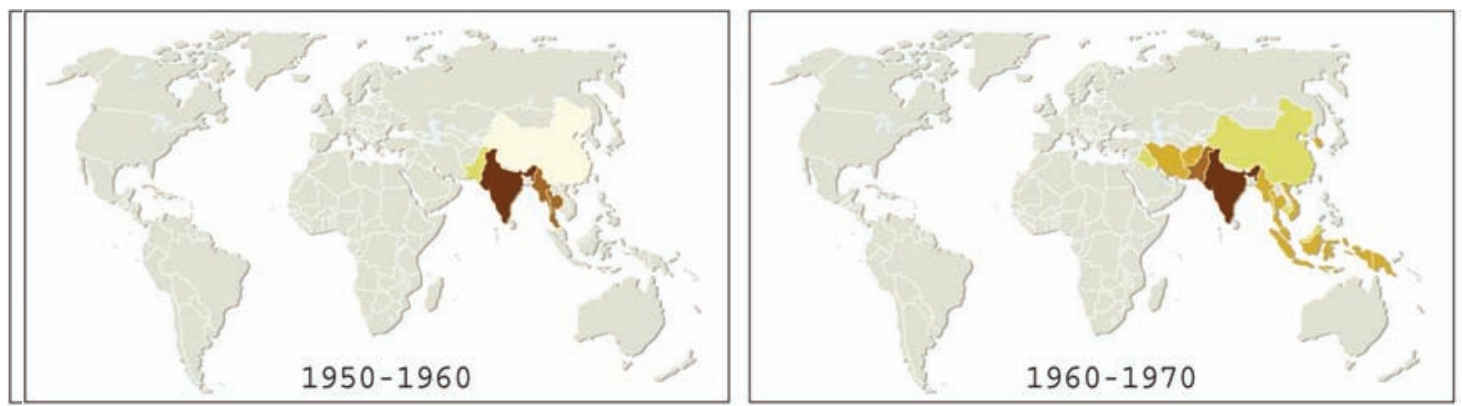

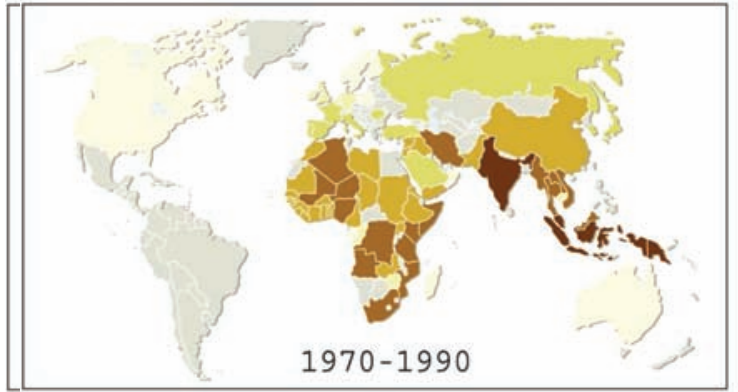

Source : Groupe de travail II et III, Rapport de synthèse du GIEC, 2007.

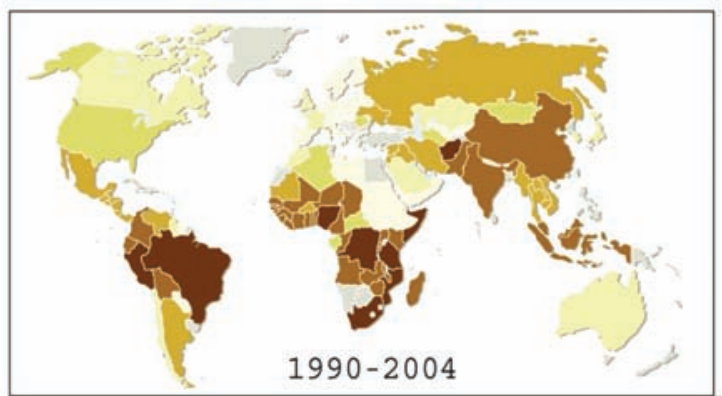

Nombre de cas de choléra déclaré par pays

$130 \quad 100 \quad 1000 \quad 10000100000$

Figure 2.24.3. Global cholera spread from 1950 to 2004. (With permission from: The spread of cholera 1950-2004. (2009). In UNEP/GRID-Arendal Maps and Graphics Library. Retrieved 20:56, January 19, 2011 from http://maps.grida.no/go/graphic/the-spread-of-cholera-1950-2004, credit to UNEP/GRID-Arendal (Working group II and III, Synthesis Report, IPCC, 2007)

Aquatic plants, seaweeds, and free floating phyto- and zooplankton can harbor vibrios in viable but nonculturable (VBNC), sporelike forms, as demonstrated by fluorescent antibody and polymerase chain reaction techniques (Islam et al., 1989; Huq et al., 1990). There is no reason to suspect that affinity for algae and weeds differs among various marine vibrios (Islam et al., 1990*; Islam et al., 1990). The growth of marine and freshwater photosynthesizers is prompted by nitrogen-rich wastewater, fertilizers, acid rain, and runoff soil (eutrophication) that may enhance also the growth of pathogenic Vibrios.

In contrast to tropical or subtropical seas, along the Swedish coastline (Skagerrak Sea) where the average temperature is $\sim 5^{\circ} \mathrm{C}$, Vibrios population was studied and surprisingly found to be widespread (Eiler et al., 2006). Total Vibrios spp. abundance was found to range from $10^{3}$ to $10^{4}$ cells/L with increasing numbers in more saline waters. $V$. anguillarum and $V$. aestuarianus genotypes were present in brackish waters. In addition, $50 \%$ of the samples were positive for $V$. cholera and $V$. mimicus $\left(>10^{3}\right.$ cells/L) in very cold water and low salinity. These authors also indicated other factors such as nutrient levels and dinoflagelate abundances that also may impact the prevalence and abundance of these Vibrios along the 
coastal line. These findings may explain the reports of wounds infected by V. cholera in Swedish swimmers (Andersson and Ekdahl, 2006; Rehnstam-Holm \& Collin, 2009).

Using an experimental approach, Wiklund et al. (2009) looked for structural changes in the pelagic food web under temperature alteration by $5^{\circ} \mathrm{C}$ in a Baltic Sea mesocosm (a brackish sea water with a salinity of $\sim 7 \%$ o near the coastal line and 10-15\% in the open, compared to $35 \%$ o found in oceans) using the amphipod Monoporeia affinis as a key benthic species. They found a structural shift in the pelagic food web from one based on algae to one based on bacteria, which decreased amphipod productivity and the efficiency of the pelagic-benthic food web (FWE). As growth of amphipods and FWE were not directly affected by the temperature raise, the authors concluded that the main ecological impact occurred through indirect structural changes in the pelagic food web and consequently on the benthic productivity. As Vibrio species also belong to the benthic food web it is very much possible that temperature rise will increase human health risk in these environments.

\subsubsection{REFERENCES}

Abd, H., Saeed, A., Weintraub, A., Nair, G.B. \& Gunnar Sandström, G. (2007) Vibrio cholerae O1strains are facultative intracellular bacteria, able to survive and multiply symbiotically inside the aquatic free-living amoeba Acanthamoeba castellanii. FEMS Microbiol. Ecol. 60, 33-39.

Abd, H., Valeru, S.P., Sami, S.M. Saeed, A., Raychaudhuri, S. \& Sandström, G. (2010) Interaction between Vibrio mimicus and Acanthamoeba castellanii. Environ Microbiol Rep 2, 166-171.e.mi4_ 166

Andersson, Y. \& Ekdahl, K. (2006) Wound infections due to Vibrio cholerae in Sweden after swimming in the Baltic Sea, summer 2006. Euro Surveill. 11, E060803.2.

Austin, B. (2010) Vibrios as causal agents of zoonoses. Vet. Microbiol. 140, 310-317.

Broza, M. \& Halpern, M. (2001) Pathogen reservoirs: chironomid egg masses and Vibrio cholerae. Nature 412, 40.

Broza, M., Gancz, H., Halpern, M., Kashi, Y. (2005) Adult non-biting midges: possible windborne carriers of Vibrio cholerae. Environ Microbiol 7, 576-585.

Bruun, B.G., Frimodt-Moller, N., Dalsgaard, A., Busk, H.E., Friis, H. et al. (1996) Vibrio vulnificus infections in Denmark during the summer of 1994. Ugeskr. Laeg. 158, 4291-4294.

Campanelli, A., Sanchez-Politta, S. \& Saurat, J.H. (2008) Cutaneous ulceration after an octopus bite: infection due to Vibrio alginolyticus, an emerging pathogen. Ann Dermatol Venereol 135, 225-227.

Codeco, C.T. (2001) Endemic and epidemic dynamics of cholera: the role of the aquatic reservoir. BMC Infect Dis. http://www.biomedcentral.com/1471-2334/1/1.

Colwell, R.R. (2002) Editorial: A voyage of discovery: cholera, climate and complexity. Environ. Microbiol. 4, 67-69.

Córdova, J.L., Astorga, J., Silva, W. \& Riquelme, C. (2002) Characterization by PCR of Vibrio parahaemolyticus isolates collected during the 1997-1998 Chilean outbreak. Biol. Res. 35, 433-440.

Eiler, A., Johansson, M. \& Bertilsson, S. (2006) Environmental influences on Vibrio populations in northern temperate and boreal coastal waters (Baltic and Skagerrak Seas). Appl. Environ. Microbiol. 72, 6004-6011.

Faruque, S.M., Biswas, K., Udden, S.M.N., Ahmad, Q.S., Sack, D.A., Nair, G.B. \& Mekalanos, J.J. (2006) Transmissibility of cholera: In vivo-formed biofilms and their relationship to infectivity and persistence in the environment. Proc. Natl. Acad. Sci. U.S.A. 103, 6350-6355.

Hayat, M.Z., Afework, K., Alizadeh, M., Masayuki, Y., Bhuiyan, N.A., Balakrish, N.G. \& Fusao, O. (2006) Isolation and molecular characterization of toxigenic Vibrio parahaemolyticus from the Kii Channel, Japan. Microbiol. Res. 161, 25-37.

Heon, K.S. \& Yeon, J.J. (2010) Correlations between climate change-related infectious diseases and meteorological factors in Korea. J Prev Med Public Health 43, 436-444.

Hsieh, J.L., Fries, J.S. \& Noble, R.T. (2008) Dynamics and predictive modelling of Vibrio spp. in the Neuse River Estuary, North Carolina, USA. Environ. Microbiol. 10, 57-64. 
Huq, A., Colwell, R.R., Rahman, R. et al. (1990) Detection of Vibrio cholerae O1 in the aquatic environment by fluorescent-monoclonal antibody and culture methods. Appl Environ Microbiol. 56, 2370-2373.

Inoue, Y., Ono, T., Matsui, T., Miyasaka, J., Kinoshita, Y. \& Ihn, H. (2008) Epidemiological survey of Vibrio vulnificus infection in Japan between 1999 and 2003. J. Dermatol. 35, 129-139.

Islam, M.S., Drasar, B.S. \& Bradley, D.J. (1989) Attachment of toxigenic Vibrio cholerae O1 to various fresh water plants and survival with a filamentous green algae, Rhizoclonium fontanum. J Trop Med Hyg. 92, 396-401.

Islam, M.S., Drasar, B.S. \& Bradley, D.J. (1990)* Longterm persistence of toxigenic Vibrio cholera O1 in the mucilaginous sheath of a blue-green algae, Anabaena variablis. J Trop Med Hyg. 93, 133-139.

Islam, M.S., Drasar, D.S. \& Bradley, D.J. (1990) Survival of toxigenic Vibrio cholerae O1 on a duckcweed, Lemna minor, in artificial aquatic ecosystems. Trans R Soc Trop Med Hyg. 84, 422-424.

Koelle, K. (2009) The impact of climate on the disease dynamics of cholera. Clin Microbiol Infect 15 (Suppl. 1), 29-31.

Lipp, E.K., Huq, A. \& Colwell, R.R. (2002) Effects of Global Climate on Infectious Disease: the Cholera Model. Clin. Microbiol. Rev. 15, 757-770.

Lizárraga-Partida, M.L., Mendez-Gómez, E., Rivas-Montaño, A.M., Vargas-Hernández, E., Portillo-López, A. et al. (2009) Association of Vibrio cholerae with plankton in coastal areas of Mexico. Environ. Microbiol. 11, 201-208.

Long, R.A., Rowley, D.C., Zamora, E., Liu, J., Bartlett, D.H. \& Farooq Azam, F. (2005) Antagonistic Interactions among Marine Bacteria Impede the Proliferation of Vibrio cholera. Appl. Environ. Microbiol. 71, 8531-8536.

McLaughlin, J.C. (1995) Vibrio. In: Manual of Clinical Microbiology (1995), 6th ed. Editor(s): Murray PR, Baron EJ, Pfaller MA, et al., pp. 465-476, ASM Press Washington, D.C.

Mezrioui, N. \& Oufdou, Kh. (1996) Abundance and antibiotic resistance of non-O1 Vibrio cholerae strains in domestic wastewater before and after treatment in stabilization ponds in an arid region (Marrakesh, Morocco). FEMS Microbiol. Ecol. 21, 277-284.

Mouchtouri, V.A., Nichols, G., Rachiotis, G., Kremastinou, J., Arvanitoyannis, I.S. et al. (2010) State of the art: public health and passenger ships. Int Marit Health 61, 53-98.

Newell, D.G., Koopmans, M., Verhoef, L., Duizer, E., Aidara-Kane, A. et al. (2010) Food-borne diseases - The challenges of 20 years ago still persist while new ones continue to emerge. Int. J. Food Microbiol. 139, S3-S15.

Oberbeckmann, S., Wichels, A., Maier, T., Kostrzewa, M., Raffelberg. S. \& Gerdts, G. (2011) Apolyphasic approach for the diferentiation of environmental Vibrio isolates from temperate waters. FEMS Microbiol. Ecol. 75, 145-162.

Oliver, J.D. \& Kaper, J.B. (1997) Vibrio species. In: Food Microbiology (1997), Editor(s): Doyle, M.P.,Beuchat, L.R. \& Montville, T.J., pp. 228-264. ASM Press, Washington, D.C.

Paz, S. (2009) Impact of Temperature Variability on Cholera Incidence in Southeastern Africa, 1971-2006. EcoHealth 6, 340-345.

Paz, S. \& Broza, M. (2007) Wind direction and its linkage with Vibrio cholerae dissemination. Environ. Health Perspect. 115,195-200.

Paz, S., Bisharat, N., Paz, E., Kidar, O. \& Cohen, D. (2007) Climate change and the emergence of Vibrio vulnificus disease in Israel. Environ. Res. 103, 390-396.

Perez-Rosas, N. \& Hazen, T.C. (1989) In situ survival of Vibrio cholerae and Escherichia coli in a tropical rain forest watershed. Appl. Environ. Microbiol. 55, 495-499.

Prapaiwong, N., Wallace, R.K. \& Arias, C.R. (2009) Bacterial loads and microbial composition in high pressure treated oysters during storage. Int. J. Food Microbiol. 131, 145-150.

Rehnstam-Holm, A-S. \& Collin, B. (2009) Vibrio species in the waters of Southern Sweden caused bath-wound fever. Increased bacteria frequency according to studies on clams. Lakartidningen 106, 435-438.

Sack, D.A., Sack, R.B., Nair, G.B. \& Siddique, A.K. (2004) Cholera. Lancet 363, 223-233.

Schwartz, B.S., Harris, J.B., Khan, A.I., Larocque, R.C., Sack, D.A., Malek, M.A. et al. (2006) Diarrheal epidemics in Dhaka, Bangladesh, during three consecutive floods: 1988, 1998, and 2004. Am. J. Trop. Med. Hyg. 74, 1067-1073.

Sedas, V.T.P. (2007) Influence of environmental factors on the presence of Vibrio cholera in the marine environment: a climate link. J Infect Dev Ctries 1, 224-241. 
Tantillo, G.M., Fontanarosa, M., Di Pinto, A. \& Musti, M. (2004) Updated perspectives on emerging vibrios associated with human infections. Lett Appl Microbiol. 39, 117-126.

Thompson, F.L., Iida, T. \& Swings, J. (2004) Biodiversity of Vibrios. Microbiol. Mol. Biol. Rev. 68, 403-431.

Wiklund, A.-K., Eriksson, D.K., Sundelin, B. \& Andersson, A. (2009) Effects of warming and shifts of pelagic food web structure on benthic productivity in a coastal marine system. Mar. Ecol. Prog. Ser. 396, 13-25. 


\section{Chapter 2.25 Yersinioses}

\section{[YERSINIA ENTEROCOLITICA AND YERSINIA PSEUDOTUBERCULOSIS]}

Both Y. enterocolitica and Y. pseudotuberculosis belong to the family of Enterobacteriaceae and genus Yersinia like their previously described relative: Y. pestis. These species are gram-negative coccobacilli, facultative anaerobes that primarily cause zoonotic diseases. Among the $~ 50$ serovars (serogroups) of Y. enterocolitica, only serogroups O:3, O:9 (Europe), O:8 (USA), O:5 and O:27 (Japan and Canada) were identified as human pathogens. Y. pseudotuberculosis has 14 serovars of which O:1 constitutes 60-70\% while 0:2 and O:3 constitutes 10-20\% (in Europe), O:4 and O:6 (mainly in Japan). The main reservoirs of these bacteria are rodents and birds with cross-transmission to humans, farm animals, pets, laboratory and wild animals, animal food and water (Mollaret, 1983). The diseases caused by these two species are enteritis/enterocolitis with symptoms such as: febrile diarrhea, pseudo-appendicitis, septicemia, erythema nodosum, arthritis, mesenterial lymphadenitis, etc.

\subsubsection{Y. ENTEROCOLITICA, Y. PSEUDOTUBERCULOSIS AND ENVIRONMENT (FIGURE 2.25.1)}

Both pathogens, Y. enterocolitica and Y. pseudotuberculosis, are well documented zoonotic foodborne pathogens (otherwise called "saprozoonoses") (Krauss et al., 2003), transmitted through direct contact or via water and food obtained from contaminated animals (farm animals: pigs, cattle, etc.) (FredrikssonAhomaa et al., 2007). In this section, the foodborne aspect will not be discussed since it was reviewed elsewhere in details (Matargas and Drosinos, 2009; Dube, 2009).

Litvin et al. (1991) showed that plants such as cabbage, lettuce, pea and oat, challenged with $Y$. enterocolitica and $Y$. pseudotuberculosis originating from soil and water revealed internal penetration of these plants (roots, seeds and leaves) and survival for up to 30 days.

A similar plant connection was reported in Finland, where an outbreak of $Y$. pseudotuberculosis occurred among schoolchildren who fed on infected carrots (Jalava et al., 2006). It is not clear if the carrots were infected previously or during preparation, though $42 \%$ of soil samples containing carrot residue (some also from the production farm), identified by pulsed-fiel gel electrophoresis (PFGE), were found positive 
for this bacterium. In Finland also, Nuorti et al. (2004) reported on a nation-wide infection with $Y$. pseudotuberculosis 0:3 originating from iceberg lettuce. Interestingly, the authors mentioned an ecologically distinct feature of a large population ( $>10,000$ animals) of nonnative roe deer (Capreolus capreolus) introduced in the 1960s as well as large quantities of roe deer feces found all over the lettuce fields and around every one of the irrigation water sources.

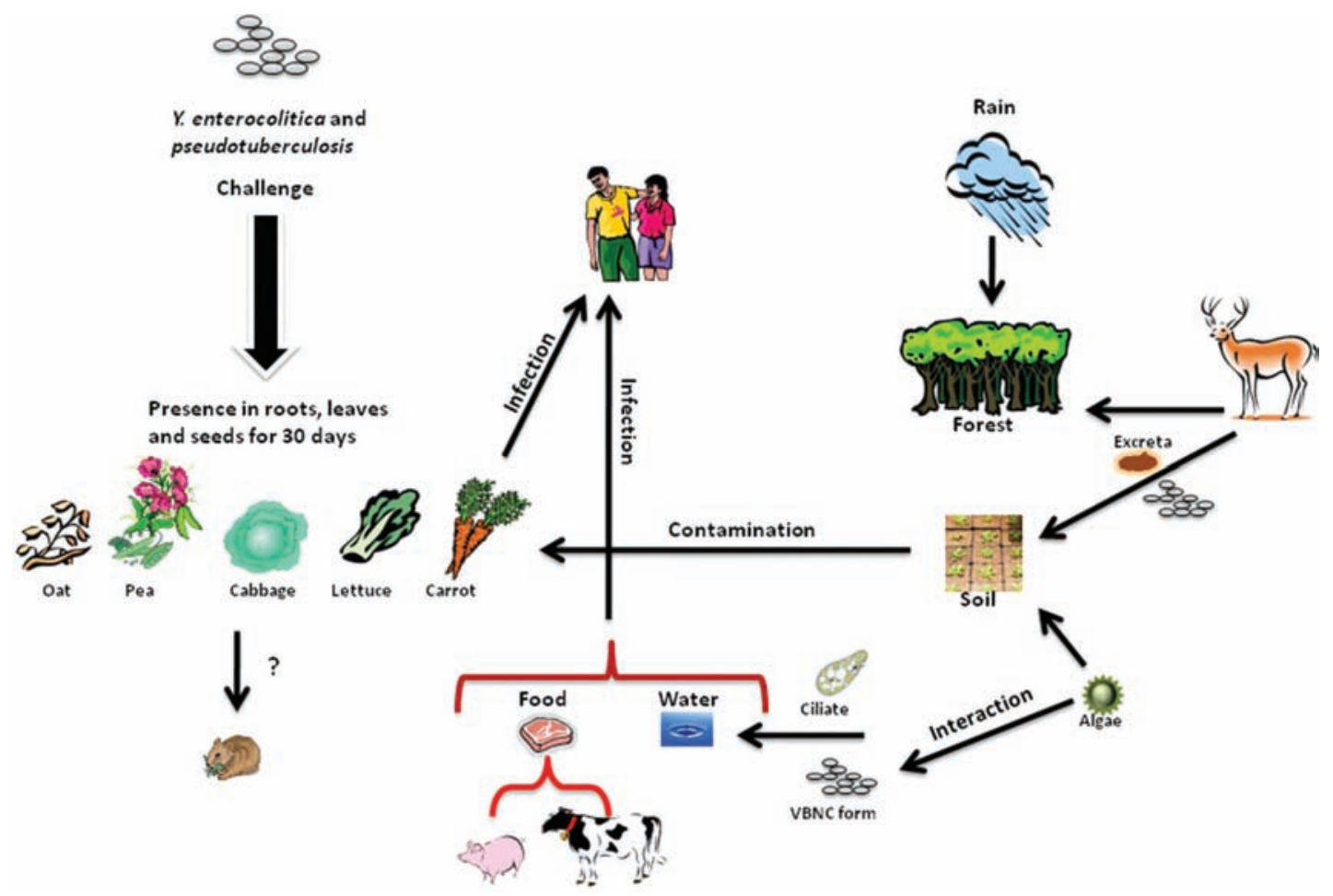

Figure 2.25.1. Y. enterocolitica and pseudotuberculosis spp. presence and interaction with environmental parameters

It is very feasible that soil is the main link between pathogens and cultivable plants. Barre et al. (1977) isolated different $Y$. pseudotuberculosis serotypes among which serotype I (an already demonstrated human pathogen) from soil samples around Paris (France) while Nastasi et al. (1986) isolated Y. enterocolitica from soil and dog feces. These reports suggest a clear potential health risk from soils as a reservoir for these pathogens. Also in relation to soil, Y. pseudotuberculosis was studied for its persistence in sterile soils (as an abiotic environment) and in natural soil (as biotic/abiotic multifaceted environment) (Litvin et al., 1990). In sterile soil, $Y$. pseudotuberculosis was resistant to a wide range of temperatures $\left(0\right.$ to $\left.30^{\circ} \mathrm{C}\right)$, humidities (15 to $50 \%$ ) and pHs (5.9 to 9.0). Under these conditions, the growth rate was only slightly affected but not the general nature of the population dynamic of this bacterium. A more marked impact was observed in natural soil containing other bacterial species such as Acinetobacter and Pseudomonas that can alter $Y$. pseudotuberculosis biotic persistence. According to the authors' results, another 
important biotic factor is the endosymbiotic relationship between $Y$. pseudotuberculosis and free-living infusorian Tetrahymena pyriformis, shown to sustain this pathogen population in soil and water.

The saprophitic characteristics of $Y$. pseudotuberculosis were shown in soil samples from the surroundings of Nero lake (Rostov district, Russia), which is a natural source of this pathogen (Maksimenkova \& Karpachevskii 1985). Soil in this area has a high content of organics, cations exchange capacity (CEC) and moisture, all favoring the growth and survival of thess organisms for prolonged periods. Soil survival of $Y$. enterocolitica was studied in natural soil, river water and well water (Tashiro et al., 1991). Among Y. enterocolitica serotypes O:3, O:4, O:5A, O:5B, O:6, O:6, O:30, O:9 and O:13 seroptypes O3, O:5B and O:9 strains survived longer at $4{ }^{\circ} \mathrm{C}$ than at $20^{\circ} \mathrm{C}$ in these soil and river water environments.

Aksenov et al. (1995) and Troitskaia et al. (1996) found higher numbers of Y. pseudotuberculosis in environmental soil samples from natural foci using the specific molecular method (PCR) than using the classical culture method. This detection disparity was attributed to a viable but non-culturable (VNBC) form of $Y$. pseudotuberculosis. VNBC forms of $Y$. pseudotuberculosis were also observed in soil in association with blue-green algae, Anabaena variabilis, closely related to seasonal changes such as temperature (Solokhina et al., 2001). Exometabolites of these algae accelerated the formation of "resting cells" of $Y$. pseudotuberculosis at $22^{\circ} \mathrm{C}$. When VNBC forms were passed through infusoria ciliated protozoa, partial reversion to vegetative form (cells capable of growing on solid culture medium) was observed. The transfer from vegetative to VNBC form in relation to algal soil presence is not clear, but it can be speculated that some "partial antibiotic activity" may be attributed to algal exometabolites that do not eradicate bacterial cells completely but act as a biostatic factor altering their growth capability. Indeed, lower enzymatic activity, agglutinability, cytopathogenicity and plasmid p45 loss were observed in revertant bacterial cells.

A potential connection to soil types and algal content was also described by Sidorenko and Buzoleva (2007) who compared two seashore soil types (maritime meadow and tidal marsh) for their growth support of two pathogens: L. monocytogenes and $Y$. pseudotuberculosis. Both soil types were supportive for growth and survival, with maritime meadow being superior.

In Germany, soil originating from deciduous forest was found to harbor Y. enterocolitica in contrast to grassland soil that was found to be negative (Botzler, 1987). In northwest California, $Y$. enterocolitica was isolated from soils inhabited by infected wapiti (an elk species, Cervus elaphus roosevelti, L.). Prevalence of $Y$. enterocolitica in soil from forest habitat was significantly higher than that from prairie habitat especially following a previous excessive rainfall of $17 \mathrm{~mm}$ (Botzler, 1979). From these reports it is clear that forest animals' excreta contribute to the prevalence of $Y$. enterocolitica in forest soil, affected strongly by moisture as a result of rainfall (French et al., 2010).

Water is one of the main carriers of Yersinia and clearly proven to infect humans (Fukushima et al., 1988). A study on stream water from urban, agricultural and forested watersheds, applying the $16 \mathrm{~S}$ rRNA gene sequencing method, revealed Yersinia spp. presence mainly in forested watershed (Belt et al., 2007). In water environment, diverse planktonic and benthos invertebrates, such as water flies, cyclops, mollusks, oligochaeta, insects' larvae were found to support prolonged survival of $Y$. pseudotuberculosis. Beside these organisms, fish and higher plants were also found to be supportive, therefore presenting a health risk (Pushkareva et al., 1994).

Bresolin et al. (2006) reported that $Y$. enterocolitica expresses virulence factors pathogenic to insects (such as Tc proteins) at low temperature $\left(10^{\circ} \mathrm{C}\right)$. The virulent $Y$. enterocolitica lives in a symbiotic complex with entomophagous nematodes. Insects are invaded by these nematodes that in turn release its gut symbiotic bacteria into the haemocoel (insect circulatory system) killing the insect host to provide more nutrients (Forst et al., 1997). These findings are probably pointing towards insects as a life stage of 
several $Y$. enterocolitica biotypes, similar to its other close relative, $Y$. pestis, that alternates between fleas and mammals. Temperature in this case is the environmental signal for $Y$. enterocolitica to switch replication from mammalian host to soil or poikilothermic insects (Palonen et al., 2010).

\subsubsection{REFERENCES}

Aksenov, M.Yu., Misurenko, E.N., Shustrova, N.M., Garovnikova, Yu.S., Gintsburg, A.L. \& Litvin, V.Yu. (1995) Detection of Yersinia pseudotuberculosis nonculturable forms and the study of the dynamics of their amount in the environment by the polymerase chain reaction. Zh. Mikrobiol. Epidemiol. Immunobiol. 2, 80-83.

Barre, N., Louzis, C., Treignier, M. \& Dubois-Darnaudpeys, A. (1977) Demonstration of Yersinia pseudotuberculosis in in cultivated soils. C. R. Acad. Sci., D, Sci. Nat. 284, 2297-2300.

Belt, K.T., Hohn, C., Gbakima, A. \& Higgins, J.A. (2007) Identification of culturable stream water bacteria from urban, agricultural, and forested watersheds using 16S rRNA gene sequencing. $J$ Water Health 5, 395-406.

Botzler, R.G. (1979) Yersiniae in the soil of an infected wapiti range. J. Wildl. Dis. 15, 529-532.

Botzler, R.G. (1987) Isolation of Yersinia enterocolitica and Y. frederiksenii from forest soil, Federal Republic of Germany. J. Wildl. Dis. 23, 311-313.

Bresolin, G., Morgan, J.A.W., Ilgen, D., Scherer, S. \& Fuchs, T.M. (2006) Low temperature-induced insecticidal activity of Yersinia enterocolitica. Mol. Microbiol. 59, 503-512.

Dube, P. (2009) Interaction of Yersinia with the gut: mechanisms of pathogenesis and immune evasion. Curr. Top. Microbiol. Immunol. 337, 61-91.

Forst, S., Dowds, B., Boemare, N. \& Stackebrandt, E. (1997) Xenorhabdus and Photorhabdus spp. bugs that kill bugs. Annu. Rev. Microbiol. 51: 47-72.

Fredriksson-Ahomaa, M., Andreas Stolle, A. \& Stephan, R. (2007) Prevalence of pathogenic Yersinia enterocolitica in pigs slaughtered at a Swiss abattoir. Int. J. Food Microbiol. 119, 207-212.

French, E., Rodriguez-Palacios, A. \& LeJeune, J.T. (2010) Enteric bacterial pathogens with zoonotic potential isolated from farm-raised deer. Foodborne Pathog. Dis. 7, 1031-1037.

Fukushima, H., Gomyoda, M., Shiozawa, K., Kaneko, S. \& Tsubokura, M. (1988) Yersinia pseudotuberculosis infection contracted through water contaminated by a wild animal. J Clin Microbiol. 26, 584-585.

Jalava, K., Hakkinen, M., Valkonen, M., Nakari, U-M., Taito Palo, T. et al. (2006) An Outbreak of gastrointestinal illness and erythema nodosum from grated carrots contaminated with Yersinia pseudotuberculosis. J. Infect. Dis. 194, 1209-1216.

Krauss, H., Weber, A., Enders, B., Isenberg, H.D., Schiefer, H.G. et al. (2003). Zoonoses: Infectious diseases transmissible from animlas to humans. 3rd Edition, ASM Press, Washington, DC.

Litvin, V.Iu., Shustrova, N.M., Gordeiko, V.A., Pushkareva, V.I. \& Misurenko, E.N. (1991) An experimental study of Yersinia in plants. Zh. Mikrobiol. Epidemiol. Immunobiol. 9, 5-7.

Litvin, V.Yu., Maksimenkova, I.A., Pushkareva, V.I., Shustrova, N.M. \& Gamaleya, N. F. (1990) Analysis of factors which determine the existence of Yersinia pseudotuberculosis in a saprophytic phase. J Hyg Epidemiol Microbiol Immunol 34, 289-298.

Maksimenkova, I.A. \& Karpachevskii, L.O. (1985) Characteristics of soils of natural sites for leptospiroses and pseudotuberculosis and enteric Yersinia infection pathogens. Moscow Univ Biol Sci Bull 10, 107-115.

Mataragas, M. \& Drosinos, E.H. (2009) Microbial foodborne pathogens. In: Nollet, L.M.L. \& Toldra, F. (Eds.) Handbook of Processed Meats and Poultry Analysis, pp. 461-497. CRC Press, Boca Raton.

Mollaret, H.H. (1983) Yersinia pseudotuberculosis and Yersinia enterocolitica. Rev Rhum Mal Osteoartic 50, 713-717.

Nastasi, A., Massenti, M.F., Scarlata, G., Mammina, C., Calco, C. \& Villafrate, M.R. (1986) Salmonella and Yersinia enterocolitica in soil and dog faeces. Boll Ist Sieroter Milan 65, 150-152.

Nuorti, J.P., Niskanen, T., Hallanvuo, S., Mikkola, J., Eija Kela, E. et al. (2004) A Widespread outbreak of Yersinia pseudotuberculosis O:3 infection from iceberg lettuce. J. Infect. Dis. 189, 766-774.

Palonen, E., Lindstroem, M. \& Korkeala, H. (2010) Adaptation of enteropathogenic Yersinia to low growth temperature. Crit. Rev. Microbiol. 36, 54-67. 
Pushkareva, V.I., Litvin, V.Iu., Shustrova, N.M. \& Osipova, L.V. (1994) Potential hosts and routes of the circulation of Yersinia pseudotuberculosis in an aqueous ecosystem. Zh. Mikrobiol. Epidemiol. Immunobiol. 3, 52-57.

Sidorenko, M.L. \& Buzoleva, L.S. (2007) Influence of chemical and physical characteristics of seashore soils in Primorsky region on preservation and reproduction of Listeria and Yersinia. Zh. Mikrobiol. Epidemiol. Immunobiol. 3, 83-86.

Solokhina, L.V., Pushkareva, V. I. \& Litvin, V. Yu. (2001) Formation of resting forms and variability of Yersinia pseudotuberculosis under the impact of blue-green algae (cyanobacteria) and their exometabolites. $Z h$. Mikrobiol. Epidemiol. Immunobiol. 3, 17-22.

Tashiro, K., Kubokura, Y., Kato, Y., Kaneko, K. \& Ogawa, M. (1991) Survival of Yersinia enterocolitica in soil and water. J. Vet. Med. Sci. 53, 23-27.

Troitskaia, V.V., Chetina, E.V., Aliapkina, Iu.S., Litvin, V.Iu. \& Gintsburg, A.L. (1996) Nonculturable forms of Yersinia pseudotuberculosis in the soils of a natural focus of pseudotuberculosis. Zh. Mikrobiol. Epidemiol. Immunobiol. 5, 13-15. 


\section{Chapter 2.26}

\section{Rare zoonotic bacteria}

In this chapter, other miscellaneous bacteria "incriminated" as potential zoonotic agents are described. Some of their characteristics are described in Table 2.26.1. Their prevalence as human zoonoses is low, although they cannot be ruled out as hazards especially due to their domestic animals' origin.

\subsubsection{MISCELLANEOUS ZOONOTIC BACTERIA AND ENVIRONMENT (FIGURE 2.26.1)}

Actinobacillus lignieresii, equuli and suis species are a common component of oropharingeal microbiota of animals such as cattle, horses, sheep and pigs. These Actinobacillus spp. are also the main human zoonotic pathogens of this genus, even if rare (Ashhuurst et al., 1988). A. lignieresii and A. suis were detected following horse and pig bites (Dibb et al., 1981; Escande et al., 1996), in a farmer (A. lignieresii) (Orda and Wiznitzer, 1980) and also directly recovered from horses, the majority exhibiting some kind of illness, in New Zealand (Carman and Hodges, 1982). In Japan they have been isolated more frequently from respiratory infections and endocarditis cases (Sakazaki et al., 1984).

Andrade et al. (1997) studied the effects of roots and of arbuscular-mycorrhizal (AM) fungi on the composition of soil bacterial colonies and their combined effects. Roots were experimentally colonized by three arbuscular-mycorrhizal (AM) fungi: G. etunicatum, G. intraradices or G. mosseae. Among the large variety of bacteria isolated from the rhizosphere and hyposphere (the soil area not directly influenced by roots), Actinobacillus lignieresii was only isolated from the hyposhere of the AM-fungi G. mosseae.

Actinobacillus suis has been shown to cause diseases in pigs, horses, geese, cats, rodents, sheep (Maddux et al., 1987; Daignault et al., 1999; Lentsch and Wagner, 1980; Peel et al., 1991) with elevated serological heterogeneity in horses (Bada et al., 1996).

Carvalho et al. (1999) tested different soil bacteria strains for their emulsification activity on water-diesel oil combinations. Actinobacillus lignieresii was among the high biosurfactant producers with high emulsification potential. This feature seems to be related to its susceptibility to hydrophobic compounds such as the antibiotic novobiocin (Hart and Champlain, 1988). 


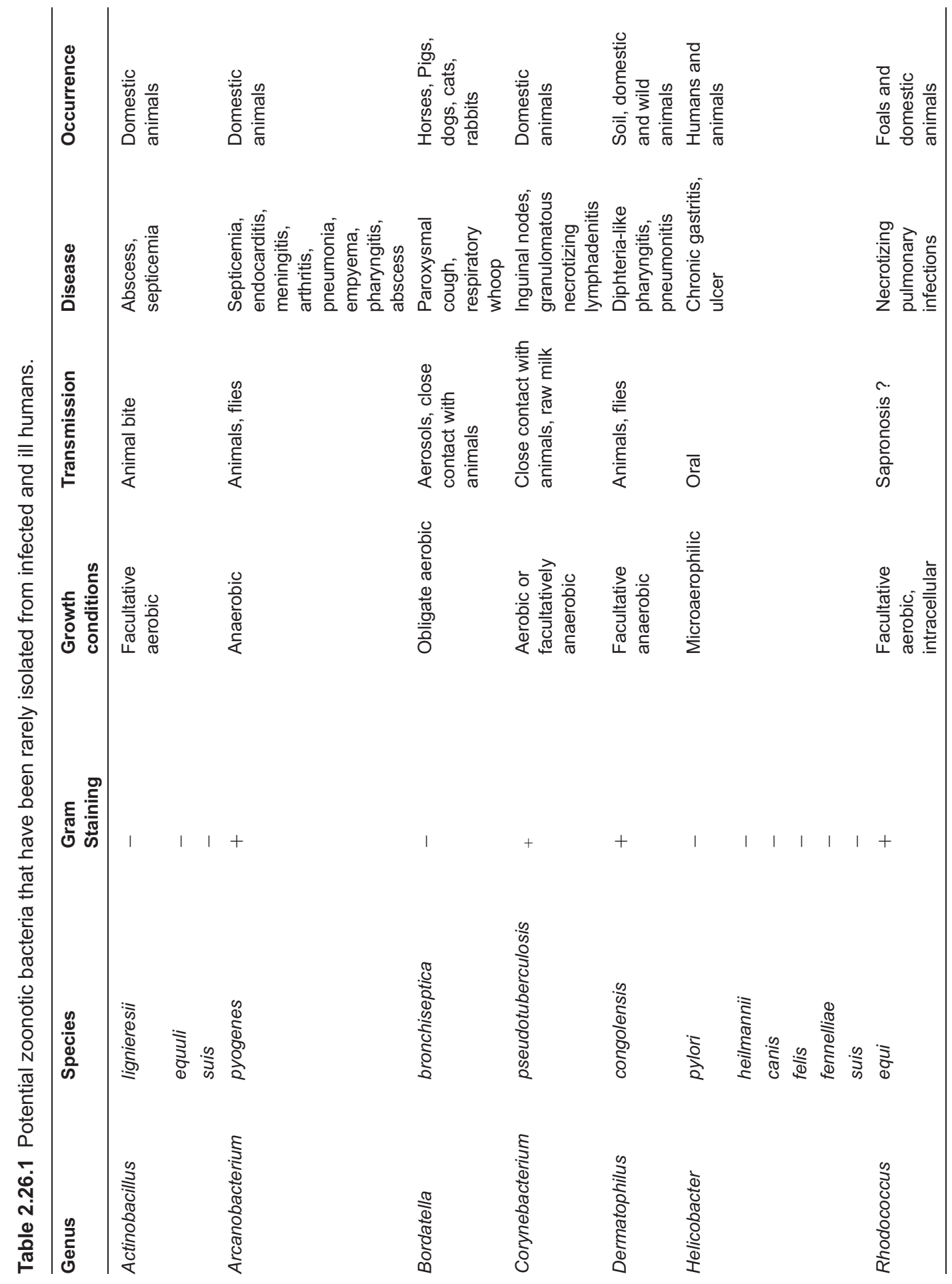




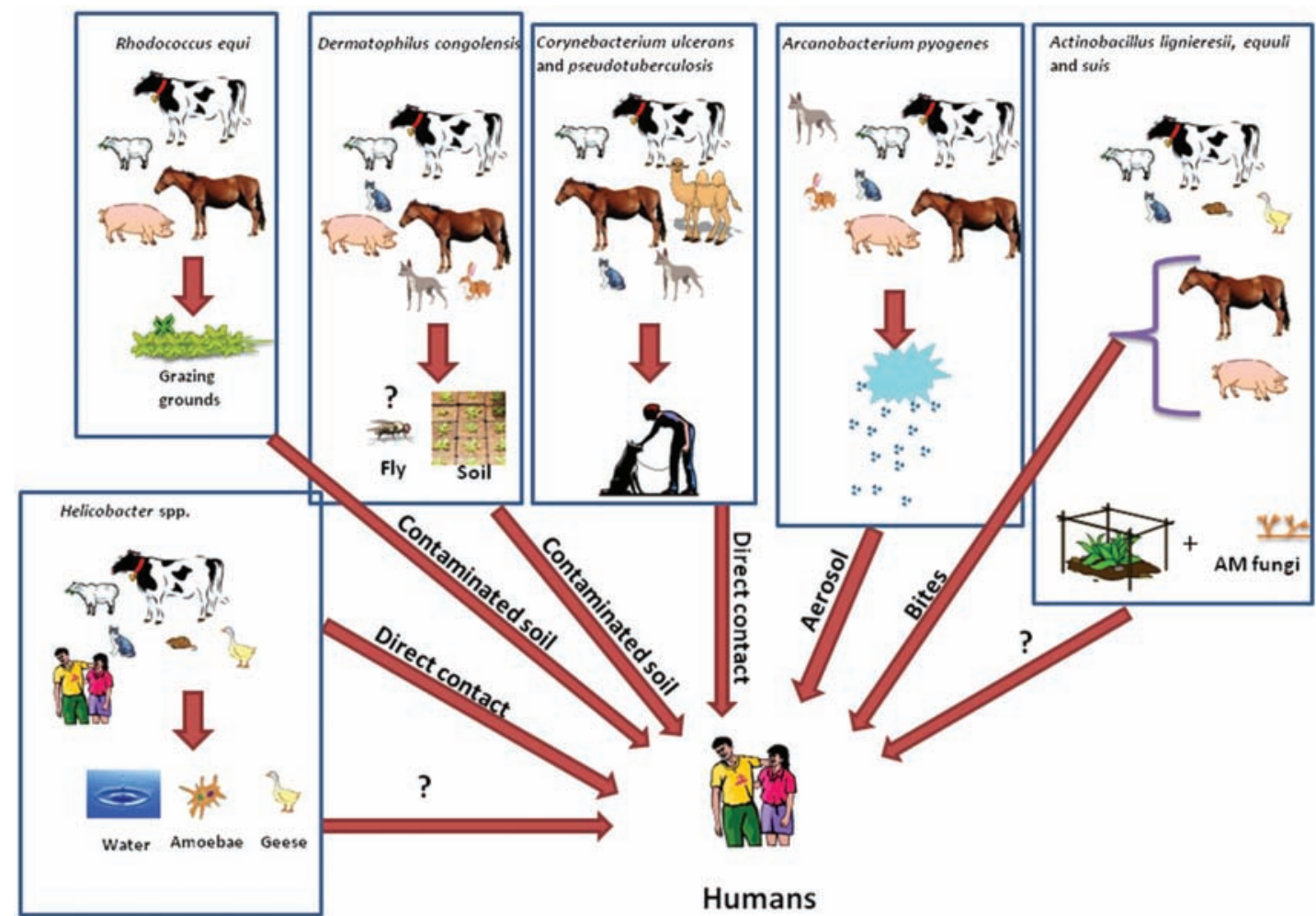

Figure 2.26.1. Actinobacillus, Arcanobacterium, Bordatella, Corynebacterium, Dermatophilus, Helicobacter and Rhodococcus spp. as miscellaneous zoonotic diseases and their suspected transmission

Arcanobacterium pyogenes is another commensal of mucous membranes of domestic animals (cattle, sheep and pigs) that may cause disease in other animals and humans (Lin et al., 2010; Levy et al., 2009; Kavitha et al., 2010). In humans, infection with Arcanobacterium pyogenes can result in severe diseases with infrequent fatality (Gomez-Mateos et al., 2009; Hermida et al. 2004; Plamondon et al. 2007). The transmission path is not clear, but direct contact with carrier or sick animals and their mucous membranes, exudates or aerosols can infect humans (Jost et al., 2002). Beside the regular domestic animals mentioned above as carrying this bacterium, cats and dogs were found also to be infected with A. pyogenes suggesting them also as a possible human infection source (Billington et al., 2002). In animals, especially ungulates, the bacterium becomes pathogenic when the animal is stressed by captivity or something else (Palmer and Whipple, 1999; Nettles et al., 2002). Lavin et al. (2004) described a foot infection in three adult male free-living fallow deer in Asturia, Spain. The authors described the area, showing some weather and geographical conditions that were possibly related to animals infection, such as mild temperature, high humidity, mixed pasture and rock land, domestic and wild herds living side by side and hunting activity (that may stress wild animals).

Bordetella bronchiseptica is another commensal of respiratory tract of horses, pigs, dogs, cats, rabbits and guinea pigs (Baetz et al., 1974). The transmission seems to be through aerosols or close contact with infected animals (Tamion et al., 1996; Stehmann et al., 1991; Hermann et al., 2008). Aerosol transmission has been shown to be supported by its enduring nature at lower and humid temperatures, especially in intensive 
husbandry (Stehmann et al., 1992). B. bronchiseptica has the potential to survive and grow in the natural environment through expression of two virulence determinants (controlled by its genomic bvg and ris loci) modulated by different environmental signals (e.g., low temperature). Experimental evidence indicated that, for B. bronchiseptica, bvg locus controlled determinants expressed under modulating conditions (e.g., motility) facilitate adaptation and survival in environments outside the host (Coote, 2001).

Corynebacterium ulcerans and pseudotuberculosis were also described as zoonoses, though much less frequent than their classical relatives (Kraeva et al., 2007). C. pseudotuberculosis found its natural hosts in many domestic animals such as: cattle, sheep, goats, horses and even camel (Cetinkaya et al., 2002; Tejedor-Junco et al., 2009; Doherr et al., 1998; Stefanska et al., 2007), while C. ulcerans is mainly found in cattle although cats were also implicated (De Zoysa et al., 2005; DeWinter et al., 2005). Wagner et al. (2010) reviewed C. ulcerans cases in United Kingdom for the period from 1986 to 2008 and found that the major risk factor of infection is contact with companion animals. In relation to $C$. pseudotuberculosis, people in direct contact with domestic animals are also at high risk (shepherds, children and animal workers) (Bartolome et al., 1995; Join-Lambert et al., 2006; Dorella et al., 2006).

Another bacterial pathogen suspected of infecting humans is Dermatophilus congolensis found mostly in tropical and subtropical and much less in temperate areas (Matheron et al., 1989; Towersey et al., 1993; Zaria, 1993; Kaminski and Sutter, 1976; Oduye, 1975; Pal, 1995; Pospisil et al., 1992). Wild and domestic animals are affected by this bacterium present in contaminated soil (Martinez and Prior, 1991). Soil type and water content were the main components impacting survival of D. congolensis in environment. Martinez and Prior (1991) also reported that organic matter content protects D. congolensis in oxisol soil as a temporary reservoir, but not in vertisol, though it retains its pathogenicity. Their conclusion was that ponds and dipping tanks may constitute sources of cattle infection as a result of soil and water environmental mix. Direct close contact with infected animals (domestic and wild) was also reported to cause infection in humans (Amor et al., 2011). Interestingly, flies were also suggested as vectors, possibly through their direct contact with soil or domestic animals urine, feces and gut mucus. Morris et al., (1997) tested the odors originating from these excretion including those produced by growth of different bacteria, among them $D$. congolensis, as attractants for the Australian sheep blowfly (Lucila cuprina), revealing significant movement of this insect towards D. congolensis cultures.

Rhodococcus equi (a soil actinomycete) was also suggested as a human zoonotic pathogen (Martens et al., 2000). In humans the disease represents itself as pulmonary infections (Silva et al., 2010). Domestic animals such as cattle, horses, sheep and pigs are also infected (Martens et al., 2000; von Bargen and Haas, 2009; Muscatello et al., 2007). The main reservoir seems to be contaminated soil where domestic animals graze (Martens et al., 2000; Barton and Hughes, 1982, 1984); however a study performed in Japan on the presence of $R$. equi in soil and sand from parks and yards, revealed a significant presence $(73.9 \%)$ but only of non-virulent strains (Takai et al., 1996). When horse farms' soil was surveyed for the presence of $R$. equi, only $18.8 \%$ of soils contained virulent strains and no correlation was found between bacterial presence and diseased horses (Takai et al., 2001). Additionally, Barton and Hughes (1984) showed that $R$. equi was isolated from gut contents, rectal feces and dung of all grazing herbivorous but not from penned animals, indicating soil as the main source of this bacterium. It is very much possible that soil containing virulent strains can be dispersed as dust and directly infects humans through respiratory system, primarily in immunocompromised individuals.

Finally, Helicobacter a genus of gram-negative bacteria, microaerophilic, helical shape, living in stomach was also incriminated as being of zoonotic origin. Helicobacter pylori is well established as a human pathogen in association with gastritis, peptic ulcer disease, gastric adenocarcinoma, and mucosa associated lymphoid tissue (MALT) lymphoma (Marshall and Warren, 1984; Ernst and Gold, 2000), although some of its closely related relatives, presented in Table 2.26.2, were isolated from animal hosts 
and already reported to be infectious in humans (Marshall and Warren, 1984; De Groote et al., 2000; Haesebrouck et al., 2009). Potential transmission patterns are: person-to-person (oral-oral, fecal-oral, iatrogenic and familial), waterborne and zoonotic (vector-borne) (Brown, 2000; Svec et al., 2000; Sasaki et al., 1999; Haesebrouck et al., 2009). De Groote et al. (2000), based on experimental data, advocated Helicobacter human infection via zoonotic path as evidential proof of transmission. Helicobacter canadensis (from avian reservoirs such as geese) was also linked to human disease (Waldenström et al., 2003; Fox et al., 2000). Some authors also pointed out that, besides direct contact with infected or carrier animals, transmission through carrier arthropods able to excrete Helicobacter in their feces is also feasible in connection with water and food (Imamura et al., 2003; Shineng and Stutzenberger, 2000).

Table 2.26.2 Helicobacter spp. natural colonizers of animals' stomach and human association.

\begin{tabular}{|c|c|c|c|c|}
\hline Helicobacter spp. & Natural host & $\begin{array}{l}\text { Human } \\
\text { association }\end{array}$ & Isolation site & $\begin{array}{l}\text { Experimental } \\
\text { water survival } \\
\text { (hours) }\end{array}$ \\
\hline H. pylori & $\begin{array}{l}\text { Humans, non-human } \\
\text { primates, cat }\end{array}$ & Yes & $\begin{array}{l}\text { Dyspeptic humans, soil, } \\
\text { flies }\end{array}$ & $>96$ \\
\hline H. suis & $\begin{array}{l}\text { Pig, macaque, } \\
\text { mandrill monkey }\end{array}$ & Yes & Pig stomach & \\
\hline H. felis & $\begin{array}{l}\text { Dog, cat, rabbit, } \\
\text { cheetah }\end{array}$ & Yes & $\begin{array}{l}\text { Dog owner, human } \\
\text { gastric biopsy, South } \\
\text { African population }\end{array}$ & 10 \\
\hline H. bizzozeronii & Dog, cat & Yes & $\begin{array}{l}\text { Finnish patient with } \\
\text { severe dyspeptic } \\
\text { symptoms }\end{array}$ & \\
\hline H. salomonis & Dog, cat, rabbit & Yes & Dams and puppies & \\
\hline $\begin{array}{l}\text { "Candidatus } \\
\text { Helicobacter } \\
\text { heilmannii" }\end{array}$ & $\begin{array}{l}\text { Dog, cat, wild felidae, } \\
\text { nonhuman primates }\end{array}$ & Yes & $\begin{array}{l}\text { Human gastric mucosa, } \\
\text { small villages, rural area, } \\
\text { patient with pets }\end{array}$ & \\
\hline H. baculoformis & Cat & No & Feline stomach mucosa & \\
\hline H. cynogastricus & Dog & No & Canine gastric mucosa & \\
\hline $\begin{array}{l}\text { "Candidatus } \\
\text { Helicobacter bovis" }\end{array}$ & Cattle & Yes & Human & \\
\hline H. mustelae & Ferret & No & $\begin{array}{l}\text { Stoats and ferrets from } \\
\text { New Zealand }\end{array}$ & $\sim 47-48$ \\
\hline H. aurati & Syrian Hamster & No & Hamster & \\
\hline H. nemestrinae & Macaque & No & Pigtailed macaque & \\
\hline H. acinonychis & Cheetah, tiger & No & Stray dogs? & \\
\hline H. cetorum & Whales, dolphins & No & $\begin{array}{l}\text { Human upper digestive } \\
\text { tract, gastric mucosa of } \\
\text { harp seals (Phoca } \\
\text { groenlandica) }\end{array}$ & \\
\hline H.muridarum & Mice & No & $\begin{array}{l}\text { Intestinal mucosa of } \\
\text { rodents }\end{array}$ & $\sim 47$ \\
\hline H. canadensis & Geese & Yes & Geese, shorebirds, & $\sim 48$ \\
\hline
\end{tabular}


Water seems to be one of the major environmental potential carriers of Helicobacter based on this pathogen's survival potential for many hours (Table 2.26.2), grown in mixed bacteria biofilms and on different abiotic materials (Azevedo et al., 2008; Percival and Thomas, 2009; Azevedo et al., 2006; Dube et al., 2009). Li et al. (2001) reported a significantly higher prevalence of $H$. pylori infection in immigrant population from a flooded area and inversely related to flood stages, indicating floods and living conditions as a source of high prevalence. Fujimura et al. (2004) reported the correlation of H. pylori prevalence in children and $H$. pylori DNA presence in water of an adjacent river in Japan. H. pylori prevalence in children living near the middle reaches was $9.8 \%$ and $23.8 \%$ for children nearby downstream reaches, both values being greater than in an area distant from this river $(0 \%)(\mathrm{p}<0.01)$ used as control.

Soil polluted by human and animals excreta was shown also to harbor the pathogen (9\% prevalence in soil tested) providing a possible source of infection for children in contact with playgrounds (Perez et al., 2010). As a final point associated to water and soil survival, H. pylori was reported to be competent to infect and internalize free-living amoebae, as a result enhancing this pathogen's environmental endurance (Winiecka-Krusnell et al., 2002).

It should be pointed out that, due to actual confusion on Helicobacter spp. classification and newly emerging species isolated from a variety of animals, an unambiguous transmission route is still not available and more research is required to clarify this important issue.

\subsubsection{REFERENCES}

Amor, A., Enríquez, A., Corcuera, M.T., Toro, C., Herrero, D. \& Baquero, M. (2011) Is infection by Dermatophilus congolensis underdiagnosed? J. Clin. Microbiol. 49, 449-451.

Azevedo, N.F., Almeida, C., Fernandes, I., Cerqueira, L. \& Dias, S. (2008) Survival of gastric and enterohepatic Helicobacter spp. in water: implications for transmission. Appl. Environ. Microbiol. 74, 1805-1811.

Azevedo, N.F., Pacheco, A.P., Keevil, C.W. \& Vieira, M.J. (2006) Adhesion of water stressed Helicobacter pylori to abiotic surfaces. J. Appl. Microbiol. 101, 718-724.

Bada, R., Mittal, K.R. \& Higgins, R. (1996) Biochemical and antigenic relationships between porcine and equine isolates of Actinobacillus suis. Vet. Microbiol. 51, 393-396.

Baetz, A.L. Kemeny, L.J. \& Graham, C.K. (1974) Blood chemical changes in growing pigs exposed to aerosol of Bordetella bronchiseptica. Am. J. Vet. Res. 35, 451-453.

Bartolome, J., Roca, M.J., Marcote, E. \& Moreno, R. (1995) Corynebacterium pseudotuberculosis adenitis in a shepherd. Med Clin (Barc). 104, 699-701.

Barton, M.D. \& Hughes, K.L. (1984) Ecology of Rhodococcus equi. Vet. Microbiol. 9, 65-76.

Barton. M.D. \& Hughes, K.L. (1982) Is Rhodococcus equi a soil organism?. J. Reprod. Fertil. Suppl. 32, 481-489.

Billington, S.J., Post, K.W. \& Jost, B.H. (2002) Isolation of Arcanobacterium (Actinomyces) pyogenes from cases of feline otitis externa and canine cystitis. J. Vet. Diagn. Invest. 14, 159-162.

Brown, L.M. (2000) Helicobacter pylori: Epidemiology and routes of transmission. Epidemiol. Rev. 22, 283-297.

Carvalho, D.F., Corsi, F.K., Furquim, F.E., Leal, P. \& Durrant, L.R. (1999) Diesel oil: a source for the production of biosurfactants. In: Alleman, B.C. \& Leeson, A. (Eds.) International in situ and on-site bioremediation symposium, 5th, San Diego, Apr. 19-22, 1999. 3, 457-462.

Cetinkaya, B., Karahan, M., Atil, E., Kalin, R., De Baere, T. \& Vaneechoutte, M. (2002) Identification of Corynebacterium pseudotuberculosis isolates from sheep and goats by PCR. Vet. Microbiol. 88, 75-83.

Coote, J.G. (2001) Environmental sensing mechanisms in Bordetella. Adv. Microb. Physiol. 44, 141-181.

Daignault, D., Chouinard, L., Moller, K., Ahrens, P., Messier, S. \& Higgins, R. (1999) Isolation of Actinobacillus suis from a cat's lung. Can. Vet. J. 40, 52-53.

De Groote, D., Ducatelle, R. \& Haesebrouck, F. (2000) Helicobacters of possible zoonotic origin: a review. Acta Gastroenterol. Belg. 63, 380-387. 
De Zoysa, A., Hawkey, P.M., Engler, K., George, R., Mann, G. et al. (2005) Characterization of toxigenic Corynebacterium ulcerans strains isolated from humans and domestic cats in the United Kingdom. J. Clin. Microbiol. 43, 4377-4381.

DeWinter, L.M., Bernard, K.A. \& Romney, M.G. (2005) Human Clinical Isolates of Corynebacterium diphtheriae and Corynebacterium ulcerans collected in Canada from 1999 to 2003 but not fitting reporting criteria for cases of diphtheria. J. Clin. Microbiol. 43, 3447-3449.

Doherr, M.G., Carpenter, T.E., Hanson, K.M., Wilson, W.D. \& Gardner, I.A. (1998) Risk factors associated with Corynebacterium pseudotuberculosis infection in California horses. Prev Vet Med. 35, 229-239.

Dorella, F.A., Pacheco, L.G.C., Oliveira, S.C., Miyoshi, A. \& Azevedo, V. (2006) Corynebacterium pseudotuberculosis: microbiology, biochemical properties, pathogenesis and molecular studies of virulence. Vet. Res. 37, 201-218.

Dube, C., Tanih, N.F. \& Ndip, R.N. (2009) Helicobacter pylori in water sources: a global environmental health concern. Rev. Environ. Health 24, 1-14.

Ernst, P.B. \& Gold, B.D. (2000) The disease spectrum of Helicobacter pylori: the immunopathogenesis of gastroduodenal ulcer and gastric cancer. Annu. Rev. Microbiol. 54, 615-640.

Fox, J.G., Chien, C.C., Dewhirst, F.E., Paster, B.J., Shen, Z. et al. (2000) Helicobacter canadensis sp. nov. isolated from humans with diarrhea as an example of an emerging pathogen. J. Clin. Microbiol. 38, 2546-2549.

Fujimura, S., Kato, S. \& Kawamura, T. (2004) Helicobacter pylori in Japanese river water and its prevalence in Japanese children. Lett. Appl. Microbiol. 38, 517-521.

Gomez-Mateos, J., Ubeda, A., Florez, C. \& Leon, E. (2009) Endocarditis due to Arcanobacterium pyogenes: the first case in Europe. Enferm. Infecc. Microbiol. Clin. 27, 251-252.

Haesebrouck, F., Pasmans, F., Flahou, B., Chiers, K. et al. (2009) Gastric helicobacters in domestic animals and nonhuman primates and their significance for human health. Clin. Microbiol. Rev. 22, 202-223.

Hart, M.E. \& Champlin, F.R. (1988) Susceptibility to hydrophobic molecules and phospholipid composition in Pasteurella multocida and Actinobacillus lignieresii. Antimicrob. Agents Chemother. 32, 1354-1359.

Hermann, J.R., Brockmeier, S.L., Yoon, K-J. \& Zimmerman, J.J. (2008) Detection of respiratory pathogens in air samples from acutely infected pigs. Can. J. Vet. Res. 72, 367-370.

Hermida, A.A., Romero, J.P., Cabarcos Ortiz De Barrón, A. \& Trevino, C.M. (2004) One case of pneumonia with Arcanobacterium pyogenes. An Med Interna 21, 334-336.

Imamura, S., Kita, M., Yamaoka, Y., Yamamoto, T. et al. (2003) Vector potential of cockroaches for Helicobacter pylori infection. Am. J. Gastroenterol. 98, 1500-1503.

Join-Lambert, O.F., Ouache, M., Canioni, D., Beretti, J-L., Blanche, S., Berche, P. \& Kayal, S. (2006) Corynebacterium pseudotuberculosis necrotizing lymphadenitis in a twelve year-old patient. Pediatr. Infect. Dis. J. 25, 848-851.

Jost, B.H., Post, K.W., Songer, J.G. \& Billington, S.J. (2002) Isolation of Arcanobacterium pyogenes from the porcine gastric mucosa. Vet. Res. Commun. 26, 419-425.

Kaminski, G.W. \& Suter, I.I. (1976) Human infection with Dermatophilus congolensis. Med J Aust. 1, $443-447$.

Kavitha, K., Latha, R., Udayashankar, C., Jayanthi, K. \& Oudeacoumar, P. (2010) Three cases of Arcanobacterium pyogenes-associated soft tissue infection. J. Med. Microbiol. 59, 736-739.

Kraeva, L.A., Manina, Zh.N., Tseneva, G.Ia. \& Radchenko, A.G. (2007) Etiologic role of Corynebacterium non diphtheriae in patients with different pathology. Zh. Mikrobiol. Epidemiol. Immunobiol. 5, 3-7.

Lavin, S., Ruiz-Bascaran, M., Marco, I., Abarca, M.L., Crespo, M.J. \& Franch, J. (2004) Foot infections associated with Arcanobacterium pyogenes in free-living fallow deer (Dama dama). J. Wildl. Dis. 40, 607-611.

Lentsch, R.H. \& Wagner, J.E. (1980) Isolation of Actinobacillus lignieresii and Actinobacillus equuli from laboratory rodents. J. Clin. Microbiol. 12, 351-354.

Levy, C.E., Pedro, R.J., von Nowakonski, A., Holanda, L.M., Brocchi, M. \& Ramos, M.C. (2009) Arcanobacterium pyogenes sepsis in farmer, Brazil. Emerg. Infect. Dis. 15, 1131-1132.

Li, G., Li, Q. \& Wang, H. (2001) A study on the epidemiology of Helicobacter pylori infection among immigrants in Three Gorges area. Chin. J. Epidemiol. 22, 90-92.

Lin, C-C., Chen, T-H., Shyu, C-L., Su, N-Y. \& Chan, J.P-W. (2010) Disseminated abscessation complicated with bone marrow abscess caused by Arcanobacterium pyogenes in a goat. J. Vet. Med. Sci. 72, 1089-1092. 
Maddux, R.L., Chengappa, M.M. \& McLaughlin, B.G. (1987) Isolation of Actinobacillus suis from a Canada goose (Branta canadensis). J. Wildl. Dis. 23, 483-484.

Marshall, B.J. \& Warren, J.R. (1984). "Unidentified curved bacilli in the stomach of patients with gastritis and peptic ulceration". Lancet 1, 1311-1315.

Martens, R.J., Takai, S., Cohen, N.D., Chaffin, M.K., Liu, H., Sakurai, K., Sugimoto, H. \& Lingsweiler, S.W. (2000) Association of disease with isolation and virulence of Rhodococcus equi from farm soil and foals with pneumonia. J. Am. Vet. Med. Assoc. 217, 220-225.

Martinez, D. \& P. Prior, P. (1991) Survival of Dermatophilus congolensis in tropical clay soils submitted to different water potentials. Vet Microbiol. 29, 135-145.

Matheron, G., Barre, N., Roger, F., Rogez, B., Martinez, D. \& Sheikboudou, C. (1989) Dermatophilus congolensis bovine dermatophilosis in the French West Indies. III. A comparison between infected and non-infected cattle. Rev Elev Med Vet Pays Trop 42, 331-347.

Morris, M.C., Joyce, M.A., Heath, A.C.G., Rabel, B . \& Delisle, G.W. (1997) The responses of Lucih cuprina to odours from sheep, offal and bacterial cultures. Med. Vet. Entomol. 11, 58-64.

Muscatello, G., Leadon, D.P., Klayt, M., Ocampo-Sosa, A., Lewis, D.A. et al. (2007) Rhodococcus equi infection in foals: the science of 'rattles'. Equine Vet. J. 39, 470-478.

Nettles, V.F., Quist, C.F., Lopez, R.R., Wilmers, T.J., Frank, P. et al. (2002) Morbidity and mortality factors in key deer (Odocoileus virginianus clavium). J. Wildl. Dis. 38, 685-692.

Oduye, O.O. (1975) Effects of various induced local environmental conditions and histopathological studies in experimental Dermatophilus congolensis infection on the bovine skin. Res Vet Sci. 19, 245-252.

Pal, M. (1995) Prevalence in India of Dermatophilus congolensis infection in clinical specimens from animals and humans. Rev. - Off. Int. Epizoot. 14, 857-863.

Palmer, M.V. \& Whipple, D.L. (1999) Arcanobacterium pyogenes as a cause of fatal pleuropneumonia after capture and transport of white-tailed deer (Odocoileus virginianus). J. Vet. Diagn. Invest. 11, 468-471.

Peel, M.M. Hornidge, K.A., Luppino, M., Stacpoole, A.M. \& Weaver, R.E. (1991) Actinobacillus spp. and related bacteria in infected wounds of humans bitten by horses and sheep. J. Clin. Microbiol. 29, 2535-2538.

Percival, S.L. \& Thomas, J.G. (2009) Transmission of Helicobacter pylori and the role of water and biofilms. J Water Health. 7, 469-477.

Perez, L.M., Codony, F., Lopez, L.D., Fittipaldi, M., Adrados, B. \& Morato, J. (2010) Quantification of Helicobacter pylori levels in soil samples from public playgrounds in Spain. J. Zhejiang. Univ. Sci. B 11, 27-29.

Plamondon, M., Martinez, G., Raynal, L., Touchette, M. \& Valiquette, L. (2007) A fatal case of Arcanobacterium pyogenes endocarditis in a man with no identified animal contact: case report and review of the literature. Eur $J$ Clin Microbiol Infect Dis 26, 663-666.

Pospisil, L., Skalka, B., Bucek, J. \& Moster, M. (1992) The first isolation of Dermatophilus congolensis van Saceghem 1913 in Czechoslovakia. Cesk Epidemiol Mikrobiol Imunol 41, 258-267.

Sasaki, K., Tajiri, Y., Sata, M., Fujii, Y., Matsubara, F. et al. (1999) Helicobacter pylori in the natural environment. Scand. J. Infect. Dis. 31, 275-279.

Shineng, L. \& Stutzenberger, F.J. (2000) The housefly (Musca domestica) as a possible vector for Helicobacter pylori at agricultural sites. Int. J. Environ. Health Res. 10, 141-152.

Silva, P., Miyata, M., Sato, D.N., Santos, A.C.B., Mendes, N.H. \& Leite, C.Q.F. (2010) Rhodococcus equi isolation from sputum of patients with suspected tuberculosis. Mem Inst Oswaldo Cruz 105, 199-202.

Stehmann, R., Mehlhorn, G. \& Neuparth, V. (1991) Characterization of strains of Bordetella bronchiseptica isolated from animal housing air and of the airborne infection pressure proceeding from them. DTW. Dtsch. Tierarztl. Wochenschr. 98, 448-450.

Stehmann, R., Rottmayer, J., Zschaubitz, K. \& Mehlhorn, G. (1992) The tenacity of Bordetella bronchiseptica in the air. Zentralblatt Veterinarmedizin Reihe B 39, 546-552.

Svec, A., Kordas, P., Pavlis, Z. \& Novotny, J. (2000) High prevalence of Helicobacter heilmannii-associated gastritis in a small, predominantly rural area: further evidence in support of a zoonosis?. Scand. J. Gastroenterol. 35, 925-928. 
Takai, S., Chaffin, M.K., Cohen, N.D., Hara, M., Nakamura, M. et al. (2001) Prevalence of virulent Rhodococcus equi in soil from five $R$. equi-endemic horse-breeding farms and restriction fragment length polymorphisms of virulence plasmids in isolates from soil and infected foals in Texas. J. Vet. Diagn. Invest. 13, 489-494.

Takai, S., Fukunaga, N., Ochiai, S., Sakai, T., Sasaki, Y. \& Tsubaki, S. (1996) Isolation of virulent and intermediately virulent Rhodococcus equi from soil and sand on parks and yards in Japan. J. Vet. Med. Sci. 58, 669-672.

Tamion, F., Girault, C., Chevron, V., Pestel, M. \& Bonmarchand, G. (1996) Bordetella bronchoseptica pneumonia with shock in an immunocompetent patient. Scand. J. Infect. Dis. 28, 197-198.

Tejedor-Junco, M.T., Lupiola, P., Caballero, M.J., Corbera, J.A. \& Gutierrez, C. (2009) Multiple abscesses caused by Salmonella enterica and Corynebacterium pseudotuberculosis in a dromedary camel. Trop Anim Health Prod 41, 711-714.

Towersey, L., de Castro Soares Martins, E., Londero, A.T., Hay, R.J., Filho, P.J.S. et al. (1993) Dermatophilus congolensis human infection. J. Am. Acad. Dermatol. 29, 351-354.

von Bargen, K. \& Haas, A. (2009) Molecular and infection biology of the horse pathogen Rhodococcus equi. FEMS Microbiol. Rev. 33, 870-891.

Wagner, K.S., White, J.M., Crowcroft, N.S., De Martin, S., Mann, G. \& Efstratiou, A. (2010) Diphtheria in the United Kingdom, 1986-2008: the increasing role of Corynebacterium ulcerans. Epidemiol Infect. 138, 1519-1530.

Waldenström, J., On, S.L., Ottvall, R., Hasselquist, D., Harrington, C.S. \& Olsen, B. (2003) Avian reservoirs and zoonotic potential of the emerging human pathogen Helicobacter canadensis. Appl. Environ. Microbiol. 69, $7523-7526$.

Winiecka-Krusnell, J., Wreiber, K., von Euler, A., Engstrand, L. \& Linder, E. (2002) Free-living amoebae promote growth and survival of Helicobacter pylori. Scand. J. Infect. Dis. 34, 253-256.

Zaria, L.T. (1993) Dermatophilus congolensis infection (Dermatophilosis) in animals and man! An update. Comp. Immunol. Microbiol. Infect. Dis. 16, 179-222. 
Downloaded from https://iwaponline.com/ebooks/book-pdf/521254/wio9781780400761.pdf

Downloaded trom https://Iwaponline.com/ebooks/book-pdt/521254/WI09/81/80400/61.pdt
by IWA Publishing user 


\section{Chapter 3}

\section{Viral Zoonoses}


Downloaded from https://iwaponline.com/ebooks/book-pdf/521254/wio9781780400761.pdf

Downloaded trom https://Iwaponline.com/ebooks/book-pdt/521254/WI09/81/80400/61.pdt
by IWA Publishing user 


\section{Chapter 3.1}

\section{Alphavirus}

\section{[FAMILY TOGAVIRIDAE, GENUS ALPHAVIRUS]}

Alphaviruses are important viruses, widely distributed throughout the world, causing localized diseases in humans and animals as well as epizootic and epidemic outbreaks. The genus Alphavirus belongs to the family Togaviridae. The Togaviridae family includes a second genus, namely Rubivirus (Powers et al., 2001). Alphaviruses have a linear, + (ss) RNA genome of approximately $11.7 \mathrm{~kb}$ size, packed in an icosahedral nucleocapsid. The viral capsid is enclosed in a detergent sensitive lipid bilayer envelope derived from the host cell membrane and modified by insertion of viral glycoproteins (Anthony and Brown, 1991). Alphavirus envelope is covered by characteristic spikes made of glycoproteins (E1 and E2), arranged in trimers $(3 \times \mathrm{E} 1 / \mathrm{E} 2)$. The glycoproteins are responsible for viral binding to host-cell receptors and the internalization process (Kielian, 2010). The virions have a diameter between 60 and $70 \mathrm{~nm}$ and are found in the cytoplasm of the host cell (Strauss and Strauss, 1994).

Alphaviruses are maintained in nature by alternate infection of vertebrate and arthropod (mosquitoes) hosts. According to this life cycle, blood sucking mosquitoes get infected during a blood meal on an infected vertebrate and further responsible for virus transmission to the next vertebrate host.

The genus Alphavirus includes $\geq 29$ different species, each species including different subspecies. Based on serologic criteria, the species can be classified into seven complexes or clusters, which among others appear to share medically important characteristics (Calisher and Karabatsos, 1988). The five complexes Eastern equine encephalitis, Western equine encephalitis, Venezuelan equine encephalitis, Semliki Forest virus and Barmah Forest viruses include important disease causing viruses. Human infections with Alphavirus can to be asymptomatic. When clinically expressed, the disease appearance depends on the virus and occurs in either of two forms: expressed by febrile illness with fever, malaise, headache, or symptoms of encephalitis, fever, rash and arthralgia (Table 3.1.1) (Zacks and Paesler, 2010).

Alphaviruses are arthropod borne viruses with mosquitoes as primary vectors in transmission of this pathogen. In their natural life cycle these viruses are maintained by transmission between mosquitoes and vertebrate hosts (birds or mammal), acting also as amplifying hosts. These potential amplifying hosts develop sufficient viremia in order to infect mosquitos vectors and still survive the infection. Human are usually dead end host due to the fact that they do not develop sufficient viremia to infect mosquitoes 
(Pfeffer and Dobler, 2010). Alphaviruses' airborne transmission is possible and has been documented for Venezuelan equine encephalitis virus infections (Zacks and Paessler, 2010). Emerging epizootic outbreaks are usually due to climatic conditions.

Table 3.1.1 Alphaviruses complexes, viruses and clinical features ${ }^{a}$.

\begin{tabular}{|c|c|c|c|c|c|}
\hline Complex & Virus & $\begin{array}{l}\text { Clinical } \\
\text { Manifestation }\end{array}$ & Host & Vector & Distribution \\
\hline $\begin{array}{l}\text { Eastern Equine } \\
\text { Encephalitis }\end{array}$ & $\begin{array}{l}\text { Eastern Equine } \\
\text { Encephalitis } \\
\text { (EEE) }\end{array}$ & Encephalitis & Birds & Culiseta melanura & $\begin{array}{l}\text { USA, Canada, } \\
\text { Central and } \\
\text { South America }\end{array}$ \\
\hline \multirow[t]{2}{*}{$\begin{array}{l}\text { Western Equine } \\
\text { Encephalitis }\end{array}$} & $\begin{array}{l}\text { Western Equine } \\
\text { Encephalitis } \\
\text { (WEE) }\end{array}$ & Encephalitis & $\begin{array}{l}\text { Birds, } \\
\text { Mammals }\end{array}$ & $\begin{array}{l}\text { Culex tarsalis } \\
\text { Ochlerotatus spp., } \\
\text { Aedes spp. }\end{array}$ & $\begin{array}{l}\text { USA, Canada, } \\
\text { Central and } \\
\text { South America }\end{array}$ \\
\hline & Sindbis (SIN) & $\begin{array}{l}\text { Febrile illness, } \\
\text { rash, arthralgia }\end{array}$ & Birds & $\begin{array}{l}\text { Culex pipiens, C. } \\
\text { univittatus, } \\
\text { C. torrentium, } \\
\text { Culiseta } \\
\text { morsitans, } \\
\text { Ochlerotatus spp., } \\
\text { Aedes spp. }\end{array}$ & $\begin{array}{l}\text { Africa, Asia, } \\
\text { Australia, Middle } \\
\text { East, Eastern } \\
\text { Europe, } \\
\text { Scandinavia }\end{array}$ \\
\hline $\begin{array}{l}\text { Venezuelan } \\
\text { Equine } \\
\text { Encephalitis }\end{array}$ & $\begin{array}{l}\text { Venezuelan } \\
\text { Equine } \\
\text { Encephalitis } \\
\text { (VEE) }\end{array}$ & $\begin{array}{l}\text { Febrile illness, } \\
\text { Encephalitis }\end{array}$ & $\begin{array}{l}\text { Rodents, } \\
\text { Horses }\end{array}$ & $\begin{array}{l}\text { Ochlerotatus } \\
\text { taeniorhynchus, } \\
\text { Culex spp }\end{array}$ & $\begin{array}{l}\text { South and } \\
\text { Central America }\end{array}$ \\
\hline \multirow[t]{5}{*}{ Semliki Forest } & Ross River (RR) & $\begin{array}{l}\text { Febrile illness, } \\
\text { rash, arthritis }\end{array}$ & $\begin{array}{l}\text { Mammals, } \\
\text { Humans }\end{array}$ & $\begin{array}{l}\text { Culex } \\
\text { annulirostris, } \\
\text { Aedes vigilax, Ae. } \\
\text { camhorhynchus }\end{array}$ & Africa \\
\hline & $\begin{array}{l}\text { Chikungunya } \\
(\mathrm{CHIK})\end{array}$ & $\begin{array}{l}\text { Febrile illness, } \\
\text { rash, arthralgia }\end{array}$ & $\begin{array}{l}\text { Primates, } \\
\text { Humans }\end{array}$ & $\begin{array}{l}\text { Aedes spp., Ae. } \\
\text { aegypti, Ae. } \\
\text { albopictus, Ae. } \\
\text { frucifer, Ae. } \\
\text { luetocephalus, } \\
\text { Culex, Mansonia, } \\
\text { and Anopheles }\end{array}$ & $\begin{array}{l}\text { Africa, India and } \\
\text { South Asia }\end{array}$ \\
\hline & $\begin{array}{l}\text { O'nyong'nyong } \\
\text { (ONN) }\end{array}$ & $\begin{array}{l}\text { Febrile illness, } \\
\text { rash, arthralgia }\end{array}$ & $\begin{array}{l}\text { Primates, } \\
\text { Humans }\end{array}$ & $\begin{array}{l}\text { Aedes aegypti, Ae. } \\
\text { furcifer, Ae. } \\
\text { Africanus, } \\
\text { Anopheles } \\
\text { funestus, } \\
\text { Anopheles gambia }\end{array}$ & Africa \\
\hline & Mayaro (MAY) & $\begin{array}{l}\text { Febrile illness, } \\
\text { rash, arthralgia }\end{array}$ & $\begin{array}{l}\text { Primates, } \\
\text { Humans }\end{array}$ & $\begin{array}{l}\text { Haemagogus } \\
\text { janthinomys }\end{array}$ & $\begin{array}{l}\text { South and } \\
\text { Central America }\end{array}$ \\
\hline & $\begin{array}{l}\text { Semliki Forest } \\
(\mathrm{SF})\end{array}$ & $\begin{array}{l}\text { Febrile illness, } \\
\text { rash, arthritis }\end{array}$ & Birds & $\begin{array}{l}\text { Aedes africanus } \\
\text { and Aedes aegypti }\end{array}$ & $\begin{array}{l}\text { Africa and Asia, } \\
\text { possibly present } \\
\text { in central and } \\
\text { southern Europe }\end{array}$ \\
\hline Barmah Forest & $\begin{array}{l}\text { Barmah Forest } \\
(\mathrm{BF})\end{array}$ & $\begin{array}{l}\text { Febrille illnes, } \\
\text { rash, arthritis }\end{array}$ & Humans & $\begin{array}{l}\text { Culex spp, Aedes } \\
\text { spp. }\end{array}$ & Australia \\
\hline
\end{tabular}

${ }^{a}$ (Adapted from ICTVdb, 2006). 
Several factors affected the spread of these viruses: vector, host and environmental changes. Periodically, the virus causes vast outbreaks, to disappear later on for a certain time interval and then reappear or/and spread to another location. Such an example is the reoccurrence of O'nyong'nyong fever outbreak after 35 years in Uganda and the 7 year intervals of Sindbis virus disease in Finland (Lutwama et al., 1999; Kurkela et al., 2005)

\subsubsection{ALPHAVIRUS AND ENVIRONMENT}

The restricted geographical distribution of Alphaviruses is based on their natural transmission cycle, including susceptible reservoir host and the species particular mosquito vector (Weaver et al., 2000; Johnston and Peters, 1996). Vector activity is seasonal and is affected for the most part by temperature and rainfall.

Due to climatic and environmental changes (deforestation, agriculture, water storage and irrigation), human population growth and urbanization, trade and travel behavior, an increasing risk of alphaviral spread to new ecological areas and countries throughout the world continues to subsist (Sutherst, 2004).

There are several reports regarding alphaviral disease emergence attributable to infected travelers. Ross River Virus (RRV), endemic and enzootic in Australia and Papua New Guinea, caused a large epidemic in 1979/1980 in Samoa, Cook Island and New Caledonia probably due to a viremic Australian traveler. It also has been supposed that RRV is frequently introduced to North America as a consequence of human travelers from Australia (Harley et al., 2001). In Germany an investigation of patients with unresolved complaints of fever with headache, skin redness and severe multiple joint arthralgia demonstrated an infection with Ross River Virus and Barmah Forest virus (BFV). These diagnosed patients had all returned from Australia (Peffer et al., 2001). BFV that is similar to RRV is endemic in Australia and the Pacific Islands, causing fever, rash polyarthritis and arthralgia similarly to German cases (Anonymous, 1991).

Similar reports were published for a Mayaro virus (MAYV) infection, enzootic in tropical humid forests of South America and maintained in a sylvatic cycle involving wild vertebrates, that occurred recently in a French citizen who suffered from severe rheumatologic disorders after visiting the Brazilian Amazon (Receveur et al., 2010). In the same year, MAYV infection was also diagnosed in a Dutch couple, complaining of a persisting arthralgia, temporary fever and rash after residing in Surinam (Hassinge et al., 2010). A similar scenario was suggested for Chikungunya (CHIK) fever, a tropical disease, occurring in Africa, India and parts of South Asia (Pialoux et al., 2007). This virus circulates in natural sylvatic pools using primates and rodents as both hosts and reservoirs. Major human epidemics occurred in cases of vector abundance subsequent to heavy rainfall. CHIK infection symptoms are flu-like; headache, fever, joint pain and arthralgia (Taubitz et al., 2007).

Since the first reported outbreak of CHIK fever in Tanzania and its isolation from humans and mosquito in 1952 (Ross, 1956), many outbreaks of Chikungunya fever have been reported from Africa and Asia from 1960 to 1982 (WHO, 2006). Between 2004 and 2005, islands located in the Southwest Indian Ocean were affected by an epidemic and approximately $1 / 3$ of the population was infected. In 2006 around 1.4 million people developed symptomatic disease of CHIK, probably due to a virus mutant, lack of vector control and trade and travel globalization (Kalantri et al., 2006). Since 2006, there have been new reports of CHIK cases in European countries (i.e. Germany, Belgium, Czech Republic, France, Italy, Spain) and the USA, directly associated with homecoming tourists who had visited India and affected islands of the Indian Ocean (Powers and Logue, 2007). Special consideration should be given to two cases of Chikungunya (in Italy, 2007 and France, 2010) where this virus was probably transmitted locally. In July 2007, an outbreak of CHIK virus infection took place in the Romagna area, in northern Italy. The initial source of this local transmission was 
an Indian immigrant, residing in the Romagna area, who returned from an epidemic area one month before the outbreak. At the time of his arrival in Italy, he was at the viremic, asymptomatic stage of the infection (Sambri et al., 2008). As a result of a viral mutation circulating in India it was possible to associate the two cases. In France, in the town of Fréjus (Provence), a child who had traveled also to India was diagnosed with Chikungunya virus infection. Two weeks after the initial event, two additional cases of Chikungunya fever occurred in the same town in persons who did not travel abroad. The chronologic time besides the local proximity of these cases, implies that the infection was transmitted and acquired locally through the mosquito vector Aedes albopictus (Grandadam, 2011). This Asian tiger mosquito, Aedes albopictus (Diptera: Culicidae) originating from Asia, is one of the fastest invading mosquitoes which now inhabit North and South America as well Africa and Europe (Benedict et al., 2007). Female mosquitoes, with breeding sites closely related to human habitats (containers with standing water, tires or containers, plant pots, etc.) lay desiccation-resistant eggs that may remain viable for several months (Hawley, 1988, Koehler and Castner 1997) (Figure 3.1.1). Therefore global trade in used tires and bamboo seems to be the main factor in the worldwide distribution of mosquito eggs and for that reason a critical factor affecting the spread of new viruses (Hawley et al., 1987; Hawley, 1988; Dalla Pozza et al., 1994; Schaffner and Krach, 2000).

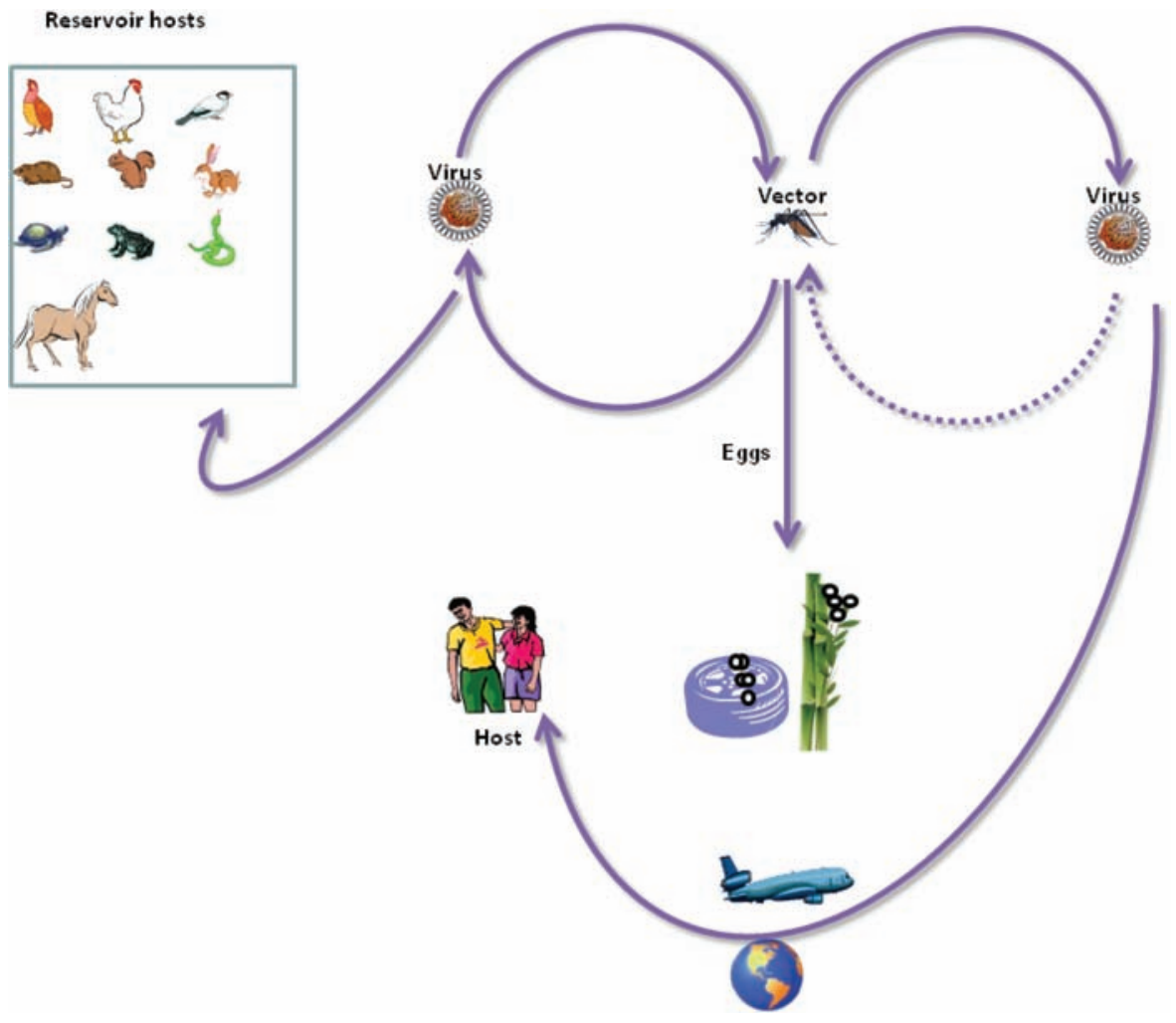

Figure 3.1.1. Infection routes of Alphaviruses 


\subsubsection{REFERENCES}

Anthony, R.P. \& Brown, D.T. (1991) Protein-protein interactions in an Alphavirus membrane. J. Virol. 65, $1187-1194$.

Benedict, M., Levine, R., Hawley, W.A. \& Lounibos, L.P. (2007) Spread of the tiger: Global risk of invasion by the mosquito Aedes albopictus. Vector Borne Zoonotic Dis. 7, 76-85

Calisher, C. H., \& Karabatsos, N. (1988) Arbovirus serogroups: definition and geographic distribution. In T. P. Monath (ed.), The arboviruses: epidemiology and ecology, vol. I. p. 19-57. CRC Press, Inc., Boca Raton, Florida, USA.

Dalla Pozza, G.L., Romi, R. \& Severini, C. (1994) Source and spread of Aedes albopictus in the Veneto region of Italy. J. Am. Mosq. Control Assoc. 10, 589-92.

Grandadam, M., Caro, V., Plumet, S., Thiberge, J.M. \& Souares, Y. (2011) Chikungunya virus, southeastern france. Emerging Infect. Dis. 17, 910-913.

Harley, D., Sleigh, A. \& Ritchie, S. (2001) Ross River virus transmission, infection, and disease: a cross-disciplinary. Clin. Microbiol. Rev. 14, 909-932.

Hassing, R.J., Leparc-Goffart, I., Blank, S.N., Thevarayan, S., Tolou, H., et al. (2010). Imported Mayaro virus infection in the Netherlands. J. Infect. 61, 343-345.

Hawley, W. (1988) The biology of Aedes albopictus. J Am Mosq Control Assoc 4, 1-40.

Hawley, W., Reiter, P., Copeland, R.S., Pumpini, C.B. \& Craig GB Jr. (1987) Aedes albopictus in North America: probable introduction in used tires from northern Asia. Science 236, 1114-1116.

ICTVdB (2006) - Index of Viruses - Togaviridae (2006) The Universal Virus Database, version 4. Büchen-Osmond, C (Ed), Columbia University, New York, USA. http://www.ncbi.nlm.nih.gov/ICTVdb/Ictv/fs_index.htm.

Johnston, R. E., \& Peters, C.J. (1996) Alphaviruses. In Fields, B.N., Knipe, D.M. \& Howley, P.M. (Eds.), Virology, 3rd edition. Lippincott-Raven, New York, N.Y. p. 843-898.

Kalantri, S.P., Joshi, R. \& Riley, L.W. (2006) Chikungunya epidemic: an Indian Perspective. Natl Med J India 19, 315-322.

Kielian, M. (2010) Structural biology: An alphavirus puzzle solved. Nature 468, 645-646.

Koehler, P.G. \& Castner, J.L. (1997). Blood sucking insects. EDIS. http://edis.ifas.ufl.edu/pdffiles/IN/IN01900.pdf

Kurkela, S., Manni, T., Myllynen, J., Vaheri, A. \& Vapalahti, O. (2005) Clinical and laboratory manifestations of Sindbis virus infection: prospective study, Finland, 2002-2003. J. Infect. Dis. 191, 1820-1829.

Lutwama, J.J., Kayondo, J., Savage, H.M., Burkot, T.R. \& Miller, B.R. (1999) Epidemic O’Nyong-Nyong fever in southcentral Uganda, 1996-1997: entomologic studies in Bbaale village, Rakai District. Am. J. Trop. Med. Hyg. 61, 158-162.

Pfeffer, M. \& Dobler, G. (2010) Emergence of zoonotic arboviruses by animal trade and migration. Parasit Vectors $\mathbf{3}$, 35.

Pfeffer, M., Emmerich, P. \& Schmitz, H, (2001) Importierte Alpha-Virusinfektionen aus Australien. Dtsch Arztebl 98, A3302-A3305.

Pialoux, G., Gaüzère, B.A., Jauréguiberry, S \& Strobel, M. (2007) Chikungunya, an epidemic arbovirosis Lancet Infect Dis 7, 319-327.

Powers, A.M., Brault, A.C., Shirako, Y., Strauss, E.G., Kang, W. et al. (2001) Evolutionary Relationships and Systematics of the Alphaviruses. J. Virol. 75, 10118-10131.

Powers, A.M. \& Logue, C.H. (2007) Changing patterns of chikungunya virus: re-emergence of a zoonotic arbovirus. J. Gen. Virol. 88, 2363-2377.

Receveur, M.C., Grandadam, M., Pistone, T. \& Malvy, D. (2010) Infection with Mayaro virus in a French traveller returning from the Amazon region, Brazil, January, 2010. Euro Surveill. 15, pii: 19563.

Ross, R.W. (1956) The Newala epidemic III; the virus: isolation, pathogenic properties and relationship to the epidemic. J. Hyg (Lond) 54, 177-191.

Sambri, V., Cavrini. F., Rossini. G., Pierro. A., Landini. M.P. (2008) The 2007 epidemic outbreak of Chikungunya virus infection in the Romagna region of Italy: a new perspective for the possible diffusion of tropical diseases in temperate areas? New Microbiol. 31, 303-304. 
Schaffner, F. \& Karch, S. (2000) First report of Aedes albopictus (Skuse, 1984) in metropolitan France. C.R. Acad. Sci. III, Sci. Vie. 323, 373-375.

Strauss, J.H. \& Strauss, E.G. (1994) The alphaviruses: gene expression, replication, and evolution. Microbiol. Rev. 58, $491-562$.

Sutherst, R.W. (2004) Global change and human vulnerability to vector-borne diseases. Clin. Microbiol. Rev. 17, $136-173$.

Taubitz, W., Cramer, P., Kapaun, A., Pfeffer, M., Drosten, C., et al. (2007) Chikungunya fever in travelers: clinical presentation and course. Clin. Infect. Dis. 45, e1-e4.

Anonymous (1991) Barmah Forest virus. Lancet 337, 948-949.

Weaver, S.C., Dalgarno L., Frey T.K., Huang H.V., Kinney R.M., et al. (2000) Family Togaviridae, p. 879-889. In M. H. V. van Regenmortel, C. M. Fauquet, D. H. L. Bishop, E. B. Carstens, M. K. Estes et al. (Eds.), Virus taxonomy. Classification and nomenclature of viruses. Seventh report of the International Committee on Taxonomy of Viruses. Academic Press, Inc., San Diego, Calif.

WHO, World Health Organization (2006) Regional Office for South-East Asia. Chikungunya fever, a reemerging disease in Asia. Available under: http://www.searo.who.int/en/Section10/Section2246.htm.

Zacks, M.A. \& Paessler, S. (2010) Encephalitic alphaviruses. Vet. Microbiol. 140, 281-286. 


\section{Chapter 3.2}

\section{Flaviviruses infections}

\section{[FAMILY FLAVIVIRIDAE, GENUS FLAVIVIRUS]}

Flaviviruses share a common symmetry (enveloped, icosahedral nucleocapsid), with a size range of 40 to $65 \mathrm{~nm}$ and an encapsulated nucleic acid +(ss) RNA, approximately 10,000-11,000 bases). Flaviviruses are transmitted by bite from an infected arthropod (mosquito or tick) and not by direct contact (person to person) (Table 3.2.1). A typical prototype of this virus family is yellow fever virus (YFV) (that beside other symptoms, causes jaundice in infected persons). Flavivirus human infections are characteristically incidental, since humans are not capable to produce enough high titers in order for it to be spread further by infected arthropods. However, yellow fever and dengue viruses are the exception, because they still require mosquitoes/ticks as vectors and they are adequately adapted to humans as to not necessarily depend upon animal hosts (even though both continue to have animal transmission routes as well) (Busquets et al., 2008). In ticks and mosquitoes, vertical transmission is possible through transovarial and transstadial routes (Figure 3.2.1). Vertebrates are used as amplification hosts from which ticks and mosquitoes get infected and in spite of high viremia they do not necessarily develop clinical diseases. Other virus transmission routes include handling infected animal carcasses, blood transfusion (Dengue fever virus, DEN), child birth and breastfeeding (West Nile virus, WNV) (Anonymous, 2002) and through consumption of unpasteurized milk products. The transmission from animals to humans without an intermediate vector arthropod is thought to be unlikely. For example, early tests with yellow fever showed that the disease is not a contagious disease. The disease course is marked by biphasic fever and prodromal phase, manifesting itself as CNS diseases, hepatitis, hemorrhagic fever, encephalitis and myalgia.

\subsubsection{FLAVIVIRUSES AND ENVIRONMENT}

It can be stated with a high degree of confidence that flaviviruses (in the past found primarily in the tropics) are now a global problem due to the intensive spread of the carrier vectors. Flaviviruses are transmitted to humans and animals by two main vectors: ticks and mosquitoes. Importantly, both arthropods can as well be used as reservoirs of flaviviruses through the "transovarial" and "transstadial" processes, in particular when 


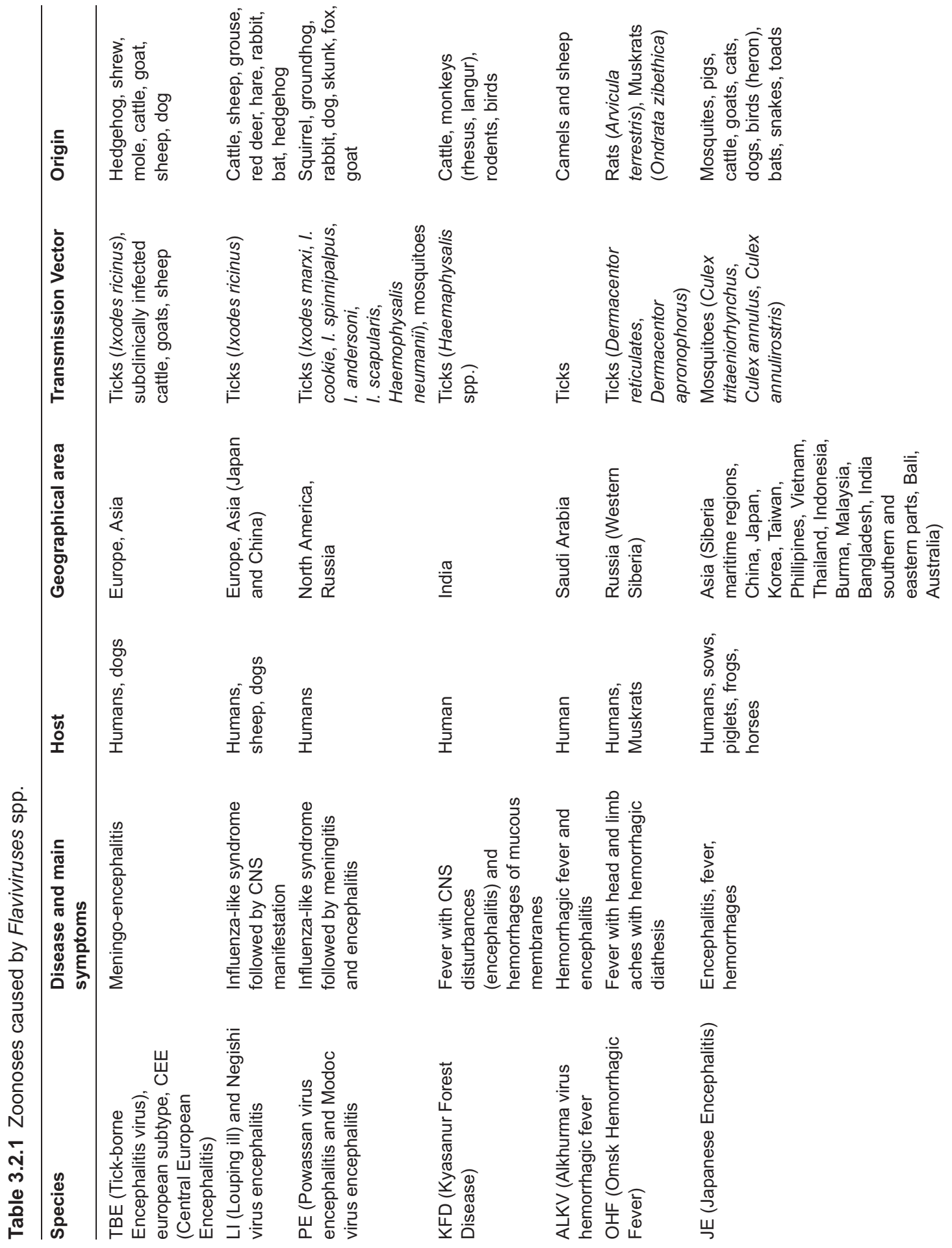


Flaviviruses infections

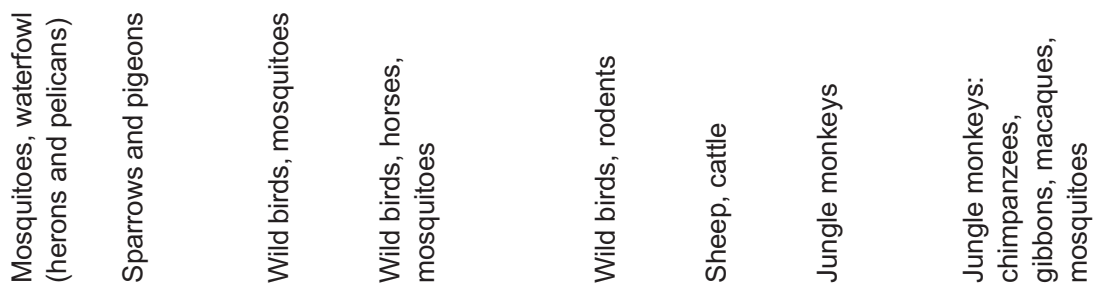

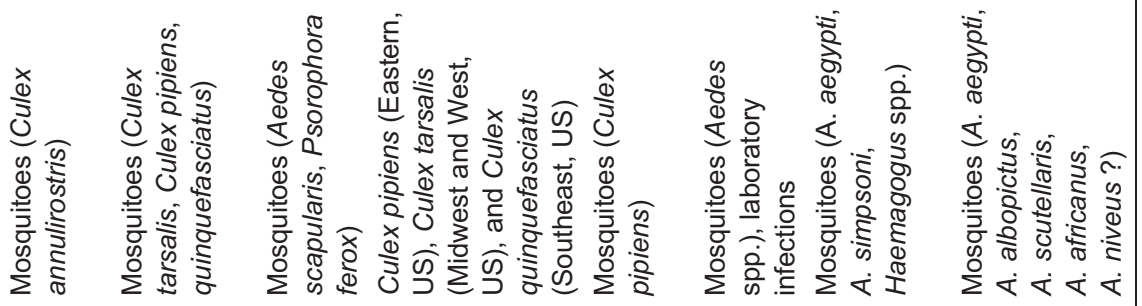

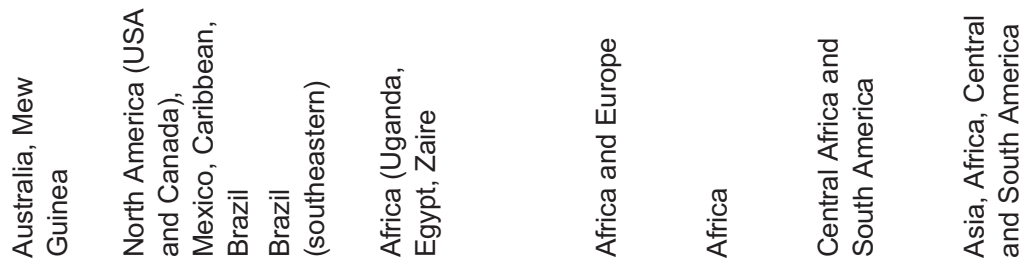

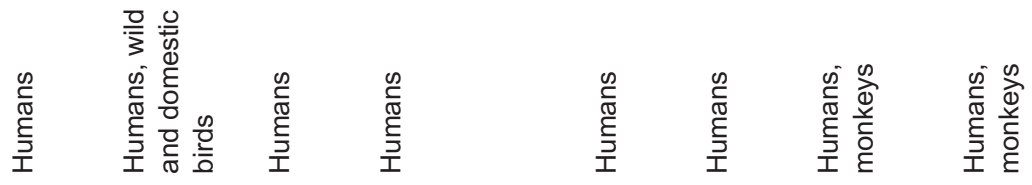

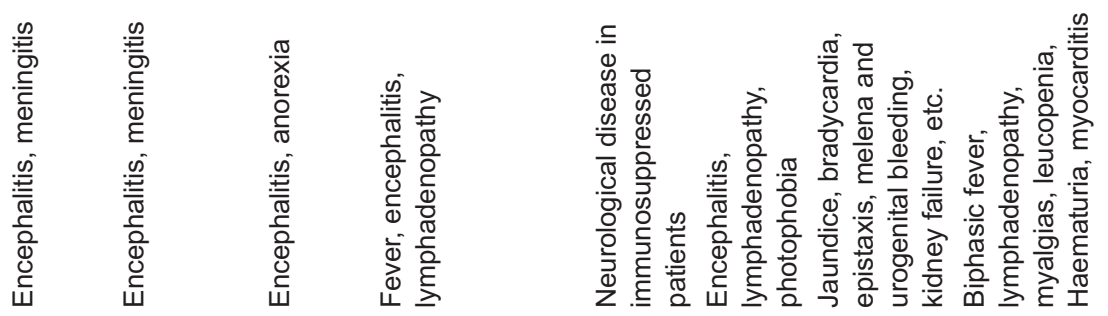

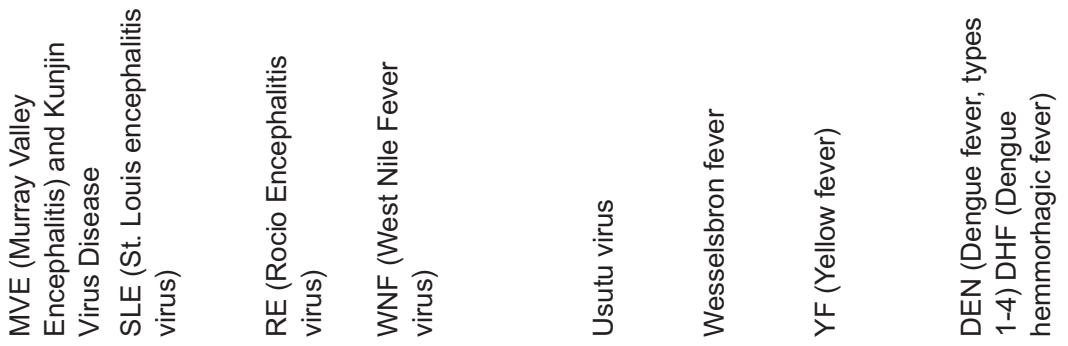


a direct vertebrate host is not directly available (Figure 3.2.2) (Joshi et al., 2002). Viral transition from invertebrates to vertebrates is an interesting phenomenon as in this particular case the arthropod vectors (invertebrates) can multiply very fast (days) and reach high numbers versus a much longer time span of replication in vertebrates and in much lower numbers (e.g., humans). In an intensive replicative system, any parasitic life form will proliferate successfully gratifying its life objective: to spread its genes. For example, A. aegypti that multiply in clean water sources (artificial containers, wasted tires, puddles, etc.) lays eggs that are highly resistant to dessication (for months) and able to hatch when submerged in water (e.g., after rainfall periods), on the site walls. Anthropophilic females of this mosquito species have the characteristic of interrupted and multiple feeding prior to gonotrophic cycle completion and once infected with one of the flaviviruses (Dengue, Chikungunya and Yellow fever viruses) or simultaneously with two (West Nile and Usutu viruses) it is for life (Calzolari et al., 2010; Tamba et al., 2010; Klowden and Briegel, 1994).

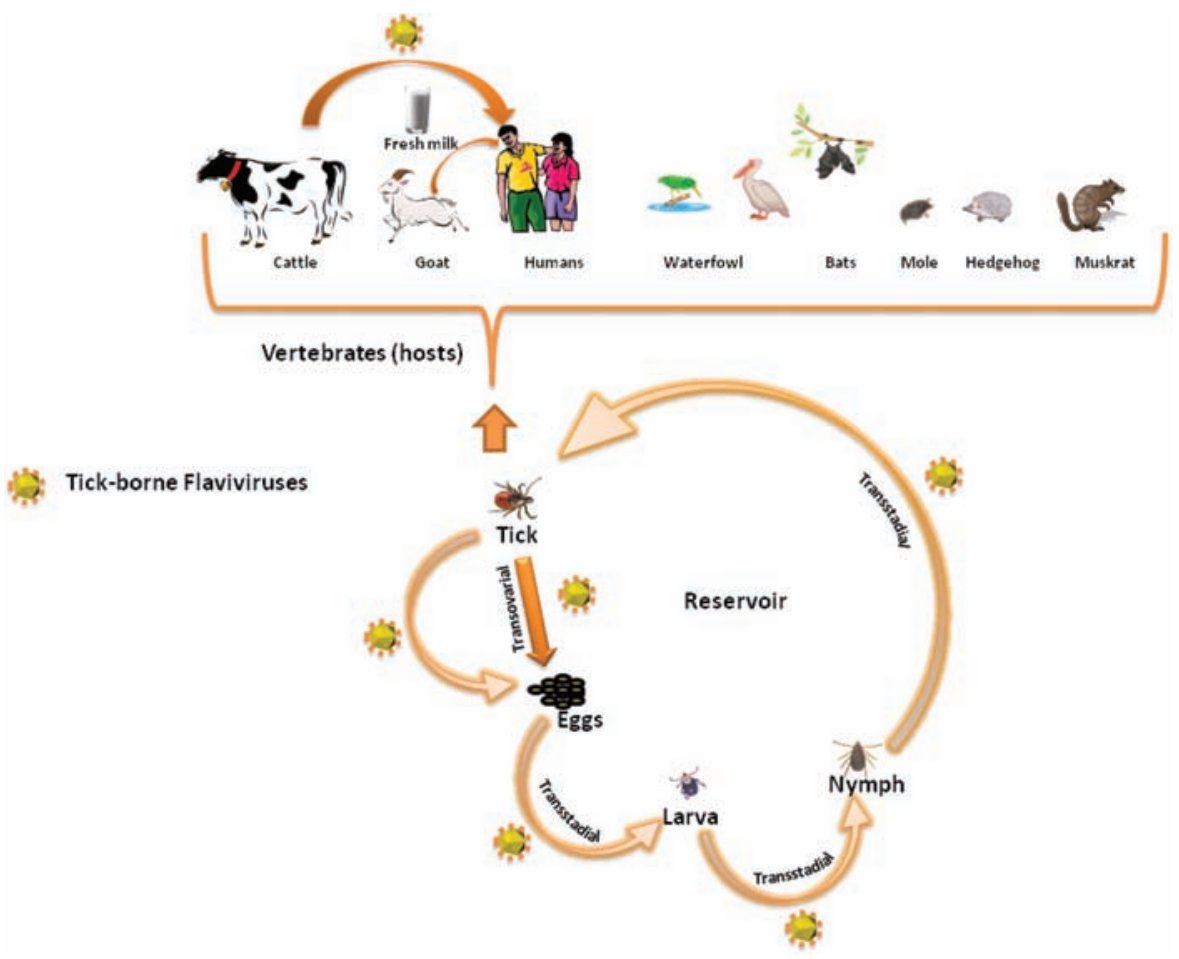

Figure 3.2.1. Transmission of tick-borne flaviviruses to vertebrates and related to tick life cycle

In tropical countries, temperature and rainfall impact the distribution of Dengue Fever virus (Halstead, 2008). The transmission of the DEN virus is almost closely related to warm and rainy seasons. Rainwater collection expands the breeding sites. Temperature was found to cut down the extrinsic incubation period the interval between the acquisition of an infectious agent by a vector and the vector's ability to transmit the agent to other susceptible vertebrate hosts and extend mosquitoes' life span, consequently increasing biting frequency. According to recent data, global warming and interannual climate variations do not seem to impact Dengue and other mosquitoes-borne flaviviruses' transmission 
significantly; nevertheless, socio-economic aspects such as people's increased mobility, international trade, urban poverty, lack of piped water, open reservoirs and air conditioning, do enhance disease spread and persistence (Figure 3.2.3) (Reiter, 2001; Arunachalam et al., 2010; Becker, 2008). Here should be mentioned a special case in which the used tire global trade has been shown to contribute to spread of mosquitoes between USA, Japan and South Korea (Reiter and Sprenger, 1987). In the case of West Nile virus (WNV), an additional factor was found to be involved in the dramatic expansion to new geographic areas beside global commerce, climate change and ecological factors. This change was related to new genotypes that evolved from the febrile illness of children in areas endemic to neurological disease as a result of a more virulent genotype emergence. From the genetic point of view, in spite of WNV stable evolutionary structure, the 1999s' North American introduction of a new genotype was linked to better and more efficient propagation at elevated temperatures (indicating temperature as a selective criteria) as well a prior mutation (under adaptive evolutionary pressure) associated with increased replication in avian hosts, demonstrating the rapid adaptation of these viruses to both hosts: vertebrates and invertabrates (Brault, 2009).

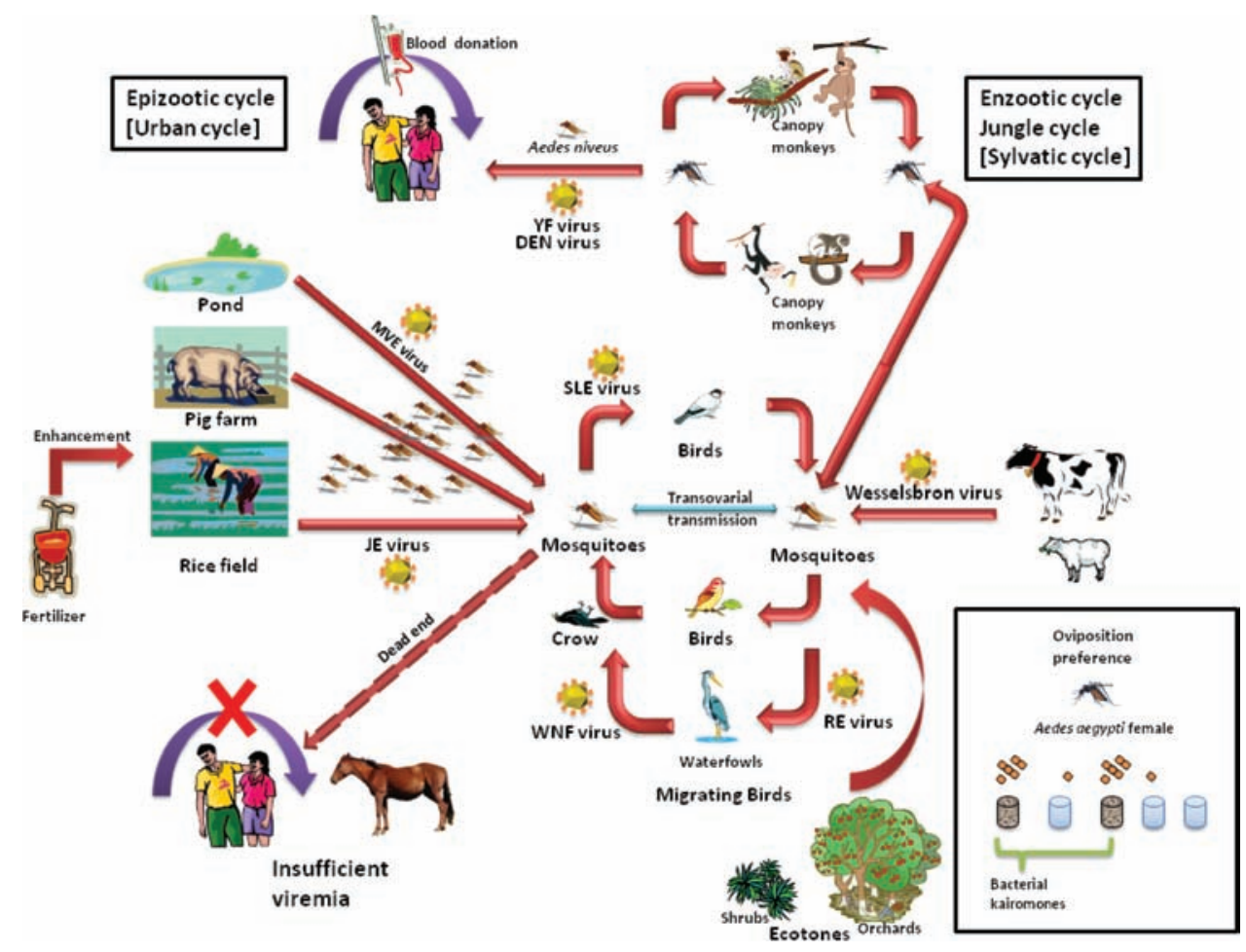

Figure 3.2.2. Transmission of mosquitoes-borne Flavoviruses

The disease spread and persistence factors are also linked to human determinants, such as blood virus titer (viremia) although till now the viremia threshold is undefined, herd immunity and household multiple infections (clusters of dengue infections) (Neff et al., 1967; Zhao, 1986).

In Thailand, known as an endemic area, Bangkok, a metropolitan area of over 9 million people, was found to be the country's endemic center. Based on the periodicity of pediatric cases hospitalized in a 
Bangkok hospital from 1983 to 1997, waves of severe cases progressed from the capital in all directions, moving at a speed of $148 \mathrm{~km}$ per month (Cummings et al., 2004). An interesting feature of the oviposition site preferences of Aedes aegypti females was recently published (Ponnusamy et al., 2008). A previous study showed that Aedes aegypti females lay and disperse their eggs in multiple water-filled containers, a phenomenon called "skip oviposition" (Colton et al. 2003). This environmental bounce behavior was related to some chemical response of mosquito females (Reiter et al., 1991; Trexler et al., 1998; Benzon and Apperson, 1988). Based on these details, Ponnusamy et al., (2008) clearly proved that kairomones, such as bamboo and white-oak leaf infusions (kairomone is a semiochemical mediator involved in inter-specific interactions), attract Aedes aegypti females to lay their eggs when present. These kairomones are specific bacteria-associated carboxylic acids and methyl esters that can serve as potent oviposition stimulants, and therefore a potential tool in biological warfare against these mosquitoes. To strengthen this phenomenon, Barrera et al., (2006) showed that Aedes aegypti larval and pupal abundance were larger in containers with leaf litter or algae. Pupal productivity and the biomass of emerging females varied in containers with litter of different tree species. The organics produced by litter are the basic nutrients for different bacteria present in a water container to produce the above kairomones.

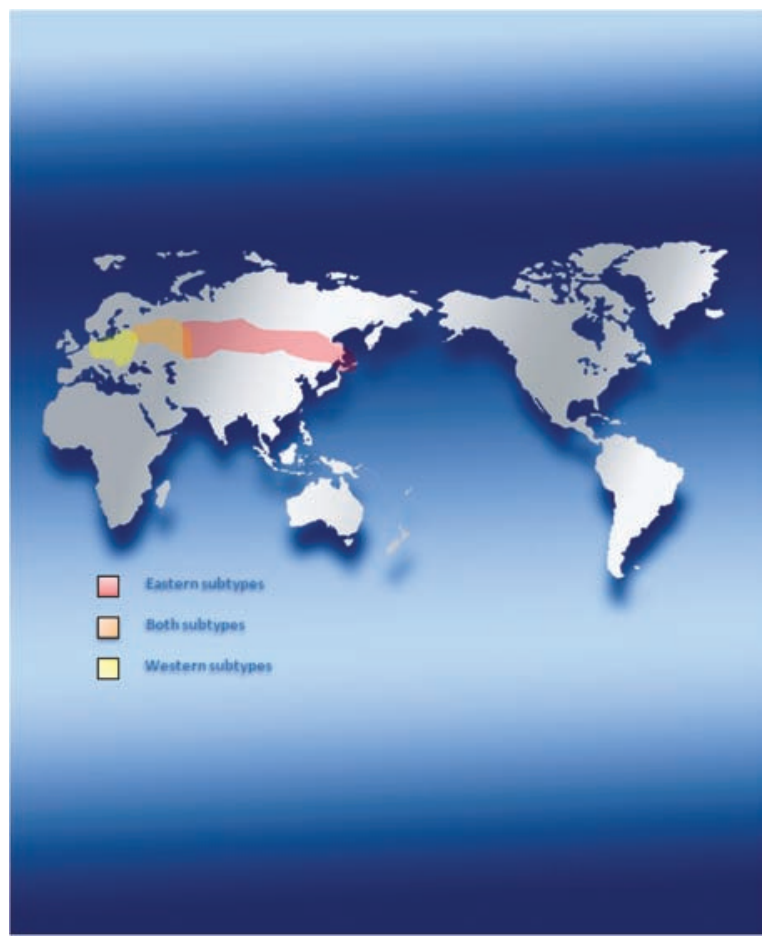

Figure 3.2.3. Tick-borne encephalitis (TBE) (Eastern and Western subtypes) endemic areas in Eurasia

In an interesting review, Reisen (2010) described the term "nidus" (in Latin- nest) (described as a place where pathogen transmission occurs) as a spatial defined focus in landscape epidemiology where host, vector, and pathogen populations interact spatially within a permissive environment. The nidus is characterized by vegetation, climate, latitude, elevation, and geology (Christofferson et al., 2010; Ciota 
et al., 2007). This author showed that in certain ecotones in which mosquito vectors and avian abundance prevail there is a significant potential increase in West Nile virus transmission in USA, which is certainly true around the globe (Weissenböck et al., 2002). Such ecotones (transects intersecting desert scrub vegetation and citrus orchard habitat) are utilized by both birds and mosquitoes: for nesting and host seeking, respectively.

Beside humans, other mammals (pigs) are also involved in the persistence of flaviviruses. Japanese Encephalitis virus (JE) is distributed throughout Southeast Asia, the Indian subcontinent, Indonesian archipelago, and into the Australasian zoogeographical region with a high level of fatal cases. While infected with JEV, humans and horses do develop fatal encephalitis, yet they are dead-end hosts due to low viremia, and thus the virus is maintained in an enzootic cycle between ardeid wading birds, Culex mosquitoes and pigs that are important for epizootic transmission (van de Hurk et al., 2009; Smartt et al., 2010). Again, birds are involved as amplifying hosts and through their long distance flight they can spread the virus to new ecosystems.

Platonov et al. (2008) studied West Nile fever (WNF) outbreaks in southern Russia from 1999 to 2007. For 4 years (200-2004) the incidence rates dropped to zero, while in 1999 and 2007 they were at their highest. 1999 and 2007 had the warmest winters and summers. Two mosquitoes types were shown to transmit WNF in this area: Culex pipiens and Culex modestus, both attracted to humans and birds. These authors emphasized the climatic conditions as predisposing factors for WNF spread in this temperate climate zone (Ranjit and Kissoon, 2011). Flood periods in temperate areas revealed an enormously high population density of mosquitoes (like the one that occurred in 1997 Morava River in South Moravia, Czech Republic) that significantly increased also the infection rate of these mosquitoes with flaviviruses (WNV) (Hubalek et al., 2000).

The spread of flaviviruses to temperate climate is coupled with the survival resistance of their vectors to much lower temperatures, especially in winter times (Huhtamo et al., 2009). Mosquitoes from the Aedes family are among those well adapted to temperate winters through hibernation, egg tolerance to sub-zero temperatures and adults' survival throughout the winter in appropriate microhabitats. (Romi et al., 2006; Hanson and Craig, 1995; Hawley et al., 1989).

TBE viruses are transmitted by ticks and maintained, amplified, and disseminated in wild vertebrate hosts (e.g., small rodents and insectivores) as endemic cycles due to inefficient vertical transmission. Individuals who work or play in tick-infested areas are the frequently infected targets, but with low potential of further transmission due to low viremia (similar to other flaviviruses transmitted by mosquitoes also to other domestic animals). However, milk and raw dairy products may pass the virus from sheep, goats, and cattle to humans as a result of virus secretion into their milk by these domestic animals (Ludwig and Iacono-Connors, 1993).

Arthropods are known for their toughness and resistance in a large variety of extreme environments. Fielden et al. (2011) studied dog tick (Dermacentor variabilis) survival when submerged in water. These authors showed that these ticks can survive underwater for extended periods using plastron respiration. Plastron is a thin permanent layer of air around the body of some aquatic insects, held in place by hydrophobic hairs or other cuticular projections acting as a physical gill. Indeed, ticks have a complex spiracular plate that is used for plastron respiration. Due to its hydrophobic property, the complex spiracular plate can hold oxygen bubbles to be used for respiration, supporting the survival period for up to 15 days. Interestingly, wetting the complex spiracular plate with alcohol (resulting in reduced hydrophobicity) lowered water submerged ticks' survival to $\sim 7$ days.

Zvereva and Kozlov (2010) performed a meta-analysis of the responses of terrestrial arthropods (decomposers and predators) to air pollution and concluded that some adverse impacts may have negative consequences on the ecosystem structure and services. However, their meta-analysis did not 
provide support that an overall decrease in diversity or promotion of herbivore outbreaks is indeed impacted by air pollution. According to their meta-analysis, a decrease in abundance of predators was found likely to be a widespread phenomenon where as an indirect factor, pollution may favor herbivores by generating an enemy-free space. In relation to climatic effects, these authors indicated that temperature and precipitation may enhance pollution therefore thereby increasing ecosystem adverse effects on arthropods. These results were also supported by a more particular study of observed changes in the geographical range of ticks in parts of Europe, showing that a complex combination of climate variables as well host availability and vegetation controls ticks' life cycle and their population dynamic (Estrada-Peña, 2008).

Natural evolution of the tick-borne encephalitis (TBE) virus was studied in eastern and western Siberia, middle Urals and European part of Russia (Pogodina et al., 2007) (Figure 3.2.4). Environmental and epidemilogical conditions that impacted this evolution were: 1) changes in TBEV subtypes over a time span of 50-60 years (from eastern to western Siberian type); 2) steady-state circulation of western Siberian type and accumulation of mutant types; 3) co-existence of both types in the common vector (Ixodes persulcatus); and 4) TBEV strains genetic mixture including genes expressing proteins E and NSI of both viruses types.

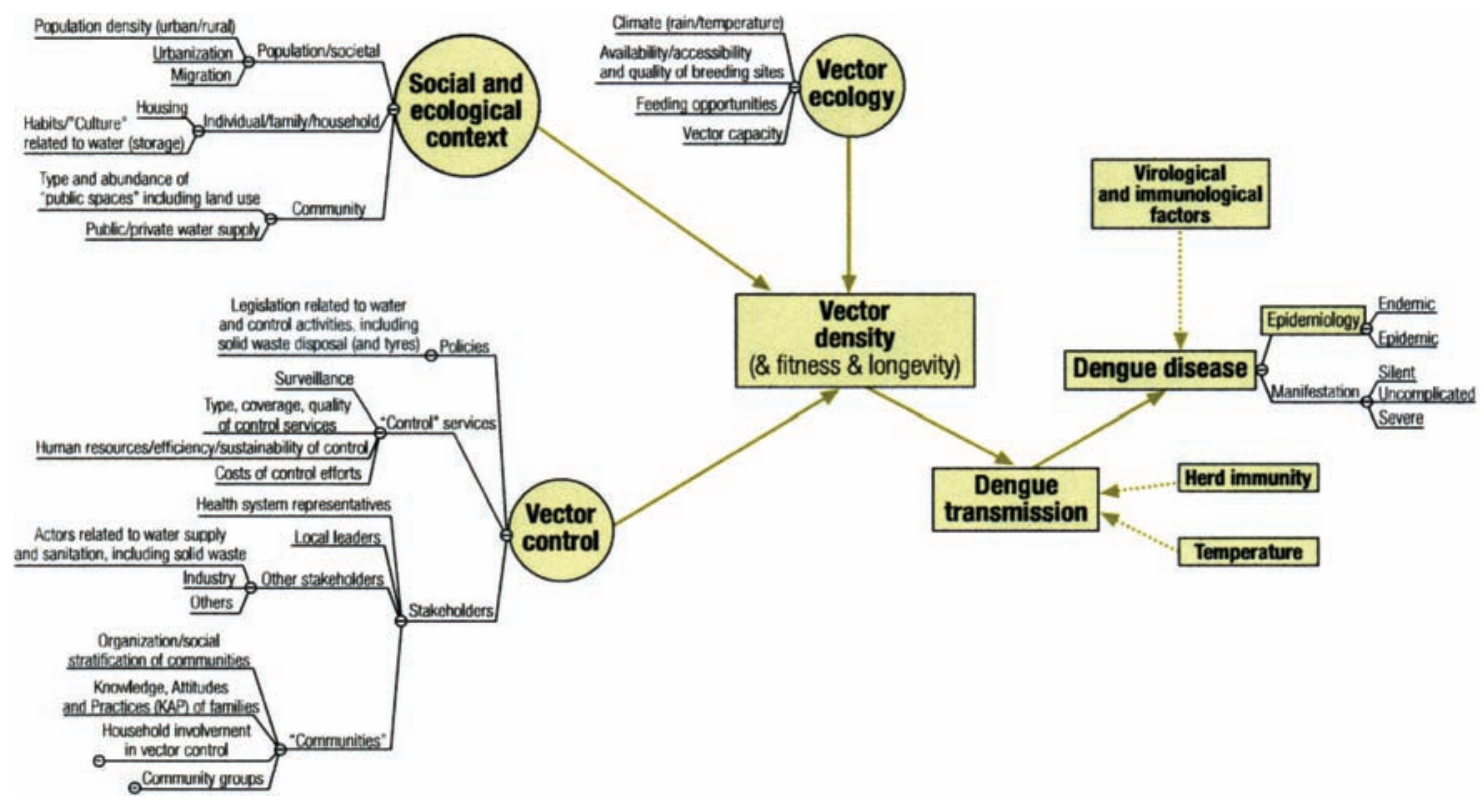

Figure 3.2.4. Frame-work of eco-bio-social determinants of dengue vector breeding: a multicountry study in urban and periurban Asia (with permission from Arunachalam et al., (2010) Bull. World Health Organ. 88, 173-184)

Haemig et al. (2008) pointed to the roadside with its different ecology compared to the surrounding landscape, as a significant environmental factor where ticks, humans, pets and livestock encounter each other, therefore constituting an important factor in tick-borne viral diseases.

Ticks are basically divided in two major groups: hard ticks (Ixodidae) and soft ticks (Argasidae) (Table 3.2.2). From the ecological point of view, hard ticks can be found in open environments (except in the nidicolous Ixodes sp., particularly immature), with seasonal activity on usually three hosts 
Flaviviruses infections

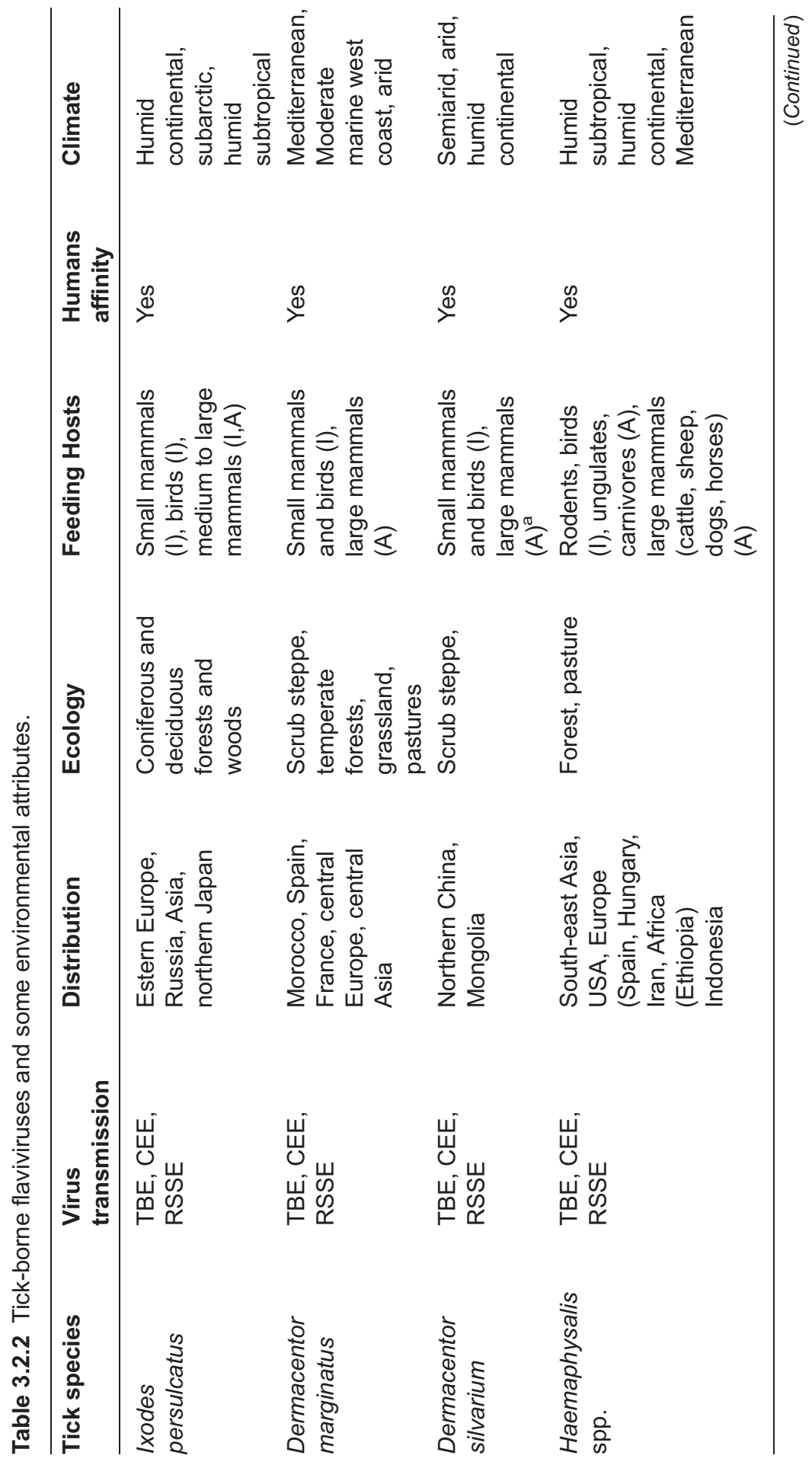




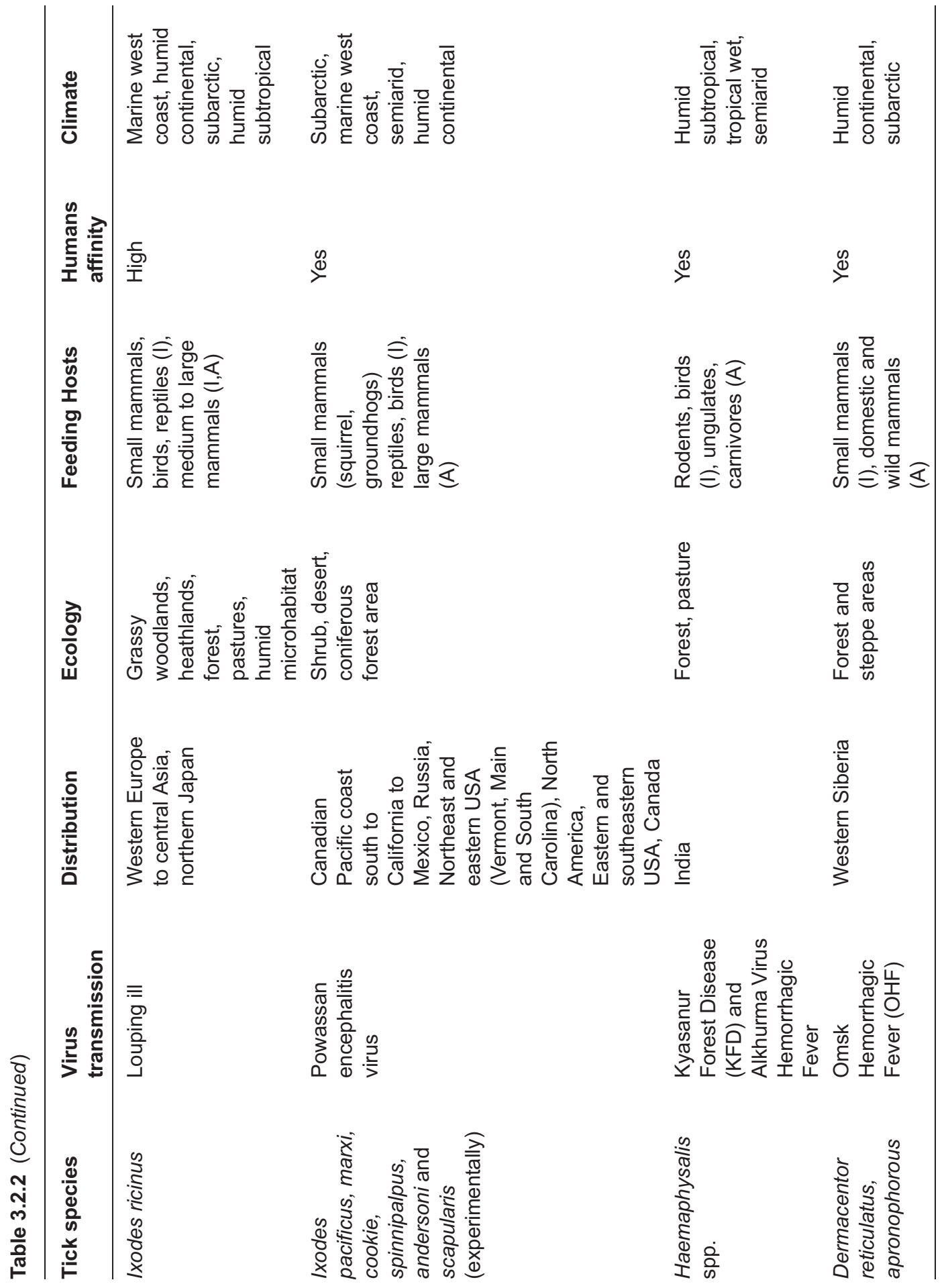


(different species, one per stage) a life span from several months to three years (less resistant to starvation and desiccation) and mostly seeking non-nidicolous free-ranging hosts, while soft ticks can be found in sheltered environments (nests, burrows, caves and man-made shelters) have no seasonal activity with multi-host feeding pattern, long life (up to 10 years), are highly resistant to starvation and mostly nidicolous in the host habitat as host-seeking behavior (Parola and Raoult, 2001).

\subsubsection{REFERENCES}

Anonymous, (2002) Possible West Nile virus transmission to an infant through breast-feeding-Michigan. JAMA 288, 1976-1977.

Arunachalam, N., Tana, S., Espino, F., Kittayapong, P., Abeyewickreme, W. et al., (2010) Eco-bio-social determinants of dengue vector breeding: a multicountry study in urban and periurban Asia. Bull. World Health Organ. 88, 173-184.

Barrera, R., Amador, M. \& Clark, G.G. (2006) Ecological factors influencing Aedes aegypti (Diptera: Culicidae) productivity in artificial containers in Salinas, Puerto Rico. J. Med. Entomol. 43, 484-492.

Becker, N. (2008) Influence of climate change on mosquito development and mosquito-borne diseases in Europe. Parasitol. Res. 103, S19-S28.

Benzon, G.L. \& Apperson, C.S. (1988) Reexamination of chemically mediated oviposition behavior in Aedes aegypti (L.) (Diptera: Culicidae). J Med Entomol 25, 158-164.

Brault, A.C. (2009) Changing patterns of West Nile virus transmission: altered vector competence and host susceptibility. Vet. Res. 40:43.

Busquets, N., Alba, A., Allepuz, A., Aranda, C. \& Nuñez, J.I. (2008) Usutu virus sequences in Culex pipiens (Diptera: Culicidae), Spain [letter]. Emerg Infect Dis. 14, 861-862.

Calzolari M, Bonilauri P, Bellini R, Albieri A, Defilippo F, et al., (2010) Evidence of simultaneous circulation of West Nile and Usutu viruses in mosquitoes sampled in Emilia-Romagna region (Italy) in 2009. PLoS ONE 5(12): e14324. doi:10.1371/journal.pone.0014324.

Christofferson, R.C., Roy, A.F. \& Mores, C.N. (2010) Factors associated with mosquito pool positivity and the characterization of the West Nile viruses found within Louisiana during 2007. Virol. J. 7:139.

Ciota, A.T., Lovelace, A.O., Jones, S.A., Payne, A. \& Kramer, L.D. (2007) Adaptation of two flaviviruses results in differences in genetic heterogeneity and virus adaptability. J. Gen. Virol. 88, 2398-2406.

Colton, Y.M., Chadee, D.D., Severson, D.W. (2003) Natural "skip oviposition" of the mosquito Aedes aegypti as evidenced by codominant genetic markers. Med Vet Entomol 17, 195-201.

Cummings, D.A., Irizarry, R.A., Huang, N.E., Endy. T.P., Nisalak. A. et al., (2004) Travelling waves in the occurrence of dengue haemorrhagic fever in Thailand. Nature 427, 344-347.

Estrada-Peña, A. (2008) Climate, niche, ticks, and models: what they are and how we should interpret them. Parasitol. Res.103, S87-S95.

Fielden, L.J., Knolhoff, L.M., Villarreal, S.M. \& Philip Ryan, P. (2011) Underwater survival in the dog tick Dermacentor variabilis (Acari:Ixodidae). J. Insect Physiol. 57, 21-26.

Haemig, P.D., Waldenstrom, J. \& Olsen, B. (2008) Roadside ecology and epidemiology of tick-borne diseases. Scand. J. Infect. Dis. 40, 853-858.

Halstead, S.B. (2008) Dengue virus-mosquito interactions. Annu. Rev. Entomol. 53, 273-291.

Hanson, S. M. \& Craig, G. B. (September 1995). “Aedes albopictus (Diptera: Culicidae) eggs: field survivorship during northern Indiana winters". J. Med. Entomol. 32, 599-604.

Hawley, W. A., Pumpuni, C. B., Brady, R. H. \& Craig, G. B. (March 1989). "Overwintering survival of Aedes albopictus (Diptera: Culicidae) eggs in Indiana”. J. Med. Entomol. 26, 122-129.

Hubalek, Z., Savage, H.M., Halouzka, J., Juricova, Z., Sanogo, Y.O. \& Lusk, S. (2000) West Nile virus investigations in South Moravia, Czechland. Viral Immunol. 13, 427-433.

Huhtamo, E., Putkuri, N., Kurkela, S., Manni, T., Vaheri, A. et al., (2009) Characterization of a novel flavivirus from mosquitoes in northern Europe that is related to mosquito-borne flaviviruses of the tropics. J. Virol. 83, 9532-9540. 
Joshi, V., Mourya, D. \& Sharma, R. (2002) Persistence of dengue-3 virus through transovarial transmission passage in successive generations of Aedes aegypti mosquitoes. Am J Trop Med Hyg 2002, 67:158-161.

Klowden, M.J. \& Briegel, H. (1994) Mosquito gonotrophic cycle and multiple feeding potential: contrasts between Anopheles and Aedes (Diptera: Culicidae). J Med Entomol. 4, 618-622.

Ludwig, G.V. \& Iacono-Connors, L.C. (1993) Insect-transmitted vertebrate viruses: Flaviviridae. In Vitro Cell. Dev. Biol. 29A, 296-309.

Neff, J.M., Morris, L., Gonzalez-Alcover, R., Coleman, P.H., Lyss, S.B. \& Negron, H. (1967) Dengue fever in a Puerto Rican community. Am. J. Epidemiol. 86,162-184.

Parola, P. \& Raoult, D. (2001) Ticks and tickborne bacterial diseases in humans: an emerging infectious threat. Clin. Infect. Dis. 32, 897-928.

Platonov, A.E. \& Fedorova, M.V., Karan, L.S., Shopenskaya, T.A., Platonova, O.V. \& Zhuravlev, V.I. (2008) Epidemiology of West Nile infection in Volgograd, Russia, in relation to climate change and mosquito (Diptera: Culicidae) bionomics. Parasitol. Res. 103, S45-S53.

Pogodina, V.V., Karan', L.S., Koliasnikova, N.M., Levina, L.S., Malenko, G.V. et al., (2007) Evolution of tick-borne encephalitis and a problem of evolution of its causative agent. Vopr. Virusol. 52, 16-21.

Ponnusamy, L., Xue, N., Nojima, S., Wesson, D.M., Schal, C. \& Apperson, C.S. (2008) Identification of bacteria and bacteria - associated chemical cues that mediate oviposition site preferences by Aedes aegypti. Proc. Natl. Acad. Sci. USA 105, 9262-9267.

Ranjit, S. \& Kissoon, N. (2011) Dengue hemorrhagic fever and shock syndromes. Pediatr Crit Care Med 12, 90-100.

Reisen, W.K. (2010) Landscape epidemiology of vector-borne diseases. Annu. Rev. Entomol. 55, 461-483.

Reiter, P. \& Sprenger, D. (1987) The used tire trade: a mechanism for the worldwide dispersal of container breeding mosquitoes. J. Am. Mosq. Control Assoc. 3, 494-501.

Reiter, P. (2001) Climate Change and Mosquito-Borne Disease. Environ. Health Perspect. 109, 141-161.

Reiter, P., Amador, M.A. \& Colon, N. (1991) Enhancement of CDC ovitrap with bay infusion for daily monitoring of Aedes aegypti populations. J Am Mosq Control Assoc 7, 52-55.

Romi, R., Severini, F. \& Toma, L. (March 2006). "Cold acclimation and overwintering of female Aedes albopictus in Roma”. J. Am. Mosq. Control Assoc. 22, 149-151.

Smartt, C.T., Richards, S.L., Anderson, S.L., Vitek, C.J. (2010) Effects of forced egg retention on the temporal progression of West Nile virus infection in Culex pipiens quinquefasciatus (Diptera: Culicidae). Environ. Entomol. 39, 190-1944.

Tamba, M., Bonilauri, P., Bellini, R., Calzolari, M., Albieri, A. et al., (2010) Detection of Usutu virus within a West Nile virus surveillance program in northern Italy. Vector Borne Zoonotic Dis. Sep 17. [Epub ahead of print]

Trexler, J.D., Apperson, C.S. \& Schal, C. (1998) Laboratory and field evaluations of oviposition responses of Aedes albopictus and Aedes triseriatus (Diptera: Culicidae) to oak leaf infusions. J Med Entomol 35, 967-976.

van den Hurk, A.F., Ritchie, S.A. \& John S. Mackenzie, J.S. (2009) Ecology and geographical expansion of Japanese encephalitis virus. Annu. Rev. Entomol. 54, 17-35.

Weissenböck, H., Kolodziejek, J., Url, A., Lussy, H., Rebel-Bauderm, B. \& Nowotny, N. (2002) Emergence of Usutu virus, an African mosquito-borne flavivirus of the Japanese encephalitis virus group, central Europe. Emerg Infect Dis. 8, 652-656.

Zhao, Z.G. (1986) Epidemiological study on dengue fever in Hainan Island. Chin. J. Epidemiol. 7, 29-32.

Zvereva, E.I. \& Kozlov, M.V. (2010) Responses of terrestrial arthropods to air pollution: a meta-analysis. Environ Sci Pollut Res Int 17, 297-311. 


\section{Chapter 3.3 Bunyaviridae}

\section{[FAMILY BUNYAVIRIDAE, GENUS HANTAVIRUS, NAIROVIRUS, ORTHOBUNYAVIRUS, PHLEBOVIRUS, TOSPOVIRUS]}

The family of Bunyaviridae viruses contains several genera and more than 300 members of enveloped, spherical particle, somewhat similar to Paramyxoviridae family with a size range of 90 to $100 \mathrm{~nm}$, without matrix proteins and a tripartite nucleic acid - (ss) RNA at a size range of $\sim 10,500$ to 22,700 bases). Bunyaviridae are mainly vector-borne viruses (ticks, mosquitoes and sandflies) with the exception of Hantaviruses genus that is transmitted through direct contact with rodents' feces. This family of viruses can infect a diverse range of hosts, from arthropods (mosquitoes) to marsupials, and thrips to plants (tomatoes) (Table 3.3.1). Some of the Bunyaviridae viruses (e.g. Crimean-Congo hemorrhagic fever virus) can cause serious disease and are associated with high levels of morbidity and mortality, therefore laboratory handled with caution at biosafety level 4 (Ergönül, 2006). Clinical aspects of Bunyaviridae may present as: fever, photophobia, myalgia, conjunctivitis, arthralgia, vomiting, diarrhea, renal insufficiency, meningitis, myocarditis, hemorrhagic diathesis with a lethality of 30 to $55 \%$.

\subsubsection{BUNYAVIRIDAE AND ENVIRONMENT}

Most of the genera belonging to Bunyaviridae family are linked to animal hosts and mainly horizontal transmition (though vertical one is also possible when vector-borne) by two major pathways: vector-borne (ticks, fleas, mosquitoes, and other biting insects) or through the inhalation of infectious aerosolized saliva or excreta of a rodent/insectivor reservoir/host (Miller et al., 1977; Song et al., 2007) (Figure 3.3.1). Among those confirmed as human Bunyaviridae viruses, three genera belong to those transmitted by arthropod vectors (known as arboviruses-arthropod borne e.g., Orthobunyaviruses are transmitted by mosquitoes or midges, Nairoviruses by ticks, and Phleboviruses by sandflies or ticks) and one that do not have arthropod vectors but are maintained in nature as persistent infections of rodents (hence the term robovirus, from rodent-borne) and are transmitted to humans via aerosolized infectious rodent secretions (e.g. Hantaviruses) (Nowotny 1994; Ullmann et al., 2008). The fourth genus Tospoviruses (that are plants' pathogens or phytopathogens) is carried and spread by thrips. 


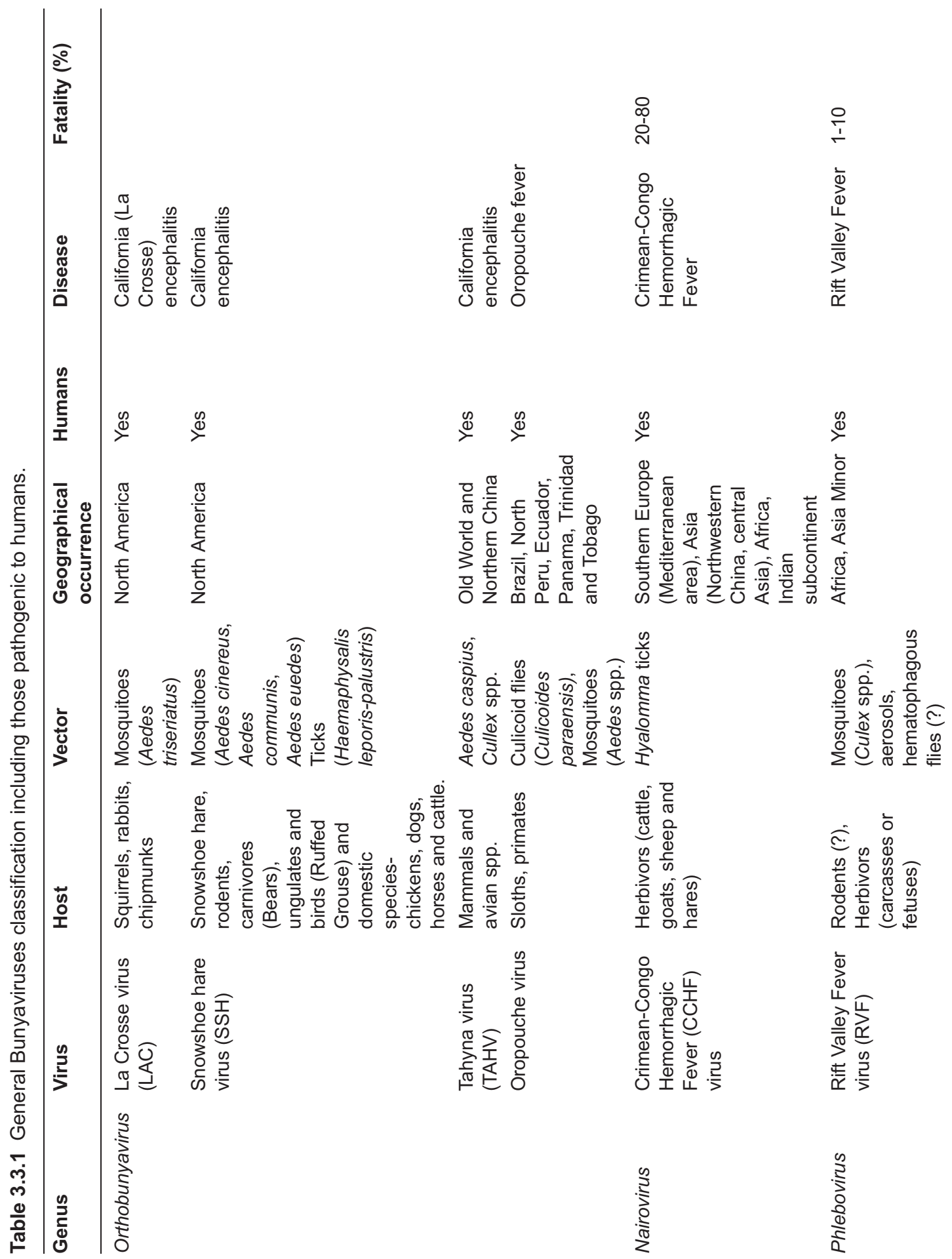



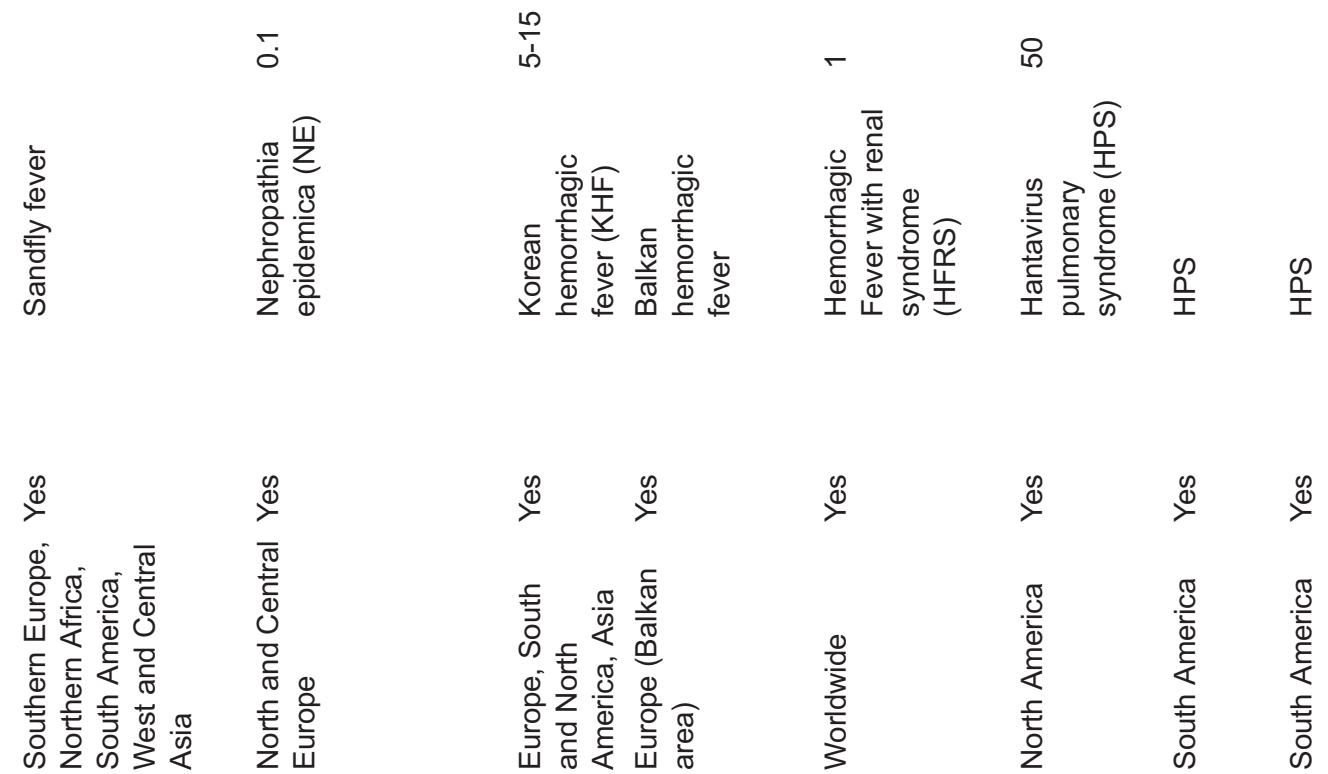

$\stackrel{\infty}{=} \quad \stackrel{0}{=}$

$\stackrel{\infty}{x}$

$\stackrel{\mathscr{D}}{\rightleftharpoons} \stackrel{\mathscr{D}}{\rightleftharpoons}$

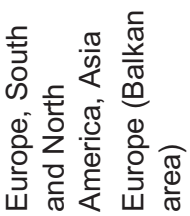

$\frac{0}{0}$
$\frac{0}{0}$
$\frac{1}{4}$
$\frac{1}{2}$
눙

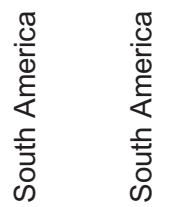

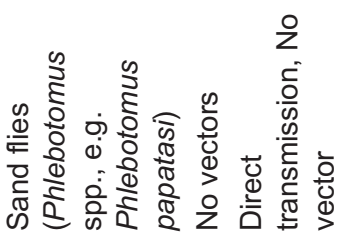

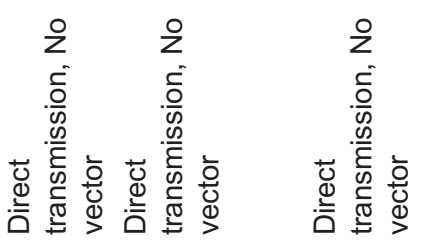

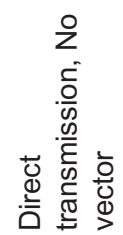

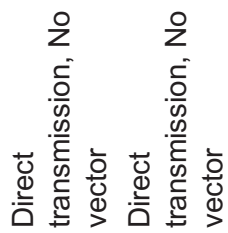

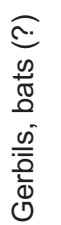
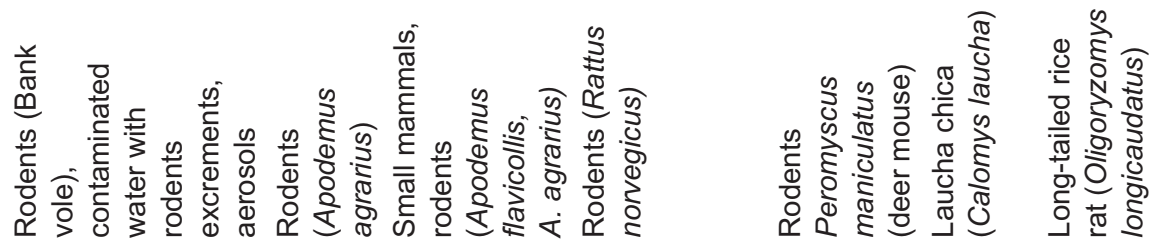

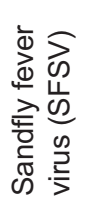

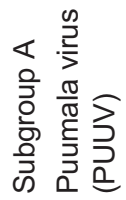

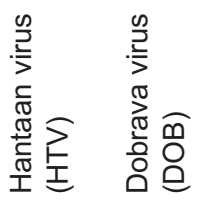

क

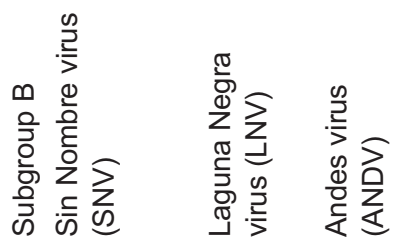

$\frac{\sqrt{0}}{\frac{0}{2}}$ 


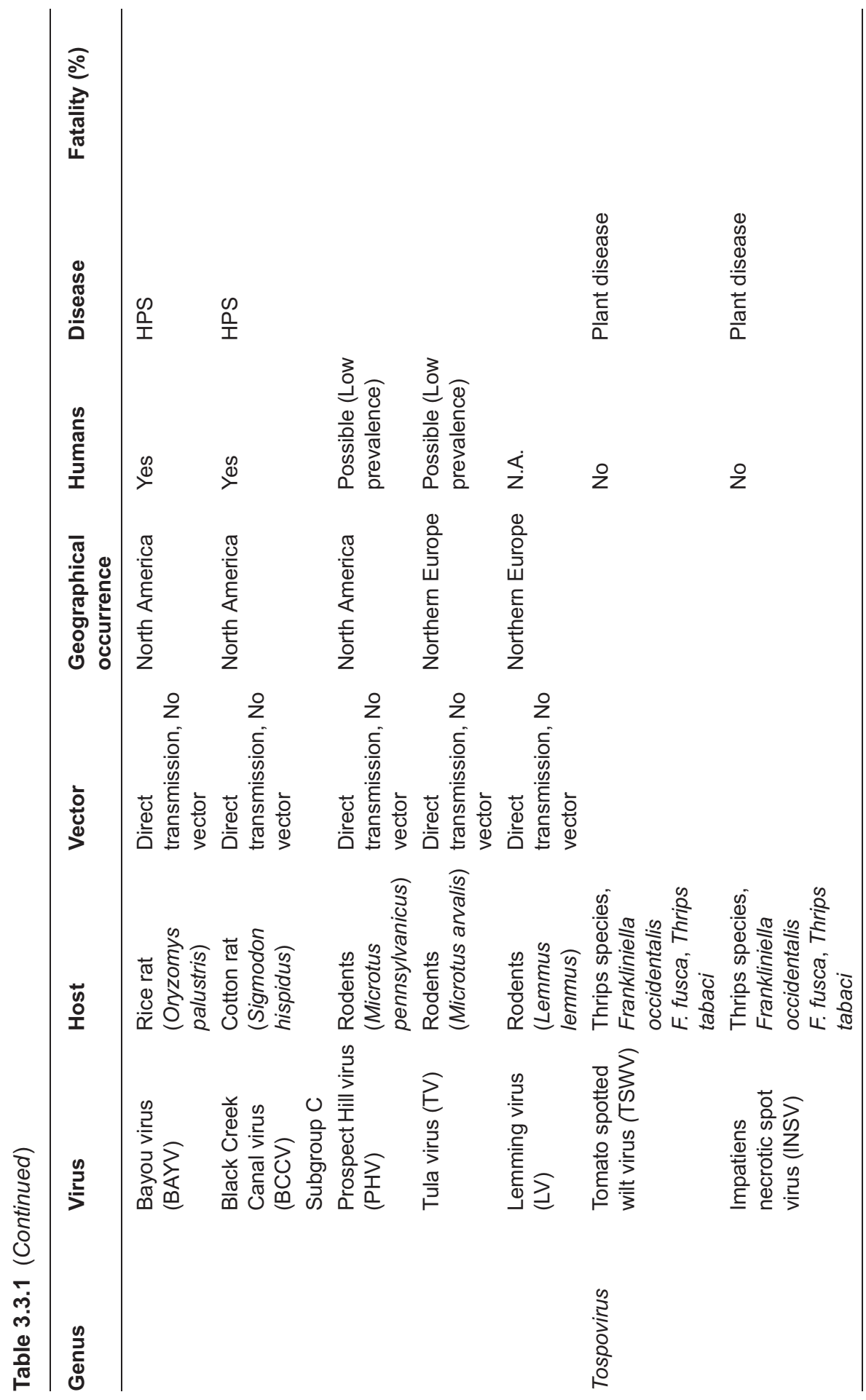




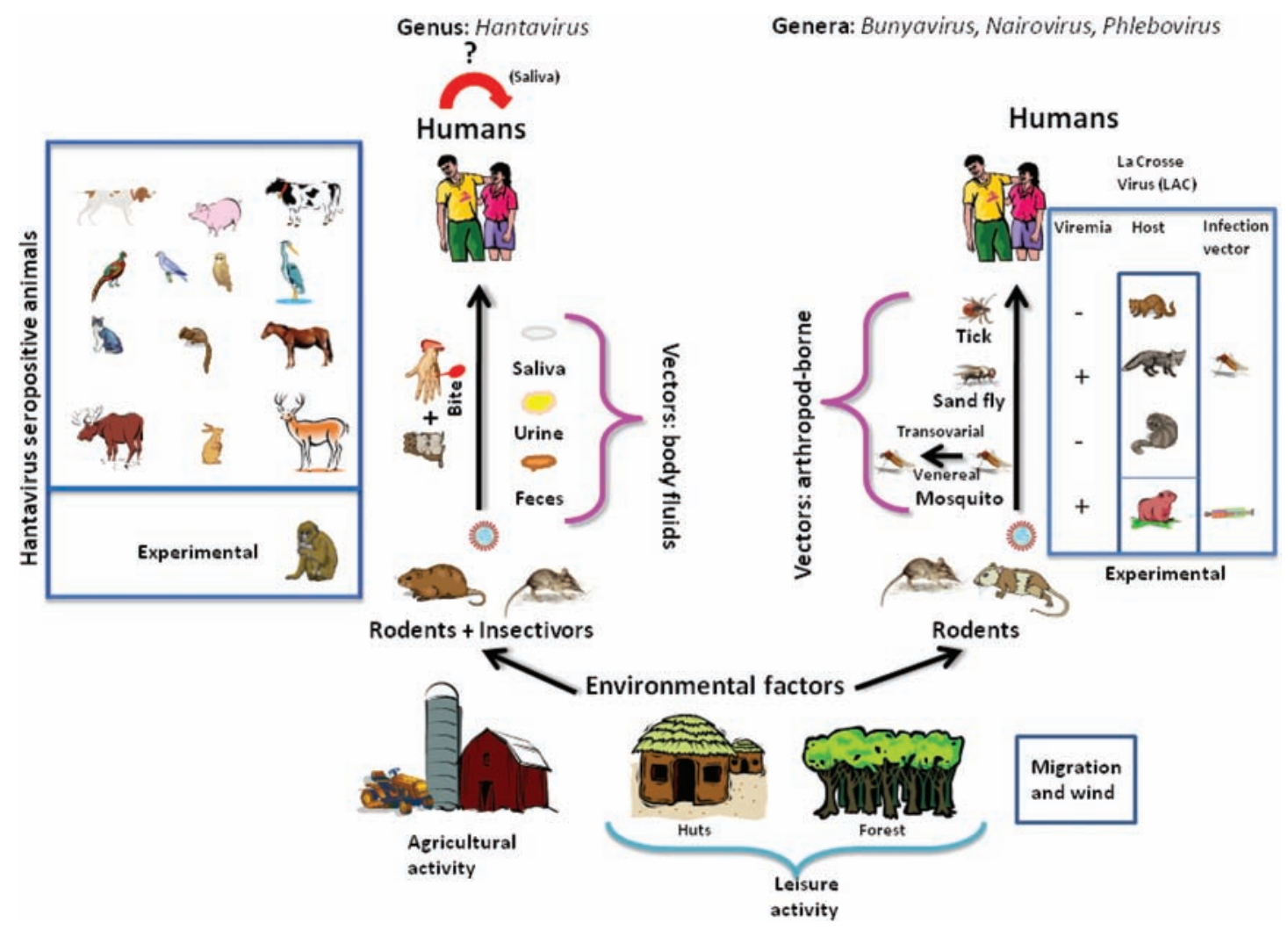

Figure 3.3.1. Bunyaviridae transmission paths and relation to different animals and environment

Here is the place to mention some pieces of evidence accepted among the members of the scientific community related to Bunyaviridae: a) the pathogens/diseases and their vectors (e.g. insects) will abound if warming indeed takes place; b) if warming occurs, dynamics of the present pathogens variability will change including interspecies cross; c) intermediate stages of vectors (mainly insects) will develop faster; d) geographic migration of hosts and vectors will take place northern to previously colder regions; e) long-distance movements of persistent organic pollutants (POP's) may affect the immunology of remote and cold region fauna (hosts), therefore making them more susceptible to new diseases and finally f) favorable physical environmental factors (e.g. temperature and humidity) affect the longevity and infectivity of roboviruses outside the rodent host.

Those bunyaviridae transmitted by insect vectors behave mostly like the Oropouche virus (Pan American Health Organization (PAHO, 2010). This virus exists in nature in two cycles, the wild and urban-epidemic cycles. In the wild cycle, wildlife such as primates, sloths, and certain arthropods serve as reservoirs, with the flies acting as vectors. In the urban epidemic cycle, the infection cycle remains vector-man-vector, with the human being acting as the principal host. Tesh (1994) described seroconversion for the Oropouche virus in Panamian population an area with unknown cases. Based on reported isolation of this virus from insects and mammals it seems that it has a wide geographic distribution in tropical South America. Endemic areas for Oropouche virus are still sparsely populated, but human new settlement and development can increase its prevalence. Other factors involved in this virus distribution are deforestation, urbanization and 
agricultural development, all connected to breeding habits of Culicoides paraensis. The preferred habitats of this biting midge are rotting cacao husks and banana stump. Both habitats contain decomposing plant material able to preserve moisture during dry periods, consequently serving as an excellent matrix for these insects' larvae. In addition, in rural areas, farmers intentionally place rotting plant material among the cacao plants, in order to encourage these insects and other ceratopogonids as pollinators of cacao flowers. In urban areas, people plant banana trees in their gardens therefore increasing the breeding sites of Culicoides paraensis and possibly other vectors.

Mosquitoes as vectors, have shown the ability to transfer La Crosse virus by two important modes: venereal (between matting partners) (Thompson and Beaty 1977) and transovarial (vertical to eggs) (Miller et al., 1977). The second mode is even more resistant environmentally as mosquito eggs are highly resistant and dormant for extended periods of time (weeks/months/years) during which virus maintain its viability.

Rift Valley fever virus (RVFV) transmitted by mosquitoes was first identified in 1930, during an outbreak of sudden deaths and abortions among sheep along the shores of Lake Naivasha in the greater Rift Valley of Kenya (Daubney and Hudson, 1932). Since then, RVFV spread all over African continent (from Egypt to South-Africa), Madagascar and between 2000-2001 towards Arabian Peninsula, causing livestock and human outbreaks (Pepin et al., 2010; Balkhy and Memish, 2003). Since the early 1900s some major ecological changes occurred in eastern and southern Africa, through establishment of colonial agriculture systems including the import of large numbers of European breed livestock that are highly susceptible to this virus. In the case of the Egyptian outbreak, the construction of the Aswan High Dam along the Nile River was associated it, while the 2006-2007 African outbreak was related to changes in rainfall patterns (Meegan, 1981; Bird et al., 2008).

When dealing with arthropods, air streams and climatic conditions play an important role in the transport of biting midges (hosts of several Bunyaviruses) (Elliott, 2009). Braverman and Chechik (1996) analyzed in Israel the temperature, relative humidity, wind speed and direction at different altitudes $(0.5,1$ and $1.5 \mathrm{~km})$ for four years and their relationship to outbreaks of bluetongue (Genus: Orbivirus) and Akabane (Genus: Orthobunyavirus) viruses, both non-zoonotic viruses. The main conclusion of these authors was that the outbreaks and seroconversion occurred only following the Persian through air-stream system, in spite of the main vector's, Culicoides (Avaritia) imicola, previous presence (March and April months) and without correlation to the amount of precipitation in the spring season. If these results are correct, other more sever zoonotic bunyaviridae may travel vectorially long distances and may spread geographically further.

The genus Hantaviruses (Bunyaviridae transmitted by infectious aerosolized saliva or excreta of rodents) is a group of at least 25 antigenically distinct viruses that do not cause evident illness but only some pathology in their reservoir hosts (Netski et al., 1999)(Table 3.3.2).

Field data suggest that transmission in host populations occurs horizontally and that this occurs more frequently among male than female rodents (Glass et al., 1998). All Hantaviruses known to cause hantavirus pulmonary syndrome (HPS) are carried by New World rats and mice of the family Muridae, subfamily Sigmodontinae, that contains at least 430 species widespread in North and South America (Schmaljohn and Hjelle, 1997). In Argentina there are increasing reports of the geographic expansion of these viruses resulting in more cases of Andes virus (Bellomo et al., 2009). Rodent-borne viruses' prevalence and transmission factors were categorized into five major classes: (1) Environmental (weather and food supply) that impacts transmission rates (reproductive success and population densities); (2) Anthropogenic (disturbance by agricultural activity) that cause decreased diversity and increase of opportunistic species; (3) Genetic (impacts mice susceptibility to infection by chronic shedding); (4) Behavioral (male and female mice relations such as fighting and communal nesting) (Kariwa et al., 1996) and (5) Physiologic (host response to infection and infectivity duration) (Mills, 2005). 
Table 3.3.2 Genus hantaviruses and their rodent/insectivore hosts.

\begin{tabular}{|c|c|c|c|}
\hline $\begin{array}{l}\text { Hantaviruses } \\
\text { species }\end{array}$ & $\begin{array}{l}\text { Rodent or } \\
\text { Insectivore Host }\end{array}$ & $\begin{array}{l}\text { Hantaviruses } \\
\text { species }\end{array}$ & $\begin{array}{l}\text { Rodent or } \\
\text { Insectivore Host }\end{array}$ \\
\hline Amur & $\begin{array}{l}\text { Apodemus } \\
\text { peninsulae (Korean } \\
\text { wood mouse) }\end{array}$ & Jemez Springs & $\begin{array}{l}\text { Sorex monticolus } \\
\text { (dusky shrew ) }\end{array}$ \\
\hline Andes & $\begin{array}{l}\text { Oligoryzomys } \\
\text { longicaudatus } \\
\text { (long-tailed pygmy } \\
\text { rice rat) }\end{array}$ & Juquitiba & $\begin{array}{l}\text { Oligoryzomys } \\
\text { nigripes (black-footed } \\
\text { pygmy rice rat) }\end{array}$ \\
\hline $\begin{array}{l}\text { Laguna Negra } \\
\text { (Andes virus variant) }\end{array}$ & $\begin{array}{l}\text { Calomys laucha (no } \\
\text { common name) }\end{array}$ & Khabarovsk & $\begin{array}{l}\text { Microtus fortis } \\
\text { (reed vole) }\end{array}$ \\
\hline $\begin{array}{l}\text { Lechiguanas (Andes } \\
\text { virus variant) }\end{array}$ & $\begin{array}{l}\text { Oligoryzomys } \\
\text { flavescens (yellow } \\
\text { pygmy rice rat) }\end{array}$ & Muleshoe & $\begin{array}{l}\text { Sigmodon hispidus } \\
\text { (cotton rat) }\end{array}$ \\
\hline $\begin{array}{l}\text { Oran (Andes virus } \\
\text { variant) }\end{array}$ & $\begin{array}{l}\text { Oligoryzomys } \\
\text { longicaudatus } \\
\text { (long-tailed colilargo) }\end{array}$ & Prospect Hill & $\begin{array}{l}\text { Microtus } \\
\text { pennsylvanicus } \\
\text { (meadow vole) }\end{array}$ \\
\hline $\begin{array}{l}\text { Rio Mamore (Andes } \\
\text { virus variant) }\end{array}$ & $\begin{array}{l}\text { Oligoryzomys } \\
\text { microtis (small-eared } \\
\text { pygmy rice rat) }\end{array}$ & Puumala & $\begin{array}{l}\text { Myodes glareolus } \\
\text { (bank vole) }\end{array}$ \\
\hline Araraquara virus & $\begin{array}{l}\text { Bolomys lasiurus (no } \\
\text { common name) }\end{array}$ & Rio Segundo & $\begin{array}{l}\text { Reithrodontomys } \\
\text { mexicanus (Mexican } \\
\text { harvest mouse) }\end{array}$ \\
\hline Ash River & $\begin{array}{l}\text { Sorex cinereus } \\
\text { (masked shrew) }\end{array}$ & $\begin{array}{l}\text { Saaremaa } \\
\text { (or DOBV-Aa) }\end{array}$ & $\begin{array}{l}\text { Apodemus agrarius } \\
\text { (striped field mouse) }\end{array}$ \\
\hline Bayou & $\begin{array}{l}\text { Oryzomys palustris } \\
\text { (rice rat) }\end{array}$ & Seewis & $\begin{array}{l}\text { Sorex araneus } \\
\text { (Eurasian common } \\
\text { shrew) }\end{array}$ \\
\hline Black Creek Canal & $\begin{array}{l}\text { Sigmodon hispidus } \\
\text { (cotton rat) }\end{array}$ & Seoul & $\begin{array}{l}\text { Rattus norvegicus } \\
\text { (Norway rat); Rattus } \\
\text { rattus (black rat) }\end{array}$ \\
\hline Bloodland Lake & $\begin{array}{l}\text { Microtus ochrogaster } \\
\text { (prairie vole) }\end{array}$ & Sin Nombre & $\begin{array}{l}\text { Peromyscus } \\
\text { maniculatus } \\
\text { (deer mouse) }\end{array}$ \\
\hline Camp Ripley & $\begin{array}{l}\text { Blarina brevicauda } \\
\text { (northern short-tailed } \\
\text { shrew) }\end{array}$ & $\begin{array}{l}\text { Monongahela } \\
\text { (Sin Nombre virus } \\
\text { variant) }\end{array}$ & $\begin{array}{l}\text { Peromyscus } \\
\text { maniculatus (deer } \\
\text { mouse) }\end{array}$ \\
\hline Choclo & $\begin{array}{l}\text { Oligoryzomys } \\
\text { fulvescens (fulvous } \\
\text { pygmy rice rat) }\end{array}$ & $\begin{array}{l}\text { New York (Sin } \\
\text { Nombre virus variant) }\end{array}$ & $\begin{array}{l}\text { Peromyscus } \\
\text { maniculatus (deer } \\
\text { mouse); P. leucopus } \\
\text { (white-footed mouse) }\end{array}$ \\
\hline Dobrava & $\begin{array}{l}\text { Apodemus flavicollis } \\
\text { (yellow-necked field } \\
\text { mouse) }\end{array}$ & Soochong & $\begin{array}{l}\text { Apodemus } \\
\text { peninsulae } \\
\text { (no common name) }\end{array}$ \\
\hline
\end{tabular}

(Continued) 
Table 3.3.2 (Continued)

\begin{tabular}{|c|c|c|c|}
\hline $\begin{array}{l}\text { Hantaviruses } \\
\text { species }\end{array}$ & $\begin{array}{l}\text { Rodent or } \\
\text { Insectivore Host }\end{array}$ & $\begin{array}{l}\text { Hantaviruses } \\
\text { species }\end{array}$ & $\begin{array}{l}\text { Rodent or } \\
\text { Insectivore Host }\end{array}$ \\
\hline El Moro Canyon & $\begin{array}{l}\text { Reithrodontomys } \\
\text { megalotis (Western } \\
\text { harvest mouse) }\end{array}$ & Tanganya & $\begin{array}{l}\text { Crocidura theresae } \\
\text { (Therese shrew) }\end{array}$ \\
\hline Hantaan & $\begin{array}{l}\text { Apodemus agrarius } \\
\text { (striped field mouse) }\end{array}$ & Thailand & $\begin{array}{l}\text { Bandicota indica } \\
\text { (bandicoot rat) }\end{array}$ \\
\hline Hu39694 & $\begin{array}{l}\text { Oligoryzomys } \\
\text { flavescens (?) (yellow } \\
\text { pygmy rice rat) }\end{array}$ & Thottapalayam & $\begin{array}{l}\text { Suncus murinus } \\
\text { (musk shrew) }\end{array}$ \\
\hline \multirow[t]{2}{*}{ Isla Vista } & $\begin{array}{l}\text { Microtus californicus } \\
\text { (California vole) }\end{array}$ & Topografov & $\begin{array}{l}\text { Lemmus sibiricus } \\
\text { (Siberian lemming) }\end{array}$ \\
\hline & & Tula & $\begin{array}{l}\text { Microtus arvalis } \\
\text { (European common } \\
\text { vole) }\end{array}$ \\
\hline
\end{tabular}

For example, rodents' host sharing by Tula virus (TULV) (Hantavirus subgroup) was recently shown in central Europe to be much more extensive than thought before, demonstrating that TULV represents a promiscuous hantavirus with a large panel of susceptible hosts, suggesting an alternative evolution mode other than a strict co-evolution (Schmidt-Chanasit et al., 2010; Plyusnin et al., 1994).

The HPS rodent hosts are in general not associated with urban environments, though some species such as deer mouse (Peromyscus maniculatus) and white-footed mouse (Peromyscus leucopus) may be found in proximity to human habitation in rural and suburban areas. Direct contact of humans with rodents' excreta or by unpredicted bite can transmit the virus (Schultze et al., 2002; Yanagihara et al., 1984; Torres-Pérez et al., 2010) and is possibly linked to certain seasons (spring-early summer) like the Sin Nombre virus in Montana rangeland (grassland and shrub-steppe habitats) close to peridomestic environments (Waltee et al., 2009). Cantoni et al. (2001) studying hantaviruses seroprevalence of rodents in southern Argentina according to seasonal variation found that summer had the highest prevalence $(59.3 \%)$ compared to spring and winter (13.7\% and 12.4\%, respectively) supporting the Montana (USA) results (Schönrich et al., 2008).

Another South American study analyzed the spatial and temporal distribution of Hantavirus Pulmonary Syndrome (HPS) cases from 1998 to 2001 in the Buenos Aires Province, Argentina. Their results showed that the spatiotemporal interaction appears to be strongly related to seasonality and the presence of particular ecological conditions. The main explanatory variables for HPS distribution cases were human population, the rodent Oxymycterus rufus' allocation and evapotranspiration. The last two variables are possibly indicators of favorable ecological conditions for the reservoirs as well for virus survival in environment (Busch et al., 2004).

Another disease caused by Hantaviruses is hemorrhagic fever with renal syndrome (HFRS) mainly by the Hantaan, Puumala, Dobrava and Seoul viruses (Papa et al., 2001). Even though viruses are present in the blood and urine of HFRS patients, no common person-to-person transmission has been ruled in cases of HPS in North America or HFRS in Eurasia (Woods et al., 2009; Kolobukhina et al., 1998). The only case of person-to-person transmission has been reported during an outbreak of Andes virus in South America (Enria et al., 1996; Padula et al., 1998; Pinna et al. 2004). This transmission pathway was recently reinforced by a brief study in which the Andes virus was shown to be more resistant to 
saliva antiviral effect than to other genus subgroups, such as Hantaan and Puumala viruses (Hardestam et al., 2009).

Linard et al. (2007) studied Puumala virus (PUUV) prevalence in Belgium in relation to landscape attributes and host abundance. A linear regression was found related to landscape configuration (e.g., deciduous forests of varying size, shape, and proximity to/connectivity with other forest patches). Other important attributes mentioned by these authors were: surrounding land cover types linked to patches connectivity and thus rodents' abundance and prevalence (e.g., the land cover matrix around forest patches), climate conditions (previous year temperature) and soil characteristics (moisture, chemistry). Their results suggest that low winter temperatures and high soil moisture favor the survival of this virus in the environment and thus the indirect transmission to bank voles (as reservoir) and humans (as deadend hosts). Kallio et al. (2006) showed experimentally that wild-type PUUV excreted by experimentally infected donor bank voles can be transmitted indirectly between rodents through contaminated beddings, and is able to maintain its infectivity to recipient voles at room temperature for 12-15 days, demonstrating that hantavirus transmission does not require direct contact between rodents, or between rodents and humans. The indirect transmission of PUUV through contaminated environment can take place among rodents for a prolonged period of time. Finally, as already pointed out by others, besides the above described factors, Puumala virus prevalence among local rodents (bank voles) depends on their abundance throughout the season (Pettersson et al., 2008). In central Paraguayan chaco, the vesper mouse (Calomys laucha), the main reservoir of another hantavirus subgroup Laguna Negra virus was reported as common in agricultural habitats and uncommon in the native forest habitat, and its population densities were greater during the dry season months and declined during the wet season (Yahnke et al., 2001; Raboni et al., 2009). Similar results were obtained in a pilot study that analyzed mosquito distribution along a 10-km transect of a West African rainforest area, which included primary forest, secondary forest, plantations, and human settlements (Junglen et al. 2009). The results of this pilot study pointed to differences in mosquito and virus prevalence in disturbed and undisturbed habitats, where disturbed habitats constitute basically human interference in pristine sites. In another geographical area (western and eastern Paraguay), a researcher reported Hantavirus clades formation according to rodents' reservoirs and land cover. A certain new viral clade was found in areas experiencing rapid land cover fragmentation and change within the interior Atlantic forest eco-regions of Paraguay (Chu et al., 2006). Here is the place to mention the Russian parasitologist and geographer E.N. Pavlovsky, who through his pioneering work, recognized the significance of landscape in the transmission of infectious diseases (Pavlovsky, 1966). Pavlovsky showed that the distribution of disease could be associated to key biotic and abiotic environmental elements, and that the landscape could be used to recognize and map the spatial and temporal patterns of disease risk. Pavlovsky also found that landscape change could be a key factor in the occurrence of disease. His research in the former USSR (of more than 30 years) coincided with a period of intensive land cover change in the country motivated by agricultural intensification and expansion. Pavlovsky also coined the term "landscape epidemiology", useful to understand the transmission dynamics of vector borne diseases, particularly those transmitted by fleas, ticks and mosquitoes. The process of Hantavirus transfer from the original natural host to an incidental host is coupled with changes in its ecology, environment and other factors that may impact the pathology of the virus. It should be remembered that seropositivity for Hantaviruses was detected in a large variety of mammals beside the main rodent hosts (Leighton et al., 2001; Nowotny, 1994). It is very possible that a second round of infection may take place when rodents come in contact with those mammals' excreta or carcasses (Amundson et al., 1985). Humans as the main incidental host reveal a modified evolutionary pressure resulting in a much more dangerous viral form (with lethal results). Therefore more studies on the influence of non-natural hosts on the ecology of hantaviruses are needed 
in order to get a clear idea of the directions that hantavirus evolution could pursue. Other pending questions related to the ecology of these viruses are: How do environmental factors, population density, and interspecific competition influence the susceptibility to and outcome of hantavirus infection in reservoir hosts? What are the limiting factors for a spillover infection and are there indications of hantavirusassociated disease in spillover-infected animals? Why do New World hantaviruses and Old World hantaviruses cause HCPS and HFRS or NE, respectively? And for example, what makes PHV nonpathogenic for humans? (Zeier et al., 2005).

In Finland, Puumala virus prevalence was also found to be clearly related to certain geographic regions. The southern part that has fewer forested areas and increased urban space (therefore lower rodent abundance) was found to have the lowest prevalence. The authors mentioned that residents from these areas possibly became infected as Finns vacation in forest and lakeside cottages located in the north (Finnish Lapland, mainly during summer and autumn) where vole' population exceeds that in the southern region (Rose et al., 2003). A recent report from Germany described a steep rise in Hantavirus infections especially in the southern part known as an endemic region for Puumala virus amplified by the bank vole (Myodes glareolus) the main animal reservoir, through increased population density (Faber et al. 2010).

Transmission from rodent to rodent is believed to occur primarily after weaning and through physical contact, perhaps through aggressive behavior, such as fighting. Studies of the genomic sequences indicate that the virus has probably evolved concurrently with its rodent host over a long period of time. The possible horizontal transmission was described by several scenarios, all linked to rodents' behavior, their nest and environmental factors, as presented in Figure 3.3.2 (Calisher et al., 2009).

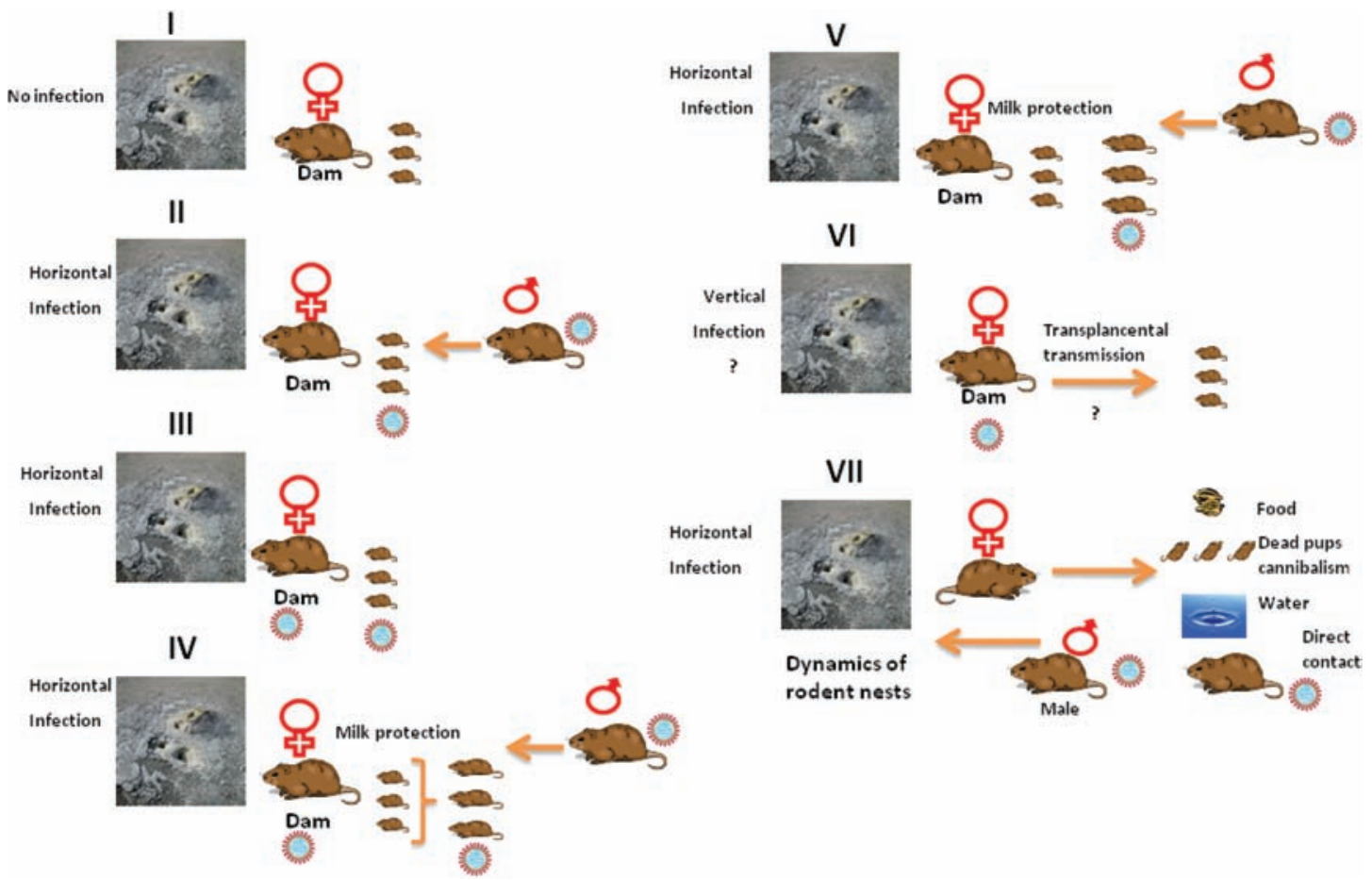

Figure 3.3.2. Different possible scenarios of rodents infection with Hantavirus 
Childs et al. (1995) conducted a case-control study in southwestern United States, where an outbreak of hantavirus pulmonary syndrome (HPS) took place. The only significant environmental factor that distinguished between cases and controls was elevated densities of small rodents in the case area (mainly heavier males), while infected rodents' prevalence was similar in both cases and controls. Transmission of the virus between rodents may occur through biting or allogrooming (saliva contains high numbers of virions) or via excreta and urine release (aerosolized during fighting) (Hinson et al., 2004). Laboratory studies with Apodemus infected with Hantaan virus (HTN) revealed shedding of this virus up to one year (Lee et al., 1981). Similar results were strengthened by data presented in a longitudinal study of the Bayou virus (BAYV) (subgroup B of Genus Hantavirus) showing excretion of viruses in saliva and excretion for at least 3 months (McIntyre et al., 2005). A third way of infection was suggested by these authors through environmental contamination with excreta by high rodent density in a certain geographical area, based on high seroprevalence detected in these high density areas. In the case of BAYV, it was shown that this virus was spatially patchy and temporally dynamic, linked to host abundance (Oryzomys palustris- rice rat) in its specific microhabitat (coastal prairie) and the lack of peridomesticity of this rodent. Concerning environmental factors, Abuzeineh et al. (2007) reported that floods did not change significantly the rice rat population density (host of BAYV) in the coastal prairie locality of southeastern Texas.

Another piece of evidence related to the impact of rodent density on Bunyaviruses human infections was described by Andes hantaviruses (ANDV) (subgroup B of Genus Hantavirus) distribution in Chile, studied in three defined eco-regions (at a latitude span of nearly $4000 \mathrm{~km}$ ), Mediterranean, Valdivian and North Patagonian rain forests, through host (O. longicaudatus) seroprevalence (Torres-Pérez et al., 2010). The authors reported that the highest relative seroprevalence in O. longicaudatus (the rodent host) was detected in the Mediterranean region, and therefore people leaving in this area were at higher risk of contracting Hantavirus cardiopulmonary syndrome (HCPS). However, from epidemiological data, the southern regions (temperate forest regions: Valdivian and Patagonia) have more cases of HCPS. One of the key explanations, according to these authors, was that these regions, in spite of their scarcer human population (by absolute numbers), has a population that is mainly rural with much closer and prevalent contact with rodent hosts, which increases the likelihood of exposure to Andes virus. Padula et al. (2004) using caged seronegative rodents that were exposed to wild seropositive individuals by freely sharing the same cage or being separated by a wire mesh. These authors reported on efficient Andes virus transmission, suggesting that this particular hantavirus may be principally transmitted via saliva or saliva aerosols rather than via feces and urine.

The ecology of rodents in terms of density was interestingly explained by Gilg et al. (2003). These authors explained the density dynamics of collared lemming in the high-Arctic tundra in Greenland where there are no food and space limitations for the lemming population and only four main predator species are available (arctic fox, snowy owl, long-tailed skua and staot). A predator-prey model clearly predicted a 4 year periodicity in lemming population dynamics. It should be remembered that the arctic environment is still a pristine one with much less human interference; however, high temperatures can change drastically this rodent cyclic balance in relation to its virus (Lemming virus). An interesting finding was reported by Holsomback et al. (2009) in relation to BAYV in United States. Seroprevalence for this virus was detected in other rodent species besides O. longicaudatus (the common host) a phenomenon called by the authors "spillover hosts". Spillover locations differed significantly from all other capture locations in terms of percent water, shrub, and grass cover. This observation was suggested for use as a predictive indicator of BAYV spillover, as $O$. longicaudatus long-lasting, virus shedding, adult males may dominate the favored habitats thereby transmitting the virus intra- and interspecific in these ecological niches. In another study, seropositive adult males were found to move farther 
(increasing their home ranges) and were larger in terms of mass and testes size in comparison to uninfected (seronegative) ones (McIntyre et al., 2009).

\subsubsection{REFERENCES}

Abuzeineh, A.A., Gwen, R.D., Mcintyre, N.E., Dick, C.W., Richard E. Strauss,R.E. \& Holsomback, T. (2007) Response of marsh rice rat (Oryzomys palustris) to inundation of habitat. Southwest. Nat. 52, 75-78.

Amundson, T.E, Yuill, T.M. \& DeFoliart, G.R. (1985) Experimental La Crosse virus infection of red fox (Vulpes fulva), raccoon (Procyon lotor), opossum (Didelphis virginiana), and woodchuck (Marmota monax). Am J Trop Med Hyg. 34, 586-595.

Balkhy, H.H. \& Memish, Z.A. (2003) Rift Valley fever: An uninvited zoonosis in the Arabian peninsula. Int. J. Antimicrob. Agents 21, 153-157.

Bellomo. C., Nudelman, J., Kwaszka, R., Vazquez, G., Cantoni, G. et al. (2009) Geographic expansion of hantavirus pulmonary syndrome in Argentina. The southernest case report. Medicina 69, 647-650.

Bird, B.H., Githinji, J.W.K., Macharia, J.M., Kasiiti, J.L., Muriithi R.M. et al. (2008) Multiple virus lineages sharing recent common ancestry were associated with a large Rift Valley fever outbreak among livestock in Kenya during 2006-2007. J. Virol. 82, 11152-11166.

Braverman, Y. \& Chechik, F. (1996) Air streams and the introduction of animal diseases borne on Culicoides (Diptera, Ceratopogonidae) into Israel. Rev Sci Tech. 15, 1037-1052.

Busch, M., Cavia, R., Carbajo, A.E., Bellomo, C., Capria, S.G. \& Padula, P. (2004) Spatial and temporal analysis of the distribution of hantavirus pulmonary syndrome in Buenos Aires Province, and its relation to rodent distribution, agricultural and demographic variables. Trop. Med. Int. Health 9, 508-519.

Calisher, C.H., Peters, C.J., Douglass, R.J. \& Kuenzi, A.J. (2009) Hantaviral infections of rodents: possible scenarios. Arch Virol 154, 1195-1197.

Cantoni, G., Padula, P., Calderón, G., Mills, J., E. Herrero, E. et al. (2001) Seasonal variation in prevalence of antibody to hantaviruses in rodents from southern Argentina. Trop. Med. Int. Health 6, 811-816.

Childs, J. E., Krebs, J.W., Ksiazek, T.G., Maupin, G.O., Gage, K.L. et al. (1995) A household-based, case-control study of environmental factors associated with hantavirus pulmonary syndrome in the southwestern United States. Am. J. Trop. Med. Hyg. 52, 393-397.

Chu,Y.K., Milligan, B., Owen, R.D., Goodin, D.G. \& Jonsson, C.B. (2006) Phylogenetic and geographical relationships of hantavirus strains in eastern and western Paraguay. Am. J. Trop. Med. Hyg. 75, 1127-1134.

Daubney, R. \& Hudson, J.R. (1932) Rift Valley fever. Lancet 1, 611-612.

Elliott, R.M. (2009) Bunyaviruses and climate change. Clin Microbiol Infect 15, 510-517.

Enria, D., Padula, P., Segura, E.L., Pini, N., Edelstein, A. et al. (1996) Hantavirus pulmonary syndrome in Argentina. Possibility of person to person transmission. Medicina (B Aires) 56, 709-711.

Ergönül O. (2006). "Crimean-Congo haemorrhagic fever". Lancet Infect Dis 6 (4): 203-214.

Faber, M.S., Ulrich, R.G., Frank, C., Brockmann, S.O., Pfaff, G.M. et al. (2010) Steep rise in notified hantavirus infections in Germany, April 2010. Euro Surveill. 15(20):pii=19574. Available online http://www. eurosurveillance.org/ViewArticle.aspx?ArticleId=19574.

Gilg,O., Ilkka Hanski, I. \& Sittler, B. (2003) Cyclic dynamics in a simple vertebrate predator-prey community. Science 302, 866-868.

Glass, G.E., Livingstone, W., Mills, J.N., Hlady, W.G., Fine, J.B. et al. (1998) Black creek canal virus infection in Sigmodon hispidus in southern Florida. Am. J. Trop. Med. Hyg. 59, 699-703.

Hardestam, J., Lundkvist, Å. \& Klingström, J. (2009) Sensitivity of Andes hantavirus to antiviral effect of human saliva. Emerging Infect. Dis. 15, 1140-1142.

Hinson, E.R., Shone, S.M., Zink, M.C., Glass, G.E. \& Klein, S.L (2004) Wounding: the primary mode of Seoul virus transmission among male Norway rats. Am. J. Trop. Med. Hyg., 70, 310-317.

Holsomback,T.S., McIntyre, N.E., Nisbett, R.A., Strauss, R.E., Chu,Y-K. et al. (2009) Bayou virus detected in non-oryzomyine rodent hosts: an assessment of habitat composition, reservoir community structure, and marsh rice rat social dynamics. J. Vector Ecol. 34, 9-21. 
Junglen, S., Kurth, A., Kuehl, H., Quan, P.-L., Ellerbrok, H. et al. (2009) Examining landscape factors influencing relative distribution of mosquito genera and frequency of virus infection. EcoHealth 6, 239-249.

Kallio, E.R., Klingström, J., Gustafsson, E., Manni, T., Vaheri, A. et al. (2006) Prolonged survival of Puumala hantavirus outside the host: evidence for indirect transmission via the environment. J. Gen. Virol. 87, 2127-2134.

Kariwa, H., Kimura, M., Yoshizumi, S., Arikawa, J., Yoshimatsu, K. et al. (1996) Modes of Seoul virus infections: persistency in newborn rats and transiency in adult rats. Arch. Virol. 141, 2327-2338.

Kolobukhina, L.V., L'vov, D.K., Skvortsova, T.M., Butenko, A.M. Gromashevskii, V.L. et al. (1998) Diseases associated with viruses of the California encephalitis serogroup, in Russia. Vopr. Virusol. 43, 14-17.

Lee, H.W., Lee, P.W., Baek, L.J., Song, C.K. \& Seong I.W. (1981) Intraspecific transmission of Hantaan virus, etiologic agent of Korean hemorraghic fever, in the rodent Apodemus agrarius. Am J Trop Med Hyg 30, 1106-1112.

Leighton, F.A., Artsob, H.A., Chu, M.C. \& Olson, J.G. (2001) A serological survey of rural dogs and cats on the southwestern Canadian prairie for zoonotic pathogens." Can. J. Public Health 92, 67-71.

Linard, C., Tersago, K., Leirs, H., \& Lambin, E.F. (2007) Environmental conditions and Puumala virus transmission in Belgium. Int J Health Geogr 6, 55 doi:10.1186/1476-072X-6-55.

McIntyre, N.E., Nisbett, R.A., Abuzeineh, A., Holsomback, T., Chu, Y-K. et al. (2009) Ecological correlates of serological status for Bayou virus in Oryzomys palustris (Rodentia: Sigmodontinae). Mastozoología Neotropical 16, 83-93.

McIntyre, N.E., Chu, Y-K., Owen, R.D., Abuzeineh, A., De La Sancha, N. et al. (2005) A longitudinal study of Bayou virus, hosts, and habitat. Am. J. Trop. Med. Hyg., 73, 1043-1049.

Meegan, J.M. (1981) Rift valley fever in Egypt: an overview of the epizootics in 1977 and 1978 .In: Swartz, T.A., Klinberg, M.A., Goldblum, N. \& Papier, C.M. (Eds.): Contributions to epidemiology and biostatistics: Rift Valley fever, S. Karger AG, Basel, pp. 100-113.

Miller, B.R., DeFoliart, G.R. \& Yuill, T.M. (1977) Vertical transmission of La Crosse virus (California encephalitis group): transovarial and filial infection rates in (Diptera: Culicidae). J. Med Entomol 14, 437-440.

Mills, J.N. (2005) Regulation of Rodent-Borne viruses in the natural host: implications for human disease. Arch. Virol. $19,45-57$.

Netski, D., Thran, B.H. \& St. Jeor, S.C. (1999) Sin Nombre virus pathogenesis in Peromyscus maniculatus. J. Virol. 73, 585-591.

Nowotny N. (1994) The domestic cat: a possible transmitter of viruses from rodents to man. Lancet 343, 921.

Padula, P., Figueroa, R., Navarrete, M., Pizarro, E., Cadiz, R. et al. (2004) Transmission study of Andes hantavirus infection in wild Sigmodontine rodents. J. Virol. 78, 11972-11979.

Padula, P.J., Edelstein, A., Miguel, S.D., López, N.M., Rossi, C.M. \& Rabinovich, R.D. (1998) Hantavirus pulmonary syndrome outbreak in Argentina: molecular evidence of person-to-person transmission of Andes virus. Virology 241, 323-330.

Pan American Health Organization (PAHO) (2010). Epidemiological alert: Outbreak of Oropouche Fever. 22 June 2010. [Accessed 9 January 2011]: Available at: http://new.paho.org/hq/index.php? option=com_content\&task=view\&id=3084\&Itemid=2206

Papa, A., Nemirov, K., Henttonen, H., Niemimaa, J., Antoniadis, A. et al. (2001) Isolation of Dobrava virus from Apodemus flavicollis in Greece. J. Clin. Microbiol. 39, 2291-2293.

Pavlovsky, E.N. (1966) Natural nidality of transmissible diseases, with special reference to the landscape epidemiology of zooanthroponoses. University of Illinois Press. Urbana, Ill.

Pepin, M., Bouloy, M., Bird, B.H., Kemp, A. \& Paweska, J. (2010) Rift Valley fever virus (Bunyaviridae: Phlebovirus): an update on pathogenesis, molecular epidemiology vectors, diagnostics and prevention. Vet. Res. 41, 61 DOI: $10.1051 /$ vetres/2010033

Pettersson, L., Boman, J., Per Juto, P., Evander, M. \& Ahlm, C. (2008) Outbreak of Puumala Virus Infection, Sweden. Emerging Infect. Dis. 14, 808-810.

Pinna, D.M., Martinez, V.P., Bellomo, C.M., Lopez, C. \& Padula, P. (2004) New epidemiologic and molecular evidence of person to person transmission of hantavirus Andes Sout. Medicina (B Aires) 64, 43-46.

Plyusnin, A., Vapalahti, O., Lankinen, H., Lehvaslaiho, H., Apekina, N. et al. (1994) Tula virus: a newly detected hantavirus carried by European common voles. J. Virol. 68, 7833-7839. 
Raboni, S.M., de Borba, L., Hoffmann, F.G., de Noronha, L., Azevedo, M.L.V. et al. (2009) Evidence of circulation of Laguna Negra-like hantavirus in the CentralWest of Brazil: Case report. J. Clin. Virol. 45, 153-156.

Rose, A., Vapalahati, O., Lyytikäinen, O. \& Nuorti, P. (2003) Patterns of Puumala virus infection in Finland. Euro Surveill. 8(1):pii=394 (online http://eurosurveillance.org/ViewArticle.aspx?ArticleID=394.

Schmaljohn, C. \& Hjelle, B. (1997) Hantaviruses: A global disease problem. Emerg. Infect. Dis. 3, 95-104.

Schmidt-Chanasit, J., Essbauer, S., Petraityte, R., Yoshimatsu, K., Tackmann, K. et al. (2010) Extensive host sharing of central European Tula virus. J. Virol. 84, 459-474.

Schönrich, G., Rang, A., Lütteke, N., Raftery, M.J., Charbonnel, N., Ulrich, R.G. (2008) Hantavirus-induced immunity in rodent reservoirs and humans. Immunol Rev 225, 163-189.

Schultze, D., Lundkvist, A., Blauenstein, U. \& Heyman, P. (2002) Tula virus infection associated with fever and exanthema after a wild rodent bite. Eur J Clin Microbiol Infect Dis. 21, 304-306.

Song, J-W., Baek, L.J., Schmaljohn, C.S. \& Yanagihara, R. (2007) Thottapalayam virus, a prototype shrewborne hantavirus. Emerging Infect. Dis.13, 980-985.

Tesh, R.B. (1994) The Emerging Epidemiology of Venezuelan Hemorrhagic Fever and Oropouche Fever in Tropical South America. Ann. N. Y. Acad. Sci. 740,129-137.

Thompson, W.H. \& Beaty, B.J. (1977) Veneral transmission of La Crosse (California encephalitis) arbovirus in Aedes triseriatus mosquitoes. Science 196, 530-531.

Torres-Pérez, F., Wilson, L., Collinge, S.K., Harmon, H., Ray, C. et al. (2010) Sin Nombre virus infection in field workers, Colorado, USA. Emerging Infect. Dis.16, 308-310.

Torres-Pérez, F., Palma, E.R., Hjelle, B., Ferrés, M., Cook, J.A. (2010) Andes virus infections in the rodent reservoir and in humans vary across contrasting landscapes in Chile. Infect. Genet. Evol. 10, 820-825.

Ullmann, L.S., Souza, L.C. \& Langoni, H. (2008) Hantaviruses as emergent zoonoses. J Venom Anim Toxins Incl Trop Dis 14, 558-571.

Waltee,D., Lonner, B.N., Kuenzi, A.J. \& Douglass, R.J. (2009) Seasonal dispersal patterns of sylvan deer mice (Peromyscus Maniculatus) within Montana rangelands. J Wildl Dis. 45, 998-1007.

Woods, C., Palekar, R., Kim, P., Blythe, D., de Senarclens, O. et al. (2009) Domestically acquired Seoul virus causing hemorrhagic fever with renal syndrome-Maryland, 2008. Clin. Infect. Dis. 49, e109-112.

Yahnke, C.J., Meserve, P.L., Ksiazek, T.G. \& Mills, J.N. (2001) Patterns of infection with Laguna Negra virus in wild populations of Calomys laucha in the central Paraguayan chaco. Am. J. Trop. Med. Hyg., 65, 768-776.

Yanagihara, R., Gajdusek, D.C., Gibbs Jr., C.J. \& Traub, R. (1984) Prospect Hill virus: serological evidence for infection in mammalogists. New England Journal of Medicine 310, pp. 1325-1326

Zeier, M., Handermann, M., Bahr, U., Rensch, B., Müller, S. et al. (2005) New ecological aspects of hantavirus infection: a change of a paradigm and a challenge of prevention - a review. Virus Genes 30, 157-180. 


\section{Chapter 3.4}

\section{Reoviruses}

\section{[COLTIVIRIDAE AND ORBIVIRIDAE]}

Reoviridae is a family of non-enveloped spherical viruses, with icosahedral capsid symmetry built of an outer and inner protein shell, $60-80 \mathrm{~nm}$ in diameter, containing a segmented (ds) RNA as genetic material. This family is divided into two subfamilies: Sedoreovirinae (smooth capsid) and Spinoreovirinae (spiked capsid). The genus Coltiviridae belong to Sedoreovirinae while genus Orbiviridae belong to Spinoreovirinae (Attoui et al., 2002). Both Coltivirus and Orbivirus are important zoonotic diseases transmitted by ticks (Ixodes spp.). Coltiviruses contain two major zoonotic viruses: Colorado tick fever virus (CTFV) and Eyach virus. CTFV is present in the Rocky Mountains, Colorado and western provinces of Canada with seasonal occurrence (spring and summer). The important reservoirs are: ground squirrels, western chipmunks, wood rats and deer mice. The vector of this virus is the hard-shell tick named Dermacentor andersoni that can be found at high elevations (between 1,500 to $3,000 \mathrm{~m}$ ). The clinical symptoms are: fever (50\% biphasic fever), headache, myalgias, photophobia, malaise, nausea, retro-orbital pain, hemorrhagic manifestation and rarely in children affected CNS (meningitis and encephalitis).

\subsubsection{REOVIRUSES AND ENVIRONMENT}

Colorado tick fever and Eyach viruses (genus Coltivirus) and Kemerovo and Lipovnik viruses (genus Orbivirus) are recognized as zoonotic viruses transmitted by ticks (Emmons, 1988). Direct contact with infected animals or tissue or via blood transfusion has been also documented (Randall et al., 1975). Colorado tick fever virus (CTFV) is spread in North America along the west coast, while Eyach virus is geographically distributed in France, Germany, Netherlands, Czech Republic (Rehse-Kupper et al., 1976; Chastel, 1998; Chastel et al., 1993; Chastel et al., 1984) and Kemorovo and Lipovnik viruses in Russia, Czech Republic, Slovakia, Austria, Scotland, Macquarie Island (Australia), Peru, Morocco, (Nuttall et al., 1981; Doherty et al., 1975; Clifford et al., 1980; Hubalek et al., 1986; Chastel et al., 1982, 1993).

Hubalek et al. (1986) studied seroprevalence against Lipovnik virus humans and domestic animals (goats, sheep and cattle) in the Roznava district (formerly Czechoslovakia). 30\% of the inhabitants were 
positive for antibodies against this virus, while $88 \%$ of goats, $55 \%$ of sheep and $45 \%$ of cattle. They also looked for the ectoparasites (Ixodes ricinus, Dermacentor marginatus, Haemaphysalis punctata and the louse-flies Melophagus ovinus) for infection with this virus. Only an Ixodes ricinus male and female from cattle were found to harbor two virus strains antigenically related to Lipovnik and Tribec viruses that belong to the Kemerovo viruses group. Chastel et al. (1982) also looked for seroprevalence in small mammals (rodents and insectivors) in Morocco for arboviruses. Using a complement fixation test, they found an Apodemous sylvaticus positive for a Kemerovo group virus. Eyach viruses or closely related viruses had been isolated in Germany and France from Ixodes ricinus and Ixodes ventalloi, respectively.

From the gender point of view, Colorado tick fever is more associated with human males (age 20 to 40) a fact that reflects leisure activities, such as fishing, hunting, lumbering and tracking. The tick vector $(D$. andersoni) has seasonal occurrence (from late February or early March to early November, but mostly May through July). The host-seeking activity in endemic areas depends on region, climate, cyclical vector and host abundance (human and animals activity). D.andersoni is the main virus reservoir through transstadial (without proved transovarial) transmission and survival for up to three years. From human case records, a sharp endemic area can be drawn for this tick vector from British Columbia and Alberta toward south along the Pacific coast states to New Mexico. The variable vegetation (e.g., sagebrush-juniper-pine containing moderate shrubs, herbs and grass cover) near streams and rocky hillsides (mainly on south-facing slopes) support both the vector and the host encounter and virus transmission and spread. Involvement of porcupines (Erethizon dorsatum) as another important host of Colorado tick fever in Rocky Mountain National Park was also studied (McLean et al., 1993). Among 20 animals not one carried CTFV but 17 had neutralizing antibody against it, revealing exposure to this virus in this ecosystem. Another important question related to climate is: What is happening with the virus in hibernating infected hosts? Experimentally, viremia had been shown to persists up to 160 days in squirrels ( $S$. lateralis) that hibernate for 4 months. Viremia persisted in these squirrels up to 47 days after their arousal (Emmons, 1966). Virus persistence in dormant host and/or nymphal and adult ticks is a highly possible way to survive through winter climate.

An interesting study has been carried out on the wood tick (Dermacentor andersoni) and its host-seeking microhabitats in two canyons: Poudre and Rocky Mountain (National Park) of Larimer county, CO, USA (Eisen et al., 2008). These authors reported that a certain vegetation (big sagebrush- Artemisia tridentate) can serve as a general indicator of high risk exposure to $D$. andersoni ticks, both sharing the same climate. Open grass, bordering rocks and shrubs had the highest host-seeking D. andersoni adult' number. Sampling sites in Rocky Mountain National Park in comparison to Poudre Canyon were characterized by more intense usage by elks (Cervus elaphus) and reduced brush coverage, and size and abundance of adult host-seeking ticks. These authors, speculated that due to the tremendous elk population increase in Rocky Mountain National Park over several decades, an ecological cascade evolved, i.e. overgrazing, rodent population suppression, tick abundance drop and therefore reduced risk of human exposure. This phenomenon is supported by another study on Theileria parva (a parasitic protozoan that causes East Coast fever-theileriosis in cattle, an important economic disease of cattle in Africa) carried by $R$. appendiculatus (the tick vector) in Zimbabwe (Norval et al., 1985). The authors reported that overgrazing resulted in a non-uniform distribution of ticks: high prevalence in commercial farming areas and very low in most overgrazed communal farming areas (Figure 3.4.1).

Clifford et al. (1980) redescribed the tick Ornithodoros (Alectorobius) amblus found on the Pacific coast and on offshore islands of Peru using as hosts several bird species, besides humans. This tick was reported to harbor Huacho virus (Reoviridae, genus Orbivirus, Kemerovo serogroup), possibly transmitting this virus to its hosts or even to spiders and lizards that prey on it. An observed side effect by the authors was that high 
density population of ticks can cause breeding birds to desert their nests, resulting in damage to Peruvian guano industry.

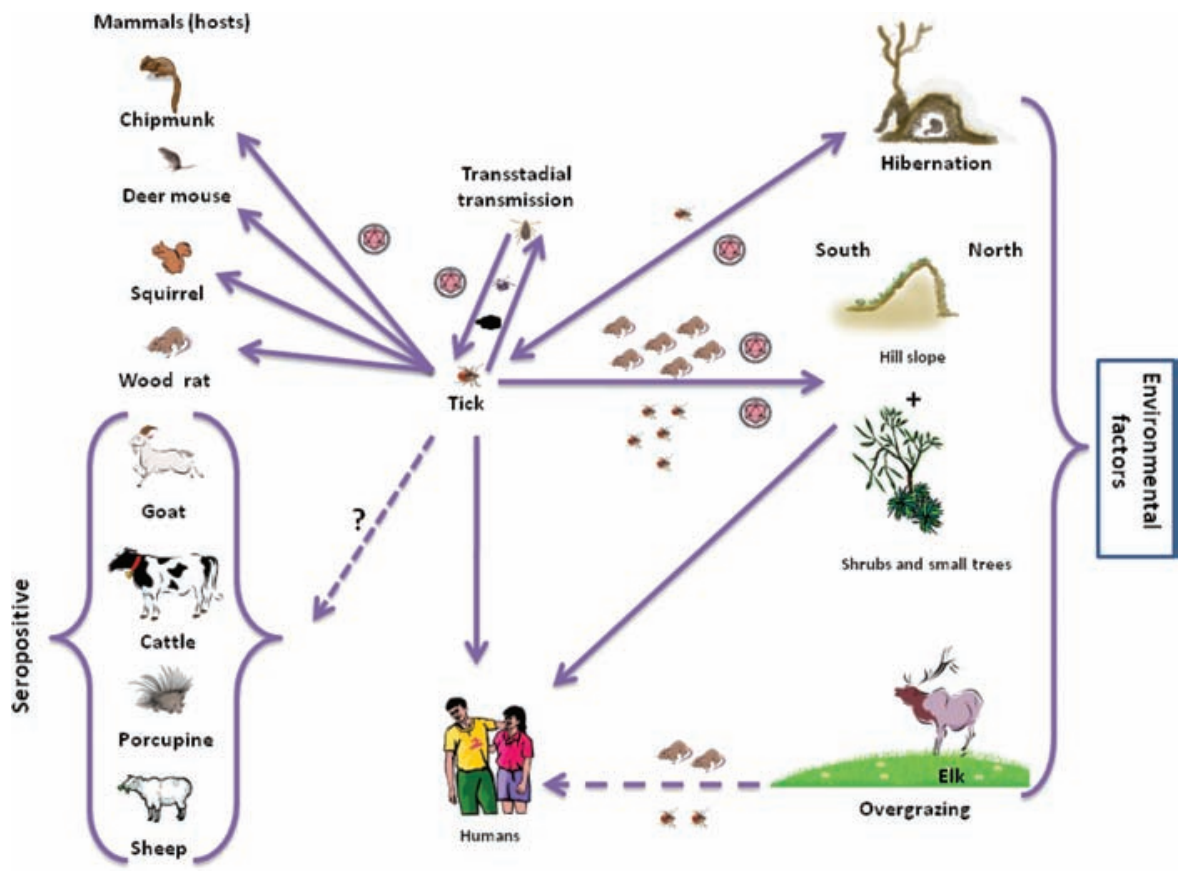

Figure 3.4.1. Host, transmission and environmental aspects of zoonotic reoviruses

\subsubsection{REFERENCES}

Attoui, H., Mohd Jaafar, F., Biagini, P., Cantaloube, J.-F., de Micco, P. et al. (2002) Genus Coltivirus (family Reoviridae): genomic and morphologic characterization of OldWorld and NewWorld viruses. Arch Virol 147, 533-561.

Chastel, C., Launay, H., Bailly-Choumara, H., Le Lay, G. \& Beaucournu, J.C. (1982) Arbovirus infections in Morocco: serosurvey in small wild mammals in the northern part of the country. Bull Soc Pathol Exot Filiales 75, 466-475.

Chastel, C. (1998) Erve and Eyach: two viruses isolated in France, neuropathogenic for man and widely distributed in Western Europe. Bull. Acad. Natl. Med. 182, 801-809.

Chastel, C., Main, A.J., Bailly-Choumara, H., Le Goff, F. \& Le Lay, G. (1993) Essaouira and Kala iris: two new orbiviruses of the Kemerovo serogroup, Chenuda complex, isolated from Ornithodoros (Alectorobius) maritimus ticks in Morocco. Acta Virol. 37, 484-492.

Chastel, C., Main, A.J., Couatarmanac'h, A., Le Lay, G., Knudson, D.L. et al. (1984) Isolation of Eyach virus (Reoviridae, Colorado tick fever group) from Ixodes ricinus and I. ventalloi ticks in France. Arch. Virol. 82, $161-71$.

Clifford, C.M., Hoogstraal, H., Radovsky, F.J., Stiller, D. \& Keirans, J.E. (1980) Ornithodoros (alectorobius) amblus (Acarina: Ixodoidea: Argasidae): identity, marine bird and human hosts, virus infections, and distribution in Peru. J. Parasitol. 66, 312-323. 
Doherty, R.L., Carley, J.G., Murray, M.D., Main, A.J.Jr., Kay, B.H. \& Domrow, R. (1975) Isolation of arboviruses (Kemerovo group, Sakhalin group) from Ixodes uriae collected at Macquarie Island, Southern ocean. Am. J. Trop. Med. Hyg. 24, 521-526.

Eisen, L., Ibarra-Juarez, L.A., Eisen, R.J. \& Piesman, J. (2008) Indicators for elevated risk of human exposure to host-seeking adults of the Rocky Mountain wood tick (Dermacentor andersoni) in Colorado. J. Vector Ecol. 33, $117-128$.

Emmons, R. W. (1966) Colorado tick fever: prolonged viremia in hibernating Citellus lateralis. Am. J. Trop. Med. Hyg. 15, 428-433.

Emmons, R.W. (1988) Ecology of colorado tick fever. Ann. Rev. Microbiol. 42, 49-64.

Hubalek, Z., Cerny, V., Mittermayer, T., Kilik, J., Halouzka, J. et al. (1986) Arbovirological survey in Silica plateau area, Roznava District, Czechoslovakia. J Hyg Epidemiol Microbiol Immunol 30, 87-98.

McLean, R.G., Carey, A.B., Kirk, L.J. \& Francy, D.B. (1993) Ecology of porcupines (Erethizon dorsatum) and Colorado tick fever virus in Rocky Mountain national park, 1975-1977. J. Med. Entomol. 30, 236-238.

Norval, R.A., Fivaz, B.H., Lawrence, J.A. \& Brown, A.F. (1985) Epidemiology of tick-borne diseases of cattle in Zimbabwe. III. Theileria parva group. Trop Anim Health Prod 17, 19-28.

Nuttall, P.A., Carey, D., Reid, H.W. \& Harrap, K.A. (1981) Orbiviruses and bunyaviruses from a seabird colony in Scotland. J. Gen. Virol. 57(Pt 1), 127-137.

Randall, W.H., Simmons, J., Casper, E.A. \& Philip, R.N. (1975) Transmission of Colorado tick fever virus by blood transfusion. Montana. Morb. Mortal.Wk/y. Rep. 24, 422-423.

Rehse-Kupper, B., Casals, J., Rehse, E. \& Ackermann, R. (1976) Eyach-an arthropod-borne virus related to Colorado tick fever virus in the Federal Republic of Germany. Acta Virol. 20, 339-342.

Theil, K.W. \& McCloskey, C.M. (1991) Rabbit syncytium virus is a Kemerovo serogroup Orbivirus. J. Clin. Microbiol. 29, 2059-2062. 


\section{Chapter 3.5}

\section{Arenavirus}

\section{[FAMILY ARENAVIRIDAE, GENUS ARENAVIRUS]}

The arenaviriuses belong to the family Arenaviridae that causes chronic infections in rodents in Africa, America, Europe and parts of Asia (Table 3.5.1). The family consists of a single genus (Arenavirus) and of fifteen species known to infect animals, five causing diseases in human (CDC $\left.{ }^{\mathrm{a}}, 2005\right)$. The virions are spherical to pleomorphic and have an approximate size of between 50 to $300 \mathrm{~nm}$ (average 110-130 nm). The genome (11 kb in size) consists of two linear(ss) RNA segments, each packed in a circular closed nuclear capsid and surrounded by a lipid envelope with embedded glycoprotein spikes.

Six arenaviruses are known to cause severe disease in humans (Table 3.5.1). LCM virus is an agent of acute central nervous system disease (Jahrling \& Peters, 1992) and congenital malformations (Barton et al., 1993) while Lassa, Junin, Machupo, Guanarito, and Sabiá viruses cause hemorrhagic fever in humans. In relation to Sabiá virus, up to now, only one known case of naturally acquired Sabiá virus infection has been documented (Gonzalez et al., 1990), while additional cases were accidental exposure of laboratory workers to this virus (Ryder et al., 1995; Barry et al., 1995, Gandsman et al., 1997), but in these cases the transmission, the reservoir host and/or vector are still unknown (Gonzalez et al., 1996).

\subsubsection{ARENAVIRUSES AND ENVIRONMENT}

In general the natural life cycle of Arenaviruses includes rodents as reservoir hosts and vectors who get chronically infected without showing any sign of illness. The virus is found in the saliva, urine, and feces of infected rodents, which remain infectious for life. Pet rodents (hamster, guinea pig, etc.) can contract infection from wild rodents that are used for pet feeding (e.g., snakes) or those intruding in human dwellings in autumn or winter (Williams \& Barker, 2001). In this case, virus transmission of the accidental individual host occurs through contaminated aerosols (rodent excreta, urine, saliva, blood) (de Manzione et al., 1998; Carballal et al., 1988), ingestion of contaminated food or via a skin lesion or a direct bite. An infected individual can pass viral infection to others (person to person transmission) via aerosol (coughing) or from direct contact with infected human body fluids (CDC $\left.{ }^{\mathrm{a}}, 2005\right)$. Infection may be also transmitted to patients who receive an organ transplant from an infected donor and in laboratory 
workers during virus handling $\left(\mathrm{CDC}^{\mathrm{b}}, 2005\right)$. The predominant groups of people who get infected are somehow involved in agricultural activities (Figure 3.5.1). Farmers get infected during the harvest season, when they are exposed to the aerosolized virus from harvesting machinery (CFSPH, 2010).

Table 3.5.1 Some features of Arenaviruses.

\begin{tabular}{llll}
\hline Virus & $\begin{array}{l}\text { Clinical } \\
\text { Manifestation }\end{array}$ & Host & Distribution \\
\hline $\begin{array}{l}\text { Lymphocytic } \\
\text { choriomeningitis } \\
\text { (LCM) }\end{array}$ & $\begin{array}{l}\text { meningitis or } \\
\text { meningoencephalitis }\end{array}$ & $\begin{array}{l}\text { Rodent (mice; Mus } \\
\text { musculus) }\end{array}$ & World wide \\
Lassa & hemorrhagic fever & $\begin{array}{l}\text { Rodent (rats; } \\
\text { (Mastomys natalensis) }\end{array}$ & Africa \\
Junin & $\begin{array}{l}\text { Argentine hemorrhagic } \\
\text { fever (AHF) }\end{array}$ & $\begin{array}{l}\text { Rodent (mice; } \\
\text { Calomys musculinus) }\end{array}$ & Argentina \\
Molivian hemorrhagic & $\begin{array}{l}\text { Rodent (mice; } \\
\text { Calomys callosus) }\end{array}$ & Bolivia \\
fever (BHF) & $\begin{array}{l}\text { Rodent (mice; } \\
\text { Venezuelan } \\
\text { hemorrhagic fever }\end{array}$ & $\begin{array}{l}\text { Zygodontomys } \\
\text { brevicauda) } \\
\text { (VHF) }\end{array}$ & Venezuela \\
& hemornown & Brazil \\
\hline
\end{tabular}

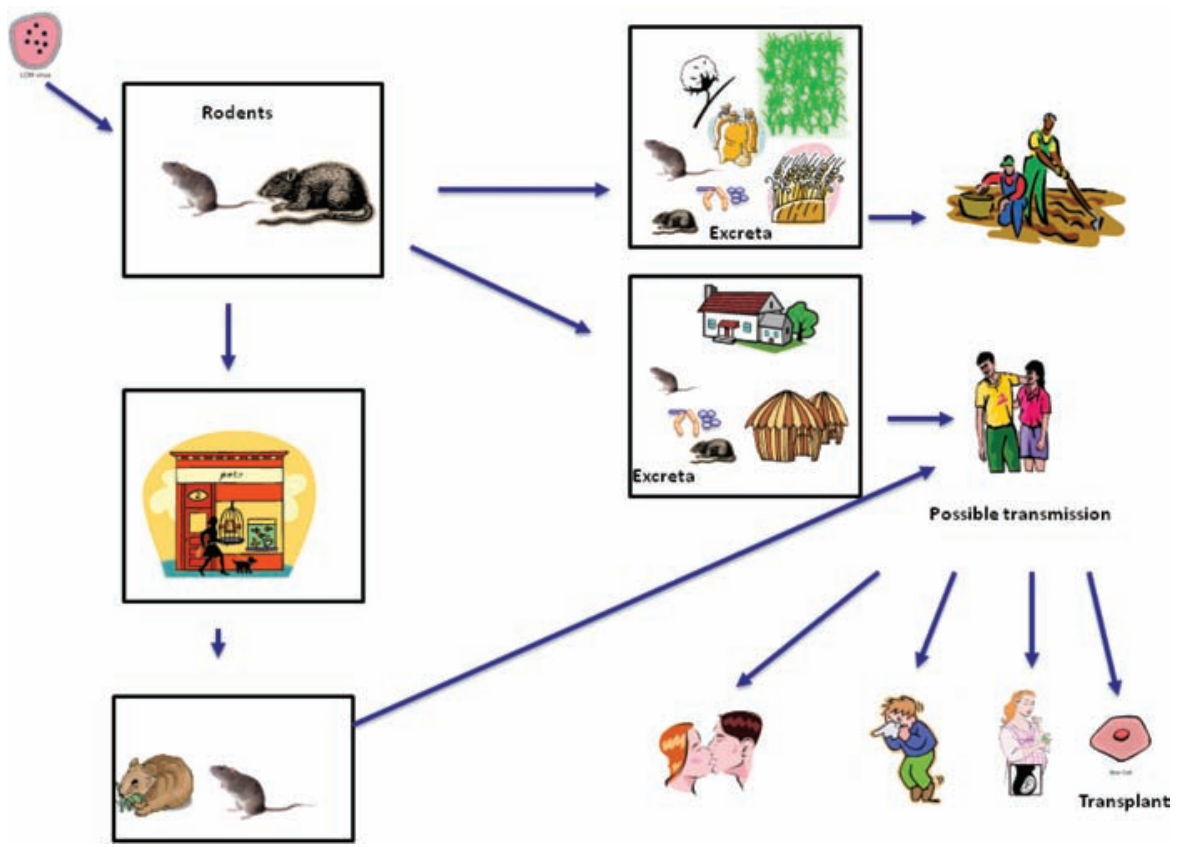

Figure 3.5.1. Arenaviruses transmission paths 
In pregnant women, Lymphocytic choriomenningitis virus infection may result in pregnancy loss or cause severe birth defects in newborns (Barton et al., 2002; Greenhow \& Weintrub, 2003; CDC, 2005).

As a result of arenaviruses' high infectivity and lethality via the aerosol route, these viruses are potential biological agents for biological warfare and terrorism (Franz et al., 2001).

The high mutation rates of the low-fidelity viral RNA-dependent RNA polymerase (RdRp) of Arenaviruses generate the existence of quasispecies, for example among lymphocytic choriomeningitis virus (LCMV) strains. The genomic heterogeneity is an environmental advantage allowing these viruses to adapt rapidly to changing environments to survive selective pressure (Sevilla \& de la Torre, 2006). Such a characteristic is aerosol stability (particularly at low relative humidity-30\% RH) and the ability to infect guinea pigs and monkeys via the respiratory route at considerable distances at a relatively low infectious dose ( $\mathrm{ID}_{50}-15$ PFU) (Stephenson et al., 1984).

In addition, one of the primary causes of hemorrhagic fever outbreaks (e.g. Lassa virus) is ecological disruption as a result of human activities. Continuous world population expansion does perturb ecosystems, facilitating closer contact between infected carrier animals (i.e. rodents) and humans. Another source of infection is poor medical hygiene hospitals (mainly in poor areas) that possibly transmit viruses nosocomially (Le Guenno, 1997).

Fichet-Calvet and Rogers (2009) carried out a spatial analysis (three models) on Lassa fever virus data based on human cases, infected rodent hosts and environmental conditions (temperature, rainfall and vegetation) for a period of 42 years. According to one of the models, Lassa fever outbreaks occurred mainly in zones receiving annual rainfall of 1,500 to 3,000 $\mathrm{mm}$. Rainfall but to a much lesser extent temperature were the most significant variables in other models, while vegetation and altitude were insignificant according to these models. Importantly, according to their models, Lassa fever virus covered $\sim 80 \%$ of Sierra Leone and Liberia, $50 \%$ of Guinea, $40 \%$ of Nigeria, $30 \%$ of Ivory Coast, Togo, Benin and only $10 \%$ of Ghana.

In six geographical areas of Nakhon Pathom Province of Thailand, rodents' seroprevalence for Arenavirus has been examined. The overall prevalence was $13.3 \%$ with higher prevalences in Bandicota savilei (35.7\%) and Rattus norvegicus (31.5\%). No significant seroprevalence diversity was reported regarding ecology, behavior and rodents' gender but geographical variability did show a significant correlation (Nitatpattana et al., 2000).

\subsubsection{REFERENCES}

Barry, M., Russi, M., Armstrong, L., Geller, D., Tesh, R. et al. (1995) Brief report: treatment of a laboratory-acquired Sabiá virus infection. N. Engl. J. Med. 333, 294-296.

Barton, L.L., Mets, M.B. \& Beauchamp, C.L. (2002) Lymphocytic choriomeningitis virus: emerging fetal teratogen. Am J Obstet Gynecol. 187, 1715-1716.

Carballal, G., Videla, C.M. \& Merani, M.S. (1988) Epidemiology of Argentine hemorrhagic fever. Eur J Epidemiol. 4, 259-274.

$\mathrm{CDC}^{\mathrm{a}}$, Center for Disease Control and Prevention (2005) Fact Sheet Arenavirus.

Available at: http://www.cdc.gov/ncidod/dvrd/spb/mnpages/dispages/Fact_Sheets/Arenavirus_Fact_Sheet.pdf

$\mathrm{CDC}^{\mathrm{b}}$, Center for Disease Control and Prevention (2005) Lymphocytic choriomeningitis virus infection in organ transplant recipients-Massachusetts, Rhode Island, MMWR Weekly 54 (Dispatch); 1-2.

$\mathrm{CDC}^{\mathrm{c}}$, Center for Disease Control and Prevention (2005) Lymphocytic Choriomenningitis Virus (LCMV) and Pregnancy Facts and Prevention. Available at: http://www.cdc.gov/ncbddd/birthdefects/documents/ LCMVQA.pdf

CFSPH, The Center for Food Security and Public Health (2010) Viral Hemorrhagic Fevers Caused by Arenaviruses. Available at: http://www.cfsph.iastate.edu/Factsheets/pdfs/viral_hemorrhagic_fever_arenavirus.pdf 
de Manzione, N., Salas, R.A., Paredes, H., Godoy, O. \& Rojas, L, (1998) Venezuelan hemorrhagic fever: clinical and epidemiological studies of 165 cases. Clin Infect Dis. 26, 308-313.

Fichet-Calvet, E. \& Rogers, D.J. (2009) Risk maps of Lassa fever in West Africa. PLoS Negl Trop Dis 3, e388.

Franz, D.R., Jahrling, P.B., McClain, D.J., Hoover, D.L., Byrne, W.R. et al. (2001) Clinical recognition and management of patients exposed to biological warfare agents. Clin Lab Med. 21, 435-473.

Gandsman, E.J., Aaslestad, H.G., Ouimet, T.C. \& Rupp, W.D. (1997) Sabia virus incident at Yale University. Am Ind Hyg Assoc J 58, 51-53.

Gonzalez, J.P., Bowen, M.D., Nichol, S.T. \& Rico-Hesse, R. (1996) Genetic characterization and phylogeny of Sabiá virus, an emergent pathogen in Brazil. Virolog. 221, 318-324.

Greenhow, T.L., \& Weintrub, P.S. (2003) Your diagnosis, please. Neonate with hydrocephalus. Pediatr Infect Dis J. 22, $1111-1112$.

Jahrling, P.B. \& Peters, C.J. (1992) Lymphocytic choriomeningitis virus. A neglected pathogen of man. Arch Pathol Lab Med 116, 486-488.

Le Guenno, B. (1997) Haemorrhagic fevers and ecological perturbations. Arch. Virol. Suppl. 13, 191-199.

Nitatpattana, N., Chauvancy, G., Jumronsawat, K., Poblap, T., Yoksan, S. \& Gonzalez, J.P. (2000) Preliminary study on potential circulation of arenaviruses in the rodent population of Nakhon Pathom Province, Thailand and their medical importance in an evoluting environment. Southeast Asian J. Trop. Med. Public Health 31, 62-65.

Ryder R.W. \& Gandsman E.J. (1995) Laboratory-acquired Sabiá virus infection. N Engl J Med 333, 1716.

Sevilla, N. \& de la Torre, J.C. (2006) Arenavirus diversity and evolution: quasispecies in vivo. Curr. Top. Microbiol. Immunol. 299, 315-335.

Stephenson, E.H., Larson, E.W. \& Dominik, J.W. (1984) Effect of environmental factors on aerosol-induced Lassa virus infection. J. Med. Virol. 14, 295-303.

Williams E.S. \& Barker I.K. (Eds.) (2001). Infectious diseases of wild mammals. $3^{\text {rd }}$ Edition. Iowa State University Press, Ames, Iowa, USA. 


\section{Chapter 3.6}

\section{Filoviridae}

\section{[ORDER MONONEGAVIRALES, FAMILY FILOVIRIDAE, GENUS MARBURGVIRUS, EBOLAVIRUS]}

Filoviridae is a family of viruses with two genera, the Ebola virus and Marburg virus. Filoviridae are enveloped -(ss) RNA viruses with a genome size of $19.1 \mathrm{~kb}$, hooded in a nucleocapsid. The virons have a filamentous or pleomorphic structure measuring about $80 \mathrm{~nm}$ in diameter and up to $1400 \mathrm{~nm}$ in length. Ebolavirus genus contains five species while Marburgviruses genus has only one species (Table 3.6.1). Filoviridae members are highly contagious, causing severe hemorrhagic fever with characteristic bleeding and high mortality rate; although outbreaks are sporadic, there is the potential for filoviruses to spread to other continents accidentally via air travel of infected individuals.

\subsubsection{FILOVIRUSES AND ENVIRONMENT}

Viruses of the Filoviridae family cause sporadic outbreaks of Ebola and Marburg Hemorrhagic Fever (HF) in Africa. Ebola HF as well as Marburg HF is a zoonotic disease transmitted accidentally by direct contact with infected live or dead humans or animals; however, the natural reservoir remains unknown. Regarding Marburg HF, only in the first simultaneous outbreak of this disease in Germany and Yugoslavia (now Serbia) could virus transmission be traced back to green monkeys (Cercopithecus aethiops) imported from Uganda for research purposes (Martini et al., 1968). All incidents or outbreaks could not be connected to a primary transmission of the virus from a natural reservoir host.

Secondary transmission (monkey to human or human to human) may occur in the surrounding community and hospital staff without appropriate precautionary measures to prevent direct contact of skin with infected organs, and droplets of fluids (blood, semen, sputum) (Martini et al., 1968; Ligon, 2005). Following cumulative evidence arising from different outbreaks, Towner et al. (2009) isolated in a recent research a Marburg virus from an Egyptian fruit bat (Rousettus aegyptiacus) living in Kitaka Cave, Uganda, thereby demonstrating that bats could be the natural reservoir of this virus. Additional indication, pointing at bats as a potential natural host, was the occurrence of several human Marburg HF incidents in miners or visitors in the vicinity of caves inhabited by fruit bats (Smith et al., 1982, Johnson 
Table 3.6.1 Some characteristics of zoonotic Filoviridae.

\begin{tabular}{|c|c|c|c|c|}
\hline Genus & Species & Distribution & $\begin{array}{l}\text { Secondary } \\
\text { Host }\end{array}$ & $\begin{array}{l}\text { Fatality rate } \\
\text { in human }\end{array}$ \\
\hline $\begin{array}{l}\text { Marburg } \\
\text { (MARV) }\end{array}$ & $\begin{array}{l}\text { Lake Victoria } \\
\text { marburgvirus }\end{array}$ & Uganda & $\begin{array}{l}\text { Vervet Monkey, } \\
\text { Human }\end{array}$ & $25 \%(C D C, 2010)$ \\
\hline \multirow[t]{5}{*}{ Ebola (EBOV) } & $\begin{array}{l}\text { Ivory Coast } \\
\text { ebolavirus } \\
\text { (CIEBOV) }\end{array}$ & $\begin{array}{l}\text { Ivory Coast, } \\
\text { Liberia }\end{array}$ & $\begin{array}{l}\text { Chimpanzees, } \\
\text { Human }\end{array}$ & $\begin{array}{l}\text { not lethal for } \\
\text { humans }\end{array}$ \\
\hline & $\begin{array}{l}\text { Reston ebolavirus } \\
\text { (REBOV) }\end{array}$ & Philippines & $\begin{array}{l}\text { Macaque, } \\
\text { Human }\end{array}$ & $\begin{array}{l}\text { not infectious for } \\
\text { humans }\end{array}$ \\
\hline & $\begin{array}{l}\text { Sudan ebolavirus } \\
\text { (SEBOV) }\end{array}$ & Sudan & Human & $\begin{array}{l}54 \% \text { (Wamala } \\
\text { et al., 2010) }\end{array}$ \\
\hline & $\begin{array}{l}\text { Zaire virus } \\
\text { (ZEBOV) }\end{array}$ & Zaire & $\begin{array}{l}\text { Fruit bats, } \\
\text { Gorilla, } \\
\text { Chimpanzee, } \\
\text { Duiker, Human }\end{array}$ & $\begin{array}{l}90 \% \text { (Sanchez } \\
\text { et al., 1995) }\end{array}$ \\
\hline & $\begin{array}{l}\text { Bundibugyo } \\
\text { ebolavirus } \\
\text { (BEBOV) }\end{array}$ & Uganda & $\begin{array}{l}\text { unknown, } \\
\text { Human }\end{array}$ & $\begin{array}{l}34 \% \text { (Wamala } \\
\text { et al., 2010) }\end{array}$ \\
\hline
\end{tabular}
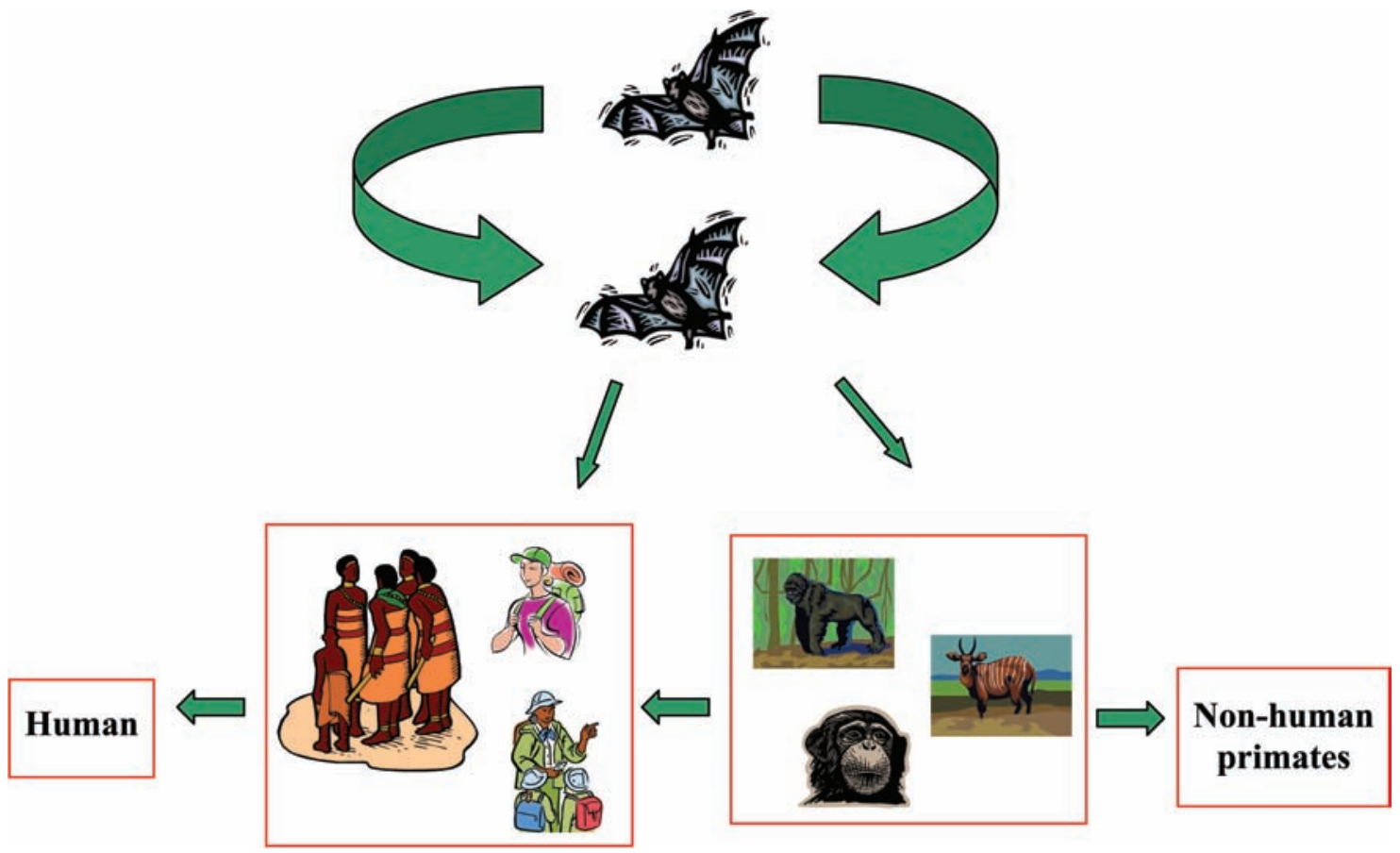

Figure 3.6.1. Filoviruses transmission pathways 
et al., 1987, Bausch et al., 2006). Over $70 \%$ of primary human infections are linked to mines or caves, implying that the natural reservoir host could be associated with these ecosystems (Towner et al., 2006). Secondary infections were observed to be transmitted to people being in proximity to an initial infected person. Marburg and Ebola virus outbreaks are sporadic, with high fatality rates and unknown natural reservoir host. Recent investigations that proposed bats as a natural reservoir host used different evidence such as geographic distribution of viral variants and the connection between bats and other virus groups (Figure 3.6.1). Specific antibodies against Ebola virus have been identified in blood samples from different bat spp. in central Africa (Pourrut et al., 2005, Swanepoel et al., 1996, Peterson et al., 2004*). The Ebola virus secondary transmission scenario is similar to that described for Marburg virus infections: index case usually connected to handling infected monkeys and further spread of the initial infection to caring family members or hospital staff (Pourrut et al., 2005).

Thus far, Marburg and Ebola HF outbreaks originate from Africa. Ecological niche modeling of outbreaks and/or isolated cases has suggested that Ebola (HF) occurs in humid rain forests of Central and Western Africa while Marburg (HF) is related to drier and more open areas of these regions (Peterson et al., 2004 \& 2006).

\subsubsection{REFERENCES}

Sanchez, A., Ksiazek, T.G., Rollin, P.E., Peters, C.J., Nichol, S.T., et al. (1995) Reemergence of Ebola Virus in Africa, EID 1, 96-97. Available at: www.cdc.gov/ncidod/EID/vol1no3/sanchez.htm.

Wamala, J.F., Lukwago, L., Malimbo, M., Nguku, P., Yoti, Z., et al. (2010) Hemorrhagic Fever Associated with Novel Virus Strain, Uganda, 2007-2008 EID 16, 1087-1092.

CDC, Center for Disease Control and Prevention (2010) Marburg Hemorrhagic Fever, Fact Sheet. Available at: http:// www.cdc.gov/ncidod/dvrd/spb/mnpages/dispages/fact_sheets/fact_sheet_marburg_ hemorrhagic_fever.pdf

Martini, G.A., Knauff, H., Schmidt, H., Mayer, G. \& Baltzer, G. (1968) A hitherto unknown infectious disease contracted from monkeys. Ger Med Mon, 13, 457, Dtsch. med. Wschr., 93, 559.

Ligon, B.L. (2005) Outbreak of Marburg hemorrhagic fever in Angola: a review of the history of the disease and its biological aspects. Semin Pediatr Infect Dis 16, 219-224.

Towner, J.S., Amman, B.R., Sealy, T.K., Reeder, C.S.A., Comer J.A., et al. (2009) Isolation of Genetically Diverse Marburg Viruses from Egyptian Fruit Bats. PLoS Pathog. 5, e1000536 1-9.

Smith, D.H., Johnson, B.K., Isaacson, M., Swanapoel, R., Johnson, K.M. et al. (1982) Marburg-virus disease in Kenya. Lancet. 1, 816-820.

Johnson, E.D., Johnson, B.K., Silverstein, D., Tukei, P., Geisbert, T.W. et al. (1996) Characterization of a new Marburg virus isolated from a 1987 fatal case in Kenya. Arch. Virol. 11, 101-114.

Bausch, D.G., Nichol, S.T., Muyembe-Tamfum, J.J., Borchert, M. et al. (2006) Marburg hemorrhagic fever associated with multiple genetic lineages of virus. N. Engl. J. Med. 355, 909-919.

Towner, J.S., Khristova, M.L., Sealy, T.K., Vincent, M.J., Erickson, B.R. et al. (2006) Marburgvirus genomics and associated with a loarge hemorrhaig fever outbreak in Angola. J. Virol. 80, 6497-6516.

Pourrut, X., Kumulungui, B., Wittmann, T., Moussavou, G., Délicat, A. et al. (2005) The natural History of Ebola virus in Africa. Microbes Infect. 7, 1005-1014.

Swanepoel, R., Leman, P.A. \& Burt, F.J (1996) Experimental inoculation of plants and animals with Ebola virus. Emerg Infect. Dis. 2, 321-325.

Peterson, A.T., Carroll, D.S., Mills, J.N. \& Johnson, A.M. (2004*) Potential mammalian filovirus reservoirs. Emerg Infect. Dis. 10, 2073-2081.

Peterson, A.T., Bauer, J.T. \& Mills, J.N. (2004) Ecologic and geographic distribution of filovirus disease. Emerging Infect. Dis. 10, 40-47.

Peterson, A.T., Lash, R.R., Carroll, D.S. \& Johnson, K.M. (2006) Geographic potential for outbreaks of Marburg hemorrhagic fever Am J Trop Med Hyg. 75, 9-15. 


\section{Chapter 3.7}

\section{Rhabdoviruses infections}

\section{[ORDER MONONEGAVIRALES, FAMILY RABDOVIRIDAE, GENUS LYSSAVIRUS, VESICULOVIRUS]}

\subsubsection{RABIES VIRUS}

[Rabies virus-lyssavirus type 1]

Rabies virus is perhaps the most notorious zoonotic virus transmitted by animal' bite to humans and probably the most fatal one. Rabies distribution is worldwide with some exceptions where it has been annihilated or was never present due to geographical morphology: insular or peninsular countries (e.g., New Zealand, Australia, UK, Japan and Scandinavia) (Figure 3.7.1). Animal import and translocation may contribute to virus introduction into non-endemic areas (Anonymous, 2008). The virus belongs to the Rhabdoviridae family and Lyssavirus genus with a cylindrical morphology, enveloped and -(ss) RNA genome ( $12 \mathrm{~kb}$ in size). The virus is neurotropic, i.e., via introduction of the virus into a muscle through an infected animal bite it will travel towards the brain through neuronal movement. Incubation of rabies can take between weeks and months while during this period the animal does not pose a risk as the virus is not excreted in saliva. When infectious particles are excreted in saliva direct contact (without bite) with skin lesions can cause rabies in humans. There are two paths for human infection: sylvatic and urban. In urban infections (mainly in developing countries), stray dogs and bats are the reservoirs and can transmit the virus. In sylvatic infections (mainly in developed countries) the main reservoirs are wild animals (e.g., bats, foxes, raccoons, jackals, wolves, stoats, etc.) as primary reservoirs and domestic animals (e.g., pet dogs and cats; sheep, horses, cattle and pigs) as secondary reservoirs for the final host, humans (Lei et al., 2009). Clinical manifestations consist of nausea, vomiting, headaches, paresthesia, bite site pain and two phases: furious and paralytic with final fatal outcome.

\subsubsection{Rabies and environment}

At the interface between animals and humans, emerging zoonoses can be classified as follows: Type 1) from wild animals to humans (e.g., Hanta, rabies viruses); Type 2) from wild animals to humans with further 
human-to-human transmission (AIDS virus); Type 3) from wild animals to domestic animals to humans (Avian flu, rabies viruses) and Type 4) from wild animals to domestic animals to humans, with further human-to-human transmission (severe acute respiratory syndrome, SARS-see chapter 3.13) (Kahn et al., 2009). Rabies virus can be spread through two main paths: directly from sylvatic animals (Type 1) and from sylvatic through domestic animals (Type 3) (Brown, 2011). Based on the literature it can be stated that bats are the most ubiquitous animal carrying the rabies virus, including in countries defined as free of canid rabies (Australia, Japan, UK, Ireland, etc.), thereby posting a future potential of reemergence! Cunha et al. (2006) surveyed bats from Sao Paulo state, Brazil and reported a prevalence range from 14.3 to $33.7 \%$, consequently raising the possibility of a high risk of infection of animals and humans related to their close environments. Sulkin et al. (1960) have shown an interesting impact of environmental temperature on bats (two species) experimentally infected with virulent rabies (one strain from a fatal human case). When these bats had been experimentally induced to hibernate, only little or no viral multiplication occurred. Transfer to a warmer room and hibernation stoppage caused the "cold storage" rabies to multiply and consequently appear at detectable levels in various tissues. These authors also showed that bat rabies virus in hibernating animals following a period of latency in those dormant animals, when activated by temperature, may reach the salivary gland more rapidly, with greater frequency, and attain higher concentrations than in animals which have not experienced a period of hibernation.

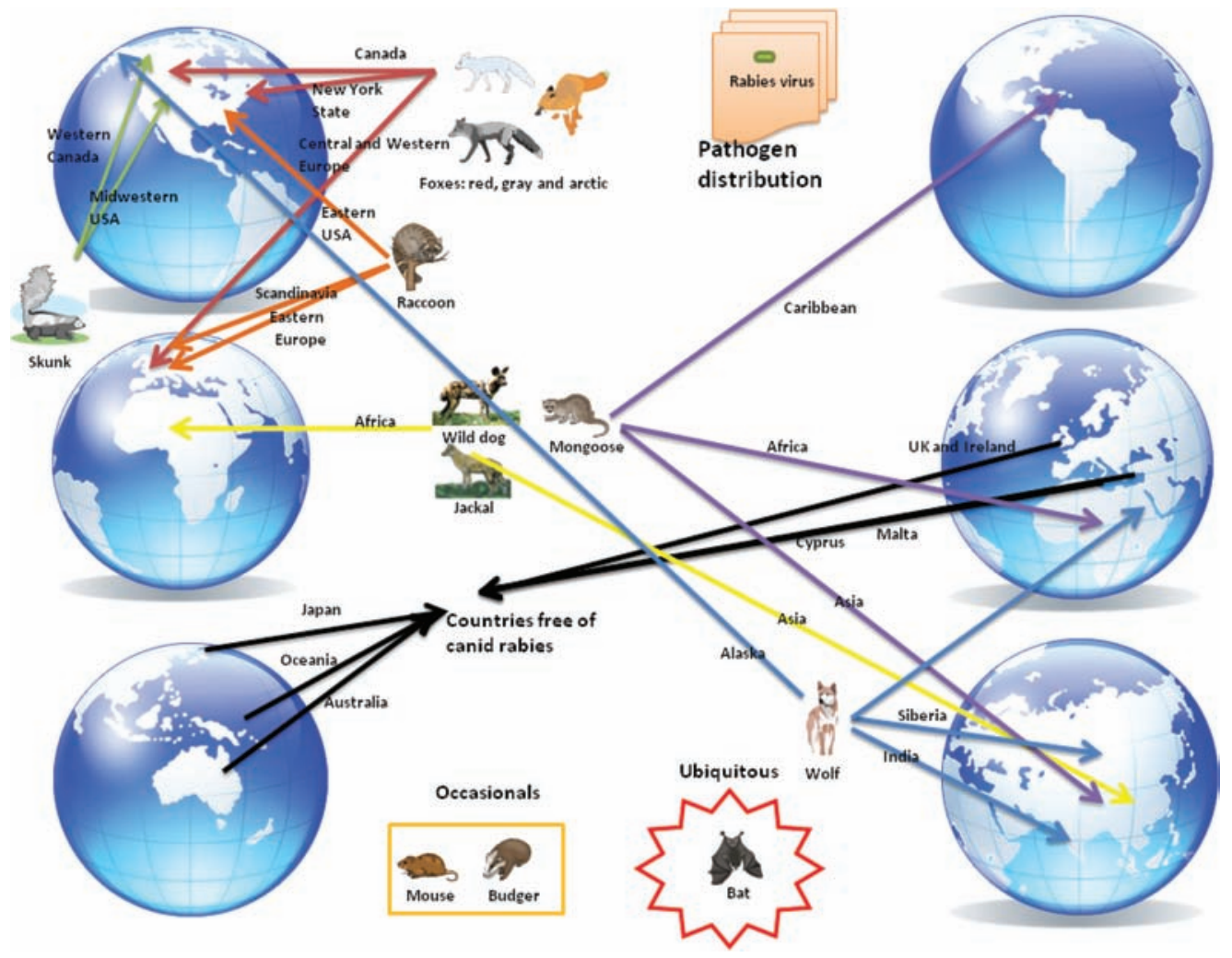

Figure 3.7.1. Global distribution of rabies virus and wildlife contributors 
In relation to environment, an interesting study was carried out on rabies infected striped skunks from central Great Plains of North America and host ecology, landscape features and two sympatric rabies strains (Barton et al., 2010). In this area, two sympatric rabies viruses shared a common host, striped skunk, circulating in this area. The two strains involved were South Central Skunk rabies strain (SCSK) that evolved from a North American bat virus and North Central Skunk rabies strain (NSCK) closely related to global dog rabies virus. The SCSK strain was found to be more infective with intense purifying selection of $\mathrm{N}$ gene (purifying selection refers to selection against non-synonymous substitutions at the DNA level), both characteristics suggesting a more transmissible strain than the NSCK strain. Being sympatric strains, the more transmissible SCSK strain seems to be more indicative of epizoosis while the NSCK of enzoosis. In relation to landscape (crossing natural barriers such as rivers) the short latency of the SCSK strain is partially restricted by landscape heterogeneity, but once it crosses the barrier the infection is more efficient among many hosts.

In relation to landscape, Hubbard (1985), following a raccoon's rabies outbreak in Loudoun County, Virginia, studied the epidemiology of the virus spread. The author suggested based on his results that reduction in favorable habitats (less rainfall) and influx of displaced raccoons caused physiological stress (intra-specific competition, hormonal and neurological changes) increasing these animals availability to rabies infection. Jones et al. (2003) assessed land use and demographic data to predict discriminatively between different close regions with epizootics of rabies among raccoons. They analyzed rabies-positive raccoon data from Maryland, Virginia and Pennsylvania versus public environmental and demographic database sources. These authors found the following parameters significantly correlated to large epizootics (expressed as odds ratio): agricultural land use (OR $=9.1$ ), high water coverage combined with low density of human population $(\mathrm{OR}=8.8)$ and low water coverage with high human population density $(\mathrm{OR}=11.7)$. Explanations for these results are simply based on human-animal encounters and environmental factors involved, i.e., agricultural land use in comparison with forested area increases the contact between the animals themselves (in this case rabid raccoons) and other animals, as well with humans. Close proximity to water has been also shown to be a critical factor in determining the quality of raccoon habitat with marshes, riparian areas, and other semi-aquatic environments supporting exceptionally high densities and linked to lower human population density.

\subsubsection{REFERENCES}

Anonymous (2008) Rabies in a dog imported from Iraq-New Jersey, June 2008. MMWR Morb. Mortal. Wkly. Rep. 57, 1076-1078.

Barton, H.D., Gregory, A.J., Davis, R., Hanlon, C.A. \& Wisely, S.M. (2010) Contrasting landscape epidemiology of two sympatric rabies virus strains. Mol Ecol. 19, 2725-2738.

Brown, K. (2011) Rabid epidemiologies: the emergence and resurgence of rabies in twentieth century South Africa. J Hist Biol 44, 81-101.

Cunha, E.M., Silva, L.H., Lara Mdo, C., Nassar, A.F., Albas, A. et al. (2006) Bat rabies in the north-northwestern regions of the state of Sao Paulo, Brazil: 1997-2002. Rev Saude Publica 40, 1082-1086.

Hubbard, D.R. (1985) A descriptive epidemiological study of raccoon rabies in a rural environment. J Wildl Dis. 21, $105-110$.

Jones, M.E., Curns, A.T., Krebs, J.W. \& Childs, J.E. (2003) Environmental and human demographic features associated with epizootic raccoon rabies in Maryland, Pennsylvania, and Virginia. J Wildl Dis. 39, 869-874.

Kahn, R.E., Clouser, D.F. \& Richt, J.A. (2009) Emerging infections: a tribute to the one medicine, one health concept. Zoonoses Public Health 56, 407-428. 
Lei, Y.L., Wang, X.G., Li, H., Chen, X.Y., Ye, B.F. et al. (2009) New animal hosts of rabies virus in mountain areas in Zhejiang province. Zhonghua liu xing bing xue za zhi 30, 344-347.

Sulkin, S.E., Allen, R., Sims, R., Krutzsch, P.H. \& Kim, C. (1960) Studies on the pathogenesis of rabies in insectivorous bats : ii. Influence of environmental temperature. J. Exp. Med. 112, 595-617.

\subsubsection{VESICULAR STOMATITIS}

\subsubsection{1 [Vesicular Stomatitis Virus-VSV, Vesiculovirus genus]}

Vesicular stomatitis virus (VSV), which infects mammals and insects, belongs to the Rabdoviridae family. Among the 20 serotypes identified, four are human pathogens: Indiana, New Jersey, Chandipura and Piry. VSV is highly contagious in horses, mules, cattle and pigs (lower frequency), but many other wild animals might be infected including sand flies (Phlebotomus). In sand flies, vertical transmission (transovarial) has been confirmed. VSV is also enveloped with a rod shape coat that contains -(ss) RNA with a size of $\sim 11 \mathrm{~Kb}$. VSV distribution has been reported in North and South America, Africa and Asia but absent is Central Europe. Transmission mode and reservoir agents are still unknown, but laboratory infections have been reported possibly linked to increased water persistence that had already been confirmed (Mahnel et al., 1977). In cattle, transmission seems to occur through milking (automatic or manual), poor hygienic conditions, the use of coarse roughage and hard-pelleted concentrates, the presence of uneaten feed (possibly contaminated with virus-laden saliva), increased interpen movement of cows and poor ground surface conditions, all poor management factors associated with clinical signs (Hansen et al., 1985). Sand fly seems to be one of the major transmission agents (therefore VSV is also called arbovirus) through persistence without cytolysis. The ability of VSV to infect arthropods as well mammals is an important feature, representing its quintessential ability to infect and perform well in multiple hosts (Novella et al., 2007). On the positive side, VSV is used as an expression vector, a basis for recombinant vaccines and recently VSV has shown oncolytic activity preferentially killing tumor cells and reducing tumors size and spread (melanoma, lung cancer, colon cancer and certain brain tumors in laboratory models) (Özduman et al., 2008; Stojdl et al., 2000). Clinical manifestations are mostly subclinical but influenza-like symptoms may develop: high fever, malaise, headache, myalgias, arthralgia, retrostenal pain, nausea, eye aches with photophobia, rarely mucosal vesicles and in some rare cases hemorrhagic fever.

\subsubsection{VSV and environment}

In recent years, it became increasingly clear that VSV is a vector-borne disease transmitted mainly by sand flies but also by other hematophagous insects such as black fly (Mead et al., 2009). Mead et al. (2004) using VSVJV (Vesicular stomatitis New Jersey virus) studied the transmission mode of these viruses by black fly. Their experimental results suggested that black flies might be infected with VSVJV via two paths connected to blood meal: 1) direct blood feed from vesicular lesions of an infected animal (in their case pigs) and 2) by cofeeding with other infected insects on an unexposed host (Mead et al., 2000). This report was the first to show that insects as vectors could become infected while feeding on infected hosts that did not express viremia. Their findings demonstrated "that during epidemics, VSNJV can circulate between livestock and black flies, and possibly other hematophagous insects, in the absence of viremic livestock hosts" (Mead et al., 2009; Lord and Tabachnick, 2002) (Figure 3.7.2.1). Recently, Smith et al. (2009) using domestic swine, have been able to prove that VSV arthropod transmission may occur although via mechanical transmission of and not only by black fly hematophagous behavior. An important factor reported almost 40 years ago, to which much less attention was paid was VSV's stability in drinking and 
surface water (Mahnel et al., 1977). At temperatures of 9 to $15^{\circ} \mathrm{C}$, VSV survived for 20 to 50 days in these waters, with survival decreasing at higher temperatures.

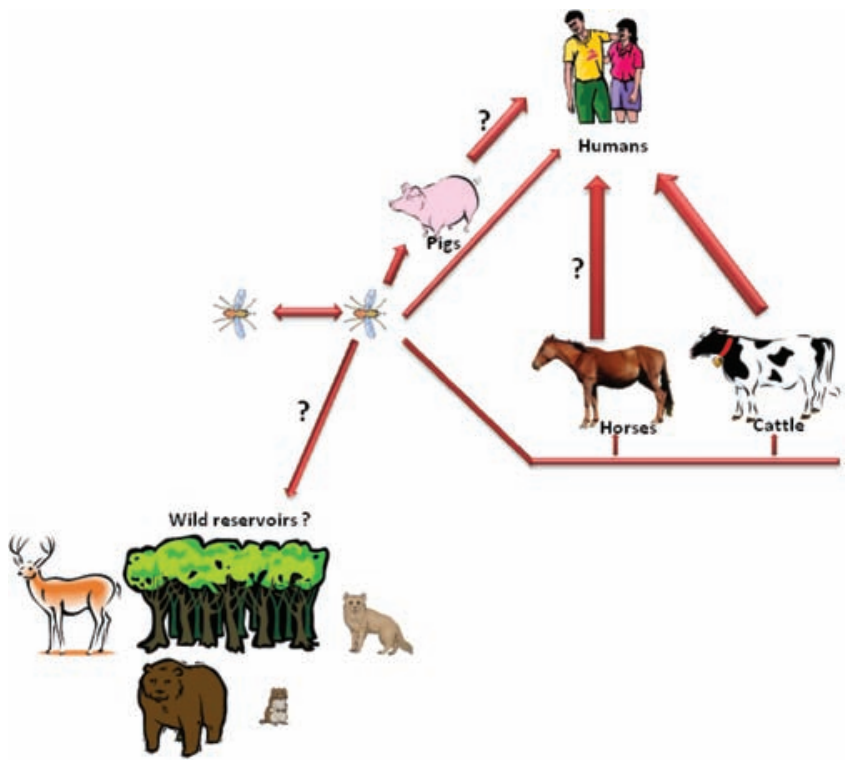

Figure 3.7.2.1. Vesicular stomatitis viruses (VSV) established and prospective infectious cycles. (Adapted from Rodriguez, 2002; question marks represent possible infective sources and reservoirs of different virus lineages also related to ecological niches)

McCluskey et al. (2003) linked climatic factors to VSV outbreaks in New Mexico, USA. Using discriminant analysis, these authors showed that increased precipitations from two months to one year previous to VSV cases are a good indicator. It seems that, like other arthropod-borne diseases, VSV spread by insects (black and sand flies) depends on temperature, precipitation and winds for its reproduction and growth (Sellers, 1980).

In another geographical area (Central America and Panama), not far away from New Mexico, Clein (1976) studied the ecological factors related to VSV in rural areas. The author reported that VSV-New Jersey seroconversion was highest "for persons living at elevations between 350 and 649 meters, with relatively open, dry vegetation and distinct seasonal alternation of dry and moist (not wet) ground conditions", while that of VSV-Indiana was highest in moist environments with dense tree cover (tropical rain forest habitats). These results suggest that VSV-New Jersey and VSV-Indiana have similar but not identical maintenance and transmission cycles (possibly due to vector developmental requirements). These results were further substantiated by a study in which VSV-New Jersey strains found in the two regions (premontane tropical moist forest and tropical dry forest) were shown to have distinct genotypes. The discovered evolutionary pattern suggested that VSV genetic divergence represents a selective adaptation to new ecological zones of this virus (Rodriguez et al., 1996). In the USA, distinct viral lineages occur in the southwestern and southeastern parts of the country (Rodriguez, 2002). The southwestern lineage seems to be closely related to viruses maintained in endemic areas of Mexico having a sporadic appearance during the last 70 years according to surveys. In comparison to 
VSV's specific ecological areas (e.g., Central America) the southwestern lineage does not have a stable endemic cycle as concluded from phylogenetic, geographical and temporal distribution of outbreaks data. It can be speculated that in such cases a wildlife reservoir exists (still undetected) that contributes to this pattern (Jimenez et al., 2000).

Vanleeuwen et al. (1995) studied cattle VSV (mainly Vesicular stomatitis New Jersey virus) prevalence in Costa Rica. They reported that VSV affected cattle were in general older and in lactation, but without predisposing diseases. Poultry presence, longer calving interval, presence of sand flies and proximity to forest land were the most significant ones related to VSV prediction.

Among other peculiarities of VSV, Bussereau (1973) reported that VSV infection of Drosophila melanogaster (the fruit fly) induces $\mathrm{CO}_{2}$ sensitivity (hypercapnia had paralyzed these flies), although some temperature recovery had been observed. What the environmental impact of this phenomenon is remains unclear as additional reports on different flies (sand or black) have not been yet reported.

Finally, Novella et al. (1995), experimenting with a wild-type strain of VSV grown continuously in sand fly tissue culture (for 10 months of continuous passages), showed that this virus increased its replicative fitness for arthropod cells but decreased its fitness for mammalian tissue cultures. However, a single passage of the arthropod-adapted virus in mammal cell culture (e.g., BHK-21 cells) at $37^{\circ} \mathrm{C}$ restored its fitness to near neutrality, as well its mouse neurovirulence. These results clearly demonstrated the enormous capacity of VSV to adapt to changing selective environments.

\subsubsection{REFERENCES}

Bussereau, F. (1973) Vesicular stomatitis virus induced carbon dioxide sensitivity in Drosophila melanogaster. III. Different serotypes of the virus. Ann. Microbiol. (Paris) 124A, 535-554.

Cline, B.L. (1976) Ecological associations of vesicular stomatitis virus in rural Central America and Panama. Am J Trop Med Hyg 25, 875-883.

Hansen, D.E., Thurmond, M.C. \& Thorburn, M. (1985) Factors associated with the spread of clinical vesicular stomatitis in California dairy cattle. Am. J. Vet. Res. 46, 789-795.

Jimenez, A.E., Vargas Herrera, F., Salman, M. \& Herrero, M.V. (2000) Survey of small rodents and hematophagous flies in three sentinel farms in a Costa Rican vesicular stomatitis endemic region. Ann. N.Y. Acad. Sci. 916, 453-463.

Lord, C.C. \& Tabachnick, W.J. (2002) Influence of nonsystemic transmission on the epidemiology of insect borne arboviruses: a case study of vesicular stomatitis epidemiology in the western United States. J. Med. Entomol. 39, 417-426.

Mahnel, H., Ottis, K. \& Herlyn, M. (1977) Stability in drinking and surface water of nine virus species from different genera (author's transl). Zentralbl Bakteriol B 164, 64-84.

McCluskey, B.J., Beaty, B.J. \& Salman, M.D. (2003) Climatic factors and the occurrence of vesicular stomatitis in New Mexico, United States of America. Rev. - Off. Int. Epizoot. 22, 849-56.

Mead, D.G., Howerth, E.W., Murphy, M.D., Gray, E.W., Noblet, R. \& Stallknecht, D.E. (2004) Black fly involvement in the epidemic transmission of vesicular stomatitis New Jersey virus (Rhabdoviridae: Vesiculovirus). Vector Borne Zoonotic Dis. 4, 351-359.

Mead, D.G., Lovett, K.R., Murphy, M.D., Pauszek, S.J., Smoliga, G. et al. (2009) Experimental transmission of vesicular stomatitis New Jersey virus from Simulium vittatum to cattle: clinical outcome is influenced by site of insect feeding. J. Med. Entomol. 46, 866-872.

Mead, D.G., Ramberg, F.B., Besselsen, D.G. \& Mar, C.J. (2000) Transmission of vesicular stomatitis virus from infected to noninfected black flies co-feeding on nonviremic deer mice. Science 287, 485-487.

Novella, I.S., Clarke, D.K., Quer, J., Duarte, E.A., Lee, C.H. et al. (1995) Extreme fitness differences in mammalian and insect hosts after continuous replication of vesicular stomatitis virus in sandfly cells. J. Virol. 69, 6805-6809.

Novella, I.S., Ebendick-Corpus, B.E., Zarate, S. \& Miller, E.L. (2007) Emergence of mammalian cell-adapted vesicular stomatitis virus from persistent infections of insect vector cells. J. Virol. 81, 6664-6668. 
Özduman, K., Wollman, G., Piepmeier, J.M. \& van den Pol, A.N. (2008). Systemic vesicular stomatitis virus selectively destroys multifocal glioma and metastatic carcinoma in brain. J. Neurosci. 28, 1882-1893.

Rodriguez, L.L. (2002) Emergence and re-emergence of vesicular stomatitis in the United States. Virus Res. 85, 211-219.

Rodriguez, L.L., Fitch, W.M. \& Nichol, S.T. (1996) Ecological factors rather than temporal factors dominate the evolution of vesicular stomatitis virus. Proc. Natl. Acad. Sci. U.S.A. 93, 13030-13035.

Sellers, R.F. (1980) Weather, host and vector-their interplay in the spread of insect-borne animal virus diseases. $J$ Hyg (Lond) 85, 65-102.

Smith, P.F., Howerth, E.W., Carter, D., Gray, E.W., Noblet, R. \& Mead, D.G. (2009) Mechanical transmission of vesicular stomatitis New Jersey virus by Simulium vittatum (Diptera: Simuliidae) to domestic swine (Sus scrofa). J. Med. Entomol. 46, 1537-15340.

Stojdl, D.F., Lichty, B., Knowles, S., Marius, R., Atkins, H. et al. (2000). Exploiting tumor-specific defects in the interferon pathway with a previously unknown oncolytic virus. Nat. Med. 6, 782-789.

Vanleeuwen, J.A., Rodriguez, L.L. \& Waltner-Toews, D. (1995) Cow, farm, and ecologic risk factors of clinical vesicular stomatitis on Costa Rican dairy farms. Am J Trop Med Hyg 53, 342-350. 


\section{Chapter 3.8}

\section{Paramyxovirus}

\section{[ORDER MONONEGAVIRALES, FAMILY PARAMYXOVIRIDAE, SUBFAMILY PARAMYXOVIRINAE, GENUS AVULAVIRUS, HENIPAVIRUS, MORBILLIVIRUS, RESPIROVIRUS, RUBULAVIRUS]}

Paramyxoviridae are enveloped, -(ss) RNA viruses with a linear genome (15-19 kb in size) and a helical, non segmented nucleocapsid. The virons are spherical to pleomorphic or filamentous, 150 to $300 \mathrm{~nm}$ in diameter with embedded glycoproteins covering virus surface involved in attachment to host cells (Enders, 1996). The family Paramyxoviridae consists of five genera; Avulavirus, Henipavirus, Morbillivirus, Respirovirus, Rubulavirus. Members of the Respirovirus and Morbillivirus genus are not zoonotic viruses causing diseases either in humans (e.g., measles) or animals (e.g., canine distemper or ovine rinderpest) and will therefore not be further discussed. Relevant zoonotic species of Paramyxoviridae family are listed in Table 3.8.1.

The genus Avulavirus contains viruses that formerly were related to genus Rubulavirus (Mayo, 2002).

\subsubsection{NEW CASTLE DISEASE AND ENVIRONMENT}

Newcastle disease virus (NDV) is one of Avulavirus genus species that causes disease in humans, migratory birds, feral pigeons and chickens. In birds, Newcastle disease (ND) is an acute infectious disease characterized by sever respiratory and digestive signs or encephalitic symptoms with a high level of mortality causing significant economic loss in the poultry industry (Cattoli et al., 2010).

In humans, NDV can cause mild conjunctivitis and influenza-like symptoms, usually among poultry farmers and veterinarians handling infected chicken or birds. Transmission of the virus occurs by direct contact with feces and secretions from the nose, mouth, and eyes or due to environmental contamination (water, food). Thus far, person to person transmission was not yet reported (Anonymous, 2004). Waterfowls are considered as important reservoirs and vectors of NDV. Various investigations showed viral infection in houseflies, probably due to the consumption of fluids and defecates of an infectious 
source or direct contact with infected birds. Therefore it was suggested that arthropods could serve as a vector in NDV transmission (Chakrabarti et al., 2007).

Table 3.8.1 Some characteristics of Paramyxoviruses.

\begin{tabular}{|c|c|c|c|c|c|}
\hline Genus & Virus & $\begin{array}{l}\text { Reservoir } \\
\text { host }\end{array}$ & Host & $\begin{array}{l}\text { Disease in } \\
\text { human }\end{array}$ & Distribution \\
\hline Avulavirus & $\begin{array}{l}\text { Newcastle } \\
\text { disease virus } \\
\text { (VDV) }\end{array}$ & $\begin{array}{l}\text { pheasant, } \\
\text { waterfowl }\end{array}$ & Chicken, Human & Conjunctivitis & Worldwide \\
\hline \multirow[t]{2}{*}{ Henipavirus } & $\begin{array}{l}\text { Hendra virus } \\
(\mathrm{HeV})\end{array}$ & Fruit bats & Horses, Human & $\begin{array}{l}\text { Acute } \\
\text { respiratory } \\
\text { syndrome, } \\
\text { encephalitis, } \\
\text { meningitis }\end{array}$ & Australia \\
\hline & Nipah virus (NiV) & Fruit bats & $\begin{array}{l}\text { Pigs, Dogs, } \\
\text { Cats, Horses } \\
\text { Human }\end{array}$ & Encephalitis & Malaysia \\
\hline Rubulavirus & $\begin{array}{l}\text { Menangle virus } \\
\text { (MenPV) }\end{array}$ & Fruit bats & Pigs, Human & $\begin{array}{l}\text { Febrile illnesses, } \\
\text { encephalitis }\end{array}$ & Australia \\
\hline
\end{tabular}

\subsubsection{MENANGLE VIRUS AND ENVIRONMENT}

In 1998, Philbey et al. described a new virus isolated from a high number of stillborn piglets with deformities in a piggery in Menangle, New South Wales, Australia. Subsequent serological investigation revealed infections in adult pigs, human workers at the affected piggery and fruit bats roosting nearby. The virus was found to be a new virus in the family Paramyxoviridae called Menangle virus after isolation site name. Worker at the above piggery who had been in contact with infected material had experienced a flu-like febrile illness with subsequent recovery (Philbey et al., 1998; Chant et al., 1998).

\subsubsection{HENDRA AND NIPHA VIRUSES AND ENVIRONMENT}

The genus Henipavirus contains two zoonotic viruses both having fruit bats as natural host; Hendra virus $(\mathrm{HeV})$, causing respiratory and neurological infection in human and respiratory infection in horses (Playford et al., 2008), and Nipah virus (NiV) causing fatal encephalitis in human and neurological and respiratory syndromes in pigs (Goh et al., 2000; Mohd Nor et al., 2000).

$\mathrm{HeV}$ that had been firstly identified in 1994 was responsible for several outbreaks of fatal diseases with elevated mortality in horses and humans in Australia between 1994 and 2008 (Selvey et al., 1995; Field et al., 2010). Humans became infected after close contact with body fluids of infected horses while fruit bats had been accepted to be $\mathrm{HeV}$ natural reservoir to transfer this virus to horses (Halpin et al., 2000). Serological investigation showed that half of fruit bat colonies located in affected regions carry antibodies against these viruses (Wild, 2009). The transmission mode from bats to horses is still unknown and remains purely hypothetical. Field et al. (2010) suggested transmission of body fluids from infected bats via contaminated feed, water or yard rails. Horse to horse transmission has been reported 
and related to contaminated surroundings with body fluids while person to person transmission was not yet reported.

First NiV outbreak was reported in Malaysia in 1998, when a viral encephalitis illness occurred among pig farmers, starting in one district and further spreading to different districts (including Singapore) due to commercial trade and transport of infected pigs (Paton et al., 1999). High mortality rates have been related to human infection through close contact with urine and feces of infected pigs. Infected fruit bats (displaying $\mathrm{NiV}$ virions in saliva and urine) located in pig farms vicinity was suspected as the natural host of this virus (Chua et al., 2002; Looi and Chua, 2007). Infection was shown to spread easily among cats, dogs and horses. Outbreaks of Henipavirus infections were also correlated with extensive deforestation behavior, slash-and-burn and El Niňo-related drought forcing the bats, the natural reservoir host, to abandon their native biotopes and approach the proximity of human habitats (Looi and Chua, 2007; Wild, 2009) (Figure 3.8.1).

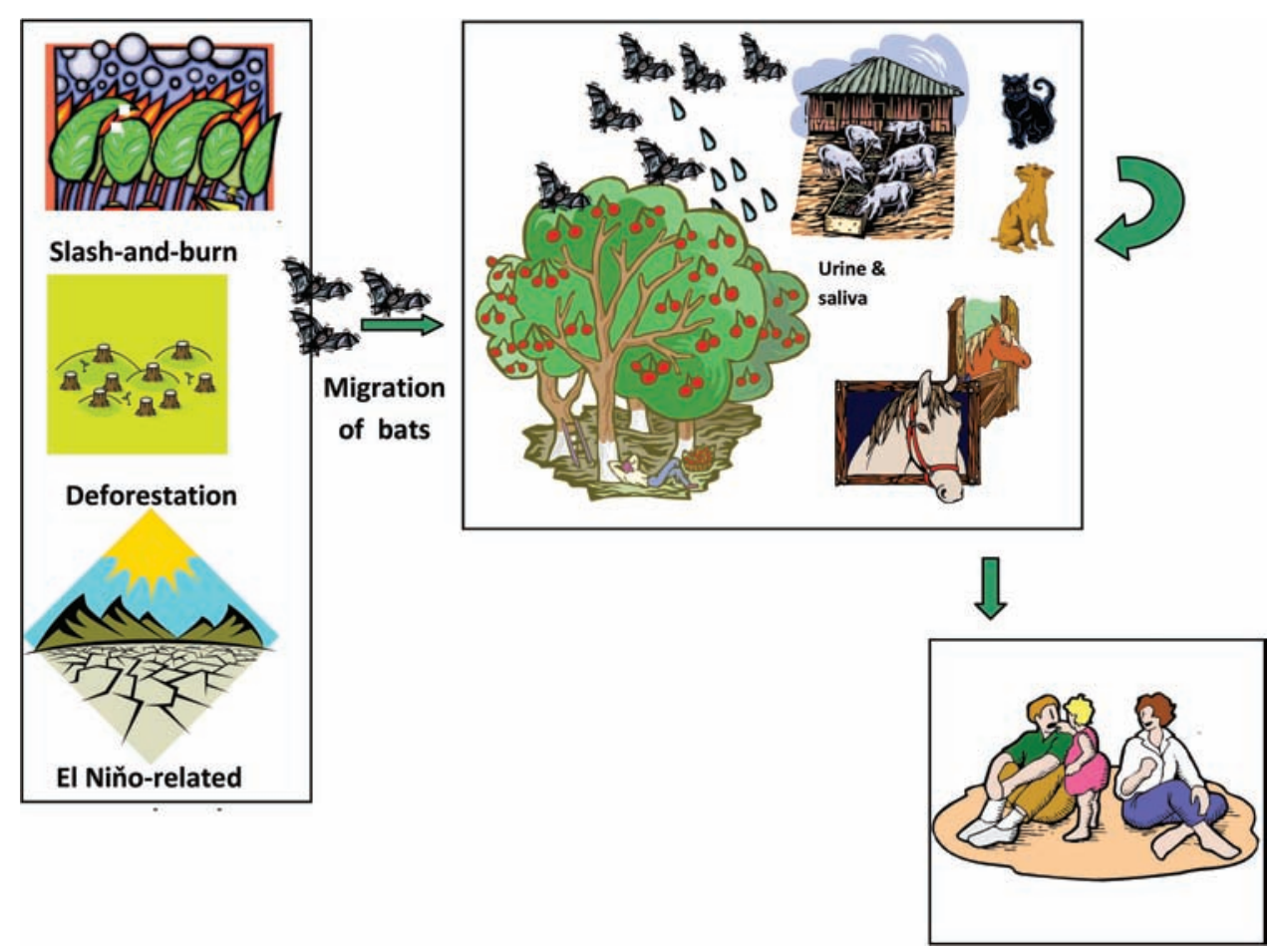

Figure 3.8.1. Henipavirus hypothetical spread

\subsubsection{REFERENCES}

Anonymous (2004), Center for Food Security and Public Health Iowa State University, 2004 Newcastle Disease. Available under: www.cfsph.iastate.edu/DiseaseInfo/ppt/NewcastleDisease.ppt.

Cattoli, G., Fusaro, A., Monne, I., Molia S., Le Menach, A. et al. (2010) Emergence of a new genetic lineage of Newcastle disease virus in West and Central Africa -Implications for diagnosis and control Vet. Microbiol. 142, $168-176$. 
Chakrabarti, S., King, D.J., Afonso, C., Swayne, D., Cardona, C.J. et al. (2007) Detection and isolation of exotic Newcastle disease virus from field-collected flies. J Med Entomol. 44, 840-844.

Chant, K., Chan, R., Smith, M., Dwyer, D.E. \& Kirkland, P. (1998) Probable human infection with a newly described virus in the family Paramyxoviridae. The NSW Expert Group. Emerging Infect. Dis. 4, 273-275.

Chua, K.B., Koh, C.L., Hooi, P.S., Wee, K.F., Khong, J.H. et al. (2002) Isolation of Nipah virus from Malaysian Island flying-foxes. Microbes Infect. 4, 145-151.

Enders, G. (1996) Paramyxoviruses. In: Baron, S. (Ed.) Medical Microbiology. $4^{\text {th }}$ edition. Galveston (TX): University of Texas Medical Branch at Galveston. Chapter 59.

Field, H., Schaaf, K., Kung, N., Simon, C., Waltisbuhl, D. et al. (2010) Hendra virus outbreak with novel clinical features, Australia. Emerging Infect. Dis. 16, 338-340.

Goh, K.J., Tan, C.T., Chew, N.K., Tan, P.S., Kamarulzaman, A. et al. (2000) Clinical features of Nipah virus encephalitis among pig farmers in Malaysia. N Engl J Med 342, 1229-1235.

Halpin, K., Young, P.L., Field, H.E. \& Mackenzie, J.S. (2000) Isolation of Hendra virus from pteropid bats: a natural reservoir of Hendra virus. J. Gen. Virol. 81, 1927-1932.

Looi, L.M. \& Chua, K.B. (2007) Lessons from the Nipah virus outbreak in Malaysia. Malays J Pathol 29, 63-67.

Mayo, M.A. (2002) Virus taxonomy - Houston 2002. Arch. Virol. 147, 1071-1076.

Mohd Nor, M.N., Gan, C.H. \& Ong, B.L. (2000) Nipah virus infection of pigs in peninsular Malaysia. Rev. - Off. Int. Epizoot. 19, 160-165.

Paton, N.I., Leo, Y.S., Zaki, S.R., Auchus, A.P., Lee, K.E. et al. (1999) Outbreak of Nipah-virus infection among abattoir workers in Singapore. Lancet 354, 1253-1256.

Philbey, A.W., Kirkland, P.D., Ross, A.D., Davis, R.J., Gleeson, A.B. et al. (1998) An apparently new virus (family Paramyxoviridae) infectious for pigs, humans, and fruit bats. Emerging Infect. Dis. 4, 269-271.

Playford, E.G., McCall, B., Smith, G., Slinko, V., Allen, G. et al. (2008) Human Hendra virus encephalitis associated with equine outbreak, Australia, 2008. Emerg Infect Dis. 16, 219-223.

Selvey, L.A., Wells, R.M., McCormack, J.G., Ansford, A.J., Murray, K. et al. (1995) Infection of humans and horses by a newly described morbillivirus. Med J Aust. 162, 642-645.

Wild, T.F. (2009) Henipaviruses: A new family of emerging Paramyxoviruses. Pathol. Biol. 57, 188-196. 


\section{Chapter 3.9}

\section{Orthomyxovirus}

\section{[SWINE INFLUENZA VIRUS H1SWN1, AVIAN INFLUENZA VIRUSES-H5N1, H7N7 AND H9N2, GENUS INFLUENZA A VIRUS]}

Swine influenza virus (H1swN1) and Avian Influenza Viruses (H5N1, H7N7 and H9N2) belong to the genus Influenza A virus (IAV). They are enveloped viruses (some pleomorphic) of a size of 80 to $120 \mathrm{~nm}$ containing segmented (6-8 segments) of - (ss) RNA of a $13.5 \mathrm{~kb}$ size. Swine influenza virus was isolated from pigs in 1930 and it was responsible for the 1918-1919 pandemic, causing more than 20 million deaths. The distribution is worldwide, with latent infections in pigs. Avian influenza virus was originally observed in 1997, in a Hong Kong outbreak with fatalities. Those viruses infecting poultry can be divided in two groups: highly pathogenic avian influenza (HPAI) (flock mortality up to $100 \%$ with subtypes $\mathrm{H} 5$ and H7) and low pathogenic avian influenza (LPAI) (mainly mild respiratory diseases) (Capua and Alexander, 2007). Avian influenza has a worldwide distribution, with latent infections of waterfowls (ducks, geese, etc.). In humans, transmission of these viruses occurs through aerosols (swine influenza virus) or direct contact with live birds (avian influenza virus) and possibly through handshake (1918-19 pandemic was a classic example of person-to-person transmission). An interesting hypothesis has been raised by Lowen and Palese (2009) in connection with influenza A virus transmission. These authors, based on previous results showing blockage of aerosol transmission by high humidity $\left(80 \%\right.$ R.H.) and temperature $\left(30^{\circ} \mathrm{C}\right)$ and the observed global seasonal behavior of this virus, hypothesized that there are two predominant modes of transmission in temperate and tropical climates. Distinctively, the aerosol mode is predominant in temperate climate while direct contact is predominant in tropical climate. Mammalian influenza viruses are more labile to environmental conditions; however, they can survive for several hours in body fluids. The avian influenza virus has a fast inactivation rate in manure though it can stay alive for up to 2 weeks in feces. Avian influenza virus can survive for 100 days in distilled water at room temperature, 200 days at $17^{\circ} \mathrm{C}$ and indefinitely when frozen. Clinical manifestations of infection with both virus types are high fever, bronchitis, pneumonia, malaise, acute myalgia and death. 


\subsubsection{SWINE INFLUENZA VIRUS AND ENVIRONMENT}

Influenza A viruses (IAV) are basically of avian origin (waterfowl and shorebirds), birds being classified as primary hosts. Among these birds, the virus is spread by fecal-oral transmission in untreated water. Frequent transmission between aquatic birds and domestic poultry occurs with emergence of highly pathogenic subtypes (e.g. H5 and H7) capable of decimating commercial poultry flocks (Webster, 1997). Interspecies transmission is less frequent; however, in environments comprising mud, water and organic material IAV undergo a high degree of genetic changes to switch hosts further (pigs, horses, humans, domestic poultry, etc.), suggesting that they may be more evolutionarily flexible than had been previously realized (Morens and Taubenberger, 2010) (Figure 3.9.1). It would not be unexpected if additional secondary reservoir hosts were found to be involved in viral maintenance, evolution, and transmission. Once IAV is established in mammals, its transmission occurs through the respiratory airborne route, therefore favoring crowded, humid and closed places as foci (Belser et al., 2010; Robinson et al., 2007). Mubareka et al. (2009) studied aerosol and fomite transmission of influenza A/Panama/2007/1999 (H3N2) among guinea pigs as models. They were able to demonstrate that aerosol transmission is a more efficient mode than fomites contact.

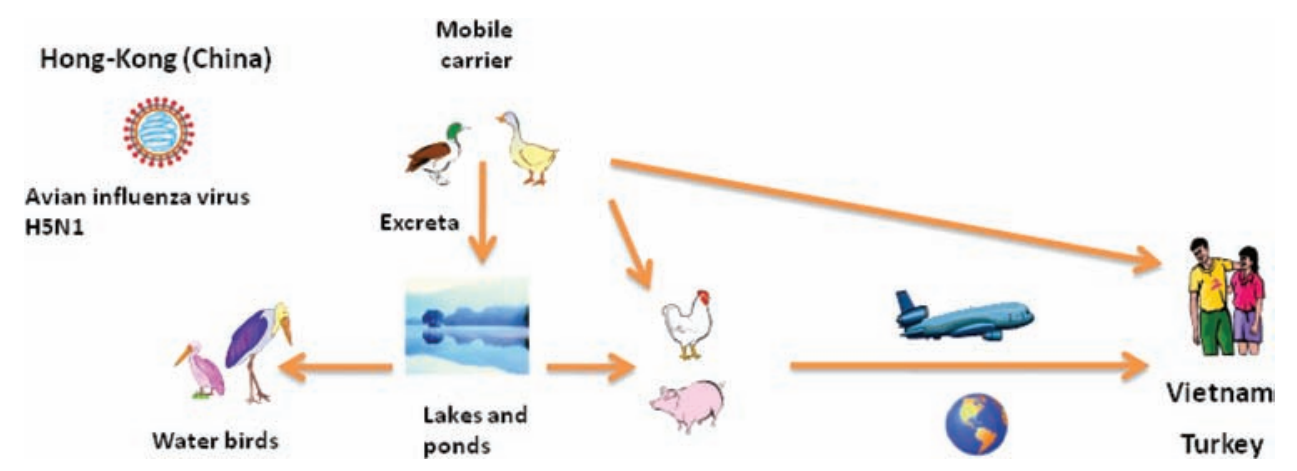

Figure 3.9.1. Transmission of Influenza A virus from waterfowls through domestic poultry and pigs to humans and rapid transmission by air-travel

Kida (1997) reported on a new pandemic strain of swine that circulated in migratory and domestic ducks in southern China. The author emphasized that pigs' co-infection with swine and avian viruses generates reassortant viruses (with genes from both viruses expressed in a new influenza virus variant). The process has been found to occur yearly in frozen lake water, a waterfowl reservoir, in the absence of ducks. Concerning a similar reassortment process in pigs, Castrucci et al. (1993) reported on influenza A virus in Italy. These authors analyzed phylogenetically the internal protein genes of classical H1N1, avian-like H1N1 and human-like H3N3 present in pigs in Italy. Indeed, the newer viruses (from a more recent pandemic) contained internal protein genes of avian-like H1N1 whereas older strains did not. These results obviously revealed that pigs could serve as "mixing vessels" for reassortment events (Ma et al., 2009). In addition, areas densely populated by pigs showed an outbreak clustering in Canada related to increased cases and virus movement among pig population (Pasma, 2008).

Conceivably, one of the main conclusions derived from the epidemiology of IAV is the separation of wild aquatic and domestic poultry and of pig and poultry farming, in order to reduce the next potential pandemic 
of influenza in humans. Potable water as a route does not seem to have a role in virus transmission, as the present water treatment strategies currently used for surface water treatment are entirely suitable for removing and/or inactivating influenza A viruses (Lenes et al., 2010).

\subsubsection{AVIAN INFLUENZA VIRUS AND ENVIRONMENT}

It is now clear that highly pathogenic avian influenza viruses are globally spread by migratory birds (Wang et al., 2008; Causey and Edwards, 2008). Different studies had also shown that the avian influenza virus can be transmitted to mammalian species (e.g., tigers, domestic cats and dogs) and also to crocodilians through ingestion of infected birds (Davis and Spackman, 2008). The significant risks of distribution and transmission of avian influenza viruses rely on competent avian hosts, their immune systems, annual cycles, feeding behaviors, migration patterns, decreased biodiversity (through active destruction and modification of wetland environments for human use) and legal and illegal trade in wild birds (Gibbs, 2010). Perez et al. (2003) showed that chickens, quails and other land-based birds that are extensively farmed are closely related to zoonotic outbreaks of avian influenza in Hong Kong through use as mixing vessels and disseminators of these viruses. These authors also demonstrated that Japanese quail could provide an environment in which H3N2 virus (A/swine/Texas/4199-2/98) could further reassort and generate influenza viruses with pandemic potential. In another study, Perez et al. (2003b) reported that quail provide an environment in which the adaptation of influenza viruses from ducks generates novel variants that can cross the species barrier.

These results are strongly supported by a study performed in Korea on live bird markets (LBMs) that provide an ideal environment for the evolution and interspecies transfer of avian influenza viruses (AIVs) (Lee et al., 2010). This study indicated that the newly evolved AIV-s have been continuously generated by reassortment in ducks, and that these reassortments could result in expanding the host range of AIVs.

Davidson et al. (2010) reported on the survival of the H9N2 strain at different temperatures (37, 20 and $4^{\circ} \mathrm{C}$ ) and $\mathrm{pH}-\mathrm{s}$ (5.0 and 7.0). This avian influenza H9N2 strain had become endemic in Israel since its introduction into this country. The authors reported that H9N2 survival decrease rapidly with temperature increase corresponding to winter outbreak occurrence. At $\mathrm{pH} 5.0$, the virus survived for one week while at $\mathrm{pH} 7.0$ it remained viable for up to three weeks (both tested at $20^{\circ} \mathrm{C}$ ).

Brown et al. (2009) studied the survival of twelve avian influenza strains isolated from wild fowl under natural ranges of $\mathrm{pH}$, salinity and temperature in water. According to their results, avian influenza viruses increased survival was dependent on slightly basic $\mathrm{pH}$-s $(7.4$ to 8.2$)$, temperatures $<17^{\circ} \mathrm{C}$ and fresh to brackish salinities ( 0 to 20,000 ppm). Conversely, Negovetich and Webster (2010) showed experimentally that the variation of thermostability of $\mathrm{H} 2 \mathrm{~N} 3$ influenza virus isolates begins at the level of the population and that the presence of highly thermostable subpopulations possibly suggests longer water persistence and better transmission susceptibility. In relation to water as an environmental factor in avian influenza virus transmission, Faust et al. (2009) showed experimentally an interesting ecosystem able to inactivate efficiently the virus present in water. These authors used the filter-feeding bivalves, Corbicula fluminea, to remove the experimentally introduced high pathogenic avian virus (A/whooper swan/Mongolia/244/05, H5N1). Wood ducks exposed to water containing HPAI but filtered through bivalves did not contract the disease while those exposed to unfiltered water exhibited morbidity or mortality. Their results indicate that filter-feeding bivalves could remove and reduce the infectivity of HPAI viruses in water. How these biotic environmental factors may influence avian influenza virus transmission requires further examination. 
According to the high fatality in the poultry industry infected with avian influenza virus, there is an urgent need to inactivate these viruses present in disposed carcasses. Graiver et al. (2009) studied the survival of H6N2 in a methanogenic landfill leachate and water as afunction of temperature, conductivity and pH. High temperatures and nonneutral $\mathrm{pH}$-s caused the fastest inactivation of this avian influenza virus, while conductivity had no impact on its survival. Leachate inactivation was similar or faster in comparison with water medium. After waste disposal, the viral inactivation rate ranged from 30 to 600 days, revealing high persistence.

Laboratory results on environmental persistence and application to field studies have been reviewed by Stallknecht et al. (2010). These authors critically reviewed the tenacity of avian influenza virus in environment compared to laboratory results, pointing at the knowledge gaps to understand the factors affecting environmental infectivity, specifically from aquatic habitats utilized by wild birds that are much more complex than the laboratory environment. Breban et al. (2009) tried to explain avian influenza persistence and periodicity in North America through an environmental transmission model. Their model consisted of host-pathogen relations based on the following factors: within-season transmission dynamics, between-season migration and reproduction and environmental variations. According to their results, the environmental transmission model supported persistence mechanism within small communities (where epidemics are not supported by direct contact), epidemics periodicity and population persistence.

Delogu et al. (2010) studied preening as an alternative route of avian influenza virus transmission. In spite of many reports on high viral loads in feces of infected birds and consequently surface water contamination, these authors questioned whether dilution and environmental conditions do not play a role in a reduced contact between virus load and aquatic birds, favoring other routes of contamination such as preening. They were able to demonstrate that feather samples and cotton swabs impregnated with preen oil attracted and concentrated avian influenza viruses, therefore pointing to the body of wild birds as a possible reservoir. This interesting study also indicates a possible direct contact between humans and birds in the poultry industry during plucking. Indeed, Busquets et al. (2010) also suggested feathers as a suitable sampling site for avian influenza virus. Yamamoto et al. (2010) strengthen this point by comparing the survival of different clades of avian influenza (H5N1) on feathers, in drinking water, and in feces collected after 3 days postinoculation and stored at $4^{\circ} \mathrm{C}$ or $20^{\circ} \mathrm{C}$. They reported a viral infectivity persistence for 160 days at $4^{\circ} \mathrm{C}$ and for 15 days at $20^{\circ} \mathrm{C}$, on feathers! This observation may also explain the report by Shivakoti et al. (2010) from Japan, of an emaciated mountain hawk-eagle infected with the highly pathogenic avian influenza (HPAI) virus subtype H5N1 and three additional outbreaks of H5N1 within three weeks that had occurred in this area, in chickens. It seems reasonable to conclude that the hawk-eagle (not an aquatic bird) contracted this highly pathogenic avian influenza virus through direct contact (feeding?) on infected chickens, as has also been shown with other experimentally infected raptors (Hall et al., 2009).

The global fatality of influenza A virus is estimated at 500,000 human deaths and many more sublethal cases. Avian viruses make a major contribution to the genetic material of human viruses (including H5N1 and H1N1). Anthropogenic changes, such as human population growth, land use, trade globalization, agricultural intensification, fast global travel and changes in vaccine technology, may impact the evolution and transmission of these viruses (Vandegrift et al., 2010). From the environmental point of view, Li et al. (2011) compiled 16 environmental variables to assess their correlation to the highly pathogenic avian virus $\mathrm{H} 5 \mathrm{~N} 1$. According to their results, the strongest positive association was with the human footprint index, certain wetland types and mild temperatures (10 to $30^{\circ} \mathrm{C}$ ). In addition, $\mathrm{H} 5 \mathrm{~N} 1$ outbreaks in poultry and wild birds were frequently connected to certain habitats (e.g., tropical and subtropical moist broadleaf forests, temperate broadleaf and mixed forests, and flooded grasslands and 
savannas) while high mountains and plateaus did not affect the speed and direction of virus transmission. Li et al. (2007) developed a new climatic approach for HPAI outbreaks by investigating prior climatic conditions of outbreaks. Their results showed that a sharp drop in temperature and dust storms exacerbate HPAI H5N1 spread.

Finally, climate change may potentially affect avian influenza epidemiology through changes in distribution, composition and migration behavior of wild birds (Gilbert et al., 2008). However, HPAI confined mainly to domestic poultry and distributed worldwide regardless of climatic conditions will be only slightly affected and mostly indirectly through the influence of climate change on agro-ecosystems associated to duck and crop production and distribution of domestic-wild waterfowl contact points.

\subsubsection{REFERENCES}

Belser, J.A., Maines, T.R., Tumpey, T.M. \& Katz, J.M. (2010) Influenza A virus transmission: contributing factors and clinical implications. Expert Rev Mol Med 12, e39/1-e39/20.

Breban, R., Drake, J.M., Stallknecht, D.E. \& Rohani, P. (2009) The role of environmental transmission in recurrent avian influenza epidemics. PLoS Comput. Biol. 5, e1000346. doi:10.1371/journal.pcbi.1000346.

Brown, J.D., Goekjian, G., Poulson, R., Valeika, S. \& Stallknecht, D.E. (2009) Avian influenza virus in water: infectivity is dependent on $\mathrm{pH}$, salinity and temperature. Vet. Microbiol. 136, 20-26.

Busquets, N., Abad, F.X., Alba, A., Dolz, R., Allepuz, A. et al. (2010) Persistence of highly pathogenic avian influenza virus (H7N1) in infected chickens: feather as a suitable sample for diagnosis. J. Gen. Virol. 91, 2307-2313.

Capua, I. \& Alexander, D.J. (2007) Avian influenza infections in birds-a moving target. Influenza Other Respi Viruses 1, $11-18$.

Castrucci, M.R., Donatelli, I., Sidoli, L., Barigazzi, G., Kawaoka, Y. \& Webster, R.G. (1993) Genetic reassortment between avian and human influenza A viruses in Italian pigs. Virology 193, 503-506.

Causey, D. \& Edwards, S.V. (2008) Ecology of avian influenza virus in birds. J. Infect. Dis. 197, S29-S33.

Davidson, I., Nagar, S., Haddas, R., Ben-Shabat, M., Golender, N. et al. (2010) Avian influenza virus H9N2 survival at different temperatures and pH's. Avian Dis. 54, 725-728.

Davis, L.M. \& Spackman, E. (2008) Do crocodilians get the flu? Looking for influenza A in captive crocodilians. J Exp Zool A Ecol Genet Physiol 309, 571-580.

Delogu, M., De Marco, M.A., Di Trani, L., Raffini, E., Cotti, C. et al. (2010) Can Preening Contribute to Influenza A Virus Infection in Wild Waterbirds? PLOS ONE 5, e11315. doi:10.1371/journal.pone.0011315.

Faust, C., Stallknecht, D., Swayne, D. \& Brown, J. (2009) Filter-feeding bivalves can remove avian influenza viruses from water and reduce infectivity. Proc. Biol. Sci. 276, 3727-3735.

Gibbs, S.E.J. (2010) Avian biology, the human influence on global avian influenza transmission, and performing surveillance in wild birds. Anim Health Res Rev 11, 35-41.

Gilbert, M., Slingenbergh, J. \& Xiao, X. (2008) Climate change and avian influenza. Rev. - Off. Int. Epizoot. 27, 459-66.

Graiver, D.A., Topliff, C.L., Kelling, C.L. \& Bartelt-Hunt, S.L. (2009) Survival of the avian influenza virus (H6N2) after land disposal. Environ. Sci. Technol. 43, 4063-4067.

Hall, J.S., Ip, H.S., Franson, J.C., Meteyer, C., Nashold, S. et al. (2009) Experimental infection of a North American raptor, American kestrel (Falco sparverius), with highly pathogenic avian influenza virus (H5N1). PLoS ONE 4, e7555. doi:10.1371/journal.pone.0007555.

Kida, H. (1997) Ecology of influenza viruses in animals and the mechanism of emergence of new pandemic strains. Nippon Rinsho 55, 2521-2526.

Lee, H.J., Kwon, J.S., Lee, D.H., Lee, Y.N., Youn, H.N., Lee, Y.J. et al., (2010). Continuing evolution and interspecies transmission of influenza viruses in live bird markets in Korea. Avian Dis. 54, 738-748.

Lenes, D., Deboosere, N., Menard-Szczebara, F., Jossent, J., Alexandre, V. et al. (2010) Assessment of the removal and inactivation of influenza viruses H5N1 and H1N1 by drinking water treatment. Water Res. 44, 2473-2486.

Li, X.H., Tian, H.D., Heiner, M. \& Li, D.M. (2011) Global occurrence and spread of highly pathogenic avian influenza virus of the subtype H5N1. Avian Dis. 55, 21-28. 
Liu, C-M., Lin, S-H., Chen, Y-C., Lin, K.C-M., Wu,T-S.J. \& King, C-C. (2007) Temperature drops and the onset of severe avian influenza A H5N1 virus outbreaks. PLOS ONE 2, e191. doi:10.1371/journal.pone.0000191.

Lowen, A. \& Palese, P. (2009) Transmission of influenza virus in temperate zones is predominantly by aerosol, in the tropics by contact: a hypothesis. PLoS Curr. RRN1002.

Ma, W., Kahn, R.E. \& Richt, J.A. (2009) The pig as a mixing vessel for influenza viruses: human and veterinary implications. J Mol Genet Med 3, 158-166.

Morens, D.M \& Taubenberger, J.K. (2010) Historical thoughts on influenza viral ecosystems, or behold a pale horse, dead dogs, failing fowl, and sick swine. Influenza Other Respi Viruses 4, 327-337.

Mubareka, S., Lowen, A.C., Steel, J., Coates, A.L., Garcia-Sastre, A. \& Palese, P. (2009) Transmission of influenza virus via aerosols and fomites in the guinea pig model. J. Infect. Dis. 199, 858-865.

Negovetich, N.J. \& Webster, R.G. (2010) Thermostability of subpopulations of H2N3 influenza virus isolates from mallard ducks. J. Virol. 84, 9369-9376.

Pasma, T. (2008) Spatial epidemiology of an H3N2 swine influenza outbreak. Can. Vet. J. 49, 167-176.

Perez, D.R., Lim, W., Seiler, J.P., Yi, G., Peiris, M. et al. (2003b) Role of quail in the interspecies transmission of H9 influenza A viruses: Molecular changes on HA that correspond to adaptation from ducks to chickens. J. Virol. 77, 3148-3156.

Perez, D.R., Webby, R.J., Hoffmann, E. \& Webster, R.G. (2003a) Land-based birds as potential disseminators of avian mammalian reassortant influenza A viruses. Avian Dis. 47, 1114-1117.

Robinson, J.L., Lee, B.E., Patel, J., Bastien, N., Grimsrud, K. et al. (2007) Swine influenza (H3N2) infection in a child and possible community transmission, Canada. Emerging Infect. Dis. 13, 1865-1870.

Shivakoti, S., Ito, H., Otsuki, K. \& Ito, T. (2010) Characterization of H5N1 highly pathogenic avian influenza virus isolated from a mountain hawk eagle in Japan. J. Vet. Med. Sci. 72, 459-463.

Stallknecht, D.E., Goekjian, V.H., Wilcox, B.R., Poulson, R.L. \& Brown, J.D. (2010) Avian influenza virus in aquatic habitats: what do we need to learn?. Avian Dis. 54, 461-465.

Vandegrift, K.J., Sokolow, S.H., Daszak, P. \& Kilpatrick, A.M. (2010) Ecology of avian influenza viruses in a changing world. Ann. N.Y. Acad. Sci. 1195, 113-128.

Wang, G., Zhan, D., Li, L., Lei, F., Liu, B. et al. (2008) H5N1 avian influenza re-emergence of Lake Qinghai: phylogenetic and antigenic analyses of the newly isolated viruses and roles of migratory birds in virus circulation. J. Gen. Virol. 89, 697-702.

Webster, R.G. (1997) Influenza virus: transmission between species and relevance to emergence of the next human pandemic. Arch. Virol. 13, 105-113.

Yamamoto, Y., Nakamura, K., Yamada, M. \& Mase, M. (2010) Persistence of avian influenza virus (H5N1) in feathers detached from bodies of infected domestic ducks. Appl. Environ. Microbiol. 76, 5496-5499. 


\section{Chapter 3.10 Picornavirus}

\section{[FAMILY PICORNAVIRIDAE, GENUS APHTHOVIRUS, CARDIOVIRUS, ENTEROVIRUS]}

Picornaviridae family includes the smallest mammalian viruses (virion size range of 22-30 nm) that possess a monopartite, non-enveloped, linear + (ss) RNA genome (7.1-8.9 kb in size) with an icosahedral nucleocapsid (Lewis-Rogers and Crandall, 2010). This family currently consists of 12 genera as well as many human pathogenic species. In spite of the large number of picornaviruses, there are only three zoonotic picornaviruses: Aphthovirus, Cardiovirus, Enterovirus (including Rhinovirus). Other nonzoonotic picornaviruses are: Erbovirus, Hepatovirus, Kobuvirus, Parechovirus, Sapelovirus, Senecavirus, Tremovirus, Teschovirus (Anonymous ${ }^{1}$, 2011). Viruses of the Picornaviridae family are infectious for a broad spectrum of animals such as: fish, reptiles, birds and mammals (Lewis-Rogers and Crandall, 2010).

Swine vesicular disease is a highly contagious disease of pigs caused by the Swine vesicular disease virus (SVDV), which is classified as a porcine variant of human Coxsackievirus B5 and a member of the genera Enterovirus. The disease is similar to foot and mouth disease, characterized by leg and mouth lesions; pigs get feeble and lose weight. Infections in pigs are usually subclinical to mild but sometimes more severe. Transmission to humans occurs rarely and has been reported in laboratory personnel working with this virus (Anonymous $\left.{ }^{2}, 2007\right)$. The clinical related virus causing food and mouth disease (FMD) belongs to the genera Aphtovirus. FMD is a highly contagious infection for cloven-hooved ruminants, especially cattle and swine. According to the United States Department of Agriculture (USDA) the disease is not recognized as a zoonotic one and is often confused with hand, foot and mouth disease (Anonymous ${ }^{3}$, 2007). Reports assuming FMD as zoonosis refer to an incident of a veterinarian's self-infection who developed clinical signs after milk ingestion from infected cows or, relying on the description of clinical incidents, with lesions of foot and mouth disease following contact with infected animals; virus isolation from infected lesions was not reported (Armstrong et al., 1967, Bauer, 1997).

Encephalomyocarditis (EMC) is a disease caused by a virus of the genus Cardiovirus. The virus has a worldwide distribution and causes myocarditis, encephalitis and reproductive disorder in many mammalian species and nonhuman primates. Rodents are considered to be the natural host of this virus 
and were linked to outbreaks in piggeries and zoos (Grobler et al., 1995; Acland and Littlejohns, 1975; Koenen et al., 1999; Canelli et al., 2010). There is one report of EMC virus isolation from a patient with febrile infection (with headache and fever symptoms) (Oberste et al., 2009). The zoonotic characteristic of this virus has not been not clearly demonstrated thus far. Different authors suggested rodents as the natural host and responsible for transmission to other animals via ingestion of infected feces, urine and carcasses (Seaman et al., 1986, Maurice et al., 2005).

\subsubsection{REFERENCES}

Acland, H.M. \& Littlejohns, I.R. (1975) Encephalomyocarditis virus infection of pigs. 1. An outbreak in New South Wales. Aust. Vet. J. 51, 409-415.

Anonymous $^{1}$, ViralZone (2011), Picornaviridae http://expasy.org/viralzone/all_by_species/33.html.

Anonymous $^{2}$, Centers for Disease Control and Prevention (2007) Swine vesicular disease http://www.cfsph.iastate. edu/Factsheets/pdfs/swine_vesicular_disease.pdf.

Anonymous $^{3}$, United States Department of Agriculture (2007) Foot and Mouth Disease Factsheet http://www.aphis. usda.gov/publications/animal_health/content/printable_version/fs_foot_mouth_disease07.pdf.

Armstrong, R., Davie, J. \& Hedger, R.S. (1967) Foot-and-mouth disease in man. Br Med J 4, 529-530.

Bauer, K. (1997) Foot- and-mouth disease as zoonosis. Arch. Virol. Suppl. 13, 95-97.

Canelli, E., Luppi, A., Lavazza, A., Lelli, D., Sozzi, E. et al. (2010) Encephalomyocarditis virus infection in an Italian zoo. Virol. J. 187, 64.

Grobler, D.G., Raath, J.P., Braack, L.E., Keet, D.F., Gerdes, G.H. et al. (1995) An outbreak of encephalomyocarditis-virus infection in free-ranging African elephants in the Kruger National Park. Onderstepoort J. Vet. Res. 62, 97-108.

Koenen, F., Vanderhallen, H., Castryck, F. \& Miry, C. (1999) Epidemiologic, pathogenic and molecular analysis of recent encephalomyocarditis outbreaks in Belgium. Zentralblatt Veterinarmedizin Reihe B 46, 217-231.

Lewis-Rogers, N. \& Crandall, K.A. (2010) Evolution of Picornaviridae: an examination of phylogenetic relationships and cophylogeny. Mol. Phylogenet. Evol. 54, 995-1005.

Maurice, H., Nielen, M., Brocchi, E., Nowotny, N., Kassimi, L.B. et al. (2005) The occurrence of encephalomyocarditis virus (EMCV) in European pigs from 1990 to 2001. Epidemiol. Infect. 133, 547-557.

Oberste, M.S., Gotuzzo, E., Blair, P., Nix, W.A., Ksiazek, T.G. et al. (2009) Human febrile illness caused by encephalomyocarditis virus infection, Peru. Emerging Infect. Dis. 15, 640-646.

Seaman, J.T., Boulton, J.G. \& Carrigan, M.J. (1986) Encephalomyocarditis virus disease of pigs associated with a plague of rodents Aust. Vet. J. 63, 292-294. 


\section{Chapter 3.11}

\section{Herpesvirus}

\section{[FAMILY HERPESVIRIDAE, SUPFAMILY ALPHAHERPESVIRINAE, GENUS SIMPLEXVIRUS, SPECIES MACACINE HERPESVIRUS 1]}

The Herpesviridae family comprises spherical to pleomorphic, enveloped viruses with a monopartite, linear $+(\mathrm{ds})$ DNA genome. Herpesviridae size ranges from 120 to $200 \mathrm{~nm}$ in diameter with glycoproteins embedded in a lipid envelope. The family of the Herpesviridae comprises many species infectious for different kind of animals, including humans. Among all these species, only one species is defined as zoonotic with severe pathogenesis in humans: the Macacine herpesvirus 1, also known as herpesvirus B or monkey B virus. In humans, monkey B virus infections cause encephalitis and myelitis with a high fatality rate. The first reported case of monkey B virus infection in a human (1933) was attributed to a bite from an apparently healthy Macacus rhesus monkey. Among other severe symptoms, the bitten patient developed encephalomyelitis and died some days after the incident (Sabin and Wright, 1933). In general the disease in humans starts with a flu-like illness, fever, headache over to parenthesis, encephalomyelitis, neurological dysfunction, coma and may conclude in death of the infected person. Macaque monkey is the natural host of the virus with lifelong carriage, latent infection (virus shedding) with intermittent disease expressions usually as a result of stress. In macaques the infection has no or mild symptoms, with lesions on tongue, lips, oral or genital mucosa.

\subsubsection{HERPES B VIRUS TRANSMISSION AND ENVIRONMENT}

The route of transmission from monkey to human is by means of bites/scratches of imported, infected animals or a scratch/cut from contaminated objects (Anonymous, 1987, 1989). A case report described the transmission through a splash in the eye of contaminate objects; human to human transmission is very rare and occurs by direct contact wounds to herpes lesions (Anonymous, 1998). The fatality rate of infected cases was reported to reach $70 \%$. Thus far there are only 31 reported cases describing monkey B virus infection with 21 fatal outcomes (Anonymous, 2010). 


\subsubsection{REFERENCES}

Anonymous (1987) Centers for Disease Control and Prevention. Epidemiologic Notes and Reports B-Virus Infection in Humans - Pensacola, Florida. MMWR 36, 289-290.

Anonymous (1989) Centers for Disease Control and Prevention. Epidemiologic Notes and Reports B Virus Infections in Humans-Michigan. MMWR 38, 453-454.

Anonymous (1998) Centers for Disease Control and Prevention (1998) Fatal Cercopithecine herpesvirus 1 (B Virus) Infection Following a Mucocutaneous Exposure and Interim Recommendations for Worker Protection. MMWR 47, 1073-1076.

Anonymous (2010) Centers for Disease Control and Prevention (last reviewed 2010). Available under http://www.cdc. gov/herpesbvirus/cause-incidence.html.

Sabin, A.B. \& Wright, A.M. (1933) Acute ascending myelitis following a monkey bite, with the isolation of a virus capable of reproducing the disease. J. Exp. Med. 59, 115-136. 


\section{Chapter 3.12}

\section{Poxvirus}

\section{[FAMILY POXVIRIDAE, SUBFAMILY CHORDOPOXVIRINAE, GENERA ORTHOPOXVIRUS, PARAPOXVIRUS, AVIPOXVIRUS, CAPRIPOXVIRUS, LEPORIPOXVIRUS, SUIPOXVIRUS, MOLLUSCIPOXVIRUS, YATAPOXVIRUS]}

The brick-shaped viruses of the Poxviridae family contain a large genome of not segmented linear (ds) DNA (size range 130 to $289 \mathrm{~kb}$ ) and presents themselves in two distinct infectious forms, the intracellular mature virus and the extracellular enveloped virus with an approximate size of 140-206 nm diameter and 220-450 nm length (SIB, 2010; Seet, 2003). The Poxviridae family consists of two sub families, Chordopoxvirinae with eight genera of which three are enzootic (Orthopoxvirus, Parapoxvirus, Yatapoxvirus) and Entomopoxvirinae with three non enzootic genera (Paran \& Sutter, 2009).

Orthopoxvirus contains beside the non-zoonotic species some zoonotic agents such as Cowpox, Monkeypox, Vaccinia, Camelpox, Buffalopox and Elephantpox viruses (Table 3.12.1). Variola virus, the most famous Orthopoxvirus that causes smallpox exclusively in humans, due to cross protection between same genera, had been eradicated in a major vaccination program initiated in the $19^{\text {th }}$ century. Still some concerns are left that genetically modified smallpox virus could be used as an agent of bioterrorist attacks (Moore et al., 2006).

\subsubsection{POXVIRUS AND TRANSMISSION AND ENVIRONMENT}

Vaccinia virus is genetically related to the Smallpox virus, but it is milder and is mainly used for vaccination against smallpox. For the majority of healthy people the vaccine is safe but some side effects have been recorded such as: rash and fever. The virus may be spread from newly immunized to non immunized humans through contact with local lesions at the vaccination site (i.e. contact transmissions). There are several reports of viral transmission from newly immunized infants to other immune naïve family members (Anreev, 1969) and also transmitted after sexual contact with recently immunized persons (Figure 3.12.1) (Egan et al., 2004; CDC, 2007). In immunosuppressed or enfeebled persons it can have a dangerous outcome. Redfield et al. (1987) reported on a fatal vaccinia virus in an HIV infected person. 
Essbauer et al. (2007) tested a vaccinia virus strain (orthopoxvirus) for survival in food and other environmental samples (storm water, potting soil and gauze) at different temperatures. In food, gauze and water, vaccinia survived well at $4^{\circ} \mathrm{C}$ for two weeks but not in storm water supplemented with potting soil. It can be hypothesized that potting soil has antiviral activity, mainly through various microorganisms present in natural soil. Interestingly, storm water supplemented with fetal calf serum (FCS) and kept at $4.5^{\circ} \mathrm{C}$ revealed infectious virions for up to 166 days. High protenaceous content of FCS bestowed protection against inactivating factors to vaccinia virus as already reported in many studies (Benbough, 1971). However, McDevitt et al. (2008) recently found that vaccinia aerosols are extremely susceptible to ultra-violet light at $254 \mathrm{~nm}$ (UVC) at low relative humidity, a fact that can reduce infections in hospital emergency rooms where infected people may congregate and spread the virus.

Table 3.12.1 Zoonotic Poxviruses.

\begin{tabular}{|c|c|c|c|c|}
\hline Genus & Species & $\begin{array}{l}\text { Clinical } \\
\text { manifestation in } \\
\text { human }\end{array}$ & Host & Distribution \\
\hline \multirow[t]{6}{*}{ Orthopoxvirus } & $\begin{array}{l}\text { Camelpox virus } \\
\text { (related Variola } \\
\text { virus) }\end{array}$ & $\begin{array}{l}\text { Skin ruptions, mild } \\
\text { local infection }\end{array}$ & Tick, Mosquitoes & $\begin{array}{l}\text { Africa, Middle-east, } \\
\text { Central Asia, India }\end{array}$ \\
\hline & Cowpox virus & Localized lesions & $\begin{array}{l}\text { Rodents, } \\
\text { Mammals }\end{array}$ & $\begin{array}{l}\text { Europe and central } \\
\text { and northern Asia }\end{array}$ \\
\hline & Monkeypox virus & $\begin{array}{l}\text { Rash causing } \\
\text { illness, Skin } \\
\text { eruption }\end{array}$ & Rodents & $\begin{array}{l}\text { Republic of Congo } \\
\text { (Arica), USA }\end{array}$ \\
\hline & $\begin{array}{l}\text { Vaccinia virus } \\
\text { (Vaccine) }\end{array}$ & Rash and fever & Human & worldwide \\
\hline & $\begin{array}{l}\text { Buffalopox virus } \\
\text { (strain of Vaccinia } \\
\text { virus) }\end{array}$ & Pox-like lesions & Buffaloes, Cows, & India \\
\hline & $\begin{array}{l}\text { Elefantpox virus } \\
\text { (strain of Cowpox } \\
\text { virus) }\end{array}$ & pox-like lesions & $\begin{array}{l}\text { Rodents, } \\
\text { Elephants, }\end{array}$ & Zoos and Circus \\
\hline \multirow[t]{3}{*}{ Parapoxvirus } & $\begin{array}{l}\text { Contagious } \\
\text { Ecthyma of sheep } \\
\text { (Orf) }\end{array}$ & Infectious lesions & $\begin{array}{l}\text { Goads, Sheep } \\
\text { (Artiodactyla) }\end{array}$ & worldwide \\
\hline & $\begin{array}{l}\text { Pseudocowpox } \\
\text { virus (syn. milkers' } \\
\text { nodules) }\end{array}$ & Infectious lesions & Cattle & worldwide \\
\hline & $\begin{array}{l}\text { Bovine Papular } \\
\text { Stomatitis }\end{array}$ & Infectious lesions & Cattle & worldwide \\
\hline Yatapoxvirus & Tanapox & $\begin{array}{l}\text { Febrile illness, } \\
\text { pox-like lesions }\end{array}$ & $\begin{array}{l}\text { Monkeys, } \\
\text { Arthropods }\end{array}$ & Kenya \\
\hline
\end{tabular}

Buffalopox virus, closely related to Vaccinia virus, causes mild infection with pox lesions on the body of infected persons, usually animal handlers, milkers and laboratory workers (Bhanuprakash et al., 2010). 
Camelpox virus is closely related genetically to variola virus, the causative agent of smallpox, yet its pathogenicity to humans is not well known and seems to be very low (Gubser and Smith, 2002). An investigation of herdsmen, handling infected camels, revealed only a partially developed localized lesion and only mild local infections in contrast to camels that presented severe clinical signs, such as drop in milk production, weight loss and high mortality. These findings suggested that this virus is rarely or almost not infectious for humans (Jezek et al., 1983). Additional investigations are necessary in order to clarify this point. Cowpox virus is also mildly infective for humans, typically causing localized lesions. Some reports described incidental cowpox transmission and infection by infected cats, fancy rats and mice, kept as home pets, to humans (Willemse and Egberink, 1985; Rjan et al., 2005; Postma et al., 1991; Wolfs et al., 2002; Lewis-Jones et al., 1993). Czerny et al. (1991) reported on an orthopox virus (OPV) transmitted from cat to man with a fatal outcome. Rodents have been already suggested as the main cowpox virus reservoir combined with chasing cats' exposure (Herder et al., 2011; Baxby, 1977; Bennett et al., 1986). Some evidence showed the potential transmission of Elephantpox virus from elephants to humans following direct contact. Signs of pox infection (ulcerating papulae) localized on fingers, arms, eyes and face of animal keepers have been reported (Kuntze, 1998; CDC, 2008). Infected rodents such as rats are considered to be the virus transmission source to elephants (Figure 3.12.1). Monkeypox virus, a virulent Orthopoxvirus, got its name owing to outbreaks in nonhuman primates in laboratories and a zoo in Europe and USA (between 1950 and 1960). In those episodes, primates were imported from Asia and Africa for poliovirus vaccine production. Africa seems to be the exclusive site of naturally occurring monkeypox virus, yet after the import and arrival in Europe and USA of these infected monkeys, they did approach other wild animals, possibly transmitting and spreading the virus (Breman, 2000). The first human monkeypox virus infection case was reported in Africa (in 1970) in a nine month old child (Ladnyj et al., 1972). Since then, the disease occurred in Africa sporadically in humans and only in 2003 was a first report on human monkeypox virus in United States described in association with an imported African rodent (prairie dogs) (Parker et al., 2007). The virus causes severe smallpox-like illness in humans, expressed by an initial fever, headache, fatigue, subsequent cutaneous eruptions and high fatality (Breman, 2000). Transmission occurs by animal bite, direct contact with animal lesions or body fluids and can be spread from human to human (Reed et al., 2004). In Africa, 59 cases of human monkeypox virus have been reported between 1970 and 1980, with severe infections and $17 \%$ mortality; the majority of these cases (47 incidents) were reported from the tropical rain forest of the Democratic Republic of Congo (Heymann et al., 1998). In the following years (1981-1986) additional cases in Africa (350 incidents) were reported with a preponderance (342 incidents) also in the tropical rain forest of the Democratic Republic of Congo (Breman, 2000). The outbreaks are thought to be attributable to intermittent smallpox vaccination, which provided cross-immunity between the different genera (Fine et al., 1988). The highest cases rate was recorded between June and August, probably caused by intensive agricultural work and hunting during this period. In the following years, human monkeypox virus continued to be reported from Africa as a consequence of human urbanization, civil unrest and economic plight. These facts may have forced people to set foot more frequently in the rain forest increasing their susceptibility to infected animals. The reality that vaccination with vaccinia virus is impractical, as a result of previous recorded high fatality rate in HIV patients, led to the conclusion of improved and enhanced health education (Heymann et al., 1998; Parker et al., 2007).

Parapoxviruses are commonly associated with domestic and wild ruminants (Artiodactyla) and cause skin infections. One of the most common poxviruses, with a worldwide distribution, is the ORF virus (genus Parapoxvirus) also known as contagious ecthyma of sheep (with lips and mouth lesions in small ruminants: sheep and goats). Clinically, Pseudocowpox virus (PCPV) and bovine Papular stomatitis virus (BPSV) are almost indistinguishable from ORF, therefore termed "farmyard pox" and only 
molecular techniques (e.g., specific real-time PCR) can differentiate them. These viruses are transmissible to humans causing pruritic, painful vesicular lesions on hands and fingers. People get infected through contact with infected goats or sheep (for ORF) or cattle (for PCPV and BPSV) or through contact with infected fomites. Several cases described transmission from animals to humans through contagious animal bites, sheep shearing and incidental injury of hands while feeding recently vaccinated animals. The disease is usually self-limited (CDC, 2006).

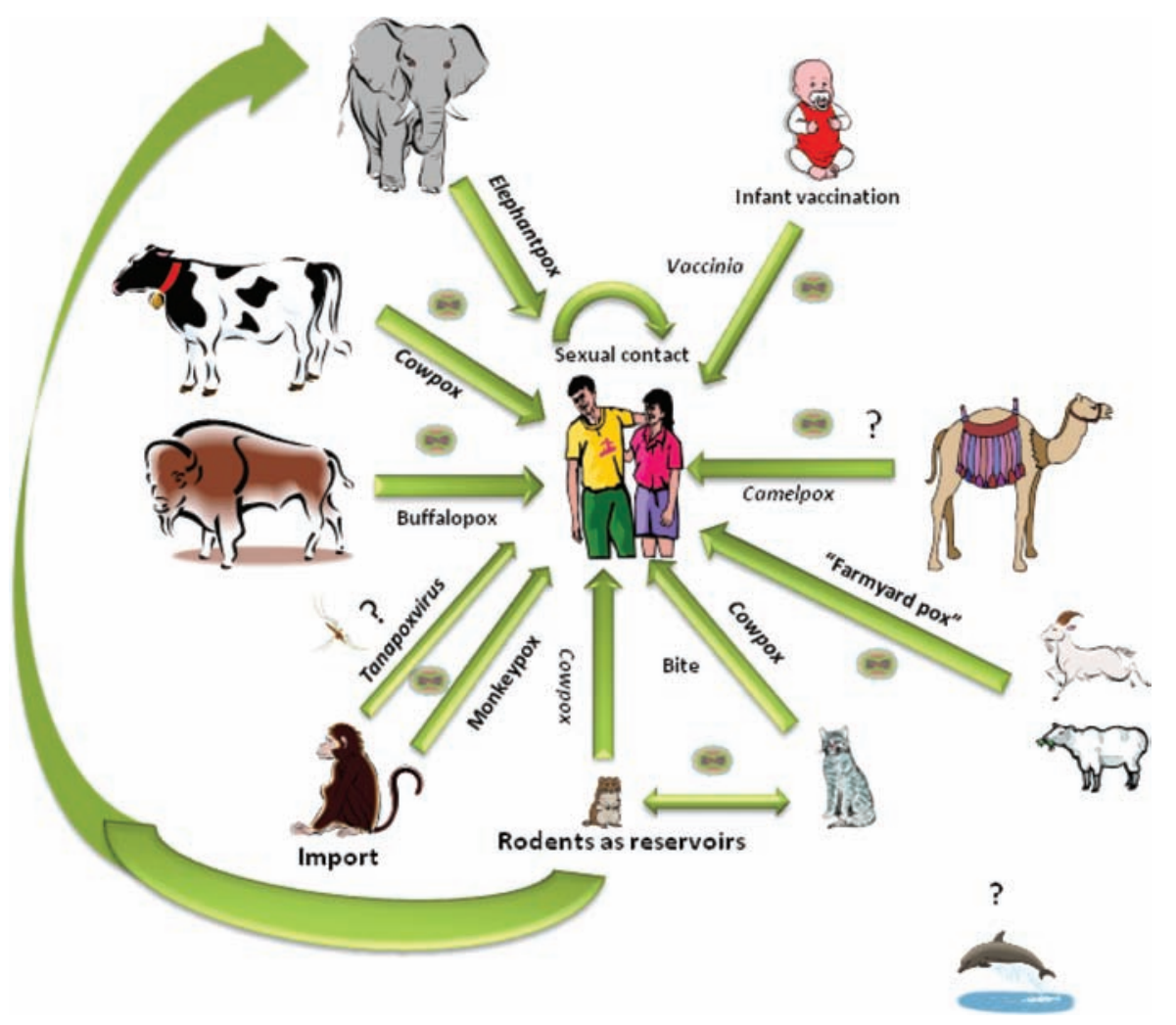

Figure 3.12.1. Poxviruses proved and potential transmission

The genus Yatapoxvirus consists of different species, with the Tanapoxvirus being the zoonotic one. Monkeys are considered to be the natural host and mosquitoes were suggested to be the vector for human infection. The disease initiates with a febrile illness, headache and pox-like lesion occurring after several days. Two outbreaks were reported in Kenya (1957 and 1962) in humans living close to the Tana River (Downie et al., 1971). In 2004 a student, returning to US after observing a chimpanzee in the Republic of Congo, was also diagnosed with tanapox infection (Dhar et al., 2004).

Finally, it should be mentioned that Maldini et al. (2010), studying the epidermal conditions of a small population of coastal bottlenose dolphins (Tursiops truncates) in Monterey Bay, found pox-like lesions affecting these animals (80\%). In spite of no laboratory evidence, the authors suggested "a possible indication of a widespread presence of a poxvirus or a similar pathogen in this population". Additional studies will be required in order to verify the etiology of these lesions and, if definitely pox viruses, are they zoonotic? 


\subsubsection{REFERENCES}

Andreev, V.C., Lachapelle, J.M. \& Rook, A.J. (1969) An outbreak of accidental vaccinia in a family. Dermatol Int. 8, 5-9.

Baxby, D. (1977) Poxvirus hosts and reservoirs. Arch. Virol. 55, 169-179.

Baxby, D., Bennett, M. \& Getty, B. (1994) Human cowpox 1969-93: a review based on 54 cases. Br J Dermatol 131, 598-607.

Benbough, J. E. (1971) Factors affecting the survival of airborne viruses. J. Gen. Virol. 10, $209-220$.

Bennett, M., Gaskell, C. J., Gaskell, R. M., Baxby, D., \& Gruffydd-Jones, T. J., (1986) Poxvirus infection in the domestic cat. Some clinical and epidemiological observations. Vet.Rec. 118, 387-390.

Bhanuprakash, V., Venkatesan, G., Balamurugan, V., Hosamani, M., Yogisharadhya, R., et al. (2010) Zoonotic infections of buffalopox in India. Zoonoses Public Health 57, 149-155.

Breman, J.G. \& Monkeypox: an Emerging Infection for Human (2000) Emerging Infections 4, Edited by W.M. Scheld, W.A. Craig and J.M. Hughes ASM Press, Washington, D.C. pp. 45-68.

CDC Centers for Disease Control and Prevention .(2006) Orf virus infection in humans-New York, Illinois, California, and Tennessee, 2004-2005 MMWR Morb Mortal Wkly Rep. 55, 65-68.

CDC, Center for Disease Control and Prevention (1985) Epidemiologic notes and reports: contact spread of vaccinia from a National Guard vaccine-Wisconsin. MMWR 34, 182-183.

CDC, Center for Disease Control and Prevention (2008) Rat-to-Elephant to human transmission of cowpox virus. EID 14, 670-671.

CDC, Centers for Disease Control and Prevention (2007) Vulvar vaccinia infection after sexual contact with a military smallpox vaccine-Alaska, 2006. MMWR Morb Mortal Wkly Rep. 56, 417-519.

CDC, Centers for Disease Control and Prevention (2003) What You Should Know About Monkeypox, Fact Sheet. http://www.cdc.gov/ncidod/monkeypox/pdf/factsheet2.pdf.

Czerny, C.P., Eis-Hubinger, A.M., Mayr, A., Schneweis, K.E. \& Pfeiff, B. (1991) Animal poxviruses transmitted from cat to man: current event with lethal end. Zentralblatt Veterinarmedizin Reihe B 38, 421-431.

Dhar, A.D., Werchniak, A.E., Li, Y., Brennick, J.B., Goldsmith, C.S. et al. (2004) Tanapox infection in a college student. N Engl J Med. 350, 361-366.

Downie, A.W., Taylor-Robinson, C.H., Caunt, A.E., Nelson, G.S., Manson-Bahr, P.E. \& Matthews, T.C. (1971) Tanapox: a new disease caused by a pox virus. Br Med J. 13, 363-368.

Egan, C., Kelly, C.D., Rush-Wilson, K., Davis, S.W., Samsonoff, W.A. et al. (2004) Laboratory-confirmed transmission of vaccinia virus infection through sexual contact with a military vaccinee. J Clin Microbiol. 42, 5409-5411.

Essbauer, S., Meyer, H., Porsch-Oezcueruemez, M. \& Pfeffer, M. (2007) Long-lasting stability of vaccinia virus (orthopoxvirus) in food and environmental samples. Zoonoses and Public Health 54, 118-124.

Fine, P.E., Jezek, Z., Grab, B. \& Dixon, H. (1988) The transmission potential of monkeypox virus in human populations. Int J Epidemiol 17, 643-650.

Foster, S.O., Brink, E.W., Hutchins, D.L., Pifer, J.M., Lourie, B. et al. (1972) Human monkeypox. Bull. World Health Organ. 46, 569-576.

Groves, R.W., Wilson-Jones, E. \& MacDonald, D.M. (1991) Human orf and milkers' nodule: a clinicopathologic study. $J$ Am Acad Dermatol. 25, 706-711.

Gubser, C. \& Smith, G.L. (2002) The sequence of camelpox virus shows it is most closely related to variola virus, the cause of smallpox. J Gen Virol. 83, 855-872.

Herder, V., Wohlsein, P., Grunwald, D., Janssen, H., Meyer, H. et al. (2011) Poxvirus infection in a cat with presumptive human transmission. Vet. Dermatol. 22, 220-224.

Heymann, D.L., Szczeniowski, M. \& Esteves, K. (1998) Re-emergence of monkeypox in Africa: a review of the past six years. Br Med Bull. 54, 693-702.

Jezek, Z., Kriz, B. \& Rothbauer, V. (1983) Camelpox and its risk to the human population. J Hyg Epidemiol Microbiol Immunol 27, 29-42.

Kuntze, A. (1998) Elephant pox and microsporum infection-two zoonoses of relevance to zoo veterinarian European Association of Zoo- and Wildlife Veterinarians (EAZWV). Second scientific meeting, 1998, Chester, United Kingdom. 
Ladnyj, I.D., Ziegler, P. \& Kima, E. (1972) A human infection caused by monkeypox virus in Basankusu Territory, Democratic Republic of the Congo. Bull. World Health Organ. 46, 593-597.

Lewis-Jones, M.S., Baxby, D., Cefai, C. \& Hart, C. A. (1993) Cowpox can mimic anthrax. Br J Dermatol. 129, 625-627.

MacNeil, A., Lederman, E., Reynolds, M.G., Ragade, N.J., Talken, R. et al. (2010) Diagnosis of bovine-associated parapoxvirus infections in humans: molecular and epidemiological evidence. Zoonoses Public Health. 57, e161-164.

McDevitt, J.J., Milton, D.K., Rudnick, S.N., First, M.W. (2008) Inactivation of poxviruses by upper-room UVC light in a simulated hospital room environment. PLOS ONE 3, e3186.

Maldini, D., Riggin, J., Cecchetti, A. \& Cotter, M.P. (2010) Prevalence of epidermal conditions in California coastal bottlenose dolphins (Tursiops truncatus) in Monterey Bay. Ambio 39, 455-462.

Moore, Z.S., Seward, J.F. \& Lane, J.M. (2006) Smallpox. Lancet 4, 425-435.

Paran, N. \& Sutter, G. (2009) Smallpox vaccines: New formulations and revised strategies for vaccination. Hum Vaccin. 5, 824-831.

Parker, S., Nuara, A., Buller, R.M.L. \& Schultz, D.A. (2007) Human monkeypox: an emerging zoonotic disease. Future Microbiol 2, 17-34.

Phuangkum, P., Lair, R.C. \& Angkawanith, T. (2005) Elephant care manual for mahouts and camp managers. Forest Resources Officer FAO Regional Office for Asia and the Pacific, Bannakij Printing, Lampang. Available under: ftp://ftp.fao.org/docrep/fao/008/ae943e/ae943e00.pdf.

Postma, B.H., Diepersloot, R.J.A., Niessen, G.J.C.M. \& Droog, R.P. (1991) Cowpox-virus like infection associated with rat bite. Lancet 337, 733-734.

Rajan, N., Carmichael, A.J. \& McCarron, B.M. (2005)Human cowpox: presentation and investigation in an era of bioterrorism. J. Infect. 51, 167-169.

Redfield, R.R., Wright, D.C., James, W.D., Jones, T.S., Brown C. \& Burke, D.S. (1987) Disseminated vaccinia in a military recruit with human immunodeficiency virus (HIV) disease. N. Engl. J. Med. 316, 673-676.

Reed, K.D., Melski, J.W., Graham, M.B., Regnery, R.L., Sotir, M.J., et al. (2004) The detection of monkeypox in humans in the Western Hemisphere. N Engl J Med. 350, 342-350.

Renner-Mueller, I.C.E., Meyer, H. \& Munz, E. (1994) Characterization of camelpoxvirus isolates from Africa and Asia. Vet. Microbiol. 45, 371-381.

Seet, B.T., Johnston, J.B., Brunetti, C.R., Barrett, J.W., Everett, H. et al. (2003) Poxviruses and immune evasion. Annu. Rev. Immunol. 21, 377-423.

SIB Swiss Institute of Bioinformatics (last update 2010) Poxviridae. Available under: http://expasy. org/viralzone/all_by_species/174.html.

Willemse, A. \& Egberink, H.F. (1985) Transmission of Cowpox virus infection from domestic cat to man Lancet 29, 1515.

Wolfs, T.F.W., Wagenaar, J.A., Niesters, H.G.M. \& Osterhaus, A.D.M.E. (2002) Rat-to-human transmission of Cowpox infection. Emerg Infect Dis. 8, 1495-1496. 


\section{Chapter 3.13 Coronaviruses}

\section{[FAMILY CORONAVIRIDAE, SUBFAMILY CORONAVIRINAE, GENUS ALPHACORONAVIRUS, BETACORONAVIRUS, GAMMACORONAVIRUS]}

Coronaviruses belong to Coronaviridae family which includes two subfamilies: Coronavirinae and Toronvirinae. The subfamily Coronavirinae contains three genera: Alphacoronavirus, Betacoronavirus and Gammacoronavirus. Coronaviruses are enveloped viruses containing + (ss) RNA with helical symmetry and a relatively large genome size, between 27 to $32 \mathrm{~kb}$. In the last years the Severe Acute Respiratory Syndrome Coronavirus (SARS-CoV) (genus Betacoronavirus) drew special attention. The 2002-2003 SARS outbreaks with initial cases in China led to over 8.000 reported cases and a fatality rate of up to $10 \%$. The outbreak got a pandemic character and spread rapidly to 37 countries around the globe. Different hosts, such as bats, civets, horses, beluga whales, birds, humans and other still undetected animals, are assumed as potential host (Rihtaric et al., 2010; Nagata et al., 2010). Clinical manifestations are linked to respiratory syndrome: fever, malaise, cough, myalgia, dyspenea, breath shortage, hypoxia, nausea, vomiting, diarrhea, headache and death. Fatality ranges from 3 to $>10 \%$ in patients older than 40 years old.

\subsubsection{SARS AND ENVIRONMENT}

Summarizing data accumulated from the 2002-2003 pandemic, it is further evidently that virus spread occurs through aerosols originating from infected individuals (as hosts and also vectors) where different animals play a significant role as reservoirs (Yu et al., 2004). Yip et al.'s (2007) study suggested that meteorological conditions had played a major role in SARS transmission in Hong-Kong epidemic of 2003. The virus was spread via aerosols by ambient wind in an apartment building at low temperatures that contributed to its survival. These results were further supported by Kuk and Tan (2009) in their statistical analysis estimates of Singapore and Hong-Kong outbreaks related to occurrence time of infections. When they correlated infection rate as a function of time it was evident that infection rate had more than one peak, revealing that the hospital environment has $\sim 10$ times greater infection rate in comparison with the nonhospital. Based on these outcomes, they raised the hypothesis that the Singapore 
outbreak was primarily nosocomial with "super spreaders" strongly affected by environmental rather than biological factors (genetic or biochemical).

In addition, it seems that SARS can survive at ambient temperature for 4 days in diarrheic stools (at alkaline $\mathrm{pH}$ ) and for $>7$ days in sputum specimens (Lai et al., 2005). Both environments hold moisture thereby supporting SARS survival while desiccation (on paper or on cotton gown) had been shown to inactivate the virus rapidly. Common disinfectants have also a high and rapid inactivation potential of these viruses, and therefore widespread disinfection practices could eliminate and prevent environmental contamination.

Food-borne infection could not be ruled out, as initial reports on the Chinese outbreaks pointed in the direction of civets as a potential reservoir of this virus, as civets are consumed in China as delicacies (Normile and Enserink, 2003) (Figure 3.13.1). In crowded markets with low hygienic standards where many animal species are kept close together interspecies transmission is very possible. Basically, we should look at such places as a factual incubator of new viral species emergence, a reality that would take a much longer time span to occur if in remote natural environments.

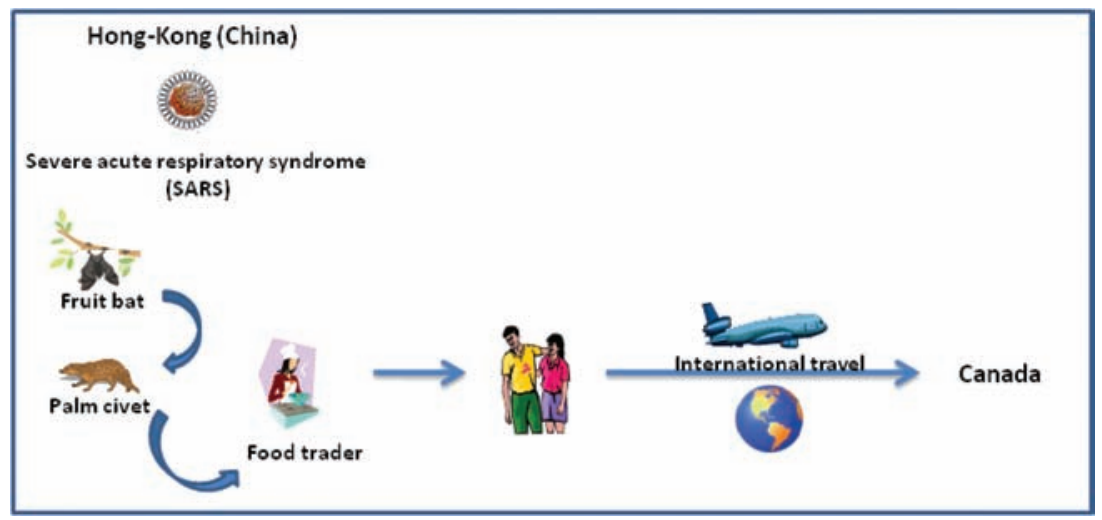

Figure 3.13.1. SARAS virus pandemic spread and potential sources of infections

The zoonotic aspect of this virus is interesting in the light of close contact between humans and domestic animals such as birds (e.g., poultry) in highly populated areas, low hygiene and crowded animals markets. Rockx et al. (2011) showed that human and zoonotic SARS-CoV could infect cynomolgus macaques with symptoms resembling those in mild human cases. Late phase human isolate revealed higher viral replication in those animals model. Woo et al., (2009) in a recent review pointed out the increasing numbers of new coronaviruses identified following the 2003 outbreak: 2 new human strains (NL63 and HKU1) and additional strains from bats, horses, beluga whale and various birds. This high diversity seems to be related to the infidelity of RNA-dependent RNA polymerase, homologous RNA recombination high frequency and as previously mentioned the relatively large coronaviruses genome. The high diversity seems to be linked to bats and birds based on their species diversity as well as their ability to fly (high dispersal) and roosting and flocking habits, along with environmental pressures. According to their analysis, it seems that closely related coronaviruses from highly diverse animals have the "jumping capability" with a high risk of future catastrophic outbreaks. 


\subsubsection{REFERENCES}

Kuk, A.Y. C. \& Tan, C.C. (2009) Estimating the time-varying rate of transmission of SARS in Singapore and Hong Kong under two environments. J. Am. Stat. Assoc. 104, 88-96.

Lai, M.Y.Y., Cheng, P.K.C. \& Lim, W.W.L. (2005) Survival of severe acute respiratory syndrome coronavirus. Clin. Infect. Dis. 41, e67-e71.

Nagata, N., Iwata-Yoshikawa, N. \& Taguchi, F. (2010) Studies of severe acute respiratory syndrome coronavirus pathology in human cases and animal models. Vet. Pathol. 47, 881-892.

Normile, D. \& Enserink, M. (2003) SARS in China: Tracking the roots of a killer. USA. Science 301, 297-299.

Rihtaric, D., Hostnik, P., Steyer, A., Grom, J. \& Toplak, I. (2010) Identification of SARS-like coronaviruses in horseshoe bats (Rhinolophus hipposideros) in Slovenia. Arch. Virol. 155, 507-514.

Rockx, B., Feldmann, F., Brining, D., Gardner, D., LaCasse, R. et al. (2011) Comparative pathogenesis of three human and zoonotic SARS-CoV strains in cynomolgus macaques. PLoS One 6, e18558.

Woo, P.C.Y., Lau, S.K.P., Huang, Y. \& Yuen, K.Y. (2009) Coronavirus diversity, phylogeny and interspecies jumping. Exp. Biol. Med. (Maywood) 234, 1117-1127.

Yip, C., Chang, W.L., Yeung, K.H. \& Yu, I.T. (2007) Possible meteorological influence on the severe acute respiratory syndrome (SARS) community outbreak at Amoy Gardens, Hong Kong. J Environ Health. 70, 39-46.

Yu, I.T., Li, Y., Wong, T.W., Tam, W., Chan, A.T. et al. (2004) Evidence of airborne transmission of the severe acute respiratory syndrome virus. N. Engl. J. Med. 350, 1731-1739. 


\section{Chapter 3.14}

\section{Prions and zoonoses}

\section{[BOVINE SPONGIFORM ENCEPHALOPATHY-BSE, NEW VARIANT OF CREUTZFELDT-JAKOB DISEASE-NVCJD, GERSTMANN- STRÄUSSLER-SCHEINKER SYNDROME-GSS AND KURU]}

Prions (proteinaceous infectious particles) is a specific group of proteins that affect central nervous system in humans and animals (so called progressive neurodegenerative diseases) resulting in spongiform encephalopathy and fatality. In humans, Creutzfeldt-Jakob seems to occur sporadically (possibly through ingestion), and is iatrogenic and familial. The natural hosts are humans and additional hosts are unknown; experimental transmission was shown in human primates: gorillas and chimpanzees. BSE is found naturally in infected cattle but additional hosts are possible: cats, zoo animals and humans, based on newly evidences that experimental transfer of a prion strain to different hosts leads to emergence of strain variants (Mahal et al., 2010). Transmission of BSE seems to be through ingestion of contaminated beef. Prions are basically proteins encoded by host genes that in their normal form (PrPc) are transmembrane proteins with still unclear functions; however, recent studies revealed that normal PrPc are involved in cell proliferation and cellular homeostasis regulation (Nicolas et al., 2009). Following infection (e.g. ingestion of infected beef) a pathological process starts when abnormal $\mathrm{PrP}^{\mathrm{Sc}}$ proteins (different fold) induce transformation/production of normal $\mathrm{PrP}^{\mathrm{c}}$ to more $\mathrm{PrP}^{\mathrm{Sc}}$ proteins (in other words simply by templating that conformation " $\mathrm{PrP}$ " (Figure 3.14.1). BSE in humans is now called a new variant of Creutzfeldt-Jakob Disease (nvCJD), however it is still a BSE related disease showing its zoonotic origin. All prion related diseases are rare (between 130 and 200 clinically identified) and most of them have been reported in European countries (probably due to much higher awareness and improved detection technology). Clinical manifestations are "slow infection", i.e., after years expressed as neurological and psychomotoric disturbances (manic depression, walking disturbances, memory loss, dementia and myoclonus).

\subsubsection{BSE AND ENVIRONMENT}

Juling et al. (2006) reported on a substantial genetic PRNP (prion protein gene) indel component for BSE susceptibility in cattle. Their conclusion was that "the main risk factor for BSE in cattle is environmental, i.e. 
exposure to feedstuffs contaminated with the infectious agent". As a result, different studies have been carried out to gain information on prions environmental stability in soil, water and on various surfaces (Smith et al., 2011). Ma et al. (2007) studied the mobility of prions in porous media of quartz sand (simulating soil and landfill waste environments) without infectivity follow-up. Their results showed

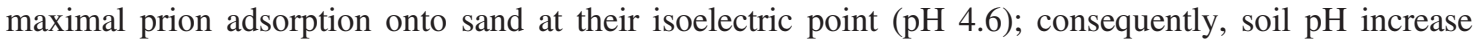
(e.g., lime or fly ash burial) may contribute to prions' mobility in soil. In a recent study, infectivity of prions following soil contact had been presented (Saunders et al., 2011). Under various ionic compositions, prions desorption ability and replication (evaluated by protein misfolding cyclic amplification -PMCA) are affected after $>30$ days but not $<7$ days. Unbound or prions bound to different soils revealed high stability expressed as replication capability even after one years suggesting a potential transmission risk in environment. These results have been further supported by Cooke and Show's (2007) study on recombinant ovine PrP (rec PrP) in soil columns (loamy sand and clay loam) under various regimes: water content, redox potential and microbial activity (normal vs. reduced). recPrP survived in soil over a long period of 9 months, but its migration was restricted to a maximum distance of $1 \mathrm{~cm}$ due to adsorption. Their conclusion was that under natural soil conditions, infected animal burial does not present a high risk of groundwater contamination as soil can act as a significant barrier.

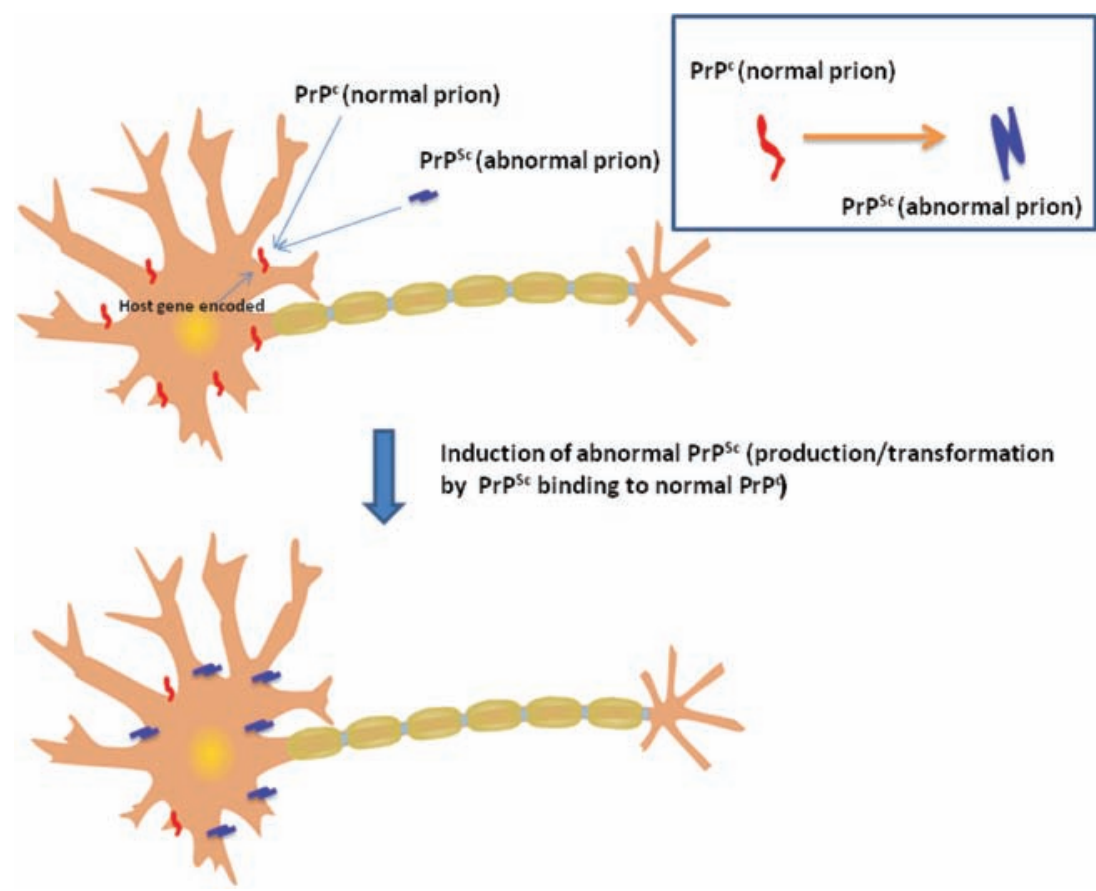

Figure 3.14.1. Prions infection of neurons as a causative of BSE

The demonstrated persistence of prions infective state in soil raised the question: What are the conditions that confer this environmental resistance? In this context, Polano et al. (2008) examined in depth the influence of organic polyanionics such as humic acids. Using a recombinant murine prion protein $(\mathrm{MoPrP})$, these authors showed that prions adsorption is driven by interaction with humic acids and clay. 
A definitive answer as to whether clay and humic acids might contribute to prions' conversion from non-pathogenic to pathogenic (through fibril growth) still awaits experimental evidence. Indeed, recent evidence was published in relation to the role of clay in infectivity preservation. Walter et al. (2011) recently reported an indirect proof of clay's role in prions' infectivity perpetuation by analyzing prion-infected deer herd data in the USA in relation to clay soil content. A $1 \%$ increase in clay content in close proximity to deer range increased the infection odds by up to $8.9 \%$ !

In environmental water ecosystem (urban sewage and seawater) prions have been shown to have limited survival compared to in buffered solutions such as phosphate buffered saline (Maluquer de Motes et al., 2008). Important evidence of high survival ability of prions through potential horizontal transmission was provided by Maddison et al. (2010). These authors used ovine scrapie and corvine wasting disease agents (prions) to follow their surface endurance on metal, plastic and wooden planes (using proteinmisfolding cyclic amplification-sPMCA as a viability method). In these experiments, prions persisted for up to 20 days revealing that even inanimate objects can present a high risk of infection. Mueller et al. (2007) studied the thermal inactivation potential of prions as a potential safety measure in the food industry. The effect of thermal inactivation of prions in the presence of components such as fat, fatty acids, and glycerol have been investigated by infectivity inactivation as well as by the degradation of prion polypeptide backbone. Results revealed that fat stabilized prions against degradation but destabilized infectivity against inactivation. In contrast, prion backbone was protected against heatinduced degradation by these components. In another study related to surgical instrument disinfection, Beekes et al. (2010) reported on the successful inactivation of prions ( $5.5 \mathrm{logs})$ among other pathogens by exposure to a solution containing SDS, $\mathrm{NaOH}$ and n-propanol. These components have been shown to change proteins' hydrophilic/hydrophobic balance and modulate the oligomerization of membrane proteins in lipid bilayers, which may explain why under basic conditions prions are inactivated (Sahini and Ionita, 2011; Otzen et al., 2007).

Prions' endurance and fascinating biochemistry have been linked to epigenetics under extreme conditions or as further defined: "a quasi-Lamarckian mechanism that connects environmental conditions to the acquisition and transgenerational inheritance of new traits" (Halfmann and Lindquist, 2010). In their publication, these authors did not treat prions as a disease agent but as complex evolutionary adaptations that helped organisms to survive and adjust to new extreme environments (at least in early biological systems).

In summary, it can be stated that prions stretch traditional views of proteins in biological systems, raising questions not only about simple soil resistance, though environmentally important, but also about their extraordinary epigenetic potential and evolutionary role (Wiggins, 2009).

\subsubsection{REFERENCES}

Beekes, M., Lemmer, K., Thomzig, A., Joncic, M., Tintelnot, K. \& Mielke, M. (2010) Fast, broad-range disinfection of bacteria, fungi, viruses and prions. J. Gen. Virol. 91, 580-589.

Cooke, C.M. \& Shaw, G. (2007) Fate of prions in soil: Longevity and migration of recPrP in soil columns. Soil Biol. Biochem. 39, 1181-1191.

Halfmann, R. \& Lindquist, S. (2010) Epigenetics in the extreme: prions and the inheritance of environmentally acquired traits. Science 330, 629-632.

Juling, K., Schwarzenbacher, H., Williams, J.L. \& Fries, R. (2006) A major genetic component of BSE susceptibility. BMC Biol. 4, 33.

Ma, X., Benson, C.H., McKenzie, D., Aiken, J.M. \& Pedersen, J.A. (2007) Adsorption of pathogenic prion protein to quartz sand. Environ. Sci. Technol. 41, 2324-2330. 
Maddison, B.C., Baker, C.A., Terry, L.A., Bellworthy, S.J., Thorne, L. et al. (2010) Environmental sources of scrapie prions. J. Virol. 84, 11560-11562.

Mahal, S.P., Browning, S., Li, J., Suponitsky-Kroyter, I. \& Weissmann, C. (2010) Transfer of a prion strain to different hosts leads to emergence of strain variants. Proc. Natl. Acad. Sci. U.S.A. 107, 22653-22658.

Maluquer de Motes, C., Cano, M.J., Torres, J.M., Pumarola, M. \& Girones, R. (2008) Detection and survival of prion agents in aquatic environments. Water Res. 42, 2465-2472.

Mueller, H., Stitz, L., Wille, H., Prusiner, S.B. \& Riesner, D. (2007) Influence of water, fat, and glycerol on the mechanism of thermal prion inactivation. J. Biol. Chem. 282, 35855-35867.

Nicolas, O., Gavin, R. \& del Rio, J.A. (2009) New insights into cellular prion protein (PrPc) functions: The "ying and yang" of a relevant protein. Brain Res Rev 61, 170-184.

Otzen, D.E., Sehgal, P. \& Nesgaard, L.W. (2007) Alternative membrane protein conformations in alcohols. Biochem 46, 4348-4359.

Polano, M., Anselmi, C., Leita, L., Negro, A. \& De Nobili, M. (2008) Organic polyanions act as complexants of prion protein in soil. Biochem. Biophys. Res. Commun. 367, 323-329.

Sahini, V.E. \& Ionita, G. (2011) Evidence of changes in hydrophilic/hydrophobic balance and in chemical activity of HSA induced by thermal treatments. Cent. Euro. J. Chem. 9, 245-252.

Saunders, S.E., Yuan, Q., Bartz, J.C. \& Bartelt-Hunt, S. (2011) Effects of solution chemistry and aging time on prion protein adsorption and replication of soil-bound prions. PLoS One 6, e18752.

Smith, C.B., Booth, C.J. \& Pedersen, J.A. (2011) Fate of prions in soil: a review. J. Environ. Qual. 40, 449-461.

Walter, W. D., Walsh, D.P., Farnsworth, M.L., Winkelman, D.L. \& Miller, M.W. (2011) Soil clay content underlies prion infection odds. Nat Commun 2, 1-6.

Wiggins, R.C. (2009) Prion Stability and Infectivity in the Environment. Neurochem. Res. 34, 158-168. 
Downloaded from https://iwaponline.com/ebooks/book-pdf/521254/wio9781780400761.pdf

Downloaded trom https://Iwaponline.com/ebooks/book-pdt/521254/WI09/81/80400/61.pdt
by IWA Publishing user 


\section{Chapter 4}

\section{Parasitic Zoonoses}


Downloaded from https://iwaponline.com/ebooks/book-pdf/521254/wio9781780400761.pdf

Downloaded trom https://Iwaponline.com/ebooks/book-pdt/521254/WI09/81/80400/61.pdt
by IWA Publishing user 


\section{Chapter 4.1}

\section{Protozoa}




\section{Chapter 4.1.1 Amebiasis}

\section{[ENTAMOEBA HISTOLYTICA]}

Entamoeba histolytica is an eukaryotic, microaerophilic parasitic protozoan, a species of the genus Entamoeba. Entamoeba spp. have basically three forms: 1) trophozoite, a vegetative motile form, 20 to $30 \mu \mathrm{m}$ in size and pathogenic (able to invade intestinal wall, phagocytize red and white blood cells, causing acute amebic dysentery); 2) minuta form, a vegetative motile lumen form, 10 to $20 \mu \mathrm{m}$ in size, that lives as a commensal in intestinal lumen, found mainly in chronic infections; and 3) the immotile cyst, a highly robust form, 10 to $15 \mu \mathrm{m}$ in size, that is excreted during infection and protect the protozoa in harsh environments outside the host (Goncalves et al., 2004). E. histolytica infects mainly humans (the reported infectious dose is 10-100 cysts) and other primates, through water and contaminated food ingestion, but arthropods (e.g. flies and cockroaches) may play the role of mechanical vectors of cysts. It is estimated that E. histolytica infects about 50 million people worldwide (Nyarango et al., 2008; Gascón, 2006). Previously, it was thought that $10 \%$ of the world population was infected, but these figures predate the recognition that at least $90 \%$ of these infections were due to a second species, $E$. dispar (a noninvasive species of mammals such as dogs and cats can become infected transiently, but are not thought to contribute significantly to transmission) (Anonymous, 1997). The invasiveness of $E$. hystolitica was reported to be linked to peroxiredoxins (an important class of antioxidant enzymes) present largely on the outer surface of this species and as much as 50 times more common than E. dispar (the non-invasive species). The peroxiredoxins are important for E. histolytica to reduce peroxides and peroxynitrites' stress exhibited by infected cells (Choi et al., 2005). Clinical manifestations are: diarrhea with alternating constipation, colics, spasms, mucoid and bloody diarrhea, many stools per day (10 to 12), fever and in more complicated forms as "tropical liver abscess" with hepatical lesions, pleuropulmonary amebiasis due to liver abscess rupture, as well peritonitis and pericarditis (both resulting in high mortality). In immunocompromised patients, Acanthamoba spp. can cause acute or chronic granulomatous amebic encephalitis (GAE).

\subsubsection{ENTAMOEBA HISTOLYTICA AND ENVIRONMENT (FIGURE 4.1.1.1)}

It is somehow difficult to call E. histolytica a zoonotic disease, as most infections are water and food-borne disease and only a small part are transmitted by dogs, monkeys and rodents that exercise as reservoirs 
(Schuster et al., 2004). In animals, a rare infection in a captive Tammar Wallaby has been reported (Stedman et al., 2003). In humans, rural populations associated to low socioeconomic factors and poor environmental sanitation conditions are at high risk of infection with this parasite (Maco et al., 2002; Mandal et al., 1990; Waikagul et al., 2002). Immigration from E. histolytica endemic areas to developed countries is also a risk factor in the reintroduction of this protozoan parasite into the general population (Gualdieri et al., 2011). Another social behavior linked to parasitic infections was described by Salit et al. (2009) in which $E$. histolytica (a highly virulent strain that caused liver abscesses) was transmitted via heterosexual and homosexual activity.

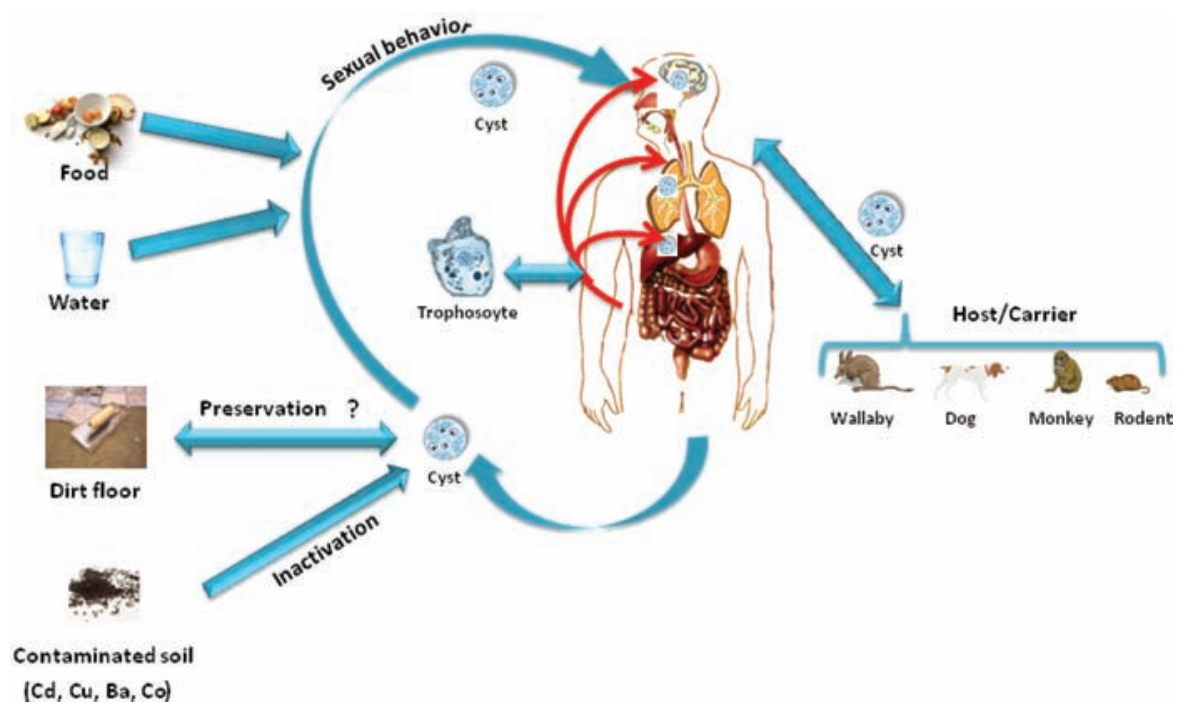

Figure 4.1.1.1. Entamoeba histolytica infection routes in humans and environmental factors

Aksoy et al. (2004) reported on the fate of E. histolytica cysts in soil contaminated with metal ions $(\mathrm{Cd}$, $\mathrm{Cu}, \mathrm{Ba}$ and $\mathrm{Co}$ ) at concentrations of $0.05,0.1$ and $0.2 \mathrm{mM}$. At these concentrations, metal ions led by $\mathrm{Cu}$ had a lethal effect on cysts' viability. Perhaps these results are somehow encouraging, as Saxena and Bhattacharyya (2005) raised the issue of increased environmental risk of hazardous wastes combined with biological (parasitic) contamination in India. In India, another study examined the pollution of beach water and sediment at seven sites receiving land drainage, along a 45-km stretch of the east coast near Visakhapatnam (Clark et al., 2003). Sediments revealed significant contamination with bacteria and protozoa, suggesting that they play a significant role in the retention of these pathogens. An interesting issue that seems to be partially answered by this study is the resistance and viability of cysts to high salt concentrations. In relation to halotolerance, Pandey et al. (2002), showed that transgenic tobacco plants that express an E. histolytica calcium binding protein exhibited greater than before resistance to high salt concentrations. In plants it has been demonstrated that $\mathrm{Ca}^{+2}$ is involved in their survival at elevated sodium concentrations. According to this report, it is evident that $\mathrm{Ca}^{+2}$ homeostasis manipulation by changing the expression level of $\mathrm{Ca}^{+2}$ binding proteins might be an important strategy to alter plants' survival rate under abiotic stress (Bressan and Hasegawa, 1998). Whether this calcium binding protein 
exhibits the same phenotypic characteristic when expressed in E. histolytica is not known, but if affirmative it may explain the survival of cysts in sea water!

Rinnea et al. (2005) using a multivariate logistic model in a population with high parasitic infections, found that the main risk factors for $E$. histolytica/E. dispar infections include $>1$ month since antiparasitic treatment, unchlorinated drinking water, poor hygiene (children not washing their hands before meals) and having a fewer number of electrical appliances at home. Though not clearly stated, the authors used electrical appliances as a poverty index for their studied population. Another important factor related to amebiasis prevalence was reported by Jacobsen et al. (2007) in the same area of Ecuador. The authors found that houses with dirt floors are significantly related to higher infections with E. histolytica $(63.4 \%$ vs $29.7 \%$, p $<0.001)$. It can be very possible that dirt floors support cysts' preservation, are difficult to clean and wash and possibly carry cysts before installation.

As mentioned earlier, E. histolytica have been isolated from primates (chacma baboons, mantled guereza, northern plains gray langurs, macaques, vervet monkeys, olive baboons, hamadryas baboons, cynomolgus monkeys, etc.) and some from fatal cases in zoo animals (Muriuki et al., 1998; Jackson et al., 1990; Howells et al., 2011; Reiner et al., 2010; Rivera et al., 2010; Ghandour et al., 1995; Takano et al., 2005). The Philippines is a major exporter of monkeys for biomedical research purposes, so screening animals before transportation to other locations lessens the risk of spreading zoonoses to a wider remote area (Rivera et al., 2010; Takano et al., 2005).

Finally, an interesting report linked to E. histolytica and its prevention has shown that ultrasonic vibrations can rapidly destroy cysts a measure that can be implemented in modern disinfection practices (Horton et al., 1952).

\subsubsection{REFERENCES}

Aksoy, U., Ustun, S., Dagci, H. \& Yazar, S. (2004) Effects of $\mathrm{Cd}^{+2}, \mathrm{Cu}^{+2}, \mathrm{Ba}^{+2}$ and $\mathrm{Co}^{+2}$ ions on Entamoeba histolytica cysts. World J Gastroenterol 10, 449-451.

Anonymous (1997) WHO, Amoebiasis. Wkly Epidemiol. Rec. 72, 97-99.

Bressan, R.A. \& Hasegawa, P.M. (1998) Plants use calcium to resolve salt stress. Trends Plant Sci. 3, 411-412.

Choi, M-H., Sajed, D., Poole, L., Hirata, K., Herdman, S. et al. (2005) An unusual surface peroxiredoxin protects invasive Entamoeba histolytica from oxidant attack. Mol. Biochem. Parasitol. 143, 80-89.

Clark, A., Turner, T., Dorothy, K.P., Goutham, J., Kalavati, C. \& Rajanna, B. (2003) Health hazards due to pollution of waters along the coast of Visakhapatnam, east coast of India. Ecotoxicol. Environ. Saf. 56, 390-397.

Gascón, J. (2006) Epidemiology, etiology and pathophysiology of traveler's diarrhea. Digestion 73, 102-108.

Ghandour, A.M., Zahid, N.Z., Banaja, A.A., Kamal, K.B. \& Bouq, A.I. (1995) Zoonotic intestinal parasites of hamadryas baboons Papio hamadryas in the western and northern regions of Saudi Arabia. J Trop Med Hyg 98, 431-439.

Goncalves, M.L., da Silva, V.L., de Andrade, C.M., Reinhard, K., da Rocha GC. et al. (2004) Amoebiasis distribution in the past: first steps using an immunoassay technique. Trans. R. Soc. Trop. Med. Hyg. 98, 88-91.

Gualdieri, L., Rinaldi, L., Petrullo, L., Morgoglione, M.E., Maurelli, M.P. et al. (2011) Intestinal parasites in immigrants in the city of Naples (southern Italy). Acta Tropica 117, 196-201.

Horton, J.P., Horwood, M.P. \& Phinney, D.E. (1952) Applicability of lethal properties of ultrasound to sanitary-engineering practice. Sewage Ind Waste 24, 457-472.

Howells, M.E., Pruetz, J., Gillespie, T.R. (2011) Patterns of gastro-intestinal parasites and commensals as an index of population and ecosystem health: the case of sympatric western chimpanzees (Pan troglodytes verus) and guinea baboons (Papio hamadryas papio) at Fongoli, Senegal. Am. J. Primatol. 73, 173-179.

Jackson, T.F., Sargeaunt, P.G., Visser, P.S., Gathiram, V., Suparsad, S. \& Anderson, C.B. (1990) Entamoeba histolytica: naturally occurring infections in baboons. Arch Invest Med (Mex) 21, 153-156. 
Jacobsen, K.H., Ribeiro, P.S., Quist, B.K. \& Rydbeck, B.V. (2007) Prevalence of intestinal parasites in young Quichua children in the highlands of rural Ecuador. J Health Popul Nutr 25, 399-405.

Maco, F.V., Marcos, R.L.A., Terashima Iwashita Angelica; Samalvides Cuba Frine; Gotuzzo Herencia Eduardo (2002) Distribution of entero-parasitic infections in the Peruvian Highland: study carried out in six rural communities of the department of Puno, Peru. Rev Gastroenterol Peru 22, 304-309.

Mandal, A.K., Tiwari, I.C. \& Sanyal, S.C. (1990) A profile of diarrhoea in an urban slum area. Indian J Public Health 34, 66-67.

Muriuki, S.M., Murugu, R.K., Munene, E., Karere, G.M. \& Chai, D.C. (1998) Some gastro-intestinal parasites of zoonotic (public health) importance commonly observed in old world non-human primates in Kenya. Acta Trop. 71, 73-82.

Nyarango,R.M., Aloo, P.A., Kabiru, E.W. \& Nyanchongi, B.O. (2008) The risk of pathogenic intestinal parasite infections in Kisii municipality, Kenya. BMC Public Health 8, 237 doi:10.1186/1471-2458-8-237.

Pandey, G.K., Reddy, V.S., Reddy, M.K., Deswal, R., Bhattacharya, A. \& Sopory, S.K. (2002) Transgenic tobacco expressing Entamoeba histolytica calcium binding protein exhibits enhanced growth and tolerance to salt stress. Plant Sci 162, 41-47.

Reiner, U., Boer, M., Herder, V., Spitzbarth, I., Hewicker-Trautwein, M. et al. (2010) Epizootic fatal amebiasis in an outdoor group of Old World monkeys. J. Med. Primatol. 39, 160-165.

Rinnea, S., Rodas, E.J., Galer-Untic, R., Glickmana,N. \& Glickmana, L.T. (2005) Prevalence and risk factors for protozoan and nematode infections among children in an Ecuadorian highland community. Trans. R. Soc. Trop. Med. Hyg. 99, 585-592.

Rivera, W.L., Yason, J.A.D.L. \& Adao, D.E.V. (2010) Entamoeba histolytica and E. dispar infections in captive macaques (Macaca fascicularis) in the Philippines. Primates 51, 69-74.

Salit, I.E., Khairnar, K., Gough, K. \& Pillai, D.R. (2009) A possible cluster of sexually transmitted Entamoeba histolytica : genetic analysis of a highly virulent strain. Clin. Infect. Dis. 49, 346-353.

Saxena, P. \& Bhattacharyya, A.K. (2005) Environment risk assessment of hazardous waste generating small scale metal finishing industries, India: a case study. Proc. Int. Conf. Solid Waste Technol. Manag. (2005), 20 ${ }^{\text {th }}, 622-633$.

Schuster, F.L. \& Visvesvara, G.S. (2004) Amebae and ciliated protozoa as causal agents of waterborne zoonotic disease. Vet. Parasitol. 126, 91-120.

Stedman, N.L., Munday, J.S., Esbeck, R. \& Visvesvara, G.S. (2003) Gastric amebiasis due to Entamoeba histolytica in a Dama wallaby (Macropus eugenii). Vet. Pathol. 40, 340-342.

Takano, J., Narita, T., Tachibana, H., Shimizu, T., Komatsubara, H. et al. (2005) Entamoeba histolytica and Entamoeba dispar infections in cynomolgus monkeys imported into Japan for research. Parasitol Res 97, 255-257.

Waikagul, J., Krudsood, S., Radomyos, P., Radomyos, B. Chalemrut, K. et al. (2002) A cross-sectional study of intestinal parasitic infections among schoolchildren in Nan Province, Northern Thailand. Southeast Asian J Trop Med Public Health 33, 218-223. 


\section{Chapter 4.1.2}

\section{Babesiosis (aka Piroplasmosis)}

\section{[BABESIA SPP.]}

Babesia is a protozoan parasite that infects humans through erythrocyte invasion. There are $>100$ Babesia species, but species infecting humans are: B. microti, B. divergens, B. bovis, B. equi, B. gibsoni and B. canis (order Piroplasmida, family Babesiidae). The parasite is transmitted by arthropod vectors' bite (hard ticks such as: Ixodes, Dermacentor, Rhipicephalus and Hyalomma) from reservoir animals, such as rodents, cattle, horses and dogs (Jonsson et al., 2008; Soares et al., 2006; Robert et al., 2005). Another pathway of transmission is iatrogenic (via blood transfusions using an infected carrier as a donor or by needle sharing), with infected donors residing in endemic areas and through their geographical migration (Cable and Leiby, 2003). Babesia spp. are distributed worldwide according to their tick vector species (Table 4.1.2.1). The parasite has mainly two reproduction cycles: sexual (mainly in tick) and asexual (mainly in human erythrocyte) (Figure 4.1.2.1). Beside salivary glands, parasite transmission by ticks may occur transovarially (from the maternal body to eggs within the ovaries) and also transstadially (from one developmental stage to its subsequent stage or stages) by eggs, larvae and nymph infestation (Iori et al., 2010). In healthy persons, infections are mostly subclinical, but in immunosuppressed patients they can manifest by means of fever, malaise, dyspnea, haemolytic anemia, hemoglobinuria, thrombocytopenia, shock, ARDS and even death.

\subsubsection{BABESIA SPP. AND ENVIRONMENT (FIGURE 4.1.2.1)}

There is an increasing number of reports of new Babesia species isolated from a large variety of animals, including wild life. The transmission of Babesia spp. from domestic to wild animals was successful only in closely related species or in humans following splenectomy. Infected animals do not present clinical manifestations; however, under stressful conditions (confinement following capture) infection can become active, including fatal outcome. This aspect raises the question of what may happen to confined infected wild animals released into natural environments as part of conservation programs? (Penzhorn, 2006). A partial response was presented by mice experimentally infected with Babesia microti. A group of mice, housed in cages furnished with shelves and nestboxes, displayed increased aggression and 
reduced resistance to parasitic infection. Serum concentrations of testosterone and corticosterone (immunodepressive hormones) were downregulated while serum total IgG (as a measure of immunocompetence) and resistance to B. microti decreased as attack numbers increased (aggression). According to this study and other studies, hormone-related reduction in resistance occurs when hormone levels and immunocompetence are decoupled (Barnard et al., 1996). A more recent study revealed that pregnant mice indirectly exposed (separated by a perforated Perspex partition) to B. microti infected neighbors had higher levels of serum corticosterone and produced later on less aggressive offsprings with accelerated immune response against this parasite. Without direct contact, the authors suggested that pregnant mice females assessed neighbors' infection via olfactory cues. This study is important to our understanding of animal and human infection and resistance to pathogens under environmental stresses (Curno et al., 2009).

Table 4.1.2.1 Babesia spp. and geographic distribution.

\begin{tabular}{|c|c|c|c|}
\hline Babesia spp. & Animal hosts & Country & Vectors (main) \\
\hline B. microti & Rodents & $\begin{array}{l}\text { USA, Mexico, Europe, China, Taiwan, } \\
\text { Egypt, Nigeria, South Africa, Poland }\end{array}$ & $\begin{array}{l}\text { Ixodes scapularis, } \\
\text { I.dammini }\end{array}$ \\
\hline B. equi & Horses & USA, Greece, Mongolia, China, Israel & \\
\hline B. divergens & Cattle & $\begin{array}{l}\text { France, UK, Germany, Russia, Spain, } \\
\text { Sweden Switzerland, former Yugoslavia, } \\
\text { Austria }\end{array}$ & Ixodes ricinus \\
\hline B. gibsoni & Dogs & Spain, USA, Japan, South Korea & $\begin{array}{l}\text { Haemophysalis } \\
\text { bispinosa and } H \text {. } \\
\text { longicornis, } \\
\text { Rhipicephalus } \\
\text { sanguineus }\end{array}$ \\
\hline B. canis & Dogs & France, Hungary, Taiwan, Russia, Brazil & $\begin{array}{l}\text { Rhipicephalus } \\
\text { sanguineus }\end{array}$ \\
\hline B. bovis & Cattle & $\begin{array}{l}\text { Spain, former Yugoslavia, Mexico, } \\
\text { Mozambique, Tanzania, Costa Rica, } \\
\text { Malaysia, Sri Lanka }\end{array}$ & $\begin{array}{l}\text { Rhipicephalus } \\
\text { microplus }\end{array}$ \\
\hline
\end{tabular}

Babesia like other vector-borne pathogens uses antigenic variations to evade its host's immunity. During a single infection, many variants (serotypes) are expressed and this is why many studies reported different subpopulations (Dalrymple et al., 1992; Arai et al., 1998; Barbour and Restrepo, 2000).

Sinski (1999) pointed to the importance of susceptible rodents in the role of competent zoonotic reservoirs for $B$. microti, especially in areas with changing farming systems that left large land areas under grassland and pasture in Poland (Mazury Lakes district). The same trend was also reported in Uganda, where babesiosis infections in rural area were assessed based on the prevalence of ticks under different grazing systems and agro-ecological zones (Rubaire-Akiiki et al., 2004). The highest tick prevalence was observed in the lowland zone under the free range and tethering grazing systems in comparison with the midland and upland zones under a zero-grazing system. The authors also mentioned that during the dry seasons farmers got additional fodder from outside their farms that possibly resulted in the import of new ticks. 


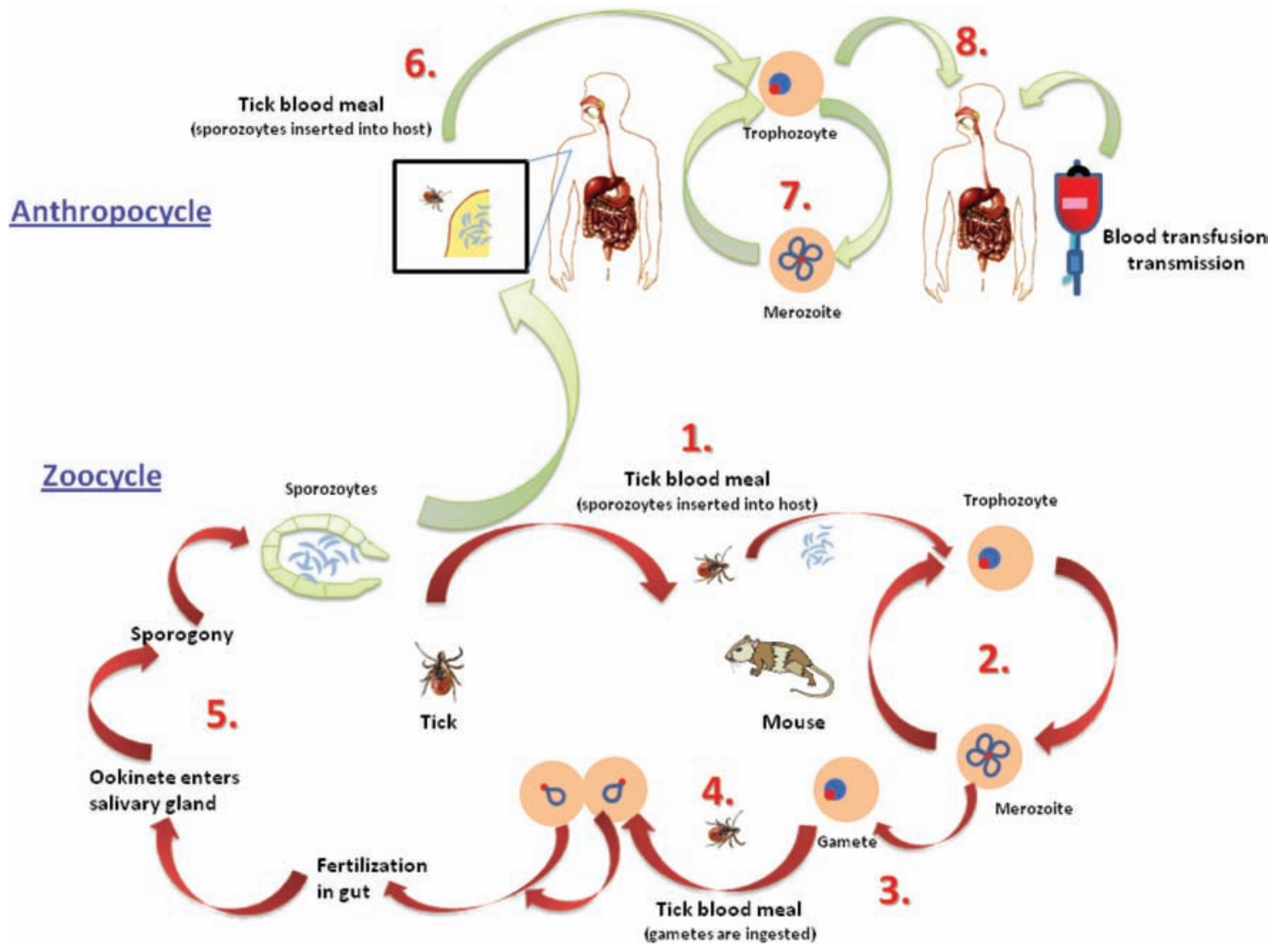

Figure 4.1.2.1. Infection and transmission cycles of Babesia spp. in different hosts (animals and humans)

Koum et al. (2010) used two models (maximum entropy ecological niche modeling-Maxent and spatial scan statistic-SaTScan) to predict geographic range and infection clusters of Babesia caballi (or equine piroplasms). The most important environmental factors contributing to these models were land cover (forested areas) and temperature (regulated temperatures and higher humidities) that are highly significant for tick survival and reproduction (Kouam et al., 2010).

There are numerous studies obviously showing the biological impact of chemical pollutants, present in different environments, on a large variety of animals (terrestrial and aquatic). Peltzer et al. (2008) looked at the health effects of agricultural runoff-polluted ponds containing organochlorine pesticides on anuran tadpoles (Scinax nasicus) as asentinel organism. Following seven days of exposure to organochlorine pesticides and high organic load, the experimental tadpoles' survival, growth and development rates, erythrocytes nuclei aberrations, parasite infection, and brain cholinesterase activity were monitored. The results showed deleterious effects on all parameters tested that can possibly lead to an increase in tadpole vulnerability to opportunistic parasite infection. In relation to chemical contaminants, similar effects on erythrocytes were observed with other environmental chemicals that, according to the author, do not follow a simple diffusion mechanism but to a great degree depend on the physiological condition of the erythrocytes (Ryasnyanskii, 1982). 
Telfer et al. (2010) pointed out an important aspect linked to simultaneous or sequential infection with various microparasites (bacteria, viruses and protozoa) and their host infection risk outcome. Four microparasites coinfections in wild animals (field voles) were analyzed: cowpox virus, Anaplasma phagocytophilum, Babesia microti and Bartonella spp. These authors analyzed time-series data of individual infected hosts and found that there is a significant interconnection between these microprasites affecting the infection risk at a much greater magnitude than environmental factors, previously thought to be of major importance. The effect can be positive, increasing the infection risk factor, but also negative concurrently reducing this factor. For example, the largest effect was observed with Bartonella reduced susceptibility in individuals infected with $B$. microti (especially in chronic infections). In this particular case, B. microti infection also decreased Bartonella spp. infection duration. The explanation for this phenomenon is based on host resource depletion as both pathogens are haemoparasites targeting erythrocytes. Another example of such interaction was shown in cattle's simultaneous infection with Babesia divergens (another Babesia sp.) and A. phagocytophilum, resulting in suppression of the first by the subsequent microparasite (Purnell et al., 1977).

Healy (1989) raised an important aspect related to the present spread of babesiosis (B. microti) in north and eastern America due to cultural and environmental changes. The first eye-catching common evidence responsible for these infections was the patients' behavioral (cultural) activities such as recreational pursuits in woodlands, forests, meadows, where the tick Ixodes dammini prevails (Spielman et al., 1985). Ixodes dammini is a three-host species rodents, humans and other mammals (raccoon, possum, dog, fox and white-tailed deer), while white-tailed deer is the most abundantly infested without clinical symptoms. Due to human intervention in the last 20-30 years, white-tailed deer population increased immensely ( $>13$ millions in USA), requiring even mandatory hunting in several states. Consequently rodents, tick, migratory host (white-tailed deer) and human behavior are the main factors that affect babesiosis epidemiology, at least in North America.

\subsubsection{REFERENCES}

Arai, S., Tsuji, M., Kim, S-J., Nakada, K., Kirisawa, R. et al. ( 1998) Antigenic and genetic diversities of Babesia ovata in persistently infected cattle. J. Vet. Med. Sci. 60, 1321-1327.

Barbour, A.G. \& Restrepo, B.I. (2000) Antigenic variation in vector-borne pathogens. Emerging Infect. Dis. 6, 449-457.

Barnard, C.J., Behnke, J.M. \& Sewell, J. (1996) Environmental enrichment, imunocompetence, and resistance to Babesia microti in male mice. Physiol. Behav. 60, 1223-1231.

Cable, R.G. \& Leiby, D.A. (2003) Risk and prevention of transfusion-transmitted babesiosis and other tick-borne diseases. Curr. Opin. Hematol. 10, 405-411.

Curno, O., Behnke, J.M, McElligott, A.G., Reader, T. \& Barnard, C.J. (2009) Mothers produce less aggressive sons with altered immunity when there is a threat of disease during pregnancy. Proc. $R$. Soc. B 276, 1047-1054.

Dalrymple, B.P., Jorgensen, W.K., De Vos, A.J. \& Wright, I.G. (1992) Analysis of the composition of samples of Babesia bovis and the influence of different environmental conditions on genetically distinct subpopulations. Int. J. Parasitol. 22, 731-737.

Healy, G. (1989) The impact of cultural and environmental changes on the epidemiology and control of human babesiosis. Trans. R. Soc. Trop. Med. Hyg. 83, 35-38.

Iori, A., Gabrielli, S., Calderini, P., Moretti, A., Pietrobelli, M. et al. (2010) Tick reservoirs for piroplasms in central and northern Italy. Vet. Parasitol. 170, 291-296.

Jonsson, N.N., Bock, R.E., Jorgensen, W.K. ( 2008) Productivity and health effects of anaplasmosis and babesiosis on Bos indicus cattle and their crosses, and the effects of differing intensity of tick control in Australia. Vet. Parasitol. $155,1-9$. 
Kouam, M.K., Masuoka, P.M., Kantzoura, V. \& Theodoropoulos, G. (2010) Geographic distribution modeling and spatial cluster analysis for equine piroplasms in Greece. Infect. Genet. Evol. 10, 1013-1018.

Peltzer, P.M., Lajmanovich, R.C., Sánchez-Hernandez, J.C., Cabagna, M.C., Attademo, A.M. \& Basso, A. (2008) Effects of agricultural pond eutrophication on survival and health status of Scinax nasicus tadpoles. Ecotoxicol. Environ. Saf. 70, 185-197.

Penzhorn, B.L. (2006) Babesiosis of wild carnivores and ungulates. Vet. Parasitol. 138, 11-21.

Purnell, R.E., Young, E.R., Brocklesby, D.W. \& Hendry, D.J. (1977) The haematology of experimentally-induced B. divergens and E. phagocytophilum infections in splenectomised calves. Vet. Rec. 100, 4-6.

Robert, N., Walzer, C., Ruegg, S.R., Kaczensky, P., Ganbaatar, O. \& Stauffer, C. (2005) Pathologic findings in reintroduced Przewalski's horses (Equus caballus przewalskii) in southwestern Mongolia. J. Zoo Wildl. Med. 36, 273-285.

Rubaire-Akiiki, C., Okello-Onen, J., Nasinyama, G.W., Vaarst, M., Kabagambe, E.K. et al. (2004) The prevalence of serum antibodies to tick-borne infections in Mbale District, Uganda: the effect of agro-ecological zone, grazing management and age of cattle. J. Insect Sci. 4:8.

Ryasnyanskii, I.V. (1982) Several features of the metabolism of erythrocytes in farm animals and poultry USSR. Sbornik SAO VASKhNIL 9, 125-136.

Sinski, E. (1999) Enzootic reservoir for new Ixodes ricinus-transmitted infection. Wiad Parazytol 45, 135-142.

Soares, A.O., Souza, A.D., Feliciano, E.A., Rodrigues, A.F.S.F., D’Agosto, M. \& Daemon, E. (2006) Evaluation of ectoparasites and hemoparasites in dogs kept in apartments and houses with yards in the city of Juiz de Fora, Minas Gerais, Brazil. Rev Bras Parasitol Vet 15, 13-16.

Spielman, A., Wilson, M.L., Levine, J.F. \& Piesman, J. (1985). Ecology of Ixodes dammini-borne human babesiosis and Lvme disease. Annu. Rev. Entomol. 30, 439-460.

Telfer, S., Lambin, X., Birtles, R., Beldomenico, P., Burthe, S., et al. (2010) Species interactions in a parasite community drive infection risk in a wildlife population. Science 330, 243-246. 


\section{Chapter 4.1.3 Balantidiasis}

\section{[BALANTIDIUM COLI]}

Balantidium coli is a protozoan ciliate parasite the only one known to be a human pathogen among the ciliate pylum. This ciliate has two stages: trophozoite (the vegetative stage found in the cecum and colon of pigs, rats, humans and other mammals) and cysts (the resistant infective form excreted in feces) (Figure 4.1.3.1). The trophozyte has an oval shape with an average size of $40 \times 70$ by $50 \times 100 \mu \mathrm{m}$, while the round cysts size is $\sim 55 \mu \mathrm{m}$. The main vertebrate host is pig but humans and other mammals can be infected through cysts transmitted by contaminated water and food (Uysal et al., 2009; Weng et al., 2005). Balantidium coli has a worldwide distribution (common in the Philippines) but the infection rate is low ( $<1 \%$ in human population) and mainly among people that come in contact with pigs or their feces (Schuster and Visvesvara, 2004; Schuster and Ramirez-Avila, 2008). Human infection is sporadic and most infections are asymptomatic. Clinical manifestations are: abdominal pain, acute diarrhea, severe colitis and in extreme cases colon perforation that can become life threatening.

\subsubsection{BALANTIDIUM COLI AND ENVIRONMENT}

In spite of its lower zoonotic importance, $B$. coli can be found in children in endemic rural communities in Venezuela with low hygienic standards (deficient sanitation), absence of basic services in dwelling, low socioeconomic level and close contact with infected pigs (Devera et al., 1999). In another distant geographical area, Nigeria, a cross-sectional study was conducted on the presence of Cryptosporidium oocysts and Balantidium coli cysts in pigs' fecal samples from a semi-intensively management. $B$. coli was also isolated from water and soil samples from an area where pigs are allowed to scavenge and defecate. In addition, the authors described usage of pigs' untreated manure in vegetable farms, thereby spreading further infections (Yatswako et al., 2007). A similar elevated B. coli infection rate has been detected in Korean rural areas (Ismail et al., 2010). Use of untreated pig manure has a great contamination potential especially in so-called "organic farming", the new trend in developed countries. Indeed, there are two recent reports of a rare form of balantidiasis affecting lungs through inhalation of 
manure aerosols: one in Canada and a second one in South Africa (Sharma and Harding, 2003; Koopowitz et al., 2010). An interesting aspect of pigs as host and carriers of B. coli was raised by SolaymaniMohammadi et al. (2005) who pointed at Iran, an Islamic country where according to Muslim religious rules, pig breeding and growth are prohibited, and which would therefore be expected to be free of human infection with pigs' parasites. Nevertheless, a very low prevalence of infection exists $(0.009 \%$ in Tehran suburbs) explained by these authors as originating from wild boars as carriers, especially in the forested areas of the country, where these animals roam freely and can contaminate water and soil environments contaminators. In a reply letter to the Editor, Cox (2005) suggested that camels that they were already proven to harbor B. coli (11.9\% fecal samples prevalence in Ethiopia) seem to be the main reservoir (especially in this geographic area) and also the intensive agricultural use of camel dung as fertilizer. The scientific debate on this issue would be solved by further research, but it seems that definitely wild boars are a more predominant wild life population than camels in Iran, albeit close contact is prohibited (*Solaymani-Mohammadi et al., 2005).

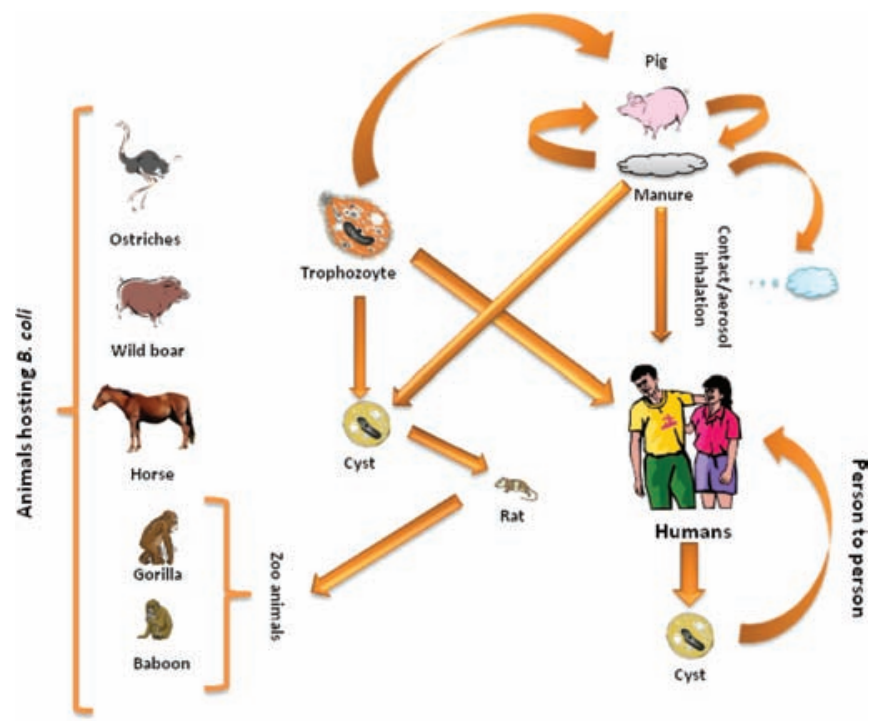

Figure 4.1.3.1. Balantidium coli infectious cycle in humans and animals involved as carriers

Finally, there are increasing reports of $B$. coli isolated from various animals, such as ostriches, ares, Old World monkeys (e.g. macaques and baboons), great apes (chimpanzees, bonobos and gorillas) and wild boars. Pomajbková et al. (2010) surveyed wild and captive great apes for the presence of $B$. coli. The captive great apes were found to harbor this parasite (prevalence 52.6\%) versus zero isolation in wild ones. The authors brought up several ideas to explain this dissimilarity: 1) in urban areas, infection of captive animals is by synantropic rats and 2) persistence due to feeding captive apes with high starch diets that support parasite growth. However, in humans, pigs remain the main host and infection source with this parasite, especially due to their close contact (Ponce-Gordo et al., 2008; Headley et al., 2008; Levecke et al., 2007). 


\subsubsection{REFERENCES}

Cox, F.E.G. (2005) Human balantidiasis in Iran: are camels reservoir hosts? Trends Parasitol. 21, 553.

Devera, R., Requena, I., Velasquez, V., Castillo, H., Guevara, R. et al. (1999) Balantidiasis in a rural community from Bolivar State, Venezuela. Bol Chil Parasitol 54, 7-12.

Headley, S.A., Kummala, E. \& Sukura, A. (2008) Balantidium coli-infection in a Finnish horse. Vet. Parasitol. 158, 129-132.

Ismail, H.A., Jeon, H.K., Yu, Y.M., Do, C. \& Lee, Y.H. (2010) Intestinal parasite infections in pigs and beef cattle in rural areas of Chungcheongnam-do, Korea. Korean J. Parasitol. 48, 347-349.

Koopowitz, A., Smith, P., van Rensburg, N. \& Rudman, A. (2010) Balantidium coli-induced pulmonary haemorrhage with iron deficiency. S. Afr. Med. J. 100, 534-536.

Levecke, B., Dorny, P., Geurden, T., Vercammen, F. \& Vercruysse. J. (2007) Gastrointestinal protozoa in non-human primates of four zoological gardens in Belgium. Vet. Parasitol. 148, 236-246.

Pomajbková, K., Petrželková, K.J., Profousová, I., Petrášová, J. \& David Modry, D. (2010) Discrepancies in the occurrence of Balantidium coli between wild and captive african great apes. J. Parasitol. 96, 1139-1144.

Ponce-Gordo, F., Jimenez-Ruiz, E. \& Martinez-Diaz, R.A. (2008) Tentative identification of the species of Balantidium from ostriches (Struthio camelus) as Balantidium coli-like by analysis of polymorphic DNA. Vet. Parasitol. 157, $41-49$.

Schuster, F.L. \& Ramirez-Avila, L. (2008) Current World Status of Balantidium coli. Clin. Microbiol. Rev. 21, 626-638.

Schuster, F.L. \& Visvesvara, G.S. (2004) Amebae and ciliated protozoa as causal agents of waterborne zoonotic disease. Vet. Parasitol. 126, 91-120.

Sharma, S. \& Harding, G. (2003) Necrotizing lung infection caused by the protozoan Balantidium coli. Can J Infect Dis 14, 163-166.

Solaymani-Mohammadi, S., Rezaian, M. \& Anwar, M.A. (2005) Human balantidiasis in Iran: an unresolved enigma? Trends Parasitol. 21, 160-161.

*Solaymani-Mohammadi, S., Rezaian, M. \& Anwar, M.A. (2005) Response to Cox: Human balantidiasis in Iran: wild boars or not? Trends Parasitol 21, 555-556.

Uysal, H.K., Boral, O., Metiner, K. \& Ilgaz, A. (2009) Investigation of intestinal parasites in pig feces that are also human pathogens. Turkiye Parazitol Derg 33, 218-221.

Weng, Y.B., Hu, Y.J., Li, Y., Li, B.S., Lin, R.Q. et al. (2005) Survey of intestinal parasites in pigs from intensive farms in Guangdong Province, People's Republic of China. Vet. Parasitol. 127, 333-336.

Yatswako, S., Faleke, O.O., Gulumbe, M.L. \& Daneji, A.I. (2007) Cryptosporidium oocysts and Balantidium coli cysts in pigs reared semi-intensively in Zuru, Nigeria. Pak. J. Biol. Sci. 10, 3435-3439. 


\section{Chapter 4.1.4 \\ Chagas' disease (American Trypanosomiasis)}

\section{[TRYPANOSOMA CRUZ]}

Trypanosoma cruzi is a vector-borne parasitic species (a hemoflagellate) of euglenoid trypanosomes genus, infecting both humans and animals (related to $>150$ domestic and wild spp. as hosts and reservoirs except birds which are refractory), that causes a serious disease called Chagas' disease or American Trypanosomiasis. Chagas' disease is spread in Central and South American countries. The parasite is mainly transmitted by bloodsucking insects (inhabiting both sylvatic and domestic areas) (Magallon-Gastelum et al., 2004) from the subfamily Triatominae (family Reduviidae) but other possible transmissions pathways are also known such as: congenital, food-borne, blood transfusion or organ transplant and laboratory accidents. Tritominae subfamily has $>35$ species, some of them important vectors of $T$. cruzi (Table 4.1.4.1). The insect deposits its feces (containing the metacyclic trypomastigote form of the parasite) on the host skin and subsequently bites in order to have a blood meal. Scratching the bitten area facilitates the entrance of fecal trypomastigotes into the blood stream and initiates infection. Trypanosoma cruzi has two major forms: trypomastigote $(\sim 20 \mu \mathrm{m}$ in length, found in human blood) and amastigote (3-5 $\mu \mathrm{m}$ in length, found in tissue) (Figure 4.1.4.1). In humans, following infection, trypomastigotes enter the peripherial blood without reproduction and shortly after infect intracellularly myocardial and endothelial cells of internal organs (e.g., spleen, liver, reticuloendothelial system, etc.). On these sites they reproduce, forming amastigote forms grouped in cysts that, after the cells burst, produce again trypomastogotes that invade again the peripheral blood for a short time period, causing further infection in host cells. Trypomastigotes are transferred to bloodsucking insects from humans or infected animals for the duration of the blood feeding process. In the anterior midgut of the insect vector, the parasite forms a different stage called epimastogote $(>30 \mu \mathrm{m}$ in length) that goes through intensive binary fission in the posterior end of the vector (Triatomae) resulting in the final infective form: metacyclic trypomastigote found in insect excreta. The disease manifestation has two forms: acute and chronic. The acute form (cutaneous-Chagoma or ocular- Romaña's sign) follows after insect vector bites and presents as a local swelling (on skin or conjugtiva) that possibly can go unnoticed 
by the host (Herrera et al., 2007). In terms of time, the chronic form may develop 10 to 20 years after the initial bite into a life threatening disease in which the parasite colonizes the heart, esophagus, colon and peripheral nervous system. The main symptoms are fever, malaise, anorexia, hepatosplenomegaly, lymphoadenopathy, myocarditis, meningoencephalitis and fatal outcome as a result of heart failure. The disease progresses slowly (see above the time span from initial bite) through progressive cell destruction due to parasite colonization of different organs, multiplication and autoimmune processes occurring in the host.

Table 4.1.4.1 Triatomine vectors geographic and ecosystem distribution.

\begin{tabular}{|c|c|c|}
\hline Species & Geographic distribution & Ecosystem distribution \\
\hline Triatoma infestans & $\begin{array}{l}\text { South America, Western and } \\
\text { Southern USA }\end{array}$ & $\begin{array}{l}\text { Exclusively domestic, with the } \\
\text { exception in Bolivia where (sylvatic } \\
\text { forms) }\end{array}$ \\
\hline Triatoma sordita & South America & Both sylvatic and domestic habitats \\
\hline Triatoma barberi & Mexico & Domestic and peridomestic habitats \\
\hline Triatoma dimidiata & $\begin{array}{l}\text { Central America, Columbia, } \\
\text { Ecuador }\end{array}$ & Both, sylvatic and domestic habitats \\
\hline Rhodnius prolixus & $\begin{array}{l}\text { Northern South America, } \\
\text { Venezuela, Western and } \\
\text { Southern USA }\end{array}$ & $\begin{array}{l}\text { Both sylvatic (associated with palm } \\
\text { trees) and domestic habitats }\end{array}$ \\
\hline Rhodnius pallescens & Panama & Both sylvatic and domestic habitats \\
\hline Panstrongylus megistus & Brazil, Peru & $\begin{array}{l}\text { Tropical Atlantic, cerrado (similar to } \\
\text { the savanna) and Atlantic forest } \\
\text { remnants habitats }\end{array}$ \\
\hline Triatoma juazeirensis & Northeast Brazil & $\begin{array}{l}\text { Exclusively rupicolous (thriving } \\
\text { among rocks) but able to invade } \\
\text { peridomestic environmental habitats }\end{array}$ \\
\hline $\begin{array}{l}\text { Triatoma } \\
\text { pseudomaculata }\end{array}$ & Northeast Brazil & Both sylvatic and domestic habitats \\
\hline Triatoma brasiliensis & Northeast Brazil & $\begin{array}{l}\text { Both sylvatic and domestic habitats } \\
\text { Semiarid areas }\end{array}$ \\
\hline Triatoma pallidipennis & Mexico & Mostly domestic (rural areas) \\
\hline
\end{tabular}

\subsubsection{TRYPANOZOMA CRUZI AND ENVIRONMENT}

Chagas' disease is perhaps one of the most prominent paradigm of this book on the environmental aspects of zoonotic diseases. Briceño-León (2007) analyzed and discussed different aspects involved in the spread of this disease towards Amazonian and new environments. The Amazon region is a river basin encompassing nine countries, Brazil, Colombia, Peru, Ecuador, Bolivia, Venezuela, Surinam, Guyana, and French Guyana, an area of approximately seven million $\mathrm{km}^{2}$, up to the last century having mainly scattered indigenous populations, and consequently considered a non-endemic area. However, in the last four decades, the disease reappeared with higher intensity due to socio-economic factors imposed by governmental decisions under local and global pressure, one of which was to build the Belém-Brasília highway to launch the country's "inward development" plan, which was subsequently followed by 
others (North-South Cuiabá-Santarém Highway and the Trans-Amazonian Highway). As a result of these developments and massive population migration several factors appear to impact the disease spread: 1) new human dwellings built (mostly closed with bricks) in contrast to indigenous open dwellings that are unfavorable to vectors colonization; 2) lower mobility of the new population and the establishment of fixed colonies in contrast to the dynamic mobility of the native population; 3) introduction of mass domestic animals that are used as host for bloodsucking vectors, in contrast with the absence of domesticated animals grown by original natives; 4) deforestation in order to increase cattle and crop production that compel vectors' migration into new niches with abundant food supply; 5) lumber industry that may disturb and disperse sylvatic vectors, originally inhabiting trees and nests, and 6) development of highway transportation that accelerates and facilitates the disease's transmission to remote places, including immigration of infected population from endemic areas, posing a new threat of spreading this disease to remote sites (Hanford et al., 2007) (Figure 4.1.4.2).

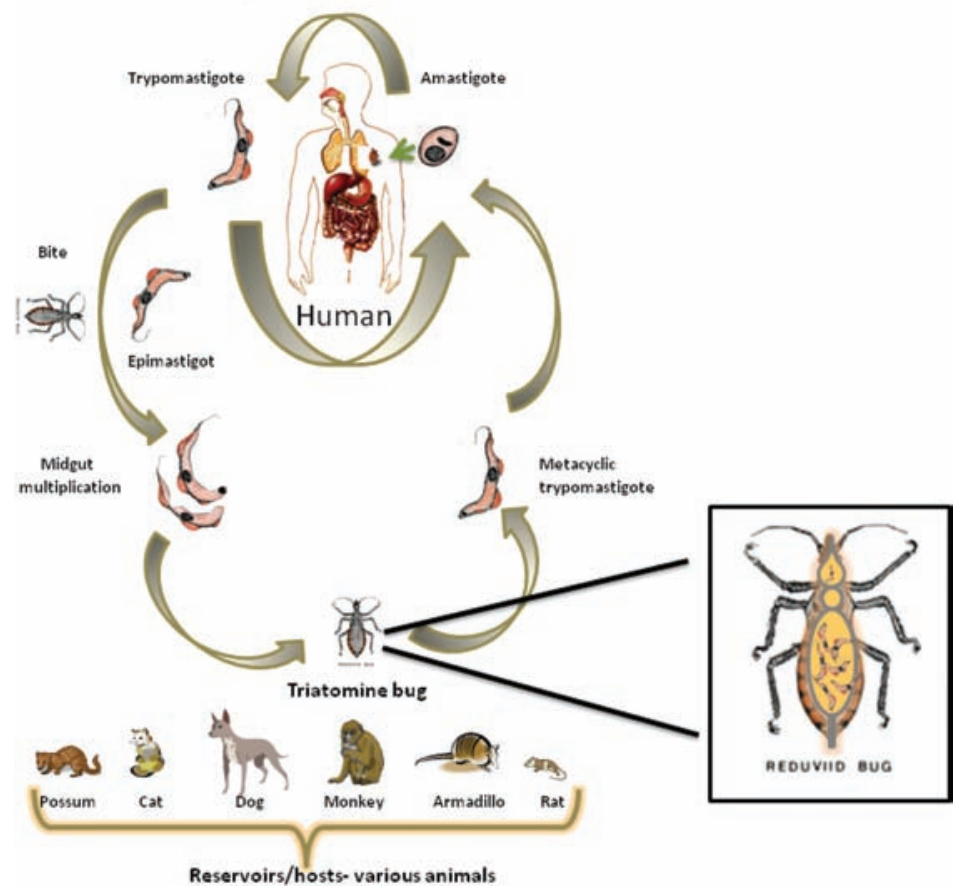

Figure 4.1.4.1. Trypanosoma cruzi life cycle and some of its hosts

In relation to domestic animal growth, Herrera et al. (2007) evaluated how landscape and cattle ranching affect transmission cycles and the patterns of tripanosomatid infection (Trypanosoma cruzi and Trypanosoma evansi) of small wild mammals in the Pantanal (world's largest tropical wetland, comprising Brazil, Bolivia and Paraguay). In relation to small mammals, the conclusions of their study, in contrast to the above described factors, was that cattle ranching in the study area did not enhance overall prevalence of $T$. cruzi infection among small wild mammals as well as biodiversity loss or risk of Chagas' disease. Chagas' disease vectors from the subfamily Triatomae are insects widespread in South and Central America. They are expected to be the main factor influenced by environmental, including 
manmade, changes when dealing with disease infection and prevalence. Lima et al. (2008) presented the health risk of Copernicia prunifera, a species of palm trees, found in both periurban and rural localities of an endemic northeast Brazilian Chagas' disease region. These palms are colonized with infested Triatomae (in this case with Rhodnius nasutus) that carry T.cruzi at high prevalence. As a result of the continuous destruction of palm trees, there is a high risk of vectors invading of periurbanic human dwellings, in search for new habitats. Researchers also reported on the demographic areas of Cochabamba (Bolivia) where $58 \%$ of the population lives in peripheral urban districts ("popular zones") which differ in social, environmental, and agricultural conditions. These areas also exhibited extremely high infection prevalence (in children age 5 to 13) with $T$. cruzi, suggesting that $T$. cruzi infection should be considered an urban health problem and not only restricted to the rural areas and small villages of Bolivia, by continuous infection and reinfection (Medrano-Mercadoet al., 2008).

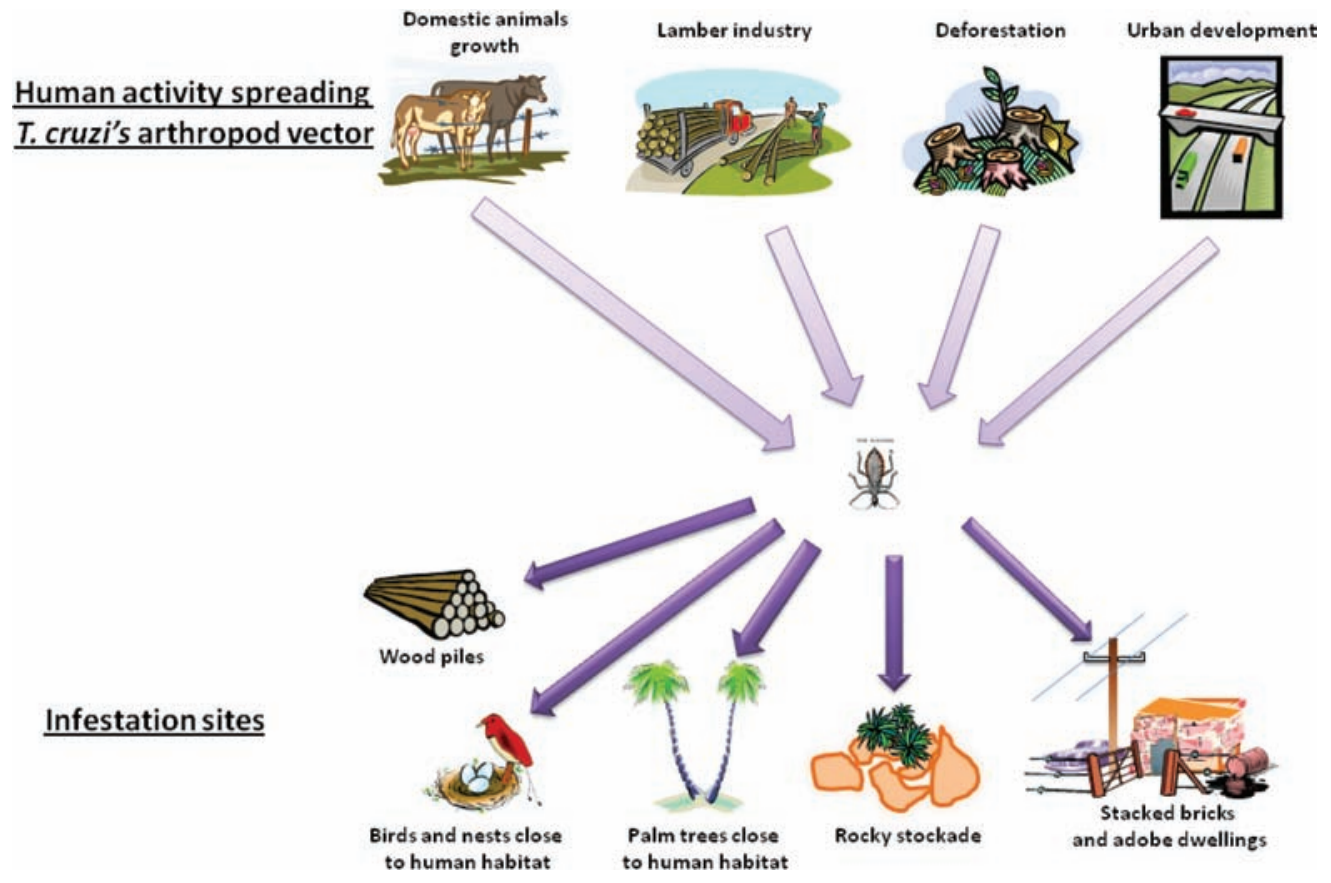

Figure 4.1.4.2. Environmental factors involved in spreading and infestation of Triatominae arthropod vectors (T. cruzi carriers)

de la Fuente et al. (2008) studied the behavior of two species: T. psudomaculata and T. juazeirensis. According to these authors, the above arthropods do not share the same habitat in sylvatic environment. T. pseudomaculata can be found in trees and bird nests without apparent tree preference, while T. juazeirensis lives exclusively in rupicolous (thriving among rocks) environments. Both were found to have behavioral plasticity to invade peridomestic structures (including wooden structures) in $>80 \%$ of cases. The synanthropic behavior evolution of these insects was studied by Abad-Franch and Monteiro (2007) in the various regions of the Amazon. The authors pointed out that evolutionarily, most of the Amazonian Triatomines live in highly humid forest environments; nevertheless, only a few species adjusted to new drier environments (mainly through anthropogenic ecological disturbance, driven by deforestation), 
forming domestic infestation foci. Thus, only a small fraction of Rhodnius spp. adapted evolutionarily to arid or semi-arid climates long before human existence in the Americas, ostensibly in drier regions of the forest, making them adapt better to human dwellings. This study confirms two obvious facts: 1) arthropod evolution is a continuous process on an immense time scale, although 2) anthropogenic activity may accelerate this process.

Click et al. (2008) applied GIS (geographical information system) to analyze the domesticity potential of three triatomine species within the United States known to harbor Trypanosoma cruzi. According to their results and based on actual minimum lower temperature threshold, the current area at increased risk of Chagas' disease includes much of the southern United States. Nevertheless, based upon the $1{ }^{\circ} \mathrm{C}\left(1.8^{\circ} \mathrm{F}\right)$ increase in temperature predicted by the Intergovernmental Panel on Climate Change (IPCC) by the year 2030, they concluded that the higher risk range is expected to expand into the central United States.

Zeledo et al. (2008) reported on a new project that used garden chicken coops as a decoy for $T$. dimidiata to prevent home colonization, with good results. However, there are some issues related to infected chickens and their possible parasite food-borne transmission to farmers. The idea of using small animals in wire meshed cages as baits is based on an entomological survey performed in Peru (Levy et al., 2006). These authors emphasized again the importance of human dwellings (fully stuccoed versus rooms of stacked bricks and adobe enclosure) for the prevention of infestation with Triatoma infestans vector.

\subsubsection{REFERENCES}

Abad-Franch, F. \& Monteiro, F.A. (2007) Biogeography and evolution of Amazonian triatomines (Heteroptera: Reduviidae): implications for Chagas disease surveillance in humid forest ecoregions. Mem. Inst. Oswaldo Cruz. 102, 57-70.

Briceño-León, R. (2007) Chagas disease and globalization of the Amazon. Cad Saude Publica. 23, S33-S40.

Click, L.R., Kolivras, K.N., Resler, L.M., Brewster, C.C. \& Paulson, S.L. (2008) The potential for emergence of Chagas disease in the United States. Geospatial health 2, 227-239.

de la Fuente, A.L.C., Dias-Lima, A., Lopes, C.M., Emperaire, L., Walter, A. et al. (2008) Behavioral plasticity of Triatominae related to habitat selection in northeast Brazil. J. Med. Entomol. 45, 14-19.

Hanford, E.J., Zhan, F.B., Lu, Y. \& Giordano, A. (2007) Chagas disease in Texas: recognizing the significance and implications of evidence in the literature. Soc Sci Med. 65, 60-79.

Herrera, H.M., Rademaker, V., Abreu, U.G.P., D’ Andrea, P.S. \& Jansen, A.M. (2007) Variables that modulate the spatial distribution of Trypanosoma cruzi and Trypanosoma evansi in the Brazilian Pantanal. Acta Trop. 102, 55-62.

Herrera, L., Martinez, C., Carrasco, H., Jansen, A.M. \& Urdaneta-Morales, S. (2007) Cornea as a tissue reservoir of Trypanosoma cruzi. Parasitol. Res. 100, 1395-1399.

Levy, M.Z., Bowman, N.M., Kawai, V., Waller, L.A., Cornejo del Carpio, J.G. et al. (2006) Periurban Trypanosoma cruzi-infected Triatoma infestans, Arequipa, Peru. Emerging Infect. Dis. 12, 1345-1352.

Lima, M.M., Coutinho, C.F.S., Gomes, T.F., Oliveira, T.G., Duarte, R. et al. (2008) Risk presented by Copernicia prunifera palm trees in the Rhodnius nasutus distribution in a Chagas disease-endemic area of the Brazilian northeast. Am. J. Trop. Med. Hyg. 79, 750-754.

Magallon-Gastelum, E., Lozano-Kasten, F., Bosseno, M-F., Cardenas-Contreras, R., Ouaissi, A. \& Breniere, S.F. (2004) Colonization of rock pile boundary walls in fields by sylvatic triatomines (Hemiptera: Reduviidae) in Jalisco State, Mexico. J. Med. Entomol. 41, 484-488.

Medrano-Mercado, N., Ugarte-Fernandez, R., Butron, V., Uber-Busek, S., Guerra, H.L. et al. (2008) Urban transmission of Chagas disease in Cochabamba, Bolivia. Mem. Inst. Oswaldo Cruz 103, 423-430.

Ribeiro, R.D., Lopes, R.A., Garcia, T.A. \& Carraro, A.A. (1990) A new aspect of the morphological transformation of Trypanosoma cruzi brought about by environmental variation. Angew Parasitol 31, 207-210.

Zeledo, R., Rojas, J.C., Urbina, A., Cordero, M., Gamboa, S.H. et al. (2008) Ecological control of Triatoma dimidiata (Latreille, 1811): five years after a Costa Rican pilot project. Mem. Inst. Oswaldo Cruz 103, 619-621. 


\section{Chapter 4.1.5 Cryptosporidiosis}

\section{[CRYPTOSPORIDIUM PARVUM]}

Cryptosporidium parvum belongs to phylum Apicomplexa and order Eucoccidiorida. It is a parasite infecting the intestinal tract of a large variety of mammals ( 152 species) including humans (Tzipori et al. 1980; Atwill et al. 2004; Torres et al. 2000). There are at least two genotypes (based on oocysts' wall protein phenotypes), genotype 1 (exclusively in humans) and genotype 2 (found in livestock animals, such as sheep, cattle, goats and rodents) that can infect humans too. Basically, the parasite has two forms: the one excreted in feces, called oocyst (5 to $6 \mu \mathrm{m}$ with an ovoidal, pea-like shape, two types: thick and thin walled) and the vegetative form found in the intestinal epithelium called sporozoite. Sporozoite development is intracellular (between the epithelial cells' cytoplasm and their membrane) following two replication paths: asexual and sexual (Figure 4.1.5.1). Oocysts are the final form excreted in feces during acute infection, in high numbers $\left(10^{6}\right.$ to $10^{10}$ oocysts/gram feces). Oocysts (thick wall) have several attributes that favor their environmental distribution: environmental survival for months, stickiness that helps infection and a relatively low infection dose ( 132 oocysts in healthy humans). Feces in diarrheic form, from infected calves (the main infected hosts), are washed out into water and soil sources, thereby contaminating human environment (Atwill et al. 2006). Infection with Cryptosporidium oocysts can take place by direct contact with infected stools, food and water, person to person (sexual contact) and aerosols. Clinical manifestations are watery, acute diarrhea, anorexia, nausea/vomiting and abdominal pain. In immunocompetent persons the disease is self-limiting while in immunocompromised patients it can be fatal (rapid dehydration due to 10-15 liters of diarrhea) with infections of other organs, such as pancreas and lungs.

\subsubsection{CRYPTOSPORIDIUM PARVUM AND ENVIRONMENT}

Cryptosporidium is now recognized as one of the major causes of zoonotic human diarrheal disease worldwide. Based on a large published data base, cryptosporidiosis is mainly a water-borne zoonosis but

*(This chapter is dedicated to late Huw V. Smith, a worldwide expert in Cryptosporidium, a friendly and thoughtful person that passed away prematurely) 
also food-borne, as infected animals' excreta reach water sources or food, and human' infection occurs through consumption or direct contact with (Figure 4.1.5.2). The best known outbreak occurred in 1993 in Milwaukee, Wisconsin, USA, where Lake Michigan contaminated drinking water with Cryptosporidium oocysts passed the filtration system of one of the city's water treatment plants affecting $>400,000$ people with a massive outbreak of watery diarrhea (Mac Kenzie et al. 1993).

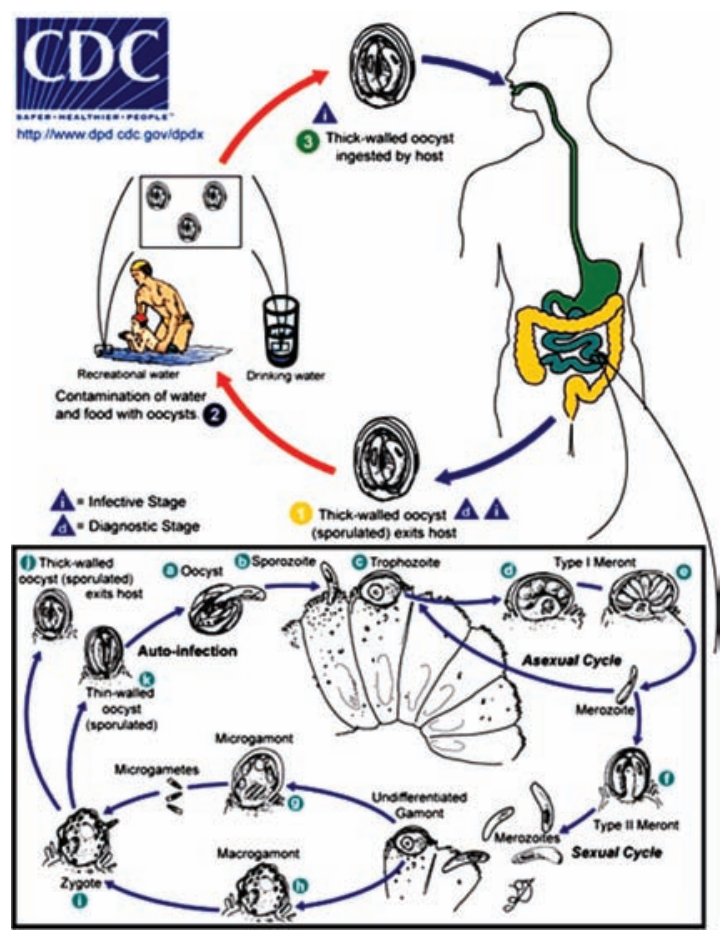

Figure 4.1.5.1. Cryptosporidium parvum life cycle. (with permission from CDC, Atlanta, USA, http://www. dpd.cdc.gov/dpdx/html/Cryptosporidiosis.htm)

Due to its environmental robustness and distribution, adequate mechanical and chemical treatments are required for oocyst removal from water prior to human supply. The main process for oocyst removal is filtration through a large variety of matrices that strains these particles and prevents their further movement into clean water outlets. In this context, Parker and Smith (1993) reported that shaking a mixture of $C$. parvum oocysts and sand particles can induce oocysts destruction, especially after chlorine addition. Agitation of oocysts with sand for 5 minutes and subsequent chlorination for additional 5 minutes resulted in $68.02 \%$ inactivation. The direct outcome of this phenomenon can be applied in large water filtration facilities, saving expensive processes used today to inactivate this protozoon parasite.

Naumova et al. (2007) proposed an analytical and conceptual framework for assessment of disease seasonality. Among six enterically transmitted reportable diseases (EDs) in Massachusetts, the authors quantified the timing and intensity of seasonal peaks of cryptosporidiosis incidence and examined the synchronization in timing of these peaks with respect to ambient temperature for a 10 years period. 
Relative to peak temperature, Cryptosporidium exhibited a significant delay of $\sim 40$ days. The long delay was explained by the following attributes: different transmission routes, person-to-person infection amplification, pathogen environmental survival, incubation time period, different disease manifestation and combination thereof.

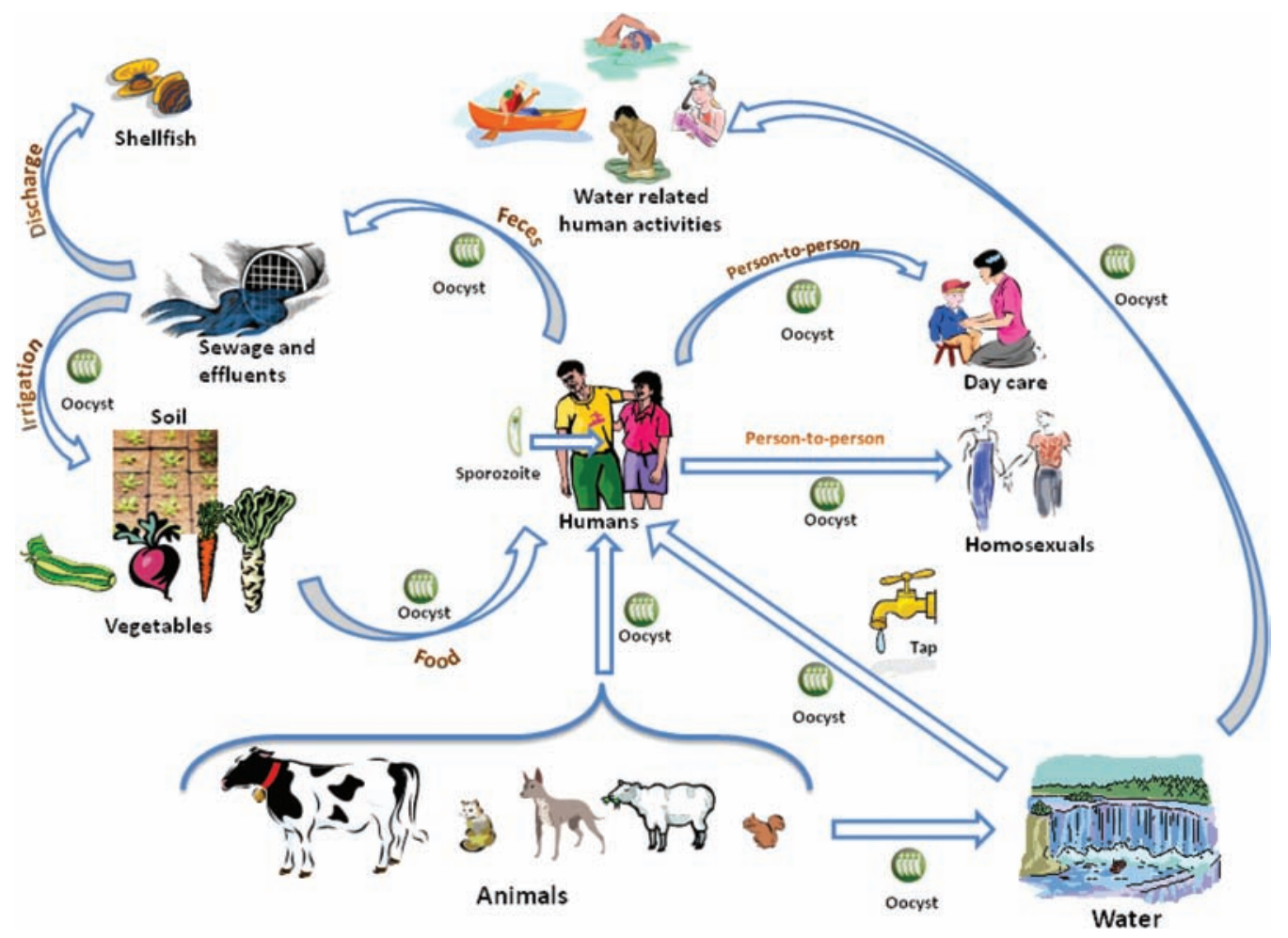

Figure 4.1.5.2. Cryptosporidium parvum environmental cycle

$\mathrm{Hu}$ et al. (2007) also pointed on temperature as a significant factor involved in Cryptosporidium transmission in Australia, by data analysis using two models: time series Poisson regression and seasonal auto-regression integrated moving average (SARIMA). It should be remembered that during warm summer months people drink more and practice more outdoor activities, increasing the risk of infection. In a more predictive study, Casman et al. (2001) analyzed qualitatively the impact of climate changes on cryptosporidiosis. Heuristically they showed that elevated temperature, changes in river flow, and increased water pollution could intensify cryptosporidiosis in the U.S., however in a developed country like U.S. with advanced public health management and high standards of living, the negative effects of climate can be overwhelmed, even in cases of climatic catastrophes.

In contrary, in a developing country like Indonesia, Katsuma et al. (1998) applied a multiple logistic regression model to find out the significant risk factors for Cryptosporidium infection. Their results revealed that direct contact with animals (in their particular case, cats), increased precipitations, floods and socio-economical aspects (e.g. crowded living conditions) are indeed the significant risk factors that 
public health management has to deal with, but much less efficiently then in USA. Here it should be pointed out another social aspect not covered by Casman et al. (2001) in their report and this is the age factor in cryptosporidiosis in other words children high susceptibility to infections, especially in developing countries (Reinthaler, 1989).

It is clear now that rainy seasons are a major factor in the spread of $C$. parvum and its high prevalence, but rain has another impact on pathogen pollution namely dilution factor (Katsumata et al., 1994; Curriero et al. 2001; Charron et al. 2004). If the main source of C. parvum is manure from calves (with elevated oocysts output), rain besides spreading and carrying manure can also dilute its content. A direct outcome of such an event is additional contaminated water sources with this specific pathogen but at lesser number, therefore in order to contract an infection, a person has to be exposed to larger volumes of water. A proof to this perception was reported by Noordeen et al. (2000) in Sri Lanka. The authors screened three agro-climatic zones in rural communities of Sri Lanka to determine Cryptosporidium species among goats. Cryptosporidium oocysts were detected in all agro-climatic zones, with highest prevalence of infection in the dry zone (33.6\%), followed by intermediate zone $(24.7 \%)$ and wet zone $(21.7 \%)(\mathrm{p}<$ 0.001). It is surprising that drier zone had higher prevalence, since water is an important parameter in infection and its extensiveness. Their logical explanation was that in dry regions, goats encounter nutritional stress under extensive management system without supplementary feed, in consequence lower immunity to parasitic infection. They also pointed out on additional environmental conditions (e.g. sheds with low standards of hygiene) that may favor a continuous fecal-oral transmission in those animals. In this case, it can be suggested a third possibility in which dry zone preserve higher concentrations of the parasite in excreta without rain dilution factor, increasing the chance of infection (based on infection dose).

In a more recent publication, Nichols et al. (2009) reported on a case-crossover study comparing rainfall and outbreaks of different pathogens, among them Cryptosporidium, for an extended time span (from 1910 to 1999). Based on weather data they found a significant correlation between excessive cumulative rainfall in the previous 7 days and pathogens outbreaks $(\mathrm{p}=0.001)$, but low rainfall $(<20 \mathrm{~mm})$ for three weeks before outbreaks was also highly correlated $(\mathrm{p}=0.002)$. Based on these results, these authors suggested that any climate change should examine both situations.

Jenkins et al. (2002) studied the survival of $C$. parvum oocysts in three soil types (silty clay loam, silt loam, and loamy sand) at different temperatures $\left(4,20\right.$, and $\left.30^{\circ} \mathrm{C}\right)$ and water potentials $(-0.033,-0.5$ and $-1.5 \mathrm{MPa}$ ). According to their experimental results, soil survival was not affected by the experimental water potentials, but affected at a certain extent by soil texture and mostly by temperature. Their conclusion was that under temperate climates' temperatures range, oocysts may survive for months in agricultural soil consequently posing a threat to surface waters.

A more extreme environmental survival study on Cryptosporidium parvum in soil was performed in Norway, where winter soil temperatures are very low with many freeze-thaw cycles (minimum ranges $-9^{\circ} \mathrm{C}$ to $-25.2^{\circ} \mathrm{C}$ and maximum $+9^{\circ} \mathrm{C}$ ) (Robertson and Gjerde, 2004). The results of this study revealed that $C$. parvum oocysts do not endure the Norwegian terrestrial environment over winter, and if despite all that oocysts are isolated from soil, their origin is from previous winter/spring excretions.

In England and Wales, a study was carried out, using ordinary least-squares regression method, to assess the role of environmental factors on cryptosporidiosis from records over an eight years period. Weather and river flow (as indicators of precipitation amount) were used as environmental factors. In general, between April and November cryptosporidiosis rate was positively related to maximum river flow, however between December to March (winter season) no such association was found (Lake et al. 2005). The authors hinted to animal-human infection route as the main factor related to disease prevalence, as during winter time animals (the main parasite carriers) are penned, hence reduced water and soil contamination. However, as already pointed out by Robertson and Gjerde (2004) in Norway, 
low temperature including freeze-thaw cycles that may occur in England and Wales should be also considered.

Graczyk et al. (2000) determined the geographical factors that contribute to watershed contamination with $C$. parvum in cattle farms in the floodplain area in Lancaster County, Pennsylvania, U.S.A. These factors are: large areas of ranches, herd streams crossing and unlimited access to, infected calves and manure that can provide continuous supply of oocysts into water sources.

As already mentioned, waterborne characteristic of $C$. parvum should be taken in consideration when applying effluents for soil irrigation. Khashiboun et al. (2007) studied the fate of C. parvum oocysts in history and non-history soils irrigated with effluents. Interestingly they found that history soil (formerly irrigated with effluents) enhances oocysts migration and infiltration into soils, concluding that effluent irrigation requires intensive treatment in order to remove soluble organic matter in addition to oocysts, in order to prevent soil and groundwater contamination.

Another aspect of water contamination with C. parvum oocysts is sewage discharge into sea or oceans. Beside their survival into the sediment fraction of these environments, oocysts of C. parvum can be up taken by a large variety of bi-valves living on the sea bottom, therefore jeopardizing the shellfish industry. There are two aspects linked to this problem: first, oocysts survival in sea water and second shellfish contamination. Sewage-borne oocysts reaching sea water can survive up to 4 weeks at a salinity of $30 \mathrm{ppt}$ at $20^{\circ} \mathrm{C}$ (Fayer et al. 1998; Robertson et al. 1992; Johnson et al. 1997) therefore shellfish can harbor infectious $C$. parvum oocysts and can serve as mechanical vectors of this pathogen (Izumi et al. 2006; Freire-Santos et al. 2000; Gomez-Bautista et al. 2000; Gomez-Couso et al. 2003). From the public health point of view, this fact is very important as shellfishes are mostly consumed uncooked.

Finally, Gomez-Couso et al. (2009) showed an interesting phenomenon upon which oocysts subjected to increased temperatures (as a result of solar water disinfection-SODIS method) excyte only up to 53.8\% from the initial titer, when exposed to a temperature of $46^{\circ} \mathrm{C}$ for 12 hours. Environmental excitation of oocysts and release of defenseless sporozoytes increase the inactivation rate of this pathogen, making this process an effective disinfection method.

\subsubsection{REFERENCES}

Atwill, E.R., Pereira, M.D.C., Alonso, L.H., Elmi, C., Epperson, W.B. et al. (2006) Environmental load of Cryptosporidium parvum oocysts from cattle manure in feedlots from the Central and Western United States. J. Environ. Qual. 35, 200-206.

Atwill, E.R., Phillips, R., Pereira, M. D-G.C., Li, X. \& McCowan, B. (2004) Seasonal shedding of multiple Cryptosporidium genotypes in California ground squirrels (Spermophilus beecheyi). Appl. Environ. Microbiol. 70, 6748-6752.

Casman, E., Fischhoff, B., Small, M. Dowlatabadi, H., Rose, J. \& Morgan, M.G. (2001) Climate change and Cryptosporidiosis: a qualitative analysis. Climatic Change 50, 219-249.

Charron, D.F., Thomas, M.K., Waltner-Toews, D., Aramini, J.J., Edge,T. et al. (2004) Vulnerability of waterborne diseases to climate change in Canada: a review. J. Toxicol. Environ. Health Part A 67, 1667-1677.

Curriero, F.C., Patz, J.A., Rose, J.B. \& Lele, S. (2001) The association between extreme precipitation and waterborne disease outbreaks in the united states, 1948-1994. Am J Public Health. 91, 1194-1199.

Fayer, R., Graczyk, T.K., Lewis, E.J., Trout, J.M. \& Farley, C.A. (1998) Survival of infectious Cryptosporidium parvum oocysts in seawater and eastern oysters (Crassostrea virginica) in the Chesapeake Bay. Appl. Environ. Microbiol. 64, 1070-1074.

Freire-Santos, F., Oteiza-Lopez, A.M., Vergara-Castiblanco, C.A., Ares-Mazas, E., Alavarez-Suarez, E. \& Garcia-Martin, O. (2000) Detection of Cryptosporidium oocysts in bivalve molluscs destined for human consumption. J Parasitol 86, 853-854. 
Gomez-Bautista, M., Ortega-Mora, L.M., Tabares, E., Lopez-Rodas, V. \& Costas, E. (2000) Detection of infectious Cryptosporidium parvum oocysts in mussels (Mytilus galloprovincialis) and cockles (Cerastoderma edule). Appl Environ Microbiol 66, 1866-1870.

Gomez-Couso, H., Freire-Santos, F., Martinez-Urtaza, J., Garcia-Martin, O. \& Ares-Mazas, M.E. (2003) Contamination of bivalve molluscs by Cryptosporidium oocysts: the need for new quality control standards. Int J Food Microbiol 87, 97-105.

Graczyk, T.K., Evans, B.M., Shiff, C.J., Karreman, H.J \& Patz, J.A. (2000) Environmental and geographical factors contributing to watershed contamination with Cryptosporidium parvum oocysts. Environ. Res. 82, $263-271$.

Hu, W., Tong, S., Mengersen, K. \& Connell, D. (2007) Weather variability and the incidence of cryptosporidiosis: comparison of time series poisson regression and SARIMA models. Ann Epidemiol 17, 679-688.

Izumi, T., Yagita, K., Endo, T. \& Ohyama, T. (2006) Detection system of Cryptosporidium parvum oocysts by brackish water benthic shellfish (Corbicula japonica) as a biological indicator in river water. Arch. Environ. Contam. Toxicol. 51, 559-566.

Jenkins, M.B., Bowman, D.D. Elizabeth A. Fogarty, E.A. \& Ghiorse, W.C. (2002) Cryptosporidium parvum oocyst inactivation in three soil types at various temperatures and water potentials. Soil Biol. Biochem. 34, 1101-1109.

Johnson, D.C., Enriquez, C.E., Pepper, I.L., Davis, T.L., Gerba, C.P. \& Rose, J.B. (1997) Survival of Giardia, Cryptosporidium, poliovirus and Salmonella in marine waters. Water Sci. Technol. 35, 261-268.

Katsumata, T., Hosea, D., Wasito, E.B., Kohno, S., Hara, K. et al. (1998) Cryptosporidiosis in Indonesia: a hospital-based study and a community-based survey. Am. J. Trop. Med. Hyg. 59, 628-632.

Khashiboun, K., Zilberman, A., Shaviv, A., Starosvetsky, J. \& Armon, R. (2007) The fate of Cryptosporidium parvum oocysts in reclaimed water irrigation-history and non-history soils irrigated with various effluent qualities. Water Air Soil Pollut 185, 33-41.

Lake, I.R., Bentham, G., Kovats, R.S. \& Nichols, G.L. (2005) Effects of weather and river flow on cryptosporidiosis. $J$ Water Health 3, 469-474.

Mac Kenzie, W.R., Hoxie, N.J., Proctor, M.E., Gradus, M.S., Blair, K.A. et al. (1994) A, massive outbreak in Milwaukee of Cryptosporidium infection transmitted through the public water supply. N. Engl. J. Med. 331, $161-167$.

Naumova, E.N., Jagai, J.S., Matyas, B., DeMaria, A.Jr., MacNeill, I.B. \& Griffiths, J.K. (2007) Seasonality in six enterically transmitted diseases and ambient temperature. Epidemiol. Infect. 135, 281-292.

Nichols, G., Lane, C., Asgari, N., Verlander, N.Q. \& Charlett, A. (2009) Rainfall and outbreaks of drinking water related disease and in England and Wales. J Water Health 7, 1-8.

Noordeen, F., Rajapakse, R.P.V.J., Faizal, A.C.M., Horadagoda, N.U. \& Arulkanthan, A. (2000) Prevalence of Cryptosporidium infection in goats in selected locations in three agroclimatic zones of Sri Lanka. Vet. Parasitol. 93, 95-101.

Parker, J. F. W. \& Smith, H. V. (1993) Destruction of oocysts of Cryptosporidium parvum by sand and chlorine. Water Res. 27, 729-731.

Reinthaler, F.F. (1989) Epidemiology of cryptosporidiosis in children in tropical countries. J Hyg Epidemiol Microbiol Immunol 33, 505-513.

Robertson, L.J. \& Gjerde, B.K. (2004) Effects of the Norwegian winter environment on Giardia cysts and Cryptosporidium oocysts. Microb. Ecol. 47, 359-365.

Robertson, L.J., Campbell, A.T. and Smith, H.V. (1992) Survival of Cryptosporidium parvum oocysts under various environmental pressures. Appl. Environ. Microbiol. 58, 3494-3500.

Torres, J., Gracenea, M., Gómez, M.S., Arrizabalaga, A. \& González-Moreno, O. (2000) The occurrence of Cryptosporidium parvum and C. muris in wild rodents and insectivores in Spain. Vet. Parasitol. 92, $253-260$.

Tzipori, S., Angus, K.W., Gray, E.W. \& Campell, I. (1980) Vomiting and diarrhea associated with cryptosporidial infection. N. Engl. J. Med. 303, 818. 


\section{Chapter 4.1.6}

\section{Giardiasis (Lambliasis)}

\section{[GIARDIA INTESTINALIS-SYN. G. LAMBLIA OR G. DUODENALIS]}

The flagellated parasitic protozoan Giardia intestinalis infects humans and animals through reproduction into the lumen of small intestine causing a disease called Giardiasis. It has a worldwide distribution with higher prevalence in tropical areas, with different genotypes independent of geographical areas (Minvielle et al., 2008; Caccio et al., 2005; Feng and Xiao, 2011). G. intestinalis is a species of the genus Giardia and phylum Metamonada. G. intestinalis has two main forms: cyst with an oval form of 8 to $14 \mu \mathrm{m}$ in length and 7 to $10 \mu \mathrm{m}$ wide (a highly resistant form excreted in feces of infected animals) and a motile, vegetative form called trophozoite. Trophozoite form has a pear-shaped (resembling human face) form with a ventral adhesive disc and eight flagella. The ventral adhesive disc helps the trophozoite to attach and colonize lumen epithelium. The reproduction is by binary fission and growth is supported by nutrients originating from lumen under anaerobic conditions. Besides humans, G. intestinalis infects a large variety of domestic and wild mammals (e.g. livestock, cats, beavers, dogs, rodents, pigs, etc.) (Bitto and Aldras, 2009; Robertson, 2009; Atwill et al., 1997) but marine animals were also reported (Deng et al., 2000). A classic example is infectious upstream beavers that contaminate mountain flows with their feces that unaware thirsty trekkers drink (Monzingo and Hibler, 1987). In humans, the infection is mainly through ingestion of contaminated water and food (by feces, sewage, effluents, etc.) but also through direct contact with animals or infected humans (person-to-person). WHO estimates 200 million infections in Asia, Africa and Latin America, with children and immunocompromised persons at higher risk (Gardner and Hill, 2001). In children aged $<5$ years experiencing recurrent diarrhoea, including Giardiasis, a significant increase in the risk of growth delays or stunting was observed (Ricci et al., 2007). Clinical manifestations of Giardiasis are acute diarrhea, with unpleasant odor, mucous, abdominal cramps, anorexia, vomiting, belching, headache, chills, constipation and weight loss.

\subsubsection{GIARDIA AND ENVIRONMENT (FIGURE 4.1.6.1)}

Giardia as a zoonotic waterborne parasite was previously described by many reports in relation to its transmission, resistance and persistence in various environments and outbreaks (Briancesco and 
Bonadonna, 2005; Lipp et al., 2001; Rimhanen-Finne et al., 2010; Maco et al., 2002; Eisenstein et al., 2008). Cysts can be transmitted through sewage and sludge, potable and recreational water, agricultural crop irrigation and livestock densities, contaminated food, direct contact with animals and their products (e.g., milk) and person-to person (daycare, homosexuals, etc.) (Winkworth, 2010; Chauret et al., 1999; Kabore et al., 2010; Amoros et al., 2010; Amahmid et al., 1999; Monzingo and Hibler, 1987; Bowman and Lucio-Forster, 2010; Carlander et al., 2009; Cody et al., 1994). Perhaps the main source of environmental contamination with Giardia cysts are dairy lots exposed to stormy seasons and rainfall events (Curriero et al., 2001). Miller et al. (2007) looked at climatic factors and farm management effects on Giardia cysts' environmental load. Cattle age (younger over older), stocking number and precipitation were the main factors associated with environmental loading of $G$. duodenalis cysts. An interesting finding of this study was that vegetated buffer strips can significantly reduce waterborne cysts in storm runoff. In Canada, in the North Saskatchewan River Basin, Alberta, Heitman et al. (2002) looked for the prevalence of Giardia cysts and Cryptosporidium oocysts in three sources: wildlife, human and agricultural (sewage and manure respectively). The lowest prevalence of Giardia cysts was obtained in wildlife (3.28\%), followed by human sewage influent (48.8\%), and the highest was in cow-calf manure ( 60\%). According to these authors, animal manure does not have access to water sources; therefore it serves only as an infectious source for feedlot animals and their human operators, while sewage effluents seem to be the main contamination source in this area with the lowest contribution from wildlife (depending on runoff severity). Here it should be mentioned that hydrological features are also important when dealing with runoffs. In New Hampshire, environmental risk of infection with Giardia cysts has been related to shallow ground water (Dennis et al., 1993). In another study, Giardia cysts have been shown to travel freely and not attached to natural soil particles, in such cases where soil particles are carried by runoff (Dai and Boll, 2003).

Another feature of Giardia cysts is their association with suspended particles versus free-state and their settling velocities, especially under storm conditions. Cizek et al. (2008) reported on a Giardia cysts association with suspended particles of $\sim 30 \%$ during dry weather and $60 \%$ during wet weather. The increase in this association value is potentially linked to increased particles wash out during wetter seasons, increasing the direct contact incidences.

If these high-cattle-use areas are close to the coast their impact on marine environments is obvious. One of these reports studied cyst accumulation in shellfish, an important human health issue as these animals are eaten mainly raw (Graczyk et al., 2003). There are different retention potentials according to the bivalve type involved and in proportion to the ambient concentrations of the parasite. Shellfish contamination with Giardia cysts seems to be a reversible process depending on water quality, therefore good depuration processes before processing can remove these pathogens completely. A range of recent studies have detected $G$. duodenalis in feces of marine vertebrates such as whales, dolphins, seals and shore birds (Lasek-Nesselquist et al., 2010; Plutzer and Tomor, 2009). A marine animal shown to harbor Giardia duodenalis is sea lion, which is therefore suggested as a marine reservoir of this parasite in marine environments (Deng et al., 2000).

Giardia removal from its main source, sewage, was studied at different sewage treatment plants (STP) according to their diverse applied processes: the bigger ones with tertiary treatment, smaller plants with enhanced secondary treatment and small ones as compact facilities. The tertiary, big STP-s were found to have a $>3 \operatorname{logs}$ reduction capability of Giardia cysts compared with $<1.5 \operatorname{logs}$ in the smaller STP-s (Kistemann et al., 2008). In Spain, in spite of relatively good practice in removal of cysts from raw sewage, the effluents discharged into a hydrological basin were still shown to harbor enough cysts to contribute to recreational area and fluvial beach contamination (Castro-Hermida et al., 2008; Castro-Hermida et al., 2010). In Switzerland, a survey study showed high prevalence of Giardia lamblia 
in recreational streams (Wicki et al., 2009). According to these authors, effluents were found to contain high numbers of $G$. lamblia cysts and consequently human wastes appear to be an important source of contamination.

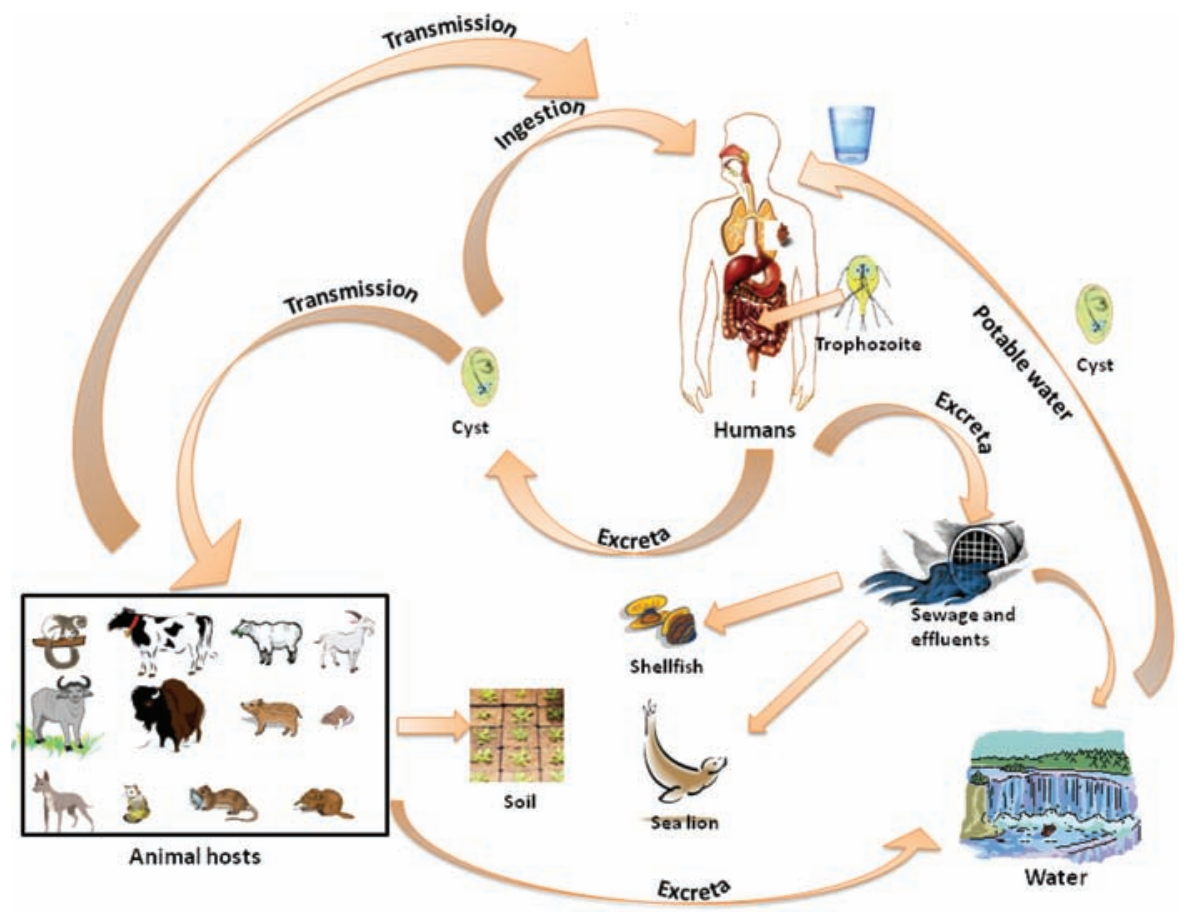

Figure 4.1.6.1. Giardia intestinalis' environmental infection patterns

Among that of other parasites, anthropogenic transmission of Giardia cysts to wild animals has been documented (Patz et al., 2000; Volotao et al., 2008). Black and gold howler monkeys were studied in relation to parasitic infections (Giardia and Cryptosporidium), closeness to human residence and residence type (wildness, rural and village) in Northern Argentina. The prevalence of Giardia sp. was significantly higher at the rural site $(67 \%)$ compared with the remote forest $(57 \%)$ and village sites (40\%). The high prevalence on all sites suggests that these monkeys can be used as a continuous reservoir for re-infection. Rural prevalence, which proved to be the highest, implies repeated zoonotic transmission among non-human primates, livestock, and/or people (Kowalewski et al., 2011). An additional example of Giardiasis introduction into a mountain gorilla population was described in Uganda. As a result of growing ecotourism and conservation activities, the area occupied by these wild animals was probably infected by human visitors (Nizeyi et al., 1999).

An interesting aspect related to environmental changes' impact on infectious diseases was shown by Eisenberg et al. (2006). These authors showed a significantly higher odds ratio of infections (including Giardia) in non-remote vs. remote villages, where non-remote ones are linked by new road construction in a previously roadless area of northern coastal Ecuador. In this case, due to easier access from one geographic location to another, the disease agent could move faster!

The ultimate, cheapest and simplest mean used to remove Giardia cysts from contaminated water is by different filtration processes combined with various pretreatments followed by various disinfectants (e.g., 
conventional sand filtration, direct filtration, slow sand filtration, contact filtration, cartridge filtration, diatomaceous earth filtration, dissolved air flotation, sedimentation, lime softening, coagulation, bank filtration, second stage filtration, continuous backwash upflow dual sand filtration, UV, chlorination, chloramination, ozonation, chlorine dioxide, bromination, etc.) (LeChevallier, 1992; Jacangelo et al., 1995; Weiss et al., 2005). Indeed, based on cyst size, filtration can retain these particles, preventing their distribution in drinking water systems. The efficiency can vary from 99 (two logs reduction) to $>99.999 \%$ (five logs reduction) depending on water turbidity, temperature, etc. in accordance with the USEPA Surface Water Treatment Rule that requires a $>3$ logs reduction effectiveness. In this context, Bichai et al. (2010) showed that Giardia cysts trapped into a granular activated carbon filter are subjected to predation by zooplankton (in this case Rotifers) through cyst internalization in these natural zooplankton. It is very conceivable that such processes take place in nature, reducing the parasite load in environments such as: river banks and dunes, granular filters and sediments.

\subsubsection{REFERENCES}

Amahmid, O., Asmama, S. \& Bouhoum, K. (1999) The effect of waste water reuse in irrigation on the contamination level of food crops by Giardia cysts and Ascaris eggs. Int J Food Microbiol 49, 19-26.

Amoros, I., Alonso, J.L. \& Cuesta, G. (2010) Cryptosporidium oocysts and Giardia cysts on salad products irrigated with contaminated water. J. Food Prot. 73, 1138-1140.

Atwill, E.R., Sweitzer, R.A., Pereira, M. D.C., Gardner, I.A., Van Vuren, D. \& Boyce, W.M. (1997) Prevalence of and associated risk factors for shedding Cryptosporidium parvum oocysts and Giardia cysts within feral pig populations in California. Appl. Environ. Microbiol. 63, 3946-3949.

Bichai, F., Barbeau, B., Dullemont, Y. \& Hijnen, W. (2010) Role of predation by zooplankton in transport and fate of protozoan (oo)cysts in granular activated carbon filtration. Water Res. 44, 1072-1081.

Bitto, A. \& Aldras, A. (2009) Prevalence of Giardia and Cryptosporidium in muskrats in northeastern Pennsylvania and New Jersey. J Environ Health 71, 20-26.

Bowman, D.D. \& Lucio-Forster, A. (2010) Cryptosporidiosis and Giardiasis in dogs and cats: veterinary and public health importance. Exp. Parasitol. 124, 121-127.

Briancesco, R. \& Bonadonna, L. (2005) An Italian Study on Cryptosporidium and Giardia in wastewater, fresh water and treated water. Environ Monit Assess 104, 445-457.

Caccio, S.M., Thompson, A.R.C., McLauchlin, J. \& Smith, H.V. (2005) Unravelling Cryptosporidium and Giardia epidemiology. Trends Parasitol. 21, 430-437.

Carlander, A., Schonning, C. \& Stenstrom, T.A. (2009) Energy forest irrigated with wastewater: a comparative microbial risk assessment. J Water Health 7, 413-433.

Castro-Hermida, J.A., Garcia-Presedo, I., Almeida, A., Gonzalez-Warleta, M. \& Mezo, M. (2010) Cryptosporidium and Giardia detection in water bodies of Galicia, Spain. Water Res. 44, 5887-5896.

Castro-Hermida, J.A., Garcia-Presedo, I., Almeida, A., Gonzalez-Warleta, M., Correia Da Costa, J.M. \& Mezo, M. (2008) Contribution of treated wastewater to the contamination of recreational river areas with Cryptosporidium spp. and Giardia duodenalis. Water Res. 42, 3528-3538.

Chauret, C., Springthorpe, S. \& Sattar, S. (1999) Fate of Cryptosporidium oocysts, Giardia cysts, and microbial indicators during wastewater treatment and anaerobic sludge digestion. Can. J. Microbiol. 45, 257-262.

Cizek, A.R., Characklis, G.W., Krometis, L-A., Hayes, J.A., Simmons, O.D. et al. (2008) Comparing the partitioning behavior of Giardia and Cryptosporidium with that of indicator organisms in stormwater runoff. Water Res. 42, 4421-4438.

Cody, M.M., Sottnek, H.M. \& O’Leary, V.S. (1994) Recovery of Giardia lamblia cysts from chairs and tables in child day-care centers. Pediatr 94, 1006-1008.

Curriero, F.C., Patz, J.A., Rose, J.B. \& Lele, S. (2001) The association between extreme precipitation and waterborne disease outbreaks in the United States, 1948-1994. Am J Public Health 91, 1194-1199. 
Dai, X. \& Boll, J. (2003) Evaluation of attachment of Cryptosporidium parvum and Giardia lamblia to soil particles. J. Environ. Qual. 32, 296-304.

Deng, M-Q., Peterson, R.P. \& Cliver, D.O. (2000) First findings of Cryptosporidium and Giardia in California sea lions (Zalophus californianus). J. Parasitol. 86, 490-494.

Dennis, D.T., Smith, R.P., Welch, J.J., Chute, C.G., Anderson, B., Herndon, J.L. \& von Reyn, C.F. (1993) Endemic Giardiasis in New Hampshire: a case-control study of environmental risks. J. Infect. Dis. 167, 13911395.

Eisenberg, J.N. S., Cevallos, W., Ponce, K., Levy, K., Bates, S.J. et al. (2006) Environmental change and infectious disease: How new roads affect the transmission of diarrheal pathogens in rural Ecuador. Proc. Natl. Acad. Sci. U.S.A. 103, 19460-19465.

Eisenstein, L., Bodager, D. \& Ginzl, D. (2008) Outbreak of Giardiasis and cryptosporidiosis associated with a neighborhood interactive water fountain-Florida, 2006. J. Environ. Health 71, 18-22.

Feng Y. \& Xiao, L. (2011) Zoonotic potential and molecular epidemiology of Giardia species and Giardiasis. Clin. Microbiol. Rev. 24, 110-140.

Gardner, T.B. \& Hill, D.R. (2001) Treatment of Giardiasis. Clin. Microbiol. Rev. 14, 114-128.

Graczyk, T.K., Conn, D.B., Marcogliese, D.J., Graczyk, H. \& De Lafontaine, Y. (2003) Accumulation of human waterborne parasites by zebra mussels (Dreissena polymorpha) and Asian freshwater clams (Corbicula fluminea). Parasitol Res. 89, 107-112.

Heitman, T.L., Frederick, L.M., Viste, J.R., Guselle, N. J., Morgan, U.M. et al. (2002) Prevalence of Giardia and Cryptosporidium and characterization of Cryptosporidium spp. isolated from wildlife, human, and agricultural sources in the North Saskatchewan River Basin in Alberta, Canada. Can. J. Microbiol. 48, 530-541.

Jacangelo, J.G., Adham, S.S. \& Laine, J-M. (1995) Mechanism of Cryptosporidium, Giardia, and MS2 virus removal by MF and UF. J Am Water Works Assoc 87, 107-121.

Kabore, H., Levallois, P., Michel, P., Payment, P., Dery, P. \& Gingras, S. (2010) Association between potential zoonotic enteric infections in children and environmental risk factors in Quebec, 1999-2006. Zoonoses Public Health 57, 195-205.

Kistemann, T., Rind, E., Rechenburg, A., Koch, C., Classen, T. et al. (2008) A comparison of efficiencies of microbiological pollution removal in six sewage treatment plants with different treatment systems. Int J Hyg Environ Health 211, 534-545.

Kowalewski, M.M., Salzer, J.S., Deutsch, J.C., Rano, M., Kuhlenschmidt, M.S. \& Gillespie, T.R. (2011) Black and gold howler monkeys (Alouatta caraya) as sentinels of ecosystem health: patterns of zoonotic protozoa infection relative to degree of human-primate contact. Am. J. Primatol. 73, 75-83.

Lasek-Nesselquist, E., Welch, D.M. \& Sogin, M.L. (2010) The identification of a new Giardia duodenalis assemblage in marine vertebrates and a preliminary analysis of $G$. duodenalis population biology in marine systems. Int. J. Parasitol. 40, 1063-1074.

LeChevallier, M.W. (1992) Characterization of Giardia and Cryptosporidium removal in drinking water treatment plants. Advances in Filtration and Separation Technology, (Ed. Bernie Scheiner), Volume 5: Separation Problems \& the Environment, October 20-23, 1991, Atlanta, Georgia, pp. 106-110.

Lipp, E.K., Farrah, S.A. \& Rose, J.B. (2001) Assessment and impact of microbial fecal pollution and human enteric pathogens in a coastal community. Mar. Pollut. Bull. 42, 286-293.

Maco, F.V., Marcos, R.L.A., Terashima, I.A., Samalvides, C.F. \& Gotuzzo, H.E. (2002) Distribution of entero-parasitic infections in the Peruvian Highland: study carried out in six rural communities of the department of Puno, Peru. Rev Gastroenterol Peru 22, 304-309.

Miller, W.A., Lewis, D.J., Lennox, M., Pereira, M.G.C., Tate, K.W. et al. (2007) Climate and on-farm risk factors associated with Giardia duodenalis cysts in storm runoff from California coastal dairies. Appl. Environ. Microbiol. 73, 6972-6979.

Minvielle, M.C., Molina, N.B., Polverino, D. \& Basualdo, J.A. (2008) First genotyping of Giardia lamblia from human and animal feces in Argentina, South America. Mem. Inst. Oswaldo Cruz 103, 98-103.

Monzingo, Jr.D.L. \& Hibler, C.P. (1987) Prevalence of Giardia sp. in a beaver colony and the resulting environmental contamination. $J$ Wildl Dis 23, 576-585. 
Nizeyi, J.B., Mwebe, R., Nanteza, A., Cranfield, M.R., Kalema, G.R.N.N. \& Graczyk, T.K. (1999) Cryptosporidium sp. and Giardia sp. infections in mountain gorillas (Gorilla gorilla beringei) of the Bwindi Impenetrable National Park, Uganda. J. Parasitol. 85, 1084-1088.

Patz, J.A., Graczyk, T.K., Geller, N. \& Vittor, A.Y. (2000) Effects of environmental change on emerging parasitic diseases. Int J Parasitol. 30, 1395-1405.

Plutzer, J. \& Tomor, B. (2009) The role of aquatic birds in the environmental dissemination of human pathogenic Giardia duodenalis cysts and Cryptosporidium oocysts in Hungary. Parasitol. Int. 58, 227-231.

Ricci, K.A., Girosi, F., Tarr, P.I., Lim, Y-W., Mason, C., et al. (2007) Reducing stunting among children: the potential contribution of diagnostics. Nat. Rev. Microbiol. Suppl.1, 29-38.

Rimhanen-Finne, R., Hanninen, M-L., Vuento, R., Laine, J., Jokiranta, T. S. et al. (2010) Contaminated water caused the first outbreak of Giardiasis in Finland, 2007: a descriptive study. Scand. J. Infect. Dis. 42, 613-619.

Robertson, L.J. (2009) Giardia and Cryptosporidium infections in sheep and goats: a review of the potential for transmission to humans via environmental contamination. Epidemiol. Infect. 137, 913-921.

Volotao, A.C.C., Souza, J.J.C., Grassini, C., Peralta, J.M. \& Fernandes, O. (2008) Genotyping of Giardia duodenalis from Southern Brown Howler Monkeys (Alouatta clamitans) from Brazil. Vet. Parasitol. 158, $133-137$.

Weiss, W.J., Bouwer, E.J., Aboytes, R., LeChevallier, M.W. O’Melia, C.R. et al. (2005) Riverbank filtration for control of microorganisms: Results from field monitoring. Water Res. 39, 1990-2001.

Wicki, M., Svoboda, P. \& Tanner, M. (2009) Occurrence of Giardia lamblia in recreational streams in Basel-Landschaft, Switzerland. Environ. Res. 109, 524-527.

Winkworth, C.L. (2010) Land-use change and emerging public health risks in New Zealand: assessing Giardia risks. N. Z. Med. J. 123, 55-66. 


\section{Chapter 4.1.7 Leishmaniasis}

\section{[LEISHMANIA SPP.]}

Leishmaniasis is a vector-transmitted disease caused by intracellular protozoan parasites that belong to order Kinetoplastida, family Trypanosomatidae and genus Leishmania. The arthropod vectors that transmit the parasite by bite are certain sand fly species (subfamily Phlebotominae), mainly from the genus Lutzomyia but also from genus Phlebotomus. In humans, infection is transmitted zoonotically from infected animals but it can be also transmitted anthroponotically from other infected humans (even congenitally) (Lysenko, 1971; Meinecke et al., 1999). Human infection is caused by about 21 species out of 30 zoonotic species found in mammals (grouped in two subgenera: Leishmania and Viannia) (Table 4.1.7.1) Leishmania: [L. donovani complex (L. archibaldi, L. donovani, L. infantum, and $L$. chagasi); L. mexicana complex (L. mexicana,L. garnhami, L.pifanoi, L. amazonensis, L. forattinii and $L$. venezuelensis); L. tropica complex (L.killicki, L. tropica); L. major complex (L. major); L. aethiopica complex (L. aethiopica) and 2) Viannia: L. braziliensis complex (L.(V.) braziliensis, L.(V.) peruviana); L.(V.) guyanensis complex ( L.(V.) panamensis, L.(V.) guyanensis, L.(V.) shawi); L.(V.) naiffi complex (L.(V.) naiffi); L.(V.) lainsoni complex (L.(V.) lainsoni); unclassified (L.(V.) colombiensis, L.(V.) equatoriensis). Subgenus Leishmania contains another group of similar organisms that is nonpathogenic for humans and includes Larabica, L. gerbilli, L. turanica (Old World) and L. aristidesi, L. enrietti, L. deanei, L. hertigi (New World) (Table 4.1.7.1). At species level, differentiation is done by isoenzyme and DNA sequence analysis or monoclonal antibodies. The parasite is introduced into humans by the sand fly vector as a flagellate form (promastigote) through blood sucking. The promastigote penetrates monocytes where intracelullar binary reproduction takes place forming a tailless form called amastigote. The amastigotes continue to multiply asexually (binary fission) into monocytes located in liver and spleen (causing the further described symptoms). A subsequent bite from a sand fly will transfer amastigote infected monocytes within blood meal into the gastro-intestinal system of the arthropod vector, where they will transform into flagellated promastigotes that can now migrate to the proboscis part of the arthropod vector (Figure 4.1.7.1). The disease can manifest in three forms, depending on leishmanial species, virulence and tropism, vector and host immune response: visceral, cutaneous and mucosal. The visceral form is the most severe and if untreated it is fatal. After an initial 


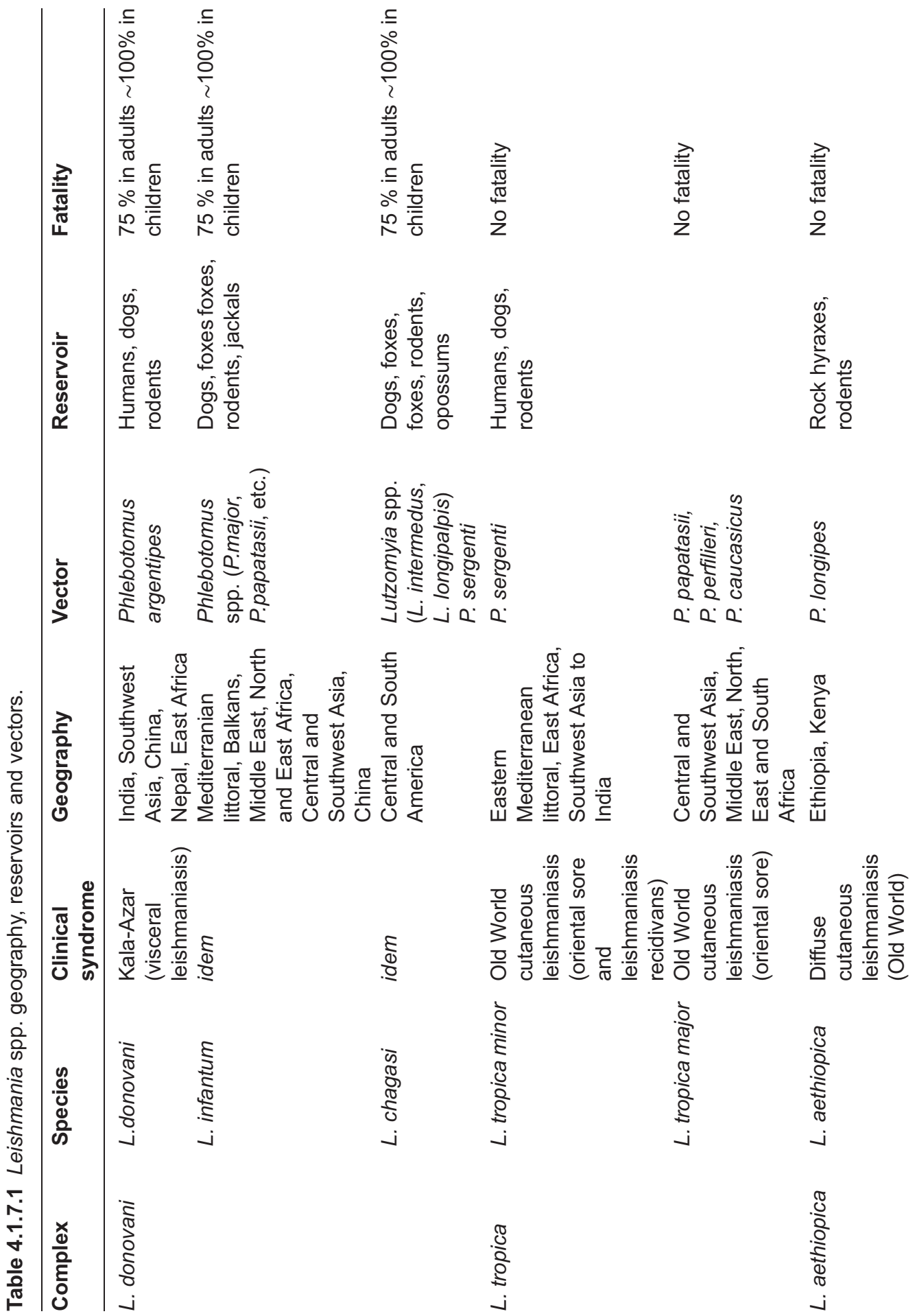



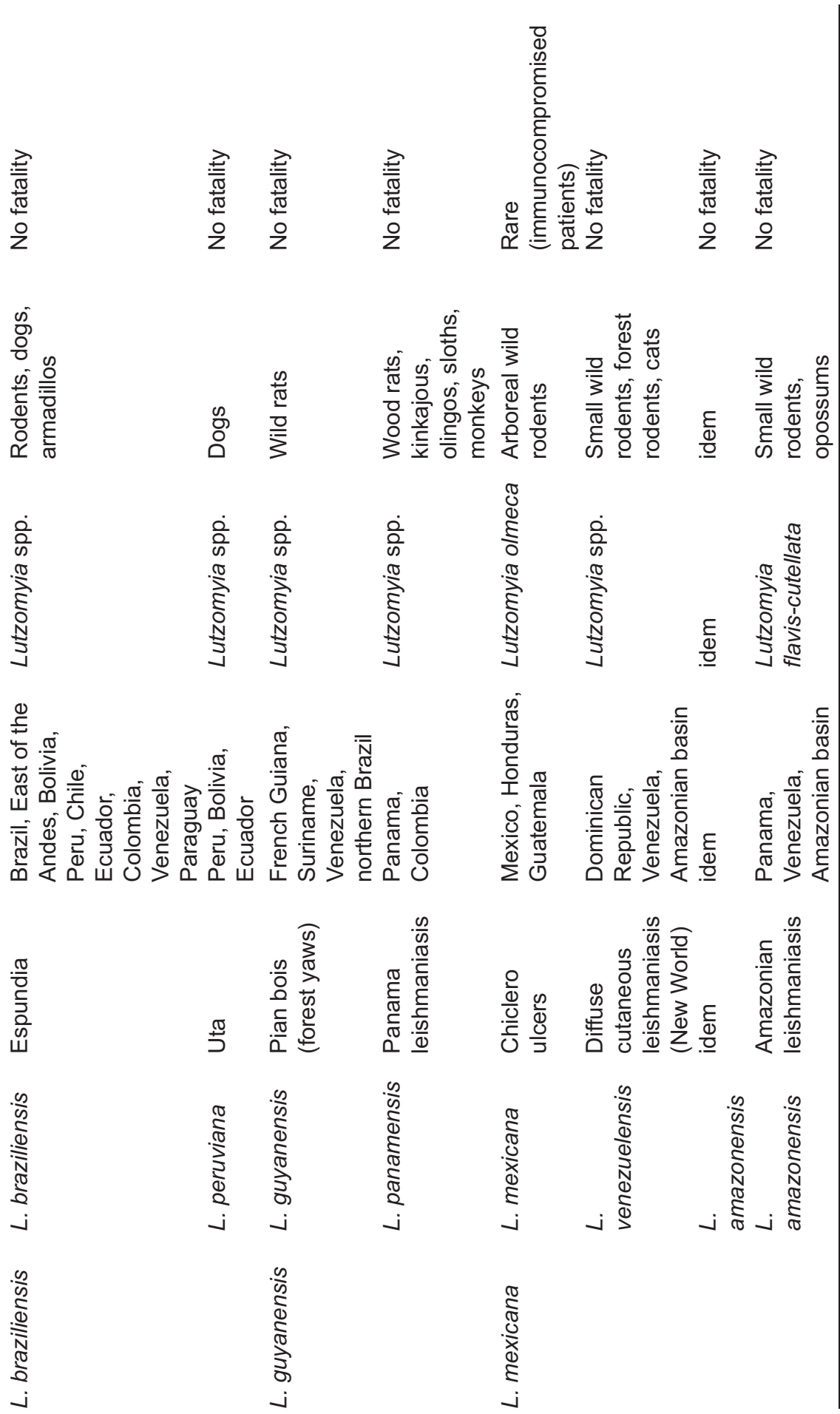
bite from an infected sand fly, a skin lesion may develop (leishmanioma), the incubation period can range from months to years with the following symptoms: hepatosplenomegaly, fever (remittent and intermittent), chills, vomiting, anemia, leukopenia, hypergammaglobulinemia and more, depending on the infected organ.

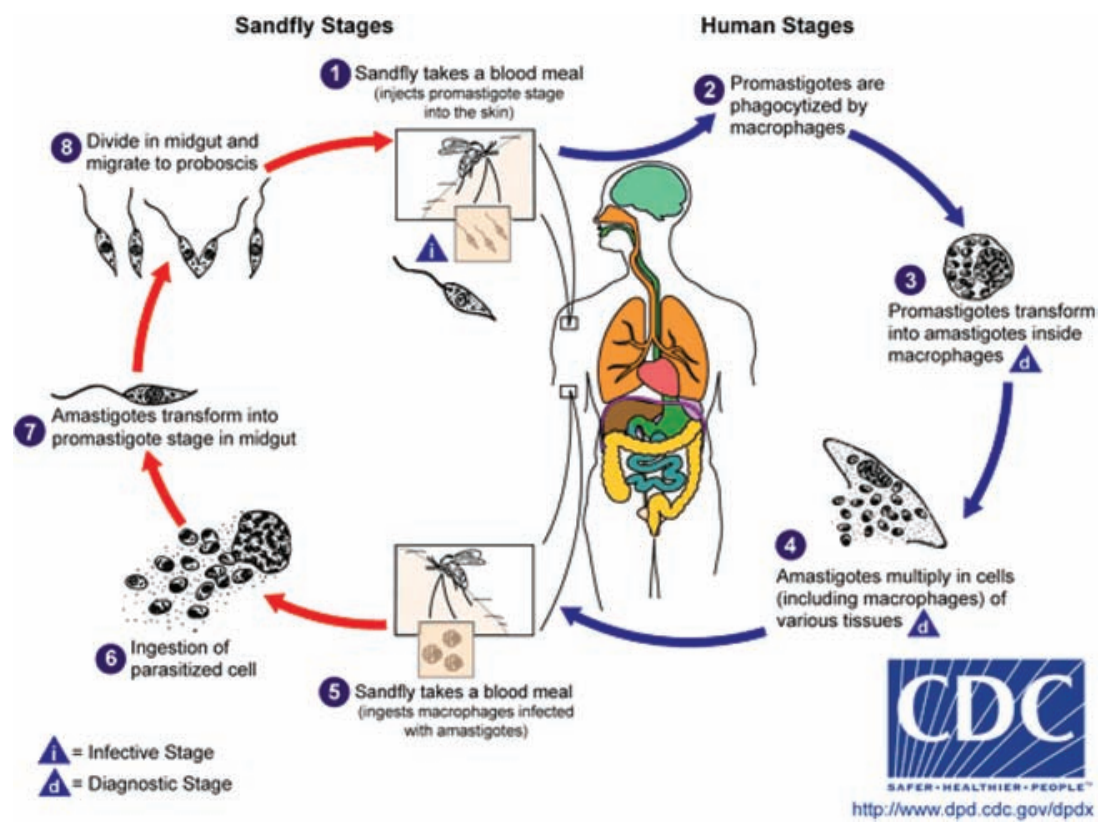

Figure 4.1.7.1. Leishmania spp. life cycle (with permission from CDC, Atlanta, USA- http://www.dpd.cdc. gov/dpdx/HTML/Leishmaniasis.htm)

\subsubsection{LEISHMANIA SPP. AND ENVIRONMENT}

According to our knowledge of Leishmania transmission, there are two main parameters that can be affected by various environmental factors: the vector (sand fly) and animals hosts (different mammals including feral cats) (Diniz et al., 2008; McCown and Grzeszak, 2010). Among these factors one can find: animals (e.g., stray and pet dogs) in the neighborhood, strongly associated with visceral leishmaniasis (Oliviera et al., 2006; Romero et al., 2009; Diniz et al., 2008; Baldi et al., 2004); landless workers movement and ecological tourism in preserved forest (Alessi et al., 2009), socio-economic status, densely populated urban area and as a result anthropogenic environmental changes (deforestation and urbanization) that impact new vectors and reservoirs/hosts at humans interface (synantropic zoonoses) creating new pathogenic complexes (Rotureau, 2006; Werneck et al., 2007; Saraiva et al., 2011; Tarallo et al., 2010; Zeilhofer et al., 2008); eclectic feed of sand flies in anthropic environments (de C Dias-Sversutti et al., 2007); climatic conditions (wet forested areas and altitude, both connected with vector abundance and interannual climatic events related to El Niño Southern Oscillation, ENSO) (Chaves and Pascual, 2006; Ozbel et al., 2011); irrigated habitats such as gardens and orchards (Kravchenko et al., 2004); anthropogenic domestic activities (hen-houses, pig-pens, deforestation and human dwellings) (da Silva et al., 2008; *Rotureau, 2006; Patz et al., 2000); intensive use of insecticides and emergence of arthropod resistance (Alexander and Maroli, 2003; Kishore et al., 2006); emergence of newly discovered 
vectors (Savani et al., 2009); changes in human population (increased number of immunodepressed and old people) (Baldi et al., 2004); and increasing global tourism (Zamarrón Fuertes et al., 2010) (Figure 4.1.7.2).

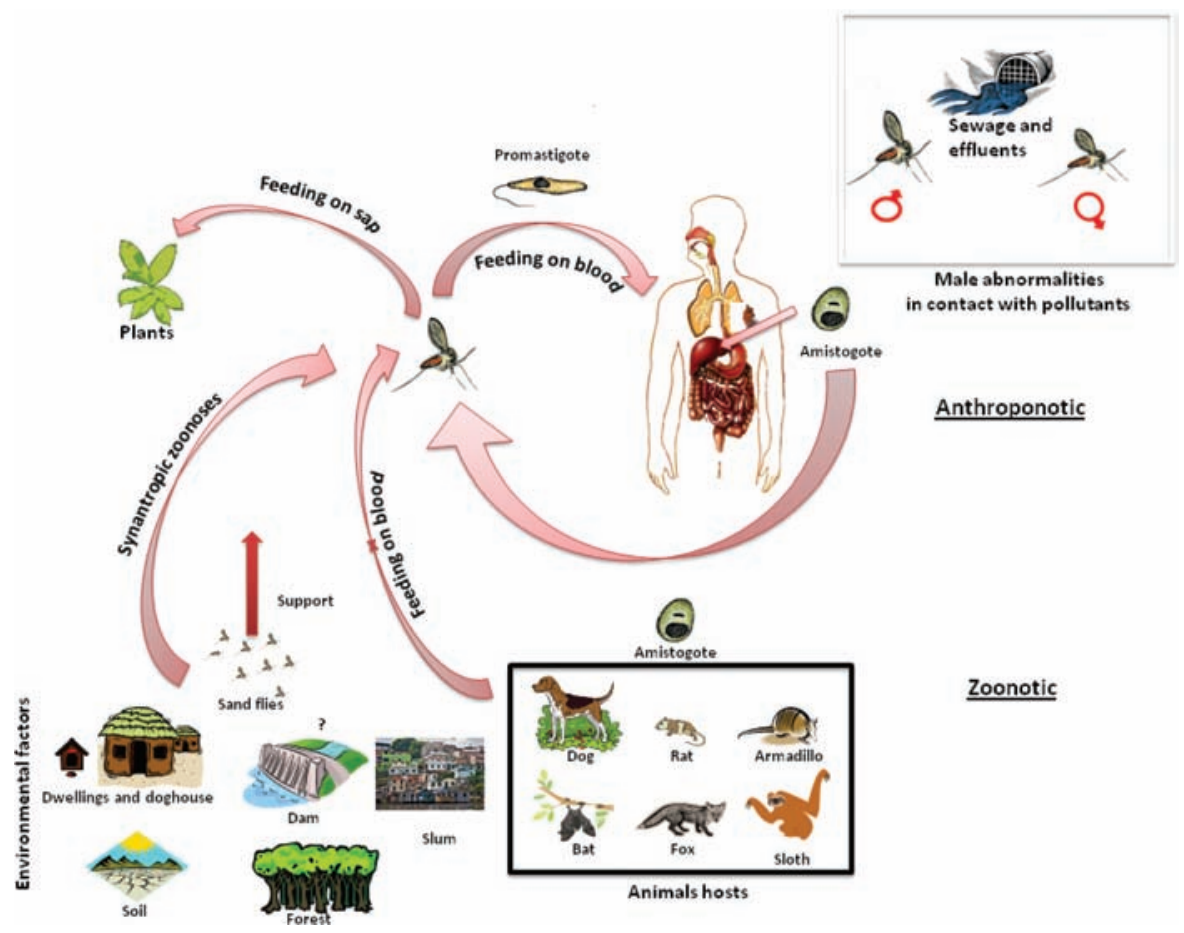

Figure 4.1.7.2. Some environmental factors involved in Leishmania and sand fly vector distribution

In relation to the sand fly vector, Kasili et al. (2009) found in Kenya, that goats significantly attract sand flies ( $P$. duboscqi sp.) among several mammals used as traps, and equally successful is the $\mathrm{CO}_{2}$-baited CDC light trap. Their study raises an interesting question related to $\mathrm{CO}_{2}$ local concentration in endemic areas: Does car and industrial pollution encourage sand flies to move in those areas? A Brazilian sand fly (Lutzomyia whitmani sp. an important vector of Leishmania) distribution related to vegetation has been studied in different geographic areas of the Maranhao state, from the dense and moist forest of the Amazon to the more xeric areas (semi-moist and semiarid), including mixed vegetation types areas (Rebêlo et al., 2009). The authors found an equal distribution between the geographic areas, with greater abundance in areas surrounding human dwellings (91.6\%) than inside the dwellings (8.4\%). They also suggested that following intensive deforestation the vector dispersion possibly reversed from west to east (from jungle towards urban area) to east to west (from peri- and urban areas to Amazonian forest). In urban areas of Teresina, Brazil, the highest incidence rates of leishmaniasis were mostly located in the city's peripheral areas. Multivariate analysis identified an interaction between population growth and the vegetation index, so that areas with high population growth and abundant vegetation showed the highest incidence rates (Cerbino et al., 2009). Again, heavy vegetation in endemic urban areas can provide an excellent growth and hide site for sand flies. 
In Argentina, phlebotomine sand flies were studied for abundance in primary vegetation-crop interface areas (Quintana et al., 2010). The highest prevalence was found in modified primary vegetation (crop areas) and the lowest near primary vegetation, supporting the Brazilian study's conclusions. In addition, these authors found a strong negative correlation between sand fly abundance and precipitation, a fact supported by the distribution of Leishmaniasis in arid zones (Middle East, Africa, etc.). In these areas, land cover has been shown to be the most influential parameter in a distribution model applied for two sand fly types: Phlebotomus papatasi (Scopoli) and P. alexandri (Sinton) (Colacicco-Mayhugh et al., 2010). In relation to vegetation, Elnaiem et al. (2003) found that increased densities of certain tree species (Acacia and Balanites) is well correlated to Leishmania prevalence. It is not clear if these tree species are biochemically favored by the sand fly vector or they just supply better hiding sites.

Other models in a more remote area (Brazil), applied to predict the distribution and potential risk of visceral leishmaniasis (VL) in this area, revealed similar results demonstrating good correlation between sand fly prevalence and a semi-arid and hot climate (Nieto et al., 2006). In contrast, in a province of Iran known for its dry and cold climate, a positive correlation was found between canine laishmaniasis seroprevalence ( $L$. infantum) and rainfall but also low temperatures $\left(<0^{\circ} \mathrm{C}\right)$ (Salahi-Moghaddam et al., 2010). To explain this inconsistency, the authors suggested that dog shelters (called "galakhs" in the local language) for cold days provide also an excellent refuge site for sand flies, consequently increasing the contact time between the vector and host. Similar results concerning animal' shelters were confirmed in a study performed in Brazil (Saraiva et al., 2006).

Soil has been shown also to play a significant role in leishmaniasis prevalence being concurrently linked to vector and host (Bhunia et al., 2010). In Israel's Western Negev Desert, rodents and sand flies have been trapped in this arid zone within three soil ecotones: loess, sand and sand-loess. The rodent Psammomys obesus was found to have the highest prevalence of Leishmania among other rodents, being soil dependent: loess $(65 \%)$, sandy-loess $(20 \%)$ and sandy habitat $(0 \%)$. The vector sand fly was positively correlated to soil moisture in this order: loess $>$ sandy-loess $>$ sandy (Wasserberg et al., 2002).

In France, researchers found two sand flies spp. ( $P$. ariasi and $P$. perniciosus) that are distributed accordingly into two endemic different climatic zones: 1) located 200-1000 $\mathrm{m}$ above sea level characterized by relatively low winter temperatures $\left(1.9^{\circ} \mathrm{C}\right.$ average $), 1042 \mathrm{~mm}$ average annual rainfall and much forest cover (vector Phlebotomus ariasi) and 2) located on the Mediterranean coastal plain, characterized by higher temperatures, lower rainfall and less forest cover (vector Phlebotomus perniciosus) (Chamaille et al., 2010).

In an interesting overview, Coutinho-Abreu and Ramalho-Ortigao (2011) described phenotypic plasticity in sand fly (as an expression of the environmental effects on genes expression) (Gibson, 2008). Sand fly saliva contains bioactive molecules involved in blood feeding and vertebrate host immune response. These molecules seem to be modulated by environmental factors (biotic and abiotic) that dictate saliva quality and quantity and further drive the outcome of Leishmania infection. Such factors are water and sap content of vegetation from arid or irrigated areas. Based on these factors, plant carbohydrate content depends on water availability and therefore sand flies have to adjust biochemically in order to obtain more nutrients even in arid zones. Schlein and Jacobson (2002) supported these findings experimentally by showing that desert sand flies exposed to excess sugar became progressively resistant to infection. Those authors also reported that $\sim 85 \%$ of first-generation sand flies colonized from desert habitat retained experimental Leishmania infection versus $25 \%$ of sand fly offspring originating from irrigated sites.

In this context, Amóra et al. (2010) reported on the monitoring of the sand fly species Lutzomyia longipalpis (one of the main vectors of visceral leishmaniasis (VL)) in Brazil. The authors found that monthly analysis of different environmental variables, such as temperature, relative humidity and 
rainfall, did not show a significant influence on sand fly population density. However, seasonal differences were found when $\sim 70 \%$ of the arthropods were captured during the rainy season. As mentioned above, it can be speculated that this event is linked to vegetation's higher sugar content correlated to water availability.

Also in Brazil, Rezende et al. (2009) surveyed the population of different arthropods vectors, among them phlebotomine, in an area where a hydroelectric power station was built and compared it with that of previous years. The results showed a record of 2,979 phlebotominae before the power station installation and 912 afterwards, revealing a reduction in this arthropod population. Their conclusion was that "environmental changes did not increase the risk in the occurrence of these diseases" including leishmaniasis. In this special case, two speculations can be brought up: 1) deforestation caused by dam construction could take away the moist, organic, dark environment required by sand fly to rest and breed and 2) the tumultuous water movement around the dam does not favor their life cycle, including egg deposition. Another possibility, based on the above study, could be that phlebotominae flies moved to another ecosystem, but this assumption should be verified further. In Tunisia, an arid country, Salah et al. (2007) found that in the contrary, a dam built in the eighties was the major factor in a leishmaniasis outbreak, revealing high incidence rates spatially clustered in regions located close to this dam. Here it can be hypothesized, based on other studies, that a certain level of moisture is required to bolster sand fly development. Again, in the Brazilian case in which moisture is much more elevated, there are no highly distinctive humid regions as in the Tunisian case (dam versus desert) or in Israel (Müller, et al., 2011). Milleron et al. (2008) presented results obtained in the process of sand fly rearing optimization by raising moisture levels that in turn increased adult blood-fed female egg development, whereas sand fly longevity decreased.

Related to sand fly gender, Guernaoui et al. (2010) surveyed P. papatasi males for genital malformation. They found that $20.4 \%$ of males tested have abnormal genitalia probably associated with environmental interference being prevalent in sewage dumps (e.g., mutagenic and teratogenic chemicals).

The host population in endemic areas has been shown also to contribute to leishmaniasis prevalence. In Israel, two clear peaks were recorded (between 1967-69 and 1980-82) (Anis et al., 2001), reflecting environmental changes such as the introduction of a new non-immune population and close extensive urbanization in areas of endemic foci, agricultural/industrial projects and also global warming. The same trends were observed also in Palestinian Authority areas and countries in Mediterranean basin.

In Ethiopia, an outbreak of L. aethiopica in a non-endemic area was linked to several environmental factors such as: house proximity to a gorge where hyraxes reside, presence of certain plants (Adhatoda schimperiana and Acacia spp.) in the compound and sharing the same room with domestic animals, which were significantly associated with developing cutaneous leishmaniasis (Negera et al., 2008).

Among the many animals (mainly mammals, e.g., dogs) reported to exercise as Leishmania spp. host, a recent report from Brazil showed seroprevalence and PCR positive results in Brazilian bats (Savani et al., 2010) suggesting their potential reservoir role. In the state of Rio de Janeiro, Brazil, researchers found that sloths are also potentially involved in transmittance of L. (Viannia) braziliensis between sylvatic and extradomiciliary areas by the sand fly Lutzomyia intermedia (Meneses et al., 2002; Herrer and Christensen, 1980).

Galvez et al. (2010) surveyed the canine population in the area of Madrid for leishmaniasis seroprevalence. They reported a higher prevalence trend that could not be explained solely by the socio-demographic characteristics of dog populations. One possible explanation could be the canines' increased outdoor abode due to warmer climate in the area, consequently exposing the host to increased contact with sand flies. Another aspect related to dogs was presented by Moreira et al. (2003) using a multivariate analysis, revealing canine short fur to be the strongest predictor of canine Leishmania 
infection in Brazil. Taking into account that many canine owners cut their dogs' fur short in summer time it is possible that in this way they increase exposure to sand fly bites.

A strong link between domestic animals and seroprevalence has been also shown in Iran (Oshaghi et al., 2010). The authors reported on Phlebotomus papatasi as the most dominant species infected with L. major in suburb an areas of a city. Patients living in these areas keep normally domestic animals in their houses which provide the appropriate environment to complete the sand fly life cycle in order to spread cutaneous leishmaniasis.

In human hosts in Central America, Convit et al. (2006) observed an interesting phenomenon linked to a frequent atypical form of cutaneous leishmaniasis (AtypCL) in patients. This atypical benign form is characterized by nonulcerating nodules containing a few parasites (L. chagasi, L. mexicana). Skin biopsies of lesions and nodules revealed numerous inorganic particles that seem to originate from volcanic ash prevalent in these areas (silica and aluminum being the most abundant components). The authors suggested that inorganic particles may play a significant immunomodulatory role in these infections, a fact that needs to be studied further.

In experimental mice infected with $L$. major, it was shown that exposure to subtoxic doses of mercury $\left(\mathrm{HgCl}_{2}\right)$ exacerbates the disease outcome and its effects on resistance are time-dependent. Pretreatment with mercury (at least 1 week before infection) induced autoimmune syndrome characterized by the induction of T-helper type 2 (Th2) cells, resulting in a higher susceptibility to parasite, footpad swelling and increased parasite burden. The authors raised the possible implication of mercury contamination in endemic areas of leishsmaniasis (Bagenstose et al., 2001).

Interaction between human population and forest was associated with the emergence of American cutaneous leishmaniasis (ACL). As a conclusion of this postulate, people living close to forest are significantly more exposed to vector and parasite, and therefore deforestation of primary forests will eradicate the infectious cycle! Chaves et al. (2008) raised an interesting issue related to the complex nature of the deforestation process in Costa Rica, finding, on the contrary, that living close to the forest edge diminishes the infection risk. They suggested that landscape alone does not explain the spatial distribution of ACL, but socioeconomic inequities (e.g., socially excluded populations or so called marginality index), climate variability caused by the El Niño Southern Oscillation (ENSO) and biodiversity changes should be considered in any model. Indeed, this topic was later supported by another study performed in Brazil, in which, using a multivariate analysis, it was shown that ACL is associated with: gas stove absence, forest distance $<200 \mathrm{~m}$, low income families, low education $\leq 4$ years, indoor birds and animals, forest-related leisure activities, rural work or school activities, absence of dogs and cats around the house and at the community level non-durable house' wall material (Pedrosa and Ximenes, 2009).

\subsubsection{REFERENCES}

Alessi, C.A., Galati, E.A., Alves, J.R. \& Corbett, C.E. (2009) American cutaneous leishmaniasis in the Pontal of Paranapanema - SP, Brazil: ecological and entomological aspects. Rev. Inst. Med. Trop. Sao Paulo 51, 277-282.

Alexander, B. \& Maroli, M. (2003) Control of phlebotomine sandflies. Med Vet Entomol 17, 1-18.

Amóra, S.S., Bevilaqua, C.M., Dias Ede, C., Feijó, F.M., Oliveira. P.G. et al. (2010) Monitoring of Lutzomyia longipalpis Lutz \& Neiva, 1912 in an area of intense transmission of visceral leishmaniasis in Rio Grande do Norte, Northeast Brazil. Rev Bras Parasitol Vet 19, 39-43.

Anis, E., Leventhal, A., Elkana, Y., Wilamowski, A. \& Pener, H. (2001) Cutaneous leishmaniasis in Israel in the era of changing environment. Public Health Rev 29, 37-47. 
Bagenstose, L.M., Mentink-Kane, M.M., Brittingham, A., Mosser, D.M. \& Monestier, M. (2001) Mercury enhances susceptibility to murine leishmaniasis. Parasite Immunol. 23, 633-640.

Baldi, L., Mizzoni, V. \& Guarino, A. (2004) Canine leishmaniasis in Campania: new and old foci. Parassitologia 46, 217-220.

Bhunia, G.S., Kumar, V., Kumar, A.J., Das, P. \& Kesari, S. (2010) The use of remote sensing in the identification of the eco-environmental factors associated with the risk of human visceral leishmaniasis (kala-azar) on the Gangetic plain, in north-eastern India. Ann Trop Med Parasitol 104, 35-53.

Cerbino, N.J., Werneck, G.L. \& Costa, C.H.N. (2009) Factors associated with the incidence of urban visceral leishmaniasis: an ecological study in Teresina, Piaui State, Brazil. Cad Saude Publica 25, 1543-1551.

Chamaille, L., Tran, A., Meunier, A., Bourdoiseau, G., Ready, P. \& Dedet, J-P. (2010) Environmental risk mapping of canine leishmaniasis in France. Parasit Vectors 3, 31.

Chaves, L.F. \& Pascual, M. (2006) Climate cycles and forecasts of cutaneous leishmaniasis, a nonstationary vector-borne disease. PLoS Med. 3, e295.

Chaves, L.F., Cohen, J.M., Pascual, M. \& Wilson, M.L. (2008) Social exclusion modifies climate and deforestation impacts on a vector-borne disease. PLoS Negl Trop Dis 2, e176.

Colacicco-Mayhugh, M.G., Masuoka, P.M. \& Grieco, J.P. (2010) Ecological niche model of Phlebotomus alexandri and P. papatasi (Diptera: Psychodidae) in the Middle East. Int J Health Geogr 9, 2.

Convit, J., Ulrich, M., Castillo, J., De Lima, H., Perez, M. et al. (2006) Inorganic particles in the skin of inhabitants of volcanic areas of Central America: their possible immunomodulatory influence in leishmaniasis and leprosy. Trans. R. Soc. Trop. Med. Hyg. 100, 734-739.

Coutinho-Abreu, I.V. \& Ramalho-Ortigao, M. (2011) Ecological genomics of sand fly salivary gland genes: An overview. J. Vector Ecol. 36, S58-S63.

da Silva, A.M., de Camargo, N.J., dos Santos, D.R., Massafera, R., Ferreira, A.C. et al., (2008) Diversity, distribution and abundance of sandflies (Diptera: Psychodidae) in Parana State, Southern Brazil. Neotrop. Entomol. 37, 209225.

de C Dias-Sversutti, A., de L Scodro, R.B., Reinhold-Castro, K.R., Neitzke, H.C. \& Teodoro, U. (2007) Preliminary study on feeding preference of Nyssomyia neivai (Pinto) and Nyssomyia whitmani (Antunes \& Coutinho) (Diptera: Psychodidae) in a rural area of the State of Parana, South Brazil. Neotrop. Entomol. 36, 953-959.

Diniz, S.A., Silva, F.L., Carvalho, N.A.C., Bueno, R., Guerra, R.M.S.N.C., Abreu-Silva, A.L. \& Santos, R.L. (2008) Animal reservoirs for visceral leishmaniasis in densely populated urban areas. J Infect Dev Ctries 2, 24-33.

Elnaiem, D.E.A., Mukhawi, A.M., Hassan, M.M., Osman, M.E., Osman, O.F. et al. (2003) Factors affecting variations in exposure to infections by Leishmania donovani in eastern Sudan. East. Mediterr. Health J. 9, 827-836.

Galvez, R., Miro, G., Descalzo, M.A., Nieto, J., Dado, D. et al. (2010) Emerging trends in the seroprevalence of canine leishmaniasis in the Madrid region (central Spain). Vet. Parasitol. 169, 327-334.

Gibson, G. (2008) The environmental contribution to gene expression profiles. Nat. Rev. Genet. 9, 575-581.

Guernaoui, S., Ramaoui, K., Rahola, N., Barnabe, C., Sereno, D. \& Boumezzough, A. (2010) Malformations of the genitalia in male Phlebotomus papatasi (Scopoli) (Diptera: Psychodidae). J. Vector Ecol. 35, 13-19.

Herrer, A. \& Christensen, H.A. (1980) Leishmania braziliensis in the Panamanian two-toed sloth, Choloepus hoffmanni. Am. J. Trop. Med. Hyg. 29, 1196-1200.

Kasili, S., Kutima, H., Mwandawiro, C., Ngumbi, P.M. \& Anjili, C.O. (2009) Comparative attractiveness of $\mathrm{CO}_{2}$-baited CDC light traps and animal baits to Phlebotomus duboscqi sandflies. J Vector Borne Dis 46, 191-196.

Keith, R.M. (2011) Controlling and coordinating development in vector-transmitted parasites. Science 331, 1149-1153.

Kishore, K., Kumar, V., Kesari, S., Dinesh, D.S., Kumar, A.J. et al. (2006) Vector control in leishmaniasis. Indian J. Med. Res. 123, 467-472.

Kravchenko, V., Wasserberg, G. \& Warburg, A. (2004) Bionomics of phlebotomine sandflies in the Galilee focus of cutaneous leishmaniasis in northern Israel. Med. Vet. Entomol. 18, 418-428.

Lysenko, A.J. (1971) Distribution of leishmaniasis in the Old World. Bull. World Health Organ. 44, 515-520.

McCown, M. \& Grzeszak, B. (2010) Zoonotic and infectious disease surveillance in Central America: Honduran feral cats positive for toxoplasma, trypanosoma, leishmania, rickettsia, and Lyme disease. J Spec Oper Med 10, 41-43. 
Meinecke, C.K., Schottelius, J., Oskam, L. \& Fleischer, .B (1999) Congenital transmission of visceral leishmaniasis (Kala Azar) from an asymptomatic mother to her child. Pediatr. 104, e65.

Meneses, C.R., de Azevedo, A.C., da Costa, S.M., Costa, W.A. \& Rangel, E.F. 2002. Ecology of American cutaneous leishmaniasis in the state of Rio de Janeiro, Brazil. J Vector Ecol 27, 207-214.

Milleron, R.S., Meneses, C.R., Elnaiem, D.A. \& Lanzaro, G.C. ( 2008) Effects of varying moisture on egg production and longevity of Lutzomyia longipalpis (Diptera: Psychodidae). J. Med. Entomol. 45, 160-165.

Moreira, E.D. Jr., de Souza, V.M.M., Sreenivasan, M., Lopes, N.L., Barreto R.B. \& de Carvalho, L.P. (2003) Peridomestic risk factors for canine leishmaniasis in urban dwellings: new findings from a prospective study in Brazil. Am. J. Trop. Med. Hyg. 69, 393-397.

Müller, G.C., Kravchenko, V.D., \& Schlein, Y. (2011) Seasonal and spatial changes of sand fly species in a canyon in the Carmel Mountains. J. Vector Ecol. 36, S118-S127.

Negera, E., Gadisa, E., Yamuah, L., Engers, H., Hussein, J. et al. (2008) Outbreak of cutaneous leishmaniasis in Silti woreda, Ethiopia: risk factor assessment and causative agent identification. Trans. R. Soc. Trop. Med. Hyg. 102, 883-890.

Nieto, P., Malone, J.B. \& Bavia, M.E. ( 2006) Ecological niche modeling for visceral leishmaniasis in the state of Bahia, Brazil, using genetic algorithm for rule-set prediction and growing degree day-water budget analysis. Geospat Health 1, 115-126.

Oliveira, C.D., Diez-Roux, A., César, C.C. \& Proietti, F.A. (2006) A case-control study of microenvironmental risk factors for urban visceral leishmaniasis in a large city in Brazil, 1999-2000. Rev. Panam. Salud Publica 20, 369-376.

Oshaghi, M.A., Rasolian, M., Shirzadi, M.R., Mohtarami, F. \& Doosti, S. (2010) First report on isolation of Leishmania tropica from sandflies of a classical urban Cutaneous leishmaniasis focus in southern Iran. Exp. Parasitol. 126, 445-450.

Ozbel, Y., Balcioglu, I.C., Olgen, M.K., Simsek, F.M., Toz, S.O. et al. (2011) Spatial distribution of phlebotomine sand flies in the Aydin Mountains and surroundings: the main focus of cutaneous leishmaniasis in western Turkey. J. Vector Ecol. 36, S99-S105.

Patz, J.A., Graczyk, T.K., Geller, N. \& Vittor, A.Y. (2000) Effects of environmental change on emerging parasitic diseases. Int. J. Parasitol. 30, 1395-1405.

Pedrosa, Fde. A. \& Ximenes, R.A. (2009) Sociodemographic and environmental risk factors for American cutaneous leishmaniasis (ACL) in the State of Alagoas, Brazil. Am. J. Trop. Med. Hyg. 81, 195-201.

Quintana, M.G., Salomon, O.D. \& De Grosso, M.S.L. (2010) Distribution of phlebotomine sand flies (Diptera: Psychodidae) in a primary forest-crop interface, Salta, Argentina. J. Med. Entomol. 47, 1003-1010.

Rebêlo, J.M., Rocha, R.V., Moraes, J.L., Alves, G.A. \& Leonardo, F.S. (2009) Distribution of Lutzomyia whitmani in phytoregions of the state of Maranhao, Northeastern Brazil. Rev Saude Publica 43, 1070-1074.

Rezende, H.R., Sessa, P.A., Ferreira, A.L., dos Santos, C.B., Leite, G.R. \& Falqueto, A. (2009) Effects of the installation of the Rosal hydroelectric power station, Itabapoana River, States of Espirito Santo and Rio de Janeiro, on anophelinae, planorbidae and phlebotominae. Rev. Soc. Bras. Med. Trop. 42, 160-164.

Romero, M.H., Lopez, M.C. \& Sanchez, J.A. (2009) An active search for cases of zoonotic visceral leishmaniasis in indigenous Colombian children and the canine population. Revista Rev Salud Publica (Bogota) 11, 944-951.

Rotureau, B. (2006) Are New World leishmaniases becoming anthroponoses?. Med. Hypotheses 67, 1235-1241.

*Rotureau, B. (2006) Ecology of the leishmania species in the guianan ecoregion complex. Am. J. Trop. Med. Hyg. 74, 81-96.

Salah, A.B., Kamarianakis, Y., Chlif, S., Alaya, N.B. \& Prastacos, P. (2007) Zoonotic cutaneous leishmaniasis in central Tunisia: spatio temporal dynamics. Int J Epidemiol 36, 991-1000.

Salahi-Moghaddam, A., Mohebali, M., Moshfae, A. Habibi, M. \& Zarei, Z. (2010) Ecological study and risk mapping of visceral leishmaniasis in an endemic area of Iran based on a geographical information systems approach. Geospat Health 5, 71-77.

Saraiva, L., Andrade Filho, J.D., Falcão, A.L., de Carvalho, D.A., de Souza, C.M. et al. (2011) Phlebotominae fauna (Diptera: Psychodidae) in an urban district of Belo Horizonte, Brazil, endemic for visceral leishmaniasis: Characterization of favored locations as determined by spatial analysis. Acta Tropica 117, 137-145. 
Saraiva, L., Lopes Jdos, S., Oliveira, G.B., Batista Fde, A., Falcão, A.L.\& Andrade Filho, J.D.(2006) Study of the sand flies in American cutaneous leishmaniasis area, in the municipality of Alto Caparao and Caparao, Minas Gerais State. Rev. Soc. Bras. Med. Trop. 39, 56-63.

Savani, E.S., de Almeida, M.F., de Oliveira Camargo, M.C., D’Auria, S.R., Silva, M.M. et al. (2010) Detection of Leishmania (Leishmania) amazonensis and Leishmania (Leishmania) infantum chagasi in Brazilian bats. Vet. Parasitol. 168, 5-10.

Savani, E.S., Nunes, V.L., Galati, E.A., Castilho, T.M., Zampieri, R.A. \& Floeter-Winter, L.M. (2009) The finding of Lutzomyia almerioi and Lutzomyia longipalpis naturally infected by Leishmania spp. in a cutaneous and canine visceral leishmaniases focus in Serra da Bodoquena, Brazil. Vet. Parasitol. 160, 18-24.

Schlein, Y. \& Jacobson, R.L. (2002) Linkage between susceptibility of Phlebotomus papatasi to Leishmania major and hunger tolerance. Parasitol 125, 343-348.

Tarallo, V.D., Dantas-Torres, F., Lia, R.P. \& Otranto, D. (2010) Phlebotomine sand fly population dynamics in a leishmaniasis endemic peri-urban area in southern Italy. Acta Trop. 116, 227-234.

Wasserberg, G., Abramsky, Z., Anders, G., El-Fari, M., Schoenian, G. et al. (2002) The ecology of cutaneous leishmaniasis in Nizzana, Israel: infection patterns in the reservoir host, and epidemiological implications. Int $J$ Parasitol 32, 133-143.

Werneck, G.L., Costa, C.H.N., Walker, A.M., David, J.R., Wand, M. \& Maguire, J.H. (2007) Multilevel modelling of the incidence of visceral leishmaniasis in Teresina, Brazil. Epidemiol. Infect. 135, 195-201.

Zamarrón Fuertes, P., Pérez-Ayala, A., Pérez Molina, J.A., Norman, F.F., Monge-Maíllo, B. et al. (2010) Clinical and epidemiological characteristics of imported infectious diseases in Spanish travelers. J Travel Med 17, 303-309.

Zeilhofer, P., Kummer, O.P., Santos, E.S., Ribeiro, A.L. \& Missawa, N.A. (2008) Spatial modelling of Lutzomyia (Nyssomyia) whitmani s.l. (Antunes \& Coutinho, 1939) (Diptera: Psychodidae: Phlebotominae) habitat suitability in the state of Mato Grosso, Brazil. Mem Inst Oswaldo Cruz. 103, 653-660. 


\section{Chapter 4.1.8}

\section{Microsporidiosis}

\section{[MICROSPORIDIA SPP.]}

The phylum Microspora that contains the Microsporidea class is a phylum of spore-forming monocellular parasites that now are classified under the kingdom of Fungi. The known families are: Encephalitozoonidea, Enterocytozoonidea, Microsporidea, Nosematidea, Pleistophoridea, Pleistophoridea, Nosematidea. Microsporidia are restricted to animal hosts (including many mammals) and the distribution is worldwide. Among other animals: insects, crustaceans and fishes are also infected. Some species are opportunistic infecting humans through contact with polluted water or aerosols inhalation, possibly food-borne, but sexual contact have been also considered as a possible transmission way (Li et al., 2003; Shaw and Kent, 1999; Hutin et al., 1998). The life cycle of microsporidia is composed of two stages: external or environmental and obligatory intracellular. The environmental stage harboring infectious spores entering hosts goes through an extrusion process that forms a tubular polar filament. Once close to intestinal cells, this "syringe" form penetrates the cell membrane injecting the sporoplasm form. The intracellular sporoplasm goes through asexual (merogony) and sexual (sporogony) paths with final disruption of the host cell and release of new infectious spores into the intestinal lumen (Figure 4.1.8.1). Infection in humans and animals occurs horizontally (feces and urine) with many organs involved, while microsporidia vertical transmission (transovarial) was observed in insect hosts. Spores are highly resistant to environmental conditions, making them a good candidate for continuous and persistent infection. The parasite infection manifests itself in immunocompetent individuals as keratoconjuctivitis, diarrhea (self-limiting), nausea, abdominal pain and occasional fever. In immunocompromised individuals, the parasite affects different organs such as: respiratory tract, kidney, prostate, liver, peritoneum and brain.

\subsubsection{ENVIRONMENT AND MICROSPORIDIA}

In relation to human zoonotic infections, Microsporidia are a relative new comer in the group of zoonoses. These intracellular protists (now belonging to the fungi kingdom) were formerly discovered in insects and fish. However, this pathogen emerged dramatically due to increasing numbers of immunosupressed AIDS 
patients or individuals under immunosuppressive drug treatment. Gradually it was realized that some species can cross borders from fish or insects into other animals, including humans (Cali and Takvorian, 2003; Mathis et al., 1999; Lono et al., 2010). For example, Brachiola algerae a parasite from invertebrates, was initially isolated from human surface infections, skin and eye, but later on it was isolated from human skeletal muscle, too (Coyle et al., 2004; Cali et al., 2005).

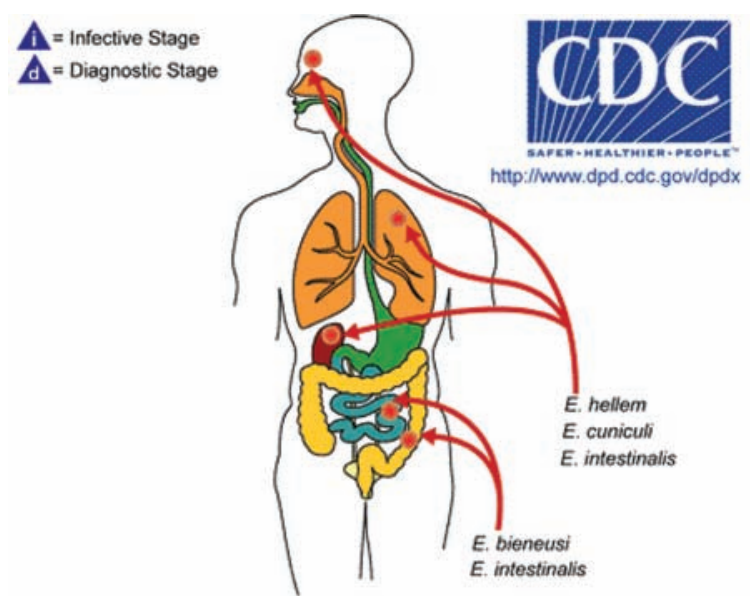

Intracellular development of $E$. bieneusi and $E$. intestinalis spores.

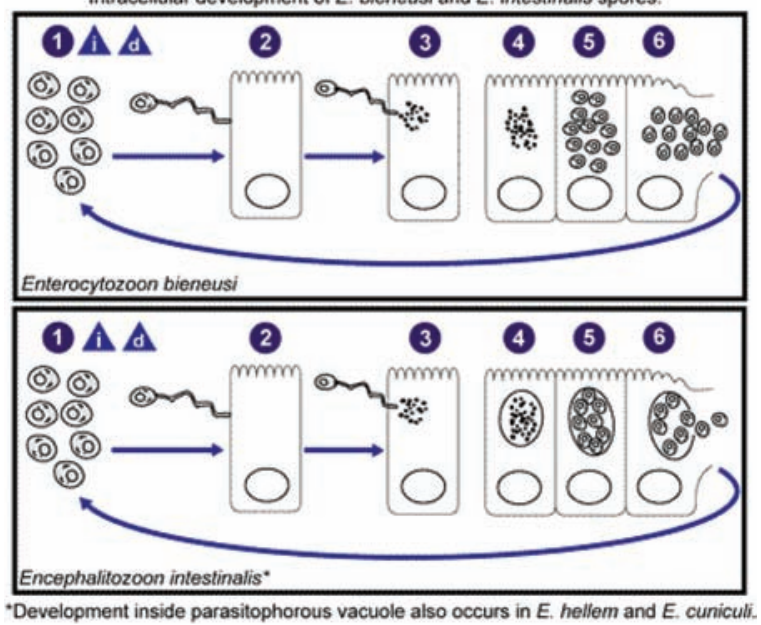

Figure 4.1.8.1. Microsporidia spp. life cycle and human infection sites. (with permission from CDC, Atlanta, USA. http://www.dpd.cdc.gov/dpdx/HTML/Microsporidiosis.html)

Slodkowicz-Kowalska (2009), using staining molecular techniques (FISH and multiplex FISH techniques) surveyed feces from 178 animal species for distribution of microsporidian species (Encephalitozoon intestinalis, E. hellem, E. cuniculi, and Enterocytozoon bieneusi) in Poland. The results showed higher distribution in birds than mammals, with preference in water fowls, possibly suggesting water as an infection source (Sparfel et al., 1997; Graczyk et al., 2008). Among the mammals, various lemur species and warty pigs were found positive for E. bieneusi and E. intestinalis. Thus, together with 


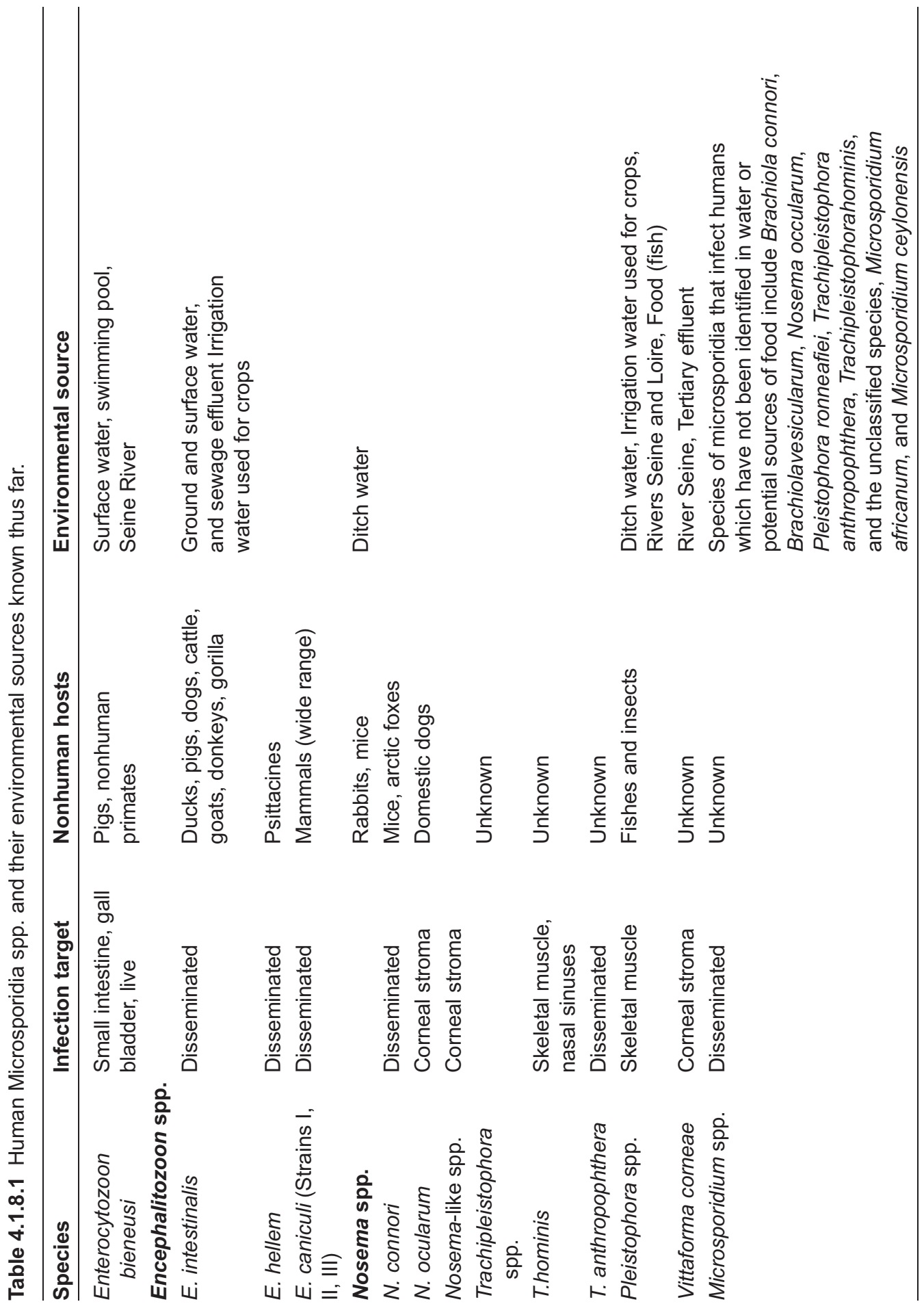


different bird species that live in various environments, the epidemiological aspect points to the ubiquity of infection with these pathogens. Water fowl in particular, have unlimited access to surface waters, including waters intended for human consumption, and therefore, as shown by Slodkowicz-Kowalska et al. (2006), a single visit of a waterfowl flock can introduce into the surface water approx. $9.1 \times 10^{8}$ microsporidian spores of species known to infect humans.

In Spain, microsporidia species Enterocytozoon bieneusi (9.7\%), Encephalitozoon intestinalis (4\%), and Encephalitozoon hellem $(0.8 \%)$ have been identified in urban park pigeons (Haro et al., 2005). These findings are important from the epidemiological and sanitary points of view as children and elderly people are the main visitors of these urban parks. Similar results were presented by Graczyk et al. (2007) on urban feral pigeons, emphasizing that exposure to those birds excrement, through cleaning of contaminated surfaces, could expose a person through direct inhalation to $3.5 \times 10^{3}$ Enterocytozoon bieneusi spores and $1.3 \times 10^{3}$ spores to a nearby person. In Portugal, a group studied various bird orders (Columbiformes, Passeriformes and Psittaciformes) as hosts for microsporidia. Enterocytozoon bieneusi have been identified in $28.9 \%$ of these birds, while the isolated species was closely related to the Peru6 genotype previously found in humans, in Peru (Lobo et al., 2006), emphasizing a worldwide distribution and the potential transmission through wild animal commerce.

In the recreational water environment, together with other protozoan parasites (Giardia and Cryptosporidium), microsporidia was isolated from bottom sediments disturbed by bathers or by their direct contribution, revealing two aspects: 1) this pathogen can survive in marine environment and 2) bathers are exposed to parasitic infections from recreational waters (the authors mentioned in their study, that these isolates were found on days deemed acceptable for bathing by fecal bacteria standards) (Graczyk et al., 2007).

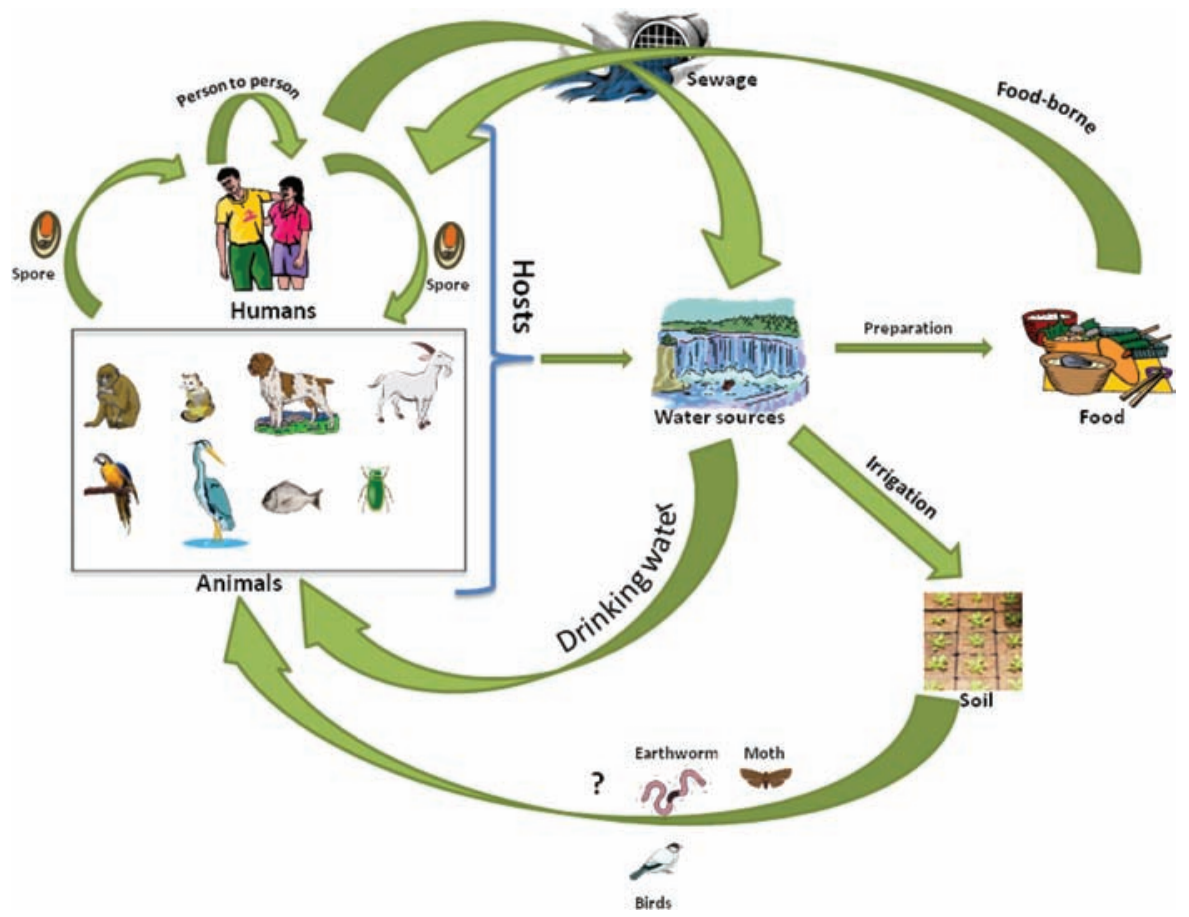

Figure 4.1.8.2. Microsporidia confirmed and potential environmental routes of infection 
Finally, it can be stated that we are only in the first stages of understanding the ecology and epidemiology of these pathogens. The fact that once this parasitic group was classified as protists then later as fungi reveals the confusion of the scientific community; however, along with a substantial advance in molecular biology, the picture became brighter. Two recent manuscripts raised several issues about the parasite-host relation, infectivity and inter-species transmission of microsporidia. Goertz and Hoch (2008) presented vertical transmission of its microsporidia E. schubergi in gypsy moth and survival for eight months in moth' cadavers on the ground. In addition, two other species' spores ( $N$. lymantriae and $V$. disparis) remained infective in overwintered cadavers only when they were snow covered for four months (Goertz and Hoch, 2008). The second manuscript described a new microsporidia as a common parasite infecting the classic nematode Caenorhabditis elegans in the wild by horizontal transmission (Troemel et al., 2008). As already pointed out by Cali et al. (2005), invertebrate and cold-blooded microsporidia can develop in human pathogens, so it can be very possible that this parasite is found also in soil and consequently infects ground and underground organisms that further transmit it to higher organisms (e.g., birds, earthworms and different mammals including humans) (Figure 4.1.8.2). These inter-connections need additional scientific evidence but they cannot be ruled out as already proved with other microorganisms. In humans, questions still exist about the persistence of microsporidia in healthy individuals, vertical transmission (pregnancy or transplantation) and possible infection with temporary unrelated microsporidia species ? (Didier and Weiss, 2006).

\subsubsection{REFERENCES}

Cali, A. \& Takvorian, P.M. (2003) Ultrastructure and development of Pleistophora ronneafiei n. sp., a microsporidium (Protista) in the skeletal muscle of an immunecompromised individual. J. Eukaryot. Microbiol. 50, 77-85.

Cali, A., Weiss, L.M. \& Takvorian, P.M. (2005) A review of the development of two types of human skeletal muscle infections from microsporidia associated with pathology in invertebrates and cold-blooded vertebrates. Folia Parasitol. 52, 1-11.

Cali, A., Weiss, L.M. \& Takvorian, P.M. (2005) A review of the development of two types of human skeletal muscle infections from microsporidia associated with pathology in invertebrates and cold-blooded vertebrates. Folia Parasitol (Praha) 52, 51-61.

Coyle, C.M., Weiss, L.M., Rhodes, L.V., Cali, A., Takvorian, P.M. et al. (2004) Fatal myositis due to the Microsporidian Brachiola algerae, a mosquito pathogen. $N$ Engl J Med 351, $42-47$.

Didier, E.S. \& Weiss, L.M. (2006) Microsporidiosis: current status. Curr. Opin. Infect. Dis. 19, 485-492.

Goertz, D. \& Hoch, G. (2008) Vertical transmission and overwintering of microsporidia in the gypsy moth, Lymantria dispar. J. Invertebr. Pathol. 99, 43-48.

Graczyk, T.K., Majewska, A.C. \& Schwab, K.J. (2008) The role of birds in dissemination of human waterborne enteropathogens. Trends Parasitol. 24, 55-59.

Graczyk, T.K., Sunderland, D., Rule, A.M., da Silva, A.J., Moura, I.N.S. et al. (2007) Urban feral pigeons (Columba livia) as a source for air- and waterborne contamination with Enterocytozoon bieneusi spores. Appl. Environ. Microbiol. 73, 4357-4358.

Graczyk, T.K., Sunderland, D., Tamang, L., Lucy, F.E. \& Breysse, P.N. (2007) Bather density and levels of Cryptosporidium, Giardia, and pathogenic microsporidian spores in recreational bathing water. Parasitol. Res. 101, 1729-1731.

Haro, M., Izquierdo, F., Henriques-Gil, N., Andres, I., Alonso, F. et al. (2005) First detection and genotyping of human-associated microsporidia in pigeons from urban parks. Appl. Environ. Microbiol. 71, 3153-3157.

Hutin, Y.J., Sombardier, M.N., Liguory, O., Sarfati, C., Derouin, F. et al. (1998) Risk factors for intestinal microsporidiosis in patients with human immunodeficiency virus infection: a case-control study. J. Infect. Dis. 178, 904-907. 
Li, X., Palmer, R., Trout, J.M. \& Fayer, R., (2003) Infectivity of microsporidia spores stored in water at environmental temperatures. J. Parasitol. 89, 185-188.

Lobo, M.L., Xiao, L., Cama, V., Magalhaes, N., Antunes, F. \& Matos, O. (2006) Identification of potentially human-pathogenic genotypes in various birds. Appl. Environ. Microbiol. 72, 7380-7382.

Lono, A., Kumar, G.S. \& Chye, T.T. (2010) Prevalence of microsporidia in an indigenous Orang Asli community in Pahang, Malaysia. Trans. R. Soc. Trop. Med. Hyg.104, 214-218.

Mathis, A., Breitenmoser, A.C. \& Deplazes, P. (1999) Detection of new Enterocytozoon genotypes in faecal samples of farm dogs and a cat. Parasite 6, 189-193.

Shaw, R.W. \& Kent, M.L. (1999) Fish microsporidia. In: Wittner, M., Weiss, L.M. (Eds.), The Microsporidia and Microsporidiosis. American Society of Microbiology, Washington, DC, pp. 418-446.

Slodkowicz-Kowalska, A. (2009) Animal reservoirs of human virulent microsporidian species. Wiad Parazytol 55, 6365.

Slodkowicz-Kowalska, A., Graczyk, T.K., Tamang, L., Jedrzejewski, S., Nowosad, A. et al. (2006) Microsporidian species known to infect humans are present in aquatic birds: implications for transmission via water? Appl. Environ. Microbiol. 72, 4540-4544.

Sparfel, J.M., Sarfati, C., Liguory, O., Caroff, B., Dumoutier, N. et al. (1997) Detection of microsporidia and identification of Enterocytozoon bieneusi in surface water by filtration followed by specific PCR. J. Eukaryot. Microbiol. 44, 78S.

Troemel, E.R., Félix, M.A., Whiteman, N.K., Barrière, A. \& Ausubel, F.M. (2008) Microsporidia are natural intracellular parasites of the nematode Caenorhabditis elegans. PLoS Biol. 6, e309. DOI: 10.1371/journal. pbio.0060309 


\section{Chapter 4.1.9}

\section{Monkey Malaria (Simian Malaria)}

\section{[PLASMODIUM SPP.]}

Genus Plasmodium causes the important disease malaria that infects humans and animals, with an estimated death toll of 1.5 to 2.7 million people each year. The parasite is vector-borne by a variety of mosquitoes from the genus Anopheles. Simian malaria like its relative human malaria (Plasmodium spp.) is also transmitted by Anopheles spp. mosquitos. In general, these Anopheles species differ from the common Anopheles spp. by their feeding habit: they feed on treetops (acrodendrophilic) while others feed at ground level (Tan et al., 2008)(Table 4.1.9.2). This feeding pattern explains the rarity of human infection with simian plasmodia. Plasmodium distribution is mainly in the tropic and sub-tropic regions (the Americas, Asia and sub-Saharan Africa). The genus Plasmodium (class: Aconoidasida and order: Haemosporida) multiply in the mosquito gut and is transmitted to animals and humans through infected female mosquito bite. Plasmodium includes at least 172 species with a wide variety of infected animals (mammals, birds, reptiles and amphibians) with $P$. falciparum, $P$. vivax, $P$. ovale and $P$. malariae as human parasites. $P$. malariae (synonym, $P$. rodhaini) can occur in chimpanzees too. Among different endemic zoonotic Plasmodia that infect primates and non-human primates, several are also transmitted to humans, and therefore are defined as travelers health risk (Table 4.1.9.1). Plasmodium species are intraerythrocytic parasites with life cycle that extends in two organisms: invertebrate (the mosquito vector) and vertebrate (mammals and other animals' hosts). The complex life cycle of Plasmodium spp. that includes asexual and sexual reproduction is shown in Figure 4.1.9.1. The clinical manifestations of simian malaria are: headache, fever, fatigue, anorexia, nausea, hepatosplenomegaly.

\subsubsection{SIMIAN MALARIA AND ENVIRONMENT}

Since mosquitoes are the main vectors of malaria transmission, it is important to understand their environmental behavior. Female mosquitoes are those that feed on blood while males feed on plants nectar, so one gender is highly connected to animals while the other is connected to plants (angiosperms). The diurnal activity of female mosquitoes is between dusk throughout the night. Water is a prerequisite for a successful reproduction, consequently most of the mosquitoes involved in simian 


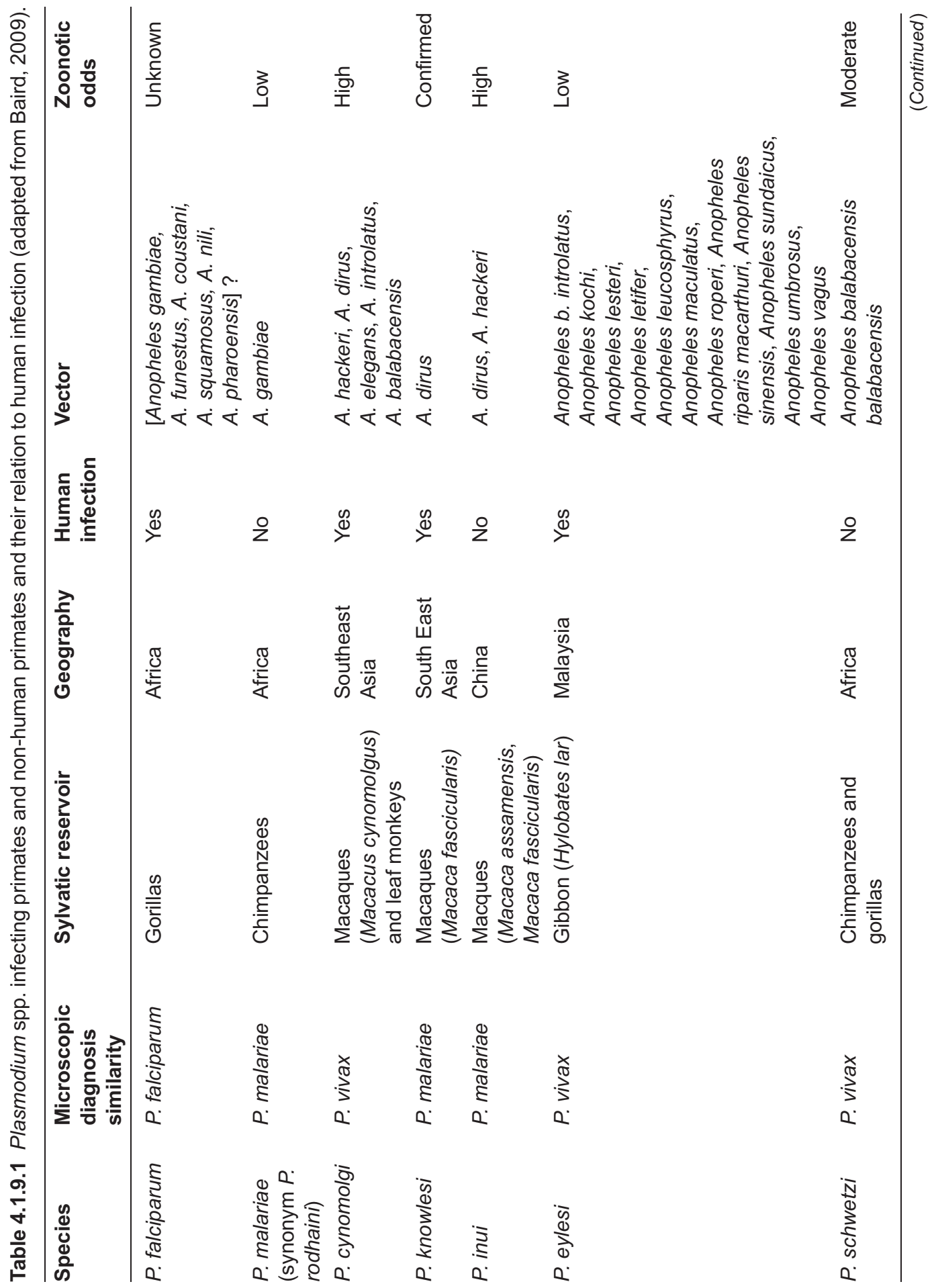




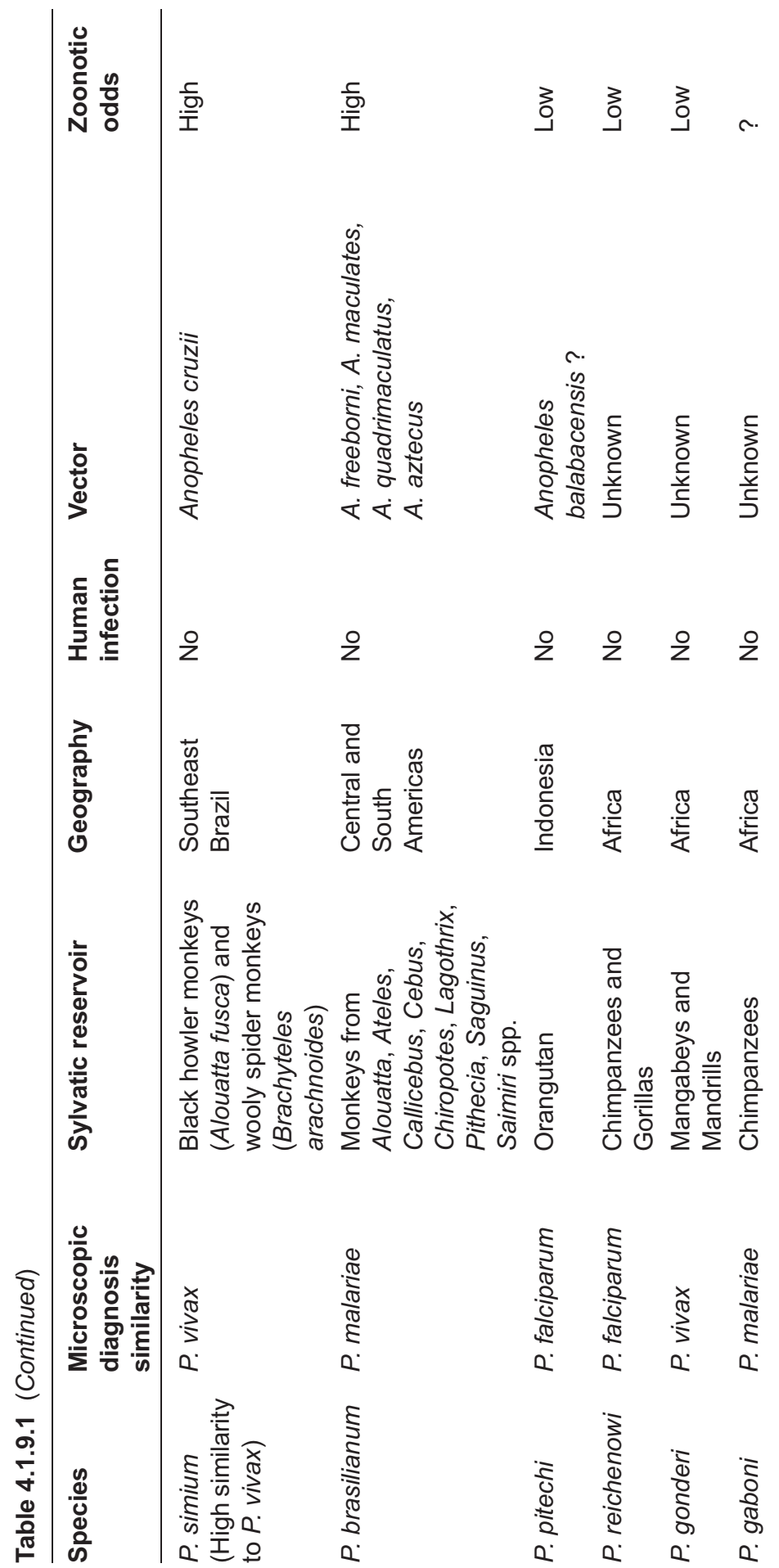




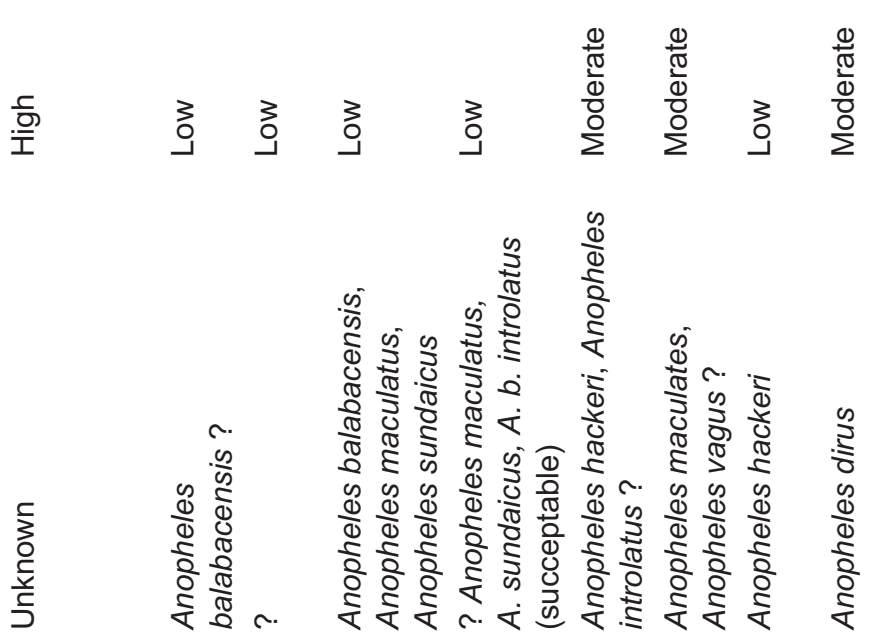

$\stackrel{\infty}{\sim} \quad \stackrel{\circ}{z} \quad \stackrel{\circ}{z} \quad \stackrel{0}{z} \quad \stackrel{\circ}{z} \quad \stackrel{\circ}{z}$

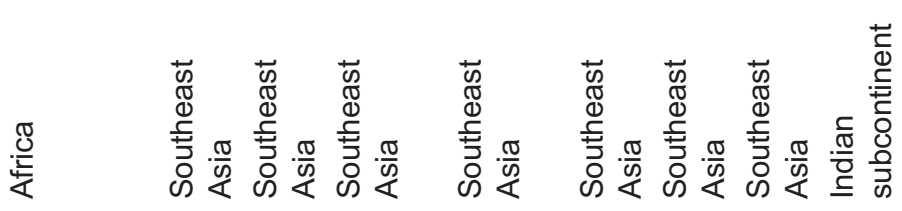

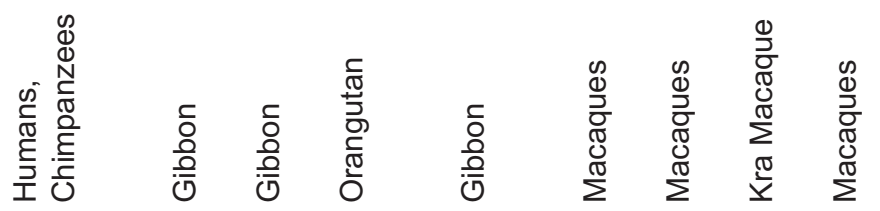

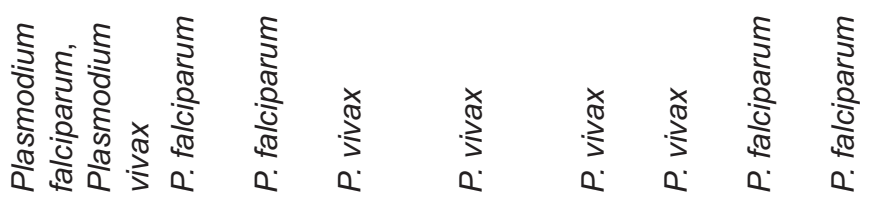

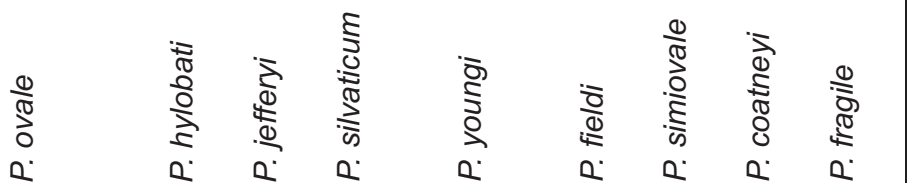




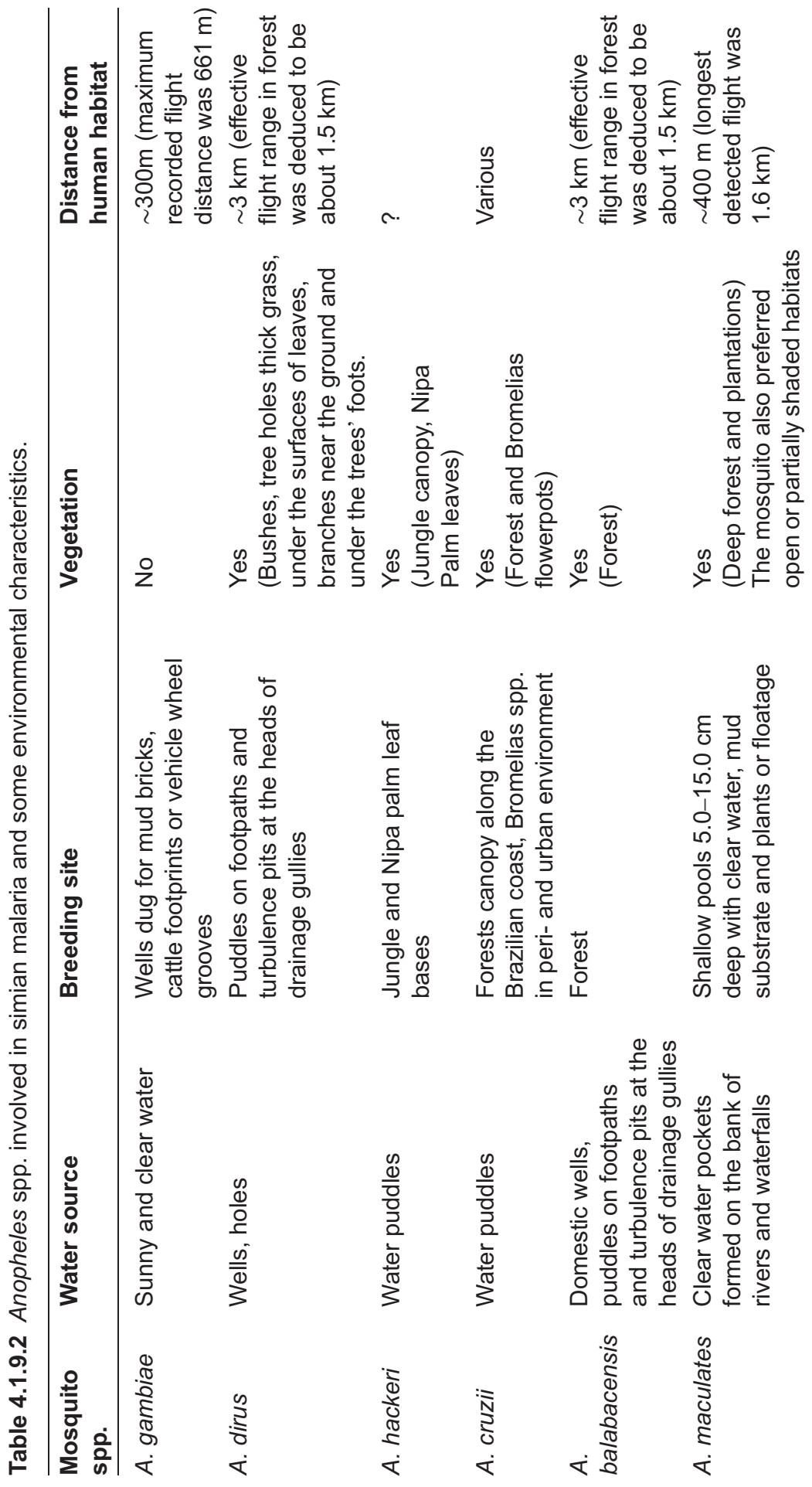


$\sim$

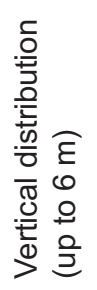

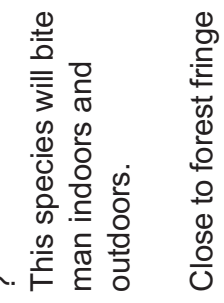

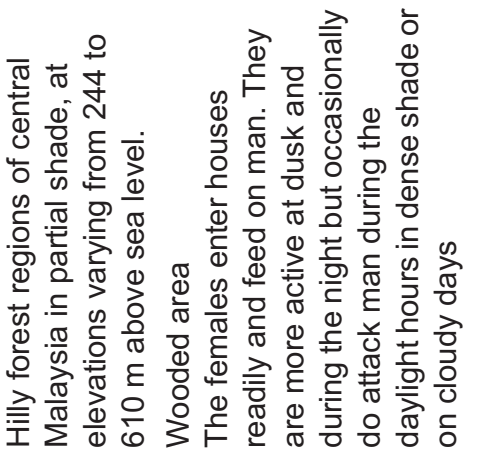

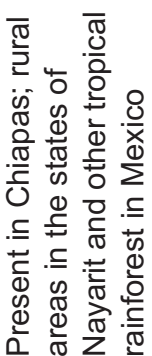

$$
\begin{aligned}
& 0 \\
& 0 \\
& 0 \\
& 0 \\
& 0 \\
& 0 \\
& 0 \\
& 0 \\
& 0 \\
& 0 \\
& 0 \\
& 0 \\
& 0
\end{aligned}
$$

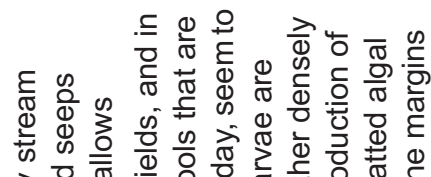

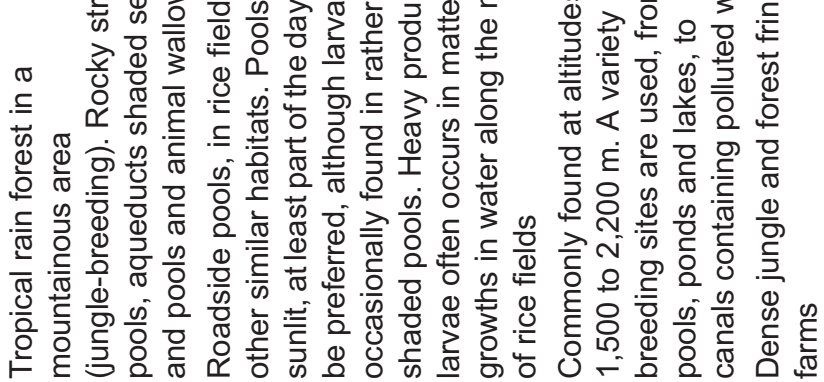
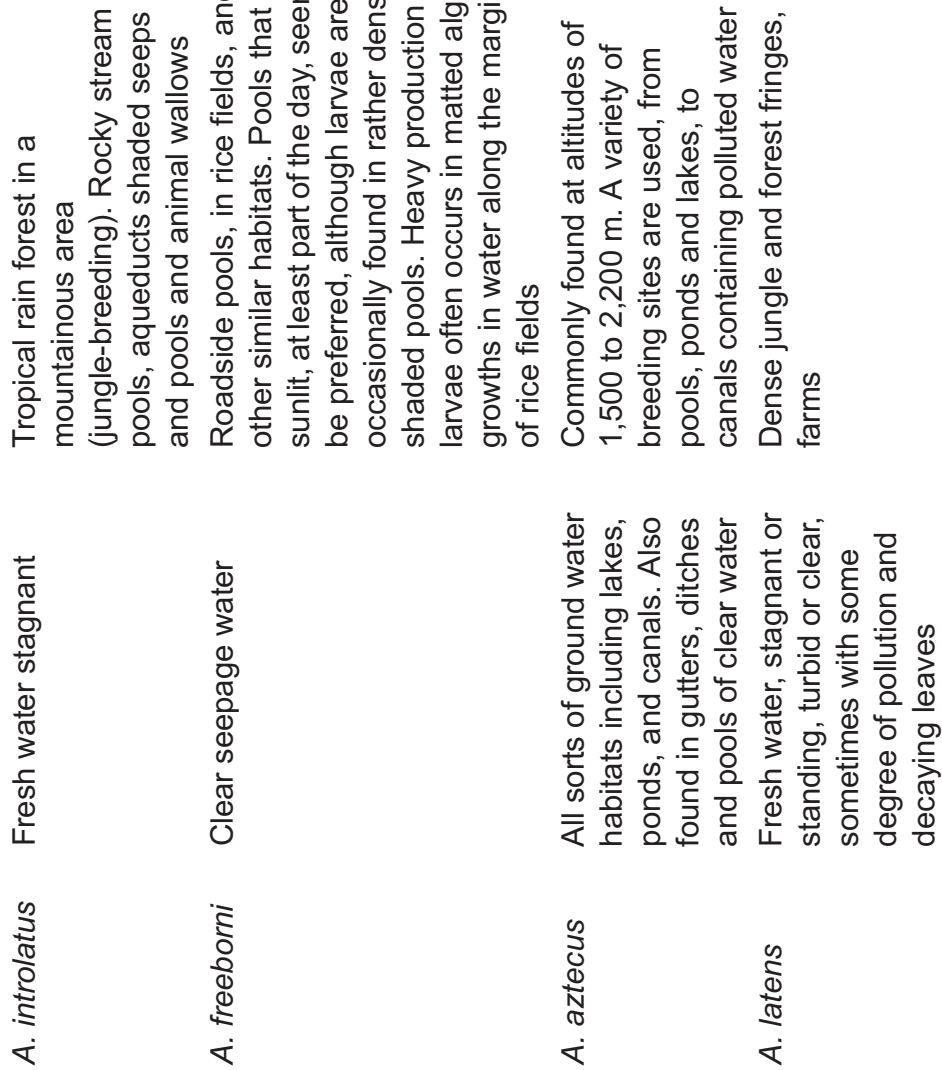
malaria live and multiply near water sources, but any puddles format is also suitable (Suwonkerd et al., 2004). Mosquitoes from the family Culicidae like the genus Anopheles, have been shown to survive well during dry seasons in Kenya, an endemic region of malaria (Minakawa et al., 2001). In this case, A. gambiae sp. practices two survival strategies during the dry season: 1) continuous reproduction throughout the year and 2) embryo dormancy in moist soil for at least several days. In South America, anophelidae were found to multiply close to certain plants (the epiphytic subfamily Bromelioideae) that are also currently grown in periurban and urban regions, therefore bringing these vectors close to human habitats (Marques and Forattini, 2009; Molez, 1999). In general, it can be stated with a high degree of confidence that malaria-carrying mosquitoes (both human and simian) are highly adapted to survive in various extreme environments (Budiansky, 2002) including human made ones, such as orchards, used tire depots, fish farms, etc. (Obsomer et al., 2007; Budiansky, 2002). In a study performed in the Peruvian Amazon region, Vittor et al. (2006) clearly showed that deforestation increased Anopheles darlingi's human-biting rate compared to forested areas. The behavior of these mosquitoes can be explained by landscape alteration via deforestation that reduces previous vertebrate host diversity, leaving humans as the main target in the absence of other warm-blooded animals in the open area, fewer sources of nutrients (plants and their flowers) and purely adaptation to new environment (Figure 4.1.9.2).

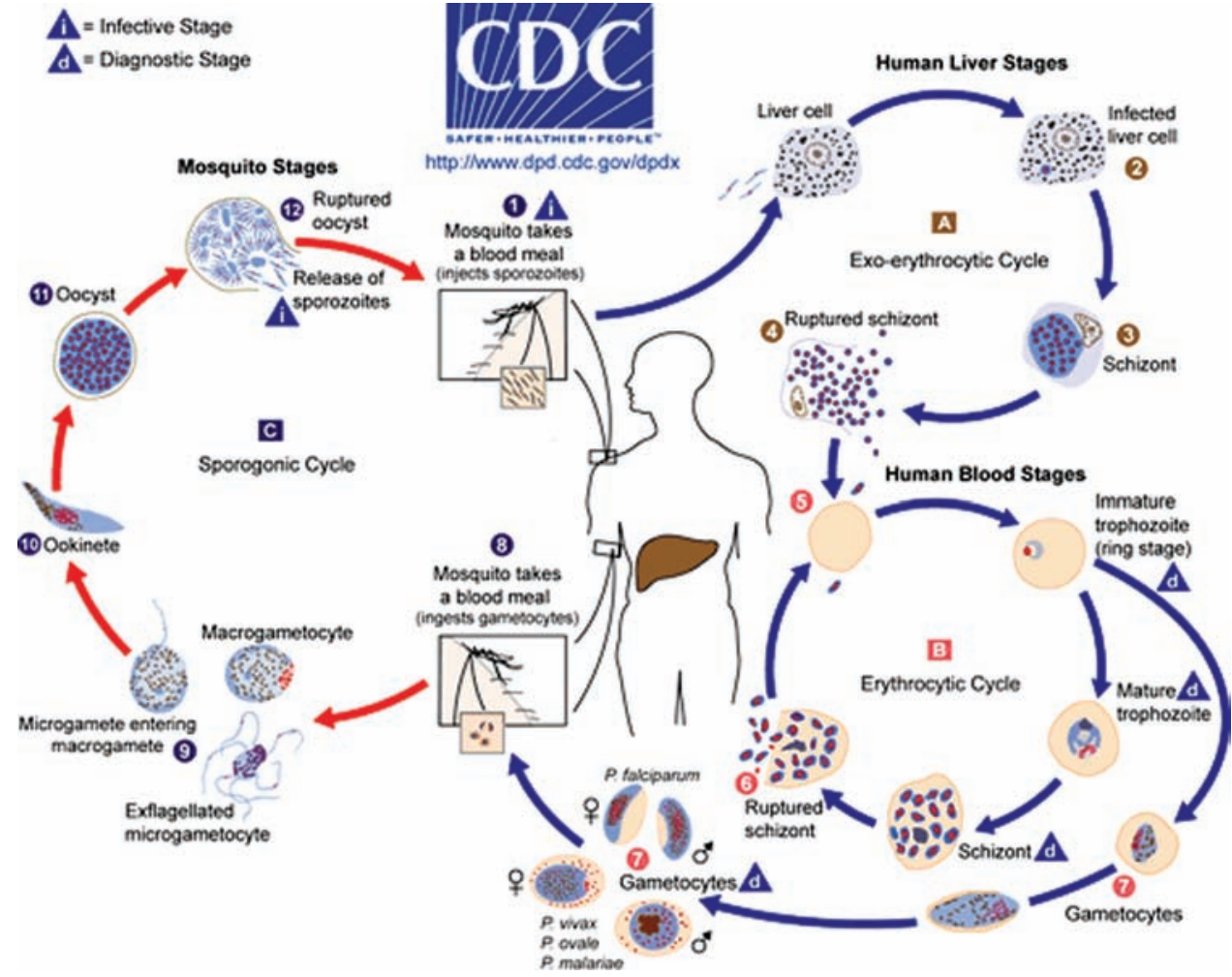

Figure 4.1.9.1. Life cycle of Plasmodium spp. in humans (with permission from CDC, Atlanta, USA; http:// www.cdc.gov/malaria/about/biology/) 
The second factor involved in this malaria type is the various primates and non-human primate species spread over tropical and sub-tropical regions. Global tourism into these regions may convey human' infection (Lee et al., 2009). Primates are also kept in reservations, parks and zoological gardens around the globe. In the wilderness, primates', and especially non-human primates', infection can be controlled only by reducing the vector habitats, which seems an enormous task. In zoological gardens, water sources should be kept under continuous control to prevent mosquito reproduction and infection with Plasmodium spp.

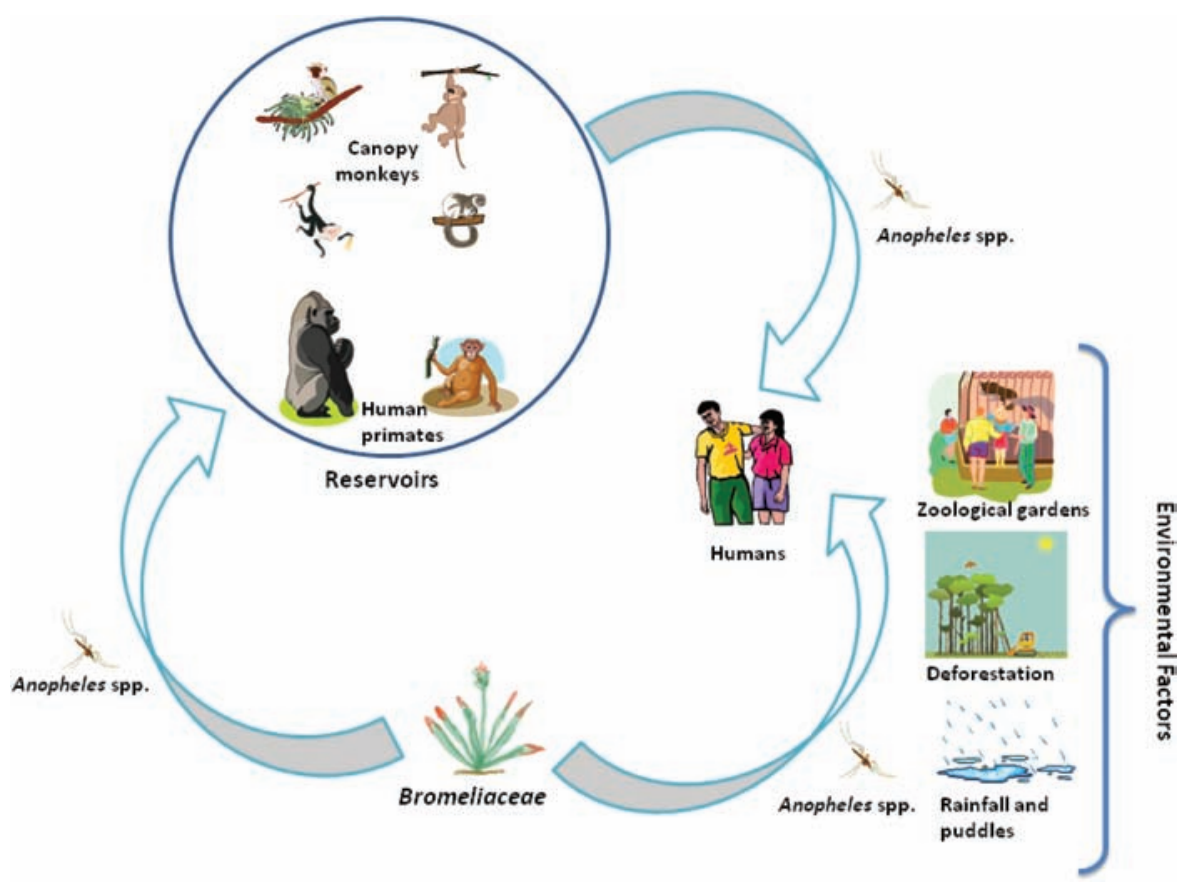

Figure 4.1.9.2. Anopheles vector transmission of simian malaria to primates (including humans) and potential environmental factors involved

Recently, it was shown that wild-living and captive gorillas in Central Africa (Cameroon and Gabon) and chimpanzees can harbor through infection two related lineages of parasites (Plasmodium GorA and P. GorB in gorrilas) not yet described previously and also $P$. falciparum, $P$. ovale and $P$. malariae, species previously considered as strictly human specific (Prugnolle et al., 2010; Duval et al., 2010). These findings reveal that close contact between closely related species can transfer different diseases and in this particular case a very versatile parasite (with an unexpected genetic diversity). In addition, it is continuously evident that African apes and other primates can serve as reservoirs of different Plasmodium species able to infect humans (Duval et al., 2010).

\subsubsection{REFERENCES}

Baird, J.K. (2009) Malaria zoonoses. Travel Med Infect Dis 7, 269-277. 
Budiansky, S. (2002) Creatures of Our Own Making. Science 298, 80-86.

Duval, L., Fourment, M., Nerrienet, E., Rousset, D., Sadeuh. S.A. et al. (2010) African apes as reservoirs of Plasmodium falciparum and the origin and diversification of the Laverania subgenus. Proc. Natl. Acad. Sci. U.S.A. 107, 1056110566.

Lee, Y.C., Tang, C.S., Ang, L.W., Han, H.K., James. L. \& Goh, K.T. (2009) Epidemiological characteristics of imported and locally-acquired malaria in Singapore. Ann. Acad. Med. Singap. 38, 840-849.

Marques, G.R.A.M and Forattini, O.P. (2009) Anopheles cruzii larvae found in bromelias in an urban area on the Brazilian coast. Rev Saude Publica 43, 369-372.

Minakawa, N., Githure, J.I., Beier, J.C. \& Yan, G. (2001) Anopheline mosquito survival strategies during the dry period in western Kenya. J. Med. Entomol. 38, 388-392.

Molez, J.F. (1999) Myths concerning malarial transmission among Amazonian Indians and their relation with 2 types of transmission encountered in the Amazonian forest. Sante 9, 157-162.

Obsomer, V., Defourny, P. \& Coosemans, M. (2007) The Anopheles dirus complex: spatial distribution and environmental drivers. Malar J. 6, 26. doi:10.1186/1475-2875-6-26.

Prugnolle, F., Durand, P., Neel, C., Ollomo, B., Ayala, F.J. et al. 2010 African great apes are natural hosts of multiple related malaria species, including Plasmodium falciparum. Proc. Natl. Acad. Sci. U.S.A. 107, $1458-1463$.

Suwonkerd, W., Tsuda, Y., Overgaard, H.J., Chawprom, S., Tuno, N. et al. (2004) Changes in malaria vector densities over a twenty-three year period in Mae Hong Son Province, northern Thailand. Southeast Asian J. Trop. Med. Public Health 35, 316-324.

Tan, C.H., Vythilingam, I., Matusop, A., Chan, S.T. \& Singh, B. (2008) Bionomics of Anopheles latens in Kapit, Sarawak, Malaysian Borneo in relation to the transmission of zoonotic simian malaria parasite Plasmodium knowlesi. Malar. J. 7, 52.

Vittor, A.Y., Gilman, R.H., Tielsch, J., Glass, G., Shields, T. et al. (2006) The effect of deforestation on the human-biting rate of Anopheles darlingi, the primary vector of falciparum malaria in the Peruvian Amazon. Am. J. Trop. Med. Hyg. 74, 3-11. 


\section{Chapter 4.1.10 Sarcosporidiosis}

\section{[SARCOCYSTIS SPP. FORMERLY ISOSPORA HOMINIS]}

Sarcocystis species belong to a genus of cyst-forming coccidia protozoan of the order Eucoccidiorida, all parasites of a large variety of animals. Sarcocystis bovihominis (synonim S. hominis) and S. suihominis are the two species infecting humans (as final host). The distribution is worldwide, where intermediate hosts are cattle and pigs (Sager et al., 2006). Infection rate in cattle and pigs depends on hygienic conditions, e.g. in Europe $S$. bovihominis prevalence rate is 21 to $64 \%$, while infested pigs in Germany carry S. suihominis at a rate of 30 to $40 \%$. There are $\sim 130$ recognized species in this genus (Sarcocystis) with various intermediate or final hosts (Dubey, 1980; Kubo et al., 2009; Cummings et al., 2000). Transmission to humans occurs through consumption of raw or undercooked contaminated meat (pork and beef) with bradyzoites containing cysts. Human incidental contamination (as intermediate host) can occur also through ingestion of water or food contaminated with fecal sporocytes. The life cycle of Sarcocystis in humans as final host starts by sexual reproduction (gamogony) in intestinal epithelium following ingestion of infested meat. Briefly, the ruptured cysts release bardyziotes that in turn enter intestinal cells to multiply and form microgametes and macrogametes. In intestinal ephitelial cells, fertilization between the micro- and macrogametes forms immature cysts (zygote) followed by sporogony (formation of sporocystes). After $\sim 7$ days post infection, oocysts containing two sporocytes are formed (each sporocyst containing four sporozoites) and further released in the environment through feces (Figure 4.1.10.1). There are two major clinical manifestations of human sarcosporidiosis: intestinal infection with oocysts and sporocysts excretion in feces and a rare extraintestinal infection of striated muscles with cysts (cardiac and skeletal muscles). The immediate symptoms are self-limiting or severe diarrhea (depending on infection magnitude), nausea, abdominal pain, dizziness, muscle swelling, myalgias and fever (Li et al., 2007).

\subsubsection{SARCOCYSTIS AND ENVIRONMENT}

Prevalence of Sarcocystis cruzi in Australian cattle has been studied in Western Australia. Savini et al. (1992) reported a high prevalence of this parasite in cattle from this area $(52 \%)$. In relation to 
environment, arid and semiarid zones had a lower prevalence (9\% and 31\% respectively) compared to tropical $(87 \%)$ and temperate $(60 \%)$ areas. The authors proposed reduced resistance of S. cruzii sporocysts under dry conditions as a factor in the epidemiology of this parasite (Fayer, 1980). Livestock manure (as wet condition) have been already shown in Germany to support presence of different parasites including Sarcocystis species (Hiepe and Buchwalder, 1991).

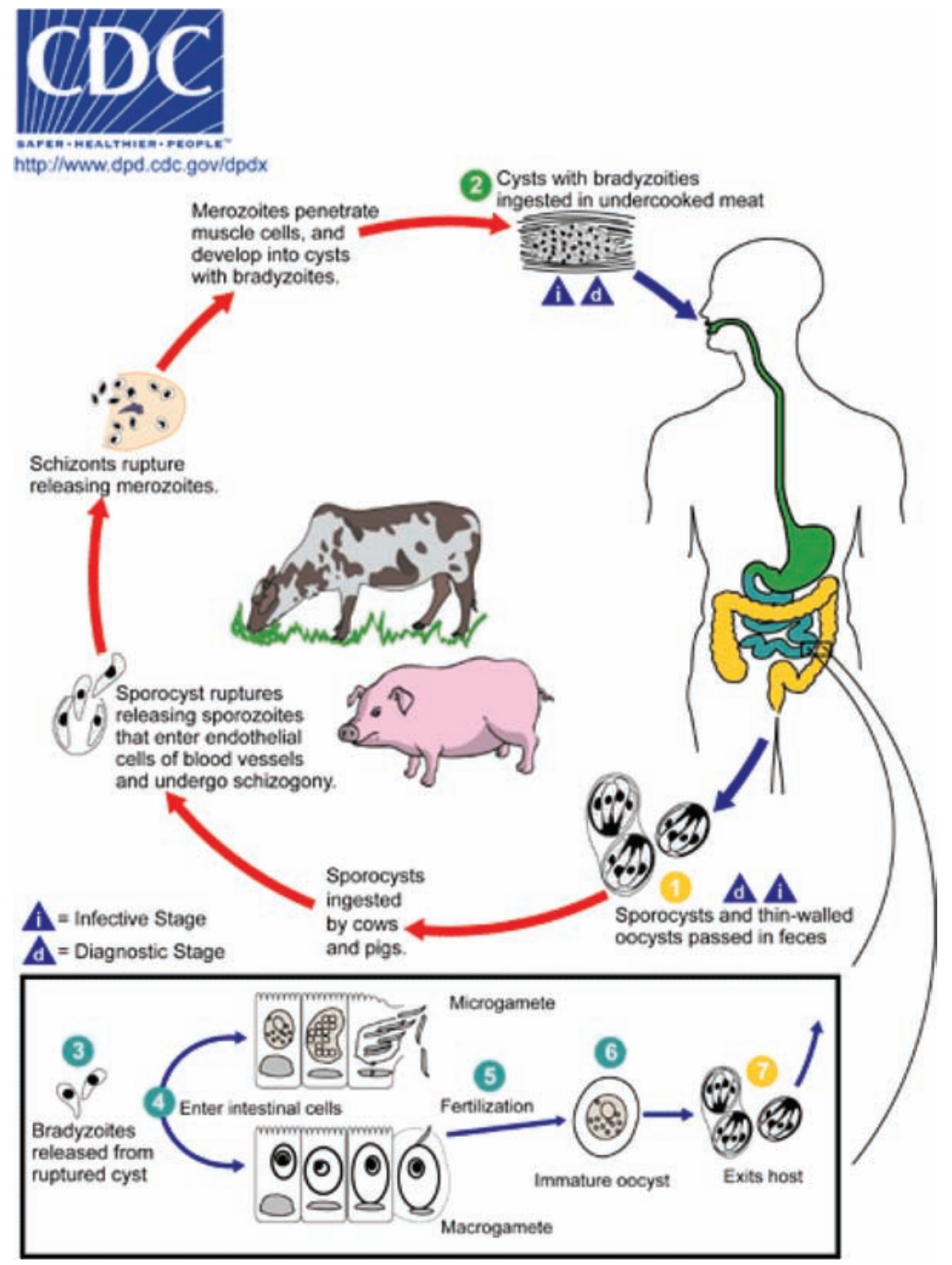

Figure 4.1.10.1. Life cycle of Sarcocystis spp. (with permission from CDC, Atlanta, USA; http://www.dpd. cdc.gov/DPDx/HTML/Sarcocystosis.htm)

A reverse result was presented by Kalubowila et al. (2004) with cattle and buffaloes from Sri Lanka where higher $S$. cruzi infection prevalence was observed in dry zone. It should be mentioned that Sri 
Lanka is defined as a tropical region; therefore dryness is relative compared to Australian desert. Cattle are an intermediate host of $S$. cruzi while infected dogs excreting them in feces are the final host. Humans are not affected by this Sarcocysytis species; however, Xiang et al. (2009) using PCRRFLP and DNA sequencing of a partial 18S rDNA gene (ssrRNA) sequence were able to distinguish successfully among three taxa: Sarcocystis hominis, Sarcocystis fusiformis and a species of Sarcocystis from water buffalo that could not be distinguished from Sarcocystis cruzi. Interestingly, among four restriction enzymes used in their analysis, three showed identical restriction digestion patterns for $S$. hominis and the Sarcocystis from water buffalo (similar to $S$. cruzi). Future studies will possibly clarify the potential infection of humans by this highly prevalent cattle parasitic species.

Dubey et al. (2002) investigated the effect of heat and several disinfectants on S. neurona's sporocysts. Sarcocystis neurona is the most common cause of equine protozoal myeloencephalitis (EPM) in America, with opossums as the definitive hosts and a variety of mammals as aberrant or natural intermediate hosts. Various disinfectants at various concentrations did not inactivate sporocytes while thermal treatment for 1 minute at $60^{\circ} \mathrm{C}$ did inactivate them, indicating that heat treatment was the most effective treatment. Supposing that oocysts of $S$. neurona are as closely resistant as $S$. bovihominis and S. suihominis, they will be also susceptible to heat treatment; for this reason well cooked meat is the best measure to prevent humans infection (Pozio, 2008).

A study performed in Argentina, on children ages 2-14 years old, for presence of intestinal parasites (frequency $50.7 \%$ of different parasites and $0 \%$ with Sarcocystis spp.) revealed a significant correlation to family hygiene level (Soriano et al., 2001). The patients were from lower middle class with adequate public services. Environmental data were continental semiarid climate and sandy soil (with low organics content). Soil samples revealed $14.6 \%$ Sarcocystis spp., the highest frequency among the intestinal parasites. The prevalence discrepancy between human cases and soil presence was explained as a result of the frequent irrigation of the region's soil (twice a day, to avoid dust in the air) with possibly sewage contaminated water.

Finally, a new coccidian was reported in the renal infection of big brown bat. Analysis of the 18S rRNA gene sequence put the parasite in the Sarcocystidae family. Whether it is related to cattle, pigs and humans infection is yet unknown.

\subsubsection{REFERENCES}

Cummings, C.A., Kocan, A.A., Barker, R.W. \& Dubey, J.P. (2000) Muscular sarcocystosis in coyotes from Oklahoma. J. Wildl. Dis. 36, 761-763.

Dubey, J.P. (1980) Coyote as a final host for Sarcocystis species of goats, sheep, cattle, elk, bison, and moose in Montana. Am. J. Vet. Res. 41, 1227-1229.

Dubey, J.P., Saville, W.J., Sreekumar, C., Shen, S.K., Lindsay, D.S. et al. (2002) Effects of high temperature and disinfectants on the viability of Sarcocystis neurona sporocysts. J. Parasitol. 88, 1252-1254.

Fayer R. (1980) Epidemiology of protozoan infections: the Coccidia. Vet. Parasitol. 6, 75-103.

Hiepe, T. \& Buchwalder, R. (1991) Livestock manure as a vector for parasites-a report of experiences. DTW. Dtsch. Tierarztl. Wochenschr. 98, 268-272.

Kalubowila, D.G.W., Udagama-Randeniya, P.V., Perera, N.A.N.D. \& Rajapakse, R.P.V.J. (2004) Seroprevalence of Sarcosystis spp. in cattle and buffaloes from the wet and dry zones of Sri Lanka: a preliminary study. J. Vet. Med. B Infect. Dis. Vet. Public Health 51, 89-93.

Kubo, M., Okano, T., Ito, K., Tsubota, T., Sakai, H. \& Yanai, T. (2009) Muscular sarcocystosis in wild carnivores in Honshu, Japan. Parasitol. Res.106, 213-219. 
Li, J-H., Lin, Z., Du, J-F. \& Qin, Y-X. (2007) Experimental infection of Sarcocystis suihominis in pig and human volunteer in Guangxi. Zhongguo Ji Sheng Chong Xue Yu Ji Sheng Chong Bing Za Zhi (Chinese journal of parasitology \& parasitic diseases) 25, 466-468.

Pozio, E. (2008) Epidemiology and control prospects of foodborne parasitic zoonoses in the European Union. Parassitologia 50, 17-24.

Sager, H., Moret, C.S., Muller, N., Staubli, D., Esposito, M. et al. (2006) Incidence of Neospora caninum and other intestinal protozoan parasites in populations of Swiss dogs. Vet. Parasitol. 139, 84-92.

Savini, G., Dunsmore, J.D., Robertson, I.D. \& Seneviratna, P. (1992) The epidemiology of Sarcocystis spp. in cattle of Western Australia. Epidemiol. Infect. 108, 107-113.

Soriano, S.V., Barbieri, L.M., Pierangeli, N.B., Giayetto, A.L., Manacorda, A. M. et al. (2001) Intestinal parasites and the environment: frequency of intestinal parasites in children of Neuquen, Patagonia, Argentina. Rev. Latinoam. Microbiol. 43, 96-101.

Wunschmann, A., Wellehan, J. F.X., Armien, A., Bemrick, W.J. Barnes, D. et al. (2010) Renal infection by a new coccidian genus in big brown bats (Eptesicus fuscus). J. Parasitol. 96, 178-183.

Xiang, Z., Chen, X., Yang, L., He, Y., Jiang, R. et al. (2009) Non-invasive methods for identifying oocysts of Sarcocystis spp. from definitive hosts. Parasitol. Int. 58, 293-296. 


\section{Chapter 4.1.11}

\section{Sleeping sickness (African Trypanosomiasis)}

\section{[TRYPANOSOMA BRUCEI GAMBIENSE, TRYPANOSOMA BRUCEI RHODESIENSE]}

African trypaniosomiasis is a human disease caused by a flagellated parasite that belongs to phylum Euglenozoa and genus Trypanosomatida. The parasite is vector-borne, transmitted by bites of the tsetse flies (order: Diptera, family: Glossinidae). Tsetse flies are multivoltine (organisms that have more than two broods or generations per year) with four generation/year and up to 31generations in their entire life span. There are two zoonotic parasites involved in human sleeping sickness: T. brucei gambiense and $T$. brucei rhodesiense (the T. brucei group) both with identical morphology. A third subspecies, T. brucei brucei infects horses (lethally) and other ruminants. Animals reservoir of the human trypanosomae are: 1) domestic: pigs, cattle, dogs, sheep (T. b. gambiense) and cattle, dogs, sheep, goats (T. b. rhodesiense) 2) wild: monkeys, antelopes (T. b. gambiense) and bushbucks, reedbucks, waterbucks, lions, hyenas (T. b. rhodesiense) (Cordon-Obras et al., 2010). The disease is endemic in a large area of Central Africa (with $>40$ countries in sub-Saharan region) between the Atlantic and Indian Oceans. Transmission is linked to the presence of the tsetse fly, the only vector and host of these parasites. Among the Glossina genus (tsetse taxonomy): Glossina palpalis, G. tachinoides and G. fuscipes transmit T. b. gambiense while G. morsitans, G. pallidipes and G. swynnertoni transmit T. $b$. rhodesiense. The life cycle consists of two stages according to host: in tsetse fly trypomastigotes from human blood reach the insect stomach and crop and then form epimastigotes by binary fission in intestine and later form the metacyclic infectious forms (trypomastigote) in salivary glands. The trypomastigotes are then injected into human blood during fly blood meal. In humans, trypomastigotes multiply in the peripherial blood infecting the CNS (central nervous system) (Figure 4.1.11.1).

Clinical manifestations are lymphoadenopathy, splenomegaly, increased vascular permebility, edema, hemostasis, intravascular coagulophaty, anemia, tissue hypoxia and immunosupression. The infected person suffers from persistent headache, memory loss, apathy, sleep disturbances (daytime somnolence and nocturnal insomnia), impaired vision (even blindness), coma and death. In humans, without 
treatment $T$. $b$. rhodesiense is more severe with fatal results in 6 to 9 months while $T$. $b$. gambiense fatality is longer, 2 to 6 years. Animal hosts infected with these parasites express subclinical symptoms.

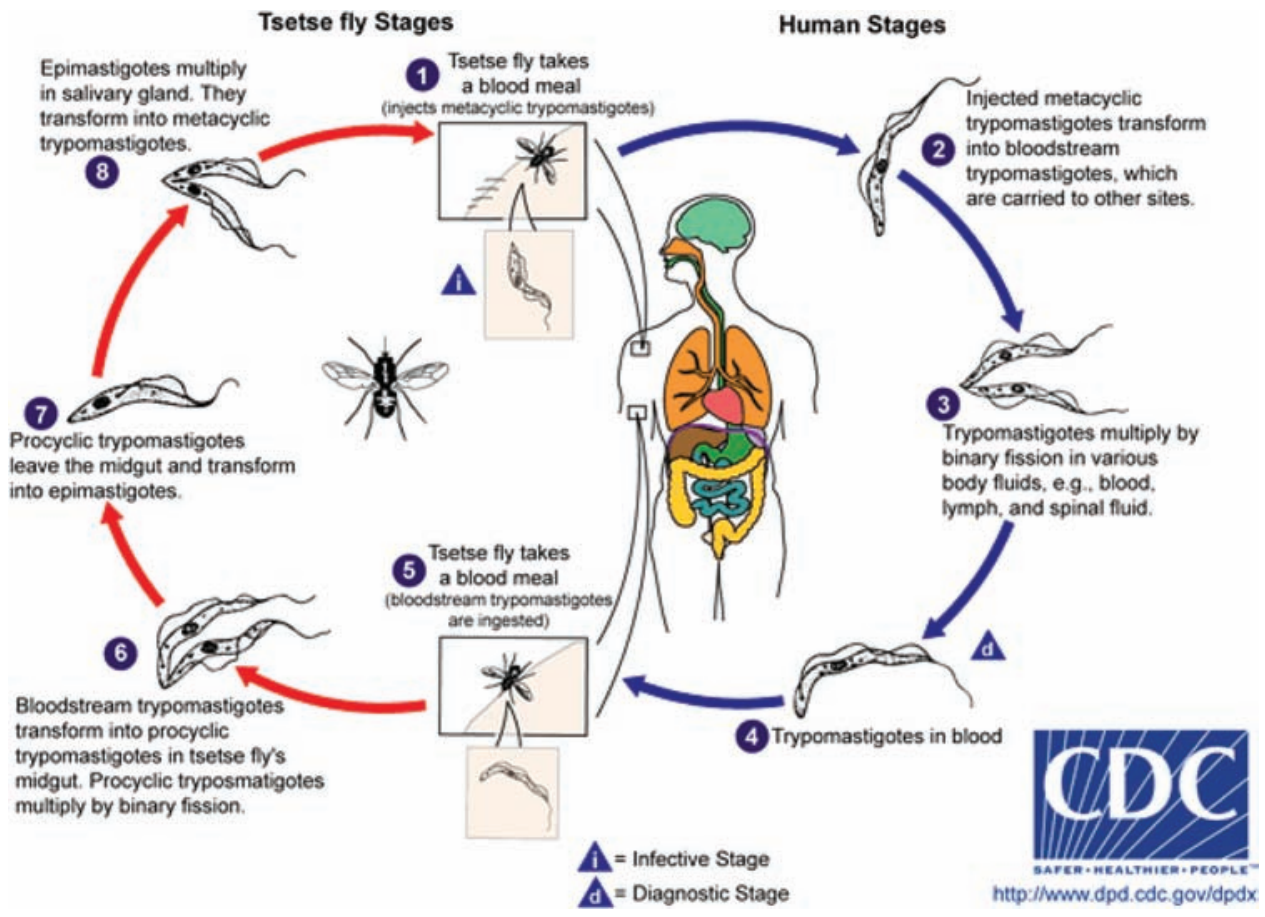

Figure 4.1.11.1. Life cycle of Trypanosoma spp. (with permission from CDC, Atlanta, USA; http://www.dpd. cdc.gov/DPDx/HTML/TrypanosomiasisAfrican.htm)

\subsubsection{AFRICAN TRYPANOSOMIASIS AND ENVIRONMENT}

In the Sub-Saharan Africa, tsetse flies occupy an area between 10 and 12 million $\mathrm{km}^{2}$ in this region, of which some 7 million $\mathrm{km}^{2}$ could potentially be used by livestock. Raising African cattle on large areas is hampered by the high pervasiveness of tsetse flies and altered agro-forestry practices (Ilemobade, 2009; Molyneux, 1998). Consequently, African farmers grow their cattle herds in arid (dry) zones to avoid tsetse flies that cannot survive well under these conditions. In this context, it should be mentioned that endemic human African trypanosomiasis (HAT) currently appears to be limited to areas where annual rainfall is higher than 1,200 $\mathrm{mm}$, although the reasons for this remain unknown (Courtain et al., 2008). New evidence was recently published possibly explaining this phenomenon based on tsetse fly water balance. Kleynhans and Terblanche (2009) showed that water loss rates (WLR) were significantly positively related to precipitation in pupa but not adults, suggesting that a reduction in WLR and increased size probably developed from a transitional ancestral state that may have facilitated survival in xeric environments. However, in recent times the water balance of pupae is critical, consequently limiting tsetse survival in dry environments (Opinel, 2008; Roubaud, 1957). 
Thus, the overstocking in a limited area results in land degradation as well as poor cattle quality. If these areas are close to forests that undergo deforestation, the new land will be further cultivated by planting cocoa, coffee, oil palms, mangoes, etc., a vegetation that favor tsetse colonization (Hausner, 1992). In the African Sahel, tsetse flies inhabit river banks and forest while in rainy season they move to drier areas (Patz et al., 2000; Jobin, 1999). Interestingly, Petney (1997) raised an arguable ecological point related to tsetse eradication. The author indicated that successful eradication programs against tsetse in Africa would remove a natural barrier that prevented in the past over exploitation of these environments by humans (overgrazing, increased desertification, vegetation changes and possibly climate change). In addition, he also pointed out the short and long terms effects of pesticides use to control this arthropod pest. One is the family of avermectins and their semi-synthetic derivatives (broad-spectrum pesticides) active against a wide range of nematodes, mites, ticks and insects (including helminthes), some with agricultural importance, and the second DDT (now banned in most world countries, although still used in developing countries). Both, beside their veterinary benefit, can alter the natural ecology, especially when they are sprayed from air (by helicopters) over a large area. For example, based on a vast published literature, DDT that has a half life of about 100 years, and is therefore highly persistent, can be further biodegraded into more toxic compounds. In turn, these compounds affect many vertebrates through hormonal unbalance and abnormality induction (Guillette et al. 1994). Other aspects of such insecticides (i.e., pyrethroids) were presented by Eisler et al. (2003) revealing that uncontrolled use may lead to environmental damage such as acaricide resistance in tick populations and a possible exacerbation of tick-borne diseases. However, as presented by Langley (1994), a brighter prospect should be mentioned here concerning the management of tsetse vector at local size. In spite of many insecticides' ban over the years, due to their environmental hazards, new trap devices, based on the role of olfactory and visual stimuli of tsetse fly found in research, have been implemented in endemic areas. Such devices treated locally with insecticides have been successful, being able to sustain fly population at manageable levels.

Wardrop et al. (2010) used spatial analysis (a generalized linear geostatistical model in a Bayesian framework) to verify the causes of increased numbers of $T$. $b$. rhodesiense in an endemic area of T. b. gambiense in Uganda. Their analysis significantly indicates that Rhodesian HAT (human African trypanosiomias) was introduced into Uganda by the movement and introduction of infected livestock (untreated from endemic areas) (Batchelor et al., 2009). Another environmental aspect was highlighted by Turner (1986) in the Kenyan Lambwe Valley, a region shared by wild animals in a national park adjoining human settlements with domestic livestock. Lambwe Valley is characterized by thicket and woodland heavily infested with Glossina pallidipes. The author reported that trypanosomiasis' aggravated situation in recent years was attributable to the extension of tsetse habitat and encroachment of settlements into the national park.

Trypanosomiasis is essentially a rural disease; however recent urban reemergence was observed in Kinshasa, in the Democratic Republic of Congo, from 254 cases in 1996 and about 500 cases/year from then on (Louis et al., 2003; Tshimungu et al., 2010). The increase in case prevalence has been explained by refugee inflow into town outskirts from endemic areas and by the movement of urban populations towards the suburbs due to economic crisis. Both processes resulted in humans living on a subsistence micro-agriculture that establishes a trypanosiomiasis belt around the urban area (Fournet et al., 2000). Grebaut et al. (2009) studied transmission sites of African trypanosomiasis in Kinshasa too. They found that dry season, argillaceous soil, raised ground cover, pig breeding, forest residues and rivers are important factors in disease transmission (Figure 4.1.11.2).

In Burkina Faso, using Landsat 7 thematic mapper (TM) images as remote sensing, similar human activities have been shown to have a high impact on riverine vegetation; the closer to the river the crops 
were, the greater the observed impact on riverine vegetation and the degree of contact with riparian tsetse flies (Roumba et al., 2009; De La Rocque et al., 2001). This and other studies confirmed that peri-riverine human activities have a negative impact on gallery forest vegetation, in contrast to "protective" swamp forests, in consequence increasing trypanosomiasis risk (De Deken et al., 2005).

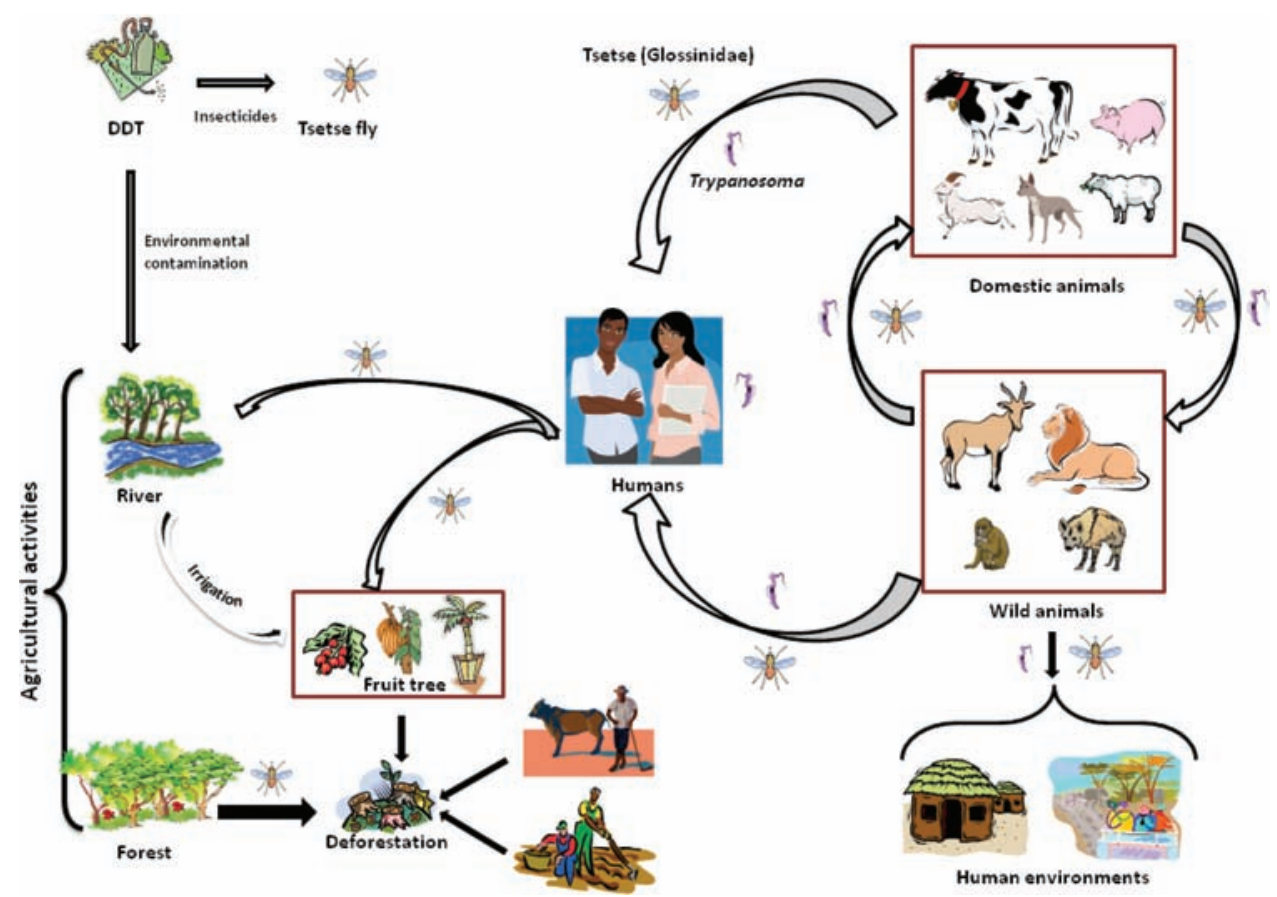

Figure 4.1.11.2. Environmental and man-made factors affecting tsetse fly and Trypanosoma spp. spread

Courtin et al. (2005) using spatial analysis studied HAT in Bonon city, a focus located in the mesophile forest of the Ivory Coast. Besides Bonon city, the authors looked at two areas connected to the town: the northern rural one with low prevalence and the southern rural one with high prevalence. The southern area was found to comprise patches of both relict forest and uncultivated lowland remains, and was therefore a favorable breeding area for tsetse flies. However, tsetse density is not utterly correlated to transmission rate and other contextual factors seem to be related. Such a factor emphasized by the authors is human mobility and presence in risky areas. Thus, the southern part's track to town crosses a tsetse favorable environment (edges of uncultivated lowland, plantations and forest) while the northern tracks do not. Courtin et al. (2010) showed in Guinea that people with more diverse spatial occupation that involves longer walking distance including mangrove forests, rice culture and attendance of pirogue jetties have higher risk of infection.

Finally, Kodama et al. (2008) reported that humic substances extract protects experimental mice against infection with T. brucei (cattle African trypanosomiasis agent). It will be interesting to find out if these results are true also for larger animals, such as cattle, thus suggesting a possible natural "external immunization" against this animal parasite! 


\subsubsection{REFERENCES}

Batchelor, N.A., Atkinson, P.M., Gething, P.W., Picozzi, K., Fevre, E.M. et al. (2009) Spatial predictions of Rhodesian Human African Trypanosomiasis (sleeping sickness) prevalence in Kaberamaido and Dokolo, two newly affected districts of Uganda. PLoS Negl Trop Dis 3, e563.

Cordon-Obras, C., García-Estébanez, C., Ndong-Mabale, N., Abaga, S., Ndongo-Asumu, P. et al. (2010) Screening of Trypanosoma brucei gambiense in domestic livestock and tsetse flies from an insular endemic focus (Luba, Equatorial Guinea). PLoS Negl Trop Dis 4, e704.

Courtin, F., Jamonneau, V., Camara, M., Camara, O., Coulibaly, B. et al. (2010) A geographical approach to identify sleeping sickness risk factors in a mangrove ecosystem. Trop. Med. Int. Health 15, 881-889.

Courtin, F., Jamonneau, V., Duvallet, G., Camara, M., Kaba, D. \& Solano, P. (2008) One century of "sleeping sickness" in West Africa. Bull Soc Pathol Exot 101, 287-289.

Courtin, F., Jamonneau, V., Oké, E., Coulibaly, B., Oswald, Y. et al. (2005) Towards understanding the presence/absence of Human African Trypanosomosis in a focus of Côte d'Ivoire: a spatial analysis of the pathogenic system. Int J Health Geogr. 4, 27.

De Deken, R., Sumbu, J., Mpiana, S., Mansinsa, P., Wat'senga, F. et al. (2005) Trypanosomiasis in Kinshasa: distribution of the vector, Glossina fuscipes quanzensis, and risk of transmission in the peri-urban area. Med. Vet. Entomol. 19, 353-359.

De La Rocque, S., Michel, J.F., De Wispelaere, G. \& Cuisance, D. (2001) New tools for the study of animal trypanosomiasis in the Sudan: model-building of dangerous epidemiological passage by remote sensing geographic information systems. Parasite 8, 171-195.

Eisler, M.C., Torr, S.J., Coleman, P.G., Machila, N. \& Morton, J.F. (2003) Integrated control of vector-borne diseases of livestock-pyrethroids: panacea or poison?. Trends Parasitol. 19, 341-345.

Fournet, F., Traore, S., Prost, A., Cadot, E. \& Hervouet, J.P. (2000) Impact of the development of agricultural land on the transmission of sleeping sickness in Daloa, Cote d'Ivoire. Ann Trop Med Parasitol 94, 113-121.

Grebaut, P., Bena, J-M., Manzambi, E.Z., Mansinsa, P., Khande, V. et al. (2009) Characterization of sleeping sickness transmission sites in rural and periurban areas of Kinshasa (Republique Democratique du Congo). Vector Borne Zoonotic Dis. 9, 631-636.

Guillette, L.J., Gross, T.S., Masson, G.R., Matter, M., Perciveal, H. F. \& Woodward, A.R. (1994) Developmental abnormalities of the gonad and abnormal sex hormone concentrations in juvenile alligators from contaminated and control lakes in Florida. Environ. Health Perspect. 102, 680-688.

Hausner, D.S. (1992) Health and ecological dilemmas. Sleeping sickness. Links 9, 22-23.

Ilemobade, A. A. (2009) Tsetse and trypanosomosis in Africa: the challenges, the opportunities. Onderstepoort J. Vet. Res. 76, 35-40.

Jobin, W. Ecological design and health impacts of large dams, canals and irrigation systems. London: E\&F.N. Spon, 1999.

Kleynhans, E. \& Terblanche, J.S. (2009) The evolution of water balance in Glossina (Diptera: Glossinidae): correlations with climate. Biol Lett. 5, 93-96.

Kodama, H., Denso, Okazaki, F. \& Ishida, S. (2008) Protective effect of humus extract against Trypanosoma brucei infection in mice. J. Vet. Med. Sci. 70, 1185-1190.

Kodama, H., Denso, Okazaki, F. \& Ishida, S. (2008) Protective effect of humus extract against Trypanosoma brucei infection in mice. J. Vet. Med. Sci. 70, 1185-1190.

Langley, P.A. (1994) Understanding tsetse flies. Onderstepoort J. Vet. Res. 61, 361-367.

Louis, F.J., Bilenge, C.M., Simarro, P.P., Meso, V.K., Lucas, P. \& Jannin, J, (2003) Human African trypanosomiasis in an urban area: an emerging problem ? Bull Soc Pathol Exot 96, 205-208.

Molyneux, D.H. (1998) Vector-borne parasitic diseases-an overview of recent changes. Int. J. Parasitol. 28, 927-934.

Opinel, A. (2008) Reconstructing an epistemological itinerary: environmental theories of variation in Roubaud's experiments on Glossina flies and Anopheles, 1900-1938. Parassitologia 50, 255-265.

Patz, J.A., Graczyk, T.K., Geller, N. \& Vittor, A.Y. (2000) Effects of environmental change on emerging parasitic diseases. Int. J. Parasitol. 30, 1395-1405. 
Petney, T.N. (1997) Ecological implications of control strategies: arthropods of domestic and production animals. Int. J. Parasitol. 27, 155-165.

Roditi, I. \& Lehane, M.J. (2008) Interactions between trypanosomes and tsetse flies. Curr. Opin. Microbiol. 11, $345-$ 351.

Rouamba, J., Jamonneau, V., Sidibe, I., Solano, P. \& Courtin, F. (2009) Impact of the dynamics of human settlement on tsetse and trypanosomosis distribution in the Mouhoun river basin (Burkina Faso). Parasite 16, 11-19.

Roubaud, E. (1957) Incidence of exterior factors on cyclic infections of Glossina by Trypanosoma cazalboui (vivax). Bull Soc Pathol Exot Filiales 50, 35-39.

Tshimungu, K., Okenge, L.N., Mukeba, J.N. \& de Mol, P. (2010) Re-emergence of human African trypanosomiasis in Kinshasa, Democratic Republic of Congo (DRC). Med Mal Infect 40, 462-467.

Turner, D.A. (1986) Tsetse and trypanosomiasis in the Lambwe Valley, Kenya. Trans R Soc Trop Med Hyg 80, 592595.

Wardrop, N.A., Atkinson, P.M., Gething, P.W., Fevre, E.M. Picozzi, K. et al. (2010) Bayesian geostatistical analysis and prediction of Rhodesian human African trypanosomiasis. PLoS Negl Trop Dis 4, e914. 


\section{Chapter 4.1.12 Toxoplasmosis}

\section{[TOXOPLASMA GONDII]}

Toxoplasma gondii is a protozoan parasite that infects a large variety of animals (felidae family are the primary host) including humans (as intermediary host) (Dubey et al. 2009). Transmission occurs through ingestion of contaminated water, milk, vegetables or consumption of undercooked meat (domestic or game), iatrogenically (blood and tissue donation) and congenitally (transplacentally from mother to fetus) (Cook et al., 2000; Aramini et al., 1999; Radon et al., 2004; Dawson, 2005; Avelino et al., 2004). The parasite is distributed worldwide; however certain countries have higher prevalence due to several factors: 1) consumption of raw or lightly cooked meat (France, serologic prevalence 88\%); 2) stray cats and favorable climatic conditions that extend oocysts' soil survival (Central and Latin America, 51 to $72 \%$ ); 3) animal' skinning and eating raw seal meat and liver (Canadian Inuit population, 59.8\%). The life cycle includes asexual and sexual reproduction of this parasite. Briefly, unsporulated oocysts are shed in cat's feces, then in environment after 1 to 5 days they become infective when oocysts sporulate. The sporulated oocysts are further ingested by intermediate hosts (birds, rodents, pigs, etc.) through contaminated soil, plant debris and water (Smith et al., 1992; Asgari et al., 2009; Dubey et al., 2003b). Inside intermediate hosts, oocysts transform in tachozoytes that are confined in neural and muscle tissue to develop into tissue bradyzoites (Figure 4.1.12.1). Cats as primary host become infected (but also other felids such as cougar and lynx) by devouring these intermediate hosts or by direct ingestion of sporulated oocysts (Aramini et al., 1998). In immunocompetent individuals infection is mostly asymptomatic; however, 10 to $20 \%$ of the cases develop a flu-like illness, fever, weakness and debilitation, ophthalmitis, severe multisystemic infections and lymphadenopathy (McAllister, 2005), while in immunocompromised individuals clinical manifestations are encephalitis and neurologic diseases, lesions in different organs (heart, liver, inner ears), dyspnea, diarrhea, and chorioretinitis (visual disorders). In the context of neurological disorders, there is accumulating evidence from many studies that $T$. gondii is somehow related, together with other pathogens (i.e., rubella, influenza and herpes simplex virus type 2) to schizophrenia. The exact path and biological interaction is not clear at the moment, as most data are based mainly on human epidemiological studies and animal models, including maternal immune activation, that have yielded evidence suggesting that these exposures may cause brain 
and behavioral phenotypes that are analogous to findings observed in patients with schizophrenia (Brown, 2011). While reflecting on such a possibility, the H. pylori scientific history instantly leaps into one's mind, where so many in the past believed that the etiology of peptic (gastric) ulcer is purely physiologic stress!

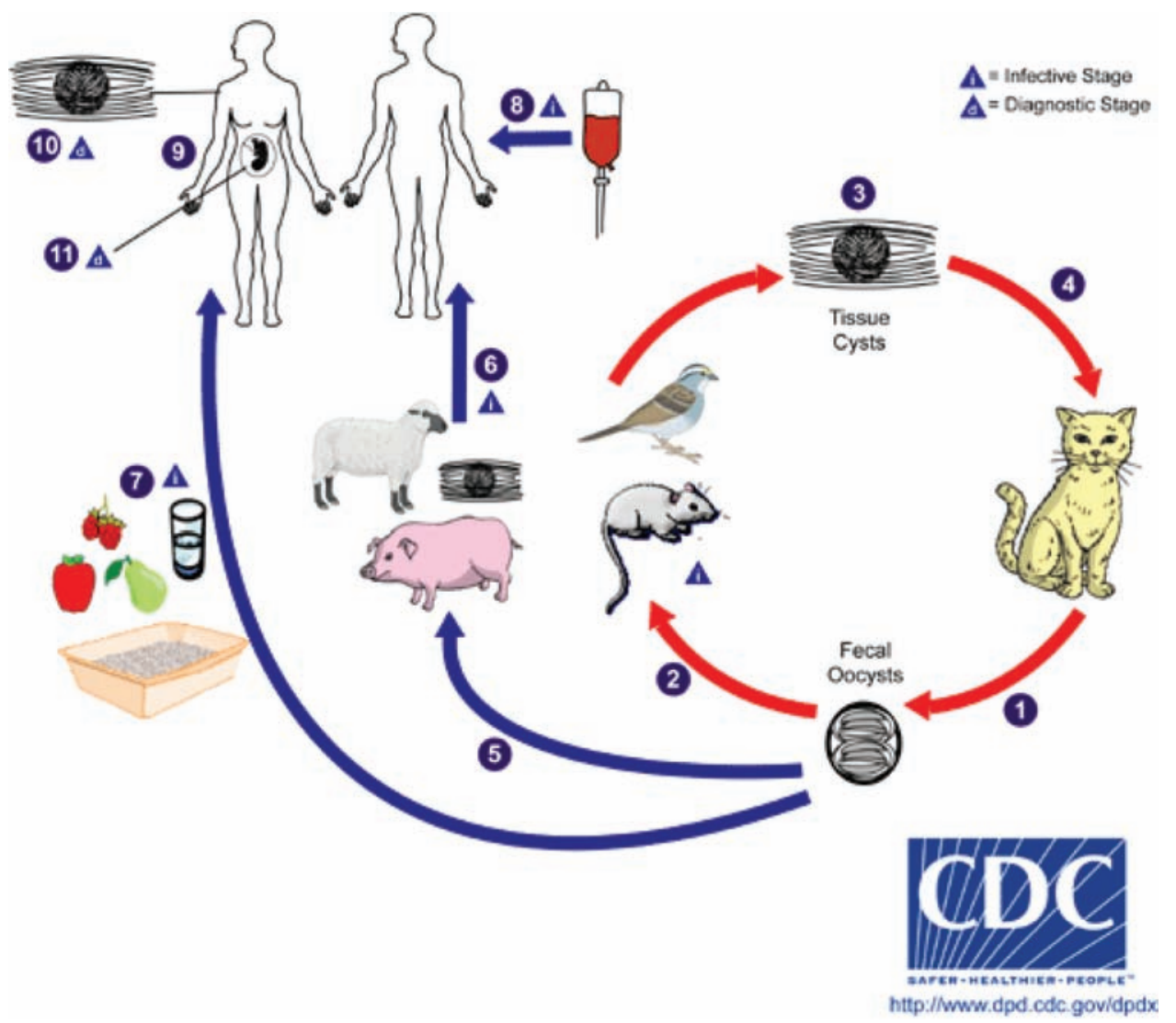

Figure 4.1.12.1. Toxoplasma gondii life cycle (with permission from CDC, Atlanta, USA; http://www.dpd.cdc. gov/DPDx/HTML/Toxoplasmosis.htm)

\subsubsection{TOXOPLASMA GONDII AND ENVIRONMENT}

Wild animals seem to carry $T$. gondii as intermediary or final hosts (Figure 4.1.12.2). In Israel, a seroprevalence survey for anti-Toxoplasma gondii antibodies has been conducted in wild pigeons. The prevalence was $4 \%$ with inverse proportionality for two environmental parameters: human proximity and water sources (Salant et al., 2009). Spanish researchers looked for seroprevalence in wild rabbits from different geographical regions. Whole country prevalence was $14.2 \%$; however, in the Catalonia region (northeast part of Spain) with rabbits living in forests the prevalence was much higher (53.8\%), while in the Cadiz region with its dry habitat it reached only $6.1 \%$. According to the authors, the parasite cycle includes infected feral cats that excrete oocysts further ingested by wild rabbits via water or soiled food 
contact and then back to carnivores (specifically felidae, but also foxes) (Aramini et al., 1999). Interestingly, Gauss et al. (2003) substantiated the high seropositivity prevalence (45\%) in domestic cats in Barcelona (Catalonia) and even higher in feral cats (51.9\%), possibly explaining the elevated seroprevalence of wild rabbits. In Holland, wild boar (game) have been also examined for $T$. gondii seroprevalence revealing an estimated $24.4 \%$, suggesting that eating undercooked wild boar meat may pose a risk of infection with this parasite. Sheep and goats as grazing domestic animals have been also shown to be affected, especially in the form of primary infection of pregnant sheep and goats, resulting in fetal death and resorption, abortion or stillbirth that have an economic consequence (Buxton, 1998). Lindsay et al. (2003) clearly showed that $T$. gondii oocysts can sporulate and remain viable in seawater for several months. Using oocysts exposed to various conditions (salinity and temperature), they were able to show mice infectivity through inoculation with oocysts kept for six months at 4 and $22^{\circ} \mathrm{C}$. This study emphasized the sturdy characteristic of this parasite in environment and its potential to infect a large variety of animals (both terrestrial and aquatic). Low temperature resistance (refrigeration) should be considered as an important environmental attribute especially in cold regions of the globe and its potential distribution in these areas (Lindsay et al., 2002). Miller et al. (2002) examined live and dead southern sea otters (Enhydra lutris nereis) along the California coast for seroprevalence against T. gondii. They reported a seroprevalence of $42 \%$ in live otters, and $62 \%$ in the dead ones. Importantly, using spatial analysis, these authors found that otters in proximity to areas with maximal freshwater runoff were three times more likely to be seropositive. However, human population density and sewage exposure were not associated with high seropositivity, therefore pointing at freshwater runoff (that may carry felids' excreta deposited on soil surface) as a source of infection for marine animals with T. gondii. In the same geographic area, Shapiro et al. (2010) evaluated how human coastal landscape alteration impacts the transport of $T$. gondii oocysts to estuarine waters, consequently affecting sea otters. Using surrogate particles that mimic the parasite's behavior in water, they found that increasing surrogates were recovered from unvegetated mudflat habitats (degraded wetlands) compared to vegetated ones. They also found on a certain location, known for its high otter infection rate, that $36 \%$ erosion of the vegetated wetlands may increase oocysts flux by 2 orders of magnitude, while complete degradation may increase the flux by 6 orders of magnitude.

Another possible source of otters' infection in marine environment has been studied by Arkush et al. (2003) with marine bivalve shellfish (Mytilus galloprovincialis mussels) as paratenic hosts. Experimental infection of these mussels with $T$. gondii oocysts revealed a persistence of up to 21 days post-exposure mainly in digestive glands (89\%). Assuming that otters do feed on this type of mussel, these bivalves can concentrate and preserve oocysts hence serving as an intermediate host. The same results have been obtained for Eastern oysters (Crassostrea virginica) exposed to T. gondii oocysts. The oysters removed successfully oocysts from seawater (thus being used as intermediate concentrators), keeping them infectious for several months (Lindsay et al., 2004). In marine environments, dolphins, walruses and sea otters are infected by T.gondii. Shellfish species have been shown to be excellent filters and concentrators of this parasite' oocysts. Recently new marine participants in the infection cycle have been shown: northern anchovies (Engraulis mordax) and Pacific sardines (Sardinops sagax) both filter-feeding fishes (Massie et al., 2010). Experimentally, those filter-feeding fishes exposed to T. gondii oocysts (even at low concentrations 1197 oocysts/L) tested positive for their alimentary canal. The authors showed in laboratory experiments that oocysts can persist and remain infective in filter-feeding fishes for 8 hours post-exposure, hypothetically serving as biotic vectors of the parasite from nearshore to pelagic environments.

A recent publication related to aquatic life of $T$. gondii showed an interesting interaction between amoebae and oocysts (Winiecka-Krusnell et al., 2009). Free-living protozoa such as Acanthamoeba 
castellanii in direct contact with oocysts were found to be capable of internalizing those cysts by active uptake. Most of the internalized oocysts kept their infectivity for long periods of time inside amoebae continuous cultivation and in addition amoebae uptake did not restrain infection transmission to murine model.

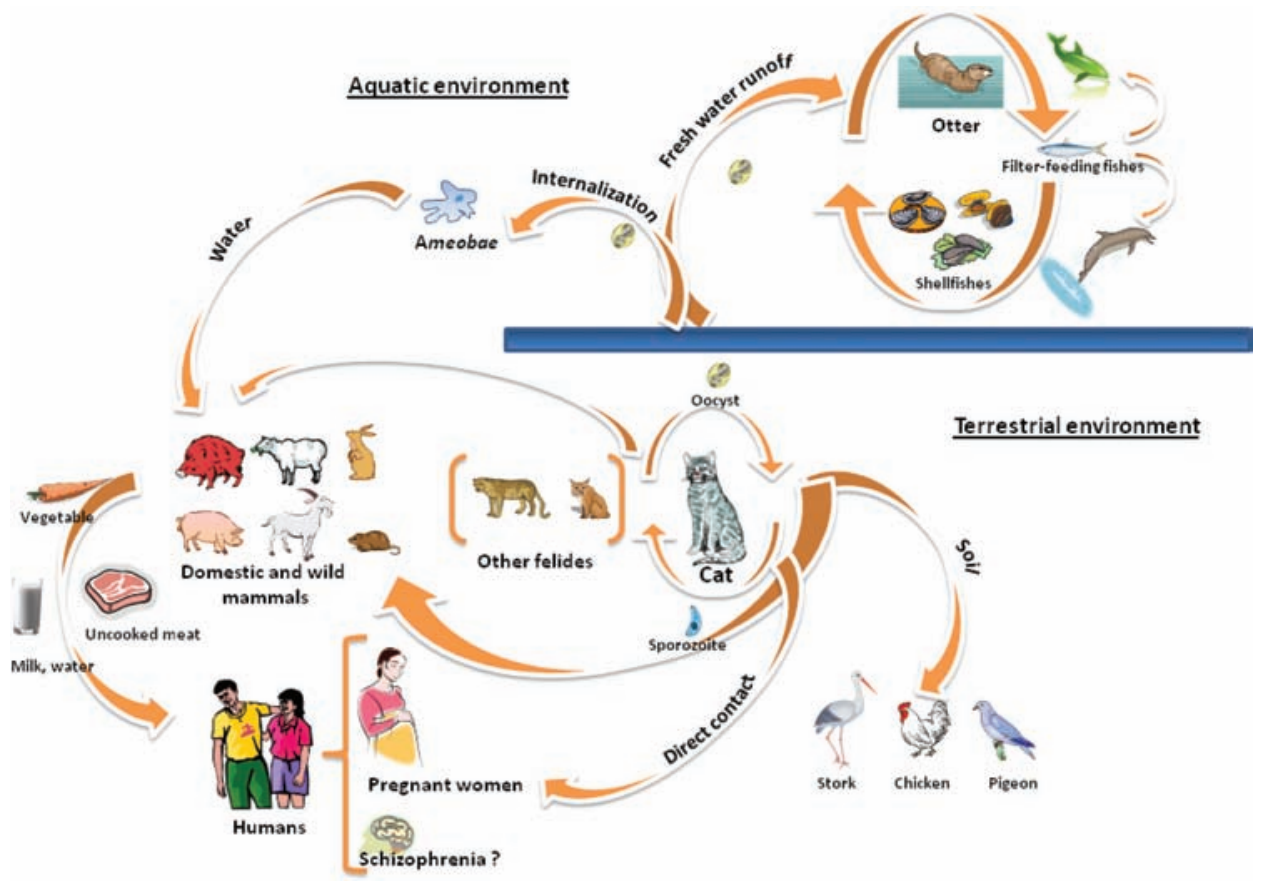

Figure 4.1.12.2. T. gondii interactions with various animals in aquatic and terrestrial environments

In Poland, Lass et al. (2009) examined different soil samples (sand-pits, farm and soil close to rubbish dumps) for the presence of $T$. gondii oocysts. Using PCR amplification of a repetitive element (REP) sequence methods, they found $17.8 \%$ samples positive for this parasite, suggesting that contaminated soil could be a risk factor for human toxoplasmosis. In relation to soil, de Thosy et al. (2003) looked for T. gondii seroprevalence in free ranging forest mammal species from different orders in French Guiana and found the following seroprevalence percentages: Marsupiala (various opossums, 8-20\%), Xenarthra (sloth- $0 \%$, anteater-39\% and armadillo-44\%), Rodentia (paca-60\%, porcupine-0\%, acouchy-4\% and gouti-18\%), Carnivora (kinkajou-10\%, tayra and coati-72\%), Artiodactyla (deer-40\% and peccary-68\%) and Primate (red howler monkey-4\% and tamarin-0\%). These authors concluded that terrestrial animals are more exposed to T. gondii infections. In this context, Dubey et al. (2003) examined prevalence of Toxoplasma gondii in free range chickens and ducks in Egypt, based on their ground feeding behavior. The seroprevalence was $40.4 \%$ in chickens, and $15.7 \%$ in ducks. The lower ducks' antibodies prevalence against $T$. gondii could be attributed to their more aquatic life habits compared to chickens that are mainly terrestrial, but this assumption should be further investigated. Similar results have been obtained in Brasil, where free range chickens where analysed for $T$. gondii in a known endemic area (da Silva et al., 2003). Chicken seroprevalence was $65.1 \%$ and more importantly viable parasites were isolated 
from $70.9 \%$ of the chickens tested, demonstrating high environmental contamination. Wild birds have a real potential of spreading zoonoses attributable to their global migratory routes. Andrzejewska et al. (2004) surveyed wild and captive white storks for $T$. gondii seroprevalence and reported $5.8 \%$ in chicks and $13.5 \%$ in adults. From the point of view of human health risk, adult storks usually nest close to human habitat with a predilection for high voltage poles and roof' chimneys, therefore posing an environmental risk.

\subsubsection{REFERENCES}

Almeria, S., Calvete, C., Pages, A., Gauss, C. \& Dubey, J.P. (2004) Factors affecting the seroprevalence of Toxoplasma gondii infection in wild rabbits (Oryctolagus cuniculus) from Spain. Vet. Parasitol. 123, 265-270.

Andrzejewska, I., Tryjanowski, P., Zduniak, P., Dolata, P.T., Ptaszyk, J. \& Cwiertnia, P. (2004) Toxoplasma gondii antibodies in the white stork Ciconia ciconia. Berl. Munch. Tierarztl. Wochenschr. 117, 274-275.

Aramini, J.J., Stephen, C. \& Dubey, J.P. (1998) Toxoplasma gondii in Vancouver Island cougars (Felis concolor vancouverensis): serology and oocyst shedding. J. Parasitol. 84, 438-440.

Aramini, J.J., Stephen, C., Dubey, J.P., Engelstoft, C., Schwantje, H. \& Ribble, C.S. (1999) Potential contamination of drinking water with Toxoplasma gondii oocysts. Epidemiol. Infect. 122, 305-315.

Arkush, K.D., Miller, M.A., Leutenegger, C.M., Gardner, I.A., Packham, A.E. et al. (2003) Molecular and bioassay-based detection of Toxoplasma gondii oocyst uptake by mussels (Mytilus galloprovincialis). Int. J. Parasitol. 33, 1087-1097.

Asgari, Q., Motazedian, M.H., Esmaeelzadeh, B., Kalantari, M. \& Hatam, Gh. R. (2009) The prevalence of Toxoplasma infection among free-ranging chickens in southern Iran using IFA and nested-PCR. Iran J Parasitol 4, 29-36.

Avelino, M.M., Campos, D.Jr., Parada, J.B. \& Castro, A.M. (2004) Risk factors for Toxoplasma gondii infection in women of childbearing age. Braz J Infect Dis 8, 164-174.

Brown, A.S. (2011) The environment and susceptibility to schizophrenia. Prog. Neurobiol. 93, 23-58.

Buxton, David. (1998) Protozoan infections (Toxoplasma gondii, Neospora caninum and Sarcocystis spp.) in sheep and goats: recent advances. Vet. Res. 29, 289-310.

Cook, A.J., Gilbert, R.E., Buffolano, W., Zufferey, J., Petersen, E. et al. (2000) Sources of toxoplasma infection in pregnant women: European multicentre case-control study. European Research Network on Congenital Toxoplasmosis. BMJ 321, 142-147.

da Silva, DS., Bahia-Oliveira, L.M.G., Shen, S.K., Kwok, O.C.H., Lehman, T. \& Dubey, J.P. (2003) Prevalence of Toxoplasma gondii in chickens from an area in southern Brazil highly endemic to humans. J. Parasitol. 89, 394-396.

Dawson, D. (2005) Foodborne protozoan parasites. Int. J. Food Microbiol. 103, 207-227.

de Thoisy, B., Demar, M., Aznar, C. \& Carme, B. (2003) Ecologic correlates of Toxoplasma gondii exposure in free-ranging neotropical mammals. $J$ Wildl Dis. 39, 456-459.

Dubey, J.P., Graham, D.H., Dahl, E., Hilali, M., El-Ghaysh, A. et al. (2003) Isolation and molecular characterization of Toxoplasma gondii from chickens and ducks from Egypt. Vet. Parasitol. 114, 89-95.

Dubey, J.P., Graham, D.H., Dahl, E., Sreekumar, C., Lehmann, T. et al. (2003b) Toxoplasma gondii isolates from free-ranging chickens from the United States. J. Parasitol. 89, 1060-1062.

Dubey, J.P., Moura, L., Majumdar, D., Sundar, N., Velmurugan, G.V. et al. (2009) Isolation and characterization of viable Toxoplasma gondii isolates revealed possible high frequency of mixed infection in feral cats (Felis domesticus) from St Kitts, West Indies. Parasitology 136, 589-594.

Gauss, C.B., Almería, S., Ortuño, A., Garcia, F. \& Dubey, J.P. (2003) Seroprevalence of Toxoplasma gondii antibodies in domestic cats from Barcelona, Spain. J. Parasitol. 89, 1067-1068.

Lass, A., Pietkiewicz, H., Modzelewska, E., Dumetre, A., Szostakowska, B. \& Myjak, P. (2009) Detection of Toxoplasma gondii oocysts in environmental soil samples using molecular methods. Eur. J. Clin. Microbiol. Infect. Dis. 28, 599-605. 
Lindsay, D.S., Blagburn, B.L. \& Dubey, J.P. (2002) Survival of nonsporulated Toxoplasma gondii oocysts under refrigerator conditions. Vet. Parasitol. 103, 309-313.

Lindsay, D.S., Collins, M.V., Mitchell, S.M., Cole, R.A. Flick, G.J. et al. (2003) Sporulation and survival of Toxoplasma gondii oocysts in seawater. J. Eukaryot. Microbiol. 50, 687-688.

Lindsay, D.S., Collins, M.V., Mitchell, S.M., Wetch, C.N., Rosypal, A.C. et al. (2004) Survival of Toxoplasma gondii oocysts in Eastern oysters (Crassostrea virginica). J. Parasitol. 90, 1054-1057.

Massie, G.N., Ware, M.W., Villegas, E.N. \& Black, M.W. (2010) Uptake and transmission of Toxoplasma gondii oocysts by migratory, filter-feeding fish. Vet. Parasitol. 169, 296-303.

McAllister, M.M. (2005) A decade of discoveries in veterinary protozoology changes our concept of "subclinical" toxoplasmosis. Vet. Parasitol. 132, 241-247.

Miller, M.A., Gardner, I.A., Kreuder, C., Paradies, D.M., Worcester, K.R. et al. (2002) Coastal freshwater runoff is a risk factor for Toxoplasma gondii infection of southern sea otters (Enhydra lutris nereis). Int. J. Parasitol. 32, 9971006.

Opsteegh, M., Swart, A., Fonville, M., Dekkers, L. \& van der Giessen, J. (2011) Age-related Toxoplasma gondii seroprevalence in dutch wild boar inconsistent with lifelong persistence of antibodies. PLoS One 6, e16240.

Radon, K., Windstetter, D., Eckart, J., Dressel, H., Leitritz, L. et al. (2004) Farming exposure in childhood, exposure to markers of infections and the development of atopy in rural subjects. Clin. Exp. Allergy 34, 1178-1183.

Salant, H., Landau, D.Y. \& Baneth, G. (2009) A cross-sectional survey of Toxoplasma gondii antibodies in Israeli pigeons. Vet. Parasitol.165, 145-149.

Shapiro, K., Conrad, P.A., Mazet, J.A.K., Wallender, W.W., Miller, W.A. \& Largier, J.L. (2010) Effect of estuarine wetland degradation on transport of Toxoplasma gondii surrogates from land to sea. Appl. Environ. Microbiol. 76, 6821-6828.

Smith, K.E., Zimmerman, J.J., Patton, S., Beran, G.W. \& Hill, H.T. (1992) The epidemiology of toxoplasmosis on Iowa swine farms with an emphasis on the roles of free-living mammals. Vet. Parasitol. 42, 199-211.

Winiecka-Krusnell, J., Dellacasa-Lindberg, I., Dubey, J.P. \& Barragan, A. (2009) Toxoplasma gondii: Uptake and survival of oocysts in free-living amoebae. Exp. Parasitol. 121, 124-131. 


\section{Chapter 4.2}

\section{Helminthic zoonoses}




\section{Chapter 4.2.1 Trematodes}

\section{[SCHISTOSOMATIDAE]}

In spite of their limited fatality towards humans, helminths in general represent a steady burden with many side effects and economic outcome. At the beginning of each helminths group description (trematodes, cestodes and nematodes), we decided to summarize some environmental parameters to emphasize the importance of zoonotic helminthology. Trematodes global infection burden is presented in Table 4.2.1.1.

\subsubsection{CERCARIAL DERMATITIS}

Swimmer's itch or cercarial dermatitis is caused by repeated infection with cercariae (larvae of trematodes, a free-living form of the schistosome worm infective to humans) released from an intermediate host (snails from different water types: ponds, lakes and oceans) able to penetrate human skin or other animals (mainly waterfowl) (Hoeffler, 1977). Cercariae are not able to propagate in humans, but due to their antigenic activity, they can cause allergenic reaction. The final hosts are waterfowls and different mammals. Among cercariae releasing trematodes, the following schistosomatids can be found: Austrobilharzia, Trichobilharzia, Gigantobilharzia and Schistosomaticum. The swimmer's itch is distributed worldwide affecting swimmers, rice field workers, marine mollusc collectors and tourists. For instance: in Central Europe it is caused by duck bilharziosis agent Trichobilharzia szidati (or Trichobilharzia ocellata), in United States coastal areas including Hawai, Austrobilharzia variglandis (sea swallows and ducks final hosts), in Southeast Asia and Iran ruminant schistosomiasis in rice fields by Schistosoma spindale and Orientobilharzia turkestanica. Transmission occurs when trematodes eggs from infected final hosts reach water through defecation. Hatched miracidia invade snails (intermediate hosts) and propagate asexually to produce cercariae that are mass released in water in search for a final host (waterfowl, etc.) (Figure 4.2.1.1). If humans are exposed to these waters, their skin is accidently penetrated by free cercariae whose survival is however, short with surface symptoms only. The clinical manifestation is primary itch (depending on past exposure), papules and lumps development, erythema, fever, malaise and if repeated infections anaphylactic reaction can occur. 
Trematodes

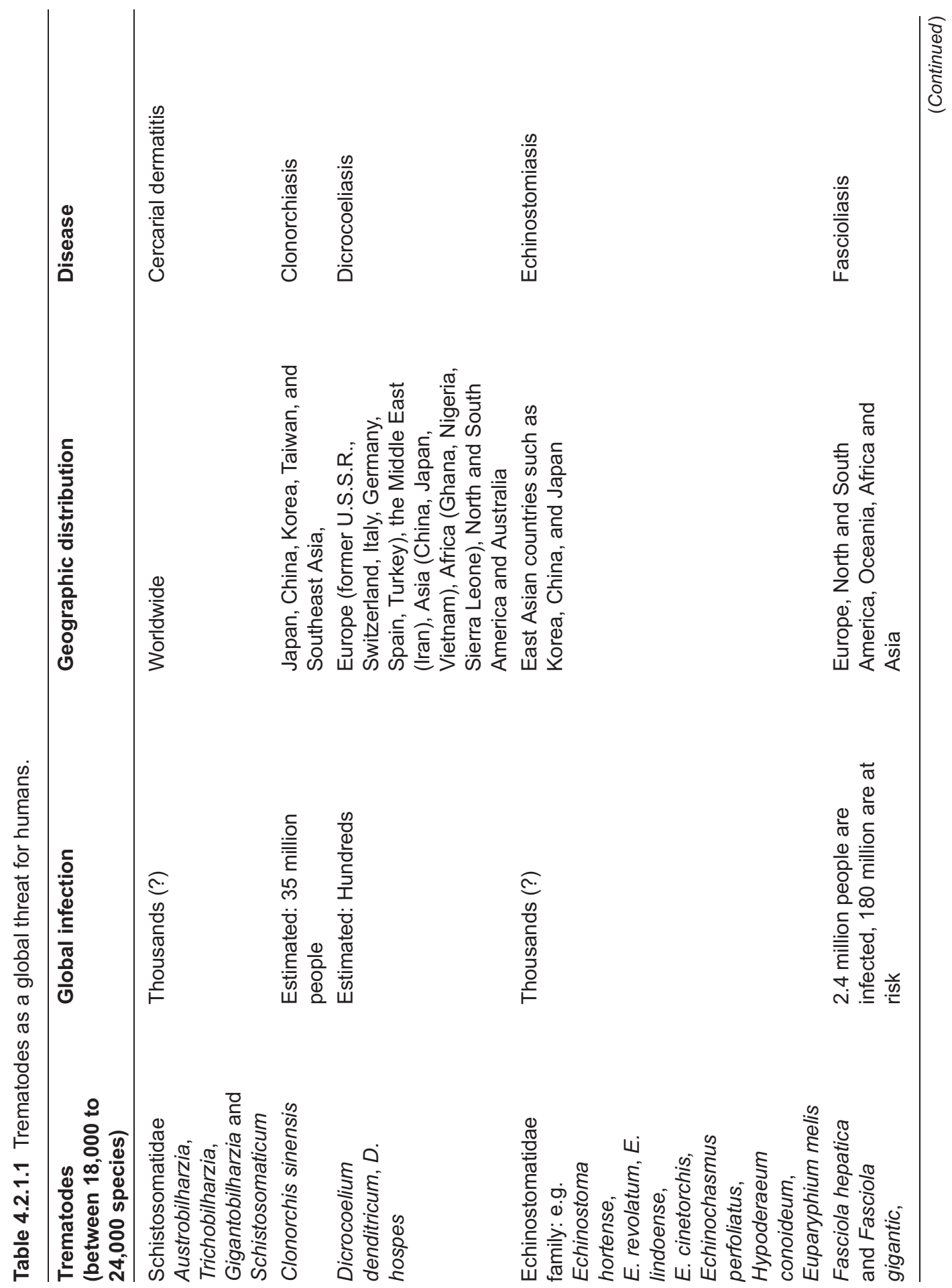




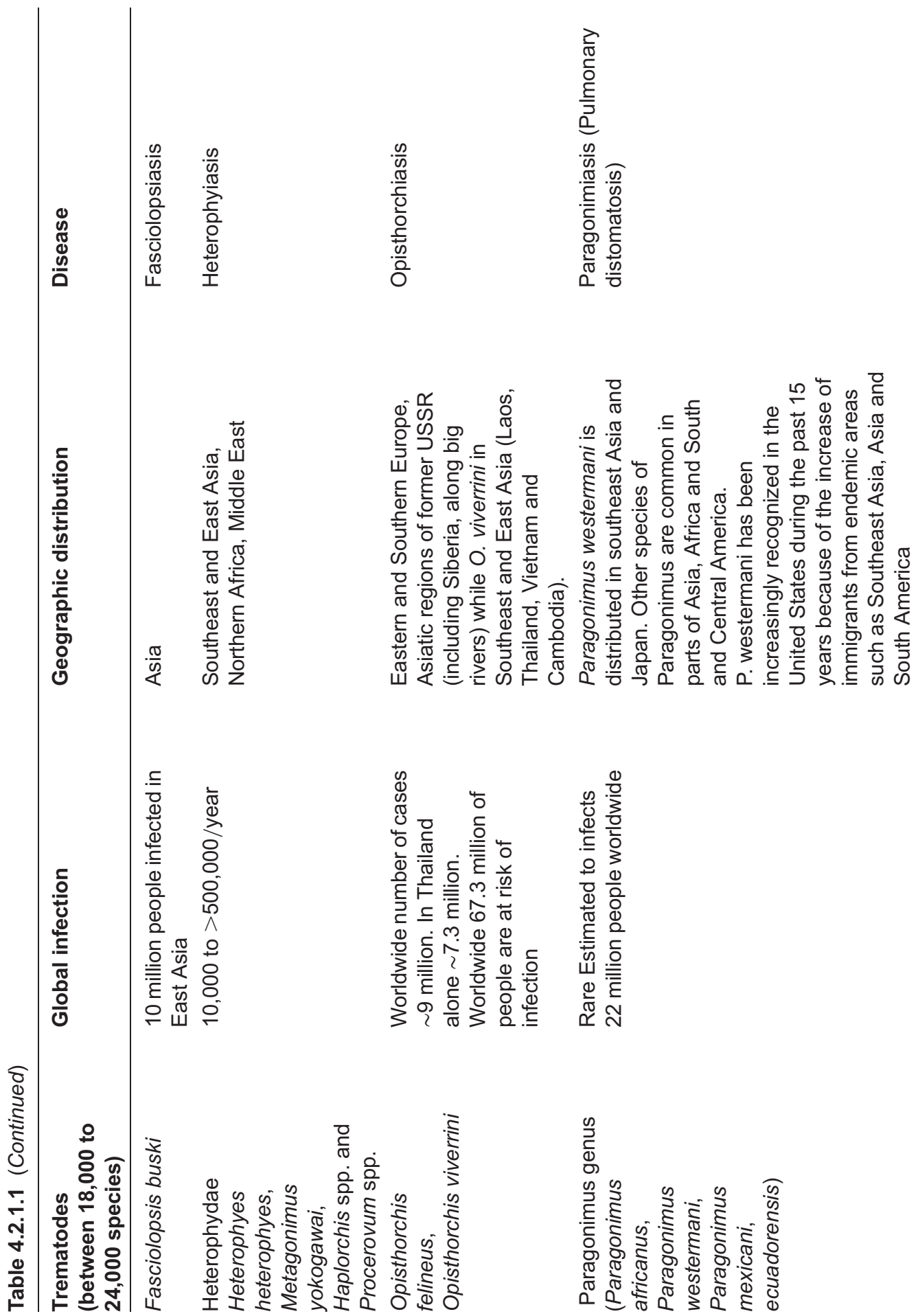




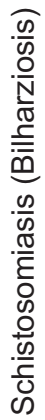

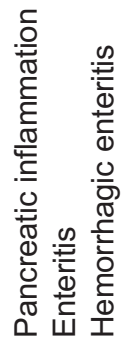

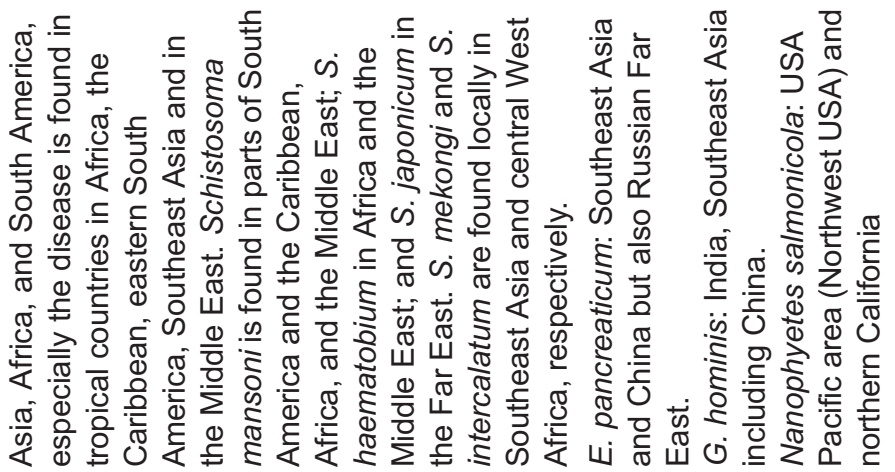
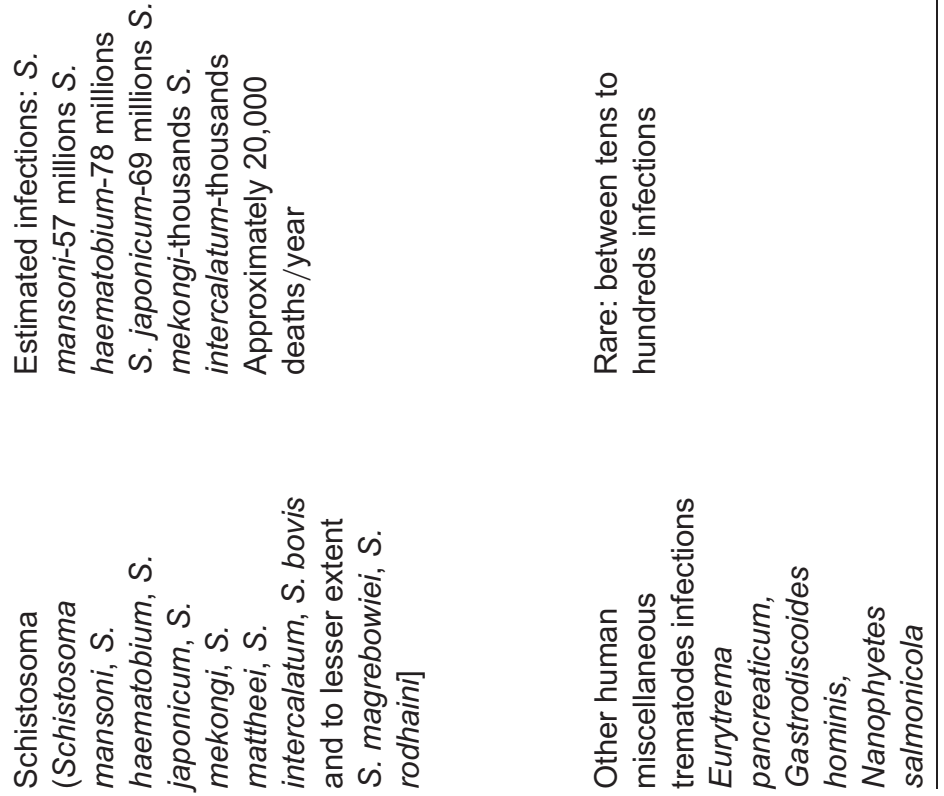


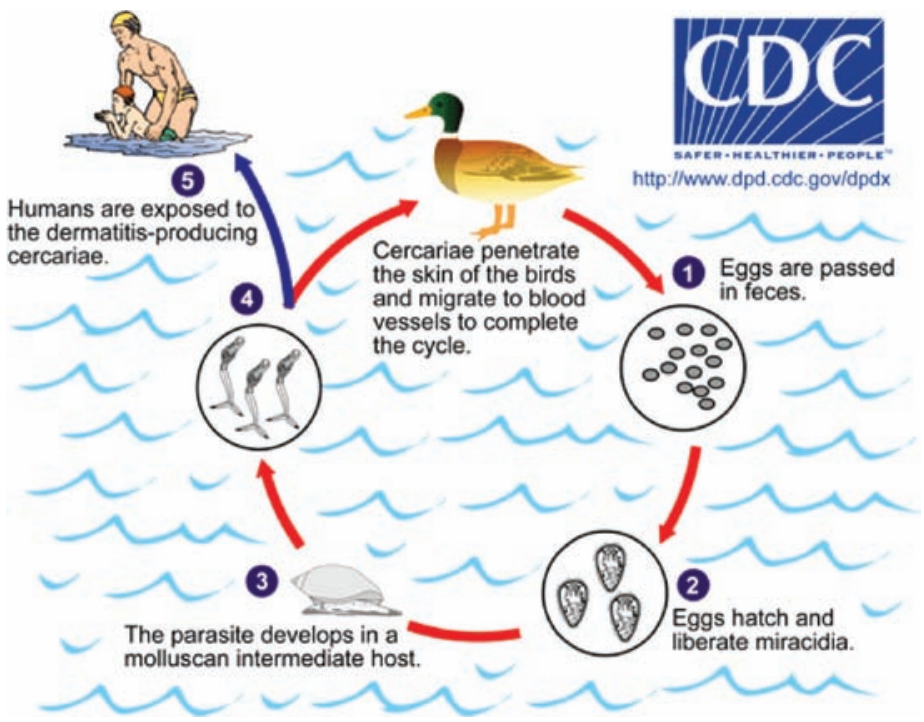

Figure 4.2.1.1. Cercarial dermatitis (swimmer's itch) life cycle (with permission from CDC, Atlanta, USA; http://www.dpd.cdc.gov/DPDx/HTML/CercarialDermatitis.htm)

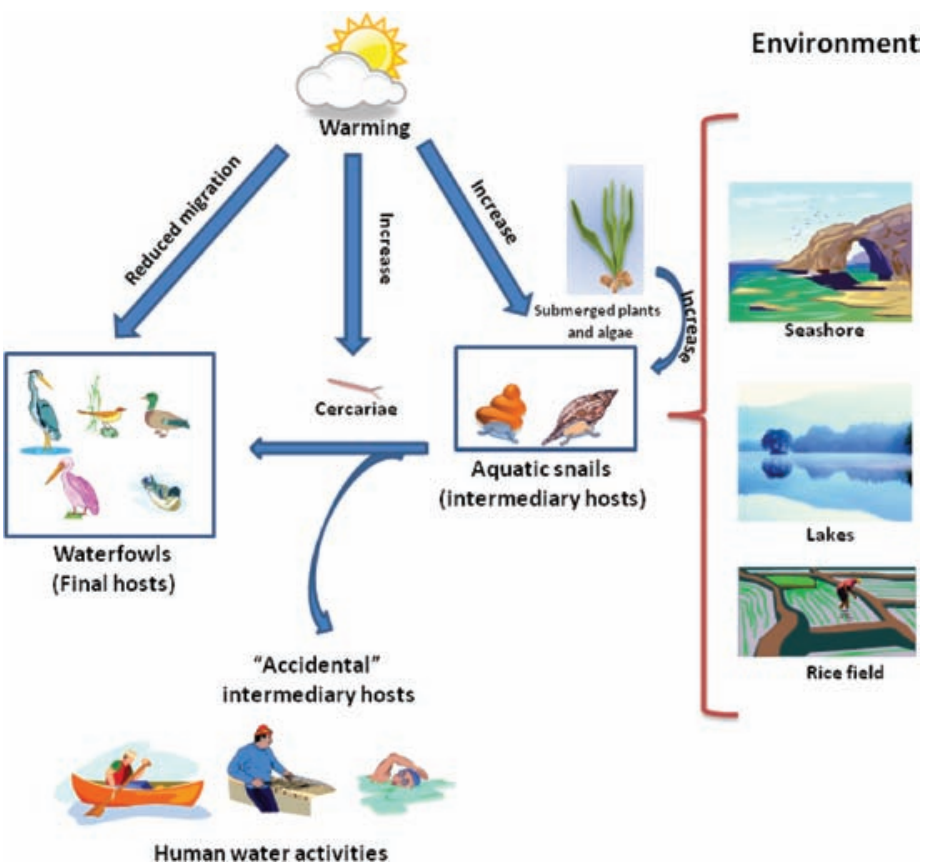

Figure 4.2.1.2. Potential impact of global warming chain on cercarial dermatitis 


\subsection{Cercarial dermatitis and environment}

Increased cases of cercarial dermatitis are directly linked to ecological and environmental factors. Because the life cycle of these trematodes is linked to water (water snails and waterfowl), any disturbance of the ecological balance can directly or indirectly impact one of those bioparameters. For example if dense mats of algae develop under anthropogenic pressure, large numbers of plant-grazing anatids and cyprinids will be attracted and in turn trematode transmission is facilitated. Anthropogenic pressure found expression in the construction of large freshwater impoundments (e.g., dams) that dramatically affects both the natural environment and wildlife parasite fauna (Soldánová et al., 2010). Parasites' responses are diverse; however, in the longrun such anthropogenic alterations result in the facilitation of trematodes life cycle and Swimmer's itch has become an increasing problem in Europe and North America lake regions (Kolárová et al., 2010; De Gentile et al., 1996). Perhaps the most striking evidence came from Israel, where fishponds and other fresh or brackish water impoundments were built for economic development of aquatic agriculture and water collection. These impoundments are visited each year by thousands of migratory birds, many of them belo waterfowl (Frumkin et al., 1995). Another important factor is climate change impact on biosphere in spite of reports on cercarial dermatitis from relatively cold climate areas such as lakes in French Alps, Savoy district, Iceland and Canada (Dubois et al., 2001; Jouet et al., 2008; Kolárová et al., 1999; Levesque et al., 2002). Thus, warmer temperature may increase algal development and consequently snail population and accelerate trematode development within snails. In addition, from the ornithological point of view, migrating birds under global warming conditions do change their habits, becoming sedentary in central European lakes (Cotton, 2003). When the final host remains in place, the life cycle of bird schostosomiasis will expand increasing cercarial numbers with higher risk for humans (Figure 4.2.1.2).

\subsection{REFERENCES}

Canestri-Trotti, G., Fioravanti, M.L. \& Pampiglione, S., 2001. Cercarial dermatitis in Italy Helminthologia 38, 245.

Cotton, P.A. (2003) Avian migration phenology and global climate change. Proc. Natl. Acad. Sci. U.S.A. 100, 1221912222.

De Gentile, L., Picot, H., Bourdeau, P., Bardet, R., Kerjan, M., et al. (1996) La dermatite cercarienne en Europe: un problème de santé publique nouveau? Bull. World Health Organ. 74, 159-163.

Dubois, J.P., Buet, A., Cusin, I., Deloraine, A., Gerdil, S. et al. (2001) Epidemiological studies related to cercarial dermatitis in lakes of the Savoy District (France). Helminthologia 38, 244.

Frumkin, R., Pinshow, B. \& Kleinha, S. (1995) A Review of bird migration over Israel. J. Ornithol. 136, 127-147.

Hoeffler, D.F. (1977) "Swimmers' itch" (cercarial dermatitis). Cutis 19, 461-465, 467.

Jouet, D., Ferté, H., Depaquit, J., Rudolfová, J., Latour, P. et al. (2008) Trichobilharzia spp. in natural conditions in Annecy Lake, France. Parasitol. Res. 103, 51-58.

Kolárová, L., Horák, P. \& Skírnisson, K. (2010) Methodical approaches in the identification of areas with a potential risk of infection by bird schistosomes causing cercarial dermatitis. J. Helminthol. 84, 327-335.

Kolárová, L., Skirnisson, K. \& Horák, P. (1999) Schistosome cercariae as the causative agent of swimmer's itch in Iceland. J. Helminthol. 73, 215-220.

Levesque, B., Giovenazzo, P., Guerrier, P., Laverdiere, D. \& Prud'Homme, H. (2002) Investigation of an outbreak of cercarial dermatitis. Epidemiol. Infect. 129, 379-386.

Soldánová, M., Selbach, C., Sures, B., Kostadinova, \& Pérez-del-Olmo, A. (2010) Larval trematode communities in Radix auricularia and Lymnaea stagnalis in a reservoir system of the Ruhr River Parasites \& Vectors 3, 56. 


\section{Chapter 4.2.1.2 Clonorchiasis}

\section{[CLONORCHIS SINENSIS]}

Clonorchiasis is a disease caused by infection with eggs of the trematode Clonorchiasis sinensis. C. sinensis is a hermaphroditic fluke that requires two intermediate hosts (snails and fish) before establishing itself in a final host (humans, cats, dogs, pigs and small carnivores). Fluke eggs are excreted in feces of infected human, feces that may reach water sources and there further ingested by various mollusks (snails of Balinus and Parafossarulus species). In snails, as the first intermediary host, the parasite goes through asexual multiplication and growth (miracidium, sporocyst and redia stages). Snails release active cercariae that can swim and penetrate the second intermediary host (small fresh water fishes mostly from Cyprinidae family). Then cercariae encyst in fish muscles to develop in metacercariae to be further transferred to the final host (humans) by ingestion of raw or inadequately cooked fish meat. Young flukes hatch in humans' duodenum and migrate to distal bile ducts via bile duct to adhere to epithelial cells (Figure 4.2.1.2.1). Following maturation, flukes produce constantly eggs excreted in human feces. The life span of this parasite (without treatment) within final host can reach 20 to 25 years. Endemic areas of clonorchiasis are found in the Far East (Korea, Japan, Vietnam, Taiwan and Southern China) where raw fish consumption is a common practice (e.g., sashimi in Japan). Clinical manifestations are acute or chronic cholangitis (depending on initial fluke load intake) with potential risk to of developing cholangiocarcinoma (biliary system neoplasm), periportal cirrhotic lesions, upper abdomen pain, jaundice, hepatosplenomegaly, flatulence, changeable diarrhea and constipation, dizziness, vomiting, headache and anemia.

\subsection{CLONORCHIASIS AND ENVIRONMENT}

As previously mentioned, C. sinensis is wide -spread in the Far East. Tang and Luo (2003) looked for prevalence of different parasitic infections (including $C$. sinensis) in rural areas of West China. They attributed the high parasitic prevalence $(51.7 \%)$ and persistence to the following factors: moist and remote environment, traditional life, education, contaminated potable water and inadequate health services. Clonorchis sinensis prevalence was low (0.04\%) in comparison with other parasites (e.g., 


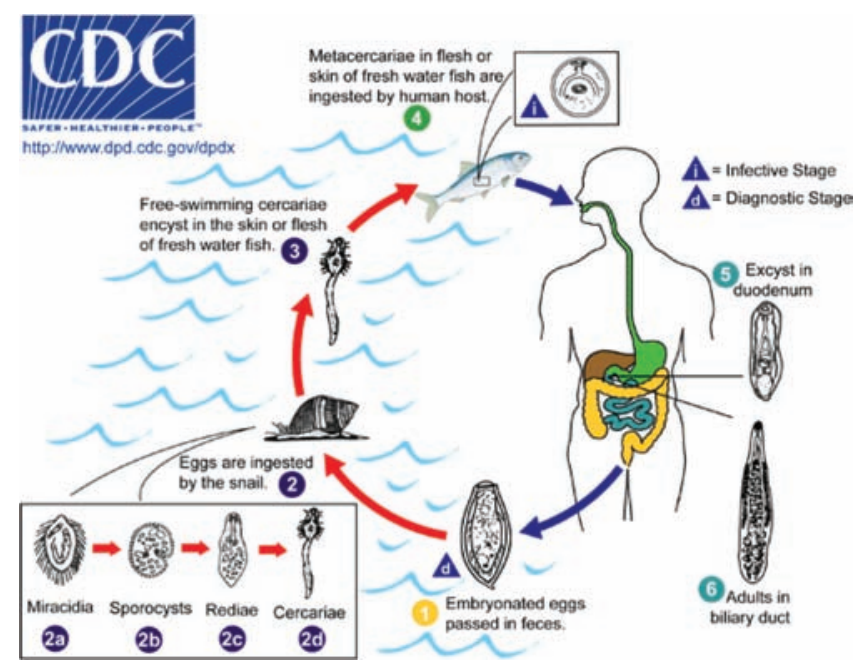

Figure 4.2.1.2.1. Clonorchis sinensis life cycle (with permission from CDC, Atlanta, USA; http://www.dpd. cdc.gov/DPDx/HTML/Clonorchiasis.htm)

41.4\% for Ascaris lumbricoides), which may be explained by low fish consumption in these rural areas. In another study performed in China, stool examinations have been performed on people suspected of C. sinensis infection. Among these individuals, $21.43 \%$ were infected with $C$. sinensis exclusively and $34.64 \%$ were co-infected with $C$. sinensis and other pathogens. These authors also attributed this helmintic infection prevalence to living environment, occupations and hygienic and eating habits. In South China, Yu et al. (2003) examined stools for presence of eggs among 1,552 individuals and found a $31.6 \%$ C. sinensis prevalence. Their study showed higher prevalence in adults than children and adolescents. The authors emphasized that while endemicity of soil-transmitted helminths is in decline in the region surveyed, $C$. sinensis cases have increased. They attributed this increase to possible socioeconomic conditions, fish pond contamination with contaminated feces, fishery practices and farm animals' infection, which need further verification. In a related studied, Zhang et al. (2007) studied $C$. sinensis infection prevalence in 1,473 individuals in the Shenzhen area (located in Zhujiang delta of Guangdong province), one of cities in the south of China with the largest number of immigrants. In addition, various snails and fishes (intermediate hosts) from this area were also tested for the presence of cercariae and metacercariae. Infection prevalence in humans was $4.75 \%$, in snails $1.15 \%$ and fishes $16.97 \%$ (carps leading with $40.74 \%$ ). A distributed epidemiologic questionnaire among the study group participants revealed the following: 1) $27 \%$ had raw fish meat one or two times a month; 2) $5 \%$ used for raw fish and cooked food the same appliances; 3) among fishpond owners, $40 \%$ fed fishes with human and animal excrements. Indeed, all these factors are plausible explanation for continuous infection of $C$. sinensis in humans in this area. A very similar study in another area of China has been conducted by Lin et al. (2005) emphasizing the same points: $51 \%$ of participants ate raw fish at least 1 to 2 times a month; utensils were used for both raw fish and other foods; and fish ponds were "fertilized" with excreta. In addition these authors also reported the prevalence of $C$. sinensis in other final hosts: cats (70\%), dogs $(50 \%)$ and pigs (27\%). In this study, fish (as intermediary host) had an infection rate of $40 \%$. In another highly endemic area, Vietnam, Nguyen et al. (2009) looked for fish borne zoonotic trematodes (including $C$. sinensis) in different domestic animals. In spite of low prevalence of $C$. sinensis in these 
animals, other trematodes revealed a similar infection prevalence pattern as presented by Lin et al. (2005): cats $(70.2 \%)$, dogs $(56.9 \%)$ and pigs $(7.7 \%)$, all affected by risky husbandry practice of feeding animals with raw fish.

In summary, it should be stated that infections with $C$. sinensis can be controlled by education, higher hygienic standards and possible elimination of one of the "players" involved in C.sinensis life cycle. Molluscides use is still questionable due to their hazardous environmental effects on other aquatic fauna, and therefore Pokora (2001) suggested biological control (predators, parasites or pathogens and intra-species competition) as a more "green" solution for snail population reduction.

\subsection{REFERENCES}

Nguyen, T.L., Nguyen, T.P., Johansen, M.V., Murrell, K.D., Phan, T.V. et al. (2009) Prevalence and risks for fishborne zoonotic trematode infections in domestic animals in a highly endemic area of North Vietnam. Acta Trop. 112, 198-203.

Pokora, Z. (2001) Role of gastropods in epidemiology of human parasitic diseases. Wiad Parazytol 47, 3-24.

Tang, N. \& Luo, N.J. (2003) A cross-sectional study of intestinal parasitic infections in a rural district of west China. Can $J$ Infect Dis 14, 159-162.

Wang, K-X., Zhang, R-B., Cui, Y-B., Tian, Y., Cai, R. \& Li, C-P. (2004) Clinical and epidemiological features of patients with clonorchiasis. World J. Gastroenterol. 10, 446-448.

Yu, S-H., Kawanaka, M., Li, X-M., Xu, L-Q., Lan, C-G. \& Rui, L. (2003) Epidemiological investigation on Clonorchis sinensis in human population in an area of South China. Jpn. J. Infect. Dis. 56, 168-171.

Zhang, R., Gao, S., Geng, Y., Huang, D., Yu, L. et al. (2007) Epidemiological study on Clonorchis sinensis infection in Shenzhen area of Zhujiang delta in China. Parasitol. Res. 101, 179-183. 


\section{Chapter 4.2.1.3}

\section{Dicrocoeliasis (Distomatosis)}

\section{[DICROCOELIM DENDRITICUM, DICROCOELIM HOSPES]}

Dicrocoelium dendriticum and Dicrocoelium hospes are trematodes that rarely infect the bile ducts of humans (Ashrafi, 2010). Other reservoirs and final hosts are mammals, such as sheep, cows, goats, pigs, llamas, rabbits, alpacas and water buffaloes (Rinaldi et al., 2009). Land snails (e.g., in USA, Cochlicopa lubrica; in Spain, Helicella itala) and specific ant species (e.g., in USA, Formica fusca; in Spain, Formica rufibarbis) are intermediate hosts. In infected land snails, ingested eggs release miracidia that transform into sporocytes and finally into cercariae. Land snails deposit slimeballs containing cercariae via respiratory pore. The slimeballs are further consumed by ants that become infected with cercariae that will further transform inside the ant into metacercariae. Accidental intake of infected ants (Formica spp. for D. dendriticum and Camponotus spp. for D. hospes) transport these parasites into the digestive system of an intermediary or final host and further to bile ducts (Figure 4.2.1.3.1). The newly infected host, sheds eggs containing larvae within feces into environment. Dicrocoeliasis is thought to be endemic worldwide, being found in Europe, the Middle East, Asia, Africa, North and South Americas, Australia, but mostly reported in more temperate zones of the Northern Hemisphere. This trematode tends to be present in intermediate hosts that favor dry, chalky and alkaline soils. Clinical symptoms are relatively mild; however, if a high infective dose is ingested, fatigue, anorexia, diarrhea, abdominal pain, fever, hepatomegaly, cirrhosis, edema, ascites, icterus and urticaria may develop.

\subsection{DICROCOELIASIS AND ENVIRONMENT}

The environmental cycle of Dicrocoelim dendriticum and Dicrocoelim hospes is somehow peculiar requiring two intermediary terrestrial hosts. In ants, infectious cercariae can cross the insect craw and one to three will settle in the suboesophageal ganglion of the ant, called "brainworm", while the rest will develop into metacercariae. The brain-infected ants are influenced by temperature and when temperature falls, ants enter a state of tetania of mandibular muscles causing them to remain temporarily attached to grass tips for the period when solar intensity and temperature decrease (until the next morning). This behavior increase fluke' odds of being ingested by a transitory grazing host together with the tetanic 
intermediary host. From the epidemiological point of view, ants are important in the dissemination of dicrocoeliosis due to their abundance, wide distribution and "brainworm" dependent behavior alteration (Manga-González et al., 2001). Finally it will be interesting to find out whether other ant' species can be infected and whether in turn ant predators such as bears and anteaters, may also be infected with this trematode. While anteaters are primarily distributed in Central to South America, bears live also in the northern hemisphere where these flukes are more common, hence additional studies may clarify this interesting question.

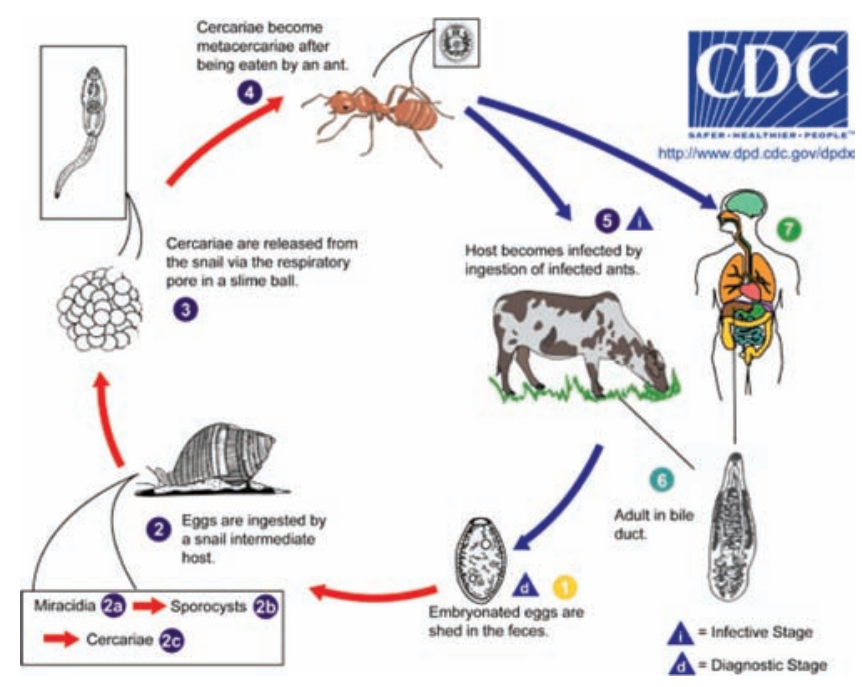

Figure 4.2.1.3.1. Life cycle of Dicrocoelium denditricum (with permission from CDC, Atlanta, USA; http:// www.dpd.cdc.gov/DPDx/html/ImageLibrary/Dicrocoeliasis_il.htm)

\subsection{REFERENCES}

Ashrafi, K. (2010) Human dicrocoeliasis in northern Iran: two case reports from Gilan province. Ann Trop Med Parasitol 104, 351-353.

Manga-González, M.Y., González-Lanza, C., Cabanas, E. \& Campo, R. (2001) Contributions to and review of dicrocoeliosis, with special reference to the intermediate hosts of Dicrocoelium dendriticum. Parasitol. 123, S91-S114.

Rinaldi, L., Musella, V., Veneziano, V., Condoleo, R.U. \& Cringoli, G. (2009) Helmintic infections in water buffaloes on Italian farms: a spatial analysis. Geospat Health 3, 233-239. 


\section{Chapter 4.2.1.4}

\section{Echinostomiasis (Intestinal Fluke Infection)}

\section{[ECHINOSTOMATIDAE FAMILY: E.G. ECHINOSTOMA HORTENSE, E. REVOLATUM, E. LINDOENSE, E. CINETORCHIS, ECHINOCHASMUS PERFOLIATUS, HYPODERAEUM CONOIDEUM, EUPARYPHIUM MELIS]}

The Echinostomiatidae family are parasitic flukes infecting humans, birds (mainly waterfowl), rats, dogs, cats and pigs. Like other trematodes, they have an intermediary host (snails, mussels and possibly freshwater fishes) with definitive hosts (humans, birds and other mammals). In humans, it is usually seen as a rare intestinal parasite of little clinical importance except in heavy infections. Humans are infected through consumption of contaminated undercooked meat, freshwater snails and mussels. Echinostomiasis is endemic in Far East and Southeast Asia; however, due to the ecological shift in the snail population composition it lost its zoonotic importance (nonetheless in certain areas its prevalence can range from $1 \%$ in Indonesia to up to $44 \%$ in the Philippines). It seems that echinostomiasis is underreported, being most prevalent in remote rural areas with malnutrition, poverty and poor sanitation. The life cycle starts from excretion of unembryonated eggs excreted by final hosts (e.g., humans or waterfowl) into feces that contaminate water sources. In water, unembryonated eggs embryonate and release developed miracidia that in turn infect snails (as an intermediate host). Hooked on snail tissue, the miracidia will develop into a final cercariae (via sporocytes and rediae stages) that can freely swim and infect other water snail (a second intermediary host). When these second intermediary hosts are consumed raw by humans or waterfowl, the metacercariae formed in this second intermediary host will excyst in the gastrointestinal system to form adult flukes colonizing the small intestine (in humans) (Figure 4.2.1.4.1). Clinical manifestation are mostly imperceptible however, heavy infestation with this fluke may cause diarrhea, anorexia, flatulence, abdominal pain and even ulcerative lesions (Miyamoto et al., 1984; Chai et al., 1994).

\subsection{ECHINOSTOMIASIS AND ENVIRONMENT}

In endemic areas, echinostomiasis express two separate life cycles: human and sylvatic. According to its intermediary hosts (primary and secondary), the parasite can be found in both fresh and brackish water 
sources. Consistent with the ecological aspects it should be mentioned here that due to their extremely broad specificity for secondary intermediate hosts, these flukes do not need humans to complete their life cycle (Chung et al., 2001) (Figure 4.2.1.4.1). As mentioned earlier, with other flukes, echinostomiasis can also spread through fishpond fertilization with "night soil" (human excreta collected from latrines). The disease is most prevalent in remote rural areas in South-East Asia at low socioeconomic status, growing free-food markets with poor sanitation and lack of food inspection (Graczyk and Fried, 1998). Some encouraging reports on possible prevention routes of this parasite have been demonstrated by the introduction of fish which prey on the larval stages of the essential molluscan hosts (Carney, 1999).

Davis (2005) showed in his study that eggs of E. revolatum, a human pathogen, recovered from Canada geese and stored at $4^{\circ} \mathrm{C}$ for up to 72 weeks hatched successfully following incubation at optimum temperature $\left(25-30^{\circ} \mathrm{C}\right)$. Experimentally, snails have been also successfully infected at a temperature range from 10 to $25^{\circ} \mathrm{C}$, demonstrating that an environmental water temperature of $10^{\circ} \mathrm{C}$ could support infections in nature. An interesting question that should be asked in relation to almost all flukes is: What is the impact of different anthropogenic chemical pollutants on the interaction between flukes and their hosts (mainly primary and secondary ones)? Recently Rohr et al. (2008) studied the net effect of common pesticides (atrazine, glyphosate, carbaryl and malathion) on Echinostoma trivolvis (albeit not a human parasite) in relation to its first and second hosts (the snail Planorbella trivolvis and the green frog tadpoles Rana clamitans respectively). In general pesticides caused significant greater mortality of E. trivolvis cercariae, with atrazine having a significant effect but at much more elevated concentrations than commonly found in aquatic environments $(\geq 200 \mu \mathrm{g} / \mathrm{L})$. None of the pesticides had significantly enhanced E. trivolvis virulence, decreased tadpole survival, or reduced snail survival, growth, or fecundity. According to these authors, their results suggested that the net effect of exposure to environmentally realistic levels of pesticides could be elevated infections of amphibians with this trematode type. Implementation of additional studies are necessary with human Echinostoma species in order to understand the impact of anthropogenic pollution.

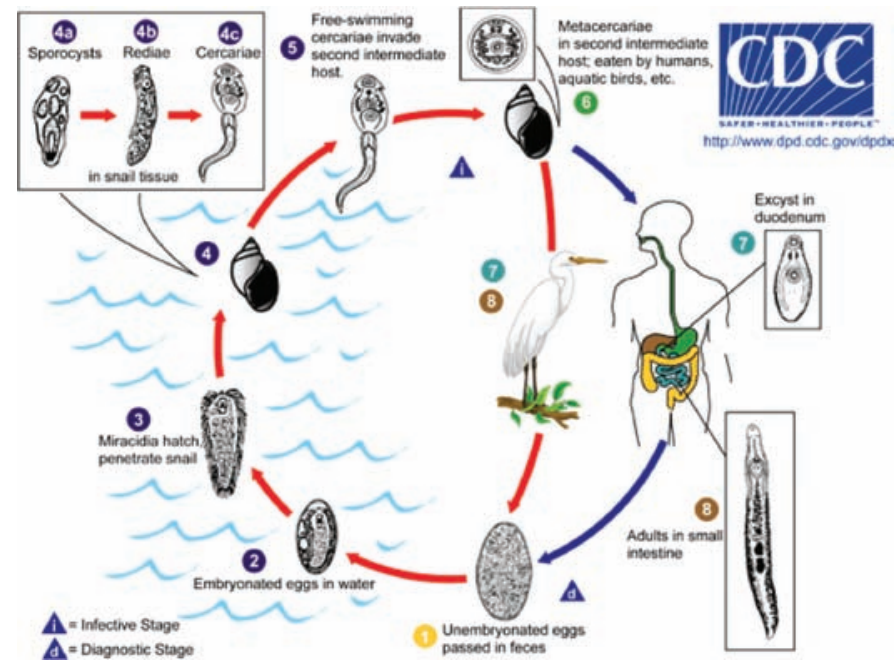

Figure 4.2.1.4.1. Echinostomidae family life cycle (with permission from CDC, Atlanta, USA; http://www.dpd. cdc.gov/DPDx/html/ImageLibrary/Echinostomiasis_il.htm) 


\subsection{REFERENCES}

Carney, W.P. (1991) Echinostomiasis-a snail-borne intestinal trematode zoonosis. Southeast Asian J. Trop. Med. Public Health 22, 206-211.

Chai, J-Y., Hong, S-T., Lee, S-H., Lee, G.C. \& Min, Y.I. (1994) A case of echinostomiasis with ulcerative lesions in the duodenum. Korean J. Parasitol. 32, 201-204.

Chung, P.R., Jung, Y. \& Park, Y.K. (2001) Segmentina hemisphaerula: a new molluscan intermediate host for Echinostoma cinetorchis in Korea. J. Parasitol. 87, 1169-1171.

Davis, N.E. (2005) Storage and incubation of Echinostoma revolutum eggs recovered from wild Branta canadensis, and their infectivity to Lymnaea tomentosa snails. J. Helminthol. 79, 321-326.

Graczyk, T.K. \& Fried, B. (1998) Echinostomiasis: a common but forgotten food-borne disease. Am. J. Trop. Med. Hyg. 58, 501-504.

Miyamoto, K., Nakao, M., Ohnishi, K. \& Inaoka, T. (1984) Studies on the zoonoses in Hokkaido, Japan. 6. Experimental human echinostomiasis. Hokkaido Igaku Zasshi 59, 696-700.

Rohr, J.R., Raffel, T.R., Sessions, S.K. \& Hudson, P.J. (2008) Understanding the net effects of pesticides on amphibian trematode infections. Ecol Appl 18, 1743-1753. 


\section{Chapter 4.2.1.5 Fasciolasis}

\section{[FASCIOLA HEPATICA AND FASCIOLA GIGANTICA]}

In humans, fasciolasis is caused by hepatic infection with two flukes: Fasciola hepatica and Fasciola gigantica. Human infection occurs mainly through ingestion of plants (e.g., raw cress) or vegetables harboring active metacercariae, but a water route is also possible (Pozio, 2008; Blaise and Raccurt, 2007). While human infections with Fasciola hepatica are common, infection with Fasciola gigantica are scarce and found only in certain geographic regions (Mas-Coma et al., 2009). Beside humans, Fasciola hepatica infects other final host such as cattle, sheep, water buffaloes, lagomorphs, rodents and pigs, causing major economic damages in endemic areas (Pritchard et al., 2005; Rinaldi et al., 2009; Menard et al., 2000). The fluke is present in moist areas (increased rainfall), lakes, canals, pools, secondary of tertiary irrigation canals and ditches obstructed by plants and much less in rice fields, all favoring the growth of the intermediate hosts: primarily snails of the genus Lymnea but also others genera (in Egypt a planorbid species named Biomphalaria alexandrina) (Wibaux-Charlois et al., 1982). Fasciola gigantica is found in tropical areas of Asia (mainly Southeast Asia), Africa, countries in the Pacific area and in secluded areas of Near East and southern republics of former USSR with a similar host spectrum as $F$. hepatica. The life cycle includes excretion of fluke eggs (containing a zygote and nutrition cells) from humans or other mammals through excreta, that contaminate water sources. In water a miracidium hatched from the egg will swim to find a molluscan intermediate host (e.g., Lymnea trunculata snail). While inside the intermediate host, the miracidium develops into sporocyst and further into redia forms. The cercarial form leaves the snail and in the water phase transforms into metacercariae (encysted cercariae) that adhere to aquatic plants where they can survive for several months in humid conditions. Consumption of these plants by animals and humans introduce metacercariae into the gastrointestinal system of these final hosts. Metacercariae develop into adult flukes through hatching into the duodenum that crosses the intestinal wall into the peritoneal cavity and finally locate themselves in the liver. After 6 to 8 weeks a fluke will reach its final destination the bile ducts (Figure 4.2.1.5.1). Clinical manifestations of fascioliasis are fever, fatigue, anemia, anorexia, weight loss, pruritus, pain and icteric episodes. It should be mentioned, that in long term of liver damage by fasciolasis the anaerobe Clostridium novy (type B) spores can be activated (under anoxic conditions) leading to the so called 
"black disease" (an immune-mediated haemolytic anaemia-IMHA) expressed as haemoglobinuria. Some recent commentaries have been published, possibly linking cholangiocarcinoma (hepatobiliary carcinoma) in Thailand to chronic exposure to $F$. hepatica infection, nitrosamine and fish contaminated with nitrosamine as potentially underlying factors leading to this carcinogenesis (Wiwanitkit, 2009).

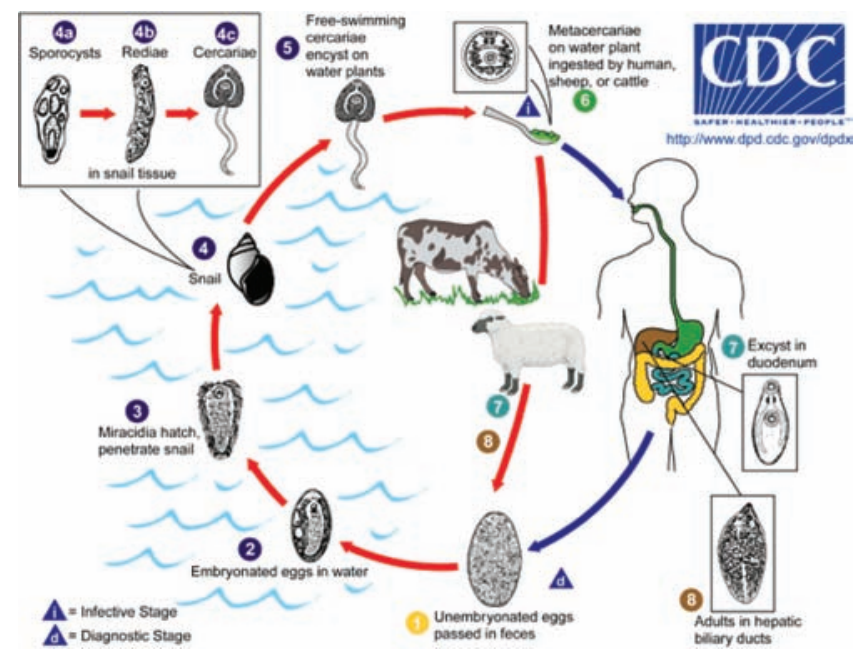

Figure 4.2.1.5.1. Fasciola hepatica life cycle (with permission from CDC, Atlanta, USA; http://www.dpd.cdc. gov/DPDx/html/ImageLibrary/Fascioliasis_il.htm)

\subsection{FASCIOLASIS AND ENVIRONMENT}

The reemergence of fasciolasis around the globe since the mid-1990s, revealed the successful expansion of this vector-borne parasite. If Europe was the original geographic area, now fasciolasis is spread over five continents despite some biological restrictions (intermediate host presence and prevalence). Environmental and human activities such as global transport of domestic animals, agriculture including irrigation and pastures, pollution, parasite genetic and newly discovered intermediary hosts are important factors in the expansion of fasciolasis (Mas-Coma, 2005; Relf et al., 2009; Mas-Coma et al., 2005; Walker et al., 2011; Canete et al., 2004; Bennema et al., 2011). Although not in the scope of this book, it should be mentioned that only $62.5 \%$ of the $F$. hepatica eggs subjected for 90 days to activated sludge processes were damaged, revealing high environmental resistance (Guenthoer, 1971).

Walker et al. (2008) studied F. hepatica and F. gigantica in East Africa (Kitulo Plateau of the Southern Highlands, Tanzania) and sustainable conditions for lymnaeid species joint existence (L. truncatula and L. natalensis) and possible hybrids creation. At high altitude, molecular methods confirmed the match of $L$. trancatula and $F$. hepatica while at lower altitudes L. natalensis and F. gigantica was the preferred match with no hybrid fasciolids in either region.

Bovine fasciolasis prevalence in Switzerland ranges from 8.4 to $21.4 \%$. Rapsch et al. (2008) created an interactive map based on different environmental factors in order to chart the relative risk of bovine F. hepatica transmission. These factors were temperature, rainfall (moisture), soil and forest, all connected to the snail Lymnaea truncatula (the intermediary host) life cycle. In Switzerland, snail 
susceptibility to $F$. hepatica infection is closely linked to: 1) temperature- snails can survive and rein a temperature range from 10 to $25^{\circ} \mathrm{C} ; 2$ ) moisture- a rainfall in the range of $\sim 90$ to $210 \mathrm{~mm} / \mathrm{month}$ is optimal while higher values probably can wash parasite larvae and snails, consequently decreasing the potential contact between these two organisms; 3) soil- clay soils are more water-retentive than sandy soils and facilitate the creation of small water courses (pools, drainage ditches, puddles, etc.); 4) forestshady areas do not allow much solar radiation penetration into water pools, and therefore snails that feed on algal growth are inhibited. Fuentes et al. (1999) pointed to similar climatic and environmental factors involved in human $F$. hepatica prevalence in Bolivia (northern Bolivian Altiplano, a highly endemic area). Lymnaea truncatula snails occur in this region at altitudes of 3800-4100 m, exposed to various conditions: large variations in daily temperature, long dry and wet seasons (with high evapotranspiration) and intense solar radiation (due to altitude and lack of shade). Consistent with these conditions, the optimal transmission time is between December and March (summer in southern hemisphere). In this particular case, involving high altitude regions, several studies emphasized the longer shedding period and a higher production of cercariae of the Altipano lymnaeid snails than of the European ones, and hence a better environmental strategic adaptation (Mas-Coma et al., 2001; Vignoles et al., 2002). In another South American area (Andean Patagonian valleys of Argentina), Kleiman et al. (2007) studied the prevalence, egg output and the dynamics of bovine fasciolasis. In this case, the specific intermediate host snails (Lymnea viatrix) that is able to live for $\sim 15$ months, have been isolated mostly from standing and temporary water sources (e.g. lagoons) and rarely from streams. L. viatrix snails carried a relatively low burden of infection with bovine fasciola (overall $0.67 \%$ ) primarily in summer and autumn when infection transmission to heifers was highest (heifers-80\% and cows-60\%) with the exception of suckling calves (15\%), suggesting highly effective transmission. Besides high summer rainfall and increased prevalence of L. trunculata, emergence of bovine fasciolasis in East England has been also attributed to sheep influx from endemic areas for seasonal grazing into nonendemic ones (Pritchard et al., 2005).

In South Africa, de Kock et al. (2003) studied the geographic distribution and habitats of Lymnaea truncatula. As environmental habitats, swamps seem to be the most populated (42\% recovery), with most samples obtained from slow-flowing water (45.8\%), muddy substratum $(62.5 \%)$, mean annual temperature and rainfall of $10-20^{\circ} \mathrm{C}(86.3 \%)$ and $600-900 \mathrm{~mm}(69 \%)$ respectivelly. The authors concluded that in this geographic area temperature and water bodies' type plays a major role in the occurrence of this snail. In relation to temperature, Thomas et al. (2007) described a heat wave in 2003 that affected bovine helminthosis (including F. hepatica) in Southern France through lower prevalence of parasite eggs in feces followed by a quick increase in the following year. The authors attributed this phenomenon to several factors: helminths' adaptation, spread of new intermediate hosts and movement of hosts and reservoirs. When dealing with $F$. hepatica it should be remembered that an intermediate host is involved in the life cycle of this fluke, and thus a heat wave can strongly affect the wet and moist habitats of snails, cutting short the spread of this fluke.

Overall climate changes have been shown to influence trematodiases akin to the Ecuadorial experience, where human fasciolasis incidences increased significantly for the 2 years following the occurrence of El Niño Southern Oscillation (Fuentes, 2007). Rainfall and temperature are central climatic factors that affect fluke free-living stages, vegetation occurrence and population dynamics of hosts (snails and mammals) (Mas-Coma et al., 2007).

Environmental pollution with a large variety of anthropogenic chemicals undoubtedly impacts the life of different parasites and their hosts in different directions, yet to be identified. Krupicer et al. (1996) studied the effect of sub-chronic heavy metal $(\mathrm{Hg}, \mathrm{Pb}, \mathrm{Cu}, \mathrm{Zn}, \mathrm{Cr}$ and $\mathrm{Cd})$ intoxication in lambs also infected with ovine' fasciolasis. In intoxicated animals, the authors reported exceeding mercury and partially exceeding copper values in parenchymatous organs and muscles. In addition, the mean intensity of $F$. hepatica 
infection also strongly increased, suggesting the negative effect of metal emission on infected animals in that they impair their immune system. Sures et al. (1998) looked for cadmium and lead concentrations in F. hepatica infecting cattle and found a lead concentration 172, 53 and 115 times higher than in the surrounding organ (muscle, kidney and liver, respectively).

Soliman (2009) looked for pre- and post-exposure of Lymnea natalensis snail (the intermediate host of $F$. gigantica) to cadmium at different concentrations $(0.1$ to $100 \mu \mathrm{g} / \mathrm{L})$ and studied the infection rates with $F$. giagantica, cercariae shedding and pattern. Cadmium pre-exposure decreased infection rates (temperature dependent) while post-exposure increased cercariae shedding (temperature independent) altering also the cercarial output pattern (higher proportion of floating and dead cercariae that might reduce transmission). The author attributed cadmium effect on both mollusk and fluke to the trematode's location within the mollusks; digestive gland, which is also the main organ for metal accumulation. The effect of temperature on cadmium could be explained based on a study performed with other aquatic mollusc (the oyster Crassostrea virginica) and one of its mitochondrial functions such as oxidative capacity (Cherkasov et al., 2006). These authors reported that oysters exposed to cadmium at $12^{\circ} \mathrm{C}$ revealed elevated intrinsic rates of mitochondrial oxidation while at $28^{\circ} \mathrm{C}$ a pronounced decline was observed including mitochondrial membrane potential, with increased sensitivity of this oyster to extramitochondrial cadmium. Consequently, cadmium toxicity at elevated temperatures may occur simultaneously in both organisms (snail and fluke) resulting in a more complex reaction.

Igbinosa and Okafor (1988) studied the effects of two commonly used chemicals, Gramoxone (an herbicide) and Hexadrin (an insecticide), on F. gigantica's miracidia. Eggs of F. gigantica were $99 \%$ inactivated at 4 to $5.5 \mathrm{ppm}$ (twice of $\mathrm{LC}_{50}$ ), for both pesticides, with enhanced synergism between the two pesticides (Okafor and Igbinosa, 1988). Additionally, sublethal concentrations of these chemicals prolonged the embryonic process and inhibited miriacidia hatching.

Lastly, Kiziewicz (2006) studied different water fungi and fungus-like organisms (known as decomposers and facultative parasites) able to grow on F. hepatica eggs. Seventeen species of fungi and straminipiles (a kingdom comprising diatoms, brown algae, chrysophites and some protozoa) have been found to be able to colonize this fluke's eggs, where most of colonizing fungi are known also as animal parasites or necrotrophs.

\subsection{REFERENCES}

Bennema, S.C., Ducheyne, E., Vercruysse, J., Claerebout, E., Hendrickx, G. \& Charlier, J. (2011) Relative importance of management, meteorological and environmental factors in the spatial distribution of Fasciola hepatica in dairy cattle in a temperate climate zone. Int. J. Parasitol. 41, 225-233.

Blaise, J. \& Raccurt, C.P. (2007) Hepatobiliary fascioliasis and echinococcosis/hydatidosis in domestic animals in Haiti. Rev. - Off. Int. Epizoot. 26, 741-746.

Canete, R., Yong, M., Sanchez, J., Wong, L. \& Gutierrez, A. (2004) Population dynamics of intermediate snail hosts of Fasciola hepatica and some environmental factors in San Juan y Martinez municipality, Cuba. Mem I Oswaldo Cruz 99, 257-262.

Cherkasov, A.S., Ringwood, A.H. \& Sokolova, I.M. (2006) Combined effects of temperature acclimation and cadmium exposure on mitochondrial function in eastern oysters Crassostrea virginica gmelin (Bivalvia: Ostreidae). Environ. Toxicol. Chem. 25, 2461-2469.

de Kock, K.N., Wolmarans, C.T. \& Bornman, M. (2003) Distribution and habitats of the snail Lymnaea truncatula, intermediate host of the liver fluke Fasciola hepatica, in South Africa. J S Afr Vet Assoc 74, 117-122.

Fuentes, M.V. (2007) Is the El Nino-Southern Oscillation likely to increase the risk of Fasciola transmission? Ann. Trop. Med. Parasitol. 101, 555-557. 
Fuentes, M.V., Valero, M.A., Bargues, M.D., Esteban, J.G., Angles, R. \& Mas-Coma, S. (1999) Analysis of climatic data and forecast indices for human fascioliasis at very high altitude. Ann Trop Med Parasitol 93, 835-850.

Guenthoer, J. (1971) Influence of activated sludge in waste water purification plants on the viability of Ascaris and Fasciola hepatica eggs. Z Wasser Abwass For 4, 180-186.

Igbinosa, I.B. \& Okafor, F.C. (1988) Environmental stress and parasitic infections: I. The effects of Gramoxone and Hexadrin on embryo and hatching of Fasciola gigantica miracidia. Angew Parasitol 29, 179-183.

Kiziewicz, B. (2006) Water fungi and fungus-like organisms isolated from surface waters situated in the Bialowieza primeval forest using the liver fluke Fasciola hepatica L. of European bison Bonasus L. as bait. Pol. J. Environ. Stud. 15, 277-281.

Kleiman, F., Pietrokovsky, S., Prepelitchi, L., Carbajo, A.E. \& Wisnivesky-Colli, C. (2007) Dynamics of Fasciola hepatica transmission in the Andean Patagonian valleys, Argentina. Vet. Parasitol. 145, 274-286.

Krupicer, I., Velebny, S. \& Legath, J. (1996) Effect of emissions from a mercury treating metallurgical works on the intensity of experimental Fasciola hepatica infection in sheep. Vet Med (Praha) 41, 103-106.

Mas-Coma, S., Bargues, M.D. \& Valero, M.A. (2007) Plant-borne trematode zoonoses: fascioliasis and fasciolopsiasis, p. 293-334. In K. D. Murrell and B. Fried (ed.), World class parasites, vol. 11. Food-borne parasitic zoonoses. Fish and plant-borne parasites. Springer, New York, NY.

Mas-Coma, S. (2005) Epidemiology of fascioliasis in human endemic areas. J. Helminthol. 79, 207-216.

Mas-Coma, S., Bargues, M.D. \& Valero, M.A. (2005) Fascioliasis and other plant-borne trematode zoonoses. Int. J. Parasitol. 35, 1255-12578.

Mas-Coma, S., Funatsu, I.R. \& Bargues, M.D. (2001) Fasciola hepatica and lymnaeid snails occurring at very high altitude in South America. Parasitol. 123, S115-S127.

Mas-Coma, S., Valero, M.A. \& Bargues, M.D. (2009) Chapter 2. Fasciola, lymnaeids and human fascioliasis, with a global overview on disease transmission, epidemiology, evolutionary genetics, molecular epidemiology and control. Adv. Parasitol. 69, 41-146.

Menard, A., L’Hostis, M., Leray, G., Marchandeau, S., Pascal, M. et al. (2000) Inventory of wild rodents and lagomorphs as natural hosts of Fasciola hepatica on a farm located in a humid area in Loire Atlantique (France). Parasite 7, 77-82.

Okafor, F.C. \& Igbinosa, I.B. (1988) Environmental stress and parasitic infections: II. Effects of gramoxone and hexadrin (pesticides) on the survival characteristics of Fasciola gigantica miracidia. Angew Parasitol 29, 221-225.

Pozio, E. (2008) Epidemiology and control prospects of foodborne parasitic zoonoses in the European Union. Parassitologia 50, 17-24.

Pritchard, G.C., Forbes, A.B., Williams, D.J.L., Salimi-Bejestani, M.R. \& Daniel, R.G. (2005) Emergence of fasciolosis in cattle in East Anglia. Vet. Rec. 157, 578-582.

Rapsch, C., Dahinden, T., Heinzmann, D., Torgerson, P.R., Braun, U. et al. (2008) An interactive map to assess the potential spread of Lymnaea truncatula and the free-living stages of Fasciola hepatica in Switzerland. Vet. Parasitol. 154, 242-249.

Relf, V., Good, B., McCarthy, E. \& de Waal, T. (2009) Evidence of Fasciola hepatica infection in Radix peregra and a mollusc of the family Succineidae in Ireland. Vet. Parasitol. 163, 152-155.

Rinaldi, L., Musella, V., Veneziano, V., Condoleo, R.U. \& Cringoli, G. (2009) Helmintic infections in water buffaloes on Italian farms: a spatial analysis. Geospat Health 3, 233-239.

Soliman, F.M. (2009) Fasciola gigantica: cercarial shedding pattern from Lymnaea natalensis after long-term exposure to cadmium at different temperatures. Exp. Parasitol. 121, 307-311.

Sures, B., Jurges, G. \& Taraschewski, H. (1998) Relative concentrations of heavy metals in the parasites Ascaris suum (Nematoda) and Fasciola hepatica (Digenea) and their respective porcine and bovine definitive hosts. Int. J. Parasitol. 28, 1173-1178.

Thomas, C., Jacquiet, P. \& Dorchies, P. (2007) Does 2003 summer heat wave modified prevalence of bovine helminthosis in southwestern France? Parasite 14, 265-268.

Vignoles, P., Favennec, L., Dreyfuss, G. \& Rondelaud, D. (2002) Highland populations of Lymnaea truncatula infected with Fasciola hepatica survive longer under experimental conditions than lowland ones. Parasitol. Res. 88, 386-388. 
Walker, S.M., Johnston, C., Hoey, E.M., Fairweather, I., Borgsteede F. et al. (2011) Population dynamics of the liver fluke, Fasciola hepatica: the effect of time and spatial separation on the genetic diversity of fluke populations in the Netherlands. Parasitol. 138, 215-223.

Walker, S.M., Makundi, A.E., Namuba, F.V., Kassuku, A.A. Keyyu, J. et al. (2008) The distribution of Fasciola hepatica and Fasciola gigantica within southern Tanzania-constraints associated with the intermediate host. Parasitol. 135, 495-503.

Wibaux-Charlois, M., Yelnik, A., Ibrahima, H., Same-Ekobo, A. \& Ripert, C. (1982) Epidemiologic study of S. haematobium bilharziasis in the rice fields of Yagoua (North Cameroon) II. Distribution and ecology of intermediate hosts. Bull Soc Pathol Exot Filiales 75, 72-93.

Wiwanitkit, V. (2009) Pesticides, fresh water fish, liver flukes and nitrosamines: A story of cholangiocarcinoma development in Thailand. Asian Pac. J. Cancer Prev. 10, 961-962. 


\section{Chapter 4.2.1.6 Fasciolopsiasis}

\section{[FASCIOLOPSIS BUSK]}

Fasciolopsis buski is a large fluke with a life cycle similar to that of his relatives $F$. hepatica and $F$. gigantica, but differing in the final animal host (instead of ruminants such as cattle and sheep it infects pigs) and final colonization site in animals and humans (duodenum instead of hepatobiliary system). The distribution of this fluke is in Southern and Eastern Asia (China, Taiwan, India, Bangladesh, Indonesia, Thailand and Vietnam). Transmission is very similar to fasciolasis, i.e., adherence of metacercariae to water plants and their fruits Trapa natans, Trapa bicornis and Elocharis tuberose, so called water nuts and used as food in China and other Asian countries. Cultivation ponds for water nuts are commonly fertilized with manure and water nuts are also used to feed pigs. Miracidia hatch from eggs in moist environment to further penetrate water snails (e.g., Planorbis and Segmentia genera) in order to multiply asexually. Developed cercariae from the intermediary host are released and than encyst, while adhering to water plants, to form metacercariae. Metacercariae are rapidly inactivated when exposed to desiccation, and therefore the disease spreads when fresh fruits are consumed. Swallowed metacercariae reach the gastrointestinal track and develop into young flukes in humans or pigs duodenum while attached to mucosa. Adult flukes will produce unembryonated eggs excreted in feces and further disseminated into water (Figure 4.2.1.6.1). The disease manifests itself as duodenal inflammatory and ulcerative lesions, epi- and hypogastric pain, altering diarrhea and constipation with whitish feces. In severe cases, anorexia, anemia, edema, cachexia and ascites may develop.

\subsection{FASCIOLOPSIASIS AND ENVIRONMENT}

Like its other relatives, F. buski is linked to freshwater habitats (stagnant or slow moving in order to allow good contact between cercariae and snails) and aquatic agriculture contaminated with feces (Mas-Coma et al., 2005). Consumption of raw aquatic plants by humans and pigs and drinking from these water sources, as well handling of water plants and their fresh fruits are the main epidemiological factors involved in the endemic persistence of fasciolopsiasis. Increased prevalence has been observed among people living close to water caltrop plantations, where in order to keep plants fresh the grower dips water 
caltrops in already contaminated water (Hsieh, 1960; Mas-Coma et al., 2005). An important factor that emerges all through the present book, related to the majority of the described pathogens and not solely to $F$. buski, is the low social and economic level of infected people. Poverty, malnutrition, poor sanitation and uncontrolled food market, all fit in the definition of a low socio-economic population (Anonymous, 1995). Quang et al. (2008) studied the prevalence of Fasciola spp. and Fasciolopsis buski in southern Laos. Prevalence of human fasciolopsiasis in Laotian villages because of $F$. buski infection was $33.7 \%$. In pigs, the main reservoir, grown with contaminated fresh aquatic fodder and water various infection prevalences have been reported from different countries: India (30\%), China (10\%) and Taiwan (52\%) (Mas-Coma et al, 2005). Seasonal variations had also affected prevalence reports (Roy and Tandon, 1992). For example, in India, the prevalence of $F$. buski -induced infection in cattle increased from June to September followed by a decline to low levels from November to March, corresponding to human cases (highest in late summer and early autumn).

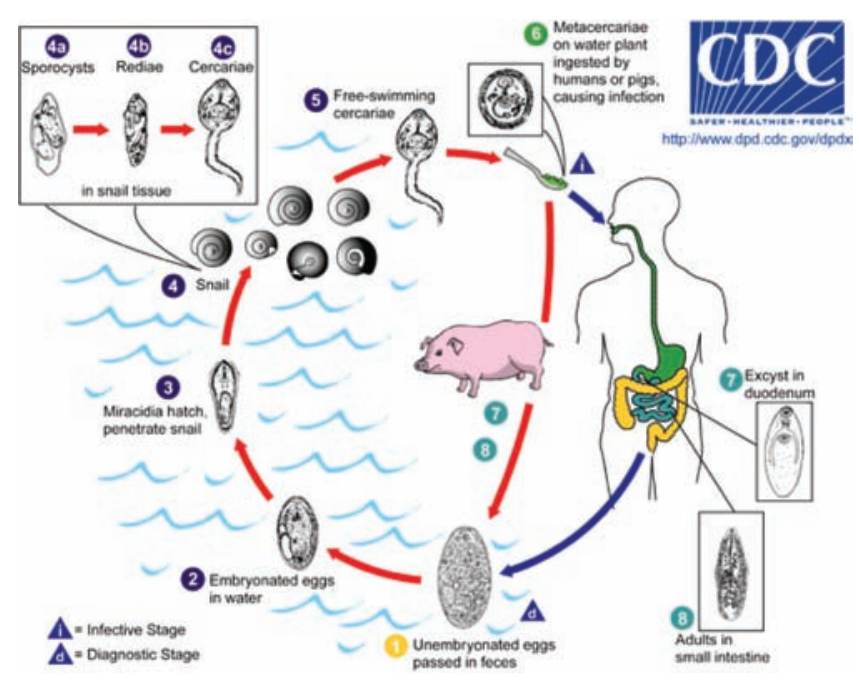

Figure 4.2.1.6.1. Fasciolopsis buski life cycle (with permission from CDC, Atlanta, USA; http://www.dpd.cdc. gov/DPDx/html/ImageLibrary/Fasciolopsiasis_il.htm)

\subsection{REFERENCES}

Anonymous (World Health Organization) (1995) Foodorne trematode infections. Bull. World Health Organ. 73, 397-399.

Hsieh, H.C. (1960) Studies on the epidemiology of Fasciolopsis buski in South Taiwan. Formosan Sci. 14, 95-120.

Mas-Coma, S., Bargues, M.D. \& Valero, M.A. (2005) Fascioliasis and other plant-borne trematode zoonoses. Int. J. Parasitol. 35, 1255-1278.

Quang, T.D., Duong, T.H., Richard-Lenoble, D., Odermatt, P. \& Khammanivong, K. (2008) Emergence in humans of fascioliasis (from Fasciola gigantica) and intestinal distomatosis (from Fasciolopsis buski) in Laos. Sante 18, 119-124.

Roy, B. \& Tandon, V. (1992) Seasonal prevalence of some zoonotic trematode infections in cattle and pigs in the north-east montane zone in India. Vet. Parasitol. 41, 69-76. 


\section{Chapter 4.2.1.7 Heterophyiasis}

\section{[HETEROPHYDAE FAMILY]}

This group of small size flukes comprises 30 species of the Heterophyidae family (e.g. Heterophyes heterophyes, Metagonimus yokogawai, Haplorchis spp. and Procerovum spp.) distributed worldwide in brackish and fresh water (Elsheikha and Elshazly, 2008). Human infections occur in tropical areas such as Southeast and East Asia but also in Northern Africa (Egypt), the Middle East and Europe (Duong et al., 1979; Taraschewski and Nicolaidou, 1987; Bastien et al., 1995; Guk et al., 2006). At high risk are fishermen and other people that consume raw fish and live near faecally contaminated sources, such as lakes of brackish and fresh water, river banks, bay waters and estuaries (Adams et al., 1986; Elshazly et al., 2007). Human prevalence in endemic areas ranges from $<10$ to $>50 \%$ (Belizario et al., 2001). Foreign residents and tourists in endemic areas are also at high risk (Hamada et al., 1998). Flukes from the Heterophyidae family have a similar life cycle to that of Clonorchis sinensis that has two intermediate hosts: snails and fishes. Final hosts are fish-eating mammals, waterfowls and humans (Schuster et al., 2009; Taraschewski, 1985b). Briefly, final hosts excrete embryonated eggs that are introduced into water sources and there are ingested by snails. Miracidia hatch from ingested eggs into snail intestine to form cercariae to be later released into the surrounding water. Released cercariae penetrate a second intermediary host (freshwater fish from salmonids and cyprinids families) to develop into metacercariae inside fish tissue. Final hosts, such as as cats, dogs, waterfowl and humans that consume raw fish infected tissue, become infected with metacercariae that will excyst into their small intestine to form mature flukes (Figure 4.2.1.7.1). Clinical manifestations are mostly very mild with intestinal symptoms such as diarrhea, abdominal pain and very rare heart (causing infarcts) and CNS conditions when hematogenous eggs spread to other organs (Bastien et al., 1995).

\subsection{HETEROPHYIASIS AND ENVIRONMENT}

Elsheikha and Elshazly (2008) studied the seasonality of heterophyid flukes' infection of brackish water fish in Egypt. All heterophyids revealed seasonality (38.2\% in summer, $>26.6 \%$ in spring, $>19.3 \%$ in autumn $>$ and $8.7 \%$ in winter) and also dependence on host type. These results were explained based on various 
factors, such as host type, climate and biotic conditions. Flukes' seasonality correlated well with the fish breeding season (summer and spring) and the release of cercariae from snails, which is highly temperature-dependent. A significantly higher prevalence of heterophyid encysted metacercariae in mullet (Mugil spp.) than in "St. Peter's fish" (Tilapia spp.) indicated species preference and susceptibility to this trematode. Environmental fecal contamination in this area has been reported to be very high during rainy season and coincided with the rapid snail population raise. The rapid development of intensive aquaculture in Egypt (Lake Manzala) for the last three decades, in order to supply fish meat as an important protein source, raises serious health risk problems related to this pathogen in spite of its mild symptoms. Lobna et al. (2010) described an interesting association related to Tilapia spp. infection by heterophyids encysted metacercariae in Northern Egypt: infection prevalence declined as fish size increased. According to these authors there are two potential explanations for this phenomenon: a) the fish stunted growth by infecting parasite that increases the prevalence of small-sized fish or b) the small-sized fish have a thinner skin that is much more easily penetrated by cercariae (Paperna, 1980).

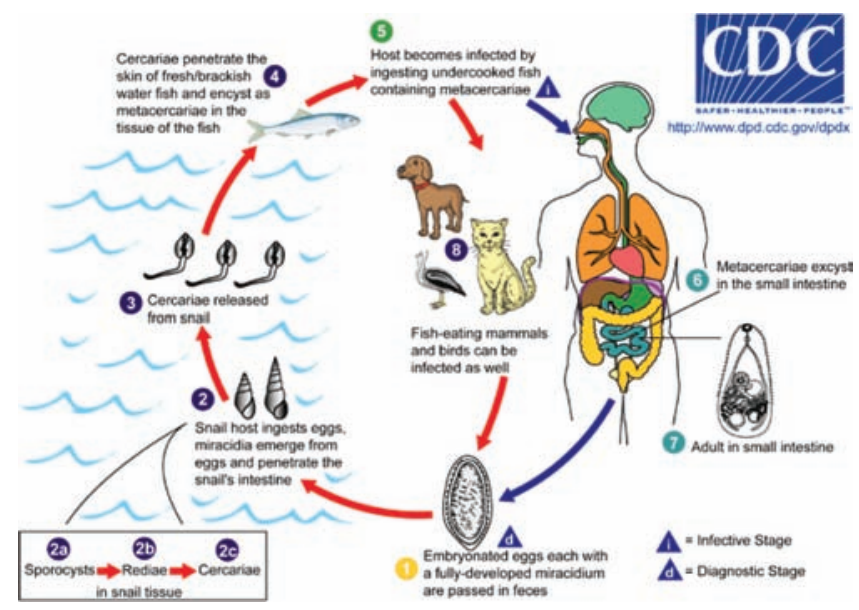

Figure 4.2.1.7.1. Heterophydae family life cycle (with permission from CDC, Atlanta, USA; http://www.dpd. cdc.gov/DPDx/html/ImageLibrary/Heterophyiasis_il.htm)

In contrast to Lake Manzala (Egypt), Taraschewski (1985a) reported that in comparison with 1950s abundance of this fluke, a decline in Heterophyes heterophyes the most prevalent heterophyid in the Nile Delta, was observed. It is very possible that the following factors were involved in this regression: intermediate hosts shift (both snail and fish) as a result of pollution and intensive drainage for intensive farming activity.

\subsection{REFERENCES}

Adams, K.O., Jungkind, D.L., Bergquist, E.J. \& Wirts, C.W. (1986) Intestinal fluke infection as a result of eating sushi. Am. J. Clin. Pathol. 86, 688-689.

Bastien, P., Basset, D. \& Dedet, J.P. (1995) Heterophyiasis and diarrhea after travel: a case report of a child returning from a trip to Egypt. Med Trop (Mars) 55, 243-245. 
Belizario, V.Y.Jr., Bersabe, M.J., de Leon, W.U., Hilomen, V.Y., Paller, G.V. et al. (2001) Intestinal heterophyidiasis: an emerging food-borne parasitic zoonosis in southern Philippines. Southeast Asian J. Trop. Med. Public Health 32, 36-42.

Duong, T.H., de Closets, F., Dupin, M., Rigal, J., Barrabes, A. \& Combescot, C. (1979) A parasitologic survey conducted in Touraine (France) in a group of South East Asia refugees (author's transl). Med Trop (Mars) 39, 659-663.

Elshazly, A.M., Soltan, D.M., Shahat, S.A.R., Hafez, A.O. \& Morsy, A.T.A. (2007) Natural infection of fresh and brackish water fish with heterophyid encysted metacercariae in Dakahlia Governorate. Egypt. J Egypt Soc Parasitol 37, 999-1010.

Elsheikha, H.M. \& Elshazly, A.M. (2008) Host-dependent variations in the seasonal prevalence and intensity of heterophyid encysted metacercariae (Digenea: Heterophyidea) in brackish water fish in Egypt. Vet. Parasitol. 153, 65-72.

Elsheikha, H.M. \& Elshazly, A.M. (2008) Preliminary observations on infection of brackish and fresh water fish by heterophyid encysted metacercariae in Egypt. Parasitol. Res. 103, 971-977.

Guk, S-M., Park, J-H., Shin, E-H., Kim, J-L., Lin, A. \& Chai, J-Y. (2006) Prevalence of Gymnophalloides seoi infection in coastal villages of Haenam-gun and Yeongam-gun, Republic of Korea. Korean J. Parasitol. 44, 1-5.

Hamada, A., Okuzawa, E., Kawabuchi, Y. \& Nishikawa, T. (1998) Prevalence of intestinal parasites among Japanese residents in developing countries. Kansenshōgaku Zasshi 72, 1283-1288.

Lobna, S.M.A., Metawea, Y.F. \& Elsheikha, H.M. (2010) Prevalence of heterophyiosis in Tilapia fish and humans in Northern Egypt. Parasitol. Res. 107, 1029-1034.

Paperna, I. (1980) Parasites, infections and diseases of fish in Africa. Committee for inland fisheries of Africa. CIFA. Technical papers, pp 51-62.

Schuster, R.K., Thomas, K., Sivakumar, S. \& O’Donovan, D. (2009) The parasite fauna of stray domestic cats (Felis catus) in Dubai, United Arab Emirates. Parasitol. Res. 105, 125-134.

Taraschewski, H. \& Nicolaidou, A. (1987) Heterophyes species in Greece: record of H. heterophyes, H. aequalis and H. dispar from the first intermediate host, Pirenella conica. J. Helminthol. 61, 28-32.

Taraschewski, H. (1985a) Investigations on the prevalence of Heterophyes species in twelve populations of the first intermediate host in Egypt and Sudan. J Trop Med Hyg 88, 265-271.

Taraschewski, H. (1985b) Transmission experiments on the host specificity of Heterophyes species in 16 potential definitive hosts. Z Parasitenkd 71, 505-518. 


\section{Chapter 4.2.1.8 Optisthorchiasis}

\section{[OPISTHORCHIS FELINEUS, OPISTHORCHIS VIVERRIN]}

Opisthorchis felineus is a cat liver fluke able to infect additional mammals (including humans). The distribution of $O$. felineus is Eastern and Southern Europe, Asiatic regions of former USSR (including Siberia, along big rivers) while $O$. viverrini is distributed in Southeast and East Asia (Laos, Thailand, Vietnam and Cambodia). In endemic areas, $80 \%$ of the population is infected with these flukes; for example, it is estimated that 1.5 million people in Russia (mainly inhabitants of Siberia) are infected via consumption of raw, slightly salted and frozen fish. Transmission occurs through ingestion of raw freshwater fish infected with metacercariae (mainly cyprinids that are used as intermediary hosts). Briefly, the life cycle route is through fecally excreted eggs from infected hosts into water sources. In water, eggs are ingested by water snails (genera Codiella for O. felineus and Bythinia for O. viverrini) to develop internally into cercariae and once more released in water. The next encounter of cercariae is with the second intermediate hosts (freshwater fishes). In fish, encystation takes place to form metacercariae ingested by a final host feeding on raw fish meat. In cats, humans and other mammals the metacercariae develop into young flukes in the duodenum, followed by migration to small bile ducts (Figure 4.2.1.8.1). Infected humans without treatment can carry this fluke for $>10$ years. Clinical symptoms are cholangitis, cirrhosis, pancreatitis and in hyperendemic areas (e.g., Thailand). O. viverrini is highly suspected of being involved in human cholangiocarcinoma.

\subsection{OPISTHORCHIASIS AND ENVIRONMENT}

In an interesting study on $O$. viverrini's comprehensive genetic characterization from different geographical localities in Thailand and Laos, Saijuntha et al. (2007) found a possible co-evolution between O.viverrini species and their first intermediate hosts (snails). They detected significant genetic variations among O. viverrini from different wetlands and among B.s. goniomphlos (a snail species) from different geographical areas, raising the important question about the relative importance of the biotic and abiotic features of different wetlands on the ecology and genetic variation of trematodes and their intermediate 
hosts. In this context, human migration and extensive floods seem to be highly important factors in the co-evolution of these organisms and the dissemination of closely related species.

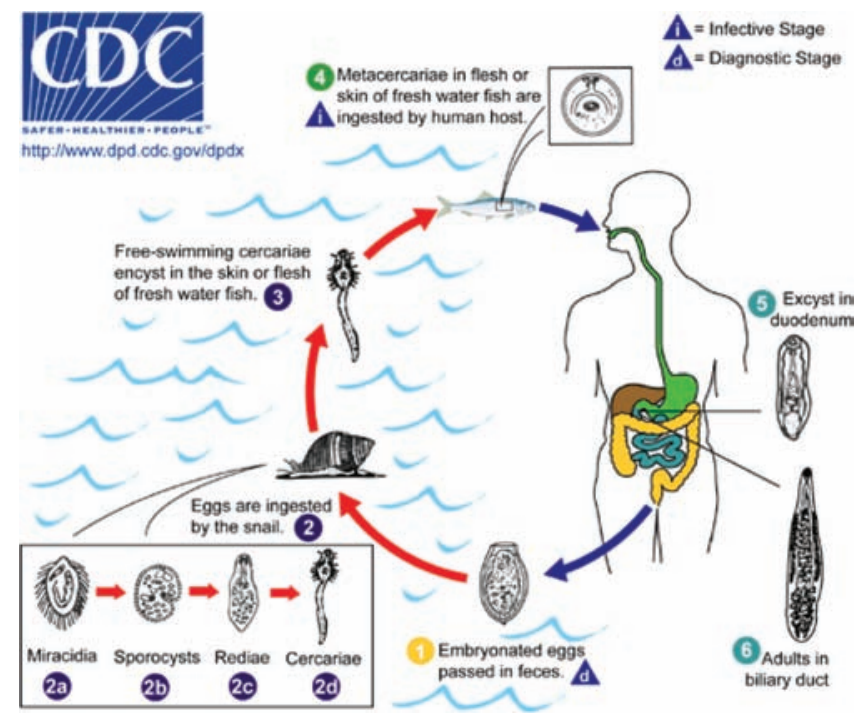

Figure 4.2.1.8.1. Opistorchis felineus and viverrini life cycle (with permission from CDC, Atlanta, USA; http:// www.dpd.cdc.gov/DPDx/html/ImageLibrary/Opisthorchiasis_il.htm)

Among mammals infected by $O$. viverrini, next to humans cats are the most prevalent (Enes et al., 2010). In northeastern Thailand, the reported infection prevalence in dogs with $O$. viverrini was $3.8 \%$ while in cats was $36.4 \%$. As cholangiocarcinoma is possible the most serious complication of infections with O. viverrini, studies carried out in this specific region of Thailand, found a positive correlation between the endemicity of opisthorchiasis and the frequency of cholangiocarcinoma (Watanapa and Watanapa, 2002; Abdel-Rahim, 2001). For example in Sakol Nakhon (upper Northeast Thailand) owing the highest national mortality rate due to liver and bile duct cancer, a mortality rate of 61.4 per 100,000 people had been reported (Sripa and Pairojkul, 2008).

\subsection{REFERENCES}

Abdel-Rahim, A.Y. (2001) Parasitic infections and hepatic neoplasia. Dig Dis 19, 288-291.

Enes, J.E., Wages, A.J., Malone, J.B. \&Tesana, S. (2010) Prevalence of Opisthorchis viverrini infection in the canine and feline hosts in three villages, Khon Kaen Province, northeastern Thailand. Southeast Asian J. Trop. Med. Public Health 41, 36-42.

Saijuntha, W., Sithithaworn, P., Wongkham, S., Laha, T., Pipitgool, V. et al. (2007) Evidence of a species complex within the food-borne trematode Opisthorchis viverrini and possible co-evolution with their first intermediate hosts. Int. J. Parasitol. 37, 695-703.

Sripa, B. \& Pairojkul, C. (2008) Cholangiocarcinoma: lessons from Thailand. Curr. Opin. Gastroenterol. 24, 349-356. Watanapa, P. \& Watanapa, W.B. (2002) Liver fluke-associated cholangiocarcinoma. Br J Surg 89, 962-970. 


\section{Chapter 4.2.1.9}

\section{Paragonimiasis (Pulmonary distomatisis)}

\section{[GENUS PARAGONIMUS, PARAGONIMUS WESTERMANI]}

Lung flukes of the genus Paragonimus that comprises 30 species infecting different animals (cats, dogs, pigs, and mustelidae family) cause Paragonimiasis while in humans as much; $>10$ species have been proved to be pathogenic. The most notorious species of Paragonimus is Paragonimus westermani. Other Paragonimus flukes are presented in Table 4.2.1.9.1. In humans infection results from ingestion of raw or insufficiently cooked crayfish or fresh-water crab' meat that are infected with the metacercarial stage, but infected uncooked pork meat may also lead to infection. The life cycle includes expectorated eggs from infected animal lungs that are again swallowed and reach the feces through digestive system. Eggs from feces are released in water and transform in miracidia that hatch and penetrate the intermediate host: snails (e.g., Melania spp., Ampullaria spp., etc.). Following asexual reproduction in snails, the developed cercariae leave snails to enter a second intermediary host, crustaceans. Crustaceans consumed as raw, uncooked meat initiates infection of final hosts with metacercariae that will develop further into young flukes that migrate from duodenum into lung tissue (Figure 4.2.1.9.1). As a cosequence of pulmonary colonization (parenchyma) ectopic invasion of other organs may occur (liver, CNS, etc.). In humans, infections may persist for 20 years. Clinical manifestations of paragonimiasis are: inflammation, chest pain, cough with brown sputum, asthma, fever, and if the brain is colonized: cramps, headaches, dizziness, vomiting and fever.

Table 4.2.1.9.1 Paragonimus spp. geographic distribution and their intermediate and final hosts.

\begin{tabular}{llll}
\hline Species & $\begin{array}{l}\text { Main geographic } \\
\text { distribution }\end{array}$ & Intermediate hosts & Final hosts \\
\hline $\begin{array}{l}\text { Paragonimus } \\
\text { westermani }\end{array}$ & $\begin{array}{l}\text { Central, Southeast } \\
\text { and East Asia, } \\
\text { South America }\end{array}$ & $\begin{array}{l}\text { Snails (Semisulcospira spp., } \\
\text { Paludomus genus, etc.), } \\
\text { fresh water crabs }\end{array}$ & $\begin{array}{l}\text { Animals such as pigs, } \\
\text { dogs, and a variety of } \\
\text { feline species and } \\
\text { humans }\end{array}$ \\
\end{tabular}

(Continued) 
Table 4.2.1.9.1 (Continued)

\begin{tabular}{|c|c|c|c|}
\hline Species & $\begin{array}{l}\text { Main geographic } \\
\text { distribution }\end{array}$ & Intermediate hosts & Final hosts \\
\hline P. ohirai & $\begin{array}{l}\text { Central, Southeast } \\
\text { and East Asia }\end{array}$ & $\begin{array}{l}\text { Snails (Oncomelania sp.), } \\
\text { fresh and brackish water crabs }\end{array}$ & $\begin{array}{l}\text { Cats, dogs, rats and } \\
\text { humans }\end{array}$ \\
\hline P. skrjabini & $\begin{array}{l}\text { China (mountain } \\
\text { regions) }\end{array}$ & $\begin{array}{l}\text { Snail (Tricula cristella), freshwater } \\
\text { crab host }\end{array}$ & Cats, dogs and humans \\
\hline P. miyazakii & Japan & $\begin{array}{l}\text { Snails, fresh water crabs } \\
\text { (Geothelphusa dehaani) }\end{array}$ & Cats, dogs and humans \\
\hline P. heterotremus & $\begin{array}{l}\text { Southern China, } \\
\text { Thailand, Laos }\end{array}$ & $\begin{array}{l}\text { Snails (Tricula wumingensis, } \\
\text { Tricula aperta), crabs } \\
\text { (Samanniathelphusa nanningensis, } \\
\text { Tiwaripotamon beusekomae) }\end{array}$ & Dogs, cats and humans \\
\hline P. kellicotti & North America & $\begin{array}{l}\text { Snails and crustaceans (crabs or } \\
\text { crayfishs) }\end{array}$ & $\begin{array}{l}\text { Bobcats, dogs, gray and } \\
\text { red foxes, raccoons, } \\
\text { mink, skunk, coyote and } \\
\text { humans }\end{array}$ \\
\hline P. mexicana & $\begin{array}{l}\text { Central and South } \\
\text { America }\end{array}$ & Snails, fresh water crabs & Cats, dogs and humans \\
\hline$P$. africanus & Tropical Africa & $\begin{array}{l}\text { Snails, fresh water crabs } \\
\text { (Sudanonautes africanus, land } \\
\text { crab S. aubryi and S. granulates) }\end{array}$ & Cats, dogs and humans \\
\hline P. uterobilateralis & Tropical Africa & $\begin{array}{l}\text { Snails, fresh water crab } \\
\text { (Sudanonautes africanus and the } \\
\text { land crab S. aubryi) }\end{array}$ & Cats, dogs and humans \\
\hline P. heterotremus & India & Snails, freshwater crab & Cats, dogs and humans \\
\hline
\end{tabular}

\subsection{PARAGONIMIASIS AND ENVIRONMENT}

A Chinese researcher investigated $P$. westermani infection in intermediate hosts (snails, crabs) and animal reservoirs (civet, wild and domestic cats, dogs, etc.) in forest farms and town. Infection in snail species Semisulcospira libertina and Sinopotamon spp. ranged from $0.21 \%$ to $54.3 \%$ respectively, and $5.6 \%$ in reservoir hosts. The authors attributed the reduction in infection rates in comparison to data obtained 20 years ago to environmental changes (Yan et al., 2004). Another Paragonimus species, Paragonimus skrjabini, has been studied in an endemic region in China (Xu et al., 2008). Intermediate hosts such as freshwater crabs (Sinopotamon denticulatum) and definitive hosts (cats and dogs) were found to be infected with metacercariae at the following rates: $20.5 \%$ and $25 \%$, respectively. The high infection rate was attributed to animals foraging and defecating close to water routes and the children's habits of consuming raw under-cooked crabs. In Western Africa, human paragonimiasis is present with a prevalence ranging from 2 to 31\% (Pozio, 1991). Macpherson (2005) emphasized the increasing proclivity for eating meat, fish, crabs, shrimp, molluscs raw, undercooked, smoked, pickled or dried that facilitates human infections with flukes, beside other environmental alterations. 


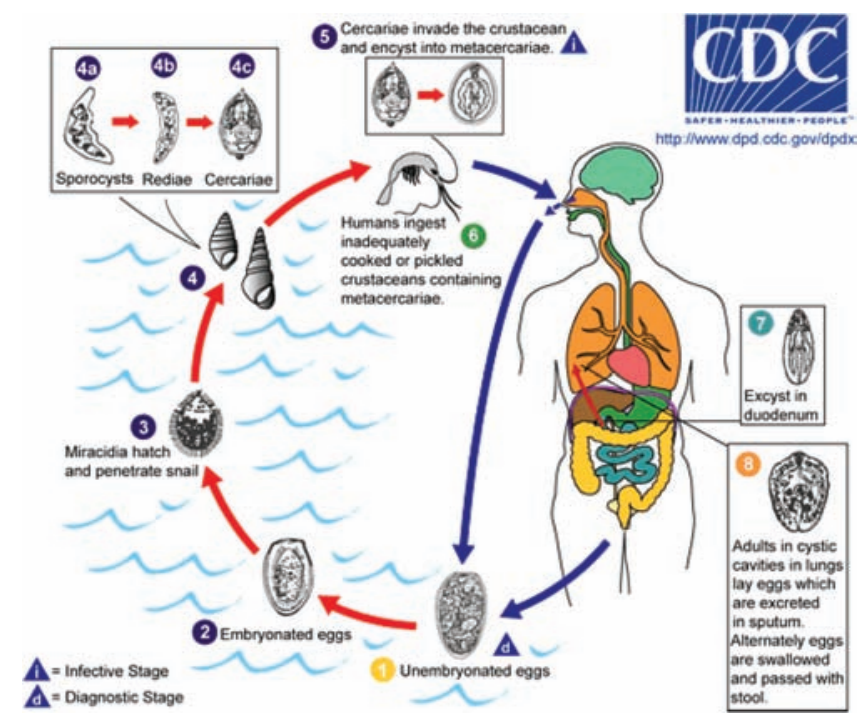

Figure 4.2.1.9.1. Paragonimus spp. life cycle (with permission from CDC, Atlanta, USA; http://www.dpd.cdc. gov/DPDx/html/ImageLibrary/Paragonimiasis_il.htm)

\subsection{REFERENCES}

Macpherson, C.N.L. (2005) Human behaviour and the epidemiology of parasitic zoonoses. Int. J. Parasitol. 35, 13191331.

Pozio, E. (1991) Current status of food-borne parasitic zoonoses in Mediterranean and African regions. Southeast Asian J. Trop. Med. Public Health 22, 85-87.

Xu, Z-M., Li, L., Wu, X-Y., Zhao, H-F., Du, A-P. et al. (2008) Paragonimus skrjabini infection in animal reservoir hosts and questionnairing in residents at a village of Hubei Province. Zhongguo Ji Sheng Chong Xue Yu Ji Sheng Chong Bing Za Zhi 26, 75-76.

Yan, Q-R., Yan, T., Zhou, X-M., Li, Y-S., Zhu, C-C. et al. (2004) Epidemiological survey on the infection of Paragonimus westermani in Jiangxi Province. Zhongguo Ji Sheng Chong Xue Yu Ji Sheng Chong Bing Za Zhi 22, 250-252. 


\section{Chapter 4.2.1.10}

\section{Schistosomiasis (Bilharziosis)}

\section{[SCHISTOSOMA MANSONI, S. HAEMATOBIUM, S. JAPONICUM, S. MEKONGI, S. MATTHEEI, S. INTERCALATUM, S. BOVIS AND TO LESSER EXTENT S. MAGREBOWIEI, S. RODHAINI]}

Schistosomiasis is one of the most significant trematodic diseases in humans in the tropical and subtropical areas of the globe, parasitizing intestinal tract, liver and urogenital tract. For example, Schistosoma mansoni occurs in Egypt, East, Central and West Africa, Middle East, Northern and Western South America and Caribbean Island; S. japonicum is limited to Southeast and East Asia; S. mekongi in Cambodia and Vietnam; S. haematobium in Middle East, India, Portugal and Africa; S. mattheii in Central Africa; $S$. intercalatum and S. bovis in Africa; S. margrebowiei in Southern and Central Africa and S. rodhaini in parts of Central Africa. Additionally, Schistosoma genus comprises atypical trematodes with two sexes (dioecious) versus most other trematodes that are hermaphroditic. Humans are the main host of $S$. mansoni, $S$ haematobium, S. japonicum while other schistosoma infect mainly animals including humans. Infections are percutaneously by free-swimming cercariae. The life cycle of this parasite includes fecal or urine eggs excretion from the final infected host into water sources. Miracidia hatch from eggs to invade water snails as an intermediate host in shallow aquatic areas. Each Schistosoma spp. has a specific intermediary snail (e.g. S. mansoni invades Biomphalaria spp.; S. haematobium invades Bulinus spp. and $S$. japonicum invades Oncomelania spp.). The snail developed cercariae actively exit into water milieu where they can reside for $\sim 2$ days in order to meet their final host, close to the water's surface. Cercarie in close encounter with their final host, rapidly penetrate loosing the tail so as to transform into a schistosomula form. Inside the lungs, after blood circulation transport, the schistosomula will develop in mature trematodes (male and female). Both male and female migrate to their final destination organ (mesenterial veins-S. mansoni and $S$. japonicum and urinary bladder veins- $S$. haematobium). In infected persons, Schistosoma sexual reproduction produces between hundreds to thousands of eggs/pair/day that can persist for 30 years, if untreated (Figure 4.2.1.10.1). Clinical manifestations are linked to the invaded organ; in bladder, the following symptoms are seen: pruritius, fever, headache, general pain, vertigo, vomiting and hematuria; in intestinal tract: fever, headache, hepatosplenomegaly, lymphadenopathy, colicky pain, alternating bloody diarrhea or constipation, 
cirrhosis and encephalopathy. Increased urinary bladder cancer rate has been linked to S. haematobium infections (Mara and Clapham, 1997).

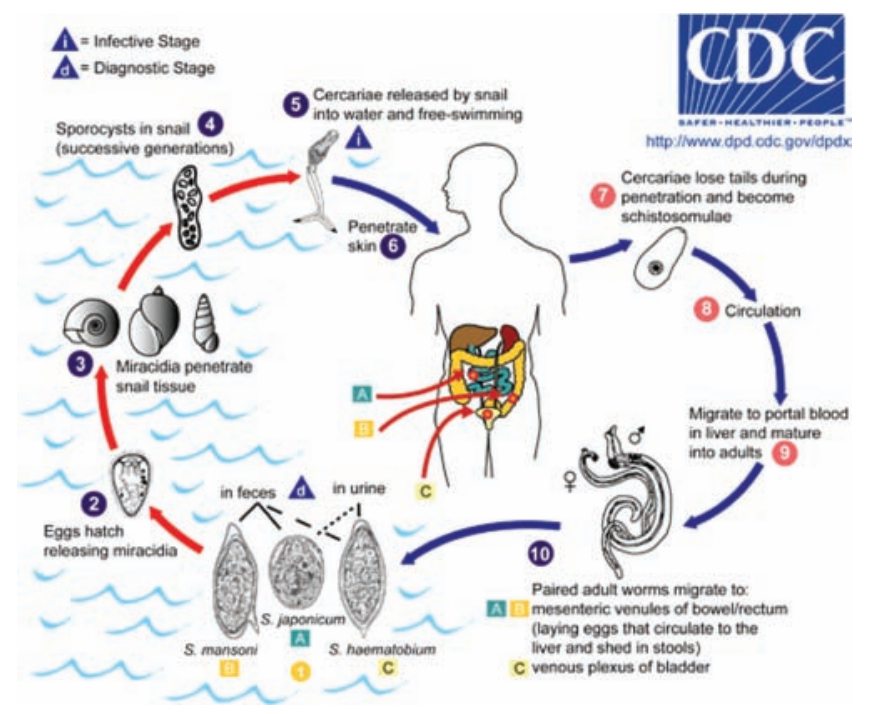

Figure 4.2.1.10.1. Schistosoma spp. life cycle (with permission from CDC, Atlanta, USA; http://www.dpd. cdc.gov/DPDx/html/Schistosomiasis.htm)

\subsection{SCHISTOSOMIASIS AND ENVIRONMENT}

Resembling other trematodes that rely on one or two intermediary hosts, Schistosoma species also depend on their specific hosts in order to accomplish their life cycle. In turn, the intermediary hosts might be influenced by modulation of environmental factors: water quality and flow dynamics, geography, human population, vegetation, climate, agricultural practices and irrigation, etc. (Klumpp and Chu, 1977; Webster et al., 2001; Ernould et al., 1999; Saliba et al., 1997). In a study carried out at Kigungu canoe landing and recreational sites on Lake Victoria (Uganda), the researchers found that, in spite of bush clearing (papyrus swamps that were the major habitats for snails species such as B. choanomphala, B. pfeifferi and Bulinus spp., the intermediate host) snails did prevail and their population density dynamic and infection rate were inversely proportional to rainfall outline. An explanation of these results can be deduced from other trematodes' behavior in which snails do survive in smaller water patches increasing the contact likelihood with miracidia, hence the infection rates. In the same way, it has been shown that rapid water flow as well high rainfall do dilute the aquatic stage of these parasites, reducing contact odds and the consequent infection (Odongo-Aginya et al., 2008). Also in Uganda, Rubaihayo et al. (2008) reported on a Schistosoma mansoni infection prevalence of $27.8 \%$ in schoolchildren living around 13 high altitude crater lakes (range of 1487 to $1682 \mathrm{~m}$ ) in Western Uganda. Using a multivariate logistic regression model these authors found that altitude and water source (crater lakes) were significantly associated with infection. The main question related to this study that needs further scientific evidence is: Does this parasite change its altidinal threshold as a result of climate change or other factors?

In a more mathematical approach, Liang et al. (2007) have showed that, in spite of regional and country campaigns to eradicate schistosomiasis by use of antihelminthic drugs (praziquantel) and molluscicides 
(niclosamide), after a sharp decline the disease reemerged in Western China. These authors attributed the parasite's reemergence on environmental factors, in particular those related to snail habitat and human agricultural and sanitation practices at village level. While preparing this chapter, we came across many studies emphasizing poverty (low income), low education and sanitation as well inhabiting waterways as the main factors of schistomiasis endemicity, besides other environmental factors (Ugbomoiko et al., 2010; Ernould et al., 2004; Ollivier et al., 1999; Matthys et al., 2007; Pereira et al., 2010; Kazibwe et al., 2010).

Yang et al. (2005) assessed the impact of climate change and water resources development on Oncomelania hupenis in China (the intermediate host snail susceptible to Schistosoma japonicum). Two databases covering a 30 year period have been analyzed for temperature change during the month of January (the critical month for survival of O. hupensis). Interestingly, China's average January temperature rose by $0.96^{\circ} \mathrm{C}$, consequently lifting up the northern temperature limit of $S$. japonicum transmission, increasing the potential transmission area by $41.000 \mathrm{~km}^{2}$ and potentially exposing 20.7 million people to the risk of Schistosomiasis. In addition, the authors also mentioned that under the new isotherm, two lakes are now included, both a part of a proposed South-North water transfer project. These results have been also stoutly supported by a biology-driven model developed to assess the potential impact of rising temperature on the transmission of schistosomiasis in China (Zhou et al., 2008). Alternatively, Mangal et al. (2008), also using a mathematical model, explored the effects of long-term mean ambient temperature increase on Schistosoma mansoni's prevalence and abundance. In this case they looked at the upper temperature limits $\left(30\right.$ to $\left.35^{\circ} \mathrm{C}\right)$ where this parasite can still proliferate and infect humans. These authors, based on their model, found that at temperatures of up to $30^{\circ} \mathrm{C}$ the mean infection burden in humans increased while at $35^{\circ} \mathrm{C}$ it crashed, primarily due to increased mortality among the snail population (the intermediate host). Based on these studies it can be concluded that a more extended approach to the effect of temperature on parasites life-cycle stages and their intermediary hosts can provide a better evaluation of schistosomiasis risk in humans.

Watts and El Katsha (1995) pointed also at man-made environmental changes that affected the Nile Delta in Egypt. For 30 years, the population and the domestic water use increased significantly in parallel with canal water pollution, lack of suitable drainage for sewage and sanitary effluent disposal, all contributing to an increase in S. mansoni infection cases. el-Sayed et al. (1995) looked for prevalence and epidemiology of $S$. mansoni and $S$. haematobium in two areas reclaimed from the desert for agricultural use (near Ismailia, Egypt). In comparison to a previous study performed ten years previously, they reported that S. mansoni infection prevalence had increased from $21.7 \%$ to $42.1 \%$ among settlers, while that of $S$. haematobium had decreased from $7.8 \%$ to $1.7 \%$. These authors suggested that increased infection prevalence was a result of irrigation practices and local environment alterations that may change the intermediate host accommodation and species competition. A similar situation was described in Brazil (Pernambuco state), where uncontrolled peripheral urbanization and environmental deprivation increased schistosomiasis cases (Barbosa et al., 2010). As a result of shortage in basic infrastructures of sanitation and health, fecal contamination perpetuates Schistosoma spp. transmission and the emergence of newly contaminated sources (Rollemberg et al., 2011).

In relation to animals as schistomiasis reservoirs, Fernandez et al. (2007) screened 50 villages in the Philippines for Schistosoma japonicum infection prevalence in different animals, as possible reservoirs of this parasite. In contrast to Chinese studies that showed cattle and water buffaloes as the primary animals infected with $S$. japonicum, in the Philippines rats and dogs showed high prevalence proportions of infection while water buffaloes showed very low. This disparity between countries might be explained by potential genotype clustering between humans and some other animal species including potential strain substructuring of $S$. japonicum, similar to clustering of human and bovine genotypes (strain 
substructuring) as suggested by Wang et al. (2006), in China. However, in order to elucidate these assumptions, further molecular epidemiological studies are requested.

Elsheika et al. (2008) looked at the clinico-pathological effects of simultaneous exposure to malathion (an insecticide) and S. mansoni in Swiss outbred albino mice. This double exposure can occur realistically, as malathion has been regularly used in the past to combat various insects (e.g., mosquitoes) that breed closely to Schistosoma spp. habitat (slow and shallow waters). Indeed, their results revealed statistically that affected hepatic functions are correlated with increasing S. mansoni cercariae infection and malathion dose. The affected hepatic functions were: 1) liver and spleen pathologies; 2) increased serum bilirubin and decline in hemoglobin content; 3) increase in certain enzymatic activities; 4) reduction in serum albumin and proteins; 5) reduced count of white and red blood cells and 6) higher mortality rate of the exposed group. To sum up, their data indicated that malathion exposure exacerbates schistosomiasis as well its clinical and pathological outcome.

Regarding organophosphate insecticides, Ibrahim et al. (1992) studied the effect of chlorpyrifos (trade name Dursban) on the snail intermediate host Biomphalaria alexandrina and hence on its parasite Schistosoma mansoni. First, they reported that snails' exposure to $0.5 \mathrm{ppm}$ chlorpyrifos for 20 days revealed high fatality (therefore reducing cercariae development and excretion) and secondly $S$. mansoni-infected snails exposed for different time periods to lower chlorpyrifos concentrations $(0.125$ and $0.25 \mathrm{ppm}$ ) revealed blockage of cercarial shedding. Interestingly from the evolutionary/ environmentally point of view, both insecticides (malathion and chlorpyrifos) do have much more impact on primary and intermediate hosts than on the parasite itself (mostly an indirect effect).

Being aware of the vast amounts of anthropogenic chemicals released or accidentally introduced into aquatic environment in developing countries, it is very possible that parasitic organisms are also affected directly or indirectly. For example, MacInnis et al. (1974) already showed that Biomphalaria glabrata, the intermediary host of $S$. mansoni, excretes certain amino acids that elicit chemotactic and chemokinetic responses by miracidia. How chemical contaminants impact this process is unknown and still a waits elucidation.

Cosseau et al. (2010) raised an interesting point concerning epigenetics (the science of heritable but modifiable information) on Schistosoma mansoni epigenotype modulation that increases the phenotypic variability of this parasite, allowing it to survive and spread into new landscapes without genotypic modification. These authors showed that treatment of $S$. mansoni larvae with an inhibitor (Trichostatin A) of histone deacetylase resulted in an increase in the phenotypic variability of this trematode. In view of the large number of environmental pollutants, it is not an overstatement to suggest that such scenarios are feasible in multi-components milieu such as contaminted environment.

Finally, several other aspects of schistosomiasis have been published revealing some interesting characteristics of this parasite. Stienstra et al. (2001) in their review on Mycobacterium ulcerans (also known as Buruli ulcer, a bacterium prevalent in riverine and swamp areas of tropical zones in Africa, Asia, South America, and much less in Australia-see Mycobacterium Chapter 2.15), mentioned that this bacterial pathogen transmission mode had not been fully elucidated, and is believed probably to occur through skin trauma penetration. These authors observed that high Schistosoma haematobium endemicity was found in many M. ulcerans foci in West Africa, with a striking increase in transmission following river dams construction. Based on this observation and other interactions between schistosomiasis and tuberculosis, they hypothesized that schistosomiasis is a risk factor for Buruli ulcer through altering the host's immune response in such a way that it debilitates the host's protection against mycobacterial infection. Further studies will be needed to confirm this interesting hypothesis through experimenting with schistosomiasis control and its impact on Buruli ulcer prevalence. 


\subsection{REFERENCES}

Barbosa, C.S., Araujo, K.C., Sevilla, M.A.A., Melo, F., Gomes, E.C.S. \& Souza-Santos, R. (2010) Current epidemiological status of schistosomiasis in the state of Pernambuco, Brazil. Mem. Inst. Oswaldo Cruz 105, 549-554.

Cosseau, C., Azzi, A., Rognon, A., Boissier, J., Gourbiere, S. et al. (2010) Epigenetic and phenotypic variability in populations of Schistosoma mansoni - a possible kick-off for adaptive host/parasite evolution. Oikos 119, 669678.

el-Sayed, H.F., Rizkalla, N.H., Mehanna, S., Abaza, S.M. \& Winch, P.J. (1995) Prevalence and epidemiology of Schistosoma mansoni and S. haematobium infection in two areas of Egypt recently reclaimed from the desert. Am. J. Trop. Med. Hyg. 52, 194-198.

Elsheikha, H.M., Hussein, H.S. \& Rahbar, M.H. (2008) Clinico-pathological effects of Schistosoma mansoni infection associated with simultaneous exposure to malathion in Swiss outbred albino mice. Acta Trop. 108, 11-19.

Ernould, J.C., Ba, K. \& Sellin, B. (1999) The impact of the local water-development programme on the abundance of the intermediate hosts of schistosomiasis in three villages of the Senegal River delta. Ann Trop Med Parasitol 93, 135145.

Ernould, J.C., Garba, A., Labbo, R., Kaman, A.K., Sidiki, A. et al. (2004) Heterogeneity of Schistosoma haematobium transmission in irrigated fields. Bull Soc Pathol Exot 97, 19-23.

Fernandez, T.J.Jr., Tarafder, M.R., Balolong, E.Jr., Joseph, L., Willingham, A.L. $3^{\text {rd }}$, et al., (2007) Prevalence of Schistosoma japonicum infection among animals in fifty villages of Samar province, the Philippines. Vector Borne Zoonotic Dis. 7, 147-155.

Ibrahim, W.L.F., Furu, P., Ibrahim, A.M. \& Christensen, N.O. (1992) Effect of the organophosphorous insecticide, chlorpyrifos (Dursban), on growth, fecundity and mortality of Biomphalaria alexandrina and on the production of Schistosoma mansoni cercariae in the snail. J. Helminthol. 66, 79-88.

Kazibwe, F., Makanga, B., Rubaire-Akiiki, C., Ouma, J., Kariuki, C. et al. (2010) Transmission studies of intestinal schistosomiasis in Lake Albert, Uganda and experimental compatibility of local Biomphalaria spp. Parasitol. Int. 59, 49-53.

Klumpp, R.K. \& Chu, K.Y. (1977) Ecological studies of Bulinus rohlfsi, the intermediate host of Schistosoma haematobium in the Volta Lake. Bull. World Health Organ. 55, 715-730.

Liang, S., Seto, E.Y.W., Remais, J.V., Zhong, B., Yang, C. et al. (2007) Environmental effects on parasitic disease transmission exemplified by schistosomiasis in western China. Proc. Natl. Acad. Sci. U.S.A. 104, 7110-7115.

MacInnis, A.J., Bethel, W.M. \& Cornford, Eain, M. (1974) Identification of chemicals of snail origin that attract Schistosoma mansoni miracidia. Nature 248, 361-363.

Mangal, T.D., Paterson, S. \& Fenton, A. (2008) Predicting the impact of long-term temperature changes on the epidemiology and control of schistosomiasis: a mechanistic model. PLoS ONE 3, e1438.

Mara, D.D. \& Clapham, D. (1997) Water-related carcinomas: environmental classification. J Environ Eng (New York) 123, 416-422.

Matthys, B., Tschannen, A.B., Tian-Bi, N.T., Comoe, H., Diabate, S. et al. (2007) Risk factors for Schistosoma mansoni and hookworm in urban farming communities in western Cote d'Ivoire. Trop. Med. Int. Health 12, 709-723.

Odongo-Aginya, E.I., Kironde, F.K., Kabatereine, N.B., Kategere, P. \& Kazibwe, F. (2008) Effect of seasonal rainfall and other environmental changes, on snail density and infection rates with Schistosoma mansoni fifteen years after the last snails' study in Kigungu, Entebbe, Uganda. East Afr Med J 85, 556-563.

Ollivier, G., Brutus, L. \& Cot, M. (1999) Intestinal schistosomiasis from Schistosoma mansoni in Madagascar: extent and center of the endemic. Bull Soc Pathol Exot 92, 99-103.

Pereira, W.R., Kloos, H., Crawford, S.B., Velasquez-Melendez, J.G., Matoso, L.F. et al. (2010) Schistosoma mansoni infection in a rural area of the Jequitinhonha Valley, Minas Gerais, Brazil: analysis of exposure risk. Acta Trop. 113, 34-41.

Rollemberg, C.V.V., Santos, C.M.B., Silva, M.M.B.L., Souza, A.M.B., da Silva, A.M. et al. (2011) Epidemiological characteristics and geographical distribution of schistosomiasis and geohelminths, in the State of Sergipe, according to data from the Schistosomiasis Control Program in Sergipe. Rev. Soc. Bras. Med. Trop. 44, 91-96. 
Rubaihayo, J., Moghusu, E., Clouds, P. \& Abaasa, A. (2008) Schistosomiasis transmission at high altitude crater lakes in western Uganda. BMC Infect. Dis. 8, 110.

Saliba, E.K., Tawfiq, M.R., Kharabsheh, S. \& Rahamneh, J. (1997) Urinary schistosomiasis contracted from an irrigation pool in Ramah, the southern Jordan Valley, Jordan. Am. J. Trop. Med. Hyg. 57, 158-161.

Stienstra, Y., Van Der Graaf, W.T.A., Te Meerman, G.J., The, T.H., De Leij, L.F. \& Van Der Werf, T.S. (2001) Susceptibility to development of Mycobacterium ulcerans disease: review of possible risk factors. Trop. Med. Int. Health 6, 554-562.

Ugbomoiko, U.S., Ofoezie, I.E., Okoye, I.C. \& Heukelbach, J. (2010) Factors associated with urinary schistosomiasis in two peri-urban communities in south-western Nigeria. Ann Trop Med Parasitol 104, 409-419.

Wang, T.P., Shrivastava, J., Johansen, M.V., Zhang, SQ, Wang, F.F. \& Webster, J.P. (2006) Do multiple hosts mean multiple parasites?: Population genetic structure of Schistosoma japonicum between definitive host species. Int. J. Parasitol. 36, 1317-1325.

Watts, S. \& El Katsha, S. (1995) Changing environmental conditions in the Nile Delta: health and policy implications with special reference to schistosomiasis. Int J Environ Health Res 5, 197-212.

Webster, J.P., Davies, C.M., Hoffman, J.I., Ndamba, J., Noble, L.R. \& Woolhouse, M.E.J. (2001) Population genetics of the schistosome intermediate host Biomphalaria pfeifferi in the Zimbabwean highveld: Implications for co-evolutionary theory. Ann Trop Med Parasitol 95, 203-214.

Yang, G.J., Vounatsou, P., Zhou, X.N., Tanner, M. \& Utzinger, J. (2005) A potential impact of climate change and water resource development on the transmission of Schistosoma japonicum in China. Parassitologia 47, 127-134.

Zhou, X-N., Yang, G-J., Yang, K., Wang, X-H., Hong, Q-B. et al. (2008) Potential impact of climate change on schistosomiasis transmission in China. Am. J. Trop. Med. Hyg. 78, 188-94. 


\section{Chapter 4.2.1.11}

\section{Other Trematodal Infections}

\section{[EURYTREMA PANCREATICUM, GASTRODISCOIDES HOMINI, NANOPHYETES SALMINCOLA]}

Eurytrema pancreaticum is a relatively rare fluke infection in humans, hogs, monkeys but mostly in ruminants (cattle, water buffaloes, sheep, camels and goats). Its main distribution is Southeast Asia and China but also in Russian Far East (Dvoriadkin, 1976). Interestingly, in spite of the aquatic phase that includes snails, it has also an arthropod terrestrial second intermediary host (grasshopper), which may explain its lower prevalence in humans and higher in ruminants. Briefly, the E. pancreaticum life cycle consists of adult flukes in infected mammals that produce eggs in the pancreatic duct. Eggs are excreted with feces and if in contact with water sources, they will be ingested by snails as first intermediary host. In snails, it reproduces asexually to produce cercariae that are shed on grass (mainly near the shore of aquatic bodies). Cercariae adhere to grass stems to be further ingested by grasshoppers (the second intermediary host). Into grasshopper, cercariae will encyst and develop into metacercariae; then accidental ingestion of this arthropod by mammals consuming grass (mainly ruminants) will produce infection and development of adult flukes (in pancreatic duct) (Figure 4.2.1.11.1). Clinical manifestation is inflammation of the pancreatic duct that may lead to pancreatitis (Ishii et al., 1983).

Gastrodiscoides hominis is also a rare fluke infection in humans and more frequent in pigs (final hosts). Its main distribution is India, Southeast Asia including China. Snails (Planorbids, Heliocorbus spp.) and water plants and fruits are the first and second intermediate hosts, respectively. Briefly, pigs and humans excreta containing eggs reach water bodies where eggs mature. Eggs hatch to release miracidia into water where they penetrate snails (the first intermediary host). Inside snails, miracidia develop into rediae that further multiply and then form cercariae. Cercariae are again released into water where they encyst and form metacercariae that adhere to aquatic plants (the second intermediary host). Final hosts, pigs, humans or other animals that ingest aquatic plants carrying metacercariae, become infected. Inside the final host, metacercariae will migrate to cecum (humans) and colon (pigs) to mature in a final fluke that will further release eggs (Figure 4.2.1.11.2). Clinical manifestations are enteritis with continuous thick diarrhea.

Nanophyetes salmonicola is a rare fluke infection of humans and more often in of animals with a broader spectrum among carnivores, such as canids, felids, mustelids, procyonidae, mephitidae, pinnipeds and 
piscivorous birds, transmitted by ingestion of raw fish meat (salmon and trout) (Kistner et al., 1979; Stroud, 1978; Foreyt et al., 1987). N. salmonicola distribution is mainly in the Pacific area (Northwest USA), but stream snails are also found west of the Cascade Mountains in Oregon, north to the Olympic Peninsula in Washington and in part of northern California. Human infection by direct contact (handling of fresh-killed salmon) was also reported; however, it is very possible that oral contact was involved (hand-to-mouth route) (Harrell and Deardorff, 1990). Among the infected animals, raccoons, skunks, and other fish-eating animals are used as reservoirs of this pathogenic fluke without pathological symptoms, by continuous eggs excretion in or near water sources. Similar to that of its other trematodes relatives, $N$. salmonicola's life cycle goes through two intermediate hosts: snails (e.g., Oxytrema silicula) and both fresh and ocean water fishes (e.g., Salmonidae, Cottidae, Cyprinidae). Briefly, excreted eggs reach water sources where miracidia hatch and swim away to infect the first intermediary host: snails. Inside snails, miracidia develop into rediae and further into cercariae, which emerge into water to encounter the second intermediate host: fish. In fish, cercariae develop into metacercariae and encyst within muscles, kidney and fins waiting for its final host. Ingestion of infected raw fish meat transfers metacercariae into the final host (humans and animals) to develop into flukes that colonize intestinal mucosa (Figure 4.2.1.11.3). In severe human infection, clinical manifestations are hemorrhagic enteritis, unexplained peripheral blood eosinophilia, abdominal discomfort, nausea and vomiting, weight loss and fatigue (Eastburn et al., 1987). It should be mentioned here that from the veterinary point of view, this parasite transfers Neorickettsia helminthoeca (a gram negative bacterium and obligate intracellular parasite, belonging to Proteobacteria family) a rickettsial agent that causes a fatal disease called "Salmon poisoning" in canines (Farrell et al., 1964; Foreyt et al., 1987).

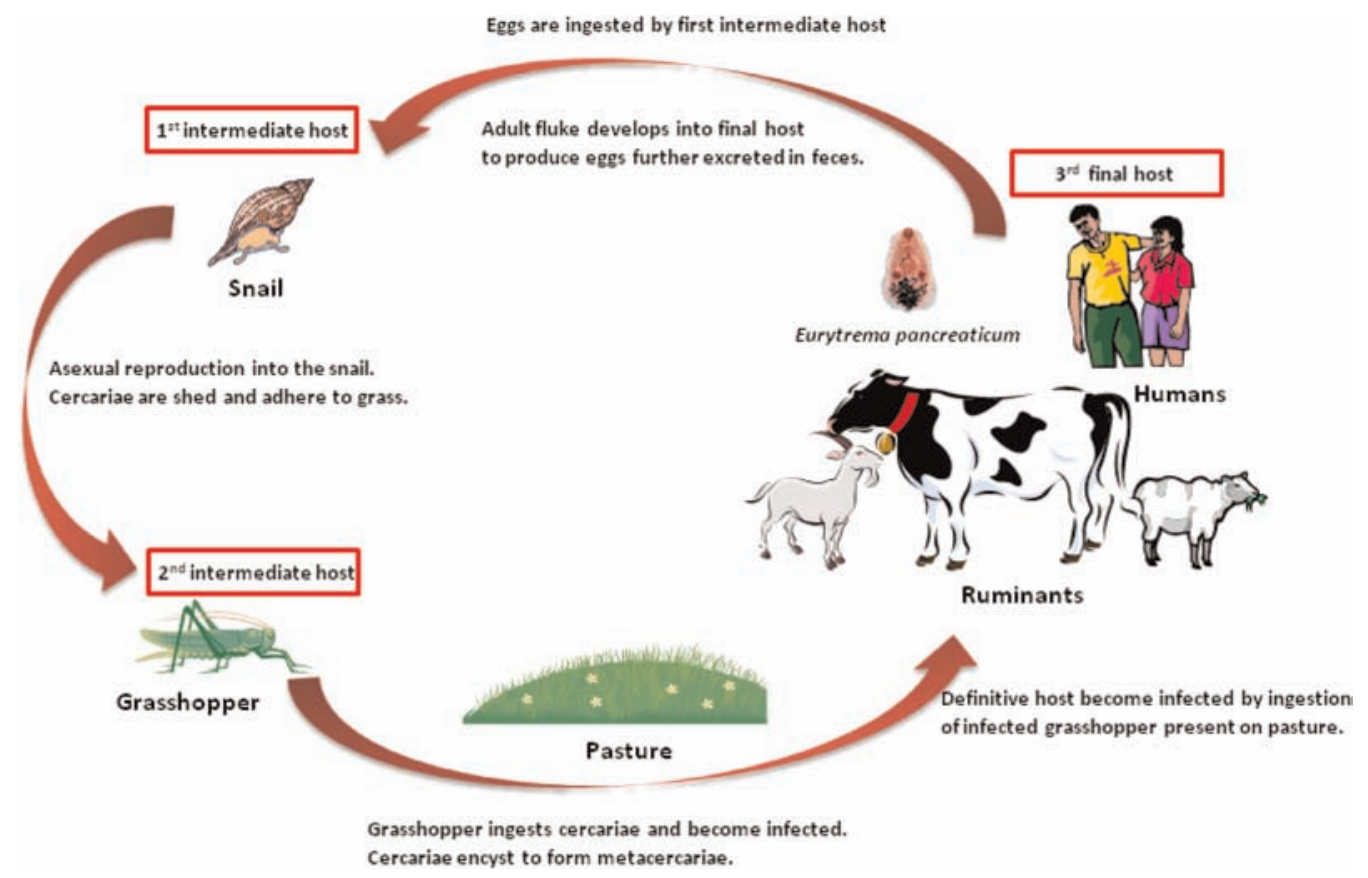

Figure 4.2.1.11.1. Eurytrema pancreaticum life cycle 


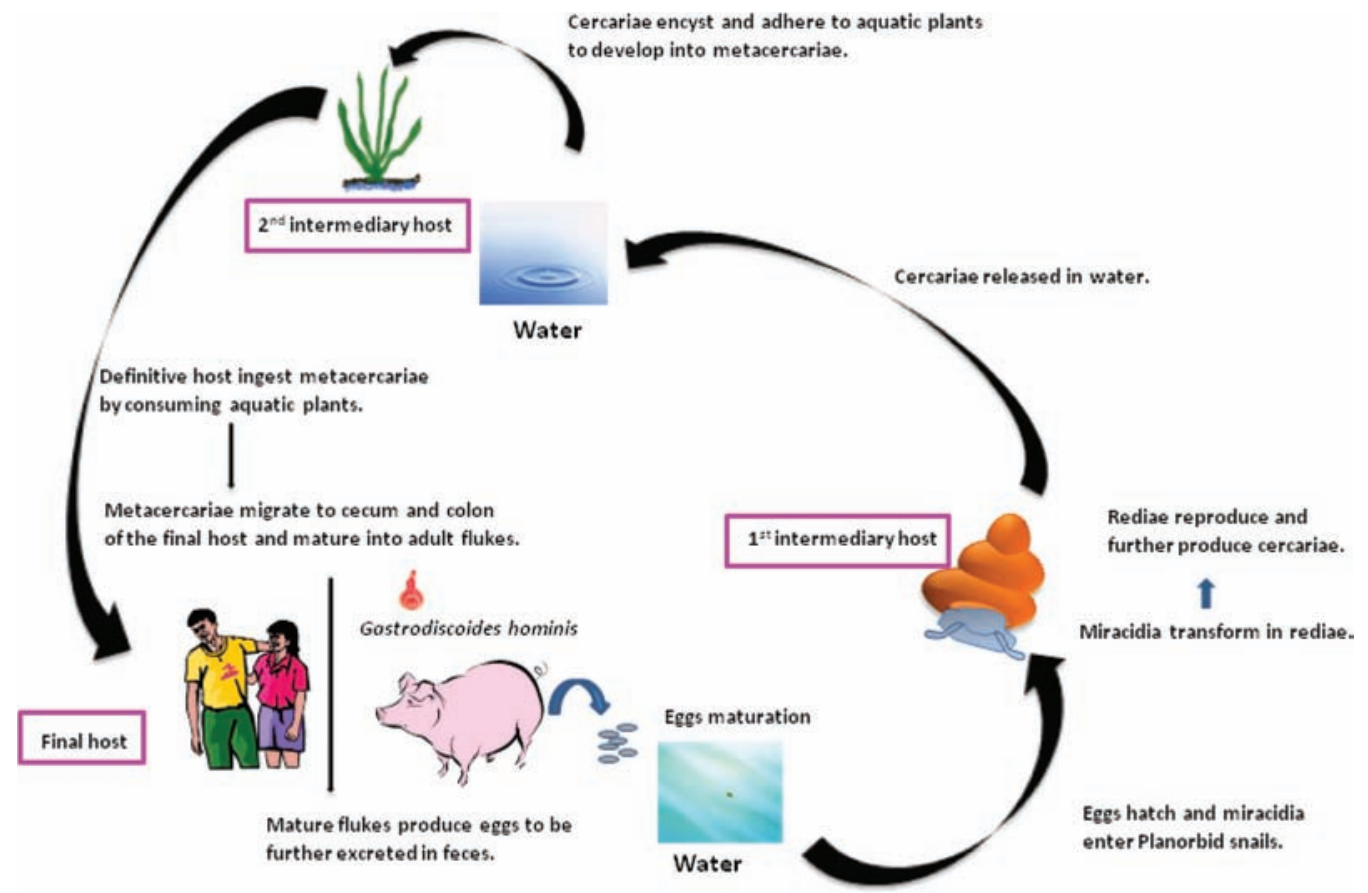

Figure 4.2.1.11.2. Gastrodiscoides hominis life cycle

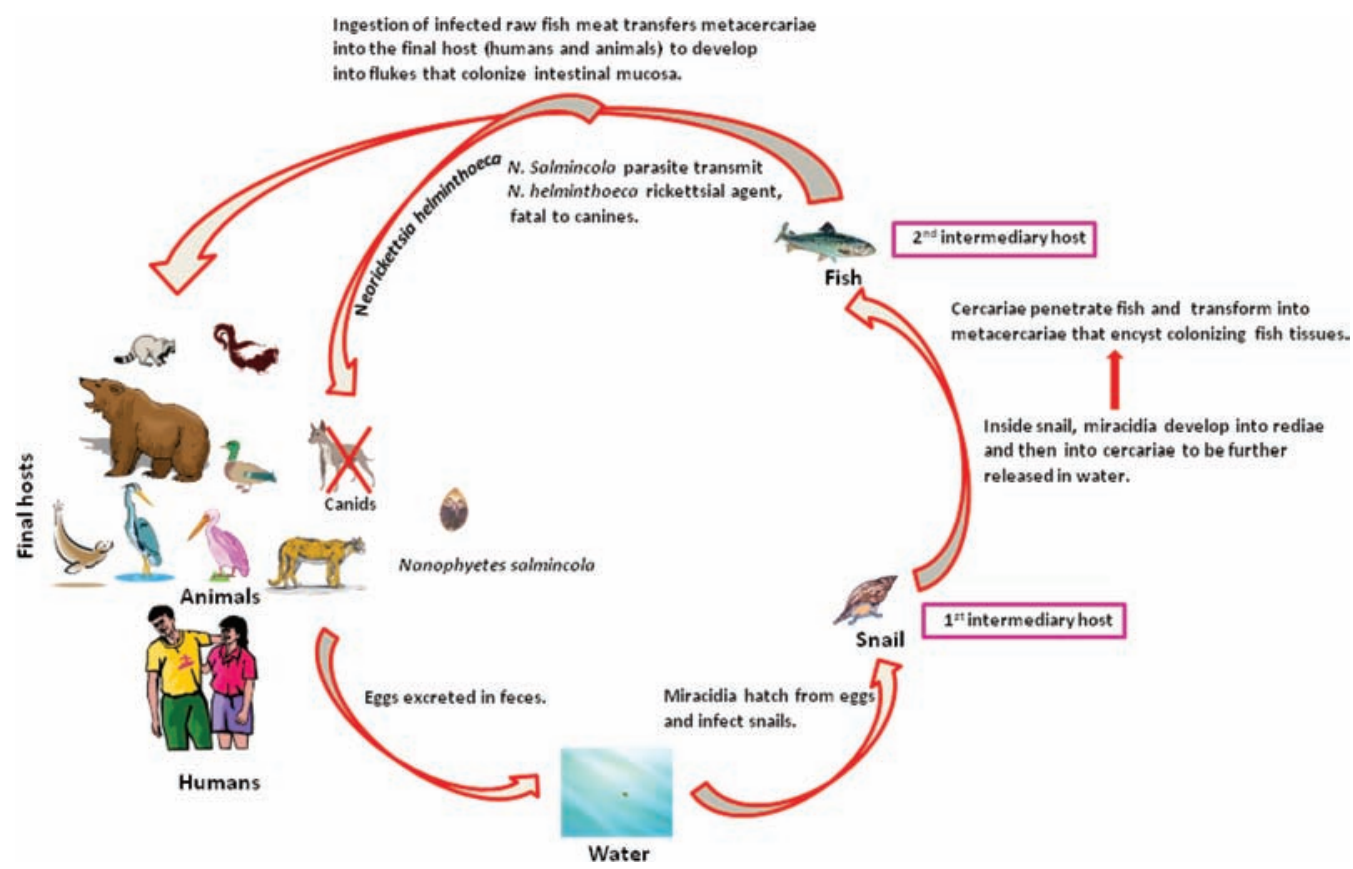

Figure 4.2.1.11.3. Nanophyetes salmincola life cycle 


\subsection{EURYTREMA PANCREATICUM, GASTRODISCOIDES HOMINI, NANOPHYETES SALMINCOLA AND ENVIRONMENT}

Roy and Tandon (1992) studied the effect of seasonal variations on the prevalence of cattle's F. giantica and E. pancreaticum in India. The study area was located in a humid, subtropical north-east hilly region of India with an average temperature of $25^{\circ} \mathrm{C}$ in summer and $10^{\circ} \mathrm{C}$ in winter. The overall prevalence rate was $53.02 \%$, with continuous annual presence and high peaks during cold winter months and lower in summer and autumn. The high winter prevalence of E. pancreaticum had been attributed to the increased availability of the second intermediary host, the grasshopper, already infected from the preceding summer and early autumn. Among other parasitic worms, they also looked for Gastrodiscoides hominis in pigs and reported an overall prevalence of $\sim 13 \%$. In pigs, G. hominis revealed a high peak during June-September, dropping to low levels during winter months. The overall high prevalence had been attributed to the presence/absence of the intermediate host species (snails). It is known that larval stages of flukes and the snail intermediate hosts are influenced by environmental factors such as temperature, water quality and flow intensity. These conclusions had been confirmed from another climatic area, the Far East of Russia, where Dvoriadkin (1976) reported an $E$. pancreaticum peak between May and October, a period coinciding with the active life of its intermediate host. When ambient temperature dropped to $8^{\circ} \mathrm{C}$, fluke growth slowed down to a final halt in October. According to this author, in contrast to tropical and subtropical zones, the extended pause in flukes' development during cold months (October to April) caused a longer development period. Parenthetically, under laboratory conditions (temperatures between 8 and $22^{\circ} \mathrm{C}$ ) this fluke development proceeded without intervals within 6.5 months. This is one of the classic examples where potential climate change may affect parasite development.

As already mentioned, Gastrodiscoides hominis distribution is in India, Southeast Asia including China. However, in 2004 Dad-Adegbola et al. (2004) reported a case of a seven year old Nigerian child who suffered from malnutrition and anemia, who was found to harbor both Gastrodiscoides hominis and Ascaris lumbricoides. These authors did not give detail of the epidemiology and environmental factors involved on the "appearance" of G. hominis in Africa. However, there is increasing evidence related to G. hominis infections in non-human primates that may allude to their possible origin in humans (Herman, 1967; Fox and Hall, 1970). G. hominis presence has been also reported in endemic foci in Russia revealing some "geographic movement" toward northern part of Asia (e.g., Siberia) (Sergiev et al., 2008).

Rodnick et al. (2008), while studying the effect of water temperature on juvenile coho salmon Oncorhynchus kisutchi, among the various parameters they tested, they also looked for parasite load (Nanophyetus salmincola and Apophallus spp.). Here it should be mentioned that a gender distribution variation has been found related to temperature: more females occupied the cooler upper reach of the river compared to males' predominance in the warmer lower reach. Parasite prevalence was higher in the warmer, lower reach (with males' predominance) and the degree of parasitism was not correlated with swimming ability or gender. Based on these results, it can be suggested that in this ecosystem, the primary intermediate hosts (snails) are the ones impacted by higher temperature, allowing better development and release of cercariae into fish environment.

Gai and Marks (2008) reported on salmon poisoning in captive Malayan sun bears. These results show that $N$. salmincola infection is not restricted to endemic areas but may be transplanted to new environments through imported infected fish for sport fishing. 


\subsection{REFERENCES}

Dada-Adegbola, H.O., Falade, C.O., Oluwatoba, O.A. \& Abiodun, O.O. (2004) Gastrodiscoides hominis infection in a Nigerian-case report. West Afr J Med 23, 185-186.

Dvoriadkin, V.A. (1976) Developmental periods and adaptation of parthenites of Eurytrema pancreaticum (Dicrocoeliidae, Trematoda) to environmental conditions. Parazitologia 10, 158-162.

Eastburn, R.L., Fritsche, T.R. \& Terhune, C.A.Jr. (1987) Human intestinal infection with Nanophyetus salmincola from salmonid fishes. Am. J. Trop. Med. Hyg. 36, 586-591.

Farrell, R.K., Lloyd, M.A. \& Earp, B. (1964) Persistence of Neorickettsiae helminthoeca in an endoparasite of the pacific salmon. Science 145, 162-163.

Foreyt, W.J., Gorham, J.R., Green, J.S., Leathers, C.W. \& LeaMaster, B.R. (1987) Salmon poisoning disease in juvenile coyotes: clinical evaluation and infectivity of metacercariae and rickettsiae. J. Wildl. Dis 23, 412-417.

Fox, J.G.\& Hall, W.C. (1970) Fluke (Gastrodiscoides hominis) in a rhesus monkey with related intussusception of the colon. J Am Vet Med Assoc 157, 714-716.

Gai, J.J. \& Marks, S.L. (2008) Salmon poisoning disease in two Malayan sun bears. J Am Vet Med Assoc 232, 586-588.

Harrell, L.W. \& Deardorff, T.L. (1990) Human nanophyetiasis: Transmission by handling naturally infected coho salmon (Oncorhynchus kisutch). J Infect Dis 161, 146-148.

Herman, L.H. (1967) Gastrodiscoides hominis infestation in two monkeys. Vet Med Small Anim Clin 62, $355-356$.

Ishii, Y., Koga, M., Fujino, T., Higo, H., Ishibashi, J. et al. (1983) Human infection with the pancreas fluke, Eurytrema pancreaticum. Am. J. Trop. Med. Hyg. 32, 1019-1022.

Khalil, M. (1923) A Description of Gastrodiscoides hominis, from the Napu mouse deer. Proc. R. Soc. Med. 16, 8-14.

Kistner, T., Wyse, D. \& Schmitz, J.A. (1979) Pathogenicity attributed to massive infection of Nanophyetus salmincola in a cougar. J. Wildl. Dis. 15, 419-420.

Macpherson, C.N.L. (2005) Human behaviour and the epidemiology of parasitic zoonoses. Int. J. Parasitol. 35, 13191331.

Rodnick, K.J., St.-Hilaire, S., Battiprolu, P.K., Seiler, S.M., Kent, M.L. et al. (2008) Habitat selection influences sex distribution, morphology, tissue biochemistry, and parasite load of juvenile Coho salmon in the West Fork Smith river, Oregon. Trans Am Fish Soc 137, 1571-1590.

Roy, B. \& Tandon, V. (1992) Seasonal prevalence of some zoonotic trematode infections in cattle and pigs in the north-east montane zone in India. Vet. Parasitol. 41, 69-76.

Sergiev, V.P., Uspenskii, A.V., Gorokhov, V.V., Moskvin, A.S., Ivanov, V.M. et al. (2008) Gastrodiscoidosis is a dangerous zoonosis. Med Parazitol (Mosk) 3, 47-51.

Stroud, R.K. (1978) Parasites and associated pathology observed in pinnipeds stranded along the Oregon coast. J. Wildl. Dis. 14, 292-298. 


\section{Chapter 4.2.2 Cestodes}

A summary of cestodes global infection burden is presented in Table 4.2.2.1.

Table 4.2.2.1 Cestodes as a global threat for humans.

\begin{tabular}{|c|c|c|c|}
\hline $\begin{array}{l}\text { Cestodes ( }>1000 \\
\text { species) }\end{array}$ & Global infection & $\begin{array}{l}\text { Geographic } \\
\text { distribution }\end{array}$ & Diseases \\
\hline $\begin{array}{l}\text { Taenia multiceps, } \\
\text { T. brauni, T. serialis, } \\
\text { T. glomerata }\end{array}$ & 150 (hundreds) & $\begin{array}{l}\text { Taenia multiceps } \\
\text { (France, Africa, } \\
\text { England, Brazil, Israel, } \\
\text { United States and } \\
\text { more), T. serialis } \\
\text { (Canada and United } \\
\text { States, T. brauni (North } \\
\text { Africa, Rwanda, and the } \\
\text { Democratic Republic of } \\
\text { Congo) and T. glomerata } \\
\text { (Nigeria and the } \\
\text { Democratic Republic of } \\
\text { Congo) }\end{array}$ & Coenurosis \\
\hline $\begin{array}{l}\text { Diphyllobothrium latum, } \\
\text { D. denditricum, } \\
\text { D. pacificum, } \\
\text { D. nihonkaiense }\end{array}$ & $\begin{array}{l}\text { Estimated } 20 \text { million } \\
\text { infections }\end{array}$ & $\begin{array}{l}\text { Scandinavia, western } \\
\text { Russia, China, Japan, } \\
\text { the Baltics, Ireland, Italy, } \\
\text { France, Romania, North } \\
\text { America, especially the } \\
\text { Pacific Northwest }\end{array}$ & Diphyllobothriasis \\
\hline
\end{tabular}


Table 4.2.2.1 (Continued)

\begin{tabular}{|c|c|c|c|}
\hline $\begin{array}{l}\text { Cestodes ( }>1000 \\
\text { species) }\end{array}$ & Global infection & $\begin{array}{l}\text { Geographic } \\
\text { distribution }\end{array}$ & Diseases \\
\hline Dipylidium caninum & Hundreds? & $\begin{array}{l}\text { Worldwide (Europe, } \\
\text { Philippines, China, } \\
\text { Japan, Argentina, and } \\
\text { United States) }\end{array}$ & Dipylidosis \\
\hline $\begin{array}{l}\text { Echinococcus genus } \\
\text { E. multilocularis } \\
\text { E. granulosus } \\
\text { E. vogeliE. oligarthus }\end{array}$ & $\begin{array}{l}\text { Estimated2-3 million } \\
\text { infections }\end{array}$ & $\begin{array}{l}\text { Worldwide (all)(except } \\
\text { Iceland and Greenland) }\end{array}$ & Echinococcosis \\
\hline $\begin{array}{l}\text { Hymenolepis nana, } \\
H . \text { fraterna, } H \text {. diminuta }\end{array}$ & Millions & $\begin{array}{l}\text { Worldwide(Higher } \\
\text { prevalence in Southern } \\
\text { Europe, North and } \\
\text { Central Africa, Near and } \\
\text { Far East, Central } \\
\text { America) }\end{array}$ & Hymenolepiasis \\
\hline $\begin{array}{l}\text { Spirometra genus } \\
\text { (S. mansoni, } \\
\text { S. ranarum, } \\
\text { S. mansonoides and } \\
\text { S. erinacei, and the } \\
\text { aberrant Sparganum } \\
\text { proliferum) }\end{array}$ & $\begin{array}{l}\text { Rare (hundreds } \\
\text { to }>\text { thousand) infections }\end{array}$ & $\begin{array}{l}\text { Southeast Asia (China, } \\
\text { Vietnam, Korea, Japan) } \\
\text { other but rare Europe, } \\
\text { USA, Australia, Africa } \\
\text { and South America }\end{array}$ & Sparganosis \\
\hline $\begin{array}{l}\text { Taenia saginata } \\
\text { saginata, Taenia } \\
\text { saginata asiatica }\end{array}$ & $\begin{array}{l}\sim 50 \text { million people } \\
\text { worldwide are infected } \\
\text { by } T \text { saginata or } T \\
\text { solium. }\end{array}$ & $\begin{array}{l}\text { Africa, Eastern Europe, } \\
\text { Southeast Asia, South } \\
\text { America }\end{array}$ & $\begin{array}{l}\text { Taeniasis Saginata } \\
\text { (Including Taeniasis } \\
\text { Asiatica) }\end{array}$ \\
\hline Taenia solium & $\begin{array}{l}\sim 50 \text { million people } \\
\text { worldwide are infected } \\
\text { by } T \text { saginata or } T \\
\text { solium. } \sim 50,000 \text { people } \\
\text { die annually of } \\
\text { cysticercosis. }\end{array}$ & $\begin{array}{l}\text { Asia, Africa, South } \\
\text { America, Southern } \\
\text { Europe and } \\
\text { partially USA }\end{array}$ & $\begin{array}{l}\text { Taeniasis solium and } \\
\text { cysticercosis }\end{array}$ \\
\hline $\begin{array}{l}\text { Other miscellaneous } \\
\text { cestodes infecting } \\
\text { humans(Bertiella spp., } \\
\text { Raillientina spp., } \\
\text { Inermicapsifer } \\
\text { madagascariensis, } \\
\text { I. cubensis, } \\
\text { Mesocestoides varibilis, } \\
\text { M. lineatus, } \\
\text { Diplogonoporus grandis }\end{array}$ & $\begin{array}{l}\text { Estimated infections: } \\
\text { hundreds }\end{array}$ & $\begin{array}{l}\text { South America, Africa, } \\
\text { Asia, Madagascar and } \\
\text { Caribbean area }\end{array}$ & Abdominal discomfort, ? \\
\hline
\end{tabular}




\section{Chapter 4.2.2.1 Coenurosis}

\section{[TAENIA MULTICEPS, T. BRAUNI, T. SERIALIS, T. GLOMERATA]}

Coenurosis is a rare disease ( $\sim 150$ cases) caused by the ingestion of eggs of dog tapeworm species Taenia multiceps (France, Africa, England, Brazil, Israel, United States and more), T. serialis (Canada and United States, T. brauni (North Africa, Rwanda, and the Democratic Republic of Congo) and T. glomerata (Nigeria and the Democratic Republic of Congo). The definitive hosts of these parasites are canids (e.g., dogs, foxes, wolves and coyotes), and humans are only accidental hosts with incomplete life cycle of these tapeworms. In humans, ingested eggs will develop into mature larvae but not into mature worms (see below life cycle). The intermediate stage of these tapeworms, the larvae, group within cysts called coenuri formed in the central nervous system (CNS), subcutaneous tissues and muscles. Intermediate hosts do exist such as goats, sheep, horses, cattle and rabbits that are infected by ingestion of dog contaminated feces with gravid proglottids (tapeworm segments, containing both male and female reproductive organs) but they do not transmit the parasite from one to another. In herbivores, the intermediate hosts, the infection is an economic problem. Briefly, the life cycle consists of adult tapeworm infecting canids and eggs production, excreted in feces as gravid proglodits containing eggs or already embryonated eggs. Ingestion of contaminated feces by an intermediate host (mainly herbivores) or an accidental host (humans) causes oncospheres to hatch from eggs into the intestine and further into a blood vessel of the intestinal wall.

Blood stream carries the embryo to various body parts with preference for the CNS. The oncospheres develop into coenuri in intermediate hosts and further into adult tapeworms in the final host. Ingestion of intermediary host meat by a final host (canids) introduces the coenuri in their digestive system with further development towards a complete adult tapeworm (Figure 4.2.2.1.1). Clinical manifestations are: in case of heavy infestation, acute meningoencephalitis develops, while in light infestation cases, a pressure-induced atrophy of surrounding CNS tissue will develop causing headaches, nausea, vomiting, paraplegia, seizure, hemiplagia aphasia, eye symptoms and death.

\subsection{COENUROSIS AND ENVIRONMENT}

Based on the life cycle of these parasites, it is obvious that low hygienic standards, poverty and low education are the main factors contributing to their successful infections in herbivores. However, in the 
published literature, human infections seem to be mostly related to accidental ingestion of contaminated canids' feces such as in close encounter with pets (El-On et al., 2008). Dalimi et al. (2006) surveying stray dogs, red foxes and golden Jackals in Iran found a Taenia multiceps prevalence of $4.82 \%$ but only in stray dogs. Beside direct contact with canids feces, other sources such as contaminated water and food with canids excreta may also infect humans, consequently creating the need for the following preventive measures: education, farming conditions improvement, improved detection methods, control of sewage sludge application on pasture and prevention of close contact between wild (the main reservoir) and domestic animals (Pazio, 2008).

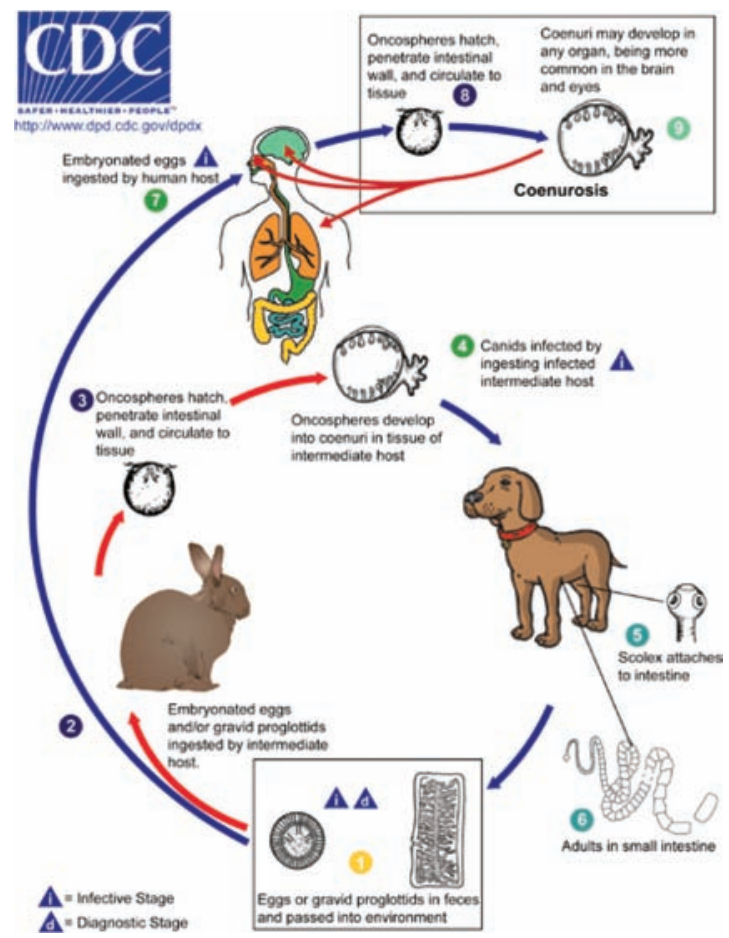

Figure 4.2.2.1.1. Taenia multiceps, T. brauni, T. serialis, T. glomerata (Coenurosis) life cycle (with permission from CDC, Atlanta, USA; http://www.dpd.cdc.gov/dpdx/HTML/Coenurosis.htm)

\subsection{REFERENCES}

Pozio, E. (2008) Epidemiology and control prospects of foodborne parasitic zoonoses in the European Union. Parassitologia 50, 17-24.

Dalimi, A., Sattari, A. \& Motamedi, Gh. (2006) A study on intestinal helminths of dogs, foxes and jackals in the western part of Iran. Vet. Parasitol. 142, 129-133.

El-On, J., Shelef, I., Cagnano, E. \& Benifla, M. (2008) Taenia multiceps: a rare human cestode infection in Israel. Vet. Ital. 44, 621-631. 


\section{Chapter 4.2.2.2 Diphyllobothriasis}

\section{[DIPHYLLOBOTHRIUM LATUM, D. DENDITRICUM, D. PACIFICUM, D. NIHONKAIENSE]}

Tapeworms of the Diphyllobothrium genus infect humans through their consumption of raw or undercooked fish. The D. latum species that infects fish and mammals (cats, dogs, pigs, bears, etc.) is found in temperate and subarctic regions such as Scandinavia, western Russia, the Baltics, Asia (Japan), Uganda, Peru, Chile and now also present in North America (especially the Pacific Northwest). In the United States, the disease is now rare; however, once it was more common and ethnically was referred to as "Jewish housewife's disease", as a Jewish traditional food specialty "gefilte fish" had been frequently tested by housewives before cooking. Briefly, the life cycle starts from an infected final hosts (animal or human) shedding eggs via their feces and contact with water sources. In water, the larva develops into a swimming coracidium ingested by small copepods (Cyclops and Diaptomus spp.) where it develops into a procercoid form. Fishes consuming copepods become infected with procercoids that settle into their tissue to become plerocercoids (the infective stage of final host). Here there are two possibilities: 1) plerocercoids ingestion by a bigger fish as a paratenic host (intermediary host) waiting to enter the final host or 2) direct ingestion by the final host. If the second scenario takes place, plerocercoids hatch in small intestine to develop into a mature tapeworm to produce new eggs (Figure 4.2.2.2.1). Clinical manifestations are mostly asymptomatic, but some people might develop megaloblastic anemia (a result of parasite vitamin $\mathrm{B}_{12}$ seizure), weakness, abdominal pain, intestinal obstruction, diarrhea and rarely paresthesia and ataxia.

\subsection{DIPHYLLOBOTHRIASIS AND ENVIRONMENT}

It is clear that continuous pollution of water sources (including estuaries) with sewage carrying fecal content from infected humans is the vicious cycle of continuous reports of this disease. Infected human migration or emigration and fecal contact with water may also cause a heavy infection load of plerocercoids in fish populations, even in lakes of considerable size. Because of Diphyllobothrium species' general broad host specificity, their life cycles are maintained in nature independently of humans (Scholz et al., 2009). 
Wardle (1933) a long time ago reported that the plerocercoid larval stage is highly tolerant to temperatures (between -2.8 to $38^{\circ} \mathrm{C}$ ), $\mathrm{HCl}$ (from 0.001 to $0.3 \mathrm{M}$ in the presence of $0.5 \%$ pepsin) and different salts (from 0.001 to $0.2 \mathrm{M}$ ) possibly explaining successful infections through marinated fish. Dupouy-Camet and Peduzzi (2004) reported infection levels of secondary hosts with D. latum as high as $33.3 \%$ in Western Europe, some lakes in Italy, Switzerland and France. These physiological characteristics make this tapeworm an excellent environmental survivor, explaining the high numbers of infections. However, eradication in humans can be easily implemented by changing their praxis to eat raw fish. In wild life pescivorous (birds, whales, seals and bears) this task would be much more difficult to accomplish, therefore a wild reservoir will always prevail.

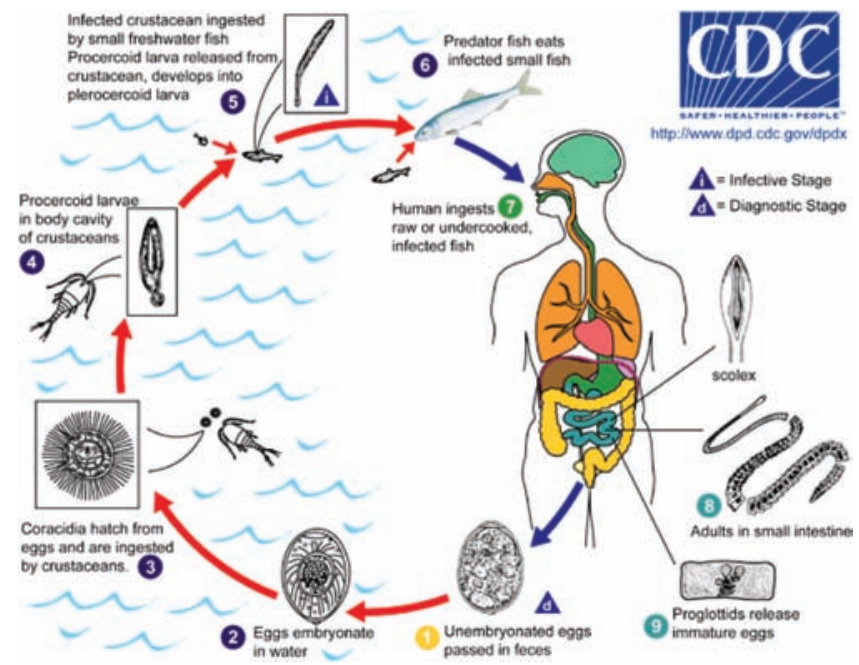

Figure 4.2.2.2. Diphyllobothrium latum life cycle (with permission from CDC, Atlanta, USA; http://www.dpd. cdc.gov/dpdx/HTML/Diphyllobothriasis.htm)

\subsection{REFERENCES}

Wardle, R.A. (1933) Significant factors in the plerocercoid environment of Diphyllobothrium latum (Linn.). J. Helminthol. 11, 25-44.

Dupouy-Camet, J. \& Peduzzi, R. (2004) Current situation of human diphyllobothriasis in Europe. Euro Surveill. 9, $31-35$.

Scholz, T., Garcia, H.H., Kuchta, R. \& Wicht, B. (2009) Update on the human broad tapeworm (genus diphyllobothrium), including clinical relevance. Clin. Microbiol. Rev. 22, 146-160. 


\section{Chapter 4.2.2.3 Dipylidosis}

\section{[DIPYLIDIUM CANINUM]}

Dipylidiosis is a rare disease caused by the tapeworm Dipylidium caninum found in dogs and cats. D. caninum is distributed worldwide, with its highest prevalence in European dogs. In humans infection occurs through ingestion of cystercoids or infected fleas. The life cycle of $D$. caninum includes release of gravid proglottides found in dogs or cats small intestine. Eggs containing larvae are hosted in proglottids in egg capsules. The egg capsules are spread around by feces and by ingestion by the larval stage of fleas (e.g., Ctenochephalides canis and Ctenochephalides felis species) (Guzman, 1984). Further, the ingested eggs hatch inside the flea's body cavity (during its pupal stage) to form oncosphere larvae that further develop to become cysticercoid larvae. This is the intermediate stage of $D$. caninum infective toward mammal hosts. Ingestion of a whole flea or direct contact with infected dogs (e.g. hand licking) that carry the infectious stage in its oral cavity will introduce the cystcercoids into the digestive system where they will reach their final stage of adult tapeworm development (Figure 4.2.2.3.1). In humans clinical manifestations are mostly asymptomatic but heavy burden infection can cause abdominal discomfort, bloody and mucous diarrhea, anal pruritus and weight loss.

\subsection{DIPYLIDOSIS AND ENVIRONMENT}

Overgaauw and Boersema (1998) surveyed 25 cat kennels in Holland for presence of the nematode Toxocara's eggs in feces, soil and dust samples. The nematode's eggs were not present in soil and dust samples, however Dipylidium caninum eggs were present in two household dust samples. Based on D. caninum's life cycle, their results indicate the presence of fleas as an infective source. Flea larvae of Ctenocephalides felis have been experimentally infected with $D$. caninum eggs at different temperatures $\left(20\right.$ to $35^{\circ} \mathrm{C}$ ) (Pugh and Moorhouse, 1985). Parasite development and host reaction were found to be independent of host maturation, although the host's marked and prolonged reactions between 20 and $25^{\circ}$ C were observed. D. caninum growth did not occur at $20^{\circ} \mathrm{C}$ while faster growth was observed at higher temperatures (highest growth rate occurred at $35^{\circ} \mathrm{C}$ ) in spite of the host's death at $35^{\circ} \mathrm{C}$ (at pupation stage). The effect of elevated temperature on $D$. caninum development in the flea host may possibly 
explain its successful infection of mammals through ingestion and exposure at these temperatures inside a mammal's body!

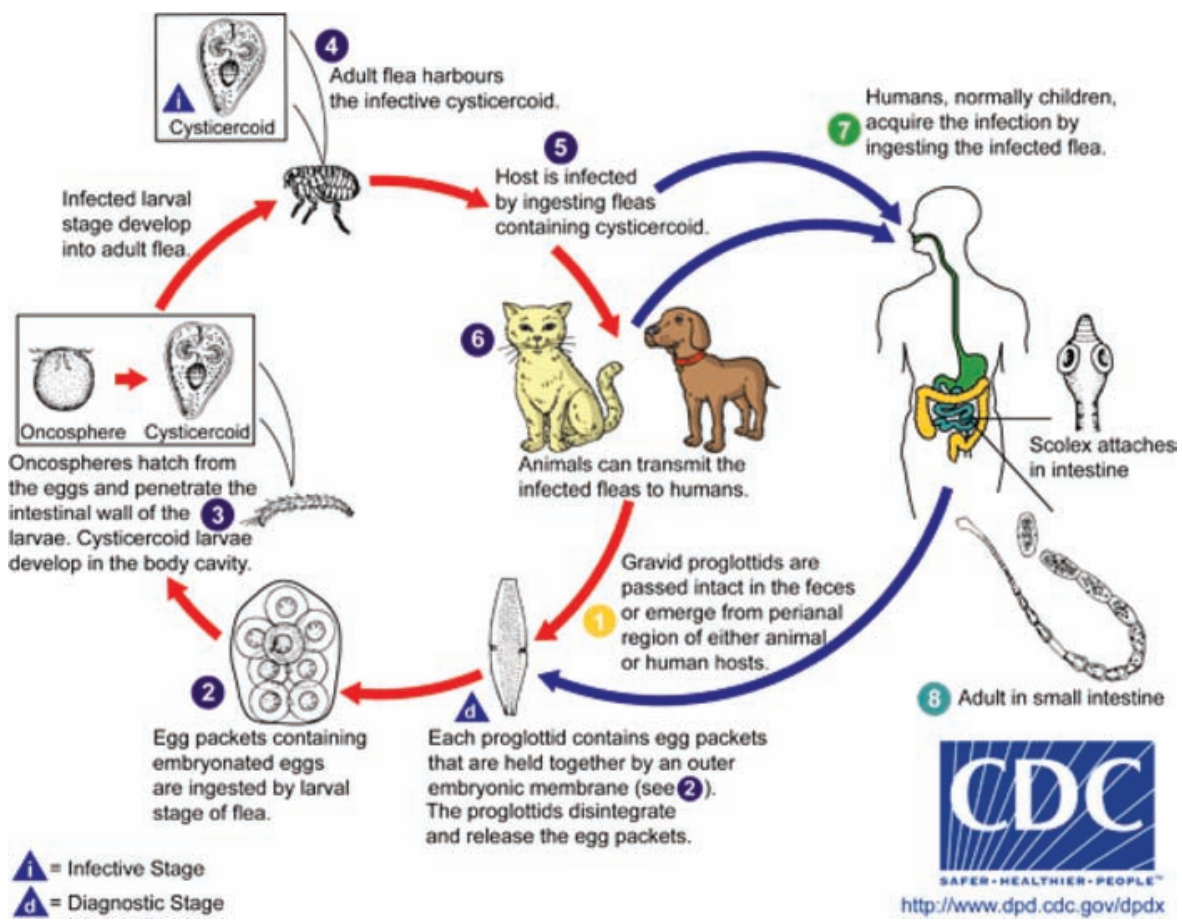

Figure 4.2.2.3.1. Dipylidium caninum life cycle (with permission from CDC, Atlanta, USA; http://www.dpd. cdc.gov/dpdx/HTML/Dipylidium.htm)

An Argentinean group studied 2000 urban and rural dogs for the presence of diverse parasites in their stool samples, in areas of the province of Neuquen, Patagonia (Soriano et al., 2010). Among the large diversity of parasites present, Dipylidium caninum had a prevalence of $0.31 \%$, with an incidence in urban dogs slightly higher than in rural ones. The authors mentioned that rural dogs in this study area were under periodic treatment with antihelmintic drugs, while the urban dog population increased as a result of a proliferation of stray dogs. Another important environmental fact brought up in relation to D. caninum prevalence, is the absence of regulations against canine fecal deposits in public areas, increasing contamination and favorable parasite transmission in such places.

In Poland, Okulewicz et al. (1994), surveying intestinal parasites among rural and urban dogs, reported on an overall higher infection prevalence in rural dogs (100\%) than in urban dogs (40-48\%) including D. caninum. This difference was attributed to different breeding conditions and to rural dogs recurrent contact with additional wild canids (wolves, foxes, etc.).

In another geographical area, Kainji Lake area in Nigeria, Okaeme (1985) investigated gastrointestinal helmithiasis in human and dog population taking into consideration inadequate health, lack of veterinary facilities, crowdedness and squalid environment. Indeed, among other helminths, Dipylidium caninum had a prevalence of $28.26 \%$. (second in magnitude) in dogs. Also in Nigeria, Maikai et al. (2008) 
surveyed soil samples for different helminth eggs in Kaduna metropolis in 14 various environmental and socio-cultural playgrounds. D. caninum overall prevalence was $26.3 \%$ with a higher prevalence during the dry harmattan period (a dry and dusty West African trade wind) revealing dust carriage. Interestingly, highly rated sites (socio-economically) were more contaminated. From the statistical point of view, parameters revealing significantly high odds ratio were: rain, dogs' presence and grass (vegetation) while insignificant parameters (low odds ratio) were: dry periods, refuse presence on playground and their topography, soil depth and socio-economic status of people attending those playgrounds.

In Wales, a foxhound pack and gundog kennel were surveyed for infestation with various cestodes. D. caninum was found in hounds but only related to diet. Owing to foxhounds' activity, they play an important role in environmental dissemination of cestodes' eggs (including $D$. caninum) because of frequent diet on uncooked carcasses and large hunting areas coverage (Stallbaumer, 1987).

Finally, Orta-de Velasquez et al. (2002) studied the inactivation of different helminth eggs by ozone. At $18.4 \mathrm{mg} / \mathrm{L} / \mathrm{min}$ ozone exposure it took 3 hours to inactivate $D$. caninum eggs completely, which reveals an increased resistance of this parasite to disinfection and explicate its environmental persistance.

\subsection{REFERENCES}

Guzman, R.F. (1984) A survey of cats and dogs for fleas: with particular reference to their role as intermediate hosts of Dipylidium caninum. $N$ Z Vet J 32, 71-73.

Maikai, B.V., Umoh, J.U., Ajanusi, O.J. \& Ajogi, I. (2008) Public health implications of soil contaminated with helminth eggs in the metropolis of Kaduna, Nigeria. J. Helminthol. 82, 113-118.

Okaeme, A.N. (1985) Canine and human gastrointestinal helminthiasis of the Kainji Lake area, Nigeria. Int J Zoonoses 12, 241-246.

Okulewicz, A., Zlotorzycka, J. \& Czulowska, A. (1994) Effect of environmental conditions on parasitic infection of dogs. Wiad Parazytol 40, 293-298.

Orta-de Velasquez, Ma.T., Rojas-Valencia, Ma.N. \& Vaca-Mier, M. (2002) Destruction of helminth eggs (Ascaris suum) by ozone: second stage. Water Sci. Technol. 2, 227-233.

Overgaauw, P.A. \& Boersema, J.H. (1998) A survey of Toxocara infections in cat breeding colonies in The Netherlands. Vet $Q 20,9-11$.

Pugh, R.E. \& Moorhouse, D.E. (1985) Factors affecting the development of Dipylidium caninum in Ctenocephalides felis felis (Bouche, 1835). Z Parasitenkd 71, 765-775.

Soriano, S.V., Pierangeli, N.B., Roccia, I., Bergagna, H.F.J., Lazzarini, L.E. et al. (2010) A wide diversity of zoonotic intestinal parasites infects urban and rural dogs in Neuquen, Patagonia, Argentina. Vet. Parasitol. 167, 81-85.

Stallbaumer M (1987) The prevalence and epidemiology of cestodes in dogs in Clwyd, Wales. II. Hunting dogs. Ann Trop Med Parasitol 81, 43-47. 


\section{Chapter 4.2.2.4 Echinococcosis}

\section{[ECHINOCOCCUS MULTILOCULARIS, E. GRANULOSUS, E.VOGELI, E. OLIGARTHUS]}

Human echinococcosis is a disease that affects both humans and animals with severe outcome. Depending on Echniococcus species there are three forms of echinococcosis in humans: 1) alveolar echinococcosis caused by the tapeworm Echinococcus multilocularis; 2) cystic echinococcosis caused by the tapeworm Echinococcus granulosus and 3) polycystic echinococcus caused by the tapeworms E. vogeli or E. oligarthus. The life cycle of Echinococci consists of eggs or proglottids containing eggs excretion in feces and spread by canids in environment (water, soil, plants, etc.). An intermediate host (sheep, goats, camels or pigs) ingests/inhales these embryonated eggs; thenafter the oncospheres hatch and penetrate the intestinal wall and are transported to the liver or other organs through blood or lymph vessels. The larval stage (oncospheres) further develops into metacestode through tissue infiltration and formation of hydatid cysts in different organs (e.g. liver, lungs, brain, etc.). The final host's ingestion of meat containing hydatid cysts releases protoscoleces that adhere to the intestine to develop into scoleces and eggs producing mature tapeworms (Figure 4.2.2.4.1). Humans are dead-end hosts and their main infection occurs through contact with canids' feces or ingestion of contaminated meat from an intermediary host.

Alveolar echinococcosis, caused by E. multilocularis, has a Northern Hemisphere distribution that includes: North America (including Alaska), Southwestern Asia (including Turkey), Northeastern Asia (including Siberia, northern China and Japan) and Central Europe (France, Germany, Austria, Czech Republic and Poland), with a tendency to spread northward (Vuitton et al., 2003). Natural final hosts are red and arctic foxes but other canids (dogs, wolves, raccoon dogs and coyotes) and cats may be infected (Thompson et al., 2006). Intermediate hosts include a large variety of rodents, such as voles spp., muskrats, lemmings and deer mice. Transmission to humans occurs through egg ingestion or inhalation (aerosolized eggs) from feces of a final infected host or direct contact with food (e.g., forest berries and mushrooms), soil, dirt or animal hair that holds eggs; coprophagic flies, carrion birds and arthropods may also act as mechanical vectors of this parasites eggs. Echniococcus eggs are highly resistant under moist and cold conditions and can survive for months ( 8 months viability after storage at $-18^{\circ} \mathrm{C}$ ), 
possibly explaining its northern extension simultaneously with growing fox population in European urban areas (Deplazes, 2006; Veit et al., 1995). Its clinical manifestations may be divided in three phases: 1st phase-incubation that may last between $<5$ to 15 years, where abortive infections may occur (no infection); $2^{\text {nd }}$ phase mainly in mature humans (average 50 years old), infection progresses with liver affected but with a variable advance (slow or rapid with metastases); $3^{\text {rd }}$ phase hepatomegaly develops, infiltration and congestion of bile ducts and blood vessels with icterus and ascites development. Lungs and brain metastases are fatal.

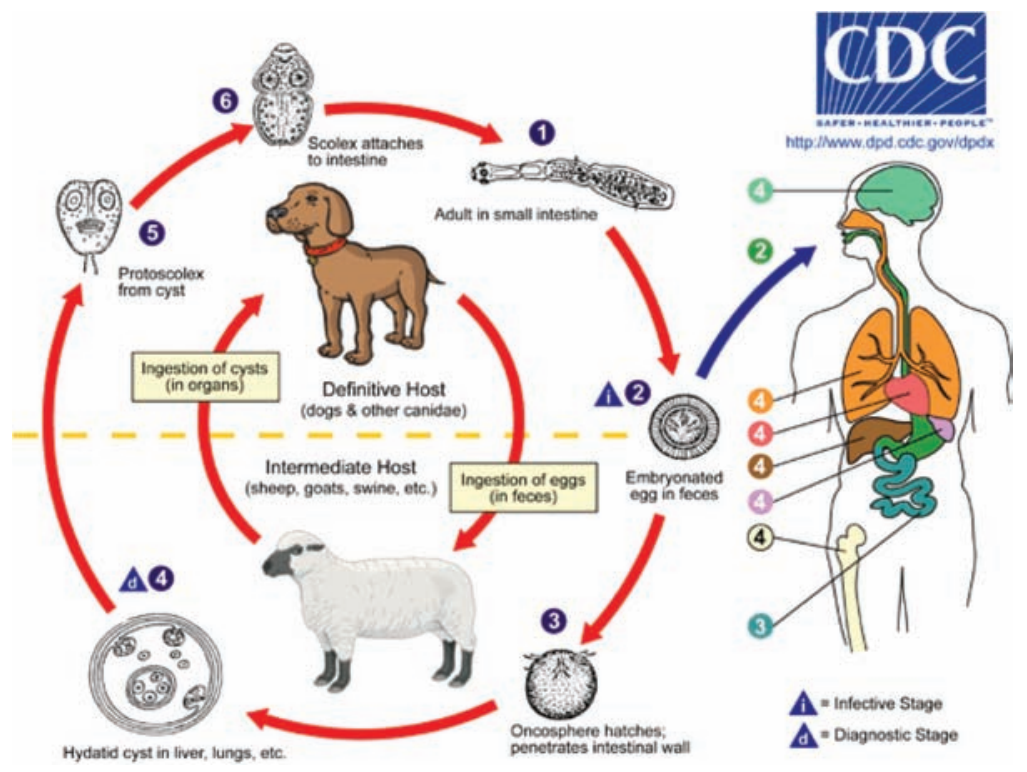

Figure 4.2.2.4.1. Echinococcus spp. life cycle (with permission from CDC, Atlanta, USA; http://www.dpd. cdc.gov/dpdx/HTML/Echinococcosis.htm)

Cystic echinococcosis, caused by E. granulosus is distributed in Mediterranean countries, the Middle East, China (Northwest), India, southern Australia, South America (mainly Chile and Uruguay), Africa (central, southern and east, mainly Ethiopia and Kenya), North America (USA partially) and Central America. Final hosts of E. granulosus are also canids (dogs and wild dogs, foxes, dingoes and wolves) but lions have been also described as a potential host (Jenkins et al., 2000). Clinical manifestations are slower in comparison with alveolar echinococcosis; cyst growth is slower but to a much bigger extension (fist or bigger size of cyst) without tissue infiltration and metastases (except when cyst is cracked), affected organs are in decreasing order of prevalence: liver $>$ lungs $>$ spleen and peritoneum $\gg$ brain. When growing, cysts impact blood vessels or bile ducts, icterus and ascites are present and any abrupt rupture of big cysts can cause sudden death by anaphylactic shock caused by the internal large amount of released antigen. Nonspecific signs may include anorexia, weight loss and weakness.

Polycystic hydatidosis distribution, caused by E. vogeli and E. oligarthrus, occurs in Central and South America, but is a rare infection in humans. The definitive hosts for E. vogeli are bush dogs (Speothos venaticus) and the intermediate hosts are South American rodents, especially pacas (Cuniculus paca) and the definitive hosts for E. oligarthrus are wild felids and the intermediate hosts are rodents too. 
E. vogeli tends to occur initially in the liver; however, the cysts are invasive and can spread to nearby organs and tissues. The clinical signs resemble alveolar echinococcosis with common symptoms, such as hepatomegaly, abdominal distension, weight loss, abdominal pain, jaundice, anemia (when liver is involved), coughing, chest pain and hemoptysis (if the lungs are involved). Rupture of esophageal varices can result in hematemesis (esophageal involvement), congestive heart failure and acute pulmonary edema (when heart is involved). Calcified metacestodes have been also reported.

E. oligarthrus is confined to internal organs of its normal intermediate hosts: subcutaneous tissues and muscles. Little is known about this organism in humans; only rare cases have been described (two cases): 1) a single cyst behind the eye caused irritation of the eye, exophthalmia and blindness, and 2) cysts found in a person heart that died of tetanus. The lesions included an enlarged heart, myocarditis, and excess pericardial fluid.

\subsection{ECHINOCOCCOSIS AND ENVIRONMENT}

Larrieu et al. (2002) performed a case-control study on the risk factors for cystic echinococcosis in children of the province of Rio Negro, Argentina. According to univariate and multivariate analyses, the significant calculated odds ratios for cystic echinococcosis in children were: 1) having a relative with this disease, 2) first years of life in contact with a large number of dogs and 3) having a father who slaughtered sheep at his workplace. Clean tap water was a protective factor on the disease spread.

In Africa (Kenya), a slaughter survey has been carried out in order to establish an accurate prevalence status of cystic echinococcosis in infected intermediate hosts (cattle, goats, sheep and camels). Animals originating from a certain area were reported to have a higher echinococcosis prevalence. This particular area had a higher mean annual rainfall $(430 \mathrm{~mm})$ than other areas $(380 \mathrm{~mm}$ and $19 \mathrm{~mm})$ and also a lower environmental temperature, two climatic factors that support E. granulosus's egg survival. Additional factors attributed to high prevalence in this specific area were: 1) constant migration of infected livestock across the border, 2) high prevalence of infected final host (dogs) and 3) higher stocking rate (Njoroge et al., 2002). Interestingly, among the surveyed post-mortem animals, camels had the highest prevalence $(61.4 \%)$ but the authors did not elucidate this divergence. It can only be speculated that camels' closeness to humans' dwellings in these areas enhances their direct contact with canids feces in comparison with cattle, sheep and goats that migrate to more distant regions as large areas free-grazers.

During a five years span, in a temperate climatic environment (Slovakia), red foxes have been studied for E. multilocularis infection throughout the country (Miterpakova et al. 2006). Northern and central parts of the country had high-endemicity foci with an estimated prevalence of 30\% (Hurnikova et al., 2009). Climatic conditions, such as low temperature annual mean, high rainfall and soil humidity, in addition to the ecological condition for instance small mammals' density, all supported E. multilocularis's distribution and consequently tapeworm' prevalence. Similar results related to climate have been supported by other experimental studies from Japan and Germany (Matsumoto and Yagi, 2008; Hansen et al., 2004). However, an interesting study performed in an inferior arid climate (Patagonia, Argentina) revealed E. multilocularis egg survival under highly different climatic conditions (Thevenet et al., 2005). The authors exposed E. multilocularis eggs for 41 months to the external climate within a temperature range from 37 to $-3^{\circ} \mathrm{C}$ (mean annual temperature of $10^{\circ} \mathrm{C}$ ) that might support viability but against a very low level of precipitation $<300 \mathrm{~mm} /$ year! Experimental infection of ovines (at 1200 eggs/ovine challenge) with these "old" eggs resulted in a successful infection of $100 \%$ (4/4) showing their capacity to penetrate, settle down and start the post-oncospheral development, as proved by hepatic and pulmonary cyst formation. The authors explained this extended infectivity of "old"eggs as related to 
their semi-senescent stage. Indeed, Gemmel et al. (1987) proposed that the processes of egg maturation and ageing of taeniids (in his case T. hydatigena) continue in the environment and that the eggs might go through different stages during those processes: immature, mature, semi-senescent, senescent, and dead. An egg in semisenescent stage overcomes the pre-cystic immunity, settling down in the target organ and starting the development of the larva stage, though later, when larva is formed, it is destroyed by the post-cystic immunity, which was not the case in the E. multilocularis ovine infection.

In Austria, a study revealed that pet animals are also a suitable risk factor of E. multicularis in humans but not consuming mushrooms or certain wild berries growing near the ground. Cat ownership $(\mathrm{OR}=6.47)$ and hunting $(\mathrm{OR}=7.83)$ were the sole risk factors reported by this study (Kreidl et al., 1998). A study performed on red foxes' infection with Echinococcus multlocularis in Switzerland, an area defined as the core of the endemic range of this zoonotic cestode in Central Europe, revealed that intensity of infection in these animals decreased from rural and residential areas to the city (as densely urban area), suggesting a lower contamination of the urban environment (Fischer et al., 2005; Reperant et al., 2007). Similar results have been also reported in a northeast endemic area of France, suggesting that the decreasing gradient observed from rural to urban area is linked to behavior and feeding habits of the host (Robardet et al., 2008).

In more extreme environments such as arctic and sub-arctic regions, Rausch (2003) proposed four predator/prey patterns in relation to E. granulosus occurrence and infection. In these areas, the final and intermediary hosts are less diverse than in other climatic regions (wolves, dogs, elks, moose and reindeer). The four patterns are illustrated in Figure 4.2.2.4.2 and include wild transmission through predation, synanthropic and semi-synanthropic pathways related to humans' sedentary life (including consumption of cervid viscera by free-roaming canids) (Himsworth et al., 2010). Indeed, in Alaska, all cystic echinococcosis cases have been related to indigenous people and significantly decreased when herding and sled dogs were replaced by machines. In Russia, in the northeastern Siberia, an increase in cystic echinococcosis has been reported, suggesting the use of herding-dogs by the locals.

Romig et al. (2006) raised the issue of an anthropogenic factor involved in human alveolar echinococcosis. According to epidemiological studies, endemic regions have been linked to deforestation and agricultural practices that created favorable conditions for parasite's animal hosts (e.g., arvicolid rodents), for example: conversion of forests or crop fields into meadows/pastures in Europe, China and North America and overgrazing of natural grassland in central Asia. An excellent example has been provided by a study performed in Kazakhstan where a substantial increase in cystic echinococcosis was observed in recent years (Shaikenov et al., 2003). The primary factors involved in this process were: the degradation of the traditional nomadic system of livestock breeding, closing of large collective farms and establishment of small private farms (with year round stock) in closer proximity to human habitation, deserting routine anthelmintic prophylaxis of dogs; and inadequate control over the use and disposal of animal carcasses; and finally an increase in people and dog population per 1000 sheep. As a result, the prevalence of E. granulosus in village dogs was $5.8 \%$ while in shepherd dogs it reached $23.2 \%$ representing a high-risk source of human infection.

Additionally, wildlife disease control by interference with host population densities through hunting pressure shift and provision of new habitats (e.g., in urban areas) are anthropogenic too. Other possible anthropogenic involvements are: growth in domestic dog population (as pet animals) and their involvement in wildlife (contact with urban foxes); introduction of neozootic host species (red foxes in northern Japan to control voles); and accidental introduction of the parasite in non-endemic regions may also increase human transmission (Eckert and Deplazes, 2004; Jenkins et al., 2005). In relation to urban areas, a recent study showed that, besides red fox distribution, rodent intermediary hosts, such as Microtus spp. and Arvicola terrestris, are also dominant factors in spreading Echinococcus multilocularis 
in urbanized areas. Since Microtus spp. have been found to have an increased population density in urban wasteland and their red fox diet predominance, these rodents definitely play a key role in E. multilocularis transmission (Robardet, et al., 2011; Reperant et al., 2009).

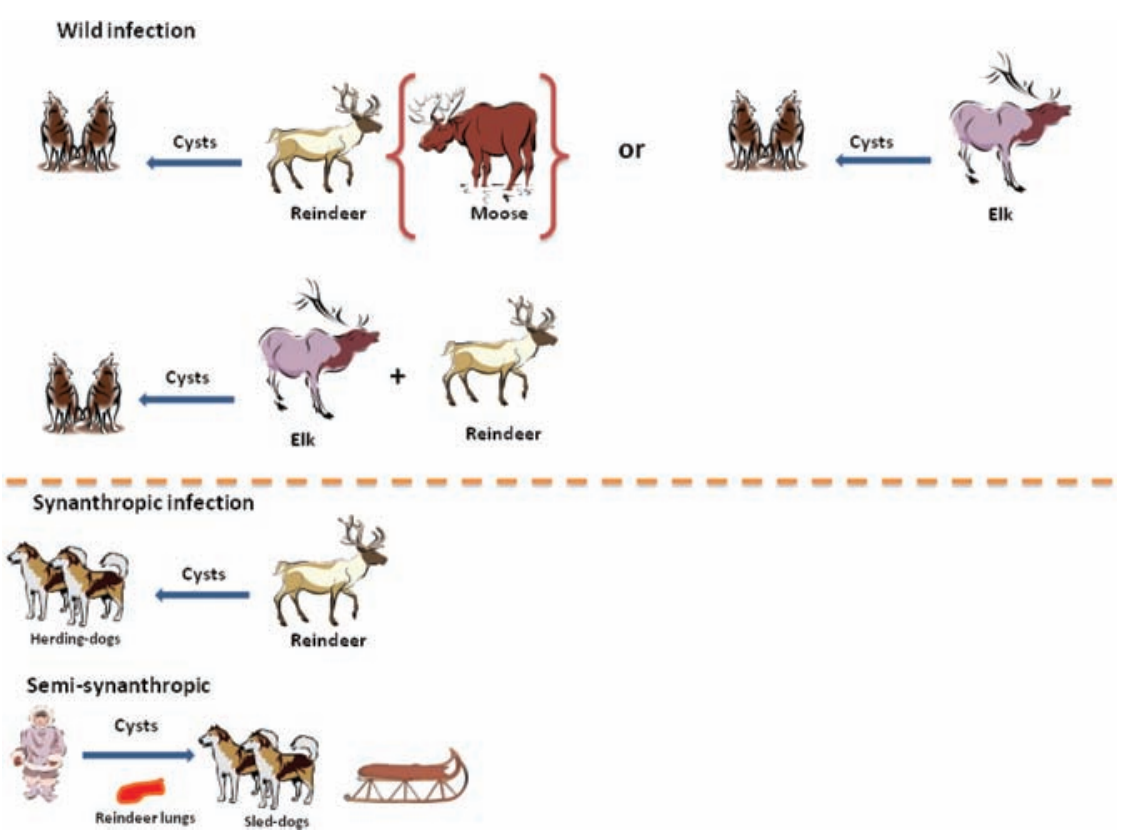

Figure 4.2.2.2. Cystic echinococcosis infection patterns in the Arctic and Sub-Arctic environments

A Japanese study targeted the Echinococcus multilocularis environmental contamination prevalence in an urban fringe-the Nopporo forest park of Sapporo city, Hokkaido, Japan (Lagapa et al., 2009). Their results of this study showed that Nopporo forest park in the urban fringe of Sapporo City, is a reservoir site with a high prevalence of zoonotic infective agents for alveolar echinococcosis, suggesting that interface habitats between forests or woodlands and open fields are indispensable for continued maintenance of E. multilocularis life-cycle.

\subsection{REFERENCES}

Deplazes, P. (2006) Ecology and epidemiology of Echinococcus multilocularis in Europe. Parassitologia 48, 37-39.

Eckert, J. \& Deplazes, P. (2004) Biological, epidemiological, and clinical aspects of echinococcosis, a zoonosis of increasing concern. Clin. Microbiol. Rev. 17, 107-135.

Fischer, C., Reperant, L.A., Weber, J.M., Hegglin, D. \& Deplazes, P. (2005) Echinococcus multlocularis infections of rural, residential and urban foxes (Vulpes vulpes) in the canton of Geneva, Switzerland. Parasite 12, 339-346.

Gemmel, M.A., Lawson, J.R. \& Roberts, M.G. (1987) Population dynamics in echinococcosis and cysticercosis: evaluation the biological parameters of Taenia hydatigena and comparison with those of Echinococcus granulosus. Parasitol. 94, 161-180.

Hansen, F., Jeltsch, F., Tackmann, K., Staubach, C. \& Thulke, H-H. (2004) Processes leading to a spatial aggregation of Echinococcus multilocularis in its natural intermediate host Microtus arvalis. Int. J. Parasitol. 34, 37-44. 
Hansen, H.J., Jama, F.M., Nilsson, C., Norrgren, L. \& Abdurahman, O.S. (1989) Silicate pneumoconiosis in camels (Camelus dromedarius L.). Zentralbl Veterinarmed A 36, 789-796.

Himsworth, C.G., Jenkins, E., Hill, J.E., Nsungu, M., Ndao, M. et al. (2010) Emergence of sylvatic Echinococcus granulosus as a parasitic zoonosis of public health concern in an indigenous community in Canada. Am. J. Trop. Med. Hyg. 82, 643-645.

Hurnikova, Z., Miterpakova, M., Chovancova, B. (2009) The important zoonoses in the protected areas of the Tatra National Park (TANAP). Wiad Parazytol 55, 395-398.

Jenkins, D.J., Fraser, A., Bradshaw, H. \& Craig, P.S. (2000) Detection of Echinococcus granulosus coproantigens in Australian canids with natural or experimental infection. J Parasitol 86, 140-145.

Jenkins, D.J., Romig, T. \& Thompson, R.C.A. (2005) Emergence/re-emergence of Echinococcus spp. -a global update. Int. J. Parasitol. 35, 1205-1219.

Kreidl, P., Allerberger, F., Judmaier, G., Auer, H., Aspock, H. \& Hall, A.J. (1998) Domestic pets as risk factors for alveolar hydatid disease in Austria. Am. J. Epidemiol. 147, 978-981.

Lagapa, J.T., Oku,Y., Kaneko, M., Ganzorig, S., Ono, T. et al. (2009) Monitoring of environmental contamination by Echinococcus multilocularis in an urban fringe forest park in Hokkaido, Japan. Environ Health Prev Med 14, 299-303.

Larrieu, E.J., Costa, M.T., del Carpio, M., Moguillansky, S., Bianchi, G. \& Yadon, Z.E. (2002) A case-control study of the risk factors for cystic echinococcosis among the children of Rio Negro province, Argentina. Ann Trop Med Parasitol 96, 43-52.

Matsumoto, J. \& Yagi, K. (2008) Experimental studies on Echinococcus multilocularis in Japan, focusing on biohazardous stages of the parasite. Exp. Parasitol. 119, 534-541.

Miterpakova, M., Dubinsky, P., Reiterova, K. \& Stanko, M. (2006) Climate and environmental factors influencing Echinococcus multilocularis occurrence in the Slovak Republic. Ann Agric Environ Med 13, 235-242.

Njoroge, E.M., Mbithi, P.M.F., Gathuma, J.M., Wachira, T.M., Gathura, P.B. et al. (2002) A study of cystic echinococcosis in slaughter animals in three selected areas of northern Turkana, Kenya. Vet. Parasitol. 104, 85-91.

Rausch, R.L. (2003) Cystic echinococcosis in the Arctic and Sub-Arctic. Parasitol. 127, S73-S85.

Reperant, L.A., Hegglin, D., Fischer, C., Kohler, L., Weber, J-M. \& Deplazes, P. (2007) Influence of urbanization on the epidemiology of intestinal helminths of the red fox (Vulpes vulpes) in Geneva, Switzerland. Parasitol. Res. 101, 605-611.

Reperant, L.A., Hegglin, D., Tanner, I., Fischer, C. \& Deplazes, P. (2009) Rodents as shared indicators for zoonotic parasites of carnivores in urban environments. Parasitol. 136, 329-337.

Robardet, E., Giraudoux, P., Caillot, C., Augot, D., Boue, F. \& Barrat, J. (2011) Fox defecation behaviour in relation to spatial distribution of voles in an urbanised area: An increasing risk of transmission of Echinococcus multilocularis?. Int. J. Parasitol. 41, 145-154.

Robardet, E., Giraudoux, P., Caillot, C., Boue, F., Cliquet, F. et al. (2008) Infection of foxes by Echinococcocus multilocularis in urban and suburban areas of Nancy, France: influence of feeding habits and environment. Parasite 15, 77-85.

Romig, T., Thoma, D. \& Weible, A-K. (2006) Echinococcus multilocularis-a zoonosis of anthropogenic environments?. J. Helminthol. 80, 207-212.

Shaikenov, B.S., Torgerson, P.R., Usenbayev, A.E., Baitursynov, K.K., Rysmukhambetova, A.T. et al. (2003) The changing epidemiology of echinococcosis in Kazakhstan due to transformation of farming practices. Acta Trop. 85, 287-293.

Thevenet, P.S., Jensen, O., Drut, R., Cerrone, G.E., Grenovero, M.S. et al. (2005) Viability and infectiousness of eggs of Echinococcus granulosus aged under natural conditions of inferior arid climate. Vet. Parasitol. 133, 71-77.

Thompson, R.C.A., Kapel, C.M.O., Hobbs, R.P. \& Deplazes, P. (2006) Comparative development of Echinococcus multilocularis in its definitive hosts. Parasitol. 132, 709-716.

Veit, P., Bilger, B., Schad, V., Schafer, J., Frank, W. \& Lucius, R. (1995) Influence of environmental factors on the infectivity of Echinococcus multilocularis eggs. Parasitol. 110, 79-86.

Vuitton, D.A., Zhou, H., Bresson-Hadni, S., Wang, Q., Piarroux, M. et al. (2003) Epidemiology of alveolar echinococcosis with particular reference to China and Europe. Parasitol. 127, S87-S107. 


\section{Chapter 4.2.2.5 Hymenolepiasis}

\section{[HYMENOLEPSIS NANA (H. FRATERNA), H. DIMINUTA]}

Hymenolepsias is an intestinal infection caused by one of the universally most common cestode: Hymenolepsis nana. H. fraterna is present in rodents and seems to be a different strain of the same species as $H$. nana. $H$. diminuta that is mainly found in rats and rarely causes human infections. Among tapeworms, $H$. nana is the smallest, also nicknamed "dwarf tapeworm" and has another unique attribute: it is the only cestode that does not need an intermediate host. Transmission occurs by eggs oral ingestion (including autoinfection and person to person) or rarely by intake of insects which contain the cysticercoid infective stage in their body. The life cycle of $H$. nana includes egg ingestion followed by oncospheres hatching in the villi of the host small intestine. Oncospheres penetrate the villi to develop into cysticercoides that later emerge from tissue to develop further into adult tapeworms (adult life span $\sim 2$ months) (Figure 4.2.2.5.1). Eggs containing progloditts are released in feces; however, if constipation occurs, larvae can hatch in intestine to repeat the infectious cycle again without leaving the host. Clinical manifestations depend on infection load: infections with low number of worms are mostly asymptomatic while heavy infestation ( $>100$ worms) cause villi atrophy with mucosal inflammation, abdominal pain, spongy feces, diarrhea, weakness, anxiety, headache and weight loss.

\subsection{HYMENOLEPIASIS AND ENVIRONMENT}

According to its life cycle, $H$. nana is mostly prevalent in places with low hygienic standards. H. nana eggs are not resistant to environmental stresses, and therefore most infections will frequently occur from soiling, for instance in nurseries as a result of direct contact with contaminated feces. Infections, yet rare, with $H$. diminuta (a rat and mice parasite) occur by accidental ingestion of arthropods (e.g., beetles and myriapods) that may carry cystercoides. A study of intestinal parasitic infections was carried out in two rural communities of Nigeria (Agi, 1997). Hymenolepsis nana had a low prevalence (2.9\%) compared to other parasitic helminths. An important feature presented by the author was the relation between toilet facilities and parasitic infections in decreasing order (from the most promiscuous to the safest): bush, shoreline, pit, bucket and water closet. In relation to drinking water, the safest water was piped water 
versus well, while other differences between the two communities were also linked to climatic and edaphic factors (soil salinity) that impact the parasites' survival (even if this is not the case of H. nana).

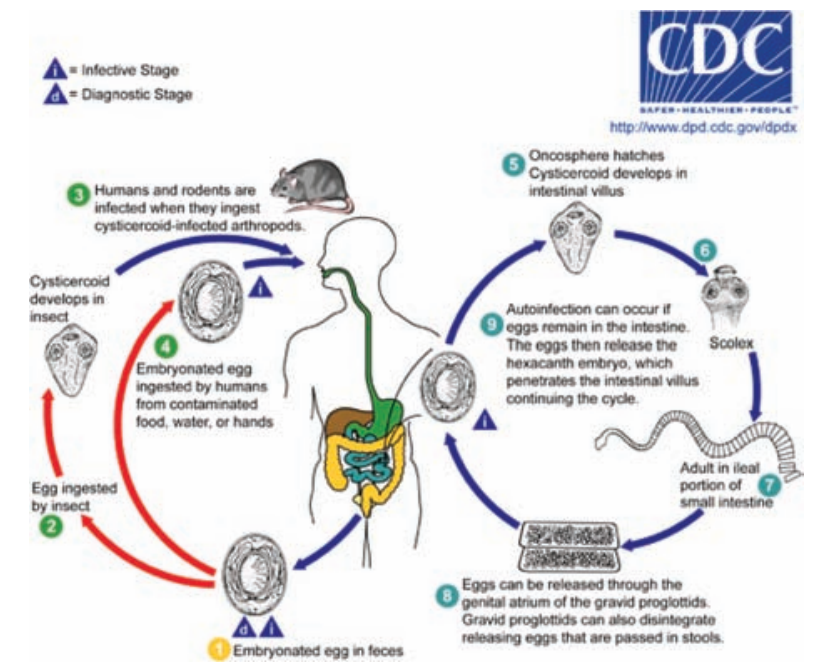

Figure 4.2.2.5.1. Hymenolepis nana life cycle (with permission from CDC, Atlanta, USA; http://www.dpd.cdc. gov/dpdx/HTML/Hymenolepiasis.htm)

Gamboa et al. (2009) compared urban, suburban and rural areas of Buenos Aires (Argentina) for geohelminths species and socioenvironmental conditions. H. nana was found to have the highest frequency in one of the suburbs. The authors, once more emphasized that "poor hygiene habits in food preparation and toileting, overcrowding, walking barefoot, and dwellings with dirt floors were significantly associated with a higher frequency of intestinal geohelminths and pseudogeohelminths". Perhaps, here is the place to mention that poverty (not a rare attribute around the globe) is one of the main reasons for parasitic infections, diarrhea and premature death. In Honduras, Kaminsky (1991) performed a longitudinal study of children from rural and marginal barrio (city suburb-Sp.) linked to diarrheotic episodes. Hymenolepis nana was found in $8 \%$ of the children most often in combination with protozoan or other helminthic parasite. Again, the recognized risk factors were environmental high fecal contamination, lack of potable water, education and poor housing. The marginal barrio was more affected than the rural villages, likely to a large extent due to overcrowding.

Finally, a study performed in Aden indicated the increased numbers of Indian house crows (Corvus splendens) as a possible source of environmental contamination with bacterial pathogens, parasitic protozoa and helminths. Among the parasites isolated, Hymenolepis nana ova were recovered too (el Salami, 1991). These findings are not surprising in light of the fact that crows do feed on carcasses of rodents and other animals, spreading their droppings close to human habitats.

\subsection{REFERENCES}

Agi, P.I. (1997) Comparative helminth infections of man in two rural communities of the Niger Delta, Nigeria. West Afr J Med 16, 232-236. 
al-Sallami, S. (1991) A possible role of crows in the spread of diarrhoeal diseases in Aden. J Egypt Public Health Assoc 66, 441-449.

Gamboa, M.I., Kozubsky, L.E., Costas, M.E., Garraza, M., Cardozo, M.I. et al. (2009) Associations between geohelminths and socioenvironmental conditions among different human populations in Argentina. Rev. Panam. Salud Publica 26, 1-8.

Kaminsky, R.G. (1991) Parasitism and diarrhoea in children from two rural communities and marginal barrio in Honduras. Trans. R. Soc. Trop. Med. Hyg. 85, 70-73. 


\section{Chapter 4.2.2.6 Sparganosis}

\section{[SPIROMETRA GENUS, S. MANSONI, S. RANARUM, S. MANSONOIDES AND S. ERINACEI, AND THE ABERRANT SPARGANUM PROLIFERUM]}

In humans, sparaganosis is an accidental rare disease caused by Spirometra genus tapeworms. Cases have been reported around the globe, however China, Japan and other Southeast Asian countries have higher prevalence (Nithiuthai et al., 2004; Park et al., 2001). Transmission occurs by ingestion of larvae found in the first or second intermediate host (via water or consumption of an undercooked second intermediate host) (Yoshimura, 1989). In the Far East, an extra infection route has been observed linked to traditional healing: application of raw, chopped frog meat on wounds, ulcers or eyes, all allowing active invasion of the patient. The life cycle of these parasites is linked to water sources and two intermediary hosts related to parasite. Predators (cats, dogs, birds, wild carnivores, etc.) harboring adult tapeworms excrete unembryonated eggs into water. In water eggs embryonate and coracidia hatch to be further ingested by crustaceans. In the crustaceans' body cavity, procercoid larvae develop and when ingested together with their hosts (crustaceans, e.g., Cyclops spp.) by a second intermediary host (fish, reptile or amphibian) they are released and further develop into plerocercoid larvae. When a predator (including humans accidentally) ingests the first or the second intermediary host, the plerocircoides larvae develop into mature tapeworms in a subcutaneous tissue following passage through intestinal wall (Figure 4.2.2.6.1). Clinical manifestations are subcutaneous painful migratory nodules, inflammation, edema, ophtalmodynia, lacrimation, ptosis (in eye infection), headache, seizures, etc. (in brain infection).

\subsection{SPARGANOSIS AND ENVIRONMENT}

In China, sparganosis is an emerging helmithiasis due to food consumption habits as well treatment of wounds and lesions with frog and snake flesh poultices (Li et al., 2011; Wiwanitkit, 2005). A Chinese study on the frog Rana nigromaculata infection with tapeworms reported a $16 \%$ prevalence of Spirometra mansoni (the tapeworm causing spaganosis in humans) in these amphibians (Mao et al., 2009). Lin et al. (2010) looked experimentally at several parameters involved in sparganosis cycle. Cyclops, tadpoles and mature frogs have been infected with spargana revealing an infection rate of 3.5\%, 35.9\% and $16.8 \%$, respectively. In 
predators (cats but mostly dogs), the Spirometra mansoni experimental infection rate was 20\% with fecal eggs excretion, revealing a high prevalence of this tapeworm in intermediate and final hosts. The authors concluded that local residents' eating habits include tadpoles, thereby increasing human infection risk. In Australia, free-ranging amphibians of the group tree frogs (e.g., Litoria caerulea, L. aurea, L. gracilenta and L. peronii) have been found to be heavily infected with spargana of Spirometra erinacei (Berger et al., 2009). According to these authors, the infection of tree frogs with spargana is now a serious recognized threat for free-ranging frogs, with unknown consequences to other wildlife.

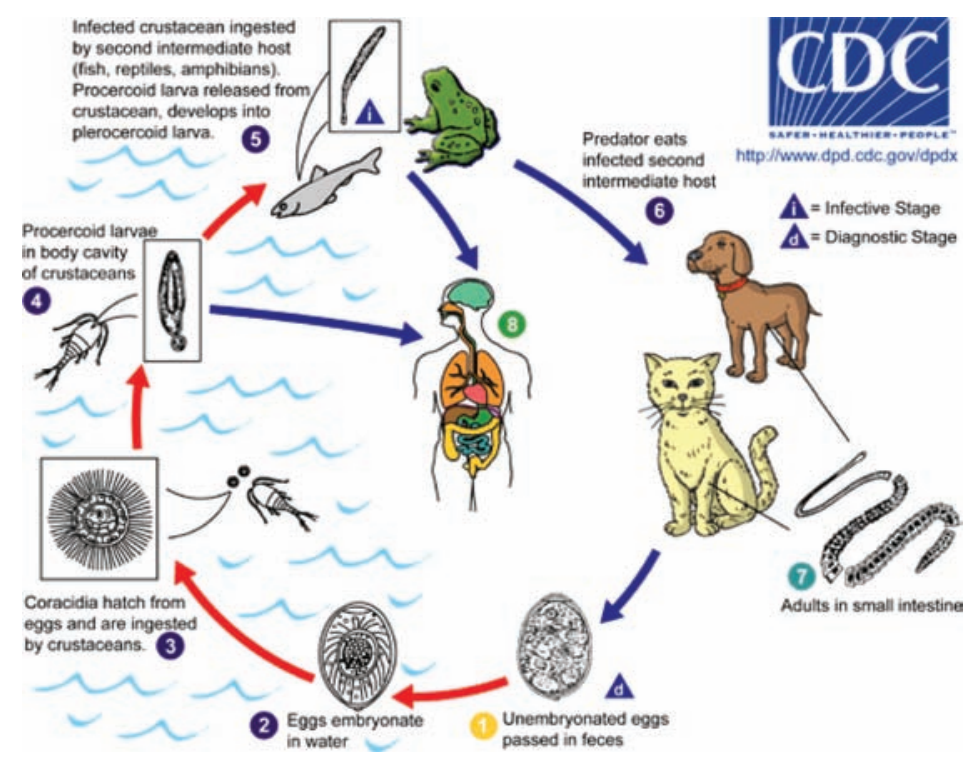

Figure 4.2.2.6.1 Spirometra genus life cycle (with permission from CDC, Atlanta, USA; http://www.dpd.cdc. gov/dpdx/HTML/Sparganosis.htm)

\subsection{REFERENCES}

Berger, L., Skerratt, L.F., Zhu, X.Q., Young, S. \& Speare, R. (2009) Severe sparganosis in Australian tree frogs. J. Wildl. Dis. 45, 921-929.

Li, M.W., Song, H.Q., Li, C., Lin, H.Y., Xie, W.T. et al. (2011) Sparganosis in mainland China. Int. J. Infect. Dis.15, e154-e156.

Lin, X.M., Liu, C.J., Zhang, H.W., Zheng, L.Y., Yan, Q.Y. et al. (2010) Epidemiological investigation on sparganosis mansoni and animal experiments. Zhongguo Ji Sheng Chong Xue Yu Ji Sheng Chong Bing Za Zhi 28, 132-134.

Mao, J.Z., Zhou, B.J., Wang, K.G. \& Wen, M. (2009) Field investigation of sparganosis in frogs in Huaxi area. Zhongguo Ji Sheng Chong Xue Yu Ji Sheng Chong Bing Za Zhi 27, 187-188.

Nithiuthai, S., Anantaphruti, M.T., Waikagul, J. \& Gajadhar, A. (2004) Waterborne zoonotic helminthiases. Vet. Parasitol. 126, 167-193.

Park, H.Y., Lee, S.U., Kim, S.H., Lee, P.C., Huh, S. et al. (2001) Epidemiological significance of sero-positive inhabitants against sparganum in Kangwon-do, Korea. Yonsei Med. J. 42, 371-374.

Wiwanitkit, V. (2005) A review of human sparganosis in Thailand. Int. J. Infect. Dis. 9, 312-316.

Yoshimura, K. (1989) Parasitic zoonoses in Japan, with special reference to the current topics. Rinsho Byori 37, $1221-1230$. 


\section{Chapter 4.2.2.7}

\section{Taeniasis Saginata (Including Taeniasis Asiatica)}

\section{[TAENIA SAGINATA SAGINATA, TAENIA SAGINATA ASIATICA]}

Taeniasis saginata is a disease caused by infection with the beef tapeworm Taenia saginata saginata that parasitizes mainly cattle. Humans are the final and exclusive hosts. T. saginata asiatica is a subspecies that is outspread in Southeast Asia. Transmission in humans occurs by consumption of raw or undercooked beef or contaminated reindeer meat containing cysterci. The life cycle of this tapeworm is too linked to its transmission. T. saginata/asiatica eggs are shed in mature proglottids within feces. In different environments where they can survive for months, an intermediary host (cattle or other ruminants) ingests eggs that hatch to produce larvae (oncospheres) in the intestine. Oncospheres penetrate the intestine wall and are spread hematogenously into striated musculature (diaphragm, heart, masseters) to develop further into cysterci in the infected animal muscles. After human ingestion of cysterci by consumption of infected beef or pork (see further on T. solium), cysterci avert their scoleces to attach to upper small intestine mucosa and initiate formation of proglottids (Figure 4.2.2.7.1). In humans as final host, $T$. saginata can survive between 30 to 40 years. T. saginata asiatica in an intermediary host is primarily found in liver and other peritoneal organs.

Clinical manifestations do not show clear symptoms (beside discomfort and embarrassment due to proglottids anal crawling), nevertheless obstruction, diarrhea, hunger pain and weight loss have been already reported.

\subsection{TAENIASIS SAGINATA AND ENVIRONMENT}

From the environmental aspect, improper excrement disposal is the main cause of these infections. Pastures treated with feces or irrigated with inadequately treated wastewater or exposed to incidental floods are the major focuses of cattle infestation. Taenia saginata eggs are able to pass sewage treatment thereby spreading them through irrigation or sludge application on soil and vegetation it allows their persistence and survival for months (5 to 6 months in Denmark) (Ilsoe et al., 1991). Arthropods and birds have been 
also suggested as vectors of $T$. saginata eggs dissemination. In an intensive epidemiological study, Ilsoe et al. (1990) identified the main sources of herd infection in Denmark. The most frequent sources of infection were reported to be sludge from septic tanks illegally applied on pasture or crops, in some cases after having been mixed with animal slurry! In contrast to earlier observations, application on farmland of sewage sludge from municipal treatment plants was not involved in any of the reported outbreaks, due to a more effective egg oval treatment. Animals in permanently housed herds were infected through fodder or by contamination of the indoor environment by slurry containing Taenia eggs. Other herds were infected by grazing on pastures located in close proximity to municipal sewage treatment plants. Sludge application on grazing pastures and short retention time proved to increase infection risk of cattle and humans (Cabaret et al., 2002).

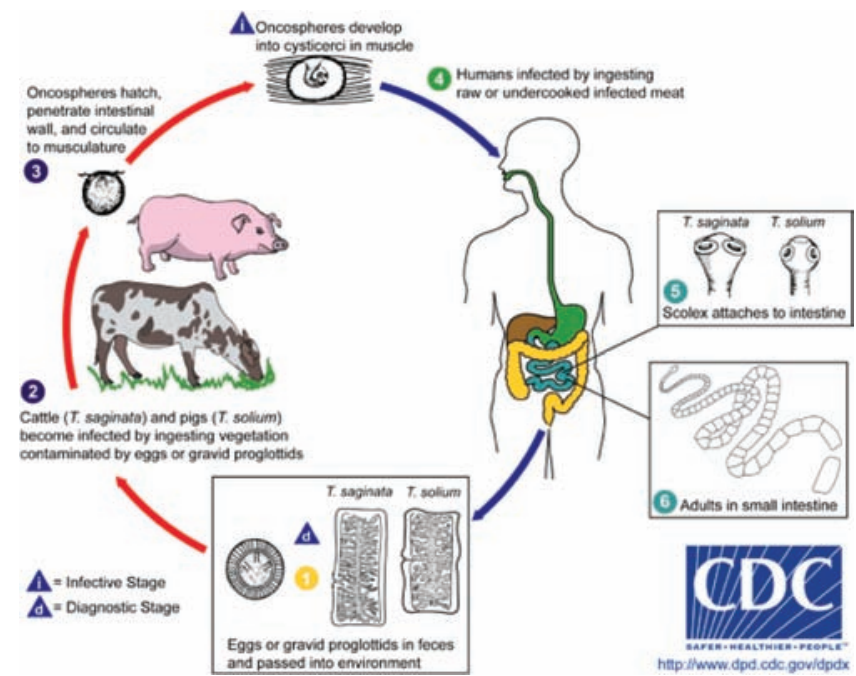

Figure 4.2.2.7.1. Taenia saginata life cycle (with permission from CDC, Atlanta, USA; http://www.dpd.cdc. gov/dpdx/HTML/Taeniasis.htm)

Pastures also harbor earthworms and insects (dung beetles). Lonc (1980a; 1980b) inoculated earthworms and dung beetles with $T$. saginata eggs and followed their intestinal transmission in these organisms. He concluded that tapeworms' eggs may be transmitted by the digestive tracts of earthworms (contributing to eggs' horizontal and vertical spreading in soil) and dung beetles (through passive transmission for long distances), consequently playing an important role in the epizootiology of cysticercosis in cattle.

Slaughterhouses are also to be blamed for the spread of this parasite, mainly due to poor veterinary inspection and even the illegal action of selling infested beef (Ring, 1992). In Poland, a study has been carried out to find taeniasis' prevalence rate in two environments: urban and rural. According to this study results, the incidence rate was higher in urban than in rural residents (Krol-Pakulska et al., 2000). It is very possible that higher urban incidences are linked to some slaughter houses decribed above that may spread contaminated meat to a larger number of people in comparison with rural areas where slaughtering is on a smaller scale and usually performed locally.

Finally, Dutto et al. (2009) have described recently an interesting aspect linked to infection sources. These authors described a case of teniasis in a child attending primary school (Piedmont Region, Italy) 
where several proglottids had been repeatedly found by cleaners on the book box of several school desks in the same classroom. Laboratory tests showed that the isolated proglottids belonged to T. saginata tapeworm. In the subsequent year, the same authors reported another case of teniasis caused by Taenia saginata (tapeworm) in a pediatric patient with done-on-purpose dispersion of proglottids (by another child carrier) that happened in an elementary school (also in Piedmont Region, Italy) (Dutto et al., 2010). Immigrant workers who carry these parasites and employed in developed countries are also a source of transmission and infection, in spite of general first-rate environmental management in these countries (Vogtle-Junkert, 1975).

\subsection{REFERENCES}

Cabaret, J., Geerts, S., Madeline, M., Ballandonne, C. \& Barbier, D. (2002) The use of urban sewage sludge on pastures: the cysticercosis threat. Vet. Res. 33, 575-597.

Dutto, M., Giovanetti, F. \& Pellegrino, A. (2009) Teniasis in a child with finding of Taenia saginata proglottids in the school environment: a case report. Ann Ig 21, 183-186.

Dutto, M., Sapino, G., Giovanetti, F. \& Pellegrino, A. (2010) Environmental spread of taenia proglottids: an atypical yet interesting public health problem in schools. Ann Ig 22, 539-544.

Ilsoe, B., Kyvsgaard, N.C., Nansen, P. \& Henriksen, S.A. (1990) A study on the survival of Taenia saginata eggs on soil in Denmark. Acta Vet. Scand. 31, 153-158.

Ilsoe, B., Kyvsgaard, N.C., Nansen, P. \& Henriksen, S.A. (1990) Bovine cysticercosis in Denmark. A study of possible causes of infection in farms with heavily infected animals. Acta Vet. Scand. 31, 159-168.

Krol-Pakulska, E., Pakulski, C. \& Szmid, J. (2000) Evaluation of taeniasis prevalence in the area supervised by the Provincial Sanitary-Epidemiological Unit in Szczecin between 1994 and 1998. Med. Sci. Monit. 6, 746-750.

Lonc, E. (1980a) The possible role of the soil fauna in the epizootiology of cysticercosis in cattle. I. Earthworms-the biotic factor in a transmission of Taenia saginata eggs. Angew Parasitol 21, 133-139.

Lonc, E. (1980b) The possible role of the soil fauna in the epizootiology of cysticercosis in cattle. II. Dung beetles-a biotic factor in the transmission of Taenia saginata eggs. Angew Parasitol 21, 139-144.

Ring, C. (1992) Environmental and food hygiene aspects of cestode infections of humans. DTW. Dtsch. Tierarztl. Wochenschr. 99, 295-297.

Vogtle-Junkert, U. (1975) Evaluation of helminth carrier rates among foreign workers (author's transl). Med Klin 70, 1920-1927. 


\section{Chapter 4.2.2.8}

\section{Taeniasis Solium and Cysticercosis}

\section{[TAENIA SOLIUM]}

Another human taeniasis is caused by the pork tapeworm Taenia solium. This cestode uses pigs as predominant intermediate hosts and humans as the definitive ones. The geographic distribution is linked to pigs growing farms or other pig related facilities. Endemicity of taeniasis can be found in Central and South America, Southern and Eastern Europe, Africa and Southeast Asia. Industrial countries have a much lower rate of infections due to regular controlled inspection of pork meat and advanced pig farming. Main human transmission occurs when infected pork meat is ingested; however, autoinfections as a consequence of insufficient personal hygiene have been also reported, as well as infections through close contact with infected persons (Somers et al., 2006; Flisser, 1991). The life cycle of this tapeworm is as follows. T. solium eggs are shed in mature proglottids within pig feces. In different environments, where they can survive for months, eggs are ingested by an intermediary host (pigs) and hatch to produce larvae (oncospheres) in the intestine. Oncospheres penetrate the intestine wall and hematogenously are spread in the striated musculature (diaphragm, heart, masseters) to develop further into cysterci in the animal's muscles. Subsequent to human ingestion of cysterci via consumption of infected pork, they avert their scoleces to attach to upper small intestine mucosa and start formation of proglottids (Figure 4.2.2.8.1). It should be mentioned that oncospheres reveal distinct neurotropism especially toward brain hemispheres but also eyes. In humans as final host, T. solium can survive up to 25 years. Clinical manifestations with adult worms do not show severe symptoms besides abdominal discomfort, indigestion or constipation, diarrhea, and hunger pain. The severity of the disease (cystercosis) differs with infection site: cerebral cysterci may cause reduced consciousness and personality changes, while multiple infections is fatal; intraventricular cysts may cause intracerebral pressure, nausea, vomiting, up to occlusive hydrocephalus, chronic meningitis, cerebral infarcts, neuritis; spinal cord cystercosis may cause paresis; heart cystercosis may cause myocarditis, etc.

\subsection{TAENIASIS SOLIUM AND CYSTICERCOSIS AND ENVIRONMENT}

$T$. solium should be rigorously prevented in comparison with $T$. saginata in consequence of infections that are more serious including their outcome in humans (neurocysticercosis, etc.). Epidemiologically, it is clear 
that $T$. solium can be easily prevented by adequate control of the environmental and social behavior factors (Joshi et al., 2001). Environmental factors found to be involved in the spread of this parasite are water, sludge application onto pastures, soil, lack of sanitary toilet, earthen floor, pigs scavenging freely and contact with pigs' feces (Gweba et al., 2010; Sanchez et al., 1998). In Mexico, a study carried out in a rural community showed a high pig cysticercosis $(32.8 \%)$ and even higher human seroprevalence $(43.8 \%)$ (Fleury et al., 2006). Among the seroprevalent persons, 9.1\% were diagnosed with neurocysticercosis but mostly asymptomatic. Also in Mexico, another study showed that the main risk factor identified for porcine cysticercosis was free-range husbandry that enables access to human faeces (Rodriguez-Canul et al., 1999). In Nepal, another endemic area of taeniasis, epidemiological assessment showed that $T$. solium infections are highly linked to: 1) meat producers and sellers; 2) animals' access to human feces in pig husbandry; and 3) nonhygienic slaughterhouses (Joshi et al., 2001).

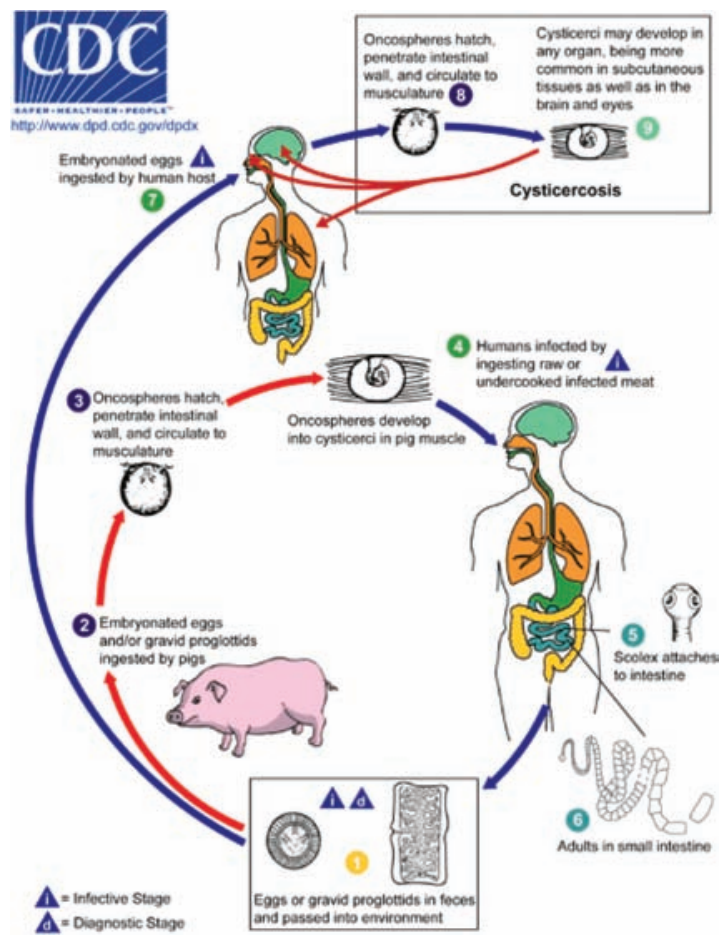

Figure 4.2.2.8.1. Taenia solium life cycle (with permission from CDC, Atlanta, USA; http://www.dpd.cdc. gov/dpdx/HTML/ImageLibrary/Cysticercosis_il.htm)

\subsection{REFERENCES}

Fleury, A., Morales, J., Bobes, R.J., Dumas, M., Yanez, O. et al. (2006) An epidemiological study of familial neurocysticercosis in an endemic Mexican community. Trans. R. Soc. Trop. Med. Hyg. 100, 551-558.

Flisser, A. (1991) Taeniasis-cysticercosis: an introduction. Southeast Asian J. Trop. Med. Public Health 22, 233-235.

Garcia, H.H., Gilman, R.H., Gonzalez, A.E., Pacheco, R. Verastegui, M. \& Tsang, V.C. (1999) Human and porcine Taenia solium infection in a village in the highlands of Cusco, Peru. Acta Trop. 73, 31-36. 
Gweba, M., Faleke, O.O., Junaidu, A., Fabiyi, J.P. \& Fajinmi, A.O. (2010) Some risk factors for Taenia solium cysticercosis in semi-intensively raised pigs in Zuru, Nigeria. Vet. Ital. 46, 57-67.

Joshi, D.D., Poudyal, P.M., Jimba, M., Mishra, P.N., Neave, L.A. \& Maharjan, M. (2001) Controlling Taenia solium in Nepal using the PRECEDE-PROCEED model. Southeast Asian J. Trop. Med. Public Health 32, 94-97.

Rodriguez-Canul, R., Fraser, A., Allan, J.C., Dominguez-Alpizar, J.L., Argaez-Rodriguez, F. \& Craig, P. S. (1999) Epidemiological study of Taenia solium taeniasis/cysticercosis in a rural village in Yucatan state, Mexico. Ann Trop Med Parasitol 93, 57-67.

Sanchez, A.L., Medina, M.T. \& Ljungstrom, I. (1998) Prevalence of taeniasis and cysticercosis in a population of urban residence in Honduras. Acta Trop. 69, 141-149.

Somers, R., Dorny, P., Nguyen, V.K., Dang, T.C.T., Goddeeris, B. et al. (2006) Taenia solium taeniasis and cysticercosis in three communities in north Vietnam. Trop. Med. Int. Health 11, 65-72. 


\section{Chapter 4.2.2.9}

\section{Other Intestinal Cestode Infections}

\section{[BERTIELLA SPP., RAILLIENTINA SPP., INERMICAPSIFER MADAGASCARIENSIS, I. CUBENSIS, MESOCESTOIDES VARIBILIS, M. LINEATUS, DIPLOGONOPORUS GRANDIS]}

Bertiella spp. (studeri and mucromata) were isolated from non-human primates; therefore, infections in humans (mostly in children) occur in South America, Africa and Asia where these animals are distributed (Howells et al., 2011). Transmission is by accidental ingestion of the intermediate hosts (free-living mites-Oribatidae). Raillientina spp. (dermerariensis, asiatica, etc.) are tapeworms distributed in rodents, primates and humans (Figure 4.2.2.9.1). Intermediated hosts are insects (flour and corn beetles and cockroaches). Inermicapsifer madagascariensis (I. cubensis) cestodes are found in small rodents of tropical areas (Africa, Asia, Madagascar and Caribbean area) (Goldsmid and Muir, 1972; Gonzalez et al., 1996; Hira, 1978). Free-living mites seem to be the intermediary hosts. Mesocestoides varibilis and M. lineatus are found in Africa, Asia, North and South America infecting humans, and yet other carnivores are their final hosts whereas free-living oribatid mites are the first intermediary hosts and various mammals (rodents), birds, amphibians and reptiles are the secondary intermediate hosts (Figure 4.2.2.9.2). Ingestion of undercooked viscera or the whole animal infected with these tapeworms induce infection in humans. Among this group of miscellaneous cestodes, Diplogonoporus grandis is the only one attributed to marine mammals such as whales (as final host). The intermediate hosts are saltwater fishes that also infect humans via uncooked or raw fish ingestion (most reports coming from Japan) with a life cycle similar to D. latum (see Figure 4.2.2.9.3). Clinical symptoms in humans are rare but massive cestodal intestinal colonization can cause abdominal pain, obstruction, diarrhea and nausea.

\subsection{OTHER INTESTINAL CESTODES AND ENVIRONMENT}

In the western part of Iran, different carnivores (dogs, foxes and jackals) have been studied for their intestinal helminthic content (Dalimi et al., 2006). Among human infectious miscellaneous cestodes, Mesocestoides lineatus, were isolated at high frequency; in stray dogs (26.5\%), red foxes (81.82\%) and jackals (70\%). In Costa Rica, Rodriguez et al. (2000) surveyed the helimithological fauna of cotton rat (Sigmodon hispidus) 


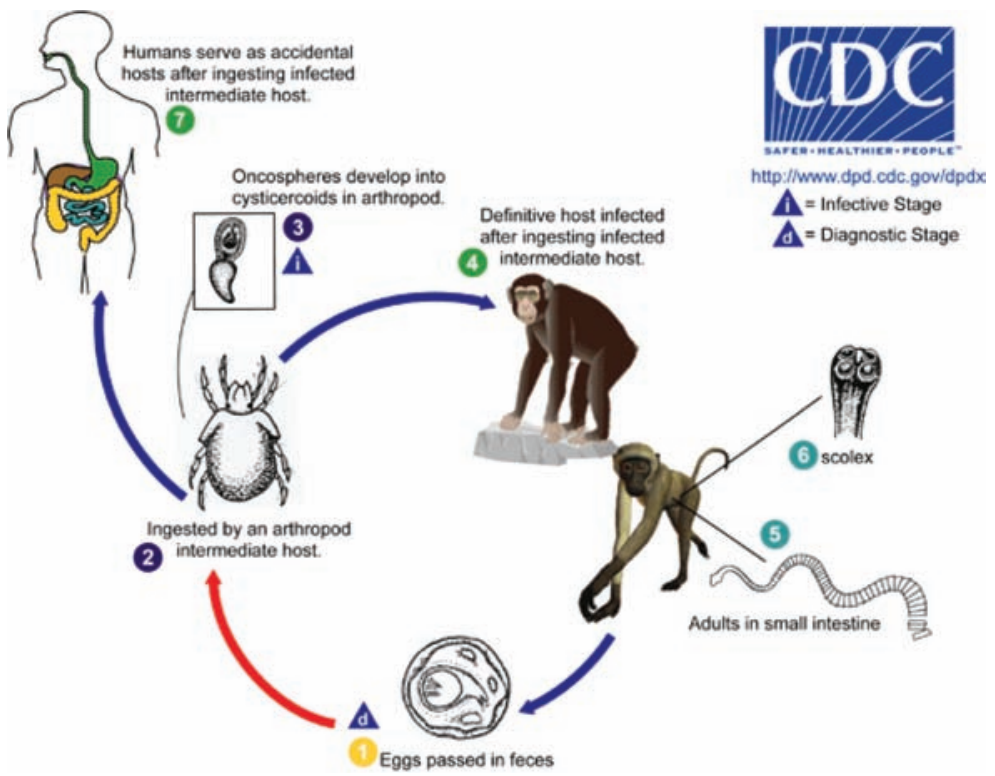

Figure 4.2.2.9.1 Bertiella spp. life cycle (with permission from CDC, Atlanta, USA; http://www.dpd.cdc. gov/dpdx/HTML/ImageLibrary/Bertiella_il.htm)

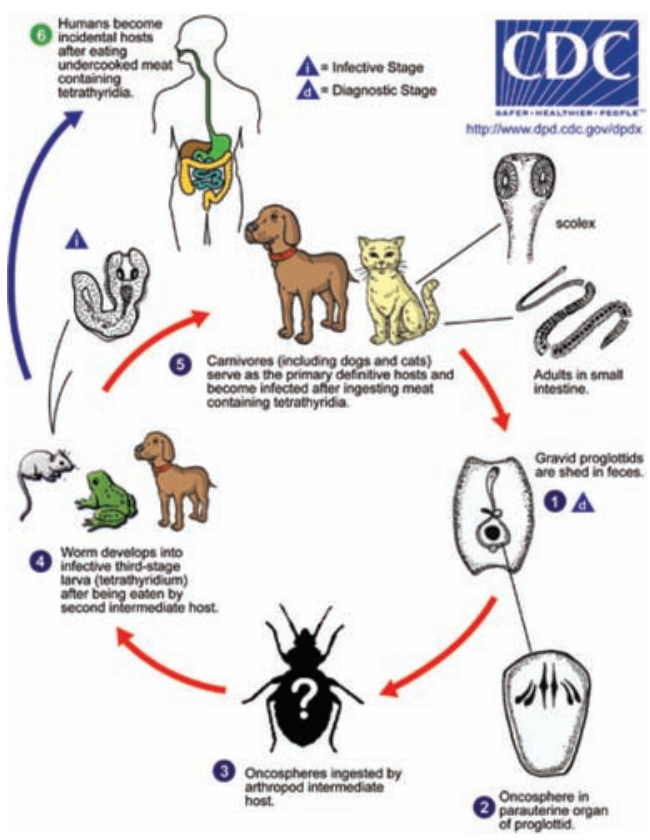

Figure 4.2.2.9.2. Mesocestoides spp. life cycle (with permission from CDC, Atlanta, USA; http://www.dpd. cdc.gov/dpdx/HTML/ImageLibrary/Mesocestoidiasis_il.htm) 
known to be related to the habitat and feeding behavior of this rodent. Indeed, Raillietina spp. colonized cotton rats from extensive dry lands with high temperatures offering a heterogeneous diet, but not those cotton rat species originating from pineapple plantation with humid and mild temperatures.

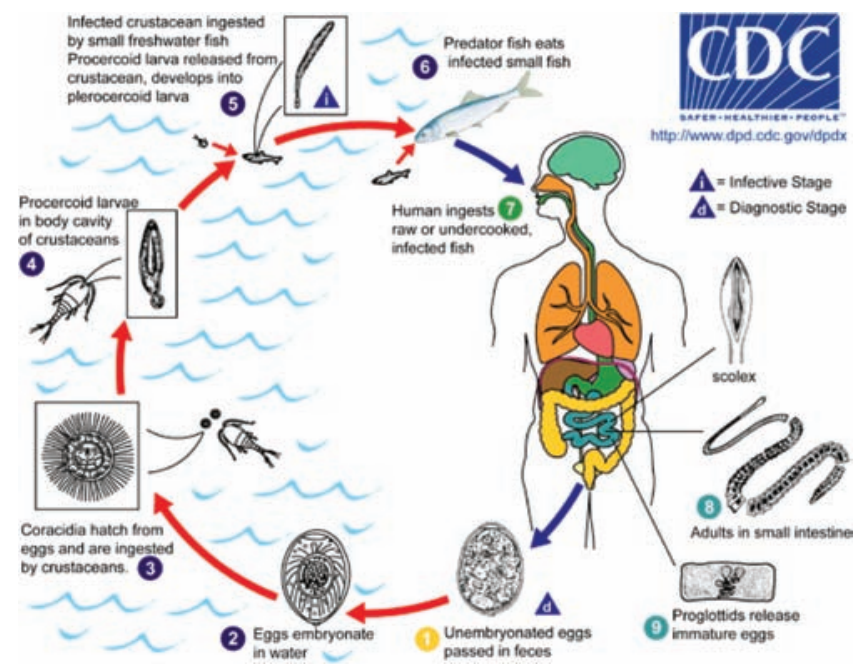

Figure 4.2.2.9.3. Diphyllobothrium latum life cycle (with permission from CDC, Atlanta, USA; http://www.dpd. cdc.gov/dpdx/HTML/ImageLibrary/Diphyllobothriasis_il.htm)

\subsection{REFERENCES}

Dalimi, A., Sattari, A. \& Motamedi, Gh. (2006) A study on intestinal helminths of dogs, foxes and jackals in the western part of Iran. Vet. Parasitol. 142, 129-133.

Goldsmid, J.M. \& Muir, M. (1972) Inermicapsifer madagascariensis (davaine, 1870), baer, 1956 (platyhelminths: cestoda) as a parasite of man in Rhodesia. Cent Afr J Med 18, 205-207.

Gonzalez, N.I., Diaz, J.M. \& Nunez, F.F. (1996) Infection by Inermicapsifer madagascariensis (Davaine, 1870); Baer, 1956. A report of 2 cases. Rev Cubana Med Trop 48, 224-226.

Hira, P.R. (1978) Some helminthozoonotic infections in Zambia. Afr J Med Med Sci 7, 1-7.

Howells, M.E., Pruetz, J. \& Gillespie, T.R. (2011) Patterns of gastro-intestinal parasites and commensals as an index of population and ecosystem health: the case of sympatric western chimpanzees (Pan troglodytes verus) and guinea baboons (Papio hamadryas papio) at Fongoli, Senegal. Am. J. Primatol. 73, 173-179.

Rodriguez, B., Gonzalez, R. \& Chinchilla, M. (2000) Parasitic helminths from Sigmodon hispidus (Rodentia: Cricetidae) from seasonal and evergreen habitats in Costa Rica. Rev. Biol. Trop. 48, 121-123. 


\section{Chapter 4.2.3}

\section{Nematodes}

A summary of nematodes global infection burden is presented in Table 4.2.3.1. 


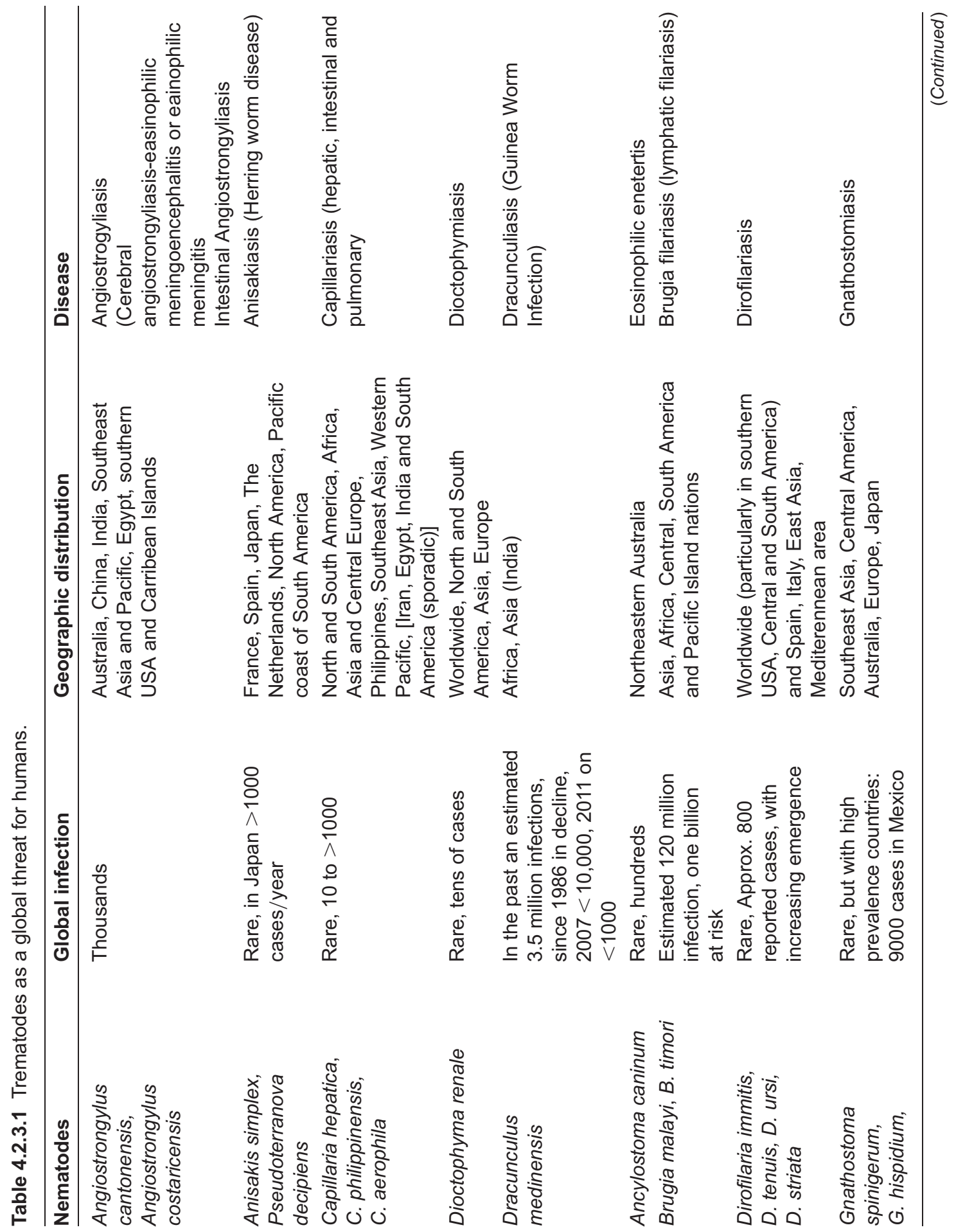




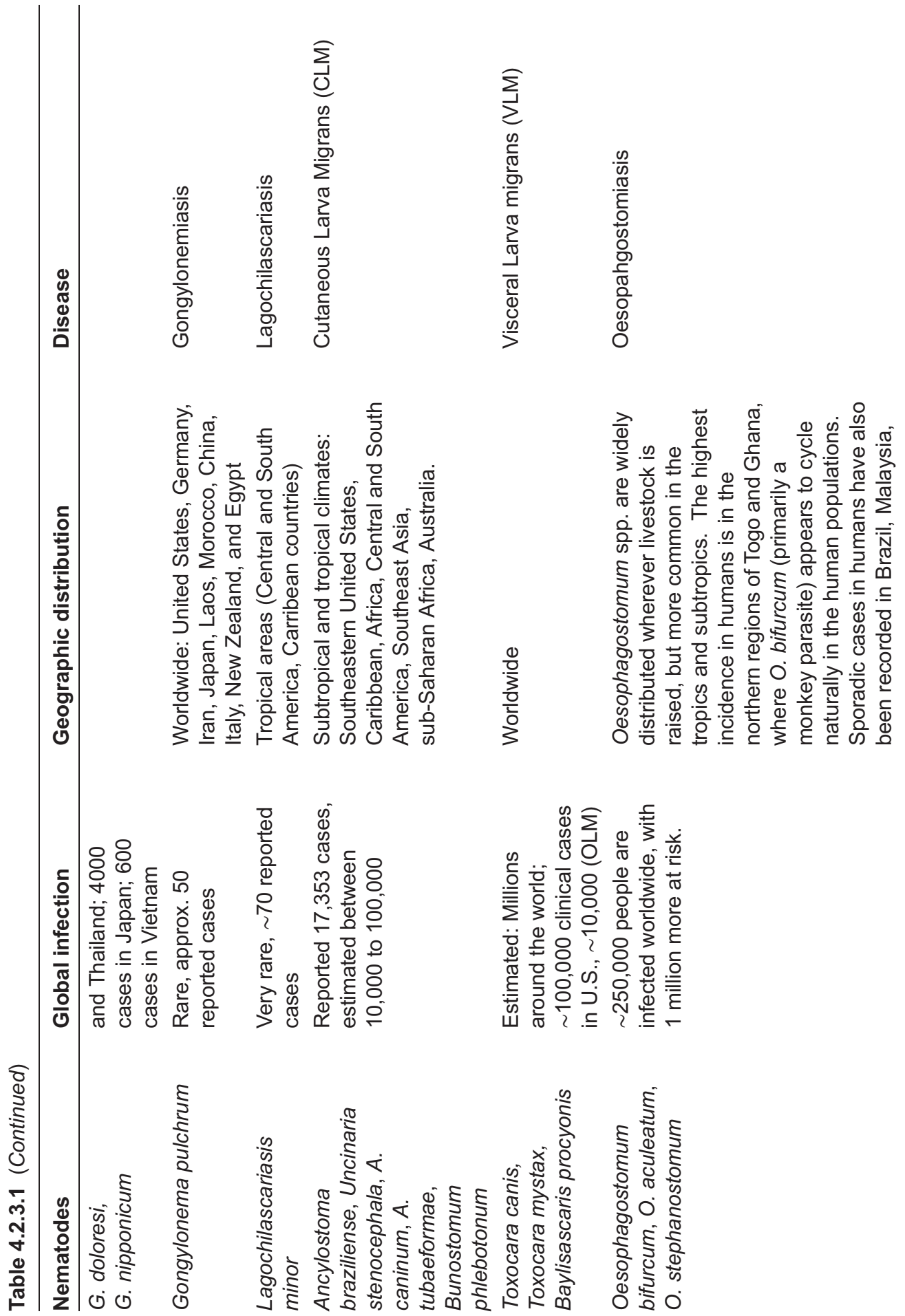




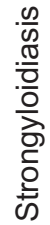
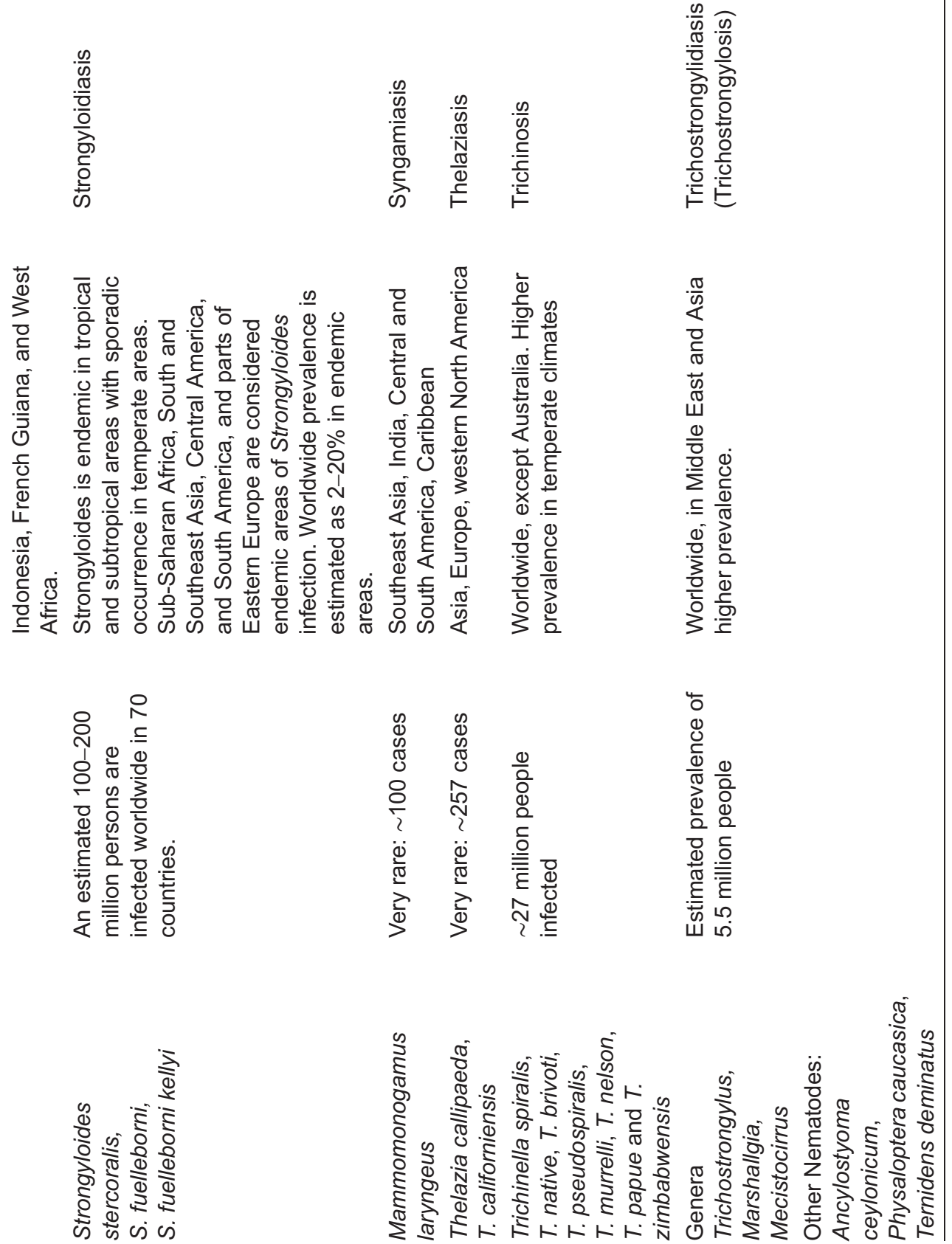


\section{Chapter 4.2.3.1}

\section{Angiostrongyliasis}

Cerebral Angiostrongyliasis (Eosinophilic Meningoencephalitis or Eosinophilic Meningitis) Intestinal Angistrongyliasis

\section{[ANGIOSTRONGYLUS CANTONENSIS, ANGIOSTRONGYLUS COSTARICENSIS]}

The nematode (roundworm) Angiostrongylus cantonensis is a parasite that infects humans and causes eosinophilic meningitis. Rodents are the definitive hosts while snails are intermediary hosts. Human infections have been reported from Southeast Asia and the Pacific Basin but recently Angiostrongylus costaricensis a closely related worm that causes intestinal Angiostrongyliasis in Central and South America has been also reported. Transmission in humans as accidental final host occurs by ingestion of larvae from raw or undercooked infected snails or contaminated water and vegetables. Other paratenic hosts that humans may consume raw are crabs, crayfishes, freshwater fishes. Life cycle consists of mature roundworms leaiving in rats' pulmonary arteries where eggs are deposited. Larvae hatch from eggs and penetrate alveoli to be coughed up, swallowed and excreted through feces. In water, larvae invade snails to develop internally into infective larvae. Ingestion of an intermediate or paratenic host by the final host (rodents and accidentally humans) produces infection. In final host, A. cantonensis larvae invade the intestinal wall to further spread hematogenously to the brain and further migrate via the venous system to the pulmonary artery and heart (right side) (Ramirez-Avila et al., 2009) (Figure 4.2.3.1). In humans, brain larvae are enclosed in granulomas where they end their lives. Clinical manifestations depend on infection burden but major symptoms are severe headaches, vomiting, fever, convulsions, facial paralysis, sleep disturbances, paresthesia, spech impediment, hearing disorders, paresis and death. In $A$. costaricensis infections, ingested larvae migrate to intestinal arteries and small blood vessels where they mature into sexually productive roundworms to produce eggs. Released eggs accumulate in intestinal blood capillaries (ileum) to develop into first-stage larvae that are subsequently excreted in feces. Clinical manifestations are induction of necrotic alterations in appendix, cecum and ascending colon, abdominal pain, fever, anorexia, vomiting, diarrhea or constipation and death in heavy infections. 


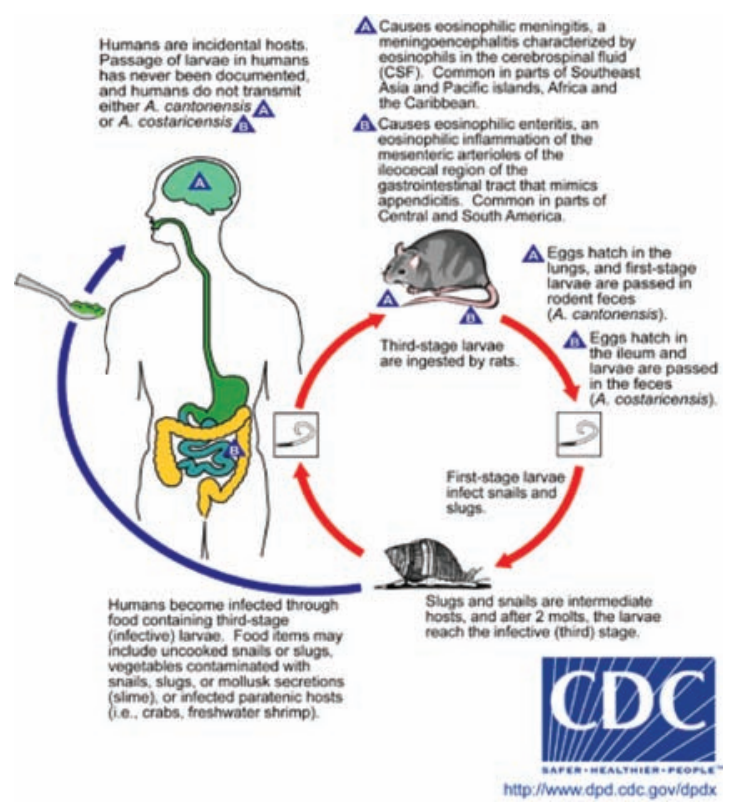

Figure 4.2.3.1. Angiostrongylus cantonensis life cycle (with permission from CDC,Atlanta, USA; http://www. dpd.cdc.gov/dpdx/HTML/ImageLibrary/Angiostrongyliasis_il.htm)

\subsection{ANGIOSTRONGYLIASIS AND ENVIRONMENT}

In recent years, population shifts and rapid transport have facilitated the spread of certain helminthic diseases from endemic to non-endemic areas (Polley, 2005). For example, with the increasing maritime world trade have dispersed this parasite in many continents, mainly carried by cargo ship rats (Pien and Pien, 1999). Among the many helminthic parasites known to cause various human diseases affecting millions of people worldwide, neurohelminthiases (e.g. A. cantonensis) are often undiagnosed because of clinicians' limited knowledge of exotic parasites or unavailable confirmatory diagnostic tests (Nishimura and Hung, 1997). Diaz (2008) described recently that Angiostrongylus cantonensis became an endemic eosinophilic meningitis in the US, following the importation of infected rats and African land snails on container ships, as biological controls and exotic pets. A. cantonensis is now enzootic in Louisiana and has caused eosinophilic meningitis in humans. Chikweto et al. (2009) described a prevalence of $23.4 \%$ of $A$. cantonensis in rats in Granada, revealing geographical expansion. Prociv and Carlisle (2001) in Australia have described a real evidence of the rapid expansion of this parasite. Since the 70s, an increasing numbers of autochthonous infections have been reported in Australia (southeast Queensland and northern New South Wales) in a variety of animals including humans, rats, dogs, horses, flying foxes and marsupials. In the 90s, the parasite was isolated from a dog in Sydney ( $1000 \mathrm{~km}$ south) and since then increasing numbers of infections were reported in dogs, flying foxes, marsupials and zoo primates. The authors suggested that ingestion of native or exotic snails and other molluscs as the intermediate hosts helped to spread this parasite. In contrast, an almost identical native species, A. mackerrasae was not identified as being competent to infect people (or other non-rodent hosts) as all roundworms recovered from a fatal human case and from many animal infections, have been confirmed as 
A. cantonensis. Finally, exotic food preparation with raw meat from snails or slugs, prawns, frogs, fish or planarians is also a source of $A$. cantonensis infection, especially for tourists (Wang et al., 2008; Malvy et al., 2008). Indeed, Eamsobhana et al. (2009) showed that, in spite of the addition of flavoring spices and alcohol to a certain Thai speciality dish, a complete inactivation of $A$. cantonensis larvae found in snail meat has not been accomplished. Kramer et al. (1998) were the first to report an intestinal (abdominal) angiostrongyliasis (A. costaricensis parasite) outbreak attributed to consumption of raw mint in Guatemala. The authors speculated that the mint leaves were contaminated with the mucous secretions of infected mollusks or that infected mollusks or planarians remained adherent onto the mint leaves even after wash.

\subsection{REFERENCES}

Chikweto, A., Bhaiyat, M.I., Macpherson, C.N.L., Deallie, C., Pinckney, R.D. et al. (2009) Existence of Angiostrongylus cantonensis in rats (Rattus norvegicus) in Grenada, West Indies. Vet. Parasitol. 162, 160-162.

Diaz, J.H. (2008) Helminthic eosinophilic meningitis: emerging zoonotic diseases in the South. J La State Med Soc 160, 333-342.

Eamsobhana, P., Yoolek, A., Punthuprapasa, P. \& Yong, H.S. (2009) Thai koi-hoi snail dish and angiostrongyliasis due to Angiostrongylus cantonensis: Effects of food flavoring and alcoholic drink on the third-stage larvae in infected snail meat. Foodborne Pathog. Dis. 6, 401-405.

Malvy, D., Ezzedine, K., Receveur, M.C., Pistone, T., Crevon, L. et al. (2008) Cluster of eosinophilic meningitis attributable to Angiostrongylus cantonensis infection in French policemen troop returning from the Pacific Islands. Travel Med Infect Dis 6, 301-304.

Nishimura, K., Hung, T. (1997) Current views on geographic distribution and modes of infection of neurohelminthic diseases. J. Neurol. Sci. 145, 5-14.

Pien, F.D. \& Pien, B.C. (1999) Angiostrongylus cantonensis eosinophilic meningitis. Int. J. Infect. Dis. 3, 161-163.

Polley, L. (2005) Navigating parasite webs and parasite flow: emerging and re-emerging parasitic zoonoses of wildlife origin. Int. J. Parasitol. 35, 1279-1294.

Prociv, P. \& Carlisle, M.S. (2001) The spread of Angiostrongylus cantonensis in Australia. Southeast Asian J. Trop. Med. Public Health 32, 126-128.

Ramirez-Avila, L., Slome, S., Schuster, F.L., Gavali, S., Schantz, P.M. et al. (2009) Eosinophilic meningitis due to Angiostrongylus and Gnathostoma species. Clin. Infect. Dis. 48, 322-327.

Wang, Q.P., Lai, D.H., Zhu, X.Q., Chen, X.G. \& Lun, Z.R. (2008) Human angiostrongyliasis. Lancet Infect Dis 8, 621-630.

Kramer, M.H., Greer, G.J., Quinonez, J.F., Padilla, N.R., Hernandez, B. et al. (1998) First reported outbreak of abdominal angiostrongyliasis. Clin. Infect. Dis. 26, 365-372. 


\section{Chapter 4.2.3.2}

\section{Anisakiasis (Herring Worm Disease)}

\section{[ANISAKIS SIMPLEX, PSEUDOTERRANOVA DECIPIENS]}

The parasitic nematodes Anisakis simplex and Pseudoterranova decipiens (now including $\sim 5$ sibling species) cause human infection following consumption of raw or undercooked saltwater fishes (e.g., salmon, sardine, mackerel, cod, flounder, etc.) and squids (Repiso et al., 2003; Kleter et al., 2009; Arizono et al., 2011; Skirnisson, 2006). This marine fauna carry the parasite in their body cavities, muscles and tissue with high prevalence (up to 100\%), and consequently raw consumption of their meat has a high risk of humans' infection. The parasite distribution is worldwide except in marine areas where cetaceans are rare. Human cases involving Anisakis simplex have been reported from Japan $(>1000$ cases/year), Spain, France, The Netherlands and North America and cases involving Pseudoterranova spp. from the northern Pacific area (Arizono et al., 2011). Life cycle of these parasites is mainly aquatic (marine environment) with humans as accidental hosts. Infected marine mammals with adult roundworms excrete unembryonated eggs into sea or ocean water (Aspholm et al., 1995). Eggs embryonation occurs in water and L2 type larvae develop. L2 larvae hatch, swim freely and are ingested by a first intermediary host (mostly crustaceans) where they mature into L3 larvae. Squids and various saltwater fishes ingest L3 larvae where upon the host's death, the L3 larvae migrate to muscle tissue (Muenker \& Karl, 2001). Predation by other fishes or marine mammals (whales, seals and dolphins) transfers L3 larvae to a second intermediary host or in the case of marine mammals to the final host. At this point, humans enter the life cycle of this parasite as an accidental player by consuming raw infected fish and turn into final hosts (in humans Anisakis simplex larvae invade intestinal tract walls-from the esophagus to the rectum while Pseudoterranova spp. favour stomach wall) (McClelland, 2002). In marine mammals, the L3 larvae stage molts twice to develop into an egg producing adult roundworm (Figure 4.2.3.2.1). Clinical signs are severe epigastric pains, nausea, vomiting, blood in gastric juice and feces an outcome of ulcerative lesions, stenosis, intestinal perforation and pruritis, urticaria and anaphylaxis as instant-type hypersensitivity. Since larvae do not survive longer that one week in humans, the disease is self-limiting. 


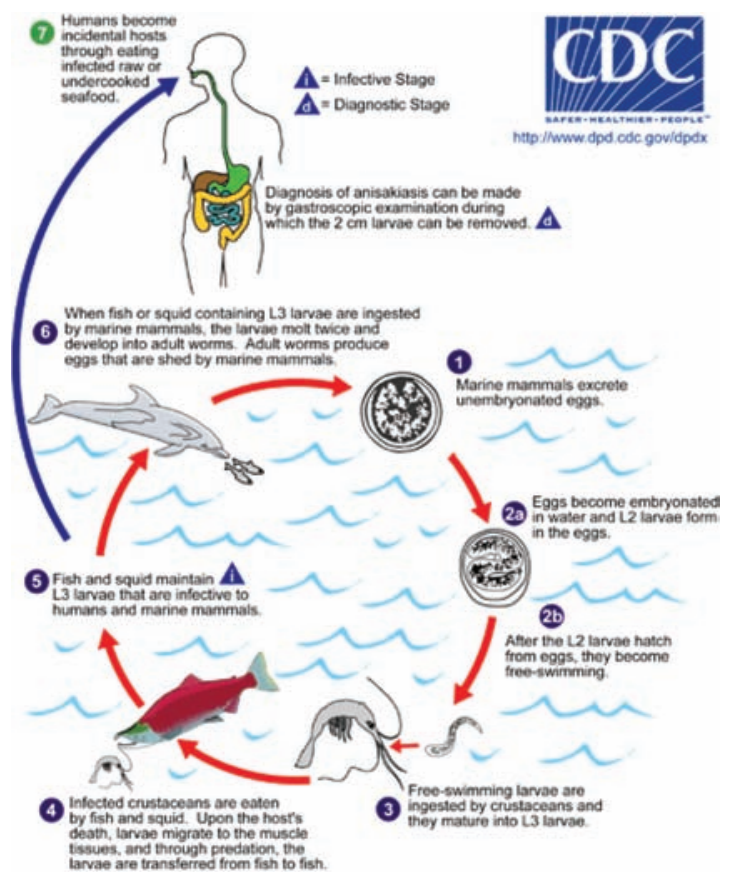

Figure 4.2.3.2.1. Anisakis simplex life cycle (with permission from CDC, Atlanta, USA: http://dpd.cdc. gov/dpdx/HTML/Anisakiasis.htm)

\subsection{ANISAKIASIS AND ENVIRONMENT}

Besprozvannykh et al. (2003) studied various fish species found in the Gulf of Peter The Great (the largest gulf of the Sea of Japan) for infection with these nematodes. The highest infection rates with Anisakis simplex have been found in chum salmon, masked greenling and Alaska pollock species. The high infection rate has been explained based on the fish seasonal migration into open marine space and back into the gulf waters while feeding on deep-sea (herrings) and bottom-dwelling (bases) fishes infected by other bottom-dwelling invertebrates (the first intermediate hosts).

Noguera et al. (2009) reported on a frequent encounter of the "red vent syndrome" of wild Atlantic salmon (Salmo salar) returning to various rivers in Scotland. The syndrome revealed itself as swollen, hemorrhagic (sometimes severe bleeding), skin erosion and scale loss of the vent (the anus adjacent to the opening of fish from where it excretes sperms or eggs), predominantly found in 1-sea-winter grilse but also in 2-sea winter salmons, without any apparent health deterioration, mortality or spawning inhibition. The researcher isolated high numbers of A. simplex from the infected vents, an unusual anatomic site for this parasite and hypothesized that this is a new parasite species. However, molecular studies did not confirm this hypothesis and therefore another theory has been proposed. The new assumption has been that ocean-scale environmental changes are involved in this syndrome's intensity. The most logical factor suspected at ocean scale (and above), is water temperature that can impact both parasite cycles and its host. North Atlantic sea water warming has been recorded, with Scottish sea-surface temperatures rising 0.2 to $0.6^{\circ} \mathrm{C}$ per decade including the foraging areas exploited by salmon (with seven out of ten warmest years occurring in the last decade, with 2006 being the second warmest 
year in UK coastal waters since records began in 1870). In addition, these authors mentioned that the $15^{\circ} \mathrm{C}$ summer isotherm has moved $330 \mathrm{~km}$ north in the last $17 \mathrm{yr}$. Therefore, temperature increase in the eastern North Atlantic pelagic ecosystem might favor different parasites, as already has been shown in terrestrial ecosystems (Kutz et al., 2004). Due to spatial and temporal differences, salmon might face reduced availability in prey, and the need to compete (temporary absence of a given prey), or variability (different feeding options, e.g., pelagic swarmfish), leading to a shift in their diet hence exposing them to increased Anisakis spp. loads (Klimpel et al., 2008). Klimpel et al.'s (2004) study supports these findings by demonstrating that this nematode is able to select its definite host species depending on the locality, apparently having a very low level of host specificity. From the epidemiological point of view, an increase in human allergic and gastro-allergic reactions to A. simplex has been reported in Spain, possibly reflecting changes in culinary and feeding habits or improved diagnosis, but also an actual general increase in anisakid parasite prevalence in a wide range of fish hosts, again related to low host specificity (Valero et al., 2006). In Peru, Cabrera et al. (2004), suggested concerning a current epidemy and the probable emergence of anisakidosis in this country that besides increased raw fish consumption the "El Niño" weather phenomenon might also be involved in the elevated prevalence of this nematode.

In relation to environmental pollution, evidence has started to pile up of an interesting feature of $A$. simplex related to this external pollution (Sures, 2004). Fish exposure to heavy metals revealed a much higher concentration of heavey metals in the colonizing parasite in comparison with the surrounding fish tissues (Pascual and Abollo, 2003; Jankovska et al., 2011). These authors by means of atomic adsorption spectrometry found that L3 larvae and adult infra-populations of the whaleworm Anisakis simplex from their respective fish, cephalopod and cetacean hosts caught or stranded in the Galician coast (north-west Spain) accumulated lead and copper to levels far in excess of their host tissues. The immediate question should be: Why do these parasites concentrate heavy metals (a real biohazard) within their tissues? Screening the published literature on this subject, we were not able to find or this type of query, or answer it either. However, several explanatory directions can be reasonable speculated: 1) the parasite tissue is by definition a good milieu for host molecule adsorption (including pollutants) in order to accomplish its parasitic functions without much energy investment, leading to heavy metals extensive accumulation; 2) by accumulating higher heavy metals concentrations (actively or passively) the parasite defends itself against the host's immunological system. Kolinkoeva et al. (1988) showed that lead and cadmium were the leading heavy metals that inhibited spermatozoa agglutination by antiserum. Karmaus et al. (2001) also looked at exposure to heavy metals and their effect on immunoglobulin levels in children. These authors identified a linear, statistically significant positive association between blood lead concentrations and IgE levels.

In environments where saltwater (sea) and freshwater (rivers) meet (mainly estuaries), anisakids (e.g., Pseudoterranova decipiens) transfer have been reported (Rausch and Adams, 2000). Burbot, a freshwater fish, could become infected (as paratenic host) by three interactions: devouring marine fishes in brackish waters at river mouths, consuming marine fishes that enter the lower reaches of rivers and by preying on anadromous fishes on their up -river migration.

Deep oceans present high pressures and cold temperatures as additional harsh environmental factors faced by anisakids. $P$. decipiens has been isolated from 23 fish species at two different sites in the Antarctic (Weddell Sea and South Shetland Islands) (Palm, 1999). The Weddell Sea is estimated to have the clearest water of any sea while South Shetland Islands harbor cold climate vegetation (mosses, lichens and algae) where seabirds, penguins and seals feed in the surrounding waters. P. decipiens occurred at water depths of 80 to $820 \mathrm{~m}$, with high prevalence in transport host fishes that feed mostly on benthic nototheniid fish species (as nematode accumulators) surrounding the South Shetland area. 
Bathypelagic, pelagic, or mainly euphausid feeding fish species were only lightly infested, thus demonstrating the benthic life cycle of $P$. decipiens in the Arctic. This author also reported on the parasite's preference to infest fish body cavity and liver and not the usual fish musculature, possibly explained by low temperature effect. Overall, this roundworm seems to be well established in the extreme Antarctic environment (with subzero temperatures).

The parasite's successful survival and distribution under extreme cold conditions has been attributed to trehalose (a biological cryptobioprotectant) accumulation as a general response to thermal stress (Stormo et al., 2009). Interestingly, acclimation to high temperatures triggered trehalose accumulation to an even greater extent than cold acclimation, a process that can be viewed evolutionarily as adaptation to heat rather than coldness, thus providing these nematodes with a moderate freeze tolerance.

Infection of secondary intermediate host such as smelts (Osmerus eperlanus) with $P$. decipiens has been studied in connection with their swimming capabilities and anthropogenic interventions (Rohlwing et al., 1998). Infection of fish musculature with larval stage 3 induced reduced swimming speed as observed by frequent collisions of infected fishes with the screen system of the cooling water inflow of a power plant. The authors emphasized the vulnerability of speed-limited infested fishes to anthropogenic activities such as suction by power plant cooling systems and/or enhanced removal by trawl fisheries, both inducing removal of infested fishes, thus in turn reducing the parasitic third-stage larvae in the local smelt population.

\subsection{REFERENCES}

Arizono, N., Miura, T., Yamada, M., Tegoshi, T. \& Onishi, K. (2011) Human Infection with Pseudoterranova azarasi Roundworm. Emerging Infect. Dis. 17, 555-556.

Aspholm, P.E., Ugland, K.I., Jodestol, K.A. \& Berland, B. (1995) Sealworm (Pseudoterranova decipiens) infection in common seals (Phoca vitulina) and potential intermediate fish hosts from the outer Oslofjord. Int. J. Parasitol. 25, 367-373.

Besprozvannykh, V.V., Ermolenko, A.V. \& Kamnev, V.D. (2003) Infection of coastal catching fishes with a nematode of Anisakis simplex (Rud., 1809), L. in the Primor'e region. Med Parazitol (Mosk) 4, 18-21.

Cabrera, R., Del Pilar, M. \& Altamirano, T. (2004) Anisakidosis a marine parasitic zoonosis: unknown or emerging in Peru?. Rev Gastroenterol Peru 24, 335-342.

Dautremepuits, C., Betoulle, S., Paris-Palacios, S. \& Vernet, G. (2004) Humoral immune factors modulated by copper and chitosan in healthy or parasitised carp (Cyprinus carpio L.) by Ptychobothrium sp. (Cestoda). Aquat. Toxicol. 68, 325-338.

Jankovska, I., Miholova, D., Petrtyl, M., Romocusky, S., Kalous, L. et al. (2011) Intestinal Parasite Acanthocephalus lucii (Acanthocephala) from European Perch (Perca fluviatilis) as a Bioindicator for Lead Pollution in the Stream "Jevansky potok" Near Prague, Czech Republic. Bull Environ Contam Toxicol 86, 342-346.

Karmaus, W., Dimitrov, P., Kruse, H., Osius, N. \& Witten, J. (2001) Exposure to heavy metals and their effect on immunoglobulin levels in children. Editor(s): Lekkas, T. D.; Proceedings of the International Conference on Environmental Science and Technology, 7th, Ermoupolis, Greece, Sept. 3-6, 2001, A 412-418. Publisher: University of the Aegean, Dep. of Environmental Studies, Lesvos, Greece.

Kleter, G.A., Prandini, A., Filippi, L. \& Marvin, H.J.P. (2009) Identification of potentially emerging food safety issues by analysis of reports published by the European Community's Rapid Alert System for Food and Feed (RASFF) during a four-year period. Food Chem. Toxicol. 47, 932-950.

Klimpel, S., Kellermanns, E., Palm, H.W. (2008) The role of pelagic swarm fish (Myctophidae: Teleostei) in the oceanic life cycle of Anisakis sibling species at the Mid-Atlantic Ridge, Central Atlantic. Parasitol. Res. 104, 43-53.

Klimpel, S., Palm, H.W., Ruckert, S. \& Piatkowski, U. (2004) The life cycle of Anisakis simplex in the Norwegian Deep (northern North Sea). Parasitol. Res. 94, 1-9. 
Kolinkoeva, A., Tomov, A. \& Milarova, E. (1988) The effect of heavy metal ions on the antigen-antibody reaction in a model system of spermatozoa-serum against spermatozoa. Veterinarna Sbirka 86, 39-44.

Kutz, S.J., Hoberg, E.P., Nagy, J., Polley, L. \& Elkin, B. (2004) Emerging parasitic infections in Arctic ungulates. Integr. Comp. Biol. 44,109-118.

McClelland, G. (2002) The trouble with sealworms (Pseudoterranova decipiens species complex, Nematoda): a review. Parasitol. 124, S183-203.

Muenker, W. \& Karl, H. (2001) Quality of Baltic and North Sea herring (Clupea harengus). Fleischwirtschaft 81, 88-91.

Noguera, P., Collins, C., Bruno, D., Pert, C., Turnbull, A. et al. (2009) Red vent syndrome in wild Atlantic salmon Salmo salar in Scotland is associated with Anisakis simplex sensu stricto (Nematoda: Anisakidae). Dis. Aquat. Org. 87, 199-215.

Palm, H.W. (1999) Ecology of Pseudoterranova decipiens (Krabbe, 1878) (Nematoda: Anisakidae) from Antarctic waters. Parasitol. Res. 85, 638-646.

Pascual, S. \& Abollo, E. (2003) Accumulation of heavy metals in the whaleworm Anisakis simplex s.l. (Nematoda: Anisakidae). J. Mar. Biolog. Assoc. U.K. 83, 905-906.

Rausch, R.L. \& Adams, A.M. (2000) Natural transfer of helminths of marine origin to freshwater fishes with observations on the development of Diphyllobothrium alascense. J. Parasitol. 86, 319-327.

Repiso, O.A., Alcantara, T.M., Gonzalez, F.C., de Artaza, V.T., Rodriguez, M.R. et al. (2003) Gastrointestinal anisakiasis. Study of a series of 25 patients. Gastroenterol Hepatol 26, 341-346.

Rohlwing, T., Palm, H.W \& Rosenthal, H. (1998) Parasitation with Pseudoterranova decipiens (Nematoda) influences the survival rate of the European smelt Osmerus eperlanus retained by a screen wall of a nuclear power plant. Dis. Aquat. Org. 32, 233-236.

Skirnisson, K. (2006) Pseudoterranova decipiens (Nematoda, Anisakidae) larvae reported from humans in Iceland after consumption of insufficiently cooked fish. Laeknabladid 92, 21-25.

Stormo, S.K., Praebel, K. \& Elvevoll, E.O. (2009) Cold tolerance in sealworm (Pseudoterranova decipiens) due to heat-shock adaptations. Parasitol. 136, 1317-1324.

Sures, B. (2004) Environmental parasitology: relevancy of parasites in monitoring environmental pollution. Trends Parasitol. 20, 170-177.

Valero, A., Paniagua, M.I., Hierro, I., Diaz, V., Valderrama, M.J. et al. (2006) Anisakid parasites of twoforkbeards (Phycis blennoides and Phycis phycis) from the Mediterranean coasts of Andalucia (southern Spain). Parasitol. Int. 55, 1-5. 


\section{Chapter 4.2.3.3 \\ Capillariasis (hepatic, intestinal and pulmonary)}

\section{[CAPILLARIA HEPATICA, C. PHILIPPINENSIS, C.AEROPHILA]}

Among capillariasis forms, hepatic capillariasis in spite of its rarity is the most life threatening one. The disease is caused by Capillaria hepatica, a nematode that invades liver parenchyma in many mammals including humans, without intermediary hosts (so called a one -host life-cycle parasite). Cases ( 50$)$ have been reported from North and South America, Africa, Asia and Central Europe. Transmission occurs in humans (as accidental hosts) through embryonated eggs ingestion from soil contaminated by carcasses of dead rodents (prevalence in wild rats can reach 100\%) (Conlogue et al., 1979; Farhang-Azad, 1977) (Figure 4.2.3.3.1). Infected rodents do not excrete eggs in feces as the eggs are enclosed within their host in granulomas and can be released only after tissue decomposition. Soil contamination with unembryonated eggs starts with the final predominant host, rat (but also other rodents, monkeys and predators), death (caused by disease or cannibalism), decomposition or ingestion by a predator/scavenger and direct infection with tissue containing eggs. After weeks in soil environment, eggs embryonate and become infective. If a human by accident ingests contaminated soil or something else, larvae hatch from eggs to invade the intestinal wall to further reach the liver via the portal system. Clinical manifestations depend on the infection burden; light infections are mostly asymptomatic while heavy infection will result in extended liver damage, hepatitis, extrahepatic symptoms (lung diseases) and death (primarily in children). In moderate infections, epigastric complaints, hepatoslenomegaly, eosinophilia, leukocytosis were reported.

Capillaria philippinensis infections are also severe with lethal outcome if untreated (el-Karaksy et al., 2004). C. philippinensis was primarily reported from the Philippines but now it has been reported from other geographic areas, such as Southeast Asia, Western Pacific, and sporadic cases from Iran, Egypt, South America and India (Hoghooghi-Rad et al., 1987). Different piscivorous birds are the natural hosts and reservoirs of this nematode (Cross and Basaca-Sevilla, 1991) (Figure 4.2.3.3.2). Infection occurs in humans through the ingestion of raw/undercooked infected fishes with larvae caught from fresh or brackish-water or via the unusual autoinfection through larviparous females producing larvae without 
leaving human body. In nature, unembryonated eggs reach water from infected birds or humans, to further embryonate and be ingested by present fishes. In fishes, embryonated eggs hatch to realease larvae that infect fishes as intermediary/paratenic hosts. The cycle is completed when pescivorous birds or humans ingest the infective larval content of fishes. Clinical manifestations also depend on the larvae number ingested or developed through autoinfection. Slight infection shows abdominal pain, diarrhea, anorexia, and weakness, while more severe infections result in weight loss, vomiting, maladsorption and diarrhea, muscle wasting, pneumonia and death.

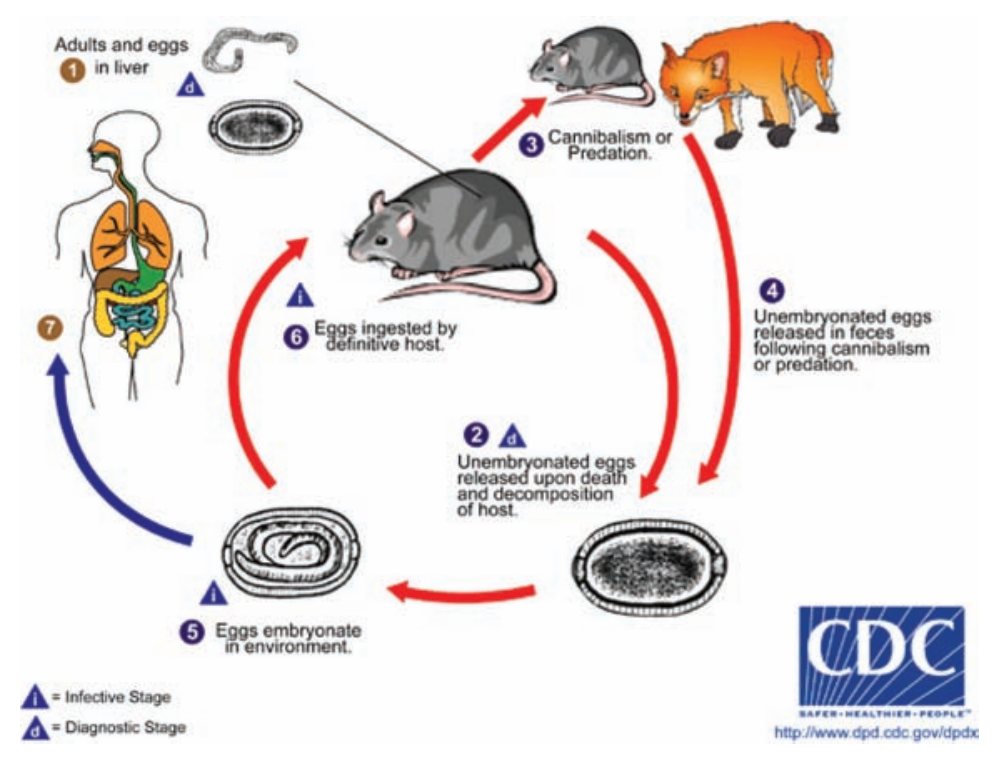

Figure 4.2.3.3.1. Capillaria hepatica life cycle (with permission from CDC, Atlanta, USA; http://dpd.cdc. gov/dpdx/HTML/Capillariasis.htm)

C. aerophila is perhaps the rarest human infection (so far 20 cases) which causes pulmonary capillariasis. This nematode can be found in a large list of predatory mammals (wild and domestic) such as: cats, dogs, foxes, mongooses, bears, marten spp., etc., and other animals such as hedgehogs and opossums (Henke et al., 2002; Magi et al., 2009; Beck, 2007; Thiess et al., 2001; Yasuda et al., 1994; Fiorello et al., 2006). The life cycle is similar to that of $C$. hepatica, meaning that it can be completed in one host. In an infected host, the adult nematode lays eggs in the lungs from where they are coughed up and swallowed to reach feces and are excreted on to soil. In soil, infective larvae develop within excreted eggs to remain infective for up to one year. Contaminated soil ingestion by a suitable host (in humans, children are the ones frequently in contact with soil) releases the infective larvae from eggs in the intestine which migrate further to the lungs. Clinical manifestations are therefore bronchitis, coughing, bloody sputum, eosynophilia and dyspenia.

\subsection{CAPILLARIASIS AND ENVIRONMENT}

The long-term exposure of parasite eggs in soil to changing environmental conditions and their persistence may increase the reemergences of these parasites (Traversa et al., 2010; Traversa et al., 2009). Lee et al. 
(2008) reported that among a large variety of bacterial, protozoan and helminthic pathogens in large-billed crow feces (from an urban setting in Kuala Lumpur, Malaysia), C. hepatica ova have been detected. Crows are known to feed on carcasses and therefore should be included as possible biovectors. In relation to birds, Cross (1990) described how, from an isolated report of a C. philippinensis infection (in 1963), a few years later epidemics of intestinal capillariasis have been reported from other Philippines areas, Thailand, Japan, Iran, Middle East (Egypt) and recently from Romania (Aftandelians et al., 1977; Mircean et al., 2010). He considered that, based on the life cycle of this parasite (small fresh and brackish water fishes as intermediate hosts), it might definitely be feasible that migratory piscivorous birds that feeds on these fishes may spread the parasite globally.

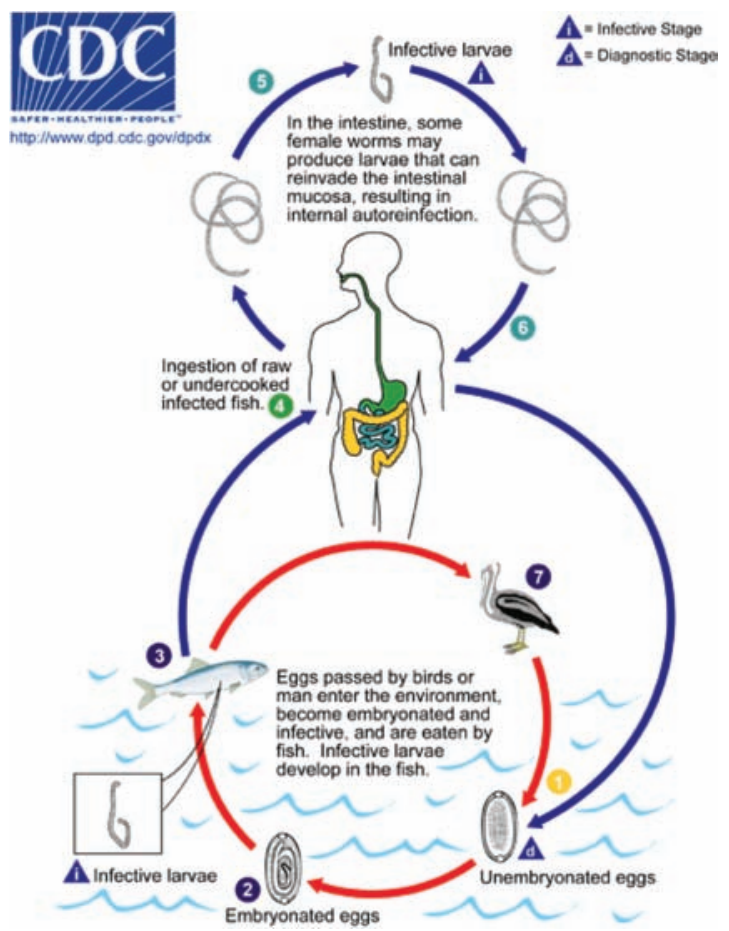

Figure 4.2.3.3.2. Capillaria philippinensis and aerophila life cycle (with permission from CDC, Atlanta, USA; http://dpd.cdc.gov/dpdx/HTML/Capillariasis.htm)

Barutzki et al. (1987) reported that among European hedgehogs' C. aerophila prevalence was 15.1 to $40.7 \%$ and concluded that these parasites are able to survive the winter in the host during the hibernation period. Here it should be mentioned that earthworms might be involved in transmission (even not as a necessary intermediate host, similar to the case of $T$. saginata eggs) since hedgehogs do feed on earthworms in addition to other soil insects, but further research is needed to substantiate this hypothesis. In Iceland, a cold climate area, arctic foxes have been screened for different parasites and C. aerophila has been found, a new record for this big island (Skirnisson et al., 1993), as well demonstrating this parasite's excellent survival in warm as well very cold climates. 
In Hungary, an extraintestinal nematode survey in red foxes revealed a high prevalence of $C$. aerophila (66\%) suggesting that dogs and cats may be infected due to fox colonization of urban areas (Sreter $e$ t al., 2003). Similar high prevalences of $C$. aerophila in wild foxes has been reported from Holland (46.8\%), Denmark (74.1\%) and Norway (88\%) (Borgsteede, 1984; Saeed et al., 2006; Davidson et al., 2006).

Finally, a recent report on pseudoparasitism involving $C$. hepatica in Brazil has been published (Carvalho-Costa et al., 2009). The authors described the isolation of $C$. hepatica eggs in a fecal sample of an old woman in a riverine community. The egg source was probably consumption of an infected liver of a tapir, but in this particular case they passed through the gut and eliminated without hepatic symptoms. The authors suggested that the evolution of these eggs to infective stages in environment and the poor sanitation of such communities could enable a high occurrence risk of hepatic disease in humans caused by this nematode.

\subsection{REFERENCES}

Aftandelians, R., Raafat, F., Taffazoli, M. \& Beaver, P.C. (1977) Pulmonary capillariasis in a child in Iran. Am. J. Trop. Med. Hyg. 26, 64-71.

Barutzki, D., Laubmeier, E. \& Forstner, M.J. (1987) Endoparasitic infestation of wild hedgehogs and hedgehogs in human care with a contribution to therapy. Tierarztl Prax 15, 325-331.

Beck, W. (2007) Endoparasites of the hedgehog. Wien. Klin. Wochenschr. 119, 40-44.

Borgsteede, F.H. (1984) Helminth parasites of wild foxes (Vulpes vulpes L.) in The Netherlands. Z Parasitenkd 70, 281-285.

Carvalho-Costa, F.A., Silva, A.G., de Souza, A.H., Moreira, C.J.C., de Souza, D.L. et al. (2009) Pseudoparasitism by Calodium hepaticum (syn. Capillaria hepatica; Hepaticola hepatica) in the Negro River, Brazilian Amazon. Trans. R. Soc. Trop. Med. Hyg. 103, 1071-1073.

Conlogue, G., Foreyt, W., Adess, M. \& Levine, H. (1979) Capillaria hepatica (Bancroft) in select rat populations of Hartford, Connecticut, with possible public health implications. J. Parasitol. 65, 105-108.

Cross, J.H. \& Basaca-Sevilla, V. (1991) Capillariasis philippinensis: a fish-borne parasitic zoonosis. Southeast Asian J Trop Med Public Health 22, 153-157.

Cross, J.H. (1990) Intestinal capillariasis. Parasitol. Today (Regul. Ed.) 6, 26-28.

Davidson, R.K., Gjerde, B., Vikoren, T., Lillehaug, A. \& Handeland, K. (2006) Prevalence of Trichinella larvae and extra-intestinal nematodes in Norwegian red foxes (Vulpes vulpes). Vet. Parasitol. 136, 307-316.

el-Karaksy, H., el-Shabrawi, M., Mohsen, N., Kotb, M., el-Koofy, N. \& el-Deeb, N. (2004) Capillaria philippinensis: a cause of fatal diarrhea in one of two infected Egyptian sisters. J. Trop. Pediatr. 50, 57-60.

Farhang-Azad, A. (1977) Ecology of Capillaria hepatica (Bancroft 1893) (Nematoda). 1; Dynamics of infection among Norway rat populations of the Baltimore Zoo, Baltimore, Maryland. J. Parasitol. 63, 117-122.

Fiorello, C.V., Robbins, R.G., Maffei, L. \& Wade, S.E. (2006) Parasites of free-ranging small canids and felids in the Bolivian Chaco. J. Zoo Wildl. Med. 37, 130-134.

Henke, S.E., Pence, D.B. \& Bryant, F.C. (2002) Effect of short-term coyote removal on populations of coyote helminths. J. Wildl. Dis. 38, 54-67.

Hoghooghi-Rad, N., Maraghi, S. \& Narenj-Zadeh, A. (1987) Capillaria philippinensis infection in Khoozestan Province, Iran: case report. Am. J. Trop. Med. Hyg. 37, 135-137.

Lee, H.Y., Stephen, A., Sushela, D. \& Mala, M. (2008) Detection of protozoan and bacterial pathogens of public health importance in faeces of Corvus spp. (large-billed crow). Trop Biomed 25, 134-139.

Magi, M., Macchioni, F., Dell'omodarme, M., Prati, M.C., Calderini, P. et al. (2009) Endoparasites of red fox (Vulpes vulpes) in central Italy. J. Wildl. Dis. 45, 881-885.

Mircean, V., Titilincu, A. \& Vasile, C. (2010) Prevalence of endoparasites in household cat (Felis catus) populations from Transylvania (Romania) and association with risk factors. Vet. Parasitol. 171, 163-166. 
Saeed, I., Maddox-Hyttel, C., Monrad, J. \& Kapel, C.M.O. (2006) Helminths of red foxes (Vulpes vulpes) in Denmark. Vet. Parasitol. 139, 168-179.

Skirnisson, K., Eydal, M., Gunnarsson, E. \& Hersteinsson, P. (1993) Parasites of the arctic fox (Alopex lagopus) in Iceland. J. Wildl. Dis. 29, 440-446.

Sreter, T., Szell, Z., Marucci, G., Pozio, E. \& Varga, I. (2003) Extraintestinal nematode infections of red foxes (Vulpes vulpes) in Hungary. Vet. Parasitol. 115, 329-334.

Thiess, A., Schuster, R., Nockler, K. \& Mix, H. (2001) Helminth findings in indigenous raccoon dogs Nyctereutes procyonoides (Gray, 1843). Berl. Munch. Tierarztl. Wochenschr. 114, 273-276.

Traversa, D., Di Cesare, A. \& Conboy, G. (2010) Canine and feline cardiopulmonary parasitic nematodes in Europe: emerging and underestimated. Parasit Vectors 3, 62.

Traversa, D., Di Cesare, A., Milillo, P., Iorio, R. \& Otranto, D. (2009) Infection by Eucoleus aerophilus in dogs and cats: is another extra-intestinal parasitic nematode of pets emerging in Italy?. Res. Vet. Sci. 87, 270-272.

Yasuda, N., Ezaki, K., Akuzawa, M., Izawa, M., Doi, T. et al. (1994) Helminth survey of wildcats in Japan. J. Vet. Med. Sci. 56, 1069-1073. 


\section{Chapter 4.2.3.4 Dioctophymiasis}

\section{[DIOCTOPHYMA RENALE]}

Dioctophymiasis is caused by infection with the "giant kidney worm" Dioctophyma renale. Humans are infected by consumption of raw fish or frog meat or by accidental ingestion of aquatic oligochaetes.

The distribution is worldwide but with a very low number of clinical cases reported. This nematode infects dogs, cats, mustelids, foxes, raccoons and pigs. The life cycle consists of $D$. renale eggs being shed by the parasitized animal (or human) in urine that contaminate water sources. In water, the first-stage larvae develop in eggs that are ingested by intermediate hosts such as aquatic oligochaetes (annelid worms, e.g. Lumbriculus variegatus). In oligochaetes intermediate hosts, larvae develop further to reach third-stage larvae in their blood vessels. At this stage ingestion by a paratenic host that feed on aquatic worms (e.g., fish or frogs) can take place. If not passed, in paratenic hosts the larvae encyst and stop their adult roundworms maturation. Proviso the paratenic hosts are ingested by carnivores or humans, larvae from the paratenic host migrate through the peritoneal cavity to kidney (to settle in parenchyma or renal pelvis) (Figure 4.2.3.4.1). Clinical manifestations are renal colic, haematuria and hydronephrosis (due to renal obstruction).

\subsection{DIOCTOPHYMIASIS AND ENVIRONMENT}

In spite of many known carnivores reported as major final hosts of D. renale, Ishizaki et al. (2010) recently reported on a capuchin monkey infected with this nematode. Capuchin monkeys are known to feed on fish among others things and therefore in nature it is very possible that these infections are more prevalent among primates feeding on fish then thought before (Hellner-Burris et al., 2010).

Among fishes infected with $D$. renale, Measures and Anderson (1985) reported a 5 to $23 \%$ prevalence in pumpkinseed sunfish (Lepomis gibbosus) in three Canadian lakes. It should be mentioned that sunfishes are subject to sport fishing, therefore have been intentionally introduced in many areas outside their original ranges to turn out to be an invasive species. Whether these ecological changes in the paratenic host distribution might increase the risk of infection in humans should be further studied. 


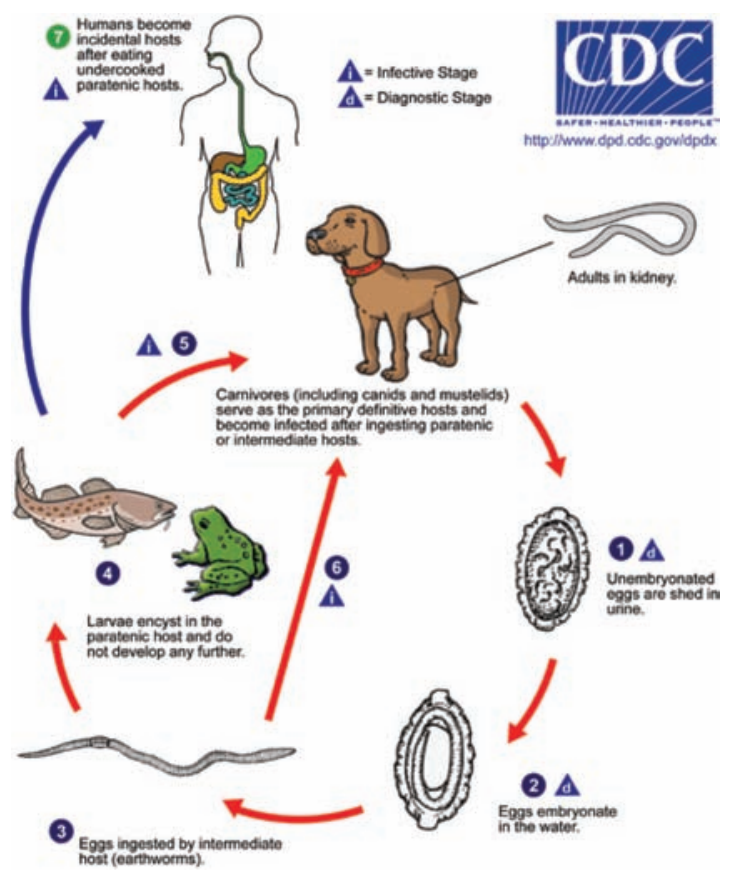

Figure 4.2.3.4.1. Dioctophyma renale life cycle (with permission from CDC, Atlanta, USA; http://dpd.cdc. gov/dpdx/HTML/Dioctophymiasis.htm)

An interesting issue raised in connection to another environmental contaminant: mercury (Klenavic et al., 2008). These authors measured mercury concentrations in different organs of two semi-aquatic fish-eating mammals: wild mink and river otter. Notably, they reported that mink infected by $D$. renale and exposed to mercury had higher mercury levels compared to the uninfected. As the kidney is the main organ involved in the removal of mercury in urine (Baselt, 2008), parasitic infection of this organ and serious damage will affect excretion and cause further damage to other internal organs in mammals.

\subsection{REFERENCES}

Hellner-Burris, K., Sobieski, C.A., Gilbert, V.R. \& Phillips, K.A. (2010) Prey capture efficiency in brown capuchin monkeys (Cebus apella) is influenced by sex and corpus callosum morphology. Am. J. Primatol. 72, 502-508.

Baselt, R. Disposition of Toxic Drugs and Chemicals in Man, 8th edition, Biomedical Publications, Foster City, CA, 2008, pp. 923-927.

Ishizaki, M.N, Imbeloni, A.A., Muniz, J.A., Scalercio, S.R., Benigno, R.N. et al. (2010) Dioctophyma renale (Goeze, 1782) in the abdominal cavity of a capuchin monkey (Cebus apella), Brazil. Vet. Parasitol. 173, 340-343.

Measures, L.N. \& Anderson, R.C. (1985) Centrarchid fish as paratenic hosts of the giant kidney worm, Dioctophyma renale (Goeze, 1782), in Ontario, Canada. J. Wildl. Dis. 21, 11-19.

Klenavic, K., Champoux, L., Mike, O., Daoust, P.Y. Evans, R.D. \& Evans, H.E. (2008) Mercury concentrations in wild mink (Mustela vison) and river otters (Lontra canadensis) collected from eastern and Atlantic Canada: relationship to age and parasitism. Environ. Pollut. 156, 359-366. 


\section{Chapter 4.2.3.5}

\section{Dracunculiasis (Guinea worm infection)}

\section{[DRACUNCULUS MEDINENSIS]}

Dracunculiasis is a disease caused by one of the longest nematodes: Dracunculus medinensis also known as Guinea worm. Humans are the final hosts. Prior to 1986, the disease affected millions of people with a high distribution in Africa and Asia (India), mainly in arid zones, while now is in a very steep decline and expected to be eradicated almost completely. Transmission occurs through accidental ingestion of unclean water containing small crustaceans (Cyclops spp.) that exercise as intermediate hosts. The life cycle of this parasite consists of rhabtidiform larvae that penetrate the digestive tract wall and locate in the connective tissues. The adult worms (a very elongated female and a short male morphology) reproduce and gravid females migrate to subcutaneous tissue of human organs (feet) that have contact with water and discharge larvae (L1 stage) through a skin blister into surrounding water. Larvae (L1 stage) in water are consumed by crustaceans that become infected (as intermediary host). Inside crustaceans, the larvae pass two molts to form the final infective L3 stage larvae. Final ingestion of water containing infected crustaceans transfers the infective larvae (L3 stage) to humans (Figure 4.2.3.5.1). Clinical manifestations are primarily asymptomatic but migration of the adult gravid female to her final destination (skin) causes: local pain, pruritis, fever, nausea, ulcerative blister and abscesses due to secondary infection.

\subsection{DRACUNCULIASIS AND ENVIRONMENT}

During the preparation of this book, we were happy to realize that probably this disease has been practically erradicated completely through education and water sources protection. However, remote rural areas still serve as potential foci for reemergence, especially in low socio-economic societies in developing countries. It can be only hypothesized that if a future peril exists it may result from an evolutionary process, i.e., a similar mammal parasite will adapt through a common intermediary host to humans! Bimi et al. (2005), sequencing the genes coding for the small-subunit rRNA (18S rRNA) gene, have been able to provide a tool to differentiate between two Dracunculus species: D. medinensis (human host) and 
D. insignis (dog host). Morphologically, those two guinea worms are undistinguishable but valid identification using molecular tools is now possible.

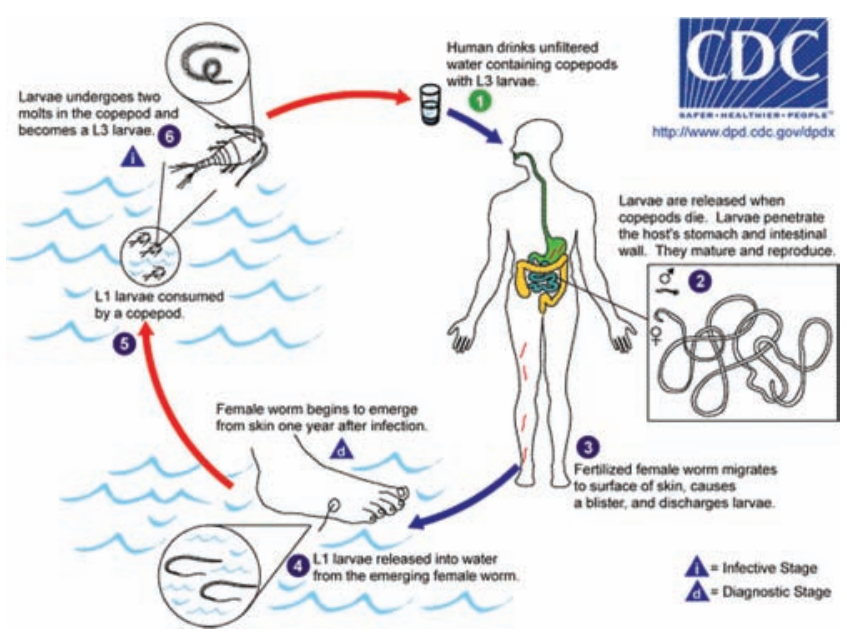

Figure 4.2.3.5.1. Dracunculus medinensis life cycle (with permission from CDC, Atlanta, USA; http://dpd. cdc.gov/dpdx/HTML/Dracunculiasis.htm)

\subsection{REFERENCES}

Miri, E.S., Hopkins, D.R., Ruiz-Tiben, E., Keana, A.S., Withers, P.C.Jr. et al. (2010) Nigeria's triumph: dracunculiasis eradicated. Am. J. Trop. Med. Hyg. 83, 215-225.

Bimi, L., Freeman, A.R., Eberhard, M.L., Ruiz-Tiben, E. \& Pieniazek, N.J. (2005) Differentiating Dracunculus medinensis from D. insignis, by the sequence analysis of the 18S rRNA gene. Ann Trop Med Parasitol 99, 511-517. 


\section{Chapter 4.2.3.6}

\section{Eosinophilic enteritis}

\section{[ANCYLOSTOMA CANINUM]}

Ancylostoma caninum is the etiological factor that causes eosinophilic enteritis in humans. The disease has been reported mainly from Australia, where infected patients revealed hypersensitivity to this nematode (Prociv and Croese, 1990). Transmission occurs from infected young dogs and is mainly limited to northeastern regions of Australia with a few hundred cases reported, but it has also a worldwide distribution: North and South America, Asia and Europe. The parasite colonizes human gut, but at low numbers with reduced size and mostly infertile matures.

The life cycle of $A$. caninum consists of third-stage larvae from dog feces that are infective stage of both dogs and humans. In humans, larvae invasion is through skin while in dogs via root sheats and carried through the blood vessels to heart and lungs. Afterward, larvae penetrate pulmonary alveoli to further ascend the bronchial tree to pharynx and finally are swallowed. Once swallowed, they move into the small intestine to mature and produce eggs (as mentioned earlier, in humans they are infertile). Adult worms living attached to the intestinal wall suck mucosal plugs to access the host's blood (Figure 4.2.3.6.1). Clinical manifestations are mostly focal reaction to infection expressed as inflammation, ulceration, epigastric colic, nausea, vomiting, and diarrhea, and in severe cases acute abdomen.

\subsection{EOSINOPHILIC ENTERITIS AND ENVIRONMENT}

Tarsitano et al. (2010) surveyed dog feces and bird guano in the city of Bari (Apulia region, Italy) for parasites on various sites, such as park green areas, playgrounds, public housing, parkways and school. Among the different parasites, this group reported Ancyllostoma caninum eggs in $9.2 \%$ of the canine fecal samples. Therefore this parasite is present in European dogs; however, due to its specific water related transmission, it seems that human infection is nadir in the semi-arid areas of Italy. Croese (1995) in Australia has underlined favorable conditions for transmission of this hookworm. In his retrospective study, the number of eosinophilic enteritis patients decreased in June and remained at this level for the rest of the winter. An infection rate boost was observed in spring proceeding the wet season (monsoon). The author obviously linked the infection prevalence with climatic conditions and also suggested that 
"extraneous infections are promoted by the irrigation of domestic gardens and possibly endogenous reinfection of the gut by hypobiotic larvae". In Nigeria, Onwuliri et al. (1993) reported also on the fecal isolation of A. caninum from dogs and pigs and found a direct relation between ecological factors (rainfall and temperature) and the parasites' prevalence. In a more extensive study in Kaduna metropolis (Nigeria), Maikai et al. (2008) surveyed soil samples for the presence of helminth eggs. Ancylostoma spp. had a prevalence of $9 \%$ and as for other screened parasites, a significant association with rainy periods was revealed, as well as the impact of the presence of dogs and vegetation in the studied area. It is also clear that dog ownership is also a significant factor especially since dogs in this area revealed a high infestation prevalence. Perec-Matysiak et al. (2008) in a much more northern area (Wroclaw, Poland) also reported on A. caninum egg presence in soil samples (from parks, backyards, playgrounds and city squares) at a prevalence of $4.9 \%$ (city squares having the highest rate of contamination). Also in Poland in a recreational area (Wolin Island), soil samples and feces of boars and foxes have been surveyed for helminth eggs. Ancylostoma caninum has been recovered only from fox feces (18.2\%) and is absent in soil samples, in spite of the fact that these animals are free ranging in the area. The authors suggested that soil characteristics (loose sand soil) as well the behavior of the parasite hosts (boars and foxes) do not favor transmission.

Granzer and Haas (1991) studied the response of A. caninum larvae to environmental and host stimuli in order to facilitate infection. They indicated four behavioral phases: 1) larvae snake-like movement stimulated by warmth and subject to defined vibrations; 2) waving behavior as a prerequisite for passive change-over to dog hairs, stimulated by heat radiation and $\mathrm{CO}_{2}$ concentration, warmth and humidity; 3 ) creeping direction, where larvae are attracted by very low temperature gradients and also by skin hydrophilic compounds (but not lipids or serum); and 4) penetration stimulated by heat and dog's hydrophilic skin compound and serum. All these factors are micro-environmental factors affecting dogs' infection when in close proximity to larvae in water milieu. These results may help in the development of a potential trap to clean $A$. caninum larvae infested water.

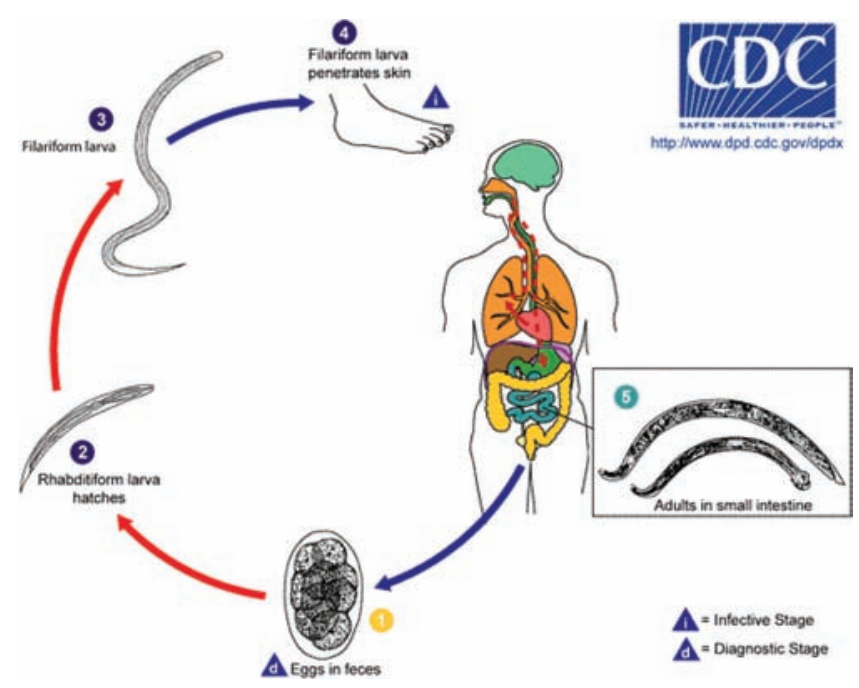

Figure 4.2.3.6.1. Ancylostoma caninum life cycle (with permission from CDC, Atlanta, USA; http://www.dpd. cdc.gov/dpdx/HTML/Hookworm.htm) 
Finally, Sciacca et al. (2002) presented results of a study carried out on the response of helminths larvae to $\mathrm{CO}_{2}$ concentrations, among them A. caninum third-stage larvae (L3). They found that at exposure to $5 \%$ $\mathrm{CO}_{2}$, A. caninum $\mathrm{L} 3$ larvae stopped crawling for 1 minute, becaming active again 9 to14 minutes after $\mathrm{CO}_{2}$ $(5 \%)$ exposure was terminated. In the same experimental set-up, activity resumed more rapidly (10 to15 sesonds) if L3 larvae were subsequently exposed to breath or breath through the scrubber (for $\mathrm{CO}_{2}$ removal) $\left(\mathrm{CO}_{2}\right.$ concentrations in human breath is 3.3 to $\left.4 \%\right)$. This study also suggests that humans breath out additional volatile organic compounds that may attract larvae, beside the recognized gases.

\subsection{REFERENCES}

Croese, J. (1995) Seasonal influence on human enteric infection by Ancylostoma caninum. Townsville General Hospital, Queensland, Australia. Am. J. Trop. Med. Hyg. 53, 158-161.

Granzer, M. \& Haas, W. (1991) Host-finding and host recognition of infective Ancylostoma caninum larvae. Int. J. Parasitol. 21, 429-440.

Maikai, B.V., Umoh, J.U., Ajanusi, O.J. \& Ajogi, I. (2008) Public health implications of soil contaminated with helminth eggs in the metropolis of Kaduna, Nigeria. J. Helminthol. 82, 113-118.

Mizgajska-Wiktor, H. \& Jarosz, W. (2010) Potential risk of zoonotic infections in recreational areas visited by Sus scrofa and Vulpes vulpes. Case study-Wolin Island, Poland. Wiad Parazytol 56, 243-251.

Onwuliri, C.O., Anosike, J.C., Nkem, C.N. \& Payne, V.K. (1993) The ecology of animal parasitic nematodes in endemic areas of Jos, Nigeria. Appl. Parasitol. 34, 131-137.

Perec-Matysiak, A., Hildebrand, J., Zalesny, G., Okulewicz, A. \& Fatula, A. (2008) The evaluation of soil contamination with geohelminth eggs in the area of Wroclaw, Poland. Wiad Parazytol 54, 319-323.

Prociv, P. \& Croese, J. (1990) Human eosinophilic enteritis caused by dog hookworm Ancylostoma caninum. Lancet 335, 1299-1302.

Sciacca, J., Forbes, W.M., Ashton, F.T., Lombardini, E., Gamble, H.R. \& Schad, G.A. (2002) Response to carbon dioxide by the infective larvae of three species of parasitic nematodes. Parasitol. Int. 51, 53-62.

Tarsitano, E., Greco, G., Decaro, N., Nicassio, F., Lucente, M.S. et al. (2010) Environmental monitoring and analysis of faecal contamination in an urban setting in the city of Bari (Apulia region, Italy): health and hygiene implications. Int J Environ Res Public Health 7, 3972-3986. 


\section{Chapter 4.2.3.7 Filariasis}

[Brugia malayi, B. timori, Dorofilaria immitis- real zoonoses] [Onchocerca volvulus, Wuchereria bancrofti, Dipetalonema perstans, D. streptocerca, Mansonella ozzardi, Loa loa, Onchocerca lienalis, O. gutturosa, etc.-pseuodo zoonoses]

\subsection{GENERAL}

The human is the definitive host of nine known filarial nematodes, divided in three groups according to their infection niche: lymphatic (Wuchereria bancrofti, Brugia malayi, and Brugia timori) (Okon et al., 2010), subcutaneous (Loa loa, Mansonella streptocerca, Onchocerca volvulus, and Dracunculus medinensis-see chapter 4.2.3.5) and serous cavity filariases (Mansonella perstans and Mansonella ozzardi). All these nematodic parasites are vectorally transmitted by insects (mosquitoes or flies) or by copepods (see Dracunculus medinensis) (Figure 4.2.3.5.1).

\subsection{BRUGIA FILARIASIS (LYMPHATIC FILARIASIS)}

Brugia filariasis is a disease caused by the nematodes Brugia malayi and Brugia timori, often asymptomatic but also with severe outcomes. B. malayi is mostly distributed in South, Southeast and East Asia (India, Thailand, Vietnam, Burma, Philippines) while B. timori has been reported from Lesser Sunda Islands of Indonesia, all characterized by presence in humid tropical and subtropical regions. B. malayi has two strains with different animal reservoirs significance: 1) the nocturnal periodic strain (found in peripheral blood during the night and in the lung capillaries during the day) found also in various animals but usually transmitted from human to human by night-active mosquitoes (Aedes and Mansonia spp.) in areas of open plains with intensive farming and 2) a sub-periodic strain (found in peripheral blood without notable periodicity) transmitted in rainforest areas by Mansonia spp. mosquitoes, active day and night with dogs, cats and wildfelids as reservoirs. In Indonesia, the location of B. timori, felids and pangolins use as reservoirs. Transmission occurs through bites of L3 larvae infected mosquitoes. The life cycle of the parasites includes a mosquito infected with L3 larvae that takes a blood meal from humans or animals, introducing the L3 larvae into the skin through the bite wound. The introduced larvae 
develop into adult worms that further locate themselves in the lymphatic system (vessels and nodes). Inside the infected animals, viviparous females release first-stage (L1) larvae called microfilaria into the blood stream. When a mosquito takes his blood meal, microfilaria are ingested and transferred into the arthropod to develop into L3 larvae, the infective form for mammals (Figure 4.2.3.7.1). Clinical manifestations can remain asymptomatic in spite of microfilaria presence in blood circulation, but in severe cases lymphangytis and lymphadenitis are observed (legs and groin), fever, headache, backache, edemas, pruritis and elephanthiasis that develops in the later stage of the disease.

\subsection{FILARIASIS AND ENVIRONMENT}

Since filariasis is a vector-borne (arthropods) disease, external temperature plays an important epidemiological role. Lardeux and Cheffort (2001) studied the ambient climatic conditions on Wuchereria bancrofti transmission by Aedes polynesesiensis Marks (Diptera: Culicidae) in the French Polynesian archipelagos. Using a statistical model of the extrinsic cycle duration as a function of temperature, the authors distinguished three patterns of $W$. bancrofti transmission dynamics: continuous, fluctuating and discontinuous, occurring geographically from north to south. Clearly, these patterns were linked to temperature, man-vector contact and seasonal agricultural activities (Sattenspiel, 2000). In Africa, bancroftian filariasis is endemic in many countries these parasites were also found to be related to rainy seasons, vector habitats and abundance (Rwegoshora et al., 2005; de Souza et al., 2010). Hassan et al. (1998) using Geographic Information System (GIS) analyzed the spatial distribution of filariasis and its mosquito vector in the Nile Delta, Egypt. The spatial pattern of microfilariasis prevalence was shown to be negatively associated with annual rainfall and relative humidity, while it was positively associated with annual daily temperature. The same significant parameter (weekly mean temperature) has been shown with $C$. pipiens mosquitoes in Buenos Aires city, Argentina (Fischer and Schweigmann, 2004). Mosquitoes spp. have been already shown to have different preferences for breeding sites, such as salinity, $\mathrm{pH}$, organic load, temperature, etc. but with large preferential brackets, explaining some of the published contradictory results (Petersen and Chapman, 1969).

Apiwathnasorn et al. (2006) presented a study on the bionomics of Mansonia spp. mosquitoes as the nocturnal vector of $B$. malayi. They reported forty-four new species belonging to 12 genera isolated from the peat swamp forest in Thailand. Among these mosquitoes, some had both day and night activity, with high biting density and various animal hosts: cats, cows, monkeys and humans. The authors concluded that biting activity patterns corresponded with the periodicity found in man and domestic cats and may play an important role in either transmission or maintenance of the filarial parasites in the peat swamp forest.

In connection with breeding sites of mosquitoes, Oemijati et al. (1978) showed an interesting environmental issue related to human activity. Six villiges in West Java (Indonesia) have been examined for microfilaremia (B. malayi) resulting in a very low number of infections in comparison with a ten year old survey in the same localities. According to these authors, without drug treatment, insecticides application or any drastic population migration the observed decrease could be attributed solely to the development of a well-organized irrigation system in parallel to swamps conversion into rice-fields, consequently diminishing Mansonia mosquitoes breeding sites! This improvement may be attributed to water level and flow rates in irrigation channels as already shown (Mogi and Motomura, 1996). Flow rates of $>20 \mathrm{~cm} / \mathrm{s}$ (the flow speed required for mosquito control) seem to be the significant factor and not water levels $(>15 \mathrm{~cm} \pm<5 \mathrm{~cm})$, and hence high-quality engineering planning is required to prevent stagnancy in irrigation channels.

Erlanger et al. (2005) in a extensive literature review on lymphatic filariasis in Africa (W. bancrofti) tried to establish global and regional estimates of populations at risk, with particular consideration of water 

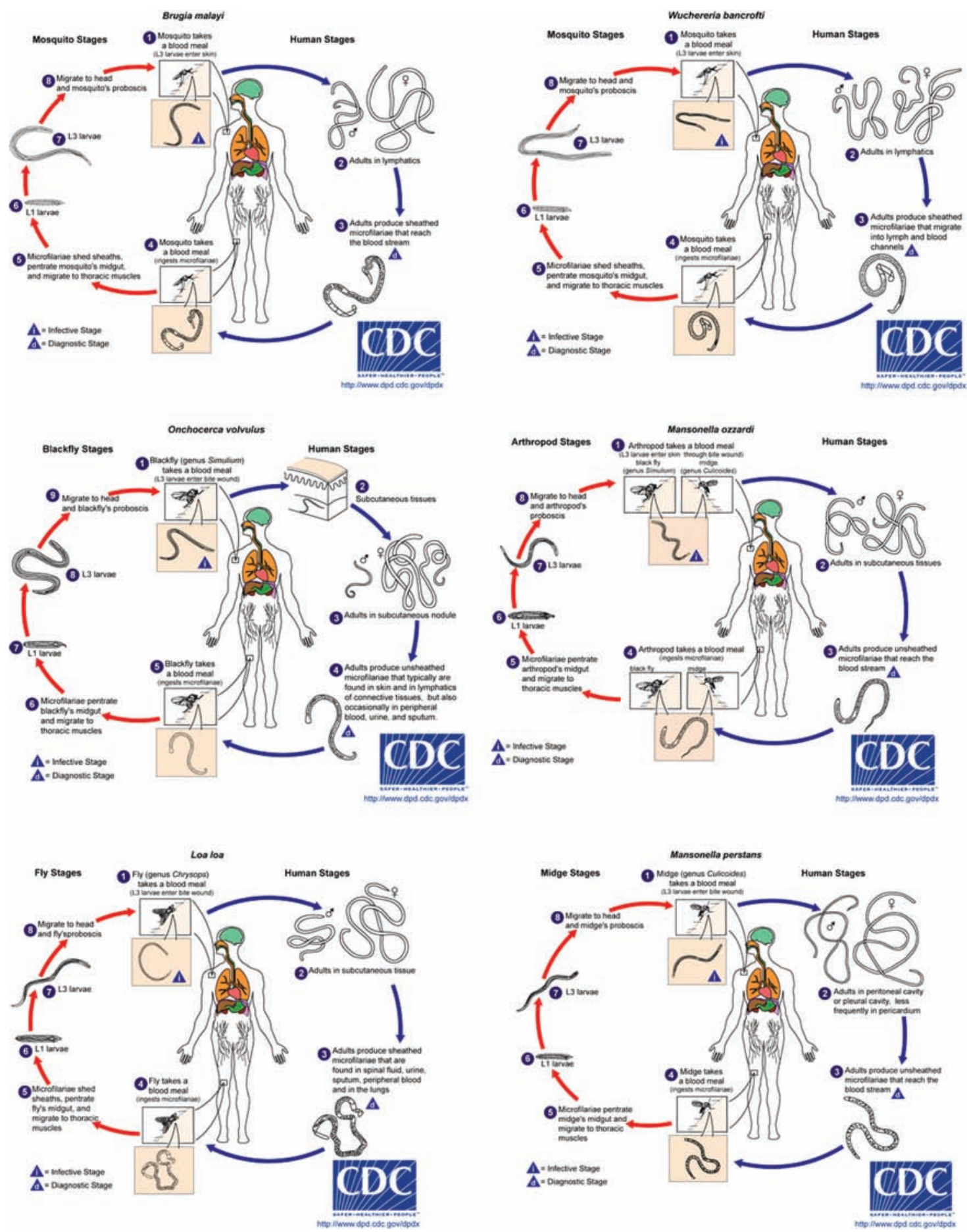

Figure 4.2.3.7.1. Brugia malayi (first raw, left), Wuchereria bancrofti (first raw, right), Onchocerca volvulus (send raw left), Mansonella ozzardi (second raw, right), Loa Loa (third raw, left) and Mansonella perstans (third raw, right) life cycles (with permission from CDC, Atlanta, USA; http://dpd.cdc.gov/dpdx/HTML/Filariasis. $\mathrm{htm})$ 
resource development projects, and to assess the effects of water resource development and management on the frequency and transmission dynamics of the disease. After almost 30 years, these authors were unable to define decisively whether implementation of water projects (including irrigation) are indeed associated with clinical symptoms. Patz et al. (2000) underlined the main environmental factors involved in filariasis expansion: rice cultivation and flooding, changes in soil moisture, polluted standing water and free-ranging domestic animals (pigs and cows) destroying the banks of unlined drains (thus creating shallow larval habitats). However, it should be noted that well designed irrigation without organic pollution does not encourage mosquitoes' proliferation resulting in minor filariasis is spread.

Adeleke et al. (2008) surveyed different environmental habitats (ground pools/ponds, gutters/open drains, tires, domestic containers and treeholes/leaf axils) for their mosquito growth support in the city of Abeokuta, Nigeria. Among the ten species encountered, Aedes aegypti bred in all the above habitats, while other species differed in their preferences. Tree holes/leaf axils was least preferred by all the surveyed mosquitoes species, emphasizing that man-made environments in contrast to natural ones are important habitats for these vectors. In Burdwan district, West Bengal (India), Adhikari and Haldar (1995) showed that preferentially $C$. quinquefasciatus spp. mosquitoes inhabit more colliery than non-colliery areas and are well correlated to microfilariae infection and infectivity rates. Nonetheless, they pointed out that the colliery environment can also affect, besides mosquito vectors, also the hosts, therefore influencing the filariasis outcome. These results are supported by another Culex species (Culex fatigans) that has been shown to breed preferentially in coalmine underground pits in India (Dutta, 1977).

In relation to mosquito vectors, Fonseca et al. (2006) studying worldwide populations of $C x$. quinquefasciatus and the southern house mosquito (in Hawaii) defined also as Cx. quinquefasciatus, reported that they are significantly genetically differentiated and well correlated to known W. bancrofti vector competence, and their pathways of expansion are remarkably similar to those inferred for Ae. aegypti, another vector species associated with humans parasites.

Another environmental problem has been reported by Poopathi et al. (2001). These authors found that Culex quinquefasciatus developed resistance to the insecticide malathion, possibly affecting filariasis persistence in spite of the mosquito control campaign in India. Malathion resistance in mosquitoes had been reported to be related to aliesterase malathion-degrading activity and not to acetylcholinesterase sensitivity to malaoxon (Miyata et al., 1984).

As a final point, Cho-Ngwa et al. (2009) studied endemic elephantiasis distribution and found evidence that podoconiosis is exacerbated by onchocerciasis (lymphatic filariasis). Podoconisis is a geochemical lymphedema seen in geographic areas of red clay soils around volcanoes (fertile volcanic highland) in Africa, Indonesia, Central and South America where susceptible families of bare-footed farmers absorb soil silica particles into their bodies. Absorption causes the patient's lymphatics to fibrose and further lymphatic ducts obstruction that finally cause enlargement of femoral nodes. As a result of both conditions it is obvious that this exacerbation does occur and it requires special physician attention to environmental conditions.

\subsection{REFERENCES}

Adeleke, M.A., Mafiana, C.F., Idowu, A.B., Adekunle, M.F. \& Sam-Wobo, S.O. (2008) Mosquito larval habitats and public health implications in Abeokuta, Ogun State, Nigeria. Tanzan J Health Res 10, 103-107.

Adhikari, P. \& Haldar, J.P. (1995) Prevalence of bancroftian filariasis in Burdwan district, West Bengal: II. Vector and microfilariae density in colliery and non-colliery areas. J Commun Dis 27, 181-185. 
Apiwathnasorn, C., Samung, Y., Prummongkol, S., Asavanich, A., Komalamisra, N. \& Mccall, P. (2006) Bionomics studies of Mansonia mosquitoes inhabiting the peat swamp forest. Southeast Asian J. Trop. Med. Public Health 37, 272-278.

Cho-Ngwa, F., Amambua, A.N., Ambele, M.A. \& Titanji, V.P.K. (2009) Evidence for the exacerbation of lymphedema of geochemical origin, podoconiosis, by onchocerciasis. J Infect Public Health 2, 198-203.

de Souza, D., Kelly-Hope, L., Lawson, B., Wilson, M. \& Boakye, D. (2010) Environmental factors associated with the distribution of Anopheles gambiae s.s in Ghana; an important vector of lymphatic filariasis and malaria. PLoS One 5, e9927.

Dutta, S.N. (1977) Evidence of Culex fatigans mosquito breeding in underground pits of a coalmine in India. Trans. R. Soc. Trop. Med. Hyg. 71, 180.

Erlanger, T.E., Keiser, J., Caldas, D.M., Bos, R., Singer, B.H. et al. (2005) Effect of water resource development and management on lymphatic filariasis, and estimates of populations at risk. Am. J. Trop. Med. Hyg. 73, 523-533.

Fischer, S. \& Schweigmann, N. (2004) Culex mosquitoes in temporary urban rain pools: seasonal dynamics and relation to environmental variables. J. Vector Ecol. 29, 365-373.

Fonseca, D.M., Smith, J.L., Wilkerson, R.C. \& Fleischer, R.C. (2006) Pathways of expansion and multiple introductions illustrated by large genetic differentiation among worldwide populations of the southern house mosquito. Am. J. Trop. Med. Hyg. 74, 284-289.

Hassan, A.N., Dister, S. \& Beck, L. (1998) Spatial analysis of lymphatic filariasis distribution in the Nile Delta in relation to some environmental variables using geographic information system technology. J Egypt Soc Parasitol 28, 119-131.

Lardeux, F. \& Cheffort, J. (2001) Ambient temperature effects on the extrinsic incubation period of Wuchereria bancrofti in Aedes polynesiensis: implications for filariasis transmission dynamics and distribution in French Polynesia. Med. Vet. Entomol. 15, 167-176.

Miyata, T., Saito, T. \& Yasutomi, K. (1984) High malathion degradation in malathion-resistant Culex pipiens quinquefasciatus. Eisei Dobutsu 35, 245-249.

Mogi, M. \& Motomura, M. (1996) Possible Culex pipiens pallens control by improvement of flow rates in water channels of Saga City, southwest Japan. J. Am. Mosq. Control Assoc. 12, 647-650.

Oemijati, S., Partono, F., Hudojo, H.T.R., Clarke, M.D., Gunning, J.J. \& Cross, J.H. (1978) Brugia malayi in Kresek, West Java, Indonesia: the effect of environmental changes of filarial endemicity. Trop Geogr Med 30, 301-304.

Okon, O.E., Iboh, C.I. \& Opara, K.N. (2010) Bancroftian filariasis among the Mbembe people of Cross River state, Nigeria. J Vector Borne Dis 47, 91-96.

Patz, J.A., Graczyk, T.K., Geller, N. \& Vittor, A.Y. (2000) Effects of environmental change on emerging parasitic diseases. Int. J. Parasitol. 30, 1395-1405.

Petersen, J.J. \& Chapman, H.C. (1969) Factors of water in tree holes and related breeding of mosquitoes. Mosq News 29, 29-36.

Poopathi, S., Arunachalam, N., Gopalan, N., Baskaran, G. \& Mani, T.R. (2001) Resistance to malathion in Culex quinquefasciatus Say (Diptera: Culicidae) from Madurai, South India. Int J Trop Insect Sci 21, 251-255.

Rwegoshora, R.T., Pedersen, E.M., Mukoko, D.A., Meyrowitsch, D.W., Masese, N. et al. (2005) Bancroftian filariasis: patterns of vector abundance and transmission in two East African communities with different levels of endemicity. Ann Trop Med Parasitol 99, 253-265.

Sattenspiel, L. (2000) Tropical environments, human activities, and the transmission of infectious diseases. Am. J. Phys. Anthropol. 31, S3-31.

Taylor, M.J., Bandi, C. \& Hoerauf, A. (2005) Wolbachia bacterial endosymbionts of filarial nematodes. Adv. Parasitol. 60, 245-284. 


\section{Chapter 4.2.3.8 Dirofilariasis}

\section{[DIROFILARIA IMMITIS, D. REPENS, D. TENUIS, D. URSI, AND D. STRIATA]}

Dirofilariasis is caused by several species of the so-called heartworm of dogs: Dirofilaria. Dirofilaria immitis has a worldwide distribution preferably in warm climates ( $\mathrm{Ng}$ and Kelly, 1975). D. immitis and D. repens have dogs and other canids as final hosts, while $D$. tenuis develops in raccoons, D. ursi in bears and lynxes and D. striata in felids (mainly North and South America) (Deem and Emmons, 2005; Anyanwu et al., 2000). Transmission occurs by blood-sucking infected mosquitoes or blackflies (simulia) that transfer L3 larvae. The D. immitis adult parasite can be found in the right heart and pulmonary artery of canids (final hosts). Blood circulating microfilariae are sucked into the intermediate host (for the duration of blood meal), develop into L3 infective larvae and are further transmitted to humans by additional insects' bites. In humans, $D$. immitis inhabits lung' parenchyma, as does $D$. repens (occasionally), and other species settle in subcutaneous tissues (Figure 4.2.3.8.1). Clinical manifestations are mostly asymptomatic; however, vasculitis and pulmonary infarcts may occur with granulomas, expressed as pain, coughing, hemoptyasis and painful subcutaneous and conjunctiva nodules (Otranto and Eberhard, 2011).

\subsection{DIROFILARIASIS AND ENVIRONMENT}

Resembling lymphatic filariasis, transmission main vectors of dirofilaria nematode species are mosquitoes and biting flies. An investigation carried out in Padova (Italy) tried to assess the actual role of Aedes albopictus, a very aggressive anthropophylic mosquito (30-48 bites/h) in the transmission of dirofilariasis. Indeed, A. albopictus was found to harbor D. immitis (highest prevalence 27.5\%) therefore presenting a high-risk source for human and canid' infection (Cancrini et al., 2003; Pietrobelli, 2008). Recently, Miller and Crosbie (2011) surveyed canine heartworm prevalence in California (Fresno and Madera Counties) where to their surprise found only a low prevalence (3.5 to 3.8\%). They attributed this low prevalence to vector distribution and density that seem to be impacted by three years drought in central California. It has been suggested that Aedes sierrensis, the main putative vector species that uses tree holes to breed is affected by lack of rain and low humidity. Other factors suggested to affect the low 
prevalence were time spent outdoor, lower number of susceptible mosquito vectors (three in Madera County vs. seventeen in Florida) and elevations (from previous studies: significantly higher in foothill habitats than in valley habitats). Dogs' outdoor activity has also been shown to be a significant factor in dirofilarisis prevalence in Korea. In rural hunting dogs, D. immitis prevalence was $22.3 \%$ and $14.6 \%$ among stray dogs found within the city limits (Lim et al., 2010).

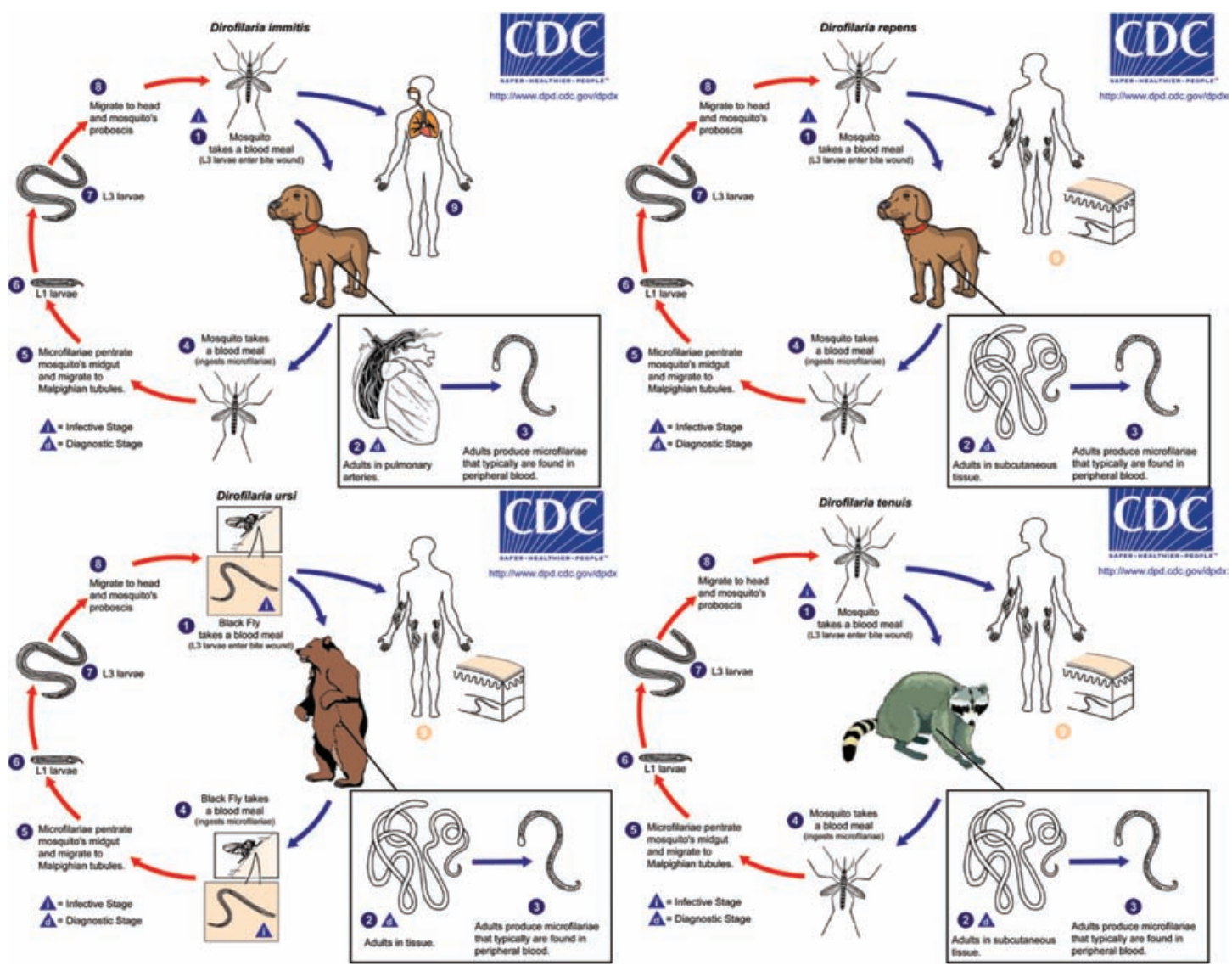

Figure 4.2.3.8.1. Dirofilaria immitis (first raw left), $D$. repens (first raw, right), $D$. ursi (send raw, left) and $D$. tenuis (second raw, right) life cycles. (with permission from CDC, Atlanta, USA; http://www.dpd.cdc. $\mathrm{gov} / \mathrm{dpdx} / \mathrm{html} / \mathrm{ImageLibrary} / \mathrm{A}-\mathrm{F} /$ Filariasis/body_Filariasis_il22.htm)

In California, a seropositivity survey in coyotes (Canis latrans) for the bacteria Bartonella vinsonii subsp. berkhoffii has been carried out to find out the environmental factors affecting the seroprevalence in these canids. Geographic clusters overlap between Bartonella sp. and Dirofilaria immitis had been reported in association with higher precipitation (with season variability) and proximity to coast. It may be very possible that proliferation of the two vectors (sandflies and mosquitoes) in these areas was well supported under these conditions. In Europe, especially in Italy, which is located at the subtropical and temperate climates boundary, a permanent rise in dirofilariasis has been observed during the last decades 
(Genchi et al., 2009). Various models are based on three limiting factors such as: 1) a threshold of $14^{\circ} \mathrm{C}$ below which Dirofilaria development will not proceed; 2) a requirement of 130 GDD (growing degree day) for parasite larvae to reach infectivity and 3) a maximum life expectancy of 30 days for a vector mosquito. They, predict that the summer temperatures (with peaks in July) are sufficient to facilitate extrinsic incubation of Dirofilaria even at high latitudes, into previously infection-free areas, including mosquito species new distribution along the new climate zone (Rinaldi et al., 2011).

In Argentina, a survey on canine heartworm epidemiology was carried out in urban areas of Buenos Aires Province (Vezzani et al., 2011). According to these authors, the best model predicted maximum heartworm prevalences around middle values of bare soil cover. It seems that this predictor is linked somehow to mosquito breeding sites and the available humidity, but the authors did not comment extensively on these findings.

\subsection{REFERENCES}

Anyanwu, I.N., Agbede, R.I., Ajanusi, O.J., Umoh, J.U. \& Ibrahim, N.D. (2000) The incrimination of Aedes (stegomyia) aegypti as the vector of Dirofilaria repens in Nigeria. Vet. Parasitol. 92, 319-327.

Beldomenico, P.M., Chomel, B.B., Foley, J.E., Sacks, B.N., Baldi, C.J. et al. (2005) Environmental factors associated with Bartonella vinsonii subsp. berkhoffii seropositivity in free-ranging coyotes from northern California. Vector Borne Zoonotic Dis. 5, 110-119.

Cancrini, G., Frangipane di Regalbono, A., Ricci, I. Tessarin, C., Gabrielli, S. \& Pietrobelli, M. (2003) Aedes albopictus is a natural vector of Dirofilaria immitis in Italy. Vet. Parasitol. 118, 195-202.

Deem, S.L. \& Emmons, L.H. (2005) Exposure of free-ranging maned wolves (Chrysocyon brachyurus) to infectious and parasitic disease agents in the Noel Kempff Mercado National Park, Bolivia. J. Zoo Wildl. Med. 36, 192-197.

Genchi, C., Rinaldi, L., Mortarino, M., Genchi, M. \& Cringoli, G. (2009) Climate and Dirofilaria infection in Europe. Vet. Parasitol. 163, 286-292.

Lim, S., Irwin, P.J., Lee, S., Oh, M., Ahn, K. et al. (2010) Comparison of selected canine vector-borne diseases between urban animal shelter and rural hunting dogs in Korea. Parasit Vectors 3, 32.

Miller, L.L. \& Crosbie, P.R. (2011) Canine heartworm (Dirofilaria immitis) in Fresno and Madera Counties, California: prevalence differences between foothill and valley habitats. Vet. Parasitol. 175, 84-91.

Ng, B.K. \& Kelly, J.D. (1975) Anthropozoonotic helminthiases in Australasia: Part 3: - studies on the prevalence and public health implications of helminth parasites of dogs and cats in urban environments. Int J Zoonoses 2, 76-91.

Otranto, D. \& Eberhard, M.L. (2011) Zoonotic helminths affecting the human eye. Parasit Vectors 4, 41.

Pietrobelli, M. (2008) Importance of Aedes albopictus in veterinary medicine. Parassitologia 50, 113-115.

Rinaldi, L., Genchi, C., Musella, V., Genchi, M. \& Cringoli, G. (2011) Geographical information systems as a tool in the control of heartworm infections in dogs and cats. Vet. Parasitol. 176, 286-290.

Vezzani, D., Carbajo, A.E., Fontanarrosa, M.F., Scodellaro, C.F., Basabe, J. et al. (2011) Epidemiology of canine heartworm in its southern distribution limit in South America: Risk factors, inter-annual trend and spatial patterns. Vet. Parasitol. 176, 240-249. 


\section{Chapter 4.2.3.9 Gnathostomiasis}

\section{[GNATHOSTOMA SPINIGERUM, G. HISPIDUM, G. DOLORESI, G. NIPPONICUM]}

Gnathostomiasis (or under its other synonyms: creeping eruption, wandering swelling, larva migrans profundus, Yangtze edema, physaloptera and Choko-Fuschu Tua chid) is caused in humans by the nematode Gnathostoma spinigerum and related species. G. spinigerum distribution is predominantly in Southeast Asia, Central America, and Australia with lower prevalence in Europe and Japan. In animals, the infection is severe with fatal outcome. Transmission occurs by consumption of raw or undercooked fish and meat. The life cycle of this parasite is linked to several intermediary and final hosts, including humans as accidental hosts. Unembryonated eggs excreted from infected hosts (dogs, cats, wild boars or pigs) contaminate water sources where they embryonate releasing L1 larvae. Copepods or Cyclops (water fleas) spp. ingest L1 larvae that develop into L2 larvae, inside these intermediary hosts. When a second intermediary host (e.g. fish, frog or snail) consumes copepods or cyclops, it becomes infected with L2 larvae that further develop into the L3 larvae infective for a final host. A paratenic host such as waterfowl or chickens can feed on a second intermediary host, thus becoming infected with L3 larvae to be further transmitted to a final host that consume the paratenic host. Humans are dead-end host that may ingest L2 or L3 larvae (individuals who are exposed to contaminated meat or water, larvae may rarely penetrate their skin) but they do not develop into adult worms to produce eggs (as in cats, dogs, pigs, etc). Inside humans, larvae penetrate the stomach wall and migrate to various inner organs or to subcutaneous tissue (Figure 4.2.3.9.1). Clinical manifestations are: epigastric pain, malaise, fever, urticaria, anorexia, nausea, vomiting, diarrhea, itching, painful skin erythematous migrating swellings including lesions, invasion of inner organs and inflammation (including eyes and central nervous system).

\subsection{GNATHOSTOMIASIS AND ENVIRONMENT}

Gnathostomiasis has been reported in Mexico since 1970, continuously increasing up to several thousand cases. Interestingly, the spread of this parasitic disease in Mexico is a lucid example of how environmental changes can affect the distribution of a zoonotic disease. Numerous gnathostomiasis cases 
have occurred near a dam (named Presidente Miguel Aleman), whose water has been also used to grow imported tilapia fishes, concurrently with the rise in the popularity of these fishes in dishes such as ceviche or callos (both popular seafood dishes made from freshly marinated raw fish). During the same time period, part of the tilapia harvest (probably already infected with G. spinigerum) had been shipped to other aquacultures areas of Mexico, therefore transferring the infective agent around the country (McCarthy and Moore, 2000; Martínez-Cruz et al., 1989). Following these emerging cases, studies have been carried out in an attempt to identify the source of infection in freshwater fishes near Culiacan, the capital of Sinaloa, a state on the north Pacific coast of Mexico. No larvae were found in the examined fishes and the authors attributed the negative results to sample size; however, larvae were found in the second intermediary hosts such as pescivorous birds (four species), thereby corroborating the presence of this parasite in the aquatic fauna (Ogata et al., 1998; Diaz Camacho et al., 1998). Humans, as dead-end hosts, resulting in non-productive adult worms, can not transmit the parasite while migrating or traveling to other geographical areas, but can be infected only in those areas, thus requiring clinicians' awareness of tropical infections (Charoenratanakul, 1997).

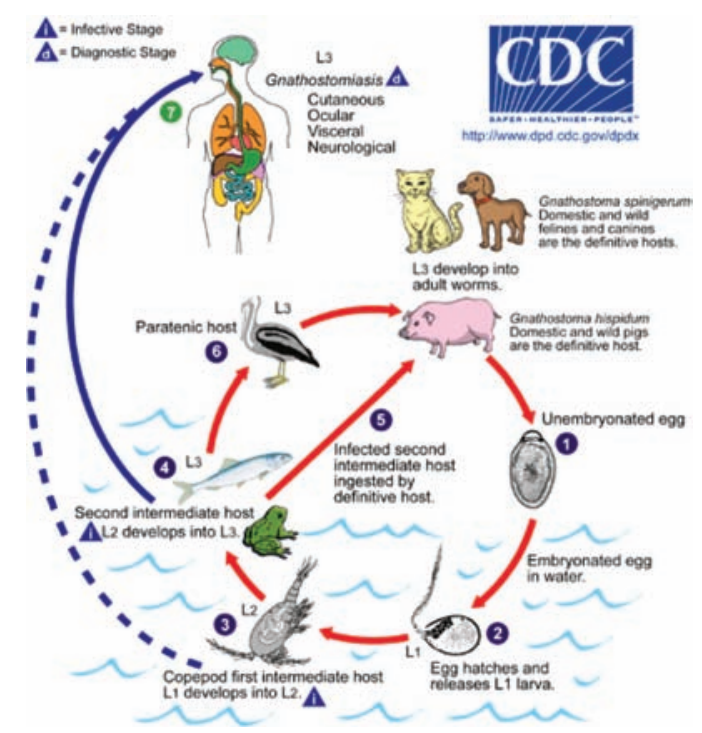

Figure 4.2.3.9.1. Gnathostoma spp. life cycle (with permission from CDC, Atlanta, USA; http://www.cdc. gov/parasites/gnathostoma/biology.html)

\subsection{REFERENCES}

Charoenratanakul, S. (1997) Tropical infection and the lung. Monaldi Arch Chest Dis 52, 376-379.

Diaz Camacho, S.P., Zazueta Ramos, M., Ponce Torrecillas, E., Osuna Ramirez, I., Castro Velazquez, R. et al. (1998) Clinical manifestations and immunodiagnosis of gnathostomiasis in Culiacan, Mexico. Am. J. Trop. Med. Hyg. 59, 908-915.

Martínez-Cruz, J.M., Bravo-Zamudio, R., Aranda-Patraca, A. \& Martínez-Marañón, R. (1989) Gnathostomiasis in Mexico. Salud Publica Mex 31, 541-549.

McCarthy, J. \& Moore, T.A. (2000) Emerging helminth zoonoses. Int. J. Parasitol. 30, 1351-1359.

Ogata, K., Nawa, Y., Akahane, H., Diaz Camacho, S.P., Lamothe-Argumedo, R. \& Cruz-Reyes, A. (1998) Short report: gnathostomiasis in Mexico. Am. J. Trop. Med. Hyg. 58, 316-318. 


\section{Chapter 4.2.3.10 Gongylonemiasis}

\section{[GENUS GONGYLONEMA, GONGYLONEMA PULCHRUM]}

Gonglylonema pulchrum parasitic nematode belongs to the genus Gongylonema and is the only one capable of infecting humans. Humans are accidental hosts who, due to poor sanitary conditions, become infected by direct ingestion of coprophagous insects, or food and water contaminated with these insects (e.g., dung beetles and cockroaches). The distribution is worldwide (Germany, United States, Iran, Laos, Japan, Morocco, China, Italy, New Zealand and Egypt) with very low numbers of reported cases ( $\sim 50$ cases). Buccal mucosa is the ideal infection site of the parasite. The final hosts include cattle, hedgehogs, dogs, cats, ruminants, rabbits, skunks, etc. while dung beetles and cockroaches are both vectors and intermediate hosts. Besides insect ingestion that transfers the infective larvae, direct ingestion of water contaminated with free-larvae (from an intermediary host) can also infect humans. Humans can support the growth of adult worms. Clinical manifestations are mainly expressed in mucosa of the oral cavity where the parasite finally migrates with local inflammation and bleeding with moderate pain.

\subsection{GONGYLONEMIASIS AND ENVIRONMENT}

Corn et al. (1985) studied the helminth community of collared peccaries of the southern plains of Texas (a known arid habitat) in order to compare it to collared peccaries from Gulf coastal prairies. Collared peccaries are mammals resembling hogs (also called musk hog and Mexican hog) that feed on fruits, roots (and bulbs), tubers, palm nuts, grasses, invertebrates and small vertebrates. The authors reported the presence of G. pulchrum in collared peccaries from drier habitats compared to none in those from the coastal plains. It seems that infection (without clinical symptoms in these animals) occurs by ingestion (as one of nutrition components) of dung beetles known as intermediate hosts. The highest densities of these coprophagous insects have been reported to be during the spring and early summer (June) with fully correlated G. pulchrum presence in its final host during and after periods of utmost intermediate host density.

Another infection with G. pulchrum has been reported in Bolivian squirrel monkeys (Saimiri boliviensis) from a zoological garden in Kyushu, Japan (Sato et al., 2005). The prevalence of eggs containing larvae was between 25.5 to $55.5 \%$ revealing a continuous infection of these monkeys and possible other zoo animals 
through the presence of dung beetles and cockroaches as intermediate hosts in this particular close environment.

\subsection{REFERENCES}

Corn, J.L., Pence, D.B. \& Warren, R.J. (1985) Factors affecting the helminth community structure of adult collared peccaries in southern Texas. J. Wildl. Dis. 21, 254-263.

Sato, H., Une, Y. \& Takada, M. (2005) High incidence of the gullet worm, Gongylonema pulchrum, in a squirrel monkey colony in a zoological garden in Japan. Vet. Parasitol. 127, 131-137. 


\section{Chapter 4.2.3.11}

\section{Lagochilascariasis}

\section{[LAGOCHILASCARIS MINOR]}

Lagochilascariasis is a very rare disease caused by the ascarid nematode Lagochilascaris minor, a parasite with felids as probable final hosts (Sakamoto and Cabrera, 2002). The distribution of this parasite is linked to remote jungle forest areas in the tropics. Humans are infected by the ingestion of intermediate hosts from rural sylvatic environments (e.g., mice, agoutis, paca, capibara and other rodents) but direct embryonated egg contact can be also a possible path of infection (including autoinfection from eggs and larvae containing nodules) (Vieira et al., 2000; Moncada et al., 1998; Paco et al., 1999). The life cycle consists of intermediate hosts (mainly rodents) infected with embryonated eggs from feces of felids that develop into larvae that migrate to inner organs and subcutaneous fatty tissue to become encapsulated. When infected rodents are preyed on by felids, the ingested larvae develop into adult worms in the esophagus, pharynx and cervical lymph nodes of this final host. Clinical manifestations are chronic nodular swellings in the neck, throat, nasal sinuses, tonsils, brain and lungs. Puss discharge from lesions contains various stages of the parasite (larvae and adults) suggesting possible autoinfections. Patients' general conditions is severe and in some cases fatal.

\subsection{LAGOCHILASCARIASIS AND ENVIRONMENT}

There are very few publications on this parasitic nematode and its environmental behavior, however, some clues can be drawn from a specific case report of the natural infection of a bush dog (found killed) on a rural road in the Northeast of Bolivar State, a locality where a patient with lagochilascariasis had lived for the past 16 years (Volcan and Medrano, 1991). Bush dog is a gregarious, diurnal carnivore (preying on Paca), mainly in wet savannahs and tropical and equatorial forests of South America. Bush dogs use hollow logs and cavities (e.g., armadillo burrows) for shelter. It is very possible that infection with Lagochilascaris minor will take place in such environments where infected rodents reside underground. 


\subsection{REFERENCES}

Moncada, L.I., Alvarez, C.A., Castellanos, C., Caceres, E., Nicholls, S. \& Corredor, A. (1998) Lagochilascaris minor in a patient from the Colombian amazon: a case report. Rev. Inst. Med. Trop. Sao Paulo 40, 387-389.

Paco, J.M., Campos, D.M. \& Oliveira, J.A. (1999) Wild rodents as experimental intermediate hosts of Lagochilascaris minor Leiper, 1909. Mem Inst Oswaldo Cruz. 94, 441-449.

Sakamoto, T. \& Cabrera, P.A. (2002) Subcutaneous infection of Lagochilascaris minor in domestic cats from Uruguay. Vet. Parasitol. 108, 145-152.

Vieira, M.A., de Oliveira, J.A., Ferreira, L.S., de Oliveira, V. \& Barbosa, C.A. (2000) A case report of human lagochilascariasis coming from Para State, Brazil. Rev. Soc. Bras. Med. Trop. 33, 87-90.

Volcan, G.S. \& Medrano, C.E. (1991) Natural infection of Speothos venaticus (Carnivora: Canidae) by adult stages of Lagochilascaris sp. Rev. Inst. Med. Trop. Sao Paulo 33, 451-458. 


\section{Chapter 4.2.3.12}

\section{Larva migrans cutanea}

\section{[ANCYLOSTOMA BRAZILIENSE, UNCINARIA STENOCEPHALA, A. CANINUM, A. TUBAEFORMAE, BUNOSTOMUM PHLEBOTONUM]}

Larva migrans cutanea (also known as creeping eruption or cutaneous larva migrans-CLM) is mainly an acute syndrome of the skin caused by the penetration of parasitic nematode larvae, mostly by Ancylostoma braziliense and Uncinaria stenocephala that are dogs' hookworms, and occasionally by other hookworms A. caninum (from dogs), A. tubaeformae (from cats) and Bunostomum phlebotonum (from cattle). The distribution is worldwide with preference in moist tropical and subtropical areas but also with U. stenocephala in moderate climates (Mukaratirwa and Taruvinga, 1999; Malgor et al., 1981). Humans are accidental hosts (tourism near warm climate beaches) by percutaneous infection with larvae in moist and warm environments while dogs, cats and cattle are the definitive hosts (Edelglass et al., 1982; Scaini et al., 2003; Watson et al., 1981). In these definitive hosts, the filariform larvae develop into adult worms to produce eggs. Rhabditiform larvae hatch from eggs excreted by the definitive hosts (cats, dogs, etc.) and further develop in moist environments (beaches and playground) into infective filariform larvae that in turn infect again its final hosts, including accidental hosts such as humans. The parasite does not develop into adult worms in humans, but can migrate subcutaneously as filariform larvae (Figure 4.2.3.12.1). Clinical manifestations are: development of papules at entrance sites of filariform larvae and burrows between skin's corium and stratum granulosum generating erythema, edema, crusts, itching and pricking pain with possible secondary infections if scratching is present.

\subsection{LARVA MIGRANS CUTANEA AND ENVIRONMENT}

Michaud et al. (2003) surveyed parasitic helmith presence in feral non-human primates' feces and compared it to that in the human population from the same area. The authors found that in Peru, non-human primates and that in the humans from the same area harbor Ancylostoma braziliensis besides other parasitic helminths.

It seems that filariform larvae of Strongyloides spp. are resistant to a variety of chemicals, have chemoattraction to plasma and $\mathrm{NaCl}$ salt and persist in moist fresh excreta, which may explain their 
infective successful routes when present on sand beaches where dogs or cats have defecated and people come in direct contact with it (Blank et al., 1959; Ma, 1987; Mukaratirwa and Taruvinga, 1999). Zhu et al. (2011) performed a model study to understand the impact of non-point pollution (from bather shedding, animals' feces, near shore sand and other environmental conditions) on the transport of bioindicators at a subtropical recreational marine beach in South Florida. These authors clearly showed that dog fecal events had the major transient impact (in this case with enterococci as indicators) in a limited area within several hours while other non-point sources had a limited impact on bacterial contamination. This model might also be applied to dog' feces containing filiform migrating larvae that under moist conditions can survive for a prolonged time. Similar persistence and resistance have been reported for Strongyloides spp. in soil samples contaminated with dog' feces in Kuala Lumpur-an urban area and Kula Lipis-a rural area (Malaysia) (Azian et al., 2008).

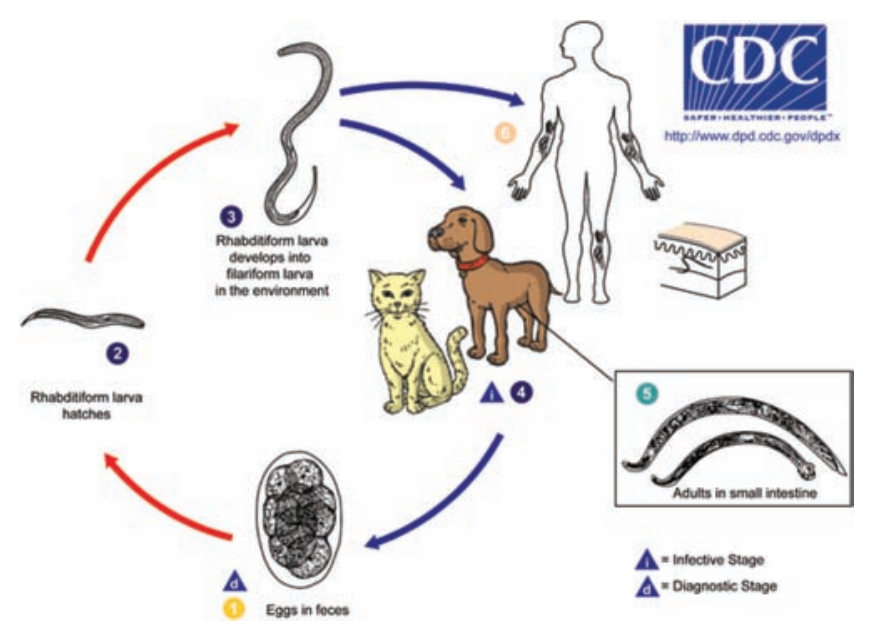

Figure 4.2.3.12.1. Ancylostoma braziliense and other Strongyloides spp. causing cutaneous larva migrans life cycle (with permission from CDC, Atlanta, USA; http://dpd.cdc.gov/dpdx/HTML/Hookworm.htm)

Reperant et al. (2007) studied the prevalence of dixenous helminths in red foxes from rural and urban area expecting to find a declining effect as a consequence of rodent' reduction in urban area. In relation to Uncinaria stenocephala (overall prevalence 78.2\%) the authors did not find any significant variation between the two environments. This result may be explained by the transmission route of this hookworm that is mainly dependent upon the abundance and survival of the free-living stages along host density on which urbanization has no significant effect (in contrast to increasing numbers of pets and stray dogs that may cause constant persistance).

In relation to domestic animals, a study from Poland showed that dogs from the Warsaw region (an area with high U. stenocephala prevalence) differ in their hookworm prevalence (Gorski et al., 1996). Housedogs' infection prevalence was between 2.7 to and $4.1 \%$, while stray dogs or dogs living in shelters had a much higher infection prevalence: from 10.1 to $47.7 \%$. Importantly, some locations with high numbers of $U$. stenocephala infections were in proximity to or surrounded by forest. The authors suggested that forest might support a better survival of hookworm larvae than open spaces and provide close contact with other infected animals (e.g., foxes) for constant transmission.

Also in Poland, a recent study of a recreational area was carried out in order to find out the relation between wild animals' helminths infestation (red foxes and wild boars) and soil contamination 
(Mizgajska-Wiktor and Jarosz, 2010). The authors reported Strongyloides spp. prevalence in positive feces of $36.6 \%$ in wild boar and $45.5 \%$ (mainly U. stenocephala) in foxes; however, no soil contamination was found. Possible explanations have been suggested based on soil characteristics (loose sand soil) that do not support the persistence and survival of larvae or eggs and wild animals' behavior in human crowded areas related to defecation.

Finally, Perec-Matysiak et al. (2008) evaluated the contamination of various urban areas with geohelminth eggs in Wroclaw, Poland. According to their results, the highest rate of contamination was observed in city squares (U. stenocephala $7 \%$ and A. caninum $4.9 \%$ among the positive samples). There are at least two supporting factors for this high prevalence: 1) city squares are one of the most crowded sites in terms of dog owners and 2) owing to municipal maintenance; street washing provides a moist milieu for these hookworms survival.

\subsection{REFERENCES}

Azian, M.Y.N., Sakhone, L., Hakim, S.L., Yusri, M.Y., Nurulsyamzawaty, Y. et al. (2008) Detection of helminth infections in dogs and soil contamination in rural and urban areas. Southeast Asian J. Trop. Med. Public Health 39, 205-212.

Blank, H., Winter, M.W. \& Beck, J.W. (1959) The effects of chemical and physical agents on filariform larvae of Ancylostoma braziliense. Am. J. Trop. Med. Hyg. 8, 401-404.

Edelglass, J.W., Douglass, M.C., Stiefler, R. \& Tessler, M. (1982) Cutaneous larva migrans in northern climates. A souvenir of your dream vacation. J. Am. Acad. Dermatol. 7, 353-358.

Gorski, P., Badowska, M. \& Wedrychowicz, H. (1996) Occurrence of the nematode Uncinaria stenocephala in dogs from the Warsaw region. Wiad Parazytol 42, 221-227.

Hoff, N-P., Mota, R., Groffik, A. \& Hengge, U.R. (2008) Cutaneous larva migrans. Hautarzt 59, $622-626$.

Ma, R. (1987) Chemoattraction of infective larvae of Ancylostoma braziliense to rodent plasmas and to salts. Acta. Biol. Hung. 38, 235-245.

Malgor, R., Oku, Y., Gallardo, R. \& Yarzabal, I. (1996) High prevalence of Ancylostoma spp. infection in dogs, associated with endemic focus of human cutaneous larva migrans, in Tacuarembo, Uruguay. Parasite 3, 131-134.

Michaud, C., Tantalean, M., Ique, C., Montoya, E. \& Gozalo, A. (2003) A survey for helminth parasites in feral New World non-human primate populations and its comparison with parasitological data from man in the region. J. Med. Primatol. 32, 341-345.

Mizgajska-Wiktor, H. \& Jarosz, W. (2010) Potential risk of zoonotic infections in recreational areas visited by Sus scrofa and Vulpes vulpes. Case study-Wolin Island, Poland. Wiad Parazytol 56, 243-251.

Mukaratirwa, S. \& Taruvinga, M. (1999) A survey on environmental contamination of suburban parks and playgrounds in Harare, Zimbabwe, with canine helminths of zoonotic significance. J S Afr Vet Assoc 70, 119-121.

Perec-Matysiak, A., Hildebrand, J., Zalesny, G., Okulewicz, A. \& Fatula, A. (2008) The evaluation of soil contamination with geohelminth eggs in the area of Wroclaw, Poland. Wiad Parazytol 54, 319-323.

Reperant, L.A., Hegglin, D., Fischer, C., Kohler, L., Weber, J-M. \& Deplazes, P. (2007) Influence of urbanization on the epidemiology of intestinal helminths of the red fox (Vulpes vulpes) in Geneva, Switzerland. Parasitol. Res. 101, 605-611.

Scaini, C.J., de Toledo, R.N., Lovatel, R., Dionello, M.A., dos Anjos, G.F. et al. (2003) Environmental contamination by helminth eggs and larvae in dog feces from central area of Cassino beach, Rio Grande do Sul. Rev. Soc. Bras. Med. Trop. 36, 617-619.

Watson, T.G., Nettles, V.F. \& Davidson, W.R. (1981) Endoparasites and selected infectious agents in bobcats (Felis rufus) from West Virginia and Georgia. J. Wildl. Dis. 17, 547-554.

Zhu, X., Wang, J.D., Solo-Gabriele, H.M. \& Fleming, L.E. (2011) A water quality modeling study of non-point sources at recreational marine beaches. Water Res. 45, 2985-2995. 


\section{Chapter 4.2.3.13}

\section{Larva migrans visceralis}

\section{[TOXOCARA CANIS, TOXOCARA CATI-SYN. MYSTAX, BAYLISASCARIS PROCYONIS]}

Larva migrans visceralis (also known as visceral larva migrans -VLM) is a worldwide syndrome caused by nematode' larvae invasion of inner organs or the eye (mainly by larvae of the dog nematode -Toxocara canis, cat nematode -Toxocara cati, syn. mystax and rarely a raccoon nematode - Baylisascaris procyonis). Distribution is worldwide in carnivorous animals (dogs, cats, raccoons, etc.) (Himsworth et al., 2010; Shalaby et al., 2010). As a paratenic host, infections in humans may occur by accidental ingestion of contaminated soil, consumption of unwashed vegetables or meat (hunting) of another paratenic host contaminated with embryonated eggs of those nematodes (Glickman et al., 1987; Borecka et al., 2010). Most of the cases are asymptomatic, with immunological responses only: eosinophilia and positive serology. However, when heavy infection occurs, two main clinical presentations will take place: visceral larva migrans (VLM) and ocular larva migrans (OLM). In preschool children, visceral larva migrans occurs when larvae invade multiple tissues (liver, heart, lungs, brain and muscle). In the general population, ocular larvae migrans occurs when larvae or even one larva reach the eye to encyst within the orbit produce lesions. The life cycle of these nematodes includes excretion of eggs by infected dogs, cats or raccoons in their feces. Outside, in the environment eggs develop into highly resistant embryonated eggs that are set to be ingested by a new healthy dog/cat or other paratenic host. Following ingestion, the embryonated eggs hatch and release larvae that develop into mature roundworms (male and female) to complete the cycle. In paratenic hosts (birds, pigs, rodents, goats, monkeys, rabbits and humans) larvae will penetrate the intestinal wall, migrate to the lungs or are disseminated through the arterial system to many organs where they enter the parenchyma to be encapsulated by connective tissue, without further development in adult worms (Talvik et al., 2006). Encapsulated larvae (L2 stage) can persist for years and even reactivate. In addition, humans may become infected by undercooked meat consumption of a paratenic host (e.g., rabbit) that will transfer its infectious larvae (Figure 4.2.3.13.1). Clinical manifestations are diverse and depend on the infestation load; most infections seem to be asymptomatic but when a serious infection occurs symptoms such as fever, abdominal pain, coughing, wheezing (asthmatic complaints) will present. Persistent reinfection will 
cause more severe symptoms, such as lymphadenophaty, hepatosplenomegaly, urticaria, interstitial pneumonia, anorexia, neurotropism (CNS seizure, as in the cases of B. procyonis infection, regarded as highly pathogenic with fatal outcome), heart invasion and death. In OLM, visual acuity is reduced with manifestation of endophtalmitis, uveitis, and chorioretinitis or with intraretinal granulomas.

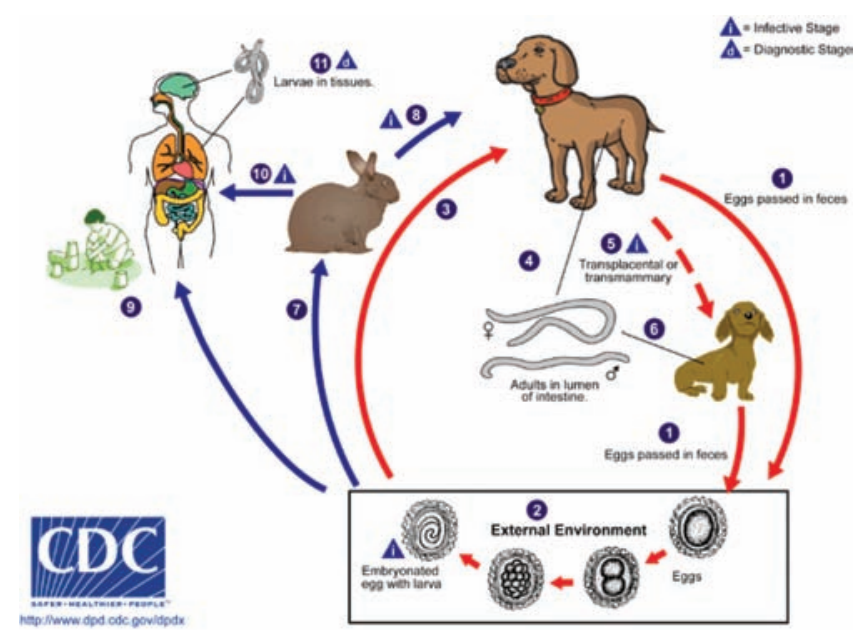

Figure 4.2.3.13.1. Toxocara canis life cycle (with permission from CDC, Atlanta, USA; http://www.dpd.cdc. gov/dpdx/HTML/ImageLibrary/Toxocariasis_il.htm)

\subsection{LARVA MIGRANS VISCERALIS AND ENVIRONMENT}

Direct human infection by ingestion of soil containing embryonated eggs occurs more often in crawling infants and preschool children that play with soil and sand in playgrounds, park green areas, public housing areas, parkways, and school yards (Tarsitano et al., 2010; Grygierczyk et al., 2003; Gillespie et al., 1991). Therefore, soil contamination in urban and rural areas by infected dogs and cats is the most important environmental factor in the enhanced transmission of these parasites (Azian et al., 2008; Mizgajska et al., 2001; Castillo et al., 2000; Ladczuk and Balicka-Ramisz, 2010). Mizgajska-Wiktor and Jarosz (2007) compared the degree of soil contamination with eggs of T. cani and T. cati in rural and urban areas of Poznan, Poland. Urban areas revealed 19.8\% positive samples while rural areas $15.6 \%$, with similar percentages in spring and autumn. T. cati eggs were more prevalent in urban areas $(97 \%$ of all eggs recovered) and $T$. canis more prevalent in rural areas (84\% of all eggs recovered). According to the defecation habits of these two animals, cats do cover their excreta while dogs do not, and therefore it can very possibly be that in areas where bare soil is scarcer (e.g., the urban area) cats' excreta will be found more often, while dogs can defecate on paved ground to be further washed or removed through municipal activity.

Another interesting aspect of eggs environmental distribution linked to dogs' behavior has been recently presented. Roddie et al. (2008) showed that dogs, in their case, stray dogs, carry T. canis eggs on their fur (67\% positive) with a significantly higher prevalence in puppies. This valuable study indicates the significant epidemiological and environmental aspects of Toxocariosis: 1) dogs do shed fur in and around human dwellings; 2) infants are very fond of puppies, and therefore close contact and 
transmission is imminent; 3) transmission occurs at long distances; 4) direct and early infection of puppies do occur and 5) potential transmission to many paratenic hosts without soil or meat ingestion.

In relation to climate, Jimenez et al. (1997) using a serological survey of human toxocariasis in the Canary Islands (Spain) reported variable exposure of the local population to those helminths. They explained this variability based on the different Canarian mesoclimates with significant differences being found between humid and arid islands (several reports revealed eggs excellent survival for several years in shaded area, appropriate humidity, temperature and oxygen) (Sommerfelt et al., 2006; Uga, 1993; Maikai et al., 2008). They found a significant positive correlation between De Martonne's humidity-aridity index (Iar-DM is the ratio between the mean annual values of precipitation $(\mathrm{P})$ and temperature $(\mathrm{T})+10^{\circ} \mathrm{C}$ (De Martonne, 1926) and the percentage of seropositive people on the different islands. Humidity and increased temperature (optimal at $19-24^{\circ} \mathrm{C}$, but not at $34^{\circ} \mathrm{C}$ where infective eggs survival declined) have been shown to enhance survival and development of Toxocara canis eggs (Gamboa, 2005; Andresiuk et al., 2007). In another study performed in rural areas in Argentina on toxocariasis-related factors, among the significantly related ones were floods and dog ownership (Chiodo et al., 2006). Considering T. canis's biological cycle, flooding will favor the evolution and survival of eggs, extending their viability that increases contamination odds.

Finally, Papajova and Juris (2009) studied the effect of aerobic composting and anaerobic stabilization of organic wastes on the survival of parasitic germs, among them T. canis. According to their results, aerobic composting $\left(>50^{\circ} \mathrm{C}\right)$ was much more efficient in this parasite's eggs inactivation (total devitalization after 48 hours) compared to anaerobic stabilization ("composting") of organic wastes from public areas (maximum temperature $35^{\circ} \mathrm{C}$ ) (only $50 \%$ devitalization after 48 hours).

\subsection{REFERENCES}

Andresiuk, V., Sardella, N. \& Denegri, G. (2007) Seasonal fluctuations in prevalence of dog intestinal parasites in public squares of Mar del Plata city, Argentina and its risk for humans. Rev. Argent. Microbiol. 39, 221-224.

Azian, M.Y.N., Sakhone, L., Hakim, S.L., Yusri, M.Y., Nurulsyamzawaty, Y. et al. (2008) Detection of helminth infections in dogs and soil contamination in rural and urban areas. Southeast Asian J. Trop. Med. Public Health 39, 205-212.

Borecka, A., Gawor, J., Niedworok, M. \& Sordyl, B. (2010) Occurrence of Toxocara spp. eggs in household environment of children with diagnosed toxocariasis in Lodz voivodeship. Wiad Parazytol 56, 141-144.

Castillo, D., Paredes, C., Zanartu, C., Castillo, G., Mercado, R. et al. (2000) Environmental contamination with Toxocara sp. eggs in public squares and parks from Santiago, Chile, 1999. Bol Chil Parasitol 55, 86-91.

Chiodo, P., Basualdo, J., Ciarmela, L., Pezzani, B., Apezteguia, M. \& Minvielle, M. (2006) Related factors to human toxocariasis in a rural community of Argentina. Mem I Oswaldo Cruz 101, 397-400.

De Martonne, E. (1926) Une nouvelle fonction climatologique: L'indice d'aridité. La Meteorologie, 449-458.

Gamboa, M.I. (2005) Effects of temperature and humidity on the development of eggs of Toxocara canis under laboratory conditions. J. Helminthol. 79, 327-331.

Gillespie, S.H., Pereira, M. \& Ramsay, A. (1991) The prevalence of Toxocara canis ova in soil samples from parks and gardens in the London area. Public health 105, 335-339.

Glickman, L.T., Magnaval, J.F., Domanski, L.M., Shofer, F.S., Lauria, S.S. et al. (1987) Visceral larva migrans in French adults: a new disease syndrome?. Am. J. Epidemiol. 125, 1019-1034.

Grygierczyk, D., Kwiatkowski, S. \& Sodowska, H. (2003) Soil contamination with Toxocara spp. eggs in the Katowice area and its environs. Wiad Parazytol 49, 57-60.

Himsworth, C.G., Skinner, S., Chaban, B., Jenkins, E., Wagner, B.A. et al. (2010) Multiple zoonotic pathogens identified in canine feces collected from a remote Canadian indigenous community. Am. J. Trop. Med. Hyg. 83, 338-341. 
Jimenez, J.F., Valladares, B., Fernandez-Palacios, J.M., de Armas, F. \& del Castillo, A. (1997) A serologic study of human toxocariasis in the Canary Islands (Spain): environmental influences. Am. J. Trop. Med. Hyg. 56, 113-115.

Ladczuk, D. \& Balicka-Ramisz, A. (2010) Occurrence of parasites in the alimentary canal of cats from Szczecin area, Poland. Wiad Parazytol 56, 235-242.

Maikai, B.V., Umoh, J.U., Ajanusi, O.J. \& Ajogi, I. (2008) Public health implications of soil contaminated with helminth eggs in the metropolis of Kaduna, Nigeria. J. Helminthol. 82, 113-118.

Mizgajska, H., Jarosz, W. \& Rejmenciak, A. (2001) Distribution of sources of Toxocara spp. infection in urban and rural environments in Poland. Wiad Parazytol 47, 399-404.

Mizgajska-Wiktor, H. \& Jarosz, W. (2007) A comparison of soil contamination with Toxocara canis and Toxocara cati eggs in rural and urban areas of Wielkopolska district in 2000-2005. Wiad Parazytol 53, 219-225.

Papajova, I. \& Juris, P. (2009) The effect of composting on the survival of parasitic germs. In: Composting: Processing, Materials and Approaches. Editor(s): Pereira, J.C. \& Bolin, J.L., pp. 113-154. Publisher: Nova Science Publishers, Inc., Hauppauge, N. Y.

Roddie, G., Stafford, P., Holland, C. \& Wolfe, A. (2008) Contamination of dog hair with eggs of Toxocara canis. Vet. Parasitol. 152, 85-93.

Shalaby, H.A., Abdel-Shafy, S. \& Derbala, A.A. (2010) The role of dogs in transmission of Ascaris lumbricoides for humans. Parasitol. Res. 106, 1021-1026.

Sommerfelt, I.E., Cardillo, N., Lopez, C., Ribicich, M., Gallo, C. \& Franco, A. (2006) Prevalence of Toxocara cati and other parasites in cats' faeces collected from the open spaces of public institutions: Buenos Aires, Argentina. Vet. Parasitol. 140, 296-301.

Talvik, H., Moks, E., Magi, E., Jarvis, T. \& Miller, I. (2006) Distribution of Toxocara infection in the environment and in definitive and paratenic hosts in Estonia. Acta Vet. Hung. 54, 399-406.

Tarsitano, E., Greco, G., Decaro, N., Nicassio, F., Lucente, M.S. et al. (2010) Environmental monitoring and analysis of faecal contamination in an urban setting in the city of Bari (Apulia region, Italy): health and hygiene implications. Int J Environ Res Public Health 7, 3972-3986.

Uga, S. (1993) Prevalence of Toxocara eggs and number of faecal deposits from dogs and cats in sandpits of public parks in Japan. J. Helminthol. 67, 78-82. 


\section{Chapter 4.2.3.14}

\section{Oesophagostomiasis}

\section{[OESOPHAGOSTOMUM BIFURCUM, O. ACULEATUM, O. STEPHANOSTOMUM]}

Oesophagostomiasis is a parasitic chronic disease of the colon, caused by a species of worms falling under the family Strongylidae definition. Oesophagostomum spp., in particular O. bifurcum, are common parasites of livestock and animals such as goats, pigs and primates, although it seems that humans are increasingly becoming complimentary hosts as well. Although the routes of human infection have not yet been adequately elucidated, it is believed that transmission occurs through oral-fecal means, with infected humans unknowingly ingesting soil or vegetables containing the infectious filariform larvae (stage L3). Recently, human-to-human transmission has been reported, questioning the classification of this disease as zoonosis! Oesophagostomum infections are largely localized to northern Togo and Ghana in western Africa, but reports have been published from other geographic regions (Brazil, Indonesia, and Malaysia).

The life cycle consists of fecal excretion of eggs produced by mature worms parasitizing its final host (goats, sheep, cows, wild boars, primates, humans, etc.). First-stage larvae (L1) develop inside the eggs and hatch as rhabdiform larva that will further develop into third-stage larvae (L3), the so called the infective filariform larvae. The filariform larvae when ingested, invade the large intestine walls to form small nodules. After additional development, including molting, the new fourth-stage (L4) migrates back to intestinal lumen to mature into adult worms (Figure 4.2.3.14.1). In some cases, the final development may be arrested following repeated infections, with formation of persistent and enlarging nodules. In high endemic areas like those in Togo and Ghana, the primate population is too small to impact the human population, and consequently it became obvious that person-to-person transmission is very possible, perhaps periodically with some animals as catalysts. Clinical manifestations range from asymptomatic to acute abdomen (mimicking appendicitis), fever (low grade), vomiting, anorexia, diarrhea, intestinal obstruction, purulent peritonitis, intestinal and even cutaneous nodules. 


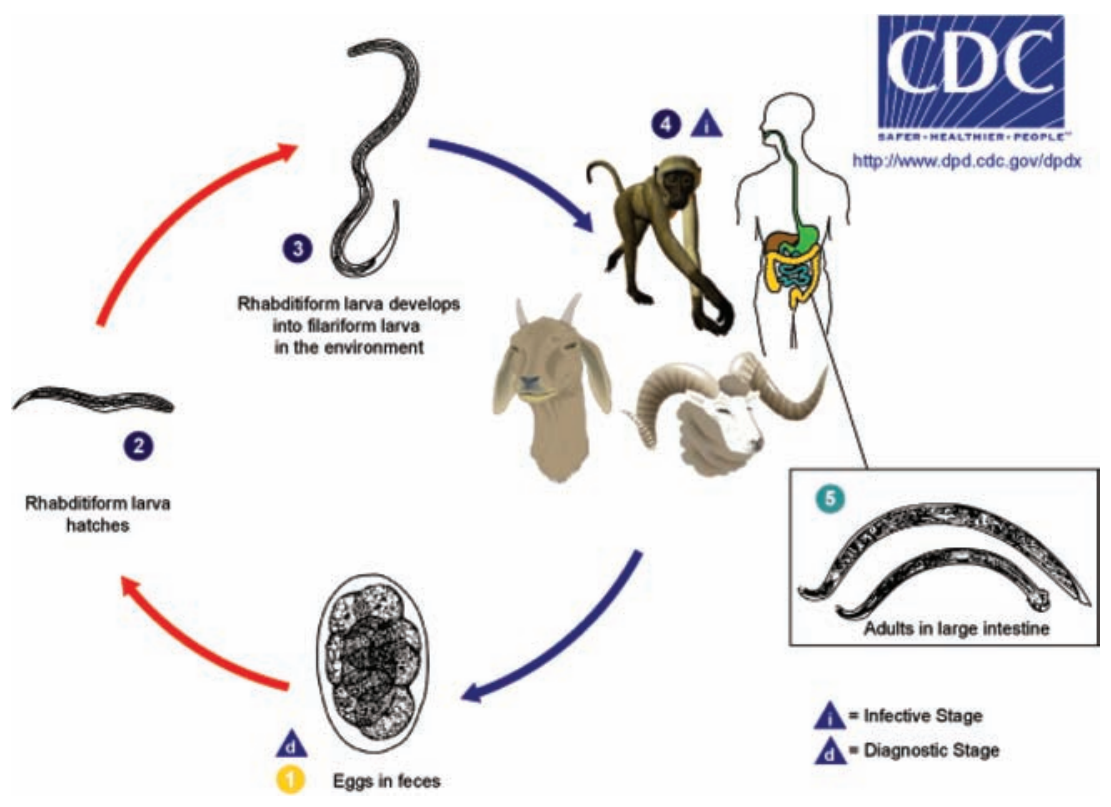

Figure 4.2.3.14.1. Oesophagostomum spp. life cycle (with permission from CDC, Atlanta, USA; http://www. dpd.cdc.gov/dpdx/HTML/Oesophagostomiasis.htm)

\subsection{OESOPHAGOSTOMIASIS AND ENVIRONMENT}

There is accumulating evidence that the $O$. bifurcum isolated from humans is different from the ones those isolated from non-human primates (de Gruijter et al., 2006; Eberhard et al., 2001). Northern parts of Ghana and Togo are well known endemic foci (as a result of poor hygiene, agricultural practices and a relative lack of potable water) where at least a quarter of a million people are infected with this parasite reaching an $\sim 70 \%$ prevalence in some villages. Researchers have screened fecal samples of various non-human primates (olive baboon, mona monkey and black and white colobus monkey) for the presence $O$. bifurcum eggs in two non-endemic areas in Ghana (Figure 4.2.3.14.2). Olive baboons and mona monkeys were found to have a high prevalence of eggs (75-99\%) while humans and black and white colobus monkeys were absolutely negative (van Lieshout et al., 2005). In spite of favorable conditions for zoonotic transmission (proximity to non-human primates, defecation habits and food consumption) no human infection with $O$. bifurcum has been observed. According to these authors, their results support the hypothesis that two distinct species of $O$. bifircum exist: one anthropogenic and one "cercopithecidaegenic", and consequently the high northern prevalence of infections is presumably human-to-human, with non-human primates as reservoirs (?) (Gasser et al., 2006). In addition, Storey et al. (2000, 2001), studying a rural community with high endemicity in Ghana, reported that patients' infection and symptoms' appearance are linked to the rainy season (most commonly presented cases were during the late rains and early dry season) implying a connection to water as a possible infection route. In another report, reinfection and transmission appeared to be also limited to the rainy season, in spite of antihelminitic treatment in the middle of the dry or in the middle of the rainy season (Krepel et al., 1995). Steenhard et al. (2000) linked rainy season and free-ranging pigs as a potential reservoir and 
spreader of $O$. bifurcum among villages' residents based on their coprophilic habits. However, only $5 \%$ of the experimental eggs fed to pigs were found to be viable/infectious (retrieved as third-stage larvae after coproculture of the pigs' feces). It seems that pigs are able to inactivate almost $95 \%$ of ingested eggs. These authors raised an interesting ecological/environmental hypothesis: preventing pigs from consuming human feces during the rainy season (being tied up) is a factor that contributes to high transmission during this season, while during dry season, when pigs are released to free-range, they manage to remove human feces, removing/inactivating also $O$. bifurcum eggs. This theory seems to be supported by there being no transmission during the dry season. This is an interesting hypothesis, but further studies are needed for a final confirmation, especially that it can help as a biological mean in transmission reduction of this parasite. Irrigation of pasture plots contaminated with helminths eggs among them Oesophagostomum columbianum (carried by infected goats), have been also shown to provide favourable conditions for eggs to develop into larvae (Gruner et al., 1989).

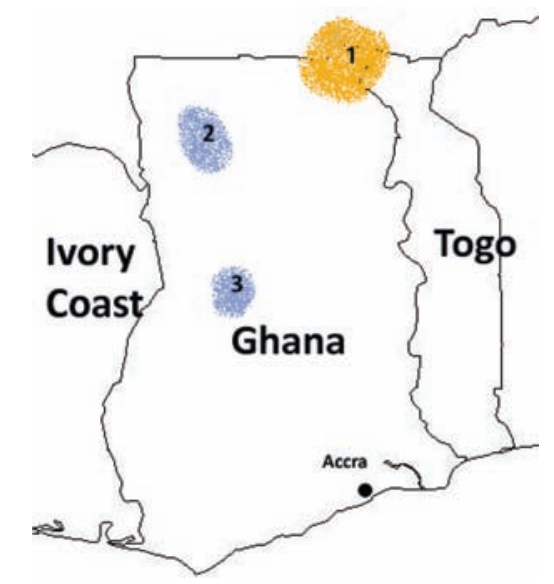

Figure 4.2.3.14.2. Ghana map including a highly endemic area (1-orange) and other two non-endemic sites (2 and 3-blue) (adapted from van Lieshout et al., 2005)

African wild great apes (chimpanzees and gorillas) have a high prevalence of fecal' O. stephanostomum, another species that has been isolated very rarely in humans (Polderman and Blotkamp, 1995; Chabaud and Larivière, 1958). Krief et al. (2008) studied oesophagostomiasis in captive gorillas, free-ranging and ex-captive chimpanzees for clinical signs (granulomas and lesions/abscesses). Their analysis revealed that great apes kept in captivity suffer from severe clinical symptoms while free-ranging wild chimpanzees are not affected, showing good health. The authors suggested an environmental factor to be responsible for this difference: wild great apes swallowing rough leaves. According to this hypothesis, leaves swallowing leaves may contribute to two factors: antihelminthic activity by physical removal and possible plant pharmacological properties (Fowler et al., 2007). The O. stephanostomum and $O$. bifurcum prevalent co-infections in chimpanzees raised the issue of a potential source for human infection, especially due to increasing contacts between humans and great apes through ecotourism, forest fragmentation in areas of high population density and crop-raiding by high-ranking males (Krief et al., 2010). 


\subsection{REFERENCES}

Chabaud, A.G. \& Larivière, M. (1958) Sur les Oesophagostomes parasites de l'homme. Bull Soc Pathol Exot 51, 384-393.

de Gruijter, J.M., Blotkamp, J., Gasser, R.B., Amponsah, S. \& Polderman, A.M. (2006) Morphological variability within Oesophagostomum bifurcum among different primate species from Ghana. J. Helminthol. 80, 357-361.

Eberhard, M.L., Kovacs-Nace, E., Blotkamp, J., Verwij, J.J., Asigri, V.A. \& Polderman, A.M. (2001) Experimental Oesophagostomum bifurcum in monkeys. J. Helminthol. 75, 51-56.

Fowler, A., Koutsioni, Y. \& Sommer, V. (2007) Leaf-swallowing in Nigerian chimpanzees: evidence for assumed self-medication. Primates 48, 73-76.

Gasser, R.B., de Gruijter, J.M. \& Polderman, A.M. (2006) Insights into the epidemiology and genetic make-up of Oesophagostomum bifurcum from human and non-human primates using molecular tools. Parasitol. 132, 453-460.

Gruner, L., Berbigier, P., Cortet, J. \& Sauve, C. (1989) Effects of irrigation on appearance and survival of infective larvae of goat gastro-intestinal nematodes in Guadeloupe (French West Indies). Int. J. Parasitol. 19, 409-415.

Krepel, H.P., Baeta, S., Kootstra, C. \& Polderman, A.M. (1995) Reinfection patterns of Oesophagostomum bifurcum after anthelmintic treatment. Trop Geogr Med 47, 160-163.

Krief, S., Jamart, A., Mahe, S., Leendertz, F.H., Matz-Rensing, K. et al. (2008) Clinical and pathologic manifestation of oesophagostomosis in African great apes: does self-medication in wild apes influence disease progression?. J. Med. Primatol. 37, 188-195.

Krief, S., Vermeulen, B., Lafosse, S., Kasenene, J.M., Nieguitsila, A. et al. (2010) Nodular worm infection in wild chimpanzees in Western Uganda: a risk for human health? PLoS Negl Trop Dis 4, e630.

MacIntosh, A.J.J., Hernandez, A.D. \& Huffman, M.A. (2010) Host age, sex, and reproductive seasonality affect nematode parasitism in wild Japanese macaques. Primates 51, 353-364.

Polderman, A.M. \& Blotkamp, J. (1995) Oesophagostomum infections in humans. Parasitol. Today (Regul. Ed.) 11, 451-456.

Steenhard, N.R., Storey, P.A., Yelifari, L., Pit, D.S., Nansen, P. \& Polderman, A.M. (2000) The role of pigs as transport hosts of the human helminths Oesophagostomum bifurcum and Necator americanus. Acta Trop. 76, 125-130.

Storey, P.A., Faile, G., Hewitt, E., Yelifari, L., Polderman, A.M. \& Magnussen, P. (2000) Clinical epidemiology and classification of human oesophagostomiasis. Trans. R. Soc. Trop. Med. Hyg. 94, 177-182.

Storey, P.A., Steenhard, N.R., Van Lieshout, L., Anemana, S., Magnussen, P. \& Polderman, A.M. (2001) Natural progression of Oesophagostomum bifurcum pathology and infection in a rural community of northern Ghana. Trans. R. Soc. Trop. Med. Hyg. 95, 295-299.

van Lieshout, L., de Gruijter, J.M., Adu-Nsiah, M., Haizel, M., Verweij, J.J. et al. (2005) Oesophagostomum bifurcum in non-human primates is not a potential reservoir for human infection in Ghana. Trop. Med. Int. Health 10, 1315-1320. 


\section{Chapter 4.2.3.15 Strongyloidiasis}

\section{[STRONGYLOIDES STERCORALIS, S. FUELLEBORNI, S. FUELLEBORNI KELLY]}

Strongyloidiasis is caused by two nematode species: Strongyloides stercoralis and S. fuelleborni (S. fuelleborni kelly has been reported only from Papua New Guinea). Mammals such as dogs, cats, non-human and human primates have been reported to be infected by these nematodes (Bezjian et al., 2008; Muehlenbein, 2005; Ashford et al., 1990). The parasite is mostly distributed in endemic areas of tropical and sub-tropical countries (e.g. Vietnam, Cambodia, Laos, Brazil as well Central America and Sub-Saharan Africa) with poor hygiene (soil and water contaminated with feces), however some sporadic cases have been reported in temperate areas too (South America and Eastern Europe) (Kitvatanachai et al., 2008; Sayasone et al., 2009; Steinmann et al., 2007; Widjana and Sutisna, 2000). Infection may occur percutaneously, through autoinfection or galactogenously by the filariform third stage larvae (L3). Following percutaneous invasion, L3 larvae migrate to the lungs (via lymph and blood vessels) to penetrate the alveolar walls and further reach the small intestine (via the trachea and esophagus). Located into intestinal mucosa, L3 larvae pass molting to produce adult parthogenetic females that produce eggs. Humans and other infected mammals excrete in their feces rhabditiform L1 larvae that in environment (e.g., moist soil) can follow two paths: 1) direct development into L3 filariform larvae that can again penetrate percutaneously the host and 2) development into free-living adult worms (male and female) that produce embryonated eggs from which rhabdiform larvae hatch. In the same environment, hatched rhabdiform larvae may develop into: free-living adult worms (to reproduce without host) or infective filariform larvae (to invade new host) (Figure 4.2.3.15.1). Beside this amazing plasticity (asexual and sexual reproduction including parthogenesis), Strongyloides spp., or in particular S. stercoralis, can produce autoinfection in immunocompromised patients (when L3 larvae develop from eggs persistent in the intestine) and galactogenous infections (when incoming larvae settle in the surrounding tissue of breast-hypobiotic larvae activated and shed during lactation). Clinical manifestations depend on infection burden; if light infection occurs, no symptoms will be present, but in chronic infections abdominal pain, nausea, intermittent diarrhea (for weeks), urticaria, dry cough, enerocolitis, damage to intestinal mucosa including sepsis, pulmonary hemorrhage, pneumonia and meningitis are found in patients. 


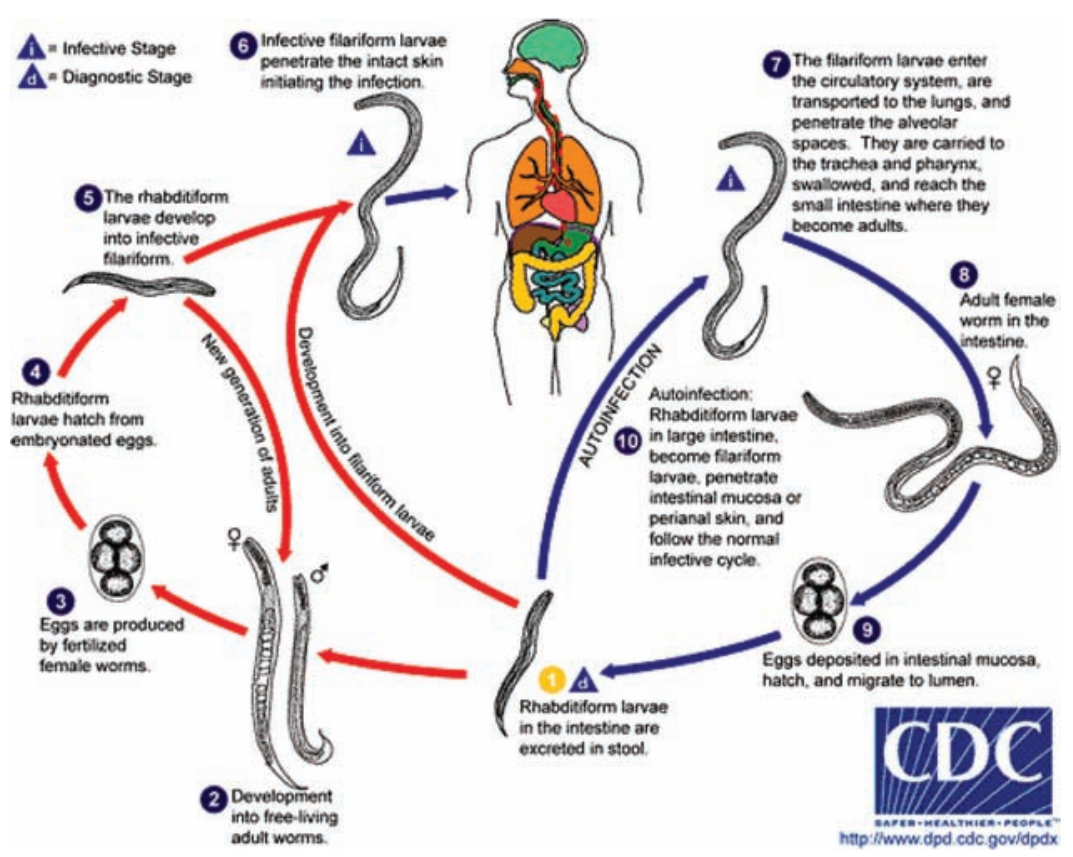

Figure 4.2.3.15.1. Strongyloides spp. life cycle (with permission from CDC, Atlanta, USA; http://www.dpd. cdc.gov/dpdx/HTML/Strongyloidiasis.htm)

\subsection{STRONGYLOIDIASIS AND ENVIRONMENT}

Strongyloidiasis has been reported worldwide with a higher prevalence in tropical and subtropical countries (where temperatures over $20^{\circ} \mathrm{C}$ and humidity enhance soil development of the parasite next to deficient hygiene). In an epidemiological study performed in the province of Valencia, Spain (characterized by a Mediterrenian climate-dry and warm summers), researchers reported a connection between strogyloidosis cases and human occupation (Alcaraz et al., 2004). In this area, the main occupation has been and continues to be agriculture. Until 1960, rice crops were the main agriculture activity while since then it changed to vegetables and citrus growth based on river irrigation or marshland draining ditches. Due to poor mechanization, irrigation activities have been performed manually, increasing the direct contact with water and mud. Indeed, the researchers found much lower strongyloidiosis cases in the interior of this area, characterized by calcareous elevations, steep slopes, hard limestone and dolomite rocks not favorable for the environmental cycle of these nematodes. In contrary st, higher numbers of cases were observed in populations inhabiting piedmonts, alluvial fans, close to marshlands areas and even in areas without stagnant or pooled waters but with intensive irrigation (comprising a wide network of irrigation ditches and canals). Barnish and Ashford (1990), in a different geographic area (Papua New Guinea), substantiated these findings, reporting on the absence of Strongyloides spp. from limestone and polygonal karst areas and altitudes $>1,000 \mathrm{~m}$ above sea level (connected to lower temperature that does not favor L3 larvae development). Knopp et al. (2008) presented similar a high prevalence of infections with $S$. stercoralis in Zanzibar's areas characterized by alluvial clayey soils, moist forest regions and increased precipitations. 
Gillespie and Chapman (2008) studied forest fragmentation impact upon host-parasite interactions in Uganda. Two populations of colobus monkeys have been studied: red colobus (Procolobus rufomitratus) and black-and-white colobus (Colobus guereza). These authors reported a significant decline in the red colobus population, an endangered species, in fragmented forest but no decline in black-and-white colobus in both fragmented and unfragmented forests. Infection prevalence and the magnitude of multiple infections (with S. fulleborni and S. stercoralis among other parasites) were greater for red colobus in fragmented than in unfragmented forest with no difference in black-and-white colobus in both ecosystems. The results suggest that forest fragmentation can alter host-parasite dynamics related to changes in host population size in forest fragments.

Tatfeng et al. (2005) studied the mechanical transmission of a large variety of pathogens (bacterial, parasitic and fungal) by cockroaches (Diploptera punctata), commonly found in the tropics. In their study, cockroaches trapped from different sites (toilets, parlours, kitchens and bedrooms) from houses with pit latrines and a water system, carried bacterial, fungal and parasitic isolates at identical magnitude irrespective of the sampling site, including Strongyloides stercoralis larvae. In the same geographical area, Nigeria, Ogbolu et al. (2009) carried out a study on parasitological contamination of vegetables sold at selected markets in the southwestern part of the country. $68.3 \%$ of the vegetables were contaminated with different parasites including S. stercoralis (prevalence 45.8\%) emphasizing the high risk transmission of these parasites in poor hygienic environments. The high parasitic prevalence in this area has been attributed to soil fertilization with human excrements and irrigation with contaminated water.

Dogs in Japan reared indoors (Itoh et al., 2003) presented another important source of transmission. Puppies from pet shops and breeding kennels revealed a higher prevalence of Strongyloides spp., consequently presenting a real threat to humans. Similar results have been reported from Finland in kennel dogs infected with this parasite (including puppies' death as a result of infection) in spite of the temperate climate (Dillard et al., 2007). This study revealed that $S$. stercoralis can complete its life cycle in dogs also in Northern Europe and may become a chronic problem in kennel environments.

\subsection{REFERENCES}

Alcaraz, C.O., Adell, R.I., Sanchez, P.S., Blasco, M.J.V., Sanchez, O.A. et al. (2004) Characteristics and geographical profile of strongyloidiasis in healthcare area 11 of the Valencian community (Spain). J. Infect. 49, 152-158.

Ashford, R.W., Reid, G.D. \& Butynski, T.M. (1990) The intestinal faunas of man and mountain gorillas in a shared habitat. Ann Trop Med Parasitol 84, 337-340.

Barnish, G. \& Ashford, R.W. (1990) Strongyloides cf. fuelleborni and other intestinal helminths in Papua New Guinea: distribution according to environmental factors. Parassitologia 32, 245-263.

Bezjian, M., Gillespie, T.R., Chapman, C.A. \& Greiner, E.C. (2008) Coprologic evidence of gastrointestinal helminths of forest baboons, Papio anubis, in Kibale National Park, Uganda. J. Wildl. Dis. 44, 878-887.

Dillard, K.J., Saari, S.A. \& Anttila, M. (2007) Strongyloides stercoralis infection in a Finnish kennel. Acta Vet Scand 49, 37.

Gillespie, T.R. \& Chapman, C.A. (2008) Forest fragmentation, the decline of an endangered primate, and changes in host-parasite interactions relative to an unfragmented forest. Am. J. Primatol. 70, 222-230.

Itoh, N., Muraoka, N., Aoki, M. \& Itagaki, T. (2003) Prevalence of Strongyloides spp. infection in household dogs. Kansenshōgaku Zasshi 77, 430-435.

Kitvatanachai, S., Boonslip, S. \& Watanasatitarpa, S. (2008) Intestinal parasitic infections in Srimum suburban area of Nakhon Ratchasima Province, Thailand. Trop Biomed 25, 237-242.

Knopp, S., Mohammed, K.A., Rollinson, D., Stothard, J.R., Khamis, I.S. et al. (2009) Changing patterns of soil-transmitted helminthiases in Zanzibar in the context of national helminth control programs. Am. J. Trop. Med. Hyg. 81, 1071-1078. 
Knopp, S., Mohammed, K.A., Simba, K.I., Mgeni, A.F., Stothard, J.R. et al. (2008) Spatial distribution of soil-transmitted helminths, including Strongyloides stercoralis, among children in Zanzibar. Geospat Health 3, $47-56$.

Muehlenbein, M.P. (2005) Parasitological analyses of the male chimpanzees (Pan troglodytes schweinfurthii) at Ngogo, Kibale National Park, Uganda. Am. J. Primatol. 65, 167-179.

Ogbolu, D.O., Alli, O.A.T., Ogunleye, V.F., Olusoga-Ogbolu, F.F. \& Olaosun, I.1. (2009) The presence of intestinal parasites in selected vegetables from open markets in south western Nigeria. Afr J Med Med Sci 38, 319-24.

Sayasone, S., Vonghajack, Y., Vanmany, M., Rasphone, O., Tesana, S. et al. (2009) Diversity of human intestinal helminthiasis in Lao PDR. Trans. R. Soc. Trop. Med. Hyg. 103, 247-254.

Steinmann, P., Zhou, X.N., Du, Z.W., Jiang, J.Y., Wang, L.B. et al. (2007) Occurrence of Strongyloides stercoralis in Yunnan Province, China, and comparison of diagnostic methods. PLoS Negl Trop Dis 1, e75.

Tatfeng, Y.M., Usuanlele, M.U., Orukpe, A., Digban, A.K., Okodua, M. et al. (2005) Mechanical transmission of pathogenic organisms: the role of cockroaches. J Vector Borne Dis 42, 129-134.

Widjana, D.P. \& Sutisna, P. (2000) Prevalence of soil-transmitted helminth infections in the rural population of Bali, Indonesia. Southeast Asian J. Trop. Med. Public Health 31, 454-459. 


\section{Chapter 4.2.3.16 Syngamiasis}

\section{[MAMMOMONOGAMUS LARYNGEUS]}

Syngamiasis is a factual rare disease ( $\sim 100$ cases so far) caused by the nematode Mammomonogamus laryngeus, a parasite of the respiratory tract of many mammals (cattle, deer, sheep, goats, cats, buffaloes, orangutans and elephants) (Foitova et al., 2008; Marques et al., 2005). Based on the reported cases, its distribution seems to be in China, Korea, Thailand, Philippines and the Caribbean (Turner et al., 2003). Humans are infected accidentally by ingestion of larvae or eggs (Sossai et al., 2007). The life cycle is not completely known into detail, but following other members of Syngamidae (the family to which it belongs systematically) the ingested eggs or larvae seem to migrate to intestine in order to invade the intestinal walls. From the intestine, the larvae are disseminated via the liver or heart towards the lungs. In the lung, mature worms develop and reproduce to produce eggs that are expelled through sputum. If ingested by sputum re-swallowing, eggs will be excreted in feces to infect reservoir animals possibly through some vectors (beetles, snails or earthworms?) (Figure 4.2.3.16.1). Clinical manifestations are heavy, dry chronic cough, hemoptysis and asthma-like symptoms.

\subsection{SYNGAMIASIS AND ENVIRONMENT}

Our knowledge about the environmental transmission of this parasite is very limited, primarily because of the very low prevalence of infections. However, some clues can be drawn from case studies. For example, a young woman visiting a resort in Jamaica complained of headache, a sore throat and a dry cough following salad consumption at this resort (Nosanchuk et al., 1995). If the life cycle of this parasite includes vectors, such as beetles, snails or earthworms (see Figure 4.2.3.16.1) that may come in contact with eggs containing feces from different mammals as final hosts, then it can be speculated that accidental ingestion of these vectors can introduce this parasite into humans' gastrointestinal system. It is somehow clear that the parasite requires warm and humid environments to survive and reproduce, conditions met in the distribution countries. Another clue allegedly connected with insects' consumption might be drawn from orangutan's infection with M. laryngeus (Foitova et al., 2008). Orangutans are known as insectivores and also eat jungle fruits; their habits include the practice of eating soil or stones. More studies are required to clarify the most potent vector for human infection with this parasite, albeit its low infection risk. 


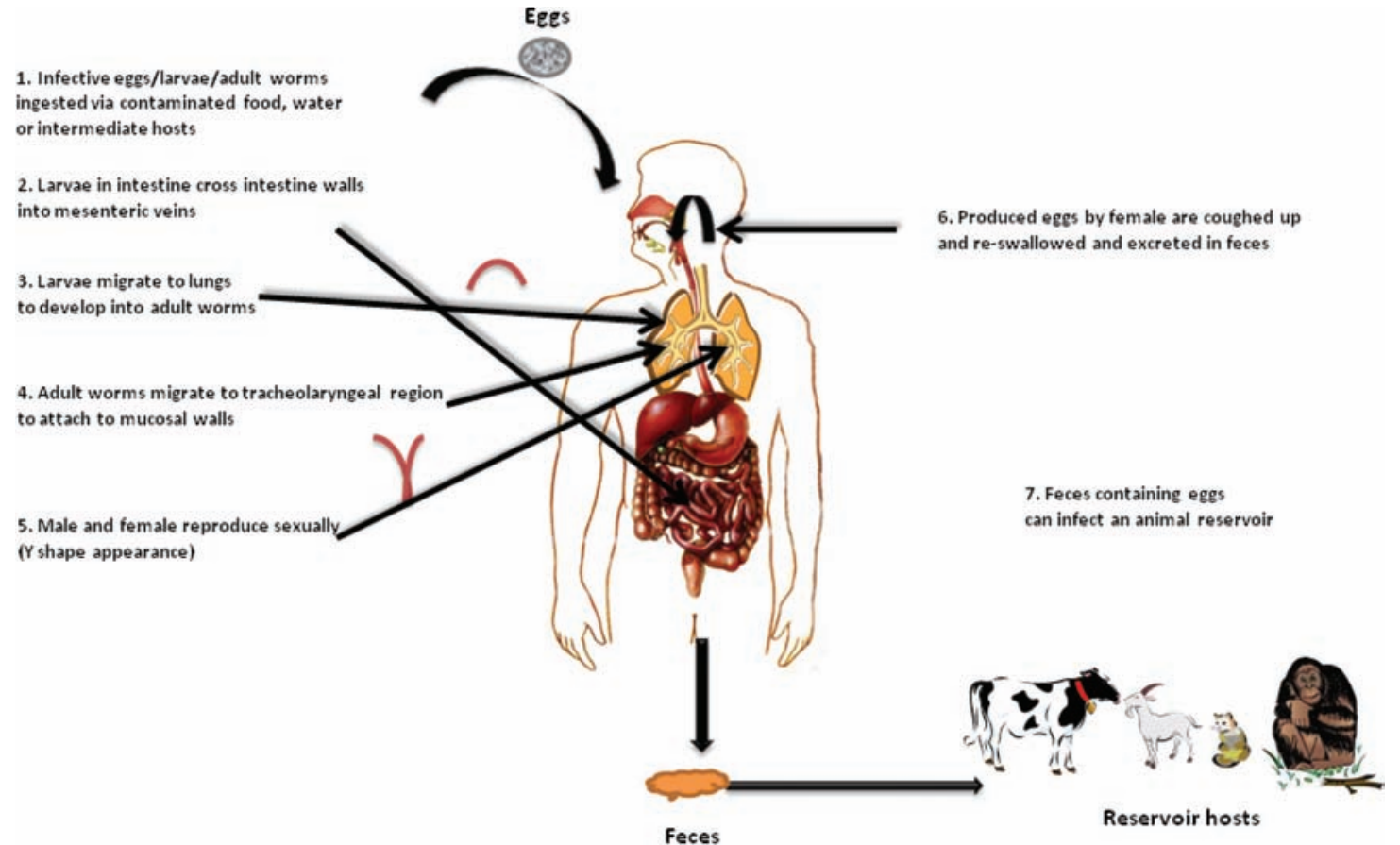

Figure 4.2.3.16.1. Mammomonogamus laryngeus presumed life cycle

\subsection{REFERENCES}

Foitova, I., Koubkova, B., Barus, V. \& Nurcahyo, W. (2008) Presence and species identification of the gapeworm Mammomonogamus laryngeus (Railliet, 1899) (Syngamidae: Nematoda) in a semi-wild population of Sumatran orangutan (Pongo abelii) in Indonesia. Res. Vet. Sci. 84, 232-236.

Marques, S.M.T., Quadros, R.M. \& Pilati, C. (2005) Mammomonogamus laryngeus (Railliet, 1899) infection in buffaloes in Rio Grande do Sul, Brazil. Vet. Parasitol. 130, 241-243.

Nosanchuk, J.S., Wade, S.E. \& Landolf, M. (1995) Case report of and description of parasite in Mammomonogamus laryngeus (human syngamosis ) infection. J. Clin. Microbiol. 33, 998-1000.

Sossai, B.B., Bussular, R.L.S., Pecanha, P.M., Ferreira, J.C., Urbano, G. \& Sessa, P.A. (2007) First description of human bronchial syngamosis in the State of Espirito Santo. Rev. Soc. Bras. Med. Trop. 40, 343-345.

Turner, P., Turner, C.G., Bowers, K.M., Gibson, D.I. \& Chiodini, P.L. (2003) A case of human syngamosis. Travel Med Infect Dis 1, 231-233. 


\section{Chapter 4.2.3.17 Thelaziasis}

\section{[THELAZIA CALLIPAEDA, T. CALIFORNIENSIS]}

Thelaziasis is also a very rare disease in humans caused by the nematodes Thelazia callipaeda and T. californiensis, affecting eyes and associated tissues resulting in inflammation. The parasite is distributed in Asia, Europe, and western North America. T. callipaeda occurs in Asia while $T$. californiensis in western United States with canids as main hosts (although birds, deer, cats can also be infected) (Dubay et al., 2000). Transmission occurs through arthropod vectors such as flies (Musca and Fannia spp.) as intermediate hosts, that carry L1 stage larvae from the infected host eye following direct contact (via conjuctival secretions ingestion). Within the fly, L1 larvae develop into L3 larvae that leave the insect through mouthparts when flies feed on the final host's conjuctival fluid to develop into mature worms in the conjunctiva sac. Adult worms produce and shed larvae (ovoviviparity) into the conjunctiva (Figure 4.2.3.17.1). Clinical manifestations are usually mild, resembling conjunctivitis, watery eyes, corneal opacity and ulcerative keratitis.

\subsection{THELAZIASIS AND ENVIRONMENT}

Thelaziasis's hosts' diversity has been clarified by many studies but the role of different insect vectors on transmission is still debatable. In a recent meticulous study on Musca domestica (Diptera: Muscidae), it has been shown that this insect cannot act as a vector of T. callipaeda in southern Europe (Otranto et al., 2005a) in contrast to a previous report (Shi et al., 1988). Consequently, other insects have been studied for their vectorial potential. Otranto et al. (2005b) reported on Phortica variegata and Phortica okadai (both belonging to Drosophilidae family) as true vectors for T. callipaeda in southern Europe and in China. In addition, these authors revealed the overwintering capacity of these vectors (hibernation) infected with $T$. callipaeda that may explain the dissemination routes under various environmental conditions. The same group went a step further and found an interesting phenomenon, possibly unique in entomology: the fruitfly Phortica variegate (the drosophiloid vector) feeds on lachrymal secretions besides vegetable matter and under natural conditions $P$. variegate males are predominant in lacrymogenic feed in contrast to other arthropodborne diseases (see malaria, Kala-Azar, etc.) (Otranto 
et al., 2006). The authors suggested that the relationship between $T$. callipaeda and the vector $P$. variegate is an example of convergent evolution in parasitology, requiring further examinations.

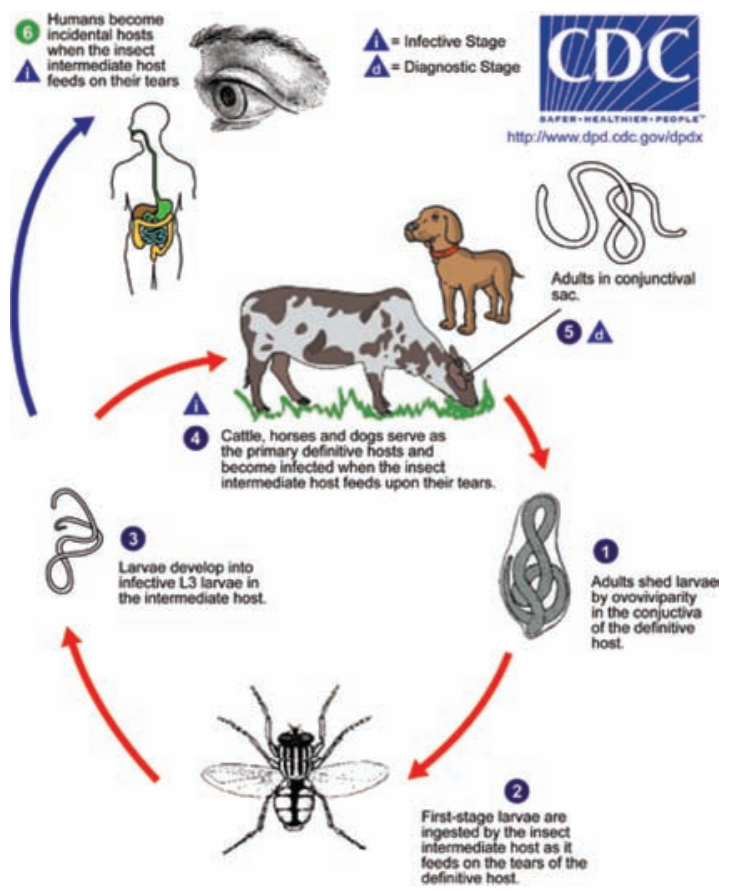

Figure 4.2.3.17.1. Thelazia spp. life cycle (with permission from CDC, Atlanta, USA; http://www.dpd.cdc. gov/dpdx/HTML/ImageLibrary/Thelaziasis_il.htm)

\subsection{REFERENCES}

Otranto, D., Lia, R.P., Cantacessi, C., Testini, G., Troccoli, A. et al. (2005b) Nematode biology and larval development of Thelazia callipaeda (Spirurida, Thelaziidae) in the drosophilid intermediate host in Europe and China. Parasitology 131, 847-855.

Dubay, S.A., Williams, E.S., Mills, K. \& Boerger-Fields, A.M. (2000) Bacteria and nematodes in the conjunctiva of mule deer from Wyoming and Utah. J. Wildl. Dis. 36, 783-787.

Otranto, D., Lia, R.P., Testini, G., Milillo, P., Shen, J.L. \& Wang, Z.X. (2005a) Musca domestica is not a vector of Thelazia callipaeda in experimental or natural conditions. Med. Vet. Entomol. 19, 135-139.

Otranto, D., Brianti, E., Cantacessi, C., Lia, R.P. \& Maca, J. (2006) The zoophilic fruitfly Phortica variegata: morphology, ecology and biological niche. Med. Vet. Entomol. 20, 358-364.

Shi, Y.E., Han, J.J., Yang, W.Y. \& Wei, D.X., (1988) Thelazia callipaeda (Nematoda: Spirurida): transmission by flies from dogs to children in Hubei, China. Trans. R. Soc. Trop. Med. Hyg. 82, 627. 


\section{Chapter 4.2.3.18}

\section{Trichinosis (Trichinellosis)}

\section{[TRICHINELLA SPIRALIS, T. NATIVE, T. BRIVOTI, T. PSEUDOSPIRALIS, T. MURRELLI, T. NELSON, T. PAPUE AND T. ZIMBABWENSIS]}

Trichinosis is a disease caused by different species of Trichinella nematodes with a worldwide distribution in almost all climates, except desert (Kia et al., 2009). Infection occurs when humans consume raw or undercooked infected meat of different animals infected with the parasite (mainly pigs, wild boars, horses, etc.) (Kia et al., 2009; Haim et al., 1997). Inspite of being the smallest nematode it may cause fatal disease in humans depending on infection burden. In spite of advanced veterinary control programs, there are still thousands of reported cases around the globe mainly due to ingestion of uncontrolled meat from a large variety of game (Kociecka et al., 1992). Trichinella spp. have two infectious cycles: sylvatic and domestic where synanthropic animals (e.g. rats, foxes, mustelids, cats, dogs, wolves, etc.) contribute to sylvatic Trichinella genotypes' flow from wildlife to domestic animals and of T. spiralis from domestic to sylvatic animals (Pozio, 2000; Beck et al., 2009). In this context, rats have been shown to play a significant role in the transmission and maintenance of $T$. spiralis in pig farms, even in the absence of infected meat, probably through cannibalism (Leiby et al., 1990). In general, it can be stated that the $T$. spiralis genotype is mainly transmitted and maintained in a domestic cycle, although it can be present also in wildlife, while other genotypes (T. nativa, T. britovi, T. pseudospiralis, T. murrelli, T. nelsoni and T. papuae, Trichinella T6, T8, and T9) are transmitted and maintained only in the sylvatic cycle (Masuoka et al., 2009). More data on the various genotypes is presented in Table 4.2.3.18.1. Generally, Trichinella nematodes are divided into two groups according to larvae status in striated muscles: encapsulated (encysted) and nonencapsulated (unencysted) larvae. Their life cycle consists of ingestion of undercooked infected meat (that holds larvae). These larvae (encapsulated or unencapsulated) are then exposed to gastric acid and pepsin and are released to invade the small bowel mucosa to develop finally into adult worms (female and male). Females release larvae that migrate to striated muscles where they encapsulate (encyst), causing various clinical symptoms (Figure 4.2.3.18.1). Since the parasite is transmitted and carried by carnivores, it can be said that humans are dead-end hosts (in contrast, in pigs, where cannibalism is present, continuous infection takes place) (Pozio, 2000). Clinical manifestations are directly related to the larval content taken up by the patient. In the intestinal 


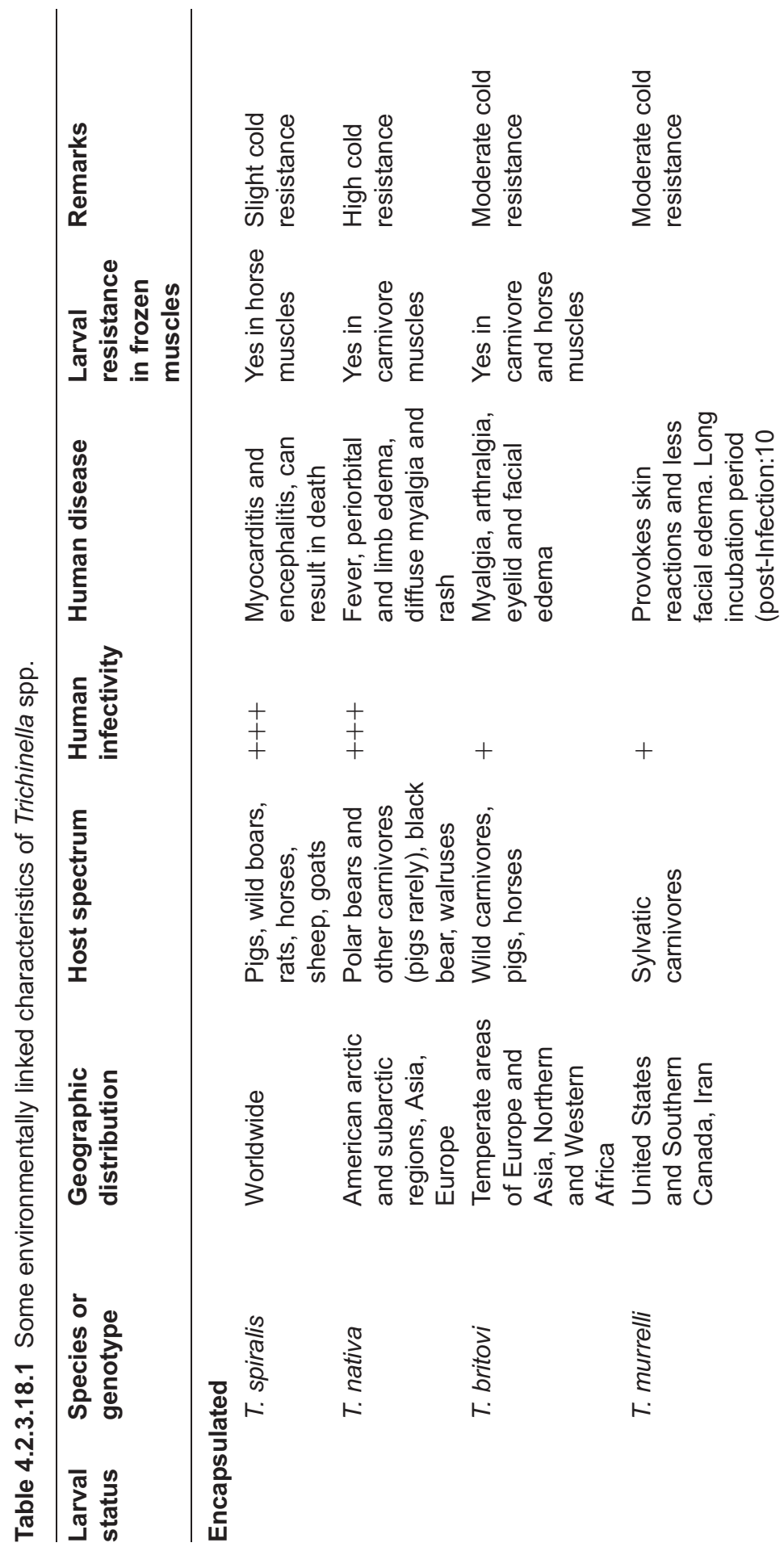


Trichinosis (Trichinellosis)
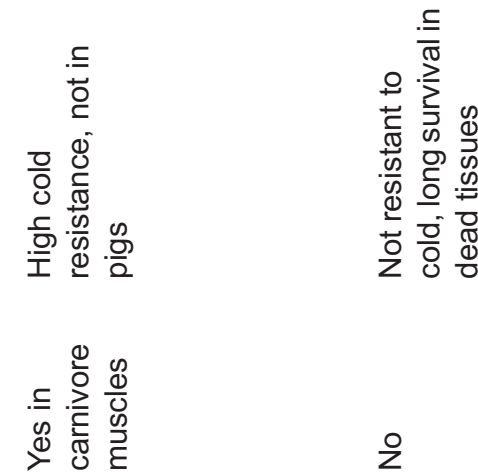

인 은
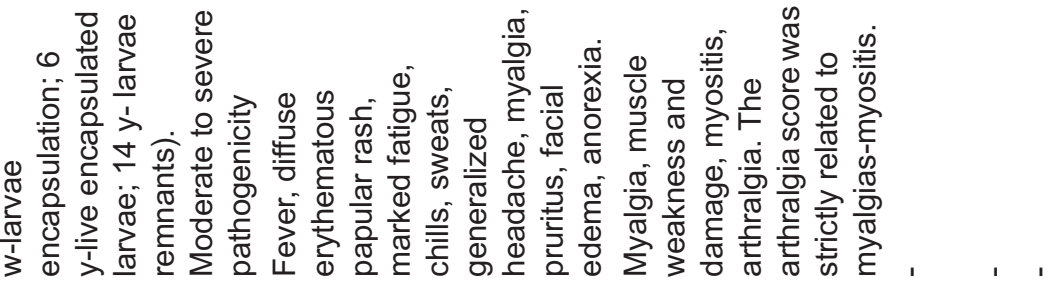

$\sim$

0

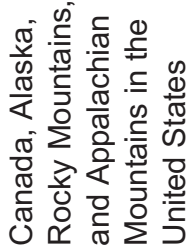

$\frac{0}{\frac{0}{0}}$
$+$

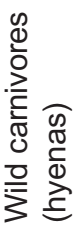

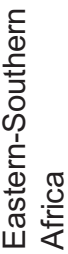

$\frac{5}{8}$
ค. $\curvearrowright$

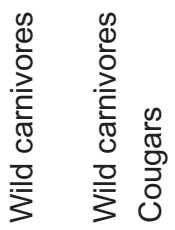

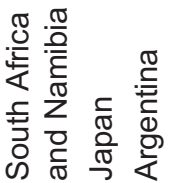

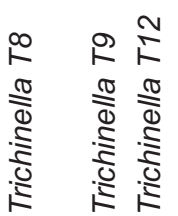




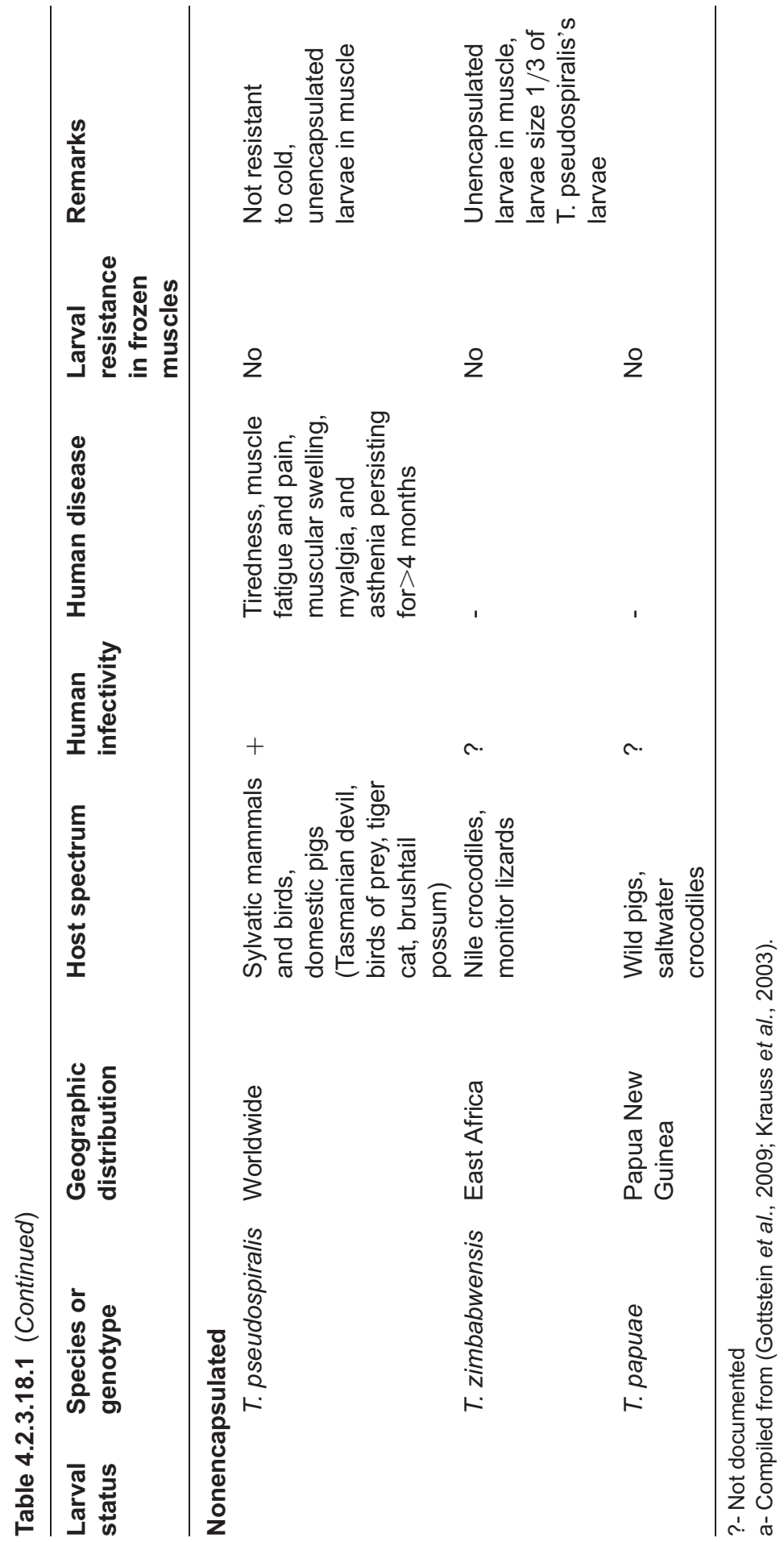


phase (development into adult worms), nausea, vomiting, epigastric pain, diarrhea or constipation prevail while during the visceral phase (migration and colonization of striated muscle) headaches, fever, arthralgias, cough, myalgia, conjunctivitis, edema, hemorrhage, anorexia, neurological complications (deafness, encephalitis, and convulsions), myocarditis and death are the main clinical manifestations.

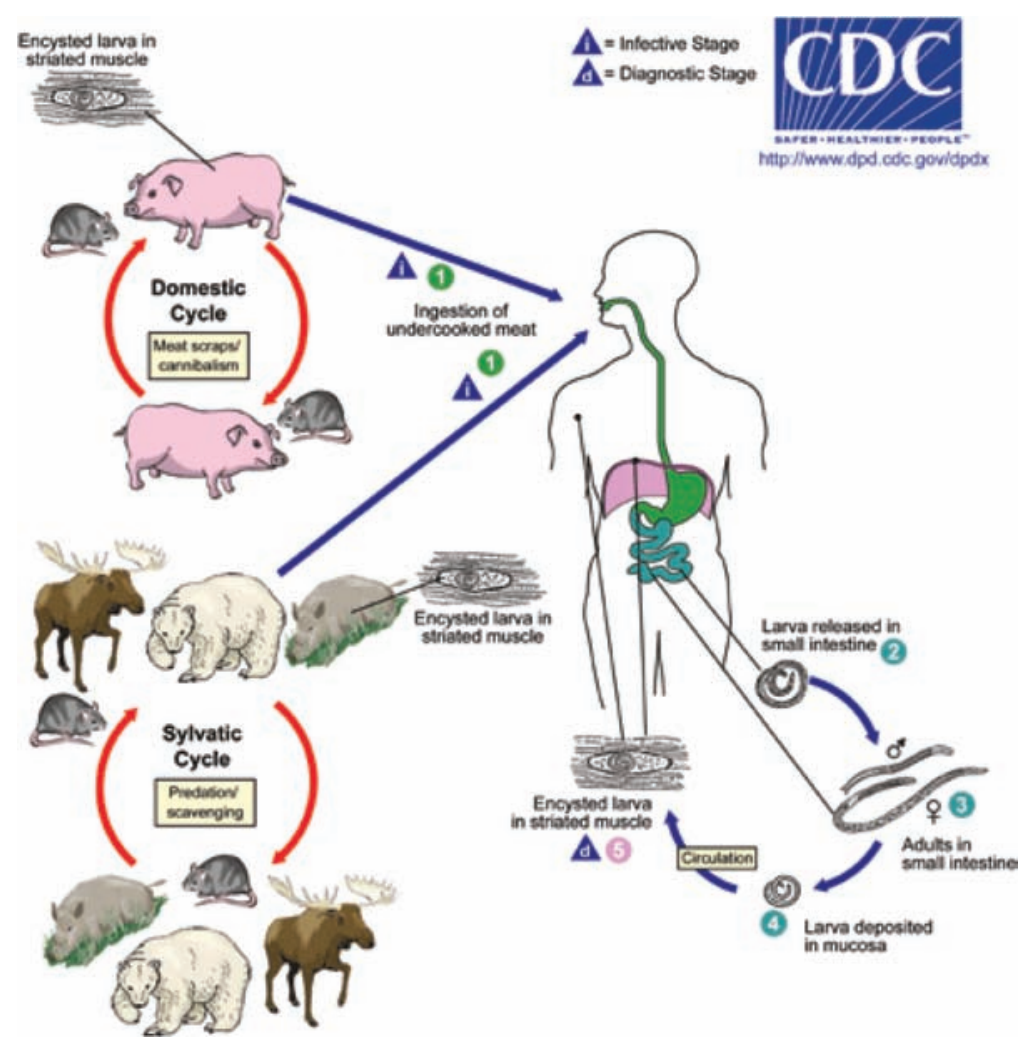

Figure 4.2.3.18.1. Trichinella spp. life cycle (with permission from CDC, Atlanta, USA; http://www.dpd.cdc. gov/dpdx/HTML/ImageLibrary/Trichostrongylosis_il.htm)

\subsection{TRICHINOSIS AND ENVIRONMENT}

Environmentally, it is clear that the prevalence of infections depends solely on human behavior. Commercial growth of pigs or fur animals (blue and silver foxes, minks and raccoon dogs) in farms can both contribute to the environmental spread of Trichinella spp. (Miller et al., 2006; Capó and Despommier, 1996). Hill et al. (2010) described a pig farm infected with T. spiralis in Maryland, USA. Six months after, depopulation of the pig farm, surrounding scavenging animals were trapped and tested for infection after 6, 12 and 18 months. The peridomestic scavenging mammal' population revealed a drastic decline in infection: 41, 10 and $0 \%$ respectively, revealing that breaking the vicious cycle of rat-pig-human transmission by eliminating the pigs could put infection to an end. In relation to rats, Oivanen et al. (2002) showed that 
Trichinella spiralis larvae in rat carcasses could survive for up to 6 weeks. Trichinosis transmission is based on two most important biological factors: 1) the muscle stage larvae's ability to survive in decaying carcasses (anaerobic metabolism in nurse cells) and 2) survival at low freezing temperatures (Owen and Reid, 2007). Both characteristics play a major role in the distribution of this parasite. For example, T. papuae, a nonencapsulated larvae, may retain infectivity in decaying pig tissue exposed at $35^{\circ} \mathrm{C}$ for nine days and for 4 months in heavily rotten meat at ambient temperature (Gottstein et al., 2009). In the other extreme, T. britovi has been reported to survive in frozen carrion for up to one year, while the $T$. nativa and Trichinella genotype T6 for up to several years, all maintaining potential infectivity for future hosts (Dick et al., 2001; Pozio et al., 2006). Another excellent environmental adaptation of this parasite has been shown by the distribution of Trichinella nativa and Trichinella britovi in a northern European country (Estonia) according to its isotherms. In sylvatic animals, T. nativa was found mostly in central-eastern regions of the country (east of isotherm $-5^{\circ} \mathrm{C}$ ) while $T$. britovi was detected in western parts of the country (west of isotherm $-4^{\circ} \mathrm{C}$ ), both isotherms being measured in January (the winter coldest month) (Pozio et al., 1998). Pozio et al. (1996) surveyed domestic and sylvatic animals for infection with T. spiralis and T. britovi in France, Italy, and in the Extremadura region of Spain. These authors showed that Trichinella spiralis and Trichinella britovi distribution is influenced by both environmental and human behavior factors. The results of this survey suggested the following issues: 1) domestic trichinellosis occurs only in rural areas of Western Europe in association with traditional swine-rearing practices, but not in industrialized pig farms; (2) sylvatic trichinellosis occurs only in natural habitats such as widespread and mountainous areas (in Western Europe); (3) vulpines are the primary reservoir of the parasite in a sylvatic cycle closed circuit and (4) among sylvatic animals, $T$. spiralis is present at a lower altitude than T. britovi. From another region on the globe (Argentina) a potential flow of the parasite from domestic to sylvatic swine in a trichinosis-free area has been reported (Cohen et al., 2010). These authors based their speculation on the fact that the wild boar has a high degree of tolerance to human presence (pasture environments) and human improper handling of domestic and wild swine carcasses (scattering pork scraps in the environment, consequently spreading Trichinella infection among wild boars (Pozio and Murrell, 2006).

Birds have been studied for their potential infection with Trichinella spp., however only T. pseudospiralis has been reported in night-birds of prey (Pozio et al., 1999). Birds have a real potential of spreading this parasite due to long distance journeys and also the potential to be preyed on by different carnivores. In a recent study, quails were exposed to larvae of the arctic strains of $T$. native in order to investigate their viability and preservation (Odevskaia, 2010). A rapid expulsion of bulk helminths was observed (due to abundant mucus excretion in response to infestation) with prolonged survival in environment (probably connected to the excess mucus as a protectant). The author suggested that according to these results it couldn't be excluded that birds could infest other marine mammals (e.g., pinnipeds). Cockroaches have been also suggested as a potential vector of Trichinella (based on preliminary results supporting these nematodes' persistence and transmissibility in the environment); however, more studies are needed to support this direction (Chan et al., 2004).

Finally, Rosenthal et al. (2008) compared the genetic diversity of T. spiralis around the globe and found a remarkable uniformity across the continents. They concluded that European lineages originate from pig domestication (several thousand years ago) where swine husbandry maintained the infective cycle. In addition, these authors implied that the New World spread was unintentionally caused via infected pigs and/or rats introduction through maritime trade. Perhaps, here is the occasion to ask: whether these parasites did previously exist in the New World? and, if affirmative, what role did humans play in its further expansion through hunting before domestication? 


\subsection{REFERENCES}

Beck, R., Beck, A., Kusak, J., Mihaljevic, Z., Lucinger, S. et al. (2009) Trichinellosis in wolves from Croatia. Vet. Parasitol. 159, 308-311.

Capó, V. \& Despommier, D.D. (1996) Clinical Aspects of Infection with Trichinella spp. Clin. Microbiol. Rev. 9, 47-54.

Chan, O.T.M., Lee, E.K.W., Hardman, J.M. \& Navin, J.J. (2004) The cockroach as a host for Trichinella and Enterobius vermicularis: implications for public health. Hawaii Med J 63, 74-77.

Cohen, M., Costantino, S.N., Calcagno, M.A., Blanco, Guillermo A., Pozio, Edoardo, Venturiello, Stella M. (2010) Trichinella infection in wild boars (Sus scrofa) from a protected area of Argentina and its relationship with the presence of humans. Vet. Parasitol. 169, 362-366.

Dick, T.A., \& E. Pozio. (2001) Trichinella spp. and trichinellosis, p. 380-396. In W. M. Samuel, M. J. Pybus, and A. A. Kocan (eds.), Parasitic diseases of wild mammals, 2nd ed. Iowa State University Press, Ames, IA.

Gottstein, B., Pozio, E. \& Karsten Nöckler, K. (2009) Epidemiology, Diagnosis, Treatment, and Control of Trichinellosis. Clin. Microbiol. Rev. 22, 127-145.

Haim, M., Efrat, M., Wilson, M., Schantz, P.M., Cohen, D. \& Shemer, J. (1997) An outbreak of Trichinella spiralis infection in southern Lebanon. Epidemiol. Infect. 119, 357-362.

Hill, D.E., Pierce, V., Darwin, M.K., Ratliffe, N., Rupp, B. et al. (2010) Cessation of Trichinella spiralis transmission among scavenging mammals after the removal of infected pigs from a poorly managed farm: implications for trichinae transmission in the US. Zoonoses Public Health 57, e116-123.

Kia, E.B., Meamar, A.R., Zahabiun, F. \& Mirhendi, H. (2009) The first occurrence of Trichinella murrelli in wild boar in Iran and a review of Iranian trichinellosis. J. Helminthol. 83, 399-402.

Kociecka, W., Majchrowicz, H. \& Szulc, M. (1992) Trichinellosis focus resulting from consumption of wild boar meat. Przegl Epidemiol 46, 195-205.

Krauss, H., G. Schieffer, G., W. Slenczka, W., A. Weber, A. \& Zahner, H. (Eds.) Zoonoses: Infectious Diseases, Transmissible from Animals to Humans, 3rd Ed. (2003). ASM Press, Washington, D.C., 400 pp.

Leiby, D.A., Duffy, C.H., Murrell, K.D. \& Schad, G.A. (1990) Trichinella spiralis in an agricultural ecosystem: transmission in the rat population. J. Parasitol.76, 360-364.

Masuoka, P.M., Burke, R., Colaccico, M., Razuri, H., Hill, D. \& Murrell, K.D. (2009) Predicted geographic ranges for North American sylvatic Trichinella species. J. Parasitol. 95, 829-837.

Miller, I., Jarvis, T. \& Pozio, E. (2006) Epidemiological investigations on Trichinella infections in farmed fur animals of Estonia. Vet. Parasitol. 139, 140-144.

Odevskaia, I.M. (2010) Role of birds in the epizootology of trichinosis in arctic marine mammals. Med Parazitol (Mosk) 3, 32-37.

Oivanen, L., Mikkonen, T., Haltia, L., Karhula, H., Saloniemi, H. \& Sukura, A. (2002) Persistence of Trichinella spiralis in rat carcasses experimentally mixed in different feed. Acta Vet. Scand. 43, 203-210.

Owen, I.L. \& Reid, S.A. (2007) Survival of Trichinella papuae muscle larvae in a pig carcass maintained under simulated natural conditions in Papua New Guinea. J. Helminthol. 81, 429-432.

Pozio, E. \& Murrell, D.K. (2006) Systematics and epidemiology of Trichinella. Adv. Parasitol. 63, 367-439.

Pozio, E. (2000) Factors affecting the flow among domestic, synanthropic and sylvatic cycles of Trichinella. Vet. Parasitol. 93, 241-262.

Pozio, E., Goffredo, M., Fico, R. \& La Rosa, G., (1999). Trichinella pseudospiralis in sedentary night-birds of prey from Central Italy. J. Parasitol. 85, 759-761.

Pozio, E., Kapel, C.M.O., Gajadhar, A.A., Boireau, P., Dupouy-Camet, J. \& Gamble, H.R. (2006) Trichinella in pork: current knowledge on the suitability of freezing as a public health measure. Euro Surveill. 11, E061116.1.

Pozio, E., La Rosa, G., Serrano, F.J., Barrat, J. \& Rossi, L. (1996) Environmental and human influence on the ecology of Trichinella spiralis and Trichinella britovi in Western Europe. Parasitol. 113, 527-533.

Pozio, E., Miller, I., Jarvis, T., Kapel, C.M. \& La Rosa, G. (1998) Distribution of sylvatic species of Trichinella in Estonia according to climate zones. J. Parasitol. 84, 193-195.

Rosenthal, B.M., LaRosa, G., Zarlenga, D., Dunams, D., Yao, C. et al. (2008) Human dispersal of Trichinella spiralis in domesticated pigs. Infect. Genet. Evol. 8, 799-805. 


\section{Chapter 4.2.3.19}

\section{Trichostrongylidiasis (Trichostrongylosis)}

\section{[TRYCHOSTRONGYLUS, MARSHALLGIA, MECISTOCIRRUS GENERA]}

Trichostrongylosis is a mild disease caused by a group of ruminants' nematodes from the genera: Trychostrongylus, Marshallgia and Mecistocirrus. The distribution of these nematodes is worldwide with some geographic differences, but herbivorous herds (cattle, sheep, donkeys, goats, deer, tapir and rabbits) are commonly infected, besides humans and primates (Freeman et al., 2004; Cruz et al., 2006). Higher prevalence has been reported from Middle East countries such as Iraq and Iran. Trichostrongyles are transmitted by ingestion of water, vegetables or other plants contaminated with third-stage larvae of the nematode and/or farmers utilizing dung for burning and fertilization. The life cycle consists of eggs excreted on pasture by infected ruminants. In environment, rabditiform larvae hatch and develop into filariform larvae (L3 stage) that are the infective to humans and animals. Once ingested, the filariform larvae move briefly into the crypts of the small intestine to develop further into eggs producer adult worms (Figure 4.2.3.19.1.1). Clinical manifestations are mostly asymptomatic but mild gastroenteritis may develop. In high infestation cases, persistent diarrhea, abdominal pain and anemia have been reported.

\subsection{TRICHOSTRONGYLOSIS AND ENVIRONMENT}

Consistent with their definitive environment, Trichostongylus spp. survival is linked to pasture moisture, temperature, migration and presence of available hosts (herbivorous herds) (Banks et al., 1990; Almeida et al., 2005; Nogareda et al., 2006; O'Connor et al., 2006). Lettini and Sukhdeo (2006) demonstrated that L3 larvae of Trichostrongylus colubriformis could enter an anhydrobiotic stage following desiccation. These larvae were capable of resisting up to seven desiccation/rehydration cycles, revealing low metabolic activity during this process. Interestingly, in the anhydrobiosis state larvae could survive low temperatures $\left(0^{\circ} \mathrm{C}\right)$, a feature that promotes their competence to persist under freezing temperatures (Garcia et al., 1997). Desiccation resistance of L3 larvae has been also shown in Guadeloupe (a tropical region tempered by trade winds with moderately high humidity), where Trichostrongylus's frequency was positively correlated to the dryness component (Simon et al., 1996). These resistance characteristics 
of the Trichostrongylus species may explain their persistence in pastures subjected to an intensive rotational grazing (IRG) regime in cold temperate regions in comparison to other gastrointestinal nematodes (Colvin et al., 2008; Rossanigo and Gruner, 1995). Another well-known phenomenon of the superfamily Trichostrongyloidea is arrested development. In temperate regions, these nematodes usually inhibit their development before the winter season in areas where transmission and infection occur mainly in summer or summer inhibition in areas where transmission is mainly from autumn to spring. Langrova et al. (2008) studied this phenomenon and concluded that in temperate climate (e.g., Europe) the hypobiosis seems to be connected to the advent of changing photoperiod and cool temperatures. Thus, exposure to low temperature and changing photoperiod could triggers the arrested development of infective larvae in favor of more preferable conditions (coinciding with lambing). It can be speculated that under global warming effect, the hypobiosis will shorten hence increasing the parasite burden in those animals (including humans) (Hudson et al., 2006).

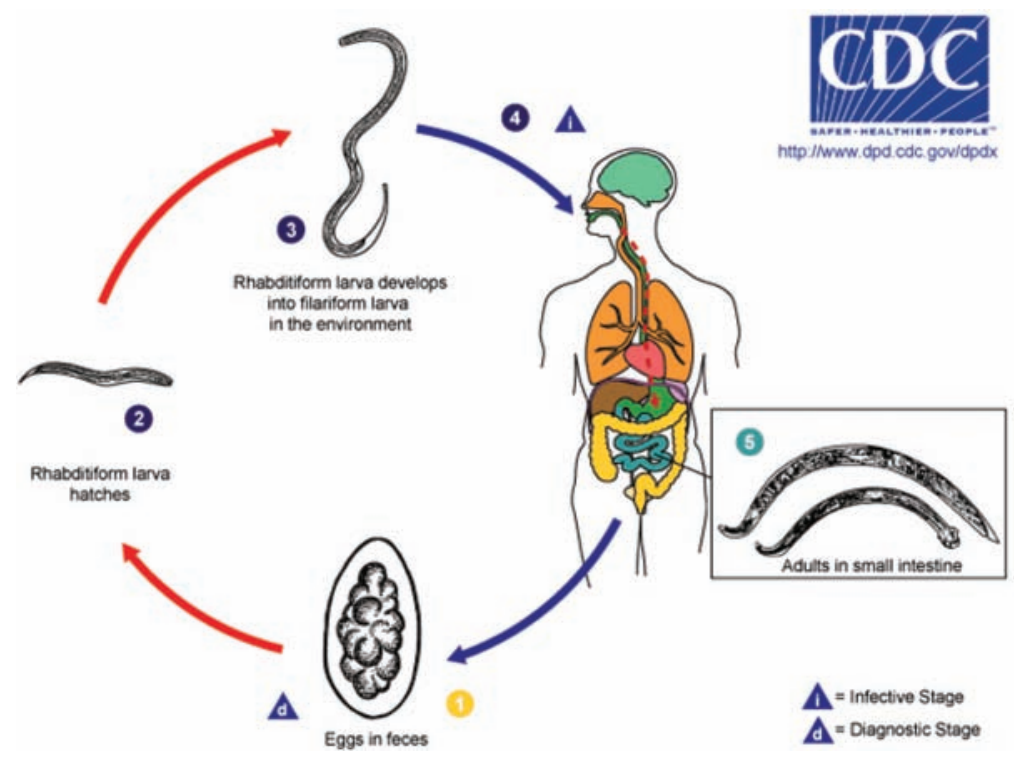

Figure 4.2.3.19.1. Trichostrongylus spp. life cycle (with permission from CDC, Atlanta, USA; http://www.dpd. cdc.gov/dpdx/HTML/ImageLibrary/Trichostrongylosis_il.htm)

Lacharme-Lora et al. (2009) studied the connection between parasitic helminths as possible vectors of pathogenic bacteria (e.g., Salmonella gp 3B -diarizonae) similar to well know free-living helminths (earthworms, see chapter 2.1 on Anthrax) in connection with soil environment (Tymczyna et al., 2000). Using fluorogenic proteins, they were able to prove bacterial internalization inside these parasites. The remaining question is: How does this "collaboration" affect animals' and human health.

Uriarte and Gruner (1994) conduct an experiment on the nematodes eggs infestation degree of pasture plots by means of two irrigation methods: flooding and spraying. A significant difference was found between the two irrigation methods in relation to the vertical distribution of larvae: spraying affected grass migration while flooding affected soil migration. These authors concluded that spray irrigated pasture has a higher risk of helminthic infection for calves. These results have been supported by another 
laboratory study carried out on simulated rain impact (closely resembling spraying irrigation) on L3 larvae (present on cowpats) translocation (Gronvold and Hogh-Schmidt, 1989). Pasture plants' composition had been shown also to play a significant role in the successful transmission of Trichostrongylus tenuis L3 larvae to a susceptible host. Saunders et al. (2001) demonstrated experimentally that L3 larvae exhibited selective migration towards heather, possibly reflecting a general response to plant cues which may be stronger for heather than for grass (used as the control in their experiments). It remains to be seen whether pasture without heather is less infectious for herbivores... Also related to pasture ecology and forested areas, Jackson et al. (1986) compared experimentally the survival of infective larvae on an open pastured block and an adjacent block forested with Pinus radiata. The results revealed a significantly higher recovery of Trichostrongylus spp. from the pine forested block, explained by these authors as most likely to be related to the more favourable climatic environment under the trees. Another bioenvironmental parameter, occasionally neglected, is the different insects involved in the ecology of herbivorous excretions. Chirico et al. (2003) studied the impact of dung beetles on the development of trichostrongylid eggs into larvae. Dung beetles (Aphodius spp.) were reported to optimize conditions in fresh dung to favor larval development of these nematodes under stable environmental conditions. An interesting observation made by the authors was that this synergistic effect is a result of the specific experimental dung beetles employed in their study: dung dwellers and not dung removers/burrowers like other dung beetle spp.

Hoste et al. (2001) compared nematode burden (including Trichostrongylus spp.) in two breeds of goats: Saanen dairy goats and Angora goats, both placed in the same rangeland environment. Angora goats repeatedly had higher nematode egg excretion levels compared to Saanen goats. The authors attributed this fact to different feeding behavior of the two goat species: Angora beeing mainly grazers whereas Saanen beeing mainly browsers. Assuming both breeds similar immunological response of toward helminthic infection, it can be positively suggested that browsing reduces infestation by means of statistical probability.

\subsection{REFERENCES}

Almeida, L.R., Castro, A.A., Silva, F.J. \& Fonseca, A.H. (2005) Development, survival and distribution of infective larvae of ruminants gastrointestinal nematodes, in the dry season of the "Fluminense lowland", State of Rio de Janeiro, Brazil. Rev Bras Parasitol Vet 14, 89-94.

Banks, D.J., Singh, R., Barger, I.A., Pratap, B. \& le Jambre, L.F. (1990) Development and survival of infective larvae of Haemonchus contortus and Trichostrongylus colubriformis on pasture in a tropical environment. Int. J. Parasitol. 20, 155-160.

Chirico, J., Wiktelius, S. \& Waller, P.J. (2003) Dung beetle activity and the development of trichostrongylid eggs into infective larvae in cattle faeces. Vet. Parasitol. 118, 157-163.

Colvin, A.F., Walkden-Brown, S.W., Knox, M.R. \& Scott, J.M. (2008) Intensive rotational grazing assists control of gastrointestinal nematodosis of sheep in a cool temperate environment with summer-dominant rainfall. Vet. Parasitol. 153, 108-120.

Cruz, A.E., Lira, T.I., Guiris, A.D.M., Osorio, S.D. \& Quintero, M.M.T. (2006) Parasites of the Central American tapir Tapirus bairdii (Perissodactyla: Tapiridae) in Chiapas, Mexico. Rev. Biol. Trop. 54, 445-450.

Freeman, A.S., Kinsella, J.M., Cipolletta, C., Deem, S.L. \& Karesh, W.B. (2004) Endoparasites of western lowland gorillas (Gorilla gorilla gorilla) at Bai Hokou, Central African Republic. J. Wildl. Dis. 40, 775-781.

Garcia, R.C., Valcarcel, F. \& Rojo, V.F.A (1997) Influence of climate on pasture infectivity of ovine trichostrongyles in dry pastures. Zentralblatt Veterinarmedizin Reihe B 44, 437-443.

Gronvold, J. \& Hogh-Schmidt, K. (1989) Factors influencing rain splash dispersal of infective larvae of Ostertagia ostertagi (Trichostrongylidae) from cow pats to the surroundings. Vet. Parasitol. 31, 57-70. 
Hoste, H., Leveque, H. \& Dorchies, P. (2001) Comparison of nematode infections of the gastrointestinal tract in Angora and dairy goats in a rangeland environment: relations with the feeding behaviour. Vet. Parasitol. 101, 127-135.

Hudson, P.J., Cattadori, I.M., Boag, B. \& Dobson, A.P. (2006) Climate disruption and parasite-host dynamics: patterns and processes associated with warming and the frequency of extreme climatic events. J. Helminthol. 80, $175-182$.

Jackson, RA., Townsend, K.G. \& Hawke, M.F. (1986) The availability of ovine infective trichostrongyle larvae on forested paddocks. N Z Vet J 34, 205-209.

Lacharme-Lora, L., Salisbury, V., Humphrey, T.J., Stafford, K. \& Perkins, S.E. (2009) Bacteria isolated from parasitic nematodes-a potential novel vector of pathogens?. Environ Health 8, S17.

Langrova, I., Makovcova, K., Vadlejch, J., Jankovska, I., Petrtyl, M. et al. (2008) Arrested development of sheep strongyles: onset and resumption under field conditions of Central Europe. Parasitol. Res. 103, 387-392.

Lettini, S.E. \& Sukhdeo, M.V.K. (2006) Anhydrobiosis increases survival of trichostrongyle nematodes. J. Parasitol. 92, 1002-1009.

Nogareda, C., Mezo, M., Uriarte, J., Lloveras, J. \& Cordero del Campillo, M. (2006) Dynamics of infestation of cattle and pasture by gastrointestinal nematodes in an Atlantic temperate environment. J. Vet. Med. B Infect. Dis. Vet. Public Health 53, 439-44.

O’Connor, L.J., Walkden-Brown, S.W. \& Kahn, L.P. (2006) Ecology of the free-living stages of major trichostrongylid parasites of sheep. Vet. Parasitol. 142, 1-15.

Rossanigo, C.E. \& Gruner, L. (1995) Moisture and temperature requirements in faeces for the development of free-living stages of gastrointestinal nematodes of sheep, cattle and deer. J. Helminthol. 69, 357-362.

Saunders, L.M., Tompkins, D.M. \& Hudson, P.J. (2001) Strategies for nematode transmission: selective migration of Trichostrongylus tenuis infective larvae. J. Helminthol. 75, 367-372.

Simon, R., Aumont, G., Aprelon, R. \& Barré, N. (1996) Herbage density of third-stage larvae of goat strongyles during the dry season in Guadeloupe. Ann N Y Acad Sci. 791, 412-420.

Tymczyna, L., Chmielowiec-Korzeniowska, A. \& Saba, L. (2000) Bacteriological and parasitological pollution of the natural environment in the vicinity of a pig farm. Pol. J. Environ. Stud. 9, 209-214.

Uriarte, J. \& Gruner, L. (1994) Development and distribution of bovine trichostrongyle infective larvae on a pasture irrigated by flooding or by spraying. Parasitol. Res. 80, 657-663. 


\section{Chapter 4.2.3.20}

\section{Other Nematodic Infections}

\section{[ANCYLOSTOMA CEYLANICUM, PHYSALOPTERA CAUCASICA, TERNIDENS DEMINATUS]}

Ancylostoma ceylanicum parasitizes carnivores' small intestine (e.g. dogs, cats) and occasionally humans (Baker et al., 1989; Chowdhury and Schad, 1972; Yoshida et al., 1968). Distribution is mainly in Africa and Asia, but recently it was reported to be present in dogs from Australia (Rep and Heinemann, 1976; Scholz et al., 2003; Setasuban et al., 1976; Yoshida et al., 1973; Palmer et al., 2007). Transmission is percutaneous by L3 stage larvae or direct ingestion (via contaminated vegetables). A. ceylanicum mature into small intestine mucosa while sucking blood, to further produce eggs. Consequently, the direct clinical manifestation can be anemia.

Physaloptera caucasica parasitizes monkey's esophagus and small intestine (suborder Simiae). In the past (early $20^{\text {th }}$ century) tropical Africa was the focus of humans infections, however additional human cases had been reported from South America (Liang-Sheng, 1957; Fain and Vandepitte, 1964; Apt et al., 1965; Pettifer, 1984). The life cycle is not clear; however, possible transmission may occur through ingestion of arthropods (beetles, cockroaches and crickets) that harbor infectious larvae. In humans, it can be found along the digestive tract (from esophagus to small intestine). Clinical manifestations are vomiting, bloody diarrhea and abdominal pain.

Ternidens deminatus is another simian parasite (e.g. red-tailed monkeys, baboons) found in Africa and Asia (Kooriyama et al., 2010; Bezjian et al., 2008; Hope et al., 2004; Hemsrichart, 2005). Humans' infections are prevalent in South Africa (Goldsmid, 1972). The life cycle is not well defined, but it seems that L3 stage larvae infect humans directly without an intermediate host, via ingestion. The parasite development in digestive tract is blood dependent; consequently, anemia has been reported in acute infections beside nodules formation.

\subsection{ANCYLOSTOMA CEYLANICUM, PHYSALOPTERA CAUCASICA, TERNIDENS DEMINATUS AND ENVIRONMENT}

Like most of the previously described nematodes, low socio-economic status, poverty, poor hygiene, ignorance and close animal contact (domestic and wildlife) are the main factors contributing to 
helminthic infections, including rare ones. The rare parasitic nematodes described here seem to accidentally infect humans mostly in Africa and Asia where primates are in close contact with. Experimental studies on cross-infection of hamster with A. ceylonum isolated from a dog revealed that this nematode has a broader distribution possibly in rodents too, implying on a possible role of rodents in transmission (Ray et al., 1972).

An interesting report came from United Arab Emirates, a desert area, revealing A. ceylanicum prevalence of $8.8 \%$ in domestic and stray cats (Schuster et al., 2009). Indeed, oral and cutaneous larval infections had been proved to be a possible route of infection in animals and humans, but according to the authors transplacental and galactogene routes or involvement of paratenic hosts could not be ruled out in the present case (similar to other known hookworms). Another reasonable possibility is import of already infected animals from other countries where this parasite is endemic.

Goldsmid and Jablonski $(1982,1986)$ reported on specific granules present (with some inconsistency) in T. deminutus that contain $\mathrm{ZnS}$. They suggested that these inorganic elements are a result of blood feeding (sulphur originating from sulphur-containing amino acids and zinc from host dietary intake). A brief glance in any elementary inorganic chemistry book shows that $\mathrm{ZnS}$ is phosphorescent on illumination with blue or ultraviolet light and can be used as infrared optical material. If $\mathrm{ZnS}$ accumulation is linked to these optical phenomena for parasite benefit in some ways or just a by-products result from host feeding is not clear. Finally, Cappelo et al. (2006) showed that a crystal protein from the bacterium B. thuringiensis (acknowledged for many years as an excellent insecticide) has antihelminthic activity against Ancylostoma ceylonicum. It will be interesting to find out if Physaloptera caucasica that is possibly transmitted by insects is also sensitive to the crystal protein of B. thuringiensis?

\subsection{REFERENCES}

Apt, W., Sapunar, J., Doren, G. \& Rojo, M. (1965) Physaloptera caucasica. First human cases in Chile. Bol Chil Parasitol 20, 111-113.

Baker, M.K., Lange, L., Verster, A. \& van der Plaat, S. (1989) A survey of helminths in domestic cats in the Pretoria area of Transvaal, Republic of South Africa. Part 1: The prevalence and comparison of burdens of helminths in adult and juvenile cats. J S Afr Vet Assoc 60, 139-142.

Bezjian, M., Gillespie, T.R., Chapman, C.A. \& Greiner, E.C. (2008) Coprologic evidence of gastrointestinal helminths of forest baboons, Papio anubis, in Kibale National Park, Uganda. J. Wildl. Dis. 44, 878-887.

Cappello, M., Bungiro, R.D., Harrison, L.M., Bischof, L.J., Griffitts, J.S. et al. (2006) A purified Bacillus thuringiensis crystal protein with therapeutic activity against the hookworm parasite Ancylostoma ceylanicum. Proc. Natl. Acad. Sci. U.S.A. 103, 15154-15159.

Chowdhury, A.B. \& Schad, G.A. (1972) Ancylostoma ceylanicum: a parasite of man in Calcutta and environs. Am. J. Trop. Med. Hyg. 21, 300-301.

Fain, A. \& Vandepitte, J. (1964) Description of Physaloptera (abbreviata caucasica linstow, 1902) collected from humans in the Congo. Bull Acad R Med Belg 4, 663-682.

Goldsmid, J. M. (1986) Inorganic elements in adult Ternidens deminutus (Nematoda: Strongylidae: Oesophagostominae) from humans and baboons. J. Helminthol. 60, 147-148.

Goldsmid, J.M. (1972) Ternidens deminutus (Railliet \& Henry, 1909) and hookworm in Rhodesia and a review of the treatment of human infections with T. deminutus. Cent Afr J Med 18, 1-14.

Goldsmid, J.M. \& Jablonski, W. (1982) Demonstration of zinc sulfide in Ternidens deminutus using EDAX analysis. Int. J. Parasitol. 12, 145-149.

Hemsrichart, V. (2005) Ternidens deminutus infection: first pathological report of a human case in Asia. J Med Assoc Thai 88, 1140-1143.

Hope, K., Goldsmith, M.L. \& Graczyk, T. (2004) Parasitic health of olive baboons in Bwindi Impenetrable National Park, Uganda. Vet. Parasitol. 122, 165-170. 
Kooriyama, T., Inaba, A., Nishida, T. \& Iwaki, T. (2010) Case report of helminths and lung mite infection in the red-tailed monkey, Cercopithecus ascanius schmidti, in Mahale Mountains National Park, Tanzania. Primates 51, 183-188.

Liang-Sheng, Y. (1957) On Physaloptera lumsdeni n. sp. from a bush-baby in Tanganyika, with a note on Abbreviata caucasica. J. Helminthol. 31, 29-32.

Palmer, C.S., Traub, R.J., Robertson, I.D., Hobbs, R.P., Elliot, A. et al. (2007) The veterinary and public health significance of hookworm in dogs and cats in Australia and the status of A. ceylanicum. Vet. Parasitol. 145, 304-313.

Pettifer, H.L. (1984) The helminth fauna of the digestive tracts of chacma baboons, Papio ursinus, from different localities in the Transvaal. Onderstepoort J. Vet. Res. 51, 161-170.

Ray, D.K., Bhopale, K.K. \& Shrivastava, V.B. (1972) Observations on cross infection experiments with Ancylostoma ceylanicum (dog strain) adapted in hamsters back to the dog. Res. Vet. Sci. 13, 201-202.

Rep, B.H. \& Heinemann, D.W. (1976) Changes in hookworm distribution in Surinam. Trop Geogr Med 28, $104-110$.

Scholz, T., Uhlirova, M. \& Ditrich, O. (2003) Helminth parasites of cats from the Vientiane province, Laos, as indicators of the occurrence of causative agents of human parasitoses. Parasite 10, 343-350.

Schuster, R.K., Thomas, K., Sivakumar, S. \& O’Donovan, D. (2009) The parasite fauna of stray domestic cats (Felis catus) in Dubai, United Arab Emirates. Parasitol. Res. 105, 125-134.

Setasuban, P., Vajrasthira, S. \& Muennoo, C. (1976) Prevalence and zoonotic potential of Ancylostoma ceylanicum in cats in Thailand. Southeast Asian J. Trop. Med. Public Health 7, 534-539.

Yoshida, Y., Okamoto, K. \& Chiu, J.K. (1968) Ancylostoma ceylanicum infection in dogs, cats, and man in Taiwan. Am. J. Trop. Med. Hyg. 17, 378-381.

Yoshida, Y., Okamoto, K., Matsuo, K., Kwo, E.H. \& Retnasabapathy, A. (1973) The occurrence of Ancylostoma braziliense (de Faria, 1910) and Ancylostoma ceylanicum (Looss, 1911) in Malaysia. Southeast Asian J. Trop. Med. Public Health 4, 498-503. 


\section{Chapter 5}

\section{Fungal Zoonoses}


Downloaded from https://iwaponline.com/ebooks/book-pdf/521254/wio9781780400761.pdf

Downloaded trom https://Iwaponline.com/ebooks/book-pdt/521254/WI09/81/80400/61.pdt
by IWA Publishing user 


\section{Chapter 5.1}

\section{Microsporum spp.}

\section{[MICROSPORUM CANIS, M. NANUM, M. AUDOUINII, M. EQUINUM, M. GALLINAE]}

Microsporum is a genus of fungi that causes various dermatophytoses such as: tinea capitis, tinea corpus, ringworm, etc. Microsporum encompass seventeen species described till now, divided by their environment: zoophilic, geophilic and anthropophilic. Microsporum has the typical fungal forms macroconidia, microconidia and conidiophores. Macroconidia range from 7 to 20 by 30 to $160 \mu \mathrm{m}$ while microconidia range from 2.5 to 3.5 by 4 to $7 \mu \mathrm{m}$ in size. The shape, size and cell wall features are important characteristics for species identification. Microsporum canis is the most significant zoonotic fungi followed by M. nanum (from pigs), M. audounii (from dogs), M. equinum (from horses) and $M$. gallinae (from chickens) (Table 5.1.1). The distribution is worldwide and via numerous animals in close contact with humans: cats (largely), dogs, horses, pigs, sheep, rabbits, hamsters, rats and zoo animals (monkeys, tigers, jaguars, lynxes) (Cafarchia et al., 2006; Cafarchia et al., 2010; Sykes and Ramsay, 2007; Galo et al., 2005; Favrot and Zaugg, 2005; Gonzalez et al., 1995; Gallo et al., 2005). Besides direct contact with infected animals, contact with arthropod carriers such as: lice, flies, fleas and mites may transmit these dermatophytes to humans. The main clinical symptoms are a result of keratolysis of skin, hair, and nails that include: rash, inflammation, lesion and secondary contamination as a result of area scratching. It can be stated that dermatophytes infection are chronic without any acute impact on human health; however, chronic infections cannot be ignored as described later on. In humans, internalization through inhalation has been suspected to cause more severe diseases (Nakachi et al, 1999). Fatal cases were only reported in pigs (Gonzalez et al, 1995).

\subsubsection{MICROSPORUM SPP. AND ENVIRONMENT (FIGURE 5.1.1)}

Based on their ubiquity, Microsporum spp. can be found almost everywhere and, besides host factors (e.g., ichthyosis, atopy, topical and systemic glucocorticoids, collagen vascular disease, mechanical lesions and injuries), local factors are also important in dermatophytic infection (e.g., sweating, occlusion, occupational exposure, geographic location, tropical or semitropical climates with high humidity). 
Dermatophytes preferences for elevated temperatures and humidity, conditions present in sub-tropical and tropical regions and in enclosures such as shoes (that preserve these conditions), will help their proliferation. Salvo and Fabiano (2007) assessed Ligurian beaches (Italy) for the presence of dermatophytes in sediments. They found that Microsporum spp. represented 5\% of the total filamentous fungi screened, particularly during the tourist season. Beside the risk of contracting a fungal infection on the beach it should be emphasized that contamination sources are humans themselves, animals and sewage. Sewage enrichment of soils (clay and sand) was shown to increase microfungal communities compared to untreated ones, including human pathogens (Microsporum spp.) (Kacprzak \& Woszczyk, 2004). Next to sewage, sewage sludge was also shown to comprise a large variety of fungi including dermatophytes. If soils are amended with sewage sludge without any further disinfection treatment, present dermatophytes pose a human and animal increased risk alongside other numerous pathogens (Ulfig, 2009).

Table 5.1.1 Some characteristics of zoonotic Microsporum spp.

\begin{tabular}{lllll}
\hline Microsporum spp. & Animal main sources & Other sources & Zoonosis & Category \\
\hline Microsporum canis & Cat, dog, horse & All mammals & Frequent & Zoophilic \\
Microsporum gallinae & Poultry & Dog, cat & Rare & Zoophilic \\
Microsporum gypseum & Soil & All mammals & Possible & Geophilic \\
Microsporum nanum & Soil & Pig & Rare & Geophilic \\
Microsporum persicolor & Rodents & Dog, cat & Possible & Geophilic \\
Microsporum audounii & Humans & Dog & Frequent & Anthropophilic \\
\hline
\end{tabular}

Dermatophytes are distributed ubiquitously as shown by Yu et al (2004) who used advanced molecular methods and found the same strains of M. canis in an outbreak of tinea capitis in school children (age 3.5 to 10 years old) and their environment, pets and even fomites (pillows and carpets). In Nigeria, school age children were found to harbor Tine capitis (Microsporum spp.) at high frequency, following head lesions (Ayanbimpe et al., 2008). Dermatophyte prevalence was affected by social and cultural habits (frequent interaction with soil and animals, poor health education and environmental hygiene) rather than population density. In relation to population, another aspect related to dermatophytes was reported by Monod et al. (2002) who screened autochthonous dermatophytes in Switzerland: new detected strains seem to be introduced by human immigration.

Sharma et al. (2010) studied the prevalence and distribution of keratinophilic fungi in a semi-arid region. Among the mixture of different fungi, Microsporum canis and Microsporum gypseum were also reported. These authors mentioned that industrial soil samples were most diverse in fungal flora. This observation is in agreement with industrial soil pollution with a large variety of anthropogenic chemicals that only fungi are competent to biodegrade, an obvious advantage of these microorganisms. Tampiri (2006) described a change in human dermatomycoses in Italy in the past century. The change consisted of a shift from anthropophilic to zoophilic fungi based on animals as substrata for pathogenic fungi growth. The life style in Italy for the last five decades, with overpopulation of birds, pets, wild and domestic animals together with humans in crowded urban area supports the growth of those fungi, increasing infection risk. In addition, animal debris creates optimal conditions for the growth and the multiplication of geophilic or saprophyitic fungi, such as Microsporum gypseum and other fungi. As a final point, the 
author emphasized the importance of environments heavily populated by fungi as a ground for allergic pulmonary reactions and worse, as already described by Nakachi et al (1999).

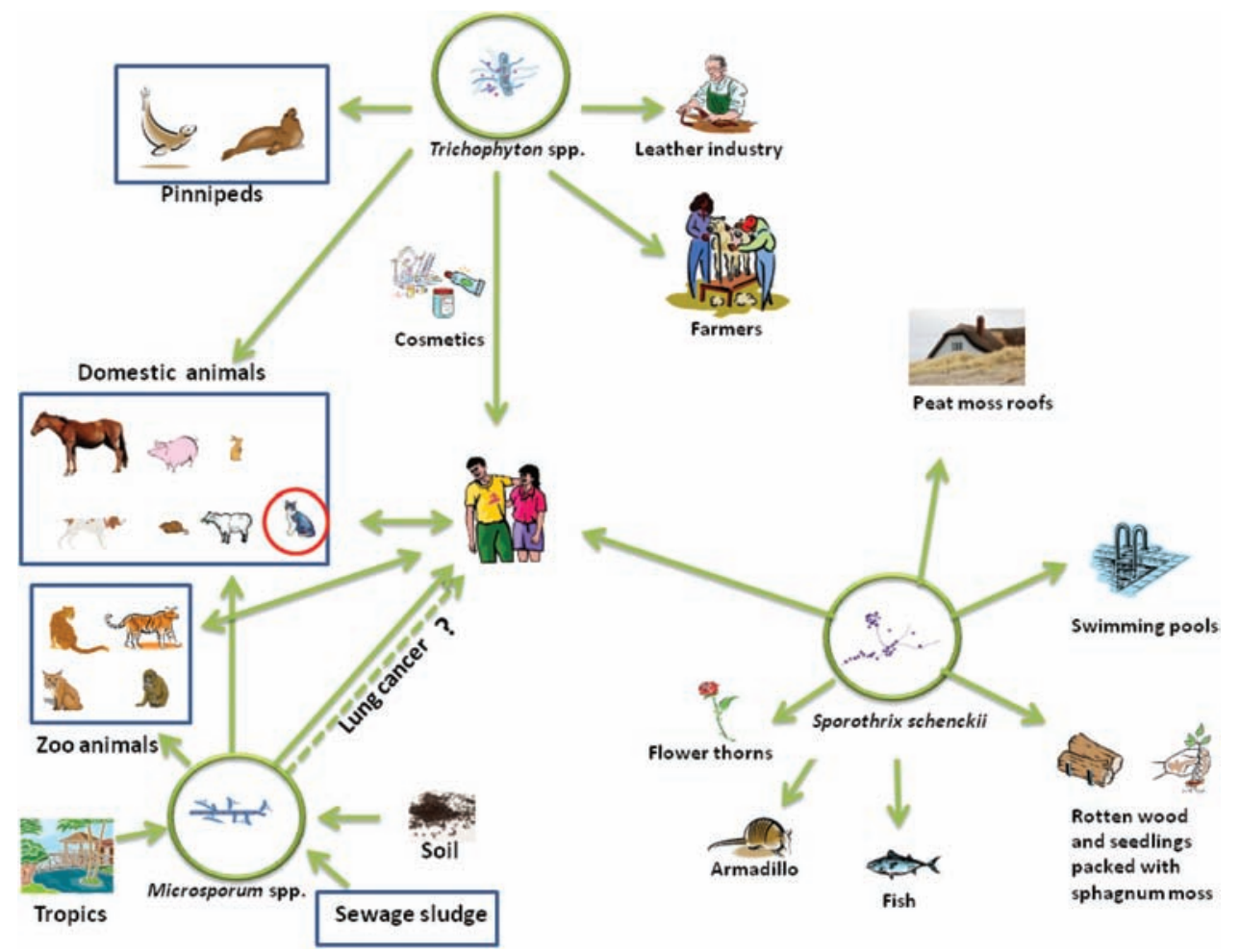

Figure 5.1.1. Zoonotic dermatophytes and environmental factors involved in human infection

Perhaps the most important report on the life threatening aspects of dermatophytes was presented by Nakachi et al (1999). These authors performed a comprehensive epidemiological study in northern Thailand where in women lung cancer incidence is very high (40.9 per 100,000, one of the highest in Asia) and compared it with a lower incidence rate (8.5 per 100,000), both groups being in closely related areas, geographically and culturally. Interestingly, among the analyzed parameters linked to high cancer prevalence, cigarette smoking was lower in the high lung cancer incidence area; nevertheless, Microsporum canis, most commonly found indoors in this area, was significantly correlated in comparison with the low incidence area (control). In addition, these authors found significant high serum concentration of a fungus constituent, concluding that $M$. canis chronic infection is likely to be involved in the etiology of female lung cancer in North Thailand. These findings are in agreement with a previous publication, in which Candida parapsilosis cell extract was demonstrated to cause sarcoma in mice. In the same study, increased frequency of leukemias and pulmonary tumors were observed with lipids extracts from Microsporum, Trichophyton, Epidermophyton and Scopulariopsis (Blank et al, 1968). This primary epidemiological link between dermatophytes and human lung cancer deserves further research in the future. 


\subsubsection{REFERENCES}

Ayanbimpe, G.M., Taghir, H., Diya, A. \& Wapwera, S. (2008) Tinea capitis among primary school children in some parts of central Nigeria. Mycoses 51, 336-340.

Blank, F., Chin, O., Just, G., Meranze, D.R., Shimkin, M.B. \& Wieder, R. (1968) Carcinogens from fungi pathogenic for man. Cancer Res. 28, 2276-2281.

Cafarchia, C., Camarda, A., Coccioli, C., Figueredo, L.A. \& Circella, E. (2010) Epidemiology and risk factors for dermatophytoses in rabbit farms. Med. Mycol. 48, 975-80.

Cafarchia, C., Romito, D., Capelli, G., Guillot, J. \& Otranto, D. (2006) Isolation of Microsporum canis from the hair coat of pet dogs and cats belonging to owners diagnosed with M. canis tinea corporis. Vet. Dermatol. 17, 327-331.

Favrot, C. \& Zaugg, N. (2005) Incidence, immunity and treatment of feline dermatophytosis. Schweiz. Arch. Tierheilkd. 147, 205-212.

Gallo, M.G., Tizzani, P., Peano, A., Rambozzi, L. \& Meneguz, P.G. (2005) Eastern cottontail (Sylvilagus floridanus) as carrier of dermatophyte fungi. Mycopathologia 160, 163-166.

Gonzalez, C.J.F., Barcena, A.M.C., Gomez, R.F. \& Amigot, L.J.A. (1995) An outbreak of dermatophytosis in pigs caused by Microsporum canis. Mycopathologia 129, 79-80.

Kacprzak, M. \& Woszczyk, K. (2004) The microfungal communities in the soils treated with sewage sludge. Environ Protect Eng 30, 51-56.

Monod, M., Jaccoud, S., Zaugg, C., Lechenne, B., Baudraz, F. \& Panizzon, R. (2002) Survey of dermatophyte infections in the Lausanne area Switzerland. Dermatology (Basel) 205, 201-203.

Nakachi, K., Limtrakul, P-N., Sonklin, P., Sonklin, O-A-N., Jarern, C.T. et al (1999) Risk factors for lung cancer among northern thai women: epidemiological, nutritional, serological, and bacteriological surveys of residents in high- and low-incidence areas. Jpn. J. Cancer Res. 90, 1187-1195.

Salvo, V-S., \& Fabiano, M. (2007) Mycological assessment of sediments in Ligurian beaches in the Northwestern Mediterranean: pathogens and opportunistic pathogens. J. Environ. Manage. 83, 365-369.

Sharma, A., Chandra, S. \& Sharma, M. (2010) Prevalence of keratinophilic fungi in semi-arid region, with particular reference to soil pH. Asian J Exp Biol Sci 24, 59-63.

Sykes, J.M. \& Ramsay, E.C. (2007) Attempted treatment of tigers (Panthera tigris) infected with Microsporum canis. J. Zoo. Wildl. Med. 38, 252-257.

Tampieri, M.P. (2006) Mycetes and urban areas. Parassitologia 48, 121-124.

Ulfig, K. (2009) Keratinolytic and keratinophilic fungi in sewage sludge: factors influencing their occurrence. In: Editor (s): Misra, J.K., Deshmukh, S.K. Fungi from Different Environments, pp. 131-168. Science Publishers, Inc., Enfield, N.H., USA.

Yu, J., Wan, Z., Chen, W., Wang, W., Li, R. \& Wang, D. (2004) Molecular typing study of the Microsporum canis strains isolated from an outbreak of tinea capitis in school. Mycopathologia 157, 37-41. 


\section{Chapter 5.2 Pneumocystosis (Pneumocystis pneumonia)}

\section{[PNEUMOCYSTIS JIROVECII FORMERLY CARINII]}

Pneumocystis is a yeast-like fungus (in the past erroneously classified as protozoa) that infects humans and animals (Lainson and Shaw, 1975). Pneumocystis pneumonia is mainly found in immunocompromised individuals, such as AIDS patients, transplant recipients, cancer patients and those exposed to ionized radiation (Hui and Kwok, 2006; Hennequin et al., 1995; Lavdovskaia et al., 1996). The old name, Pneumocysitis carinii applies now to an animal variant. Domestic and free-living animals, such as rodents, pigs, rabbits, sheep, goats and dogs, are possible sources of human infections. However, there is an increasing collection of evidence that this fungus is mostly transmitted through the airborne route (aerosols and contaminated dust) (Schmoldt et al., 2008). Wakefield et al. (1992), applying DNA amplification and subsequent sequencing of a portion of the mitochondrial gene encoding the large subunit ribosomal RNA, found that $P$. carinii is closely related to the ustomycetous red yeast fungi, a group of fungi environmentally distributed with airborne spores characteristics. The life cycle is not completely known; nevertheless, inhaled mature cysts containing trophozoites break up and release these haploid bodies along lung alveolus surface. Then, asexual and sexual pathways take place. In the asexual path, trophozoites multiply by binary fission, while in the sexual path two trophozoites fuse to form a zygote. The zygote will form the early precyst with eight haploid nuclei following meiotic and mitotic divisions (Figure 5.2.1). The mature cyst contains eight trophozoites that will be further spread in the host or a new host after cyst wall rupture. In humans, clinical manifestations are: pneumonia (Pneumocystis pneumonia), dry cough, moderate fever, dyspnea, retrosternal pain, tachypnea, tachycardia and cyanosis. In AIDS patients, other organs are also infected (lymph nodes, bone morrow, liver, and spleen) where fatality can reach $20 \%$.

\subsubsection{PNEUMOCYSTIS AND ENVIRONMENT}

Hughes (1982) clearly showed that Pneumocystis jirovecii (formerly carinii) is transmitted by air. This author exposed axenic rats to natural air, food and water versus filtered air. Experimental animals fed with contaminated lung tissue and contaminated water did not acquire infection. Those exposed to 
unfiltered air but fed with sterile food and water did contract pneumocytosis. Thus, this fungus is mainly air-borne as also shown by positive nasal swab samples taken from contact health care workers and their family (Powierska-Czarny et al., 2004). In this context, it will be interesting to find out if mostly children (but some adults too) that pick their nose are indirectly inoculating themselves to develop immunity against this opportunistic pathogen.

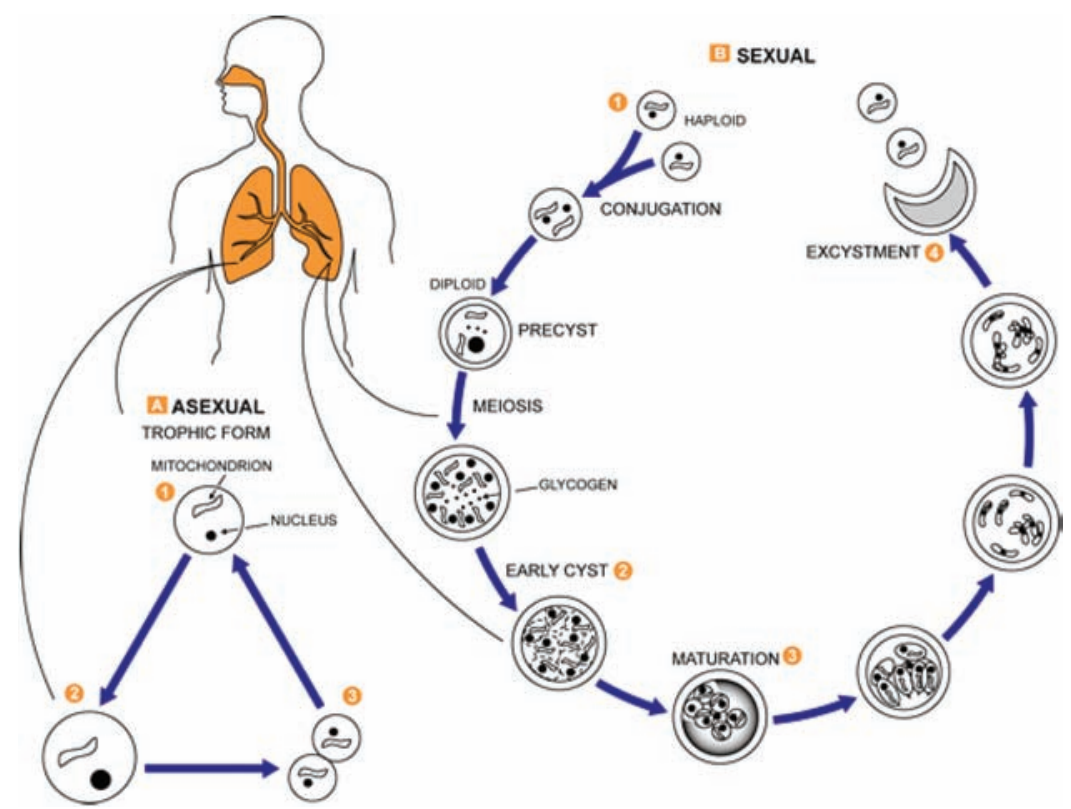

Figure 5.2.1. Pneumocystis jurovecii life cycle (with permission from CDC, Atlanta, USA; http://dpd.cdc. gov/dpdx/HTML/Pneumocystis.htm)

Kunakbaeva et al. (2006) used PCR to detect $P$. jirovecii (carinii) in air and rinse from medical equipment. These authors reported on intact DNA from the fungus for 12 days including 2 hours of UV irradiation. A $0.1 \%$ solution of chloramine with a subsequent 30 minutes UV irradiation eliminated Pneumocystis DNA. Similar results connected to hospital environments have been reported from samples taken by air-filtration from rooms of $P$. carinii-infected patients (Bartlett et al., 1997; Olsson et al., 1998).

Using multiple linear regression statistics, Sing et al. (2009) looked for a correlation between $P$. jirovecii pneumonia and climatic factors in Germany. Pneumonia prevalence caused by this fungus was found to be positively correlated to temperature (being maximal in the summer months, temperature $14.2-18.6^{\circ} \mathrm{C}$ ) but not to rainfall and wind strength. In Spain, Varela et al. (2004) reported also that minimum mean temperature $\left(7-9.7^{\circ} \mathrm{C}\right)$ was the main meteorological factor influencing infection; in other words the seasonality of $P$. jiroveci infection could result directly from increased infection, but in their case during the colder months. From these studies, it can be epidemiologically speculated that in Spain, during winter time, people will reside more indoors possibly infecting each other, while in Germany during summer time, people are more outdoor and their behavior or type of leisure activity might be relevant for Pneumocystis transmission. Thus, it is still unclear how this opportunistic pathogen is transmitted, though it is very possible that different animals surrounding human habitat and environment can play a role as reservoirs. 


\subsubsection{REFERENCES}

Bartlett, M.S., Vermund, S.H, Jacobs, R., Durant, P.J., Shaw, M.M. et al. (1997) Detection of Pneumocystis carinii DNA in air samples: likely environmental risk to susceptible persons. J. Clin. Microbiol. 35, 2511-2513.

Hennequin, C., Page, B., Roux, P., Legendre, C. \& Kreis, H. (1995) Outbreak of Pneumocystis carinii pneumonia in a renal transplant unit. Eur. J. Clin. Microbiol. Infect. Dis.14, 122-126.

Hughes, W.T. (1982) Natural mode of acquisition for de novo infection with Pneumocystis carinii. J. Infect. Dis. 145, 842-848.

Hui, M. \& Kwok, W.T. (2006) Pneumocystis carinii pneumonia in Hong Kong: a 10 year retrospective study. J. Med. Microbiol. 55, 85-88.

Kunakbaeva, A.F., Karazhas, N.V., Zigangirova, N.A., Rybalkina, T.N., Galstian, G.M. et al. (2006) Detection of Pneumocystis carinii DNA in air and washes from medical equipment in hospitals. Zh. Mikrobiol. Epidemiol. Immunobiol. 7, 100-103.

Lainson, R. \& Shaw, J.J. (1975) Pneumocystis and Histoplasma infections in wild animals from the Amazon region of Brazil. Trans. R. Soc. Trop. Med. Hyg. 69, 505-508.

Lavdovskaia, M.V., Lysenko, A.Ia., Basova, E.N., Lozovaia, G.A., Baleva, L.S. \& Rybalkina, T.N. (1996) The host-opportunistic protozoa system. The effect of ionizing radiation on the prevalence of cryptosporidiosis and pneumocystosis. Parazitologia 30, 153-158.

Olsson, M., Lidman, C., Latouche, S., Bjorkman, A., Roux, P. et al. (1998) Identification of Pneumocystis carinii f. sp. hominis gene sequences in filtered air in hospital environments. J. Clin. Microbiol. 36, 1737-1740.

Powierska-Czarny, J., Gospodarek, E. \& Czerwionka-Szaflarska, M. (2004) New aspects of epidemiology and treatment of Pneumocystis carinii infection. Pol. Merkur. Lekarski 17, 534-537.

Schmoldt S, Schuhegger R, Wendler T, et al. (2008) Molecular evidence of nosocomial Pneumocystis jirovecii transmission among 16 patients after kidney transplantation. J. Clin. Microbiol. 46, 966-971.

Sing, A., Schmoldt, S., Laubender, R.P., Heesemann, J., D. Sing, D. \& Wildner, M. (2009) Seasonal variation of Pneumocystis jirovecii infection: analysis of underlying climatic factors. Clin. Microbiol. Infect. 15, 957-960.

Varela, J.M., Regordán, C., Medrano, F.J., Respaldiza, N., de la Horra, C. et al. (2004) Climatic factors and Pneumocystis jiroveci infection in southern Spain. Clin. Microbiol. Infect. 10, 770-772.

Wakefield, A.E., Peters, S.E., Banerji, S., Bridge, P.D., Hall, G.S. et al. (1992) Pneumocystis carinii shows DNA homology with the ustomycetous red yeast fungi. Mol. Microbiol. 6, 1903-1911. 


\section{Chapter 5.3}

\section{Trichophyton spp.}

\section{[TRICHOPHYTON MENTAGROPHYTES, VERRUCOSUM, EQUINUM, QUINKEANUM, ERINACE[]}

Trichophyton is a fungus genus characterized by formation of smooth-wall macroconidia and microconidia. Macroconidia (clavate to fusiform shape) have a size range from 40 to 8 by 8 to $50 \mu \mathrm{m}$, organized directly on hyphae or on short pedicels. Macroconidia are few or absent in many species. Microconidia (clavate, pyriform, spherical or irregular shape) have a size range from 2 to 3 by 2 to $4 \mu \mathrm{m}$. The genus comprises approximately 26 spp., where Trichophyton mentagrophytes, T. verrucosum, T. equinum, $T$. quinckeanum and T. erinacei are zoonotic (Table 5.3.1). The distribution is worldwide in many animals including farm animals and more exotic ones such as pinnipeds (Takatori et al., 1993; Pollock et al., 2000; Tanaka et al., 1994; Torres-Rodriguez et al., 1992; Otcenasek et al., 1980). Children are at increased risk by direct and continuous contact with their pets as well laboratory workers with animals (Van Rooij et al., 2006; Hironaga et al., 1981). Transmission occurs mainly directly between humans and animals, but indirect contamination may occur via fomites (mainly leather products). Infected humans are carriers of these dermatophytes (anthropization) even into extreme conditions such as Antarctic environments, but their survival there is still unknown (Mercantini et al, 1993). Presentation of clinical manifestations is via acute inflammation (deep-seated) called "kerion celsi" (pustular inflammation of hair follicles), subcutaneous abscesses, lymphoadenopathy, fever and malaise (Van Rooij et al., 2006).

\subsubsection{TRICHOPHYTON SPP. AND ENVIRONMENT}

Besides clinical damage, dermatophytes (e.g. Trichophyton spp.) are sturdy biodegraders of hair, nails and skin (typically of keratin nature) and consequently destructive of a variety of natural products such as wool, leather and horn made tools. Shrivastava et al. (1996) described T. simii with increased keratinolytic and sulphitolysis (oxidation of cystine to S-sulphocysteine) able to biodegrade wool. A similar destructive activity of these fungi was also reported in France, where $40 \%$ of the skins to be treated by tannery are damaged with ringworm lesions (Chermette et al., 2008). In environment, arthrospores of Trichophyton 
mentagrophytes were found to germinate under certain conditions, such as high temperature (optimal $37^{\circ} \mathrm{C}$ ), $\mathrm{pH}$ from 5.5 to 8.0, in the presence of certain single amino acids or oligopeptides known to be present in the human cutaneous tissues, oxygen dependent and relative tolerance to $\mathrm{NaCl}$ and various fungicides (clotrimazole, cycloheximide, griseofulvin, and tolnaftate) (Hashimoto and Blumenthal, 1977). Together with other pathogenic fungi, T. mentagrophytes was exposed in vitro to seawater (various salinity, 6$50 \%)$ at different temperatures $\left(20-35^{\circ} \mathrm{C}\right)$ in a diurnal rhythm of 12 hour cycles and found to survive for up to 52 weeks, suggesting possible human infection from this environmental source (Hashimoto and Blumenthal, 1977). Related to seawater, Pollock et al. (2000) reported on fungal infection in captive pinnipeds and concluded in accordance with their findings that this infection was caused by two key environmental factors: pool water excessive chlorination (excessive chlorination can cause scorching skin damage that facilitates fungi infection) and warm water temperature.

Table 5.3.1 Some characteristics of zoonotic Trichophyton spp.

\begin{tabular}{|c|c|c|c|c|}
\hline $\begin{array}{l}\text { Trichophyton } \\
\text { spp. }\end{array}$ & Animal main sources & Other sources & Zoonosis & Category \\
\hline $\begin{array}{l}\text { Trichophyton } \\
\text { mentagrophytes }\end{array}$ & $\begin{array}{l}\text { Rodents (hamster, } \\
\text { mouse, chinchilla, guinea } \\
\text { pig, rat), rabbit, dog, cat, } \\
\text { horse, cattle, sheep, pig, } \\
\text { zoo animals (particularly } \\
\text { monkeys) }\end{array}$ & $\begin{array}{l}\text { All mammals, } \\
\text { pinnipeds }\end{array}$ & Frequent & $\begin{array}{l}\text { Zoophilic, } \\
\text { Anthropophilic }\end{array}$ \\
\hline $\begin{array}{l}\text { Trichophyton } \\
\text { equinum }\end{array}$ & Horse & Cat, dog (rare) & Rare & Zoophilic \\
\hline $\begin{array}{l}\text { Trichophyton } \\
\text { erinacei }\end{array}$ & Hedgehog & Dog & Possible & Zoophilic \\
\hline $\begin{array}{l}\text { Trichophyton } \\
\text { sarkisovii }\end{array}$ & Camel & $\begin{array}{l}\text { Cattle, horse, } \\
\text { dog, cat }\end{array}$ & $?$ & Zoophilic \\
\hline $\begin{array}{l}\text { Trichophyton } \\
\text { simii }\end{array}$ & Primate, chicken & Fowl, dog, cat & Rare & Zoophilic \\
\hline $\begin{array}{l}\text { Trichophyton } \\
\text { verrucosum }\end{array}$ & $\begin{array}{l}\text { Cattle, other ruminants } \\
\text { (sheep) }\end{array}$ & All mammals & Frequent & Zoophilic \\
\hline
\end{tabular}

A clear characteristic of these fungi is their inactivation by nitrogenous compounds (urea, ammonia, and nitrate) at high concentrations (Kosuge et al., 2002). Distribution of these compounds in cattle breeding soil inhibited the growth of $T$. verrucosum, reducing soil as a potential reservoir for infection. In relation to soil, wild animals are the closest organisms to this environment, suggesting that wild animals play a significant role as carriers of dermatophytes (geophilic and zoophilic) (Mantovani et al., 1982) (Figure 5.1.1).

From data on dermatophytoses' cases reported for a period of five years in the Florence area (Italy), $T$. mentagrophytes represented 6\% of people infected with different dermatophytes (Sberna et al., 1993). The authors pointed out that the largest part of the patients resided in rural areas with pets, and hence were infected through direct contact with soil or domestic animals. An important feature that may boost dermatophytoses is the growing use of cosmetics. In the past, cosmetics were based on mainly natural products (with less antifungal protection) while in the last century almost all cosmetics are amended with 
antidermatophytic compounds. However, Mahe et al. (1994; 2003) reported dermatophytic infections following use of skin bleaching agents in Mali and Senegal.

Industrial utilization of keratinolytic fungi to biodegrade poultry feathers waste was also suggested (Kalyankar and Kalyankar, 2005). Among the dominant keratinolytic fungi isolated were T. verrucosum and T. equinum, both known human pathogens, therefore raising the question of this process' safety as such.

Finally, although less directly connected to zoonotic dermatophytes, socio-ethnological factors involved and favoring transmission were studied in places of worship. Raboobee et al. (1998) found a significantly higher prevalence of Tinea pedis and unguium among regular male worshippers in a Muslim community (Durban, South Africa) related to the spread of fungal organisms in the communal ablution areas and prayer carpets of the mosques. Consequently, other communal environments, such as gymnasia, health spas, swimming pools, changing rooms of sports clubs, public showers, and even hotels should be considered at high risk as assembling the most favorable conditions requested by fungi to infect: humidity, high temperature, crowded people and physical contact.

\subsubsection{REFERENCES}

Anderson, J.H. (1979) In vitro survival of human pathogenic fungi in seawater. Sabouraudia 17, 1-12.

Chermette, R., Ferreiro, L. \& Jacques Guillot, J. (2008) Dermatophytoses in Animals. Mycopathologia 166, 385-405.

Hashimoto, T. \& Blumenthal, H.J. (1977) Factors affecting germination of Trichophyton mentagrophytes arthrospores. Infect Immun 18, 479-486.

Hironaga, M., Fujigaki, T. \& Watanabe, S. (1981) Trichophyton mentagrophytes skin infections in laboratory animals as a cause of zoonosis. Mycopathologia 73, 101-104.

Kalyankar, N.V. \& Kalyankar, S.N. (2005) Management of poultry feather waste using keratinolytic fungi. Proc. Int. Conf. Solid Waste Technol. Manage. (2005), 21 ${ }^{\text {st }}, 1051-1058$.

Kosuge, J., Goto, Y., Shinjo, T., Ri, N. \& Takatori, K. (2002) The influence of urea, ammonia, and nitrate as they affect growth and viability of Trichophyton verrucosum. Nippon Ishinkin Gakkai Zasshi 43, 99-102.

Mahé, A., Keita, S. \& Bobin, P. (1994) Dermatologic complications of the cosmetic use of bleaching agents in Bamako (Mali). Ann Dermatol Venereol 121, 142-146.

Mahé, A., Ly, F., Aymard, G. \& Dangou, J.M. (2003) Skin diseases associated with the cosmetic use of bleaching products in women from Dakar, Senegal. Br J Dermatol. 148, 493-500.

Mantovani, A., Morganti, L., Battelli, G., Mantovani, A., Poglayen, G., Tampieri, M.P. \& Vecchi, G. (1982) The role of wild animals in the ecology of dermatophytes and related fungi. Folia Parasitol. 29, 279-284.

Mercantini, R., Marsella, R., Moretto, D. \& Finotti, E. (1993) Keratinophilic fungi in the antarctic environment. Mycopathologia 122, 169-175.

Otcenasek, M., Hubalek, Z. \& Sixl, W. (1980) Survey of dermatophytes in the hair of small mammals from Austria. Folia Parasitol. 27, 83-87.

Pollock, C.G., Rohrbach, B.W. \& Ramsay, E.C. (2000) Fungal dermatitis in captive pinnipeds. J. Zoo Wildl. Med. 31, 374-378.

Raboobee, N., Aboobaker, J. \& Peer, A.K. (1998) Tinea pedis et unguium in the Muslim community of Durban, South Africa. Int J Dermatol. 37, 759-765.

Sberna, F., Farella, V., Geti, V., Taviti, F., Agostini, G. et al. (1993) Epidemiology of the dermatophytoses in the Florence area of Italy: 1985-1990. Trichophyton mentagrophytes, Epidermophyton floccosum and Microsporum gypseum infections. Mycopathologia 122, 153-162.

Shrivastava, J.N., Ghawana, V.K. \& Kumar, A. (1996) Biodegradation of wool by Trichophyton simii and Aspergillus niger. Mycoses 39, 483-487.

Takatori, K., Takahashi, A., Kawai, S., Ichijo, S. \& Hasegawa, A. (1993) Isolation of Trichophyton verrucosum from lesional and non-lesional skin in calves. J. Vet. Med. Sci. 55, 343-344. 
Tanaka, E., Kimura, T., Wada, S., Hatai, K. \& Sonoda, S. (1994) Dermatophytosis in a Steller sea lion (Eumetopias jubatus). J. Vet. Med. Sci. 56, 551-553.

Torres-Rodriguez, J.M., Dronda, M.A., Rossell, J. \& Madrenys, N. (1992) Incidence of dermatophytoses in rabbit farms in Catalonia, Spain, and its repercussion on human health. Eur. J. Epidemiol. 8, 326-329.

Van Rooij, P., Detandt, M. \& Nolard, N. (2006) Trichophyton mentagrophytes of rabbit origin causing family incidence of kerion: an environmental study. Mycoses 49, 426-430. 


\section{Chapter 5.4 \\ Sporotrichosis}

\section{[SPOROTHRIX SCHENCKII]}

Sporothrix schenckii is the only active species of genus Sporothrix that ccurs worldwide. S. schenckii is a thermally dimorphic fungus (conversion from mould form to yeast form). The dimorphism is used to identify Sporothrix schenckii. Septate hyphae grow conidiophores at right angles, where conidia are clustered in a flower like arrangement. Conidia are hyaline, elongated ovals, 3 to 6 by 2 to $3 \mu \mathrm{m}$ with smooth walls. Optimal growth requires 92 to $100 \%$ humidity at 26 to $29^{\circ} \mathrm{C}$, conditions found mainly in moist tropical and sub-tropical zones, such as South America, Southeast Asia, Australia, south USA (Mississipi River Delta) and Europe (mainly in Italy). Environmentally, the fungus is ubiquitous in nature found on rotting organic matter (wood, peat moss, debris, etc.), surface water and wet sites (swimming pools). Beside humans, it can infect horses, mules, dogs and cats. Clinically, it can manifest as cutaneous form (nodule formation with purulent lesions), mucosal form affecting nose, mouth, pharynx, larynx and trachea (causing tonsillitis, stomatitis, glossitis, laryngitis and rhinitis like syndromes) with ulcerative nodules and lymphoadenopathy development (Rippon, 1988). In more rare cases, internal mucosal spread of sporotrichosis may affect lungs, bones and joints (osteomyelitis and synovitis), eyes (chorioretinitis), muscles, testes and epididymis, brain (meningitis) (Ewing et al, 1980).

\subsubsection{SPOROTHRIX SCHENCKII AND ENVIRONMENT}

As mentioned before, the potential growth and development of S. schenckii on peat moss was emphasized by the famous 1988 largest outbreak in the USA of cutaneous sporotrichosis (Coles et al., 1992). The contamination sources seem to be a one to three years old sphagnum moss, used to pack evergreen tree seedlings, wetted with pond water and kept under favorable conditions for the development of $S$. schenckii. In South America, natural habitats/reservoirs of this particular fungus are armadillo nests, flowers, hay, trees, mosses, soil, etc. where it can grow and multiply saprobically or parasitically (Conti Diaz, 1989; Mendoza et al., 2007; Hajjeh et al., 1997; McDonough et al., 1970) (Figure 5.1.1). Infection routes can be through direct contact as pointed out earlier, but also through contaminated spines or thorns, corn-stalks, armadillo's claws, hooks, animals and also human nails (that also cause skin injuries) 
(Mehta et al, 2007). Among animal' sources of contamination, fish was reported in Guatemala, where fish workers contracted this dermatophyte showing clinical manifestations, such as ascending lymphocutaneous sporotrichosis of the limbs with some cases of ulcerative or verrucous lesions (Mayorga et al., 1978).

From the environmental point of view, soil supplemented with sewage sludge was found to contain a large variety of fungi, including human pathogenic ones such as: Sporothrix schenckii (Kacprzak and Woszczyk, 2004). In the same study, soil supplemented with sewage sludge was reported to increase soil fungi content independently of sludge, soil and plant types. Sludge supplementation of soils can also increase its salinity; however, Brazilian Sporothrix schenckii isolates were shown to be highly resistant to salt concentrations (Fernandes et al., 2009). Finally, high temperatures were found to be inhibitory to experimental infections, in both animals and humans, influencing also the clinical forms (Mackinnon and Conti Diaz, 1962). Based on these characteristics, MacKinnon (1972) proposed a hypothesis that high temperature may modify the clinical course of Sporothrix schenckii in human infection from lymphangitis to fixed cutaneous forms of the disease.

\subsubsection{REFERENCES}

Coles, F.B., Schuchat, A., Hibbs, J.R., Kondracki, S.F., Salkin, I.F. et al (1992) A multistate outbreak of sporotrichosis associated with sphagnum moss. Am. J. Epidemiol. 136, 475-487.

Conti Diaz, I.A. (1989) Epidemiology of sporotrichosis in Latin America. Mycopathologia 108, 113-116.

Ewing, G.E., Bosl, G.J. \& Peterson, P.K. (1980) Sporothrix schenckii meningitis in a farmer with Hodgkin's disease. Am. J. Med. 68, 455-457.

Fernandes, G.F., Oliveira dos Santos, P., Candida do Amaral, C., Sasaki, A.A., Godoy-Martinez, P. \& Pires de Camargo, Z. (2009) Characteristics of 151 Brazilian Sporothrix schenckii Isolates from 5 Different Geographic Regions of Brazil: A Forgotten and Re-Emergent Pathogen. Open Mycol J 3, 48-58.

Hajjeh, R., McDonnell, S., Reef, S., Licitra, C., Hankins M. et al (1997) Outbreak of sporotrichosis among tree nursery workers. J. Infect. Dis. 176, 499-504.

Kacprzak, M. \& Woszczyk, K. (2004) The microfungal communities in the soils treated with sewage sludge. Environ Protect Eng 30, 51-56.

Mackinnon, J.E. \& Conti Diaz, I.A. (1962) The effect of temperature on sporotrichosis. Sabouraudia 2, 56-59.

Mackinnon, J.E. (1972) Regional peculiarities of some deep mycoses. Mycopathol Mycol Appl 46, 249-265.

Mayorga, R., Caceres, A., Toriello, C., Gutierrez, G., Alvarez, O. et al (1978) An endemic area of sporotrichosis in Guatemala. Sabouraudia 16, 185-198.

McDonough, E.S., Lewis, A.L. \& Meister, M. (1970) Sporothrix (Sporotrichum) schenckii in a nursery barn containing sphagnum. Public Health Rep 85, 579-86.

Mehta, K.I.S., Sharma, N.L., Kanga, A.K., Mahajan, V.K. \& Ranjan, N. (2007) Isolation of Sporothrix schenckii from the environmental sources of cutaneous sporotrichosis patients in Himachal Pradesh, India: results of a pilot study. Mycoses 50, 496-501.

Mendoza, M., Diaz, E., Alvarado, P., Romero, E. \& Bastardo de Albornoz, M. C. (2007) Isolation of Sporothrix schenckii from environmental samples in Venezuela. Rev Iberoam Micol 24, 317-319.

Rippon, J.W. (1988) Medical Mycology. 3rd Edition. W.B. Saunders Co., Philadelphia, USA. 
Downloaded from https://iwaponline.com/ebooks/book-pdf/521254/wio9781780400761.pdf

Downloaded trom https://Iwaponline.com/ebooks/book-pdt/521254/WI09/81/80400/61.pdt
by IWA Publishing user 


\section{Index}

Note: $\mathrm{t}=$ Table, $\mathrm{f}=$ Figure

A

Acanthamoeba castellanii, 148, 153

ACL (American cutaneous leishmaniasis), 294

Actinobacillus, 165, 167

Aedes aegypti, 178, 427

Aedes albopictus, 180, 429

Africa, 17, 46-7, 67, 108, 178-80, 218, 243, 333, $354,360,371-3,381-2,397,425$

African Trypanosomiasis, 317-19

agriculture, 19, 23, 66, 179, 345, 450

AIVs. See avian influenza viruses

Alphaviruses, 177-80

American cutaneous leishmaniasis. See ACL

AMF (arbuscular mycorrhizal fungus), 93

amoebae, 128, 148, 151, 153, 325-6

Ancylostoma caninum, 421-2

Ancylostoma ceylanicum, 468-69

Andes virus, 200, 202, 205

Angiostrongylus cantonensis, 404-6

Anisakiasis, 407-9

Anisakis simplex, 407-8

anthrax, 31-8, 465

anthropophilic, 473-4

apes, 135, 268, 447

arbuscular mycorrhizal fungus (AMF), 93

Arcanobacterium pyogenes, 167

Arenaviruses, 213, 215

Argentina, 26, 85, 200, 202, 285, 292, 315, 346, 372, $382,387,443,462$ arid zones, 292, 419

arthropods, 21, 41, 119, 123-4, 136, 145, 147, 183, 189-90, 195, 199-200, 228, 425

ASE (artificial soil ecosystem), 112

Atlanta, 45, 276, 290, 299, 310, 314, 318, 324, 337, 340, $342,398-9,413-14$

Australia, 34-5, 61, 76, 89, 93, 98, 129, 136, 178-9, 220-1, 228, 405, 421

avian influenza virus transmission, 233-4

avian influenza viruses (AIVs), 231, 233-5

B

Babesia spp, 262-4

babesiosis, 22, 262-3, 265

Bacillus anthracis, 31

Balantidium coli, 267-8

bank voles, 12, 41, 203-4

Barmah Forest virus (BFV), 177, 179

Bartonella, 40-2, 265

bartonellosis, 41-2

bats, fruit, 62, 217, 228-29

Bayou virus, 205

Bertiella spp, 372, 397-8

BFV (Barmah Forest virus), 177, 179

biodegradation, $79-80$

bioterrorism, 53

birds, 3, 37, 44, 47-8, 52-3, 55, 61, 189, 227, 234-5, $247-8,301-2,341,462$

Bolivia, 271-3, 346 
Borrelia, 44, 47

Borrelia burgdorferi, 44, 48

Borreliosis, 44-5, 47

bovine papular stomatitis virus (BPSV), 243-4

Brazil, 65, 85, 221, 271-2, 291-4, 362, 371, 373,415

Brucella, 50, 53

brucellosis, 50, 53

buffaloes, 314-15, 453

Bunyaviridae, 195, 199-201, 203, 205

Burkholderia mallei, 79, 80-1

Burkholderia pseudomallei, 92-3

C

cadmium, 104, 347, 409

camels, 111, 243, 268, 366, 380, 382

Campylobacter, 55-6, 58, 116

Campylobacterioses, 55, 58

canids, 113, 366, 373, 380-1, 429-30, 455

cannibalism, 113, 412, 457

Capillariasis, 401t, 412-13, 415

Cardiovirus, 237

cattle, 21, 31-2, 35, 52, 55, 57t, 71, 72t, 76, 140, 141t, 165, 167-9, 209-10, 223, 225, 250, $313-15,350-1,391-2$

CDC, 45, 218, 241, 243-4, 276, 290, 299, 310, 314, $318,324,337,340,398-9,413-14,418 \mathrm{f}$, 420f, 422f, 426f, 430f, 433f, 439f, 442f, 446f, $450,456 \mathrm{f}, 461 \mathrm{f}, 465 \mathrm{f}$

Central America, 155, 178t, 224, 272, 294, 332t, 372t, 381,432

cercariae, 330, 336, 337, 339, 346-7, 350, 352, 353, $355,357,360,363,366-7,369$

cestodes, 330, 371t-2t, 379, 397

Chagas disease, 270-274

chickens, 22, 76, 136, 140, 227-8, 233-4, 274, $326-7,432,473$

Chikungunya, 179-80

cholera, 8, 14, 153, 155-7

civets, $247-8,358$

clay, $35,103,251-2,474$

climate, 11-12, 14, 33, 68, 153, 155, 188, 190t-192t, 210, $277,292,319,353,361$

clonorchiasis, 331t, 336-7

CNS (coagulase-negative staphylococci), 137-8, 184t, $209,317,352,357,373$

$\mathrm{CO}_{2}$ concentrations, 14,423

cockroaches, 140, 258, 397, 434-5, 451, 462, 468

Coenurosis, 371t, 373-4

Colorado tick fever virus(CTFV), 209-10 composting, 57t, 443

contamination, $18,33,53,58,71,74,84,89,92,117,127$, $130-1,259,282-3,439-40,442-3$

copepods, $375,424,432$

coronaviruses, $247-8$

crustaceans, 61, 76, 123, 146, 298, 357, 358t, 389, 407,419

cryptosporidiosis, 275, 277-79

Cryptosporidium, 24, 116, 275, 277-8, 282-4, 301-2

CTFV. See Colorado tick fever virus cutaneous larva migrans, 402t, 438-40 cutaneous leishmaniasis, 288t-9t, 293-4 cysticercosis, 372t, 392, 394-6

cysts, 258-60, 267, 270, 281-4, 313, 326, $373,381-2$

D

deer, 32-3, 35t, 48, 51t, 65-66, 71, 73, 265, 453, 455,464

deforestation, 11, 16, 38, 42, 47, 98, 112, 123, 179, 199, 272-3, 290, 293-4, 310

Democratic Republic of Congo (DRC), 243, 319, $371 \mathrm{t}, 373$

Denmark, 57t, 58, 155, 391-2, 415

Dermatophilus congolensis, 166t, 168, dermatophytes, 473-5, 480-2

dermatophytoses, 473, 481-2

Diptera, 180, 317, 425, 455

Dipylidium caninum, 372t, 377-9

Dipylidosis, 372t, 377, 379

Dirofilaria immitis, 22, 429-31

dirofilariasis, 401t, 429-31

distribution, socio-economic, 3-10

dogs, 42, 51t, 55, 60, 64-5, 72t, 76, 79, 102, 106, 110, $116,122,125,141 \mathrm{t}, 166 \mathrm{t}, 167,169 \mathrm{t}, 288 \mathrm{t}-9 \mathrm{t}$, 293-4, 336-8, 356-8, 377-83, 421-2, 429-32, $438-43$

Dracunculus medinensis, 401t, 419-20, 424

drought, 9-10, 32, 34t, 229, 429

dry season, 33, 34t-5t, 108, 130-1, 137, 203, 263, 310, $319,446-7$

ducks, 76, 141t, 231-3, 235, 300t, 326-7, 330

dung beetles, 392, 434, 466

E

Eastern Equine Encephalitis (EEE), 177, 178t

Ebola virus, 217, 219

echinococcosis, 22, 372t, 380-4

Echinococcus multilocularis, 380, 383-4 
echinostomiasis, 331t, 341-2

Egypt, 79, 81, 200, 263t, 326, 344, 352-3, 360, 362, $401 \mathrm{t}-2 \mathrm{t}, 412,414,425$

EHEC (Enterohemorrhagic Esherichia Coli), 71, 72t, 73,74

Ehrlichia, 64-6, 68

Ehrlichioses, 64-5, 67

El Niño, 14, 153-5, 290, 294, 346, 409

elephants, 32, 34t-5t, 242-3, 453

Entamoeba histolytica, 258, 260-1

Enterobacteriaceae, 126, 130, 160

Enterovirus, 237

environment, 22, 102-6, 126-8, 202-3, 227-8, 232-4, 247-51, 313-14, 318-20, 323-5, 391-2, 449-50, 461-2, 473-8, 480-1

epidemiology, 14, 38, 49, 70, 78, 90, 95, 100, 139, 147, $170-1,316,348,364,463$

epigenetics, 252, 363-4

epizootics, 2, 34-5, 85, 104, 110, 115, 177, 207, 222

erysipelas, 76, 78, 140

erysipeloid, 76-8

Europe, 17, 42, 48-9, 61, 63, 66, 70, 76, 106, 155, 160, 193-4, 242-3, 383-5, 455-6

Eurytrema pancreaticum, 366, 369-70

excreta, 62, 99, 126, 145, 162, 195, 202-3, 205, 276, $278,325,337,344,442$

Eyach virus, 209, 211

F

Fasciola gigantica, 344, 348, 351

Fasciola hepatica, 344, 347-9

fasciolasis, 344-7, 349-50

fasciolopsiasis, 348, 350-1

feathers, 33, 234-6

filariasis, 424-5, 427, 430

Filoviruses, 217

fish, 47, 49, 52, 61, 130, 139-42, 146, 298-9, 336-7, $352-5,367,406-8,413-14,417,432-3$

Flaviviruses, 183, 186, 189, 193

fleas, 40-2, 107-10, 112-13, 119, 124, 136, 139, 145, $163,195,203,377,379,473$

floods, 9, 32-3, 38, 83-4, 86, 92, 150, 170, 205, 277, 356,443

flukes, 20, 336, 339-42, 344, 346-7, 350, 352-3, 355, $358,367,369-70$

forest fragmentation, 48, 447, 451

forests, 9, 15-16, 47-8, 66, 204-5, 265, 274, 292, 294, 319-20, 324, 345, 383-4, 439

foxes, $51,220,265,325,373-4,378,381,385,397,399$, $413,417,422,439-40,457$
France, 93, 131, 150, 161, 179-80, 209-11, 292, 323, 335, $348,354,371,373,376,380$

Francisella tularensis, 145, 149-50

fungi, 79, 93, 132, 165, 252, 298, 302, 347, 473-8, 480-2, 484-5

G

gardens, zoological, 269, 311, 434-5

Gastrodiscoides hominis, 366, 369-70

GBS (group B streptococci), 142-4

Geographic Information System (GIS), 49, 147, 425

Germany, 11, 14, 58, 66, 142, 149, 162, 179, 204, 209-10, 217, 263, 313-14, 380, 478

GFP (green fluorescent protein), 74, 104

Ghana, 215, 428, 445-6, 448

Giardia, 23, 116, 280-1, 283-5, 301-2

Giardiasis, 281, 283-6

Glanders, 79, 81-2

goats, 35, 71, 79, 122, 135, 168, 170-1, 189, 209-10, 243, $275,278,325,382,445$

grass, 32, 89, 93, 103, 105, 205, 210, 366, 379, 434, 466

grasshoppers, 123, 366, 369

groundwater, 117, 127, 132

group B streptococci (GBS), 142-4

H

habitats, $23,48,60,66,70,93,137,147,200,206-7,222$, 234, 273, 346-7, 427

hantavirus, $11,204-5$

hantavirus pulmonary syndrome (HPS), 200, 202, 205-6

Haverhill fever (HF), 116, 217, 219

heavy metals, 55, 348, 409-11

hedgehogs, 413-15, 434

Helicobacter, 168, 170, 172

hemoparasites, 65, 70, 266

Henipavirus, 227, 229

herbivores, 190, 373, 466

herpesvirus, 239

highly pathogenic avian influenza (HPAI), 20, 231, 233-6

HIV (human immunodeficiency virus), 241, 246, 302

Hong Kong, 231, 233, 249

hookworms, 364, 421, 438-9, 469-70

horses, 32-3, 35, 64, 69, 71-2, 76, 79, 81, 85, 140-1, 165, 167-8, 228-30, 247-8, 473-4

human African trypanosomiasis (HAT), 318, 322

human migrations, 94, 98, 356

Human monkeypox, 245-6

hunters, 51, 66, 140, 148

hunting dogs, rural, 65, 70, 430-1

Hymenolepiasis, 372, 386-7 
I

IAV. See Influenza A virus

Iceland, 335, 372, 411, 414, 416

India, 5, 13, 108, 112, 151, 155, 172, 179-81, 242, 259-61, 333, 350-1, 360, 369-70, 427-8

Indonesia, 6, 79, 155, 277, 280, 341, 350, 424-5, 427-8, $445,452,454$

industries, 11, 17-18, 22

Inermicapsifer madagascariensis, 372, 397, 399

infection prevalence, 337, 351, 353, 378, 421, 439,451

infection rates, $189,247,267,313,325,337,347,358$, $361,389-90,408,421$

infection risk, 66, 265, 294, 390, 392, 453, 477

infections, 22, 33, 36, 55, 58, 60, 77, 79, 87, 98, 104, $122-3,128,134,136-7,140,142-3,148,151$, $153,165,168,177-8,183,187,195,204-5$, $213,219,220,223,228-9,231,238-9,242-3$, 247, 258-60, 262-3, 265, 267, 275-8, 281-3, 294, 298-9, 303, 331, 336, 357-8, 360-1, 369, $373,374,376,381,387,391,394-5,397$, 404-5, 413-14, 417, 422, 425, 433, 436, 438-9, 441, 445-7, 449, 451, 453, 461, 468-9, $473,477,482,488$

Influenza A virus (IAV), 231-6

ingestion, 23, 31, 50, 55, 84, 116, 126, 147, 233, 237-8, $250,259,289,313,323,336,344,357,377-8$, 404-5, 412, 441-2, 457, 468

insecticides, 67, 70, 290, 319, 347, 363

insects, 33, 35, 40-1, 61-2, 92, 99, 100, 124, 136, $153,162,189,193,199-200,223-4,272-3$, $298-9,455$

invertebrates, 61, 76, 162, 186, 299, 408, 435

Iran, 155, 268, 292, 294, 330, 374, 397, 399, 412, 414,434

IRG (intensive rotational grazing), 465

Israel, 94, 119, 123, 128, 143, 154, 200, 233, 263t, 292-3, $324,335,371 \mathrm{t}, 373$

Italy, 123, 179-80, 232, 371, 376, 392-3, 421, 429-30, $434,462,474,481$

Ixodes ricinus, 66, 68, 210, 263t

$\mathbf{J}$

jackals, 220, 374, 397

Japan, 42, 76, 85, 123, 145, 160, 165, 168, 170, 187, 220-1, 336, 371t-2t, 384, 389, 407-8, 434

$\mathbf{L}$

larva migrans cutanea, 438-9

larva migrans visceralis, $441-3$ larvae, 136, 138, 162, 200, 267, 330, 339, 346, 363, $373,377,386,389,391,394,404,407,409-10$, 412-3, 417, 419, 421-3, 424-5, 429-31, 433-4, $436,438-41,445,447,449-51,453,458,462$, 465-6, 469

LCMV (Lymphocytic Choriomenningitis Virus), 215

Leishmania, 287, 290-4

leishmaniasis, 11, 22, 287, 291-4,

Leptospira, 83-5

leptospirosis, $12,83,85,163$

Listeria, 87, 89, 110

Lyme disease, 44, 47-8

M

malaria, 13, 304, 308t, 310, 458

malathion, 342, 363, 427

marburg hemorrhagic fever, 217, 219

marine environments, 85, 282, 301, 325, 407

melioidosis, 92-4

Menangle virus, 228t, 228

mercury, 294, 346, 418

metacercariae, 336-7, 339, 341, 344, 350, 352, 355, $357-8,366-7,370$

methicillin-resistant Staphylococcus aureus (MRSA), 136-9

Mexico, 128, 132, 154, 158, 224, 263, 274, 289t, 395-6, $432-3$

microsporidia, 298, 301-2

Microsporidiosis, 298-9, 301-2

Microsporum, 473-5

milk, 32, 52-3, 55, 71, 99, 117, 137, 183, 189, 282,323

miracidia, 341, 357, 361, 363, 366-7

moisture, 77, 130, 162, 200, 203, 248, 293, 345-6

monkeypox virus, 242t, 243

mosquitoes, $14,33,39,99,147,177,183,184 t-5 t, 186-9$, 193, 195, 196t, 200, 304, 310, 424-5, 427

Mountain, Rocky, 119, 210

mussels, 128, 325, 341

Mycobacteria, $97-9$

Mycoses, 474

\section{$\mathbf{N}$}

Namibia, 33, 34t

NDV (Newcastle disease virus), 227, 228t, 229

Nematoda, 404, 408-10

New Mexico, 108, 224-5

Newcastle disease (ND), 227-9

Nigeria, 80-1, 215, 263t, 267, 371t, 373, 378-9, 386-7, $422,427,431,451$ 
Nipah virus, 228

northern hemisphere, 147, 339-40

O

Oesophagostomiasis, 445-7

OLM (ocular larva migrans), 441-2

oncospheres, 373, 380, 391, 394

oocysts, 275-6, 278-80, 313, 315, 323, 325-7

Orbiviruses, 209-10

Oropouche virus, 199

Orthomyxovirus, 231, 233

orthopoxvirus, 241-2, 243

outbreaks, 22, 31-3, 36, 41-2, 102, 112, 116, 143-4, 179-80, 200, 217, 234-5, 243-5, 247-8

P

Panama, 69, 130-2, 225

pandemic, 114, 231-3, 247

Papua New Guinea, 449-51, 463

Paragonimiasis, 357-9

Parapoxvirus, 241

parks, 168, 173, 311, 421-2, 442-3

Pasteurelloses, 102-3, 105

pastures, 35, 66, 71, 73-4, 263, 345, 374, 391-3, 395, 464-7

pathogen survival, 131,148

pathogen transmission, $84,110,188$

pathogens, 52-3, 59-61, 65-6, 69-71, 73, 84-5, 98-9, $102-4,112-13,123-5,127-31,147-50,153$, 160-2, 277-9

Peru, 41, 209-11, 238, 261, 271, 274, 285, 301, 375, $395,409-10,438$

pesticides, 10, 342-3, 347-9

pets, 21 , 42, 60, 102, 137, 160, 169, 190, 374, 416, 439, 474, 480-1

pigs, 21, 76-8, 140-1, 167-9, 230-2, 236-8, 267-9, 315-17, 336-9, 350-1, 366, 369-70, 394-5, 447-8, 473

plague, 105-15, 238

Plasmodium spp, 304, 310-11

playgrounds, 170, 379, 421-2, 438, 440, 442

Poland, 43, 66, 112, 263, 299, 326, 378, 392, 422-3, 439-40, 442, 444

pollution, 7, 11, 17, 22, 190, 259-60, 345, 353

population, 2-3, 5-7, 9, 11, 17, 23, 204-5, 244, 259-60, $272-3,293,354-5,378,383,415$

Poxvirus, 241, 243-5

prairie, 110, 112-13, 115

predators, 189-90, 338, 389-90, 412 primates, 178-9, 199, 243, 258, 260-1, 311, 326, 397, $445,448,464,469-70$

prions, 250-3

protozoa, 61, 127-8, 131, 145, 148-9, 257-9, 265, 347,477

Pseudoterranova decipiens, 407, 409-11

Puumala Virus Infection, 207-8

Q

quails, 76, 78, 233, 236, 462

$\mathbf{R}$

rabies, 21, 220, 222-3

rain, 17, 47-8, 89, 110, 278, 379, 429

rainy season, 33-4, 92, 129, 137, 186, 278, 293, 319, 353, $425,446-7$

rats, $23,26,51,57,76,85,98,107,111,113,116-17$, $243,386,404-6,457$

recreational areas, 282, 422-3, 439-40

Reoviruses, 209, 211

reptiles, 61, 76, 83, 126-7, 130-1, 237, 304, 389, 397

reservoirs, 23, 40, 44, 47-9, 52-3, 64, 100, 110, 137-9, $145,160-1,202-3,220,311-12,424$

Respirovirus, 227

Rhodococcus equi, 168, 170, 172

Rickettsia, 119, 122, 124, 295

Rickettsioses, 114, 119, 122-3, 125

Rift Valley fever virus (RVFV), 200, 207

risk factors, 39, 53-4, 67, 70, 85, 94, 105, 114, 136, $143-4,171,259-61,277,382-3,476$

rodents, 40-1, 46-9, 107, 109-10, 115-17, 122, 145, 178-9, 195, 202-7, 213, 215, 292, 384-7, 397

Ross River (RR), 178-9, 181, 428

roundworm, 404-5, 410

runoff, 33, 129-30, 282

RVFV (Rift Valley fever virus), 200, 207

S

saliva, 205, 213, 220, 229

Salmonella, 56, 58-9, 126-8, 130-3, 280

Salmonelloses, 126-9, 131-3

sand fly, 40, 223, 287, 290, 292-3

sandflies, 41, 195, 295-6, 430

Sarcocystis spp, 313-16

SARS (severe acute respiratory syndrome), 20, 221, 247-9

schistosomiasis, 333, 360-5

sea water, 84, 98, 130, 137, 260, 279

Semliki Forest (SF), 177-8

sewage treatment plants (STP), 90, 282, 285 
SFGR (spotted fever group rickettsiae), 119, 122, 125 sheep, 10, 21, 31-2, 35, 55, 71, 76, 165, 167-8, 172, 209-10, 242-4, 317, 382-3, 466-7

shellfish, 23, 55, 128, 279, 282

Singapore, 229-30, 247, 249, 312

sludges, activated, 73-4, 104, 348

smallpox, 241, 243, 245-6

snails, 23, 330, 335-7, 341-2, 344-7, 350, 352-3, $355,357-8,360-1,363-4,366-7,369,404,453$

soil, 31-5, 37-9, 76-9, 83-4, 86-7, 89-95, 103-5, 130, $134-5,160-5,168-70,251-3,278-9,412-13$, 484-5

soil contamination, 278, 412, 439-40, 442-4

soil environment, 37, 81, 84, 104, 110, 134, 412, 465

South America, 13, 15, 155, 178-80, 200, 202, 223, 285, 310, 339-40, 357-8, 372, 381, 397, 484

Southeast and East Asia, 352, 355, 357-8, 360, 424

Southern Europe, 178, 355, 372, 455

Spain, 107, 117, 128, 132, 167, 172, 179, 193, 263, 280, 282, 339, 443-4, 450-1, 478

sparganosis, 372, 389-90

Sri Lanka, 263, 278, 280, 314-15

staphylococci, 134, 136-8

starvation, 100, 129-30, 193

STP (sewage treatment plants), 90, 282, 285

stray dogs, 21, 169, 220, 374, 378, 397, 430, 439, 442

streptococci, 140, 143-4

summer, 58, 73-4, 123, 140, 157, 189, 202, 204, 209, 346, $352-3,369,465,478$

sunlight, 58, 130, 133

survival, 10, 73-4, 86-7, 89-90, 95, 104, 147-9, 162, 189, 233-5, 259-60, 278-9, 439-40, 443, 466-7

sylvatic, 220-1, 270-1, 293, 341, 457

\section{T}

taeniasis, 392, 394-6

tapeworms, 373, 375-6, 380, 382, 386, 389-94, 397

temperature, 107-10, 129-30, 153-4, 161-3, 186-7, 224, 233-6, 277-80, 339, 345-8, 362, 369, 376-8, 425,443

Texas, 32, 34, 38, 173, 434

Thailand, 86, 94, 187, 193, 215-16, 345, 349-50, 355-6, $358,390,414,424-5,451,453,470$

Tick-borne encephalitis (TBE), 10, 68, 188, 190, 194

ticks, 40, 42, 44, 47-9, 66-7, 69-70, 76, 99-100, 122-4, $145,183,189-90,193-5,209-12,262-3$

Toxocara canis, 441, 443-4

Toxoplasma gondii, 323-4, 326-8

trematodes, 330-1, 333, 335, 338-41, 353, 355, 360-1, 363
Trichinella spp, 457, 461-3, 465

Trichinosis, 457, 461, 463

Trichophyton spp, 480-1, 483

Trichostrongylosis, 464-5, 467

trophozoites, 258, 267, 281, 477

tropical, 23, 98, 129, 153, 156, 168, 224, 234, 311, 314, $360,369,436,449-50,473$

trypanosomiasis, 270, 319, 321-2

tsetse, 317-22

tularemia, 145, 147, 149-50

$\mathbf{U}$

Uganda, 101, 179, 217, 219, 263, 266, 283, 286, 319, 321, $361,364,375,451-2,469$

United States, 39, 48, 69, 78, 85, 90, 115, 125, 149, 226, $243,274,279,284,371-3$

urine, 33, 62, 83, 99, 116-17, 202, 205, 213, 229, 238, 298, 417-18

V

vaccinia virus, $241-3$

vectors, 13, 39-42, 68-70, 109-10, 112-13, 144-5, 171-2, 183, 188-9, 199-200, 209-10, 290-2, 427-31, 452-3, 455-6

Venezuela, 267, 269, 271, 485

Vibrio cholerae, 151, 157-8

virus transmission, 177, 210, 213, 217, 233, 235, 239

visceral leishmaniasis (VL), 290, 292, 294-7

VSV (Vesicular stomatitis virus), 223-6

W

wastewater, 17, 19-20, 53, 57, 73-4, 284

water, 17, 22-3, 31-6, 79-81, 83-4, 100-5, 116-17, $126-7,145-6,153,160,162,170$, $232-5,432-4$

waterfowls, 103, 227-8, 231-2, 330, 335, 341, 352, 432

West Nile virus (WNV), 49, 183, 187, 189, 193-4

wetlands, 102, 105, 355

wild animals, 2, 20-1, 48, 73, 100, 105, 116, 127, 160, 220-1, 223, 243, 283, 439-40, 481-2

Wroclaw, 422-3, 440

$\mathbf{Y}$

Yatapoxvirus, 241

yellow fever virus (YFV), 183, 186

Yersinia, 162-4

$\mathbf{Z}$

zoonoses, 15, 21, 38-41, 49, 78, 139, 153, 157, 163, 168, $172,220,237-8,250-1,384-5$ 


\section{Environmental Aspects of Zoonotic Diseases}

\section{Robert Armon and Uta Cheruti}

Environmental Aspects of Zoonotic Diseases provides a definitive description, commentary and research needs of environmental aspects related to zoonotic diseases.

There are many interrelated connections between the environment and zoonotic diseases such as: water, soil, air and agriculture.

The book presents investigations of these connections, with specific reference to environmental processes such as: deforestation, floods, draughts, irrigation practices, soil transfer and their impact on bacterial, viral, fungal, and parasitological spread.

Environmental aspects such as climate (tropical, sub-tropical, temperate, arid and semi-arid), developed and undeveloped countries, animal (domestic and wild) traffic animal border crossing, commercial animal trade, transportation, as well geography and weather on zoonosis, are also discussed and relevant scientific data is condensed and organized in order to give a better picture of interrelationship between the environment and current spread of zoonotic diseases.

Altogether, the book presents a remarkable and vast amount of potential future research directions based on the link: environment-vectors-pathogens-humans.

The most up-to-date source of information on this increasingly important crossdisciplinary subject, Environmental Aspects of Zoonotic Diseases will be invaluable for environmentalists, veterinarians, medical staff, environmental engineer, government agencies and consultants working in this field.

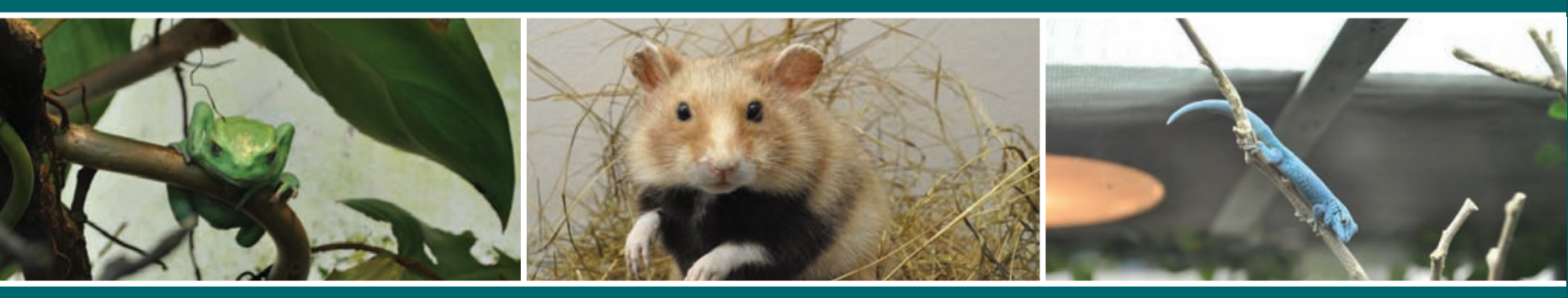

